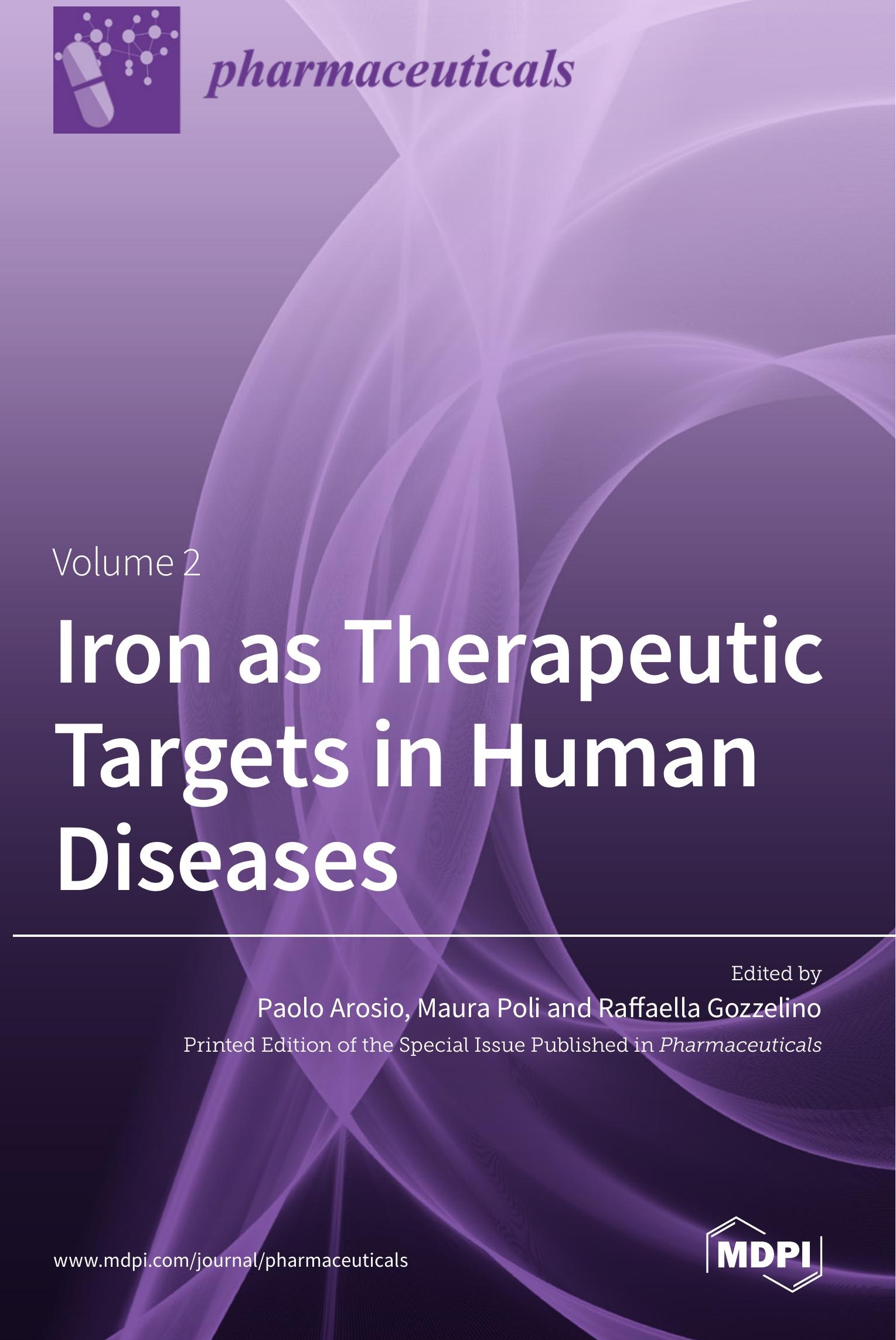




\section{Iron as Therapeutic Targets in Human Diseases}





\section{Iron as Therapeutic Targets in Human Diseases}

\section{Volume 2}

Special Issue Editors

Paolo Arosio

Maura Poli

Raffaella Gozzelino 
Special Issue Editors

Paolo Arosio

University of Brescia

Italy

Raffaella Gozzelino

NOVA University of Lisbon

Portugal
Maura Poli

University of Brescia

Itay

\section{Editorial Office}

MDPI

St. Alban-Anlage 66

4052 Basel, Switzerland

This is a reprint of articles from the Special Issue published online in the open access journal Pharmaceuticals (ISSN 1424-8247) from 2018 to 2019 (available at: https:/ /www.mdpi.com/journal/ pharmaceuticals/special_issues/Iron_TTHD).

For citation purposes, cite each article independently as indicated on the article page online and as indicated below:

LastName, A.A.; LastName, B.B.; LastName, C.C. Article Title. Journal Name Year, Article Number, Page Range.

\section{Volume 2}

ISBN 978-3-03928-116-9 (Pbk)

ISBN 978-3-03928-117-6 (PDF)
Volume 1-2

ISBN 978-3-03928-114-5 (Pbk)

ISBN 978-3-03928-115-2 (PDF)

(c) 2020 by the authors. Articles in this book are Open Access and distributed under the Creative Commons Attribution (CC BY) license, which allows users to download, copy and build upon published articles, as long as the author and publisher are properly credited, which ensures maximum dissemination and a wider impact of our publications.

The book as a whole is distributed by MDPI under the terms and conditions of the Creative Commons license CC BY-NC-ND. 


\section{Contents}

About the Special Issue Editors $\ldots \ldots \ldots \ldots \ldots \ldots \ldots \ldots \ldots$

Mayra Vera-Aviles, Eleni Vantana, Emmy Kardinasari, Ngat L. Koh and Gladys O. Latunde-Dada

Protective Role of Histidine Supplementation Against Oxidative Stress Damage in the Management of Anemia of Chronic Kidney Disease

Reprinted from: Pharmaceuticals 2018, 11, 111, doi:10.3390/ph11040111 . . . . . . . . . . . . 1

József Balla, György Balla and Abolfazl Zarjou

Ferritin in Kidney and Vascular Related Diseases: Novel Roles for an Old Player

Reprinted from: Pharmaceuticals 2019, 12,96, doi:10.3390/ph12020096 . . . . . . . . . . . . 16

Faisal Nuhu and Sunil Bhandari

Oxidative Stress and Cardiovascular Complications in Chronic Kidney Disease, the Impact of Anaemia

Reprinted from: Pharmaceuticals 2018, 11, 103, doi:10.3390/ph11040103 . . . . . . . . . . . . 30

Vida Zhang, Elizabeta Nemeth and Airie Kim

Iron in Lung Pathology

Reprinted from: Pharmaceuticals 2019, 12, 30, doi:10.3390/ph12010030 . . . . . . . . . . . . . 45

Joana Neves, Thomas Haider, Max Gassmann and Martina U. Muckenthaler

Iron Homeostasis in the Lungs-A Balance between Health and Disease

Reprinted from: Pharmaceuticals 2019, 12, 5, doi:10.3390/ph12010005 . . . . . . . . . . . . 56

Verena Petzer, Igor Theurl and Günter Weiss

Established and Emerging Concepts to Treat Imbalances of Iron Homeostasis in Inflammatory Diseases

Reprinted from: Pharmaceuticals 2018, 11, 135, doi:10.3390/ph11040135 . . . . . . . . . . . . 84

Renata Ribeiro, Frederico Batista, Filipe Seguro Paula and José Delgado Alves

Changes in Iron Metabolism Induced by Anti-Interleukin-6 Receptor Monoclonal Antibody are

Associated with an Increased Risk of Infection

Reprinted from: Pharmaceuticals 2019, 12, 100, doi:10.3390/ph12030100 . . . . . . . . . . . . 108

Ana Cordeiro Gomes, Ana C. Moreira, Gonçalo Mesquita and Maria Salomé Gomes

Modulation of Iron Metabolism in Response to Infection: Twists for All Tastes

Reprinted from: Pharmaceuticals 2018, 11,84, doi:10.3390/ph11030084 . . . . . . . . . . . . . 118

John Muthii Muriuki and Sarah H. Atkinson

How Eliminating Malaria May Also Prevent Iron Deficiency in African Children

Reprinted from: Pharmaceuticals 2018, 11,96, doi:10.3390/ph12020096 . . . . . . . . . . . 135

Andrew E. Armitage and Diego Moretti

The Importance of Iron Status for Young Children in Low- and Middle-Income Countries:

A Narrative Review

Reprinted from: Pharmaceuticals 2019, 12,59, doi:10.3390/ph12020059 . . . . . . . . . . . . 146

Fabiana Busti, Giacomo Marchi, Sara Ugolini, Annalisa Castagna and Domenico Girelli

Anemia and Iron Deficiency in Cancer Patients: Role of Iron Replacement Therapy

Reprinted from: Pharmaceuticals 2018, 11,94, doi:10.3390/ph12020094 . . . . . . . . . . . . 177 
Nyamdelger Sukhbaatar and Thomas Weichhart

Iron Regulation: Macrophages in Control

Reprinted from: Pharmaceuticals 2018, 11, 137, doi:10.3390/ph11040137 . . . . . . . . . . . . . . 191

Rafiou Agoro and Catherine Mura

Iron Supplementation Therapy, A Friend and Foe of Mycobacterial Infections?

Reprinted from: Pharmaceuticals 2019, 12, 75, doi:10.3390/ph12020075 . . . . . . . . . . . . . 211

Maria Rangel, Tânia Moniz, André M. N. Silva and Andreia Leite

Tuning the Anti(myco)bacterial Activity of 3-Hydroxy-4-pyridinone Chelators through Fluorophores

Reprinted from: Pharmaceuticals 2018, 11, 110, doi:10.3390/ph11040110 . . . . . . . . . . . . 239

\section{Samira Lakhal-Littleton}

Iron Deficiency as a Therapeutic Target in Cardiovascular Disease

Reprinted from: Pharmaceuticals 2019, 12, 125, doi:10.3390/ph12030125 . . . . . . . . . . . . 263

Enikő Balogh, György Paragh and Viktória Jeney

Influence of Iron on Bone Homeostasis

Reprinted from: Pharmaceuticals 2018, 11, 107, doi:10.3390/ph11040107 . . . . . . . . . . . . 272

Eka Ginanjar, Lilik Indrawati, Iswari Setianingsih, Djumhana Atmakusumah, Alida Harahap, Ina S. Timan and Joannes J. M. Marx

Iron Absorption in Iron-Deficient Women, Who Received $65 \mathrm{mg}$ Fe with an Indonesian Breakfast, Is Much Better from $\mathrm{NaFe}(\mathrm{III})$ EDTA than from $\mathrm{Fe}(\mathrm{II}) \mathrm{SO}_{4}$, with an Acceptable Increase of Plasma NTBI. A Randomized Clinical Trial

Reprinted from: Pharmaceuticals 2018, 11, 85, doi:10.3390/ph11030085 _ . . . . . . . . . . 290

Sunil Bhandari, Dora I. A. Pereira, Helen F. Chappell and Hal Drakesmith

Intravenous Irons: From Basic Science to Clinical Practice

Reprinted from: Pharmaceuticals 2018, 11, 82, doi:10.3390/ph11030082 . . . . . . . . . . . . . 304

Susana Gómez-Ramírez, Elisa Brilli, Germano Tarantino and Manuel Muñoz

Sucrosomial ${ }^{\circledR}$ Iron: A New Generation Iron for Improving Oral Supplementation

Reprinted from: Pharmaceuticals 2018, 11,97, doi:10.3390/ph11040097 . . . . . . . . . . . . . 324

Mateusz Szudzik, Rafał R. Starzyński, Aneta Jończy, Rafał Mazgaj, Małgorzata Lenartowicz and Paweł Lipiński

Iron Supplementation in Suckling Piglets: An Ostensibly Easy Therapy of Neonatal Iron Deficiency Anemia

Reprinted from: Pharmaceuticals 2018, 11, 128, doi:10.3390/ph11040128 . . . . . . . . . . . . 347

Mateusz Szudzik, Rafał R. Starzyński, Aneta Jończy, Rafał Mazgaj, Małgorzata Lenartowicz and Paweł Lipiński

Correction: Mateusz, S., et al. Iron Supplementation in Suckling Piglets: An Ostensibly Easy Therapy of Neonatal Iron Deficiency Anemia. Pharmaceuticals 2018, 11, 128

Reprinted from: Pharmaceuticals 2019, 12, 22, doi:10.3390/ph12010022 . . . . . . . . . . . . 360

Marija Lesjak and Surjit K. S. Srai

Role of Dietary Flavonoids in Iron Homeostasis

Reprinted from: Pharmaceuticals 2019, 12,119, doi:10.3390/ph12030119 . . . . . . . . . . . . 361

\section{Bahtiyar Yilmaz and Hai Li}

Gut Microbiota and Iron: The Crucial Actors in Health and Disease

Reprinted from: Pharmaceuticals 2018, 11,98, doi:10.3390/ph11040098 . . . . . . . . . . . . . 382 
Stefania Recalcati, Elena Gammella and Gaetano Cairo

Ironing out Macrophage Immunometabolism

Reprinted from: Pharmaceuticals 2019, 12,94, doi:10.3390/ph12020094 . . . . . . . . . . . . 402

Michela Asperti, Luca Cantamessa, Simone Ghidinelli, Magdalena Gryzik, Andrea Denardo, Arianna Giacomini, Giovanna Longhi, Alessandro Fanzani, Paolo Arosio and Maura Poli

The Antitumor Didox Acts as an Iron Chelator in Hepatocellular Carcinoma Cells

Reprinted from: Pharmaceuticals 2019, 12, 129, doi:10.3390/ph12030129 . . . . . . . . . . . . . . 412 



\section{About the Special Issue Editors}

Paolo Arosio is full professor in Molecular Biology. He graduated in Milan, than as a post-doc worked at Tufts University in Boston, US. Then he moved to Italy, at the University of Milan and eventually at the University of Brescia in the medical school. He then retired in 2017. He has been working on proteins of iron metabolism, with particular attention to the ferritin structure, about which he wrote numerous research papers and also review articles of success. He then studied the role of ferritin in iron homeostasis, ferritin-linked disorders, some regulatory aspects of iron metabolism and the use of heparin as inhibitor of hepcidin expression. He directed a laboratory on iron metabolism first in San Raffaele Institute of Milan, and then in University of Brescia. He organized congresses of the European Iron Club and of the International Society of Bioiron. He has been guest editor of an issue of Frontiers in Pharmacology (2014) titled "The importance of Iron in Pathophysiologic Conditions", of IUBMB Life (2016) titled "Iron in Biology". He is coauthor in about 230 papers on international peer review journals that have been cited more than 15.000 times. He has an $\mathrm{H}$-index $¿ 65$.

Maura Poli is a professor in Biochemistry in the University of Brescia, Italy. She is working from more than 10 years in the University of Brescia in the Lab. of Molecular Biology with Prof. Arosio on iron metabolism. Prof. Maura Poli received her PhD in 2010, from the Faculty of Medicine of the University of Brescia, and the Clinical Biochemistry Specialization in 2011. She continues to work on iron field, first as post-doctoral fellow, then as researcher and finally as professor. Actually, she has her independent team of approximately 10 researchers, between PhD, Master and Bachelor students and she is involved in studies of different aspects of iron metabolism. She has been invited to national and international conferences. She is author of about 53 publications in peer review scientific journals and Co-Author of one European patent $\left(\mathrm{N}^{\circ} \mathrm{EP} 10192809\right)$ for the use of heparin derivatives to control hepcidin.

Raffaella Gozzelino is an Assistant Professor at NOVA Medical School, NOVA University of Lisbon and an Invited Professor to a number of national and international PhD and Master Programs. She is also an Invited Lecturer at the ENAGO Academy of Science, where she also provides consulting services. She is a Group Leader at the Chronic Diseases Research Center (CEDOC) in Lisbon, where she directs the Inflammation and Neurodegeneration Laboratory and a team of approximately 10 researchers, between PhD, Master and Bachelor students. She is also a member of the Scientific Advisory Board at Thelial Technologies S.A., and one of the Board of Directors of The International BioIron Society. 



\title{
Protective Role of Histidine Supplementation Against Oxidative Stress Damage in the Management of Anemia of Chronic Kidney Disease
}

\author{
Mayra Vera-Aviles, Eleni Vantana, Emmy Kardinasari, Ngat L. Koh and \\ Gladys O. Latunde-Dada * \\ King's College London, Department of Nutritional Sciences, Faculty of Life Sciences and Medicine, \\ Franklin-Wilkins Building, 150 Stamford Street, London SE1 9NH, UK; mayra.vera_aviles@kcl.ac.uk (M.V.-A.); \\ el.vantana@outlook.com (E.V.); ekardinasari@gmail.com (E.K.); lea.koh@gmail.com (N.L.K.) \\ * Correspondence: yemisi.latunde-dada@kcl.ac.uk
}

Received: 30 August 2018; Accepted: 16 October 2018; Published: 21 October 2018

\begin{abstract}
Anemia is a major health condition associated with chronic kidney disease (CKD). A key underlying cause of this disorder is iron deficiency. Although intravenous iron treatment can be beneficial in correcting CKD-associated anemia, surplus iron can be detrimental and cause complications. Excessive generation of reactive oxygen species (ROS), particularly by mitochondria, leads to tissue oxidation and damage to DNA, proteins, and lipids. Oxidative stress increase in CKD has been further implicated in the pathogenesis of vascular calcification. Iron supplementation leads to the availability of excess free iron that is toxic and generates ROS that is linked, in turn, to inflammation, endothelial dysfunction, and cardiovascular disease. Histidine is indispensable to uremic patients because of the tendency toward negative plasma histidine levels. Histidine-deficient diets predispose healthy subjects to anemia and accentuate anemia in chronic uremic patients. Histidine is essential in globin synthesis and erythropoiesis and has also been implicated in the enhancement of iron absorption from human diets. Studies have found that L-histidine exhibits antioxidant capabilities, such as scavenging free radicals and chelating divalent metal ions, hence the advocacy for its use in improving oxidative stress in CKD. The current review advances and discusses evidence for iron-induced toxicity in CKD and the mechanisms by which histidine exerts cytoprotective functions.
\end{abstract}

Keywords: histidine; iron; anemia; oxidative stress; kidney

\section{Introduction}

Chronic kidney disease (CKD) is a generic term that includes the majority of renal disorders. Anemia, an invariable consequence of CKD, is higher in patients with renal disease compared to the unaffected population (15.4\% vs. $7.6 \%$, respectively) globally according to the 2014 outcome of the National Health and Nutrition Examination Survey (NHANES) [1]. Judging by the glomerular filtrate rate, CKD is classified in stages from 1-5, with 5 being the last stage, also known as end-stage renal disease (ESRD) [2]. In the U.K., the prevalence of stages 3-5 CKD is estimated to be $9 \%$ of the adult population [3]. Approximately $50 \%$ of patients with CKD in the U.S. are reported to be anemic [4]. Observational studies also reported a 13\% increased risk of hospitalizations for patients with low hematocrits [5,6], as well as $6 \%$ increased risk of cardiovascular events per $10 \mathrm{~g} / \mathrm{L}$ decrease in hemoglobin $(\mathrm{Hb})$, for patients with anemia in CKD [7]. Data from patients with hemodialysis from five European countries showed that lower hemoglobin levels are associated with increased morbidity and mortality [8]. This result is of particular public health concern as anemia in CKD has been reported to significantly reduce quality of life compared to the general population, with $\mathrm{Hb}$ levels as the 
predictive factor [9]. Oxidative stress and chronic inflammation are hallmarks of CKD; the magnitude of the resultant adverse consequences ranges across the different stages of the manifestation of the disorder and depends on the nature of the therapy employed. The origin of oxidative stress in CKD is varied and includes toxicity induced by excess iron supplements, uremic toxins, and the burden imposed by the hemodialysis process and the equipment employed. Consequently, the inflammation that ensues is associated with elevated ferritin and hepcidin levels; the latter inhibits ferroportin, which blocks iron efflux into circulation. This results in low iron availability for erythropoiesis and hyporesponsiveness to iron and Erythropoietin Stimulating Agent (ESA) therapy. The complexity inherent in inflammation-induced elevated serum ferritin and hepcidin levels poses complications when setting predictive cut-off values for these biomarkers of iron deficiency anemia in CKD [10]. Hence, inflammatory confounders are a contentious issue attracting debate on consensus values for international guidelines on biomarkers of ferritin and hepcidin levels, as well as for iron and ESA dosage and routes of administration. Untreated anemia triggers several debilitating symptoms, such as lethargy, muscle fatigue, and deterioration of renal function. These culminate consequently in high prevalence of cardiovascular diseases, such as left ventricular hypertrophy and heart failure, which constitute the main causes of death in patients with CKD [11,12].

\section{Anemia of Chronic Kidney Disease (ACKD)}

Anemia is a common complication in CKD that increases in prevalence as the disease progresses [1]. Anemia is defined as $\mathrm{Hb}$ concentrations $<13.0 \mathrm{~g} / \mathrm{dL}$ in men and $<12.0 \mathrm{~g} / \mathrm{dL}$ in women [13]. Suboptimal levels of $\mathrm{Hb}$ and hematocrit in CKD patients are associated with declining survival rate $[14,15]$. This was evident in a population study that reported anemia as a critical factor in the development of cardiovascular disease (CVD) in CKD patients [16]. Consequently, CVDs such as heart failure and stroke have been implicated as major causes of mortality in CKD patients [11,12,17]. Anemia of CKD could also be due to multifactorial causes (Figure 1). Dysfunctional platelets, the shortening life span of red blood cells, iron deficiency, and inflammation are some of the factors that can trigger the onset of anemia [18]. The primary cause of anemia, however, is iron deficiency which may, in turn, be caused by low iron intake, low iron absorption, or disruption of body iron regulation. The damage that is caused to the kidney induces rapid activation of the immune system, and the inflammatory response, which stimulates IL-6 signal enhancement of hepcidin in the liver $[19,20]$. Inflammation inhibits erythropoiesis, affects erythropoietin (EPO) hyporesponsiveness [21], and reduces systemic circulation of iron levels by the production of hepcidin [22,23]. This response cascade indirectly contributes to the development of iron deficiency anemia (IDA) [24]. Excess hepcidin causes reduced circulation of iron in the plasma by a mechanism that involves the degradation of ferroportin, the iron efflux protein. Subsequently, iron release into the circulation from enterocytes and macrophages decreases $[25,26]$ as shown in Figure 1. Levels of EPO decrease as a result of kidney damage and this culminates in lower erythroid cell production in the bone marrow. Bleeding during CKD causes loss of red blood cells leading to the development of anemia during CKD. Thus, the etiology of ACKD is a spectrum that involves both absolute and functional iron deficiency. The latter is compounded by an interplay of inflammation, tissue iron sequestration, and a hyporesponsiveness to ESA therapy [27]. Hypoxia-Inducible Factors (HIFs) that are secreted in the kidney during hypoxia can induce EPO production, and provide alternative therapy for (ACKD) [28]. Antibodies against hepcidin have been proposed as alternative approaches to increase iron absorption and iron efflux from the tissues [29]. 


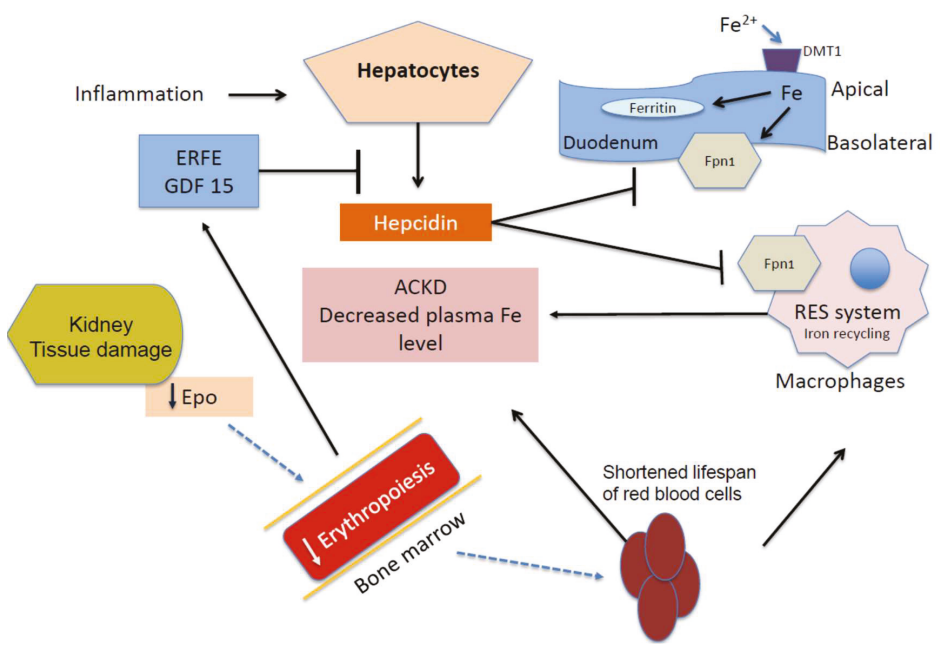

Figure 1. Iron metabolism in anemia of kidney disease. Hepcidin increases during inflammatory conditions and its clearance decreases in dysfunctional kidney cells. Fpn1 is degraded by hepcidin and, as a result, iron transport in the basolateral membrane of enterocytes reduces, as well as the mobilization of iron in macrophages, resulting in lower plasma levels of iron. The hepcidin level decreases during ineffective erythropoiesis and anemia by the actions of erythroid regulators erythroferrone (ERFE) and growth differentiation factor 15 (GDF15). EPO: Erythropoietin; Fpn1: Ferroportin; DMT1: Divalent Metal Transporter; and NTBI: Non-Transferrin Bound Iron.

\section{Treatment of ACKD}

Reduced production of red blood cell is proposed as the main cause of anemia in CKD patients. This arises from damage to the peritubular cells of the kidney, which produce erythropoietin (EPO), an essential hormone in erythropoiesis [30,31]. Erythropoietin induces the production and proliferation of erythrocytes; hence, a disruption in normal EPO levels causes anemia [32], as shown in Figure 1. Thus, the treatment for ACKD implies the administration of Erythropoiesis Stimulating Agents (ESAs). Recombinant human EPO (rHuEPO) is medically prescribed and several guidelines for promoting its efficacy in alleviating $\mathrm{Hb}$ levels have been reported [13,32,33].

The administration of $\mathrm{rHuEPO}$ is effective for correcting anemia and increasing hematocrit and reticulocyte count, although a concomitant increase in hypertension among the patients has been reported [34,35]. Currently, a $\mathrm{Hb}$ target range of 11.0 to $12.0 \mathrm{~g} / \mathrm{dL}$ is recommended [36] because full normalization $(\mathrm{Hb}>13 \mathrm{~g} / \mathrm{dL})$, according to Correction of Hemoglobin and Outcomes in Renal Insufficiency (CHOIR), is not prescribed due to increased cardiovascular events [37]. Additionally, in a post-hoc analysis of the CHOIR trial [38], increased mortality was found to be significantly associated with both the inability to achieve the $\mathrm{Hb}$ target and the use of high ESA doses. This was confirmed by a meta-analysis of 24 randomized controlled trials (RCTs), in which higher $\mathrm{Hb}$ targets resulted in increased hypertension risk ( $R R=1.40,95 \%$ confidence interval $(C I) 1.11-1.75)$, stroke $(\mathrm{RR}=1.73 ; 95 \% \mathrm{CI} 1.31-2.29)$ and hospitalization $(\mathrm{RR}=1.07,95 \% \mathrm{CI} 1.01-1.14)$ [6]. It was reported that rHuEPO induces hypo-responsiveness at high doses [39], and causes a greater risk of death due to the oxidative stress that exacerbates cardiovascular risk [40]. Recombinant HuEPO treatment is furthermore associated with increased blood pressure and blood clotting [41,42]. rHuEPO therapy is associated with iron deficiency as iron stores are largely transferred from the bone marrow to the erythroid progenitor cells due to enhanced erythropoiesis. Iron deficiency is observed in most hemodialysis patients arising from recurrent chronic blood losses. Thus, iron supplementation is often required to optimise or complement $\mathrm{rHuEPO}$ administration in the treatment of anemia in patients 
with CKD [18]. Consequently, if iron therapy is used alongside ESAs, significant increases in $\mathrm{Hb}$ levels and response are observed without the need to increase ESA dosage [43]. Thus, in practice, Kidney Disease Improving Global Outcomes (KDIGO) guidelines recommended a trial of intravenous iron to treat anemia in CKD, irrespective of ESA treatment [44]. In advanced stages of kidney disease, intravenous (IV) iron in combination with EPO therapy is currently the most effective treatment $[44,45]$. In light of this, the use of high intravenous iron doses was adopted in the U.S., despite the concerns raised by nephrologists regarding the resultant iron overload [46]. Supporting evidence from an analysis of 32,435 hemodialysis patients showed increased mortality (hazard ratio (HR) $=1.13,95 \%$ CI $1.00-1.27$ ) and hospitalization ( $\mathrm{HR}=1.12,95 \% \mathrm{CI} 1.07-1.18$ ) in those receiving above $300 \mathrm{mg} / \mathrm{month}$ of intravenous iron compared to other patients receiving only $100 \mathrm{mg} / \mathrm{month}$ [47].

Although IV iron and rHuEPO led to improvement of hematological profiles, the risk of toxicity caused by excess iron predisposes patients to oxidative stress, inflammation, and pathogenic consequences $[48,49]$. Allergic reactions and anaphylactic shock, as well as oxidative stress that is related to cardiovascular complications and tissue injury, have been reported during the administration of IV iron supplementation $[46,48,50]$. The basis and mechanisms of the oxidative stress are not completely understood; however, excess iron from IV administration could cause iron overload and increase the levels of ROS in patients [12,51]. Also, IV iron supplementation raises levels of malondialdehyde (MDA), a biomarker of lipid peroxidation [52].

Several iron compounds including iron isomaltoside, iron sucrose, iron dextran, iron gluconate, or ferric carboxymaltose [53] are used for the treatment of ACKD. Intravenous iron formulations are colloidal suspensions, composed of a core of iron (iron-oxyhydroxide/oxide) surrounded by a carbohydrate shell [54]. The iron formulation varies in core size, affinity of bound iron to carbohydrate excipient, and electrovalence of iron, all of which influence the reactivity of iron [55].

Exposure of CKD patients to high concentrations of iron supplementation thus poses a potential risk of ROS generation with concomitant damage to DNA, proteins, or lipids [56]. Iron supplementation in patients with ACKD can subsequently result in iron overload, characterized by a "spill over" into hepatocytes if non-transferrin bound iron (NTBI) is present. Clinically relevant concentrations of NTBI would be expected if the iron-carrying capacity of transferrin is saturated [57]. Recommendations for iron management in CKD patient care are currently conflicting and is an ongoing process because of limited research evidence. A number of randomized controlled trials (RCTs) and observational studies have produced varying results on the effectiveness and adverse effects of iron or ESA supplementation. Variability or confounders, mostly associated with study design, have been identified [58] including type, dosage, duration or route of iron administration, population size, and the inherent variability within the baseline hematological status of patients.

\section{Iron, Oxidative Stress, and Anemia}

Iron $(\mathrm{Fe})$, when supplied in excess, leads to oxidative stress in the mitochondria. Iron molecules trigger the initiation of the Fenton reaction and promote the formation of $\mathrm{ROS}$, such as $\mathrm{O}_{2}{ }^{-}, \mathrm{OH}$, and $\mathrm{H}_{2} \mathrm{O}_{2}$, as depicted in the equation: $\mathrm{Fe}^{2+}+\mathrm{H}_{2} \mathrm{O}_{2} \rightarrow \mathrm{Fe}^{3+}+\mathrm{OH}+\mathrm{OH}^{-}$[59]. These reactive species bind to macromolecules, such as lipids, proteins, and nucleic acids, causing lipid peroxidation and oxidative modifications of proteins and DNA [60]. Peroxidation of membrane lipids results in loss of membrane fluidity, elasticity, and disordered cellular functioning. Protein oxidation causes fragmentation of amino acid residues leading to cross-linkage and loss of protein configuration and functions. Oxidative damage of DNA causes mutation in DNA bases. These aberrations play major roles in cell death, ageing, and in degenerative diseases [61]. Observations in clinical trials showed a significant increase in the levels of MDA, a key oxidative stress marker, after IV iron infusion [62], and this is correlated with markers of early atherosclerosis [63]. Patients with CKD have a reduced mitochondrial DNA copy number, reduced energy production, and higher levels of stress markers [64]. Cytochrome c oxidase, an enzyme of the oxidative chain, is reduced in patients suffering from CKD in the final stages $[65,66]$. In addition, there are increasing concerns regarding the risk of iron therapy in potentially exacerbating 
oxidative stress, inflammation, and adverse cardiovascular outcomes from excess iron deposition in this population [11]. Atherosclerosis caused by oxidative damage, and evidenced by increased circulating mononuclear superoxide production and vascular cell adhesion molecule-1 (VCAM-1) and triggered by NADPH oxidase (NOx) and NF-kB activation in CKD patients, is associated with IV iron administration [67-70]. Against this evidence, some studies on the role of iron in CKD pathogenesis showed contradictory results [71]. Iron deposition in the liver of both humans [72] and rats [73] did not develop into cirrhosis, possibly because of iron sequestration into innocuous ferritin $\mathrm{L}$ and $\mathrm{H}$ subunits. Another mechanism that was proposed as a process that prevents iron overload in tissues such as the liver is the secretion of iron-loaded ferritin [74], possibly by an iron-regulated exocytosis efflux process [75] into blood circulation. However, other evidence revealed that high doses of iron were associated with high mortality due to iron-induced oxidative stress [68,71].

CKD patients, apart from a dysregulated iron metabolism, often exhibit hyperphosphatemia, which is associated with vascular calcification $[69,76]$. Paradoxically, heme iron, rather than being a pro-oxidant, was found to prevent the calcification and osteoblastic differentiation of human aortic smooth muscle cells (HSMCs) $[77,78]$. Evidence in this study attributed the inhibition of calcification to the upregulation of ferritin in the cells, even in the presence of phosphate. Heme releases Fe, CO, and biliverdin when catabolized. Thereby, iron performs the dual role of chelating phosphate and inducing the transcription of ferritin [79], particularly H-ferritin that exhibits high ferroxidase activity. Although the molecular mechanisms of vascular calcification require further investigation, emerging evidence indicates that ferritin might also function as a transcriptional regulator of gene expression in osteoblastic differentiation and $\beta$-globin synthesis [80].

\section{Cytoprotective Functions of Histidine against Iron Toxicity during the Treatment of ACKD}

L-histidine, a conditionally essential amino acid in adults, was found at significantly lower levels in patients with kidney disease and uremia [81,82]. Histidine, when administered orally or intravenously co-supplemented with iron, showed a positive response as judged by anemia markers, increased levels of plasma iron and $\mathrm{Hb}$ during anemia [83-85].

The beneficial effect of histidine is partly mediated by its ability to promote net nitrogen synthesis [84], which prevents negative nitrogen balance and loss of protein in CKD patients. Combined supplementation of IV iron with histidine rather than IV iron alone was more effective in treating anemia in CKD patients [86]. Additional evidence supports the beneficial role of histidine supplementation in uremic and dialysis patients, as a slight increase in $\mathrm{Hb}$ levels was triggered. Low histidine levels were shown to be correlated with high mortality ( $\mathrm{HR}=1.55,95 \%$ CI 1.02, 2.40, $p<0.05$ ), even after adjustments for age, sex, cardiovascular disease, inflammation, diabetes mellitus, serum albumin, and amino acid supplementation [81]. Histidine administration was negatively correlated $(p<0.05)$ with levels of 8-OHdG, an oxidative stress biomarker [81]. Histidine is known as an efficient scavenger of ROS [87], and its antioxidant properties have been advocated in the prevention of iron toxicity.

\section{Antioxidant Function of Histidine against Oxidative Stress}

The management of anemia of CKD presents a conundrum that arises from a role in the treatment of iron deficiency and in improvement of the resultant toxicity of excess iron. Endogenous and dietary antioxidants prevent, neutralize, and terminate chain reactions that produce ROS.

Studies by Halliwell and Wade identified that histidine could serve as an antioxidant as well as a buffer, similar to albumin in the plasma $[88,89]$. Hence, histidine could function as a buffer regulating free metal ion concentration, thereby providing a safe temporary transport for divalent metals before they are metabolized. In cardiovascular studies, histidine afforded protection to the cardiovascular system because of its ability to scavenge singlet oxygen and hydroxyl radicals in isolated hearts tissues that are predisposed to oxidative stress [90]. The scavenging of singlet oxygen by histidine was found to be significantly higher than that of tryptophan or methionine [89]. Moreover, histidine is 
suggested to be protective against oxidative stress in a drug model, reflected in its storage stability [91]. Histidine has been shown to have an inhibitory effect on $\mathrm{H}_{2} \mathrm{O}_{2}$-induced IL- 8 secretion in Caco-2 and HT-29 cells [92]. Lipid peroxidation was considerably inhibited when histidine was added to ferric iron in vitro [93], suggesting that histidine formed a complex with ferric iron and prevented the formation of ferrous iron and the Fenton reaction [94]. Histidine quenches and scavenges hydroxyl radicals and singlet oxygen [89]. The intracellular concentration of histidine is higher than found in plasma $[89,95]$, resulting in different cellular responses in the protection against ROS. Histidine and its dipeptides have also been associated with increased expression of catalase and glutathione peroxidase antioxidant enzymes [96,97]. Although histidine exerts a positive effect on the amino acid pool within the cell, the deprivation of histidine could specifically induce a decrease in enzymatic antioxidant defenses [98]. The use of histidine as a scavenger increases the defense of cells against oxidative damage [99]. Histidine supplementation was shown to enhance the expression and the activities of catalase and glutathione peroxidase (GPX), in response to ethanol-induced liver damage in mice [100]. Consequently, the potential resides in histidine to enhance enzymatic antioxidant activity during oxidative stress and inflammatory conditions in the cell [100-102].

A study of the cytoprotective effect of histidine on the nervous system was related to the activity of histidine in the transport of glutamine into mitochondria during edema and inflammatory conditions [97]. As L-histidine readily traverses the blood-brain barrier, supplementations with this amino acid were shown to increase both total nitric oxide synthases (NOS) and total antioxidant capacity, conferring protection against oxidative stress and encephalopathy in rats [103]. Moreover, histidine was reported to be a scavenger of the hydroxyl radical in a study conducted on rabbits [104]. The scavenging of singlet oxygen by histidine was further confirmed in rats [105]. Histidine is, therefore, regarded as an efficient scavenger of the both hydroxyl radical and singlet oxygen based on its antioxidant abilities [87], as well as possessing the capacity to chelate divalent metals such as iron $[51,54,63]$.

Histidine was shown to protect against iron-induced oxidative stress in human embryonic kidney (HEK-293) cells (Figure 2). Cells were pre-treated with histidine at 100, 250, and $500 \mu \mathrm{M}$ concentrations overnight, and then subjected to iron challenge with $20 \mu \mathrm{M}$ of 8-hydroquinoline (8-HQ) and $50 \mu \mathrm{M}$ of ferric ammonium citrate (FAC) for two hours. Histidine significantly protected cell viability in cultured HEK-293 cells at all histidine concentrations [106]. This finding confirms earlier results from the literature on the lowering of inflammation and oxidative stress by histidine in other cell culture models [92]. The molecular mechanisms by which histidine exerts the protective function against iron and oxidative stress require further investigation.

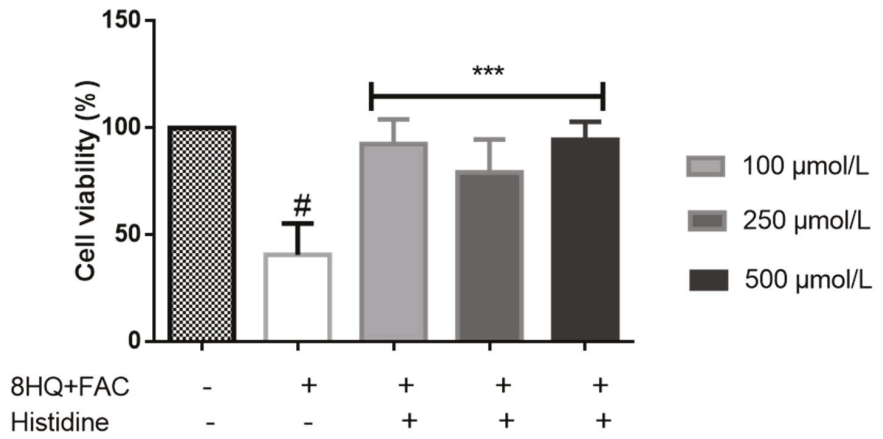

Figure 2. Protective effect of histidine against iron-induced stress in HEK-293 cells. Cells were treated with histidine (100-500 $\mu \mathrm{M})$ overnight and subjected to $20 \mu \mathrm{M}$ 8-hydroxyquinoline (8HQ) and $50 \mu \mathrm{M}$ ferric ammonium citrate (FAC) for two hours, after which cell viability was performed using 3-(4,5-dimethylthiazol-2-yl)-2,5-diphenyltetrazolium bromide (MTT) assay. ${ }^{* * *} p<0.001$ between 8HQ + FAC and the treatments, $\# p<0.001$ between the control and iron treatment. 


\section{Metal Chelation Capacity of Histidine}

Free histidine is an amino acid that is present in cells of the brain, skeletal muscle, and liver [100]. It has an imidazole ring that, in combination with the amino group, facilitates binding and chelation of other compounds. Histidine is also a constituent of some dipeptides such as carnosine, anserine and a precursor of the neurotransmitter histamine $[89,96,107,108]$. Notably, the iron-chelating property of carnosine has been ascribed to the imidazole ring of histidine $[96,102,108]$. Histidine is a proximal ligand of heme iron in the $\mathrm{Hb}$ molecule [109]. In equimolar solutions, divalent metals can interact with histidine via the amino, imidazole, or carboxyl moiety (Figure 3). This is probably highly specific and selective amongst different divalent metal ions. The formation and stability of most histidine-divalent metal complexes are favored by slightly acidic $\mathrm{pH}(\mathrm{pH}<5)$. The histidine molecule thus forms stable strong bonds with iron ions, displaying a bidentate and protonated activity on the primary amino-group at $\mathrm{pH} 5$. Tridentate metal chelate can also form with histidine via the imidazole ring [110-112]. Histidine forms stable bidentate complexes in aqueous systems with $\mathrm{Cu}^{2+}, \mathrm{Fe}^{2+}$, and $\mathrm{Ni}^{2+}[112,113]$. Incidentally, complexes of histidine with $\mathrm{Zn}^{2+}, \mathrm{Cu}^{2+}, \mathrm{Ni}^{2+}$, or $\mathrm{Co}^{2+}$ have higher stability constants than with $\mathrm{Fe}^{2+}$, and the binding stability is dependent on the binding moiety, temperature, and $\mathrm{pH}$ of the solution [112]. Histidine-divalent metal $\left(\mathrm{Cu}^{2+}, \mathrm{Zn}^{2+}\right.$, and $\left.\mathrm{Ni}^{2+}\right)$ complexes, in aqueous solutions, form with the imidazole and amine group at $\mathrm{pH} 6$ [111]. The iron chelating property of histidine is therefore dependent on $\mathrm{pH}$ and the nature of the three possible interacting bonds with ligands (Figure 3). The $\mathrm{pKa}$ values of histidine in proteins range between $\mathrm{pH} 6$ and $\mathrm{pH} 8$. Consequently, side chains of histidine contribute to the buffering potentials of proteins such as $\mathrm{Hb}$ at the physiological $\mathrm{pH}$ of blood. A simulation of the titration curve of histidine reacting with ferrous iron, presented in Figure 4, shows that histidine at $1 \mathrm{mM}$ forms a complex with iron at neutral $\mathrm{pH}$; however, when the concentration of histidine is lowered 10 fold, the formation of the complex decreases and peaks at $\mathrm{pH}$ 8 . This speciation plot shows that, at neutral $\mathrm{pH}$, histidine, at high concentrations, can bind iron with high affinity; however, this reaction is not at the physiological concentration of histidine in tissues or plasma.

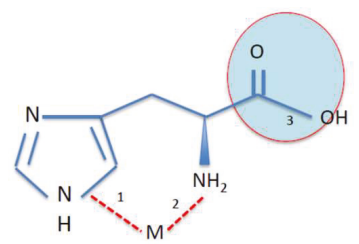

Figure 3. Structure of the histidine molecule showing the imidazole ring, amino, carboxyl groups, and metal ion (M) binding sites.

In vitro studies demonstrated that histidine is the most effective hydroxyl radical scavenger out of the several amino acids that were investigated [114]. The scavenging ability of histidine seems to involve a chelating mechanism that interferes with the redox reaction of metal ions producing hydroxyl radicals [89]. Nair et al. [115] reported that histidine displays a strong binding affinity to $\mathrm{Fe}^{3+}$ ions, thereby reducing the amount of ROS generated via the Fenton reaction, and protecting cells from damage due to iron overload [87]. In addition, histidine can interact directly with singlet oxygen through its imidazole ring [89]. Some other studies have shown, in contrast, that histidine may function as a pro-oxidant. Tachon reported that the enhancing effect of histidine on DNA degradation by ferric ions is dependent on the chelator/metal ratio, and is likely mediated by an oxidant such as ferrous-dioxygen-ferric chelate complex or a chelate-ferryl ion [116]. Evidence from studies to support the protective effect of histidine against oxidative stress remains both fragmentary and contradictory. This discrepancy is perhaps due to differences in experimental methodology and design; for example, the types of established cell lines, and histidine dosage employed in the studies. 


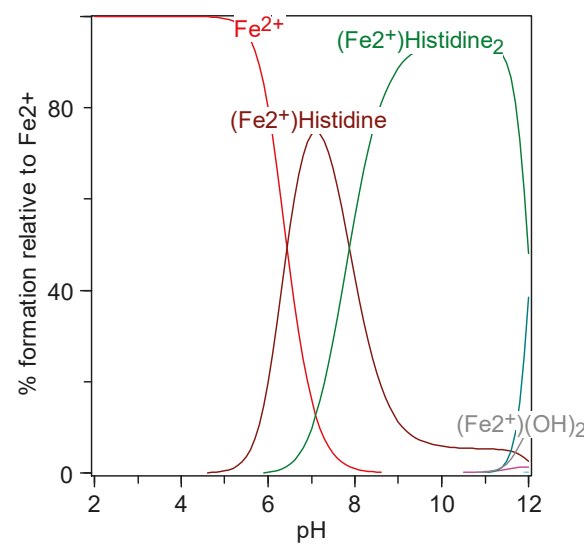

(A)

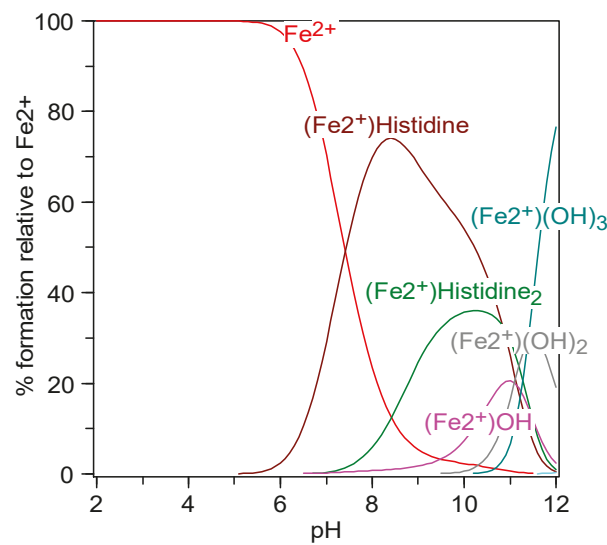

(B)

Figure 4. Speciation plots of histidine and ferrous $\left(\mathrm{Fe}^{2+}, \mathrm{Fe}(\mathrm{II})\right)$ iron. Speciation plots with parameters of $50 \mu \mathrm{M}$ Fe (II) and (A) $1 \mathrm{mM}$ histidine or (B) $100 \mu \mathrm{M}$ histidine.

The chelating property of histidine has been correlated with some physiological functions such as the capacity to increase iron uptake [117], as well as its ability to protect against ROS in the nervous system [92]. Histidine has the capacity to bind divalent metal ions (including those of copper, zinc, and iron) and enhance iron absorption $[117,118]$. The ligand formed by histidine possibly prevents iron precipitation, enhancing iron absorption in the intestine $[118,119]$. Histidine-containing peptides chelated iron for enhanced iron absorption in the segments of rat intestine [120]. This is, however, in contrast to an earlier finding in a human study in which histidine did not enhance iron absorption [121]. The ratio of histidine content in different peptides has been contradictorily reported regarding either its inorganic iron absorption or enhancing function [117].

Histidine has been associated with the capacity to chelate iron and enhance iron solubility in the duodenum, as ferrous iron is poorly soluble at neutral $\mathrm{pH}$. By binding to histidine and other chelating compounds, the uptake of the metal increases [119]. The role of histidine in binding iron and increasing its uptake is debatable; the positive evidence suggested that the co-supplementation of histidine doses of about $100 \mathrm{mM}$ could increase iron uptake in rats, and in combination with ascorbic acid, this could doubly enhance the positive effect of ascorbic acid [122]. This was also observed in cultured Caco-2 cells [123]. However, another study on intestinal cells and on humans did not report such increases of iron uptake upon histidine supplementation [121,124]. In food extracts, histidine has been found to increase inorganic iron solubility; however, these results arose from vegetables and meat extracts wherein the efficacy of histidine could have been confounded by the presence of other amino acids and peptides $[117,125,126]$. Histidine undoubtedly has the capacity to bind iron; however, as this reaction is $\mathrm{pH}$-dependent, histidine might serve the important function of maintaining iron in soluble form to enhance iron bioavailability. The presence of other compounds or stronger metal chelators could influence the stability of the histidine-iron complex.

\section{Anti-Inflammatory Potential of Histidine}

As inflammation promotes iron disorders in anemia of chronic kidney disease, factors that increase or inhibit inflammatory signals are important in the manifestation of the disease symptoms. Inflammatory conditions or responses lead to the secretion of different cytokines, such as interleukin 6 (IL-6), interleukin 8 (IL-8), interleukin-1beta (IL-1b), as well as tumor necrosis factor-alpha (TNF- $\alpha$ ) [92]. The physiological effects of histidine as an antioxidant have been associated with the inhibition of the secretion of some of these pro-inflammatory biomarkers, particularly during chronic diseases [89]. 
Liu et al. [100] reported that mice fed with histidine (at 0.5, 1, or $2 \mathrm{~g} / \mathrm{L}$ ) after the induction of ethanol hepatotoxicity had lower levels of the inflammation markers IL-6, c-reactive protein (CRP), and TNF-a. Histidine suppressed the accumulation of IL- 6 and TNF- $\alpha$ mRNA in a dose-dependent manner. This indicates that histidine is not only a scavenger of ROS but could directly affect the regulation of pro-inflammatory cytokines [100]. A similar effect was found in cultured cells, in which histidine protected Caco-2 cells in a dose-dependent manner against hydrogen peroxide-induced damage [89]. Histidine, apart from reducing morphological damage in these cells, suppressed the secretion of IL-8 as well. This outcome is presumably due to the inhibition of signals for TNF- $\alpha$ and NF-k $\beta$ to activate transcriptional regulation of IL-8 [92]. Down-regulation of IL- 6 and TNF- $\alpha$ by histidine has been reported in a diabetic mouse model [127]. The inhibition of pro-inflammatory cytokines by histidine is linked to its potential to increase the amino acid pool and the antioxidant status of the cells [107]. These changes contribute to the attenuation of ROS in tissues and organs. Histidine was reported to alleviate clinical symptoms and protect mice from intestinal, nervous, and cardiovascular damage [89]. These effects are possibly associated with the anti-inflammatory properties of histidine. Consequently, histidine administration could be an option for reducing and preventing oxidative stress in inflammatory conditions in chronic diseases. Dietary supplementation with histidine could be protective against oxidative damage, arising from the scavenging activity and anti-inflammatory effects of this amino acid in cells and tissues [127].

Arginine is another amino acid that exhibits antioxidant properties as a substrate in nitric oxide (NO) biosynthesis and was shown to be beneficial to kidney functions in both in vivo and in vitro models $[128,129]$. As well as other histidine dipeptides, carnosine also scavenges ROS and was reported to be beneficial to CKD patients [130].

\section{Conclusions}

Anemia of chronic kidney disease is a worldwide public health problem, with a constantly-increasing trend in both developed and developing countries. Iron supplementation treatment of ACKD leads to oxidative damage that is associated with iron overload and pro-inflammatory conditions. Co-supplementation with histidine, could have an ameliorating effect against oxidative damage in chronic kidney disease. Histidine can protect against iron overload and oxidative stress caused by CKD, as demonstrated with the Fenton substrate in the HK-2 cell model. The molecular mechanisms of the cytoprotection conferred by histidine are based on its capacity and potential as a metal chelator as well as its ability to scavenge oxygen radicals. Histidine can also function intracellularly to induce enzymatic antioxidant and anti-inflammatory activities in tissues and organs in different disorders $[113,114]$. The imidazole ring of histidine, as well as binding singlet oxygen molecules, can bind divalent metal ions; however, the effects of $\mathrm{pH}$ and histidine concentration that maintains iron in solution have only been clearly demonstrated in cultured cells and in animal models. It remains for these effects to be demonstrated in human subjects. The iron quenching capacity appears to be related to the reactive ability of the imidazole ring of histidine in extracellular solutions. No clear evidence currently exists for the localization of histidine-iron bound complexes or chelates intracellularly.

Further studies are required to clearly delineate the molecular mechanisms by which histidine attenuates oxidative stress damage attendant upon iron toxicity in kidney cells and specific models during the treatment of ACKD.

Author Contributions: G.O.L.-D. and M.V.A. wrote the manuscript, M.V.A. performed the experiments and E.V., E.K., and N.K.L. contributed to the review of literature.

Funding: This research received no external funding. Mayra Vera-Aviles is supported by Consejo Nacional de Ciencia y Tecnologia (CONACYT) Mexico.

Acknowledgments: We thank Yu-Lin Chen and Robert Hider for their assistance with histidine chemistry.

Conflicts of Interest: The authors declare no conflict of interest. 


\section{References}

1. Stauffer, M.E.; Fan, T. Prevalence of anemia in chronic kidney disease in the united states. PLoS ONE 2014, 9, e84943. [CrossRef] [PubMed]

2. Macdougall, I.C.; Bircher, A.J.; Eckardt, K.-U.; Obrador, G.T.; Pollock, C.A.; Stenvinkel, P.; Swinkels, D.W.; Wanner, C.; Weiss, G.; Chertow, G.M. Iron management in chronic kidney disease: Conclusions from a "kidney disease: Improving global outcomes" (KDIGO) controversies conference. Kidney Int. 2016, 89, $28-39$. [CrossRef] [PubMed]

3. National Health System. Diabetes with Kidney Disease: Key Facts; Diabetes Kindey Care, Ed.; National Health System England: London, UK, 2011.

4. McClellan, W.; Aronoff, S.L.; Bolton, W.K.; Hood, S.; Lorber, D.L.; Tang, K.L.; Tse, T.F.; Wasserman, B.; Leiserowitz, M. The prevalence of anemia in patients with chronic kidney disease. Curr. Med. Res. Opin. 2004, 20, 1501-1510. [CrossRef] [PubMed]

5. Khan, S.S.; Kazmi, W.H.; Abichandani, R.; Tighiouart, H.; Pereira, B.J.G.; Kausz, A.T. Health care utilization among patients with chronic kidney disease. Kidney Int. 2002, 62, 229-236. [CrossRef] [PubMed]

6. Jing, Z.; Wei-jie, Y.; Nan, Z.; Yi, Z.; Ling, W. Hemoglobin targets for chronic kidney disease patients with anemia: A systematic review and meta-analysis. PLoS ONE 2012, 7, e43655. [CrossRef] [PubMed]

7. Levin, A.; Singer, J.; Thompson, C.R.; Ross, H.; Lewis, M. Prevalent left ventricular hypertrophy in the predialysis population: Identifying opportunities for intervention. Am. J. Kidney Dis. 1996, 27, 347-354. [CrossRef]

8. Locatelli, F.; Pisoni, R.L.; Combe, C.; Bommer, J.; Andreucci, V.E.; Piera, L.; Greenwood, R.; Feldman, H.I.; Port, F.K.; Held, P.J. Anaemia in haemodialysis patients of five european countries: Association with morbidity and mortality in the dialysis outcomes and practice patterns study (DOPPS). Nephrol. Dial. Transplant. 2004, 19, 121-132. [CrossRef] [PubMed]

9. Hansen, R.A.; Chin, H.; Blalock, S.; Joy, M.S. Predialysis chronic kidney disease: Evaluation of quality of life in clinic patients receiving comprehensive anemia care. Res. Soc. Adm. Pharm. 2009, 5, 143-153. [CrossRef] [PubMed]

10. Ueda, N.; Takasawa, K. Impact of inflammation on ferritin, hepcidin and the management of iron deficiency anemia in chronic kidney disease. Nutrients 2018, 10, 1173. [CrossRef] [PubMed]

11. Macdougall, I.C. Anaemia of chronic kidney disease. Medicine 2007, 35, 457-460. [CrossRef]

12. Babitt, J.L.; Lin, H.Y. Mechanisms of anemia in CKD. J. Am. Soc. Nephrol. 2012, 23, 1631-1634. [CrossRef] [PubMed]

13. Locatelli, F.; Bárány, P.; Covic, A.; De Francisco, A.; Del Vecchio, L.; Goldsmith, D.; Hörl, W.; London, G.; Vanholder, R.; Van Biesen, W.; et al. Kidney disease: Improving global outcomes guidelines on anaemia management in chronic kidney disease: A european renal best practice position statement. Nephrol. Dial. Transplant. 2013, 28, 1346-1359. [CrossRef] [PubMed]

14. Ofsthun, N.; Labrecque, J.; Lacson, E.; Keen, M.; Lazarus, J.M. The effects of higher hemoglobin levels on mortality and hospitalization in hemodialysis patients. Kidney Int. 2003, 63, 1908-1914. [CrossRef] [PubMed]

15. Phrommintikul, A.; Haas, S.J.; Elsik, M.; Krum, H. Mortality and target haemoglobin concentrations in anaemic patients with chronic kidney disease treated with erythropoietin: A meta-analysis. Lancet 2007, 369, 381-388. [CrossRef]

16. Abramson, J.L.; Jurkovitz, C.T.; Vaccarino, V.; Weintraub, W.S.; Mcclellan, W. Chronic kidney disease, anemia, and incident stroke in a middle-aged, community-based population: The aric study. Kidney Int. 2003, 64, 610-615. [CrossRef] [PubMed]

17. Malik, J. Heart disease in chronic kidney disease - Review of the mechanisms and the role of dialysis access. J. Vasc. Access 2018, 19, 3-11. [CrossRef] [PubMed]

18. Dull, R.B.; Davis, E. Heme iron polypeptide for the management of anaemia of chronic kidney disease. J. Clin. Pharm. Ther. 2015, 40, 386-390. [CrossRef] [PubMed]

19. Wang, H.; Li, H.; Jiang, X.; Shi, W.; Shen, Z.; Li, M. Hepcidin is directly regulated by insulin and plays an important role in iron overload in streptozotocin-induced diabetic rats. Diabetes 2014, 63, 1506-1518. [CrossRef] [PubMed]

20. Weiss, G.; Goodnough, L.T. Anemia of chronic disease. N. Engl. J. Med. 2005, 352, 1011-1023. [CrossRef] [PubMed] 
21. De Francisco, A.L.M.; Stenvinkel, P.; Vaulont, S. Inflammation and its impact on anaemia in chronic kidney disease: From haemoglobin variability to hyporesponsiveness. NDT Plus 2009, 2, i18-i26. [CrossRef] [PubMed]

22. Silverstein, D.M. Inflammation in chronic kidney disease: Role in the progression of renal and cardiovascular disease. Pediatr. Nephrol. 2009, 24, 1445-1452. [CrossRef] [PubMed]

23. Atkinson, M.A.; White, C.T. Hepcidin in anemia of chronic kidney disease: Review for the pediatric nephrologist. Pediatr. Nephrol. 2012, 27, 33-40. [CrossRef] [PubMed]

24. Weinstein, D.A.; Roy, C.N.; Fleming, M.D.; Loda, M.F.; Wolfsdorf, J.I.; Andrews, N.C. Inappropriate expression of hepcidin is associated with iron refractory anemia: Implications for the anemia of chronic disease. Blood 2002, 100, 3776-3781. [CrossRef] [PubMed]

25. Nemeth, E.; Tuttle, M.S.; Powelson, J.; Vaughn, M.B.; Donovan, A.; McVey Ward, D.; Ganz, T.; Kaplan, J. Hepcidin regulates cellular iron efflux by binding to ferroportin and inducing its internalization. Science 2004, 306, 2090-2093. [CrossRef] [PubMed]

26. Young, B.; Zaritsky, J. Hepcidin for clinicians. Clin. J. Am. Soc. Nephrol. 2009, 4, 1384-1387. [CrossRef] [PubMed]

27. Goodnough, L.T.; Nemeth, E.; Ganz, T. Detection, evaluation, and management of iron-restricted erythropoiesis. Blood 2010, 116, 4754-4761. [CrossRef] [PubMed]

28. Locatelli, F.; Fishbane, S.; Block, G.A.; Macdougall, I.C. Targeting hypoxia-inducible factors for the treatment of anemia in chronic kidney disease patients. Am. J. Nephrol. 2017, 45, 187-199. [CrossRef] [PubMed]

29. Gummer, J.; Trengove, R.; Pascoe, E.M.; Badve, S.V.; Cass, A.; Clarke, P.; McDonald, S.P.; Morrish, A.T.; Pedagogos, E.; Perkovic, V.; et al. Association between serum hepcidin-25 and primary resistance to erythropoiesis-stimulating agents in chronic kidney disease: A secondary analysis of the hero trial. Nephrology 2017, 22, 548-554. [CrossRef] [PubMed]

30. Lacombe, C.; Da Silva, J.L.; Bruneval, P.; Fournier, J.G.; Wendling, F.; Casadevall, N.; Camilleri, J.P.; Bariety, J.; Varet, B.; Tambourin, P. Peritubular cells are the site of erythropoietin synthesis in the murine hypoxic kidney. J. Clin. Investig. 1988, 81, 620-623. [CrossRef] [PubMed]

31. Maxwell, P.H.; Osmond, M.K.; Pugh, C.W.; Heryet, A.; Nicholls, L.G.; Tan, C.C.; Doe, B.G.; Ferguson, D.J.P.; Johnson, M.H.; Ratcliffe, P.J. Identification of the renal erythropoietin-producing cells using transgenic mice. Kidney Int. 1993, 44, 1149-1162. [CrossRef] [PubMed]

32. Koury, M.J.; Haase, V.H. Anaemia in kidney disease: Harnessing hypoxia responses for therapy. Nat. Rev. Nephrol. 2015, 11, 394-410. [CrossRef] [PubMed]

33. Kopple, J.D. The national kidney foundation $\mathrm{k} /$ doqi clinical practice guidelines for dietary protein intake for chronic dialysis patients. Am. J. Kidney Dis. 2001, 38, S68-S73. [CrossRef] [PubMed]

34. Apsangikar, P.; Chaudhry, S.; Naik, M.; Deoghare, S.; Joseph, J. Comparative efficacy and safety of biosimilar darbepoetin alfa in adults with anemia of chronic kidney disease. Indian J. Transplant. 2018, 12, 30-34. [CrossRef]

35. Locatelli, F.; Covic, A.; Eckardt, K.-U.; Wiecek, A.; Vanholder, R. Anaemia management in patients with chronic kidney disease: A position statement by the anaemiaworking group of european renal best practice (ERBP). Nephrol Dial Transplant. 2009, 24, 348-354. [CrossRef] [PubMed]

36. National Clinical Guideline Centre. Anaemia Management in Chronic Kidney Disease: Partial Update 2015; NICE Guideline, No. 8. Royal College of Physicians (UK); National Clinical Guideline Centre: London, UK, 2015.

37. Singh, A.K.; Szczech, L.; Tang, K.L.; Barnhart, H.; Sapp, S.; Wolfson, M.; Reddan, D. Correction of anemia with epoetin alfa in chronic kidney disease. N. Engl. J. Med. 2006, 355, 2085-2098. [CrossRef] [PubMed]

38. Szczech, L.A.; Barnhart, H.X.; Inrig, J.K.; Reddan, D.N.; Sapp, S.; Califf, R.M.; Patel, U.D.; Singh, A.K. Secondary analysis of the choir trial epoetin-alpha dose and achieved hemoglobin outcomes. Kidney Int. 2008, 74, 791-798. [CrossRef] [PubMed]

39. Singh, A.K. The controversy surrounding hemoglobin and erythropoiesis-stimulating agents: What should we do now? Am. J. Kidney Dis. 2008, 52, S5-S13. [CrossRef] [PubMed]

40. Vaziri, N.D.; Zhou, X.J. Potential mechanisms of adverse outcomes in trials of anemia correction with erythropoietin in chronic kidney disease. Nephrol. Dial. Transplant. 2009, 24, 1082-1088. [CrossRef] [PubMed]

41. Krapf, R.; Hulter, H.N. Arterial hypertension induced by erythropoietin and erythropoiesis-stimulating agents (ESA). Clin. J. Am. Soc. Nephrol. 2009, 4, 470-480. [CrossRef] [PubMed] 
42. Pfeffer, M.A.; Burdmann, E.A.; Chen, C.-Y.; Cooper, M.E.; de Zeeuw, D.; Eckardt, K.-U.; Feyzi, J.M.; Ivanovich, P.; Kewalramani, R.; Levey, A.S.; et al. A trial of darbepoetin alfa in type 2 diabetes and chronic kidney disease. N. Engl. J. Med. 2009, 361, 2019-2032. [CrossRef] [PubMed]

43. Coyne, D.W.; Kapoian, T.; Suki, W.; Singh, A.K.; Moran, J.E.; Dahl, N.V.; Rizkala, A.R. Ferric gluconate is highly efficacious in anemic hemodialysis patients with high serum ferritin and low transferrin saturation: Results of the dialysis patients' response to iv iron with elevated ferritin (drive) study. J. Am. Soc. Nephrol. 2007, 18, 975-984. [CrossRef] [PubMed]

44. Kidney Disease Improving Global Outcomes (KDIGO). Chapter 2: Use of iron to treat anemia in CKD. Kidney Int. Suppl. 2012, 2, 292-298. [CrossRef] [PubMed]

45. Ribeiro, S.; Belo, L.; Reis, F.; Santos-Silva, A. Iron therapy in chronic kidney disease: Recent changes, benefits and risks. Blood Rev. 2016, 30, 65-72. [CrossRef] [PubMed]

46. Del Vecchio, L.; Longhi, S.; Locatelli, F. Safety concerns about intravenous iron therapy in patients with chronic kidney disease. Clin. Kidney J. 2016, 9, 260-267. [CrossRef] [PubMed]

47. Bailie, G.R.; Larkina, M.; Goodkin, D.A.; Li, Y.; Pisoni, R.L.; Bieber, B.; Mason, N.; Tong, L.; Locatelli, F.; Marshall, M.R.; et al. Data from the dialysis outcomes and practice patterns study validate an association between high intravenous iron doses and mortality. Kidney Int 2015, 87, 162-168. [CrossRef] [PubMed]

48. Slotki, I.; Cabantchik, Z.I. The labile side of iron supplementation in CKD. J. Am. Soc. Nephrol. 2015, 26, 2612-2619. [CrossRef] [PubMed]

49. Macdougall, I.C.; Geisser, P. Use of intravenous iron supplementation in chronic kidney disease. An update. Iran. J. Kidney Dis. 2013, 7, 9-22. [PubMed]

50. Shah, S.V.; Rajapurkar, M.M.; Baliga, R. The role of catalytic iron in acute kidney injury. Clin. J. Am. Soc. Nephrol. 2011, 6, 2329-2331. [CrossRef] [PubMed]

51. Elliott, S.; Sinclair, A.; Collins, H.; Rice, L.; Jelkmann, W. Progress in detecting cell-surface protein receptors: The erythropoietin receptor example. Ann. Hematol. 2014, 93, 181-192. [CrossRef] [PubMed]

52. Connor, J.R.; Zhang, X.; Nixon, A.M.; Webb, B.; Perno, J.R. Comparative evaluation of nephrotoxicity and management by macrophages of intravenous pharmaceutical iron formulations. PLoS ONE 2015, 10, e0125272. [CrossRef] [PubMed]

53. Geisser, P.; Burckhardt, S. The pharmacokinetics and pharmacodynamics of iron preparations. Pharmaceutics 2011, 3, 12. [CrossRef] [PubMed]

54. Kalra, P.A.; Bhandari, S. Efficacy and safety of iron isomaltoside (monofer( $(\circledR))$ in the management of patients with iron deficiency anemia. Int. J. Nephrol. Renov. Dis. 2016, 9, 53-64. [CrossRef] [PubMed]

55. Gupta, A.; Pratt, R.D.; Crumbliss, A.L. Ferrous iron content of intravenous iron formulations. BioMetals 2016, 29, 411-415. [CrossRef] [PubMed]

56. Locatelli, F.; Mazzaferro, S.; Yee, J. Iron therapy challenges for the treatment of nondialysis ckd patients. Clin. J. Am. Soc. Nephrol. 2016, 11, 1269-1280. [CrossRef] [PubMed]

57. Wish, J.B.; Aronoff, G.R.; Bacon, B.R.; Brugnara, C.; Eckardt, K.U.; Ganz, T.; Macdougall, I.C.; Núñez, J.; Perahia, A.J.; Wood, J.C. Positive iron balance in chronic kidney disease: How much is too much and how to tell? Am. J. Nephrol. 2018, 47, 72-83. [CrossRef] [PubMed]

58. Macdougall, I.C. Intravenous iron therapy in patients with chronic kidney disease: Recent evidence and future directions. Clin. Kidney J. 2017, 10, i16-i24. [CrossRef] [PubMed]

59. Kruszewski, M. Labile iron pool: The main determinant of cellular response to oxidative stress. Mutat. Res. Fundam. Mol. Mech. Mutagen. 2003, 531, 81-92. [CrossRef]

60. Meneghini, R. Iron homeostasis, oxidative stress, and DNA damage. Free Radic. Biol. Med. 1997, 23, 783-792. [CrossRef]

61. Small, D.M.; Coombes, J.S.; Bennett, N.; Johnson, D.W.; Gobe, G.C. Oxidative stress, anti-oxidant therapies and chronic kidney disease. Nephrology 2012, 17, 311-321. [CrossRef] [PubMed]

62. Lim, P.-S.; Wei, Y.-H.; Yu, Y.L.; Kho, B. Enhanced oxidative stress in haemodialysis patients receiving intravenous iron therapy. Nephrol. Dial. Transplant. 1999, 14, 2680-2687. [CrossRef] [PubMed]

63. Drueke, T.; Witko-Sarsat, V.; Massy, Z.; Descamps-Latscha, B.; Guerin, A.P.; Marchais, S.J.; Gausson, V.; London, G.M. Iron therapy, advanced oxidation protein products, and carotid artery intima-media thickness in end-stage renal disease. Circulation 2002, 106, 2212-2217. [CrossRef] [PubMed]

64. Malik, A.N.; Shahni, R.; Iqbal, M.M. Increased peripheral blood mitochondrial DNA in type 2 diabetic patients with nephropathy. Diabetes Res. Clin. Pract. 2009, 86, e22-e24. [CrossRef] [PubMed] 
65. Malik, A.N.; Czajka, A. Is mitochondrial DNA content a potential biomarker of mitochondrial dysfunction? Mitochondrion 2013, 13, 481-492. [CrossRef] [PubMed]

66. Granata, S.; Dalla Gassa, A.; Tomei, P.; Lupo, A.; Zaza, G. Mitochondria: A new therapeutic target in chronic kidney disease. Nutr. Metab. 2015, 12, 49. [CrossRef] [PubMed]

67. Kuo, K.-L.; Hung, S.-C.; Lin, Y.-P.; Tang, C.-F.; Lee, T.-S.; Lin, C.-P.; Tarng, D.-C. Intravenous ferric chloride hexahydrate supplementation induced endothelial dysfunction and increased cardiovascular risk among hemodialysis patients. PLoS ONE 2012, 7, e50295. [CrossRef] [PubMed]

68. Kuo, K.-L.; Hung, S.-C.; Lee, T.-S.; Tarng, D.-C. Iron sucrose accelerates early atherogenesis by increasing superoxide production and upregulating adhesion molecules in ckd. J. Am. Soc. Nephrol. 2014, 25, 2596-2606. [CrossRef] [PubMed]

69. Neven, E.; De Schutter, T.M.; Behets, G.J.; Gupta, A.; D’Haese, P.C. Iron and vascular calcification. Is there a link? Nephrol. Dial. Transplant. 2011, 26, 1137-1145. [CrossRef] [PubMed]

70. Nakanishi, T.; Kuragano, T.; Nanami, M.; Nagasawa, Y.; Hasuike, Y. Misdistribution of iron and oxidative stress in chronic kidney disease. Free Radic. Biol. Med. 2018, in press. [CrossRef] [PubMed]

71. Kawada, S.; Nagasawa, Y.; Kawabe, M.; Ohyama, H.; Kida, A.; Kato-Kogoe, N.; Nanami, M.; Hasuike, Y.; Kuragano, T.; Kishimoto, H.; et al. Iron-induced calcification in human aortic vascular smooth muscle cells through interleukin-24 (il-24), with/without tnf-alpha. Sci. Rep. 2018, 8, 658. [CrossRef] [PubMed]

72. Eschbach, J.W.; Adamson, J.W. Iron overload in renal failure patients: Changes since the introduction of erythropoietin therapy. Kidney Int. 1999, 55, s-35-S-43. [CrossRef]

73. Malik, I.A.; Wilting, J.; Ramadori, G.; Naz, N. Reabsorption of iron into acutely damaged rat liver: A role for ferritins. World J. Gastroenterol. 2017, 23, 7347-7358. [CrossRef] [PubMed]

74. Ghosh, S.; Hevi, S.; Chuck, S.L. Regulated secretion of glycosylated human ferritin from hepatocytes. Blood 2004, 103, 2369-2376. [CrossRef] [PubMed]

75. Tran, T.N.; Eubanks, S.K.; Schaffer, K.J.; Zhou, C.Y.J.; Linder, M.C. Secretion of ferritin by rat hepatoma cells and its regulation by inflammatory cytokines and iron. Blood 1997, 90, 4979-4986. [PubMed]

76. Giachelli, C.M. Vascular calcification: In vitro evidence for the role of inorganic phosphate. J. Am. Soc. Nephrol. 2003, 14, S300-S304. [CrossRef] [PubMed]

77. Zarjou, A.; Jeney, V.; Arosio, P.; Poli, M.; Antal-Szalmás, P.; Agarwal, A.; Balla, G.; Balla, J. Ferritin prevents calcification and osteoblastic differentiation of vascular smooth muscle cells. J. Am. Soc. Nephrol. 2009, 20, 1254-1263. [CrossRef] [PubMed]

78. Zarjou, A.; Jeney, V.; Arosio, P.; Poli, M.; Zavaczki, E.; Balla, G.; Balla, J. Ferritin ferroxidase activity: A potent inhibitor of osteogenesis. J. Bone Miner. Res. 2010, 25, 164-172. [CrossRef] [PubMed]

79. Arosio, P.; Levi, S. Ferritin, iron homeostasis, and oxidative damage. Free Radic. Biol. Med. 2002, 33, 457-463. [CrossRef]

80. Broyles, R.H.; Belegu, V.; DeWitt, C.R.; Shah, S.N.; Stewart, C.A.; Pye, Q.N.; Floyd, R.A. Specific repression of $\beta$-globin promoter activity by nuclear ferritin. Proc. Natl. Acad. Sci. USA 2001, 98, 9145-9150. [CrossRef] [PubMed]

81. Watanabe, M.; Suliman, M.E.; Qureshi, A.R.; Garcia-Lopez, E.; Bárány, P.; Heimbürger, O.; Stenvinkel, P.; Lindholm, B. Consequences of low plasma histidine in chronic kidney disease patients: Associations with inflammation, oxidative stress, and mortality. Am. J. Clin. Nutr. 2008, 87, 1860-1866. [CrossRef] [PubMed]

82. Kopple, J.D.; Swendseid, M.E. Evidence that histidine is an essential amino-acid in normal and chronically uremic man. J. Clin. Investig. 1975, 55, 881-891. [CrossRef] [PubMed]

83. Jontofsohn, R.; Trivisas, G.; Katz, N.; Kiuthe, I. Amino acid content of erythrocytes in uremia. Am. J. Clin. Nutr. 1978, 31, 1956-1960. [CrossRef] [PubMed]

84. Bergström, J.; Furst, P.; Josephson, B.; Norée, L.-O. Improvement of nitrogen balance in a uremic patient by the addition of histidine to essential amino acid solutions given intravenously. Life Sci. 1970, 9, 787-794. [CrossRef]

85. Blumenkrantz, M.J.; Shapiro, D.J.; Swendseid, M.E.; Kopple, J.D. Histidine supplementation for treatment of anaemia of uraemia. Br. Med. J. 1975, 2, 530-533. [CrossRef] [PubMed]

86. Jontofsohn, R.; Heinze, V.; Katz, N.; Stuber, U.; Wilke, H.; Kluthe, R. Histidine and iron supplementation in dialysis and pre-dialysis patient. Proc. Eur. Dial. Transpl. Assoc. 1974, 11, 391-397. 
87. Kaplan, P.; Matejovicova, M.; Herijgers, P.; Flameng, W. Effect of free radical scavengers on myocardial function and $\mathrm{Na}^{+}, \mathrm{K}^{+}$-atpase activity in stunned rabbit myocardium. Scand. Cardiovasc. J. 2005, 39, 213-219. [CrossRef] [PubMed]

88. Halliwell, B. How to characterize a biological antioxidant. Free Radic. Res. Commun. 1990, 9, 1-32. [CrossRef] [PubMed]

89. Wade, A.M.; Tucker, H.N. Antioxidant characteristics of L-histidine. J. Nutr. Biochem. 1998, 9, 308-315. [CrossRef]

90. Pisarenko, O.I. Mechanisms of myocardial protection by amino acids: Facts and hypotheses. Clin. Exp. Pharmacol. Physiol. 1996, 23, 627-633. [CrossRef] [PubMed]

91. Lim, J.Y.; Kim, N.A.; Lim, D.G.; Kim, K.H.; Hada, S.; Jeong, S.H. Evaluation of etanercept degradation under oxidative stress and potential protective effects of various amino acids. Int. J. Pharm. 2015, 492, 127-136. [CrossRef] [PubMed]

92. Son, D.O.; Satsu, H.; Shimizu, M. Histidine inhibits oxidative stress- and tnf-a-induced interleukin- 8 secretion in intestinal epithelial cells. FEBS lett. 2005, 579, 4671-4677. [CrossRef] [PubMed]

93. Erickson, M.C.; Hultin, H.O. A unique role of histidine in fe-catalyzed lipid oxidation by fish sarcoplasmic reticulum. In Oxygen Radicals in Biology and Medicine; Simic, M.G., Taylor, K.A., Ward, J.F., Sonntag, C., Eds.; Springer: Boston, MA, USA, 1988; pp. 307-312.

94. Erickson, M.C.; Hultin, H.O. Influence of histidine on lipid peroxidation in sarcoplasmic reticulum. Arch. Biochem. Biophys. 1992, 292, 427-432. [CrossRef]

95. Filho, J.C.D.; Bergström, J.; Stehle, P.; Fürst, P. Simultaneous measurements of free amino acid patternsof plasma, muscle and erythrocytes in healthy human subjects. Clin. Nutr. 1997, 16, 299-305. [CrossRef]

96. Hobart, L.J.; Seibel, I.; Yeargans, G.S.; Seidler, N.W. Anti-crosslinking properties of carnosine: Significance of histidine. Life Sci. 2004, 75, 1379-1389. [CrossRef] [PubMed]

97. Rama Rao, K.V.; Reddy, P.V.B.; Tong, X.; Norenberg, M.D. Brain edema in acute liver failure: Inhibition by L-histidine. Am. J. Pathol. 2010, 176, 1400-1408. [CrossRef] [PubMed]

98. Baldbige, K.C. Effects of thiamine and biboflavin deficiency on histidine metabolism. J. Nutr. 1958, 66, 29-34.

99. Ruszkiewicz, J.; Albrecht, J. Changes of the thioredoxin system, glutathione peroxidase activity and total antioxidant capacity in rat brain cortex during acute liver failure: Modulation by L-histidine. Neurochem. Res. 2015, 40, 293-300. [CrossRef] [PubMed]

100. Liu, W.-H.; Liu, T.-C.; Yin, M.-C. Beneficial effects of histidine and carnosine on ethanol-induced chronic liver injury. Food Chem. Toxicol. 2008, 46, 1503-1509. [CrossRef] [PubMed]

101. Liu, F.; Lu, W.; Fang, Y.; Liu, J. Evolution of oxidation dynamics of histidine: Nonreactivity in the gas phase, peroxides in hydrated clusters, and ph dependence in solution. Phys. Chem. Chem. Phys. 2014, 16, 22179-22191. [CrossRef] [PubMed]

102. Wu, H.-C.; Shiau, C.-Y.; Chen, H.-M.; Chiou, T.-K. Antioxidant activities of carnosine, anserine, some freeamino acids and their combination. J. Food Drug Anal. 2003, 11, 148-153.

103. Milewski, K.; Hilgier, W.; Albrecht, J.; Zielinska, M. The dimethylarginine (adma)/nitric oxide pathway in the brain and periphery of rats with thioacetamide-induced acute liver failure: Modulation by histidine. Neurochem. Int. 2015, 88, 26-31. [CrossRef] [PubMed]

104. Babizhayev, M.A.; Seguin, M.-C.; Gueynej, J.; Evstigneeva, R.P.; Ageyeva, J.E.A.; Zheltukhina, G.A. L-carnosine (beta-alanyl-L-histidine) and carcinine (beta-alanylhistamine) act as natural antioxidants with hydroxyl-radical-scavenging and lipid-peroxidase activities. Biochem. J. 1994, 304, 509-516. [CrossRef] [PubMed]

105. Lee, J.W.; Miyawaki, H.; Bobst, E.V.; Hester, J.D.; Ashraf, M.; Bobst, A.M. Improved functional recovery of ischemic rat hearts due to singlet oxygen scavengers histidine and carnosine. J. Mol. Cell Cardiol. 1999, 31, 113-121. [CrossRef] [PubMed]

106. Vera-Aviles, M.; Latunde-Dada, G.O. Protective effect of histidine against iron-induced toxicity in hek-293 cells. Proc. Nutr. Soc. 2017, 76, E188. [CrossRef]

107. Tyfield, L.A.; Holton, J.B. The effect of high concentrations of histidine on the level of other amino acids in plasma and brain of the mature rat. J. Neurochem. 1976, 26, 101-105. [PubMed]

108. Kim, N.H.; Kang, J.H. Protective effects of histidine dipeptides on the modification of neurofilament-l by the cytochrome c/hydrogen peroxide system. J. Biochem. Mol. Biol. 2007, 40, 125-129. [CrossRef] [PubMed] 
109. Tabor, H. Metabolic studies on histidine, histamine, and related imidazoles. Pharmacol. Rev. 1954, 6, $299-343$. [PubMed]

110. Sundberg, R.J.; Martin, R.B. Interactions of histidine and other imidazole derivatives with transition metal ions in chemical and biological systems. Chem. Rev. 1973, 74, 471-516. [CrossRef]

111. Meyer, J.L.; Bauman, J.; John, E. Copper (II) -histidine complexes. J. Am. Chem. Soc. 1970, 92, 4210-4216. [CrossRef] [PubMed]

112. Leberman, R.; Rabin, B.R. Metal complexes of histidine. Trans. Faraday Soc. 1959, 55, 1660-1670. [CrossRef]

113. Williams, D.R. Thermodynamic considerations in co-ordination. Part VII. Solubility of the histidine- $\mathrm{H}^{+}$ system and stability constants, free energies, enthalpies, and entropies of protonation of histidine and tryptophan and of formation of their manganese(II), iron(II), cobalt(II), nickel(II), copper(II), and zinc(II) complexes. J. Chem. Soc. A 1970, 1550-1555.

114. Zs.-Nagy, I.; Floyd, R.A. Hydroxyl free radical reactions with amino acids and proteins studied by electron spin resonance spectroscopy and spin-trapping. Biochim. Biophys. Acta 1984, 790, 238-250. [CrossRef]

115. Nair, N.G.; Perry, G.; Smithc, M.A.; Reddya, V.P. Nmr studies of zinc, copper, and iron binding to histidine, the principal metal ion complexing site of amyloid- $\beta$ peptide. J. Alzheimer's Dis. 2010, 20, 57-66. [CrossRef] [PubMed]

116. Tachon, P. DNA single strand breakage by $\mathrm{H}_{2} \mathrm{O}_{2}$ and ferric or cupric ions: Its modulation by histidine. Free Radic. Res. Commun. 1990, 9, 39-47. [CrossRef] [PubMed]

117. Torres-Fuentes, C.; Alaiz, M.; Vioque, J. Iron-chelating activity of chickpea protein hydrolysate peptides. Food Chem. 2012, 134, 1585-1588. [CrossRef] [PubMed]

118. Sandstrom, B.; Davidsson, L.; Cederblad, A.; Lonnerdal, B. Oral iron, dietary ligands and zinc absorption. J. Nutr. 1985, 115, 411-414. [CrossRef] [PubMed]

119. Van Campen, D.; Gross, E. Effect of histidine and certain other amino acids on the absorption of iron-59 by rats. J. Nutr. 1969, 99, 68-74. [CrossRef] [PubMed]

120. Fairbanks, V.F.; Beutler, E. Iron metabolism. In Hematology; Beutler, E., Ed.; McGraw-Hill: New York, NY, USA, 1995; pp. 369-380.

121. Layrisse, M.; Martinez-Torres, C.; Leets, I.; Taylor, P.; Ramirez, J. Effect of histidine, cysteine, glutathione or beef on iron absorption in humans. J. Nutr. 1984, 114, 217-223. [CrossRef] [PubMed]

122. Van Campen, D. Effect of histidine and ascorbic acid on the absorption and retention of ${ }^{59} \mathrm{Fe}$ by iron-depleted rats. J. Nutr. 1972, 102, 165-170. [CrossRef] [PubMed]

123. Iyengar, V.; Pullakhandam, R.; Nair, K.M. Dietary ligands as determinants of iron-zinc interactions at the absorptive enterocyte. J. Food Sci. 2010, 75, H260-H264. [CrossRef] [PubMed]

124. Glahn, R.P.; Van Campen, D.R. Iron uptake is enhanced in caco-2 cell monolayers by cysteine and reduced cysteinyl glycine. J. Nutr. 1997, 127, 642-647. [CrossRef] [PubMed]

125. Swain, J.H.; Tabatabai, L.B.; Reddy, M.B. Histidine content of low-molecular-weight beef proteins influences nonheme iron bioavailability in Caco-2 cells. Nutr Interact. Toxic. 2002, 245-251. [CrossRef] [PubMed]

126. Storcksdieck, S.; Bonsmann, G.; Hurrell, R.F. Iron-binding properties, amino acid composition, and structure of muscle tissue peptides from in vitro digestion of different meat sources. J. Food Sci. 2007, 72, S019-S029. [CrossRef] [PubMed]

127. Lee, Y.T.; Hsu, C.C.; Lin, M.H.; Liu, K.S.; Yin, M.C. Histidine and carnosine delay diabetic deterioration in mice and protect human low density lipoprotein against oxidation and glycation. Eur. J. Pharmacol. 2005, 513, 145-150. [CrossRef] [PubMed]

128. Liakopoulos, V.; Roumeliotis, S.; Gorny, X.; Dounousi, E.; Mertens, P.R. Oxidative stress in hemodialysis patients: A review of the literature. Oxid. Med. Cell. Longev. 2017, 2017, 22. [CrossRef] [PubMed]

129. Baylis, C. Arginine, arginine analogs and nitric oxide production in chronic kidney disease. Nat. Clin. Pract. Nephrol. 2006, 2, 209. [CrossRef] [PubMed]

130. Coombes, J.S.; Fassett, R.G. Antioxidant therapy in hemodialysis patients: A systematic review. Kidney Int. 2012, 81, 233-246. [CrossRef] [PubMed]

(c) 2018 by the authors. Licensee MDPI, Basel, Switzerland. This article is an open access article distributed under the terms and conditions of the Creative Commons Attribution (CC BY) license (http:/ / creativecommons.org/licenses/by/4.0/). 


\title{
Review \\ Ferritin in Kidney and Vascular Related Diseases: Novel Roles for an Old Player
}

\author{
József Balla ${ }^{1,2}$, György Balla ${ }^{1,3}$ and Abolfazl Zarjou ${ }^{4,5, *}$ \\ 1 HAS-UD Vascular Biology and Myocardial Pathophysiology Research Group, Hungarian Academy of \\ Sciences, H-4032 Debrecen, Hungary; balla@belklinika.com (J.B.); balla@med.unideb.hu (G.B.) \\ 2 Division of Nephrology, Department of Medicine, Faculty of Medicine, University of Debrecen, \\ H-4032 Debrecen, Hungary \\ 3 Department of Pediatrics, Faculty of Medicine, University of Debrecen, H-4032 Debrecen, Hungary \\ 4 Department of Medicine, University of Alabama at Birmingham, Birmingham, AL 35294, USA \\ 5 Nephrology Research and Training Center, University of Alabama at Birmingham, Birmingham, \\ AL 35294, USA \\ * Correspondence: azarjou@uabmc.edu; Tel.: +1-(205)-934-9285; Fax: +1-(205)-996-6686
}

Received: 30 April 2019; Accepted: 19 June 2019; Published: 21 June 2019

\begin{abstract}
Iron is at the forefront of a number of pivotal biological processes due to its ability to readily accept and donate electrons. However, this property may also catalyze the generation of free radicals with ensuing cellular and tissue toxicity. Accordingly, throughout evolution numerous pathways and proteins have evolved to minimize the potential hazardous effects of iron cations and yet allow for readily available iron cations in a wide variety of fundamental metabolic processes. One of the extensively studied proteins in the context of systemic and cellular iron metabolisms is ferritin. While clinicians utilize serum ferritin to monitor body iron stores and inflammation, it is important to note that the vast majority of ferritin is located intracellularly. Intracellular ferritin is made of two different subunits (heavy and light chain) and plays an imperative role as a safe iron depot. In the past couple of decades our understanding of ferritin biology has remarkably improved. Additionally, a significant body of evidence has emerged describing the significance of the kidney in iron trafficking and homeostasis. Here, we briefly discuss some of the most important findings that relate to the role of iron and ferritin heavy chain in the context of kidney-related diseases and, in particular, vascular calcification, which is a frequent complication of chronic kidney disease.
\end{abstract}

Keywords: iron; ferritin; acute kidney injury; chronic kidney disease; vascular calcification

\section{The Superfamily of Ferritins}

The ability of iron cations (the second most abundant element on earth) to change its valence serves as a unique and central capacity to contribute in multiple biological pathways, yet underscores its potential hazardous effects mainly by participating in Fenton's reaction [1,2].

$\mathrm{O}_{2}^{\bullet-}+\mathrm{Fe}^{3+} \leftarrow \rightarrow \mathrm{O}_{2}+\mathrm{Fe}^{2+}$

$\mathrm{Fe}^{2+}+\mathrm{H}_{2} \mathrm{O}_{2} \rightarrow \mathrm{Fe}^{3+}+\mathrm{HO}^{\bullet}+\mathrm{OH}^{-}$(Fenton's reaction)

$\mathrm{O}_{2} \bullet-+\mathrm{H}_{2} \mathrm{O}_{2} \leftarrow \rightarrow \mathrm{O}_{2}+\mathrm{HO}^{\bullet}+\mathrm{OH}^{-}$(Haber-Weiss reaction)

The discovery of ferritin, a protein isolated from horse spleen, was a major step in our understanding of iron metabolism [3]. This discovery was followed by numerous studies that examined this multifaceted protein in various aspects of physiological and pathological conditions [4]. The highly conserved structure of ferritin and its universal expression among species further highlights the importance of this protein at the crossroads of multiple biological pathways that are mainly dictated by iron trafficking and homeostasis [4-6]. Ferritin is a globular protein made up of 24 subunits with a spherical hollow 
shell that allows for the safe storage of up to 4500 atoms of $\mathrm{Fe}^{3+}$. These subunits are composed of heavy (FtH) and light (FtL) chains and their proportional contribution to the hollow spherical shell depends on the tissue and developmental stage of the organism [5,7]. For instance, while brain and heart ferritin is primarily composed of $\mathrm{FtH}$ chains, the liver and spleen mainly possess FtL [7]. One intriguing aspect of ferritin biology relates to serum ferritin that is predominantly composed of FtL chain, as evidenced by immunological cross reactivity with anti-ferritin $L$ antibodies [8-10]. Serum ferritin is also relatively iron poor and its source was not completely understood until it was revealed by Cohen and colleagues that macrophages are the primary source of serum ferritin [11]. It must be noted that several investigators have reported that other cells, particularly hepatocytes, are also capable of secreting ferritin [12-14]. The study by Cohen et al. elegantly confirmed the light chain predominance of serum ferritin and its relatively low iron cations content, and provided evidence to support its secretion through the non-classical lysosomal secretory pathway [11]. More recently, another study reported that secretion of ferritin is mediated through two distinct non-classical pathways [15]. This study also examined the release of iron-rich ferritin and demonstrated that such secretion occurs via the multivesicular body-exosome pathway [15]. The release of iron-rich ferritin is particularly interesting as it may serve as an iron cargo predominantly in a paracrine fashion. The receptors, precise mode of uptake, and relevance of ferritin uptake by cells among species continues to be debated in the literature and future studies are needed to unequivocally describe the nature and significance of these processes.

Serum ferritin has long been used by clinicians to assess body iron stores in humans. However, it is also recognized that levels of serum ferritin rise in response to a number of clinical conditions particularly during inflammatory states and injury models, such as AKI [16-18]. Such elevation in response to inflammatory stimuli and the relatively iron-poor status of serum ferritin resulted in investigations to examine other potential roles in health and disease that were reviewed by Wang and colleagues [19]. More recently, an interesting pilot study examined the feasibility of measuring urinary ferritin (FtL) as a non-invasive diagnostic approach to assess neonates and young children for iron deficiency or iron overload [20]. This study was based on previous reports that confirmed the presence of urinary ferritin in healthy individuals [21,22] and, despite some limitations, found a correlation with paired serum ferritin. In contrast to $\mathrm{FtL}$, the $\mathrm{FtH}$ subunit has crucial ferroxidase activity that converts $\mathrm{Fe}^{2+}$ to $\mathrm{Fe}^{3+}$, facilitating its safe storage in the form of mineral ferrihydrite within the inner wall of the sphere [23,24]. Such functional properties have led to a significant amount of investigations into this field, leading to the discovery of seminal findings into the role of this superfamily of proteins in physiological processes and injury models $[4,6,25,26]$.

The first description of a function for ferritin other than mere iron cation storage was reported by Balla and colleagues [27]. This seminal manuscript described an anti-oxidant role for ferritin in endothelial cells. In this study authors validated the cytotoxic properties of heme, but surprisingly found that briefly pulsing cells with heme remarkably increased their resistance against oxidant-mediated injury. While administration of apoferritin mimicked these beneficiary effects, a site-directed mutant form of $\mathrm{FtH}$ with subsequent loss of ferroxidase activity failed to recapitulate such protection against oxidative damage [27]. These findings generated significant interest in this field and were followed by additional pivotal findings. For instance, while ferritin was traditionally regarded as a cytosolic protein, others demonstrated its localization in other subcellular compartments, such as mitochondria [28,29] and the nucleus [30-32]. This review is intended to briefly discuss some of the aspects of ferritin in the context of kidney-related diseases and one of its major cardiovascular complications, namely vascular calcification.

\section{Role of Iron and Ferritin in Acute Kidney Injury}

Acute kidney injury (AKI) is a common clinical syndrome characterized by a sudden decrement in kidney function with ensuing derangements in multiple essential physiological parameters, such as dysregulated volume and electrolyte homeostasis [33,34]. It is well documented that AKI increases morbidity and mortality, particularly among critically ill patients $[33,35,36]$. Moreover, AKI incidence is 
on the rise and patients who survive AKI have an increased risk for the development of chronic kidney disease (CKD) [37-39]. These detrimental clinical consequences have led to vigorous investigations to better understand the individual and overlapping pathways that are involved in the pathogenesis of AKI. Iron metabolism and trafficking has emerged as one such pathway. The kidney was not considered a major organ involved in the regulation of iron homeostasis, mainly because of the lack of evidence of its involvement in hereditary hemochromatosis and the assumption that transferrin bound iron cations are not filtered by the glomerulus. However, along with other recent breakthroughs in the field of iron metabolism, our understanding of the delicate and well-orchestrated iron regulatory machinery in the kidney has evolved thanks to a number of pivotal observations. For example, the urinary proteomic analysis of Fanconi syndrome, which is characterized by overall dysfunctional proximal tubules and poor reabsorption capacity, demonstrates significantly elevated levels of transferrin in the urine samples of subjects, confirming its filtration $[40,41]$. Transferrin can be reabsorbed in the tubules via transferrin receptor- 1 or cubilin-mediated endocytosis [42,43]. The kidneys also express high levels of divalent metal transporter-1, which was first described by Gunshin et al. [44], and their importance in renal iron handling under physiological and pathological conditions was subsequently confirmed by other investigations [45-49]. Some other iron regulatory proteins that are expressed in kidneys include neutrophil gelatinase-associated lipocalin [50], ferroportin [51,52], as well as hepcidin [53]. Additionally, among other tissues, mouse kidney expresses the highest levels of iron regulatory protein- 1 with important functions in renal iron cations handling [54]. It must also be noted that the proximal tubules, workhouse of nephrons, possess a significant amount of mitochondria that contain notable amounts of heme, which encloses iron cations in its porphyrin ring. Based on the aforementioned evidence, it is apparent that the kidneys, particularly proximal tubules, are heavily involved in iron trafficking under both physiological and pathological conditions, and are accordingly more susceptible to injury [55]. In fact, several lines of evidence suggest a role for iron cations-mediated kidney injury in both humans and animal models of kidney disease [56-59]. The participation of iron cations in Fenton's reaction and their ability to aggravate oxidative stress led to the hypothesis that their removal would prove beneficial in kidney injury. In support of this premise, multiple investigations demonstrated that the removal of iron cations via deferoxamine (DFO), a potent iron cations chelator, was protective against AKI. These studies utilized DFO in the setting of glycerol-induced rhabdomyolysis [60], hemoglobinand myoglobin-induced AKI [61], gentamicin nephrotoxicity [62], and ischemia-reperfusion (I/R) [63]. Notably, these salutary effects were recapitulated by the administration of apotransferrin in a model of I/R-mediated AKI [64]. The evidence to suggest iron as a main culprit and mediator of AKI has also been demonstrated in human studies. Work by Leaf and colleagues focused on the association between catalytic iron cations, non-transferrin bound iron cations, and the course of AKI in patients undergoing cardiac surgery with cardiopulmonary bypass [65]. They reported that primary outcomes, defined as in-hospital death or need for renal replacement therapy, AKI, and other adverse events post-operatively, were directly associated with higher plasma catalytic iron cation levels on post-operative day one [65]. In another study, the same group examined such association in 121 critically ill patients admitted to medical or surgical intensive care units [66]. Similarly, higher plasma catalytic iron cation levels were associated with a greater risk of death/need for renal replacement therapy, AKI, and hospital mortality. Importantly, the authors stated that these associations are independent of age, estimated glomerular filtration rate, and number of packed red blood cell transfusions [66]. Others also evaluated the role of plasma catalytic iron cations in relation to contrast-induced nephropathy. Their results confirmed higher levels of catalytic iron cations were associated with a higher risk of contrast nephropathy, as well as higher rates of mortality [67]. Other studies have suggested a role for catalytic iron cations in the context of glomerulopathies and proteinuria. For instance, in a rat model of nephrotic syndrome, a significant increase in the levels of glomerular catalytic iron cations was observed [68]. Importantly, chelation of iron cations with DFO was associated with complete protection against proteinuria [68]. Another clinical study validated these findings, where deferiprone, an oral iron cation chelator, was used in diabetic and non-diabetic glomerular disease [69]. While this study was rather small and 
non-randomized, iron cation chelation demonstrated a marked reduction of proteinuria in both groups of patients with and without diabetic glomerular nephropathy.

The above-mentioned evidence led to further investigations to examine how the proximal tubular expression of ferritin may affect the course of AKI. The importance and non-redundant function of FtH and its ferroxidase activity was reported by Ferreira and colleagues [70]. They demonstrated that global deletion of $\mathrm{FtH}$ in mice leads to embryonic lethality between 3.5 and 9.5 days of development [70]. Therefore, to understand the role of proximal tubule FtH expression during AKI, we generated transgenic mice with conditional deletion of $\mathrm{FtH}$ in proximal tubules. This was achieved by crossing $\mathrm{FtH}^{\mathrm{lox} / \mathrm{lox}}$ mice that were generated and characterized by Darshan and colleagues [71] with phosphoenolpyruvate carboxykinase (PEPCK)-Cre mice [72]. Targeted deletion of FtH in proximal tubules led to heightened rhabdomyolysis-induced AKI, as evidenced by the higher rate of mortality, serum creatinine, and the higher expression of cleaved caspase-3, a marker of apoptosis [18]. The protective nature of FtH expression in proximal tubules was further supported by a histological analysis that revealed a greater number of tubular casts, necrotic tubules, and more prominent loss of proximal tubule brush border in the absence of FtH expression. Notably, rhabdomyolysis is primarily a heme-mediated injury model, given the significant amount of heme present in myoglobin. Therefore, to investigate whether FtH may play a protective role in other models of AKI that are not predominantly heme driven, cisplatin nephrotoxicity was used. These results indicated that, irrespective of the model of injury, deletion of FtH led to worse renal function, as evidenced by serum creatinine. Furthermore, the overall architecture of the kidneys was less preserved in the absence of $\mathrm{FtH}$ [18]. These studies led to another interesting observation that $\mathrm{FtH}$ deletion was accompanied by markedly higher levels of heme oxygenase-1 (HO-1) expression. HO-1 is a well-characterized anti-oxidant enzyme that has been shown to have protective effects against a number insults and kidney injury models [73,74]. Aggravated AKI, despite such high levels of $\mathrm{HO}-1$, indicates that beneficial effects of $\mathrm{HO}-1$ are co-dependent on $\mathrm{FtH}$ expression and this premise is further supported in a model of rodent anti-thymocyte antigen-1-induced glomerulonephritis [75]. This study showed that inhibition of $\mathrm{HO}$ activity was accompanied with downregulation of FtH expression and enhanced mesangial cell death. Additionally, while induction of HO-1 in cultured rat mesangial cells augmented its resistance to oxidative stress, $\mathrm{FtH}$ knockdown by RNA interference caused loss of such protective influences. Also of note, this study demonstrated adjacent expression of HO-1 and FtH in inflammatory glomeruli of human lupus nephritis biopsies [75]. In another study, Hatcher and colleagues examined FtH overexpression in a model of ischemia-reperfusion-induced AKI [76]. Using a conditional tissue-specific doxycycline-inducible system, about 6.5-fold higher levels of FtH expression was shown in mouse kidneys. Following injury, the authors demonstrated that $\mathrm{FtH}$ overexpression was associated with lesser apoptosis and improved tubular viability [76]. It was concluded that $\mathrm{FtH}$ overexpression protects the kidney via limiting oxidative stress induced by $\mathrm{I} / \mathrm{R}$. Another line of evidence to support the role of $\mathrm{FtH}$ in protecting the kidney against injurious insults comes from a more recent study by Scindia and colleagues [77]. In this study, the authors examined how modulation of iron homeostatic pathways via hepcidin alters the course of I/R-induced AKI. Hepcidin, a hormone produced primarily by hepatocytes [78], acts by directly binding to ferroportin, leading to its internalization and subsequent degradation in lysosomes [79]. This eventually leads to decreased iron cation absorption, as well as increased iron cation retention with subsequent upregulation of intracellular ferritin. It was demonstrated that hepcidin, given $24-48 \mathrm{~h}$ before $\mathrm{I} / \mathrm{R}$, mitigated kidney injury and reduced renal and systemic inflammation caused by I/R [77]. These effects were attributed to increased FtH expression in the kidney and the spleen. These overall beneficial properties were also corroborated in a model of hemoglobin-induced AKI, where hepcidin administration mitigated the upregulation of urinary kidney injury markers (neutrophil gelatinase-associated lipocalin and kidney injury molecule-1) and renal Interleukin-6 [80].

To further elaborate on the role of $\mathrm{FtH}$ and how its expression in different cells may contribute to the course of kidney damage, effects of FtH expression in myeloid cells were further investigated [81]. 
Using transgenic mice with conditional deletion of $\mathrm{FtH}$ in the proximal tubules or myeloid cells, it was found that myeloid FtH deficiency did not affect activation or accumulation of macrophages in the injured kidney compared with wild-type littermate controls. In contrast, a significant increase in the number of pro-inflammatory macrophages accompanied $\mathrm{FtH}$ deletion in proximal tubules in a model of unilateral ureteral obstruction (UUO). Moreover, while deletion of FtH in the myeloid compartment resulted in lesser fibrosis in a UUO model of kidney injury, the lack of FtH expression in proximal tubules exacerbated both inflammation and fibrosis [81]. These findings suggest a central role for $\mathrm{FtH}$ expression in various compartments that underscores its importance in the context of tubular-macrophage cross-talk during kidney injury. More recently, the effects of FtH expression in myeloid cells during sepsis and its clinical sequelae, including sepsis-induced AKI, were examined [82]. Results of this study demonstrated that the deletion of FtH in the myeloid compartment was associated with marked protection in two models of sepsis, namely cecal ligation puncture and lipopolysaccharide-induced endotoxemia. Deletion of FtH led to improved survival, reduced cytokine levels, and more preserved renal function. Mechanistic studies revealed that the protective effects were primarily mediated by the compensatory increase in circulating ferritin $(\mathrm{FtL})$ in the absence of myeloid $\mathrm{FtH}$ [82]. It must be noted that the main circulatory form of ferritin is FtL and macrophages have been shown to be the primary source of serum ferritin [11]. Results also demonstrated that the protective effects of FtL during sepsis are attributed to its inhibitory actions against the activation of the NF- $\mathrm{KB}$ pathway. These findings not only provide a novel platform for future studies to better understand the pathogenesis of sepsis but also shed light on the immunomodulatory roles of circulating FtL.

\section{Ferritin: A Potent Inhibitor of Osteoblastic Activity}

Cardiovascular-related diseases remain the foremost cause of death in patients with CKD and those requiring renal replacement therapy [83-85]. About $10-15 \%$ of the U.S. population is estimated to have CKD and more than 450,000 Americans require dialysis resulting in a major burden of morbidity, mortality, and healthcare expenditure [86]. In this regard, vascular calcification (VC) is a common complication of CKD and is recognized as a portentous contributing factor to cardiovascular death in these patients [87-90]. The prevalence of VC is exceptionally high among patients with CKD and can be observed even in very young dialysis patients [91,92]. Two distinct patterns of VC have been described [93]. While intimal calcification occurs in atherosclerotic plaques, mineralization of the medial compartment is a common pathological finding in aging patients and patients with diabetes and advanced CKD $[93,94]$. The diffuse calcification that occurs in the medial layer of the vasculature is an important marker for all-cause mortality in patients undergoing dialysis $[87,88,95]$. There are several detrimental hemodynamic consequences of VC, including loss of arterial elasticity, increase in pulse wave velocity, development of left ventricular hypertrophy, and decrease in coronary artery perfusion, ensuing in myocardial ischemia and failure $[95,96]$. Following the description of $\mathrm{VC}$ as a tightly regulated cellular process where vascular smooth muscle cells (VSMC) transition into "osteoblast-like" cells, major research efforts have identified various pathways and mechanisms involved in the development and propagation of VC $[97,98]$. These proposed mechanisms include elastin degradation, apoptosis of VSMC, release of exosomes loaded with microRNAs, and extracellular vesicles that are rich in calcium and phosphate $[99,100]$. Nevertheless, multiple pivotal questions remain unanswered and currently no therapies exist for the treatment or prevention of VC. To better understand novel pathways that may be involved in the development and pathogenesis of VC, it was important to examine how derangements in iron metabolism may be contributing to the development of such detrimental pathological conditions. This principle was based on the fact that many patients with advanced CKD are also predisposed to iron-restricted erythropoiesis. Several factors lead to the development of anemia in patients with CKD and those requiring dialysis. These include decreased erythropoietin production, frequent diagnostic testing, blood loss during hemodialysis, and cannula puncture sites following hemodialysis, as well as a "functional iron deficiency state" [101-104]. This process, also known as anemia of chronic disease, is principally a result of the increased synthesis and 
secretion of hepcidin, which is a common paradigm of chronic inflammatory states such as CKD [105]. It must be noted that other cytokines have been demonstrated to have additional effects and further aggravate this state of functional iron deficiency [106]. Hepcidin leads to the internalization and degradation of ferroportin (membrane iron transporter) and the overall outcome is the decreased iron cation absorption from the small intestine along with the decreased egress of iron cations from the reticuloendothelial system [105]. Accordingly, while macrophages are loaded with iron cations, other cells within the body have a relatively lower iron cation content. It was therefore necessary to examine whether the repletion of iron cations and the subsequent upregulation of ferritin in VSMC mitigates the osteoblastic differentiation of these cells when exposed to high phosphate levels. Notably, increasing levels of serum phosphorus manifest during advanced stages of CKD and such hyperphosphatemia is a well-known risk factor for the development of VC [107-109]. Indeed, we found that the addition of hemin was able to significantly arrest the calcification and osteoblastic transition of VSMC [110].

To identify the mediator of such a salutary effect, we examined products of the HO/ferritin system that include biliverdin, bilirubin, carbon monoxide, and iron cations. It was demonstrated that iron administration inhibited calcium deposition and led to about a five-fold increment in intracellular ferritin levels. Subsequent studies using recombinant ferritin proteins confirmed the paramount role of ferritin upregulation in this inhibitory process. Using exogenous recombinant $\mathrm{FtH}, \mathrm{FtL}$, and a mutant form of $\mathrm{FtH}$ that lacks ferroxidase activity, we demonstrated the paramount role of $\mathrm{FtH} /$ ferroxidase activity in the abrogation of VSMC mineralization and osteoblastic transformation [110]. Importantly, the inhibitory role of $\mathrm{FtH}$ was not limited to the mere inhibition of hydroxyapatite deposition, but it also prevented the expression of the core binding factor alpha-1 (cbfa-1), a key transcription factor in osteogenesis [111].

Other studies have also suggested a potential inhibitory role for iron and iron-induced upregulation of ferritin in the context of VC. For example, Rajendran et al. used various detection methods to map the spatial distribution of the elements and quantify them simultaneously in atherosclerotic rabbit arteries [112]. They demonstrated that within atherosclerotic plaques, iron cations (likely sequestered within ferritin shell) and calcium exhibited a highly significant spatial inverse correlation. Moreover, an adenine-induced model of CKD in rats was employed to investigate the role of PA-21, an iron-based non-calcium phosphate binder in VC. They reported a higher degree of inhibition of VC when compared to another frequently used phosphate binder, calcium carbonate [113]. Furthermore, Seto et al. examined the role of iron loading on the progression of VC in an adenine diet-induced CKD rat model [114]. It was demonstrated that iron loading resulted in the suppression of VC and attributed these findings to the reduced expression of phosphate transporter (Pit-1) and cbfa-1. Others have also reported the inhibition of high phosphate-induced VC using ferric citrate and attributed these results to the suppression of apoptosis [115]. These results are interesting when taking into account a study that was published in 1995 and reported the inhibition of calcium deposition in bioprostethic valves when pre-treated with iron [116]. However, it is also noteworthy that some studies have failed to recapitulate the overall inhibitory effects of iron during VC [117].

Based on these findings, we hypothesized that osteoporosis induced by iron overload states, such as primary hemochromatosis $[118,119]$, may be attributed to the increased expression of FtH in osteoblasts secondary to excessive iron accumulation. Indeed, investigating the mechanism(s) leading to decreased bone deposition in iron overload states, we were able to demonstrate the central role of $\mathrm{FtH}$ in this process [120]. We showed that the administration of apoferritin or recombinant $\mathrm{FtH}$ (both devoid of iron cations) markedly inhibited the mineralization and expression of osteoblastic specific genes, such as osteocalcin, alkaline phosphatase, and cbfa-1 [120]. Overall these results confirmed previous findings that increased iron cation levels mitigate calcification, but they also provided a novel mechanism for this process and identified $\mathrm{FtH}$ upregulation as a main inhibitory factor in this regard.

The potential hazardous effects of excessive iron cations are well recognized, and their optimal dosage and utilization frequency in CKD patients have been a major point of debate among nephrologists [121-123]. Accordingly, based on the aforementioned evidence, we sought to identify 
other approaches to upregulate $\mathrm{FtH}$ expression in VSMC without using excessive iron and examine how the pharmacological induction of ferritin may affect VC. To achieve this objective, we tested the effects of 3H-1,2-Dithiole-3-thione (D3T), a well-known cancer chemopreventive agent [124] and inducer of FtH expression [125], in a model of VSMC calcification. It was demonstrated that D3T inhibited osteoblastic transition of VSMC in a dose-dependent manner [126]. However, the central role of ferritin was further corroborated in experiments where the inhibitory effects of D3T on osteoblastic transition were arrested during FtH knockdown by RNA interference [126]. The overall effect of iron/D3T-induced FtH upregulation and inhibition of VSMC calcification is illustrated in Figure 1.

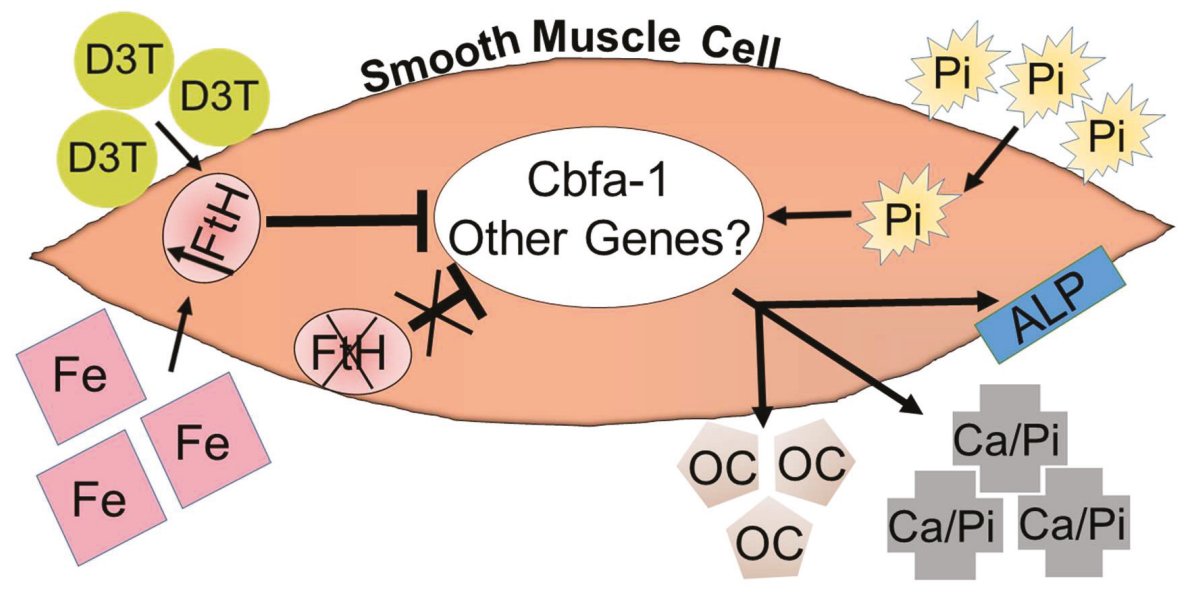

Figure 1. Overall schematic of the proposed mechanism of the inhibition of VSMC calcification via the upregulation of FtH. The figure depicts a vascular smooth muscle cell (VSMC) where elevated levels of $\mathrm{Pi}$ (phosphorus) induce the upregulation of cbfa-1 (core binding factor alpha-1), leading to the deposition of extracellular $\mathrm{Ca} / \mathrm{Pi}$ (hydroxyapatite crystals) and the activation of osteoblastic genes, including OC (osteocalcin) and ALP (alkaline phosphatase). This process can be exacerbated by the deletion of FtH (ferritin heavy chain) or mitigated via D3T (3H-1,2-Dithiole-3-thione) and Fe (iron)-induced $\mathrm{FtH}$ upregulation. There may still be novel genes and pathways modulated by $\mathrm{FtH}$ expression that require further investigations.

More recently, similar inhibitory effects in mitigating the calcification of valvular tissues were demonstrated [127]. Valvular calcification and stenosis (particularly aortic valve) is a common finding in patients undergoing dialysis and the elderly population. In this study we showed that the induction of FtH was associated with the decreased osteoblastic activity of valvular interstitial cells. This inhibitory effect was attributed to the reduced nuclear accumulation of cbfa-1, and as a reciprocal effect, its enhancement of the nuclear localization of transcription factor Sox9 (SRY [sex-determining region Y]-box 9) [127]. These findings provide additional support to previous observations that identified reduced Sox9 function as a potential culprit of calcific valvular disease [128] and further corroborate the "anti-osteoblastic activity" of FtH. It must be emphasized that while a significant body of evidence is emerging to support the role of intracellular FtH expression as an inhibitory mechanism against calcification, additional targeted studies in animal models are required to unequivocally demonstrate and confirm these results.

It is also noteworthy that the implication and functional significance of iron and ferritin in the context of atherosclerosis and coronary artery disease continues to generate contradicting results and is heavily debated in the literature. While we do not elaborate further on these studies in this review, others have discussed these results in detail [129-134] 
In conclusion, it is evident that ferritin and its role in both cellular and systemic iron homeostasis, as well as its participation in a number of pathways that are central to various pathological conditions, is increasingly recognized. Future studies and additional genetic manipulations (for instance, the targeted deletion of $\mathrm{FtL}$ or the over-expression of $\mathrm{FtH}$ ) would be germane to pave the way for potential therapeutic targets utilizing this intriguing, ancient, and almost ubiquitous superfamily of proteins.

Author Contributions: Writing—original draft preparation: A.Z., G.B., and J.B.; writing—review and editing: A.Z., G.B., and J.B.; funding acquisition: A.Z. and J.B.

Funding: This work was supported by NIH grant (K08HL140294 to A.Z.) and Hungarian Government grant, OTKA-K112333 (J.B.), GINOP-2.3.2-15-2016-00043 (IRONHEART), and EFOP-3.6.2-16-2017-00006 project. The research group was supported by the Hungarian Academy of Sciences (11003). The project was co-financed by the European Union, the European Regional Development Fund (J.B., G.B.).

Conflicts of Interest: The authors declare no conflict of interest.

\section{References}

1. Haber, F.; Weiss, J. The Catalytic Decomposition of Hydrogen Peroxide by Iron Salts. Proc. R. Soc. Lond. Ser. A Math. Phys. Sci. 1934, 147, 332-351.

2. Fenton, H.J.H. LXXIII.-Oxidation of tartaric acid in presence of iron. J. Chem. Soc. Trans. 1894, 65, 899-910. [CrossRef]

3. Laufberger, V. Sur la cristallisation de la ferritine. Bull. Soc. Chim. Biol. 1937, 19, 1575-1582.

4. Arosio, P.; Ingrassia, R.; Cavadini, P. Ferritins: A family of molecules for iron storage, antioxidation and more. Biochim. Biophys. Acta 2009, 1790, 589-599. [CrossRef] [PubMed]

5. Arosio, P.; Levi, S. Cytosolic and mitochondrial ferritins in the regulation of cellular iron homeostasis and oxidative damage. Biochim. Biophys. Acta 2010, 1800, 783-792. [CrossRef]

6. Arosio, P.; Levi, S. Ferritin, iron homeostasis, and oxidative damage. Free Radic. Biol. Med. 2002, 33, 457-463. [CrossRef]

7. Harrison, P.M.; Arosio, P. The ferritins: Molecular properties, iron storage function and cellular regulation. Biochim. Biophys. Acta 1996, 1275, 161-203. [CrossRef]

8. Santambrogio, P.; Cozzi, A.; Levi, S.; Arosio, P. Human serum ferritin G-peptide is recognized by anti-L ferritin subunit antibodies and concanavalin-A. Br. J. Haematol. 1987, 65, 235-237. [CrossRef]

9. Cazzola, M.; Arosio, P.; Bellotti, V.; Bergamaschi, G.; Dezza, L.; Iacobello, C.; Ruggeri, G.; Zappone, E.; Albertini, A.; Ascari, E. Immunological reactivity of serum ferritin in patients with malignancy. Tumori 1985, 71,547-554. [CrossRef]

10. Lukina, E.A.; Levina, A.A.; Mokeeva, R.A.; Tokarev Yu, N. The diagnostic significance of serum ferritin indices in patients with malignant and reactive histiocytosis. Br. J. Haematol. 1993, 83, 326-329. [CrossRef]

11. Cohen, L.A.; Gutierrez, L.; Weiss, A.; Leichtmann-Bardoogo, Y.; Zhang, D.L.; Crooks, D.R.; Sougrat, R.; Morgenstern, A.; Galy, B.; Hentze, M.W.; et al. Serum ferritin is derived primarily from macrophages through a nonclassical secretory pathway. Blood 2010, 116, 1574-1584. [CrossRef] [PubMed]

12. Ghosh, S.; Hevi, S.; Chuck, S.L. Regulated secretion of glycosylated human ferritin from hepatocytes. Blood 2004, 103, 2369-2376. [CrossRef]

13. Mack, U.; Cooksley, W.G.; Ferris, R.A.; Powell, L.W.; Halliday, J.W. Regulation of plasma ferritin by the isolated perfused rat liver. Br. J. Haematol. 1981, 47, 403-412. [CrossRef] [PubMed]

14. Tran, T.N.; Eubanks, S.K.; Schaffer, K.J.; Zhou, C.Y.; Linder, M.C. Secretion of ferritin by rat hepatoma cells and its regulation by inflammatory cytokines and iron. Blood 1997, 90, 4979-4986. [PubMed]

15. Truman-Rosentsvit, M.; Berenbaum, D.; Spektor, L.; Cohen, L.A.; Belizowsky-Moshe, S.; Lifshitz, L.; Ma, J.; Li, W.; Kesselman, E.; Abutbul-Ionita, I.; et al. Ferritin is secreted via 2 distinct nonclassical vesicular pathways. Blood 2018, 131, 342-352. [CrossRef] [PubMed]

16. Kalantar-Zadeh, K.; Kalantar-Zadeh, K.; Lee, G.H. The fascinating but deceptive ferritin: To measure it or not to measure it in chronic kidney disease? Clin. J. Am. Soc. Nephrol. 2006, 1 (Suppl. 1), S9-S18. [CrossRef]

17. Zandman-Goddard, G.; Shoenfeld, Y. Ferritin in autoimmune diseases. Autoimmun. Rev. 2007, 6, 457-463. [CrossRef] [PubMed] 
18. Zarjou, A.; Bolisetty, S.; Joseph, R.; Traylor, A.; Apostolov, E.O.; Arosio, P.; Balla, J.; Verlander, J.; Darshan, D.; Kuhn, L.C.; et al. Proximal tubule H-ferritin mediates iron trafficking in acute kidney injury. J. Clin. Invest. 2013, 123, 4423-4434. [CrossRef]

19. Wang, W.; Knovich, M.A.; Coffman, L.G.; Torti, F.M.; Torti, S.V. Serum ferritin: Past, present and future. Biochim. Biophys. Acta 2010, 1800, 760-769. [CrossRef] [PubMed]

20. Bahr, T.M.; Christensen, R.D.; Ward, D.M.; Meng, F.; Jackson, L.K.; Doyle, K.; Christensen, D.R.; Harvey, A.G.; Yaish, H.M. Ferritin in serum and urine: A pilot study. Blood Cells Mol. Dis. 2019, 76, 59-62. [CrossRef] [PubMed]

21. Ishikawa, K.; Narita, O.; Saito, H.; Kato, K. Determination of ferritin in urine and in serum of normal adults with a sensitive enzyme immunoassay. Clin. Chim. Acta 1982, 123, 73-81. [CrossRef]

22. Gonzales, P.A.; Pisitkun, T.; Hoffert, J.D.; Tchapyjnikov, D.; Star, R.A.; Kleta, R.; Wang, N.S.; Knepper, M.A. Large-scale proteomics and phosphoproteomics of urinary exosomes. J. Am. Soc. Nephrol. 2009, 20, 363-379. [CrossRef] [PubMed]

23. Hentze, M.W.; Keim, S.; Papadopoulos, P.; O’Brien, S.; Modi, W.; Drysdale, J.; Leonard, W.J.; Harford, J.B.; Klausner, R.D. Cloning, characterization, expression, and chromosomal localization of a human ferritin heavy-chain gene. Proc. Natl. Acad. Sci. USA 1986, 83, 7226-7230. [CrossRef] [PubMed]

24. Lawson, D.M.; Treffry, A.; Artymiuk, P.J.; Harrison, P.M.; Yewdall, S.J.; Luzzago, A.; Cesareni, G.; Levi, S.; Arosio, P. Identification of the ferroxidase centre in ferritin. FEBS Lett. 1989, 254, 207-210. [CrossRef]

25. Arosio, P.; Elia, L.; Poli, M. Ferritin, cellular iron storage and regulation. IUBMB Life 2017, 69, 414-422. [CrossRef] [PubMed]

26. Watt, R.K. The many faces of the octahedral ferritin protein. Biometals 2011, 24, 489-500. [CrossRef]

27. Balla, G.; Jacob, H.S.; Balla, J.; Rosenberg, M.; Nath, K.; Apple, F.; Eaton, J.W.; Vercellotti, G.M. Ferritin: A cytoprotective antioxidant strategem of endothelium. J. Biol. Chem. 1992, 267, 18148-18153.

28. Levi, S.; Corsi, B.; Bosisio, M.; Invernizzi, R.; Volz, A.; Sanford, D.; Arosio, P.; Drysdale, J. A human mitochondrial ferritin encoded by an intronless gene. J. Biol. Chem. 2001, 276, 24437-24440. [CrossRef]

29. Drysdale, J.; Arosio, P.; Invernizzi, R.; Cazzola, M.; Volz, A.; Corsi, B.; Biasiotto, G.; Levi, S. Mitochondrial ferritin: A new player in iron metabolism. Blood Cells Mol. Dis. 2002, 29, 376-383. [CrossRef]

30. Cai, C.X.; Birk, D.E.; Linsenmayer, T.F. Nuclear ferritin protects DNA from UV damage in corneal epithelial cells. Mol. Biol. Cell 1998, 9, 1037-1051. [CrossRef]

31. Cai, C.; Ching, A.; Lagace, C.; Linsenmayer, T. Nuclear ferritin-mediated protection of corneal epithelial cells from oxidative damage to DNA. Dev. Dyn. 2008, 237, 2676-2683. [CrossRef] [PubMed]

32. Thompson, K.J.; Fried, M.G.; Ye, Z.; Boyer, P.; Connor, J.R. Regulation, mechanisms and proposed function of ferritin translocation to cell nuclei. J. Cell Sci. 2002, 115, 2165-2177. [PubMed]

33. Zarjou, A.; Sanders, P.W.; Mehta, R.L.; Agarwal, A. Enabling innovative translational research in acute kidney injury. Clin. Transl. Sci. 2012, 5, 93-101. [CrossRef] [PubMed]

34. Choudhury, D. Acute kidney injury: Current perspectives. Postgrad. Med. 2010, 122, 29-40. [CrossRef] [PubMed]

35. Maxwell, R.A.; Bell, C.M. Acute Kidney Injury in the Critically Ill. Surg. Clin. N. Am. 2017, 97, 1399-1418. [CrossRef] [PubMed]

36. Bevc, S.; Ekart, R.; Hojs, R. The assessment of acute kidney injury in critically ill patients. Eur. J. Intern. Med. 2017, 45, 54-58. [CrossRef] [PubMed]

37. Chawla, L.S.; Eggers, P.W.; Star, R.A.; Kimmel, P.L. Acute kidney injury and chronic kidney disease as interconnected syndromes. N. Engl. J. Med. 2014, 371, 58-66. [CrossRef]

38. Basile, D.P.; Donohoe, D.; Roethe, K.; Osborn, J.L. Renal ischemic injury results in permanent damage to peritubular capillaries and influences long-term function. Am. J. Physiol. Ren. Physiol. 2001, 281, F887-F899. [CrossRef]

39. Chawla, L.S.; Kimmel, P.L. Acute kidney injury and chronic kidney disease: An integrated clinical syndrome. Kidney Int. 2012, 82, 516-524. [CrossRef]

40. Cutillas, P.R.; Chalkley, R.J.; Hansen, K.C.; Cramer, R.; Norden, A.G.; Waterfield, M.D.; Burlingame, A.L.; Unwin, R.J. The urinary proteome in Fanconi syndrome implies specificity in the reabsorption of proteins by renal proximal tubule cells. Am. J. Physiol. Ren. Physiol. 2004, 287, F353-F364. [CrossRef] 
41. Norden, A.G.; Lapsley, M.; Lee, P.J.; Pusey, C.D.; Scheinman, S.J.; Tam, F.W.; Thakker, R.V.; Unwin, R.J.; Wrong, O. Glomerular protein sieving and implications for renal failure in Fanconi syndrome. Kidney Int. 2001, 60, 1885-1892. [CrossRef] [PubMed]

42. Kozyraki, R.; Fyfe, J.; Verroust, P.J.; Jacobsen, C.; Dautry-Varsat, A.; Gburek, J.; Willnow, T.E.; Christensen, E.I.; Moestrup, S.K. Megalin-dependent cubilin-mediated endocytosis is a major pathway for the apical uptake of transferrin in polarized epithelia. Proc. Natl. Acad. Sci. USA 2001, 98, 12491-12496. [CrossRef] [PubMed]

43. Smith, C.P.; Lee, W.K.; Haley, M.; Poulsen, S.B.; Thevenod, F.; Fenton, R.A. Proximal tubule transferrin uptake is modulated by cellular iron and mediated by apical membrane megalin-cubilin complex and transferrin receptor 1. J. Biol. Chem. 2019, 294, 7025-7036. [CrossRef] [PubMed]

44. Gunshin, H.; Mackenzie, B.; Berger, U.V.; Gunshin, Y.; Romero, M.F.; Boron, W.F.; Nussberger, S.; Gollan, J.L.; Hediger, M.A. Cloning and characterization of a mammalian proton-coupled metal-ion transporter. Nature 1997, 388, 482-488. [CrossRef] [PubMed]

45. Tchernitchko, D.; Bourgeois, M.; Martin, M.E.; Beaumont, C. Expression of the two mRNA isoforms of the iron transporter Nramp2/DMTI in mice and function of the iron responsive element. Biochem. J. 2002, 363, 449-455. [CrossRef] [PubMed]

46. Abouhamed, M.; Gburek, J.; Liu, W.; Torchalski, B.; Wilhelm, A.; Wolff, N.A.; Christensen, E.I.; Thevenod, F.; Smith, C.P. Divalent metal transporter 1 in the kidney proximal tubule is expressed in late endosomes/lysosomal membranes: Implications for renal handling of protein-metal complexes. Am. J. Physiol. Ren. Physiol. 2006, 290, F1525-F1533. [CrossRef] [PubMed]

47. Wareing, M.; Ferguson, C.J.; Delannoy, M.; Cox, A.G.; McMahon, R.F.; Green, R.; Riccardi, D.; Smith, C.P. Altered dietary iron intake is a strong modulator of renal DMT1 expression. Am. J. Physiol. Ren. Physiol. 2003, 285, F1050-F1059. [CrossRef]

48. Ferguson, C.J.; Wareing, M.; Ward, D.T.; Green, R.; Smith, C.P.; Riccardi, D. Cellular localization of divalent metal transporter DMT-1 in rat kidney. Am. J. Physiol. Ren. Physiol. 2001, 280, F803-F814. [CrossRef]

49. Ferguson, C.J.; Wareing, M.; Delannoy, M.; Fenton, R.; McLarnon, S.J.; Ashton, N.; Cox, A.G.; McMahon, R.F.; Garrick, L.M.; Green, R.; et al. Iron handling and gene expression of the divalent metal transporter, DMT1, in the kidney of the anemic Belgrade (b) rat. Kidney Int. 2003, 64, 1755-1764. [CrossRef]

50. Mori, K.; Lee, H.T.; Rapoport, D.; Drexler, I.R.; Foster, K.; Yang, J.; Schmidt-Ott, K.M.; Chen, X.; Li, J.Y.; Weiss, S.; et al. Endocytic delivery of lipocalin-siderophore-iron complex rescues the kidney from ischemia-reperfusion injury. J. Clin. Investig. 2005, 115, 610-621. [CrossRef]

51. Donovan, A.; Brownlie, A.; Zhou, Y.; Shepard, J.; Pratt, S.J.; Moynihan, J.; Paw, B.H.; Drejer, A.; Barut, B.; Zapata, A.; et al. Positional cloning of zebrafish ferroportin1 identifies a conserved vertebrate iron exporter. Nature 2000, 403, 776-781. [CrossRef] [PubMed]

52. Wolff, N.A.; Liu, W.; Fenton, R.A.; Lee, W.K.; Thevenod, F.; Smith, C.P. Ferroportin 1 is expressed basolaterally in rat kidney proximal tubule cells and iron excess increases its membrane trafficking. J. Cell Mol. Med. 2011, 15, 209-219. [CrossRef] [PubMed]

53. Kulaksiz, H.; Theilig, F.; Bachmann, S.; Gehrke, S.G.; Rost, D.; Janetzko, A.; Cetin, Y.; Stremmel, W. The iron-regulatory peptide hormone hepcidin: Expression and cellular localization in the mammalian kidney. J. Endocrinol. 2005, 184, 361-370. [CrossRef] [PubMed]

54. Meyron-Holtz, E.G.; Ghosh, M.C.; Iwai, K.; LaVaute, T.; Brazzolotto, X.; Berger, U.V.; Land, W.; Ollivierre-Wilson, H.; Grinberg, A.; Love, P.; et al. Genetic ablations of iron regulatory proteins 1 and 2 reveal why iron regulatory protein 2 dominates iron homeostasis. EMBO J. 2004, 23, 386-395. [CrossRef] [PubMed]

55. Smith, C.P.; Thevenod, F. Iron transport and the kidney. Biochim. Biophys. Acta 2009, 1790, 724-730. [CrossRef] [PubMed]

56. Leaf, D.E.; Swinkels, D.W. Catalytic iron and acute kidney injury. Am. J. Physiol. Ren. Physiol. 2016, 311, F871-F876. [CrossRef] [PubMed]

57. Walker, V.J.; Agarwal, A. Targeting Iron Homeostasis in Acute Kidney Injury. Semin. Nephrol. 2016, 36, 62-70. [CrossRef] [PubMed]

58. Martines, A.M.; Masereeuw, R.; Tjalsma, H.; Hoenderop, J.G.; Wetzels, J.F.; Swinkels, D.W. Iron metabolism in the pathogenesis of iron-induced kidney injury. Nat. Rev. Nephrol. 2013, 9, 385-398. [CrossRef] [PubMed]

59. Swaminathan, S. Iron Homeostasis Pathways as Therapeutic Targets in Acute Kidney Injury. Nephron 2018, 140, 156-159. [CrossRef] 
60. Shah, S.V.; Walker, P.D. Evidence suggesting a role for hydroxyl radical in glycerol-induced acute renal failure. Am. J. Physiol. 1988, 255, F438-F443. [CrossRef]

61. Paller, M.S. Hemoglobin- and myoglobin-induced acute renal failure in rats: Role of iron in nephrotoxicity. Am. J. Physiol. 1988, 255, F539-F544. [CrossRef] [PubMed]

62. Walker, P.D.; Shah, S.V. Evidence suggesting a role for hydroxyl radical in gentamicin-induced acute renal failure in rats. J. Clin. Investig. 1988, 81, 334-341. [CrossRef] [PubMed]

63. Paller, M.S.; Hedlund, B.E. Role of iron in postischemic renal injury in the rat. Kidney Int. 1988, 34, 474-480. [CrossRef] [PubMed]

64. De Vries, B.; Walter, S.J.; von Bonsdorff, L.; Wolfs, T.G.; van Heurn, L.W.; Parkkinen, J.; Buurman, W.A. Reduction of circulating redox-active iron by apotransferrin protects against renal ischemia-reperfusion injury. Transplantation 2004, 77, 669-675. [CrossRef] [PubMed]

65. Leaf, D.E.; Rajapurkar, M.; Lele, S.S.; Mukhopadhyay, B.; Rawn, J.D.; Frendl, G.; Waikar, S.S. Increased plasma catalytic iron in patients may mediate acute kidney injury and death following cardiac surgery. Kidney Int. 2015, 87, 1046-1054. [CrossRef]

66. Leaf, D.E.; Rajapurkar, M.; Lele, S.S.; Mukhopadhyay, B.; Waikar, S.S. Plasma catalytic iron, AKI, and death among critically ill patients. Clin. J. Am. Soc. Nephrol. 2014, 9, 1849-1856. [CrossRef]

67. Lele, S.S.; Mukhopadhyay, B.N.; Mardikar, M.M.; Patel, T.A.; Vasavada, A.K.; Banker, D.N.; Kapasi, K.D.; Chauhan, V.C.; Chawla, K.C.; Raju, S.R.; et al. Impact of catalytic iron on mortality in patients with acute coronary syndrome exposed to iodinated radiocontrast-The Iscom Study. Am. Heart J. 2013, 165, 744-751. [CrossRef]

68. Ueda, N.; Baliga, R.; Shah, S.V. Role of 'catalytic' iron in an animal model of minimal change nephrotic syndrome. Kidney Int. 1996, 49, 370-373. [CrossRef]

69. Rajapurkar, M.M.; Hegde, U.; Bhattacharya, A.; Alam, M.G.; Shah, S.V. Effect of deferiprone, an oral iron chelator, in diabetic and non-diabetic glomerular disease. Toxicol. Mech. Methods 2013, 23, 5-10. [CrossRef]

70. Ferreira, C.; Bucchini, D.; Martin, M.E.; Levi, S.; Arosio, P.; Grandchamp, B.; Beaumont, C. Early embryonic lethality of $\mathrm{H}$ ferritin gene deletion in mice. J. Biol. Chem. 2000, 275, 3021-3024. [CrossRef]

71. Darshan, D.; Vanoaica, L.; Richman, L.; Beermann, F.; Kuhn, L.C. Conditional deletion of ferritin H in mice induces loss of iron storage and liver damage. Hepatology 2009, 50, 852-860. [CrossRef] [PubMed]

72. Rankin, E.B.; Tomaszewski, J.E.; Haase, V.H. Renal cyst development in mice with conditional inactivation of the von Hippel-Lindau tumor suppressor. Cancer Res. 2006, 66, 2576-2583. [CrossRef] [PubMed]

73. Bolisetty, S.; Zarjou, A.; Agarwal, A. Heme Oxygenase 1 as a Therapeutic Target in Acute Kidney Injury. Am. J. Kidney Dis. 2017, 69, 531-545. [CrossRef] [PubMed]

74. Ayer, A.; Zarjou, A.; Agarwal, A.; Stocker, R. Heme Oxygenases in Cardiovascular Health and Disease. Physiol. Rev. 2016, 96, 1449-1508. [CrossRef] [PubMed]

75. Cheng, H.T.; Yen, C.J.; Chang, C.C.; Huang, K.T.; Chen, K.H.; Zhang, R.Y.; Lee, P.Y.; Miaw, S.C.; Huang, J.W.; Chiang, C.K.; et al. Ferritin heavy chain mediates the protective effect of heme oxygenase-1 against oxidative stress. Biochim. Biophys. Acta 2015, 1850, 2506-2517. [CrossRef] [PubMed]

76. Hatcher, H.C.; Tesfay, L.; Torti, S.V.; Torti, F.M. Cytoprotective Effect of Ferritin H in Renal Ischemia Reperfusion Injury. PLoS ONE 2015, 10, e0138505. [CrossRef] [PubMed]

77. Scindia, Y.; Dey, P.; Thirunagari, A.; Liping, H.; Rosin, D.L.; Floris, M.; Okusa, M.D.; Swaminathan, S. Hepcidin Mitigates Renal Ischemia-Reperfusion Injury by Modulating Systemic Iron Homeostasis. J. Am. Soc. Nephrol. 2015, 26, 2800-2814. [CrossRef]

78. Roetto, A.; Papanikolaou, G.; Politou, M.; Alberti, F.; Girelli, D.; Christakis, J.; Loukopoulos, D.; Camaschella, C. Mutant antimicrobial peptide hepcidin is associated with severe juvenile hemochromatosis. Nat. Genet. 2003, 33, 21-22. [CrossRef]

79. Girelli, D.; Nemeth, E.; Swinkels, D.W. Hepcidin in the diagnosis of iron disorders. Blood 2016, 127, 2809-2813. [CrossRef]

80. Van Swelm, R.P.; Wetzels, J.F.; Verweij, V.G.; Laarakkers, C.M.; Pertijs, J.C.; van der Wijst, J.; Thevenod, F.; Masereeuw, R.; Swinkels, D.W. Renal Handling of Circulating and Renal-Synthesized Hepcidin and Its Protective Effects against Hemoglobin-Mediated Kidney Injury. J. Am. Soc. Nephrol. 2016, 27, 2720-2732. [CrossRef] 
81. Bolisetty, S.; Zarjou, A.; Hull, T.D.; Traylor, A.M.; Perianayagam, A.; Joseph, R.; Kamal, A.I.; Arosio, P.; Soares, M.P.; Jeney, V.; et al. Macrophage and epithelial cell H-ferritin expression regulates renal inflammation. Kidney Int. 2015, 88, 95-108. [CrossRef] [PubMed]

82. Zarjou, A.; Black, L.M.; McCullough, K.R.; Hull, T.D.; Esman, S.K.; Boddu, R.; Varambally, S.; Chandrashekar, D.S.; Feng, W.; Arosio, P.; et al. Ferritin Light Chain Confers Protection Against Sepsis-Induced Inflammation and Organ Injury. Front. Immunol. 2019, 10, 131. [CrossRef] [PubMed]

83. Schiffrin, E.L.; Lipman, M.L.; Mann, J.F. Chronic kidney disease: Effects on the cardiovascular system. Circulation 2007, 116, 85-97. [CrossRef] [PubMed]

84. Bloembergen, W.E. Cardiac disease in chronic uremia: Epidemiology. Adv. Ren. Replace. Ther. 1997, 4, 185-193. [CrossRef]

85. Herzog, C.A.; Asinger, R.W.; Berger, A.K.; Charytan, D.M.; Diez, J.; Hart, R.G.; Eckardt, K.U.; Kasiske, B.L.; McCullough, P.A.; Passman, R.S.; et al. Cardiovascular disease in chronic kidney disease. A clinical update from Kidney Disease: Improving Global Outcomes (KDIGO). Kidney Int. 2011, 80, 572-586. [CrossRef] [PubMed]

86. Norton, J.M.; Newman, E.P.; Romancito, G.; Mahooty, S.; Kuracina, T.; Narva, A.S. CE: Improving Outcomes for Patients with Chronic Kidney Disease: Part 1. Am. J. Nurs. 2017, 117, 22-32. [CrossRef] [PubMed]

87. Covic, A.; Kanbay, M.; Voroneanu, L.; Turgut, F.; Serban, D.N.; Serban, I.L.; Goldsmith, D.J. Vascular calcification in chronic kidney disease. Clin. Sci. (Lond.) 2010, 119, 111-121. [CrossRef] [PubMed]

88. McIntyre, C.W. The functional cardiovascular consequences of vascular calcification. Semin. Dial. 2007, 20, 122-128. [CrossRef]

89. London, G.M.; Marchais, S.J.; Guerin, A.P.; Metivier, F. Arteriosclerosis, vascular calcifications and cardiovascular disease in uremia. Curr. Opin. Nephrol. Hypertens. 2005, 14, 525-531. [CrossRef]

90. Gusbeth-Tatomir, P.; Covic, A. Causes and consequences of increased arterial stiffness in chronic kidney disease patients. Kidney Blood Press Res. 2007, 30, 97-107. [CrossRef]

91. Goodman, W.G.; Goldin, J.; Kuizon, B.D.; Yoon, C.; Gales, B.; Sider, D.; Wang, Y.; Chung, J.; Emerick, A.; Greaser, L.; et al. Coronary-artery calcification in young adults with end-stage renal disease who are undergoing dialysis. N. Engl. J. Med. 2000, 342, 1478-1483. [CrossRef] [PubMed]

92. Lumpaopong, A.; Mathew, A.V.; John, E.; Jelnin, V.; Benedetti, E.; Testa, G.; Oberholzer, J.; Sankary, H.; Ruiz, C. Early coronary calcification in children and young adults with end-stage renal disease. Transplant. Proc. 2007, 39, 37-39. [CrossRef]

93. Jono, S.; Shioi, A.; Ikari, Y.; Nishizawa, Y. Vascular calcification in chronic kidney disease. J. Bone Miner. Metab. 2006, 24, 176-181. [CrossRef]

94. Yamada, S.; Giachelli, C.M. Vascular calcification in CKD-MBD: Roles for phosphate, FGF23, and Klotho. Bone 2017, 100, 87-93. [CrossRef] [PubMed]

95. Mizobuchi, M.; Towler, D.; Slatopolsky, E. Vascular calcification: The killer of patients with chronic kidney disease. J. Am. Soc. Nephrol. 2009, 20, 1453-1464. [CrossRef] [PubMed]

96. Zhu, D.; Mackenzie, N.C.; Farquharson, C.; Macrae, V.E. Mechanisms and clinical consequences of vascular calcification. Front. Endocrinol. (Lausanne) 2012, 3, 95. [CrossRef] [PubMed]

97. El-Abbadi, M.; Giachelli, C.M. Mechanisms of vascular calcification. Adv. Chronic Kidney Dis. 2007, 14, 54-66. [CrossRef] [PubMed]

98. Shroff, R.C.; Shanahan, C.M. The vascular biology of calcification. Semin. Dial. 2007, 20, 103-109. [CrossRef]

99. McCarty, M.F.; DiNicolantonio, J.J. The molecular biology and pathophysiology of vascular calcification. Postgrad. Med. 2014, 126, 54-64. [CrossRef]

100. Liberman, M.; Marti, L.C. Vascular Calcification Regulation by Exosomes in the Vascular Wall. Adv. Exp. Med. Biol. 2017, 998, 151-160.

101. Zarychanski, R.; Houston, D.S. Anemia of chronic disease: A harmful disorder or an adaptive, beneficial response? CMAJ 2008, 179, 333-337. [CrossRef]

102. Webster, A.C.; Nagler, E.V.; Morton, R.L.; Masson, P. Chronic Kidney Disease. Lancet 2017, 389, $1238-1252$. [CrossRef]

103. Panwar, B.; Gutierrez, O.M. Disorders of Iron Metabolism and Anemia in Chronic Kidney Disease. Semin. Nephrol. 2016, 36, 252-261. [CrossRef] [PubMed]

104. Babitt, J.L.; Lin, H.Y. Mechanisms of anemia in CKD. J. Am. Soc. Nephrol. 2012, 23, 1631-1634. [CrossRef] [PubMed] 
105. Ueda, N.; Takasawa, K. Role of Hepcidin-25 in Chronic Kidney Disease: Anemia and Beyond. Curr. Med. Chem. 2017, 24, 1417-1452. [CrossRef] [PubMed]

106. Cassat, J.E.; Skaar, E.P. Iron in infection and immunity. Cell Host Microbe 2013, 13, 509-519. [CrossRef] [PubMed]

107. Fuery, M.A.; Liang, L.; Kaplan, F.S.; Mohler, E.R., 3rd. Vascular ossification: Pathology, mechanisms, and clinical implications. Bone 2018, 109, 28-34. [CrossRef] [PubMed]

108. Burke, S.K. Phosphate is a uremic toxin. J. Ren. Nutr. 2008, 18, 27-32. [CrossRef] [PubMed]

109. Block, G.A.; Klassen, P.S.; Lazarus, J.M.; Ofsthun, N.; Lowrie, E.G.; Chertow, G.M. Mineral metabolism, mortality, and morbidity in maintenance hemodialysis. J. Am. Soc. Nephrol. 2004, 15, 2208-2218. [CrossRef]

110. Zarjou, A.; Jeney, V.; Arosio, P.; Poli, M.; Antal-Szalmas, P.; Agarwal, A.; Balla, G.; Balla, J. Ferritin prevents calcification and osteoblastic differentiation of vascular smooth muscle cells. J. Am. Soc. Nephrol. 2009, 20, 1254-1263. [CrossRef]

111. Lian, J.B.; Stein, G.S. Runx2/Cbfa1: A multifunctional regulator of bone formation. Curr. Pharm. Des. 2003, 9, 2677-2685. [CrossRef] [PubMed]

112. Rajendran, R.; Minqin, R.; Ronald, J.A.; Rutt, B.K.; Halliwell, B.; Watt, F. Does iron inhibit calcification during atherosclerosis? Free Radic. Biol. Med. 2012, 53, 1675-1679. [CrossRef] [PubMed]

113. Phan, O.; Maillard, M.; Peregaux, C.; Mordasini, D.; Stehle, J.C.; Funk, F.; Burnier, M. PA21, a new iron-based noncalcium phosphate binder, prevents vascular calcification in chronic renal failure rats. J. Pharmacol. Exp. Ther. 2013, 346, 281-289. [CrossRef] [PubMed]

114. Seto, T.; Hamada, C.; Tomino, Y. Suppressive effects of iron overloading on vascular calcification in uremic rats. J. Nephrol. 2014, 27, 135-142. [CrossRef] [PubMed]

115. Ciceri, P.; Elli, F.; Braidotti, P.; Falleni, M.; Tosi, D.; Bulfamante, G.; Block, G.A.; Cozzolino, M. Iron citrate reduces high phosphate-induced vascular calcification by inhibiting apoptosis. Atherosclerosis 2016, 254, 93-101. [CrossRef] [PubMed]

116. Carpentier, S.M.; Carpentier, A.F.; Chen, L.; Shen, M.; Quintero, L.J.; Witzel, T.H. Calcium mitigation in bioprosthetic tissues by iron pretreatment: The challenge of iron leaching. Ann. Thorac. Surg. 1995, 60, S332-S338. [CrossRef]

117. Neven, E.; De Schutter, T.M.; Behets, G.J.; Gupta, A.; D’Haese, P.C. Iron and vascular calcification. Is there a link? Nephrol. Dial. Transplant. 2011, 26, 1137-1145. [CrossRef]

118. Balogh, E.; Paragh, G.; Jeney, V. Influence of Iron on Bone Homeostasis. Pharmaceuticals (Basel) 2018, 11, 107. [CrossRef]

119. Jeney, V. Clinical Impact and Cellular Mechanisms of Iron Overload-Associated Bone Loss. Front. Pharmacol. 2017, 8, 77. [CrossRef]

120. Zarjou, A.; Jeney, V.; Arosio, P.; Poli, M.; Zavaczki, E.; Balla, G.; Balla, J. Ferritin ferroxidase activity: A potent inhibitor of osteogenesis. J. Bone Miner. Res. 2010, 25, 164-172. [CrossRef]

121. Fishbane, S.; Mathew, A.; Vaziri, N.D. Iron toxicity: Relevance for dialysis patients. Nephrol. Dial. Transplant. 2014, 29, 255-259. [CrossRef] [PubMed]

122. Afzali, B.; Goldsmith, D.J. Intravenous iron therapy in renal failure: Friend and foe? J. Nephrol. 2004, 17, 487-495. [PubMed]

123. Brewster, U.C. Intravenous iron therapy in end-stage renal disease. Semin. Dial. 2006, 19, 285-290. [CrossRef] [PubMed]

124. Zhang, Y.; Munday, R. Dithiolethiones for cancer chemoprevention: Where do we stand? Mol. Cancer Ther. 2008, 7, 3470-3479. [CrossRef] [PubMed]

125. Pietsch, E.C.; Chan, J.Y.; Torti, F.M.; Torti, S.V. Nrf2 mediates the induction of ferritin H in response to xenobiotics and cancer chemopreventive dithiolethiones. J. Biol. Chem. 2003, 278, 2361-2369. [CrossRef]

126. Becs, G.; Zarjou, A.; Agarwal, A.; Kovacs, K.E.; Becs, A.; Nyitrai, M.; Balogh, E.; Banyai, E.; Eaton, J.W.; Arosio, P.; et al. Pharmacological induction of ferritin prevents osteoblastic transformation of smooth muscle cells. J. Cell. Mol. Med. 2016, 20, 217-230. [CrossRef] [PubMed]

127. Sikura, K.E.; Potor, L.; Szerafin, T.; Zarjou, A.; Agarwal, A.; Arosio, P.; Poli, M.; Hendrik, Z.; Mehes, G.; Oros, M.; et al. Potential Role of H-Ferritin in Mitigating Valvular Mineralization. Arterioscler. Thromb. Vasc. Biol. 2019, 39, 413-431. [CrossRef]

128. Peacock, J.D.; Levay, A.K.; Gillaspie, D.B.; Tao, G.; Lincoln, J. Reduced sox9 function promotes heart valve calcification phenotypes in vivo. Circ. Res. 2010, 106, 712-719. [CrossRef] 
129. Kraml, P. The role of iron in the pathogenesis of atherosclerosis. Physiol. Res. 2017, 66, S55-S67.

130. Das De, S.; Krishna, S.; Jethwa, A. Iron status and its association with coronary heart disease: Systematic review and meta-analysis of prospective studies. Atherosclerosis 2015, 238, 296-303. [CrossRef]

131. Silvestre, O.M.; Goncalves, A.; Nadruz, W., Jr.; Claggett, B.; Couper, D.; Eckfeldt, J.H.; Pankow, J.S.; Anker, S.D.; Solomon, S.D. Ferritin levels and risk of heart failure-the Atherosclerosis Risk in Communities Study. Eur. J. Heart Fail. 2017, 19, 340-347. [CrossRef] [PubMed]

132. Galesloot, T.E.; Janss, L.L.; Burgess, S.; Kiemeney, L.A.; den Heijer, M.; de Graaf, J.; Holewijn, S.; Benyamin, B.; Whitfield, J.B.; Swinkels, D.W.; et al. Iron and hepcidin as risk factors in atherosclerosis: What do the genes say? BMC Genet. 2015, 16, 79. [CrossRef] [PubMed]

133. Lapice, E.; Masulli, M.; Vaccaro, O. Iron deficiency and cardiovascular disease: An updated review of the evidence. Curr. Atheroscler. Rep. 2013, 15, 358. [CrossRef] [PubMed]

134. Sullivan, J.L. Do hemochromatosis mutations protect against iron-mediated atherogenesis? Circ. Cardiovasc. Genet. 2009, 2, 652-657. [CrossRef] [PubMed]

(C) 2019 by the authors. Licensee MDPI, Basel, Switzerland. This article is an open access article distributed under the terms and conditions of the Creative Commons Attribution (CC BY) license (http://creativecommons.org/licenses/by/4.0/). 


\title{
Oxidative Stress and Cardiovascular Complications in Chronic Kidney Disease, the Impact of Anaemia
}

\author{
Faisal Nuhu ${ }^{1, *}$ and Sunil Bhandari ${ }^{2}$ \\ 1 School of Life Sciences (Biomedical), University of Hull, Cottingham Rd, Hull HU6 7RX, UK \\ 2 Hull York Medical School \& Department of Renal Medicine, Hull and East Yorkshire NHS Hospital Trust, \\ Hull HU3 2JZ, UK; Sunil.Bhandari@hey.nhs.uk \\ * Correspondence: f.nuhu@hull.ac.uk; Tel.: +44-744-570-9458
}

Received: 11 September 2018; Accepted: 1 October 2018; Published: 11 October 2018

\begin{abstract}
Patients with chronic kidney disease (CKD) have significant cardiovascular morbidity and mortality as a result of risk factors such as left ventricular hypertrophy (LVH), oxidative stress, and inflammation. The presence of anaemia in CKD further increases the risk of LVH and oxidative stress, thereby magnifying the deleterious consequence in uraemic cardiomyopathy (UCM), and aggravating progression to failure and increasing the risk of sudden cardiac death. This short review highlights the specific cardio-renal oxidative stress in CKD and provides an understanding of the pathophysiology and impact of uraemic toxins, inflammation, and anaemia on oxidative stress.
\end{abstract}

Keywords: oxidative stress; anaemia; cardiovascular disease; chronic kidney disease; IV iron therapy

\section{Introduction}

Oxidative stress refers to an imbalance in the reactive oxygen species (ROS) production/degradation ratio. ROS such as superoxide anions $\left(\mathrm{O}_{2}{ }^{\bullet}\right)$, hydrogen peroxide $\left(\mathrm{H}_{2} \mathrm{O}_{2}\right)$, and hydroxyl radicals $\left(\mathrm{OH}^{\bullet}\right)$ (by-products of mitochondrial respiration) are important for cell signalling and immune response [1,2]. Inappropriate or excess generation of ROS can lead to deleterious cellular consequences including damage to DNA, proteins, and cell membrane lipids [3]. To limit these damaging effects, cells are equipped with endogenous capacity comprising enzymatic and non-enzymatic components to detoxify excess ROS. The latter consist of reductants such as reduced glutathione (GSH), vitamin C, beta carotenes, and vitamin E. GSH can deactivate ROS through its oxidation to the oxidised form (GSSG). Vitamin E, on the other hand, protects the cell membrane by reacting with lipid radicals. The enzymatic components consist of superoxide dismutase (SOD), glutathione peroxidase (GPx), glutathione reductase (GR), and catalase [4]. These enzymes together catalyse the dismutation of $\mathrm{O}_{2}{ }^{\bullet}$ into water. Ineffective antioxidant capacity or excess generation of ROS is implicated in the development and progression of renal and cardiovascular diseases $[5,6]$.

The association between renal and cardiac oxidative stress in chronic kidney disease (CKD) is poorly defined, and the impact of anaemia on the oxidant status of the kidney and heart is not completely characterized. In addition, many of the clinical studies in uraemic patients are limited to systemic oxidative stress, creating an information vacuum on cardiac oxidant status that must be filled by studies using experimental uraemic cardiomyopathy (UCM) models. Moreover, given that iron deficiency anaemia in CKD may exacerbate oxidative stress and worsen the poor cardiovascular outcome, how can parenteral iron therapy which is employed in current clinical practice modify oxidative stress at both the systemic and tissue level? This review aims to provide insight into these questions and highlight research questions that need to be answered in the future. 


\section{Oxidative Stress in Chronic Kidney Disease}

The mechanism behind the oxidative stress in patients with chronic kidney disease is complex and multifactorial and not fully elucidated [7]. Mainly, it results from an imbalance between oxidant-antioxidant processes causing a pro-oxidant state [8]. Factors including decreased levels of the antioxidants such as GSH, and ascorbic acid and enhanced ROS generation (arising from uraemic toxins) in CKD predispose patients to potential oxidative damage [9]. In addition, by-products of oxidative stress including peroxide lipid (see Figure 1) oxidise low density lipoproteins and lipid radicals activate immune cells including monocytes and macrophages leading to inflammation and further oxidative stress [10].

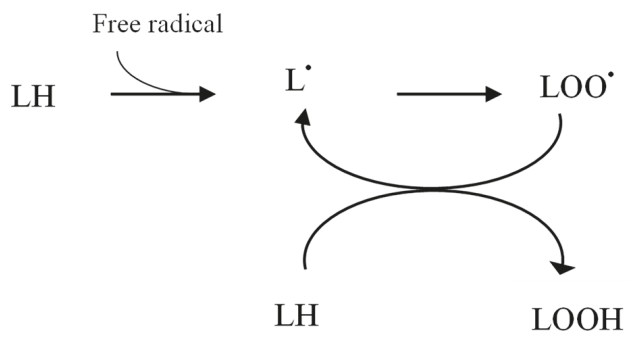

Figure 1. Reactive oxygen species (ROS)-induced lipid peroxidation. LH (lipid), LOOH (peroxide lipid), $\mathrm{L}^{\bullet}$ (lipid radical), LOO• (peroxidised lipid radical).

\subsection{Increased Pro-Oxidant Activity}

Oxidative stress in uraemia may in part be due to increased pro-oxidant activities leading to excessive ROS production. This argument is supported by evidence of increased nicotinamide adenine dinucleotide phosphate (NADPH) oxidase activity or expression in models of renal dysfunction [11,12]. In diabetic nephropathy, elevated expression of renal NADPH oxidase and endothelial nitric oxide synthase (eNOS) resulted in oxidative stress with elevated lipid peroxidation which was inhibited following treatment with an angiotensin-converting enzyme inhibitor (ACEi) or an angiotensin receptor blocker (ARB) agent in rat models [13]. Increased expression of NADPH mediated an increased production of $\mathrm{O}_{2} \bullet$ which was attenuated through treatment with apocynin (an inhibitor of NADPH oxidase) [14]. NADPH oxidases are a group of enzymes that reduce oxygen to $\mathrm{O}_{2} \bullet$ radical (see Figure 2), which provides the starting point for the generation of other reactive oxidants including $\mathrm{H}_{2} \mathrm{O}_{2}$, lipid peroxides, and peroxynitrites $\left(\mathrm{ONOO}^{\bullet}\right)[15,16]$. The NADPH oxidase family consists of five isoforms (Nox1 to Nox5) with p22phox as a bridge between the Nox family and the p47phox organizer factor $[17,18]$. Nox4 is expressed in vascular endothelial, smooth muscle cells, and renal proximal tubules $[19,20]$, thus explaining why pathological insults involving the kidney affect its expression or activity.

Another possible source of ROS in CKD is xanthine oxidase whose activity can markedly increase in uraemia [21]. With molecular oxygen as the electron acceptor, xanthine oxidase catalyses the oxidation of hypoxanthine to uric acid, releasing ROS including $\mathrm{O}_{2}{ }^{\bullet}, \mathrm{OH}^{\bullet}$, and $\mathrm{H}_{2} \mathrm{O}_{2}$ as by-products. The metabolite uric acid is associated with CKD progression to renal failure and increased risk of cardiovascular events [22]. Thus, targeting xanthine oxidase as a way of lowering oxidative stress and uric acid levels (the increase of which causes severe joint pains such as gout) could be a putative therapeutic strategy in CKD. The observation that enhanced uptake of indoxyl sulphate by Nox4 via organic anion transporter 1 (OAT1) and 3 (OAT3) induces the production of $\mathrm{O}_{2}{ }^{\bullet}$ radical [23] and supports the argument that uraemic toxins in CKD are associated with oxidative stress. 


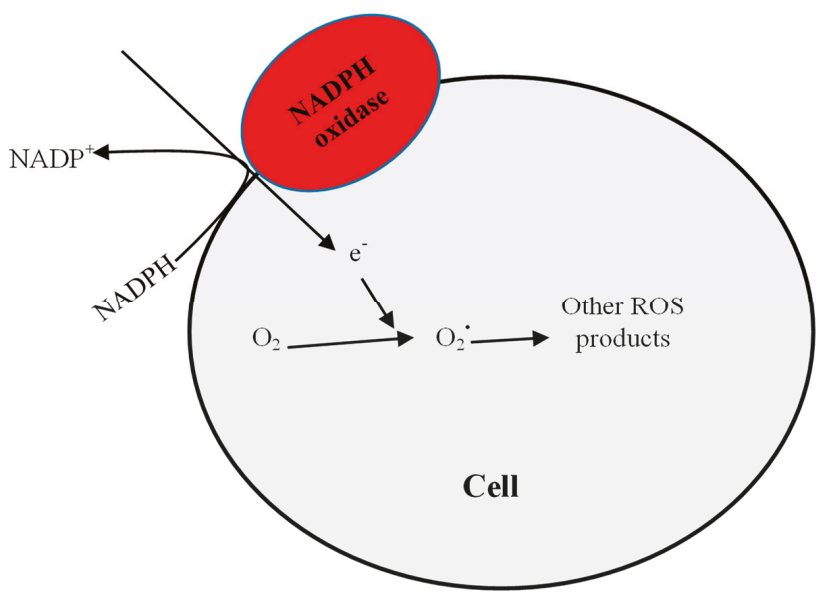

Figure 2. Schematic representation of NADPH oxidase-dependant ROS generation. NADPH under the influence of the plasma membrane-bound NADPH oxidase donates an electron, which is accepted by molecular oxygen to form the superoxide $\left(\mathrm{O}_{2}{ }^{\bullet}\right)$ radical.

\subsection{Uraemic Toxins}

Impaired renal clearance in CKD leads to the accumulation of toxins of which $p$-cresol and indoxyl sulphate have been most widely studied [24]. Indeed, the uraemic toxin indoxyl sulphate confers an additional cardiovascular risk in CKD and upregulates the expression of intercellular adhesion molecule-1 (ICAM) and monocyte chemotactic protein-1 (MCP-1) [25]. It also induces the activation of NADPH oxidase and causes the production of ROS. $p$-Cresol sulphate, a conjugated form of $p$-Cresol, is reported to induce ROS in a time- and concentration-dependent manner [26]. Concentrations of indoxyl sulphate and $p$-Cresol sulphate have been shown to correlate inversely with GPx activity, indicating toxin-associated reduction in antioxidant capacity [27]. Indoxyl sulphate- and $p$-Cresol sulphate-mediated induction of oxidative stress are reported to occur through the activation of the nuclear factor-kappaB (NF- $\mathrm{BB}$ ) pathway [28]. This mechanism was supported by in vivo experimental studies which demonstrated inhibition/reduction of oxidative stress following treatment with NF- $\mathrm{KB}$ inhibitors [29] and antioxidants [30]. Furthermore, a dose-dependent decrease in indoxyl sulphate through treatment with the drug AST-120 was found to significantly reduce oxidative stress in patients with CKD [31] and uraemic rats [32]. Oxidative stress-dependent loss of NO was alleviated in AST-120-treated CKD rats via the reduction of indoxyl sulphate [33]. This could explain the recently revealed benefits of AST-120 on the progression and prognosis of pre-dialysis CKD, including the reduction in the prevalence of dialysis requirement, mortality, and cardiovascular- and stroke-related events in treated patients after three and five years relative to untreated patients [34]. The accumulation of uraemic toxins in patients with CKD can also enhance inflammation, a potent inducer of oxidative stress $[35,36]$.

\subsection{Inflammation}

Patients with CKD are in a constant inflammatory state attributable to a number of factors, including the uraemic state, malnutrition, chronic volume overload, increased infection, metabolic acidosis, and autonomic dysfunction [37,38]. Inflammatory cells (e.g., phagocytes, monocytes/macrophages, or polymorphonuclear leukocytes) release reactive substances such as $\mathrm{O}_{2}{ }^{\bullet}$ at the site of inflammation causing oxidative stress and ROS that, in turn, can initiate intracellular signalling cascade that activates pro-inflammatory gene expression [39]. For example, an increase in ROS is associated with the induction of inflammation, consequently increasing the levels of mediators 
such as interleukin-6 (IL-6) and tumour necrosis factor $\beta$ (TGF- $\beta$ ) [40]. Thus, inflammation and oxidative stress in CKD are interlinked, with synergy between them magnifying the deleterious consequences associated with either of them alone (see Figure 3). Elevated concentrations of the pro-inflammatory markers C-reactive protein (CRP) and IL-6 significantly correlated with protein carbonyl (caused by oxidative damage to proteins) levels in early CKD [41]. The upregulation of inflammatory markers (e.g., tumour necrosis factor- $\alpha$ and platelet-derived growth factor) in CKD [42] are linked to NADPH oxidase activation leading to the generation of intracellular $\mathrm{O}_{2}{ }^{\bullet}$ and $\mathrm{H}_{2} \mathrm{O}_{2}$ [43] . The inflammatory state in CKD can lead to activation/recruitment of polymorphonuclear neutrophils and monocytes, causing the activation of myeloperoxidase (MPO) and triggering ROS production [44].

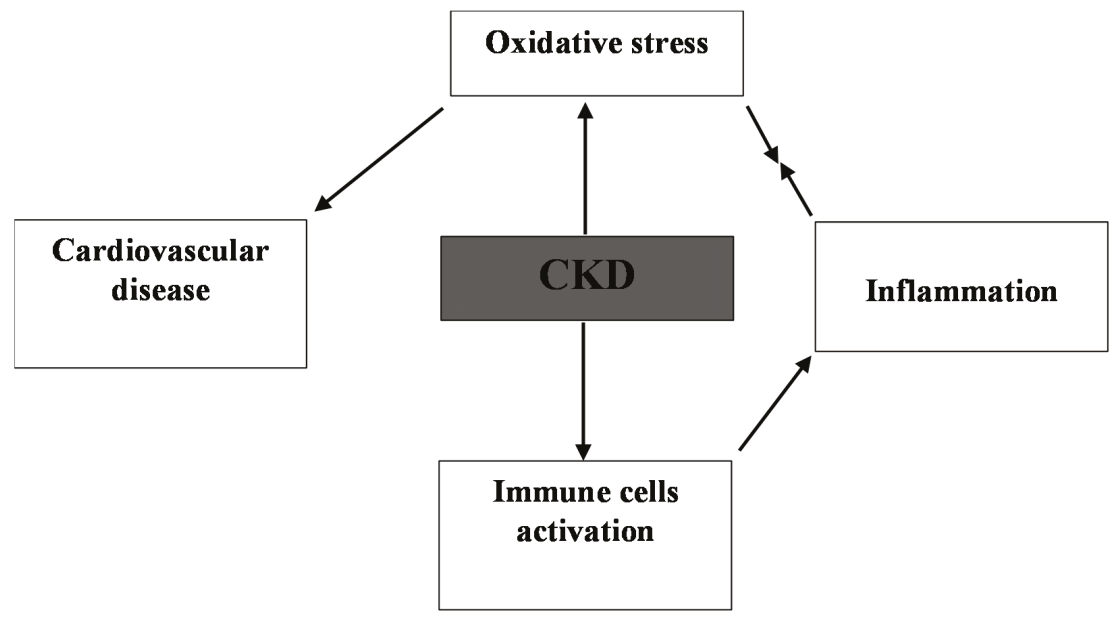

Figure 3. Risks of oxidative stress in CKD.

\subsection{Impaired Antioxidant System}

Chronic deficiency in the antioxidant system, including the reduction of vitamin E, melatonin, SOD, catalase, and activity of glutathione system, has been reported in patients with kidney disease [45]. The reduction of SOD suggests the accumulation of $\mathrm{O}_{2}{ }^{\bullet}$ radical causing increased lipid peroxidation [46]. The reduction of the endogenous thiol tripeptidic GSH antioxidant [47] together with the increased accumulation of GSSG due to the reduced GR activity [48] in patients with kidney disease further explain the prevalence of oxidative stress in this patient population. In addition, oxidative stress in CKD resulted from decreased catalase which compromised the conversion of $\mathrm{H}_{2} \mathrm{O}_{2}$ to $\mathrm{H}_{2} \mathrm{O}$ and $\mathrm{O}_{2}$ [44].

Eight isoforms of GPx enzymes (GPx1-GPx8) thus far have been recognised in mammals [49]. Only five (GPx1-GPx4 and GPx6) are found to contain selenium and are called seleno-GPx [50]. The kidney is increasingly found to be a major source of GPx3 [51], although GPx3 is also found in small concentrations in the liver, heart, and skeletal muscle. Thus, any kidney injury (acute and chronic) could affect GPx3 expression and total GPx activity. A reduction in GPx activity has been reported early during the development of CKD and continued to decrease with the severity of the disease [52]. This was in contrast to the observation that GPx activity negatively correlated with creatinine clearance in CKD stage 1-5, although the authors also reported a progressively decreased activity at two- and four-month follow-up in untreated patients with CKD at stage 3-5 [53]. Such discordance in the literature highlights the need for further investigation into the role of antioxidants such as GPx in CKD-related oxidative stress, a focus of our ongoing research. Decreased activity of SOD, catalase, and GPx with concomitant accumulation of nitrotyrosine were observed in the blood of chronic kidney failure patients [54]. Nitrotyrosine formation and other forms of ROS-mediated inactivation of nitric 
oxide (NO) may contribute to hypertension and its associated cardiac remodelling in uraemic patients as a result of inhibited vasodilation. Evidentially, hypertension and increased oxidative stress in the animal model of CKD were both attenuated by antioxidant therapy $[55,56]$.

\subsection{Anaemia and Oxidative Stress in CKD}

Iron deficiency anaemia (IDA), a common complication in many chronic diseases including $\mathrm{CKD}$, is caused by iron and erythropoietin deficiencies and a decreased responsiveness to the actions of erythropoietin [57,58]. Iron deficiency (ID) in CKD can be grouped into absolute and functional deficiency. Absolute iron deficiency in this patient group can be caused by low iron intake and complicated by impairment of dietary iron absorption in the gut, gastrointestinal bleeding, and increased blood loss [59]. Functional iron deficiency, on the other hand, is mediated by pro-inflammatory activation and hepcidin overproduction $[60,61]$. Hepcidin, which is produced by the liver, binds to and induces the degradation of ferroportin on hepatocytes, duodenal enterocytes, and reticuloendothelial macrophages, thereby inhibiting the absorption of dietary iron in the intestines and the release of iron from storage [62]. Hepcidin is also regulated transcriptionally by the inflammatory mediator IL-6 (known to be increased in CKD) via the STAT-3 signalling pathway $[63,64]$. Thus, enhanced inflammation in patients with CKD induces hepcidin production, causing iron sequestration and hypoferraemia and resulting in ID anaemia (see Figure 4) and oxidative stress [65].

Iron deficiency anaemia reduces the lifespan of red blood cells (RBCs) through increased premature RBC death [66] resulting from increased membrane stiffness and decreased deformability. The death of RBCs liberates iron which enhances the risk of oxidative stress. Oxidative stress itself can alter membrane properties of RBCs $[67,68]$. Indeed, exposure to $\mathrm{H}_{2} \mathrm{O}_{2}$ has been shown to increase lipid peroxidation and decrease cell deformability and membrane rigidity of erythrocytes [69], thereby increasing RBC removal in the spleen. This enhanced susceptibility of RBCs to oxidative damage [70] and the increased risk of ROS production in iron deficiency anaemia in CKD create a vicious cycle culminating in greater RBC death, anaemia, and severity of oxidative stress [71]. The accompanying decrease in haemoglobin content in ID anaemia lowers the partial pressure of oxygen similar to the hypoxic state. Under these conditions, hypoxia exacerbates oxidative stress through auto-oxidation of haemoglobin to met-haemoglobin $(\mathrm{metHb})$ and with the generation of $\mathrm{O}_{2} \bullet[72,73]$. Endogenous antioxidant proteins such as catalase and peroxidase are iron-containing enzymes whose expression is affected in iron deficiency anaemia [74]. Iron deficiency adversely affects selenium concentration [75], which may explain the reduction in activity of the selenium-dependent enzyme GPx [76]. This evidence supports the argument that oxidative stress in iron deficiency anaemia is partly mediated via the reduction of antioxidant capacity [77] and suggests that timely iron replacement (via intravenous (IV) infusion rather than oral) and antioxidant therapies in clinical setting could lead to improvement. ID anaemia is associated with an adverse outcome in CKD; it certainly reduces the quality of life by increasing the risk of morbidity [78]. Hence, the management of anaemia and the treatment of its underlying cause, such as ID, must be a high priority.

Iron replacement can be done via oral, intravenous, or intramuscular routes, the former best given without food. Oral iron therapy is based on the premise that intestinal iron absorption is enhanced during iron deficiency and declines upon correction of the deficiency and replenishment of iron stores. Non-compliance among patients with CKD is complicated by the frequent side effects including nausea, constipation, diarrhoea, or abdominal pain associated with oral iron [79]. Moreover, oral iron therapy in advanced CKD is not recommended due to impaired intestinal iron absorption [80] as a result of increased hepcidin production. Examples of oral iron supplements include ferrous sulphate, ferrous fumarate, and ferrous gluconate. Unequivocally, IV iron therapy in CKD has been shown to be more efficacious than oral iron administration in stimulating haemoglobin synthesis and replenishing iron stores [81]. Intravenous iron regimes including iron dextran, iron sucrose, and ferric gluconate release bioactive iron associated with oxidative stress and inflammation [82]. There are mixed reports on the impact of IV iron on oxidative stress in patients with CKD. While some investigators associate IV 
iron with increased systemic oxidative stress [83], others see no effect [84]. It is increasingly becoming clear that the oxidative stress impact of IV iron is dependent on the iron formulation, the stage of $\mathrm{CKD}$, the question of whether the patient is on dialysis, as well as the dose and time of investigation post-therapy [85].
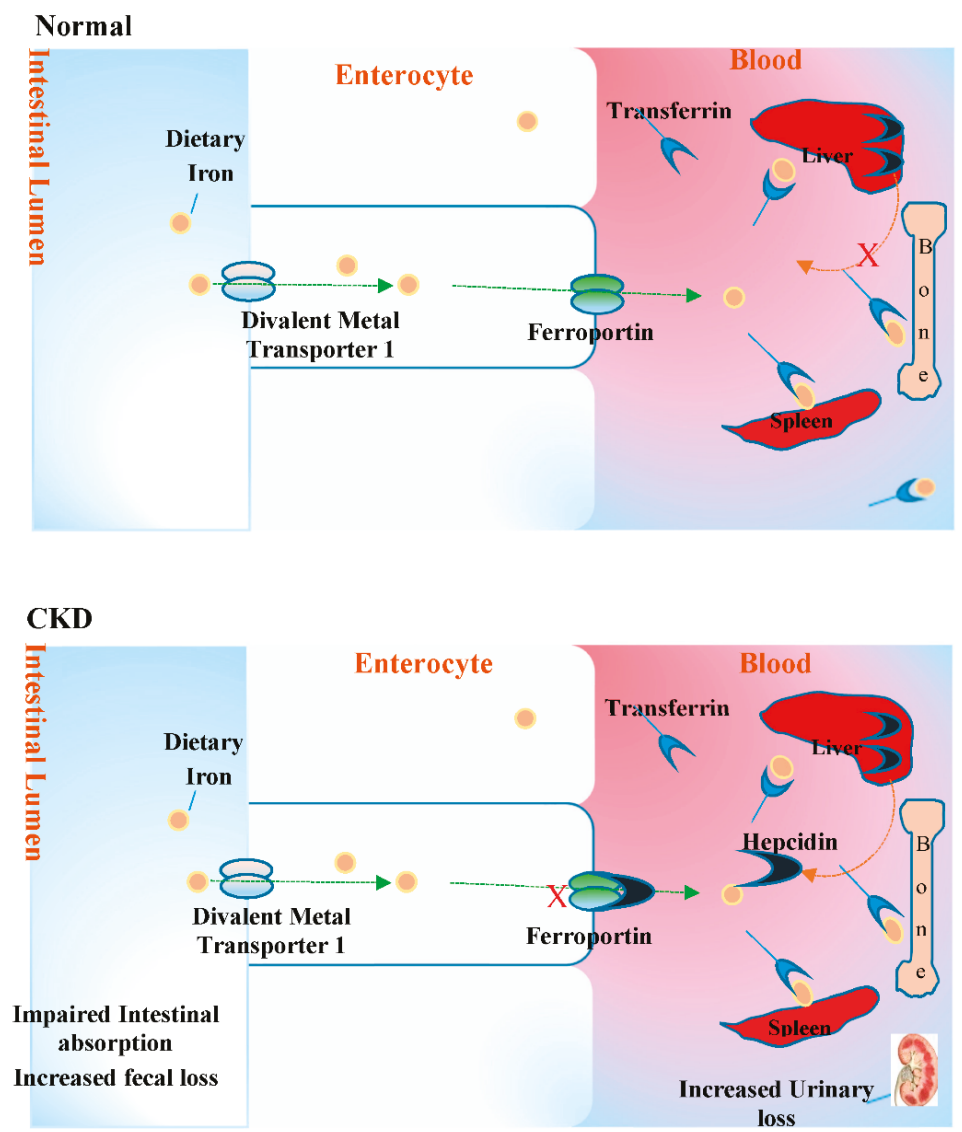

Figure 4. Mechanism of iron deficiency anaemia (IDA) in CKD. Normally, liver hepcidin synthesis is inhibited, allowing the uptake of dietary iron to replace the average 1-2 mg daily iron loss in adults via divalent metal transporter 1 (DMT1) at the apical brush border of enterocytes. Ferric reductase reduces the predominant $\mathrm{Fe}^{3+}$ to $\mathrm{Fe}^{2+}$ prior to DMT1 transport. Intracellular iron is stored as ferritin in the enterocytes while basolateral iron is transported by ferroportin into the circulation, where iron $\mathrm{Fe}^{3+}$ (generated by oxidation of $\mathrm{Fe}^{2+}$ by ferroxidases such as hephaestin) is loaded onto transferrin to be transported to storage (e.g., liver) or utilization site (bone marrow). In CKD, the presence of chronic inflammation with elevated cytokines such as IL-6 levels results in increased hepcidin secretion. Consequently, the binding of hepcidin to the iron transporter ferroportin induces its endocytosis and proteolytic destruction, thus preventing the transport of dietary iron into the circulation. Hepcidin secretion prevents the release of iron from storage sites [62]. Additionally, the apparent loss of iron via urine which is associated with kidney dysfunction may exacerbate IDA and reduce the efficacy of IV iron in the late stages of CKD. 
Oxidative stress as evidenced by increased lipid and protein oxidation ensued following iron sucrose administration [86]. This side effect may be attributed to "free" (labile) iron levels which increase during iron therapy [87]. Free iron (biological active form) readily cycles between ferrous and ferric oxidation states. This property enables iron to aid the catalysis of biochemical reactions involved in the production of ROS, including hydroxyl radical, ferryl, and perferryl ion [88]. Hydroxyl radicals from the iron-catalysed Haber-Weiss reaction contribute to mitochondrial lipid peroxidation. Iron-induced lipid peroxidation is associated with intense mitochondrial damage [89] that may lead to a decline in oxidative capacity. Despite the well-documented acute and systemic oxidative toxicity of IV iron, not much is known of the long-term effect on the heart, skeletal muscle, and liver. Intravenous iron therapy however may enhance the risk of bacterial infection. Bacterial pathogens utilise iron to grow and increase virulence. Certain IV iron regimes such as ferric gluconate and iron sucrose reduce chemotaxis and phagocytosis of polymorphonuclear leukocytes, decreasing the immune response to bacterial infection [90]. However, the impact of IV iron therapy on cardiac mitochondrial function and mitochondrial oxidative stress in CKD is poorly defined, but given the central role of mitochondrial dysfunction in the development of heart failure, this may provide a major therapeutic strategy in limiting cardiovascular damage in CKD.

\section{Consequence of Oxidative Stress in CKD}

Oxidative stress in CKD can affect a number of organ systems with far-reaching clinical implications. It can both exacerbate kidney dysfunction and enhance progression and failure in other organs such as the heart, inducing cardiac hypertrophy which is an independent risk factor for heart failure (HF) and resulting in endothelial dysfunction. In considering the progression of CKD, part of the mechanism is via oxidant-induced damage to glomerular basement membrane [91,92]. Glomerular membrane integrity and thus glomerular ultrafiltration are compromised by oxidant-mediated impairment of glomerular heparin sulphate proteoglycans. Renal dysfunction is associated with the activation of the renin-angiotensin system (RAAS) [93], evidenced by the elevation of angiotensinogen (Ang) in CKD [94] and the increased release of renin in diabetic nephropathy [95,96]. RAAS activation is actively involved in the process of left ventricular (LV) remodelling partly through the induction of hypertension. Renin released in response to increased $\mathrm{Na}^{+}$retention and local renal hypotension [97] converts angiotensinogen to angiotensin I (Ang I), which is further cleaved to give Ang II by the angiotensin converting enzyme (ACE). Ang II causes vasoconstriction and aldosterone release and consequently aggravates $\mathrm{Na}^{+}$and water retention [98]. Thus, Ang II mediates haemodynamic alterations that culminate into cardiac and vascular remodelling. Therefore, the treatment of patients with LV dysfunction using ACE inhibitors such as captopril, enalapril, and Lisinopril has been associated with improved outcome and attenuation of ventricular enlargement [99].

Moreover, Ang II and aldosterone elicit non-haemodynamic effects that lead to the activation of mitogen-activated protein kinases (MAPKs), Ki-ras2A, and c-Src pathways involved in inflammation, ROS release $\left(\mathrm{O}_{2} \bullet\right.$ and $\left.\mathrm{H}_{2} \mathrm{O}_{2}\right)$, and endothelial dysfunction [100]. Ang II mediates the formation of $\mathrm{O}_{2} \bullet$ via activation of NADPH oxidases [101]. This is supported by the finding of NADPH-mediated $\mathrm{O}_{2} \bullet$ production following Ang II infusion [102]. Similarly, the treatment of rat aortic vascular smooth muscle cells (VSMCs) with Ang II increased intracellular generated $\mathrm{O}_{2}{ }^{\bullet}$ by three-fold [103]. Increased $\mathrm{O}_{2} \bullet$ resulted in increased protein kinase C (PKC) activity and NOS uncoupling causing impaired NO/cGMP signalling [104]. Thus, oxidative stress can cause loss of vasodilation, a hallmark of endothelial dysfunction. Cellular NO originates from NOS with tetrahydrobiopterin (BH4) as a cofactor. Excess ROS can oxidise $\mathrm{BH} 4$ which modifies NOS activity from NO generation to an $\mathrm{O}_{2}{ }^{\bullet}$-producing oxidase [105], decreasing NO concentration and vasodilation. Endothelial dysfunction mediated by $\mathrm{ONOO}^{\bullet}$-associated loss of vasodilation is implicated in hypertension, a unique contributor to hypertrophic remodelling [106].

Oxidative stress also leads to left ventricular hypertrophy (LVH) in CKD [107]. Thus, the co-existence of oxidative stress and LVH as independent complications of CKD further increases 
the risk of heart failure (HF) and cardiac events. ROS are pivotal in the initiation and propagation of signal transduction pathways, including tyrosine kinase Src, GTP-binding protein Ras, PKC, mitogen-activated protein kinase (MAPK), and Jun-nuclear kinase (JNK) implicated in hypertrophic growth [108]. Oxidative stress caused by elevated NADPH oxidase activity was associated with MAPK activation in a pressure overload model of LVH [109]. Similarly, NADPH oxidase-dependent generation of ROS in $\alpha 1$-adrenoreceptor-stimulated hypertrophy in adult rat ventricular myocytes (ARVMs) culture was associated with RAAS activation mediated through thiol oxidation [110]. The overexpression of thioredoxin-1 abolished the thiol oxidation and inhibited phosphorylation of MEK1/2 and ERK1/2, causing the inactivation of RAAS and the prevention of cellular hypertrophy.

Both chronic and acute renal dysfunction are unequivocally associated with cardiac abnormalities. In addition, mitochondrial targeted antioxidant therapy ameliorated cardiac hypertrophy and diastolic dysfunction via the attenuation of oxidative stress in experimental studies [111], further indicating the association between LVH and oxidative stress. Thus, antioxidant therapy in CKD could regress LVH and lessen progression to heart failure.

\section{Cardio-Renal Oxidative Stress}

Relative to the general population, patients with CKD have an additional risk of cardiovascular-related death [112]. Indeed, about $44-50 \%$ of deaths in the renal failure (RF) patient population were from cardiovascular causes [113], a mortality that is 15-30 times higher compared to the general population [114]. Likewise, congestive heart failure patients are associated with chronic kidney dysfunction such that every $1-\mathrm{mL} / \mathrm{min}$ decrease in creatinine clearance increases the mortality rate by $1 \%$ in this patient population [115]. These epidemiological data suggest synergistic effects between heart and kidney dysfunction resulting in poorer outcomes relative to either disease alone. This synergy gives rise to a clinical state known as cardio-renal syndrome. Cardio-renal syndrome (CRS) refers to the coexistence of both heart and kidney diseases, whereby dysfunction in one organ precipitates dysfunction in the other $[116,117]$. The unique interaction of the two clinical diseases (HF and RF) could in part be attributed to the distinct but interdependent function of the two organs and the existence of common causes, including hypertension and diabetes mellitus [118,119].

Invariably, oxidative stress in one organ induces injury in the other organ. The increased ROS associated with uraemia can induce cardiac injury because the exposure of rat ventricular myocytes to hydrogen peroxide resulted in cardiac remodelling with contractile dysfunction [120]. The role of oxidative stress in the induction of cardiac dysfunction in renal patients was highlighted in the Secondary Prevention with Antioxidants of Cardiovascular Disease in End-stage Renal Disease (SPACE) trial. In this study, antioxidant therapy using high dose vitamin $\mathrm{E}$ was associated with reduced cardiovascular disease endpoints in patients with kidney disease [121]. Moreover, increased NADPH oxidase mRNA and protein expression in HF rats has been observed along with increased accumulation of lipid peroxidation production and decreased endothelial NO synthase expression [122]. Conversely, renal oxidative stress is found in several models of CKD associated with cardiac dysfunction. In diabetic nephropathy, elevated expression of renal NADPH oxidase and eNOS resulted in oxidative stress with elevated lipid peroxidation, which was prevented following treatment with an angiotensin-converting enzyme inhibitor (ACEI) or an angiotensin receptor blocker (ARB) [13]. Similarly, diabetic nephropathy in Sprague Dawley rats was associated with increased glomerular expression of the NADPH oxidase subunit (p47phox), which is associated with enhanced oxidative stress [122-124].

Also, antioxidant therapy using the thiol-containing compound acetylcysteine reduced the risk of primary cardiovascular endpoint (including fatal and non-fatal myocardial infarction) by $40 \%$ in haemodialysis patients [125]. However, data from other clinical trials showed that antioxidant therapy was ineffective in patients with heart failure without renal disease [40]. These data support the argument that systemic oxidative stress in the uraemic milieu is central to the development of cardiac disease in renal patients as compared to non-renal HF patients. The disparity in the literature regarding the efficacy of antioxidant therapy on cardiovascular disease could partly be due to the differences 
in dosage, patient selection, and trial duration [40]. More importantly, this disparity highlights fundamental differences in the causes and effects of oxidative stress in cardio-renal patients and HF patients without renal dysfunction.

\section{Future Questions}

At what stage of CKD does remodelling of the oxidant-antioxidant system in the heart begin and how does systemic oxidative stress predict cellular derailment in both the heart and kidney? What associations exist between iron deficiency anaemia and mitochondrial dysfunction in CKD which is linked to oxidative stress? Ongoing work in our lab is focusing on providing insight into these important questions to allow us to develop therapies in the future.

\section{Conclusions}

Oxidative stress, anaemia, and LVH are complications in CKD which can individually contribute to the adverse cardiovascular outcomes in this patient population. There remains a need to discover viable and novel therapeutic regimes targeting the oxidative stress pathway early in CKD before the onset of significant irreversible renal failure.

Author Contributions: Conceptualization, F.N. and S.B. Original Draft Preparation, F.N. Writing-Review and Editing, F.N. and S.B. Visualization, F.N. Project Administration, F.N. and S.B.

Funding: F. Nuhu was funded by the Hull and E. Yorkshire NHS Renal Research Charity Fund.

Acknowledgments: The authors would like to thank John Greenman for his invaluable contribution to this paper.

Conflicts of Interest: The authors declare no conflict of interest.

\section{References}

1. Cachofeiro, V.; Goicochea, M.; Garca de Vinuesa, S.; Oubina, P.; Lahera, V.; Luno, J. Oxidative stress and inflammation, a link between chronic kidney disease and cardiovascular disease. Kidney Int. 2008, 74, S4-S9. [CrossRef] [PubMed]

2. Sinha, N.; Dabla, P.K. Oxidative stress and antioxidants in hypertension-A current review. Curr. Hypertens. Rev. 2015, 11, 132-142. [CrossRef] [PubMed]

3. Blair, A.I. DNA adducts with lipid peroxidation products. J. Biol. Chem. 2008, 283, 15545-15549. [CrossRef] [PubMed]

4. Kabel, A.M. Free Radicals and Antioxidants: Role of Enzymes and Nutrition. World J. Nutr. Health 2014, 2,35-38.

5. Panth, N.; Paudel, K.R.; Parajuli, K. Reactive Oxygen Species: A Key Hallmark of Cardiovascular Disease. Adv. Med. 2016, 2016. [CrossRef] [PubMed]

6. Kao, M.P.C.; Ang, D.S.C.; Pall, A.; Struthers, A.D. Oxidative stress in renal dysfunction: Mechanisms, clinical sequelae and therapeutic options. J. Hum. Hypertens. 2010, 24, 1-8. [CrossRef] [PubMed]

7. Dennis, J.M.; Witting, P.K. Protective Role for Antioxidants in Acute Kidney Disease. Nutrients 2017, $97,718$. [CrossRef] [PubMed]

8. Sung, C.C.; Hsu, Y.C.; Chen, C.C.; Lin, Y.F.; Wu, C.C. Oxidative stress and nucleic acid oxidation in patients with chronic kidney disease. Oxid. Med. Cell. Longev. 2013, 2013. [CrossRef] [PubMed]

9. Vaziri, N.D. Roles of oxidative stress and antioxidant therapy in chronic kidney disease and hypertension. Curr. Opin. Nephrol. Hypertens. 2004, 13, 93-99. [CrossRef] [PubMed]

10. Oberg, B.P.; McMenamin, E.; Lucas, F.L.; McMonagle, E.; Morrowm, J.; Ikizler, T.A.; Himmelfarb, J. Increased prevalence of oxidant stress and inflammation in patients with moderate to severe chronic kidney disease. Kidney Int. 2004, 65, 1009-1016. [CrossRef] [PubMed]

11. Perianayagam, M.C.; Liangos, O.; Kolyadam, A.Y.; Wald, R.; MacKinnon, R.W.; Li, L.; Rao, M.; Balakrishnan, V.S.; Bonventre, J.V.; Pereira, B.J.; et al. NADPH oxidase p22phox and catalase gene variants are associated with biomarkers of oxidative stress and adverse outcomes in acute renal failure. J. Am. Soc. Nephrol. 2007, 18, 255-263. [CrossRef] [PubMed] 
12. Castilla, P.; Dávalos, A.; Teruel, J.L.; Cerrato, F.; Fernández-Lucas, M.; Merino, J.L.; Sánchez-Martín, C.C.; Ortuño, J.; Lasunción, M.A. Comparative effects of dietary supplementation with red grape juice and vitamin E on production of superoxide by circulating neutrophil NADPH oxidase in hemodialysis patients. Am. J. Clin. Nutr. 2008, 87, 1053-1061. [CrossRef] [PubMed]

13. Onozato, M.L.; Tojo, A.; Goto, A.; Fujita, T.; Wilcox, C.S. Oxidative stress and nitric oxide synthase in rat diabetic nephropathy: Effects of ACEI and ARB. Kidney Int. 2002, 61, 186-194. [CrossRef] [PubMed]

14. Thallas-Bonke, V.; Thorpe, S.R.; Coughlan, M.T.; Fukami, K.; Yap, F.Y.; Sourris, K.; Penfold, S.; Bach, L.A.; Cooper, M.E.; Forbesm, J.M. Inhibition of NADPH oxidase prevents AGE-mediated damage in diabetic nephropathy through a protein kinase C- $\alpha$-dependent pathway. Diabetes 2007, 57, 460-469. [CrossRef] [PubMed]

15. Bryk, D.; Olejarz, W.; Zapolska-Downar, D. The role of oxidative stress and NADPH oxidase in the pathogenesis of atherosclerosis. Postepy Hig. Med. Dosw. 2017, 28, 57-68. [CrossRef] [PubMed]

16. Schulz, A.M.; Terne, C.; Jankowski, V.; Cohen, G.; Schaefer, M.; Boehringer, F.; Tepel, M.; Kunkel, D.; Zidek, W.; Jankowski, J. Modulation of NADPH oxidase activity by known uraemic retention solutes. Eur. J. Clin. Investig. 2014, 44, 802-811. [CrossRef] [PubMed]

17. Shimoishi, K.; Anraku, M.; Kitamura, K.; Tasaki, Y.; Taguchi, K.; Hashimoto, M.; Fukunaga, E.; Maruyama, T.; Otagiri, M. An oral adsorbent, AST-120 protects against the progression of oxidative stress by reducing the accumulation of indoxyl sulfate in the systemic circulation in renal failure. Pharm. Res. 2007, 24, 1283-1289. [CrossRef] [PubMed]

18. Sirker, A.; Zhang, M.; Shah, A.M. NADPH oxidases in cardiovascular disease: Insights from in vivo models and clinical studies. Basic Res. Cardiol. 2011, 106, 735-747. [CrossRef] [PubMed]

19. Sachse, A.; Wolf, G. Angiotensin II-Induced Reactive Oxygen Species and the Kidney. J. Am. Soc. Nephrol. 2007, 18, 2439-2446. [CrossRef] [PubMed]

20. Flyvbjerg, A.; Denner, L.; Schrijvers, B.F.; Tilton, R.G.; Mogensen, T.H.; Paludan, S.R.; Rasch, R. Long-term renal effects of a neutralizing RAGE antibody in obese type 2 diabetic mice. Diabetes 2004, 53, 166-172. [CrossRef] [PubMed]

21. Choi, J.Y.; Yoon, Y.J.; Choi, H.J.; Park, S.H.; Kim, C.D.; Kim, I.S.; Kwon, T.H.; Do, J.Y.; Kim, S.H.; Ryu, D.H.; et al. Dialysis modality-dependent changes in serum metabolites: Accumulation of inosine and hypoxanthine in patients undergoing hemodialysis. Nephrol. Dial. Transplant. 2011, 26, 1304-1313. [CrossRef] [PubMed]

22. Su, X.; Xu, B.; Yan, B.; Qiao, X.; Wang, L. Effects of uric acid-lowering therapy in patients with chronic kidney disease: A meta-analysis. PLoS ONE 2017, 12, e0187550. [CrossRef] [PubMed]

23. Oshima, N.; Onimaru, H.; Matsubara, H.; Uchida, T.; Watanabe, A.; Takechi, H.; Nishida, Y.; Kumagai, H. Uric acid, indoxyl sulfate, and methylguanidine activate bulbospinal neurons in the rvlm via their specific transporters and by producing oxidative stress. Neuroscience 2015, 304, 133-145. [CrossRef] [PubMed]

24. Evenepoel, P.; Meijers, B.K.; Bammens, B.R.; Verbeke, K. Uremic toxins originating from colonic microbial metabolism. Kidney Int. 2009, 76, S12-S19. [CrossRef] [PubMed]

25. Tumur, Z.; Shimizu, H.; Enomoto, A.; Miyazaki, H.; Niwa, T. Indoxyl sulfate upregulates expression of ICAM-1 and MCP-1 by oxidative stress-induced NF-kappaB activation. Am. J. Nephrol. 2010, 31, 435-441. [CrossRef] [PubMed]

26. Watanabe, H.; Miyamoto, Y.; Honda, D.; Tanaka, H.; Wu, Q.; Endo, M.; Noguchi, T.; Kadowaki, D.; Ishima, Y.; Kotani, S.; et al. P-Cresyl sulfate causes renal tubular cell damage by inducing oxidative stress through the activation of NADPH oxidase. Kidney Int. 2013, 83, 582-592. [CrossRef] [PubMed]

27. Rossi, M.; Campbell, K.L.; Johnson, D.W.; Stanton, T.; Vesey, D.A.; Coombes, J.S.; Weston, K.S.; Hawley, C.M.; McWhinney, B.C.; Ungerer, J.P.J.; et al. Protein-bound Uremic Toxins, Inflammation and Oxidative Stress: A Cross-sectional Study in Stage 3-4 Chronic Kidney Disease. Arch. Med. Res. 2014, 45, 309-317. [CrossRef] [PubMed]

28. Meijers, B.K.I.; Evenepoel, P. The gut-kidney axis: Indoxyl sulfate, $p$-cresyl sulfate and CKD progression. Nephrol. Dial. Transplant. 2011, 26, 759-761. [CrossRef] [PubMed]

29. Motojima, M.; Hosokawa, A.; Yamato, H.; Muraki, T.; Yoshioka, T. Uremic toxins of organic anions up-regulate PAI-1 expression by induction of NF-kappaB and free radical in proximal tubular cells. Kidney Int. 2003, 63, 1671-1680. [CrossRef] [PubMed]

30. Yu, M.; Kim, Y.J.; Kang, D.H. Indoxyl sulfate-induced endothelial dysfunction in patients with chronic kidney disease via an induction of oxidative stress. Clin. J. Am. Soc. Nephrol. 2011, 6, 30-39. [CrossRef] [PubMed] 
31. Yamamoto, S.; Kazama, J.J.; Omori, K.; Matsuo, K.; Takahashi, Y.; Kawamura, K.; Matsuto, T.; Watanabe, H.; Maruyama, T.; Narita, I. Continuous Reduction of Protein-Bound Uraemic Toxins with Improved Oxidative Stress by Using the Oral Charcoal Adsorbent AST-120 in Haemodialysis Patients. Sci. Rep. 2015, 5, 14381. [CrossRef] [PubMed]

32. Taki, K.; Niwa, T. Indoxyl sulfate-lowering capacity of oral sorbents affects prognosis of kidney function and oxidative stress in chronic kidney disease. J. Ren. Nutr. 2007, 17, 48-52. [CrossRef] [PubMed]

33. Tumur, Z.; Niwa, T. An oral sorbent AST-120 increases renal NO synthesis in uremic rats. J. Ren. Nutr. 2008, 18, 60-64. [CrossRef] [PubMed]

34. Sato, E.; Tanaka, A.; Oyama, J.; Yamasaki, A.; Shimomura, M.; Hiwatashi, A.; Ueda, Y.; Amaha, M.; Nomura, M.; Matsumura, D.; et al. Long-term effects of AST-120 on the progression and prognosis of pre-dialysis chronic kidney disease: A 5-year retrospective study. Heart Vessels 2016, 31, 1625-1632. [CrossRef] [PubMed]

35. Chiu, C.A.; Lu, L.F.; Yu, T.H.; Hung, W.C.; Chung, F.M.; Tsai, I.T.; Yang, C.Y.; Hsu, C.C.; Lu, Y.C.; Wang, C.P.; et al. Increased levels of total P-cresylsulphate and indoxyl sulphate are associated with coronary artery disease in patients with diabetic nephropathy. Rev. Diabet. Stud. 2010, 7, 275-284. [CrossRef] [PubMed]

36. Sun, C.Y.; Hsu, H.H.; Wu, M.S. $p$-Cresol sulfate and indoxyl sulfate induce similar cellular inflammatory gene expressions in cultured proximal renal tubular cells. Nephrol. Dial. Transplant. 2012, 28, 70-78. [CrossRef] [PubMed]

37. DeFllippi, C.R.; Herzog, C.A. Interpreting Cardiac Biomarkers in the Setting of Chronic Kidney Disease. Clin. Chem. 2017, 63, 59-65. [CrossRef] [PubMed]

38. Ori, Y.; Bergman, M.; Bessler, H.; Zingerman, B.; Levy-Drummer, R.S.; Gafter, U.; Salman, H. Cytokine secretion and markers of inflammation in relation to acidosis among chronic hemodialysis patients. Blood Purif. 2013, 35, 181-186. [CrossRef] [PubMed]

39. Taetzsch, T.; Levesque, S.; McGraw, C.; Bookins, S.; Luqa, R.; Bonini, G.M.; Mason, P.R.; Oh, U.; Block, L.M. Redox regulation of NF-kB p50 and M1 polarization in microglia. Glia 2015, 63, 423-440. [CrossRef] [PubMed]

40. Giam, B.; Kaye, D.M.; Rajapakse, N.W. Role of Renal Oxidative Stress in the Pathogenesis of the Cardiorenal Syndrome. Heart Lung Circ. 2016, 25, 874-880. [CrossRef] [PubMed]

41. Oberg, B.P.; McMenamin, E.; Lucas, F.L.; McMonagle, E.; Morrow, J.; Ikizler, T.A.; Himmelfarb, J. Increased prevalence of oxidant stress and inflammation in patients with moderate to severe chronic kidney disease. Kidney Int. 2004, 65, 1009-1016. [CrossRef] [PubMed]

42. Imig, J.D.; Ryan, M.J. Immune and Inflammatory Role in Renal Disease. Compr. Physiol. 2013, 3, 957-976. [PubMed]

43. Forbes, J.M.; Coughlan, M.T.; Cooper, M.E. Oxidative Stress as a Major Culprit in Kidney Disease in Diabetes. Diabetes 2008, 5, 1446-1454. [CrossRef] [PubMed]

44. Kalantar-Zadeh, K.; Brennan, M.L.; Hazen, S.L. Serum myeloperoxidase and mortality in maintenance hemodialysis patients. Am. J. Kidney Dis. 2006, 48, 59-68. [CrossRef] [PubMed]

45. Zargari, M.; Sedighi, O. Influence of hemodialysis on lipid peroxidation, enzymatic and non-enzymatic antioxidant capacity in chronic renal failure patients. Nephro-Urol. Mon. 2015, 7, e28526. [CrossRef] [PubMed]

46. Tbahriti, H.F.; Kaddous, A.; Bouchenak, M.; Mekki, K. Effect of Different Stages of Chronic Kidney Disease and Renal Replacement Therapies on Oxidant-Antioxidant Balance in Uremic Patients. Biochem. Res. Int. 2013, 2013. [CrossRef] [PubMed]

47. Gonzalez-Rico, M.; Puchades, M.J.; Garcia, R.; Saez, G.; Tormos, M.C.; Miguel, A. Effect of oxidative stress in patients with chronic renal failure. Nefrologia 2006, 26, 218-225. [PubMed]

48. Niwa, T.; Tsukushi, S. 3-Deoxyglucosone and AGEs in uraemic complications: Inactivation of glutathione peroxidase by 3-deoxyglucosone. Kidney Int. 2001, 59, S37-S41. [CrossRef] [PubMed]

49. Song, J.; Yu, Y.; Xing, R.; Guo, X.; Liu, D.; Wei, J.; Song, H. Unglycosylated recombinant human glutathione peroxidase 3 mutant from Escherichia coli is active as a monomer. Sci. Rep. 2014, 4, 6698. [CrossRef] [PubMed]

50. Labunskyy, M.V.; Hatfield, L.D.; Gladyshev, N.V. Selenoproteins: Molecular Pathways and Physiological Roles. Physiol. Rev. 2014, 94, 739-777. [CrossRef] [PubMed] 
51. Avissar, N.; Ornt, D.B.; Yagil, Y.; Horowitz, S.; Watkins, R.H.; Kerl, E.A.; Takahashi, K.; Palmer, I.S.; Cohen, H.J. Human kidney proximal tubules are the main source of plasma glutathione peroxidase. Am. J. Physiol. 1994, 266, C367-C375. [CrossRef] [PubMed]

52. Kuchta, A.; Pacanis, A.; Kortas-Stempak, B.; Ćwiklińska, A.; Ziętkiewicz, M.; Renke, M.; Rutkowski, B. Estimation of Oxidative Stress Markers in Chronic Kidney Disease. Kidney Blood Press Res. 2011, 34, 12-19. [CrossRef] [PubMed]

53. Papavasiliou, E.C.; Gouva, C.; Siamopoulos, K.C.; Tselepis, A.D. Erythrocyte PAF-acetylhydrolase activity in various stages of chronic kidney disease: Effect of long-term therapy with erythropoietin. Kidney Int. 2005, 68, 246-255. [CrossRef] [PubMed]

54. Michea, L.; Villagrán, A.; Urzúa, A.; Kuntsmann, S.; Venegas, P.; Carrasco, L.; González, M.; Marusic, E. Mineralocorticoid receptor antagonism attenuates cardiac hypertrophy and prevents oxidative stress in uremic rats. Hypertension 2008, 52, 295-300. [CrossRef] [PubMed]

55. Vaziri, N.D.; Oveisi, F.; Ding, Y. Role of increased oxygen free radical activity in the pathogenesis of uremic hypertension. Kidney Int. 1998, 53, 1748-1754. [CrossRef] [PubMed]

56. Kalk, P.; Godes, M.; Relle, K.; Rothkegel, C.; Hucke, A.; Stasch, J.P.; Hocher, B. NO-independent activation of soluble guanylate cyclase prevents disease progression in rats with $5 / 6$ nephrectomy. Br. J. Pharmacol. 2006, 148, 853-859. [CrossRef] [PubMed]

57. Goodnough, L.T.; Nemeth, E.; Ganz, T. Detection, evaluation, and management of iron-restricted erythropoiesis. Blood 2010, 116, 4754-4761. [CrossRef] [PubMed]

58. Sathyan, S.; George, S.; Vijayan, P. Prevalence of anemia and cardiovascular diseases in chronic kidney disease patients: A single tertiary care centre study. Int. J. Adv. Med. 2017, 4, 247-251. [CrossRef]

59. Mehdi, U.; Toto, R.D. Anemia, Diabetes, and Chronic Kidney Disease. Diabetes Care 2009, 32, 1320-1326. [CrossRef] [PubMed]

60. Babitt, J.L.; Lin, H.Y. Mechanisms of anemia in CKD. J. Am. Soc. Nephrol. 2012, 23, 1631-1634. [CrossRef] [PubMed]

61. Franchini, M.; Montagnana, M.; Lippi, G. Hepcidin and iron metabolism: From laboratory to clinical implications. Clin. Chim. Acta 2010, 411, 1565-1569. [CrossRef] [PubMed]

62. Ganz, T.; Nemeth, E. Hepcidin and iron homeostasis. Biochim. Biophys. Acta 2012, 1823, 1434-1443. [CrossRef] [PubMed]

63. Pietrangelo, A.; Dierssen, U.; Valli, L.; Garuti, C.; Rump, A.; Corradini, E.; Ernst, M.; Klein, C.; Trautwein, C. STAT3 is required for IL-6-gp130-dependent activation of hepcidin in vivo. Gastroenterology 2007, 132, 294-300. [CrossRef] [PubMed]

64. Falzacappa, M.V.; Vujic, S.M.; Kessler, R.; Stolte, J.; Hentze, M.W.; Muckenthaler, M.U. STAT3 mediates hepatic hepcidin expression and its inflammatory stimulation. Blood 2007, 109, 353-358. [CrossRef] [PubMed]

65. David, V.; Martin, A.; Isakova, T.; Spaulding, C.; Qi, L.; Ramirez, V.; Zumbrennen-Bullough, K.B.; Sun, C.C.; Lin, H.Y.; Babitt, J.L.; et al. Inflammation and functional iron deficiency regulate fibroblast growth factor 23 production. Kidney Int. 2016, 89, 135-146. [CrossRef] [PubMed]

66. Kempe, D.S.; Lang, P.A.; Duranton, C.; Akel, A.; Lang, K.S.; Huber, S.M.; Wieder, T.; Lang, F. Enhanced programmed cell death of iron-deficient erythrocytes. Faseb. J. 2006, 20, 368-370. [CrossRef] [PubMed]

67. Malorni, W.; Straface, E.; Pagano, G.; Monti, D.; Zatterale, A.; Del Principe, D.; Deeva, I.B.; Franceschi, C.; Masella, R.; Korkina, L.G. Cytoskeleton alterations of erythrocytes from patients with Fanconi's anemia. FEBS Lett. 2000, 468, 125-128. [CrossRef]

68. Ghosh, S.; Bandyopadhyay, S.; Bhattacharya, D.K.; Mandal, C. Altered erythrocyte membrane characteristics during anemia in childhood acute lymphoblastic leukemia. Ann. Hematol. 2005, 84, 76-84. [CrossRef] [PubMed]

69. Samanta, S.; Ghoshal, A.; Bhattacharya, K.; Saha, B.; Walden, P.; Mandal, C. Sialoglycosylation of RBC in Visceral Leishmaniasis Leads to Enhanced Oxidative Stress, Calpain-Induced Fragmentation of Spectrin and Hemolysis. PLoS ONE 2012, 7, e42361. [CrossRef] [PubMed]

70. Snyder, L.M.; Fortier, N.L.; Trainor, J.; Jacobs, J.; Leb, L.; Lubin, B.; Chiu, D.; Shohet, S.; Mohandas, N. Effect of hydrogen peroxide exposure on normal human erythrocyte deformability, morphology, surface characteristics, and spectrin-hemoglobin cross-linking. J. Clin. Investig. 1985, 76, 1971-1977. [CrossRef] [PubMed] 
71. Vives-Corrons, J.L.; Miguel-Garcia, A.; Pujades, M.A.; Miguel-Sosa, A.; Cambiazzo, S.; Linares, M.; Dibarrart, M.T.; Calvo, M.A. Increased susceptibility of microcytic red blood cells to in vitro oxidative stress. Eur. J. Haematol. 1995, 55, 327-331. [CrossRef] [PubMed]

72. Nagababu, E.; Gulyani, S.; Earley, C.J.; Cutler, R.G.; Mattson, M.P.; Rifkind, J.M. Iron-deficiency anaemia enhances red blood cell oxidative stress. Free Radic. Res. 2008, 42, 824-829. [CrossRef] [PubMed]

73. Hebert, P.C.; Van der Linden, P.; Biro, G.; Hu, L.Q. Physiologic aspects of anemia. Crit. Care Clin. 2004, 20, 187-212. [CrossRef] [PubMed]

74. Rifkind, J.M.; Nagababu, E. Hemoglobin Redox Reactions and Red Blood Cell Aging. Antioxid. Redox Signal. 2013, 18, 2274-2283. [CrossRef] [PubMed]

75. Lazarte, S.S.; Mónaco, M.E.; Jimenez, C.L.; Achem, M.E.L.; Terán, M.M.; Issé, B.A. Erythrocyte Catalase Activity in More Frequent Microcytic Hypochromic Anemia: Beta-Thalassemia Trait and Iron Deficiency Anemia. Adv. Hematol. 2015, 2015. [CrossRef] [PubMed]

76. Yetgin, S.; Hincal, F.; Basaran, N.; Ciliv, G. Serum selenium status in children with iron deficiency anemia. Acta Haematol. 1992, 88, 85-88. [CrossRef] [PubMed]

77. Prats, M.; Font, R.; García, C.; Muñoz-Cortés, M.; Cabré, C.; Jariod, M.; Romeu, M.; Giralt, M.; Martinez-Vea, A. Oxidative stress markers in predicting response to treatment with ferric carboxymaltose in nondialysis chronic kidney disease patients. Clin. Nephrol. 2014, 81, 419-426. [CrossRef] [PubMed]

78. Steinmetz, H.T. The role of intravenous iron in the treatment of anemia in cancer patients. Ther. Adv. Hematol. 2012, 3, 177-191. [CrossRef] [PubMed]

79. Kumerova, A.; Lece, A.; Skesters, A.; Silova, A.; Petuhovs, V. Anaemia and antioxidant defence of the red blood cells. Mater. Med. Pol. 1998, 30, 12-15. [PubMed]

80. Kidney International KDIGO Clinical. Practice Guidelines for the Diagnosis, Evaluation, Prevention and Treatment of Chronic Kidney Disease-Mineral and Bone Disorders. J. Int. Soc. Nephrol. 2009, 7, S22-S31.

81. Bhandari, S. Beyond efficacy and safety-the need for convenient and cost-effective iron therapy in health care. NDT Plus 2011, 4, i14-i19. [CrossRef] [PubMed]

82. Hayat, A. Safety Issues with Intravenous Iron Products in the Management of Anemia in Chronic Kidney Disease. Clin. Med. Res. 2008, 6, 93-102. [CrossRef] [PubMed]

83. Ganguli, A.; Kohli, H.S.; Khullar, M.; Lal Gupta, K.; Jha, V.; Sakhuja, V. Lipid peroxidation products formation with various intravenous iron preparations in chronic kidney disease. Ren. Fail. 2009, 31, 106-110. [CrossRef] [PubMed]

84. Connor, J.; Butcher, A. Evaluation of Serum Oxidative Stress Indices Following Intravenous Iron Delivery in Women with Iron Deficiency Anemia. Blood 2014, 124, 2683.

85. Bailie, G.R.; Schuler, C.; Leggett, R.E.; Li, H.; Li, H.D.; Patadia, H.; Levin, R. Oxidative effect of several intravenous iron complexes in the rat. Biometals 2013, 26, 473-478. [CrossRef] [PubMed]

86. Swarnalatha, G.; Ram, R.; Neela, P.; Naidu, M.U.; Dakshina Murty, K.V. Oxidative stress in hemodialysis patients receiving intravenous iron therapy and the role of $\mathrm{N}$-acetylcysteine in preventing oxidative stress. Saudi J. Kidney Dis. Transpl. 2010, 21, 852-858. [PubMed]

87. Schaller, G.; Scheiber-Mojdehkar, B.; Wolzt, M.; Puttinger, H.; Mittermayer, F.; Hörl, W.H.; Fodinger, M.; Sunder-Plassmann, G.; Vychytil, A. Intravenous iron increases labile serum iron but does not impair forearm blood flow reactivity in dialysis patients. Kidney Int. 2005, 68, 2814-2822. [CrossRef] [PubMed]

88. Pietrangelo, A. Mechanisms of iron hepatotoxicity. Hepatology 2016, 65, 226-227. [CrossRef] [PubMed]

89. Almeida, A.M.; Bertoncini, C.R.A.; Boreky, J.; Souza-Pinto, N.C.; Vercesi, A.E. Mitochondrial DNA damage associated with lipid peroxidation of the mitochondrial membrane induced by $\mathrm{Fe} 2^{+}-\mathrm{citrate}$. Ann. Braz. Acad. Sci. 2006, 78, 505-514. [CrossRef]

90. Bhandari, S.; Pereira, D.I.A.; Chappell, H.F.; Drakesmith, H. Intravenous irons: From basic science to clinical practice. Pharmaceuticals 2018, 11, 82. [CrossRef] [PubMed]

91. Brewster, U.C.; Perazella, M.A. Intravenous iron and the risk of infection in end-stage renal disease patients. Semin. Dial. 2004, 17, 57-60. [PubMed]

92. Diamond, J.R. The role of reactive oxygen species in animal models of glomerular disease. Am. J. Kidney Dis. 1992, 19, 292-300. [CrossRef]

93. Takimoto, E.; Kass, D.A. Role of oxidative stress in cardiac hypertrophy and remodeling. Hypertension 2007, 49, 241. [CrossRef] [PubMed] 
94. Siragy, H.M.; Carey, R.M. Role of the Intrarenal Renin-Angiotensin-Aldosterone System in Chronic Kidney Disease. Am. J. Nephrol. 2010, 31, 541-550. [CrossRef] [PubMed]

95. Toma, I.; Kang, J.J.; Sipos, A.; Vargas, S.; Bansal, E.; Hanner, F.; Meer, E.; Peti-Peterdi, J. Succinate receptor GPR91 provides a direct link between high glucose levels and renin release in murine and rabbit kidney. J. Clin. Investig. 2008, 118, 2526-2534. [CrossRef] [PubMed]

96. Kobori, H.; Alper, A.B.; Shenava, R.; Katsurada, A.; Saito, T.; Ohashi, N.; Urushihara, M.; Miyata, K.; Satou, R.; Hamm, L.L.; et al. Urinary angiotensinogen as a novel biomarker of the intrarenal renin-angiotensin system status in hypertensive patients. Hypertension 2009, 53, 344-350. [CrossRef] [PubMed]

97. Saito, T.; Urushihara, M.; Kotani, Y.; Kagami, S.; Kobori, H. Increased urinary angiotensinogen is precedent to increased urinary albumin in patients with type 1 diabetes. Am. J. Med. Sci. 2009, 338, 478-480. [CrossRef] [PubMed]

98. Ruster, C.; Wolf, G. Renin-angiotensin-aldosterone system and progression of renal disease. J. Am. Soc. Nephrol. 2009, 17, 2985-2991. [CrossRef] [PubMed]

99. Manrique, C.; Lastra, G.; Gardner, M.; Sowers, J.R. The Renin Angiotensin Aldosterone System in Hypertension: Roles of Insulin Resistance and Oxidative Stress. Med. Clin. N. Am. 2009, 93, 569-582. [CrossRef] [PubMed]

100. Morrone, D.; Marzilli, M. Role of RAAS inhibition in preventing left ventricular remodeling in patients post myocardial infarction. Heart Metab. 2010, 47, 9-13.

101. Montezano, A.C.; Callera, G.E.; Yogi, A.; He, Y.; Tostes, R.C.; He, G.; Schiffrin, E.L.; Touyz, R.M. Aldosterone and Angiotensin II Synergistically Stimulate Migration in Vascular Smooth Muscle Cells Through c-Src-Regulated Redox-Sensitive RhoA Pathways. Arterioscler. Thromb. Vasc. Biol. 2008, 28, 1511-1518. [CrossRef] [PubMed]

102. Cat, A.N.D.; Montezano, A.C.; Burger, D.; Touyz, R.M. Angiotensin II, NADPH Oxidase, and Redox Signaling in the Vasculature. Antioxid. Redox Signal. 2013, 19, 1110-1120.

103. Mollnau, H.; Wendt, M.; Szocs, K.; Lassegue, B.; Schulz, E.; Oelze, M.; Li, H.; Bodenschatz, M.; August, M.; Kleschyov, A.L.; et al. Effects of angiotensin II infusion on the expression and function of NAD(P)H oxidase and components of nitric oxide/cGMP signaling. Circ. Res. 2002, 90, E58-E65. [CrossRef] [PubMed]

104. Herbert, K.E.; Mistry, Y.; Hastings, R.; Poolman, T.; Niklason, L.; Williams, B. Angiotensin II-mediated oxidative DNA damage accelerates cellular senescence in cultured human vascular smooth muscle cells via telomere-dependent and independent pathways. Circ. Res. 2008, 102, 201-208. [CrossRef] [PubMed]

105. Johnson, R.J.; Lovett, D.; Lehrer, R.I.; Couser, W.G.; Klebanoff, S.J. Role of oxidants and protease in glomerular injury. Kidney Int. 1994, 45, 352-359. [CrossRef] [PubMed]

106. Taddei, S.; Virdis, A.; Ghiadoni, L.; Magagna, A.; Salvetti, A. Vitamin C improves endothelium-dependent vasodilation by restoring nitric oxide activity in essential hypertension. Circulation 1998, 97, 2222-2229. [CrossRef] [PubMed]

107. Paoletti, E.; Bellino, D.; Cassottana, P.; Rolla, D.; Cannella, G. Left ventricular hypertrophy in nondiabetic predialysis CKD. Am. J. Kidney Dis. 2005, 46, 320-327. [CrossRef] [PubMed]

108. Cave, A.C.; Grieve, D.J.; Johar, S.; Zhang, M.; Shah, A.M. NADPH oxidase-derived reactive oxygen species in cardiac pathophysiology. Philos. Trans. R. Soc. 2005, 360, 2327-2334. [CrossRef] [PubMed]

109. Li, J.M.; Gall, N.P.; Grieve, D.J.; Chen, M.; Shah, A.M. Activation of NADPH oxidase during progression of cardiac hypertrophy to failure. Hypertension 2002, 40, 477-484. [CrossRef] [PubMed]

110. Kuster, G.M.; Pimentel, D.R.; Adachi, T.; Ido, Y.; Brenner, D.A.; Cohen, R.A.; Liao, R.; Siwik, D.A.; Colucci, W.S. Alpha-adrenergic receptor-stimulated hypertrophy in adult rat ventricular myocytes is mediated via thioredoxin-1-sensitive oxidative modification of thiols on Ras. Circulation 2005, 111, 1192-1198. [CrossRef] [PubMed]

111. Dai, D.F.; Chen, T.; Szeto, H.; Nieves-Cintrón, M.; Kutyavin, V.; Santana, L.F.; Rabinovitch, P.S. Mitochondrial targeted antioxidant peptide ameliorates hypertensive cardiomyopathy. J. Am. Coll. Cardiol. 2011, 58, 73-82. [CrossRef] [PubMed]

112. Alani, H.; Tamimi, A.; Tamimi, N. Cardiovascular co-morbidity in chronic kidney disease: Current knowledge and future research needs. World J. Nephrol. 2014, 3, 156-168. [CrossRef] [PubMed]

113. Shah, B.N.; Greaves, K. The Cardiorenal Syndrome: A Review. Int. J. Nephrol. 2011, 2011. [CrossRef] [PubMed] 
114. Kon, V.; Yang, H.; Fazio, S. Residual Cardiovascular Risk in Chronic Kidney Disease: Role of High-density Lipoprotein. Arch. Med. Res. 2015, 46, 379-391. [CrossRef] [PubMed]

115. McAlister, F.A.; Ezekowitz, J.; Tonelli, M.; Armstrong, P.W. Renal insufficiency and heart failure: Prognostic and therapeutic implications from a prospective cohort study. Circulation 2004, 109, 1004-1009. [CrossRef] [PubMed]

116. Ronco, C.; Haapio, M.; House, A.A.; Anavekar, N.; Bellomo, R. Cardiorenal syndrome. J. Am. Coll. Cardiol. 2008, 52, 1527-1539. [CrossRef] [PubMed]

117. Ronco, F.; Ronco, C. Cardiorenal syndrome, current understanding. Recenti Prog. Med. 2009, 100, $202-213$. [PubMed]

118. Rosner, M.H.; Ronco, C.; Okusa, M.D. The role of inflammation in the cardio-renal syndrome: A focus on cytokines and inflammatory mediators. Semin. Nephrol. 2012, 32, 70-78. [CrossRef] [PubMed]

119. Small, D.M.; Gobe, G.C. Oxidative Stress and Antioxidant Therapy in Chronic Kidney and Cardiovascular Disease. InTech 2013, 233-264. [CrossRef]

120. Josephson, R.A.; Silverman, H.S.; Lakatta, E.G.; Stern, M.D.; Zweier, J.L. Study of the mechanisms of hydrogen peroxide and hydroxyl free radical-induced cellular injury and calcium overload in cardiac myocytes. J. Biol. Chem. 1991, 266, 2354-2361. [PubMed]

121. Boaz, M.; Smetana, S.; Weinstein, T.; Matas, Z.; Gafter, U.; Iaina, A.; Knecht, A.; Weissgarten, Y.; Brunner, D.; Fainaru, M.; et al. Secondary prevention with antioxidants of cardiovascular disease in endstage renal disease (SPACE): Randomised placebo-controlled trial. Lancet 2000, 356, 1213-1218. [CrossRef]

122. Tojo, A.; Onozato, M.L.; Kobayashi, N. Angiotensin II and oxidative stress in Dahl Salt-sensitive rat with heart failure. Hypertension 2002, 40, 834-839. [CrossRef] [PubMed]

123. Kitada, M.; Koya, D.; Sugimoto, T.; Isono, M.; Araki, S.; Kashiwagi, A.; Haneda, M. Translocation of Glomerular p47phox and p67phox by Protein Kinase C- $\beta$ Activation Is Required for Oxidative Stress in Diabetic Nephropathy. Diabetes 2003, 52, 2603-2614. [CrossRef] [PubMed]

124. De Blasio, M.J.; Ramalingam, A.; Cao, A.H.; Prakoso, D.; Ye, J.M.; Pickering, R.; Watson, A.M.D.; de Haan, J.B.; Kaye, D.M.; Ritchie, R.H. The superoxide dismutase mimetic tempol blunts diabetes-induced upregulation of NADPH oxidase and endoplasmic reticulum stress in a rat model of diabetic nephropathy. Eur. J. Pharmacol. 2017, 15, 12-20. [CrossRef] [PubMed]

125. Tepel, M.; van der Giet, M.; Statz, M.; Jankowski, J.; Zidek, W. The antioxidant acetylcysteine reduces cardiovascular events in patients with end-stage renal failure: A randomized, controlled trial. Circulation 2003, 107, 992-995. [CrossRef] [PubMed]

(C) 2018 by the authors. Licensee MDPI, Basel, Switzerland. This article is an open access article distributed under the terms and conditions of the Creative Commons Attribution (CC BY) license (http:/ / creativecommons.org/licenses/by/4.0/). 


\title{
Review
}

\section{Iron in Lung Pathology}

\author{
Vida Zhang ${ }^{1}$, Elizabeta Nemeth ${ }^{2}$ and Airie Kim ${ }^{2, *}$ \\ 1 Department of Molecular and Medical Pharmacology, David Geffen School of Medicine at the University of \\ California, Los Angeles, CA 90095, USA; vzhang@mednet.ucla.edu \\ 2 Department of Medicine, David Geffen School of Medicine at the University of California, Los Angeles, \\ CA 90095, USA; enemeth@mednet.ucla.edu \\ * Correspondence: airiekim@mednet.ucla.edu
}

Received: 14 December 2018; Accepted: 10 February 2019; Published: 15 February 2019

\begin{abstract}
The lung presents a unique challenge for iron homeostasis. The entire airway is in direct contact with the environment and its iron particulate matter and iron-utilizing microbes. However, the homeostatic and adaptive mechanisms of pulmonary iron regulation are poorly understood. This review provides an overview of systemic and local lung iron regulation, as well as the roles of iron in the development of lung infections, airway disease, and lung injury. These mechanisms provide an important foundation for the ongoing development of therapeutic applications.
\end{abstract}

Keywords: hepcidin; iron; lung; acute lung injury; COPD; lung infection; cystic fibrosis

\section{Introduction}

Iron is an essential trace mineral for normal biological function in almost all organisms. Most of the body's iron is contained within the heme of hemoglobin, the vital oxygen carrier in blood. Iron is also required for cell viability and proliferation as a catalytic constituent of iron-containing proteins that are involved in DNA synthesis and repair, and cellular energy metabolism [1]. As expected, iron deficiency results in the impairment of both systemic oxygen delivery and cellular function. Conversely, an excess of iron also has deleterious effects for the host, leading to cellular toxicity via iron-generated oxyradicals and peroxidation of lipid membranes [2]. Systemically, increased iron availability is also associated with the increased virulence of multiple pathogens, including Yersinia enterocolitica [3], Escherichia coli [4], and Klebsiella pneumoniae [5]. In order to maintain an appropriate iron balance, organisms have evolved complex systemic homeostatic and cellular iron transport mechanisms [6].

Iron homeostasis in the lung faces unique challenges. The entire lung epithelium is exposed to inhaled air containing iron particulate matter and infectious pathogens, and is also part of a delicate air-blood interface whose gas exchange function is highly susceptible to impairment by cytotoxic injury. Thus, lung iron bioavailability must be highly regulated to prevent its use by microbes during infection and to ensure sequestration of catalytically active iron to prevent cytotoxicity. The terminal respiratory unit, the alveolus, is composed of three major cell types, all of which are active in the maintenance of lung iron homeostasis: types 1 and 2 alveolar epithelial cells, and alveolar macrophages. Alveolar macrophages are a specialized subset of macrophages that defend against pulmonary infections, and mediate damage and repair of the lung parenchyma [7]. However, the specific roles of these cell types in basal iron regulation or in response to injury or infection is still poorly understood. The purpose of this review is to explore recent scientific advances in understanding the role of iron regulation in lung pathologies. 


\section{Iron Regulation}

\subsection{Systemic Iron Homeostasis}

A human adult requires $\sim 25 \mathrm{mg} /$ day of iron for baseline homeostasis and the replacement of minor unregulated iron losses. The majority of this iron comes from the recycling of senescent erythrocytes, while 1-2 $\mathrm{mg}$ is obtained from the absorption of dietary iron in the form of heme or non-heme iron [8]. During times of stress erythropoiesis, iron utilization by the bone marrow can increase 10-fold to accommodate the increased hemoglobin synthesis [9]. Thus, rapidly acting compensatory mechanisms have evolved to increase dietary iron absorption and to allow the rapid mobilization of iron from stores.

Hepcidin, a 25 amino acid peptide hormone produced primarily by hepatocytes [10], is the key regulator of systemic iron homeostasis. Hepcidin acts by binding to the transmembrane protein ferroportin (Fpn), the only known cellular iron exporter [11], causing its internalization and degradation within lysosomes [11,12]. As Fpn is highly expressed on duodenal enterocytes, macrophages, and hepatocytes, hepcidin controls the flow of iron from dietary gut absorption, recycling of erythrocytes, and tissue iron stores. Hepcidin production is stimulated by increases in plasma iron or iron stores, and during times of inflammation [13,14].

In addition to the mechanisms controlling systemic iron availability, each cell possesses regulatory mechanisms to coordinate its iron uptake, storage, and export. Most cells acquire iron by importing transferrin bound iron from blood via the membrane transferrin receptor (TfR1), after which iron is used for basal cellular requirements or stored in the form of ferritin. Splenic and hepatic macrophages also acquire iron through the phagocytosis of damaged or senescent erythrocytes, and this iron is similarly stored as ferritin or utilized for basic cellular functions [15]. Cellular iron export occurs through Fpn, which allows cells such as duodenal enterocytes and macrophages to release iron into circulation and maintain systemic iron homeostasis. In addition, Fpn expression is increased in iron-overloaded tissues and acts as a safety valve to export excess cellular iron to prevent oxidative damage.

Coordination of cellular iron acquisition and distribution is regulated post-transcriptionally in response to changes in intracellular iron levels by the iron regulatory protein/iron responsive elements (IRP/IRE) system [16-18]. The iron regulatory proteins, IRP1 and IRP2, bind to IREs, which are untranslated regions of mRNA located at either the $5^{\prime}$ or $3^{\prime}$ end. IREs at the $5^{\prime}$ end are associated with genes involved in the storage or export of iron (ferritin, Fpn), while $3^{\prime}$ IREs are associated with genes involved in iron uptake (TfR1, DMT1). Under conditions of cellular iron depletion, IRP1/IRP2 bind to IREs, preventing translation of mRNA containing $5^{\prime}$ IREs and stabilizing mRNA containing $3^{\prime}$ IREs. This leads to the increased expression of iron uptake proteins and decreased expression of iron storage and export proteins. Conversely, in iron-loaded cells, IRP1 is converted to c-aconitase and IRP2 is degraded, resulting in decreased IRP binding to IREs. This leads to increased expression of iron storage and export proteins and decreased expression of iron uptake proteins.

\subsection{Lung Iron Regulation}

Iron regulation in the lung has not been well characterized, with only a few in vitro and in vivo studies attempting to identify the iron transporters in pulmonary cells (Figure 1). TfR1 has been identified as an importer of transferrin-bound iron in the alveolar epithelium and alveolar macrophages. In response to systemic iron deficiency, TfR1 protein levels increased in whole rat lung. Conversely, TfR1 protein expression in whole lung did not increase with intratracheally instilled iron oxide [19]. The DMT1 transporter, a principal importer of dietary non-heme iron and an importer of endosomal iron from the Tf-TfR1 complex into cytoplasm, has also been shown to be expressed in both alveolar epithelial cells and alveolar macrophages [20]. While respiratory DMT1 appears to be regulated by the IRP/IRE system, there is inconclusive evidence on the effects of iron deficiency and overload on the production of DMT1 mRNA and protein in the lung [19,21,22]. Multiple studies utilizing DMT1 mutated murine models have implicated this iron transporter in the pathogenesis of lung 
injury. The Belgrade rat, an animal model of functional DMT1 deficiency, develops more severe lung injury in response to lipopolysaccharide (LPS) and oil fly ash [23,24]. Similarly, $m k / m k$ mice, also defective in DMT1, have increased bleomycin-induced lung injury compared to wild-type controls [25]. The mechanism of DMT1 attenuating the lung's response to inflammatory stimuli is unclear, but these descriptive studies demonstrate a link between DMT1 and the lung's inflammatory response. Thus, although iron importers are present in the lung, little is understood about their regulation and role in specific cell types and under different pathophysiological conditions.

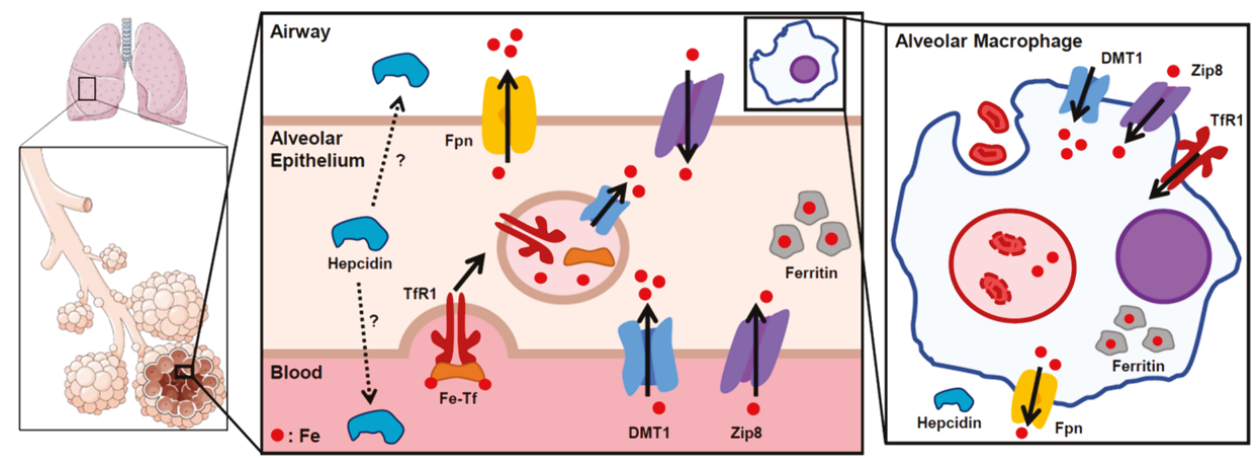

Figure 1. Proposed scheme of lung iron homeostasis. Iron is taken up into the alveolar epithelial cells through transferrin receptor (TfR1) and DMT1, and exported through ferroportin (Fpn), which was reported to be localized on the apical/airway facing layer of the epithelium. Within the cells, iron is stored in a non-reactive state in ferritin. Though hepcidin is mostly produced in the liver for systemic circulation, local production of hepcidin has also been suggested to play a role in lung iron homeostasis. Zip8 is highly expressed in the lung and facilitates iron intake, though its specific distribution remains unknown. Inset depicts an alveolar macrophage. Macrophages phagocytose airway red blood cells to recycle iron from heme. Solid arrows indicate direction of iron transport.

Fpn was reported to be localized on the apical layer of the airway epithelia of human lung [26] and also expressed in alveolar macrophages [27]. While the liver is the predominant source of circulating hepcidin, the hormone is also expressed at lower levels in human airway epithelial cells and alveolar macrophages [28], raising the possibility that hepcidin has a paracrine role in the lung. One ex vivo study showed that LPS-stimulated mouse alveolar macrophages increased the expression of hepcidin mRNA and decreased Fpn mRNA. Iron treatment had no effect on hepcidin mRNA expression, but did upregulate both Dmt1 and Fpn [29]. Interestingly, another in vitro study showed that Fpn in airway epithelial cells did not internalize in response to hepcidin and that hepcidin itself had no significant effect on iron transport in either airway epithelial cells or alveolar macrophages [30]. However, Fpn levels do correlate with changes in iron status [27,31], suggesting that lung Fpn expression may be controlled preferentially by the IRP/IRE regulatory system, rather than a purely hepcidin-dependent mechanism. Additionally, the reported distribution pattern of Fpn on the apical layer of airway epithelial cells suggests that Fpn may play a tissue-specific role of iron detoxification in lungs [26].

Recent studies in mouse models with genetic iron overload have begun characterizing the roles of hepcidin and Fpn in lung iron homeostasis. Neves et al. investigated a murine disease model of hereditary hemochromatosis type 4, created by a global C326S amino acid substitution in Fpn that confers resistance to hepcidin binding and leads to systemic iron overload [32]. They reported that the Fpn mutant mice develop increased iron levels in airway epithelial cells and bronchoalveolar lavage (BAL) fluid [27]. Interestingly, while splenic and hepatic macrophages are predictably iron-depleted from the increased Fpn protein exporting iron, a subset of alveolar macrophages showed iron overload. The authors suggest that these differences could be partially due to the varying levels of Fpn expression in alveolar macrophages. 
Deschemin et al. characterized the lungs in hepcidin knockout (HKO) mice, a mouse model of severe genetic iron overload [31]. The lack of hepcidin results in increased gut iron absorption with systemic iron overload, iron deposition in parenchymal tissues, and iron depletion of macrophages in the liver and spleen. Iron content in the lung increased, which resulted in compensatory decreases in Tfrc and Dmt1 mRNA expression, and increased levels of Fpn and ferritin mRNA and protein levels. Specific examination of the alveolar macrophages also demonstrated increased levels of Fpn and ferritin. However, similar to the paper by Neves et al., these macrophages were iron-loaded, which is in stark contrast to the iron depletion of splenic macrophages. This is likely related to the much lower expression of Fpn in the alveolar macrophages of HKO mice compared to the splenic macrophages. While these genetic mouse models of iron overload clearly demonstrate some unique characteristics of lung iron homeostasis, further studies are necessary to clarify the role of the hepcidin-Fpn axis in the lung.

ZIP8, encoded by the SLC39A8 gene, is a member of the SLC39A transmembrane metal importer family and is expressed many-fold higher in the lung than in any other organ system [33]. Initially identified as a zinc transporter, recent studies have shown that Zip8 also imports iron into the cytosolic space [33]. Early in vitro and animal studies consistently show that inflammatory stimulation with LPS greatly increases Zip8 expression, suggesting that this iron importer has a function in host defense [34,35]. As of yet, there have been no studies investigating the role of Zip8 in human lung infections or lung injury.

\section{Iron in Lung Pathology}

\subsection{Acute Lung Injury}

Acute lung injury (ALI), clinically known as acute respiratory distress syndrome (ARDS), is an acute inflammatory process with neutrophil infiltration, increased vascular permeability, and diffuse alveolar damage [36]. ARDS can occur as a result of a direct insult to the lung, including pneumonia, aspiration, and smoke inhalation, or a systemic inflammatory response, including sepsis, trauma, burns, and transfusion-related ALI. The pathophysiology of ARDS is largely mediated by the release of free radicals and reactive oxygen species and their injurious effects on endothelial integrity [37]. In the presence of iron, peroxides are converted to damaging radicals and enhance cytotoxicity by the Fenton reaction [38]. The relevance of iron in the development of ARDS has been evaluated with numerous clinical studies, showing strong correlations with iron and iron-related proteins, as well as the presence or severity of ARDS. One study found increased concentrations of BAL total iron and non-heme iron in ARDS patients, as compared to healthy controls. Iron-related proteins, including hemoglobin, transferrin, TfR1, lactoferrin, and ferritin, were also all elevated in BAL [39]. Future studies are needed to examine whether these changes in BAL iron and iron-related proteins have a causal effect on lung injury or are simply a byproduct of lung injury and increased vascular permeability. Serum ferritin has also been investigated as a predictor of ARDS, and was found to predict the development of ARDS with high sensitivity and specificity in one clinical study [40]. As ferritin is a known acute phase reactant and could simply be rising as part of the inflammatory response, a second clinical study confirmed the predictive value of serum ferritin for the progression to ARDS while also demonstrating no correlation of ferritin with the degree of hypoxia, time of invasive ventilation, or mortality [41]. These studies consistently illustrate a strong association between iron-related proteins and the development of lung injury, but further clinical and basic mechanistic studies are necessary to delineate the causative effects of iron on ARDS.

\subsection{Lung Infections}

Host defense of the lung organ system is particularly challenging as the entire epithelium is in constant and direct contact with environmental air containing numerous potential infectious pathogens. As the delicate single-cell-layer alveolar epithelium is responsible for vital air-blood gas exchange, 
non-cytotoxic nutrient deprivation mechanisms of host defense play an important role against lung microbial pathogens. The biological relevance of iron in the pathology of infections has been established through numerous clinical and animal studies. Iron overload has been associated with increased incidence of bacteremia with hemodialysis [42], and increased virulence of multiple microbes, including Yersinia enterocolitica [3], Escherichia coli [4], and Klebsiella pneumoniae [5]. One clinical study found a significant correlation between high dietary iron and the development of active tuberculosis in a high-risk population [43]. Another study of 137 iron-deficient Somali patients found that iron repletion resulted in a significant increase in infection incidence, with the activation of pre-existing malaria, brucellosis, and tuberculosis [44].

Both invading pathogens and their hosts have developed multiple mechanisms to control the supply of iron necessary for microbial survival (Figure 2). One particularly effective and well-described method of iron scavenging by microbes is through the siderophore-dependent pathways, in which microbes secrete small compounds called siderophores that complex with iron for active uptake by the microbe [45]. In response, the host circumvents this pathway with neutrophil gelatinase-associated lipocalin (NGAL), otherwise known as siderocalin or lipocalin-2. Produced by neutrophil granules and epithelial cells in response to inflammation, this innate immune protein acts by binding to, and sequestering, iron-loaded bacterial siderophores [46]. One murine study showed that intratracheal Escherichia coli instillation resulted in a strong induction of NGAL expression in bronchial epithelium and type 2 pneumocytes [47]. An in vitro study of Mycobacterium tuberculosis found that recombinant NGAL restricted the growth of the organism in broth media in an iron-dependent manner [48]. Another major iron-binding protein in the airways is lactoferrin, a member of the transferrin gene family that is found in nasobronchial epithelial secretions and neutrophil granules. Lactoferrin sequesters airway iron away from microbes and is taken up by the lactoferrin receptor on lung epithelial cells and macrophages for iron reabsorption. Levels of lactoferrin correlate with the severity of infectious pneumonia, pulmonary tuberculosis, and sepsis [49]. Another iron transporter that is vital in host defense is natural resistance-associated macrophage protein 1 (NRAMP1), a divalent metal transporter expressed specifically in phagosomes. NRAMP1 reduces phagosomal iron availability and confers resistance to several intraphagosomal microbes [50,51].
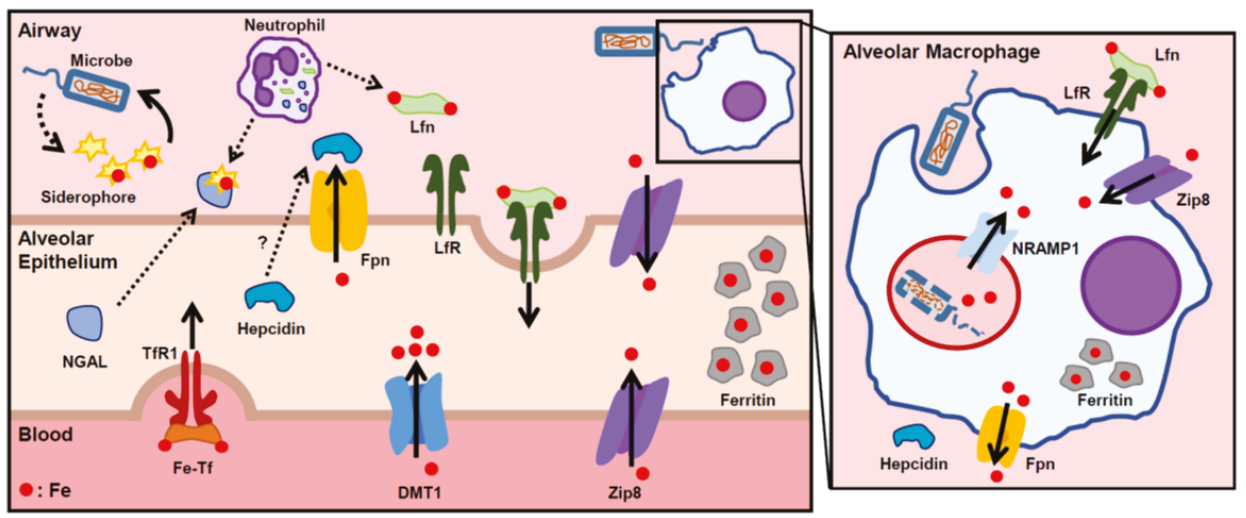

Figure 2. Proposed scheme of lung iron regulation during infection and inflammation. Bacteria secrete siderophores to capture host iron. The host combats this by increasing import of iron (lactoferrin (Lfn), DMT1), decreasing export of iron through ferroportin (Fpn), and increasing iron stores through ferritin. Secreted Lfn and NGAL bind free iron and siderophore-bound iron in the airway to prevent bacterial iron uptake. Inset shows an alveolar macrophage during infection. Alveolar macrophages phagocytose bacteria as a host defense response. NRAMP1 is expressed in macrophage phagosomes and transports iron out of the phagosome to limit iron availability to pathogens. Solid arrows indicate direction of iron transport. 
The hepcidin-Fpn axis also has a principal role in innate immunity. Hepcidin plays a role in host defense by sequestering iron to hinder the growth and proliferation of invading pathogens [52]. During times of infection and inflammation, there appears to be multiple mechanisms of hepcidin expression regulation. The primary regulator of inflammation-induced hepcidin production is the inflammatory cytokine IL-6. A single infusion of IL-6 into healthy human subjects increased hepcidin production and decreased serum iron [13]. In an inflammatory state, increased IL-6 causes the activation of STAT3 (signal transducer and activator of transcription 3) and its binding to the hepcidin promoter [53]. In response to bacterial stimulation, myeloid cells have also been shown to upregulate hepcidin and decrease Fpn expression in a Toll-like receptor 4 (TLR4)-dependent manner [54].

Recently, several transgenic murine studies have established the roles of hepcidin and iron status in the morbidity and mortality of various pathogenic infections. Hepcidin knockout mice developed hyperferremia with a profound susceptibility to bacteremia from Klebsiella pneumoniae, Yersinia enterocolitica, and E. coli, and treatment with a hepcidin analogue restored hypoferremia, decreased bacterial burden, and improved survival in each model of infection $[5,55,56]$. These studies indicate that hepcidin has a protective effect against siderophilic pathogens by limiting the availability of non-transferrin bound iron, a form of iron that is readily accessed by microbes. Another study showed that cell-specific knockdown of hepcidin in airway epithelium increased lung bacterial burden and injury in mice after cecal ligation and puncture, a model of polymicrobial sepsis [57]. By contrast, hepcidin-Fpn regulation may have a deleterious effect on the host during infections with intracellular pathogens. For example, one in vitro study demonstrated that the intracellular growth of Chlamydia psittaci, C. trachomatis, and Legionella pneumophila in macrophages is enhanced by the addition of hepcidin. Accordingly, macrophages from flatiron mice, a mouse strain heterozygous with a loss-of-function Fpn mutation (H32R), had increased bacterial proliferation that was unchanged by the addition of exogenous hepcidin [58]. Another study used murine macrophages to show decreased virulence of intracellular Salmonella enterica when Fpn expression was increased, and increased virulence with hepcidin-induced Fpn downregulation [59].

\subsection{Cystic Fibrosis}

Cystic fibrosis (CF) is a genetic disorder caused by mutations in the cystic fibrosis transmembrane conductance regulator (CFTR) gene, and is characterized by the retention of thick airway secretions and chronic pulmonary infections. Patients with $\mathrm{CF}$ also have increased levels of iron and iron-related proteins in their lower respiratory tract [60], and these iron levels are strongly correlated with increases in inflammatory cytokines [61]. A clinically important area of study in CF is the microbial pathogen Pseudomonas aeruginosa, which is responsible for the majority of CF infectious exacerbations. This pathogen forms biofilms that are more resistant to antibiotics than the free-floating (planktonic) state and hinder the eradication of these bacteria. Construction of this biofilm is highly dependent on iron availability, and Pseudomonas aeruginosa has developed sophisticated mechanisms to acquire iron from the environment, including both siderophore-dependent and independent systems [62].

\subsection{Chronic Obstructive Pulmonary Disease}

Both cigarette smoking and chronic obstructive pulmonary disease (COPD) are associated with a disruption of iron homeostasis in the lung. Regular cigarette smoking results in a great increase in lung exposure to iron, estimated at 5.2-13.8 $\mu \mathrm{g}$ of iron daily in a subject smoking 20 cigarettes per day [63]. Compared to nonsmokers, smokers have increased total non-heme iron and ferritin levels in BAL fluid and in alveolar macrophages [64], as well as increased serum ferritin levels [65]. Smokers also have increased redox-active iron levels in exhaled breath condensate [66].

Although cigarette smoking is the largest risk factor for the development of COPD, genetic association studies have uncovered differentially expressed iron-related genes that indicate a role for iron in the susceptibility to developing COPD. The most relevant is the iron-regulatory protein IRP2 that was discovered to be a major COPD susceptibility gene in a case-control study [67]. Notably, 
IRP2 is located within a cluster of genes on a chromosome that also includes several components of the nicotinic acetylcholine receptor [68]. As in smokers, levels of iron and iron-binding proteins are increased in the lung tissue, BAL fluid, and alveolar macrophages of COPD patients, and iron levels are correlated with disease severity and with worsening lung function [64]. A recent study used mouse models of COPD to investigate the mechanism of IRP2's role in the development of COPD [69]. The group showed that IRP2 increases mitochondrial iron loading and levels of cytochrome c oxidase (COX), leading to mitochondrial dysfunction and COPD development. Frataxin-deficient mice, which develop higher mitochondrial iron loading due to lack of the mitochondrial iron-sulfur regulator frataxin, were shown to develop worse airway mucociliary clearance and higher pulmonary inflammation at baseline. Conversely, mice with decreased COX synthesis were protected from cigarette smoke-induced lung inflammation and impairment in mucociliary clearance. Mice treated with the mitochondrial iron chelator deferiprone were protected from impaired mucociliary clearance, pulmonary inflammation, and the development of COPD. Together, these data indicate that IRP2 functions as a COPD susceptibility gene by increasing mitochondrial iron overload and levels of COX, leading to mitochondrial dysfunction and the development of COPD.

\section{Potential Therapeutics}

Due to the apparent importance of iron homeostasis in the development of many lung pathologies and infections, there has been a lot of interest in manipulating iron availability for potential therapeutic applications. Conventional means of reducing iron load in the body include dietary restriction [70], phlebotomy, and chelators, including deferoxamine, deferiprone, and deferasirox [71]. However, such systemic iron depletion can predispose patients to multiple adverse effects, including nutritional deficiency, anemia, and infection. For example, systemic iron chelators such as deferoxamine have been shown to eliminate Pseudomonas aeruginosa biofilms on a CF line in vitro [72], but deferoxamine also functions as a bacterial siderophore and can paradoxically act as an iron supply to specific microbes such as Rhizopus [73]. Newer synthetic iron chelators with fewer adverse effects are also being considered for a broad range of oxidative stress-related conditions, ranging from cardiovascular to inflammatory and malignant pathologies [74]. In addition, there has been early work examining the therapeutic potential of modulating specific iron transporters, including DMT1 and Fpn [12,75]. Studies in mice have shown that hepcidin mimetics are effective in lowering systemic iron and modulating the virulence and mortality of gram-negative pneumonia [5,76]. Another approach in the field of CF research is the use of an iron competitor. Interfering with iron uptake by Pseudomonas aeruginosa, with the cationic metal gallium, has been shown to have antimicrobial and antibiofilm activity [77]. Another proposed, but undeveloped, therapeutic approach would be the local or regional delivery of iron modulators, such as chelators, iron competitors, or hepcidin analogues.

While there have been substantial scientific advances in our understanding of systemic iron regulation and the pathogenesis of different iron disorders in recent years, lung iron regulation and its role in pulmonary pathology has been an understudied area. Future basic and translational studies are clearly necessary to advance this field and to enable the development of clinical therapeutic applications. On a mechanistic level, the field requires a systematic characterization of the roles and regulation of the principal iron transporters and iron-related proteins in each of the major alveolar cell types as well as the bronchial airway epithelium. Transgenic mice with lung-specific deletions of iron transporters, and further mouse models of key pulmonary pathologies, could be utilized to study the roles of specific iron-related proteins in the development of lung disease.

Funding: NIH NHLBI K08-HL127293 (AK).

Conflicts of Interest: E.N. is a stockholder of Intrinsic LifeSciences and Silarus Therapeutics. V.Z. and A.K. have no conflicts of interest. 


\section{References}

1. Ganz, T.; Nemeth, E. Regulation of iron acquisition and iron distribution in mammals. Biochim. Biophys. Acta 2006, 1763, 690-699. [CrossRef] [PubMed]

2. Ramm, G.A.; Ruddell, R.G. Hepatotoxicity of iron overload: Mechanisms of iron-induced hepatic fibrogenesis. Semin. Liver Dis. 2005, 25, 433-449. [CrossRef] [PubMed]

3. Chiu, H.Y.; Flynn, D.M.; Hoffbrand, A.V.; Politis, D. Infection with Yersinia enterocolitica in patients with iron overload. Br. Med. J. (Clin. Res. Ed.) 1986, 292, 97. [CrossRef]

4. Parrow, N.L.; Fleming, R.E.; Minnick, M.F. Sequestration and scavenging of iron in infection. Infect. Immun. 2013, 81, 3503-3514. [CrossRef]

5. Michels, K.R.; Zhang, Z.; Bettina, A.M.; Cagnina, R.E.; Stefanova, D.; Burdick, M.D.; Vaulont, S.; Nemeth, E.; Ganz, T.; Mehrad, B. Hepcidin-mediated iron sequestration protects against bacterial dissemination during pneumonia. JCI Insight 2017, 2, e92002. [CrossRef] [PubMed]

6. Muckenthaler, M.U.; Rivella, S.; Hentze, M.W.; Galy, B. A Red Carpet for Iron Metabolism. Cell 2017, 168, 344-361. [CrossRef]

7. Hussell, T.; Bell, T.J. Alveolar macrophages: Plasticity in a tissue-specific context. Nat. Rev. Immunol. 2014, 14, 81-93. [CrossRef]

8. Finberg, K.E. Unraveling mechanisms regulating systemic iron homeostasis. Hematol. Am. Soc. Hematol. Educ. Progr. 2011, 2011, 532-537. [CrossRef]

9. Finch, C. Regulators of iron balance in humans. Blood 1994, 84, 1697-1702.

10. Park, C.H.; Valore, E.V.; Waring, A.J.; Ganz, T. Hepcidin, a urinary antimicrobial peptide synthesized in the liver. J. Biol. Chem. 2001, 276, 7806-7810. [CrossRef]

11. Nemeth, E.; Tuttle, M.S.; Powelson, J.; Vaughn, M.B.; Donovan, A.; Ward, D.M.; Ganz, T.; Kaplan, J. Hepcidin regulates cellular iron efflux by binding to ferroportin and inducing its internalization. Science 2004, 306, 2090-2093. [CrossRef] [PubMed]

12. Ganz, T.; Nemeth, E. The hepcidin-ferroportin system as a therapeutic target in anemias and iron overload disorders. Hematol. Am. Soc. Hematol. Educ. Progr. 2011, 2011, 538-542. [CrossRef] [PubMed]

13. Nemeth, E.; Rivera, S.; Gabayan, V.; Keller, C.; Taudorf, S.; Pedersen, B.K.; Ganz, T. IL-6 mediates hypoferremia of inflammation by inducing the synthesis of the iron regulatory hormone hepcidin. J. Clin. Investig. 2004, 113, 1271-1276. [CrossRef] [PubMed]

14. Rodriguez, R.; Jung, C.L.; Gabayan, V.; Deng, J.C.; Ganz, T.; Nemeth, E.; Bulut, Y. Hepcidin induction by pathogens and pathogen-derived molecules is strongly dependent on interleukin-6. Infect. Immun. 2014, 82, 745-752. [CrossRef] [PubMed]

15. Ganz, T.; Nemeth, E. Iron homeostasis in host defence and inflammation. Nat. Rev. Immunol. 2015, 15, 500-510. [CrossRef]

16. Rouault, T.A. The role of iron regulatory proteins in mammalian iron homeostasis and disease. Nat. Chem. Biol. 2006, 2, 406-414. [CrossRef]

17. Anderson, C.P.; Shen, M.; Eisenstein, R.S.; Leibold, E.A. Mammalian iron metabolism and its control by iron regulatory proteins. Biochim. Biophys. Acta 2012, 1823, 1468-1483. [CrossRef]

18. Wilkinson, N.; Pantopoulos, K. The IRP/IRE system in vivo: Insights from mouse models. Front. Pharmacol. 2014, 5, 176. [CrossRef]

19. Heilig, E.A.; Thompson, K.J.; Molina, R.M.; Ivanov, A.R.; Brain, J.D.; Wessling-Resnick, M. Manganese and iron transport across pulmonary epithelium. Am. J. Physiol. Lung Cell Mol. Physiol. 2006, 290, L1247-L1259. [CrossRef]

20. Ghio, A.J.; Wang, X.; Silbajoris, R.; Garrick, M.D.; Piantadosi, C.A.; Yang, F. DMT1 expression is increased in the lungs of hypotransferrinemic mice. Am. J. Physiol. Lung Cell Mol. Physiol. 2003, 284, L938-L944. [CrossRef]

21. Wang, X.; Ghio, A.J.; Yang, F.; Dolan, K.G.; Garrick, M.D.; Piantadosi, C.A. Iron uptake and Nramp2/ DMT1/DCT1 in human bronchial epithelial cells. Am. J. Physiol. Lung Cell Mol. Physiol. 2002, 282, L987-L995. [CrossRef] [PubMed]

22. Giorgi, G.; D'Anna, M.C.; Roque, M.E. Iron homeostasis and its disruption in mouse lung in iron deficiency and overload. Exp. Physiol. 2015, 100, 1199-1216. [CrossRef] 
23. Ghio, A.J.; Piantadosi, C.A.; Wang, X.; Dailey, L.A.; Stonehuerner, J.D.; Madden, M.C.; Yang, F.; Dolan, K.G.; Garrick, M.D.; Garrick, L.M. Divalent metal transporter-1 decreases metal-related injury in the lung. Am. J. Physiol. Lung Cell Mol. Physiol 2005, 289, L460-L467. [CrossRef] [PubMed]

24. Kim, J.; Molina, R.M.; Donaghey, T.C.; Buckett, P.D.; Brain, J.D.; Wessling-Resnick, M. Influence of DMT1 and iron status on inflammatory responses in the lung. Am. J. Physiol. Lung Cell Mol. Physiol. 2011, 300, L659-L665. [CrossRef] [PubMed]

25. Yang, F.; Stonehuerner, J.G.; Richards, J.H.; Nguyen, N.B.; Callaghan, K.D.; Haile, D.J.; Ghio, A.J. Deficiency in the divalent metal transporter 1 increases bleomycin-induced lung injury. Biometals Int. J. Role Met. Ions Biol. Biochem. Med. 2010, 23, 657-667. [CrossRef] [PubMed]

26. Yang, F.; Haile, D.J.; Wang, X.; Dailey, L.A.; Stonehuerner, J.G.; Ghiom, A.J. Apical location of ferroportin 1 in airway epithelia and its role in iron detoxification in the lung. Am. J. Physiol. Lung Cell Mol. Physiol. 2005, 289, L14-L23. [CrossRef]

27. Neves, J.; Leitz, D.; Kraut, S.; Brandenberger, C.; Agrawal, R.; Weissmann, N.; Muhlfeld, C.; Mall, M.A.; Altamura, S.; Muckenthaler, M.U. Disruption of the Hepcidin/Ferroportin Regulatory System Causes Pulmonary Iron Overload and Restrictive Lung Disease. EBioMedicine 2017, 20, 230-239. [CrossRef]

28. Chen, Q.; Wang, L.; Ma, Y.; Wu, X.; Jin, L.; Yu, F. Increased hepcidin expression in non-small cell lung cancer tissue and serum is associated with clinical stage. Thorac. Cancer 2014, 5, 14-24. [CrossRef]

29. Nguyen, N.B.; Callaghan, K.D.; Ghio, A.J.; Haile, D.J.; Yang, F. Hepcidin expression and iron transport in alveolar macrophages. Am. J. Physiol. Lung Cell Mol. Physiol. 2006, 291, L417-L425. [CrossRef]

30. Frazier, M.D.; Mamo, L.B.; Ghio, A.J.; Turi, J.L. Hepcidin expression in human airway epithelial cells is regulated by interferon-gamma. Respir. Res. 2011, 12, 100. [CrossRef]

31. Deschemin, J.C.; Mathieu, J.R.R.; Zumerle, S.; Peyssonnaux, C.; Vaulont, S. Pulmonary Iron Homeostasis in Hepcidin Knockout Mice. Front. Physiol. 2017, 8, 804. [CrossRef] [PubMed]

32. Altamura, S.; Kessler, R.; Grone, H.J.; Gretz, N.; Hentze, M.W.; Galy, B.; Muckenthaler, M.U. Resistance of ferroportin to hepcidin binding causes exocrine pancreatic failure and fatal iron overload. Cell Metab. 2014, 20, 359-367. [CrossRef] [PubMed]

33. Wang, C.Y.; Jenkitkasemwong, S.; Duarte, S.; Sparkman, B.K.; Shawki, A.; Mackenzie, B.; Knutson, M.D. ZIP8 is an iron and zinc transporter whose cell-surface expression is up-regulated by cellular iron loading. J. Biol. Chem. 2012, 287, 34032-34043. [CrossRef] [PubMed]

34. Liu, M.J.; Bao, S.; Galvez-Peralta, M.; Pyle, C.J.; Rudawsky, A.C.; Pavlovicz, R.E.; Killilea, D.W.; Li, C.; Nebert, D.W.; Wewers, M.D.; et al. ZIP8 regulates host defense through zinc-mediated inhibition of NF-kappaB. Cell Rep. 2013, 3, 386-400. [CrossRef] [PubMed]

35. Pyle, C.J.; Akhter, S.; Bao, S.; Dodd, C.E.; Schlesinger, L.S.; Knoell, D.L. Zinc Modulates Endotoxin-Induced Human Macrophage Inflammation through ZIP8 Induction and C/EBPbeta Inhibition. PLoS ONE 2017, 12, e0169531. [CrossRef] [PubMed]

36. Johnson, E.R.; Matthay, M.A. Acute lung injury: Epidemiology, pathogenesis, and treatment. J. Aerosol Med. Pulm. Drug Deliv. 2010, 23, 243-252. [CrossRef]

37. Chabot, F.; Mitchell, J.A.; Gutteridge, J.M.; Evans, T.W. Reactive oxygen species in acute lung injury. Eur. Respir. J. 1998, 11, 745-757.

38. Dixon, S.J.; Stockwell, B.R. The role of iron and reactive oxygen species in cell death. Nat. Chem. Biol. 2014, 10, 9-17. [CrossRef]

39. Ghio, A.J.; Carter, J.D.; Richards, J.H.; Richer, L.D.; Grissom, C.K.; Elstad, M.R. Iron and iron-related proteins in the lower respiratory tract of patients with acute respiratory distress syndrome. Crit. Care Med. 2003, 31, 395-400. [CrossRef]

40. Connelly, K.G.; Moss, M.; Parsons, P.E.; Moore, E.E.; Moore, F.A.; Giclas, P.C.; Seligman, P.A.; Repine, J.E. Serum ferritin as a predictor of the acute respiratory distress syndrome. Am. J. Respir. Crit. Care Med. 1997, 155, 21-25. [CrossRef]

41. Sharkey, R.A.; Donnelly, S.C.; Connelly, K.G.; Robertson, C.E.; Haslett, C.; Repine, J.E. Initial serum ferritin levels in patients with multiple trauma and the subsequent development of acute respiratory distress syndrome. Am. J. Respir. Crit. Care Med. 1999, 159, 1506-1509. [CrossRef] [PubMed]

42. Jean, G.; Charra, B.; Chazot, C.; Vanel, T.; Terrat, J.C.; Hurot, J.M.; Laurent, G. Risk factor analysis for long-term tunneled dialysis catheter-related bacteremias. Nephron 2002, 91, 399-405. [CrossRef] [PubMed] 
43. Gangaidzo, I.T.; Moyo, V.M.; Mvundura, E.; Aggrey, G.; Murphree, N.L.; Khumalo, H.; Saungweme, T.; Kasvosve, I.; Gomo, Z.A.; Rouault, T.; et al. Association of pulmonary tuberculosis with increased dietary iron. J. Infect. Dis. 2001, 184, 936-939. [CrossRef] [PubMed]

44. Murray, M.J.; Murray, A.B.; Murray, M.B.; Murray, C.J. The adverse effect of iron repletion on the course of certain infections. Br. Med. J. 1978, 2, 1113-1115. [CrossRef] [PubMed]

45. Weinberg, E.D. Iron and susceptibility to infectious disease. Science 1974, 184, 952-956. [CrossRef] [PubMed]

46. Bao, G.H.; Barasch, J.; Xu, J.; Wang, W.; Hu, F.L.; Deng, S.X. Purification and Structural Characterization of "Simple Catechol", the NGAL-Siderocalin Siderophore in Human Urine. RSC Adv. 2015, 5, 28527-28535. [CrossRef] [PubMed]

47. Wu, H.; Santoni-Rugiu, E.; Ralfkiaer, E.; Porse, B.T.; Moser, C.; Hoiby, N.; Borregaard, N.; Cowland, J.B. Lipocalin 2 is protective against E. coli pneumonia. Respir. Res. 2010, 11, 96. [CrossRef]

48. Martineau, A.R.; Newton, S.M.; Wilkinson, K.A.; Kampmann, B.; Hall, B.M.; Nawroly, N.; Packe, G.E.; Davidson, R.N.; Griffiths, C.J.; Wilkinson, R.J. Neutrophil-mediated innate immune resistance to mycobacteria. J. Clin. Investig. 2007, 117, 1988-1994. [CrossRef]

49. Baynes, R.; Bezwoda, W.; Bothwell, T.; Khan, Q.; Mansoor, N. The non-immune inflammatory response: Serial changes in plasma iron, iron-binding capacity, lactoferrin, ferritin and C-reactive protein. Scand. J. Clin. Lab. Investig. 1986, 46, 695-704. [CrossRef]

50. Cellier, M.F.; Courville, P.; Campion, C. Nramp1 phagocyte intracellular metal withdrawal defense. Microbes Infect. Inst. Pasteur 2007, 9, 1662-1670. [CrossRef]

51. Wessling-Resnick, M. Nramp1 and Other Transporters Involved in Metal Withholding during Infection. J. Biol. Chem. 2015, 290, 18984-18990. [CrossRef] [PubMed]

52. Michels, K.; Nemeth, E.; Ganz, T.; Mehrad, B. Hepcidin and Host Defense against Infectious Diseases. PLoS Pathog. 2015, 11, e1004998. [CrossRef] [PubMed]

53. Wrighting, D.M.; Andrews, N.C. Interleukin-6 induces hepcidin expression through STAT3. Blood 2006, 108, 3204-3209. [CrossRef] [PubMed]

54. Peyssonnaux, C.; Zinkernagel, A.S.; Datta, V.; Lauth, X.; Johnson, R.S.; Nizet, V. TLR4-dependent hepcidin expression by myeloid cells in response to bacterial pathogens. Blood 2006, 107, 3727-3732. [CrossRef] [PubMed]

55. Stefanova, D.; Raychev, A.; Deville, J.; Humphries, R.; Campeau, S.; Ruchala, P.; Nemeth, E.; Ganz, T.; Bulut, Y. Hepcidin Protects against Lethal Escherichia coli Sepsis in Mice Inoculated with Isolates from Septic Patients. Infect. Immun. 2018, 86. [CrossRef] [PubMed]

56. Stefanova, D.; Raychev, A.; Arezes, J.; Ruchala, P.; Gabayan, V.; Skurnik, M.; Dillon, B.J.; Horwitz, M.A.; Ganz, T.; Bulut, Y.; et al. Endogenous hepcidin and its agonist mediate resistance to selected infections by clearing non-transferrin-bound iron. Blood 2017, 130, 245-257. [CrossRef] [PubMed]

57. Chen, Q.X.; Song, S.W.; Chen, Q.H.; Zeng, C.L.; Zheng, X.; Wang, J.L.; Fang, X.M. Silencing airway epithelial cell-derived hepcidin exacerbates sepsis induced acute lung injury. Crit. Care 2014, 18, 470. [CrossRef]

58. Paradkar, P.N.; De Domenico, I.; Durchfort, N.; Zohn, I.; Kaplan, J.; Ward, D.M. Iron depletion limits intracellular bacterial growth in macrophages. Blood 2008, 112, 866-874. [CrossRef]

59. Chlosta, S.; Fishman, D.S.; Harrington, L.; Johnson, E.E.; Knutson, M.D.; Wessling-Resnick, M.; Cherayil, B.J. The iron efflux protein ferroportin regulates the intracellular growth of Salmonella enterica. Infect. Immun. 2006, 74, 3065-3067. [CrossRef]

60. Stites, S.W.; Plautz, M.W.; Bailey, K.; O’Brien-Ladner, A.R.; Wesselius, L.J. Increased concentrations of iron and isoferritins in the lower respiratory tract of patients with stable cystic fibrosis. Am. J. Respir. Crit. Care Med. 1999, 160, 796-801. [CrossRef]

61. Reid, D.W.; Lam, Q.T.; Schneider, H.; Walters, E.H. Airway iron and iron-regulatory cytokines in cystic fibrosis. Eur. Respir. J. 2004, 24, 286-291. [CrossRef] [PubMed]

62. Reid, D.W.; Anderson, G.J.; Lamont, I.L. Role of lung iron in determining the bacterial and host struggle in cystic fibrosis. Am. J. Physiol. Lung Cell Mol. Physiol. 2009, 297, L795-L802. [CrossRef] [PubMed]

63. Mussalo-Rauhamaa, H.; Leppanen, A.; Salmela, S.S.; Pyysalo, H. Cigarettes as a source of some trace and heavy metals and pesticides in man. Arch. Environ. Health 1986, 41, 49-55. [CrossRef] [PubMed]

64. Cloonan, S.M.; Mumby, S.; Adcock, I.M.; Choi, A.M.K.; Chung, K.F.; Quinlan, G.J. The "Iron"-y of Iron Overload and Iron Deficiency in Chronic Obstructive Pulmonary Disease. Am. J. Respir. Crit. Care Med. 2017, 196, 1103-1112. [CrossRef] [PubMed] 
65. Ghio, A.J.; Hilborn, E.D.; Stonehuerner, J.G.; Dailey, L.A.; Carter, J.D.; Richards, J.H.; Crissman, K.M.; Foronjy, R.F.; Uyeminami, D.L.; Pinkerton, K.E. Particulate matter in cigarette smoke alters iron homeostasis to produce a biological effect. Am. J. Respir. Crit. Care Med. 2008, 178, 1130-1138. [CrossRef] [PubMed]

66. Mumby, S.; Saito, J.; Adcock, I.M.; Chung, K.F.; Quinlan, G.J. Decreased breath excretion of redox active iron in COPD: A protective failure? Eur. Respir. J. 2016, 47, 1267-1270. [CrossRef] [PubMed]

67. DeMeo, D.L.; Mariani, T.; Bhattacharya, S.; Srisuma, S.; Lange, C.; Litonjua, A.; Bueno, R.; Pillai, S.G.; Lomas, D.A.; Sparrow, D.; et al. Integration of genomic and genetic approaches implicates IREB2 as a COPD susceptibility gene. Am. J. Hum. Genet. 2009, 85, 493-502. [CrossRef]

68. Kim, W.J.; Wood, A.M.; Barker, A.F.; Brantly, M.L.; Campbell, E.J.; Eden, E.; McElvaney, G.; Rennard, S.I.; Sandhaus, R.A.; Stocks, J.M.; et al. Association of IREB2 and CHRNA3 polymorphisms with airflow obstruction in severe alpha-1 antitrypsin deficiency. Respir Res. 2012, 13, 16. [CrossRef]

69. Cloonan, S.M.; Glass, K.; Laucho-Contreras, M.E.; Bhashyam, A.R.; Cervo, M.; Pabon, M.A.; Konrad, C.; Polverino, F.; Perez, E.; Mizumura, K.; et al. Mitochondrial iron chelation ameliorates cigarette smoke-induced bronchitis and emphysema in mice. Nat. Med. 2016, 22, 163-174. [CrossRef]

70. Ghio, A.J.; Jaskot, R.H.; Hatch, G.E. Lung injury after silica instillation is associated with an accumulation of iron in rats. Am. J. Physiol. 1994, 267, L686-L692. [CrossRef]

71. Kim, J.; Wessling-Resnick, M. The Role of Iron Metabolism in Lung Inflammation and Injury. J. Allergy 2012, 3. [CrossRef] [PubMed]

72. Moreau-Marquis, S.; O'Toole, G.A.; Stanton, B.A. Tobramycin and FDA-approved iron chelators eliminate Pseudomonas aeruginosa biofilms on cystic fibrosis cells. Am. J. Respir. Cell Mol. Biol. 2009, 41, 305-313. [CrossRef] [PubMed]

73. Andrianaki, A.M.; Kyrmizi, I.; Thanopoulou, K.; Baldin, C.; Drakos, E.; Soliman, S.S.M.; Shetty, A.C.; McCracken, C.; Akoumianaki, T.; Stylianou, K.; et al. Iron restriction inside macrophages regulates pulmonary host defense against Rhizopus species. Nat. Commun. 2018, 9, 3333. [CrossRef] [PubMed]

74. Hatcher, H.C.; Singh, R.N.; Torti, F.M.; Torti, S.V. Synthetic and natural iron chelators: Therapeutic potential and clinical use. Future Med. Chem. 2009, 1, 1643-1670. [CrossRef] [PubMed]

75. Wetli, H.A.; Buckett, P.D.; Wessling-Resnick, M. Small-molecule screening identifies the selanazal drug ebselen as a potent inhibitor of DMT1-mediated iron uptake. Chem. Biol. 2006, 13, 965-972. [CrossRef] [PubMed]

76. Preza, G.C.; Ruchala, P.; Pinon, R.; Ramos, E.; Qiao, B.; Peralta, M.A.; Sharma, S.; Waring, A.; Ganz, T.; Nemeth, E. Minihepcidins are rationally designed small peptides that mimic hepcidin activity in mice and may be useful for the treatment of iron overload. J. Clin. Investig. 2011, 121, 4880-4888. [CrossRef] [PubMed]

77. Kaneko, Y.; Thoendel, M.; Olakanmi, O.; Britigan, B.E.; Singh, P.K. The transition metal gallium disrupts Pseudomonas aeruginosa iron metabolism and has antimicrobial and antibiofilm activity. J. Clin. Investig. 2007, 117, 877-888. [CrossRef] [PubMed]

(C) 2019 by the authors. Licensee MDPI, Basel, Switzerland. This article is an open access article distributed under the terms and conditions of the Creative Commons Attribution (CC BY) license (http://creativecommons.org/licenses/by/4.0/). 


\title{
Iron Homeostasis in the Lungs-A Balance between Health and Disease
}

\author{
Joana Neves ${ }^{1,2,+}$, Thomas Haider ${ }^{3,4, \dagger}$, Max Gassmann ${ }^{3, \ddagger, *}$ and Martina U. Muckenthaler ${ }^{1,2,5, \ddagger, *}$ \\ 1 Department of Pediatric Oncology, Hematology and Immunology, University of Heidelberg, 69120 \\ Heidelberg, Germany; joanamatosneves@gmail.com \\ 2 Translational Lung Research Center Heidelberg (TLRC), German Center for Lung Research (DZL), \\ University of Heidelberg, 69120 Heidelberg, Germany \\ 3 Institute of Veterinary Physiology, Vetsuisse Faculty, and Zurich Center for Integrative Human \\ Physiology (ZIHP), University of Zurich, 8057 Zurich, Switzerland; thomas.j.haider@gmail.com \\ 4 Department of Cardiology, University Heart Center Zurich, University Hospital Zurich, \\ 8091 Zurich, Switzerland \\ 5 Molecular Medicine Partnership Unit, University of Heidelberg, 69120 Heidelberg, Germany \\ * Correspondence: maxg@access.uzh.ch (M.G.); Martina.Muckenthaler@med.uni-heidelberg.de (M.U.M.) \\ + These authors contributed equally and share first-authorship. \\ $\ddagger$ These authors contributed equally and share the senior authorship.
}

Received: 20 November 2018; Accepted: 25 December 2018; Published: 1 January 2019

\begin{abstract}
A strong mechanistic link between the regulation of iron homeostasis and oxygen sensing is evident in the lung, where both systems must be properly controlled to maintain lung function. Imbalances in pulmonary iron homeostasis are frequently associated with respiratory diseases, such as chronic obstructive pulmonary disease and with lung cancer. However, the underlying mechanisms causing alterations in iron levels and the involvement of iron in the development of lung disorders are incompletely understood. Here, we review current knowledge about the regulation of pulmonary iron homeostasis, its functional importance, and the link between dysregulated iron levels and lung diseases. Gaining greater knowledge on how iron contributes to the pathogenesis of these diseases holds promise for future iron-related therapeutic strategies.
\end{abstract}

Keywords: iron homeostasis; lung diseases; oxygen sensing; hypoxia

\section{Introduction}

Every cell requires sufficient oxygen to satisfy its demand for oxidative metabolism. Red blood cells (RBCs) are in the center of this process by transporting oxygen from the lungs to every tissue. Efficient oxygen transported by RBCs relies on the presence of hemoglobin, a protein containing four heme groups that have the ability to bind oxygen through their central iron atom. To sustain adequate erythropoiesis, approximately $20-25 \mathrm{mg}$ of iron are required daily [1]. In addition to hemoglobin synthesis, iron is necessary for other fundamental metabolic processes, including DNA synthesis and repair, transcription, and energy production in the mitochondria [2]. Therefore, iron is essential for the biology of almost all organisms. Insufficient intracellular iron levels impair the activity of iron-containing proteins, ultimately compromising cell function and viability. Iron's critical role is explained by its potential to fluctuate between oxidation states, mainly between divalent ferrous $\left(\mathrm{Fe}^{2+}\right)$ and trivalent ferric $\left(\mathrm{Fe}^{3+}\right)$ iron [3]. However, this chemical property as a transition metal makes free iron very reactive and potentially toxic. Iron catalyzes the production of reactive oxygen species (ROS) via the Fenton and Haber-Weiss reactions [4]. Exposure to these highly reactive radicals damages lipids, nucleic acids, and proteins, causing cell and thus tissue damage. To counteract its chemical reactivity, iron in the body is mainly bound to prosthetic groups, such as heme in hemoglobin or 
myoglobin, and to proteins, such as the plasma iron transport protein transferrin or the intracellular iron storage protein ferritin. This dual role of iron makes it essential to tightly control iron homeostasis to meet the cellular and systemic metabolic needs while preventing detrimental iron overload. In other words, like oxygen, iron represents a double-edge sword and thus requires exact regulation.

Adequate iron supply and homeostasis depends on systemic plasma availability. Under balanced conditions, only 1-2 mg of iron from dietary sources are absorbed daily by duodenal enterocytes to compensate for small iron losses (e.g., blood loss and desquamation of epithelial surfaces) or increased demand (e.g., pregnancy or hypoxic exposure). Most of the iron required to sustain the body's metabolic needs is provided by reticuloendothelial macrophages that recycle iron from senescent RBCs [5]. Hepatocytes in the liver are specialized for iron storage, acting as an iron buffer system. Since nature has not come up with a regulated way to eliminate iron from the organism, the coordination of iron fluxes from tissues to circulation is essential to maintain plasma iron levels within a physiological range $(10-30 \mu \mathrm{M})$ [6]. Plasma iron levels are mainly controlled by the hepcidin/ferroportin regulatory system (Figure 1) [1]. The hepatic hormone hepcidin is secreted in conditions of high systemic iron levels and binds to the only known cellular iron exporter ferroportin (FPN), thereby inducing its ubiquitination, endocytosis, and lysosomal degradation $[7,8]$. This causes a decrease in iron export from FPN expressing cell-types, such as duodenal enterocytes and iron-recycling macrophages, ultimately leading to a decrease in plasma iron levels.

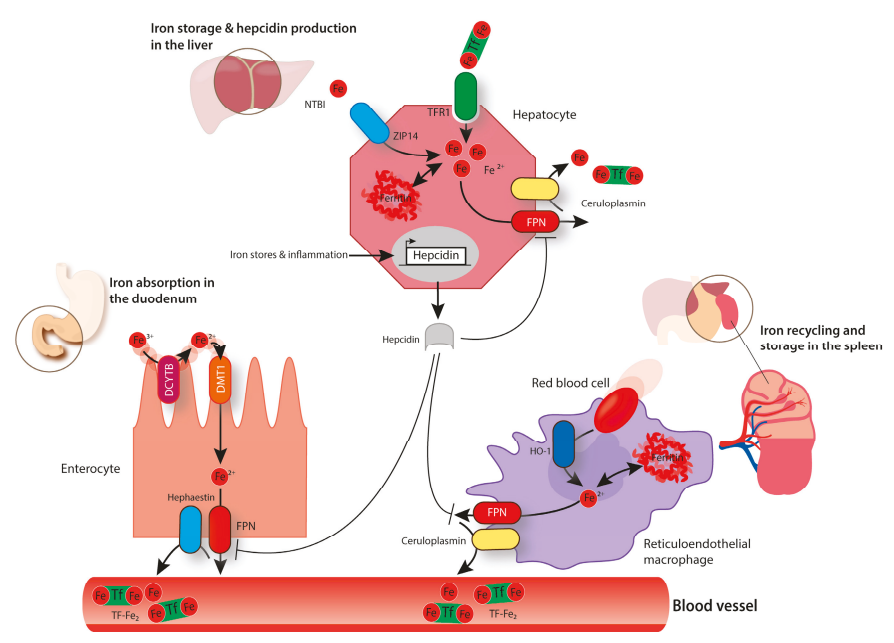

Figure 1. The above image represents systemic iron homeostasis. Dietary iron absorption occurs at the brush-border membrane of duodenal enterocytes. Ferric iron $\left(\mathrm{Fe}^{3+}\right)$ is reduced to ferrous iron $\left(\mathrm{Fe}^{+}\right)$by duodenal cytochrome B (DCYTB) and is transported across the membrane via divalent metal transporter 1 (DMT1). The export of iron through the basolateral membrane of enterocytes occurs via ferroportin (FPN) and is coupled to the reoxidation of $\mathrm{Fe}^{2+}$ to $\mathrm{Fe}^{3+}$, a process that is catalyzed by hephaestin. Ferric iron circulates in the blood bound to transferrin $\left(\mathrm{Tf}-\mathrm{Fe}_{2}\right)$. Transferrin-bound iron can be taken up via transferrin receptor 1 (TfR1) by every cell type in the organism, including hepatocytes that store high amounts of iron in ferritin. Hepatocytes can also take up non-transferrin-bound iron (NTBI) via ZRT/IRT-like protein (ZIP14). When required, iron can be exported from hepatocytes via FPN back to circulation (a process combined with the re-oxidation of $\mathrm{Fe}^{2+}$ to $\mathrm{Fe}^{3+}$ mediated by ceruloplasmin). Senescent erythrocytes are engulfed by reticuloendothelial macrophages. Iron is released from heme by heme oxygenase (HO1) and it can be either stored in ferritin or exported back to the circulation, depending on systemic iron requirements. Iron export from macrophages via FPN is also coupled to the activity of ceruloplasmin. Hepcidin produced by hepatocytes has the ability to decrease cellular iron export by binding to FPN and inducing its endocytosis and degradation. The expression of hepcidin is controlled by several factors including body iron stores and inflammation. 
The lung is the major organ for gas exchange and like all other organs it is exposed to circulating iron. Additionally, lung cells are directly exposed to exogenous iron sources via inhalation (e.g., cigarette smoke). A disruption of iron homeostasis in the lung is frequently associated with respiratory diseases, such as chronic obstructive pulmonary disease (COPD), acute respiratory distress syndrome, and cystic fibrosis [9-11]. This review focuses on the regulation of pulmonary iron levels and its functional importance as well as potential intrinsic and extrinsic factors modulating lung iron homeostasis. We will further address the impact of iron in the pathogenesis of human lung diseases as well as other diseases with a pathological lung phenotype associated with alterations in iron metabolism.

\section{Lung Iron Homeostasis}

\subsection{Balancing Lung Iron Homeostasis}

Lungs are composed of numerous cell types that work together to ensure efficient gas exchange between the atmosphere and the bloodstream. As every other cell, lung cells must acquire enough iron to sustain metabolic demand, thus ensuring their survival and lung function. At the same time, lung cells must prevent iron overload, oxidative stress, and resulting injury, which would ultimately impair lung function. The risk of oxidative stress in the lung is increased due to the exposure to physiologically high oxygen levels in the atmosphere. Lung cells are not only exposed to circulating iron but also to iron present in inhaled particles, such as mineral aerosols generated by wind erosion of soils or iron-rich air pollution particles [12,13]. In response to these challenges, the lung maintains protective mechanisms to avoid oxidative damage. The epithelial surface of the respiratory tract is covered by a thin layer of fluid containing high levels of antioxidant molecules, such as ascorbic acid, reduced glutathione, and mucin [14]. Furthermore, human airway secretions contain transferrin and lactoferrin, and glycoproteins are able to bind iron and maintain a chemically inert form $[15,16]$. Iron bound to transferrin or lactoferrin can be taken up by epithelial cells through their receptors, namely transferrin receptor 1 (TfR1) and lactoferrin receptor (LfR), respectively, to be stored safely bound to ferritin (Figure 2), a multimeric iron storage protein consisting of 24 subunits of heavy and light chains capable of accommodating up to 4000 iron atoms [17-19]. Excess of pulmonary iron caused by endogenous or exogenous factors can override these protective mechanisms and cause pulmonary oxidative stress. Experimentally, this was tested by intravenously injecting iron-containing compounds (e.g., iron dextran and ferric carboxymaltose) in rats that subsequently showed high levels of pulmonary oxidative stress, indicated by increased levels of nitrotyrosine and protein carbonyl modifications [20]. Likewise, pulmonary administration of $\mathrm{Fe}_{2} \mathrm{O}_{3}$ nanoparticles via inhalation also generates ROS in the rat lung [21]. 

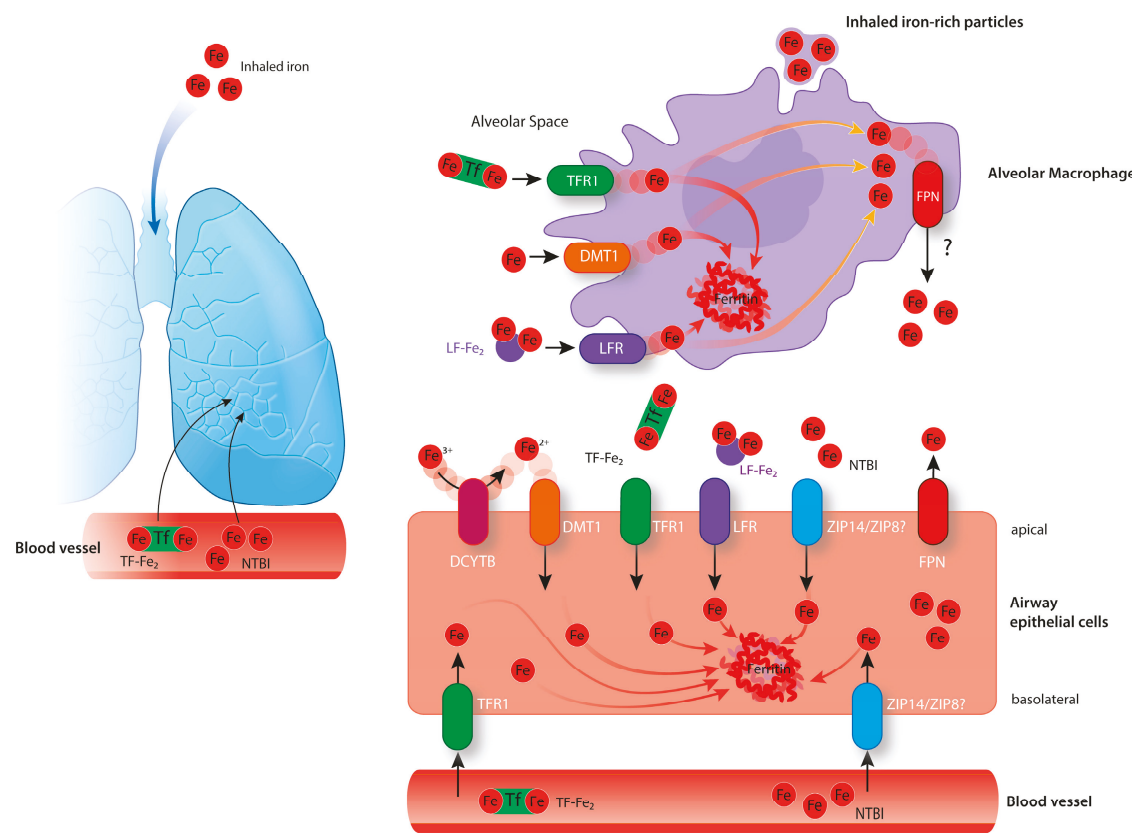

Figure 2. The above image shows pulmonary iron homeostasis. Lung cells are exposed to iron circulating in the bloodstream and to exogenous iron sources via inhalation. Epithelial cells likely take up the iron required for their metabolic needs from the lung vasculature via TfR1. Additionally, airway epithelial cells also take up iron from the airway space via TfR1, LFR, DMT1 (associated with the reduction of $\mathrm{Fe}^{3+}$ to $\mathrm{Fe}^{2+}$ by DCYTB), and possibly via ZIP14 or ZIP8. These cells store iron intracellularly bound to ferritin or export it via FPN expressed at their apical surface. Alveolar macrophages may take up free iron as well as iron bound to proteins from the alveolar space via DMT1, TFR1 or lactoferrin receptor (LFR). They might further take up inhaled iron-rich particles via phagocytosis. Alveolar macrophages are believed to be crucial in the maintenance of lung iron homeostasis by storing high amounts of iron intracellularly bound to ferritin. It is still not clear if alveolar macrophages express FPN and export iron under physiological conditions.

\subsection{Pulmonary Iron Modulation is a Potent Intrinsic Defense Strategy Against Respiratory Pathogens}

Respiration not only provides oxygen to support life but also exposes the respiratory system to external pathogens. Iron homeostasis and immune responses are tightly connected, likely reflecting the essential role of iron in the survival, proliferation, and virulence of most pathogens [22]. A central host defense strategy is to limit iron availability for extracellular pathogens by intracellular sequestration [23]. Inflammatory cytokines (e.g., IL6) induce the expression of the iron-regulated hormone hepcidin that degrades the iron exporter FPN located in macrophages and duodenal enterocytes, thereby reducing iron export to the circulation [24]. Additionally, transcription of FPN in macrophages is reduced via the TLR4- or TLR2/TLR6-signalling pathways, further contributing to inflammation-associated hypoferremia [25-27]. Indeed, failure to decrease systemic iron levels upon infection strongly increases the susceptibility of hepcidin knock-out $(\mathrm{KO})$ mice to some pathogens, such as Vibrio vulnificus or Klebsiella pneumonia [28]. In line with this observation, individuals with iron overload disorders, such as hereditary hemochromatosis, display a higher susceptibility to various infectious diseases [29,30]. Moreover, supplementation of iron and folic acid in preschool children increased the incidence of malaria and other infectious diseases in Pemba (Tanzania), an area with high infectious burdens [31]. 
As iron plays a critical role in the development of infectious diseases, the maintenance of low iron levels in the lung is crucial not only to prevent oxidative stress but also to sustain the pulmonary defense against inhaled pathogens. A positive correlation between sputum iron content and $P$. aeruginosa levels in clinically stable cystic fibrosis patients supports this idea [10]. Iron is a strong regulator of P. aeruginosa survival and behavior, as $6 \%$ of its transcribed genes respond to iron [32]. The success of this Gram-negative bacterium in colonizing the airways is in part due to its ability to form biofilms. Interestingly, several studies showed that iron is necessary for $P$. aeruginosa biofilm formation and application of iron chelators impairs this process by sequestering free iron $[33,34]$. Based on these findings, pulmonary administration of high-affinity iron chelators via inhalation might emerge as a possible therapeutic approach to fight $P$. aeruginosa lung infections in cystic fibrosis patients [32,34]. Consistently, the incidence of respiratory infections in children with mild-to-moderate iron-deficiency was substantially lower compared to iron-depleted children in Kilimanjaro (Tanzania) [35]. Finally, an association between increased dietary iron intake and increased odds of developing active pulmonary tuberculosis was observed in individuals from Zimbabwe [36].

Patients who underwent lung transplantation showed increased pulmonary iron levels in the allografts after transplantation that possibly contributed to the risk of oxidative stress and lung injury [37,38]. In addition, high iron levels in a tracheal allograft mouse model increased the risk for A. fumigatus invasion, a well-known pathogen causing common respiratory infectious disease in lung transplant recipients [39].

During evolution, microorganisms developed high-affinity iron uptake systems, such as siderophores, to acquire iron from the host [22]. The host fights back by increasing the expression of lipocalin-2, a protein mainly produced by neutrophils that binds to the siderophore enterobactin and prevents its uptake by the pathogen [22]. During infection, lipocalin-2 is not only secreted by recruited neutrophils but also from lung epithelial cells [40]. The importance of lipocalin-2 in sequestering iron in the lung is highlighted by the observation that pneumonia caused by intratracheal instillation of E. coli is aggravated in lipocalin-2 knock-out mice [40]. Furthermore, lipocalin-2 binding is specific and does not prevent iron uptake and consequent colonization by bacteria that produce modified forms of enterobactin or other types of siderophores [41].

\subsection{Molecular Regulation of Lung Iron Homeostasis}

Iron uptake, utilization, storage, and export must be coordinated to maintain cellular iron homeostasis in every organ. The iron-responsive element (IRE)/iron-regulatory protein (IRP) system plays a central role in this process by controlling the expression of iron-related proteins in response to intracellular iron levels (Figure 3) [42,43]. Iron regulatory protein 1 and 2 (IRP1 and IRP2) interact with conserved hairpin structures named iron-responsive elements (IREs) present in the $5^{\prime}$ or $3^{\prime}$ untranslated regions (UTRs) of mRNAs of iron-regulated genes (Figure 3). In iron-deficient cells, IRPs bind to the IRE in the 5' UTR of ferritin light chain (FtL), ferritin heavy chain (FtH), FPN, and the transcription factor HIF-2 $\alpha$ (see below) mRNAs, inhibiting their translation [44-48]. Additionally, IRPs bind to IREs located in the 3' UTR of TfR1 or Dmt1 (see below) mRNAs, blocking their degradation [49-51]. Subsequently, in conditions of cellular iron deficiency, iron uptake increases while iron storage and export decrease, resulting in higher intracellular iron availability. On the other hand, in iron-loaded cells, IRPs cannot bind to IREs. IRP1 is converted from its RNA-binding form to a cytoplasmatic aconitase containing a $4 \mathrm{Fe}-4 \mathrm{~S}$ cluster and IRP2 is targeted for proteasomal degradation [52-54]. As a result, iron storage and export are increased and iron uptake decreased. 


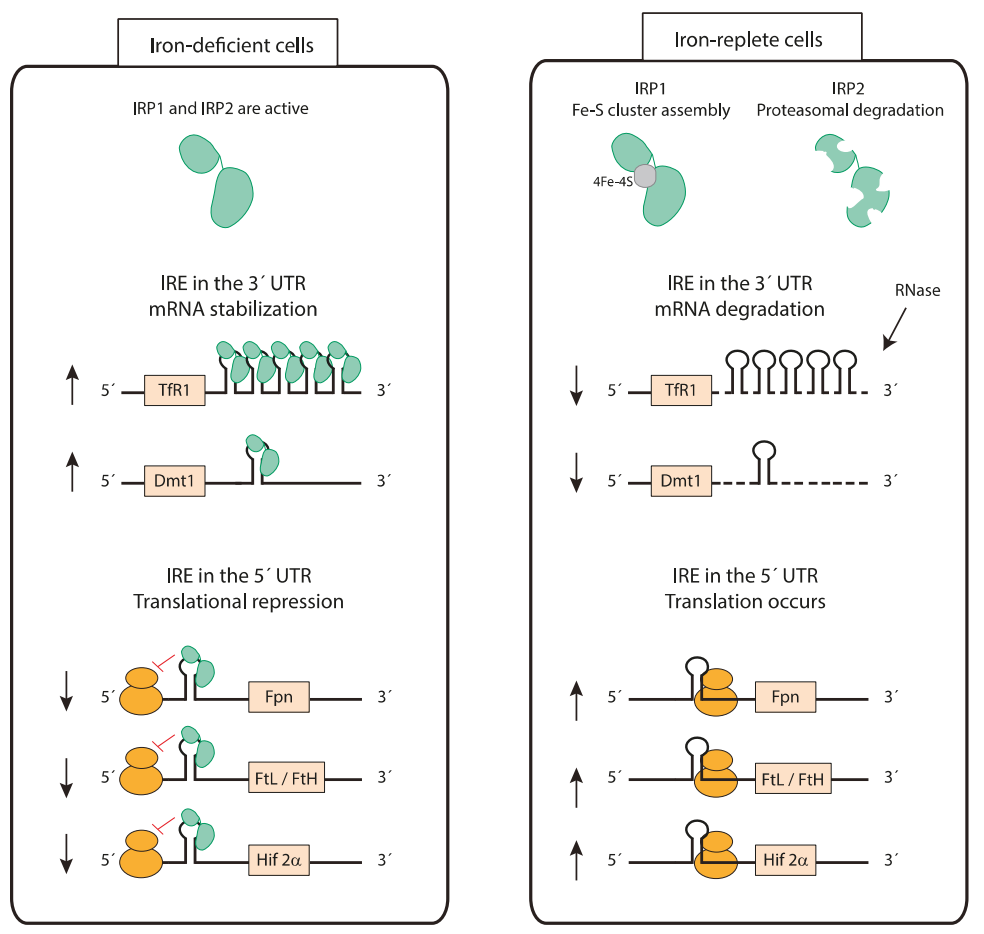

Figure 3. Cellular iron homeostasis: iron responsive element (IRE)/ iron regulatory protein (IRP) system. IRP1 and IRP2 bind to IREs present in either the 5' untranslated regions (UTR) or 3' UTR of mRNAs and regulate their translation and stability, respectively. In iron-depleted cells, IRPs bind to an IRE localized in the 5' UTR of mRNAs to repress translation, while IRP binding to IREs in the 3' UTR stabilizes mRNAs. In iron-replete cells, IRP1 switches from its IRE-binding form to a Fe-S cluster containing aconitase and IRP2 is degraded. The lack of IRP binding to IREs allows for the translation of mRNAs containing an IRE in the 5' UTR and degradation of mRNAs containing IREs in the 3' UTR. This mechanism counterbalances both cellular iron deficiency and iron overload. (Fpn-ferroportin; FtL—ferritin light chain; FtH—ferritin heavy chain; HIF- $\alpha$ - hypoxia-inducible factor- $2 \alpha$ ).

\subsubsection{Control of Pulmonary Iron Uptake}

Similar to most cells, lung cells express TfR1 and likely acquire transferrin-bound iron from pulmonary vessels (Figure 2). Increased pulmonary iron levels in mouse models of iron overload are associated with decreased pulmonary TfR1 mRNA levels, suggesting that the IRE/IRP regulatory system controls the expression of iron-related genes in the lung [55,56]. In healthy humans, approximately $30 \%$ of plasma transferrin is saturated with iron. In conditions of systemic iron overload, which cause transferrin saturation to rise above $60 \%$, non-transferrin-bound iron (NTBI) accumulates. Exposure to high levels of systemic iron causes accumulation in different pulmonary cell types, such as alveolar macrophages, epithelial cells, and vascular smooth muscle cells $[55,56]$. So far, the exact iron uptake mechanisms are not understood. The lung expresses the NTBI importers DMT1, ZIP14, and ZIP8, that may further contribute to the iron loading under high systemic and/or local iron levels.

The divalent metal transporter 1 (DMT1) is localized at the brush-border membrane of duodenal enterocytes and was first discovered due to its crucial role in dietary iron absorption (Figure 1) [57]. Dietary inorganic ferric iron $\left(\mathrm{Fe}^{3+}\right)$ needs to be reduced to ferrous iron $\left(\mathrm{Fe}^{2+}\right)$ by the ferrireductase duodenal cytochrome B (DCYTB) before being transported from the duodenal lumen into the cytosol 
of enterocytes via DMT1 [58]. Airway epithelial cells express both DMT1 and DCYTB, and therefore are likely able to take up NTBI from the airway space (Figure 2) [59,60]. How lung DMT1 expression is regulated in response to pulmonary iron levels is unclear. Different Dmt1 mRNA isoforms are expressed in the lung, including one isoform harboring an IRE in the 3'UTR and another isoform lacking the IRE [61,62]. Increased iron levels inactivate the IRE/IRP system and cause a decrease in the mRNA levels of the IRE-containing DMT1 isoform (Figure 3). Consistently, lower mRNA levels of this isoform are observed in the iron-loaded lung of a murine mouse model of hereditary hemochromatosis type 4 [56]. In addition, lower pulmonary DMT1 mRNA and protein levels were also reported in the iron-loaded lung of hepcidin deficient mice [55]. By contrast, DMT1 protein levels remain unchanged upon lung iron loading via intraperitoneal injection of iron-saccharate [63]. Moreover, another group observed an increase in the non-IRE DMT1 isoform in the rat lung, following instillation with ferric ammonium citrate, without differences in the levels of the IRE-containing DMT1 isoform [64]. Future studies are required to further dissect the molecular mechanisms regulating Dmt1 expression in the lung.

NTBI can also be taken up by cells via ZRT/IRT-like protein (ZIP) 14. Genetic inactivation revealed that ZIP14 is a key player for NTBI uptake by hepatocytes under iron overload conditions [65]. Besides hepatocytes, ZIP14 is expressed by cells in other tissues such as the pancreas and the heart $[65,66]$. In addition, ZIP14 is detected in airway epithelial cells, and protein levels were shown to increase in the iron loaded murine lung [63]. In 2012, another ZIP protein able to transport iron, named ZIP8, was reported. It is abundantly expressed in the human lung [66]. A disruption in both alleles of the mouse ZIP8 gene causes lethality between the gestational day 18.5 and 48 hours postnatal [67]. Interestingly, the newborns present with anemia and reduced iron levels in some tissues, including the lung [67].

Finally, in conditions of intravascular hemolysis, lung cells can also be exposed to hemoglobin and heme-iron circulating in the bloodstream. When released from RBCs, hemoglobin forms a complex with the glycoprotein haptoglobin in the plasma, which is mainly taken up by reticuloendothelial macrophages; heme released from hemoglobin in the blood forms a complex with the glycoprotein hemopexin and is taken up by liver parenchymal cells [68]. In vivo studies have shown that the uptake of hemoglobin-haptoglobin and heme-hemopexin complexes by the lung is relatively low [69-72]. Nevertheless, alveolar macrophages express the haptoglobin receptor CD163 and the hemopexin receptor CD91, and therefore are likely able to take up these complexes [73,74]. Alveolar macrophages exposed to heme upregulate the expression of HO-1 that is responsible for heme degradation and protection against the toxic effects of this prosthetic group $[75,76]$.

\subsubsection{Iron Storage in the Lung}

Lung cells store iron intracellularly bound to ferritin, keeping it in a non-toxic ferric form and thus preventing oxidative damage. Consistent with the role of the IRE/IRP system in controlling ferritin expression, pulmonary ferritin levels increase upon lung iron loading in murine mouse models $[55,56]$. Higher levels of ferritin were also detected in the bronchoalveolar lavage fluid of individuals instilled with iron-containing particles [77]. When needed, iron stored in ferritin can be made available to the cell. In conditions of low levels of intracellular iron, NCOA4 (Nuclear Receptor Coactivator 4) targets the ferritin complex to degradation in autolysosomes and iron is released into the cytoplasm [78,79]. Genetic inactivation of NCOA4 impairs iron mobilization from stores in several tissues such as the liver and the spleen [80]. Future studies must address the possible role of NCOA4 in the mobilization of ferritin-stored iron in lung cells.

\subsubsection{Iron Export from the Lung}

The only known iron exporter FPN is expressed in the lung, too, albeit at a much lower level compared to the spleen, the key iron recycling site [55]. Using an in vitro model, it was shown that polarized airway epithelial cells export iron through their apical surface [81]. FPN expression at this site was confirmed using immunohistochemical analysis [55,81]. Additionally, several studies reported 
an association between increased pulmonary iron content and higher protein levels of FPN in this organ $[63,82]$. Increased levels of FPN are likely a consequence of the inactivation of the IRE/IRP system and an increase at the transcriptional level. Iron export via FPN is combined with iron oxidation from $\mathrm{Fe}^{2+}$ to $\mathrm{Fe}^{3+}$, mediated by ceruloplasmin (or hephaestin in the basal membrane of duodenal enterocytes) (Figure 1) [83,84]. Interestingly, ceruloplasmin was detected in human bronchial lavage fluid, suggesting that it might be involved in FPN-mediated iron export in the lung [15]. Note that the $\mathrm{pH}$ of lung fluids (e.g., the alveolar lining fluid) may affect the complex process of spontaneous oxidation of ferrous to ferric iron following a sigmoid shaped oxidation rate in relation to $\mathrm{pH}$ [85]. Therefore, changes in $\mathrm{pH}$ may alter the iron redox-states within the alveolar lining fluid, that in turn would affect trans-epithelial iron uptake and intracellular iron availability.

\subsubsection{Pulmonary Hepcidin Expression}

Hepcidin is mainly produced and secreted by hepatocytes to control systemic iron levels [1]. Of note, low levels of hepcidin are also detected in other tissues, such as the heart, kidney, and lung [55,86-88]. Hepatocyte-specific hepcidin knock-out mice recapitulate the hemochromatosis phenotype observed in constitutive hepcidin deficient mice, indicating that extra-hepatic hepcidin is not enough to maintain systemic iron homeostasis [89]. However, recent studies proposed the existence of cell-type specific regulatory circuitries in some tissues. For example, through the analysis of mice with cardiomyocyte-specific deletion of hepcidin, a cell-autonomous role for cardiac hepcidin in maintaining cardiac iron homeostasis was identified [86]. It is still not clear whether there is a local role of hepcidin in the lung. Some reported that the induction of pulmonary hepcidin expression by bacterial lipopolysaccharide (LPS) instillation does not affect FPN protein levels in the lung [55]. Consistently, others showed that an increase in hepcidin expression in human bronchial epithelial cells in vitro does not cause a decrease in FPN protein levels [90]. By contrast, an increase in lung FPN protein levels was observed upon knocking down hepcidin in airway epithelial cells in a mouse model of sepsis-induced acute lung injury [91]. Overall, future studies are necessary to fully understand the potential role of lung hepcidin in pulmonary iron homeostasis.

\subsubsection{Alveolar Macrophages}

Alveolar macrophages frequently accumulate iron in lung diseases and conditions of iron overload $[11,55,56,63]$. While splenic and liver macrophages are essential to recycle iron from aged RBCs, the location of alveolar macrophages in the alveolar space suggests that at least in healthy conditions these cells do not contribute to hemoglobin-derived iron recycling. Instead, alveolar macrophages are expected to have a protective role by scavenging the excess of iron in the lung (derived from inhaled iron particles or from plasma iron) thereby limiting its availability to induce oxidative damage [92]. The expression of TfR, LfR, and DMT1 was reported in alveolar macrophages, indicating that these cells might be able to take up iron-bound to proteins as well as 'free' iron from the alveolar space, storing it intracellularly in ferritin (Figure 2) [55,93-95]. However, it is still not known which iron-uptake mechanism is predominant under physiological conditions. It is further possible that alveolar macrophages take up iron-rich particles from the alveolar space via phagocytosis. Whether these macrophages express FPN under normal iron conditions is unclear. In earlier work, we did not detect FPN in alveolar macrophages isolated from the bronchoalveolar lavage of wild-type mice by immunocytochemical analysis [56]. Similarly, others reported very low protein levels of FPN in these cells by western blot analysis [55]. In contrast, another group detected FPN at the cell membrane of freshly isolated alveolar macrophages, that was significantly reduced in the presence of hepcidin [93]. Consistent in most studies is the observation that higher levels of FPN were detected in alveolar macrophages in murine and rat models under iron loading conditions [55,56,82]. Finally, alveolar macrophages express hepcidin, which increases upon an inflammatory stimulus, but not upon iron loading $[55,93]$. 


\subsection{Modulating Factors of Lung Iron Homeostasis}

Pulmonary iron levels depend on plasma iron availability. Consequently, alterations in systemic iron levels have an impact on lung iron content. Mice injected intraperitoneally with iron-saccharate or rats maintained on a high iron diet increased lung iron levels compared to control animals $[63,96]$. Similarly, mice with genetic iron overload due to either hepcidin deficiency or a mutation in FPN that confers resistance to hepcidin binding show pulmonary iron accumulation $[55,56]$. Interestingly, high lung iron content was also observed in liver-specific hepcidin deficient mice [55]. This finding strengthens the hypothesis that lung iron loading occurs as a consequence of increased plasma iron levels and not due to the absence of a functional hepcidin/ferroportin system in the lung. By contrast, an increase in lung iron content was not observed in HFE deficient mice with a less severe form of hemochromatosis [87]. Note that HFE is a positive regulator of hepcidin and in its absence hepcidin expression is attenuated [97].

Patients with thalassemia major are hallmarked with ineffective erythropoiesis and therefore require frequent blood transfusions to ensure an adequate oxygen supply to the body [98]. Red blood cells contain high amounts of iron (1 mg of iron per milliliter of erythrocytes [6]). As a consequence of multiple transfusions and due to the absence of a regulated way to excrete iron, these patients develop massive systemic iron overload [99]. Iron accumulation was detected in alveolar macrophages from these patients further supporting the hypothesis that increased systemic iron levels elevates pulmonary iron content [100,101].

On the other end of the spectrum, iron deficiency does not seem to alter pulmonary iron levels. Iron deficiency induced by repeated bleeding of mice or a low iron diet (20-25 ppm Fe versus control diet with 200 ppm Fe) in rats caused decreased iron content in liver and spleen but not in the lung $[63,102]$. Contrasting these studies, rats fed for three weeks on an iron-deficient diet $(5,9$ ppm Fe) showed a reduction in lung iron levels compared with control animals fed on a diet containing 128 ppm Fe [103]. Differences may reflect the degree of systemic iron deficiency achieved in different studies, whereby the lung iron content may only be altered under conditions of severe iron deficiency. It would be of interest to analyze pulmonary iron levels in mice with genetic iron deficiency, such as Tmprss6 knock-out mice, an animal model with severely impaired iron uptake due to elevated hepcidin levels [104]. Note that TMPRSS6 is a well-known negative regulator of hepcidin [105].

Approximately 60 to $70 \%$ of the body's iron is localized in RBCs. The lung vasculature accommodates the entire cardiac output, allowing almost all RBCs to pass through the alveolar capillaries in order to be loaded with oxygen. Conditions that affect alveolar capillary integrity/permeability (e.g., Goodpasture's disease) [106] can lead to hemorrhage into the alveolar space. These patients show alterations in lung iron homeostasis with increased iron levels in alveolar macrophages, likely resulting from hemoglobin-derived iron from phagocytosed RBCs [107]. Such cases are examples of disorders that modulate lung iron homeostasis but are not a direct consequence of alterations in iron regulatory mechanisms.

\section{Environmental Factors that Impact Lung Iron Homeostasis}

Environmental factors also affect systemic and lung iron homeostasis. For example, global air pollution and exposure to cigarette smoke are well known to alter pulmonary iron homeostasis. Another potent environmental factor is the exposure to high altitude, which is further exaggerated when combined with physical activity, e.g., during mountaineering at high altitude or altitude training. Pollutants from soil and drinking water (e.g., heavy metals) can significantly disrupt iron homeostasis as well. Finally, thermal stress induced by extremely warm or cold environmental conditions may also affect iron metabolism but are not within the scope of the present review. 


\subsection{The Impact of Air Pollution and Cigarette Smoke on Iron Homeostasis}

According to a recently released WHO news report [108], it is estimated that 9 out of 10 people worldwide breathe polluted air, resulting in 7 million additional deaths each year. Fine particles from polluted air penetrate the airways and subsequently reach the cardiopulmonary system causing a variety of diseases such as stroke, heart disease, COPD, lung cancer, and pneumonia [108]. These airborne fine particles, including iron-containing and iron-binding particles, accumulate in the lower respiratory tract, e.g., within the bronchial epithelium. Several groups reported that instillation of iron-containing particles in mice and rats induces increased cellular oxidative stress and lung inflammation [21,109].

Apart from air pollution, cigarette smoke also causes fine (iron) particle exposure of the airways and modulates lung iron homeostasis [110]. The cigarette smoke-induced lung injury was shown to be particle related and is clinically associated with a loss of lung function, increased bronchial hyper-responsiveness, and a pathological lung tissue transformation (e.g., emphysema, fibrosis) [111]. The tracheal lavage from rats exposed to cigarette smoke contained higher levels of iron, transferrin and ferritin. Consistently, the lung non-heme iron content was increased. By contrast, serum iron and transferrin concentrations were reduced in these exposed rats. Additionally, serum ferritin and liver non-heme iron concentrations were increased, indicating a combined disturbance of lung and systemic iron homeostasis [110]. A similar expression pattern in the bronchial lavage of smokers with or without COPD was confirmed by the same authors.

Overall, the majority of cigarette smoke induced lung diseases are of inflammatory nature and strongly depend on activated immune-modulatory signaling pathways [112]. It was suggested that particle-induced ROS-driven mitochondrial dysfunction could have a key role in the pathophysiology of air pollution/cigarette smoke related lung diseases [113]. Although the underlying molecular mechanisms of how environmental fine particle exposure affects pulmonary cellular iron homeostasis are not fully understood, there is a fundamental link to the most globally frequent and deadliest respiratory diseases such as pneumonia, COPD, and lung cancer.

\subsection{Does Environmental Pollution Alter Iron Homeostasis?}

The environmental iron content depends on the soil iron content in given geographical regions and often influences iron levels in the drinking water. For example, the Tibetan Plateau contains a higher percentage of soil iron in comparison to the Chinese region [114]. As Tibetans often live from farming and mining, this living habit suggests a higher exogenous exposure to iron. Unfortunately, reports are not available as to whether this affects iron homeostasis and health in Tibetans. On the other hand, it is well-known that other environmental pollutants derived from soil and drinking water, such as persistent organic pollutants, heavy metals, and pesticides, significantly affect body iron homeostasis with toxic effects on organic functions [115]. Finally, the habit of open-fire cooking has to be considered as a source of iron pollution, too. As systemic iron availability directly affects lung iron availability these environmental factors may also impact on lung function and health in exposed individuals. Future research is needed to prove this assumption.

\subsection{High-Altitude Exposure and Physical Exercise}

More than 140 million people permanently live at altitudes of $2500 \mathrm{~m}$ above sea level and millions of other people travel to high altitude every year [116]. Adequate iron homeostasis is essential for oxygen uptake, transport, and delivery in the body, ultimately allowing aerobic metabolism. Therefore, it is not surprising that iron metabolism and aerobic metabolism are strongly linked to each other. Humans can, at least to a certain extent, adapt to high altitude and subsequently also to reduced atmospheric oxygen partial pressure levels, as exemplified by the highest permanent human settlements at altitudes of $5500 \mathrm{~m}$ above sea level at the Qinghai-Tibetan plateau in Asia [117]. On the 
other hand, exposure to high altitude can also lead to pathological maladaptations, which result in the well-known acute and chronic forms of high-altitude-related diseases [118].

At the systemic level, the mechanisms by which the human body can adapt to high altitude by altering iron acquisition have been recently discussed. This involves key organs of iron homeostasis such as the liver, the bone marrow, and the small intestine (duodenum), as well as signaling molecules such as erythropoietin, hepcidin, and erythroferrone that interact to control plasma iron levels [119]. Briefly, the recently discovered erythroid regulator erythroferrone (ERFE) [120] is released mainly from erythropoietin (Epo)-stimulated erythroblasts to suppress hepcidin production in hepatocytes resulting in increased iron absorption in the duodenum and iron export from reticuloendothelial macrophages. This elevates systemic iron availability required for RBC synthesis [121]. Higher levels of circulating RBCs improve tissue oxygenation by increasing blood oxygen transport capacity to compensate for the reduced alveolar oxygen diffusion at high altitude.

Oxygen demand increases upon physical exercise at high altitude. As a consequence, the iron turnover increases by a combination of an elevated iron demand due to exercise induced enlargement of red blood cell volume and an enhanced iron loss due to exercise induced sweating, hemolysis, hematuria, gastrointestinal bleeding, and, as recently reported, a modification of hepcidin levels [122]. Furthermore, iron deficiency is quite common in athletes, especially in females, and significantly compromises exercise performance [123], especially when performing at high altitude [124]. A very recent in vitro study found that iron chelator deferoxamine (DFO)-induced intracellular iron deficiency reversibly compromises contractility and relaxation of human cardiomyocytes by a significant impairment of mitochondrial respiration [125]. This indicates a direct impact of iron deficiency on cardiac function.

At the pulmonary level, convincing evidence exists for a crucial role of iron homeostasis in the maintenance of physiological lung function as well. This becomes particularly evident under stress conditions, such as high-altitude exposure. Here, the functional units of the cardiopulmonary system, namely the airways, the pulmonary vasculature, the respiratory control, the respiratory muscles, and the heart must interact in a precise and integrative manner. Balanced iron availability is important for every single functional compartment of the cardiopulmonary system to successfully adapt to high altitude.

Apart from the previously mentioned impact of cellular iron scavenging on human cardiac muscle cell function, other experimental studies showed that the chronic application of the iron chelator ciclopirox olamine (CPX) negatively affected the acute hypoxic ventilatory response of rats $[126,127]$. This response is crucial for high altitude adaption and is primarily mediated by the carotid bodies, the main arterial oxygen-sensing organs [128]. Of note, structural changes and altered HIF-1 $\alpha$ expression (see below) were found in the tissue of harvested carotid bodies of CPX-treated rats [129,130].

The airways and the pulmonary vasculature must also respond in an orchestrated manner to optimize oxygen transfer and gas exchange within the lungs at high altitude and the functional quality of this process is reflected by an improved ventilation/perfusion (V/Q) balance [131]. Physiological studies clearly demonstrated the importance of iron balance for the hypoxic pulmonary vasoconstriction (HPV), also known as the Euler-Liljestrand reflex, and generally for the response of the pulmonary vasculature to acute and sustained hypoxia [132]. By infusing iron or the iron chelator DFO in healthy adults, the authors showed that iron infusion can abolish the HPV sensitization after re-exposure to hypoxia. In contrast, DFO application increased the effect. An exaggerated HPV is associated with high altitude-related diseases (see disease section). Notably, the ventilatory response of the study subjects to acute hypoxia was also affected by the different treatment interventions $[132,133]$.

Finally, the Tibetan highlanders living on the Tibetan plateau represent the most successful human example of high-altitude adaption, having a unique setting of a potentially replenished iron status [134], an increased pulmonary capacity, and a blunted hypoxic ventilatory response [135], a naturally-selected and genetically-based hypo-responsive HIF-signaling system [136], and a superior physical capacity at high altitude, which led to their nomination as 'King of the mountains' [137]. 


\section{The Role of Heterodimeric Hypoxia-Inducible Factors 1 and 2 (HIF-1 and HIF-2) in the Lung}

During mammalian lung development, a close interaction between airway epithelium and vascular endothelium occurs, which is driven by hypoxic stimuli. The HIF-VEGF-axis is essential for this process. HIF-1 and HIF-2 are heterodimeric transcriptional key regulators of epithelial, mesenchymal, and vascular lung morphogenesis, which are composed of an oxygen-regulated $\alpha$-subunit and a constitutively expressed $\beta$-subunit, the latter also named ARNT. HIF- $1 \alpha$ expression is known to dominate early lung development, while HIF- $2 \alpha$ up-regulation starts at the saccular stage. Although global deficiency of HIF-1 $\alpha$ results in lethality at embryonic day 11 (E11) in mice, the deletion of HIF- $2 \alpha$ causes defective lung development, decreased surfactant production, postnatal respiratory distress, and neonatal lethality $[138,139]$.

Several recent reviews have discussed the cellular interference between iron- and oxygen-sensing within the lungs [133,135,140-142]. Mammalian cells seem to have multiple molecular structures for sensing intracellular iron and oxygen levels of which some also act as metabolic sensors, while the mitochondrion seems to be the central sensing organelle. The process of intracellular oxygen sensing and signaling has been described in great detail recently [143-145] and thus these mechanisms will not be repeated here.

Although the prolyl-hydroxylase domain (PHD)-HIF-oxygen-sensing cascade and the IRP-IRE-signaling machinery are ubiquitously expressed within mammalian organs including the lungs [146,147], the cellular interferences between the two pathways as shown in other organs (e.g., liver and kidneys) have not yet been translated to the lungs. However, the responses of the cardiopulmonary system to alterations of iron- and oxygen availability as reported previously, strongly suggest their presence also within the lungs.

First of all, ferrous iron $\left(\mathrm{Fe}^{2+}\right)$ is a critical co-factor apart from the presence of oxygen, ascorbate, and 2-oxoglutarate (2-OGH) for the function of PHDs (PHD1-3), which act as intracellular oxygen sensors that require iron to regulate HIF-degradation [143]. The PHD2-HIF2-signaling pathway is believed to play an important role in the hypoxic response of the lungs [146] and is affected by alterations in iron availability. In low oxygen conditions, IRP1 activity is reversible reduced while IRP2 activity is increased, which suggests a different role of the two iron regulatory proteins (IRPs) in this context [140]. It was shown that during hypoxic exposure HIF-1 $\alpha$ can interact with the hypoxia response elements (HREs) of the IRP1 5'-regulatory region and down-regulate IRP1 expression (HIF-1 $\alpha$-IRP1-axis) [148]. The increase in the levels of IRP2 upon hypoxic exposure is caused by inhibition of its degradation mediated by the iron- and oxygen-dependent F-box and Leucine Rich Repeat Protein 5 (FBXL5) $[43,149]$. As mentioned earlier, HIF- $2 \alpha$ mRNA has an IRE in its $5^{\prime}$ UTR, allowing the translational regulation of HIF-2 $\alpha$ via IRPs, dependent on intracellular iron availability [48]. The HIF-2 $\alpha$-IRE primarily interacts with IRP1 [150]. The IRP1-HIF-2 $\alpha$-signaling axis is proposed to be one of the most important links between intracellular iron homeostasis and oxygen sensing [151].

We and others [147] speculate that this mechanism also occurs in the lungs and is potentially involved in the response of the pulmonary vasculature and the airways to acute and sustained hypoxia. Early on, it was shown that the exposure of cells to the iron chelator DFO induces HIF- $1 \alpha$ expression [152], suggesting that intracellular iron deficiency has an hypoxia-mimicking effect. It is now well-known that several HIF target genes are involved in the regulation of iron homeostasis. For example, HIFs activate the transcription of genes encoding for TfR1, DMT1, heme oxygenase 1 (HO-1), FPN, and ceruloplasmin [144]. Additionally, during hypoxia, HIF-1 $\alpha$ induces the microRNA miR-210, which represses the iron sulfur cluster units 1 and 2 (ISCU1/2), proteins that facilitate the assembly of Fe-S clusters $[153,154]$. Thus, the miR-210-ISCU1/2-Fe-S cluster axis is proposed to be another important interference pathway between intracellular iron homeostasis and oxygen sensing within the lungs. 


\section{Linking Lung-Related Diseases to Disrupted Lung Iron Homeostasis}

A growing number of acute and chronic lung diseases as well as other diseases with a pathological manifestation within the lung are associated with disrupted lung iron homeostasis, leading to either iron deficiency or iron overload (summarized in Table 1). These diseases were also reviewed by other research groups, albeit with a different primary focus [19,133,135,155-157]. Generally, the lungs are not considered as a primary iron regulating/storing organ, especially in contrast to the liver, the skeletal muscles, the duodenum, the reticuloendothelial system, and the bone marrow including the RBC pool [2]. However, the regulation of iron homeostasis within the mammalian lungs is tightly controlled (iron content range: $0.4-0.9 \mathrm{mg} / \mathrm{g}$ lung tissue according to [155]) in order to maintain proper lung function and also to adapt to changes in iron needs upon changing body conditions, e.g., during exposure to environmental stress as experienced at high altitude. Thus, the iron balance within the lungs is crucial for health and disease. Below we mention selected lung and lung-related diseases in which a link to disturbed iron homeostasis was established. It is beyond the scope of the current review to mention all pulmonary diseases in which iron eventually plays a role.

Table 1. Lung diseases and other diseases with a pathological lung phenotype associated with disturbed iron homeostasis.

\begin{tabular}{ccccc}
\hline Disease & $\begin{array}{c}\text { Primary Lung } \\
\text { Dysfunction }\end{array}$ & $\begin{array}{c}\text { Systemic Iron } \\
\text { Availability }\end{array}$ & $\begin{array}{c}\text { Lung Iron } \\
\text { Availability }\end{array}$ & References \\
\hline Asthma & Obstructive & $\leftrightarrow$ to $\downarrow$ & $\downarrow$ & {$[156,158,159]$} \\
ARDS & Shunt, V/Q mismatch & $\leftrightarrow$ & $\uparrow$ & {$[9,19,156,157,160]$} \\
CF & Obstructive & $\leftrightarrow$ to $\downarrow$ & $\uparrow$ & {$[19,156,161,162]$} \\
CMS & V/Q mismatch & $\leftrightarrow$ to $\downarrow$ & $\downarrow$ & {$[1$} \\
COPD & Obstructive & $\leftrightarrow$ to $\downarrow$ & $\uparrow$ & {$[133,135,163,164]$} \\
HAPE & Diffusion Limitation & $\leftrightarrow$ to $\downarrow$ & $\downarrow$ & {$[157,165,166]$} \\
IPF & Restrictive & $\leftrightarrow$ & $\uparrow$ & {$[156,169]$} \\
Lung CA & N.A. & $\leftrightarrow$ to $\downarrow$ & $\uparrow$ & {$[156,157,171-176]$} \\
PAP & Shunt & $\leftrightarrow$ & $\uparrow$ & {$[19,156,177,178]$} \\
PH & V/Q mismatch & $\leftrightarrow$ to $\downarrow$ & $\downarrow$ & {$[133,135,179-185]$} \\
TM & Restrictive & $\leftrightarrow$ to $\uparrow$ & $\uparrow 1$ & {$[98,100,186-189]$} \\
\hline
\end{tabular}

ARDS: Acute respiratory distress syndrome; CF: Cystic fibrosis; CMS: Chronic mountain sickness; COPD: Chronic obstructive pulmonary disease; HAPE: High-altitude pulmonary edema; IPF: Idiopathic pulmonary fibrosis; Lung CA: Lung cancer; PAP: Pulmonary alveolar proteinosis; PH: Pulmonary hypertension; TM: Thalassemia Major; V/Q mismatch: Ventilation/Perfusion mismatch; N.A.: Not applicable; $\leftrightarrow$ normal iron availability; $\downarrow$ reduced iron availability; $\uparrow$ increased iron availability; ${ }^{1}$ Treatment induced.

\subsection{Acute High-Altitude Illnesses and High-Altitude Pulmonary Edema (HAPE)}

The classical high-altitude illnesses are also comprised under the term 'mountain sickness'. Acute mountain sickness (AMS) is a common manifestation of high-altitude illness and related to a cerebral intolerance to hypoxia. The same is the case in high-altitude cerebral edema (HACE), a severe and life threating condition $[167,190]$. In the lungs, the development of high-altitude pulmonary edema (HAPE) can occur in unacclimatized healthy individuals at high altitude ( $\geq 2500 \mathrm{~m}$ above sea level) within 1-5 days upon arrival $[167,190,191]$. The early clinical symptoms are excessive exertional dyspnea, mild cough, chest tightness, and reduced exercise capacity, which can continue to worsen with dyspnea at rest and cough as the edema progresses. In the advanced stage, it can lead to gurgling sounds in the chest and pink frothy sputum. The chest radiograph shows a patchy to confluent edema distribution. The bronchoalveolar lavage shows protein-rich exudate and mild alveolar hemorrhage. Although the exact pathophysiology is not fully understood, it is widely accepted that HAPE is primarily induced by hemodynamic changes within the pulmonary circuitry $[167,190,191]$. A recent field study reported elevated serum hepcidin levels in HAPE patients exposed to high altitude in comparison to control subjects, that was correlated with higher levels of IL6 [168]. Although no correlation between serum iron levels and pulmonary arterial systolic pressure (PASP) was found in that study, the cellular iron 
availability within the lungs might have been altered in these HAPE patients, which is critical for the hypoxic pulmonary vasoconstriction (HPV) response. Interestingly, the baseline PASP values in the later HAPE patients were already significantly elevated when compared to healthy controls, indicating a different pre-setting of the pulmonary vasculature tone. Of note, C-reactive protein (CRP) levels were also significantly increased in HAPE patients at high altitude, which may have interfered with serum ferritin levels but also other iron parameters and thus these values have to be interpreted with caution [192]. Overall, an a priori iron status check before ascending to high altitude may help mountaineers to optimize the acclimatization process leading to an increased exercise performance and potentially prevent an iron depleted status with eventually negative health consequences at high altitude.

\subsection{Chronic Mountain Sickness (CMS)}

CMS or Monge's disease is a highly prevalent disease in high-altitude residents such as the Andeans, with exception of Tibetans where CMS is very rarely seen [193]. The hallmark characteristics of CMS are accentuated hypoxemia, excessive erythrocytosis (women: $\mathrm{Hb} \geq 190$ $\mathrm{g} / \mathrm{L}$, men: $\mathrm{Hb} \geq 210 \mathrm{~g} / \mathrm{L}$ ), and pulmonary hypertension, which often results in right ventricular enlargement and hypertrophy, and in the later disease stage, leads to chronic heart failure. Therapy usually comprises of regular phlebotomy [163]. Iron deficiency itself, e.g., induced by the iron chelator $\mathrm{DFO}$, is associated with an elevated pulmonary vascular resistance (PVR), as observed during exposure to hypoxia [194]. In this context, two randomized placebo-controlled trials were performed [164]. In the first trial, they showed that a single infusion of iron lead to $40 \%$ reduction of the pulmonary hypertensive response in healthy sea-level residents after exposure to high altitude $(4340 \mathrm{~m}$ above sea level). In the second cross-over trial, they could show that repeated isovolemic venesection ( $2 \mathrm{~L}$ of blood) was associated with a $25 \%$ increase in PASP in CMS patients. Although the subsequent iron replacement did not acutely reverse the effect of iron deficiency on PASP in their setting, the authors argued that the chosen time window might have been too short and further concluded that careful adjustment of iron balance might be a promising strategy to ameliorate the severity in CMS. In summary, it still needs to be proven by future clinical trials whether tight iron status monitoring eventually in combination with therapeutic iron correction improves disease severity and quality of life in CMS patients.

\subsection{Pulmonary Hypertension (PH)}

$\mathrm{PH}$ is a complex pathophysiological state characterized by a mean pulmonary artery pressure above $25 \mathrm{mmHg}$ at rest, assessed by catheterization of the right heart. PH is currently subdivided into five different groups [195] and can lead to pulmonary vascular remodeling, right ventricular hypertrophy, and right heart failure (for further detailed clinical information, see $[179,196])$. A central role of an imbalance between iron homeostasis and oxygen sensing in the pathophysiology of $\mathrm{PH}$ was recently discussed $[180,181]$. The authors proposed a model of combined inflammation driven (via the IL-6-STAT3-hepcidin axis) iron deficiency and exaggerated activation of HIFs. In line with this, it was shown that IRP1 ${ }^{-/-}$mice develop polycythemia and $\mathrm{PH}$ via translational de-repression of HIF- $2 \alpha$ [182]. Moreover, the same authors also reported that the cultured pulmonary endothelial cells of IRP1 ${ }^{-/-}$mice showed elevated HIF- $2 \alpha$ expression levels. Additionally, rats fed on an iron deficient diet have higher levels of HIF- $1 \alpha$ and HIF- $2 \alpha$ in the lungs, which was associated with an increased pulmonary artery pressure (PAP) and pulmonary vascular resistance [197]. In humans, it was reported that iron deficiency is quite common in idiopathic $\mathrm{PH}$ patients [183]. Recent association studies between iron deficiency and $\mathrm{PH}$ prevalence suggest that the $\mathrm{PH}$-subtype and eventually also ethnicity may play role in this context $[198,199]$. These studies together, with the previously reported applied lab studies [132] and clinical trials in humans [164,200], clearly suggest a protective effect of iron against $\mathrm{PH}$ and hypoxia-related diseases. 
On the contrary, strong positive iron shifts, e.g., in iron overload conditions seem to induce opposite effects, potentially via increased oxidative stress [201]. Indeed, a very recent animal study found that chronic iron overload of rats via daily iron-dextran injections (i.p.) for 28 days induced vascular hyperreactivity and inward remodeling of pulmonary arteries, as well as heart dysfunction [202]. Interestingly, it was recently found that miR-210 was up-regulated in several $\mathrm{PH}$ animal models and that the inhibition of mir-210 significantly reduced pulmonary pressure and vascular remodeling in a PH animal model [203], further suggesting a significant role of the miR210-ISCU1/2-Fe-S cluster axis in the PH pathophysiology [184]. Although the lungs seem to have a well-balanced 'buffer capacity' for iron, an excessive disruption of iron balance in either direction has detrimental consequences on cardiopulmonary function. Overall, iron homeostasis and HIF oxygen-sensing seem to be crucial in the pathology of $\mathrm{PH}$. Accordingly, therapeutic modifications of these interacting signaling pathways hold great promise for $\mathrm{PH}$ patients.

\subsection{Chronic Obstructive Pulmonary Disease (COPD)}

COPD is meanwhile the third leading cause of death worldwide, inducing a significant global socioeconomic burden. Tobacco smoking is the most well-known risk factor for the development of COPD and also for lung cancer. COPD is typically marked by chronic respiratory symptoms and airflow limitations, which are caused by small airways disease and parenchymal destruction (emphysema). The key symptoms of COPD are shortness of breath and dyspnea, as well as chronic cough and sputum $[165,204]$. COPD pathophysiology is complex, however chronic systemic inflammation potentially triggered by cigarette-induced ROS formation is suspected to be a central aspect of it [205]. Considering the main cause (cigarette smoke) and patho-mechanism (chronic inflammation), it is highly suggestive that COPD is also linked to a disturbance of iron homeostasis. The special setting in COPD of local iron containing and non-containing particle load of airways and potential systemic iron deficiency would suggest a shift towards a mixed iron status. Importantly, cigarette smoke not only contains a certain quantity of iron particles but also over 4000 chemicals of which 100 are known carcinogens and 900 suspected carcinogens. A recent large cohort study found that in both smokers and non-smokers, certain markers of iron homeostasis, such as serum ferritin concentration, serum iron concentration, and transferrin saturation, were associated with critical parameters of lung function (e.g., positive correlation for all three markers in both groups combined with forced vital capacity and forced expiratory capacity) [206]. Another indicator for the presence of disrupted iron homeostasis is the high prevalence of anemia and systemic iron deficiency in COPD patients. The prevalence of anemia in two different cohorts of COPD patients ranged between $23 \%$ to $33 \%[207,208]$. In another COPD patient cohort, it was found that iron deficiency was associated with an increased frequency of self-reported exacerbations and reduced exercise capacity [209].

It has been recently proposed that in patients with COPD, pro-inflammatory cytokines (e.g., IL-6) trigger increased hepatic hepcidin expression and secretion [155]. This causes FPN degradation and subsequently reduces cellular iron export into the blood stream, likely resulting in the systemic iron deficiency and anemia observed in these patients. On the other hand, alveolar macrophages from COPD patients were shown to accumulate iron and the percentage of iron-loaded macrophages increased with disease severity [11]. Another team demonstrated that IRP2 ${ }^{-/-}$mice were protected from cigarette smoke-induced experimental COPD [166]. These authors also demonstrated that IRP2 increased mitochondrial iron content and concentrations of cytochrome c oxidase (COX), resulting in impaired mitochondrial function and subsequently COPD in cigarette smoke-exposed mice. On the contrary, mitochondrial iron chelator or a low-iron diet protected mice from cigarette-induced COPD. Overall, regular monitoring of iron status and eventual therapeutic modulation of local and systemic iron homeostasis may avoid the negative consequences of lung iron overload and systemic iron deficiency in COPD patients. 


\subsection{Asthma}

Asthma and COPD belong to the subgroup of obstructive pulmonary diseases [158]. The potential role of a disrupted iron homeostasis in asthma was reviewed in great detail recently [159]. Briefly, the author reported profound evidence of disturbed iron homeostasis in asthma by systematically evaluating the known demographic (e.g., ethnicity), physiologic (e.g., exercise), and pathologic (e.g., infections) asthma determinants in the context of iron availability and concluded a setting of absolute or functional iron deficiency in asthma, which may have therapeutic implications in the future.

\subsection{Cystic Fibrosis (CF)}

$\mathrm{CF}$ is a severe genetic pulmonary disorder triggered by impaired function of the anion transporter CF transmembrane conductance regulator (CFTR) that results in increased secretion of abnormally viscous mucus and at the clinical level, CF is characterized by chronic bacterial airway infection (e.g., Pseudomonas aeruginosa), prominent neutrophilic inflammation, mucus accumulation within the airways, and progressive bronchiectasis (formation of irreversible airway enlargements). The structural changes within the lungs can be visible early using chest imaging. The host-defense defect in the airways of CF patients plays a central role in the disease pathophysiology and leads to chronic airway infections with inflammatory driven airway remodeling [161]. Evidence of disturbed iron homeostasis in CF was found in experimental CF models and also in humans suffering from CF; a setting of systemic iron deficiency and abnormal local iron sequestration within the airway cells were reported [156]. Indeed, elevated iron levels were found in the bronchoalveolar lavage, sputum, macrophages, and in explanted lung tissue from CF patients compared to healthy controls [162]. Furthermore, an increased expression of ferritin, DMT1, and FPN was found in the lung tissue of these patients. Overall, the reported disruption of host iron homeostasis within the lungs of CF patients might be a therapeutic target, especially to reduce chronic airway infections [210]. Alternatively, a recent study showed that it is also possible to directly target bacterial iron homeostasis to control airway P. aeruginosa infections via the administration of the metal gallium [211]. Gallium is taken up by bacteria instead of iron because bacterial uptake systems cannot differentiate between them. Gallium is then incorporated into iron-containing proteins, but, since it cannot be reduced under physiological conditions, it impairs their normal activity and therefore bacterial survival and proliferation.

\subsection{Lung Cancer}

As iron is an indispensable component for cell metabolism, proliferation, and growth, it is equally crucial for tumor metabolism, tumor proliferation, and tumor growth [171]. In fact, population-based studies suggest that higher levels of overall body iron are linked to a higher risk of developing cancer [172]. In particular, subjects with transferrin saturation level above $60 \%$ were reported to have increased risk to develop lung cancer [212]. It was proposed that cancer cells reprogram their cellular iron metabolism towards an increase in cellular iron uptake and decrease of iron export [172]. Briefly, cancer cells increase iron uptake by increasing the expression of TfR 1 and also via increased secretion of lipocalin-2. Tumour cells expressing TfR1 were detected in $88 \%$ of patients with non-small-cell lung cancer (NSCLC), while TfR1 was not detected in the tumor stroma [173]. Furthermore, it was shown that the microRNA miR-20a is inversely correlated with FPN expression in NSCLC cells and that low cellular FPN expression stimulates tumor cell proliferation and colony formation, potentially via increased cellular iron availability [174]. In parallel, a reduction in FPN protein levels in tumor cells might also result from increased hepcidin expression in these cells, probably acting in an autocrine manner [172]. Together, these modifications of cellular iron homeostasis lead to an increased labile iron pool (LIP) within cancer cells.

The role of the IRE/IRP system in regulating intracellular iron levels in tumor cells is still incompletely understood [172]. However, it is worth mentioning that IRP2 was suggested to have pro-oncogenic activity in lung cancers based on tumor tissue microarray analyses [175]. Lung 
adenocarcinomas, as numerous other cancers, induce tumor-associated inflammation, a mechanism that is triggered by activating central inflammatory pathways, such as the NFKB-signaling pathway. $\mathrm{NFKB}$ signaling is important for tumor cell proliferation, apoptosis, metabolism, as well as for tumor angiogenesis and metastasis. NFKB itself can induce the HIF-signaling pathway in both, normoxic and hypoxic conditions. Conversely, HIFs can modulate NFKB-signaling in a bidirectional manner [213].

Overall, the strong iron dependency of lung cancer offers the opportunity for treatment interventions that target iron availability (e.g., iron chelators); however, future pre-clinical and clinical studies are needed to address this potential treatment. In a different perspective, iron modulation in tumor-associated macrophages (TAMs) might also emerge as a possible therapeutic target. Recent studies indicate that the iron loading of TAMs can differentiate them towards a pro-inflammatory phenotype and inhibit tumour growth $[176,214]$. Supporting this idea, the presence of iron loaded TAMs correlates with reduced tumor size in patients with non-small cell lung cancer [176].

\subsection{Other Diseases}

Acute respiratory distress syndrome (ARDS) is clinically characterized by severe hypoxemia resulting from pulmonary gas exchange failure [160]. A potential source of iron in ARDS may derive from 'low grade bleeding' and hemorrhage, which might be present in certain subsets of this heterogenous pathological lung condition [215]. Analysis of the bronchoalveolar lavage of patients suffering from ARDS revealed the presence of higher levels of iron and iron-related proteins, such as ferritin, lactoferrin, and transferrin, likely reflect disturbances in lung iron homeostasis [9]. Similarly, patients with pulmonary alveolar proteinosis (PAP), a disease defined by severe accumulation of surfactant in the airspaces and hypoxemia [177], also present higher concentrations of iron, ferritin, transferrin, and lactoferrin in the bronchoalveolar lavage [178]. Finally, patients with idiopathic pulmonary fibrosis (IPF), a restrictive lung disease with a prominent gas diffusion limitation [169], have a higher frequency of HFE allelic variants associated with the iron overload disease hemochromatosis, when compared to healthy controls [170]. Hemosiderin accumulation in alveolar macrophages was increased in these patients. Whether these alterations in pulmonary iron homeostasis contribute to the pathology of these diseases is still unknown.

Pulmonary dysfunction, in particular restrictive lung disease, is frequently observed in patients with thalassemia major (TM), a disease characterized by severe iron accumulation [186-189]. It has been speculated that abnormal lung function in those patients might be a consequence of chronic iron overload [189]. Supporting this hypothesis, a restrictive pattern was observed in a mouse model of iron overload, caused by a mutation in FPN that confers resistance to hepcidin binding [56]. In addition to thalassemia, other hemolytic diseases, such as sickle cell disease, are also associated with increased susceptibility to pulmonary diseases and abnormal lung function [216-218]. However, future studies are needed to fully understand the impact of iron overload in lung function in humans and whether additional factors such as hemoglobin and heme release in these hemoglobinopathies contribute for the lung disorders observed in these patients.

\section{Therapeutic Potential of Iron Modulation}

The profound numbers of lung diseases associated with disrupted iron homeostasis offer a great potential for the therapeutic careful use of iron modulators. Before corrective interventions can be applied in patients, we require a better knowledge of iron's role in pulmonary disease and markers to properly evaluate the systemic and pulmonary iron status. Currently, dietary interventions, phlebotomy, blood and iron infusions, as well as iron chelator treatment, are used to correct systemic disturbances of iron homeostasis. For example, blood infusions and iron-chelation therapy are standard in the treatment of hemolytic anemias. In PH patients, the therapeutic correction of the frequently observed iron deficiency may ameliorate the disease outcome and clinical trials are ongoing to further investigate this potential [180]. The first trial results seem to support this concept, however so far only for the idiopathic PH-subtype [185]. 
Future approaches will directly target regulatory molecules of iron metabolism by applying small agonistic/antagonistic molecules. It is tempting to speculate that such molecules might be applied by inhalation. For example, hepcidin as the major regulator of iron metabolism and its receptor FPN are promising targets for future drug development [219]. Indeed, hepcidin agonists are currently under development to treat iron overload diseases such as hereditary hemochromatosis. On the other hand, hepcidin antagonists are developed to treat inflammation-induced anemias.

Moreover, diseases such as COPD that are characterized by systemic iron deficiency and lung iron accumulation would benefit from a more specific strategy. For example, inhalation of chelators (or iron sources, in case of lung iron deficiency) would have the potential to directly modulate pulmonary iron homeostasis while hopefully having no or only a mild effect on systemic iron homeostasis. Apart from direct targeting of regulators of iron metabolism, indirect targeting of signaling pathways, such as the HIFs, may be an option [220,221]. In summary, therapeutic possibilities to control iron metabolism are widespread, and the pros and cons of these novel therapeutic approaches need to be carefully evaluated.

\section{Conclusion and Outlook}

In healthy conditions, pulmonary iron homeostasis is tightly controlled to maintain proper lung function. In environmental (e.g., high-altitude exposure) and behavioral (e.g., exercise) stress conditions it requires adaptation. Importantly, numerous acute and chronic respiratory diseases are associated with disrupted iron homeostasis in the lungs. The close cellular interaction between iron regulatory pathways via IREs/IRPs or hepcidin/ferroportin and the oxygen sensing pathway via HIFs seems to be critical for healthy adaption but also for pathologic maladaptation within the lungs. Enormous progress has been made in our molecular understanding of these pathways and their suppression and/or enhancement. However, this knowledge currently needs to be applied to the lung. An improved understanding of iron trafficking and storage in the lung and its role in lung disease onset and progression will improve interventional modification of iron homeostasis within the lungs via iron-modulators.

Author Contributions: J.N. and T.H. conceptualized the article; J.N., T.H., M.G. and M.U.M. wrote and reviewed the manuscript.

Funding: M.U.M. received funding from the German Center for Lung Research (DZL). M.G. received funding from the Swiss National Science Foundation (SNSF) and from the Stiftung für wissenschaftliche Forschung an der Universität Zürich.

Acknowledgments: The authors kindly thank J. Peter and P. A. Lawan for making excellent art out of our hand-drawn figures.

Conflicts of Interest: The authors declare no conflict of interest.

\section{References}

1. Muckenthaler, M.U.; Rivella, S.; Hentze, M.W.; Galy, B. A Red Carpet for Iron Metabolism. Cell 2017, 168, 344-361. [CrossRef]

2. Geissler, C.; Singh, M. Iron, meat and health. Nutrients 2011, 3, 283-316. [CrossRef] [PubMed]

3. Ilbert, M.; Bonnefoy, V. Insight into the evolution of the iron oxidation pathways. Biochim. Biophys. Acta 2013, 1827, 161-175. [CrossRef]

4. Papanikolaou, G.; Pantopoulos, K. Iron metabolism and toxicity. Toxicol. Appl. Pharmacol. 2005, 202, $199-211$. [CrossRef]

5. Ganz, T. Macrophages and systemic iron homeostasis. J. Innate Immun. 2012, 4, 446-453. [CrossRef] [PubMed]

6. Ganz, T.; Nemeth, E. Hepcidin and iron homeostasis. Biochim. Biophys. Acta 2012, 1823, 1434-1443. [CrossRef] [PubMed]

7. Nemeth, E.; Tuttle, M.S.; Powelson, J.; Vaughn, M.B.; Donovan, A.; Ward, D.M.; Ganz, T.; Kaplan, J. Hepcidin regulates cellular iron efflux by binding to ferroportin and inducing its internalization. Science 2004, 306, 2090-2093. [CrossRef] 
8. Qiao, B.; Sugianto, P.; Fung, E.; Del-Castillo-Rueda, A.; Moran-Jimenez, M.-J.; Ganz, T.; Nemeth, E. Hepcidin-induced endocytosis of ferroportin is dependent on ferroportin ubiquitination. Cell Metab. 2012, 15, 918-924. [CrossRef]

9. Ghio, A.J.; Carter, J.D.; Richards, J.H.; Richer, L.D.; Grissom, C.K.; Elstad, M.R. Iron and iron-related proteins in the lower respiratory tract of patients with acute respiratory distress syndrome. Crit. Care Med. 2003, 31, 395-400. [CrossRef]

10. Reid, D.W.; Carroll, V.; O'May, C.; Champion, A.; Kirov, S.M. Increased airway iron as a potential factor in the persistence of Pseudomonas aeruginosa infection in cystic fibrosis. Eur. Respir. J. 2007, 30, 286-292. [CrossRef]

11. Philippot, Q.; Deslée, G.; Adair-Kirk, T.L.; Woods, J.C.; Byers, D.; Conradi, S.; Dury, S.; Perotin, J.M.; Lebargy, F.; Cassan, C.; et al. Increased Iron Sequestration in Alveolar Macrophages in Chronic Obtructive Pulmonary Disease. PLoS ONE 2014, 9, e96285. [CrossRef] [PubMed]

12. Ghio, A.J.; Stoneheurner, J.; McGee, J.K.; Kinsey, J.S. Sulfate content correlates with iron concentrations in ambient air pollution particles. Inhal. Toxicol. 1999, 11, 293-307. [PubMed]

13. Mahowald, N.M.; Engelstaedter, S.; Luo, C.; Sealy, A.; Artaxo, P.; Benitez-Nelson, C.; Bonnet, S.; Chen, Y.; Chuang, P.Y.; Cohen, D.D.; et al. Atmospheric iron deposition: Global distribution, variability, and human perturbations. Annu. Rev. Mar. Sci. 2009, 1, 245-278. [CrossRef] [PubMed]

14. Cross, C.E.; van der Vliet, A.; O'Neill, C.A.; Louie, S.; Halliwell, B. Oxidants, antioxidants, and respiratory tract lining fluids. Environ. Health Perspect. 1994, 102 (Suppl. 10), 185-191. [PubMed]

15. Szabó, S.; Barbu, Z.; Lakatos, L.; László, I.; Szabó, A. Local production of proteins in normal human bronchial secretion. Respir. Int. Rev. Thorac. Dis. 1980, 39, 172-178. [CrossRef] [PubMed]

16. Ganz, T. Antimicrobial polypeptides in host defense of the respiratory tract. J. Clin. Invest. 2002, 109, 693-697. [CrossRef] [PubMed]

17. Ghio, A.J.; Carter, J.D.; Dailey, L.A.; Devlin, R.B.; Samet, J.M. Respiratory epithelial cells demonstrate lactoferrin receptors that increase after metal exposure. Am. J. Physiol. 1999, 276, L933-L940. [CrossRef]

18. Arosio, P.; Levi, S. Cytosolic and mitochondrial ferritins in the regulation of cellular iron homeostasis and oxidative damage. Biochim. Biophys. Acta 2010, 1800, 783-792. [CrossRef]

19. Ghio, A.J. Disruption of iron homeostasis and lung disease. Biochim. Biophys. Acta 2009, 1790, 731-739. [CrossRef]

20. Bailie, G.R.; Schuler, C.; Leggett, R.E.; Li, H.; Li, H.-D.; Patadia, H.; Levin, R. Oxidative effect of several intravenous iron complexes in the rat. Biometals Int. J. Role Met. Ions Biol. Biochem. Med. 2013, 26, 473-478. [CrossRef]

21. Sadeghi, L.; Yousefi Babadi, V.; Espanani, H.R. Toxic effects of the Fe2O3 nanoparticles on the liver and lung tissue. Bratisl. Lek. Listy 2015, 116, 373-378. [CrossRef]

22. Skaar, E.P. The battle for iron between bacterial pathogens and their vertebrate hosts. PLoS Pathog. 2010, 6, e1000949. [CrossRef] [PubMed]

23. Ganz, T. Iron in innate immunity: Starve the invaders. Curr. Opin. Immunol. 2009, 21, 63-67. [CrossRef] [PubMed]

24. Nemeth, E.; Rivera, S.; Gabayan, V.; Keller, C.; Taudorf, S.; Pedersen, B.K.; Ganz, T. IL-6 mediates hypoferremia of inflammation by inducing the synthesis of the iron regulatory hormone hepcidin. J. Clin. Investig. 2004, 113, 1271-1276. [CrossRef] [PubMed]

25. Guida, C.; Altamura, S.; Klein, F.A.; Galy, B.; Boutros, M.; Ulmer, A.J.; Hentze, M.W.; Muckenthaler, M.U. A novel inflammatory pathway mediating rapid hepcidin-independent hypoferremia. Blood 2015, 125, 2265-2275. [CrossRef] [PubMed]

26. Liu, X.-B.; Nguyen, N.-B.H.; Marquess, K.D.; Yang, F.; Haile, D.J. Regulation of hepcidin and ferroportin expression by lipopolysaccharide in splenic macrophages. Blood Cells Mol. Dis. 2005, 35, 47-56. [CrossRef] [PubMed]

27. Peyssonnaux, C.; Zinkernagel, A.S.; Datta, V.; Lauth, X.; Johnson, R.S.; Nizet, V. TLR4-dependent hepcidin expression by myeloid cells in response to bacterial pathogens. Blood 2006, 107, 3727-3732. [CrossRef]

28. Arezes, J.; Jung, G.; Gabayan, V.; Valore, E.; Ruchala, P.; Gulig, P.A.; Ganz, T.; Nemeth, E.; Bulut, Y. Hepcidin-induced hypoferremia is a critical host defense mechanism against the siderophilic bacterium Vibrio vulnificus. Cell Host Microbe 2015, 17, 47-57. [CrossRef]

29. Bullen, J.J.; Spalding, P.B.; Ward, C.G.; Gutteridge, J.M. Hemochromatosis, iron and septicemia caused by Vibrio vulnificus. Arch. Intern. Med. 1991, 151, 1606-1609. [CrossRef] 
30. Khan, F.A.; Fisher, M.A.; Khakoo, R.A. Association of hemochromatosis with infectious diseases: Expanding spectrum. Int. J. Infect. Dis. 2007, 11, 482-487. [CrossRef]

31. Sazawal, S.; Black, R.E.; Ramsan, M.; Chwaya, H.M.; Stoltzfus, R.J.; Dutta, A.; Dhingra, U.; Kabole, I.; Deb, S.; Othman, M.K.; et al. Effects of routine prophylactic supplementation with iron and folic acid on admission to hospital and mortality in preschool children in a high malaria transmission setting: community-based, randomised, placebo-controlled trial. Lancet 2006, 367, 133-143. [CrossRef]

32. Smith, D.J.; Lamont, I.L.; Anderson, G.J.; Reid, D.W. Targeting iron uptake to control Pseudomonas aeruginosa infections in cystic fibrosis. Eur. Respir. J. 2013, 42, 1723-1736. [CrossRef] [PubMed]

33. Singh, P.K.; Parsek, M.R.; Greenberg, E.P.; Welsh, M.J. A component of innate immunity prevents bacterial biofilm development. Nature 2002, 417, 552-555. [CrossRef] [PubMed]

34. O'May, C.Y.; Sanderson, K.; Roddam, L.F.; Kirov, S.M.; Reid, D.W. Iron-binding compounds impair Pseudomonas aeruginosa biofilm formation, especially under anaerobic conditions. J. Med. Microbiol. 2009, 58, 765-773. [CrossRef] [PubMed]

35. Wander, K.; Shell-Duncan, B.; Brindle, E. Lower incidence of respiratory infections among iron-deficient children in Kilimanjaro, Tanzania. Evol. Med. Public Health 2017, 2017, 109-119. [CrossRef] [PubMed]

36. Gangaidzo, I.T.; Moyo, V.M.; Mvundura, E.; Aggrey, G.; Murphree, N.L.; Khumalo, H.; Saungweme, T.; Kasvosve, I.; Gomo, Z.A.; Rouault, T.; et al. Association of pulmonary tuberculosis with increased dietary iron. J. Infect. Dis. 2001, 184, 936-939. [CrossRef]

37. Baz, M.A.; Ghio, A.J.; Roggli, V.L.; Tapson, V.F.; Piantadosi, C.A. Iron accumulation in lung allografts after transplantation. Chest 1997, 112, 435-439. [CrossRef] [PubMed]

38. Pugh, C.; Hathwar, V.; Richards, J.H.; Stonehuerner, J.; Ghio, A.J. Disruption of iron homeostasis in the lungs of transplant patients. J. Heart Lung Transplant. Off. Publ. Int. Soc. Heart Transplant. 2005, 24, 1821-1827. [CrossRef]

39. Hsu, J.L.; Manouvakhova, O.V.; Clemons, K.V.; Inayathullah, M.; Tu, A.B.; Sobel, R.A.; Tian, A.; Nazik, H.; Pothineni, V.R.; Pasupneti, S.; et al. Microhemorrhage-associated tissue iron enhances the risk for Aspergillus fumigatus invasion in a mouse model of airway transplantation. Sci. Transl. Med. 2018, 10, eaag2616. [CrossRef]

40. Wu, H.; Santoni-Rugiu, E.; Ralfkiaer, E.; Porse, B.T.; Moser, C.; Høiby, N.; Borregaard, N.; Cowland, J.B. Lipocalin 2 is protective against E. coli pneumonia. Respir. Res. 2010, 11, 96. [CrossRef]

41. Bachman, M.A.; Miller, V.L.; Weiser, J.N. Mucosal lipocalin 2 has pro-inflammatory and iron-sequestering effects in response to bacterial enterobactin. PLoS Pathog. 2009, 5, e1000622. [CrossRef] [PubMed]

42. Muckenthaler, M.U.; Galy, B.; Hentze, M.W. Systemic iron homeostasis and the iron-responsive element/iron-regulatory protein (IRE/IRP) regulatory network. Annu. Rev. Nutr. 2008, 28, 197-213. [CrossRef]

43. Anderson, C.P.; Shen, M.; Eisenstein, R.S.; Leibold, E.A. Mammalian iron metabolism and its control by iron regulatory proteins. Biochim. Biophys. Acta 2012, 1823, 1468-1483. [CrossRef] [PubMed]

44. Hentze, M.W.; Caughman, S.W.; Rouault, T.A.; Barriocanal, J.G.; Dancis, A.; Harford, J.B.; Klausner, R.D. Identification of the iron-responsive element for the translational regulation of human ferritin mRNA. Science 1987, 238, 1570-1573. [CrossRef] [PubMed]

45. Muckenthaler, M.; Gray, N.K.; Hentze, M.W. IRP-1 binding to ferritin mRNA prevents the recruitment of the small ribosomal subunit by the cap-binding complex eIF4F. Mol. Cell 1998, 2, 383-388. [CrossRef]

46. Donovan, A.; Brownlie, A.; Zhou, Y.; Shepard, J.; Pratt, S.J.; Moynihan, J.; Paw, B.H.; Drejer, A.; Barut, B.; Zapata, A.; et al. Positional cloning of zebrafish ferroportin1 identifies a conserved vertebrate iron exporter. Nature 2000, 403, 776-781. [CrossRef] [PubMed]

47. McKie, A.T.; Marciani, P.; Rolfs, A.; Brennan, K.; Wehr, K.; Barrow, D.; Miret, S.; Bomford, A.; Peters, T.J.; Farzaneh, F; et al. A novel duodenal iron-regulated transporter, IREG1, implicated in the basolateral transfer of iron to the circulation. Mol. Cell 2000, 5, 299-309. [CrossRef]

48. Sanchez, M.; Galy, B.; Muckenthaler, M.U.; Hentze, M.W. Iron-regulatory proteins limit hypoxia-inducible factor-2alpha expression in iron deficiency. Nat. Struct. Mol. Biol. 2007, 14, 420-426. [CrossRef] [PubMed]

49. Casey, J.L.; Hentze, M.W.; Koeller, D.M.; Caughman, S.W.; Rouault, T.A.; Klausner, R.D.; Harford, J.B. Iron-responsive elements: Regulatory RNA sequences that control mRNA levels and translation. Science 1988, 240, 924-928. [CrossRef] 
50. Müllner, E.W.; Kühn, L.C. A stem-loop in the 3' untranslated region mediates iron-dependent regulation of transferrin receptor mRNA stability in the cytoplasm. Cell 1988, 53, 815-825. [CrossRef]

51. Gunshin, H.; Allerson, C.R.; Polycarpou-Schwarz, M.; Rofts, A.; Rogers, J.T.; Kishi, F.; Hentze, M.W.; Rouault, T.A.; Andrews, N.C.; Hediger, M.A. Iron-dependent regulation of the divalent metal ion transporter. FEBS Lett. 2001, 509, 309-316. [CrossRef]

52. Haile, D.J.; Rouault, T.A.; Harford, J.B.; Kennedy, M.C.; Blondin, G.A.; Beinert, H.; Klausner, R.D. Cellular regulation of the iron-responsive element binding protein: Disassembly of the cubane iron-sulfur cluster results in high-affinity RNA binding. Proc. Natl. Acad. Sci. USA 1992, 89, 11735-11739. [CrossRef] [PubMed]

53. Haile, D.J.; Rouault, T.A.; Tang, C.K.; Chin, J.; Harford, J.B.; Klausner, R.D. Reciprocal control of RNA-binding and aconitase activity in the regulation of the iron-responsive element binding protein: Role of the iron-sulfur cluster. Proc. Natl. Acad. Sci. USA 1992, 89, 7536-7540. [CrossRef] [PubMed]

54. Iwai, K.; Klausner, R.D.; Rouault, T.A. Requirements for iron-regulated degradation of the RNA binding protein, iron regulatory protein 2. EMBO J. 1995, 14, 5350-5357. [CrossRef]

55. Deschemin, J.-C.; Mathieu, J.R.R.; Zumerle, S.; Peyssonnaux, C.; Vaulont, S. Pulmonary Iron Homeostasis in Hepcidin Knockout Mice. Front. Physiol. 2017, 8, 804. [CrossRef] [PubMed]

56. Neves, J.; Leitz, D.; Kraut, S.; Brandenberger, C.; Agrawal, R.; Weissmann, N.; Mühlfeld, C.; Mall, M.A.; Altamura, S.; Muckenthaler, M.U. Disruption of the Hepcidin/Ferroportin Regulatory System Causes Pulmonary Iron Overload and Restrictive Lung Disease. EBioMedicine 2017, 20, 230-239. [CrossRef]

57. Gunshin, H.; Mackenzie, B.; Berger, U.V.; Gunshin, Y.; Romero, M.F.; Boron, W.F.; Nussberger, S.; Gollan, J.L.; Hediger, M.A. Cloning and characterization of a mammalian proton-coupled metal-ion transporter. Nature 1997, 388, 482-488. [CrossRef]

58. McKie, A.T.; Barrow, D.; Latunde-Dada, G.O.; Rolfs, A.; Sager, G.; Mudaly, E.; Mudaly, M.; Richardson, C.; Barlow, D.; Bomford, A.; et al. An iron-regulated ferric reductase associated with the absorption of dietary iron. Science 2001, 291, 1755-1759. [CrossRef]

59. Brain, J.D.; Heilig, E.; Donaghey, T.C.; Knutson, M.D.; Wessling-Resnick, M.; Molina, R.M. Effects of iron status on transpulmonary transport and tissue distribution of Mn and Fe. Am. J. Respir. Cell Mol. Biol. 2006, 34, 330-337. [CrossRef]

60. Turi, J.L.; Wang, X.; McKie, A.T.; Nozik-Grayck, E.; Mamo, L.B.; Crissman, K.; Piantadosi, C.A.; Ghio, A.J. Duodenal cytochrome b: A novel ferrireductase in airway epithelial cells. Am. J. Physiol. Lung Cell. Mol. Physiol. 2006, 291, L272-L280. [CrossRef]

61. Lee, P.L.; Gelbart, T.; West, C.; Halloran, C.; Beutler, E. The human Nramp2 gene: Characterization of the gene structure, alternative splicing, promoter region and polymorphisms. Blood Cells. Mol. Dis. 1998, 24, 199-215. [CrossRef] [PubMed]

62. Hubert, N.; Hentze, M.W. Previously uncharacterized isoforms of divalent metal transporter (DMT)-1: Implications for regulation and cellular function. Proc. Natl. Acad. Sci. USA 2002, 99, 12345-12350. [CrossRef] [PubMed]

63. Giorgi, G.; D'Anna, M.C.; Roque, M.E. Iron homeostasis and its disruption in mouse lung in iron deficiency and overload. Exp. Physiol. 2015, 100, 1199-1216. [CrossRef] [PubMed]

64. Ghio, A.J.; Piantadosi, C.A.; Wang, X.; Dailey, L.A.; Stonehuerner, J.D.; Madden, M.C.; Yang, F.; Dolan, K.G.; Garrick, M.D.; Garrick, L.M. Divalent metal transporter-1 decreases metal-related injury in the lung. Am. J. Physiol. Lung Cell. Mol. Physiol. 2005, 289, L460-L467. [CrossRef] [PubMed]

65. Jenkitkasemwong, S.; Wang, C.-Y.; Coffey, R.; Zhang, W.; Chan, A.; Biel, T.; Kim, J.-S.; Hojyo, S.; Fukada, T.; Knutson, M.D. SLC39A14 Is Required for the Development of Hepatocellular Iron Overload in Murine Models of Hereditary Hemochromatosis. Cell Metab. 2015, 22, 138-150. [CrossRef] [PubMed]

66. Wang, C.-Y.; Jenkitkasemwong, S.; Duarte, S.; Sparkman, B.K.; Shawki, A.; Mackenzie, B.; Knutson, M.D. ZIP8 is an iron and zinc transporter whose cell-surface expression is up-regulated by cellular iron loading. J. Biol. Chem. 2012, 287, 34032-34043. [CrossRef] [PubMed]

67. Gálvez-Peralta, M.; He, L.; Jorge-Nebert, L.F.; Wang, B.; Miller, M.L.; Eppert, B.L.; Afton, S.; Nebert, D.W. ZIP8 zinc transporter: Indispensable role for both multiple-organ organogenesis and hematopoiesis in utero. PloS ONE 2012, 7, e36055. [CrossRef]

68. Smith, A.; McCulloh, R.J. Hemopexin and haptoglobin: Allies against heme toxicity from hemoglobin not contenders. Front. Physiol. 2015, 6, 187. [CrossRef] 
69. Smith, A.; Morgan, W.T. Transport of heme by hemopexin to the liver: Evidence for receptor-mediated uptake. Biochem. Biophys. Res. Commun. 1978, 84, 151-157. [CrossRef]

70. Smith, A.; Morgan, W.T. Haem transport to the liver by haemopexin. Receptor-mediated uptake with recycling of the protein. Biochem. J. 1979, 182, 47-54. [CrossRef]

71. Liem, H.H. Hepatic uptake of heme and hemopexin but not albumin. Biochim. Biophys. Acta 1974, 343, 546-550. [CrossRef]

72. Ship, N.J.; Toprak, A.; Lai, R.P.; Tseng, E.; Kluger, R.; Pang, K.S. Binding of acellular, native and cross-linked human hemoglobins to haptoglobin: Enhanced distribution and clearance in the rat. Am. J. Physiol. Gastrointest. Liver Physiol. 2005, 288, G1301-G1309. [CrossRef] [PubMed]

73. Van Gorp, H.; Delputte, P.L.; Nauwynck, H.J. Scavenger receptor CD163, a Jack-of-all-trades and potential target for cell-directed therapy. Mol. Immunol. 2010, 47, 1650-1660. [CrossRef] [PubMed]

74. Pinilla-Vera, M.; Xiong, Z.; Zhao, Y.; Zhao, J.; Donahoe, M.P.; Barge, S.; Horne, W.T.; Kolls, J.K.; McVerry, B.J.; Birukova, A.; et al. Full Spectrum of LPS Activation in Alveolar Macrophages of Healthy Volunteers by Whole Transcriptomic Profiling. PLoS ONE 2016, 11, e0159329. [CrossRef] [PubMed]

75. Simões, R.L.; Arruda, M.A.; Canetti, C.; Serezani, C.H.; Fierro, I.M.; Barja-Fidalgo, C. Proinflammatory responses of heme in alveolar macrophages: Repercussion in lung hemorrhagic episodes. Mediators Inflamm. 2013. [CrossRef] [PubMed]

76. Hualin, C.; Wenli, X.; Dapeng, L.; Xijing, L.; Xiuhua, P.; Qingfeng, P. The anti-inflammatory mechanism of heme oxygenase-1 induced by hemin in primary rat alveolar macrophages. Inflammation 2012, 35, 1087-1093. [CrossRef] [PubMed]

77. Ghio, A.J.; Carter, J.D.; Richards, J.H.; Brighton, L.E.; Lay, J.C.; Devlin, R.B. Disruption of normal iron homeostasis after bronchial instillation of an iron-containing particle. Am. J. Physiol. 1998, 274, L396-L403. [CrossRef] [PubMed]

78. Dowdle, W.E.; Nyfeler, B.; Nagel, J.; Elling, R.A.; Liu, S.; Triantafellow, E.; Menon, S.; Wang, Z.; Honda, A.; Pardee, G.; et al. Selective VPS34 inhibitor blocks autophagy and uncovers a role for NCOA4 in ferritin degradation and iron homeostasis in vivo. Nat. Cell Biol. 2014, 16, 1069-1079. [CrossRef] [PubMed]

79. Mancias, J.D.; Wang, X.; Gygi, S.P.; Harper, J.W.; Kimmelman, A.C. Quantitative proteomics identifies NCOA4 as the cargo receptor mediating ferritinophagy. Nature 2014, 509, 105-109. [CrossRef]

80. Bellelli, R.; Federico, G.; Matte', A.; Colecchia, D.; Iolascon, A.; Chiariello, M.; Santoro, M.; De Franceschi, L.; Carlomagno, F. NCOA4 Deficiency Impairs Systemic Iron Homeostasis. Cell Rep. 2016, 14, 411-421. [CrossRef]

81. Yang, F.; Haile, D.J.; Wang, X.; Dailey, L.A.; Stonehuerner, J.G.; Ghio, A.J. Apical location of ferroportin 1 in airway epithelia and its role in iron detoxification in the lung. Am. J. Physiol. Lung Cell. Mol. Physiol. 2005, 289, L14-L23. [CrossRef] [PubMed]

82. Yang, F.; Wang, X.; Haile, D.J.; Piantadosi, C.A.; Ghio, A.J. Iron increases expression of iron-export protein MTP1 in lung cells. Am. J. Physiol. Lung Cell. Mol. Physiol. 2002, 283, L932-L939. [CrossRef] [PubMed]

83. Harris, Z.L.; Durley, A.P.; Man, T.K.; Gitlin, J.D. Targeted gene disruption reveals an essential role for ceruloplasmin in cellular iron efflux. Proc. Natl. Acad. Sci. USA 1999, 96, 10812-10817. [CrossRef] [PubMed]

84. Vulpe, C.D.; Kuo, Y.M.; Murphy, T.L.; Cowley, L.; Askwith, C.; Libina, N.; Gitschier, J.; Anderson, G.J. Hephaestin, a ceruloplasmin homologue implicated in intestinal iron transport, is defective in the sla mouse. Nat. Genet. 1999, 21, 195-199. [CrossRef] [PubMed]

85. Morgan, B.; Lahav, O. The effect of $\mathrm{pH}$ on the kinetics of spontaneous Fe(II) oxidation by $\mathrm{O} 2$ in aqueous solution-basic principles and a simple heuristic description. Chemosphere 2007, 68, 2080-2084. [CrossRef] [PubMed]

86. Lakhal-Littleton, S.; Wolna, M.; Chung, Y.J.; Christian, H.C.; Heather, L.C.; Brescia, M.; Ball, V.; Diaz, R.; Santos, A.; Biggs, D.; et al. An essential cell-autonomous role for hepcidin in cardiac iron homeostasis. eLife 2016, 5, e19804. [CrossRef] [PubMed]

87. Benesova, K.; Vujić Spasić, M.; Schaefer, S.M.; Stolte, J.; Baehr-Ivacevic, T.; Waldow, K.; Zhou, Z.; Klingmueller, U.; Benes, V.; Mall, M.A.; et al. Hfe deficiency impairs pulmonary neutrophil recruitment in response to inflammation. PLoS ONE 2012, 7, e39363. [CrossRef]

88. Kulaksiz, H.; Theilig, F.; Bachmann, S.; Gehrke, S.G.; Rost, D.; Janetzko, A.; Cetin, Y.; Stremmel, W. The iron-regulatory peptide hormone hepcidin: Expression and cellular localization in the mammalian kidney. J. Endocrinol. 2005, 184, 361-370. [CrossRef] 
89. Zumerle, S.; Mathieu, J.R.R.; Delga, S.; Heinis, M.; Viatte, L.; Vaulont, S.; Peyssonnaux, C. Targeted disruption of hepcidin in the liver recapitulates the hemochromatotic phenotype. Blood 2014, 123, 3646-3650. [CrossRef]

90. Frazier, M.D.; Mamo, L.B.; Ghio, A.J.; Turi, J.L. Hepcidin expression in human airway epithelial cells is regulated by interferon- $\gamma$. Respir. Res. 2011, 12, 100. [CrossRef]

91. Chen, Q.X.; Song, S.W.; Chen, Q.H.; Zeng, C.L.; Zheng, X.; Wang, J.L.; Fang, X.M. Silencing airway epithelial cell-derived hepcidin exacerbates sepsis induced acute lung injury. Crit. Care 2014, 18, 470. [CrossRef] [PubMed]

92. Olakanmi, O.; McGowan, S.E.; Hayek, M.B.; Britigan, B.E. Iron sequestration by macrophages decreases the potential for extracellular hydroxyl radical formation. J. Clin. Investig. 1993, 91, 889-899. [CrossRef] [PubMed]

93. Nguyen, N.-B.; Callaghan, K.D.; Ghio, A.J.; Haile, D.J.; Yang, F. Hepcidin expression and iron transport in alveolar macrophages. Am. J. Physiol. Lung Cell. Mol. Physiol. 2006, 291, L417-L425. [CrossRef] [PubMed]

94. Campbell, E.J. Human leukocyte elastase, cathepsin G, and lactoferrin: Family of neutrophil granule glycoproteins that bind to an alveolar macrophage receptor. Proc. Natl. Acad. Sci. USA 1982, 79, 6941-6945. [CrossRef] [PubMed]

95. Hirata, T.; Bitterman, P.B.; Mornex, J.F.; Crystal, R.G. Expression of the transferrin receptor gene during the process of mononuclear phagocyte maturation. J. Immunol. 1986, 136, 1339-1345. [PubMed]

96. Thompson, K.; Molina, R.; Donaghey, T.; Brain, J.D.; Wessling-Resnick, M. The influence of high iron diet on rat lung manganese absorption. Toxicol. Appl. Pharmacol. 2006, 210, 17-23. [CrossRef]

97. Zhou, X.Y.; Tomatsu, S.; Fleming, R.E.; Parkkila, S.; Waheed, A.; Jiang, J.; Fei, Y.; Brunt, E.M.; Ruddy, D.A.; Prass, C.E.; et al. HFE gene knockout produces mouse model of hereditary hemochromatosis. Proc. Natl. Acad. Sci. USA 1998, 95, 2492-2497. [CrossRef]

98. Taher, A.T.; Weatherall, D.J.; Cappellini, M.D. Thalassaemia. Lancet 2018, 391, 155-167. [CrossRef]

99. Porter, J.B.; Garbowski, M. The pathophysiology of transfusional iron overload. Hematol. Oncol. Clin. N. Am. 2014, 28, 683-701. [CrossRef]

100. Parakh, A.; Dubey, A.P.; Chowdhury, V.; Sethi, G.R.; Jain, S.; Hira, H.S. Study of pulmonary function tests in thalassemic children. J. Pediatr. Hematol. Oncol. 2007, 29, 151-155. [CrossRef]

101. Priftis, K.N.; Anthracopoulos, M.B.; Tsakanika, C.; Tapaki, G.; Ladis, V.; Bush, A.; Nicolaidou, P. Quantification of siderophages in bronchoalveolar fluid in transfusional and primary pulmonary hemosiderosis. Pediatr. Pulmonol. 2006, 41, 972-977. [CrossRef] [PubMed]

102. Heilig, E.; Molina, R.; Donaghey, T.; Brain, J.D.; Wessling-Resnick, M. Pharmacokinetics of pulmonary manganese absorption: Evidence for increased susceptibility to manganese loading in iron-deficient rats. Am. J. Physiol. Lung Cell. Mol. Physiol. 2005, 288, L887-L893. [CrossRef] [PubMed]

103. Yokoi, K.; Kimura, M.; Itokawa, Y. Effect of dietary iron deficiency on mineral levels in tissues of rats. Biol. Trace Elem. Res. 1991, 29, 257-265. [CrossRef] [PubMed]

104. Folgueras, A.R.; de Lara, F.M.; Pendás, A.M.; Garabaya, C.; Rodríguez, F.; Astudillo, A.; Bernal, T.; Cabanillas, R.; López-Otín, C.; Velasco, G. Membrane-bound serine protease matriptase-2 (Tmprss6) is an essential regulator of iron homeostasis. Blood 2008, 112, 2539-2545. [CrossRef] [PubMed]

105. Silvestri, L.; Pagani, A.; Nai, A.; De Domenico, I.; Kaplan, J.; Camaschella, C. The serine protease matriptase-2 (TMPRSS6) inhibits hepcidin activation by cleaving membrane hemojuvelin. Cell Metab. 2008, 8, 502-511. [CrossRef] [PubMed]

106. Pedchenko, V.; Kitching, A.R.; Hudson, B.G. Goodpasture's autoimmune disease-A collagen IV disorder. Matrix Biol. J. Int. Soc. Matrix Biol. 2018, 71-72, 240-249. [CrossRef]

107. Corhay, J.L.; Weber, G.; Bury, T.; Mariz, S.; Roelandts, I.; Radermecker, M.F. Iron content in human alveolar macrophages. Eur. Respir. J. 1992, 5, 804-809.

108. Shimizu, Y. World Health Organization (WHO). News Report on Air Pollution. Available online: http:/ / www.who.int/airpollution/en/ (accessed on 7 September 2018).

109. Park, E.-J.; Kim, H.; Kim, Y.; Yi, J.; Choi, K.; Park, K. Inflammatory responses may be induced by a single intratracheal instillation of iron nanoparticles in mice. Toxicology 2010, 275, 65-71. [CrossRef]

110. Ghio, A.J.; Hilborn, E.D.; Stonehuerner, J.G.; Dailey, L.A.; Carter, J.D.; Richards, J.H.; Crissman, K.M.; Foronjy, R.F.; Uyeminami, D.L.; Pinkerton, K.E. Particulate matter in cigarette smoke alters iron homeostasis to produce a biological effect. Am. J. Respir. Crit. Care Med. 2008, 178, 1130-1138. [CrossRef] 
111. Sangani, R.G.; Ghio, A.J. Lung injury after cigarette smoking is particle related. Int. J. Chron. Obstruct. Pulmon. Dis. 2011, 6, 191-198.

112. Crotty Alexander, L.E.; Shin, S.; Hwang, J.H. Inflammatory Diseases of the Lung Induced by Conventional Cigarette Smoke: A Review. Chest 2015, 148, 1307-1322. [CrossRef] [PubMed]

113. Liu, X.; Chen, Z. The pathophysiological role of mitochondrial oxidative stress in lung diseases. J. Transl. Med. 2017, 15, 207. [CrossRef] [PubMed]

114. Zhang, B.; Yang, L.; Wang, W.; Li, Y.; Li, H. Quantification and Comparison of Soil Elements in the Tibetan Plateau Kaschin-Beck Disease Area: A Case Study in Zamtang County, Sichuan Province, China. Biol. Trace Elem. Res. 2010, 138, 69-78. [CrossRef] [PubMed]

115. Guo, W.; Zhang, J.; Li, W.; Xu, M.; Liu, S. Disruption of iron homeostasis and resultant health effects upon exposure to various environmental pollutants: A critical review. J. Environ. Sci. China 2015, 34, 155-164. [CrossRef] [PubMed]

116. Pasha, M.A.Q.; Newman, J.H. High-altitude disorders: Pulmonary hypertension: Pulmonary vascular disease: The global perspective. Chest 2010, 137, 13S-19S. [CrossRef] [PubMed]

117. $\mathrm{Wu}, \mathrm{T}$. The Qinghai-Tibetan plateau: how high do Tibetans live? High Alt. Med. Biol. 2001, 2, 489-499. [CrossRef] [PubMed]

118. Dempsey, J.A.; Morgan, B.J. Humans in Hypoxia: A Conspiracy of Maladaptation?! Physiology 2015, 30, 304-316. [CrossRef] [PubMed]

119. Gassmann, M.; Muckenthaler, M.U. Adaptation of iron requirement to hypoxic conditions at high altitude. J. Appl. Physiol. 2015, 119, 1432-1440. [CrossRef]

120. Kautz, L.; Jung, G.; Valore, E.V.; Rivella, S.; Nemeth, E.; Ganz, T. Identification of erythroferrone as an erythroid regulator of iron metabolism. Nat. Genet. 2014, 46, 678-684. [CrossRef]

121. Ganz, T. Erythropoietic regulators of iron metabolism. Free Radic. Biol. Med. 2018. [CrossRef]

122. Peeling, P.; Dawson, B.; Goodman, C.; Landers, G.; Trinder, D. Athletic induced iron deficiency: New insights into the role of inflammation, cytokines and hormones. Eur. J. Appl. Physiol. 2008, 103, 381-391. [CrossRef] [PubMed]

123. Clénin, G.; Cordes, M.; Huber, A.; Schumacher, Y.O.; Noack, P.; Scales, J.; Kriemler, S. Iron deficiency in sports-definition, influence on performance and therapy. Swiss Med. Wkly. 2015, 145, w14196. [CrossRef] [PubMed]

124. Khodaee, M.; Grothe, H.L.; Seyfert, J.H.; VanBaak, K. Athletes at High Altitude. Sports Health 2016, 8, $126-132$. [CrossRef] [PubMed]

125. Hoes, M.F.; Grote Beverborg, N.; Kijlstra, J.D.; Kuipers, J.; Swinkels, D.W.; Giepmans, B.N.G.; Rodenburg, R.J.; van Veldhuisen, D.J.; de Boer, R.A.; van der Meer, P. Iron deficiency impairs contractility of human cardiomyocytes through decreased mitochondrial function. Eur. J. Heart Fail. 2018, 20, 910-919. [CrossRef] [PubMed]

126. Pokorski, M.; Antosiewicz, J.; Di Giulio, C.; Lahiri, S. Iron chelation and the ventilatory response to hypoxia. Adv. Exp. Med. Biol. 2009, 648, 215-221. [PubMed]

127. Pokorski, M.; Antosiewicz, J. Hypoxic ventilatory response in limited iron in the rat. J. Biol. Regul. Homeost. Agents 2012, 26, 653-661.

128. López-Barneo, J.; Macías, D.; Platero-Luengo, A.; Ortega-Sáenz, P.; Pardal, R. Carotid body oxygen sensing and adaptation to hypoxia. Pflugers Arch. 2016, 468, 59-70. [CrossRef]

129. Baby, S.M.; Roy, A.; Mokashi, A.M.; Lahiri, S. Effects of hypoxia and intracellular iron chelation on hypoxia-inducible factor-1alpha and -1beta in the rat carotid body and glomus cells. Histochem. Cell Biol. 2003, 120, 343-352. [CrossRef]

130. Roy, A.; Volgin, D.V.; Baby, S.M.; Mokashi, A.; Kubin, L.; Lahiri, S. Activation of HIF-1alpha mRNA by hypoxia and iron chelator in isolated rat carotid body. Neurosci. Lett. 2004, 363, 229-232. [CrossRef]

131. Dunham-Snary, K.J.; Wu, D.; Sykes, E.A.; Thakrar, A.; Parlow, L.R.G.; Mewburn, J.D.; Parlow, J.L.; Archer, S.L. Hypoxic Pulmonary Vasoconstriction: From Molecular Mechanisms to Medicine. Chest 2017, 151, 181-192. [CrossRef]

132. Smith, T.G.; Balanos, G.M.; Croft, Q.P.P.; Talbot, N.P.; Dorrington, K.L.; Ratcliffe, P.J.; Robbins, P.A. The increase in pulmonary arterial pressure caused by hypoxia depends on iron status. J. Physiol. 2008, 586, 5999-6005. [CrossRef] [PubMed] 
133. Frise, M.C.; Robbins, P.A. Iron, oxygen, and the pulmonary circulation. J. Appl. Physiol. 2015, 119, 1421-1431. [CrossRef] [PubMed]

134. Bai, Z.; Zhao, C.; Liu, S.; Feng, R.; Cui, S.; Ge, R.; McClain, D. Higher Serum Ferritin in Tibetan and Han Populations with Diabetes Living on the Tibetan Plateau. Endocrinol. Diabetes Metab. J. 2017, 2, 1-7.

135. Frise, M.C.; Robbins, P.A. The pulmonary vasculature-lessons from Tibetans and from rare diseases of oxygen sensing. Exp. Physiol. 2015, 100, 1233-1241. [CrossRef] [PubMed]

136. Petousi, N.; Robbins, P.A. Human adaptation to the hypoxia of high altitude: The Tibetan paradigm from the pregenomic to the postgenomic era. J. Appl. Physiol. 2014, 116, 875-884. [CrossRef] [PubMed]

137. Gilbert-Kawai, E.T.; Milledge, J.S.; Grocott, M.P.W.; Martin, D.S. King of the mountains: Tibetan and Sherpa physiological adaptations for life at high altitude. Physiology 2014, 29, 388-402. [CrossRef]

138. Woik, N.; Kroll, J. Regulation of lung development and regeneration by the vascular system. Cell. Mol. Life Sci. CMLS 2015, 72, 2709-2718. [CrossRef]

139. Suresh, K.; Shimoda, L.A. Lung Circulation. Compr. Physiol. 2016, 6, 897-943.

140. Kühn, L.C. Iron regulatory proteins and their role in controlling iron metabolism. Met. Integr. Biometal Sci. 2015, 7, 232-243. [CrossRef]

141. Robinson, J.C.; Graham, B.B.; Rouault, T.C.; Tuder, R.M. The crossroads of iron with hypoxia and cellular metabolism. Implications in the pathobiology of pulmonary hypertension. Am. J. Respir. Cell Mol. Biol. 2014, 51, 721-729. [CrossRef]

142. Bailey, P.S.J.; Nathan, J.A. Metabolic Regulation of Hypoxia-Inducible Transcription Factors: The Role of Small Molecule Metabolites and Iron. Biomedicines 2018, 6, 60. [CrossRef] [PubMed]

143. Schofield, C.J.; Ratcliffe, P.J. Oxygen sensing by HIF hydroxylases. Nat. Rev. Mol. Cell Biol. 2004, 5, 343-354. [CrossRef] [PubMed]

144. Prabhakar, N.R.; Semenza, G.L. Oxygen Sensing and Homeostasis. Physiology 2015, 30, 340-348. [CrossRef]

145. Semenza, G.L. Oxygen sensing, hypoxia-inducible factors, and disease pathophysiology. Annu. Rev. Pathol. 2014, 9, 47-71. [CrossRef]

146. Urrutia, A.A.; Aragonés, J. HIF Oxygen Sensing Pathways in Lung Biology. Biomedicines 2018, 6, 68. [CrossRef] [PubMed]

147. Zhang, D.-L.; Ghosh, M.C.; Rouault, T.A. The physiological functions of iron regulatory proteins in iron homeostasis-An update. Front. Pharmacol. 2014, 5, 124. [CrossRef] [PubMed]

148. Luo, Q.-Q.; Wang, D.; Yu, M.-Y.; Zhu, L. Effect of hypoxia on the expression of iron regulatory proteins 1 and the mechanisms involved. IUBMB Life 2011, 63, 120-128. [CrossRef]

149. Vashisht, A.A.; Zumbrennen, K.B.; Huang, X.; Powers, D.N.; Durazo, A.; Sun, D.; Bhaskaran, N.; Persson, A.; Uhlen, M.; Sangfelt, O.; et al. Control of iron homeostasis by an iron-regulated ubiquitin ligase. Science 2009, 326, 718-721. [CrossRef]

150. Zimmer, M.; Ebert, B.L.; Neil, C.; Brenner, K.; Papaioannou, I.; Melas, A.; Tolliday, N.; Lamb, J.; Pantopoulos, K.; Golub, T.; et al. Small-molecule inhibitors of HIF-2a translation link its 5'UTR iron-responsive element to oxygen sensing. Mol. Cell 2008, 32, 838-848. [CrossRef]

151. Anderson, S.A.; Nizzi, C.P.; Chang, Y.-I.; Deck, K.M.; Schmidt, P.J.; Galy, B.; Damnernsawad, A.; Broman, A.T.; Kendziorski, C.; Hentze, M.W.; et al. The IRP1-HIF-2 $\alpha$ axis coordinates iron and oxygen sensing with erythropoiesis and iron absorption. Cell Metab. 2013, 17, 282-290. [CrossRef]

152. Wang, G.L.; Semenza, G.L. Desferrioxamine induces erythropoietin gene expression and hypoxia-inducible factor 1 DNA-binding activity: Implications for models of hypoxia signal transduction. Blood 1993, 82, 3610-3615. [PubMed]

153. Castoldi, M.; Muckenthaler, M.U. Regulation of iron homeostasis by microRNAs. Cell. Mol. Life Sci. CMLS 2012, 69, 3945-3952. [CrossRef] [PubMed]

154. Ivan, M.; Huang, X. miR-210: Fine-Tuning the Hypoxic Response. Adv. Exp. Med. Biol. 2014, 772, $205-227$. [PubMed]

155. Cloonan, S.M.; Mumby, S.; Adcock, I.M.; Choi, A.M.K.; Chung, K.F.; Quinlan, G.J. The "Iron"--y of Iron Overload and Iron Deficiency in Chronic Obstructive Pulmonary Disease. Am. J. Respir. Crit. Care Med. 2017, 196, 1103-1112. [CrossRef] [PubMed]

156. Ali, M.K.; Kim, R.Y.; Karim, R.; Mayall, J.R.; Martin, K.L.; Shahandeh, A.; Abbasian, F.; Starkey, M.R.; Loustaud-Ratti, V.; Johnstone, D.; et al. Role of iron in the pathogenesis of respiratory disease. Int. J. Biochem. Cell Biol. 2017, 88, 181-195. [CrossRef] [PubMed] 
157. Khiroya, H.; Turner, A.M. The role of iron in pulmonary pathology. Multidiscip. Respir. Med. 2015, 10, 34. [CrossRef] [PubMed]

158. Papi, A.; Brightling, C.; Pedersen, S.E.; Reddel, H.K. Asthma. Lancet 2018, 391, 783-800. [CrossRef]

159. Ghio, A.J. Asthma as a disruption in iron homeostasis. Biometals Int. J. Role Met. Ions Biol. Biochem. Med. 2016, 29, 751-779. [CrossRef]

160. Rawal, G.; Yadav, S.; Kumar, R. Acute Respiratory Distress Syndrome: An Update and Review. J. Transl. Intern. Med. 2018, 6, 74-77. [CrossRef]

161. Stoltz, D.A.; Meyerholz, D.K.; Welsh, M.J. Origins of cystic fibrosis lung disease. N. Engl. J. Med. 2015, 372, 351-362. [CrossRef]

162. Ghio, A.J.; Roggli, V.L.; Soukup, J.M.; Richards, J.H.; Randell, S.H.; Muhlebach, M.S. Iron accumulates in the lavage and explanted lungs of cystic fibrosis patients. J. Cyst. Fibros. Off. J. Eur. Cyst. Fibros. Soc. 2013, 12, 390-398. [CrossRef] [PubMed]

163. Villafuerte, F.C.; Corante, N. Chronic Mountain Sickness: Clinical Aspects, Etiology, Management, and Treatment. High Alt. Med. Biol. 2016, 17, 61-69. [CrossRef] [PubMed]

164. Smith, T.G.; Talbot, N.P.; Privat, C.; Rivera-Ch, M.; Nickol, A.H.; Ratcliffe, P.J.; Dorrington, K.L.; León-Velarde, F.; Robbins, P.A. Effects of iron supplementation and depletion on hypoxic pulmonary hypertension: two randomized controlled trials. JAMA 2009, 302, 1444-1450. [CrossRef] [PubMed]

165. Rabe, K.F.; Watz, H. Chronic obstructive pulmonary disease. Lancet 2017, 389, 1931-1940. [CrossRef]

166. Cloonan, S.M.; Glass, K.; Laucho-Contreras, M.E.; Bhashyam, A.R.; Cervo, M.; Pabón, M.A.; Konrad, C.; Polverino, F.; Siempos, I.I.; Perez, E.; et al. Mitochondrial iron chelation ameliorates cigarette smoke-induced bronchitis and emphysema in mice. Nat. Med. 2016, 22, 163-174. [CrossRef] [PubMed]

167. Luks, A.M.; Swenson, E.R.; Bärtsch, P. Acute high-altitude sickness. Eur. Respir. Rev. Off. J. Eur. Respir. Soc. 2017, 26. [CrossRef]

168. Altamura, S.; Bärtsch, P.; Dehnert, C.; Maggiorini, M.; Weiss, G.; Theurl, I.; Muckenthaler, M.U.; Mairbäurl, H. Increased hepcidin levels in high-altitude pulmonary edema. J. Appl. Physiol. 2015, 118, 292-298. [CrossRef]

169. Lederer, D.J.; Martinez, F.J. Idiopathic Pulmonary Fibrosis. N. Engl. J. Med. 2018, 378, 1811-1823. [CrossRef]

170. Sangiuolo, F.; Puxeddu, E.; Pezzuto, G.; Cavalli, F.; Longo, G.; Comandini, A.; Di Pierro, D.; Pallante, M.; Sergiacomi, G.; Simonetti, G.; et al. HFE gene variants and iron-induced oxygen radical generation in idiopathic pulmonary fibrosis. Eur. Respir. J. 2015, 45, 483-490. [CrossRef]

171. Le, N.T.V.; Richardson, D.R. The role of iron in cell cycle progression and the proliferation of neoplastic cells. Biochim. Biophys. Acta 2002, 1603, 31-46. [CrossRef]

172. Torti, S.V.; Torti, F.M. Iron and cancer: more ore to be mined. Nat. Rev. Cancer 2013, 13, 342-355. [CrossRef] [PubMed]

173. Kukulj, S.; Jaganjac, M.; Boranic, M.; Krizanac, S.; Santic, Z.; Poljak-Blazi, M. Altered iron metabolism, inflammation, transferrin receptors, and ferritin expression in non-small-cell lung cancer. Med. Oncol. Northwood Lond. Engl. 2010, 27, 268-277. [CrossRef] [PubMed]

174. Babu, K.R.; Muckenthaler, M.U. miR-20a regulates expression of the iron exporter ferroportin in lung cancer. J. Mol. Med. Berl. Ger. 2016, 94, 347-359. [CrossRef] [PubMed]

175. Maffettone, C.; Chen, G.; Drozdov, I.; Ouzounis, C.; Pantopoulos, K. Tumorigenic properties of iron regulatory protein 2 (IRP2) mediated by its specific 73-amino acids insert. PLoS ONE 2010, 5, e10163. [CrossRef] [PubMed]

176. Costa da Silva, M.; Breckwoldt, M.O.; Vinchi, F.; Correia, M.P.; Stojanovic, A.; Thielmann, C.M.; Meister, M.; Muley, T.; Warth, A.; Platten, M.; et al. Iron Induces Anti-tumor Activity in Tumor-Associated Macrophages. Front. Immunol. 2017, 8, 1479. [CrossRef] [PubMed]

177. Kumar, A.; Abdelmalak, B.; Inoue, Y.; Culver, D.A. Pulmonary alveolar proteinosis in adults: Pathophysiology and clinical approach. Lancet Respir. Med. 2018, 6, 554-565. [CrossRef]

178. Ghio, A.J.; Stonehuerner, J.G.; Richards, J.H.; Crissman, K.M.; Roggli, V.L.; Piantadosi, C.A.; Carraway, M.S. Iron homeostasis and oxidative stress in idiopathic pulmonary alveolar proteinosis: A case-control study. Respir. Res. 2008, 9, 10. [CrossRef]

179. Thenappan, T.; Ormiston, M.L.; Ryan, J.J.; Archer, S.L. Pulmonary arterial hypertension: Pathogenesis and clinical management. BMJ 2018, 360, j5492. [CrossRef]

180. Ramakrishnan, L.; Pedersen, S.L.; Toe, Q.K.; Quinlan, G.J.; Wort, S.J. Pulmonary Arterial Hypertension: Iron Matters. Front. Physiol. 2018, 9, 641. [CrossRef] 
181. Sutendra, G.; Bonnet, S. The iron paradigm of pulmonary arterial hypertension: Popeye knows best. Circ. Res. 2015, 116, 1636-1638. [CrossRef]

182. Ghosh, M.C.; Zhang, D.-L.; Jeong, S.Y.; Kovtunovych, G.; Ollivierre-Wilson, H.; Noguchi, A.; Tu, T.; Senecal, T.; Robinson, G.; Crooks, D.R.; et al. Deletion of iron regulatory protein 1 causes polycythemia and pulmonary hypertension in mice through translational derepression of HIF2 $\alpha$. Cell Metab. 2013, 17, 271-281. [CrossRef] [PubMed]

183. Ruiter, G.; Lankhorst, S.; Boonstra, A.; Postmus, P.E.; Zweegman, S.; Westerhof, N.; van der Laarse, W.J.; Vonk-Noordegraaf, A. Iron deficiency is common in idiopathic pulmonary arterial hypertension. Eur. Respir. J. 2011, 37, 1386-1391. [CrossRef] [PubMed]

184. Tang, H.; Ayon, R.J.; Yuan, J.X.-J. New insights into the pathology of pulmonary hypertension: Implication of the miR-210/ISCU1/2/Fe-S axis. EMBO Mol. Med. 2015, 7, 689-691. [CrossRef] [PubMed]

185. Ruiter, G.; Manders, E.; Happé, C.M.; Schalij, I.; Groepenhoff, H.; Howard, L.S.; Wilkins, M.R.; Bogaard, H.J.; Westerhof, N.; van der Laarse, W.J.; et al. Intravenous iron therapy in patients with idiopathic pulmonary arterial hypertension and iron deficiency. Pulm. Circ. 2015, 5, 466-472. [CrossRef] [PubMed]

186. Carnelli, V.; D'Angelo, E.; Pecchiari, M.; Ligorio, M.; D'Angelo, E. Pulmonary dysfunction in transfusiondependent patients with thalassemia major. Am. J. Respir. Crit. Care Med. 2003, 168, 180-184. [CrossRef]

187. Kanj, N.; Shamseddine, A.; Gharzeddine, W.; Kanj, M.; Nasr, T.A.; Koussa, S.; Jibrail, J.; Taher, A. Relation of ferritin levels to pulmonary function in patients with thalassemia major and the acute effects of transfusion. Eur. J. Haematol. 2000, 64, 396-400. [CrossRef]

188. Piatti, G.; Allegra, L.; Fasano, V.; Gambardella, C.; Bisaccia, M.; Cappellini, M.D. Lung function in beta-thalassemia patients: A longitudinal study. Acta Haematol. 2006, 116, 25-29. [CrossRef]

189. Guidotti, F.; Piatti, G.; Marcon, A.; Cassinerio, E.; Giuditta, M.; Roghi, A.; Fasano, V.; Consonni, D.; Cappellini, M.D. Pulmonary dysfunction in thalassaemia major: Is there any relationship with body iron stores? Br. J. Haematol. 2017, 176, 309-314. [CrossRef]

190. Bärtsch, P.; Swenson, E.R. Clinical practice: Acute high-altitude illnesses. N. Engl. J. Med. 2013, 368, 2294-2302. [CrossRef]

191. Swenson, E.R.; Bärtsch, P. High-altitude pulmonary edema. Compr. Physiol. 2012, 2, 2753-2773.

192. Suchdev, P.S.; Williams, A.M.; Mei, Z.; Flores-Ayala, R.; Pasricha, S.-R.; Rogers, L.M.; Namaste, S.M. Assessment of iron status in settings of inflammation: Challenges and potential approaches. Am. J. Clin. Nutr. 2017, 106, 1626S-1633S. [CrossRef] [PubMed]

193. Moore, L.G.; Armaza, F.; Villena, M.; Vargas, E. Comparative aspects of high-altitude adaptation in human populations. Adv. Exp. Med. Biol. 2000, 475, 45-62. [PubMed]

194. Balanos, G.M.; Dorrington, K.L.; Robbins, P.A. Desferrioxamine elevates pulmonary vascular resistance in humans: Potential for involvement of HIF-1. J. Appl. Physiol. 2002, 92, 2501-2507. [CrossRef] [PubMed]

195. Simonneau, G.; Gatzoulis, M.A.; Adatia, I.; Celermajer, D.; Denton, C.; Ghofrani, A.; Gomez Sanchez, M.A.; Krishna Kumar, R.; Landzberg, M.; Machado, R.F.; et al. Updated clinical classification of pulmonary hypertension. J. Am. Coll. Cardiol. 2013, 62, D34-D41. [CrossRef] [PubMed]

196. Galiè, N.; Hoeper, M.M.; Humbert, M.; Torbicki, A.; Vachiery, J.-L.; Barbera, J.A.; Beghetti, M.; Corris, P.; Gaine, S.; Gibbs, J.S.; et al. Guidelines for the diagnosis and treatment of pulmonary hypertension: The Task Force for the Diagnosis and Treatment of Pulmonary Hypertension of the European Society of Cardiology (ESC) and the European Respiratory Society (ERS), endorsed by the International Society of Heart and Lung Transplantation (ISHLT). Eur. Heart J. 2009, 30, 2493-2537. [PubMed]

197. Cotroneo, E.; Ashek, A.; Wang, L.; Wharton, J.; Dubois, O.; Bozorgi, S.; Busbridge, M.; Alavian, K.N.; Wilkins, M.R.; Zhao, L. Iron homeostasis and pulmonary hypertension: Iron deficiency leads to pulmonary vascular remodeling in the rat. Circ. Res. 2015, 116, 1680-1690. [CrossRef]

198. Jankowich, M.; Elston, B.; Evans, S.K.; Wu, W.-C.; Choudhary, G. Relationship of Iron Deficiency and Serum Ferritin Levels with Pulmonary Hypertension: The Jackson Heart Study. PLoS ONE 2016, 11, e0167987. [CrossRef] [PubMed]

199. Yu, X.; Luo, Q.; Liu, Z.; Zhao, Z.; Zhao, Q.; An, C.; Huang, Z.; Jin, Q.; Gao, L.; Yan, L. Prevalence of iron deficiency in different subtypes of pulmonary hypertension. Heart Lung J. Crit. Care 2018, 47, 308-313. [CrossRef]

200. Frise, M.C.; Cheng, H.-Y.; Nickol, A.H.; Curtis, M.K.; Pollard, K.A.; Roberts, D.J.; Ratcliffe, P.J.; Dorrington, K.L.; Robbins, P.A. Clinical iron deficiency disturbs normal human responses to hypoxia. J. Clin. Investig. 2016, 126, 2139-2150. [CrossRef] 
201. Winterbourn, C.C. Toxicity of iron and hydrogen peroxide: The Fenton reaction. Toxicol. Lett. 1995, 82-83, 969-974. [CrossRef]

202. Bertoli, S.R.; Marques, V.B.; Rossi, E.M.; Krause, M.; Carneiro, M.T.W.D.; Simões, M.R.; Dos Santos, L. Chronic iron overload induces vascular dysfunction in resistance pulmonary arteries associated with right ventricular remodeling in rats. Toxicol. Lett. 2018, 295, 296-306. [CrossRef] [PubMed]

203. White, K.; Lu, Y.; Annis, S.; Hale, A.E.; Chau, B.N.; Dahlman, J.E.; Hemann, C.; Opotowsky, A.R.; Vargas, S.O.; Rosas, I.; et al. Genetic and hypoxic alterations of the microRNA-210-ISCU1/2 axis promote iron-sulfur deficiency and pulmonary hypertension. EMBO Mol. Med. 2015, 7, 695-713. [CrossRef]

204. Vogelmeier, C.F.; Criner, G.J.; Martinez, F.J.; Anzueto, A.; Barnes, P.J.; Bourbeau, J.; Celli, B.R.; Chen, R.; Decramer, M.; Fabbri, L.M.; et al. Global Strategy for the Diagnosis, Management, and Prevention of Chronic Obstructive Lung Disease 2017 Report: GOLD Executive Summary. Eur. Respir. J. 2017, 195, 557-582.

205. Boukhenouna, S.; Wilson, M.A.; Bahmed, K.; Kosmider, B. Reactive Oxygen Species in Chronic Obstructive Pulmonary Disease. Oxid. Med. Cell. Longev. 2018, 2018, 5730395. [CrossRef]

206. Ghio, A.J.; Hilborn, E.D. Indices of iron homeostasis correlate with airway obstruction in an NHANES III cohort. Int. J. Chron. Obstruct. Pulmon. Dis. 2017, 12, 2075-2084. [CrossRef] [PubMed]

207. John, M.; Lange, A.; Hoernig, S.; Witt, C.; Anker, S.D. Prevalence of anemia in chronic obstructive pulmonary disease: Comparison to other chronic diseases. Int. J. Cardiol. 2006, 111, 365-370. [CrossRef]

208. Shorr, A.F.; Doyle, J.; Stern, L.; Dolgitser, M.; Zilberberg, M.D. Anemia in chronic obstructive pulmonary disease: Epidemiology and economic implications. Curr. Med. Res. Opin. 2008, 24, 1123-1130. [CrossRef]

209. Nickol, A.H.; Frise, M.C.; Cheng, H.-Y.; McGahey, A.; McFadyen, B.M.; Harris-Wright, T.; Bart, N.K.; Curtis, M.K.; Khandwala, S.; O'Neill, D.P.; et al. A cross-sectional study of the prevalence and associations of iron deficiency in a cohort of patients with chronic obstructive pulmonary disease. BMJ Open 2015, 5, e007911. [CrossRef]

210. Tyrrell, J.; Callaghan, M. Iron acquisition in the cystic fibrosis lung and potential for novel therapeutic strategies. Microbiol. Read. Engl. 2016, 162, 191-205. [CrossRef]

211. Goss, C.H.; Kaneko, Y.; Khuu, L.; Anderson, G.D.; Ravishankar, S.; Aitken, M.L.; Lechtzin, N.; Zhou, G.; Czyz, D.M.; McLean, K.; et al. Gallium disrupts bacterial iron metabolism and has therapeutic effects in mice and humans with lung infections. Sci. Transl. Med. 2018, 10, eaat7520. [CrossRef]

212. Knekt, P.; Reunanen, A.; Takkunen, H.; Aromaa, A.; Heliövaara, M.; Hakulinen, T. Body iron stores and risk of cancer. Int. J. Cancer 1994, 56, 379-382. [CrossRef] [PubMed]

213. D'Ignazio, L.; Batie, M.; Rocha, S. Hypoxia and Inflammation in Cancer, Focus on HIF and NF-кB. Biomedicines 2017, 5, 21. [CrossRef] [PubMed]

214. Zanganeh, S.; Hutter, G.; Spitler, R.; Lenkov, O.; Mahmoudi, M.; Shaw, A.; Pajarinen, J.S.; Nejadnik, H.; Goodman, S.; Moseley, M.; et al. Iron oxide nanoparticles inhibit tumour growth by inducing pro-inflammatory macrophage polarization in tumour tissues. Nat. Nanotechnol. 2016, 11, 986-994. [CrossRef] [PubMed]

215. Thompson, B.T.; Chambers, R.C.; Liu, K.D. Acute Respiratory Distress Syndrome. N. Engl. J. Med. 2017, 377, 562-572. [CrossRef] [PubMed]

216. Mehari, A.; Klings, E.S. Chronic Pulmonary Complications of Sickle Cell Disease. Chest 2016, 149, $1313-1324$. [CrossRef] [PubMed]

217. Lunt, A.; McGhee, E.; Sylvester, K.; Rafferty, G.; Dick, M.; Rees, D.; Height, S.; Thein, S.L.; Greenough, A. Longitudinal assessment of lung function in children with sickle cell disease. Pediatr. Pulmonol. 2016, 51, 717-723. [CrossRef] [PubMed]

218. Koumbourlis, A.C. Lung function in sickle cell disease. Paediatr. Respir. Rev. 2014, 15, 33-37. [CrossRef]

219. Fung, E.; Nemeth, E. Manipulation of the hepcidin pathway for therapeutic purposes. Haematologica 2013, 98, 1667-1676. [CrossRef]

220. Haase, V.H. HIF-prolyl hydroxylases as therapeutic targets in erythropoiesis and iron metabolism. Hemodial. Int. 2017, 21, S110-S124. [CrossRef]

221. Haase, V.H. Therapeutic targeting of the HIF oxygen-sensing pathway: Lessons learned from clinical studies. Exp. Cell Res. 2017, 356, 160-165. [CrossRef]

(C) 2019 by the authors. Licensee MDPI, Basel, Switzerland. This article is an open access article distributed under the terms and conditions of the Creative Commons Attribution (CC BY) license (http:/ / creativecommons.org/licenses/by/4.0/). 
Review

\title{
Established and Emerging Concepts to Treat Imbalances of Iron Homeostasis in Inflammatory Diseases
}

\author{
Verena Petzer ${ }^{1}$, Igor Theurl ${ }^{1}$ and Günter Weiss ${ }^{1,2, *}$ \\ 1 Department of Internal Medicine II, Medical University of Innsbruck, 6020 Innsbruck, Austria; \\ verena.petzer@i-med.ac.at (V.P.); igor.theurl@i-med.ac.at (I.T.) \\ 2 Christian Doppler Laboratory for Iron Metabolism and Anemia Research, Medical University of Innsbruck, \\ 6020 Innsbruck, Austria \\ * Correspondence: guenter.weiss@i-med.ac.at; Tel.: +43-512-504-23251
}

Received: 10 November 2018; Accepted: 6 December 2018; Published: 11 December 2018

\begin{abstract}
Inflammation, being a hallmark of many chronic diseases, including cancer, inflammatory bowel disease, rheumatoid arthritis, and chronic kidney disease, negatively affects iron homeostasis, leading to iron retention in macrophages of the mononuclear phagocyte system. Functional iron deficiency is the consequence, leading to anemia of inflammation (AI). Iron deficiency, regardless of anemia, has a detrimental impact on quality of life so that treatment is warranted. Therapeutic strategies include (1) resolution of the underlying disease, (2) iron supplementation, and (3) iron redistribution strategies. Deeper insights into the pathophysiology of AI has led to the development of new therapeutics targeting inflammatory cytokines and the introduction of new iron formulations. Moreover, the discovery that the hormone, hepcidin, plays a key regulatory role in AI has stimulated the development of several therapeutic approaches targeting the function of this peptide. Hence, inflammation-driven hepcidin elevation causes iron retention in cells and tissues. Besides pathophysiological concepts and diagnostic approaches for AI, this review discusses current guidelines for iron replacement therapies with special emphasis on benefits, limitations, and unresolved questions concerning oral versus parenteral iron supplementation in chronic inflammatory diseases. Furthermore, the review explores how therapies aiming at curing the disease underlying AI can also affect anemia and discusses emerging hepcidin antagonizing drugs, which are currently under preclinical or clinical investigation.
\end{abstract}

Keywords: Anemia of chronic disease; anemia of inflammation; hepcidin; anti-hepcidin therapy; iron supplementation

\section{Introduction}

Iron has a crucial role in all living organisms. In humans, iron is essential for many biochemical processes, including electron transfer reactions in mitochondria, the citric acid cycle, gene expression, binding and transport of oxygen, regulation of cell growth and differentiation as well as the cellular immune response [1]. From a systemic point of view, hepcidin, a liver-derived hormone, has been found to be the master regulator of iron homeostasis, controlling cellular iron efflux [2]. Hepcidin binds to the sole known iron exporter, ferroportin (FPN), mediating internalization and degradation of this transporter [3,4]. As a further consequence, dietary iron absorption as well as iron release from cells, such as macrophages, is prevented [5]. Hepcidin expression is regulated by different stimuli, such as anemia, hypoxia, and inflammation [6]. Different molecular pathways involved in hepcidin expression have been uncovered $[7,8]$. Among these, the bone morphogenetic protein (BMP)-SMAD signaling pathway is the most critical. Liver endothelial cell-derived BMP6 and BMP2 have non-redundant 
roles to induce hepcidin expression. However, BMP6 is the dominant ligand and a threshold signaling of BMP6 via the BMP-SMAD pathway is indispensable for sufficient and appropriate hepcidin induction [9-12]. During inflammation, hepcidin expression is induced via the interleukin (IL)6-JAK-STAT and Activin B-SMAD1/5/8 signaling pathways [2,13-15]. As FPN regulates iron release from absorptive enterocytes in the duodenum and from iron recycling macrophages of the mononuclear phagocyte system (MPS), elevated hepcidin levels during inflammation cause diminished systemic iron availability [16]. While iron retention in the MPS appears to be beneficial for host responses during infections, as it withholds this metal from invading extracellular pathogens, anemia is an undesired, ultimate consequence of iron restriction in patients suffering from chronic diseases [17-19]. Consequently, anemia of inflammation (AI) or anemia of chronic disease (ACD) represents the most common disease-related complication in patients suffering from rheumatoid arthritis (RA) inflammatory bowel diseases (IBD), cancer, infectious diseases, and chronic kidney disease (CKD) [1,20-26].

Whereas the development and persistence of anemia in several diseases, including infections and cancer, has been associated with a poor prognosis, the true impact of alterations in iron homeostasis or anemia on the pathology of the underlying disease remains largely elusive [27]. However, anemia negatively impacts on many aspects of the patients [28]. Moreover, iron exerts multiple effects on immune cell differentiation, functionality, and plasticity, which has been studied in depth toward the interconnection of iron homeostasis with the biology of M1 and M2 macrophages [29,30]. M1 macrophages, being either activated upon pathogen recognition or stimulated by cytokines (e.g., interferon-gamma (IFN $\gamma$ ), tumor necrosis factor-alpha (TNF $\alpha$ ), or IL1, IL6 and IL10), induce subtle changes of transcellular iron fluxes, aiming to limit the availability of the essential nutrient iron for circulating pathogens. Therefore, the term, "nutritional immunity", has been proposed [31]. Thereafter, cytokines directly or cytokine-inducible products, such as oxygen radicals and nitric oxide, regulate the expression of critical iron transport and storage proteins [19,32-38]. Consequently, the accessibility of iron for microbes is modulated and their growth and pathogenicity is impacted. Moreover, bacteria can acquire iron from holo-transferrin. Therefore, limitation of circulating transferrin-bound iron levels and mutations of the iron binding sites of transferrin were shown to be protective against infections with circulating bacteria [39-41].

Of note, iron per se also affects immune effector pathways of macrophages and, subsequently, T-cell differentiation by regulating IFN $\gamma$ activity, nitric oxide formation, or T-helper cell plasticity [42-46]. Thus, local and systemic iron availability determines not only microbial growth, but also the efficacy of anti-microbial immune effector pathways. It appears that the alterations of systemic and macrophage-responsible iron fluxes are specifically regulated depending on the nature and localization of the pathogen $[19,32,33,39,47]$. The hepcidin-FPN axis has attracted specific attention regarding alterations of iron fluxes during infections. Hepatocytes produce large amounts of hepcidin following challenge with circulating bacteria, resulting in iron retention with the MPS and low circulating iron levels $[17,18]$. Moreover, autocrine formation of hepcidin by macrophages further reduces cellular iron availability for circulating pathogens $[19,39,48,49]$. In contrast, invasion of cells and macrophages with bacteria, such as Listeria, Mycobacteria, or Salmonella, induces alternative mechanisms. Specifically, the upregulation of FPN by different mechanisms results in macrophage iron efflux and limitation of bacterial growth [50-54]. In addition, M1 macrophages and other immune cells produce several factors, such as lipocalin-2, lactoferrin, and calprotectin, which limit the bacterial access to iron [55-57]. Of note, in addition to iron flux regulation by the FPN-hepcidin axis, several hepcidin-independent mechanisms have been identified that control iron trafficking during infection [33,50,58-61].

In contrast, M2 macrophages exert anti-inflammatory effects and these cells are highly specialized for iron recycling from senescent erythrocytes via erythrophagocytosis, yielding approximately $90 \%$ of the daily needs of iron for erythropoiesis [30]. Iron is released from heme by the anti-inflammatory enzyme, heme oxygenase- $1[62,63]$. The latter enzyme has attracted specific interest because it exerts 
immune regulatory effects, but, importantly, it also exerts disease tolerance during certain infections by limiting tissue damage, thereby improving the outcome from sepsis [64,65].

While it has long been known that iron is essential for the production of hemoglobin of red blood cells, our knowledge on the regulation of iron homeostasis under steady state conditions and in association with different pathologies has dramatically expanded over the past centuries thanks to the identification and characterization of numerous iron genes and associated regulatory molecules [1]. Indeed, unbiased iron supplementation or withdrawal therapy via phlebotomy dates to the middle ages. However, due to our expanding knowledge on iron metabolism regulation during inflammation, targeted modulation of specific iron metabolic pathways, including the hepcidin-FPN axis, has emerged only recently $[3,66,67]$. Although we have several established and novel iron therapies at hand, there are still many unresolved questions and unmet needs when treating imbalances of iron homeostasis in patients with inflammatory diseases. This includes lack of gold-standard tests to properly distinguish between absolute versus functional ID, lack of knowledge regarding safe and efficient therapeutic start and end points as well as complications of iron redistribution and supplementation strategies towards the course of the diseases underlying AI.

\section{Diagnosis}

The diagnosis of $\mathrm{AI}$ is based on several laboratory markers. Classically, hemoglobin levels are decreased; markers of inflammation, such as C-reactive protein (CRP) or IL6, are increased; and iron homeostasis is altered as follows: Circulating iron levels are low, transferrin saturation (Tf-Sat) is reduced, and ferritin concentrations are normal or increased (Table 1) [68]. Diagnosis becomes challenging if $\mathrm{AI}$ is associated with true ID (AI/ID), as there is still a lack of a gold standard for differentiation between $\mathrm{AI}$ and $\mathrm{AI} / \mathrm{ID}$. However, as therapies to overcome anemia differ, proper diagnosis and understanding of underlying pathophysiological regulations are necessary [69]. While ferritin strongly correlates with the body's iron stores in IDA, ferritin levels are not reliable during inflammation. Thus, low ferritin levels $(<30 \mathrm{mg} / \mathrm{mL})$ in any case indicate true ID, but ferritin levels are upregulated during inflammation largely independently of iron availability [70]. This fact has led to corrections towards elevated cut-off values for ferritin during concomitant inflammation [71,72]. Until now, the gold standard for diagnosis of ID is still the microscopic evaluation of iron-stained bone marrow aspirates, which is not routinely used due to its high invasiveness [73]. A recent study in heart failure patients proposed to use serum iron and Tf-Sat instead of ferritin to diagnose true ID, which was evaluated by bone marrow staining [74]. Compared to ferritin-based definition of ID (with a sensitivity and specificity of $82 \%$ and $72 \%$, respectively), the diagnosis of ID based on reduced Tf-Sat (cut-off: $\leq 19.8 \%$ ) and low serum iron (cut-off: $\leq 13 \mu \mathrm{mol} / \mathrm{L}$ ) had an improved sensitivity $(94 \%)$ and specificity ( $84 \%$ and $88 \%$ ) in this specific group of patients. Although these findings need further confirmation among other disease entities, it highlights that ferritin-based definitions of ID appear to be suboptimal.

As erythrocytes are the main consumers of iron and thus most affected by ID, efforts have been undertaken to establish markers that are related to red blood cell morphology and iron content of these cells. Alongside the well-established classical hematological indices of the mean corpuscular volume $(\mathrm{MCV})$ and mean corpuscular hemoglobin $(\mathrm{MCH})$, new parameters, such as the hemoglobin content of reticulocytes, percentage of hypochromic red blood cells, and the soluble TfR (sTfR), were introduced as indicators of iron availability for the erythron and/or efficacy of erythropoiesis $[68,75,76]$. Some studies recommend the sTfR as an alternative biomarker to distinguish between absolute (or true) and functional ID. In general, absolute ID and higher rates of erythroid output causes an up-regulation of the TfR on erythrocytes, which then concomitantly leads to higher detectable forms of its cleaved monomer, the sTfR, in the plasma [77]. As inflammation negatively impacts erythropoiesis and TfR expression, sTfR values are also altered during inflammation [26,36]. Therefore, the use of this marker led to unsatisfactory sensitivity and specificity ( $83 \%$ and $50 \%$, respectively) for the detection of ID compared to bone marrow findings in a cohort of 180 anemic children in Mozambique [78]. Attempts 
to correct this marker for inflammation, using a sTfR versus log ferritin ratio, did not classify patients properly, thus limiting the diagnostic potential of this test [79]. While these parameters add additional information on true iron availability for erythropoiesis in patients with AI, none of these measurements are adjudged as efficient for distinguishing between $\mathrm{AI}$ and AI/ID.

A number of reports indicating that hepcidin is competent to distinguish between IDA and AI in several diseases, including RA, anemia of cancer, anemia of critical illness, and IBD, have suggested hepcidin to be a promising biomarker in the future [16,80-83]. Moreover, other reports also exist suggesting that plasma hepcidin levels could predict the response to oral iron in different settings [84-87]. However, there are also reports from studies in hemodialysis patients to the contrary, highlighting the need for further detailed investigations [88-90]. Further discussion on hepcidin is presented in Section 3.2.2. The measurements of molecules that affect hepcidin expression under different conditions may turn out to be of diagnostic benefit. Erythroferron, hypoxia inducible factors (HIFs), and platelet derived growth factor BB are all signaling peptides induced by hypoxia and were found to impact directly or via modulation of hepcidin on iron availability for erythropoiesis [91-93]. The biomarkers of hypoxia thus hold promise to better identify subjects suffering from AI/ID and to predict the erythroid response in patients with AI with and without ID, once commercially available ELISAs are available [94-96]. Of importance, none of these tests is currently standardized, which is a necessity to make them a reliable routine biomarker for the evaluation of iron status. Consequently, trials investigating these parameters cannot be easily compared, making interpretations even more difficult. However, according to a recent report, a hepcidin reference standard allows equivalence and comparability between hepcidin measurement results [97].

Despite ongoing efforts to find and establish new biomarkers, a recently published study conducted in a cohort of IBD patients revealed that differentiation between AI and iron deficiency anemia (IDA) and the combination thereof was only possible in $22 \%$ of all anemic patients, because only CRP, hemoglobin, and ferritin levels were available as diagnostic markers. [98]. This highlights that improvement of diagnostic approaches to identify patients with true ID in the setting of inflammation is urgently needed and is still a challenging field of investigation.

Table 1. Diagnostic markers for the diagnosis of different types of inflammatory anemia.

\begin{tabular}{|c|c|c|c|}
\hline Marker & $\begin{array}{c}\text { Anemia of } \\
\text { Inflammation }\end{array}$ & $\begin{array}{c}\text { Anemia of Inflammation } \\
\text { plus Iron Deficiency } \\
\text { Anemia }\end{array}$ & Limitations/Comments \\
\hline $\begin{array}{l}\text { Bone marrow } \\
\text { iron staining }\end{array}$ & Normal-Elevated & Normal-Reduced & $\begin{array}{l}\text { - } \quad \text { Gold standard } \\
\text { Invasive method, not } \\
\text { routinely used }\end{array}$ \\
\hline Serum Iron & Low & Low & Underlies diurnal variations \\
\hline Ferritin & Elevated & Reduced-Normal-Elevated & $\begin{array}{l}\text { - } \\
\text { Most commonly used marker } \\
\text { Ferritin is an acute phase protein } \\
\text { and does not accurately reflect } \\
\text { iron status during inflammation } \\
\text { Ferritin }<30 \mathrm{ng} / \mathrm{mL} \text { always } \\
\text { associated with true } \\
\text { iron deficiency }\end{array}$ \\
\hline Transferrin & Normal-Reduced & Normal-High & \\
\hline Tf-Sat & Low & Low & $\begin{array}{l}\text { Dependent on iron and } \\
\text { transferrin levels }\end{array}$ \\
\hline sTfR & Normal-Elevated & Elevated & $\begin{array}{l}\text { - Good marker for needs of iron for } \\
\text { erythropoiesis in absence } \\
\text { of inflammation } \\
\text { Values affected by inflammation } \\
\text { and ESA application }\end{array}$ \\
\hline
\end{tabular}


Table 1. Cont.

\begin{tabular}{|c|c|c|c|}
\hline Marker & $\begin{array}{l}\text { Anemia of } \\
\text { Inflammation }\end{array}$ & $\begin{array}{l}\text { Anemia of Inflammation } \\
\text { plus Iron Deficiency } \\
\text { Anemia }\end{array}$ & Limitations/Comments \\
\hline sTfR/log Ferritin & Normal & Elevated & $\begin{array}{l}\text { Used for differentiation, but there is a } \\
\text { lack of a prospective study }\end{array}$ \\
\hline Hepcidin & Elevated & Normal-Reduced & $\begin{array}{ll}\text { - } & \text { Expression is more affected by } \\
\text { iron deficiency (suppressing) than } \\
\text { by inflammation } \\
\text { - } & \text { Not standardized } \\
\text { - } & \text { Weak correlations in CKD patients } \\
\text { - } & \text { Possible predictive parameter for } \\
\text { success of iron and/or } \\
\text { ESA treatment }\end{array}$ \\
\hline Erythroferron & Not known & Not known & $\begin{array}{ll}- & \text { Not standardized } \\
\text { - } & \text { Higher ERFE levels in } \\
& \text { CKD patients } \\
\text { - } & \text { Positively correlated with serum } \\
\text { erythropoietin and negatively } \\
\text { with hemoglobin }\end{array}$ \\
\hline $\mathrm{MCV} / \mathrm{MCH}$ & Normal & Normal-Reduced & If reduced, indication of iron deficiency \\
\hline $\begin{array}{l}\text { Reticulocyte } \mathrm{Hb} \\
\text { content }\end{array}$ & Normal-Reduced & Reduced & $\begin{array}{c}\text { Indicated insufficient iron availability } \\
\text { for erythropoiesis, not prospectively } \\
\text { studied }\end{array}$ \\
\hline $\begin{array}{l}\text { Hypochromic } \\
\text { RBC }\end{array}$ & Normal & Normal-Elevated & $\begin{array}{l}\text { - } \quad \text { Related to MCV, as a sensitive } \\
\text { marker for iron availability for } \\
\text { erythroid progenitors } \\
\text { - Cut-off values are different } \\
\text { between different machines }\end{array}$ \\
\hline CRP & Increased & Increased & $\begin{array}{l}\text { - } \quad \text { Non-specific inflammatory marker } \\
\text { - } \quad \text { Iron-independent parameter } \\
\text { of anemia }\end{array}$ \\
\hline IL6 & Increased & Increased & $\begin{array}{l}\text { - Non-specific inflammatory marker } \\
\text { - Iron-independent parameter }\end{array}$ \\
\hline
\end{tabular}

\section{Treatment Strategies}

Treatment of ID and IDA is paramount as it is associated with several detrimental effects on quality of life, exercise capacity, mental status, and activity of patients [99,100]. To this end, two strategies can be pursued. First, treatment of the underlying disease; second, if a cure cannot be achieved, therapies directly or indirectly addressing imbalances of iron homeostasis are indicated.

\section{1. "First line": Treatment of the Underlying Inflammation}

If possible, treatment of the underlying disease is decidedly the pivotal approach to treat AI. Resolution of inflammation results in the normalization of hepcidin levels, leading to the correction of macrophage iron retention and normalization of duodenal iron uptake. In addition, the negative cytokine-mediated proliferative effects on hematopoiesis are abrogated, overall leading to anemia improvement. One approach, which has been shown to be effective, is the neutralization of inflammatory cytokines. Accordingly, targeted therapy using an anti-IL6 receptor antibody (Tocilizumab) improved anemia in patients suffering from multicentric Castleman's disease (MCD), a lymphoproliferative disorder where IL6 was found to be the main cytokine contributing to its pathogenesis [101,102]. Of note, IL6 is one major driver for hypoferremia in patients suffering from AI [2]. Further work-up revealed that anemia amelioration due to IL6 receptor blockade is related to down-regulation of hepcidin levels [103,104]. In parallel, a monoclonal anti-IL6 antibody (Siltuximab) 
has also been evaluated for its potential to decrease hepcidin plasma levels and consequently improved anemia not only in patients suffering from MCD, but also in subjects with multiple myeloma and solid tumors [105-107].

Of interest, not only systemic, but also autocrine hepcidin expression in macrophages has been found to be of importance in AI and possibly also for iron distribution in cancer cells $[48,108]$. In patients with ovarian cancer, polarization towards an M1 phenotype and high IL6 levels were associated with more profound anemia. Treatment with Tocilizumab resulted in the reversion of iron restriction and improvement of anemia, supporting previous evidence that anti IL6-directed therapy may be effective for anemia in cancer $[108,109]$.

$\mathrm{TNF} \alpha$ is also a target to treat the underlying complications and ameliorate anemia. Monoclonal antibodies directed against TNF $\alpha$ (e.g., Infliximab, Adalimumab, Golimumab) are routinely applied in patients suffering from RA and IBD. As TNF $\alpha$ 's contribution to AI is different from IL6, the beneficial effect on anemia was ascribed to discontinuation of TNF $\alpha$ 's negative impact on bone marrow erythropoiesis or, likewise, erythrocyte's half-life, without having direct effects on hepcidin levels [15,110-114]. However, a study investigating two different TNF $\alpha$ inhibitors in IBD patients found that the beneficial effect of anti-TNF $\alpha$ is indirect and it is mediated via down-regulation of IL6 [115]. Anti-TNF therapy may also reduce intravascular radical formation, thereby preventing the radical-mediated damage of erythrocyte membranes and increasing their circulating half-life. Moreover, comparative evaluation of TNF $\alpha$ inhibitors and Tocilizumab revealed that IL6-mediated therapy, directly affecting hepcidin levels, is more effective than TNF $\alpha$ inhibitors in respect to anemia correction [116]. Furthermore, hematological response after one year of anti-TNF $\alpha$ treatment was only observed in $34 \%$ of patients, even with oral iron supplementation [117].

Patients suffering from myeloproliferative neoplasms (MPN) have been shown to develop anemia, in part as a consequence of elevated hepcidin levels [118]. As mutations related to the activity of Janus kinase 2 (Jak2), resulting in constant activation, were found to be central to the pathogenesis of MPN, Jak2 inhibitors became one treatment option However, erythropoietin (EPO) is an essential hormone for sufficient production of red blood cells and also signals via the JAK2 pathway [119]. Consequently, anemia dose-dependently developed in patients who were treated with a JAK2 inhibitor (Ruxolitinib) and this was a dose-limiting adverse event [120,121]. In contrast, results from a phase II study for the treatment of myelofibrosis with a different Jak2 inhibitor (Momelotinib) surprisingly resulted even in an improvement of anemia [122]. Further dissection of the underlying mechanisms demonstrated that Momelotinib not only effectively inhibited Jak2 signaling, but also blocked ACVR1/ALK2-driven induction of hepcidin, resulting in an egress of iron from macrophages to sites of erythropoiesis [123].

Although these therapies are effective in lowering hepcidin levels and therefore ameliorate the anemia seen in chronic diseases, these therapies are probably not be suitable for sole treatment of AI because of potential side effects of these therapies, such as increased risk of infections due to impaired host responses [124]. A compromise might be a combinatorial therapeutic approach to target both the improvement of iron status and the treatment of infections.

\subsection{Iron Supplementation and Iron Redistribution Therapies}

Despite ongoing development of new treatment strategies and efforts towards personalized-based medicine, diseases, such as cancer, chronic heart failure, autoimmune diseases, and end stage kidney diseases, are proving unattainable because of persistent chronic inflammation. This being the case, anemia must be addressed via different approaches. Besides direct iron supplementation, iron redistribution strategies are emerging. The choice of the most appropriate therapy depends on the categorization of anemia whether there is pure AI with functional ID versus AI in combination with true ID. While iron replacement therapy appears to be mandatory in the latter setting, iron supplementation is questionable in patients with pure AI and strategies aiming at iron redistribution from macrophages to the circulation may be the more pragmatic approach. 


\subsubsection{Iron Supplementation}

In general, iron can be directly supplemented either via the oral or intravenous (i.v.) route. However, this decision is based on several factors, including the availability and cost of drugs, the underlying disease, the degree of inflammation, therapeutic efficacy, and side effects, but also on patients' compliance and convenience (Table 2). Oral iron may be used in ID and mild to moderate anemia, specifically among patients with a stable disease or only a low grade of inflammation $[14,15,69,125]$. Oral iron may also be effective in patients with AI and combined true ID due to the fact that ID-mediated inhibition of hepcidin expression dominates over inflammation-driven hepcidin induction $[126,127]$. Indications when i.v. iron therapy should be initiated are not that straight forward, based on the low grade of available evidence, and heterogeneity between guidelines for different disease entities [128]. However, i.v. iron may be used if oral iron therapy is ineffective, causes therapy-related side effects, and in patients with impaired oral iron absorption (Table 2). Of note, guidelines for recommendations whether to use oral or iv iron supplementation vary in different countries, in particular with regard to CKD. Examples include the Canadian guidelines, the Caring for Australians with Renal Impairment (CARI), the National Institute for Health and Care Excellence (NICE), and the Kidney Disease: Improving Global Outcomes (KDIGO), with each of them having their own guidelines and diagnostic algorithms, as well as choice of preferred administration route (oral vs. i.v.) [129-132]. This situation is far from being satisfactory as it causes deterrence and confusion among physicians and highlights the necessity of prospective clinical outcome data from rigorously conducted randomized controlled trials.

Nevertheless, the importance of i.v. iron supplementation among CKD patients became clear when the first human EPO preparation was licensed for use in dialysis-associated anemia nearly 30 years ago. Patients who suffered from EPO hypo-responsiveness experienced resolution of this condition with concomitant administration of i.v. iron. Hence, KDIGO guidelines propose that iron therapy should be aimed to treat ID, increase iron stores prior to initiation of therapy with erythropoiesis stimulating asgents (ESA), and enhance the response to these drugs [129].

In addition, within the last few years, concerns regarding the use of ESA (including EPO) for the treatment of anemia in CKD patients have been raised [133,134]. This was because of increased risk of adverse clinical outcomes, such as stroke and venous thromboembolic disease, culminating in high mortality [113-116]. Indeed, the US Food and Drug Administration (FDA) released a black box warning on the use of high EPO doses. Consequently, iron supplementation, either alone or in combination with ESA agents, are recommended as front-line options [129-132]. The latter is also related to findings of the TREAT (Trial to Reduce Cardiovascular Events with Aranesp ${ }^{\circledR}$ Therapy) study, which not only emphasized the possible risks related to ESA therapy, but also revealed that iron therapy increases hemoglobin levels and is capable of delaying the initiation need of ESA therapy [133,134]. Furthermore, another multicenter, prospective, and randomized study, FIND-CKD (Ferinject ${ }^{\circledR}$ assessment in patients with IDA and non-dialysis-dependent chronic kidney disease), reported that both i.v. and oral iron supplementation were capable of maintaining hemoglobin levels, thus reducing the dosages of ESA [135]. However, a recent randomized trial in non-dialyzed patients with CKD found that the use of i.v. iron was associated with an increased risk for adverse cardiovascular events and infections when compared to oral iron treatment [136].

Iron supplementation in patients with IBD is also still far from being consistent and many questions are still open, including the value of iron supplementation in subjects without anemia, or the preferred route of iron supplementation. Anemia seen in IBD is unique, as most patients suffer from AI together with ID, which is the consequence of continuous blood loss by the inflammatory mucosa and impaired iron intake as a consequence of malnutrition $[125,137,138]$. I.v. iron, as a sole treatment, has been shown to correct anemia in more than $80 \%$ of patients [139]. According to the European Crohn's and Colitis Organisation (ECCO) guidelines published in 2015, iron supplementation is recommended whenever IDA is present. In contrast to recommendations made for CKD patients, iron supplementation aims to normalize hemoglobin levels in patients with IBD [140]. I.v. iron is 
recommended in patients with a clinically active disease, previous intolerance to oral iron, severe anemia $(\mathrm{Hb}<10 \mathrm{~g} / \mathrm{dL})$, and who have initiated combination therapy with an ESA. Otherwise, oral iron therapy may be applied. However, several comparative studies, where i.v. versus oral iron supplementation was investigated, revealed that in IBD patients with AI and true ID and low disease activity, oral iron is as effective as i.v. iron to correct anemia [141-146]. Although AI is listed as a common cause for "non-IDA" in IBD subjects, no guidelines are provided regarding the practice of iron supplementation for these patients. Indeed, data from clinical trials on this issue are scarce. However, in view of published evidence that IBD patients with anemia have higher CRP values and a more active disease status, the necessity for further evaluation of this eventual relationship and its clinical management is evident $[147,148]$.

In conclusion, no matter which subtype of $\mathrm{AI}$ is present, today's evidence and treatment recommendations are based on altered biomarkers of haematology and inflammation and their correction, while end-point data on the effects of iron therapies (e.g., death, survival and disease resolution or progression) are almost completely lacking. Moreover, hardly any information from prospective trials is available regarding optimal therapeutic targets (e.g., hemoglobin or ferritin levels), which, however, may be different according to the underlying disease. One pioneering study (PIVOTAL for Proactive IV Iron Therapy in Hemodialysis Patients) addressed some of these end-points (risk of death, major adverse cardiovascular events, and infection) in patients undergoing hemodialysis and has just been published $[149,150]$. A high-dose regimen of i.v. iron (400 $\mathrm{mg}$ of iron sucrose per month, administered in a proactive fashion) was compared to a low-dose regimen ( $0 \mathrm{mg}-400 \mathrm{mg}$ of iron sucrose per month, administered in a reactive fashion). While the high iron regimen led to a reduced cumulative dose of administered ESA, there was no association with any of the end-points. How this study will influence existing guidelines and iron supplementation strategies remains to be seen.

Table 2. Characteristics of oral and intravenous iron therapy.

\begin{tabular}{|c|c|c|c|c|}
\hline & Indication(s) & Benefits & Limitations & Uncertainties/Comments \\
\hline Oral iron & $\begin{array}{l}\text { - } \quad \text { True iron deficiency } \\
\text { - Combined true and } \\
\text { functional iron } \\
\text { deficiency with low } \\
\text { grade inflammation }\end{array}$ & $\begin{array}{ll}\text { - } & \text { Low costs } \\
\text { - } & \text { Easy to apply } \\
\text { - } & \text { Effective if } \\
\text { applied appropriately }\end{array}$ & $\begin{array}{ll}\text { - } & \text { High pill burden } \\
\text { - } & \text { Low bioavailability } \\
\text { High rate } \\
\text { of non-responders } \\
\text { - } & \text { Ineffective in the } \\
\text { presence of high } \\
\text { hepcidin levels } \\
\text { - } \quad \begin{array}{l}\text { Gastro-intestinal } \\
\text { side effects }\end{array} \\
\text { - } \quad \text { Low compliance }\end{array}$ & $\begin{array}{l}\text { - Identification of the } \\
\text { underlying cause } \\
\text { Absorption defect must } \\
\text { be excluded } \\
\text { - No predictor for response } \\
\text { - Oral iron as a trigger for } \\
\text { cancer or } \\
\text { intestinal inflammation } \\
\text { - Effects on gut microbiome } \\
\text { - Disease specific } \\
\text { therapeutic start } \\
\text { and endpoints }\end{array}$ \\
\hline $\begin{array}{l}\text { Intravenous } \\
\text { iron }\end{array}$ & $\begin{array}{ll}\text { - } & \text { True and functional } \\
\text { iron deficiency } \\
\text { - } & \text { Absorption defects } \\
\text { - } & \text { Severe anemia } \\
\text { Intolerance to oral } \\
\text { iron therapy } \\
\text { Lack of efficacy of } \\
\text { oral iron therapy }\end{array}$ & $\begin{array}{l}\text { - Faster replacement of } \\
\text { iron stores than with } \\
\text { oral iron } \\
\text { Fewer gastro-intestinal } \\
\text { side effects } \\
\text { - New i.v. iron } \\
\text { formulations allowing } \\
\text { high single } \\
\text { dose administration } \\
\text { Effective in the presence } \\
\text { of inflammation } \\
\text { Better control } \\
\text { of compliance }\end{array}$ & $\begin{array}{l}\text { Rare but possible life } \\
\text { threatening } \\
\text { anaphylactic reactions } \\
\text { - } \quad \begin{array}{l}\text { Route of application } \\
\text { requires consultation } \\
\text { of a physician }\end{array} \\
\text { - } \quad \text { Higher costs } \\
\text { - Hypophosphatemia }\end{array}$ & $\begin{array}{l}\text { - } \quad \text { Long-term outcome on } \\
\text { underlying disease unclear } \\
\text { - } \quad \text { No predictor of response } \\
\text { Possible iron-induced } \\
\text { oxidative/nitrosative stress } \\
\text { - } \quad \text { Unknown efficacy in } \\
\text { patients with more } \\
\text { advanced inflammation } \\
\text { and/or high } \\
\text { hepcidin levels } \\
\text { Disease specific } \\
\text { therapeutic start } \\
\text { and endpoints }\end{array}$ \\
\hline
\end{tabular}

\subsubsection{Hepcidin Modulation}

As mentioned above, hepcidin is the master regulator of systemic iron homeostasis, as this hormone is decisive for FPN expression, regulating iron efflux [151]. Thus, circulating levels of hepcidin determine the transfer of iron from the diet via the duodenum and release of iron from macrophages of the MPS. Since hepcidin is central to the pathophysiology of AI, several strategies 
that either modulate the synthesis of hepcidin or neutralize its activity have been developed [152,153]. The purpose of hepcidin modulation is to reverse iron retention in the MPS, thus enhancing iron availability for erythropoiesis in AI. As multiple causes lead to AI (e.g., negative impact of cytokines on erythropoiesis, impaired EPO activity), it needs to be investigated if increase of iron availability on its own is sufficient to effectively restore hemoglobin levels. Alternatively, a combination with an ESA could lead to a more favorable outcome [25,154-158].

The first approach that has been used were antibodies directed against hepcidin, which initially were only effective to reverse anemia in animal models when combined with ESA, whereas a subsequently developed human antibody modulated iron homeostasis in mice and cynomolgus monkeys without concomitant ESA administration [159].

Another approach for hepcidin neutralization is based on the use of antichalins (bioengineered lipocalin; small ligand-binding protein) or aptamers (also called Spiegelmer or Lexaptepid pegol L-stereoisomeric RNA aptamer). Indeed, these compounds have also been proven to be effective in preclinical models, and phase I trials have been successfully completed. In detail, positive data were obtained from a phase I study for the anticalin PRS-080 thus a phase II study was initiated, which is evaluating the effect of PRS-080 administration in anemic hemodialysis CKD patients (https:/ / clinicaltrials.gov/ct2/show/NCT03325621) [160]. The outcomes of this clinical study on anti-hepcidin treatment are awaited. In addition, details on the impact of this compound on iron metabolism in cynomolgus monkeys has just recently been published [161]. In parallel, a placebo-controlled study on the safety, pharmacokinetics, and pharmacodynamics of the spiegelmer NOX-H94 in healthy humans demonstrated that hepcidin was inhibited dose-dependently, thus causing an increase in serum iron and Tf-Sat [162]. Furthermore, clinical phase II studies for the treatment of AI in patients suffering from multiple myeloma, low grade non-, or Hodgkin lymphoma, and ESA-hypo-responsive chronic hemodialysis patients have shown favorable effects, but cohorts were small, so further assessment is warranted [163,164].

As BMPs, specifically BMP2 and BMP6, are potent inducers of hepcidin, inhibition of the BMP-SMAD pathway is an attractive therapeutic approach to control hepcidin production $[10-12,165]$. Since this pathway is highly complex, involving different players, many possible targets can be contemplated [166]: First, BMP sequestration is one strategy. Therefore, BMP6 antibodies, a soluble hemojuvelin-Fc fusion protein, and modified heparins have been developed [167-170]. A phase I clinical trial of such a latter compound (Roneparstat, SST0001), which has competitive heparanase inhibitor properties, has been conducted in patients suffering from multiple myeloma, regarding its anti-myeloma effect, dosing, and safety profile (https://clinicaltrials.gov/ct2/show/record/ NCT01764880) [171]. Impacts on hepcidin and iron metabolism have not been published yet.

Representing one step further down the BMP/SMAD pathway, efforts have been undertaken to target the BMP receptor (BMPR). TP-0184, a small-molecule inhibitor of ALK2 activity, has entered a phase I study this year (https: / / clinicaltrials.gov/ct2/show/NCT03429218), after having shown promising effects on hepcidin suppression in vitro and in preclinical mouse models [172]. Not only BMPR, but also BMP co-receptors, have been investigated as hepcidin lowering strategies. Two monoclonal antibodies targeting hemojuvelin have been developed, and are still in preclinical development [173].

A third reasonable approach to counteract hepcidin activity is to block hepcidin-induced internalization of FPN. Even though a phase II trial for such a stabilizing FPN antibody has been successfully completed in 2015, its further development has been stopped [174,175].

Notably, EPO at high doses can decrease hepcidin levels [176]. This effect is only of short duration and seems to be indirect, as signals derived from expanding erythroid progenitors in the bone marrow mediate this suppression $[177,178]$. Indeed, among CKD patients, no long-term effects of EPO on hepcidin levels have been observed, which, however, may also be partly related to impaired urinary hepcidin excretion [179]. In addition, HIF-prolyl hydroxylase inhibitors (HIF-PHIs), stabilizing HIFs, and thus activating HIF-controlled pathways, such as intrinsic EPO expression, have been reported 
to impact on iron homeostasis $[93,180]$. However, these effects can be traced back to transcriptional regulation, resulting in enhanced expression of specific iron transporters in the intestine (such as FPN and divalent metal transporter 1), thereby promoting iron absorption. Table 3 gives an overview of the drugs that directly or indirectly modulate hepcidin levels.

Table 3. Drugs impacting on hepcidin-mediated alteration of iron homeostasis.

\begin{tabular}{|c|c|c|c|c|}
\hline Name(s) & Primary Indication(s) & Target & Drug Type & Mechanism \\
\hline Tocilizumab & $\begin{array}{ll}\text { - } & \text { Rheumatoid arthritis } \\
\text { - } & \text { Systemic juvenile } \\
& \text { idiopathic arthritis } \\
\text { - } & \text { Giant cell arteritis } \\
\text { - } & \text { MCD } \\
\text { - } & \text { Cytokine release syndrome }\end{array}$ & IL6R & $\begin{array}{l}\text { Humanized monoclonal } \\
\text { antibody }\end{array}$ & IL6 signaling inhibition \\
\hline Siltuximab & MCD & IL6 & $\begin{array}{l}\text { Chimeric monoclonal } \\
\text { Antibody }\end{array}$ & IL6 binding \\
\hline Infliximab & $\begin{array}{l}\text { - IBD (Crohn's disease, } \\
\text { Ulcerative colitis) } \\
\text { - } \quad \text { Rheumatoid arthritis } \\
\text { - } \quad \text { Psoriatic arthritis } \\
\text { - Ankylosing spondylitis } \\
\text { - Psoriasis }\end{array}$ & $\mathrm{TNF} \alpha$ & $\begin{array}{l}\text { Chimeric monoclonal } \\
\text { antibody }\end{array}$ & TNF $\alpha$ binding/blocker \\
\hline Adalimumab & $\begin{array}{ll}\text { - } & \text { IBD (Crohn's disease, } \\
\text { Ulcerative colitis) } \\
\text { - } \quad \text { Rheumatoid arthritis } \\
\text { - } \quad \text { Psoriatic arthritis } \\
\text { - } \quad \text { Ankylosing spondylitis } \\
\text { - } \quad \text { Hidradenitis suppurativa } \\
\quad \text { Juvenile idiopathic arthritis }\end{array}$ & $\mathrm{TNF} \alpha$ & $\begin{array}{l}\text { Humanized monoclonal } \\
\text { antibody }\end{array}$ & TNF $\alpha$ binding/blocker \\
\hline $\begin{array}{l}\text { Momelotinib } \\
\text { GS-0387 } \\
\text { CYT-387 }\end{array}$ & Myelofibrosis & $\begin{array}{l}\text { JAK1 and } \\
\text { JAK2 }\end{array}$ & Small molecule & $\begin{array}{ll}- & \text { Jak1 and } \\
\text { Jak2 inhibition } \\
\text { Blockig of hepcidin } \\
\text { production via } \\
\text { ALK2 inhibition }\end{array}$ \\
\hline CSJ137 & $\begin{array}{ll}\text { - } & \text { Hepcidin modulation } \\
\text { - } & \text { Anemia amelioration }\end{array}$ & BMP6 & Antibody & BMP6 binding/blocking \\
\hline $\begin{array}{c}\text { SST0001 } \\
\text { RO- } 82 \\
\text { RO-68 } \\
\text { NAc-91 } \\
\text { NAcRO-00 }\end{array}$ & $\begin{array}{ll}\text { - } & \text { Myeloma therapy } \\
\text { - } & \text { Hepcidin modulation }\end{array}$ & BMP6 & Modified heparin & BMP6 binding \\
\hline TP-0184 & $\begin{array}{l}\text { - } \\
\text { Antitumor activity in advanced } \\
\text { - } \quad \text { Hepcidin modulation } \\
\text { - } \quad \text { Anemia amelioration }\end{array}$ & ALK2 & Small molecule & ALK2 inhibition \\
\hline $\begin{array}{c}\text { h5F9.23, } \\
\text { h5F9-AM8 }\end{array}$ & $\begin{array}{l}\text { - Hepcidin modulation } \\
\text { - } \quad \text { Anemia amelioration }\end{array}$ & $\mathrm{HJV} / \mathrm{RGMc}$ & Antibody & $\begin{array}{l}\text { BMP Co-receptor binding } \\
\text { binding }\end{array}$ \\
\hline $\begin{array}{l}\text { Spiegelmer } \\
\text { Aptamers } \\
\text { NOX-H94H }\end{array}$ & $\begin{array}{l}\text { - } \quad \text { Hepcidin modulation } \\
\text { - }\end{array}$ & Hepcidin & $\begin{array}{l}\text { Lexaptepid pegol } \\
\text { L-stereoisomeric RNA } \\
\text { aptamer }\end{array}$ & Hepcidin binding \\
\hline PRS-080 & 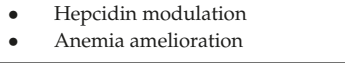 & Hepcidin & $\begin{array}{c}\text { Antichalin, } \\
\text { bioengineered lipocalin }\end{array}$ & Hepcidin binding \\
\hline Erythropoetin & Anemia & EpoR & Protein & $\begin{array}{l}\text { Induction of Erythroferron } \\
\text { and blockage of hepcidin }\end{array}$ \\
\hline
\end{tabular}

\section{Perspectives}

Anemia, being the final consequence of imbalances in iron homeostasis, in the setting of chronic diseases must be recognized as a clinical condition contributing to the morbidity of patients and awareness for ID must be improved. Indeed, due to the knowledge gap in clearly defining and diagnosing this condition, IDA, AI, and combined AI/ID are often used mutually. However, ID itself precedes anemia and should be detected, even outside the context of anemia. Efforts to counteract 
this common misconception have been made and a group of experts has proposed the following overarching definition for ID: "Iron deficiency is a health-related condition in which iron availability is insufficient to meet the body's needs and which can be present with or without anemia" [181]. Of importance, ID is not only associated with anemia, but also higher morbidity and mortality among certain chronic diseases, which could be alleviated after treatment [100,182-185]. For example, in patients suffering from chronic heart failure, ID has been shown to adversely impact performance status and quality of life, including prolonged hospitalizations independent of anemia [186-188]. Another significant upcoming challenge will be the management of anemia of the elderly, which often has a heterogeneous and multifactorial etiology, but is also specifically related to age-related changes [189].

Although $\mathrm{AI}$ is a condition that should be treated, there is also an evolutionary rational for iron restriction during inflammation: Iron restriction is beneficial during acute infections, especially to withhold iron from circulating microbes [19,39]. Malaria represents one of the best studied examples in this context $[65,190,191]$. The fact that red blood cells are the host for plasmodia highlights their dependency on iron metabolism. An important finding was just recently made to better understand underlying pathomechanisms: FPN expression on red blood cells is critical to prevent detrimental intracellular iron accumulation and hemolysis, all in all leading to a more severe course of malaria. Of interest, these authors found that a human mutation in $F P N(\mathrm{Q} 248 \mathrm{H})$, which is unresponsive to hepcidin-mediated degradation, has been positively selected in sub-Saharan African populations [192]. Thus, anti-hepcidin treatment strategies as listed above could be discussed as a treatment option for malaria in the future. Despite anemia being associated with this infection, iron supplementation has been shown to be detrimental. This is also in line with studies showing that iron supplementation in children of developing countries resulted in higher morbidity and mortality from infections [193,194].

Moreover, there is increasing evidence for the role of iron availability for the gut microbiome and oral versus i.v. iron have different effects on the composition of the microbiome $[143,195,196]$. This is of interest, because the composition of the gut microbiome was found to play decisive roles for the progression of IBD and carcinogenesis in different mouse models [197]. Further workup in vitro showed that certain iron formulations (ferric citrate and ferric ethylenediaminetetraacetic acid) also bear the risk of exacerbation of colon cancer advancement in an amphiregulin-dependent fashion, however, it needs to be defined whether or not the dosages used in such models are relevant for humans [198].

Another issue of general importance are the effects of iron supplementation or hepcidin targeting strategies on immune regulation. This is based on the observation that iron impacts on the differentiation and proliferation of immune cells, but also directly impacts on immune effector pathways either by promoting oxygen radical formation or inhibiting pro-inflammatory cytokine production or anti-microbial immune effector pathways of macrophages [29,199,200]. Pre-clinical and clinical models have shown that iron supplementation reduces TNF $\alpha$ formation in CKD patients while negatively impacting on the host response in mammalian models of invasive fungal infection [44,201]. Thus, depending on the underlying disease, iron supplementation could have disease modifying effects through its regulatory effects on the immune function $[44,202]$.

\section{Conclusions}

Anemia and ID in the setting of chronic inflammatory diseases are leading causes of morbidity worldwide. While we have gained significant knowledge on the mechanism underlying iron misdistribution and development of AI, highlighting the role of immune mediators and the iron hormone hepcidin, there is still the need for reliable biomarkers to evaluate iron homeostasis in patients suffering from inflammatory diseases and to choose the best therapy or to predict its efficacy. Specifically, distinction between AI versus AI combined with true iron deficiency is of importance because these groups of patients may likewise need different iron redistribution therapies. The development of new drugs (e.g., hepcidin antagonists) and the improvement of 
old drugs (novel formulation for oral and intravenous iron preparations) are the subject of future investigations. Although there is good evidence that iron supplementation improves quality of life, the effect of iron supplementation on the course of an underlying disease or associated co-morbidities are poorly understood. There is only limited information on therapeutic start- and end-points for iron supplementation and anemia correction in such patients. However, negligence of anemia and iron deficiency may also exacerbate the underlying disease state and cause clinical deterioration $[203,204]$. Thus, there is still a lot to learn to optimize and personalize treatment in subjects with AI. Therefore, investigations through pre-clinical models, but also through prospective randomized trials, are urgently needed to gain more detailed insights into this clinically very frequent, but poorly understood condition.

Author Contributions: Conceptualization, V.P.; I.T. and G.W.; writing-original draft preparation, V.P.; writing-review and editing, I.T. and G.W.; supervision, G.W.; project administration, G.W.

Funding: This research was funded by the doctoral college project [W1253 HOROS to V.P. and G.W.], the Austrian Research Funds (FWF) project [P 28302 to I.T.], the "Verein zur Förderung von Forschung und Weiterbildung in Infektiologie und Immunologie, Innsbruck" [to G.W.], the Christian Doppler Society, Austria [to G.W.]

Conflicts of Interest: The authors declare no conflict of interest.

$\begin{array}{ll}\text { Abbreviations } \\ \text { ACD } & \text { Anemia of chronic disease } \\ \text { ACVR } & \text { Activin A receptor } \\ \text { AI } & \text { Anemia of inflammation } \\ \text { ALK } & \text { Activin receptor-like kinase } \\ \text { BMP } & \text { Bone morphogenic protein } \\ \text { BMPR } & \text { Bone morphogenic protein receptor } \\ \text { CKD } & \text { Chronic kidney disease } \\ \text { CRP } & \text { C-reactive protein } \\ \text { EPO } & \text { Erythropoietin } \\ \text { EPOR } & \text { Erythropoietin receptor } \\ \text { ERFE } & \text { Erythroferrone } \\ \text { ESA } & \text { Erythropoiesis stimulating agent } \\ \text { FDA } & \text { Food and drug administration } \\ \text { FPN } & \text { Ferroportin-1 AKA SLC40A1 } \\ \text { Hb } & \text { Hemoglobin } \\ \text { HIFs } & \text { Hypoxia inducible factors } \\ \text { HIF-PHD } & \text { Hypoxia inducible factor prolyl hydroxylase inhibitors } \\ \text { IBD } & \text { Inflammatory bowel disease } \\ \text { ID } & \text { Iron deficiency } \\ \text { IDA } & \text { Iron deficiency anemia } \\ \text { IFN } \gamma & \text { Interferon gamma } \\ \text { IL } & \text { Interleukin } \\ \text { IL6R } & \text { Interleukin 6 receptor } \\ \text { i.v. } & \text { Intravenous } \\ \text { JAK } & \text { Janus kinase } \\ \text { MCD } & \text { Multicentric Castleman's disease } \\ \text { MCH } & \text { Mean corpuscular hemoglobin } \\ \text { MCV } & \text { Mean corpuscular volume } \\ \text { MPN } & \text { Myeloproliferative neoplasms } \\ \text { MPS } & \text { Mononuclear Phagocyte system } \\ \text { RA } & \text { Rheumatoid arthritis } \\ \text { RBC } & \text { Red blood cell } \\ \end{array}$


SMAD Homologues of Sma and Mad (mothers against decapentaplegic) proteins

STAT Signal transducer and activator of transcription

STfR Soluble transferrin receptor

TfR Transferrin receptor

Tf-Sat Transferrin saturation

TNF $\alpha \quad$ Tumor necrosis factor alpha

\section{References}

1. Muckenthaler, M.U.; Rivella, S.; Hentze, M.W.; Galy, B. A Red Carpet for Iron Metabolism. Cell 2017, 168, 344-361. [CrossRef] [PubMed]

2. Nemeth, E.; Rivera, S.; Gabayan, V.; Keller, C.; Taudorf, S.; Pedersen, B.K.; Ganz, T. IL-6 mediates hypoferremia of inflammation by inducing the synthesis of the iron regulatory hormone hepcidin. J. Clin. Investig. 2004, 113, 1271-1276. [CrossRef] [PubMed]

3. Nemeth, E.; Tuttle, M.S.; Powelson, J.; Vaughn, M.B.; Donovan, A.; Ward, D.M.; Ganz, T.; Kaplan, J. Hepcidin regulates cellular iron efflux by binding to ferroportin and inducing its internalization. Science 2004, 306, 2090-2093. [CrossRef] [PubMed]

4. Donovan, A.; Brownlie, A.; Zhou, Y.; Shepard, J.; Pratt, S.J.; Moynihan, J.; Paw, B.H.; Drejer, A.; Barut, B.; Zapata, A.; et al. Positional cloning of zebrafish ferroportin1 identifies a conserved vertebrate iron exporter. Nature 2000, 403, 776-781. [CrossRef] [PubMed]

5. Donovan, A.; Lima, C.A.; Pinkus, J.L.; Pinkus, G.S.; Zon, L.I.; Robine, S.; Andrews, N.C. The iron exporter ferroportin/Slc40a1 is essential for iron homeostasis. Cell Metab. 2005, 1, 191-200. [CrossRef] [PubMed]

6. Nicolas, G.; Chauvet, C.; Viatte, L.; Danan, J.L.; Bigard, X.; Devaux, I.; Beaumont, C.; Kahn, A.; Vaulont, S. The gene encoding the iron regulatory peptide hepcidin is regulated by anemia, hypoxia, and inflammation. J. Clin. Investig. 2002, 110, 1037-1044. [CrossRef] [PubMed]

7. Verga Falzacappa, M.V.; Spasic, M.V.; Kessler, R.; Stolte, J.; Hentze, M.W.; Muckenthaler, M.U. STAT3 mediates hepatic hepcidin expression and its inflammatory stimulation. Blood 2007, 109, 353-358. [CrossRef]

8. Meynard, D.; Kautz, L.; Darnaud, V.; Canonne-Hergaux, F.; Coppin, H.; Roth, M.-P. Lack of the bone morphogenetic protein BMP6 induces massive iron overload. Nat. Genet. 2009, 41, 478-481. [CrossRef]

9. Fillebeen, C.; Wilkinson, N.; Charlebois, E.; Katsarou, A.; Wagner, J.; Pantopoulos, K. Hepcidin-mediated hypoferremic response to acute inflammation requires a threshold of Bmp6/Hjv/Smad signaling. Blood 2018, 132, 1829-1841. [CrossRef]

10. Koch, P.-S.; Olsavszky, V.; Ulbrich, F.; Sticht, C.; Demory, A.; Leibing, T.; Henzler, T.; Meyer, M.; Zierow, J.; Schneider, S.; et al. Angiocrine Bmp2 signaling in murine liver controls normal iron homeostasis. Blood 2017, 129, 415-419. [CrossRef]

11. Canali, S.; Wang, C.-Y.; Zumbrennen-Bullough, K.B.; Bayer, A.; Babitt, J.L. Bone morphogenetic protein 2 controls iron homeostasis in mice independent of Bmp6. Am. J. Hematol. 2017, 92, 1204-1213. [CrossRef] [PubMed]

12. Canali, S.; Zumbrennen-Bullough, K.B.; Core, A.B.; Wang, C.-Y.; Nairz, M.; Bouley, R.; Swirski, F.K.; Babitt, J.L. Endothelial cells produce bone morphogenetic protein 6 required for iron homeostasis in mice. Blood 2017, 129, 405-414. [CrossRef] [PubMed]

13. Armitage, A.E.; Eddowes, L.A.; Gileadi, U.; Cole, S.; Spottiswoode, N.; Selvakumar, T.A.; Ho, L.P.; Townsend, A.R.M.; Drakesmith, H. Hepcidin regulation by innate immune and infectious stimuli. Blood 2011, 118, 4129-4139. [CrossRef] [PubMed]

14. Camaschella, C. New insights into iron deficiency and iron deficiency anemia. Blood Rev. 2017, 31, 225-233. [CrossRef] [PubMed]

15. Weiss, G.; Goodnough, L.T. Anemia of chronic disease. N. Engl. J. Med. 2005, 352, 1011-1023. [CrossRef] [PubMed]

16. Theurl, I.; Aigner, E.; Theurl, M.; Nairz, M.; Seifert, M.; Schroll, A.; Sonnweber, T.; Eberwein, L.; Witcher, D.R.; Murphy, A.T.; et al. Regulation of iron homeostasis in anemia of chronic disease and iron deficiency anemia: Diagnostic and therapeutic implications. Blood 2009, 113, 5277-5286. [CrossRef] [PubMed] 
17. Stefanova, D.; Raychev, A.; Arezes, J.; Ruchala, P.; Gabayan, V.; Skurnik, M.; Dillon, B.J.; Horwitz, M.A.; Ganz, T.; Bulut, Y.; et al. Endogenous hepcidin and its agonist mediate resistance to selected infections by clearing non-transferrin-bound iron. Blood 2017, 130, 245-257. [CrossRef] [PubMed]

18. Michels, K.R.; Zhang, Z.; Bettina, A.M.; Cagnina, R.E.; Stefanova, D.; Burdick, M.D.; Vaulont, S.; Nemeth, E.; Ganz, T.; Mehrad, B. Hepcidin-mediated iron sequestration protects against bacterial dissemination during pneumonia. JCI Insight 2017, 2, e92002. [CrossRef] [PubMed]

19. Soares, M.P.; Weiss, G. The Iron age of host-microbe interactions. EMBO Rep. 2015, 16, 1482-1500. [CrossRef]

20. Van Assche, G.; Dignass, A.; Bokemeyer, B.; Danese, S.; Gionchetti, P.; Moser, G.; Beaugerie, L.; Gomollón, F.; Häuser, W.; Herrlinger, K.; et al. European Crohn's and Colitis Organisation Second European evidence-based consensus on the diagnosis and management of ulcerative colitis Part 3: Special situations. J. Crohns Colitis 2013, 7, 1-33. [CrossRef]

21. Khan, A.N.; Hameed, A.; Naeem, M.; Murtaza, G.; Shah, N.A. Iron status and hemoglobin level in chronic renal insufficiency. Med. Forum Mon. 2008, 19, 11-15. [CrossRef]

22. Macdougall, I.C.; Bircher, A.J.; Eckardt, K.-U.; Obrador, G.T.; Pollock, C.A.; Stenvinkel, P.; Swinkels, D.W.; Wanner, C.; Weiss, G.; Chertow, G.M.; et al. Iron management in chronic kidney disease: Conclusions from a “Kidney Disease: Improving Global Outcomes" (KDIGO) Controversies Conference. Kidney Int. 2016, 89, 28-39. [CrossRef] [PubMed]

23. Del Vecchio, L.; Locatelli, F. Anemia in chronic kidney disease patients: Treatment recommendations and emerging therapies. Expert Rev. Hematol. 2014, 7, 495-506. [CrossRef] [PubMed]

24. Heath, J.; Weiss, J.; Lavau, C.; Wechsler, D. Iron Deprivation in Cancer-Potential Therapeutic Implications. Nutrients 2013, 5, 2836-2859. [CrossRef] [PubMed]

25. Weiss, G.; Schett, G. Anaemia in inflammatory rheumatic diseases. Nat. Rev. Rheumatol. 2013, 9, $205-215$. [CrossRef] [PubMed]

26. Weiss, G.; Ganz, T.; Goodnough, L.T. Anemia of inflammation. Blood 2018. [CrossRef] [PubMed]

27. Busti, F.; Marchi, G.; Ugolini, S.; Castagna, A.; Girelli, D. Anemia and Iron Deficiency in Cancer Patients: Role of Iron Replacement Therapy. Pharmaceuticals 2018, 11, 94. [CrossRef]

28. Camaschella, C. Iron-Deficiency Anemia. N. Engl. J. Med. 2015, 373, 484-486. [CrossRef]

29. Weiss, G.; Schaible, U.E. Macrophage defense mechanisms against intracellular bacteria. Immunol. Rev. 2015, 264, 182-203. [CrossRef]

30. Recalcati, S.; Locati, M.; Gammella, E.; Invernizzi, P.; Cairo, G. Iron levels in polarized macrophages: Regulation of immunity and autoimmunity. Autoimmun. Rev. 2012, 11, 883-889. [CrossRef]

31. Nairz, M.; Theurl, I.; Swirski, F.K.; Weiss, G. "Pumping iron"-How macrophages handle iron at the systemic, microenvironmental, and cellular levels. Pflügers Arch. Eur. J. Physiol. 2017, 469, 397-418. [CrossRef] [PubMed]

32. Drakesmith, H.; Prentice, A.M. Hepcidin and the iron-infection axis. Science 2012, 338, 768-772. [CrossRef] [PubMed]

33. Ludwiczek, S.; Aigner, E.; Theurl, I.; Weiss, G. Cytokine-mediated regulation of iron transport in human monocytic cells. Blood 2003, 101, 4148-4154. [CrossRef] [PubMed]

34. Weiss, G.; Bogdan, C.; Hentze, M.W. Pathways for the regulation of macrophage iron metabolism by the anti-inflammatory cytokines IL-4 and IL-13. J. Immunol. 1997, 158, 420-425. [PubMed]

35. Pantopoulos, K.; Weiss, G.; Hentze, M.W. Nitric oxide and oxidative stress $\left(\mathrm{H}_{2} \mathrm{O}_{2}\right)$ control mammalian iron metabolism by different pathways. Mol. Cell. Biol. 1996, 16, 3781-3788. [CrossRef] [PubMed]

36. Byrd, T.F.; Horwitz, M.A. Regulation of transferrin receptor expression and ferritin content in human mononuclear phagocytes. Coordinate upregulation by iron transferrin and downregulation by interferon gamma. J. Clin. Investig. 1993, 91, 969-976. [CrossRef] [PubMed]

37. Mulero, V.; Brock, J.H. Regulation of iron metabolism in murine J774 macrophages: Role of nitric oxide-dependent and -independent pathways following activation with gamma interferon and lipopolysaccharide. Blood 1999, 94, 2383-2389. [CrossRef]

38. Tilg, H.; Ulmer, H.; Kaser, A.; Weiss, G. Role of IL-10 for Induction of Anemia During Inflammation. J. Immunol. 2002, 169, 2204-2209. [CrossRef]

39. Ganz, T.; Nemeth, E. Iron homeostasis in host defence and inflammation. Nat. Rev. Immunol. 2015, 15, 500-510. [CrossRef] 
40. Nairz, M.; Schroll, A.; Haschka, D.; Dichtl, S.; Tymoszuk, P.; Demetz, E.; Moser, P.; Haas, H.; Fang, F.C.; Theurl, I.; et al. Genetic and Dietary Iron Overload Differentially Affect the Course of Salmonella Typhimurium Infection. Front. Cell. Infect. Microbiol. 2017, 7, 110. [CrossRef]

41. Barber, M.F.; Elde, N.C. Escape from bacterial iron piracy through rapid evolution of transferrin. Science 2014, 346, 1362-1366. [CrossRef] [PubMed]

42. Weiss, G.; Fuchs, D.; Hausen, A.; Reibnegger, G.; Werner, E.R.; Werner-Felmayer, G.; Wachter, H. Iron modulates interferon-gamma effects in the human myelomonocytic cell line THP-1. Exp. Hematol. 1992, 20, 605-610. [PubMed]

43. Weiss, G.; Werner-Felmayer, G.; Werner, E.R.; Grunewald, K.; Wachter, H.; Hentze, M.W. Iron regulates nitric oxide synthase activity by controlling nuclear transcription. J. Exp. Med. 1994, 180, 969-976. [CrossRef] [PubMed]

44. Mencacci, A.; Cenci, E.; Boelaert, J.R.; Bucci, P.; Mosci, P.; Fè d'Ostiani, C.; Bistoni, F.; Romani, L. Iron overload alters innate and T helper cell responses to Candida albicans in mice. J. Infect. Dis. 1997, 175, 1467-1476. [CrossRef] [PubMed]

45. Oexle, H.; Kaser, A.; Möst, J.; Bellmann-Weiler, R.; Werner, E.R.; Werner-Felmayer, G.; Weiss, G. Pathways for the regulation of interferon-gamma-inducible genes by iron in human monocytic cells. J. Leukoc. Biol. 2003, 74, 287-294. [CrossRef] [PubMed]

46. Cherayil, B.J.; Ellenbogen, S.; Shanmugam, N.N. Iron and intestinal immunity. Curr. Opin. Gastroenterol. 2011, 27, 523-528. [CrossRef] [PubMed]

47. Cassat, J.E.; Skaar, E.P. Iron in Infection and Immunity. Cell Host Microbe 2013, 13, 509-519. [CrossRef]

48. Theurl, I.; Theurl, M.; Seifert, M.; Mair, S.; Nairz, M.; Rumpold, H.; Zoller, H.; Bellmann-Weiler, R.; Niederegger, H.; Talasz, H.; et al. Autocrine formation of hepcidin induces iron retention in human monocytes. Blood 2008, 111, 2392-2399. [CrossRef]

49. Peyssonnaux, C.; Zinkernagel, A.S.; Datta, V.; Lauth, X.; Johnson, R.S.; Nizet, V. TLR4-dependent hepcidin expression by myeloid cells in response to bacterial pathogens. Blood 2006, 107, 3727-3732. [CrossRef]

50. Nairz, M.; Schleicher, U.; Schroll, A.; Sonnweber, T.; Theurl, I.; Ludwiczek, S.; Talasz, H.; Brandacher, G.; Moser, P.L.; Muckenthaler, M.U.; et al. Nitric oxide-mediated regulation of ferroportin-1 controls macrophage iron homeostasis and immune function in Salmonella infection. J. Exp. Med. 2013, 210, 855-873. [CrossRef]

51. Wu, A.; Tymoszuk, P.; Haschka, D.; Heeke, S.; Dichtl, S.; Petzer, V.; Seifert, M.; Hilbe, R.; Sopper, S.; Talasz, H.; et al. Salmonella Utilizes Zinc To Subvert Antimicrobial Host Defense of Macrophages via Modulation of NF-кB Signaling. Infect. Immun. 2017, 85. [CrossRef] [PubMed]

52. Paradkar, P.N.; De Domenico, I.; Durchfort, N.; Zohn, I.; Kaplan, J.; Ward, D.M. Iron depletion limits intracellular bacterial growth in macrophages. Blood 2008, 112, 866-874. [CrossRef] [PubMed]

53. Ben-Othman, R.; Flannery, A.R.; Miguel, D.C.; Ward, D.M.; Kaplan, J.; Andrews, N.W. Leishmania-mediated inhibition of iron export promotes parasite replication in macrophages. PLoS Pathog. 2014, 10, e1003901. [CrossRef] [PubMed]

54. Wu, Q.; Shen, Y.; Tao, Y.; Wei, J.; Wang, H.; An, P.; Zhang, Z.; Gao, H.; Zhou, T.; Wang, F.; et al. Hemojuvelin regulates the innate immune response to peritoneal bacterial infection in mice. Cell Discov. 2017, 3, 17028. [CrossRef] [PubMed]

55. Neumann, W.; Hadley, R.C.; Nolan, E.M. Transition metals at the host-pathogen interface: How Neisseria exploit human metalloproteins for acquiring iron and zinc. Essays Biochem. 2017, 61, 211-223. [CrossRef]

56. Weiss, G.; Carver, P.L. Role of divalent metals in infectious disease susceptibility and outcome. Clin. Microbiol. Infect. 2018, 24, 16-23. [CrossRef] [PubMed]

57. Skaar, E.P.; Raffatellu, M. Metals in infectious diseases and nutritional immunity. Metallomics 2015, 7, $926-928$. [CrossRef] [PubMed]

58. Kim, A.; Fung, E.; Parikh, S.G.; Valore, E.V.; Gabayan, V.; Nemeth, E.; Ganz, T. A mouse model of anemia of inflammation: Complex pathogenesis with partial dependence on hepcidin. Blood 2014, 123, 1129-1136. [CrossRef] [PubMed]

59. Nairz, M.; Ferring-Appel, D.; Casarrubea, D.; Sonnweber, T.; Viatte, L.; Schroll, A.; Haschka, D.; Fang, F.C.; Hentze, M.W.; Weiss, G.; et al. Iron Regulatory Proteins Mediate Host Resistance to Salmonella Infection. Cell Host Microbe 2015, 18, 254-261. [CrossRef] [PubMed] 
60. Guida, C.; Altamura, S.; Klein, F.A.; Galy, B.; Boutros, M.; Ulmer, A.J.; Hentze, M.W.; Muckenthaler, M.U. A novel inflammatory pathway mediating rapid hepcidin-independent hypoferremia. Blood 2015, 125, 2265-2275. [CrossRef] [PubMed]

61. Moreira, A.C.; Neves, J.V.; Silva, T.; Oliveira, P.; Gomes, M.S.; Rodrigues, P.N. Hepcidin-(in)dependent mechanisms of iron metabolism regulation during infection by Listeria and Salmonella. Infect. Immun. 2017, 85, IAI-00353. [CrossRef] [PubMed]

62. Mitterstiller, A.-M.; Haschka, D.; Dichtl, S.; Nairz, M.; Demetz, E.; Talasz, H.; Soares, M.P.; Einwallner, E.; Esterbauer, H.; Fang, F.C.; et al. Heme oxygenase 1 controls early innate immune response of macrophages to Salmonella Typhimurium infection. Cell. Microbiol. 2016, 18, 1374-1389. [CrossRef] [PubMed]

63. Weis, S.; Carlos, A.R.; Moita, M.R.; Singh, S.; Blankenhaus, B.; Cardoso, S.; Larsen, R.; Rebelo, S.; Schäuble, S.; Del Barrio, L.; et al. Metabolic Adaptation Establishes Disease Tolerance to Sepsis. Cell 2017, 169, 1263.e14-1275.e14. [CrossRef] [PubMed]

64. Gozzelino, R.; Jeney, V.; Soares, M.P. Mechanisms of cell protection by heme oxygenase-1. Annu. Rev. Pharmacol. Toxicol. 2010, 50, 323-354. [CrossRef] [PubMed]

65. Portugal, S.; Carret, C.; Recker, M.; Armitage, A.E.; Gonçalves, L.A.; Epiphanio, S.; Sullivan, D.; Roy, C.; Newbold, C.I.; Drakesmith, H.; et al. Host-mediated regulation of superinfection in malaria. Nat. Med. 2011, 17, 732-737. [CrossRef] [PubMed]

66. Stockman, R. The Treatment of Chlorosis by Iron and some Other Drugs. Br. Med. J. 1893, 1, 942-944. [CrossRef] [PubMed]

67. Nairz, M.; Haschka, D.; Demetz, E.; Weiss, G. Iron at the interface of immunity and infection. Front. Pharmacol. 2014, 5, 152. [CrossRef] [PubMed]

68. Weiss, G. Anemia of Chronic Disorders: New Diagnostic Tools and New Treatment Strategies. Semin. Hematol. 2015, 52, 313-320. [CrossRef]

69. Nairz, M.; Theurl, I.; Wolf, D.; Weiss, G. Iron deficiency or anemia of inflammation?: Differential diagnosis and mechanisms of anemia of inflammation. Wien. Med. Wochenschr. 2016, 166, 411-423. [CrossRef]

70. Torti, F.M.; Torti, S.V. Regulation of ferritin genes and protein. Blood 2002, 99, 3505-3516. [CrossRef]

71. Garcia-Casal, M.N.; Peña-Rosas, J.P.; Pasricha, S.-R. Rethinking ferritin cutoffs for iron deficiency and overload. Lancet Haematol. 2014, 1, e92-e94. [CrossRef]

72. Suchdev, P.S.; Namaste, S.M.; Aaron, G.J.; Raiten, D.J.; Brown, K.H.; Flores-Ayala, R. BRINDA Working Group Overview of the Biomarkers Reflecting Inflammation and Nutritional Determinants of Anemia (BRINDA) Project. Adv. Nutr. 2016, 7, 349-356. [CrossRef] [PubMed]

73. Gale, E.; Torrance, J.; Bothwell, T. The quantitative estimation of total iron stores in human bone marrow. J. Clin. Investig. 1963, 42, 1076-1082. [CrossRef] [PubMed]

74. Grote Beverborg, N.; Klip, I.T.; Meijers, W.C.; Voors, A.A.; Vegter, E.L.; van der Wal, H.H.; Swinkels, D.W.; van Pelt, J.; Mulder, A.B.; Bulstra, S.K.; et al. Definition of Iron Deficiency Based on the Gold Standard of Bone Marrow Iron Staining in Heart Failure Patients. Circ. Heart Fail. 2018, 11, e004519. [CrossRef] [PubMed]

75. Speeckaert, M.M.; Speeckaert, R.; Delanghe, J.R. Biological and clinical aspects of soluble transferrin receptor. Crit. Rev. Clin. Lab. Sci. 2010, 47, 213-228. [CrossRef] [PubMed]

76. Brugnara, C.; Mohandas, N. Red cell indices in classification and treatment of anemias. Curr. Opin. Hematol. 2013, 20, 222-230. [CrossRef] [PubMed]

77. Harms, K.; Kaiser, T. Beyond soluble transferrin receptor: Old challenges and new horizons. Best Pract. Res. Clin. Endocrinol. Metab. 2015, 29, 799-810. [CrossRef] [PubMed]

78. Aguilar, R.; Moraleda, C.; Quintó, L.; Renom, M.; Mussacate, L.; Macete, E.; Aguilar, J.L.; Alonso, P.L.; Menéndez, C. Challenges in the Diagnosis of Iron Deficiency in Children Exposed to High Prevalence of Infections. PLoS ONE 2012, 7, e50584. [CrossRef]

79. Castel, R.; Tax, M.G.H.M.; Droogendijk, J.; Leers, M.P.G.; Beukers, R.; Levin, M.-D.; Sonneveld, P.; Berendes, P.B. The transferrin $/ \log$ (ferritin) ratio: A new tool for the diagnosis of iron deficiency anemia. Clin. Chem. Lab. Med. 2012, 50, 1343-1349. [CrossRef]

80. Lasocki, S.; Baron, G.; Driss, F.; Westerman, M.; Puy, H.; Boutron, I.; Beaumont, C.; Montravers, P. Diagnostic accuracy of serum hepcidin for iron deficiency in critically ill patients with anemia. Intensive Care Med. 2010, 36, 1044-1048. [CrossRef] 
81. Shu, T.; Jing, C.; Lv, Z.; Xie, Y.; Xu, J.; Wu, J. Hepcidin in tumor-related iron deficiency anemia and tumor-related anemia of chronic disease: Pathogenic mechanisms and diagnosis. Eur. J. Haematol. 2015, 94, 67-73. [CrossRef] [PubMed]

82. Bergamaschi, G.; Di Sabatino, A.; Albertini, R.; Costanzo, F.; Guerci, M.; Masotti, M.; Pasini, A.; Massari, A.; Campostrini, N.; Corbella, M.; et al. Serum Hepcidin in Inflammatory Bowel Diseases. Inflamm. Bowel Dis. 2013, 19, 2166-2172. [CrossRef] [PubMed]

83. Van Santen, S.; van Dongen-Lases, E.C.; de Vegt, F.; Laarakkers, C.M.M.; van Riel, P.L.C.M.; van Ede, A.E.; Swinkels, D.W. Hepcidin and hemoglobin content parameters in the diagnosis of iron deficiency in rheumatoid arthritis patients with anemia. Arthritis Rheum. 2011, 63, 3672-3680. [CrossRef] [PubMed]

84. Bregman, D.B.; Morris, D.; Koch, T.A.; He, A.; Goodnough, L.T. Hepcidin levels predict nonresponsiveness to oral iron therapy in patients with iron deficiency anemia. Am. J. Hematol. 2013, 88, 97-101. [CrossRef] [PubMed]

85. Steensma, D.P.; Sasu, B.J.; Sloan, J.A.; Tomita, D.K.; Loprinzi, C.L. Serum hepcidin levels predict response to intravenous iron and darbepoetin in chemotherapy-associated anemia. Blood 2015, 125, 3669-3671. [CrossRef] [PubMed]

86. Theurl, M.; Nairz, M.; Schroll, A.; Sonnweber, T.; Asshoff, M.; Haschka, D.; Seifert, M.; Willenbacher, W.; Wilflingseder, D.; Posch, W.; et al. Hepcidin as a predictive factor and therapeutic target in erythropoiesis-stimulating agent treatment for anemia of chronic disease in rats. Haematologica 2014, 99, 1516-1524. [CrossRef] [PubMed]

87. Takasawa, K.; Takaeda, C.; Maeda, T.; Ueda, N.; Takasawa, K.; Takaeda, C.; Maeda, T.; Ueda, N. Hepcidin-25, Mean Corpuscular Volume, and Ferritin as Predictors of Response to Oral Iron Supplementation in Hemodialysis Patients. Nutrients 2014, 7, 103-118. [CrossRef] [PubMed]

88. Gaillard, C.A.; Bock, A.H.; Carrera, F.; Eckardt, K.-U.; Van Wyck, D.B.; Bansal, S.S.; Cronin, M.; Meier, Y.; Larroque, S.; Roger, S.D.; et al. Hepcidin Response to Iron Therapy in Patients with Non-Dialysis Dependent CKD: An Analysis of the FIND-CKD Trial. PLoS ONE 2016, 11, e0157063. [CrossRef]

89. Ford, B.A.; Eby, C.S.; Scott, M.G.; Coyne, D.W. Intra-individual variability in serum hepcidin precludes its use as a marker of iron status in hemodialysis patients. Kidney Int. 2010, 78, 769-773. [CrossRef]

90. Tessitore, N.; Girelli, D.; Campostrini, N.; Bedogna, V.; Pietro Solero, G.; Castagna, A.; Melilli, E.; Mantovani, W.; De Matteis, G.; Olivieri, O.; et al. Hepcidin is not useful as a biomarker for iron needs in haemodialysis patients on maintenance erythropoiesis-stimulating agents. Nephrol. Dial. Transplant. 2010, 25, 3996-4002. [CrossRef]

91. Kautz, L.; Jung, G.; Nemeth, E.; Ganz, T. Erythroferrone contributes to recovery from anemia of inflammation. Blood 2014, 124, 2569-2574. [CrossRef] [PubMed]

92. Sonnweber, T.; Nachbaur, D.; Schroll, A.; Nairz, M.; Seifert, M.; Demetz, E.; Haschka, D.; Mitterstiller, A.M.; Kleinsasser, A.; Burtscher, M.; et al. Hypoxia induced downregulation of hepcidin is mediated by platelet derived growth factor BB. Gut 2014, 63, 1951-1959. [CrossRef] [PubMed]

93. Haase, V.H. Regulation of erythropoiesis by hypoxia-inducible factors. Blood Rev. 2013, 27, 41-53. [CrossRef] [PubMed]

94. Hanudel, M.R.; Rappaport, M.; Chua, K.; Gabayan, V.; Qiao, B.; Jung, G.; Salusky, I.B.; Ganz, T.; Nemeth, E. Levels of the erythropoietin-responsive hormone erythroferrone in mice and humans with chronic kidney disease. Haematologica 2018, 103, e141-e142. [CrossRef] [PubMed]

95. Ganz, T.; Jung, G.; Naeim, A.; Ginzburg, Y.; Pakbaz, Z.; Walter, P.B.; Kautz, L.; Nemeth, E. Immunoassay for human serum erythroferrone. Blood 2017, 130, 1243-1246. [CrossRef]

96. Mastrogiannaki, M.; Matak, P.; Mathieu, J.R.R.; Delga, S.; Mayeux, P.; Vaulont, S.; Peyssonnaux, C. Hepatic hypoxia-inducible factor-2 down-regulates hepcidin expression in mice through an erythropoietin-mediated increase in erythropoiesis. Haematologica 2012, 97, 827-834. [CrossRef]

97. Van der Vorm, L.N.; Hendriks, J.C.M.; Laarakkers, C.M.; Klaver, S.; Armitage, A.E.; Bamberg, A.; Geurts-Moespot, A.J.; Girelli, D.; Herkert, M.; Itkonen, O.; et al. Toward Worldwide Hepcidin Assay Harmonization: Identification of a Commutable Secondary Reference Material. Clin. Chem. 2016, 62, 993-1001. [CrossRef] 
98. Burisch, J.; Vegh, Z.; Katsanos, K.H.; Christodoulou, D.K.; Lazar, D.; Goldis, A.; O’Morain, C.; Fernandez, A.; Pereira, S.; Myers, S.; et al. Occurrence of Anaemia in the First Year of Inflammatory Bowel Disease in a European Population-based Inception Cohort-An ECCO-EpiCom Study. J. Crohns Colitis 2017, 11, 1213-1222. [CrossRef]

99. Ershler, W.B.; Chen, K.; Reyes, E.B.; Dubois, R. Economic Burden of Patients with Anemia in Selected Diseases. Value Heal. 2005, 8, 629-638. [CrossRef]

100. Wouters, H.J.C.M.; van der Klauw, M.M.; de Witte, T.; Stauder, R.; Swinkels, D.W.; Wolffenbuttel, B.H.R.; Huls, G. Association of anemia with health-related quality of life and survival: A large population-based cohort study. Haematologica 2018. [CrossRef]

101. Nishimoto, N.; Sasai, M.; Shima, Y.; Nakagawa, M.; Matsumoto, T.; Shirai, T.; Kishimoto, T.; Yoshizaki, K. Improvement in Castleman's disease by humanized anti-interleukin-6 receptor antibody therapy. Blood 2000, 95, 56-61. [PubMed]

102. Yoshizaki, K.; Matsuda, T.; Nishimoto, N.; Kuritani, T.; Taeho, L.; Aozasa, K.; Nakahata, T.; Kawai, H.; Tagoh, H.; Komori, T. Pathogenic significance of interleukin-6 (IL-6/BSF-2) in Castleman's disease. Blood 1989, 74, 1360-1367. [CrossRef] [PubMed]

103. Song, S.-N.J.; Tomosugi, N.; Kawabata, H.; Ishikawa, T.; Nishikawa, T.; Yoshizaki, K. Down-regulation of hepcidin resulting from long-term treatment with an anti-IL-6 receptor antibody (tocilizumab) improves anemia of inflammation in multicentric Castleman disease. Blood 2010, 116, 3627-3634. [CrossRef] [PubMed]

104. Kawabata, H.; Tomosugi, N.; Kanda, J.; Tanaka, Y.; Yoshizaki, K.; Uchiyama, T. Anti-interleukin 6 receptor antibody tocilizumab reduces the level of serum hepcidin in patients with multicentric Castleman's disease. Haematologica 2007, 92, 857-858. [CrossRef] [PubMed]

105. Kurzrock, R.; Voorhees, P.M.; Casper, C.; Furman, R.R.; Fayad, L.; Lonial, S.; Borghaei, H.; Jagannath, S.; Sokol, L.; Usmani, S.Z.; et al. A phase I, open-label study of siltuximab, an anti-IL-6 monoclonal antibody, in patients with B-cell non-hodgkin lymphoma, multiple myeloma, or castleman disease. Clin. Cancer Res. 2013, 19, 3659-3670. [CrossRef] [PubMed]

106. Casper, C.; Chaturvedi, S.; Munshi, N.; Wong, R.; Qi, M.; Schaffer, M.; Bandekar, R.; Hall, B.; van de Velde, H.; Vermeulen, J.; et al. Analysis of Inflammatory and Anemia-Related Biomarkers in a Randomized, Double-Blind, Placebo-Controlled Study of Siltuximab (Anti-IL6 Monoclonal Antibody) in Patients With Multicentric Castleman Disease. Clin. Cancer Res. 2015, 21, 4294-4304. [CrossRef] [PubMed]

107. Angevin, E.; Tabernero, J.; Elez, E.; Cohen, S.J.; Bahleda, R.; van Laethem, J.-L.; Ottensmeier, C.; Lopez-Martin, J.A.; Clive, S.; Joly, F.; et al. A phase I/II, multiple-dose, dose-escalation study of siltuximab, an anti-interleukin-6 monoclonal antibody, in patients with advanced solid tumors. Clin. Cancer Res. 2014, 20, 2192-2204. [CrossRef]

108. Madeddu, C.; Gramignano, G.; Kotsonis, P.; Coghe, F.; Atzeni, V.; Scartozzi, M.; Macciò, A. Microenvironmental M1 tumor-associated macrophage polarization influences cancer-related anemia in advanced ovarian cancer: Key role of Interleukin-6. Haematologica 2018. [CrossRef]

109. Noguchi-Sasaki, M.; Sasaki, Y.; Shimonaka, Y.; Mori, K.; Fujimoto-Ouchi, K. Treatment with anti-IL-6 receptor antibody prevented increase in serum hepcidin levels and improved anemia in mice inoculated with IL-6-producing lung carcinoma cells. BMC Cancer 2016, 16, 270. [CrossRef]

110. Bergamaschi, G.; Di Sabatino, A.; Albertini, R.; Ardizzone, S.; Biancheri, P.; Bonetti, E.; Cassinotti, A.; Cazzola, P.; Markopoulos, K.; Massari, A.; et al. Prevalence and pathogenesis of anemia in inflammatory bowel disease. Influence of anti-tumor necrosis factor- treatment. Haematologica 2010, 95, 199-205. [CrossRef]

111. Bes, C.; Yazici, A.; Soy, M. Monoclonal anti-TNF antibodies can elevate hemoglobin level in patients with ankylosing spondylitis. Rheumatol. Int. 2013, 33, 1415-1418. [CrossRef] [PubMed]

112. Davis, D.; Charles, P.J.; Potter, A.; Feldmann, M.; Maini, R.N.; Elliott, M.J. Anaemia of chronic disease in rheumatoid arthritis: In vivo effects of tumour necrosis factor alpha blockade. Br. J. Rheumatol. 1997, 36, 950-956. [CrossRef] [PubMed]

113. Doyle, M.K.; Rahman, M.U.; Frederick, B.; Birbara, C.A.; de Vries, D.; Toedter, G.; Wu, X.; Chen, D.; Ranganath, V.K.; Westerman, M.E.; et al. Effects of subcutaneous and intravenous golimumab on inflammatory biomarkers in patients with rheumatoid arthritis: Results of a phase 1, randomized, open-label trial. Rheumatology 2013, 52, 1214-1219. [CrossRef] [PubMed] 
114. Papadaki, H.A.; Kritikos, H.D.; Valatas, V.; Boumpas, D.T.; Eliopoulos, G.D. Anemia of chronic disease in rheumatoid arthritis is associated with increased apoptosis of bone marrow erythroid cells: Improvement following anti-tumor necrosis factor- $\alpha$ antibody therapy. Blood 2002, 100, 474-482. [CrossRef] [PubMed]

115. Cavallaro, F.; Duca, L.; Pisani, L.F.; Rigolini, R.; Spina, L.; Tontini, G.E.; Munizio, N.; Costa, E.; Cappellini, M.D.; Vecchi, M.; et al. Anti-TNF-Mediated Modulation of Prohepcidin Improves Iron Availability in Inflammatory Bowel Disease, in an IL-6-Mediated Fashion. Can. J. Gastroenterol. Hepatol. 2017, 2017, 1-12. [CrossRef] [PubMed]

116. Song, S.-N.J.; Iwahashi, M.; Tomosugi, N.; Uno, K.; Yamana, J.; Yamana, S.; Isobe, T.; Ito, H.; Kawabata, H.; Yoshizaki, K. Comparative evaluation of the effects of treatment with tocilizumab and TNF- $\alpha$ inhibitors on serum hepcidin, anemia response and disease activity in rheumatoid arthritis patients. Arthritis Res. Ther. 2013, 15, R141. [CrossRef] [PubMed]

117. Koutroubakis, I.E.; Ramos-Rivers, C.; Regueiro, M.; Koutroumpakis, E.; Click, B.; Schwartz, M.; Swoger, J.; Baidoo, L.; Hashash, J.G.; Barrie, A.; et al. The Influence of Anti-tumor Necrosis Factor Agents on Hemoglobin Levels of Patients with Inflammatory Bowel Disease. Inflamm. Bowel Dis. 2015, 21, 1587-1593. [CrossRef] [PubMed]

118. Pardanani, A.; Finke, C.; Abdelrahman, R.A.; Lasho, T.L.; Tefferi, A. Associations and prognostic interactions between circulating levels of hepcidin, ferritin and inflammatory cytokines in primary myelofibrosis. Am. J. Hematol. 2013, 88, 312-316. [CrossRef]

119. Parganas, E.; Wang, D.; Stravopodis, D.; Topham, D.J.; Marine, J.C.; Teglund, S.; Vanin, E.F.; Bodner, S.; Colamonici, O.R.; van Deursen, J.M.; et al. Jak2 is essential for signaling through a variety of cytokine receptors. Cell 1998, 93, 385-395. [CrossRef]

120. Pardanani, A.; Gotlib, J.R.; Jamieson, C.; Cortes, J.E.; Talpaz, M.; Stone, R.M.; Silverman, M.H.; Gilliland, D.G.; Shorr, J.; Tefferi, A. Safety and Efficacy of TG101348, a Selective JAK2 Inhibitor, in Myelofibrosis. J. Clin. Oncol. 2011, 29, 789-796. [CrossRef]

121. Verstovsek, S.; Mesa, R.A.; Gotlib, J.; Levy, R.S.; Gupta, V.; DiPersio, J.F.; Catalano, J.V.; Deininger, M.; Miller, C.; Silver, R.T.; et al. A Double-Blind, Placebo-Controlled Trial of Ruxolitinib for Myelofibrosis. N. Engl. J. Med. 2012, 366, 799-807. [CrossRef] [PubMed]

122. Pardanani, A.; Laborde, R.R.; Lasho, T.L.; Finke, C.; Begna, K.; Al-Kali, A.; Hogan, W.J.; Litzow, M.R.; Leontovich, A.; Kowalski, M.; et al. Safety and efficacy of CYT387, a JAK1 and JAK2 inhibitor, in myelofibrosis. Leukemia 2013, 27, 1322-1327. [CrossRef]

123. Asshoff, M.; Petzer, V.; Warr, M.R.; Haschka, D.; Tymoszuk, P.; Demetz, E.; Seifert, M.; Posch, W.; Nairz, M.; Maciejewski, P.; et al. Momelotinib inhibits ACVR1/ALK2, decreases hepcidin production, and ameliorates anemia of chronic disease in rodents. Blood 2017, 129, 1823-1830. [CrossRef] [PubMed]

124. Cornez, I.; Yajnanarayana, S.P.; Wolf, A.M.; Wolf, D. JAK/STAT disruption induces immuno-deficiency: Rationale for the development of JAK inhibitors as immunosuppressive drugs. Mol. Cell. Endocrinol. 2017, 451, 88-96. [CrossRef] [PubMed]

125. Nielsen, O.; Soendergaard, C.; Vikner, M.; Weiss, G. Rational Management of Iron-Deficiency Anaemia in Inflammatory Bowel Disease. Nutrients 2018, 10, 82. [CrossRef] [PubMed]

126. Theurl, I.; Schroll, A.; Nairz, M.; Seifert, M.; Theurl, M.; Sonnweber, T.; Kulaksiz, H.; Weiss, G. Pathways for the regulation of hepcidin expression in anemia of chronic disease and iron deficiency anemia in vivo. Haematologica 2011, 96, 1761-1769. [CrossRef] [PubMed]

127. Lasocki, S.; Millot, S.; Andrieu, V.; Lettéron, P.; Pilard, N.; Muzeau, F.; Thibaudeau, O.; Montravers, P.; Beaumont, C. Phlebotomies or erythropoietin injections allow mobilization of iron stores in a mouse model mimicking intensive care anemia. Crit. Care Med. 2008, 36, 2388-2394. [CrossRef]

128. Del Vecchio, L.; Locatelli, F. Clinical practice guidelines on iron therapy: A critical evaluation. Hemodial. Int. 2017, 21, S125-S131. [CrossRef]

129. Drüeke, T.B.; Parfrey, P.S. Summary of the KDIGO guideline on anemia and comment: Reading between the (guide)line(s). Kidney Int. 2012, 82, 952-960. [CrossRef]

130. Locatelli, F.; Bárány, P.; Covic, A.; De Francisco, A.; Del Vecchio, L.; Goldsmith, D.; Hörl, W.; London, G.; Vanholder, R.; Van Biesen, W.; et al. Kidney Disease: Improving Global Outcomes guidelines on anaemia management in chronic kidney disease: A European Renal Best Practice position statement. Nephrol. Dial. Transplant. 2013, 28, 1346-1359. [CrossRef] 
131. The National Collaborating Centre for Chronic Conditions. Anaemia Management in Chronic Kidney Disease: National Clinical Guideline for Management in Adults and Children; Royal College of Physicians: London, UK, 2006; ISBN 9781860162930.

132. Kliger, A.S.; Foley, R.N.; Goldfarb, D.S.; Goldstein, S.L.; Johansen, K.; Singh, A.; Szczech, L. KDOQI US Commentary on the 2012 KDIGO Clinical Practice Guideline for Anemia in CKD. Am. J. Kidney Dis. 2013, 62, 849-859. [CrossRef] [PubMed]

133. Singh, A.K.; Szczech, L.; Tang, K.L.; Barnhart, H.; Sapp, S.; Wolfson, M.; Reddan, D. CHOIR Investigators Correction of Anemia with Epoetin Alfa in Chronic Kidney Disease. N. Engl. J. Med. 2006, 355, 2085-2098. [CrossRef] [PubMed]

134. Drüeke, T.B.; Locatelli, F.; Clyne, N.; Eckardt, K.-U.; Macdougall, I.C.; Tsakiris, D.; Burger, H.-U.; Scherhag, A. CREATE Investigators Normalization of hemoglobin level in patients with chronic kidney disease and anemia. N. Engl. J. Med. 2006, 355, 2071-2084. [CrossRef] [PubMed]

135. Macdougall, I.C.; Bock, A.H.; Carrera, F.; Eckardt, K.-U.; Gaillard, C.; Van Wyck, D.; Roubert, B.; Nolen, J.G.; Roger, S.D. FIND-CKD Study Investigators FIND-CKD: A randomized trial of intravenous ferric carboxymaltose versus oral iron in patients with chronic kidney disease and iron deficiency anaemia. Nephrol. Dial. Transplant. 2014, 29, 2075-2084. [CrossRef] [PubMed]

136. Agarwal, R.; Kusek, J.W.; Pappas, M.K. A randomized trial of intravenous and oral iron in chronic kidney disease. Kidney Int. 2015, 88, 905-914. [CrossRef] [PubMed]

137. Gasche, C.; Lomer, M.C.E.; Cavill, I.; Weiss, G. Iron, anaemia, and inflammatory bowel diseases. Gut 2004, 53, 1190-1197. [CrossRef] [PubMed]

138. Nielsen, O.H.; Ainsworth, M.; Coskun, M.; Weiss, G. Management of Iron-Deficiency Anemia in Inflammatory Bowel Disease. Medicine 2015, 94, e963. [CrossRef]

139. Gasche, C.; Dejaco, C.; Reinisch, W.; Tillinger, W.; Waldhoer, T.; Fueger, G.F.; Lochs, H.; Gangl, A. Sequential Treatment of Anemia in Ulcerative Colitis with Intravenous Iron and Erythropoietin. Digestion 1999, 60, 262-267. [CrossRef]

140. Dignass, A.U.; Gasche, C.; Bettenworth, D.; Birgegård, G.; Danese, S.; Gisbert, J.P.; Gomollon, F.; Iqbal, T.; Katsanos, K.; Koutroubakis, I.; et al. European Consensus on the Diagnosis and Management of Iron Deficiency and Anaemia in Inflammatory Bowel Diseases. J. Crohns Colitis 2015, 9, 211-222. [CrossRef]

141. Gisbert, J.P.; Bermejo, F.; Pajares, R.; Pérez-Calle, J.-L.; Rodríguez, M.; Algaba, A.; Mancenido, N.; de la Morena, F.; Carneros, J.A.; McNicholl, A.G.; et al. Oral and intravenous iron treatment in inflammatory bowel disease: Hematological response and quality of life improvement. Inflamm. Bowel Dis. 2009, 15, 1485-1491. [CrossRef]

142. Reinisch, W.; Staun, M.; Tandon, R.K.; Altorjay, I.; Thillainayagam, A.V.; Gratzer, C.; Nijhawan, S.; Thomsen, L.L. A Randomized, Open-Label, Non-Inferiority Study of Intravenous Iron Isomaltoside 1000 (Monofer) Compared with Oral Iron for Treatment of Anemia in IBD (PROCEED). Am. J. Gastroenterol. 2013, 108, 1877-1888. [CrossRef] [PubMed]

143. Lee, T.; Clavel, T.; Smirnov, K.; Schmidt, A.; Lagkouvardos, I.; Walker, A.; Lucio, M.; Michalke, B.; Schmitt-Kopplin, P.; Fedorak, R.; et al. Oral versus intravenous iron replacement therapy distinctly alters the gut microbiota and metabolome in patients with IBD. Gut 2017, 66, 863-871. [CrossRef] [PubMed]

144. Onken, J.E.; Bregman, D.B.; Harrington, R.A.; Morris, D.; Acs, P.; Akright, B.; Barish, C.; Bhaskar, B.S.; Smith-Nguyen, G.N.; Butcher, A.; et al. A multicenter, randomized, active-controlled study to investigate the efficacy and safety of intravenous ferric carboxymaltose in patients with iron deficiency anemia. Transfusion 2014, 54, 306-315. [CrossRef] [PubMed]

145. Kulnigg, S.; Stoinov, S.; Simanenkov, V.; Dudar, L.V.; Karnafel, W.; Garcia, L.C.; Sambuelli, A.M.; D’Haens, G.; Gasche, C. A Novel Intravenous Iron Formulation for Treatment of Anemia in Inflammatory Bowel Disease: The Ferric Carboxymaltose (FERINJECT ${ }^{\circledR}$ ) Randomized Controlled Trial. Am. J. Gastroenterol. 2008, 103, 1182-1192. [CrossRef] [PubMed]

146. Lindgren, S.; Wikman, O.; Befrits, R.; Blom, H.; Eriksson, A.; Grännö, C.; Ung, K.-A.; Hjortswang, H.; Lindgren, A.; Unge, P. Intravenous iron sucrose is superior to oral iron sulphate for correcting anaemia and restoring iron stores in IBD patients: A randomized, controlled, evaluator-blind, multicentre study. Scand. J. Gastroenterol. 2009, 44, 838-845. [CrossRef] [PubMed] 
147. Koutroubakis, I.E.; Ramos-Rivers, C.; Regueiro, M.; Koutroumpakis, E.; Click, B.; Schwartz, M.; Swoger, J.; Baidoo, L.; Hashash, J.G.; Barrie, A.; et al. Five-Year Period Prevalence and Characteristics of Anemia in a Large US Inflammatory Bowel Disease Cohort. J. Clin. Gastroenterol. 2016, 50, 638-643. [CrossRef] [PubMed]

148. Iqbal, T.; Stein, J.; Sharma, N.; Kulnigg-Dabsch, S.; Vel, S.; Gasche, C. Clinical Significance of C-Reactive Protein Levels in Predicting Responsiveness to Iron Therapy in Patients with Inflammatory Bowel Disease and Iron Deficiency Anemia. Dig. Dis. Sci. 2015, 60, 1375-1381. [CrossRef] [PubMed]

149. Macdougall, I.C.; White, C.; Anker, S.D.; Bhandari, S.; Farrington, K.; Kalra, P.A.; McMurray, J.J.V.; Murray, H.; Steenkamp, R.; Tomson, C.R.V.; et al. Randomized Trial Comparing Proactive, High-Dose versus Reactive, Low-Dose Intravenous Iron Supplementation in Hemodialysis (PIVOTAL): Study Design and Baseline Data. Am. J. Nephrol. 2018, 48, 260-268. [CrossRef]

150. Macdougall, I.C.; White, C.; Anker, S.D.; Bhandari, S.; Farrington, K.; Kalra, P.A.; McMurray, J.J.V.; Murray, H.; Tomson, C.R.V.; Wheeler, D.C.; et al. Intravenous Iron in Patients Undergoing Maintenance Hemodialysis. N. Engl. J. Med. 2018. [CrossRef]

151. Drakesmith, H.; Nemeth, E.; Ganz, T. Ironing out Ferroportin. Cell Metab. 2015, 22, 777-787. [CrossRef]

152. Crielaard, B.J.; Lammers, T.; Rivella, S. Targeting iron metabolism in drug discovery and delivery. Nat. Rev. Drug Discov. 2017, 16, 400-423. [CrossRef] [PubMed]

153. Sebastiani, G.; Wilkinson, N.; Pantopoulos, K. Pharmacological Targeting of the Hepcidin/Ferroportin Axis. Front. Pharmacol. 2016, 7, 160. [CrossRef] [PubMed]

154. Means, R.T.; Krantz, S.B. Inhibition of human erythroid colony-forming units by tumor necrosis factor requires beta interferon. J. Clin. Investig. 1993, 91, 416-419. [CrossRef] [PubMed]

155. La Ferla, K.; Reimann, C.; Jelkmann, W.; Hellwig-Bürgel, T. Inhibition of erythropoietin gene expression signaling involves the transcription factors GATA-2 and NF-kappaB. FASEB J. 2002, 16, 1811-1813. [CrossRef] [PubMed]

156. Cazzola, M.; Ponchio, L.; de Benedetti, F.; Ravelli, A.; Rosti, V.; Beguin, Y.; Invernizzi, R.; Barosi, G.; Martini, A. Defective iron supply for erythropoiesis and adequate endogenous erythropoietin production in the anemia associated with systemic-onset juvenile chronic arthritis. Blood 1996, 87, 4824-4830. [CrossRef] [PubMed]

157. Khalil, S.; Delehanty, L.; Grado, S.; Holy, M.; White, Z.; Freeman, K.; Kurita, R.; Nakamura, Y.; Bullock, G.; Goldfarb, A. Iron modulation of erythropoiesis is associated with Scribble-mediated control of the erythropoietin receptor. J. Exp. Med. 2018, 215, 661-679. [CrossRef] [PubMed]

158. Weiss, G.; Houston, T.; Kastner, S.; Jöhrer, K.; Grünewald, K.; Brock, J.H. Regulation of cellular iron metabolism by erythropoietin: Activation of iron-regulatory protein and upregulation of transferrin receptor expression in erythroid cells. Blood 1997, 89, 680-687.

159. Cooke, K.S.; Hinkle, B.; Salimi-Moosavi, H.; Foltz, I.; King, C.; Rathanaswami, P.; Winters, A.; Steavenson, S.; Begley, C.G.; Molineux, G.; et al. A fully human anti-hepcidin antibody modulates iron metabolism in both mice and nonhuman primates. Blood 2013, 122, 3054-3061. [CrossRef]

160. Rothe, C.; Skerra, A. Anticalin ${ }^{\circledR}$ Proteins as Therapeutic Agents in Human Diseases. BioDrugs 2018, 32, 233-243. [CrossRef]

161. Hohlbaum, A.M.; Gille, H.; Trentmann, S.; Kolodziejczyk, M.; Rattenstetter, B.; Laarakkers, C.M.; Katzmann, G.; Christian, H.J.; Andersen, N.; Allersdorfer, A.; et al. Sustained plasma hepcidin suppression and iron elevation by Anticalin-derived hepcidin antagonist in cynomolgus monkey. Br. J. Pharmacol. 2018, 175, 1054-1065. [CrossRef]

162. Boyce, M.; Warrington, S.; Cortezi, B.; Zöllner, S.; Vauléon, S.; Swinkels, D.W.; Summo, L.; Schwoebel, F.; Riecke, K. Safety, pharmacokinetics and pharmacodynamics of the anti-hepcidin Spiegelmer lexaptepid pegol in healthy subjects. Br. J. Pharmacol. 2016, 173, 1580-1588. [CrossRef] [PubMed]

163. Macdougall, I.C.; Rumjon, A.; Cinco, J.; Goldstein, L.; Summo, L.; Vauleon, S.; Riecke, K. FP660 Pharmacokinetics and Pharmacodynamics of Lexaptepid, a Novel Anti-Hepcidin Molecule, in ESA-Resistant Haemodialysis Patients. Nephrol. Dial. Transplant. 2015, 30, iii294-iii295. [CrossRef]

164. Georgiev, P.; Lazaroiu, M.; Ocroteala, L.; Grudeva-Popova, J.; Gheorghita, E.; Vasilica, M.; Popescu, S.M.; Cucuianu, A.; Summo, L.; Schwoebel, F.; et al. Abstract 3847: The anti-hepcidin Spiegelmer ${ }^{\circledR}$ Lexaptepid Pegol (NOX-H94) as treatment of anemia of chronic disease in patients with multiple myeloma, low grade lymphoma, and CLL: A phase II pilot study. Cancer Res. 2014, 74, 3847. [CrossRef] 
165. Andriopoulos, B.; Corradini, E.; Xia, Y.; Faasse, S.A.; Chen, S.; Grgurevic, L.; Knutson, M.D.; Pietrangelo, A.; Vukicevic, S.; Lin, H.Y.; et al. BMP6 is a key endogenous regulator of hepcidin expression and iron metabolism. Nat. Genet. 2009, 41, 482-487. [CrossRef]

166. Parrow, N.L.; Fleming, R.E. Bone Morphogenetic Proteins as Regulators of Iron Metabolism. Annu. Rev. Nutr. 2014, 34, 77-94. [CrossRef] [PubMed]

167. Theurl, I.; Schroll, A.; Sonnweber, T.; Nairz, M.; Theurl, M.; Willenbacher, W.; Eller, K.; Wolf, D.; Seifert, M.; Sun, C.C.; et al. Pharmacologic inhibition of hepcidin expression reverses anemia of chronic inflammation in rats. Blood 2011, 118, 4977-4984. [CrossRef] [PubMed]

168. Babitt, J.L.; Huang, F.W.; Xia, Y.; Sidis, Y.; Andrews, N.C.; Lin, H.Y. Modulation of bone morphogenetic protein signaling in vivo regulates systemic iron balance. J. Clin. Investig. 2007, 117, 1933-1939. [CrossRef] [PubMed]

169. Poli, M.; Asperti, M.; Ruzzenenti, P.; Mandelli, L.; Campostrini, N.; Martini, G.; Di Somma, M.; Maccarinelli, F.; Girelli, D.; Naggi, A.; et al. Oversulfated heparins with low anticoagulant activity are strong and fast inhibitors of hepcidin expression in vitro and in vivo. Biochem. Pharmacol. 2014, 92, 467-475. [CrossRef] [PubMed]

170. Petzer, V.; Tymoszuk, P.; Wake, M.; Bayliss, L.; Papworth, J.; Carvalho, J.; Deantonio, C.; Asshoff, M.F.; Seifert, M.; Berger, S.; et al. A Fully Human Anti-BMP6 Antibody Reduces the Need for Erythropoietin Stimulating Agent in Two Rodent Anemia of Chronic Disease Models. Blood 2018, 132, 1045. [CrossRef]

171. Galli, M.; Chatterjee, M.; Grasso, M.; Specchia, G.; Magen, H.; Einsele, H.; Celeghini, I.; Barbieri, P.; Paoletti, D.; Pace, S.; et al. Phase I study of the heparanase inhibitor Roneparstat: An innovative approach for multiple myeloma therapy. Haematologica 2018. [CrossRef]

172. Peterson, P.; Whatcott, C.; Siddiqui-Jain, A.; Weitman, S.; Kieran, M.; Bearss, D.J.; Warner, S.L. TP-0184 Inhibits ALK2/ACVR1, Decreases Hepcidin Levels, and Demonstrates Activity in Preclinical Mouse Models of Functional Iron Deficiency. Blood 2017, 130, 937.

173. Kovac, S.; Böser, P.; Cui, Y.; Ferring-Appel, D.; Casarrubea, D.; Huang, L.; Fung, E.; Popp, A.; Mueller, B.K.; Hentze, M.W. Anti-hemojuvelin antibody corrects anemia caused by inappropriately high hepcidin levels. Haematologica 2016, 101, e173-e176. [CrossRef] [PubMed]

174. Barrington, P.; Sheetz, M.J.; Callies, S.; Waters, D.G.; Berg, P.H.; Pappas, D.; Marbury, T.C.; Decker, B.S.; Berg, J.K. Safety, Tolerability, Pharmacokinetics and Pharmacodynamics of an Anti-Ferroportin Antibody in Patients with Anemia Due to Chronic Renal Failure. Blood 2016, 128, 1280.

175. Leung, D.; Hill, K.A.; De Rosa, D.C.; Xu, J.; Manetta, J.; Wroblewski, V.J.; Benschop, R.J. LY2928057, An Antibody Targeting Ferroportin, Is a Potent Inhibitor Of Hepcidin Activity and Increases Iron Mobilization In Normal Cynomolgus Monkeys. Blood 2013, 122, 3433.

176. Ashby, D.R.; Gale, D.P.; Busbridge, M.; Murphy, K.G.; Duncan, N.D.; Cairns, T.D.; Taube, D.H.; Bloom, S.R.; Tam, F.W.K.; Chapman, R.; et al. Erythropoietin administration in humans causes a marked and prolonged reduction in circulating hepcidin. Haematologica 2010, 95, 505-508. [CrossRef] [PubMed]

177. Kautz, L.; Jung, G.; Valore, E.V.; Rivella, S.; Nemeth, E.; Ganz, T. Identification of erythroferrone as an erythroid regulator of iron metabolism. Nat. Genet. 2014, 46, 678-684. [CrossRef] [PubMed]

178. Camaschella, C.; Pagani, A. Advances in understanding iron metabolism and its crosstalk with erythropoiesis. Br. J. Haematol. 2018, 182, 481-494. [CrossRef]

179. Provenzano, R.; Besarab, A.; Wright, S.; Dua, S.; Zeig, S.; Nguyen, P.; Poole, L.; Saikali, K.G.; Saha, G.; Hemmerich, S.; et al. Roxadustat (FG-4592) Versus Epoetin Alfa for Anemia in Patients Receiving Maintenance Hemodialysis: A Phase 2, Randomized, 6- to 19-Week, Open-Label, Active-Comparator, Dose-Ranging, Safety and Exploratory Efficacy Study. Am. J. Kidney Dis. 2016, 67, 912-924. [CrossRef]

180. Peyssonnaux, C.; Zinkernagel, A.S.; Schuepbach, R.A.; Rankin, E.; Vaulont, S.; Haase, V.H.; Nizet, V.; Johnson, R.S. Regulation of iron homeostasis by the hypoxia-inducible transcription factors (HIFs). J. Clin. Investig. 2007, 117, 1926-1932. [CrossRef]

181. Cappellini, M.D.; Comin-Colet, J.; de Francisco, A.; Dignass, A.; Doehner, W.; Lam, C.S.; Macdougall, I.C.; Rogler, G.; Camaschella, C.; Kadir, R.; et al. Iron deficiency across chronic inflammatory conditions: International expert opinion on definition, diagnosis, and management. Am. J. Hematol. 2017, 92, 1068-1078. [CrossRef] 
182. Avni, T.; Leibovici, L.; Gafter-Gvili, A. Iron supplementation for the treatment of chronic heart failure and iron deficiency: Systematic review and meta-analysis. Eur. J. Heart Fail. 2012, 14, 423-429. [CrossRef] [PubMed]

183. Çekiç, C.; İpek, S.; Aslan, F.; Akpınar, Z.; Arabul, M.; Topal, F.; Sarıtaş Yüksel, E.; Alper, E.; Ünsal, B. The Effect of Intravenous Iron Treatment on Quality of Life in Inflammatory Bowel Disease Patients with Nonanemic Iron Deficiency. Gastroenterol. Res. Pract. 2015, 2015, 1-5. [CrossRef] [PubMed]

184. Kovesdy, C.P.; Trivedi, B.K.; Kalantar-Zadeh, K.; Anderson, J.E. Association of anemia with outcomes in men with moderate and severe chronic kidney disease. Kidney Int. 2006, 69, 560-564. [CrossRef] [PubMed]

185. Okonko, D.O.; Mandal, A.K.J.; Missouris, C.G.; Poole-Wilson, P.A. Disordered iron homeostasis in chronic heart failure: Prevalence, predictors, and relation to anemia, exercise capacity, and survival. J. Am. Coll. Cardiol. 2011, 58, 1241-1251. [CrossRef] [PubMed]

186. Enjuanes, C.; Bruguera, J.; Grau, M.; Cladellas, M.; Gonzalez, G.; Meroño, O.; Moliner-Borja, P.; Verdú, J.M.; Farré, N.; Comín-Colet, J. Iron Status in Chronic Heart Failure: Impact on Symptoms, Functional Class and Submaximal Exercise Capacity. Rev. Española Cardiol. 2016, 69, 247-255. [CrossRef]

187. Anker, S.D.; Comin Colet, J.; Filippatos, G.; Willenheimer, R.; Dickstein, K.; Drexler, H.; Lüscher, T.F.; Bart, B.; Banasiak, W.; Niegowska, J.; et al. Ferric Carboxymaltose in Patients with Heart Failure and Iron Deficiency. N. Engl. J. Med. 2009, 361, 2436-2448. [CrossRef] [PubMed]

188. Ponikowski, P.; van Veldhuisen, D.J.; Comin-Colet, J.; Ertl, G.; Komajda, M.; Mareev, V.; McDonagh, T.; Parkhomenko, A.; Tavazzi, L.; Levesque, V.; et al. Beneficial effects of long-term intravenous iron therapy with ferric carboxymaltose in patients with symptomatic heart failure and iron deficiency. Eur. Heart J. 2015, 36, 657-668. [CrossRef]

189. Stauder, R.; Valent, P.; Theurl, I. Anemia at older age: Etiologies, clinical implications, and management. Blood 2018, 131, 505-514. [CrossRef]

190. Mabeza, G.F.; Loyevsky, M.; Gordeuk, V.R.; Weiss, G. Iron chelation therapy for malaria: A review. Pharmacol. Ther. 1999, 81, 53-75. [CrossRef]

191. Zlotkin, S.; Newton, S.; Aimone, A.M.; Azindow, I.; Amenga-Etego, S.; Tchum, K.; Mahama, E.; Thorpe, K.E.; Owusu-Agyei, S. Effect of Iron Fortification on Malaria Incidence in Infants and Young Children in Ghana. JAMA 2013, 310, 938-947. [CrossRef]

192. Zhang, D.-L.; Wu, J.; Shah, B.N.; Greutélaers, K.C.; Ghosh, M.C.; Ollivierre, H.; Su, X.-Z.; Thuma, P.E.; Bedu-Addo, G.; Mockenhaupt, F.P.; et al. Erythrocytic ferroportin reduces intracellular iron accumulation, hemolysis, and malaria risk. Science 2018, 359, 1520-1523. [CrossRef] [PubMed]

193. Sazawal, S.; Black, R.E.; Ramsan, M.; Chwaya, H.M.; Stoltzfus, R.J.; Dutta, A.; Dhingra, U.; Kabole, I.; Deb, S.; Othman, M.K.; et al. Effects of routine prophylactic supplementation with iron and folic acid on admission to hospital and mortality in preschool children in a high malaria transmission setting: Community-based, randomised, placebo-controlled trial. Lancet 2006, 367, 133-143. [CrossRef]

194. Soofi, S.; Cousens, S.; Iqbal, S.P.; Akhund, T.; Khan, J.; Ahmed, I.; Zaidi, A.K.; Bhutta, Z.A. Effect of provision of daily zinc and iron with several micronutrients on growth and morbidity among young children in Pakistan: A cluster-randomised trial. Lancet 2013, 382, 29-40. [CrossRef]

195. Kortman, G.A.M.; Reijnders, D.; Swinkels, D.W. Oral iron supplementation: Potential implications for the gut microbiome and metabolome in patients with CKD. Hemodial. Int. 2017, 21, S28-S36. [CrossRef] [PubMed]

196. Paganini, D.; Uyoga, M.; Zimmermann, M. Iron Fortification of Foods for Infants and Children in Low-Income Countries: Effects on the Gut Microbiome, Gut Inflammation, and Diarrhea. Nutrients 2016, 8, 494. [CrossRef] [PubMed]

197. Moschen, A.R.; Gerner, R.R.; Wang, J.; Klepsch, V.; Adolph, T.E.; Reider, S.J.; Hackl, H.; Pfister, A.; Schilling, J.; Moser, P.L.; et al. Lipocalin 2 Protects from Inflammation and Tumorigenesis Associated with Gut Microbiota Alterations. Cell Host Microbe 2016, 19, 455-469. [CrossRef] [PubMed]

198. Scheers, N.M.; Pereira, D.I.A.; Faria, N.; Powell, J.J. Ferric citrate and ferric EDTA but not ferrous sulfate drive amphiregulin-mediated activation of the MAP kinase ERK in gut epithelial cancer cells. Oncotarget 2018, 9, 17066-17077. [CrossRef] [PubMed]

199. Porto, G.; De Sousa, M. Iron overload and immunity. World J. Gastroenterol. 2007, 13, 4707-4715. [CrossRef]

200. Hara, N.; Okamoto, N.; Imanishi, K.; Takahashi, T.; Makiyama, K. Improvement in reliability of InP-based HEMTs by suppressing impact ionization. Electron. Commun. Jpn. Part II Electron. 2007, 90, 33-38. [CrossRef] 
201. Weiss, G.; Meusburger, E.; Radacher, G.; Garimorth, K.; Neyer, U.; Mayer, G. Effect of iron treatment on circulating cytokine levels in ESRD patients receiving recombinant human erythropoietin. Kidney Int. 2003, 64, 572-578. [CrossRef]

202. Ibrahim, A.S.; Gebermariam, T.; Fu, Y.; Lin, L.; Husseiny, M.I.; French, S.W.; Schwartz, J.; Skory, C.D.; Edwards, J.E.; Spellberg, B.J. The iron chelator deferasirox protects mice from mucormycosis through iron starvation. J. Clin. Investig. 2007, 117, 2649-2657. [CrossRef]

203. Jankowska, E.A.; Rozentryt, P.; Witkowska, A.; Nowak, J.; Hartmann, O.; Ponikowska, B.; Borodulin-Nadzieja, L.; Banasiak, W.; Polonski, L.; Filippatos, G.; et al. Iron deficiency: An ominous sign in patients with systolic chronic heart failure. Eur. Heart J. 2010, 31, 1872-1880. [CrossRef]

204. Macdougall, I.C.; Canaud, B.; De Francisco, A.L.M.; Filippatos, G.; Ponikowski, P.; Silverberg, D.; Van Veldhuisen, D.J.; Anker, S.D. Beyond the cardiorenal anaemia syndrome: Recognizing the role of iron deficiency. Eur. J. Heart Fail. 2012, 14, 882-886. [CrossRef]

(C) 2018 by the authors. Licensee MDPI, Basel, Switzerland. This article is an open access article distributed under the terms and conditions of the Creative Commons Attribution (CC BY) license (http:/ / creativecommons.org/licenses/by/4.0/). 
Article

\title{
Changes in Iron Metabolism Induced by Anti-Interleukin-6 Receptor Monoclonal Antibody are Associated with an Increased Risk of Infection
}

\author{
Renata Ribeiro ${ }^{1,2, *}$, Frederico Batista ${ }^{1,2}$, Filipe Seguro Paula ${ }^{1,2}$ and José Delgado Alves ${ }^{1,2}$ \\ 1 Immune Response and Vascular Disease-CEDOC, Chronic Diseases Research Center, \\ NOVA Medical School, 1150-082 Lisbon, Portugal \\ 2 Systemic Immune-mediated Diseases Unit (UDIMS), Department of Medicine IV, \\ Hospital Professor Doutor Fernando Fonseca, 2720-276 Amadora, Portugal \\ * Correspondence: renata.ribeiro@nms.unl.pt
}

Received: 1 June 2019; Accepted: 25 June 2019; Published: 28 June 2019

\begin{abstract}
Background: Treatment of patients with rheumatoid arthritis (RA) with an anti-IL-6 receptor (anti-IL-6R) monoclonal antibody (tocilizumab) has been found to influence iron metabolism. The objective of the present study was to ascertain whether changes in iron metabolism induced by anti-IL-6R biologic therapy were independently associated with an increased infection risk. (2) Methods: A prospective longitudinal study of patients with RA treated with tocilizumab was conducted. RA patients treated with an antitumor necrosis factor $\alpha$ monoclonal antibody were also included as a control group. The primary outcome was occurrence of infection during the first 24 months of biologic therapy. (3) Results: A total of 15 patients were included, with a mean age of $51.0 \pm 4,1$ and $73.3 \%(n=11)$ female. A multivariate survival regression model, adjusted for confounding factors, was fitted for each of the iron metabolism variables. Hazard ratios for being above the median of each parameter was considered. Transferrin saturation above the median value $(>32.1 \%)$ was associated with a higher infection risk (HR 4.3; 95\%CI 1.0-19.69; p = 0.05). Similarly, although non-significantly, higher serum iron was strongly associated with infection occurrence. (4) Conclusions: This study identified a probable association between infection risk and higher serum iron and transferrin saturation in patients with RA on anti-IL-6R biologic therapy. We suggest that both these parameters should be considered relevant contributing factors for infection occurrence in patients on anti-IL-6R therapy.
\end{abstract}

Keywords: iron; hepcidin; ferroportin; Interleukin-6; infection; rheumatoid arthritis

\section{Introduction}

Infection is a frequent complication during the natural clinical evolution of rheumatoid arthritis (RA), contributing to disease-associated morbidity and mortality [1]. Age-adjusted mortality in RA might be increased about twofold when compared to the general population, and infectious diseases are one of the leading causes of death [2]. This infection risk has been found to be influenced by several disease-related conditions, patient-associated comorbidities, and the immunomodulatory drugs used. Scores of disease activity, such as the disease activity score 28 (DAS-28), have been found to correlate with infection risk [1,3]. Corticosteroids, synthetic disease-modifying anti-rheumatic drugs (DMARDs), and biologic DMARDs may also suppress the immune response, which might translate into an additional risk for infection [2,4].

In the complex pathophysiology of RA, interleukin-6 (IL-6) overproduction is of major relevance. IL-6 is a pleiotropic cytokine with a role in eliciting the acute-phase response in the liver, B-cell proliferation and antibody production, and T-cell differentiation and cytotoxicity [5]. Chronic inflammatory states, 
such as the one present in RA, through increased levels of IL-6 and other cytokines, result in an increased transcription of the HAMP gene in the liver, which encodes hepcidin [6]. After binding to its receptor in hepatocytes, IL-6 induces a Janus kinase 1 (JAK1)-mediated phosphorylation of STAT3, which in turn activates the transcription of the HAMP gene [6]. Hepcidin is an iron regulatory hormone [7] whose best-documented activity is binding to and promoting endocytosis and degradation of ferroportin, the only known iron exporter expressed in cells involved in iron metabolism [7-9]. High concentrations of circulating hepcidin, characteristic of inflammatory states, results in low expression of ferroportin in duodenal enterocytes, hepatocytes, Kupffer cells, and splenic macrophages, decreasing iron export to the extracellular fluid and plasma [7,8]. The result, called hypoferremia of inflammation, has been proposed to be evolutionarily advantageous [9]. Three adaptive functions have been proposed for the hypoferremia of inflammation: inhibition of extracellular bacterial growth by sequestering available iron (considering that most infectious agents need to scavenge iron from the host to multiply); protection from the toxicity caused by high levels of iron and heme released during tissue necrosis and erythrocyte destruction; and increased transferrin capacity to bind to iron released during infection and inflammation $[6,8]$.

Considering the IL-6 overproduction observed in RA, one of the biologic DMARDs used successfully for its treatment is tocilizumab, a humanized anti-IL-6 receptor (anti-IL-6R) monoclonal antibody designed to block IL-6 signaling [10]. In patients with RA treated with tocilizumab, infection is considered the most frequent adverse event and respiratory infections are the most frequently documented [11-13]. Although clinical trials initially reported low infection rates associated with tocilizumab therapy in patients with RA [11-13], some observational studies of real-life registries have found higher infection rates [5]. Comparisons of infection rates between anti-IL-6R and antitumor necrosis factor $\alpha(\mathrm{TNF} \alpha)$ therapy have also been conducted, with some observational cohort studies finding a higher infection rate in tocilizumab $[14,15]$.

The IL-6 signal blockade may suppress hypoferremia of inflammation [5]. It has been demonstrated that blocking IL- 6 or TNF $\alpha$ pathways with tocilizumab or anti-TNF $\alpha$ monoclonal antibodies resulted in significantly lower serum hepcidin and significantly higher serum iron [16]. However, the effect on hepcidin was noted to be stronger in patients treated with tocilizumab when compared with patients treated with anti-TNF $\alpha$ monoclonal antibodies [16]. Analysis of the relationship between these parameters and infection risk observed in this type of patients has never been evaluated before.

The objective of the present study was to ascertain whether changes in iron metabolism induced by anti-IL-6R biologic therapy were associated with an increased risk of infection.

\section{Results}

This was a prospective longitudinal study of patients with a diagnosis of RA and treated with an anti-IL-6R biologic. RA patients treated with an anti-TNF $\alpha$ were also included as a control group. Both groups had a 24-month follow-up, with serum samples collected every semester and any infections during this period registered by clinical interview.

A total of 15 patients were included, with a mean age of $51.0 \pm 4.1$ and $73.3 \%(n=11)$ female. All patients completed the follow-up time without censoring. Mean disease duration was $10.8 \pm 9.5$ years. Regarding biologic DMARD therapy, 10 patients were treated with an anti-IL-6R monoclonal antibody (tocilizumab) and 5 with an anti-TNF $\alpha$ monoclonal antibody (either infliximab, golimumab, or adalimumab). Baseline characteristics and additional drugs used at any time during follow-up are summarized in Tables 1 and 2, respectively. Corticosteroid daily dosages were relatively low (median $=5 \mathrm{mg} /$ day, IQR 5-10 mg/day, maximum of $20 \mathrm{mg} /$ day, in prednisolone-equivalent dosages). 
Table 1. Baseline characteristics.

\begin{tabular}{ccccc}
\hline Baseline Characteristics & $\begin{array}{c}\text { All } \\
(\mathbf{n}=\mathbf{1 5})\end{array}$ & $\begin{array}{c}\text { Anti-IL-6R } \\
(\mathbf{n}=\mathbf{1 0})\end{array}$ & $\begin{array}{c}\text { Anti-TNF } \alpha \\
(\mathbf{n}=\mathbf{5})\end{array}$ & $p$-value \\
\hline Patient-related characteristics & & & & \\
Age (years) & $51.0 \pm 4.1$ & $51.1 \pm 5.7$ & $51.0 \pm 5.4$ & 0.9986 \\
Female & $11(73.3 \%)$ & $7(70 \%)$ & $4(80 \%)$ & 0.6900 \\
\hline Disease-related characteristics & & & & \\
Disease duration (years) & $10.8 \pm 9.5$ & $10,7 \pm 9.7$ & $10.9 \pm 10.8$ & 0.7815 \\
First biologic therapy & $8(53.3 \%)$ & $4(40 \%)$ & $4(80 \%)$ & 0.1573 \\
\hline Comorbidities & & & & \\
Hypertension & $7(46.7 \%)$ & $5(50 \%)$ & $2(40 \%)$ & 0.7237 \\
Diabetes mellitus & $3(20 \%)$ & $2(20 \%)$ & $1(20 \%)$ & 1.0000 \\
Structural lung disease & $3(20 \%)$ & $2(20 \%)$ & $1(20 \%)$ & 1.0000 \\
Urolithiasis & $2(13.3 \%)$ & $2(20 \%)$ & 0 & 0.2994 \\
Tympanic perforation & $2(13.3 \%)$ & $2(20 \%)$ & 0 & 0.2994 \\
Gastrectomy & $1(6.7 \%)$ & $1(10 \%)$ & 0 & 0.2994 \\
\hline
\end{tabular}

Anti-IL-6R-anti-interleukin-6 receptor; anti-TNF $\alpha$-antitumor necrosis factor $\alpha$.

Table 2. Additional drugs used. ${ }^{1}$

\begin{tabular}{ccccc}
\hline Drugs & $\begin{array}{c}\text { All } \\
(\mathbf{n}=\mathbf{1 5})\end{array}$ & $\begin{array}{c}\text { Anti-IL-6R } \\
(\mathbf{n}=\mathbf{1 0})\end{array}$ & $\begin{array}{c}\text { Anti-TNF } \alpha \\
(\mathbf{n}=\mathbf{5})\end{array}$ & $\boldsymbol{p}$-value \\
\hline Proton pump inhibitor & $9(60 \%)$ & $6(60 \%)$ & $1(60 \%)$ & 1.0000 \\
Corticosteroid & $11(73.3 \%)$ & $8(80 \%)$ & $2(60 \%)$ & 0.4250 \\
Methotrexate & $11(73.3 \%)$ & $6(60 \%)$ & $5(100 \%)$ & 0.1106 \\
Sulfasalazine & $4(26.7 \%)$ & $1(10 \%)$ & $3(60 \%)$ & 0.0461
\end{tabular}

${ }^{1}$ At any time during follow-up. Anti-IL-6R-anti-interleukin-6 receptor; anti-TNF $\alpha$-antitumor necrosis factor $\alpha$.

\subsection{Iron Metabolism}

Median serum iron levels were significantly higher in the anti-IL-6R group (131.3 ug/dL (IQR 112.0-135.3 ug/dL) vs. $91.0 \mathrm{ug} / \mathrm{dL}$ (IQR 77.8-109.0 ug/dL); $\mathrm{p}=0.028$ ). Median serum IL-6 levels were also higher in the anti-IL-6R group $(58.6 \mathrm{pg} / \mathrm{mL}$ (IQR $23.5-134.4 \mathrm{pg} / \mathrm{mL}$ ) vs. $21.2 \mathrm{pg} / \mathrm{mL}$ (IQR 6.4-41.0 pg/mL); $\mathrm{p}=0.090$ )—Figure $1 \mathrm{a}, \mathrm{b}$ - which is consistent with the known mechanism of action of tocilizumab and corroborates good patient adherence. The relationship between serum IL- 6 and hepcidin levels tended to be inverse (Figure 1c) and there was a direct positive relationship between hepcidin and serum iron levels $(p=0.018)$-Figure $1 \mathrm{~d}$. 


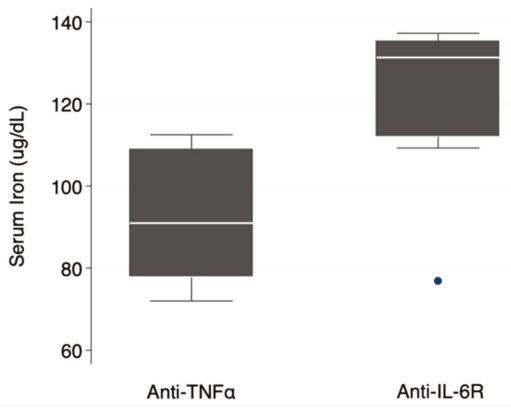

(a)

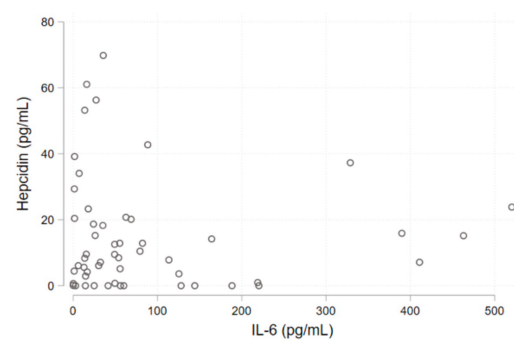

(c)

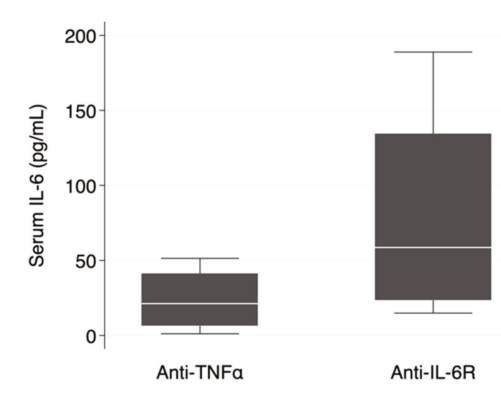

(b)

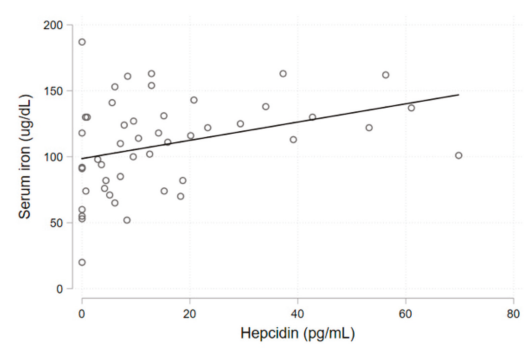

(d)

Figure 1. Iron metabolism. (a) Box plots showing median levels of serum iron in the two groups; (b) box plots showing median levels of serum IL-6 in the two groups; (c) inverse relationship between hepcidin and IL-6 levels; (d) positive correlation between serum iron and hepcidin, with the linear regression line shown. Please see text for details.

\subsection{Infection Risk}

During follow-up, a total of 29 infections were registered, 89.66\% $(n=26)$ in the anti-IL-6R group and $10.34 \%(n=3)$ in the anti-TNF $\alpha$ group. The types of infections are summarized in Table 3. Definitive microbiological identification of the infectious agents was not extensively pursued. The type of infectious agent (bacterial, viral, or fungal) was mainly presumptive considering clinical, analytical, and epidemiological data. Three infections were considered serious, 1 in the anti-IL-6R group and 2 in the anti-TNF $\alpha$ group. All serious infections were pneumonias requiring inpatient intravenous therapy. None of the infections resulted in death.

Table 3. Type of infection in subgroups.

\begin{tabular}{cccc}
\hline Anti-IL-6R $^{\mathbf{1}}$ & \multicolumn{3}{c}{ Anti-TNF $^{\mathbf{2}}$} \\
\hline Respiratory & 9 & Respiratory & 3 \\
Genitourinary & 8 & - & - \\
Skin and soft tissue & 4 & - & - \\
Ear & 3 & - & - \\
Gastrointestinal & 1 & - & - \\
Eye & 1 & - & -
\end{tabular}

${ }^{1} 26$ infections in 8 patients. ${ }^{2} 3$ infections in 1 patient. Anti-IL-6R-anti-interleukin-6 receptor; anti-TNF $\alpha$ —antitumor necrosis factor $\alpha$. 
A first non-adjusted analysis of mean serum iron levels and number of infections during follow-up revealed an association between higher serum iron and a higher number of infections (Poisson regression, $p=0.030$ )-Figure 2 .

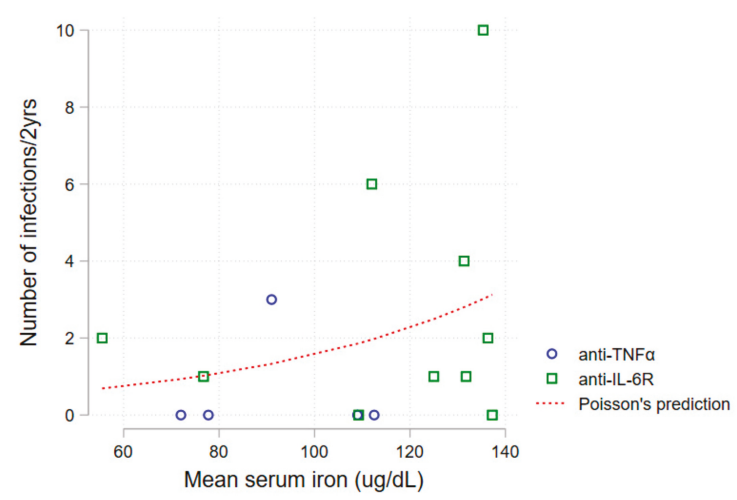

Figure 2. Relationship between mean serum iron level and number of infections during follow-up of patients both on anti-IL-6R (green squares) and anti-TNF $\alpha$ (blue circles) subgroups. The Poisson regression curve is depicted (dashed red), $p=0.030$. Anti-IL-6R - anti-interleukin-6 receptor; anti-TNF $\alpha$-antitumor necrosis factor $\alpha$.

Next, a multiple failure-time survival analysis was performed through fitting of an Anderson-Gill Cox proportional hazards regression model. Univariate analysis of patient's characteristics identified a higher risk of infection in the presence of diabetes mellitus and a lower risk of infection in the presence of corticosteroid therapy-Table 4 .

Table 4. Univariate survival analysis results.

\begin{tabular}{cccc}
\hline Patient and Disease-Associated Variables & Hazard Ratio & $p$-value & 95\% Confidence Interval \\
\hline Constant baseline variables & & & \\
Age & 1.004915 & 0.800 & $0.9675943-1.043676$ \\
Male gender & 0.2343794 & 0.124 & $0.0369132-1.488188$ \\
Disease duration & 0.9324102 & 0.300 & $0.8169411-1.0642$ \\
Anti-IL-6R therapy & 2.66909 & 0.335 & $0.3622716-19.66492$ \\
First-line therapy & 0.9597915 & 0.955 & $0.2281255-4.038127$ \\
Hypertension & 2.357254 & 0.295 & $0.4742625-11.71639$ \\
Diabetes mellitus & 4.870464 & 0.023 & $1.249398-18.98629$ \\
Structural lung disease & 1.031864 & 0.964 & $0.2653836-4.012092$ \\
Urolithiasis & 2.224302 & 0.417 & $0.3229469-15.31991$ \\
Proton pomp inhibitor therapy & 0.9087983 & 0.896 & $0.2176265-3.7951$ \\
Time-varying variables & & & \\
DAS28 & 0.7218875 & 0.357 & $0.3610093-1.443513$ \\
Dedimentation rate (mm/1hr) & 0.9997664 & 0.994 & $0.9405976-1.062657$ \\
Corticosteroids & 0.2458265 & 0.073 & $0.0529271-1.141771$ \\
Erythrocyte sedis & 1.100572 & 0.394 & $0.8829673-1.371804$ \\
Prednisolone daily dose (mg) & 0.3458809 & 0.185 & $0.0719138-1.66357$ \\
Methotrexate & 0.9233559 & 0.159 & $0.8264177-1.031665$ \\
Methotrexate weekly dose (mg) & 0.3954318 & 0.353 & $0.0558712-2.798691$
\end{tabular}

\footnotetext{
${ }^{1}$ Sulfasalazine daily dose relative risk estimates were not calculated due to the low number of patients on this drug
} $(\mathrm{n}=4)$ and non-significant daily dose variation. DAS28-disease activity score 28 . 
Considering the potential confounding variables identified in the univariate analysis, a multivariate survival regression model, adjusted for the presence of diabetes mellitus and for corticosteroid therapy, was fitted for each of the iron metabolism variables (Table 5, Figure 3). Hazard ratios for being above the median of each parameter distribution was considered. Transferrin saturation above the median value $(>32.1 \%)$ was associated with a higher infection risk (HR 4.3; 95\%CI 1.0-19.69; $p=0.05$ ). This result was similar when a sub-analysis was performed in the anti-IL-6R group (HR 6.46; $95 \%$ CI 1.05-39.72; $p=0.044)$. Ferritin above the median value $(>72 \mathrm{mg} / \mathrm{dL})$ presented as a protective factor (HR 0.16; 95\%CI 0.05-0.53; $p=0.003)$. As serum iron above the median value was, although non-significantly, still strongly associated with a higher infection risk ( $\mathrm{HR}=3.2$ for all patients), we performed a quartile sub-analysis that showed a consistently higher risk of infection for each higher quartile (Table 6, Figure 4).

Table 5. Multivariate survival analysis for iron metabolism parameters. Hazard ratios presented are for being above the median for each variable (relative to being below the median).

\begin{tabular}{ccccc}
\hline \multirow{2}{*}{ Iron Metabolism Parameters } & Hazard Ratio & $p$-value & 95\% Confidence Interval \\
\hline \multirow{2}{*}{ Serum iron } & All & 3.163589 & 0.089 & $0.8386898-11.93325$ \\
\cline { 2 - 5 } & Anti-IL-6R & 2.570872 & 0.238 & $0.5356937-12.33799$ \\
\hline \multirow{2}{*}{ Transferrin } & All & 1.314897 & 0.637 & $0.4223613-4.09354$ \\
\cline { 2 - 5 } & Anti-IL-6R & 1.874245 & 0.447 & $0.3708102-9.4733$ \\
\hline \multirow{2}{*}{ TIBC } & All & 1.314897 & 0.637 & $0.4223613-4.09354$ \\
\cline { 2 - 5 } Transferrin Saturation & Anti-IL-6R & 1.874245 & 0.447 & $0.3708102-9.4733$ \\
\cline { 2 - 5 } & All & 4.321854 & 0.050 & $0.999262-18.69222$ \\
\hline \multirow{2}{*}{ Ferritin } & Anti-IL-6R & 6.461889 & 0.044 & $1.051171-39.72334$ \\
\cline { 2 - 5 } & All & 0.600787 & 0.003 & $0.048141-0.5322946$ \\
\hline \multirow{2}{*}{ Hepcidin } & Anti-IL-6R & 0.2356835 & 0.112 & $0.0395527-1.404372$ \\
\cline { 2 - 5 } & All & 2.183736 & 0.465 & $0.2691971-1.71454$ \\
\hline \multirow{2}{*}{ IL-6 } & Anti-IL-6R & 9.408961 & 0.084 & $0.7420833-119.2973$ \\
\cline { 2 - 5 } & All & 2.654745 & 0.271 & $0.4658854-15.12748$ \\
\cline { 2 - 5 } & Anti-IL-6R & 2.173225 & 0.335 & $0.4478064-10.54677$ \\
\hline
\end{tabular}

TIBC-Total iron binding capacity; anti-IL-6R-anti-interleukin-6 receptor.

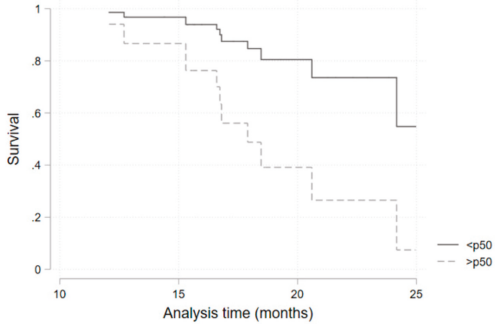

(a)

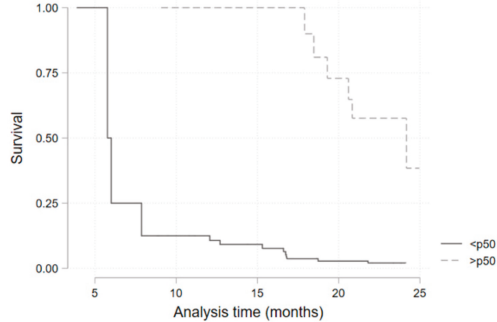

(b)

Figure 3. Kaplan-Meier survival curves for transferrin saturation (a) and ferritin (b) values above (solid lines) or below (dashed lines) the median. 
Table 6. Multivariate survival analysis for quartile distribution of serum iron.

\begin{tabular}{|c|c|c|c|c|}
\hline & & Hazard Ratio & $p$-value & 95\% Confidence Interval \\
\hline \multirow{4}{*}{ All } & Q1 & $(1)$ & - & - \\
\hline & Q2 & 2.654559 & 0.363 & $0.3244244-21.72057$ \\
\hline & Q3 & 3.633011 & 0.221 & $0.4601984-28.6806$ \\
\hline & Q4 & 12.50757 & 0.085 & $0.7074825-221.1213$ \\
\hline \multirow{4}{*}{ Anti-IL-6R } & Q1 & (1) & - & - \\
\hline & Q2 & 0.1373109 & 0.239 & $0.0050287-3.749356$ \\
\hline & Q3 & 0.6592579 & 0.596 & $0.1414934-3.071671$ \\
\hline & Q4 & 1,112208 & 0,909 & $0,1806099-6,849054$ \\
\hline
\end{tabular}

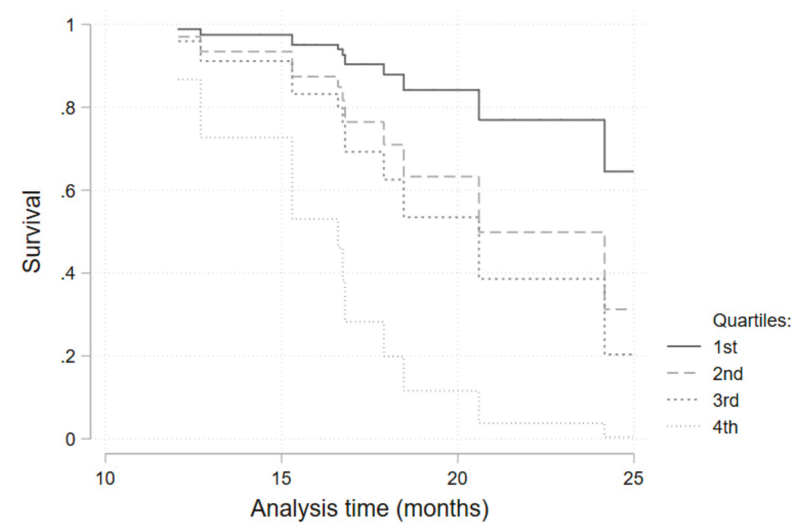

Figure 4. Kaplan-Meier survival curves for each quartile of serum iron values.

\section{Discussion}

This was a prospective longitudinal pilot study designed to evaluate whether changes in iron metabolism induced by anti-IL-6R biologic therapy were independently associated with an increased risk of infection in patients with RA. Higher infection risk was associated with higher serum iron and transferrin saturation.

Baseline characteristics were as expected for a cohort of patients with RA. Gender, median age, disease duration, and co-morbidities of patients on anti-IL-6R therapy did not differ when compared with a subgroup of patients on anti-TNF $\alpha$. Non-biologic DMARD therapy use was also similar, with the exception of a significantly higher sulfasalazine use in the anti-TNF $\alpha$ group. Posterior analysis did not find a higher relative risk of infection in sulfasalazine users, and this difference was not considered relevant.

As expected, patients on anti-IL-6R monoclonal antibody therapy tended to have higher levels of free serum IL- 6 than patients on anti-TNF $\alpha$. These data are in accordance with drug pharmacodynamics and result from a diminished serum clearance of receptor-bound IL- 6 . The relationship between serum IL-6 and hepcidin levels seemed to be inverse, most probably as a result of a reduced IL-6 receptor-JAK1-STAT3 signal for HAMP gene transcription due to the IL-6-receptor blockade. Therefore, higher IL-6 serum levels (and consequently, a higher IL-6 receptor blockade) were associated with a lower hepcidin concentration. This was expected to have resulted in less endocytosis and degradation of ferroportin in duodenal enterocytes, hepatocytes, Kupffer cells, and splenic macrophages, higher iron efflux and, consequently, higher serum iron levels in patients on anti-IL-6R therapy. However, 
an unexpected positive linear correlation between serum iron and hepcidin was obtained, and higher levels of hepcidin were associated with higher levels of serum iron. This relationship may have been affected by the presence of unmeasured confounding regulatory factors of hepcidin production or may have derived from the stimulatory effect that serum iron has on hepcidin transcription in hepatocytes, through a mechanism of extracellular iron sensing [6].

In the univariate analysis of patient and disease-related characteristics, diabetes mellitus was the only statistically significant risk predictor for infection. The relationship between diabetes and infection risk is well-known in the general population and is expected to be similar in patients on biologic DMARD therapy. Corticosteroid therapy, on the other hand, tended to constitute a protective independent factor for infection occurrence in this study. It is commonly accepted that corticosteroid use increases infection risk [2], but it should be noted that the median daily dose per patient in our study was $5 \mathrm{mg} /$ day. Such low dosages may have an immunomodulatory rather than an immunosuppressive effect, such that controlling chronic inflammation may translate into a lower infection risk. In light of this, survival analysis was adjusted for these two variables.

The relationship found between higher serum iron levels and transferrin saturation, and a higher infection risk was initially proposed and expected. Infective microorganisms use available iron as a catalytic component of enzymes that mediate many redox reactions, making it crucial for energy production and proliferation [6]. Concentration of iron in plasma and extracellular fluid decreases dramatically within hours of infection or other inflammatory stimuli through a cytokine-driven increase in hepcidin concentration [8]. This adaptative function of hepcidin is of particular importance when most common extracellular infective microorganisms are considered [8]. For intracellular agents (e.g., Legionella pneumophila and Mycobacterium tuberculosis) the hepcidin-ferroportin axis may play an opposing role, as iron release from infected cells into plasma could deprive microorganisms of the iron they need to grow [8]. Even without a definitive microbiologic identification, the infections reported here have a very low probability of being caused by intracellular organisms, based on clinical and epidemiological data. Furthermore, assistant physicians considered the majority of infections as being caused by extracellular bacteria and treated them accordingly and successfully. Infections were, as stated in previously published work [15], mainly respiratory, and none were considered serious. Transferrin saturation presented as a significant predictive factor for infection occurrence when above $32.1 \%$ (median). Although not statistically significant, a very consistent and progressive increase in the hazard ratio for each quartile of serum iron levels (when compared with the first quartile) was obtained. The reduced number of patients included may have contributed to a loss of statistical power. Additionally, a statistically significant protective effect of ferritin on infection risk was obtained. Higher serum ferritin probably reflects higher cellular ferritin and iron storage as a consequence of ferroportin degradation and lower serum iron availability.

This study has some limitations. Blood sampling was not performed before biologic therapy was initiated, which limited the evaluation of the dynamic evolution of iron-related parameters. A small number of patients were included, and the anti-TNF $\alpha$ control group was smaller than the anti-IL-6R group, which might have limited statistical power. However, to the best of our knowledge, this investigation is the first to evaluate the relationship between iron metabolism and infection risk in patients with RA on anti-IL-6R biologic therapy, and it has consistently demonstrated that a trend in iron metabolism for a higher extracellular iron availability predicts infection occurrence. Given its intrinsically potent immunosuppressor effect, we would not suggest that elevated iron availability is the only mechanism through which tocilizumab increases infection risk, but our results show that it should be considered as a relevant contributing factor. Studies with larger cohorts are needed to confirm these data. 


\section{Materials and Methods}

\subsection{Study Design and Patient Eligibility}

We conducted an observational prospective longitudinal study of patients with seropositive RA treated at the Systemic Immune-Mediated Diseases Unit in Portugal, under biologic DMARD therapy with either anti-IL-6R or anti-TNF $\alpha$. All patients gave written informed consent for participation in the study, which was conducted in accordance with the Declaration of Helsinki, and after approval by the Ethics Committee of Hospital Professor Doutor Fernando Fonseca. Patients entered the study at the start of biological therapy and were followed up for 24 months. All blood samples were collected in the morning without fasting. Patients were 18 years old or older. Exclusion criteria were pregnancy; chronic kidney disease KDIGO classification 4 or higher; chronic liver disease Child-Pugh $\mathrm{B}$ or higher; cancer; transfusion therapy, iron or erythropoietin supplementation during or three months before starting biologic therapy; primary or secondary immunodeficiency not related with the immunomodulatory therapy; refusal or inability to sign informed consent.

\subsection{Assessments}

We collected demographic, clinical, and therapy-related data such as comorbidities, disease activity, and type and time of exposure to additional non-biologic immunomodulatory therapy. Disease activity was measured with the DAS28 score [17] at the time of each blood sample collection.

Hepcidin and IL-6 plasma concentrations were measured using commercial ELISA kits (DY8307 and DY206, respectively-R\&D systems, Minneapolis, MN, USA). All other biochemical and hematological parameters were measured using standard laboratory techniques. Blood samples from infection episodes were excluded.

\subsection{Outcomes}

The primary outcome was occurrence of infection during the first 24 months of biologic therapy. Infections were identified through clinical interviews during each regular follow-up visit at our clinic. Infections were grouped into respiratory (including upper and lower respiratory tract infections); genitourinary (including cystitis), pyelonephritis, and vulvovaginitis; skin and soft tissue (including cellulitis), erysipelas, abscesses, and wound infections; ear infections (including otitis media and externa); gastrointestinal infections (including acute gastroenteritis); and eye infections (such as purulent conjunctivitis). Serious infections were defined as requiring hospitalization or intravenous antibiotics.

\subsection{Statistical Analysis}

Differences in dichotomous variables between treatment groups were assessed by Spearman's or Chi-square tests as appropriate. Continuous variables were compared using t-tests or Mann-Whitney tests as appropriate, judging normality by a Shapiro-Wilk test. As an initial analysis, the number of infection events was counted and directly compared between patients, as all patients had the same follow-up time (24 months), and the association with mean serum iron values was tested using a Poisson's regression. Next, a survival analysis considering multiple failure-time data, with all patients starting follow-up at the start of biologic drug administration (time 0 ). No censoring events resulted in all patients being followed until the end of the 24 months. An Anderson-Gill Cox regression model was used to assess each independent covariate to the outcome of interest (infection rate) to check for potential confounders. Variables with a $p$-value of $<0,1$ were selected for inclusion in the multivariate model for each of the components of iron kinetics available. The association of each variable of interest (serum iron, transferrin, transferrin saturation, total iron binding capacity, ferritin, hepcidin, and IL-6) was performed by stratifying it to above/below the median. Kaplan-Meier survival curves were developed for significant associations. Sub-analyses with a quartile stratification was also possible. Analyses were conducted with the use of STATA software, version 14.0 (StataCorp). 
Author Contributions: Conceptualization, R.R., F.B., and F.S.P.; Data curation, R.R. and F.B.; Formal analysis, F.S.P.; Investigation, R.R., F.B., and F.S.P.; Methodology, R.R., F.B., and F.S.P.; Project administration, J.D.A.; Resources, J.D.A.; Supervision, J.D.A.; Validation, F.S.P.; Writing—original draft, R.R. and F.B.; Writing—review \& editing, F.S.P. and J.D.A.

Funding: This research received no external funding

Conflicts of Interest: The authors declare no conflict of interest.

\section{References}

1. Au, K.; Reed, G.; Curtis, J.R.; Kremer, J.M.; Greenberg, J.D.; Strand, V.; Furst, D.E. High disease activity is associated with an increased risk of infection in patients with rheumatoid arthritis. Ann. Rheum. Dis. 2011, 70, 785-791. [CrossRef] [PubMed]

2. Listing, J.; Gerhold, K.; Zink, A. The risk of infections associated with rheumatoid arthritis, with its comorbidity and treatment. Rheumatology 2013, 52, 53-61. [CrossRef] [PubMed]

3. Weaver, A.; Troum, O.; Hooper, M.; Koenig, A.S.; Chaudhari, S.; Feng, J.; Wenkert, D. Rheumatoid arthritis disease activity and disability affect the risk of serious infection events in radius 1. J. Rheum. 2013, 40, 1275-1281. [CrossRef] [PubMed]

4. Keyser, F.D. Choice of biologic therapy for patients with rheumatoid arthritis: The infection perspective. Curr. Rheumatol. Rev. 2011, 7, 77-87. [CrossRef] [PubMed]

5. Lang, V.R.; Englbrecht, M.; Rech, J.; Nüsslein, H.; Manger, K.; Schuch, F.; Zwerina, J. Risk of infections in rheumatoid arthritis patients treated with tocilizumab. Rheumatology 2012, 51, 852-857. [CrossRef] [PubMed]

6. Ganz, T.; Nemeth, E. Iron homeostasis in host defense and inflammation. Nat. Rev. Immunol. 2015. [CrossRef] [PubMed]

7. Ganz, T. Iron and infection. Int. J. Hematol. 2018, 107, 7-15. [CrossRef] [PubMed]

8. Drakesmith, H.; Nemeth, E.; Ganz, T. Ironing out ferroportin. Cell. Metab. 2015, 22, 777-787. [CrossRef] [PubMed]

9. Langer, A.L.; Ginzburg, Y.Z. Role of hepcidin-ferroportin axis in the pathophysiology, diagnosis, and treatment of anemia of chronic inflammation. Hemodial. Int. 2017, 21, S37-S46. [CrossRef] [PubMed]

10. Murakami, N.; Nishimoto, N. The value of blocking IL-6 outside of rheumatoid arthritis: Current perspective. Curr. Opin. Rheumatol. 2011, 23, 273-277. [CrossRef] [PubMed]

11. Jones, G.; Sebba, A.; Gu, J.; Lowenstein, M.B.; Calvo, A.; Gomez-Reino, J.J.; Genovese, M.C. Comparison of tocilizumab monotherapy versus methotrexate monotherapy in patients with moderate to severe rheumatoid arthritis: The AMBITION study. Ann. Rheum. Dis. 2010, 69, 88-96. [CrossRef] [PubMed]

12. Kremer, J.M.; Blanco, R.; Brzosko, M.; Burgos-Vargas, R.; Halland, A.M.; Vernon, E.; Fleischmann, R. Tocilizumab inhibits structural joint damage in rheumatoid arthritis patients with inadequate responses to methotrexate. Arthritis Rheum. 2011, 63, 609-621. [CrossRef] [PubMed]

13. Smolen, J.F.; Beaulieu, A.; Rubbert-Roth, A.; Ramos-Remus, C.; Rovensky, J.; Alecock, E. Effect of interleukin-6 receptor inhibition with tocilizumab in patients with rheumatoid arthritis (OPTION study): A double-blind, placebo-controlled, randomised trial. Lancet 2008, 371, 987-997. [CrossRef]

14. Pawar, A.; Desai, R.J.; Solomon, D.H.; Ortiz, A.J.S.; Gale, S.; Bao, M.; Kim, S.C. Risk of serious infections in tocilizumab versus other biologic drugs in patients with rheumatoid arthritis: A multidatabase cohort study. Ann. Rheum. Dis. 2019, 78, 456-464. [CrossRef] [PubMed]

15. Rutherford, A.I.; Subesinghe, S.; Hyrich, K.L.; Galloway, J.B. Serious infection across biologic-treated patients with rheumatoid arthritis: Results from the British society for rheumatolgy biologics register for rheumatoid arthritis. Ann. Rheum. Dis. 2018, 77, 905-910. [CrossRef] [PubMed]

16. Song, S.J.; Iwahashi, M.; Tomosugi, N.; Uno, K.; Yamana, J.; Yamana, S.; Yoshizaki, K. Comparative evaluation of the effects of treatment with tocilizumab and TNF- $\alpha$ inhibitors on serum hepcidin, anemia response and disease activity in rheumatoid arthritis patients. Arthritis Res. Ther. 2013, 15, R141. [CrossRef] [PubMed]

17. Prevoo, M.L.; van 't Hof, M.A.; Kuper, H.H.; Van Leeuwen, M.A.; Van De Putte, L.B.A.; Van Riel, P.L.C.M. Modified disease activity scores that include twenty-eight-joint counts: Development and validation in a prospective longitudinal study of patients with rheumatoid arthritis. Arthritis Rheum. 1995, 38, 44-48. [CrossRef] [PubMed]

(C) 2019 by the authors. Licensee MDPI, Basel, Switzerland. This article is an open access article distributed under the terms and conditions of the Creative Commons Attribution (CC BY) license (http://creativecommons.org/licenses/by/4.0/). 


\title{
Review \\ Modulation of Iron Metabolism in Response to Infection: Twists for All Tastes
}

\author{
Ana Cordeiro Gomes ${ }^{1,2}$, Ana C. Moreira ${ }^{1,2}$, Gonçalo Mesquita ${ }^{1,2}$ and \\ Maria Salomé Gomes 1,2,3,* \\ 1 Instituto de Investigação e Inovação em Saúde, Universidade do Porto, 4200-135 Porto, Portugal; \\ ana.c.gomes@i3s.up.pt (A.C.G.); ana.s.moreira@ibmc.up.pt (A.C.M.); goncalo.mesquita@i3s.up.pt (G.M.) \\ 2 Instituto de Biologia Molecular e Celular, Universidade do Porto, 4200-135 Porto, Portugal \\ 3 Instituto de Ciências Biomédicas de Abel Salazar, Universidade do Porto, 4050-313 Porto, Portugal \\ * Correspondence: sgomes@ibmc.up.pt; Tel.: +351-226074950
}

Received: 6 August 2018; Accepted: 28 August 2018; Published: 1 September 2018

\begin{abstract}
Iron is an essential nutrient for almost all living organisms, but is not easily made available. Hosts and pathogens engage in a fight for the metal during an infection, leading to major alterations in the host's iron metabolism. Important pathological consequences can emerge from the mentioned interaction, including anemia. Several recent reports have highlighted the alterations in iron metabolism caused by different types of infection, and several possible therapeutic strategies emerge, based on the targeting of the host's iron metabolism. Here, we review the most recent literature on iron metabolism alterations that are induced by infection, the consequent development of anemia, and the potential therapeutic approaches to modulate iron metabolism in order to correct iron-related pathologies and control the ongoing infection.
\end{abstract}

Keywords: iron metabolism; infection; innate immunity; hepcidin; ferritin; anemia of inflammation; pharmaceutical targets

\section{Introduction}

The virulence of a pathogen is directly related to its capacity to adapt to the environment present within the host, and also its ability to escape or subvert the host's immune response. Amongst all the nutritional needs of the pathogens, the acquisition of iron is probably one of the major determinants for their maintenance and proliferation within a host. Most pathogens synthesize small molecules, called siderophores, which have a high affinity for iron, to ensure their iron acquisition. There are several types of siderophores and the same bacterial species can produce different molecules [1]. Several pathogens also have heme uptake systems and are able to take up iron from transferrin or other host iron-binding proteins [2]. Additional evidence for the importance of iron, during an infection, comes from epidemiological studies which correlate between the host's iron status and the clinical outcome of several infections [3]. For instance, the iron status of the host, at the time of an HIV infection diagnosis, modulates the risk for subsequent development of tuberculosis [4]. Additionally, iron-supplementation programs increase the risk of malaria, diarrhea and respiratory infections in endemic regions $[5,6]$. It is increasingly recognized that together with the other components of the immune response, the host uses a variety of mechanisms and strategies to deprive pathogens of the essential nutrients, such as iron, zinc, and copper [7]. This host response to infection has been coined "nutriprive" or "nutritional immunity" and results from extensive fine-tuning throughout animal evolution $[8,9]$. Nutritional immunity, and in particular iron deprivation, may be a valuable target in the development of host-directed therapies against infection. However, this development would require a deeper knowledge of the iron metabolic and distribution pathways, which are essential not only for pathogens but also for the host. 
Animals are highly dependent on iron for fundamental processes such as DNA replication, oxygen transport, and immune function. Conversely, iron's high reactivity makes it highly toxic when left in a free form. Therefore, iron acquisition, storage, and transport are tightly regulated processes [10]. An increasing amount of data shows that infections have an enormous impact on the host's iron metabolism and distribution, not only through the innate mechanisms of iron withholding but also by the effects of the pathogen, the immune response, tissue damage or other indirect consequences of an infection. The diverse effects seen in different infections may have host-protective as well as host-deleterious consequences, the most well-known of which is anemia of infection.

Here, we will review the most recent evidence linking iron metabolism and infection, highlighting studies that have been performed in vivo, which put in an evidence for systemic rather than cell-intrinsic alterations. We will also address the mechanisms leading to anemia of inflammation, which is an important co-morbidity associated with infections and iron availability. Finally, we will discuss the potential modulation of these pathways to be used as therapeutic targets in the clinics.

\section{Iron Homeostasis in Animal Hosts}

Due to its high toxicity, the amount of iron in the body must be tightly regulated. There are no known active iron excretion systems in mammals. Therefore, only small amounts of iron are normally lost by bleeding, the sloughing of mucosal cells, the desquamation of skin cells, and in the urine. Conversely, iron uptake from the diet is tightly regulated. In mammals, iron is absorbed mostly in the proximal duodenum, either in the ferrous form, through the divalent metal transporter 1 (DMT-1) or in the form of heme, presumably through the heme carrier protein 1 (HCP-1). However, the identity of the transporter(s) involved is still a matter of debate [11,12]. Once inside the enterocytes, heme is degraded by the enzyme heme oxygenase 1 (HO-1) into carbon monoxide, bilirubin, and iron. Absorbed iron can be used by the body, stored intracellularly in ferritins, or exported through the ferroportin 1 (FPN1) and complexed with the transferrin in the serum. Most of the circulating iron reaches all tissues being safely bound to transferrin, and most cells acquire iron through the receptor-mediated endocytosis of iron-bound transferrin. However, in situations of iron overload, the amount of iron in circulation may exceed the transferrin carrying capacity, and as a result, the metal is complexed with low molecular-weight molecules, constituting the so-called non-transferrin bound iron (NTBI). NTBI can be taken up by hepatocytes, astrocytes and T lymphocytes. Importantly, in some circumstances, astrocytes and lymphocytes are capable of acquiring iron in the ferric form, suggesting the existence of a selective NTBI carrier $[13,14]$. It is worthy of note that iron in the form of NTBI has a much higher toxic potential [15].

In quantitative terms, the red blood cell (RBC) formation is the major consumer of iron in the body [10]. An efficient recycling system ensures that the iron resulting from the degradation of aged or damaged erythrocytes, degraded by the liver and spleen macrophages, is made available for all the body needs. During erythrophagocytosis, RBCs are contained inside a phagolysosome, and upon hemoglobin degradation, heme is transported to the cytoplasm by the protein heme-responsive gene, the homolog 1(HRG-1) [16]. In the cytoplasm, heme is either exported through the heme exporter, the feline leukemia virus subgroup C cellular receptor (FLVCR), [17] or catabolized into CO, biliverdin, and iron by HO-1 $[18,19]$. The regulation of heme catabolism and its export after erythrophagocytosis is important not only due to the toxicity of free heme but also because heme can be used by pathogens as a source of iron. In this context, the serum protein hemopexin plays an important protective role [20-22]. Hemopexin is responsible for heme-binding in the serum, protecting the cells from its nefarious effects, and for the subsequent transport of heme to the sites of iron recycling.

The iron released from the heme degradation is either stored intracellularly in ferritin or exported from the cell by FPN1, which is up-regulated during erythrophagocytosis [23,24]. FPN1 expression at the cell membrane is regulated by hepcidin. Hepcidin is a small peptide (coded by the Hamp1 gene) produced mainly in the liver, the expression of which is regulated by several stimuli, including tissue iron levels, anemia, hypoxia and inflammatory cytokines [25]. 
Macrophages are key players in both iron homeostasis and response to infections. On one hand, macrophages are responsible for iron recycling and storage. On the other hand, they play fundamental tasks in the immune response, by secreting different types of cytokines, directly killing phagocytosed microbes or serving as the host cell for others. It was proposed that specific stimuli act on macrophages, polarizing their activation towards M1 or M2 phenotypes [26]. Interferon gamma (IFNG), lipopolysaccharide (LPS), Tumor Necrosis Factor alpha (TNF) and Granulocyte-Macrophage Colony-Stimulating Factor (GM-CSF) induce macrophage polarization towards an M1 phenotype, with the production of pro-inflammatory cytokines and effector molecules, which mediate, for instance, the clearance of intracellular pathogens. On the flip-side, cytokines like IL-4 and IL-13, among others, activate macrophages towards an M2 phenotype, which facilitates tissue regeneration. This dichotomy is not always clear and intermediate polarization of phenotypes may occur. Regarding the iron metabolism, it has been described that M1 macrophages seem more prone to store iron whereas M2 macrophages seem keener in exporting iron [27]. On the other hand, high iron levels induce an M2 polarization, repressing the M1 phenotype [28]. These observations have important consequences in the regulation of iron metabolism during pathological situations, such as infections.

\section{Different Pathogens, Different Impacts on the Iron Metabolism of the Host}

First identified as a liver-derived antimicrobial peptide [29], hepcidin is now considered the main regulator of iron homeostasis in mammals. Hepcidin expression and release follow the pattern of acute phase proteins, being induced by pro-inflammatory cytokines, namely IL-6 [30,31]. The main effect of this peptide is to decrease the circulating iron levels, by binding and promoting the internalization and degradation of the only known cellular iron exporter, FPN1 [32]. The induction of hepcidin production by inflammatory mediators and microbial products, such as LPS, has been interpreted as a nutriprive host strategy to fight infectious agents. However, the real impact of hepcidin production and hepcidin-induced hypoferremia, in resistance to infection, has only recently been addressed, experimentally. It is now apparent that hepcidin-mediated protection is limited to certain types of pathogens [33,34].

Following the first studies showing a Toll-like receptor (TLR) 4-dependent induction of hepcidin by LPS, in vivo mouse studies showed increased levels of hepcidin during infections with Salmonella [35,36], Pseudomonas aeruginosa, group A Streptococcus [37], Vibrio vulnificus [38], and Candida albicans or Influenza A virus [39]. Additionally, in humans, several types of infections, including HIV, Salmonella, tuberculosis, sepsis, and malaria, have been reported to be accompanied by increased levels of serum hepcidin [40-44]. In marked contrast, the Hepatitis C virus inhibits hepcidin production in humans, which contributes to the pathology of this disease [45]. Interestingly, when infected with Vibrio vulnificus, Y. enterocolitica serotype O9 or Klebsiella pneumoni, a dramatic increase in pathogen growth and host mortality occurred in mice that were genetically deficient in hepcidin production $[38,46,47]$. Overall, data from these experiments showed that hepcidin decreased the levels of circulating iron and especially NTBI, which is critical to avoid the proliferation of highly siderophilic bacteria, such as V. vulnificus and particular strains of $Y$. enterocolitica, in the blood. In the case of the animal model of pneumonia caused by Klebsiella pneumonia, hepcidin mostly exerted a protective role also through an inhibition of the bacterial dissemination to the blood [46]. The host-protective role of hepcidin in these particular cases was further demonstrated by the significant therapeutic effect of hepcidin mimics $[38,46,47]$. Hepcidin administration or overexpression was also protective against the hepatic stage of Plasmodium infection, and may be implicated in the natural resistance to hepatic infections seen in the blood-stage carrying individuals [48].

In contrast, studies in Hamp1-knock-out (KO) mice showed that the lack of hepcidin had no effect on host resistance against Yersinia enterocolitica serotype O8, Staphylococcus aureus or Mycobacterium tuberculosis [47,49], presumably because these pathogens do not depend on an abundance of the serum NTBI, for their proliferation. 
Another interesting observation made in the Hamp1-KO model was that LPS injection induces a significant degree of hypoferremia by hepcidin-independent mechanisms [50]. One such mechanism is the decrease in the transcription of the Fpn1 gene, with a subsequent decrease in cell iron export. In fact, TLR4, but not TLR2 ligands were shown to induce hepcidin expression in myeloid cells, but both caused a down-modulation of FPN1 expression in vitro [51]. In vivo, different TLR agonists induced hypoferremia without a concomitant increase in the hepcidin expression but were accompanied by Fpn1 down-regulation [50,52]. The same effect was seen in mice during infections by Listeria monocytogenes, a Gram-positive bacterium [35].

Most infections are thus accompanied by hypoferremia, which may result from the action of hepcidin and/or FPN1 down-modulation. This hypoferremia is concomitant with iron accumulation in the macrophages, which may favor the growth of intramacrophagic pathogens. This possible dilemma has been extensively investigated in Salmonella enterica serovar Typhimurium, with conflicting results.

In vitro studies with cultured macrophages showed that overexpression of FPN1 increases iron export and decreases the intracellular growth of Salmonella $[53,54]$. Furthermore, the treatment of these cells with hepcidin increased the growth of the bacteria [54,55]. It was also found that infection with Salmonella naturally induces FPN1 overexpression in macrophages, by an inducible nitric oxide synthase and nuclear factor erythroid 2-related factor 2 (Nrf2)-dependent pathway, resulting in an increase of iron export [53]. FPN1 expression inversely correlates with the intracellular growth of Salmonella and also of other intracellular bacteria, such as Legionella and Chlamydia $[53,56]$.

In vivo experimental infections with $S$. Typhimurium, either by the intravenous or the oral route, consistently resulted in an increased expression of hepcidin in the liver and spleen, hypoferremia, and mild anemia $[35,53,57]$. However, contradictory results were reported with respect to the impact of Salmonella infections on FPN1 expression in the liver and spleen, as well as on the tissue iron levels, in these organs $[35,53,57,58]$. Interestingly, one study found that pharmacological inhibition of hepcidin production had a protective effect, inducing lower bacterial burden and decreased mortality by Salmonella infections [57,59], while in another study no differences were seen in bacterial growth between wild-type (WT) and Hamp1-KO mice [60]. Further studies are needed in order to explain these discrepancies, which may result from the different infection routes (intravenous, intraperitoneal or oral). The levels of hepcidin produced, and the related consequences for the kinetics of the iron dysregulation also need to be investigated. So far, the emerging picture is that although hepcidin is produced during Salmonella infection, it has no host-protective role, being even a possible disease promoter.

Other paradigmatic intra-macrophagic infections are those caused by mycobacteria. Despite extensive evidence of a link between host iron status and the severity of disease, in this particular type of infections, hepcidin does not seem to play a critical role in the host-pathogen interaction. Mice infected with Mycobacterium avium did not exhibit any significant alteration in hepcidin expression in the liver, while in animals, infected with $M$. tuberculosis, hepcidin expression was repressed at later time-points $[49,61]$. Moreover, hepcidin deficiency had no impact on susceptibility to $M$. tuberculosis [49]. In both experimental models of infection, with M. avium and M. tuberculosis, FPN1 expression in the liver was up-regulated $[49,61]$ This up-regulation of FPN1 is probably related to expression in hepatocytes, rather than macrophages, since mice infected with M. avium exhibit iron accumulation inside infected macrophages, in the liver granulomas [62].

Another consequence of mycobacteria infection and iron accumulation inside macrophages is the induction of $\mathrm{H}$-ferritin. Infection with $M$. avium or M. bovis BCG increased the expression of $\mathrm{H}$-ferritin, upon activation of TLR2 in macrophages, in an Iron Regulatory Proteins (IRP)- independent manner [51,63]. Ferritins are iron storage proteins composed of a combination of 24 subunits of the $\mathrm{H}$ or L types. Ferritins are mainly thought of as intracellular iron storage proteins. H-ferritin has an oxidase activity, promoting the oxidation of Fe (II) to Fe (III), without which iron cannot be incorporated inside the ferritin cages. L-Ferritin facilitates the nucleation and mineralization of the iron core [64]. The expression of both the H-ferritin and L-ferritin genes is regulated post-transcriptionally by the IRPs. However, H-ferritin transcription is also responsive to inflammatory stimuli, including TNF 
and IL-2 [65-67]. Consequently, one of the iron-related hallmarks of the inflammatory response is hyperferritinemia (rise in the serum levels of ferritin) $[64,68,69]$. Serum ferritin levels are higher, for example, in the plasma of humans infected with Plasmodium vivax in comparison with non-infected individuals [70]. Serum ferritin was shown to be mostly composed of L-subunits with a few H-subunits, to have a low iron content, and to be derived from macrophages through a non-classical secretory pathway [71]. The exact role of the serum ferritin, and the mechanism triggering its release into circulation, during inflammatory conditions, are not known. Some controversy persists as to the role of ferritin in inflammation, with some authors defending that ferritin has an anti-inflammatory effect and others claiming that ferritin is pro-inflammatory $[67,72]$.

Cell surface receptors for both subunits of ferritin have been described and are expressed in immune cells and in the liver [73-75]. It has been hypothesized that ferritin serves as an alternative source of iron but it may also be involved in the host's strategy to overcome the potential cytotoxic effects of iron, during infections. H-ferritin has been recently reported to interfere with Hypoxia induced factor (HIF) $1 \alpha$-mediated response to hypoxia [76]. In this regard, it is important to note that $\mathrm{H}$-ferritin confers tolerance to malaria and sepsis through the decrease in tissue damage and independently from parasite load [70,77]. On the other hand, mice deficient in H-ferritin are more susceptible to $M$. tuberculosis infection, having higher bacterial loads and exacerbated inflammatory response [78]. These models highlight the importance of iron homeostasis, in the control of pathology, during an infection. It is thus evident that iron sequestration and re-distribution by the host has a key influence in the outcome of infectious processes, beyond its role in pathogen nutrient-deprivation.

In this context, another top contender in the host-pathogen interaction is heme. Heme is an important source of iron but is also highly toxic, and is an important cause of tissue damage. Heme transport and metabolism are, thus, handled very tightly within the host. It is increasingly evident that several infections lead to hemolysis, even if at a low level. This leads to increased levels of free hemoglobin and heme in the plasma, which in turn increases the production and release of hemopexin and haptoglobin, and also increases the expression of HO-1 in several tissues. Whether HO-1 activation is protective and/or detrimental for the host is a matter of discussion (reviewed in [79]). HO-1 expression in macrophages is induced upon an infection by mycobacteria and salmonella, both in vitro and in vivo. HO-1 induction has a protective role against these pathogens, being associated with a decrease in bacterial growth and also in oxidative stress-associated pathology [80-82]. Additionally, in vitro experiments showed that HO-1 is necessary for IFNG-induced autophagy and M. tuberculosis growth-arrest inside macrophages [83]. Moreover, the chemical induction of Hmox1 (the gene which codes for HO-1) reduces the pathogen load of macrophages infected with Trypanosoma cruzi [84], and in vivo experiments with Hmox1-KO, or myeloid-specific Hmox1-deficient animals showed that these are more susceptible to sepsis caused by E. coli or Listeria monocytogenes [85]. Heme toxicity may be avoided by the binding of the molecule to proteins such as hemopexin and haptoglobin. IL-22 produced during an immune response to enteric pathogens, elicits the expression of hemopexin to scavenge the plasmatic heme [86]. This pathway reduces the growth of the bacteria, although it is not clear whether this results only from the removal of iron from the pathogens or also from the reduction of the cytotoxic effects of free plasma heme.

Contrasting results were obtained in different infection models. In mice, HO-1 induction was associated with immunomodulation and exacerbation of infection by Fasciola hepatica [87]. Experiments with chemical HO-1 inhibitors suggested that HO-1 was detrimental to the host infected with $M$. tuberculosis [88]. Interestingly, high levels of serum HO-1 were found in patients with active pulmonary tuberculosis, in contrast with latent $M$. tuberculosis carriers or healthy people $[89,90]$. Overall, these studies suggest that, although uniformly induced, HO-1 has specific effects, depending on the type and localization of the invading pathogen. In humans, polymorphisms in the promoter of Hmox1, associated with higher expression of the enzyme, correlate with a more severe presentation of malaria [91]. Murine models of malaria have shown that the higher expression of HO-1 correlated with higher hepatic parasite loads due to an attenuated inflammatory response, 
promoting the establishment of infections [92]. However, during the cerebral stage of malaria, induction of HO-1 does not alter parasitemia but prevents the tissue damage associated with the disease, maintaining the integrity of the blood-brain barrier and that of the brain microvasculature, and preventing neuroinflammation $[93,94]$.

The intricate relationship between the HO- 1 and infections gets another level of complexity in situations of co-infections. Malaria and other hemolytic disorders are often associated with non-typhoid Salmonella septicemia. It is now understood that during malaria-induced progressive hemolysis, the free heme resulting from the bursting erythrocytes is catabolized by the $\mathrm{HO}-1$, releasing $\mathrm{CO}$, biliverdin, and iron, thus reducing the ROS production by the phagocytes, and facilitate the bacterial replication. Therefore, in the context of co-infections, HO-1 mediates a protective response against malaria but impairs the immune response to non-typhoid Salmonella infections $[95,96]$.

\section{Nutritional Immunity and Infection-Induced Anemia}

Infectious diseases, especially those with a chronic evolution, are often accompanied by anemia. For a long time, anemia of infection and inflammation was considered to be a side effect of nutritional immunity. According to this view, by lowering the levels of circulating iron in order to limit pathogen growth, the host makes iron unavailable for the formation of new red blood cells. Anemia of inflammation has thus been linked to hepcidin-mediated iron redistribution, lower levels of circulating iron and increased iron storage in tissues [97]. Experimental models of anemia of inflammation brought on by turpentine-induced sterile abscesses, caused systemic hypoferremia at the early stages of inflammation but it resolved at the later stages. However, anemia persisted due to inefficient development of erythrocyte maturation in the bone marrow [98]. Mice treated with heat-killed Brucella abortus developed hypoferremia at early stages with subsequent development of anemia [36]. Despite these observations linking hypoferremia to the development of anemia, the causal relationships between hepcidin, hypoferremia, and anemia in the context of specific infections have not been established and the mechanisms triggering anemia during infections are still not fully understood.

In some infections, systemic iron levels remain unchanged. For instance, M. avium infection induces anemia independently of hepcidin induction and hypoferremia [61]. The dysregulation of erythrocyte formation during infections may result from factors other than iron deficiency [99-102]. The inflammatory cytokine IFNG was implicated in the pathogenesis of several hematological disturbances, during infections, through its impact on the turnover of hematopoietic stem cells (HSC), either leading to their exhaustion or skewing their differentiation towards the myeloid lineage in detriment to other lineages, like the erythroid [99,100]. IFNG was also implicated in emergency erythropoiesis with reticulocytosis (i.e., increased circulating reticulocytes), in response to infections by Plasmodium [103]. Other cytokines, like IL-6 produced by the bone marrow stromal compartment, were shown to be involved in the impairment of erythropoiesis, during infections with Toxoplasma gondii [104].

Interestingly, hepcidin- or IL-6-deficient mice still developed anemia in response to heat-killed Brucella abortus injection. In this infection model, anemia had a multifactorial origin, including erythropoiesis impairment and reduced erythrocyte lifespan [36,105]. In this context, it is important to note that an increasing number of reports associate infectious diseases with the appearance of hemophagocytic macrophages. Hemophagocytes are myeloid cells with increased avidity to engulf erythrocytes and, in some instances, leukocytes. These cells are frequently observed during infections by pathogens, such as Salmonella enterica, Brucella abortus, Epstein-Barr virus and M. tuberculosis [106109]. S. Typhimurium infections were shown to result in anemia and lead to the development of hemophagocytic macrophages, related to IFNG and IL-12-induced iron efflux from tissues [58]. The mechanisms activating the macrophage to engulf erythrocytes are not fully described, but there is some evidence suggesting that pro-inflammatory cytokines produced by the immune response to the ongoing infections, such as IFNG and TNF, stimulate macrophages to phagocytize erythrocytes, which in turn causes the development of anemia and other hematologic disorders [110,111]. In the absence of 
infections, the prolonged infusion of IFNG led to the appearance of hemophagocytic macrophages and the subsequent development of anemia [112,113]. Hemophagocytic macrophages that appeared in response to infection, had markers of anti-inflammatory M2 phenotype [114]. Genetic mutations may predispose patients to the development of hemophagocytes in response to infections [107,115].

The observation that during the inflammatory response, anemia may occur due to increased degradation of erythrocytes rather than decreased formation, represents an alternative view of anemia etiology and has important implications for the clinical management of infections and infection-induced anemia.

Increased erythrocyte degradation may result from different triggering events depending on the infectious agent. Two recent reports have demonstrated how the immune response itself may induce anemia, by the production of auto-antibodies against erythrocyte intrinsic proteins, during malaria [116]. The deposition of these auto-antibodies-purified from anemic malaria patients-on the surface of non-infected erythrocytes, altered the dynamic fluidity of the erythrocytes and led to their phagocytosis [117]. Type I interferons may also induce the exposure of phosphatidylserine (PS) on the surface of erythrocytes and the expression of PS receptors on myeloid cells, triggering erythrophagocytosis upon infection with lymphocytic choriomeningitis virus (LCMV) [118]. Along with cytokines, activation of TLR4 also stimulates hemophagocytosis [119]. On the other side, the pathogen may also have an active role in inducing alterations in erythrocytes, to cause their phagocytosis. Trypanosoma vivax produces and secretes enzymes that desialylate the host RBC, causing their erythrophagocytosis [120]. S. Typhimurium resides within macrophages containing phagocytized erythrocytes, which may benefit the acquisition of iron by the pathogen [121].

The engulfment of erythrocytes potentially increases the release of free heme, which as we discussed before, is an important player for the host and for the pathogen. Heme itself has the capacity to induce the differentiation of macrophages into an iron-recycling phenotype through the induction of the gene SpiC, degradation of the transcription factor BACH1, and Nrf2-mediated induction of HO-1, the high expression of which is a characteristic of hemophagocytic macrophages during sepsis $[122,123]$. Heme released during erythrocyte engulfment may be detrimental for the host response, besides providing iron for the pathogen, as it inhibits phagocytosis and the migration of phagocytes, due to a disruption of the cytoskeletal dynamics [85]. It is possible that the host developed a strategy to overcome these detrimental effects by the induction of ferroptosis in macrophages engaged in hemophagocytosis [124]. Ferroptosis is a regulated form of cell death due to the iron-dependent accumulation of lethal levels of lipid hydroperoxides [125]. Upon the death of ferroptotic macrophages, circulating and bone-marrow-derived monocytes are recruited to the tissues, where they differentiate into FPN1-expressing iron-recycling macrophages [126]. The development of this population of macrophages during situations of heavy hemophagocytosis is dependent on the growth factor, Csf1, and the transcription factor, Nrf2 [126]. Together, these observations suggest that iron induces important changes in the immune populations during the response to infection, implying that nutritional and immune responses are deeply interlinked and have to modulate each other, in order to maintain the host homeostasis and the capacity to fight the ongoing infection. The understanding of whether hemophagocytosis benefits the host immune response or the pathogen is important for the design of adjuvant therapies to treat infection and the associated anemia.

\section{Targets for Pharmacological Intervention}

In the context of infection, iron metabolism is an important therapeutic target for several reasons: (1) iron is needed by the pathogen; (2) iron dysregulation may lead to anemia; (3) iron may contribute to the pathology. A deeper understanding of the impact of infection on the host's iron metabolism is thus needed in order to allow the planning of efficient therapeutic interventions. Some of the most recent strategies proposed to target host iron metabolism during infections, are summarized in Table 1.

A wide range of chelators (molecules with high affinity for iron) have been extensively designed and synthesized in the search for the treatment of diseases: from cardiac to neurodegenerative 
disorders and cancer $[127,128]$. As pathogens deeply need iron to survive, the introduction of chelators seems a plausible strategy to treat infections and overcome the increasing resistance developed by pathogens, to the available drugs. In vitro, the potential use of hexadentate iron chelators was shown to control mycobacteria growth [129]. The action of these molecules was improved by the conjugation of rhodamine fluorophores [130]. Iron chelators were shown to increase the efficacy of chemotherapeutic agents against Candida albicans, Staphylococcus aureus and polymicrobial sepsis [131-133]. Given the host's need of iron for his own metabolic needs, one important concern related to iron chelation therapies is the development of adequate cell-targeting strategies that may guarantee pathogen's iron depletion, without a concomitant iron deficiency in the host. Altogether, there is a huge potential for medical applications of iron chelators and the beneficial effects of different iron chelators were already shown in several experimental infections. However, chelators-based therapies have not been shown to be sufficiently effective in the treatment of infections in clinical trials $[134,135]$.

One alternative to the administration of iron chelators is to block pathogen's iron acquisition pathways. Lipocalin (Len)-1 and 2 are host proteins, with high affinity for iron-loaded microbial siderophores that restrict microbial growth by inhibiting iron uptake. In a mouse model of fungal corneal infection, the topical administration of Lcn-1or the inhibition of siderophore synthesis by the fungus, had a therapeutic effect with respect to iron starvation [136]. In a different approach to decrease the pathogen's capacity to internalize iron, siderophores were successfully used as antigens for the development of a vaccine against uropathogenic Escherichia coli [137]. In the same line, a vaccine containing live Yersinia pestis was found to have a high potential therapeutic value, successfully limiting pathogen proliferation and the progression of the disease, by inducing the production of hemopexin and transferrin, with consequent iron sequestration [138]. The modulation of hepcidin function during infections is another potential target to control pathogen growth, as suggested by the observation that Plasmodium erythrocytic stages inhibit liver-stage superinfection, through hepcidin induction [139]. The use of minihepcidins, synthetic hepcidin agonists, are known to bind ferroportin and induce its internalization, was initially studied in iron overload disorders, such as hemochromatosis [140]. The administration of hepcidin mimetics was then tested in experimental models of infection and shown to clearly protect from Vibrio and Yersinia-induced mortality, by reducing bacterial loads. These hepcidin mimetics were shown to be effective not only in preventing but also at treating infections $[38,46]$. In the case of Salmonella infections, a therapeutic effect was seen with the pharmacological inhibition of hepcidin production [57].

Regarding the correction of anemia associated with infections, it is important to distinguish the cases involving hepcidin activity from those that do not. Several inhibitors of hepcidin production have been successfully tested to correct anemia of inflammation [141], but their usefulness in the context of infection awaits confirmation.

The above-mentioned examples show that pharmacological approaches to alter iron homeostasis and iron trafficking, during infections, may make an important contribution to the anti-infective therapeutic armamentarium. However, it should be kept in mind that different pathogens have different strategies to acquire iron in the host and the same intervention may have positive results in one case and negative or neutral consequences in others.

Table 1. Iron-targeted strategies to fight infection.

\begin{tabular}{ccc}
\hline Approach & Mechanism & Reference \\
\hline Iron chelators & Direct reduction of available iron & {$[129-134]$} \\
Vaccines & Inhibition of iron uptake & {$[137-139]$} \\
Hepcidin agonists & Reduction of NTBI & {$[38,47]$} \\
Hepcidin inhibitors & Reduction of hepcidin production & {$[57]$} \\
\hline
\end{tabular}




\section{Conclusions}

Infections lead to important alterations in the host's iron metabolism, including iron redistribution within the tissues. Different pathogens have different impacts, some of which favor pathogen growth while others protect the host. We are still far from having a comprehensive picture of the pathways involved. Therefore, it is imperative that basic research work continues to be developed in order to gain a deeper understanding of the specific changes occurring in host iron homeostasis in response to each specific pathogen.

Author Contributions: A.C.G. and M.S.G. conceptualized and outlined the manuscript. All the authors wrote and reviewed the manuscript. M.S.G. reviewed and prepared it to submission.

Funding: This work is a result of the project Norte-01-0145-FEDER-000012-Structured program on bioengineered therapies for infectious diseases and tissue regeneration, supported by Norte Portugal Regional Operational Programme (NORTE 2020), under the PORTUGAL 2020 Partnership Agreement, through the European Regional Development Fund (FEDER). This work was financed by FEDER-Fundo Europeu de Desenvolvimento Regional funds through the COMPETE 2020-Operacional Programme for Competitiveness and Internationalisation (POCI), Portugal 2020, and by Portuguese funds through FCT-Fundação para a Ciência e a Tecnologia/Ministério da Ciência, Tecnologia e Ensino Superior in the framework of the project PTDC/IMI-MIC/1683/2014 (POCI-01-0145-FEDER-016590). A.C.M. receives the individual fellowship SFRH/BPD/101405/2014 from FCT.

Conflicts of Interest: The authors declare no conflicts of interest.

\section{References}

1. Hider, R.C.; Kong, X. Chemistry and biology of siderophores. Nat. Prod. Rep. 2010, 27, 637-657. [CrossRef] [PubMed]

2. Choby, J.E.; Skaar, E.P. Heme Synthesis and Acquisition in Bacterial Pathogens. J. Mol. Biol. 2016, 428, 3408-3428. [CrossRef] [PubMed]

3. Isanaka, S.; Aboud, S.; Mugusi, F.; Bosch, R.J.; Willett, W.C.; Spiegelman, D.; Duggan, C.; Fawzi, W.W. Iron Status Predicts Treatment Failure and Mortality in Tuberculosis Patients: A Prospective Cohort Study from Dar es Salaam, Tanzania. PLoS ONE 2012, 7, e37350. [CrossRef] [PubMed]

4. McDermid, J.M.; Hennig, B.J.; van der Sande, M.; Hill, A.V.; Whittle, H.C.; Jaye, A.; Prentice, A.M. Host iron redistribution as a risk factor for incident tuberculosis in HIV infection: An 11-year retrospective cohort study. BMC Infect. Dis. 2013, 13, 48. [CrossRef] [PubMed]

5. Esan, M.O.; van Hensbroek, M.B.; Nkhoma, E.; Musicha, C.; White, S.A.; ter Kuile, F.O.; Phiri, K.S. Iron supplementation in HIV-infected Malawian children with anemia: A double-blind, randomized, controlled trial. Clin. Infect. Dis. 2013, 57, 1626-1634. [CrossRef] [PubMed]

6. Soofi, S.; et al. Effect of provision of daily zinc and iron with several micronutrients on growth and morbidity among young children in Pakistan: A cluster-randomised trial. Lancet 2013, 382, 29-40. [CrossRef]

7. Apelberg, R. Macrophage nutriprive antimicrobial mechanisms. J. Leuko. Biol. 2006, 79, 1117-1128. [CrossRef] [PubMed]

8. Weinberg, E.D. Nutritional immunity. Host's attempt to withold iron from microbial invaders. JAMA 1975, 231, 39-41.

9. Barber, M.F.; Elde, N.C. Nutritional immunity. Escape from bacterial iron piracy through rapid evolution of transferrin. Science 2014, 346, 1362-1366. [CrossRef] [PubMed]

10. Muckenthaler, M.U.; Rivella, S.; Hentze, M.W.; Galy, B. A Red Carpet for Iron Metabolism. Cell 2017, 168, 344-361. [CrossRef] [PubMed]

11. Le Blanc, S.; Garrick, M.D.; Arredondo, M. Heme carrier protein 1 transports heme and is involved in heme-Fe metabolism. Am. J. Physiol Cell. Physiol. 2012, 302, C1780-C1785. [CrossRef] [PubMed]

12. Shayeghi, M.; Latunde-Dada, G.O.; Oakhill, J.S.; Laftah, A.H.; Takeuchi, K.; Halliday, N.; Khan, Y.; Warley, A.; McCann, F.E.; Hider, R.C.; et al. Identification of an intestinal heme transporter. Cell 2005, 122, 789-801. [CrossRef] [PubMed]

13. Lane, D.J.R.; Robinson, S.R.; Czerwinska, H.; Bishop, G.M.; Lawen, A. Two routes of iron accumulation in astrocytes: Ascorbate-dependent ferrous iron uptake via the divalent metal transporter (DMT1) plus an independent route for ferric iron. Biochem. J. 2010, 432, 123-132. [CrossRef] [PubMed] 
14. Arezes, J.; Costa, M.; Vieira, I.; Dias, V.; Kong, X.L.; Fernandes, R.; Vos, M.; Carlsson, A.; Rikers, Y.; Porto, G.; et al. Non-Transferrin-Bound Iron (NTBI) Uptake by T Lymphocytes: Evidence for the Selective Acquisition of Oligomeric Ferric Citrate Species. PLoS ONE 2013, 8, e79870. [CrossRef] [PubMed]

15. Brissot, P.; Ropert, M.; Lan, C.L.; Loréal, O. Non-transferrin bound iron: A key role in iron overload and iron toxicity. BBA-Gen. Subjects 2012, 1820, 403-410. [CrossRef] [PubMed]

16. White, C.; Yuan, X.; Schmidt, P.J.; Bresciani, E.; Samuel, T.K.; Campagna, D.; Hall, C.; Bishop, K.; Calicchio, M.L.; Lapierre, A.; et al. HRG1 is essential for heme transport from the phagolysosome of macrophages during erythrophagocytosis. Cell Metab. 2013, 17, 261-270. [CrossRef] [PubMed]

17. Quigley, J.G.; Yang, Z.; Worthington, M.T.; Phillips, J.D.; Sabo, K.M.; Sabath, D.E.; Berg, C.L.; Sassa, S.; Wood, B.L.; Abkowitz, J.L. Identification of a Human Heme Exporter that Is Essential for Erythropoiesis. Cell 2004, 118, 757-766. [CrossRef] [PubMed]

18. Delaby, C.; Pilard, N.; Puy, H.; Canonne-Hergaux, F. Sequential regulation of ferroportin expression after erythrophagocytosis in murine macrophages: Early mRNA induction by haem, followed by iron-dependent protein expression. Biochem. J. 2008, 411, 123-131. [CrossRef] [PubMed]

19. Kovtunovych, G.; Eckhaus, M.A.; Ghosh, M.C.; Ollivierre-Wilson, H.; Rouault, T.A. Dysfunction of the heme recycling system in heme oxygenase 1-deficient mice: Effects on macrophage viability and tissue iron distribution. Blood 2010, 116, 6054-6062. [CrossRef] [PubMed]

20. Lin, T.; Maita, D.; Thundivalappil, S.R.; Riley, F.E.; Hambsch, J.; van Marter, L.J.; Christou, H.A.; Berra, L.; Fagan, S.; Christiani, D.C.; et al. Hemopexin in severe inflammation and infection: Mouse models and human diseases. Crit. Care 2015, 19, 166. [CrossRef] [PubMed]

21. Smith, A.; McCulloh, R.J. Hemopexin and haptoglobin: Allies against heme toxicity from hemoglobin not contenders. Front. Physiol. 2015, 6, 187. [CrossRef] [PubMed]

22. Elphinstone, R.E.; Riley, F.; Lin, T.; Higgins, S.; Dhabangi, A.; Musoke, C.; Cserti-Gazdewich, C.; Regan, R.F.; Warren, H.S.; Kain, K.C. Dysregulation of the haem-haemopexin axis is associated with severe malaria in a case-control study of Ugandan children. Malar. J. 2015, 14, 511. [CrossRef] [PubMed]

23. Knutson, M.D.; Oukka, M.; Koss, L.M.; Aydemir, F.; Wessling-Resnick, M. Iron release from macrophages after erythrophagocytosis is up-regulated by ferroportin 1 overexpression and down-regulated by hepcidin. Proc. Natl. Acad. Sci. USA 2005, 102, 1324-1328. [CrossRef] [PubMed]

24. Knutson, M.D.; Vafa, M.R.; Haile, D.J.; Wessling-Resnick, M. Iron loading and erythrophagocytosis increase ferroportin 1 (FPN1) expression in J774 macrophages. Blood 2003, 102, 4191-4197. [CrossRef] [PubMed]

25. Nicolas, G.; Chauvet, C.; Viatte, L.; Danan, J.L.; Bigard, X.; Devaux, I.; Beaumont, C.; Kahn, A.; Vaulont, S. The gene encoding the iron regulatory peptide hepcidin is regulated by anemia, hypoxia, and inflammation. J. Clin. Investig. 2002, 110, 1037-1044. [CrossRef] [PubMed]

26. Murray, P.J.; Wynn, T.A. Protective and pathogenic functions of macrophage subsets. Nat. Rev. Immunol. 2011, 11, 723. [CrossRef] [PubMed]

27. Recalcati, S.; Locati, M.; Marini, A.; Santambrogio, P.; Zaninotto, F.; de Pizzol, M.; Zammataro, L.; Girelli, D.; Cairoet, G. Differential regulation of iron homeostasis during human macrophage polarized activation. Eur. J. Immunol. 2010, 40, 824-835. [CrossRef] [PubMed]

28. Agoro, R.; Taleb, M.; Quesniaux, V.F.J.; Mura, C. Cell iron status influences macrophage polarization. PLoS ONE 2018, 13, e0196921. [CrossRef] [PubMed]

29. Pigeon, C.; Ilyin, G.; Courselaud, B.; Leroyer, P.; Turlin, B.; Brissot, P.; Loréal, O. A new mouse liver-specific gene, encoding a protein homologous to human antimicrobial peptide hepcidin, is overexpressed during iron overload. J. Biol. Chem. 2001, 276, 7811-7819. [CrossRef] [PubMed]

30. Nemeth, E.; Rivera, S.; Gabayan, V.; Keller, C.; Taudorf, S.; Pedersen, B.K.; Ganz, T. IL-6 mediates hypoferremia of inflammation by inducing the synthesis of the iron regulatory hormone hepcidin. J. Clin. Investig. 2004, 113, 1271-1276. [CrossRef] [PubMed]

31. Lee, P.; Peng, H.; Gelbart, T.; Beutler, E. The IL-6- and lipopolysaccharide-induced transcription of hepcidin in HFE-, transferrin receptor 2-, and beta 2-microglobulin-deficient hepatocytes. Proc. Natl. Acad. Sci. USA 2004, 101, 9263-9265. [CrossRef] [PubMed]

32. Nemeth, E.; Tuttle, M.S.; Powelson, J.; Vaughn, M.B.; Donovan, A.; Ward, D.M.; Ganz, T.; Kaplan, J. Hepcidin regulates cellular iron efflux by binding to ferroportin and inducing its internalization. Science 2004, 306, 2090-2093. [CrossRef] [PubMed] 
33. Drakesmith, H.; Prentice, A.M. Hepcidin and the iron-infection axis. Science 2012, 338, 768-772. [CrossRef] [PubMed]

34. Michels, K.; Nemeth, E.; Ganz, T.; Mehrad, B. Hepcidin and Host Defense against Infectious Diseases. PLoS Pathog. 2015, 11, e1004998. [CrossRef] [PubMed]

35. Moreira, A.C.; Neves, J.V.; Silva, T.; Oliveira, P.; Gomes, M.S.; Rodrigues, P.N. Hepcidin-(In)dependent Mechanisms of Iron Metabolism Regulation during Infection by Listeria and Salmonella. Infect. Immun. 2017, 85. [CrossRef] [PubMed]

36. Kim, A.; Fung, E.; Parikh, S.G.; Valore, E.V.; Gabayan, V.; Nemeth, E.; Ganzet, T. A mouse model of anemia of inflammation: Complex pathogenesis with partial dependence on hepcidin. Blood 2014, 123, 1129-1136. [CrossRef] [PubMed]

37. Peyssonnaux, C.; Zinkernagel, A.S.; Datta, V.; Lauth, X.; Johnson, R.S.; Nizet, V. TLR4-dependent hepcidin expression by myeloid cells in response to bacterial pathogens. Blood 2006, 107, 3727-3732. [CrossRef] [PubMed]

38. Arezes, J.; Jung, G.; Gabayan, V.; Valore, E.; Ruchala, P.; Gulig, P.A.; Ganz, T.; Nemeth, E.; Bulut, Y. Hepcidin-Induced Hypoferremia Is a Critical Host Defense Mechanism against the Siderophilic Bacterium Vibrio vulnificus. Cell Host Microbe 2015, 17, 47-57. [CrossRef] [PubMed]

39. Armitage, A.E.; Eddowes, L.A.; Gileadi, U.; Cole, S.; Spottiswoode, N.; Selvakumar, T.A.; Ho, L.P.; Townsend, A.R.M.; Drakesmith, H. Hepcidin regulation by innate immune and infectious stimuli. Blood 2011, 118, 4129-4139. [CrossRef] [PubMed]

40. Casals-Pascual, C.; Huang, H.; Lakhal-Littleton, S.; Thezenas, M.L.; Kai, O.; Newton, C.R.J.C.; Roberts, D.J. Hepcidin demonstrates a biphasic association with anemia in acute Plasmodium falciparum malaria. Haematologica 2012, 97, 1695-1698. [CrossRef] [PubMed]

41. Kerkhoff, A.D.; Meintjes, G.; Burton, R.; Vogt, M.; Wood, R.; Lawn, S.D. Relationship Between Blood Concentrations of Hepcidin and Anemia Severity, Mycobacterial Burden, and Mortality Among Patients With HIV-Associated Tuberculosis. J. Infect. Dis. 2016, 213, 61-70. [CrossRef] [PubMed]

42. Minchella, P.A.; Armitage, A.E.; Darboe, B.; Jallow, M.W.; Drakesmith, H.; Jaye, A.; Prentice, A.M.; McDermid, J.M. Elevated Hepcidin Is Part of a Complex Relation That Links Mortality with Iron Homeostasis and Anemia in Men and Women with HIV Infection. J. Nutr. 2015, 145, 1194-1201. [CrossRef] [PubMed]

43. Van Eijk, L.T.; Kroot, J.J.C.; Tromp, M.; van der Hoeven, J.G.; Swinkels, D.W.; Pickkers, P. Inflammation-induced hepcidin-25 is associated with the development of anemia in septic patients: An observational study. Crit. Care 2011, 15, R9. [CrossRef] [PubMed]

44. Darton, T.C.; Blohmke, C.J.; Giannoulatou, E.; Waddington, C.S.; Jones, C.; Sturges, P.; Webster, C.; Drakesmith, H.; Pollard, A.J.; Armitage, A.E. Rapidly Escalating Hepcidin and Associated Serum Iron Starvation Are Features of the Acute Response to Typhoid Infection in Humans. PLoS Negl. Trop. Dis. 2015, 9, e0004029. [CrossRef] [PubMed]

45. Girelli, D.; Pasino, M.; Goodnough, J.B.; Nemeth, E.; Guido, M.; Castagna, A.; Busti, F.; Campostrini, N.; Martinelli, N.; Vantini, I.; Corrocher, R.; et al. Reduced serum hepcidin levels in patients with chronic hepatitis C. J. Hepatol. 2009, 51, 845-852. [CrossRef] [PubMed]

46. Michels, K.R.; Zhang, Z.; Bettina, A.M.; Cagnina, R.E.; Stefanova, D.; Burdick, M.D.; Vaulont, S.; Nemeth, E.; Ganz, T.; Mehrad, B. Hepcidin-mediated iron sequestration protects against bacterial dissemination during pneumonia. JCI Insight 2017, 2, e92002. [CrossRef] [PubMed]

47. Stefanova, D.; Raychev, A.; Arezes, J.; Ruchala, P.; Gabayan, V.; Skurnik, M.; Dillon, B.J.; Horwitz, M.A.; Ganz, T.; Bulut, Y.; et al. Endogenous hepcidin and its agonist mediate resistance to selected infections by clearing non-transferrin-bound iron. Blood 2017, 130, 245-257. [CrossRef] [PubMed]

48. Portugal, S.; Carret, C.; Recker, M.; Armitage, A.E.; Gonçalves, L.A.; Epiphanio, S.; Sullivan, D.; Roy, C.; Newbold, C.I.; Drakesmith, H.; Carret, C.; et al. Host-mediated regulation of superinfection in malaria. Nat. Med. 2011, 17, 732-737. [CrossRef] [PubMed]

49. Harrington-Kandt, R.; Stylianou, E.; Eddowes, L.A.; Lim, P.J.; Stockdale, L.; Pinpathomrat, N.; Bull, N.; Pasricha, J.; Ulaszewska, M.; Beglov, Y.; et al. Hepcidin deficiency and iron deficiency do not alter tuberculosis susceptibility in a murine M.tb infection model. PLoS ONE 2018, 13, e0191038. [CrossRef] [PubMed]

50. Deschemin, J.C.; Vaulont, S. Role of hepcidin in the setting of hypoferremia during acute inflammation. PLoS ONE 2013, 8, e61050. [CrossRef] [PubMed] 
51. Abreu, R.; Quinn, F.; Giri, P.K. Role of the hepcidin-ferroportin axis in pathogen-mediated intracellular iron sequestration in human phagocytic cells. Blood Adv. 2018, 2, 1089-1100. [CrossRef] [PubMed]

52. Guida, C.; Altamura, S.; Klein, F.A.; Galy, B.; Boutros, M.; Ulmer, A.J.; Hentze, M.W.; Muckenthaler, M.U. A novel inflammatory pathway mediating rapid hepcidin-independent hypoferremia. Blood 2015, 125, 2265-2275. [CrossRef] [PubMed]

53. Nairz, M.; Schleicher, U.; Schroll, A.; Sonnweber, T.; Theurl, I.; Ludwiczek, S.; Talasz, H.; Brandacher, G.; Moser, P.L.; Muckenthaler, M.U.; et al. Nitric oxide-mediated regulation of ferroportin-1 controls macrophage iron homeostasis and immune function in Salmonella infection. J. Exp. Med. 2013, 210, 855-873. [CrossRef] [PubMed]

54. Chlosta, S.; Fishman, D.S.; Harrington, L.; Johnson, E.E.; Knutson, M.D.; Wessling-Resnick, M.; Cherayil, B.J. The iron efflux protein ferroportin regulates the intracellular growth of Salmonella enterica. Infect. Immun. 2006, 74, 3065-3067. [CrossRef] [PubMed]

55. Liu, D.; Gan, Z.S.; Ma, W.; Xiong, H.T.; Li, Y.Q.; Wang, Y.Z.; Du, H.H. Synthetic Porcine Hepcidin Exhibits Different Roles in Escherichia coli and Salmonella Infections. Antimicrob. Agents Chemother. 2017, 61, e02638-16. [CrossRef] [PubMed]

56. Paradkar, P.N.; de Domenico, I.; Durchfort, N.; Zohn, I.; Kaplan, J.; Ward, D.M. Iron depletion limits intracellular bacterial growth in macrophages. Blood 2008, 112, 866-874. [CrossRef] [PubMed]

57. Kim, D.K.; Jeong, J.H.; Lee, J.M.; Kim, K.S.; Park, S.H.; Kim, Y.D.; Koh, M.; Shin, M.; Jung, Y.S.; Kim, H.S.; et al. Inverse agonist of estrogen-related receptor gamma controls Salmonella typhimurium infection by modulating host iron homeostasis. Nat. Med. 2014, 20, 419-424. [CrossRef] [PubMed]

58. Brown, D.E.; Nick, H.J.; McCoy, M.W.; Moreland, S.M.; Stepanek, A.M.; Benik, R.; O'Connell, K.E.; Pilonieta, M.C.; Nagy, T.A.; Detweiler, C.S. Increased Ferroportin-1 Expression and Rapid Splenic Iron Loss Occur with Anemia Caused by Salmonella enterica Serovar Typhimurium Infection in Mice. Infect. Immun. 2015, 83, 2290-2299. [CrossRef] [PubMed]

59. Lim, D.; Kim, K.S.; Jeong, J.H.; Marques, O.; Kim, H.J.; Song, M.; Lee, T.H.; Kim, J.I.; Choi, H.S.; Min, J.J.; et al. The hepcidin-ferroportin axis controls the iron content of Salmonella-containing vacuoles in macrophages. Nat. Commun. 2018, 9, 2091. [CrossRef] [PubMed]

60. Willemetz, A.; Beatty, S.; Richer, E.; Rubio, A.; Auriac, A.; Milkereit, R.J.; Thibaudeau, O.; Vaulont, S.; Malo, D.; Canonne-Hergaux, F. Iron- and Hepcidin-Independent Downregulation of the Iron Exporter Ferroportin in Macrophages during Salmonella Infection. Front. Immunol. 2017, 8, 498. [CrossRef] [PubMed]

61. Rodrigues, P.N.; Gomes, S.S.; Neves, V.J.; Gomes-Pereira, S.; Correia-Neves, M.; Nunes-Alves, C.; Stolte, J.; Sanchez, M.; Appelberg, R.; Muckenthaler, M.U.; et al. Mycobacteria-induced anaemia revisited: A molecular approach reveals the involvement of NRAMP1 and lipocalin-2, but not of hepcidin. Immunobiology 2011, 216, 1127-1134. [CrossRef] [PubMed]

62. Gomes-Pereira, S.; Rodrigues, P.N.; Appelberg, R.; Gomes, M.S. Increased susceptibility to Mycobacterium avium in hemochromatosis protein HFE-deficient mice. Infect. Immun. 2008, 76, 4713-4719. [CrossRef] [PubMed]

63. Silva-Gomes, S.; Bouton, C.; Silva, T.; Santambrogio, P.; Rodrigues, P.; Appelberg, R.; Gomes, M.S. Mycobacterium avium Infection Induces H-Ferritin Expression in Mouse Primary Macrophages by Activating Toll-Like Receptor 2. PLoS ONE 2013, 8, e82874. [CrossRef] [PubMed]

64. Jutz, G.; van Rijn, P.; Miranda, B.S.; Böker, A. Ferritin: A versatile building block for bionanotechnology. Chem. Rev. 2015, 115, 1653-1701. [CrossRef] [PubMed]

65. Torti, F.M.; Torti, S.V. Regulation of ferritin genes and protein. Blood 2002, 99, 3505-3516. [CrossRef] [PubMed]

66. Pham, C.G.; Bubici, C.; Zazzeroni, F.; Papa, S.; Jones, J.; Alvarez, K.; Jayawardena, S.; de Smaele, E.; Cong, R.; Beaumont, C.; et al. Ferritin heavy chain upregulation by NF-kappaB inhibits TNFalpha-induced apoptosis by suppressing reactive oxygen species. Cell 2004, 119, 529-542. [CrossRef] [PubMed]

67. Recalcati, S.; Invernizzi, P.; Arosio, P.; Cairo, G. New functions for an iron storage protein: The role of ferritin in immunity and autoimmunity. J. Autoimmun. 2008, 30, 84-89. [CrossRef] [PubMed]

68. Wang, W.; Knovich, M.A.; Coffman, L.G.; Torti, F.M.; Torti, S.V. Serum ferritin: Past, present and future. BBA-GEN. Subjects 2010, 1800, 760-769. [CrossRef] [PubMed]

69. Cullis, J.O.; Fitzsimons, E.J.; Griffiths, W.J.H.; Tsochatzis, E.; Thomas, D.W. Investigation and management of a raised serum ferritin. Br. J. Haematol. 2018, 181, 331-340. [CrossRef] [PubMed] 
70. Gozzelino, R.; Andrade, B.B.; Larsen, R.; Luz, N.F.; Vanoaica, L.; Seixas, E.; Coutinho, A.; Cardoso, S.; Rebelo, S.; Poli, M.; et al. Metabolic adaptation to tissue iron overload confers tolerance to malaria. Cell Host Microbe 2012, 12, 693-704. [CrossRef] [PubMed]

71. Cohen, L.A.; Gutierrez, L.; Weiss, A.; Leichtmann-Bardoogo, Y.; Zhang, D.; Crooks, D.; Sougrat, R.; Morgenstern, A.; Galy, B.; Hentze, M.W.; et al. Serum ferritin is derived primarily from macrophages through a nonclassical secretory pathway. Blood 2010, 116, 1574-1584. [CrossRef] [PubMed]

72. Ruscitti, P.; Cipriani, P.; Benedetto, P.D.; Liakouli, V.; Berardicurti, O.; Carubbi, F.; Ciccia, F.; Guggino, G.; Triolo, G.; Giacomelli, R.; et al. H-ferritin and proinflammatory cytokines are increased in the bone marrow of patients affected by macrophage activation syndrome. Clin. Exp. Immunol. 2018, 191, 220-228. [CrossRef] [PubMed]

73. Li, J.Y.; Paragas, N.; Ned, R.M.; Qiu, A.; Viltard, M.; Leete, T.; Drexler, I.R.; Chen, X.; Sanna-Cherchi, S.; Mohammed, F.; et al. Scara5 is a ferritin receptor mediating non-transferrin iron delivery. Dev. Cell 2009, 16, 35-46. [CrossRef] [PubMed]

74. Chen, T.T.; Li, L.; Chung, D.H.; Allen, C.D.C.; Torti, S.V.; Torti, F.M.; Cyster, J.G.; Chen, C.Y.; Brodsky, F.M.; Niemi, E.C.; et al. TIM-2 is expressed on B cells and in liver and kidney and is a receptor for H-ferritin endocytosis. J. Exp. Med. 2005, 202, 955-965. [CrossRef] [PubMed]

75. Han, J.; Seaman, W.E.; Di, X.; Wang, W.; Willingham, M.; Torti, F.M.; Torti, S.V. Iron uptake mediated by binding of $\mathrm{H}$-ferritin to the TIM-2 receptor in mouse cells. PLoS ONE 2011, 6, e23800. [CrossRef] [PubMed]

76. Jin, P.; Kang, J.; Lee, M.K.; Park, J.W. Ferritin heavy chain controls the HIF-driven hypoxic response by activating the asparaginyl hydroxylase FIH. Biochem. Biophys. Res. Commun. 2018, 499, 475-481. [CrossRef] [PubMed]

77. Weis, S.; Carlos, A.R.; Moita, M.R.; Singh, S.; Blankenhaus, B.; Cardoso, S.; Larsen, R.; Rebelo, S.; Schäuble, S.; Barrio, L.D.; et al. Metabolic Adaptation Establishes Disease Tolerance to Sepsis. Cell 2017, 169, 1170-1172. [CrossRef] [PubMed]

78. Reddy, V.P.; Chinta, K.C.; Saini, V.; Glasgow, J.N.; Hull, T.D.; Traylor, A.; Rey-Stolle, F.; Soares, M.P.; Madansein, R.; Rahman, M.A.; et al. Ferritin H Deficiency in Myeloid Compartments Dysregulates Host Energy Metabolism and Increases Susceptibility to Mycobacterium tuberculosis Infection. Front. Immunol. 2018, 9, 860. [CrossRef] [PubMed]

79. Singh, N.; Ahmad, Z.; Baid, N.; Kumar, A. Host heme oxygenase-1: Friend or foe in tackling pathogens? IUBMB Life 2018. [CrossRef] [PubMed]

80. Silva-Gomes, S.; Appelberg, R.; Larsen, R.; Soares, M.P.; Gomes, M.S. Heme Catabolism by Heme Oxygenase-1 Confers Host Resistance to Mycobacterium Infection. Infect. and Immun. 2013, 81, 2536-2545. [CrossRef] [PubMed]

81. Nairz, M.; Theurl, I.; Ludwiczek, S.; Theurl, M.; Mair, S.M.; Fritsche, G.; Weiss, G. The co-ordinated regulation of iron homeostasis in murine macrophages limits the availability of iron for intracellular Salmonella typhimurium. Cell Microbiol. 2007, 9, 2126-2140. [CrossRef] [PubMed]

82. Zaki, M.H.; Fujii, S.; Okamoto, T.; Islam, S.; Khan, S.; Ahmed, K.A.; Sawa, T.; Akaike, T. Cytoprotective Function of Heme Oxygenase 1 Induced by a Nitrated Cyclic Nucleotide Formed during Murine Salmonellosis. J. Immunol. 2009, 182, 3746-3756. [CrossRef] [PubMed]

83. Singh, N.; Kansal, P.; Ahmad, Z.; Baid, N.; Kushwaha, H.; Khatri, N.; Kumar, A. Antimycobacterial effect of IFNG (interferon gamma)-induced autophagy depends on HMOX1 (heme oxygenase 1)-mediated increase in intracellular calcium levels and modulation of PPP3/calcineurin-TFEB (transcription factor EB) axis. Autophagy 2018, 14, 1-20. [CrossRef] [PubMed]

84. Paiva, C.N.; Feijó, D.F.; Dutra, F.F.; Carneiro, V.C.; Freitas, G.B.; Alves, L.S.; Mesquita, J.; Fortes, G.B.; Figueiredo, R.T.; Souza, H.S.P.; et al. Oxidative stress fuels Trypanosoma cruzi infection in mice. J. Clin. Investig. 2012, 122, 2531-2542. [CrossRef] [PubMed]

85. Martins, R.; Maier, J.; Gorki, A.D.; Huber, K.V.W.; Sharif, O.; Starkl, P.; Saluzzo, S.; Quattrone, F.; Gawish, R.; Lakovits, K.; et al. Heme drives hemolysis-induced susceptibility to infection via disruption of phagocyte functions. Nat. Immunol. 2016, 17, 1361-1372. [CrossRef] [PubMed]

86. Sakamoto, K.; Kim, Y.G.; Hara, H.; Kamada, N.; Caballero-Flores, G.; Tolosano, E.; Soares, M.P.; Puente, J.L.; Inohara, N.; Núñez, G. IL-22 Controls Iron-Dependent Nutritional Immunity Against Systemic Bacterial Infections. Sci. Immunol. 2017, 2, eaai8371. [CrossRef] [PubMed] 
87. Carasi, P.; Rodríguez, E.; da Costa, V.; Frigerio, S.; Brossard, N.; Noya, V.; Robello, C.; Anegón, I.; Freire, T. Heme-Oxygenase-1 Expression Contributes to the Immunoregulation Induced by Fasciola hepatica and Promotes Infection. Front. Immunol. 2017, 8, 883. [CrossRef] [PubMed]

88. Scharn, C.R.; Collins, A.C.; Nair, V.R.; Stamm, C.E.; Marciano, D.K.; Graviss, E.A.; Shiloh, M.U. Heme Oxygenase-1 Regulates Inflammation and Mycobacterial Survival in Human Macrophages during Mycobacterium tuberculosis Infection. J. Immunol. 2016, 196, 4641-4649. [CrossRef]

89. Andrade, B.B.; Kumar, N.P.; Mayer-Barber, K.D.; Barber, D.L.; Sridhar, R.; Rekha, V.V.B.; Jawahar, M.S.; Nutman, T.B.; Sher, A.; Babu, A. Plasma Heme Oxygenase-1 Levels Distinguish Latent or Successfully Treated Human Tuberculosis from Active Disease. PLoS ONE 2013, 8, e62618. [CrossRef] [PubMed]

90. Andrade, B.B.; Kumar, N.P.; Amaral, E.P.; Riteau, N.; Mayer-Barber, K.D.; Tosh, K.W.; Maier, N.; Conceição, E.L.; Kubler, A.; Sridhar, R.; et al. Heme Oxygenase-1 Regulation of Matrix Metalloproteinase-1 Expression Underlies Distinct Disease Profiles in Tuberculosis. J. Immunol. 2015, 195, 2763-2773. [CrossRef] [PubMed]

91. Walther, M.; de Caul, A.; Aka, P.; Njie, M.; Amambua-Ngwa, A.; Walther, B.; Predazzi, I.M.; Cunnington, A.; Deininger, S.; Takem, E.N.; et al. HMOX1 gene promoter alleles and high HO-1 levels are associated with severe malaria in Gambian children. PLoS Pathog. 2012, 8, e1002579. [CrossRef] [PubMed]

92. Epiphanio, S.; Mikolajczak, S.A.; Gonçalves, L.A.; Pamplona, A.; Portugal, S.; Albuquerque, S.; Goldberg, M.; Rebelo, S.; Anderson, D.G.; Akinc, A.; et al. Heme oxygenase-1 is an anti-inflammatory host factor that promotes murine plasmodium liver infection. Cell Host Microbe 2008, 3, 331-338. [CrossRef] [PubMed]

93. Pamplona, A.; Ferreira, A.; Balla, J.; Jeney, V.; Balla, G.; Epiphanio, S.; Chora, A.; Rodrigues, C.D.; Gregoire, I.P.; Cunha-Rodrigues, M.; et al. Heme oxygenase-1 and carbon monoxide suppress the pathogenesis of experimental cerebral malaria. Nat. Med. 2007, 13, 703-710. [CrossRef] [PubMed]

94. Seixas, E.; Mikolajczak, S.A.; Gonçalves, L.A.; Pamplona, A.; Portugal, S.; Albuquerque, S.; Goldberg, M.; Rebelo, S.; Anderson, D.G.; Akinc, A.; et al. Heme oxygenase-1 affords protection against noncerebral forms of severe malaria. Proc. Natl. Acad. Sci. USA 2009, 106, 15837-15842. [CrossRef] [PubMed]

95. Cunnington, A.J.; de Souza, J.B.; Walther, M.; Riley, E.M. Malaria impairs resistance to Salmonella through heme- and heme oxygenase-dependent dysfunctional granulocyte mobilization. Nat. Med. 2011, 18, 120. [CrossRef] [PubMed]

96. Lokken, K.L.; Stull-Lane, A.R.; Poels, K.; Tsolis, R.M. Malaria parasite-mediated alteration of macrophage function and increased iron availability predispose to disseminated non-typhoidal Salmonella infection. Infect. Immun. 2018, 86, e00301-e00318. [CrossRef] [PubMed]

97. Jonker, F.A.M.; van Hensbroek, M.B. Anaemia, iron deficiency and susceptibility to infections. J. Infection 2014, 69, S23-S27. [CrossRef] [PubMed]

98. Prince, O.D.; Langdon, J.M.; Layman, A.J.; Prince, I.C.; Sabogal, M.; Mak, H.H.; Berger, A.E.; Cheadle, C.; Chrest, F.J.; Yu, Q.; et al. Late stage erythroid precursor production is impaired in mice with chronic inflammation. Haematologica 2012, 97, 1648-1656. [CrossRef] [PubMed]

99. Baldridge, M.T.; King, K.Y.; Boles, N.C.; Weksberg, D.C.; Goodell, M.A. Quiescent haematopoietic stem cells are activated by IFN-gamma in response to chronic infection. Nature 2010, 465, 793-797. [CrossRef] [PubMed]

100. Matatall, K.A.; Jeong, M.; Chen, S.; Sun, D.; Chen, F.; Mo, Q.; Kimmel, M.; King, K.Y. Chronic Infection Depletes Hematopoietic Stem Cells through Stress-Induced Terminal Differentiation. Cell Reports 2016, 17, 2584-2595. [CrossRef] [PubMed]

101. De Bruin, A.M.; Voermans, C.; Nolte, M.A. Impact of interferon- $\gamma$ on hematopoiesis. Blood 2014, 124, 2479-2486. [CrossRef] [PubMed]

102. Lafuse, W.P.; Jeong, M.; Chen, S.; Sun, D.; Chen, F.; Mo, Q.; Kimmel, M.; King, K.Y. Leishmania donovani Infection Induces Anemia in Hamsters by Differentially Altering Erythropoiesis in Bone Marrow and Spleen. PLoS ONE 2013, 8, e59509. [CrossRef] [PubMed]

103. Okada, H.; Suzue, K.; Imai, T.; Taniguchi, T.; Shimokawa, C.; Onishi, R.; Hirata, J.; Hisaeda, H. A transient resistance to blood-stage malaria in interferon- $\gamma$-deficient mice through impaired production of host cells preferred by malaria parasites. Front. Microbiol. 2015, 6, 600. [CrossRef] [PubMed] 
104. Chou, D.B.; Sworder, B.; Bouladoux, N.; Roy, C.N.; Uchida, A.M.; Grigg, M.; Robey, P.G.; Belkaid, Y. Stromal-derived IL-6 alters the balance of myeloerythroid progenitors during Toxoplasma gondii infection. J. Leuko. Biol. 2012, 92, 123-131. [CrossRef] [PubMed]

105. Gardenghi, S.; Renaud, T.M.; Meloni, A.; Casu, C.; Crielaard, B.J.; Bystrom, L.M.; Greenberg-Kushnir, N.; Sasu, B.J.; Cooke, K.S.; Rivella, S. Distinct roles for hepcidin and interleukin-6 in the recovery from anemia in mice injected with heat-killed Brucella abortus. Blood 2014, 123, 1137-1145. [CrossRef] [PubMed]

106. Fisman, D.N. Hemophagocytic syndromes and infection. Emerg. Infect. Dis. 2000, 6, 601. [CrossRef] [PubMed]

107. Ramos-Casals, M.; Brito-Zerón, P.; López-Guillermo, A.; Khamashta, M.A.; Bosch, X. Adult haemophagocytic syndrome. Lancet 2014, 383, 1503-1516. [CrossRef]

108. Schulert, G.S.; Grom, A.A. Pathogenesis of Macrophage Activation Syndrome and Potential for CytokineDirected Therapies. Annu Rev. Med. 2015, 66, 145-159. [CrossRef] [PubMed]

109. Sato, K.; Misawa, N.; Nie, C.; Satou, Y.; Iwakiri, D.; Matsuoka, M.; Takahashi, R.; Kuzushima, K.; Ito, M.; Takada, K.; et al. A novel animal model of Epstein-Barr virus-associated hemophagocytic lymphohistiocytosis in humanized mice. Blood 2011, 117, 5663-5673. [CrossRef] [PubMed]

110. Milner, J.D.; Orekov, T.; Ward, J.M.; Cheng, L.; Torres-Velez, F.; Junttila, I.; Sun, G.; Buller, M.; Morris, S.C.; Finkelman, F.D.; et al. Sustained IL-4 exposure leads to a novel pathway for hemophagocytosis, inflammation, and tissue macrophage accumulation. Blood 2010, 116, 2476-2483. [CrossRef] [PubMed]

111. Morimoto, A.; Omachi, S.; Osada, Y.; Chambers, J.K.; Uchida, K.; Sanjoba, C.; Matsumoto, Y.; Goto, Y. Hemophagocytosis in Experimental Visceral Leishmaniasis by Leishmania donovani. PLoS Negl. Trop. Dis. 2016, 10, e0004505. [CrossRef] [PubMed]

112. Zoller, E.E.; Lykens, J.E.; Terrell, C.E.; Aliberti, J.; Filipovich, A.H.; Henson, P.M.; Jordan, M.B. Hemophagocytosis causes a consumptive anemia of inflammation. J. Exp. Med. 2011, 208, 1203-1214. [CrossRef] [PubMed]

113. Cnops, J.; de Trez, C.; Stijlemans, B.; Keirsse, J.; Kauffmann, F.; Barkhuizen, M.; Keeton, R.; Boon, L.; Brombacher, F.; Magez, S. NK-, NKT- and CD8-Derived IFNgamma Drives Myeloid Cell Activation and Erythrophagocytosis, Resulting in Trypanosomosis-Associated Acute Anemia. PLoS Pathog. 2015, 11, e1004964. [CrossRef] [PubMed]

114. McCoy, M.W.; Moreland, S.M.; Detweiler, C.S. Hemophagocytic Macrophages in Murine Typhoid Fever Have an Anti-Inflammatory Phenotype. Infect. Immu. 2012, 80, 3642-3649. [CrossRef] [PubMed]

115. Munde, E.O.; Okeyo, W.A.; Anyona, S.B.; Raballah, E.; Konah, S.; Okumu, W.; Ogonda, L.; Vulule, J.; Ouma, C. Polymorphisms in the FC Gamma Receptor IIIA and Toll-Like Receptor 9 Are Associated with Protection against Severe Malarial Anemia and Changes in Circulating Gamma Interferon Levels. Infect. Immun. 2012, 80, 4435-4443. [CrossRef] [PubMed]

116. Mourão, L.C.; de Paula Baptista, R.; de Almeida, Z.B.; Grynberg, P.; Pucci, M.M.; Castro-Gomes, T.; Fontes, C.J.F.; Rathore, S.; Sharma, Y.D.; da Silva-Pereira, R.A.; et al. Anti-band 3 and anti-spectrin antibodies are increased in Plasmodium vivax infection and are associated with anemia. Scientific Reports 2018, 8, 8762. [CrossRef] [PubMed]

117. Mourão, L.C.; da Silva Roma, P.M.; da Silva Sultane Aboobacar, J.; Medeiros, C.M.P.; de Almeida, Z.B.; Fontes, C.J.F.; Agero, U.; de Mesquita, O.N.; Bemquerer, M.P.; Braga, E.M. Anti-erythrocyte antibodies may contribute to anaemia in Plasmodium vivax malaria by decreasing red blood cell deformability and increasing erythrophagocytosis. Malaria J. 2016, 15, 397. [CrossRef] [PubMed]

118. Ohyagi, H.; Onai, N.; Sato, T.; Yotsumoto, S.; Liu, J.; Akiba, H.; Yagita, H.; Atarashi, K.; Honda, K.; Roers, A.; et al. Monocyte-Derived Dendritic Cells Perform Hemophagocytosis to Fine-Tune Excessive Immune Responses. Immunity 2013, 39, 584-598. [CrossRef] [PubMed]

119. McDonald, E.M.; Pilonieta, M.C.; Nick, H.J.; Detweiler, C.S. Bacterial Stimulation of Toll-Like Receptor 4 Drives Macrophages To Hemophagocytose. Infect. Immun. 2016, 84, 47-55. [CrossRef] [PubMed]

120. Fabien, G.; Plazolles, N.; Baltz, T.; Coustou, V. Erythrophagocytosis of desialylated red blood cells is responsible for anaemia during Trypanosoma vivax infection. Cell Microbiol. 2013, 15, 1285-1303. [CrossRef] 
121. Pilonieta, M.C.; Moreland, S.M.; English, C.N.; Detweiler, C.S. Salmonella enterica Infection Stimulates Macrophages to Hemophagocytose. mBio 2014, 5, e02211-14. [CrossRef] [PubMed]

122. Haldar, M.; Kohyama, M.; So, A.Y.L.; KC, W.; Wu, X.; Briseño, C.G.; Satpathy, A.T.; Kretzer, N.M.; Arase, H.; Rajasekaran, N.S.; et al. Heme-mediated SPI-C induction promotes monocyte differentiation into iron-recycling macrophages. Cell 2014, 156, 1223-1234. [CrossRef] [PubMed]

123. Schaer, D.J.; Schaer, C.A.; Schoedon, G.; Imhof, A.; Kurrer, M.O. Hemophagocytic macrophages constitute a major compartment of heme oxygenase expression in sepsis. Eur. J. Haematol. 2006, 77, 432-436. [CrossRef] [PubMed]

124. Youssef, L.A.; Rebbaa, A.; Pampou, S.; Weisberg, S.P.; Stockwell, B.R.; Hod, E.A.; Spitalnik, S.L. Increased erythrophagocytosis induces ferroptosis in red pulp macrophages in a mouse model of transfusion. Blood 2018, 131, 2581-2593. [CrossRef] [PubMed]

125. Stockwell, B.R.; Angeli, J.P.F.; Bayir, H.; Bush, A.I.; Conrad, M.; Dixon, S.J.; Fulda, S.; Gascón, S.; Hatzios, S.K.; Kagan, V.E.; et al. Ferroptosis: A Regulated Cell Death Nexus Linking Metabolism, Redox Biology, and Disease. Cell 2017, 171, 273-285. [CrossRef] [PubMed]

126. Theurl, I.; Hilgendorf, I.; Nairz, M.; Tymoszuk, P.; Haschka, D.; Asshoff, M.; He, S.; Gerhardt, L.M.S.; Holderried, T.A.W.; Seifert, M.; et al. On-demand erythrocyte disposal and iron recycling requires transient macrophages in the liver. Nat. Med. 2016, 22, 945-951. [CrossRef] [PubMed]

127. Kalinowski, D.S.; Richardson, D.R. The evolution of iron chelators for the treatment of iron overload disease and cancer. Pharmacol. Rev. 2005, 57, 547-583. [CrossRef] [PubMed]

128. Dusek, P.; Schneider, S.A.; Aaseth, J. Iron chelation in the treatment of neurodegenerative diseases. J. Trace Elem. Med. Biol. 2016, 38, 81-89. [CrossRef] [PubMed]

129. Fernandes, S.S.; Nunes, A.; Gomes, A.R.; de Castro, B.; Hider, R.C.; Rangel, M.; Appelberg, R.; Gomes, M.S. Identification of a new hexadentate iron chelator capable of restricting the intramacrophagic growth of Mycobacterium avium. Microbes Infect. 2010, 12, 287-294. [CrossRef] [PubMed]

130. Moniz, T.; Nunes, A.; Silva, A.M.G.; Queirós, C.; Ivanova, G.; Gomes, M.S.; Rangel, M. Rhodamine labeling of 3-hydroxy-4-pyridinone iron chelators is an important contribution to target Mycobacterium avium infection. J. Inorg. Biochem. 2013, 121, 156-166. [CrossRef] [PubMed]

131. Savage, K.A.; del Carmen Parquet, M.; Allan, D.S.; Davidson, R.J.; Holbein, B.E.; Lilly, E.A.; Fidel, P.L. Iron Restriction to Clinical Isolates of Candida albicans by the Novel Chelator DIBI Inhibits Growth and Increases Sensitivity to Azoles In Vitro and In Vivo in a Murine Model of Experimental Vaginitis. Antimicrob Agents Chemother. 2018, 62. [CrossRef] [PubMed]

132. Richter, K.; Thomas, N.; Zhang, G.; Prestidge, C.A.; Coenye, T.; Wormald, P.G.; Vreugde, S. Deferiprone and Gallium-Protoporphyrin Have the Capacity to Potentiate the Activity of Antibiotics in Staphylococcus aureus Small Colony Variants. Front. Cell. Infect. Microbiol. 2017, 7, 280. [CrossRef] [PubMed]

133. Islam, S.; Jarosch, S.; Zhou, J.; del Carmen Parquet, M.; Toguri, J.T.; Colp, P.; Holbein, B.E.; Lehmann, C. Anti-inflammatory and anti-bacterial effects of iron chelation in experimental sepsis. J. Surg. Res. 2016, 200, 266-273. [CrossRef] [PubMed]

134. Mabeza, G.F.; Loyevsky, M.; Gordeuk, V.R.; Weiss, G. Iron chelation therapy for malaria: A review. Pharmacol. Ther. 1999, 81, 53-75. [CrossRef]

135. Spellberg, B.; Ibrahim, A.S.; Chin-Hong, P.V.; Kontoyiannis, D.P.; Morris, M.I.; Perfect, J.R.; Fredricks, D.; Brass, E.P. The Deferasirox-AmBisome Therapy for Mucormycosis (DEFEAT Mucor) study: A randomized, double-blinded, placebo-controlled trial. J. Antimicrob. Chemother. 2012, 67, 715-722. [CrossRef] [PubMed]

136. Leal, S.M.; Roy, S.; Vareechon, C.; de Jesus Carrion, S.; Clark, H.; Lopez-Berges, M.S.; di Pietro, A.; Schrettl, M.; Beckmann, N.; Redl, B. Targeting iron acquisition blocks infection with the fungal pathogens Aspergillus fumigatus and Fusarium oxysporum. PLoS Pathog. 2013, 9, e1003436. [CrossRef]

137. Mike, L.A.; Smith, S.N.; Sumner, C.A.; Eaton, K.A.; Harry, L.T. Siderophore vaccine conjugates protect against uropathogenic Escherichia coli urinary tract infection. Proc. Natl. Acad. Sci. USA 2016, 113, 13468-13473. [CrossRef] [PubMed] 
138. Zauberman, A.; Vagima, Y.; Tidhar, A.; Aftalion, M.; Gur, D.; Rotem, S.; Chitlaru, T.; Levy, Y.; Mamroud, E. Host Iron Nutritional Immunity Induced by a Live Yersinia pestis Vaccine Strain Is Associated with Immediate Protection against Plague. Front. Cell. Infect. Microbiol. 2017, 7, 277. [CrossRef] [PubMed]

139. Portugal, S.; Drakesmith, H.; Mota, M.M. Superinfection in malaria: Plasmodium shows its iron will. EMBO Rep. 2011, 12, 1233-1242. [CrossRef] [PubMed]

140. Ramos, E.; Ruchala, P.; Goodnough, J.B.; Kautz, L.; Preza, G.C.; Nemeth, E.; Ganz, T. Minihepcidins prevent iron overload in a hepcidin-deficient mouse model of severe hemochromatosis. Blood 2012, 120, 3829-3836. [CrossRef] [PubMed]

141. Sebastiani, G.; Wilkinson, N.; Pantopoulos, K. Pharmacological Targeting of the Hepcidin/Ferroportin Axis. Front. Pharmacol. 2016, 7, 160. [CrossRef] [PubMed]

(C) 2018 by the authors. Licensee MDPI, Basel, Switzerland. This article is an open access article distributed under the terms and conditions of the Creative Commons Attribution (CC BY) license (http:/ / creativecommons.org/licenses/by/4.0/). 
Hypothesis

\title{
How Eliminating Malaria May Also Prevent Iron Deficiency in African Children
}

\author{
John Muthii Muriuki ${ }^{1, *}$ and Sarah H. Atkinson ${ }^{1,2,3, *}$ \\ 1 KEMRI-Wellcome Trust Research Programme, 80108 Kilifi, Kenya \\ 2 Centre for Tropical Medicine and Global Health, Nuffield Department of Medicine, University of Oxford, \\ Oxford OX3 7FZ, UK \\ 3 Department of Paediatrics, University of Oxford, Oxford OX3 9DU, UK \\ * Correspondence: jmuriuki@kemri-wellcome.org (J.M.M.); satkinson@kemri-wellcome.org (S.H.A.); \\ Tel.: +25-47-0998-3106 (J.M.M.)
}

Received: 30 August 2018; Accepted: 21 September 2018; Published: 26 September 2018

\begin{abstract}
Malaria and iron deficiency are common among children living in sub-Saharan Africa. Several studies have linked a child's iron status to their future risk of malaria infection; however, few have examined whether malaria might be a cause of iron deficiency. Approximately a quarter of African children at any one time are infected by malaria and malaria increases hepcidin and tumor necrosis factor- $\alpha$ concentrations leading to poor iron absorption and recycling. In support of a hypothetical link between malaria and iron deficiency, studies indicate that the prevalence of iron deficiency in children increases over a malaria season and decreases when malaria transmission is interrupted. The link between malaria and iron deficiency can be tested through the use of observational studies, randomized controlled trials and genetic epidemiology studies, each of which has its own strengths and limitations. Confirming the existence of a causal link between malaria infection and iron deficiency would readjust priorities for programs to prevent and treat iron deficiency and would demonstrate a further benefit of malaria control.
\end{abstract}

Keywords: malaria; iron deficiency; hepcidin; TNF; children; Africa

\section{Introduction}

Malaria and iron deficiency are important public health problems especially in developing countries [1,2]. In 2016, malaria caused an estimated 216 million cases of sickness and 445,000 deaths ( $91 \%$ in sub-Saharan Africa) [2]. Among African children under the age of five years, malaria caused an estimated 292,000 deaths in 2015 [3]. The disease has remained persistent and widespread across sub-Saharan Africa (SSA), affecting $24 \%$ of the population at any one time [4]. Similarly, iron deficiency is common in SSA, where it affects more than half of children $[5,6]$. Iron deficiency is associated with poor child growth including impaired brain development and long-term impairment of behavioral and cognitive performance [7-9]. Furthermore, iron deficiency is the main cause of anemia and iron deficiency anemia (IDA) is the leading cause of years lived with disability in children [1].

Iron supplements are inexpensive and widely used for the prevention and treatment of iron deficiency in African children. However, there are long-standing concerns regarding the safety of iron supplementation $[10,11]$. A large trial in Pemba, Tanzania reported an increased risk of malaria-related events among the group supplemented with iron [12] and other trials have reported inconsistent findings [13-16]. In 2016, a Cochrane review reported that iron supplementation was not associated with an increased risk of clinical malaria when malaria prevention and management services were provided [17]. Thus, the World Health Organization (WHO) updated its recommendations for iron supplements and micronutrient powders in malaria endemic areas to include supplementation when the prevalence of anemia is $40 \%$ or higher in conjunction with malaria control and management 
practices [18]. However, questions remain regarding how adequate malaria control and prevention measures need to be before iron supplementation is deemed safe in resource-limited settings [3]. Moreover, prospective cohort studies have indicated that iron replete children may be at increased risk from malaria infection [19-23]. In addition to the risk of malaria, iron supplements/fortification may not be absorbed in children with malaria and hence would be ineffective [24] and have also been associated with pathogenic gut microbiota and bacterial infection [25]. New strategies are therefore needed to prevent and treat iron deficiency. In this paper we outline the hypothesis that malaria could contribute to the burden of iron deficiency in children living in SSA.

\section{The Malaria Iron Deficiency Hypothesis}

We hypothesize that malaria may be causally linked to iron deficiency in African children by increasing concentrations of the iron hormone hepcidin, as well as increasing inflammatory cytokines, such as tumor necrosis factor- $\alpha$ (TNF- $\alpha$ ). In SSA, up to $50 \%$ of children may be asymptomatically infected with malaria and $24 \%$ have febrile malaria at any one time $[4,26]$. Asymptomatic individuals carry malaria parasites but are unlikely to seek medical attention and there may be delays in the treatment of febrile malaria and other illnesses in resource-limited settings. Many children are therefore likely to have chronically up-regulated hepcidin, and inflammatory cytokines such as TNF- $\alpha$, which in turn block the absorption and recycling of iron. Indeed a study in Ivorian children showed that iron absorption was halved in children with afebrile malaria and increased when malaria infection was treated [24].

The iron hormone hepcidin may link malaria with iron deficiency. Both clinical and asymptomatic malaria infections increase hepcidin concentrations. Clinical episodes of Plasmodium falciparum malaria are associated with markedly increased hepcidin concentrations in African children [27-31]. Similarly, even asymptomatic P. falciparum is associated with a doubling of hepcidin concentrations [31,32]. Treatment of malaria significantly reduces hepcidin concentrations [28,32,33]. Furthermore, the up-regulatory effects of malaria on hepcidin concentrations appear to occur both in the presence and absence of inflammation suggesting that malaria may further increase hepcidin independently of inflammation [31]. The mechanisms through which malaria up-regulates hepcidin production are not fully elucidated, but may include the bone morphogenetic protein (BMP)/sons of mothers against decapentaplegic (SMAD) pathways [34].

Increased hepcidin concentrations due to frequent and chronic malaria parasitemia in children with iron-poor diets may lead to iron deficiency. Hepcidin prevents iron absorption and recycling by inhibiting the activity of ferroportin [35], the sole known iron exporter which is abundant in macrophages [36,37], enterocytes and hepatocytes [36,38,39], as well as erythrocytes [40]. Hepcidin also degrades and inhibits the transcription of divalent metal transporter 1 (DMT1), thus blocking iron absorption through the duodenal enterocytes [41,42]. Furthermore, hepcidin blocks iron export from red blood cells (RBCs) leading to accumulation of iron, oxidative stress and hemolysis [40]. This may explain why both infected and uninfected RBCs burst during malaria infection leading to anemia (and probably further spread of the malaria parasites). Figure 1 illustrates how malaria-induced hepcidin might contribute to iron deficiency.

Malaria may also cause iron deficiency through increasing inflammatory cytokines such as tumor necrosis factor- $\alpha$ (TNF- $\alpha$ ). Uncomplicated and asymptomatic malaria significantly raise TNF- $\alpha$ concentrations $[43,44]$. TNF- $\alpha$ blocks iron recycling from macrophages and inhibits erythropoiesis [45,46]. In addition, TNF- $\alpha$, independently of hepcidin, blocks intestinal iron absorption by reducing DMT1 expression [47], increasing deposition of iron into ferritin and degrading ferroportin [48]. In a cohort of Gambian children, the $\mathrm{TNF}_{-308}$ AA genotype (which is associated with higher TNF- $\alpha$ transcription compared with $\mathrm{TNF}_{-308} \mathrm{AG}_{\text {and }} \mathrm{TNF}_{-308}$ GG genotypes $[49,50]$ ) was strongly associated with increased risk of iron deficiency and IDA [51]. Interestingly, this effect was observed at the end of a malaria season when the prevalence of clinical malaria was 
highest [51]. Furthermore, zinc protoporphyrin concentrations were significantly raised in the TNF-308 AA genotype indicating dyserythropoiesis [51].
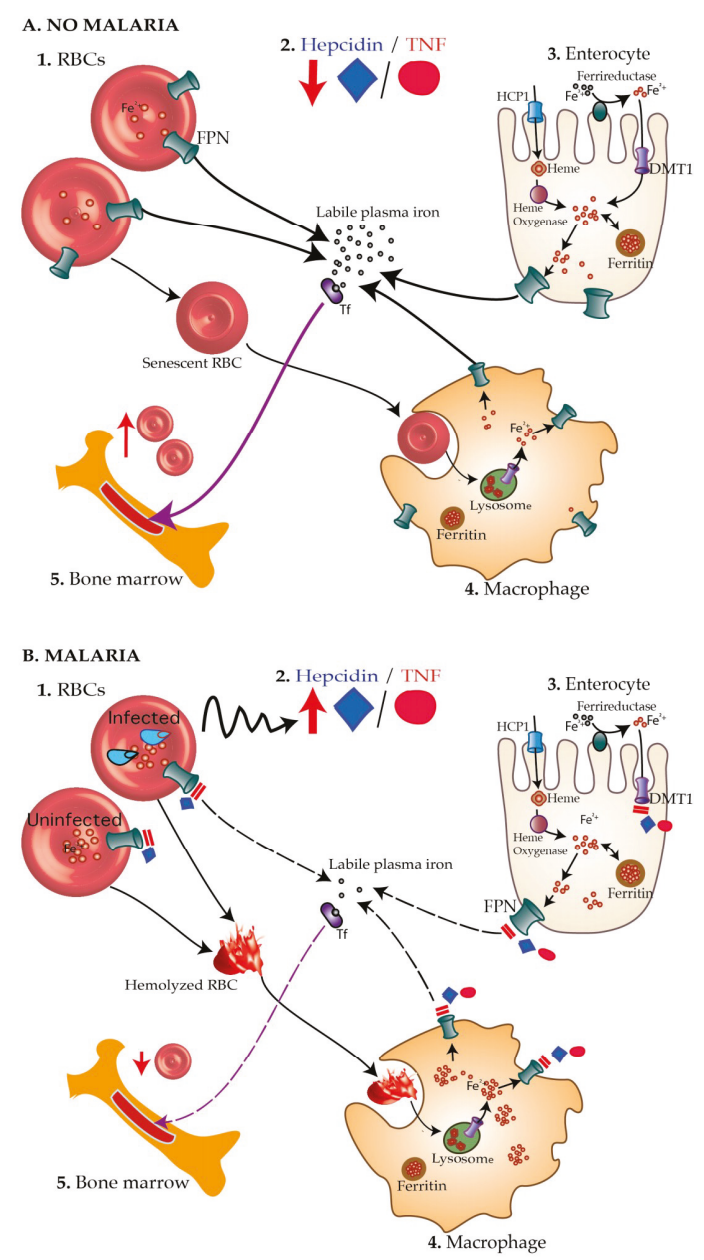

Figure 1. The malaria-iron deficiency hypothesis. (A) In healthy children without malaria (A1), concentrations of hepcidin and TNF- $\alpha$ are low (A2) leading to increased absorption of iron through enterocytes (A3), reduced hemolysis of RBCs and increased recycling of iron recovered from senescent RBCs by macrophages (A4). More iron is thus available for the production of new RBCs (A5). (B) On the other hand, during malaria infection, blood-stage malaria parasites (B1) elicit increased production of hepcidin and TNF- $\alpha$ (B2), which, in turn, block absorption of iron through DMT1 and ferroportin (FPN) on enterocytes (B3). Hepcidin also degrades ferroportin on both infected and uninfected RBCs leading to accumulation of intracellular iron, oxidative stress, and consequently hemolysis. Hemolyzed RBCs are taken up by the macrophage (B4). Hepcidin and TNF- $\alpha$ inhibit recycling of iron recovered from hemolyzed RBCs back into the circulation leading to deficiency of the amount of biologically available iron. Consequently, little iron is available to produce new RBCs by the bone marrow leading to iron deficiency anemia (B5). Tf, transferrin.

Several studies support the hypothesis that malaria causes iron deficiency. A study in Kenyan and Gambian children observed that the prevalence of iron deficiency and IDA was markedly higher at the 
end of a malaria season compared to the start [52]. Interruption of malaria transmission in the Kenyan highlands with antimalarials and indoor residual spraying reduced the prevalence of iron deficiency from $36 \%$ to $25 \%$ and more than halved the prevalence of IDA (from $27 \%$ to $12 \%$ ) [53]. However, the observational nature of these studies does not necessarily imply a causal relationship. Additionally, a meta-analysis of intermittent preventive treatment (IPT) of malaria reported a $29 \%$ reduction of anemia in children following treatment [54]. Moreover, in Ivorian children, treatment of asymptomatic malaria significantly reduced hepcidin concentrations and inflammation and doubled iron absorption [24].

A key difficulty is distinguishing between uncomplicated IDA and the anemia of inflammation (AI) among children living in sub-Saharan Africa where malaria and other infections are highly prevalent. This challenge can be addressed by measuring a wide range of iron markers [55] including hepcidin [56]. Hepcidin was demonstrated to be significantly lower in children with IDA compared to those with AI [56]. Other markers of iron status that can be used to discriminate IDA and AI include soluble transferrin receptors (sTfR) and total iron binding capacity (TIBC), which are elevated during IDA compared to AI, or serum ferritin, which is normally decreased during IDA and increased during AI [55]. However, the effects of inflammation or infection on iron status may obscure the true prevalence of IDA in African children [57].

\section{Testing the Hypothesis}

How can the hypothesis be tested? Below, we look at potential study designs as well as their strengths and limitations.

\subsection{Observational Studies}

Longitudinal cohort studies following up malaria exposed and unexposed children for iron status would allow investigation of whether malaria causes iron deficiency. However, since individuals in malaria endemic areas are likely to be exposed to malaria repeatedly and in varying degrees over time [4], it would be difficult to group them as exposed or unexposed with certainty. Individuals who are continuously exposed to malaria develop partial immunity to malaria and may be misclassified as unexposed [58]. Moreover, it is difficult to specifically determine the degree of malaria exposure [59,60]. Another challenge is the fact that host iron status may also influence malaria risk making reverse causality a possibility [19-21]. Pragmatic cohort studies would involve comparing iron deficiency during the course of malaria seasons although many other factors may influence iron status during that period [52]. For example, the nutritional status of children may improve during harvest seasons, which may coincide with rainy seasons (or peak malaria transmission) thereby confounding a possible effect of malaria on iron status.

Another approach would be to spatially and temporally map-out the distribution of malaria and iron deficiency. If malaria causes iron deficiency, then areas or periods of high malaria transmission would also be associated with higher prevalence of iron deficiency. Carefully gathered and mapped epidemiological data of malaria in Africa, both in space and time, are available [4,61]. Likewise, a number of iron deficiency studies have been conducted in African children over the years although not mapped. However, this approach is limited by the fact that some markers of iron especially ferritin and soluble transferrin receptors (which are commonly measured), are raised during malaria infection [62-64]. Thus, malaria may obscure the true picture of iron deficiency so that children in malaria regions may appear more iron replete. Social economic status may further confound the geographical distribution of malaria and iron deficiency since both are more likely to occur in the poorest communities.

\subsection{Randomized Controlled Trials}

Randomized controlled trials (RCTs) remain the gold standard study designs for investigating a causal relationship. Individuals could be randomized to receive interventions known to be effective against malaria such as antimalarials and insecticide-treated bed nets and then iron status could be 
assessed after a period of time. For example, children could be randomized to receive intermittent preventive treatment (IPT) of malaria followed by assessment of iron status. A few previous trials have reported a non-significant improvement in concentrations of ferritin $[13,65]$ and a decrease in sTfR [14] following IPT. However, both ferritin and sTfR are raised during malaria infection [62-64] making interpretation of iron status difficult and thus they may not be the best indicators of the effect of IPT on iron status. Transferrin saturation may be a good indicator of improved iron absorption while reduced ZPP concentrations may indicate improved erythrocyte iron incorporation. However, it may be difficult to justify large trials randomizing children to either malaria prevention/treatment or none.

\subsection{Mendelian Randomization Studies}

Another approach is Mendelian randomization (MR) which utilizes genetic variants as proxies for modifiable environmental exposures (or instrumental variables) to infer a causal relationship between an exposure and an outcome [66]. This study design provides an alternative to RCTs since genetic variants are unlikely to be confounded by environmental factors and reverse causality is eliminated as genetic variants are allocated at conception [67]. MR also reflects a life-time of exposure, which is important since age is a critical determinant of infectious risk. This approach has been successfully employed in other disease processes and has helped to explain previous controversies [68-70].

Similarly, MR can be utilized to study whether malaria causes iron deficiency. There are known genetic polymorphisms that are associated with resistance to malaria. For example, sickle cell trait which results from inheritance of one abnormal allele of the beta-globin gene is associated with $50 \%$ protection against uncomplicated clinical malaria and $86 \%$ protection against severe malaria [71]. Alpha- and beta-thalassemias, glucose-6-phosphodehydrogenase (G6PD), ABO blood group, and glycophorins are additional genes known to be associated with resistance to severe malaria [72]. If malaria causes iron deficiency, then polymorphisms that protect from malaria would also be associated with reduced risk of iron deficiency. However, the polymorphisms should only influence iron status through malaria, thus the effect of the polymorphism(s) on iron status should only be observed in populations at risk of malaria but not in malaria-free populations (i.e., there should be no pleiotropy or independent effect of the polymorphisms on iron status). Additionally, each of the protective polymorphisms should influence iron deficiency in the same direction [73,74]. Figure 2 illustrates the conceptual MR causal diagram for malaria and iron deficiency.

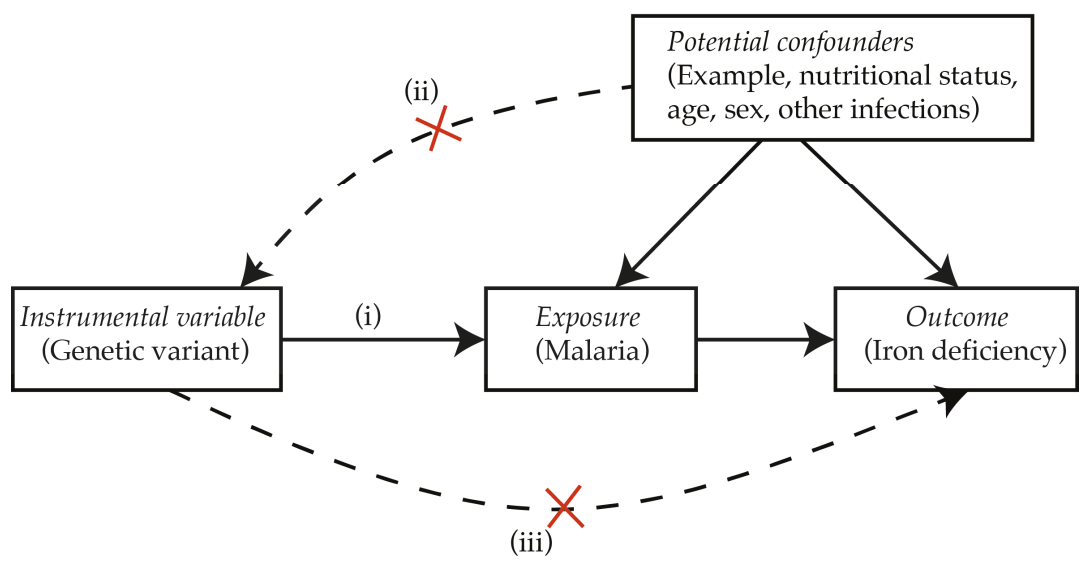

Figure 2. Conceptual MR causal inference framework. (i) Genetic variants reliably associated with malaria are required, for example, the sickle cell trait. (ii) The genetic variant should not be associated with any measured potential confounders. (iii) The genetic variant should influence iron deficiency only in populations at risk of malaria. Adapted from Sheehan et al. [75]. 


\section{Implications of the Hypothesis}

Since individuals in malaria-endemic regions are likely to have chronically up-regulated hepcidin concentrations, the current efforts of iron supplementation in these populations may not address the problem of iron deficiency. Raised hepcidin levels in malaria-infected individuals would not only block iron absorption [24] but also utilization [76-78]. A systematic review of randomized controlled trials evaluating the effect of iron supplementation on hemoglobin/anemia in children reported limited gains in malarial hyperendemic areas [76]. Furthermore, unabsorbed iron due to malaria infection may disturb gut microbiota leading to gastrointestinal disorders [79-81]. In the largest iron supplementation trial in Pemba, Tanzania, increased risk of adverse events were reported among children in the supplemented arm [12]. Thus, the effectiveness and safety of iron supplementation or fortification in malaria-endemic regions has remained questionable.

If, indeed, malaria causes iron deficiency, then strategies aimed at malaria elimination may also address iron deficiency. Causality in the malaria-iron deficiency relationship could be tested using randomized trials of interventions that protect against malaria, such as IPT trials, or by Mendelian randomization studies where randomization would be by genetic variants that protect from malaria, such as the sickle cell trait. Advantages of Mendelian randomization are that genes confer life-long protection against malaria and that it may be unethical to randomize children to not receive an intervention of proven efficacy. Furthermore, our hypothetical concept could also be extended to other causes of chronic infection, which may contribute to the burden of iron deficiency through inflammation-induced up-regulation of hepcidin. Confirmation of a role of malaria and other infections in causing iron deficiency could lead to a readjustment of priorities for public health programs to prevent and treat iron deficiency in sub-Saharan Africa. Thus, we recommend further studies to test the malaria-iron deficiency hypothesis and suggest that control of malaria and other infections could be utilized as an additional strategy to improve the iron status of children living in Africa.

Author Contributions: Writing—original draft preparation: J.M.M. and S.H.A.; writing—review and editing: J.M.M. and S.H.A.; funding acquisition: S.H.A.

Funding: This research was funded by the Wellcome Trust grant number 110255/Z/15/Z to SHA, and also by the DELTAS Africa Initiative [DEL-15-003]. The DELTAS Africa Initiative is an independent funding scheme of the Alliance for Accelerating Excellence in Science in Africa (AESA) under the African Academy of Sciences (AAS) and is supported by the New Partnership for Africa's Development Planning and Coordinating Agency (NEPAD Agency) with funding from the Wellcome Trust [107769/Z/10/Z] and the UK government.

Acknowledgments: We thank Thomas N. Williams and Alison M. Elliott for providing insightful comments on the manuscript. This study is published with permission from the Director of KEMRI.

Conflicts of Interest: The authors declare no conflict of interest. The funders had no role in the design of the study; in the collection, analyses, or interpretation of data; in the writing of the manuscript; or in the decision to publish the results.

\section{References}

1. Kyu, H.H.; Pinho, C.; Wagner, J.A.; Brown, J.C.; Bertozzi-Villa, A.; Charlson, F.J.; Coffeng, L.E.; Dandona, L.; Erskine, H.E.; Ferrari, A.J.; et al. Global and National Burden of Diseases and Injuries Among Children and Adolescents Between 1990 and 2013. JAMA Pediatr. 2016, 170, 267. [CrossRef] [PubMed]

2. World Health Organization. World Malaria Report 2017; World Health Organization: Geneva, Switzerland, 2017; ISBN 9789241565523.

3. World Health Organization. World Malaria Report 2015; World Health Organization: Geneva, Switzerland, 2015; ISBN 9789241564403.

4. Snow, R.W.; Sartorius, B.; Kyalo, D.; Maina, J.; Amratia, P.; Mundia, C.W.; Bejon, P.; Noor, A.M. The Prevalence of Plasmodium Falciparum in Sub-Saharan Africa Since 1900. Nature 2017, 550, 515-518. [CrossRef] [PubMed]

5. Kassebaum, N.J.; Jasrasaria, R.; Naghavi, M.; Wulf, S.K.; Johns, N.; Lozano, R.; Regan, M.; Weatherall, D.; Chou, D.P.; Eisele, T.P.; et al. A Systematic Analysis of Global Anemia Burden from 1990 to 2010. Blood J. 2014, 123, 615-625. [CrossRef] [PubMed] 
6. Mwangi, M.N.; Phiri, K.S.; Abkari, A.; Gban, M.; Bourdet-sicard, R.; Braesco, A.; Zimmermann, M.B.; Prentice, A.M. Iron for Africa-Report of an Expert Workshop. Nutrients 2017, 9, 576. [CrossRef] [PubMed]

7. Doom, J.R.; Georgieff, M.K. Striking While the Iron is Hot: Understanding the Biological and Neurodevelopmental Effects of Iron Deficiency to Optimize Intervention in Early Childhood. Curr. Pediatr. Rep. 2014, 2, 291-298. [CrossRef] [PubMed]

8. Lozoff, B. Early Iron Deficiency Has Brain and Behavior Effects Consistent with Dopaminergic Dysfunction. J. Nutr. 2011, 141, 740-746. [CrossRef] [PubMed]

9. Beard, J. Recent Evidence from Human and Animal Studies Regarding Iron Status and Infant Development. J. Nutr. 2007, 137, 524S-530S. [CrossRef] [PubMed]

10. Suchdev, P.; Leeds, I.; McFarland, D.; Flores, R. Is It Time to Change Guidelines for Iron Supplementation in Malarial Areas? J. Nutr. 2010, 140, 875-876. [CrossRef] [PubMed]

11. Brittenham, G.M. Safety of Iron Fortification and Supplementation in Malaria-Endemic Areas. Nestle Nutr. Inst. Work. Ser. 2012, 70, 117-127. [CrossRef]

12. Sazawal, S.; Black, R.; Ramsan, M.; Chwaya, H.; Stoltzfus, R.; Dutta, A.; Dhingra, U.; Kabole, I.; Deb, S.; Othman, M.; et al. Effect of Routine Prophylactic Supplementation with Iron and Folic Acid on Admission to Hospital and Mortality in Preschool Children in a High Malaria Transmission Setting: Community Based, Randomised, Placebo-Controlled Trial. Lancet 2006, 367, 133-143. [CrossRef]

13. Verhoef, H.; West, C.E.; Nzyuko, S.M.; de Vogel, S.; van der Valk, R.; Wanga, M.A.; Kuijsten, A.; Veenemans, J.; Kok, F.J. Intermittent Administration of Iron and Sulfadoxine-Pyrimethamine to Control Anaemia in Kenyan Children: A Randomised Controlled Trial. Lancet 2002, 360, 908-914. [CrossRef]

14. Desai, M.R.; Mei, J.V.; Kariuki, S.K.; Wannemuehler, K.A.; Phillips-Howard, P.A.; Nahlen, B.L.; Kager, P.A.; Vulule, J.M.; ter Kuile, F.O. Randomized, Controlled Trial of Daily Iron Supplementation and Intermittent Sulfadoxine-Pyrimethamine for the Treatment of Mild Childhood Anemia in Western Kenya. J. Infect. Dis. 2003, 187, 658-666. [CrossRef] [PubMed]

15. Ouédraogo, H.Z.; Dramaix-Wilmet, M.; Zeba, A.N.; Hennart, P.; Donnen, P. Effect of Iron or Multiple Micronutrient Supplements on the Prevalence of Anaemia Among Anaemic Young Children of a Malaria-Endemic Area: A Randomized Double-Blind Trial. Trop. Med. Int. Health 2008, 13, 1257-1266. [CrossRef] [PubMed]

16. Zlotkin, S.; Newton, S.; Aimone, A.M.; Azindow, I.; Amenga-Etego, S.; Tchum, K.; Mahama, E.; Thorpe, K.E.; Owusu-Agyei, S. Effect of Iron Fortification on Malaria Incidence in Infants and Young Children in Ghana: A Randomized Trial. JAMA 2013, 310, 938-947. [CrossRef] [PubMed]

17. Neuberger, A.; Okebe, J.; Yahav, D.; Paul, M. Oral Iron Supplements for Children in Malaria-Endemic Areas. Cochrane Database Syst. Rev. 2016. [CrossRef] [PubMed]

18. World Health Organization. Guideline: Daily Iron Supplementation in Infants and Children; World Health Organization: Geneva, Switzerland, 2016.

19. Nyakeriga, A.M.; Troye-blomberg, M.; Chemtai, A.K.; Marsh, K.; Williams, T.N. Iron Deficiency and Malaria among Children Living on the Coast of Kenya. J. Infect. Dis. 2004, 190, 439-447. [CrossRef] [PubMed]

20. Gwamaka, M.; Kurtis, J.D.; Sorensen, B.E.; Holte, S.; Morrison, R.; Mutabingwa, T.K.; Fried, M.; Duffy, P.E. Iron Deficiency Protects Against Severe Plasmodium Falciparum Malaria and Death in Young Children. Clin. Infect. Dis. 2012, 54, 1137-1144. [CrossRef] [PubMed]

21. Jonker, F.A.M.; Calis, J.C.J.; van Hensbroek, M.B.; Phiri, K.; Geskus, R.B.; Brabin, B.J.; Leenstra, T. Iron Status Predicts Malaria Risk in Malawian Preschool Children. PLoS ONE 2012, 7, 1-8. [CrossRef] [PubMed]

22. Moya-Alvarez, V.; Cottrell, G.; Ouedraogo, S.; Accrombessi, M.; Massougbodgi, A.; Cot, M. High Iron Levels Are Associated with Increased Malaria Risk in Infants during the First Year of Life in Benin. Am. J. Trop. Med. Hyg. 2017, 97, 497-503. [CrossRef] [PubMed]

23. Muriuki, J.M.; Mentzer, A.J.; Kimita, W.; Ndungu, F.M.; Macharia, A.W.; Webb, E.L.; Lule, S.A.; Morovat, A.; Hill, A.V.S.; Bejon, P.; et al. Iron Status and Associated Malaria Risk Among African Children. Clin. Infect. Dis. 2018. [CrossRef] [PubMed]

24. Glinz, D.; Hurrell, R.F.; Righetti, A.A.; Zeder, C.; Adiossan, L.G.; Tjalsma, H.; Utzinger, J.; Zimmermann, M.B.; N'Goran, E.K.; Wegmüller, R. In Ivorian School-Age Children, Infection with Hookworm Does Not Reduce Dietary Iron Absorption or Systemic Iron Utilization, Whereas Afebrile Plasmodium Falciparum Infection Reduces Iron Absorption By Half. Am. J. Clin. Nutr. 2015, 101, 462-470. [CrossRef] [PubMed] 
25. Paganini, D.; Zimmermann, M.B. Effects of Iron Fortification and Supplementation on the Gut Microbiome and Diarrhea in Infants and Children: A Review. Am. J. Clin. Nutr. 2017, 106, 1688S-1693S. [CrossRef] [PubMed]

26. Baliraine, F.N.; Afrane, Y.A.; Amenya, D.A.; Bonizzoni, M.; Menge, D.M.; Zhou, G.; Zhong, D.; Vardo-Zalik, A.M.; Githeko, A.K.; Yan, G. High Prevalence of Asymptomatic Plasmodium Falciparum Infections in a Highland Area of Western Kenya: A Cohort Study. J. Infect. Dis. 2009, 200, 66-74. [CrossRef] [PubMed]

27. Howard, C.T.; McKakpo, U.S.; Quakyi, I.A.; Bosompem, K.M.; Addison, E.A.; Sun, K.; Sullivan, D.; Semba, R.D. Relationship of Hepcidin with Parasitemia and Anemia Among Patients with Uncomplicated Plasmodium Falciparum Malaria in Ghana. Am. J. Trop. Med. Hyg. 2007, 77, 623-626. [CrossRef] [PubMed]

28. De Mast, Q.; Nadjm, B.; Reyburn, H.; Kemna, E.H.J.M.; Amos, B.; Laarakkers, C.M.M.; Silalye, S.; Verhoef, H.; Sauerwein, R.W.; Swinkels, D.W.; et al. Assessment of Urinary Concentrations of Hepcidin Provides Novel Insight into Disturbances in Iron Homeostasis during Malarial Infection. J. Infect. Dis. 2009, 199, $253-262$. [CrossRef] [PubMed]

29. Casals-Pascual, C.; Huang, H.; Lakhal-Littleton, S.; Thezenas, M.L.; Kai, O.; Newton, C.R.J.C.; Roberts, D.J. Hepcidin Demonstrates a Biphasic Association with Anemia in Acute Plasmodium Falciparum Malaria. Haematologica 2012, 97, 1695-1698. [CrossRef] [PubMed]

30. Ayoya, M.A.; Stoltzfus, R.J.; Nemeth, E.; Traoré, A.K.; Ganz, T. Hepcidin and Plasmodium Falciparum Malaria in Anemic School Children in Mali. Bull. Soc. Pathol. Exot. 2009, 120, 219-220.

31. Atkinson, S.H.; Uyoga, S.M.; Armitage, A.E.; Khandwala, S.; Mugyenyi, C.K.; Bejon, P.; Marsh, K.; Beeson, J.G.; Prentice, A.M.; Drakesmith, H.; et al. Malaria and Age Variably but Critically Control Hepcidin Throughout Childhood in Kenya. EBIOM 2015, 2, 1478-1486. [CrossRef] [PubMed]

32. de Mast, Q.; Syafruddin, D.; Keijmel, S.; Riekerink, T.O.; Deky, O.; Asih, P.B.; Swinkels, D.W.; van der Ven, A.J. Increased Serum Hepcidin and Alterations in Blood Iron Parameters Associated with Asymptomatic P. Falciparum and P. Vivax Malaria. Haematologica 2010, 95, 1068-1074. [CrossRef] [PubMed]

33. Cercamondi, C.I.; Egli, I.M.; Ahouandjinou, E.; Dossa, R.; Zeder, C.; Salami, L.; Tjalsma, H.; Wiegerinck, E.; Tanno, T.; Hurrell, R.F.; et al. Afebrile Plasmodium Falciparum Parasitemia Decreases Absorption of Fortification Iron but does not Affect Systemic Iron Utilization: A Double Stable-Isotope Study in Young Beninese Women. Am. J. Clin. Nutr. 2010, 92, 1385-1392. [CrossRef] [PubMed]

34. Spottiswoode, N.; Armitage, A.E.; Williams, A.R.; Fyfe, A.J.; Biswas, S.; Hodgson, S.H.; Llewellyn, D.; Choudhary, P.; Draper, S.J.; Duffy, P.E.; et al. Role of Activins in Hepcidin Regulation During Malaria. Infect. Immun. 2017, 85, 1-17. [CrossRef] [PubMed]

35. Nemeth, E.; Tuttle, M.S.; Powelson, J.; Vaughn, M.B.; Donovan, A.; Ward, D.M.; Ganz, T.; Kaplan, J. Hepcidin Regulates Cellular Iron Efflux by Binding to Ferroportin and Inducing Its Internalization. Science 2004, 306, 2090-2093. [CrossRef] [PubMed]

36. Abboud, S.; Haile, D.J. A Novel Mammalian Iron-Regulated Protein Involved in Intracellular Iron Metabolism. J. Biol. Chem. 2000, 275, 19906-19912. [CrossRef] [PubMed]

37. Yang, F.; Liu, X.B.; Quinones, M.; Melby, P.C.; Ghio, A.; Haile, D.J. Regulation of Reticuloendothelial Iron Transporter MTP1 (Slc11a3) by Inflammation. J. Biol. Chem. 2002, 277, 39786-39791. [CrossRef] [PubMed]

38. Donovan, A.; Brownlie, A.; Zhou, Y.; Shepard, J.; Pratt, S.J.; Moynihan, J.; Paw, B.H.; Drejer, A.; Barut, B.; Zapata, A.; et al. Positional Cloning of Zebrafish Ferroportin1 Identifies a Conserved Vertebrate Iron Exporter. Nature 2000, 403, 776-781. [CrossRef] [PubMed]

39. McKie, A.T.; Marciani, P.; Rolfs, A.; Brennan, K.; Wehr, K.; Barrow, D.; Miret, S.; Bomford, A.; Peters, T.J.; Farzaneh, F.; et al. A Novel Duodenal Iron-Regulated Transporter, IREG1, Implicated in the Basolateral Transfer of Iron to the Circulation. Mol. Cell 2000, 5, 299-309. [CrossRef]

40. Zhang, D.L.; Wu, J.; Shah, B.N.; Greutélaers, K.C.; Ghosh, M.C.; Ollivierre, H.; Su, X.Z.; Thuma, P.E.; Bedu-Addo, G.; Mockenhaupt, F.P.; et al. Erythrocytic Ferroportin Reduces Intracellular Iron Accumulation, Hemolysis, and Malaria Risk. Science 2018, 359, 1520-1523. [CrossRef] [PubMed]

41. Mena, N.P.; Esparza, A.; Tapia, V.; Valdés, P.; Núñez, M.T. Hepcidin Inhibits Apical Iron Uptake in Intestinal Cells. Am. J. Physiol. Gastrointest. Liver Physiol. 2008, 294, G192-G198. [CrossRef] [PubMed]

42. Brasselagnel, C.; Karim, Z.; Letteron, P.; Bekri, S.; Bado, A.; Beaumont, C. Intestinal DMT1 Cotransporter is Down-Regulated by Hepcidin via Proteasome Internalization and Degradation. Gastroenterology 2011, 140, 1261-1271. [CrossRef] [PubMed] 
43. Kwiatkowski, D.; Sambou, I.; Twumasi, P.; Greenwood, B.M.; Hill, A.V.S.; Manogue, K.R.; Cerami, A.; Castracane, J.; Brewster, D.R. TNF Concentration in Fatal Cerebral, Non-Fatal Cerebral, AND Uncomplicated Plasmodium Falciparum Malaria. Lancet 1990, 336, 1201-1204. [CrossRef]

44. Kurtzhals, J.A.L.; Addae, M.M.; Akanmori, B.D.; Dunyo, S.; Koram, K.A.; Appawu, M.A.; Nkrumah, F.K.; Hviid, L. Anaemia Caused by Asymptomatic PIasmodium Falciparum Infection in Semi-Immune African Schoolchildren. Trans. R. Soc. Trop. Med. Hyg. 1999, 93, 623-627. [CrossRef]

45. Alvarez-Hernández, X.; Licéaga, J.; McKay, I.C.; Brock, J.H. Induction of Hypoferremia and Modulation of Macrophage Iron Metabolism by Tumor Necrosis Factor. Lab. Investig. 1989, 61, 319-322. [PubMed]

46. Roodman, G.; Bird, A.; Hutzler, D.; Montgomery, W. Tumor Necrosis Factor-Alpha and Hematopoietic Progenitors: Effects of Tumor Necrosis Factor on the Growth of Erythroid Progenitors CFU-E and BFU-E and the Hematopoietic Cell Lines K562, HL60, and HEL Cells. Exp. Hematol. 1987, 15, 928-935. [PubMed]

47. Johnson, D.; Bayele, H.; Johnston, K.; Tennant, J.; Srai, S.K.; Sharp, P. Tumour Necrosis Factor Alpha Regulates Iron Transport and Transporter Expression in Human Intestinal Epithelial Cells. FEBS Lett. 2004, 573, 195-201. [CrossRef] [PubMed]

48. Laftah, A.H.; Sharma, N.; Brookes, M.J.; McKie, A.T.; Simpson, R.J.; Iqbal, T.H.; Tselepis, C. Tumour Necrosis Factor Alpha Causes Hypoferraemia and Reduced Intestinal Iron Absorption in Mice. Biochem. J. 2006, 397, 61-67. [CrossRef] [PubMed]

49. Kroeger, K.M.; Carville, K.S.; Abraham, L.J. The -308 Tumor Necrosis Factor-a Promotor Polymorphism Effects Transcription. Mol. Immunol. 1997, 34, 391-399. [CrossRef]

50. Wilson, A.G.; Symons, J.A.; McDowell, T.L.; McDevitt, H.O.; Duff, G.W. Effects of a Polymorphism in the Human Tumor Necrosis Factor Alpha Promoter on Transcriptional Activation. Proc. Natl. Acad. Sci. USA 1997, 94, 3195-3199. [CrossRef] [PubMed]

51. Atkinson, S.H.; Rockett, K.A.; Morgan, G.; Bejon, P.A.; Sirugo, G.; O'Connell, M.A.; Hanchard, N.; Kwiatkowski, D.P.; Prentice, A.M. Tumor Necrosis Factor SNP Haplotypes are Associated with Iron Deficiency Anemia in West African Children. Blood 2008, 112, 4276. [CrossRef] [PubMed]

52. Atkinson, S.H.; Armitage, A.E.; Khandwala, S.; Mwangi, T.W.; Uyoga, S.; Bejon, P.A.; Williams, T.N.; Prentice, A.M.; Drakesmith, H. Combinatorial Effects of Malaria Season, Iron Deficiency, and Inflammation Determine Plasma Hepcidin Concentration in African Children. Blood 2014, 123, 3221-3229. [CrossRef] [PubMed]

53. Frosch, A.E.P.; Ondigo, B.N.; Ayodo, G.A.; Vulule, J.M.; John, C.C.; Cusick, S.E. Decline in Childhood Iron Deficiency after Interruption of Malaria Transmission in Highland Kenya. Am. J. Clin. Nutr. 2014, 100, 968-973. [CrossRef] [PubMed]

54. Meremikwu, M.; Donegan, S.; Sinclair, D.; Esu, E.; Oringanje, C. Intermittent Preventive Treatment for Malaria in Children Living in Areas with Seasonal Transmission (Review). Cochrane Database Syst. Rev. 2012. [CrossRef] [PubMed]

55. Nairz, M.; Theurl, I.; Wolf, D.; Weiss, G. Iron Deficiency or Anemia of Inflammation? Wien. Med. Wochenschr. 2016, 166, 411-423. [CrossRef] [PubMed]

56. Pasricha, S.R.; Atkinson, S.H.; Armitage, A.E.; Khandwala, S.; Veenemans, J.; Cox, S.E.; Eddowes, L.A.; Hayes, T.; Doherty, C.P.; Demir, A.Y.; et al. Expression of the Iron Hormone Hepcidin Distinguishes Different Types of Anemia in African Children. Sci. Transl. Med. 2014, 6. [CrossRef] [PubMed]

57. Suchdev, P.S.; Williams, A.M.; Mei, Z.; Flores-ayala, R.; Pasricha, S.; Rogers, L.M. Assessment of Iron Status in Settings of Inflammation: Challenges and Potential Approaches. Am. J. Clin. Nutr. 2017, 106, 1626-1633. [CrossRef] [PubMed]

58. Bejon, P.; Warimwe, G.; Mackintosh, C.L.; Mackinnon, M.J.; Kinyanjui, S.M.; Musyoki, J.N.; Bull, P.C.; Marsh, K. Analysis of Immunity to Febrile Malaria in Children that Distinguishes Immunity from Lack of Exposure. Infect. Immun. 2009, 77, 1917-1923. [CrossRef] [PubMed]

59. Langhorne, J.; Ndungu, F.M.; Sponaas, A.-M.; Marsh, K. Immunity to Malaria: More Questions Than Answers. Nat. Immunol. 2008, 9, 725-732. [CrossRef] [PubMed]

60. Olotu, A.; Fegan, G.; Wambua, J.; Nyangweso, G.; Ogada, E.; Drakeley, C.; Marsh, K.; Bejon, P. Estimating Individual Exposure to Malaria Using Local Prevalence of Malaria Infection in the Field. PLoS ONE 2012, 7. [CrossRef] [PubMed] 
61. Noor, A.M.; Kinyoki, D.K.; Mundia, C.W.; Kabaria, C.W.; Mutua, J.W.; Alegana, V.A.; Fall, I.S.; Snow, R.W. The Changing Risk of Plasmodium Falciparum Malaria Infection in Africa: 2000-10: A Spatial And Temporal Analysis of Transmission Intensity. Lancet 2014, 383, 1739-1747. [CrossRef]

62. Das, B.S.; Thurnham, D.I.; Das, D.B. Influence of Malaria on Markers of Iron Status in Children: Implications for Interpreting Iron Status in Malaria-Endemic Communities. Br. J. Nutr. 1997, 78, 751-760. [CrossRef] [PubMed]

63. Phiri, K.S.; Calis, J.C.J.; Siyasiya, A.; Bates, I.; Brabin, B.; van Hensbroek, M.B. New Cut-Off Values for Ferritin and Soluble Transferrin Receptor for the Assessment of Iron Deficiency in Children in a High Infection Pressure Area. J. Clin. Pathol. 2009, 62, 1103-1106. [CrossRef] [PubMed]

64. Aguilar, R.; Moraleda, C.; Quintó, L.; Renom, M.; Mussacate, L.; Macete, E.; Aguilar, J.L.; Alonso, P.L.; Menéndez, C. Challenges in the Diagnosis of Iron Deficiency in Children Exposed to High Prevalence of Infections. PLoS ONE 2012, 7, 3-9. [CrossRef] [PubMed]

65. Glinz, D.; Hurrell, R.F.; Ouattara, M.; Zimmermann, M.B.; Brittenham, G.M.; Adiossan, L.G.; Righetti, A.A.; Seifert, B.; Diakité, V.G.; Utzinger, J.; et al. The Effect of Iron-Fortified Complementary Food and Intermittent Preventive Treatment of Malaria on Anaemia in 12- to 36-Month-Old Children: A Cluster-Randomised Controlled Trial. Malar. J. 2015, 1-12. [CrossRef] [PubMed]

66. Smith, G.D.; Ebrahim, S. "Mendelian randomization": Can Genetic Epidemiology Contribute to Understanding Environmental Determinants of Disease? Int. J. Epidemiol. 2003, 32, 1-22. [CrossRef] [PubMed]

67. Evans, D.M.; Davey Smith, G. Mendelian Randomization: New Applications in the Coming Age of Hypothesis-Free Causality. Annu. Rev. Genom. Hum. Genet. 2015, 16, 327-350. [CrossRef] [PubMed]

68. Afzal, S.; Brøndum-Jacobsen, P.; Bojesen, S.E.; Nordestgaard, B.G. Genetically Low Vitamin D Concentrations and Increased Mortality: Mendelian Randomisation Analysis in Three Large Cohorts. BMJ 2014, 349, g6330. [CrossRef] [PubMed]

69. Voight, B.F.; Peloso, G.M.; Orho-Melander, M.; Frikke-Schmidt, R.; Barbalic, M.; Jensen, M.K.; Hindy, G.; Hólm, H.; Ding, E.L.; Johnson, T.; et al. Plasma HDL Cholesterol and Risk of Myocardial Infarction: A Mendelian Randomisation Study. Lancet 2012, 380, 572-580. [CrossRef]

70. Elliott, P.; Chambers, J.C.; Zhang, W.; Clarke, R.; Hopewell, J.C.; Peden, J.F.; Erdmann, J.; Braund, P.; Engert, J.C.; Bennett, D.; et al. Genetic Loci Associated with C-Reactive Protein Levels and Risk of Coronary Heart Disease. J. Am. Med. Assoc. 2009, 302, 37-48. [CrossRef] [PubMed]

71. Williams, T.N.; Mwangi, T.W.; Wambua, S.; Alexander, N.D.; Kortok, M.; Snow, R.W.; Marsh, K. Sickle Cell Trait and the Risk of Plasmodium falciparum Malaria and Other Childhood Diseases. J. Infect. Dis. 2005, 192, 178-186. [CrossRef] [PubMed]

72. Malaria Genomic Epidemiology Network. Reappraisal of Known Malaria Resistance Loci in a Large Multicenter Study. Nat. Genet. 2014, 46, 1197-1204. [CrossRef] [PubMed]

73. Bowden, J.; Smith, G.D.; Burgess, S. Mendelian Randomization with Invalid Instruments: Effect Estimation and Bias Detection Through Egger Regression. Int. J. Epidemiol. 2015, 44, 512-525. [CrossRef] [PubMed]

74. Burgess, S.; Butterworth, A.; Thompson, S.G. Mendelian Randomization Analysis with Multiple Genetic Variants Using Summarized Data. Genet. Epidemiol. 2013, 37, 658-665. [CrossRef] [PubMed]

75. Sheehan, N.A.; Didelez, V.; Burton, P.R.; Tobin, M.D. Mendelian Randomisation and Causal Inference in Observational Epidemiology. PLoS Med. 2008, 5, 1205-1210. [CrossRef] [PubMed]

76. Gera, T.; Sachdev, H.; Nestel, P.; Sachdev, S.S. Effect of Iron Supplementation on Haemoglobin Response in Children: Systematic Review of Randomised Controlled Trials. J. Pediatr. Gastroenterol. Nutr. 2007, 44, 468-486. [CrossRef] [PubMed]

77. Doherty, C.P.; Cox, S.E.; Fulford, A.J.; Austin, S.; Hilmers, D.C.; Abrams, S.A.; Prentice, A.M. Iron Incorporation and Post-Malaria Anaemia. PLoS ONE 2008, 3. [CrossRef] [PubMed]

78. Prentice, A.M.; Doherty, C.P.; Abrams, S.A.; Cox, S.E.; Atkinson, S.H.; Verhoef, H.; Armitage, A.E.; Drakesmith, H. Hepcidin is the Major Predictor of Erythrocyte Iron Incorporation in Anemic African Children. Blood 2012, 119, 1922-1928. [CrossRef] [PubMed]

79. Zimmermann, M.B.; Chassard, C.; Rohner, F.; Goran, K.N.E.; Nindjin, C.; Dostal, A.; Utzinger, J.; Ghattas, H.; Lacroix, C.; Hurrell, R.F. The Effects of Iron Fortification on the Gut Microbiota in African Children: A Randomized Controlled Trial in Cote d'Ivoire. Am. J. Clin. Nutr. 2010, 92, 1406-1415. [CrossRef] [PubMed] 
80. Jaeggi, T.; Kortman, G.A.M.; Moretti, D.; Chassard, C.; Holding, P.; Dostal, A.; Boekhorst, J.; Timmerman, H.M.; Swinkels, D.W.; Tjalsma, H.; et al. Iron Fortification Adversely Affects the Gut Microbiome, Increases Pathogen Abundance and Induces Intestinal Inflammation in Kenyan Infants. Gut 2015, 64, 731-742. [CrossRef] [PubMed]

81. Tang, M.; Frank, D.N.; Hendricks, A.E.; Ir, D.; Esamai, F.; Liechty, E.; Hambidge, K.M.; Krebs, N.F. Iron in Micronutrient Powder Promotes an Unfavorable Gut Microbiota in Kenyan Infants. Nutrients 2017, 9, 776. [CrossRef] [PubMed]

(C) 2018 by the authors. Licensee MDPI, Basel, Switzerland. This article is an open access article distributed under the terms and conditions of the Creative Commons Attribution (CC BY) license (http://creativecommons.org/licenses/by/4.0/). 


\title{
The Importance of Iron Status for Young Children in Low- and Middle-Income Countries: A Narrative Review
}

\author{
Andrew E. Armitage ${ }^{1, *}$ and Diego Moretti ${ }^{2,3}$ \\ 1 MRC Human Immunology Unit, MRC Weatherall Institute of Molecular Medicine, University of Oxford, \\ John Radcliffe Hospital, Oxford, OX3 9DS, UK \\ 2 Laboratory of Human Nutrition, Institute of Food Nutrition and Health, Department of Health Sciences and \\ Technology, ETH Zürich, CH-8092 Zürich, Switzerland; diego.moretti@ffhs.ch \\ 3 Nutrition Group, Health Department, Swiss Distance University of Applied Sciences, \\ $\mathrm{CH}-8105$ Regensdorf, Switzerland \\ * Correspondence: andrew.armitage@imm.ox.ac.uk; Tel.: +44-1865-222547
}

Received: 6 March 2019; Accepted: 12 April 2019; Published: 16 April 2019

\begin{abstract}
Early childhood is characterised by high physiological iron demand to support processes including blood volume expansion, brain development and tissue growth. Iron is also required for other essential functions including the generation of effective immune responses. Adequate iron status is therefore a prerequisite for optimal child development, yet nutritional iron deficiency and inflammation-related iron restriction are widespread amongst young children in low- and middle-income countries (LMICs), meaning iron demands are frequently not met. Consequently, therapeutic iron interventions are commonly recommended. However, iron also influences infection pathogenesis: iron deficiency reduces the risk of malaria, while therapeutic iron may increase susceptibility to malaria, respiratory and gastrointestinal infections, besides reshaping the intestinal microbiome. This means caution should be employed in administering iron interventions to young children in LMIC settings with high infection burdens. In this narrative review, we first examine demand and supply of iron during early childhood, in relation to the molecular understanding of systemic iron control. We then evaluate the importance of iron for distinct aspects of physiology and development, particularly focusing on young LMIC children. We finally discuss the implications and potential for interventions aimed at improving iron status whilst minimising infection-related risks in such settings. Optimal iron intervention strategies will likely need to be individually or setting-specifically adapted according to iron deficiency, inflammation status and infection risk, while maximising iron bioavailability and considering the trade-offs between benefits and risks for different aspects of physiology. The effectiveness of alternative approaches not centred around nutritional iron interventions for children should also be thoroughly evaluated: these include direct targeting of common causes of infection/inflammation, and maternal iron administration during pregnancy.
\end{abstract}

Keywords: iron; anaemia; infection; malaria; immunity; brain development; growth; microbiome; hepcidin; ferritin; iron supplementation; infants; children; low and middle income countries

\section{Introduction}

Young children growing up in low- and middle-income countries (LMICs) are frequently exposed to concurrent physiological challenges and environmental hazards that may influence both their current health and future development. In such settings, a high infection risk often co-exists with nutritional deficiencies, amongst which iron deficiency (ID) is of major importance. ID is best known for causing anaemia, affecting hundreds of millions of young children, particularly in LMICs [1]. Iron deficiency anaemia (IDA) affects over 1.2 billion people globally and was recently classified as the leading cause 
of years lived with disability (YLDs) in low/low-middle socioeconomic settings [2]. However, ID also occurs frequently without manifesting anaemia, meaning the number of people affected globally will be considerably higher. Importantly, the clinical and developmental impacts of iron deficiency also go beyond anaemia [3].

In this narrative review, we discuss the biology of iron in early childhood, with a particular focus on children living in settings with high burdens of infection, nutritional deficiency and anaemia. We aim to identify research gaps, controversies and accepted principles from biological, nutritional and epidemiological points of view. In the first section, we consider why iron is required during the early years of life, how iron status is defined, and how iron handling is regulated. In the second section, we examine the implications of iron status and therapeutic iron interventions for different physiological and developmental processes of particular relevance in early childhood. The final section summarises factors that should be accounted for when planning interventions aimed at adjusting iron status in such populations.

\section{Regulation of Iron Status during Early Childhood}

\subsection{Iron Demand in Early Childhood}

Iron is widely used as a cofactor in cellular biochemistry owing to its ability to act as an electron donor or acceptor. The numerous examples of proteins that use haem prosthetic groups or iron-sulphur clusters as cofactors, or which directly coordinate iron for catalytic functions, demonstrate the wide utility of iron in biology. Box 1 provides a far from exhaustive list of examples of how such proteins are used across key cellular processes. An adequate supply of iron is thus required to support normal physiology.

The daily requirement for iron is greater in early childhood than during adulthood [4,5]. Adulthood requires a "steady-state" turn-over of iron to maintain tissue homeostasis while ensuring flexibility to adapt iron handling according to changes in physiological or environmental circumstances (e.g., blood loss, infection, pregnancy, nutritional limitations, changes in altitude) [6]. In contrast to adults, young children must expand their blood volume, increase muscle and tissue mass, and are at a key stage in terms of neurodevelopment and brain growth: growing tissues therefore require an absolute increase in iron content to maintain a state of iron repletion.

Box 1. Examples of iron involvement in cellular biochemistry.

- The haem group of oxygen-transporting haemoglobins is the major and best-known destination of absorbed iron, supporting adequate erythropoiesis, with an estimated two-thirds of body iron found within erythrocyte haemoglobin.

- Haem moieties, in which iron is coordinated within protoporphyrin IX, also mediate oxygen-storage by myoglobin in muscle, and are used by cytochrome P450 monooxygenases, and by cytochrome $\mathrm{c}$ and cytochrome c oxidase in the mitochondrial electron transport chain for oxidative ATP production.

- The final step of haem biosynthesis is itself iron dependent, catalysed by the $\mathrm{Fe}_{2}-\mathrm{S}_{2}$-containing protein ferrochelatase.

- Iron-sulphur clusters are central as cofactors in energy production, being complexed within mitochondrial aconitase in the tricarboxylic acid (TCA) cycle, and complexes I-III in the electron transport chain. They are used by DNA polymerases, DNA primase subunits, and DNA helicases reflecting involvement in DNA replication and repair.

- Nucleotide biosynthesis provides the substrate for DNA replication and depends on ribonucleotide reductase $(\mathrm{RnR})$, a di-iron monooxygenase.

- Iron(II)- and 2-oxogluatarate-dependent dioxygenases include the prolyl hydroxylases PHD-1, 2 and 3 which regulate the Hypoxia-Inducible Factor (HIF)-dependent response to hypoxia, and the TET family of methylcytosine dioxygenases which are involved in histone demethylation and consequent epigenetic regulation.

- Iron is centrally involved in the antimicrobial oxidative burst employed during neutrophil responses to infection, involving the haem-dependent NADPH oxidase, and iron-dependent myeloperoxidase. 


\subsection{Iron Supply in Early Childhood}

\subsubsection{The Maternal Iron Endowment}

Neonates are born with an endowment of iron from their mother, estimated as approximately $75 \mathrm{mg} / \mathrm{kg}$ (approximately $260 \mathrm{mg}$ total body iron) in a healthy full-term neonate [7]. The size of the iron endowment is strongly influenced by gestational age, birthweight and timing of cord clamping [7]. Maternal iron status does not appear to predict neonatal iron status during maternal iron sufficiency $[8,9]$ or in the presence of maternal iron-restricted erythropoiesis [10]. However, several studies report compromised infant iron status following maternal iron deficiency anaemia (e.g., [11,12]). This suggests that unless maternal iron is severely limited, foetuses tend to acquire maternal iron efficiently during gestation irrespective of maternal iron status. The size of the maternal iron endowment and its consumption rate vary between infants, with declines in iron status greater in boys than girls $[13,14]$. A significant proportion of maternal-foetal iron transfer occurs during the final weeks of gestation [9]. Consequently, pre-term infants are at high risk of earlier onset ID. Similarly, since most of the iron is contained within haemoglobin, lower birthweight infants-who have a smaller total blood volume - carry lower absolute body iron content and are at higher risk of ID [13]. Delaying cord clamping, which can enable blood volume increases of $\sim 40 \mathrm{~mL} / \mathrm{kg}$ birthweight, is associated with significantly improved iron status and lower ID risk during the first year (reviewed in [7]).

The maternal iron endowment is thought to sustain the iron requirements of an exclusively breastfed healthy term infant for up to half of the first year [7]. Since iron is utilised to support growth and development, the initial iron stores become depleted as infancy progresses, with steeper declines in more rapidly growing infants [13,15-17]. This means iron must be obtained from exogenous sources including complementary foods and via food fortification or supplementation [7]. Human breastmilk is often considered to contain highly bioavailable iron but only in small quantities that are insufficient to sustain iron requirements as infancy progresses [18-20]. Therefore, weaning diets must contain adequate sources of bioavailable iron.

\subsubsection{Dietary Iron: Differences between High- and Low-Income Settings}

Two categories of dietary iron exist: haem iron, present in animal-source foods, is highly bioavailable ( $20-50 \%$ of ingested iron is absorbed); in contrast, non-haem iron, which accounts for a higher proportion of dietary intake, has highly variable but typically substantially lower bioavailability [21]. Absorption of non-haem iron, unlike haem iron, is influenced by the presence of dietary enhancers (e.g., ascorbic acid (AA) and muscle protein) and inhibitors (e.g., phytates and polyphenols) (Reviewed in [22]). Based on overall dietary composition, iron bioavailability can be classified as poor (average fractional absorption (FA) $<5 \%$ ), intermediate (FA, 5-15\%) or high (FA, $>15 \%$ ). Bioavailability relates to the relative balance of unrefined cereals and pulses (high in inhibitory phytates), fresh fruits and vegetables (sources of AA), refined cereals (lower in phytates), and meat, fish and poultry (rich in haem iron and muscle protein). Weaning foods should possess high iron bioavailability, as the iron/energy requirement ratio is particularly elevated in infancy. These factors likely contribute to differences in iron status between young children from higher-income settings, where fortification of weaning diets, cereals and meat-based diets are commonplace, compared with those from LMICs where diets often contain lower absolute iron content, combined with lower dietary bioavailability enhancer:inhibitor ratios.

The recommended nutrient intake (RNI) of iron for 7-12-month-old infants (i.e., required quantity of absorbed iron) has been estimated as $0.69 \mathrm{mg} /$ day $(97.5$ th percentile, $1.07 \mathrm{mg} /$ day) $[5,23]$. If bioavailability of dietary iron is below $10 \%$, intake of $>10.7 \mathrm{mg} /$ day would be required to guarantee reaching the 97.5th RNI percentile, which may present a challenge in resource-limited settings; accordingly, children may frequently fail to meet the RNI, and ID may ensue [23]. Risk of nutritional ID can be classified via markers of dietary exposure relating to both iron intake and overall iron dietary bioavailability (reviewed in detail by the Biomarkers of Nutrition for Development (BOND) 
project [24]). However, dietary intake and bioavailability assessment remains challenging, with reliable intake estimates requiring 7-10 days of weighed food records. Nonetheless, at the individual level, dietary counselling and advice to increase iron intakes [25] and bioavailability may concomitantly increase the likelihood of RNI being met [26]. Programmatic evidence for a benefit of such a strategy is lacking yet would be highly desirable.

Differences between high- and low-income settings in intake of bioavailable iron could become further accentuated over the coming decades in relation to anthropogenic increases in atmospheric $\mathrm{CO}_{2}$ concentrations. The absolute iron content of widely consumed crops, specifically $\mathrm{C} 3$ grasses (wheat and rice) and legumes (field peas and soybeans), decreases with increasing $\mathrm{CO}_{2}$ [27], and modelling suggests this would translate to an increase in global iron deficiency prevalence, focussed particularly on LMIC populations for whom these cereals constitute dietary staples [28]. Climate change is also predicted to contribute significantly to a declining fish catch over the coming decades, reducing consumption of highly bioavailable iron and increasing micronutrient deficiency in coastal communities, again predominantly in LMIC settings [29].

As discussed below, iron uptake may also be inhibited by infection and inflammation for which the burden is higher in LMICs compared to higher-income countries. Furthermore, young children from LMIC populations are at higher risk of parasitic (most notably hookworm) infection, which is associated with intestinal blood loss, and therefore additional iron depletion [30,31]. Together, these factors illustrate the greater challenge faced by young children in LMIC settings in maintaining adequate iron status to sustain growth and development, in comparison to children of similar age in higher income settings.

\subsection{Molecular Control of Iron Handling}

In understanding the relationships between iron deficiency, iron absorption and inflammation, and in seeking to develop safe and effective interventional strategies, it is important to appreciate the molecular basis of iron control. While the redox properties of iron make it useful for cellular biochemistry, unchaperoned iron can catalyse the generation of toxic free radicals. Iron transport and storage must therefore be carefully regulated to ensure it is effectively targeted and employed in a controlled manner. Details of cellular and systemic iron handling have been reviewed in detail recently [6]. It has been long-established that systemic iron homeostasis is maintained through regulation of absorption, with iron losses not specifically regulated [32]. Iron sensing mechanisms must ensure non-regulated losses (e.g., through bleeding, intestinal cellular sloughing, or helminth infection) are replaced through appropriate absorption. When control of iron absorption is lost, either iron loading or iron deficiency may ensue: failures to prevent excess iron absorption, as in hereditary haemochromatosis or during non-transfusion-dependent beta-thalassaemia, lead to gradual toxic iron accumulation in the liver and other organs. Conversely, failure to absorb sufficient amounts of bioavailable iron eventually leads to anaemia, as in dietary iron deficiency, during chronic inflammation, and in the rare heritable iron-refractory iron deficiency anaemia (IRIDA) [6].

Iron balance must therefore be carefully maintained. This is achieved by coordinating cellular and systemic iron homeostasis [33]. Posttranscriptional regulation by the IRE/IRP (iron response element/iron regulatory protein) system is central in the control of cellular iron homeostasis. IRPs are RNA binding proteins which, during cellular iron deficiency, either stabilise iron-related mRNAs (e.g., TFR1, for iron acquisition) by binding 3'UTR IREs, or mediate translational repression of mRNAs by binding 5 'UTRs (e.g., FPN1, for iron export; FTH1, FTL encoding ferritin heavy and light chains respectively for iron storage) [6]. Systemic iron homeostasis on the other hand centres on the regulation and activity of the iron regulatory hormone hepcidin [34].

\subsubsection{The Hepcidin-Ferroportin Interaction}

Hepcidin coordinates both iron uptake through duodenal enterocytes and iron recycling (primarily derived from senescent erythrocytes) by reticuloendothelial macrophages. Hepcidin binds the 
iron exporter ferroportin, which is highly expressed on these cells, triggering its internalisation and ubiquitin-mediated degradation; this prevents the export of cellular iron into circulation [35]. Hepcidin-binding also directly occludes the ferroportin ion channel, providing an additional inhibitory mechanism [36]. Thus, when hepcidin concentrations are high, dietary iron uptake is inhibited, iron becomes sequestered in ferroportin-expressing macrophages, and serum iron concentrations decline. Hepcidin acts very rapidly: serum iron falls by $\sim 80 \%$ within an hour of hepcidin injection into mice [37]. The erythroid compartment also contributes to systemic iron homeostasis by returning iron to circulation: hepcidin-sensitive ferroportin is expressed by erythroblasts and is found on mature erythrocyte membranes [38,39]; erythroid-specific ferroportin knockout mice display mild serum iron deficiency, consistent with a proportion of circulating iron being derived from the erythron [40].

Inherited disorders of iron homeostasis reveal the centrality of the hepcidin-ferroportin interaction in maintaining iron balance. Iron overloading in haemochromatosis can be caused by mutation in the gene encoding hepcidin (HAMP) itself. More frequently, it links to mutations in genes encoding components of the signalling pathways mediating hepcidin upregulation in response to iron (including HFE, HJV, TfR2, BMP6) [41,42]. Hepcidin insufficiency characterises each of these conditions. Likewise, patients with "gain-of-function" ferroportin mutations (rendering ferroportin hepcidin-resistant) develop iron overload $[43,44]$. Patients with "loss-of-function" ferroportin disease display a distinct disordered iron phenotype (including macrophage rather than parenchymal iron loading) [45]. Contrastingly, IRIDA results from loss-of-function mutations in TMPRSS6, which encodes the protein matriptase-2 that normally inhibits the production of hepcidin [46].

\subsubsection{Hepcidin Regulation by Iron}

Details of the molecular pathways regulating hepcidin have been reviewed extensively elsewhere [34,47]. Broadly speaking, to maintain homeostasis, hepcidin is upregulated in hepatocytes in response to sensing increased iron via the BMP-SMAD (Bone Morphogenetic Protein-Sons of Mothers against Decapentaplegic) pathway [47]. Liver Sinusoidal Endothelial Cell (LSEC)-derived BMP6 and BMP2 are key in this process [48-51]. BMP6 is more responsive than BMP2 to tissue iron loading [52], although how iron sensing leads to BMP6 upregulation is yet to be described. Hemojuvelin $(\mathrm{HJV})$ is a key accessory receptor that enhances BMP-mediated signalling [53]. Sensing of acute changes in serum iron concentration and transferrin saturation also converges on the BMP-SMAD pathway, involving transferrin receptor 1 (TfR1/CD71), transferrin receptor 2 (TfR2), the haemochromatosis protein HFE and BMP receptors (although not requiring BMP6 induction) (reviewed in [47]).

\subsubsection{Hepcidin Regulation during Inflammation}

Hepcidin is also induced during the acute phase response to inflammatory stimuli $[54,55]$. Upregulation is primarily mediated via the JAK-STAT3 (Janus Kinase-Signal Transducer and Activator of Transcription proteins 3) pathway, most notably by interleukin-6 (IL-6) [56-58], but probably also by other cytokines including IL-22, type I interferon, and IL-1beta [55,59-61]. Cross-talk with BMP6/SMAD signalling is also required for the normal response to inflammatory stimuli, since loss of HJV blunts the hepcidin response in this context [62]. Activin B, which also signals via SMAD pathways, is induced during inflammation/infection and can upregulate hepcidin in vitro, although its role in inflammatory hepcidin induction in vivo remains uncertain [63-67]. Hepcidin activity during infection and inflammation leads to characteristic hypoferremia [68], shown to be protective against extracellular siderophilic bacterial infections [69,70]; hepcidin-independent mechanisms including the transcriptional downregulation of ferroportin expression also likely contribute [71]. Prolonged inflammatory stimulation of hepcidin and consequent hypoferremia contributes to the pathogenesis of anaemia of inflammation (AI) by limiting iron supply to the erythron [72]. 


\subsubsection{Hepcidin Suppression during Erythropoietic Demand}

Erythropoiesis is highly iron-demanding, especially when expanded physiologically in response to acute blood loss or when it is ineffective as during beta-thalassaemia. Erythropoietic expansion is stimulated by erythropoietin signalling, whose activity induces the production of the hepcidin suppressive hormone erythroferrone in erythroblasts [73]. Erythroferrone suppresses liver hepcidin production through binding and inhibiting BMP6 and the related BMP family members, BMP5 and BMP7 [74] (which themselves are upregulated by iron in the absence of BMP6 [75]). Iron consumption by enhanced erythropoiesis also reduces the hepcidin-stimulatory signal from serum iron [76,77]. Similarly, during hypoxia, hepcidin can be suppressed through the cAMP Response Element Binding protein (CREB/CREB-H) pathways in response to high concentrations of Platelet-Derived Growth Factor-BB (PDGF-BB) activity [78]. Together, these mechanisms inhibit hepcidin production, liberating iron from hepatic and macrophage stores and facilitating iron absorption to supply erythropoiesis. Moreover, duodenal iron absorption is further promoted when hepcidin is low since ferroportin-dependent iron flux through enterocytes leads to stabilisation of the hypoxia-inducible factor HIF-2alpha leading to the upregulation of genes involved in iron absorption (Dcytb, Dmt1, and Slc40a1—encoding ferroportin itself) [79].

In summary, multiple signals derived from diverse physiological systems are integrated at the level of hepcidin regulation to ensure adequate iron supply whilst mitigating against the dangers of iron loading and, as discussed below, acute siderophilic infection.

\subsection{Regulation of Hepcidin and Iron Status in Infancy and Early Childhood}

Concentrations of hepcidin, although variable, are relatively high in the first few months of life, when iron availability is not limited; this is consistent with the regulation of hepcidin operating in infancy in response to iron status as in adults $[17,80]$. Evidence has been presented however that in the first 6 months, absorption of iron supplements does not correlate with iron status, suggesting dietary iron absorption may bypass hepcidin-mediated regulation at this point $[18,19,81]$. Nonetheless, most of the iron entering circulation is derived from iron-recycling erythrophagocytic macrophages. An acute hypoferremia in neonates occurs during the first 48 hours of life [82,83], which is associated with raised hepcidin (Prentice, A.M.; et al., personal communication). This is consistent with hepcidin-mediated control of macrophage iron release being functional even in neonates, despite potential differences in intestinal iron absorption between early and later stages of infancy.

Studies in Gambian infants reveal profound reduction in serum iron concentration during the first months of life [17], to levels well below those typical in infants from high-income settings [84]. Ferritin decreases through the first year, more profoundly in males, as stores are consumed for expanding the erythron and growth and development of tissues (as discussed below) [8,14]. Related decreases in hepcidin also occur in African infants, again more notably in boys than girls $[80,85,86]$, with the extent of weight gain dominantly predicting the extent of hepcidin and ferritin decline [17]. Hepcidin concentrations in African pre-school children are associated with other biomarkers of iron status, inflammation and erythropoietic demand, suggesting hepcidin is regulated similarly in young children and adults [87].

In contrast to the studies in African infants, declines in hepcidin during the first year were not observed in two studies of European infants [88,89]. This may relate to higher contents of bioavailable iron in typical European weaning diets. A recent study in Gambian infants (6-27 months) found that respiratory infections and fever incidence (but not diarrhoea or faecal calprotectin-a marker of intestinal inflammation) were strongly associated with raised hepcidin; inflammation (marked by CRP), even if very low-grade, was the dominant predictor of hepcidin [90]. Chronic, even mild, inflammation may therefore play a key role in inhibiting dietary iron uptake, contributing to the declining iron status of early childhood in such settings. 


\subsection{Classification of Iron Deficiency}

Before discussing how low iron status influences key physiological processes in young LMIC children, it is useful to review how iron status can be classified. Haemoglobin $(\mathrm{Hb})$ is a standardized and accessible marker whose concentration is directly proportional to oxygen carrying capacity. However, it is a poor indicator of ID with low sensitivity (ability to identify iron deficiency when present) and specificity (ability to correctly identify subjects without deficiency). This reflects anaemia being a late manifestation of ID and having multiple aetiologies, especially in LMIC children. Thus, iron status must be assessed using more sensitive and specific biomarkers. Ideally, these should identify different degrees of iron status, ranging from depletion of iron stores, to iron-deficient erythropoiesis without anaemia, to iron-deficiency anaemia [24].

The gold standard approaches for assessing ID are bone marrow iron (Prussian blue) staining and, in the case of anaemia, evaluation of the haematological response to therapeutic iron [91]. Bone marrow staining reveals absence of reticuloendothelial iron storage and therefore true ID. Neither of these are appropriate for routine clinical or epidemiological assessment and, without an individually effective biochemical biomarker of iron balance, classification of ID is challenging, especially in LMIC children.

\subsubsection{Ferritin and Iron Stores}

Serum ferritin is linearly predictive of iron stores in the absence of inflammation, with $1 \mu \mathrm{g} / \mathrm{L}$ corresponding to $120 \mu \mathrm{g}$ storage iron $/ \mathrm{kg}$ body weight [92]. It reflects intracellular iron content of macrophages and hepatocytes. The commonly used cut-off of $12-15 \mu \mathrm{g} / \mathrm{L}$ is diagnostic for iron deficiency, but it has low sensitivity. Consequently, appropriate cut-offs for use in different settings and purposes are commonly debated; for example, higher cut-offs may be advisable for confirming a diagnosis (avoiding false negatives) compared to those used for population screening (where it is desirable to avoid false positives) [91]. Moreover, ferritin is an acute phase protein, induced during inflammation, infection and liver damage. Promising approaches that adjust ferritin values according to concurrent inflammation have recently been proposed [93], but will require further validation. The characteristics of iron metabolism in infancy and early childhood may return different thresholds for defining deficiency especially in settings with high infectious disease pressure, and clearly more evidence is required [94,95].

\subsubsection{Markers of Iron-Restricted Erythropoiesis}

The soluble transferrin receptor (sTfR1) represents a detectable circulating truncated form of the cellular iron uptake receptor, TfR1, increasingly expressed once tissue iron supply becomes scarce. Other than during the first few months of life, the bone marrow is the most avid iron consumer, and sTfR 1 concentration is generally thought to reflect iron demand from erythroid precursor cells. It is less affected than ferritin by inflammation and infection, but may be modified by conditions affecting erythropoiesis, including thalassaemia and sickle cell anaemia [96]. The ratio between sTfR and log-ferritin (ferritin index) offers the advantage of combining two markers covering different aspects in iron depletion, generally improving sensitivity and specificity compared to their individual use [24]. Of note, paper-based smartphone-app-guided point-of-care assays for ferritin and sTfR show promise in proof-of-principle studies, suggesting field measurement of these markers in children from resource-limited settings may become feasible $[97,98]$. Other markers of iron-restricted erythropoiesis are zinc protoporphyrin (ZPP) and the ZPP/haem ratio in red blood cells; ZPP accumulates in the last step of haemoglobin synthesis when iron is lacking [99]. Certain red cell indices may also be useful as markers of iron deficient erythropoiesis [24], among which reticulocyte haemoglobin content (Ret- $\mathrm{Hb} / \mathrm{CHr}$ ) is prominent $[100,101]$ and included in the American Academy of Pediatrics guidelines for the evaluation of anaemia [24]. Red cell indices are reported to be more suitable than ferritin alone in predicting response to intravenous iron in patients with chronic kidney disease [102], but their performance in detecting nutritional anaemia in childhood has not been evaluated systematically [24]. 


\subsubsection{Serum Iron and Transferrin Saturation}

Serum iron and transferrin saturation (Tsat, the proportion of iron-binding sites of the iron-transport protein transferrin occupied by iron) reflect iron availability for tissues at any given moment, and thus potentially provide information on peripheral iron delivery. However, they are affected by circadian rhythm and decreased by inflammation and infection, rendering their interpretation challenging in young children [24]. Nevertheless, extremely low serum iron concentrations described in concert with low ferritin/hepcidin in African infants, well below the typical range in infants elsewhere, does likely reflect a severe deficiency in iron supply for iron-requiring tissues [17,84].

\subsubsection{Hepcidin}

Hepcidin shows promise as a further reliable marker to identify ID (during which it is suppressed), and to distinguish IDA from inflammatory anaemia in settings with high infection pressure [103]. It had moderate performance in predicting bone marrow ID in severely anaemic children in Malawi when compared to ferritin index [104]. As the hormone that regulates iron uptake, it also predicts oral iron responsiveness $[103,105,106]$. Like ferritin, hepcidin is an acute phase protein potentially confounded by inflammation [54,55] but, unlike ferritin, hepcidin synthesis is directly suppressed by expanded erythropoiesis. Hepcidin also shows diurnal variation [107]. High quality hepcidin assays are increasingly available and accessible, with efforts being made towards their harmonisation and standardisation $[108,109]$. With increased understanding of hepcidin biology and further analytical refinements, hepcidin may become more frequently used in assessing iron status [110], including in young children.

The extent to which these serum biomarkers indicate true iron deficiency must be considered. A recent study assessed the performance of biochemical iron status markers in predicting bone marrow ID in 1-5-year-old anaemic children in Mozambique, a setting with a high burden of infection/inflammation. As expected, serum ferritin displayed poor sensitivity but $100 \%$ specificity (zero false positives) in identifying bone marrow ID. In contrast, sTfR 1 showed $83 \%$ sensitivity and $50 \%$ specificity. Combining the two markers into the ratio, resulted in improved performance, but overall, even the best-performing markers failed to identify $25 \%$ of children with ID correctly [111]. The standardization of assays across different suppliers and instruments is an issue for all iron status markers, in particular for sTfR1 and hepcidin. Further research to improve interpretation, accessibility and analytics of current and experimental markers of iron status in settings with high infection pressure is clearly a research priority.

\section{The Importance of Iron Status for Different Physiological Systems in Early Childhood}

\subsection{Iron and Oxygen Delivery}

\subsubsection{Erythropoiesis in Early Childhood}

Anaemia refers to a state in which the oxygen-carrying capacity of blood, mediated by haemoglobin, falls below the level required to support normal physiological functions. In a healthy neonate, approximately $70 \%$ of total body iron (estimated as $234-334 \mathrm{mg}$, depending on birthweight and cord clamping time) is contained within haemoglobin, which is more concentrated in neonates than in adults (typically $\sim 170 \mathrm{~g} / \mathrm{L}$, calculated to contain $155 \mathrm{mg}$ iron in a $3.5 \mathrm{~kg}$ neonate) [4]. Higher haemoglobin concentrations at birth reflect a relatively hypoxic environment in utero. The transition to a normoxic environment after birth leads to a marked decline in erythropoietic output. Combined with shorter erythrocyte lifespan and dilution effects related to growth, haemoglobin concentrations fall notably in the first 1-2 months [112]. This "physiological anaemia of infancy" is accompanied by redistribution of iron from senescent red cells to iron stores (indicated by ferritin concentrations) [113]. From 6-8 weeks, erythropoietin concentrations and erythropoietic output increase, typically raising haemoglobin concentrations modestly [112]. The daily iron demand for normal erythropoietic output requires 
considerably higher quantities than are absorbed each day, bearing in mind the low iron content of breastmilk. Thus, most iron is supplied from iron stores derived from recycling of senescent red cells by the reticuloendothelial system.

As infancy progresses into early childhood, failure to meet the iron demand of growth-related blood volume expansion can lead to iron-restricted erythropoiesis. This is commonly observed in young children from LMICs. Failure in iron supply can result from either nutritional iron deficiency, or physiological restriction of macrophage iron recycling and iron absorption (functional iron deficiency), or commonly both. Iron restriction is a feature of the response to infection and inflammation, relating to elevated hepcidin concentrations and suppressed ferroportin activity. Erythropoietic suppression and increased erythrocyte turnover rate also likely contribute to anaemia pathogenesis during inflammation [72].

\subsubsection{Molecular Interplay between Iron Handling and Erythropoiesis}

Erythropoiesis is sensitive to decreased iron availability [114]. With decreasing transferrin saturation, ex vivo erythroblast differentiation is diminished relative to granulopoiesis and megakaryopoiesis, involving aconitase-mediated regulation [115]. Transferrin receptor 2 (TfR2) contributes to hepcidin induction in response to circulating iron in hepatocytes but is also expressed on erythroblasts. Erythroblast TfR2 interacts with the erythropoietin receptor (EpoR) to modulate sensitivity to Epo signalling via interactions with Scribble, a key regulator of cellular trafficking and signalling [116-119]. Together, this provides a plausible mechanism by which erythropoietic output can be adjusted during iron deficiency (reviewed in [120]). Moreover, as stated above, erythroblasts express hepcidin-sensitive ferroportin (from a transcript $(F P N 1 B)$ that is not subject to IRP-mediated regulation) [38,39]. Erythroid-specific ferroportin knockout mice displayed mild serum iron deficiency consistent with a contribution of erythroid iron to the circulating iron pool [40]. During iron deficiency (when hepcidin concentrations are low), this has been proposed as a safety mechanism to ensure supply of iron to iron-sensitive tissues at the expense of erythropoiesis, also protecting erythrocytes from oxidative stress [40].

\subsubsection{The Burden of Anaemia in LMIC Children}

Anaemia is typically defined by haemoglobin concentrations falling below specific thresholds. The World Health Organisation (WHO) recommends thresholds of 100-109 g/L, 70-99 g/L and $<70$ g/L to identify mild, moderate and severe anaemia respectively in children under 5 years of age [121]. However, it should be noted that a re-evaluation of the use and interpretation of anaemia-defining haemoglobin thresholds is underway [122]. Anaemia was estimated to affect 273 million children globally in 2011, disproportionately exerting its burden in low-income settings [123]. Iron deficiency is often purported to account for about half of the anaemia burden, yet estimates of the proportion of anaemia that is iron responsive are lower than this (42\% globally, and only $32 \%$ in Africa) $[1,124]$. These estimates point to the diverse aetiologies of anaemia: other causes include inflammation and infection (notably malaria), inherited erythrocyte disorders (e.g., sickle cell anaemia, thalassaemia, Glucose-6-phosphate dehydrogenase (G6PD) deficiency), and other micronutrient deficiencies (e.g., Vitamin A, Vitamin B12).

Chronic but mild iron-deficiency anaemia may not manifest symptomatically, and could even provide benefit in terms of reduced malarial risk (discussed further below) [125]. However, while anaemia in young children could lead to lethargy, it may more importantly influence longer-term developmental outcomes [126].

\subsection{Iron and Neurological Development}

Iron deficiency, both with and without anaemia, is associated with impaired cognitive, behavioural and motor function development $[3,127,128]$. Consequently, low iron status may have long-term effects, for example affecting educational attainment and career potential later in life [129]. Iron requirements in the developing brain are considered spatially and temporally sensitive [130,131]. A "scaffolding" 
process during development has been suggested, where each developmental stage depends on completion of the previous one [132]. This underlies the concern for ensuring adequate iron status during the critical first 3 years of life [126].

As discussed above, erythropoiesis is sensitive to iron status. Based on animal models, it has been suggested that erythroid iron is rechannelled back to circulation during iron limitation for prioritised use by other tissues, including brain, [39,40]. However, other studies suggest that iron limitation may lead to brain iron deficiency prior to the development of frank anaemia, suggesting erythropoiesis may not be compromised first [100]. After iron deprivation, decreased brain iron that preceded anaemia was reported in phlebotomized lambs [133], in human infants born from diabetic mothers [134], and in sheep affected by intrauterine hypoxemia [135]. During repletion, decreased brain iron levels persisted in infant rats [136] and haemoglobin repletion preceded brain iron accrual [137].

\subsubsection{Roles for Iron in Brain Development}

Normal neurological development involves an array of iron- and haem-dependent proteins. Studies, primarily using rodent models, demonstrate links between ID and multiple neurodevelopmental impairments. These range from decreased axon myelination and impaired monoamine and gamma-aminobutyric acid (GABA) neurotransmitter system development to reduced hippocampal function and compromised central nervous system (CNS) energy metabolism (reviewed in $[3,100,138]$ ). The specific brain region or process affected is likely to depend on the timing of ID, with those undergoing most rapid growth and development concurrent with ID principally affected [138]. IDA could also indirectly affect the CNS by impairing thyroid function [139] or by increasing the risk of lead poisoning $[140,141]$, both of which are associated with compromised neurological development.

Tools for investigating the impact of brain region-specific iron deficiency in the absence of anaemia are emerging. For example, a mouse model with reversible (Tet-OFF) hippocampal TfR1 deficiency enables comparison of chronic hippocampal ID with reversed early-life hippocampal ID [142]; restoration of hippocampal TfR1 expression at postnatal day 21 (heuristically corresponding to $\sim 2$ years of age in human infants) reversed some, but not all, of the gene expression changes associated with ID [142]. This further points to lasting impact of early-life ID on neurodevelopmental phenotype, and calls for further investigation into optimal timings of interventions aimed at restoring iron status in infancy [143].

\subsubsection{Iron Interventions and Cognitive Outcomes}

In population studies, meta-analyses of the effect of iron supplementation on cognition in young children have yielded ambiguous results. No significant collective detectable benefit was reported in one recent meta-analysis (mean difference 1.65 [95\% Confidence Interval (CI): $-0.63,3.94], p=0.16$; 6 trials; children aged 4-23 months) [144]. This could reflect a genuine lack of effect, or alternatively the inability of the study designs to adequately detect a true effect. Assessing cognitive performance is challenging in young children: test methods typically designed to detect "macroscopic" neurological deficits during early perinatal life may lack sensitivity for subtle changes in performance [145]. In contrast, several studies indicate the benefits of iron supplementation on cognitive function in older children [145-147], in particular following longer-term supplementation. Within this discussion, it should also be borne in mind that iron-replete Chilean infants who received high iron formulas displayed reduced cognitive performance at 10 years of age [148].

Together, these analyses highlight the general physiological importance of correcting ID for cognitive development, while at the same time calling for further detailed investigation during early perinatal life. Indeed, few high quality adequately-powered placebo-controlled trials in low-income countries aimed at assessing the impact of iron interventions on cognitive function have been performed [146]. Such data would be highly desirable for informing global health policies regarding universal iron intervention in young children; one such trial-BRISC ("Benefits and Risks of Iron interventionS in Children") — is currently ongoing in Bangladesh [149]. 


\subsection{Iron and Growth}

While more rapid growth is associated with greater decline in iron status [13,15-17], conflicting evidence exists on the effect of iron status and supplementation on growth. Severe iron deficiency impairs thyroid function [139], and as discussed below, iron status may influence the likelihood of acquiring growth-limiting infections. A limited number of studies, in particular in IDA populations, have found positive effects of iron on growth $[150,151]$ including a recent quasi-randomized study in Ethiopia [152]. However, most studies find no effect [153], with several reporting detrimental growth outcomes in iron-replete infants and children $[151,154,155]$. A recent meta-analysis reported no overall effect of iron supplementation on length and length-for-age, but a detrimental effect on length gain [144]. The physiological mechanisms underlying these observations require further research. Iron supplementation could inhibit zinc absorption, resulting in reduced growth [19]. Unnecessary supplementation in iron-replete children could also promote oxidative stress via non-transferrin bound iron (NTBI) generation [156], or gut inflammation and dysbiosis (discussed further below) [157,158], again possibly affecting growth. In summary, while growth rate clearly impacts upon iron status, iron status and interventions are not reciprocally or straightforwardly associated with subsequent growth. In particular, the possible relationship of iron interventions with reduced growth in initially iron-replete infants should be investigated further and considered as a component of planning intervention programmes [159].

\subsection{Iron and Immunity}

Vaccination programmes significantly contribute to reducing childhood mortality. However, 5.8 million (95\% CI: 5.7, 6.0) under-5 year olds died in 2015, mostly in LMICs, with infections as the major cause [160]. Despite the success of immunization, determinants of both immune system development and efficacious immune responses in infants, especially those from LMICs, are not fully understood. Immune responses to vaccines and natural antigen challenges may differ between lower and higher income countries [161,162]. Understanding childhood immunity specifically in LMICs, in comparison with more developed settings, is therefore of great importance. Inadequate nutritional status, including iron deficiency, represents a plausible contributory factor to impaired immune function in such contexts. Probing immune function in young LMIC children is challenging [163], yet for these populations that are most susceptible to infection-related mortality, even modest enhancement of immunity achieved through novel approaches could bring important benefits [164].

\subsubsection{Iron and Immune Ontogeny}

The early-life immune system is not static, or equivalent to the adult immune system, but undergoes dynamic age-related changes during ontogeny [163]. This was recently shown with great resolution in Swedish neonates using multidimensional mass cytometry analyses [165]. Non-heritable environmental factors (including age, cytomegalovirus (CMV) status, cohabitation) account for a large part of the inter-individual variation in adult immune phenotypic profiles [166,167]; environmental factors including nutritional status very likely influence early childhood immune development [164]. Iron status and iron supplementation may therefore constitute environmental determinants of immune variation in infants, potentially influencing phenotypic profiles later in life. Effects of iron could be direct (e.g., through affecting lymphopoiesis, which depends on TfR1 suggesting iron requirement [168]) or indirect through modifying the intestinal microbiota [169], which can influence systemic immune phenotypes [170].

\subsubsection{Iron and Innate Immune Responses}

Altered cellular iron status impacts upon several aspects of the innate immune response [171]. Key effector functions of innate cells such as neutrophils are iron dependent; for example, Saha, et al. recently showed that the bacterial iron-binding siderophore Enterochelin impaired neutrophil antibacterial 
functions (neutrophil extracellular trap and reactive oxygen species (ROS) generation) by chelating iron (see Box 1) [172]. Cellular iron status also influences macrophage polarization, response to interferon-gamma, and microbicidal effector functions, reviewed in detail elsewhere (e.g., $[173,174])$. Less precisely characterized is the influence of iron on adaptive immune responses.

\subsubsection{Iron and the Adaptive Immune Response}

Effective adaptive immune responses involve rapid proliferative expansion of antigen-specific effector $\mathrm{T}$ and $\mathrm{B}$ cells, accompanied by characteristic metabolic changes that are influenced by nutrient availability [175]. The role of nutrients such as amino acids in supporting normal lymphocyte responses is well-appreciated (e.g., [176]). Key aspects of cellular proliferation and metabolic activity are iron dependent. However, definitive conclusions regarding the precise role of iron in antigen-specific adaptive immunity have remained scarce despite many reports over the last 50 years [177]. Insight from experimental studies has been limited to crude responses to polyclonal stimuli or bulk IgG production, rather than antigen-specific responses, and most studies lack the depth of insight now attainable from more up-to-date immunological methodology. Furthermore, many clinical studies of iron involvement in immunity are inadequately powered, poorly controlled, or potentially confounded by co-morbidities of iron deficiency in resource-limited settings [177].

Iron restriction restricts the proliferation of lymphocytic cell lines in vitro and induces expression of TfR1 (CD71), consistent with increased cellular iron demand [178]. Correspondingly, antibody-mediated blocking of TfR1 function inhibits lymphocyte proliferation [179]. Lymphocytes from iron-deficient elderly individuals showed less proliferative capacity than those from iron-replete controls [180]. In other studies, ID has also been shown to influence $\mathrm{T}$ cell numbers, the response to mitogenic stimulation and IL-2 production $[181,182]$. Conversely, iron supplementation has been associated with restoration of T cell numbers in children [183]. In mice, ID limited T cell-mediated inflammatory liver injury following Concanavilin-A administration [184]. Moreover, a recent study by Wang, et al. [185] demonstrated that iron promoted proinflammatory cytokine expression in $\mathrm{T}$ cells by preventing the degradation of the RNA-binding protein PCBP1, allowing stabilisation of RNAs encoding the cytokines granulocyte-macrophage colony-stimulating factor (GM-CSF) and IL-2.

However, the most compelling evidence demonstrating the critical role of iron in adaptive immunity comes from the recent characterization of a rare inherited combined immunodeficiency. Jabara, et al. [186] described two families from Kuwait and Saudi Arabia in whom several affected children presented with recurrent, in some cases fatal, infections. Haematological parameters including lymphocyte counts were essentially normal, although several of the children displayed hypo- or a-gammaglobulinaemia. The affected individuals shared a hypomorphic mutation in the gene encoding TfR1 ( Tfrc $\mathrm{Y20H} / \mathrm{Y20H}$ ) that caused impaired cellular iron acquisition as TfR1 internalization was abrogated. This defect markedly inhibited T/B cell proliferation and antibody class-switching, accounting for the immunodeficiency. Provision of non-transferrin-bound iron rescued lymphocyte proliferation ex vivo. These data showed that adaptive immunity is highly compromised when lymphocytes are unable to access iron [186].

This inherited combined immunodeficiency is rare; however, the low serum iron concentrations observed during the first year of life in Gambian infants [17] - a time when several Expanded Programme of Immunisation (EPI) vaccines are administered-may occur in millions of infants across LMIC settings. Lack of available serum iron could analogously limit the ability of lymphocytes to acquire iron to support clonal expansion and differentiation of adaptive responses. Whether this contributes to impaired vaccine responses [161,162], and whether adaptive immune responses can be enhanced through iron interventions around the time of vaccination should be investigated. More generally, how iron status and iron interventions influence immune ontogeny during early life should also be assessed, preferably in a variety of settings (urban, rural, malaria-endemic), ideally in combination with long-term outcomes. 


\subsection{Iron and Infection}

While evidence that iron restriction may limit adaptive immune responses increases, strong epidemiological, experimental and evolutionary evidence that iron limitation is a protective strategy against some infections has accumulated (reviewed extensively elsewhere, e.g., [187-189]).

\subsubsection{Iron Status and Malaria Risk}

Nutritional ID in young children (the identification of which typically relies on the interpretation of the acute phase protein serum ferritin) was found to be associated with reduced risk of subsequent malaria in multiple studies from distinct malaria-endemic regions within Africa: namely Tanzania (children aged 0-3 years; reduced parasitaemia, severe disease and mortality) [190], Malawi (6-60 months; reduced parasitaemia and clinical malaria) [191], Uganda (1-5 years) and Kenya (0-7 years; reduced risk of malaria episodes) [125], besides an earlier study in Kenya (8 months-8 years; reduced clinical malaria risk) [192]. Ex vivo Plasmodium falciparum cultures show that erythrocytes from iron-replete individuals are favoured for invasion compared to those from iron deficient individuals, and that supplementation of individuals with ID makes their erythrocytes more permissive to invasion in vitro [193]. This effect likely reflects the preferential invasion of reticulocytes and young erythrocytes by Plasmodium falciparum merozoites: by definition, iron interventions that effectively correct anaemia create such preferred targets for parasite invasion. Thus, it is plausible that a mild iron deficiency can represent an adaptive state protecting against malaria and/or other infections.

Iron intervention trials in similar settings have found increased risk of malaria and mortality in children administered therapeutic iron. The most prominent amongst these was a large trial in Pemba, Tanzania, that was halted early due to increased deaths and hospital admissions, both malaria- and non-malaria-related, among children given iron-containing supplements [194]. No such effect was found in another supplementation trial in Nepal (an area without endemic malaria) [195], yet other studies have also reported increased malaria risk in iron-supplemented iron deficient children [196,197]. The importance of the co-administration of malaria prophylaxis with iron interventions is revealed by stratified analysis of a Cochrane review: although no overall effect of iron interventions on malaria risk was found, malaria risk was increased if no control measures were available [198]. These findings underlie the WHO recommendations that iron interventions should only be administered when concurrent measures for diagnosis, prevention and treatment are in place (discussed in detail in [124]).

However, interactions between iron and infective agents are not restricted to malaria. Iron administration was also associated with increased risk of respiratory infections, and of diarrhoea in a large randomised controlled trial (RCT) in Pakistan [199]. Oral iron supplementation influences intestinal microbiome composition, favouring the outgrowth of more pathogenic bacteria over commensals, and driving inflammatory gut phenotypes.

\subsubsection{Iron and the Microbiome}

Similarly to brain and immune development, critical changes in microbiome development occur during the first few years of life [169]. Indeed, it is becoming clear that these systems are not mutually exclusive. For example, changes in microbiome composition can influence systemic immunity [170]. Variability in microbiome development in infancy is driven by factors including mode of delivery, breast- versus formula-feeding, nature of weaning diets, exposure to antibiotics and geographic setting [169].

Early studies assessing the efficacy of iron interventions tended not to include systematic assessment of morbidity. However, an early systematic review and meta-analysis evaluating the effect of iron supplementation and fortification on infectious diseases did identify increased diarrhoea risk with interventions [200], corresponding to an extra 0.05 episodes/child year. Several more recent studies have likewise reported increased diarrhoea risk with iron supplementation and provision of multiple micronutrient powder (MNP, containing iron equivalent to $12-15 \mathrm{mg} / \mathrm{day}$ ) in young children, notably 
in Bangladesh [201], Peru [202] and Ghana [203] (reviewed in [204]). The large study in Pakistan described above similarly reported increases in diarrhoea and bloody diarrhoea prevalence in the groups receiving iron-containing MNPs compared to control [199]. This study was blinded within the two MNP groups (with and without zinc), but the control group was unblinded to the intervention meaning the authors could not fully exclude reporter bias in collection of self-reported morbidity data. Nonetheless, an increase in bloody diarrhoea incidence of $\sim 0.08$ episodes per child year was reported, equivalent to approximately one additional bloody diarrhoea episode per year for every 12-13 children administered MNPs containing iron [199,204]. Furthermore, a meta-analysis of studies also identified that iron supplementation was associated with vomiting and fever [144].

Modification of the colonic microbiota ecosystem potentially underlies the iron-associated increase in diarrhoea prevalence in LMIC settings [205]. Iron is a required nutrient for almost all microorganisms, with a few notable exceptions (e.g., Lactobacillaceae, which utilize manganese) [206]. Bacteria that are well-adapted for acquiring iron may experience a fitness advantage during iron supplementation, as shown elegantly for the probiotic strain E. Coli Nissle, which effectively outcompetes Salmonella for iron, displacing it from its ecologic niche [207]. Many conditional pathogenic bacterial species have evolved elaborate iron acquisition mechanisms (e.g., siderophore production), enabling thriving at low iron concentrations (e.g., 10-30 $\mu \mathrm{M}$ in blood). These mechanisms may similarly confer growth advantages in environments richer in iron: faecal iron concentrations in adults and weaned infants may reach $1800 \mu \mathrm{M}$ [205]. In contrast, human milk typically contains $<10 \mu \mathrm{M}$ iron [7,204], meaning iron concentrations in the gut in pre-weaning infants are likely considerably lower. At weaning, iron concentrations are likely to increase, potentially affecting microbiota composition, and are associated with barrier function and immune stimulating properties.

Within the intestinal microbiome, Bifidobacteria spp. and Lactobacilli spp. are generally associated with increased short chain fatty acid production and improved gut barrier function (highly desirable in infancy, particularly in resource-poor settings), while Enterobacteriaceae may include several potentially pathogenic species. Several recent studies in African LMICs have found increases in Enterobacteriaceae spp. with concurrent decreases in Lactobacilli spp. and Bifidobacteria spp. following provision of iron interventions [157,158,208,209]. Zimmermann, et al. reported such effects together with increased faecal calprotectin (marking gut inflammation) in Ivorian children receiving $20 \mathrm{mg} \mathrm{Fe} /$ day [209]. In infants administered MNPs containing $12 \mathrm{mg} \mathrm{Fe}$ /day, Jäggi, et al. similarly observed raised faecal calprotectin coupled with increased pathogenic E. coli abundance [157]. The effect on calprotectin was not detected at a lower dose (2.5 $\mathrm{mg} \mathrm{Fe} /$ day), or in a subsequent trial using $5 \mathrm{mg} \mathrm{Fe} /$ day [158]. However, the latter trial confirmed reduced Bifidobacterium spp. and Lactobacillus spp. abundance, and also reported increased expression of virulence and toxin genes and fatty acid binding protein, a marker of enterocyte damage, following iron administration [158].

The effects of iron on the microbiome may be strongly setting specific. In the Kenyan study described above [157], baseline prevalence of potential enteropathogens (e.g., Bacillus cereus, Streptococcus aureus, Clostridium difficile) was very high. In contrast, a study of iron interventions to South African school children living an area with improved water supply, and generally better hygiene and sanitation, did not observe effects on gut microbiota with high-dose therapeutic iron (50 mg Fe/day) [210]. Similarly, the administration of iron drops to Swedish infants was associated with decreased Bifidobacteria spp. and increased Clostridium spp. abundance, but no enhanced growth of specific pathogenic bacterial strains, or any effect on faecal calprotectin; at the same time, provision of high iron formula decreased Lactobacilli abundance [211].

More nuanced approaches for iron supplementation in resource-poor settings may be effective and practicable. For example, provision of prebiotic fibres such as galacto-oligosaccharides (GOS, reminiscent of human milk oligosaccharide (HMO) structures) may counteract iron-associated perturbations of the gut microbiota [158]. This approach was also coupled with measures to improve iron bioavailability such as the use of ascorbic acid, NaFeEDTA (ferric sodium ethylenediaminetetraacetate) and an exogenous phytase enabling substantial reduction of iron dosing while maintaining efficacy [158]. 
The remarkable effects of GOS on iron bioavailability [212] require further investigation; specifically, how different structures and sources of fibers with similarities to GOS influence gut microbiota and iron absorption in infants should be studied.

\subsubsection{Iron and the Hepcidin Response to Infection/Inflammation}

While baseline iron status and iron interventions may influence malaria risk and microbiome profiles, perturbations in host iron homeostasis occur as part of the response to infection, with a central role for hepcidin likely $[114,213]$. Hepcidin upregulation is observed during many important human infections including uncomplicated malaria [67,214,215], HIV-1 [216], Mycobacterium tuberculosis [217] and HIV-associated tuberculosis [218], and Salmonella Typhi [219] infections with accompanying hypoferremia or anaemia. It is likely that childhood infections similarly encompass hepcidin induction. Indeed, associations between elevated hepcidin and respiratory infection or fever, but not diarrhoea, in young children were recently reported [90].

Various consequences of hepcidin induction during infection have been shown using mouse models. Hepcidin-mediated iron redistribution during blood-stage parasitaemia in murine malaria models limited susceptibility to secondary liver stage infections; modelling suggested that this effect could explain why young children in areas of high malaria transmission tend to carry higher parasite densities but with fewer parasite genotypes than older children [220]. Hepcidin-mediated limitation of serum iron protects against extracellular siderophilic bacterial infections [69,70], most likely through limiting availability of non-transferrin bound iron (NTBI) to the bacteria. In contrast, macrophage iron retention due to hepcidin activity may favour the proliferation of intracellular macrophage-tropic infections such as Salmonella Typhimurium, although not through limiting bacterial iron acquisition, but by reduced generation of vacuolar antimicrobial ROS [221,222].

Another context where hepcidin upregulation may have a key protective role in the context of infancy relates to physiological neonatal hypoferremia. Despite neonates typically being iron replete and cord blood containing a high serum iron concentration, a significant hypoferremia is described in the hours following birth, lasting for a couple of days, consistent with hepcidin activity [82,83]. Neonatal septicaemia is a major contributor to infant mortality, especially in resource-limited settings. A recent study demonstrated significantly enhanced the growth of exemplar sentinel bacterial in sera taken from adults $4 \mathrm{~h}$ post-iron-supplementation $(2 \mathrm{mg} / \mathrm{kg})$, compared to pre-supplementation, and importantly that growth rate was strongly positively associated with transferrin saturation, irrespective of supplementation status [223]. Thus, variations in the degree of hypoferremia induced immediately after birth could influence the likelihood of septicaemic infections becoming established.

\subsubsection{Infection and Inflammation, and Iron Utilisation}

Recurrent or chronic infections, or other drivers of persistent inflammation, even if mild, may also lead to raised hepcidin and relative inhibition of dietary iron absorption $[90,106]$. The specific relationship between hepcidin upregulation and iron absorption may be context dependent. A recent study found that an acute mild inflammatory response to vaccination is associated with raised hepcidin and decreased serum iron, but no detectable difference in iron absorption in Moroccan women with and without IDA [224]. It is conceivable that dietary iron absorption and macrophage iron release are differentially sensitive to mildly raised hepcidin, or that during hypoferremia, enterocyte cellular iron metabolism (IRP/IRE and/or HIF-2alpha) compensates for the inhibitory effect of hepcidin on mucosal iron transport. Nevertheless, chronic (even mild) infection and inflammation are still likely to contribute to the burden of iron deficiency through persistent hepcidin-mediated impairment of iron absorption. In line with this principle, treatment of asymptomatic Plasmodium parasitaemia in Beninese women and Ivorian school-age children reduced mild inflammation, normalised hepcidin concentrations, with consequent increases in iron absorption $[225,226]$. Targeting infections, including malaria, and limiting inflammation are therefore likely very important not only as ends in themselves, but also as interventions for iron deficiency and adjuncts to effective oral iron-based interventions $[124,227]$. 


\section{Interventional Strategies: How and Should Iron Status Be "Improved"?}

\subsection{Risk-Benefit Assessments}

To summarise the discussion above, iron is critical for erythrocyte function and oxygen carriage, for brain development, in supporting immune function and, more generally, for numerous cellular processes. Although treating or preventing iron deficiency gives clear haematological benefits, it may concurrently increase risk of infections such as malaria, or those involving gastrointestinal and respiratory systems. Furthermore, delivery of iron to iron-replete children may be associated with reduced growth, and a risk of toxicity when iron is in excess. The issue of whether to administer iron at preventive or therapeutic doses in LMIC settings with limited sanitary and health infrastructure therefore presents a classic risk-benefit problem. Systematic risk-benefit assessments including data-based simulations have been initiated [228], while large, rigorous randomised-controlled trials such as BRISC (Benefits and Risks of Iron interventionS in Children) promise to provide further insight towards guidelines for iron administration in young children [149]. Nonetheless, it may be unlikely that a single recommendation will ever find global validity; approaches that are adapted to the geographical settings the population and ideally at the individual level, are likely needed.

Iron supplementation, industrial food fortification with iron, and point-of-use fortification with iron-containing multiple micronutrient powders are some of the approaches recommended to address the anaemia burden. These interventions generally increase ferritin and haemoglobin concentrations and reduce anaemia prevalence [229-233]. However, despite examples of efficacy of fortification programs and MNP/iron-supplement interventions [234,235], anaemia persists as a global health problem. The reasons are clearly multifactorial, including lack of political awareness and recognition, programmatic limitations, uncertainty of the accuracy of population iron status assessment [236], besides lack of efficacy in the presence of infection or inflammation, and because a large proportion of anaemia is not iron-responsive in high-risk populations [1,124]. Moreover, caution should be employed in administering high therapeutic iron doses in settings with high infection burden. In line with principles for tackling anaemia of chronic disease [237], underlying infections should be treated first. Indeed, this approach alone may increase erythropoiesis and haemoglobin levels even when iron itself is not administered $[124,225,238]$. Correspondingly, raised haemoglobin and iron status was found to correlate with a documented interruption in malarial transmission in highland Kenya [239].

\subsection{Optimisation of Iron Intervention Strategies}

Global recommendations for providing iron supplements have evolved from a view of indiscriminately providing iron at high dosage ( $2 \mathrm{mg} \mathrm{Fe} / \mathrm{Kg}$ body weight) to all infants and children if anaemia prevalence at 1 year of age in a population exceeds a given threshold (e.g., 40\%) [240]. Recent recommendations stress the multifactorial nature of nutritional anaemia [241], recognising that control programs need to include multiple components. Currently suggested supplementation regimens for children aged 6-23 months are lower in iron dosages (10-12 mg/day, 1.1-1.4 mg/Kg body weight [241]) than previously recommended. However, besides improving iron status, these doses have still been associated with detrimental effects [194,199]. Approaches which integrate knowledge of local risk factors with known biological, nutritional and epidemiological contributors to anaemia are needed, including addressing the underlying causes of ID and anaemia.

Given that detrimental effects of iron may be dose dependent, lower or intermittent dose schemes which have higher fractional bioavailability [105,242] may yield fewer side effects [243]. Lower dosing has been shown to be effective in elderly patients and for maintaining iron status in regular blood donors [244,245]. These approaches have been tested experimentally in high resource settings and may similarly improve the safety and tolerability of therapeutic iron doses in lower-resourced settings.

Preventing ID onset through dietary approaches is highly desirable, and probably safer than universal therapeutic supplementation because of the lower iron doses involved. Such approaches should be promoted, recognising that diets with high iron bioavailability may not always be 
economically feasible in many LMICs. Fortification approaches with low yet bioavailable iron levels may be a prudent and realistic approach, and some food-based examples pointing in this direction have been recently published [246,247]. Alternative novel approaches to enhance iron bioavailability from foods, such as the use of GOS described above, show promise, particularly when they also promote the growth of barrier function bacteria [158,212]. Increasing consumption of ascorbic acid-rich foods likewise improves iron status [248], suggesting that dietary approaches to improve iron status do not necessarily need to include increased dietary iron content.

\subsection{Maternal Iron-Based Interventions}

Furthermore, prevention of childhood ID provides an additional rationale for investing in measures aimed at preventing preterm births and increasing birthweight-including promotion of delayed cord clamping and maternal iron supplementation to prevent IDA during pregnancy. As discussed, longer gestation, higher birthweight and delayed cord clamping lead to reduced ID risk later in infancy [7]. An RCT of iron supplementation ( $60 \mathrm{mg}$ daily) during pregnancy in a malaria-endemic setting in Kenya found no increased risk of malaria infection when iron supplementation was given, but increased birthweight and length of gestation; effects were more notable in women with baseline ID [249]. Similar trends have also been reported across other trials of iron interventions during pregnancy [250]. Thus, ensuring positive birth outcomes provides a further strategy for enhancing childhood iron status, apparently without the same infection risks that are associated with early childhood therapeutic iron administration.

\section{Concluding Remarks}

In conclusion, defining iron status in settings with high infection and inflammation remains a challenge. Similarly, the biological understanding of optimal iron status for specified ideal functional outcomes (neurological, immunological, physical) remains limited despite the rapid and substantial advances in the understanding of iron biology experienced in the last two decades. Translating markers of positive functional outcomes to clinically and field-suitable definitions of iron status, balanced against known side-effects and risks of "improving" iron status in young children in such settings, presents a challenge to be tackled by the iron and health community in the coming years (Box 2). Programmatically, it will be desirable for iron interventions to be adapted to the local sanitary and dietary circumstances and to contain iron levels appropriately targeted to the prevailing iron status. While dietary and fortification approaches appear safer due to the lower iron levels involved, higher-dose therapeutic and supplemental approaches may be appropriate in well-defined settings of highly prevalent deficiency with developed/controlled sanitary conditions, and when they can be individually targeted. In areas affected by high burdens of infection/inflammation and iron deficiency, strategies aimed at improving iron status and anaemia prevalence without the necessity of administering interventional iron to children should be thoroughly evaluated. These include direct targeting of the causes of infection/inflammation, the use of enhancers of iron absorption, and through maternal iron interventions during pregnancy which appear safer and should benefit both maternal and infant outcomes. 
Box 2. Research questions and priorities.

Defining iron status in young children

- Priority: standardisation of assays for hepcidin and sTfR.

- Can point-of-care diagnostics for ferritin, sTfR and other analytes including hepcidin be developed, optimised and made cost-effective for use in LMIC settings?

- What is the optimal non-invasive definition of iron deficiency in infancy?

- Can the mechanistic understanding of iron homeostasis in infancy and early childhood be harnessed to define cut-offs of deficiency (e.g., haemoglobin, ferritin, hepcidin, erythrocyte markers such as MCV) in infancy and early childhood?

- Is hepcidin an optimal biomarker of iron absorption/utilisation in young children?

- Is it more important to classify iron deficiency, or the ability to safely and efficiently absorb iron?

Iron in key physiological processes of early childhood

- How is iron prioritised between the brain, bone marrow and other iron-demanding tissues during different degrees of iron depletion, and at different stages of infancy/early childhood?

- Is there a hierarchy of sensitivity of different cellular processes (e.g., mitochondrial function, nucleotide synthesis) to cellular iron deficiency?

- Are erythroferrone or other hepcidin-suppressive proteins involved in iron handling during the iron-demand of early childhood?

- What are the main drivers of low-grade inflammation in LMIC settings, and are these associated with raised hepcidin and impaired iron utilisation?

- Is there a beneficial effect of iron interventions on cognitive outcomes in infants in LMIC settings? Larger, high quality trials are likely required to establish this, and the potential of supplementing iron early in post-natal life should be considered.

- Does iron reduce child growth when given to iron-replete infants and, if so, by what mechanism?

- How does iron deficiency influence both innate and cell-mediated adaptive immune responses to infections and vaccines?

- Do iron-associated microbiome changes associate with changes in systemic phenotypes including immunity and brain development?

- Will higher resolution microbiome analysis of iron-associated changes yield useful information on specific iron-related effects?

Interventions aimed at adjusting iron status

- Can iron status be improved in LMIC settings in the absence of exogenous iron interventions? E.g., by treating infection/inflammation; by increasing bioavailability using absorption enhancers?

- Is there an optimal combination of dietary components (e.g., phytase, ascorbic acid, organic acids, muscle protein, GOS, other dietary fibres) that can enhance bioavailability while reducing iron dosage to facilitate supplementation without microbiome-associated adverse effects?

- Could strategies for delivering haem-iron therapeutically be broadly implemented?

- Is there a role for intravenous iron in addressing disturbed iron status in LMIC settings?

- Are antenatal iron interventions and perinatal interventions (e.g., delayed cord clamping) effective in improving neonatal outcomes, including iron status later in infancy, across varied LMIC settings?

- Can setting-specific recommendations be made for the likely relative risks and benefits of giving iron, and the likely optimal mode of delivering iron?

- Is there benefit from programmatically promoting dietary counselling relating to iron intake and bioavailability enhancement?

Author Contributions: Conceptualization, A.E.A.; Writing—original draft, A.E.A. and D.M.; Writing-review and editing, A.E.A. and D.M.

Funding: A.E.A. is funded through the core MRC grant to the MRC Human Immunology Unit, MRC Weatherall Institute of Molecular Medicine, University of Oxford (MC_UU_12010/3), and receives research funding from the IMPRINT network (Immunising Pregnant Women and Infants Network, part of GCRF Networks in Vaccines Research and Development co-funded by the MRC and BBSRC). D.M. receives funding from the Laboratory of Human Nutrition, ETH Zürich, Switzerland and from the Distance University of Applied Sciences, Regensdorf, Switzerland. 
Acknowledgments: The authors would like to thank the following people for helpful comments and discussion: Hal Drakesmith, Joe Frost, Alexandra Preston (MRC HIU, MRC WIMM, University of Oxford, Oxford, UK); Andrew Prentice (MRC Gambia Unit at the London School of Hygiene and Tropical Medicine, London, UK); and Gary Brittenham (Columbia University Medical Center, New York, NY, USA).

Conflicts of Interest: The authors declare no conflict of interest in relation to this manuscript.

\section{References}

1. WHO. The Global Prevalence of Anaemia in 2011; WHO: Geneva, Switzerland, 2015.

2. GBD-2016-Disease-and-Injury-Incidence-and-Prevalence-Collaborators. Global, regional, and national incidence, prevalence, and years lived with disability for 328 diseases and injuries for 195 countries, 1990-2016: A systematic analysis for the global burden of disease study 2016. Lancet 2017, 390, 1211-1259. [CrossRef]

3. Georgieff, M.K. Long-term brain and behavioral consequences of early iron deficiency. Nutr. Rev. 2011, 69 (Suppl. 1), S43-S48. [CrossRef]

4. Domellof, M.; Braegger, C.; Campoy, C.; Colomb, V.; Decsi, T.; Fewtrell, M.; Hojsak, I.; Mihatsch, W.; Molgaard, C.; Shamir, R.; et al. Iron requirements of infants and toddlers. J. Pediatr. Gastroenterol. Nutr. 2014, 58, 119-129. [CrossRef] [PubMed]

5. Institute-of-Medicine. Dietary Reference Intakes: Vitamin A, Vitamin K, Arsenic, Boron, Chromium, Copper, Iodine, Iron, Manganese, Molybdenum, Nickel, Silicon, Vanadium, and Zinc; Food and Nutrition Board, National Academy Press: Washington, DC, USA, 2001.

6. Muckenthaler, M.U.; Rivella, S.; Hentze, M.W.; Galy, B. A red carpet for iron metabolism. Cell 2017, 168, 344-361. [CrossRef]

7. Dewey, K.G.; Chaparro, C.M. Session 4: Mineral metabolism and body composition iron status of breast-fed infants. Proc. Nutr. Soc. 2007, 66, 412-422. [CrossRef]

8. Ziegler, E.E.; Nelson, S.E.; Jeter, J.M. Iron stores of breastfed infants during the first year of life. Nutrients 2014, 6, 2023-2034. [CrossRef] [PubMed]

9. Siimes, A.S.; Siimes, M.A. Changes in the concentration of ferritin in the serum during fetal life in singletons and twins. Early Hum. Dev. 1986, 13, 47-52. [CrossRef]

10. Harthoorn-Lasthuizen, E.J.; Lindemans, J.; Langenhuijsen, M.M. Does iron-deficient erythropoiesis in pregnancy influence fetal iron supply? Acta Obstet. Gynecol. Scand. 2001, 80, 392-396. [CrossRef]

11. Kilbride, J.; Baker, T.G.; Parapia, L.A.; Khoury, S.A.; Shuqaidef, S.W.; Jerwood, D. Anaemia during pregnancy as a risk factor for iron-deficiency anaemia in infancy: A case-control study in Jordan. Int. J. Epidemiol. 1999, 28, 461-468. [CrossRef] [PubMed]

12. Colomer, J.; Colomer, C.; Gutierrez, D.; Jubert, A.; Nolasco, A.; Donat, J.; Fernandez-Delgado, R.; Donat, F.; Alvarez-Dardet, C. Anaemia during pregnancy as a risk factor for infant iron deficiency: Report from the valencia infant anaemia cohort (viac) study. Paediatr. Perinat. Epidemiol. 1990, 4, 196-204. [CrossRef] [PubMed]

13. Yang, Z.; Lonnerdal, B.; Adu-Afarwuah, S.; Brown, K.H.; Chaparro, C.M.; Cohen, R.J.; Domellof, M.; Hernell, O.; Lartey, A.; Dewey, K.G. Prevalence and predictors of iron deficiency in fully breastfed infants at 6 mo of age: Comparison of data from 6 studies. Am. J. Clin. Nutr. 2009, 89, 1433-1440. [CrossRef] [PubMed]

14. Domellof, M.; Lonnerdal, B.; Dewey, K.G.; Cohen, R.J.; Rivera, L.L.; Hernell, O. Sex differences in iron status during infancy. Pediatrics 2002, 110, 545-552. [CrossRef] [PubMed]

15. Michaelsen, K.F.; Milman, N.; Samuelson, G. A longitudinal study of iron status in healthy danish infants: Effects of early iron status, growth velocity and dietary factors. Acta Paediatr. 1995, 84, 1035-1044. [CrossRef] [PubMed]

16. Thorsdottir, I.; Gunnarsson, B.S.; Atladottir, H.; Michaelsen, K.F.; Palsson, G. Iron status at 12 months of age-Effects of body size, growth and diet in a population with high birth weight. Eur. J. Clin. Nutr. 2003, 57, 505-513. [CrossRef]

17. Armitage, A.E.; Agbla, S.C.; Betts, M.; Sise, E.A.; Jallow, M.W.; Sambou, E.; Darboe, B.; Worwui, A.; Weinstock, G.M.; Antonio, M.; et al. Rapid growth is a dominant predictor of hepcidin suppression and declining ferritin in gambian infants. Haematologica 2019. [CrossRef] [PubMed] 
18. Helman, S.L.; Anderson, G.J.; Frazer, D.M. Dietary iron absorption during early postnatal life. Biometals 2019. [CrossRef] [PubMed]

19. Lonnerdal, B. Development of iron homeostasis in infants and young children. Am. J. Clin. Nutr. 2017, 106, 1575S-1580S. [CrossRef]

20. Friel, J.K. There is no iron in human milk. J. Pediatr. Gastroenterol. Nutr. 2017, 64, 339-340. [CrossRef]

21. Hallberg, L.; Hulten, L.; Gramatkovski, E. Iron absorption from the whole diet in men: How effective is the regulation of iron absorption? Am. J. Clin. Nutr. 1997, 66, 347-356. [CrossRef] [PubMed]

22. Hurrell, R.; Egli, I. Iron bioavailability and dietary reference values. Am. J.Clin. Nutr. 2010, 91, 1461S-1467S. [CrossRef]

23. Zlotkin, S.H.; Davidsson, L.; Lozoff, B. Balancing the benefits and risks of iron fortification in resource-constrained settings. J. Pediatr. 2015, 167, S26-S30. [CrossRef]

24. Lynch, S.; Pfeiffer, C.M.; Georgieff, M.K.; Brittenham, G.; Fairweather-Tait, S.; Hurrell, R.F.; McArdle, H.J.; Raiten, D.J. Biomarkers of nutrition for development (bond)-iron review. J. Nutr. 2018, 148, 1001S-1067S. [CrossRef]

25. Harvey, L.J.; Berti, C.; Casgrain, A.; Cetin, I.; Collings, R.; Gurinovic, M.; Hermoso, M.; Hooper, L.; Hurst, R.; Koletzko, B.; et al. Eurreca-estimating iron requirements for deriving dietary reference values. Crit. Rev. Food Sci. Nutr. 2013, 53, 1064-1076. [CrossRef]

26. Shet, A.S.; Zwarenstein, M.; Mascarenhas, M.; Risbud, A.; Atkins, S.; Klar, N.; Galanti, M.R. The karnataka anemia project 2-Design and evaluation of a community-based parental intervention to improve childhood anemia cure rates: Study protocol for a cluster randomized controlled trial. Trials 2015, 16, 599. [CrossRef]

27. Myers, S.S.; Zanobetti, A.; Kloog, I.; Huybers, P.; Leakey, A.D.; Bloom, A.J.; Carlisle, E.; Dietterich, L.H.; Fitzgerald, G.; Hasegawa, T.; et al. Increasing $\mathrm{CO}_{2}$ threatens human nutrition. Nature 2014, 510, 139-142. [CrossRef]

28. Smith, M.R.; Myers, S.S. Impact of anthropogenic $\mathrm{CO}_{2}$ emissions on global human nutrition. Nat. Clim. Chang. 2018, 8, 834-839. [CrossRef]

29. Golden, C.D.; Allison, E.H.; Cheung, W.W.; Dey, M.M.; Halpern, B.S.; McCauley, D.J.; Smith, M.; Vaitla, B.; Zeller, D.; Myers, S.S. Nutrition: Fall in fish catch threatens human health. Nature 2016, 534, 317-320. [CrossRef]

30. Loukas, A.; Hotez, P.J.; Diemert, D.; Yazdanbakhsh, M.; McCarthy, J.S.; Correa-Oliveira, R.; Croese, J.; Bethony, J.M. Hookworm infection. Nat. Rev. Dis. Primers 2016, 2, 16088. [CrossRef]

31. Stoltzfus, R.J.; Albonico, M.; Chwaya, H.M.; Savioli, L.; Tielsch, J.; Schulze, K.; Yip, R. Hemoquant determination of hookworm-related blood loss and its role in iron deficiency in African children. Am. J. Trop. Med. Hyg. 1996, 55, 399-404. [CrossRef]

32. McCance, R.A.; Widdowson, E.M. Absorption and excretion of iron. Lancet 1937, 230, 680-684. [CrossRef]

33. Hentze, M.W.; Muckenthaler, M.U.; Galy, B.; Camaschella, C. Two to tango: Regulation of mammalian iron metabolism. Cell 2010, 142, 24-38. [CrossRef]

34. Ganz, T. Systemic iron homeostasis. Physiol. Rev. 2013, 93, 1721-1741. [CrossRef]

35. Nemeth, E.; Tuttle, M.S.; Powelson, J.; Vaughn, M.B.; Donovan, A.; Ward, D.M.; Ganz, T.; Kaplan, J. Hepcidin regulates cellular iron efflux by binding to ferroportin and inducing its internalization. Science 2004, 306, 2090-2093. [CrossRef]

36. Aschemeyer, S.; Qiao, B.; Stefanova, D.; Valore, E.V.; Sek, A.C.; Ruwe, T.A.; Vieth, K.R.; Jung, G.; Casu, C.; Rivella, S.; et al. Structure-function analysis of ferroportin defines the binding site and an alternative mechanism of action of hepcidin. Blood 2018, 131, 899-910. [CrossRef]

37. Rivera, S.; Nemeth, E.; Gabayan, V.; Lopez, M.A.; Farshidi, D.; Ganz, T. Synthetic hepcidin causes rapid dose-dependent hypoferremia and is concentrated in ferroportin-containing organs. Blood 2005, 106, 2196-2199. [CrossRef]

38. Zhang, D.L.; Hughes, R.M.; Ollivierre-Wilson, H.; Ghosh, M.C.; Rouault, T.A. A ferroportin transcript that lacks an iron-responsive element enables duodenal and erythroid precursor cells to evade translational repression. Cell Metab. 2009, 9, 461-473. [CrossRef]

39. Zhang, D.L.; Senecal, T.; Ghosh, M.C.; Ollivierre-Wilson, H.; Tu, T.; Rouault, T.A. Hepcidin regulates ferroportin expression and intracellular iron homeostasis of erythroblasts. Blood 2011, 118, 2868-2877. [CrossRef] 
40. Zhang, D.L.; Ghosh, M.C.; Ollivierre, H.; Li, Y.; Rouault, T.A. Ferroportin deficiency in erythroid cells causes serum iron deficiency and promotes hemolysis due to oxidative stress. Blood 2018, 132, 2078-2087. [CrossRef]

41. Pantopoulos, K. Inherited disorders of iron overload. Front Nutr 2018, 5, 103. [CrossRef]

42. Brissot, P.; Pietrangelo, A.; Adams, P.C.; de Graaff, B.; McLaren, C.E.; Loreal, O. Haemochromatosis. Nat. Rev. Dis. Primers 2018, 4, 18016. [CrossRef]

43. Drakesmith, H.; Schimanski, L.M.; Ormerod, E.; Merryweather-Clarke, A.T.; Viprakasit, V.; Edwards, J.P.; Sweetland, E.; Bastin, J.M.; Cowley, D.; Chinthammitr, Y.; et al. Resistance to hepcidin is conferred by hemochromatosis-associated mutations of ferroportin. Blood 2005, 106, 1092-1097. [CrossRef]

44. Fernandes, A.; Preza, G.C.; Phung, Y.; De Domenico, I.; Kaplan, J.; Ganz, T.; Nemeth, E. The molecular basis of hepcidin-resistant hereditary hemochromatosis. Blood 2009, 114, 437-443. [CrossRef]

45. Pietrangelo, A. Ferroportin disease: Pathogenesis, diagnosis and treatment. Haematologica 2017, 102, $1972-1984$. [CrossRef]

46. Finberg, K.E.; Heeney, M.M.; Campagna, D.R.; Aydinok, Y.; Pearson, H.A.; Hartman, K.R.; Mayo, M.M.; Samuel, S.M.; Strouse, J.J.; Markianos, K.; et al. Mutations in tmprss6 cause iron-refractory iron deficiency anemia (irida). Nat. Genet. 2008, 40, 569-571. [CrossRef]

47. Wang, C.Y.; Babitt, J.L. Liver iron sensing and body iron homeostasis. Blood 2018. [CrossRef]

48. Canali, S.; Zumbrennen-Bullough, K.B.; Core, A.B.; Wang, C.Y.; Nairz, M.; Bouley, R.; Swirski, F.K.; Babitt, J.L. Endothelial cells produce bone morphogenetic protein 6 required for iron homeostasis in mice. Blood 2017, 129, 405-414. [CrossRef]

49. Koch, P.S.; Olsavszky, V.; Ulbrich, F.; Sticht, C.; Demory, A.; Leibing, T.; Henzler, T.; Meyer, M.; Zierow, J.; Schneider, S.; et al. Angiocrine bmp2 signaling in murine liver controls normal iron homeostasis. Blood 2017, 129, 415-419. [CrossRef]

50. Andriopoulos, B., Jr.; Corradini, E.; Xia, Y.; Faasse, S.A.; Chen, S.; Grgurevic, L.; Knutson, M.D.; Pietrangelo, A.; Vukicevic, S.; Lin, H.Y.; et al. Bmp6 is a key endogenous regulator of hepcidin expression and iron metabolism. Nat. Genet. 2009, 41, 482-487. [CrossRef]

51. Meynard, D.; Kautz, L.; Darnaud, V.; Canonne-Hergaux, F.; Coppin, H.; Roth, M.P. Lack of the bone morphogenetic protein bmp6 induces massive iron overload. Nat. Genet. 2009, 41, 478-481. [CrossRef]

52. Canali, S.; Wang, C.Y.; Zumbrennen-Bullough, K.B.; Bayer, A.; Babitt, J.L. Bone morphogenetic protein 2 controls iron homeostasis in mice independent of bmp6. Am. J. Hematol. 2017, 92, 1204-1213. [CrossRef]

53. Babitt, J.L.; Huang, F.W.; Wrighting, D.M.; Xia, Y.; Sidis, Y.; Samad, T.A.; Campagna, J.A.; Chung, R.T.; Schneyer, A.L.; Woolf, C.J.; et al. Bone morphogenetic protein signaling by hemojuvelin regulates hepcidin expression. Nat. Genet. 2006, 38, 531-539. [CrossRef]

54. Nemeth, E.; Valore, E.V.; Territo, M.; Schiller, G.; Lichtenstein, A.; Ganz, T. Hepcidin, a putative mediator of anemia of inflammation, is a type ii acute-phase protein. Blood 2003, 101, 2461-2463. [CrossRef]

55. Armitage, A.E.; Eddowes, L.A.; Gileadi, U.; Cole, S.; Spottiswoode, N.; Selvakumar, T.A.; Ho, L.P.; Townsend, A.R.; Drakesmith, H. Hepcidin regulation by innate immune and infectious stimuli. Blood 2011, 118, 4129-4139. [CrossRef]

56. Verga Falzacappa, M.V.; Vujic Spasic, M.; Kessler, R.; Stolte, J.; Hentze, M.W.; Muckenthaler, M.U. Stat3 mediates hepatic hepcidin expression and its inflammatory stimulation. Blood 2007, 109, 353-358. [CrossRef]

57. Wrighting, D.M.; Andrews, N.C. Interleukin-6 induces hepcidin expression through stat3. Blood 2006, 108, 3204-3209. [CrossRef]

58. Nemeth, E.; Rivera, S.; Gabayan, V.; Keller, C.; Taudorf, S.; Pedersen, B.K.; Ganz, T. Il-6 mediates hypoferremia of inflammation by inducing the synthesis of the iron regulatory hormone hepcidin. J. Clin. Investig. 2004, 113, 1271-1276. [CrossRef]

59. Smith, C.L.; Arvedson, T.L.; Cooke, K.S.; Dickmann, L.J.; Forte, C.; Li, H.; Merriam, K.L.; Perry, V.K.; Tran, L.; Rottman, J.B.; et al. Il-22 regulates iron availability in vivo through the induction of hepcidin. J. Immunol. 2013, 191, 1845-1855. [CrossRef]

60. Kanamori, Y.; Murakami, M.; Matsui, T.; Funaba, M. Jnk facilitates il-1beta-induced hepcidin transcription via junb activation. Cytokine 2018, 111, 295-302. [CrossRef]

61. Ryan, J.D.; Altamura, S.; Devitt, E.; Mullins, S.; Lawless, M.W.; Muckenthaler, M.U.; Crowe, J. Pegylated interferon-alpha induced hypoferremia is associated with the immediate response to treatment in hepatitis $\mathrm{C}$. Hepatology 2012, 56, 492-500. [CrossRef] 
62. Fillebeen, C.; Wilkinson, N.; Charlebois, E.; Katsarou, A.; Wagner, J.; Pantopoulos, K. Hepcidin-mediated hypoferremic response to acute inflammation requires a threshold of bmp6/hjv/smad signaling. Blood 2018, 132, 1829-1841. [CrossRef]

63. Besson-Fournier, C.; Gineste, A.; Latour, C.; Gourbeyre, O.; Meynard, D.; Martin, P.; Oswald, E.; Coppin, H.; Roth, M.P. Hepcidin upregulation by inflammation is independent of smad1/5/8 signaling by activin b. Blood 2017, 129, 533-536. [CrossRef]

64. Besson-Fournier, C.; Latour, C.; Kautz, L.; Bertrand, J.; Ganz, T.; Roth, M.P.; Coppin, H. Induction of activin b by inflammatory stimuli up-regulates expression of the iron-regulatory peptide hepcidin through smad1/5/8 signaling. Blood 2012, 120, 431-439. [CrossRef]

65. Canali, S.; Core, A.B.; Zumbrennen-Bullough, K.B.; Merkulova, M.; Wang, C.Y.; Schneyer, A.L.; Pietrangelo, A.; Babitt, J.L. Activin b induces noncanonical smad1/5/8 signaling via bmp type i receptors in hepatocytes: Evidence for a role in hepcidin induction by inflammation in male mice. Endocrinology 2016, 157, 1146-1162. [CrossRef]

66. Kanamori, Y.; Sugiyama, M.; Hashimoto, O.; Murakami, M.; Matsui, T.; Funaba, M. Regulation of hepcidin expression by inflammation-induced activin b. Sci. Rep. 2016, 6, 38702. [CrossRef] [PubMed]

67. Spottiswoode, N.; Armitage, A.E.; Williams, A.R.; Fyfe, A.J.; Biswas, S.; Hodgson, S.H.; Llewellyn, D.; Choudhary, P.; Draper, S.J.; Duffy, P.E.; et al. Role of activins in hepcidin regulation during malaria. Infect. Immun. 2017, 85, e0191-17. [CrossRef] [PubMed]

68. Armitage, A.E.; Lim, P.J.; Frost, J.N.; Pasricha, S.R.; Soilleux, E.J.; Evans, E.; Morovat, A.; Santos, A.; Diaz, R.; Biggs, D.; et al. Induced disruption of the iron-regulatory hormone hepcidin inhibits acute inflammatory hypoferraemia. J. Innate Immun. 2016, 8, 517-528. [CrossRef] [PubMed]

69. Arezes, J.; Jung, G.; Gabayan, V.; Valore, E.; Ruchala, P.; Gulig, P.A.; Ganz, T.; Nemeth, E.; Bulut, Y. Hepcidin-induced hypoferremia is a critical host defense mechanism against the siderophilic bacterium vibrio vulnificus. Cell Host Microbe 2015, 17, 47-57. [CrossRef] [PubMed]

70. Stefanova, D.; Raychev, A.; Arezes, J.; Ruchala, P.; Gabayan, V.; Skurnik, M.; Dillon, B.J.; Horwitz, M.A.; Ganz, T.; Bulut, Y.; et al. Endogenous hepcidin and its agonist mediate resistance to selected infections by clearing non-transferrin-bound iron. Blood 2017, 130, 245-257. [CrossRef]

71. Guida, C.; Altamura, S.; Klein, F.A.; Galy, B.; Boutros, M.; Ulmer, A.J.; Hentze, M.W.; Muckenthaler, M.U. A novel inflammatory pathway mediating rapid hepcidin-independent hypoferremia. Blood 2015, 125, 2265-2275. [CrossRef]

72. Weiss, G.; Ganz, T.; Goodnough, L.T. Anemia of inflammation. Blood 2019, 133, 40-50. [CrossRef] [PubMed]

73. Kautz, L.; Jung, G.; Valore, E.V.; Rivella, S.; Nemeth, E.; Ganz, T. Identification of erythroferrone as an erythroid regulator of iron metabolism. Nat. Genet. 2014, 46, 678-684. [CrossRef]

74. Arezes, J.; Foy, N.; McHugh, K.; Sawant, A.; Quinkert, D.; Terraube, V.; Brinth, A.; Tam, M.; LaVallie, E.R.; Taylor, S.; et al. Erythroferrone inhibits the induction of hepcidin by bmp6. Blood 2018, 132, 1473-1477. [CrossRef] [PubMed]

75. Pauk, M.; Grgurevic, L.; Brkljacic, J.; Kufner, V.; Bordukalo-Niksic, T.; Grabusic, K.; Razdorov, G.; Rogic, D.; Zuvic, M.; Oppermann, H.; et al. Exogenous bmp7 corrects plasma iron overload and bone loss in bmp6-/mice. Int. Orthop. 2015, 39, 161-172. [CrossRef] [PubMed]

76. Mirciov, C.S.G.; Wilkins, S.J.; Hung, G.C.C.; Helman, S.L.; Anderson, G.J.; Frazer, D.M. Circulating iron levels influence the regulation of hepcidin following stimulated erythropoiesis. Haematologica 2018, 103, 1616-1626. [CrossRef] [PubMed]

77. Artuso, I.; Pettinato, M.; Nai, A.; Pagani, A.; Sardo, U.; Billore, B.; Lidonnici, M.R.; Bennett, C.; Mandelli, G.; Pasricha, S.R.; et al. Transient decrease of serum iron after acute erythropoietin treatment contributes to hepcidin inhibition by erfe in mice. Haematologica 2019, 104, e87-e90. [CrossRef]

78. Sonnweber, T.; Nachbaur, D.; Schroll, A.; Nairz, M.; Seifert, M.; Demetz, E.; Haschka, D.; Mitterstiller, A.M.; Kleinsasser, A.; Burtscher, M.; et al. Hypoxia induced downregulation of hepcidin is mediated by platelet derived growth factor bb. Gut 2014, 63, 1951-1959. [CrossRef]

79. Schwartz, A.J.; Das, N.K.; Ramakrishnan, S.K.; Jain, C.; Jurkovic, M.T.; Wu, J.; Nemeth, E.; Lakhal-Littleton, S.; Colacino, J.A.; Shah, Y.M. Hepatic hepcidin/intestinal hif-2alpha axis maintains iron absorption during iron deficiency and overload. J. Clin. Investig. 2019, 129, 336-348. [CrossRef] 
80. Atkinson, S.H.; Uyoga, S.M.; Armitage, A.E.; Khandwala, S.; Mugyenyi, C.K.; Bejon, P.; Marsh, K.; Beeson, J.G.; Prentice, A.M.; Drakesmith, H.; et al. Malaria and age variably but critically control hepcidin throughout childhood in Kenya. EBioMedicine 2015, 2, 1478-1486. [CrossRef]

81. Domellof, M.; Lonnerdal, B.; Abrams, S.A.; Hernell, O. Iron absorption in breast-fed infants: Effects of age, iron status, iron supplements, and complementary foods. Am. J. Clin. Nutr. 2002, 76, 198-204. [CrossRef]

82. Sturgeon, P. Studies of iron requirements in infante and children. I. Normal values for serum iron, copper and free erythrocyte protoporphyrin. Pediatrics 1954, 13, 107-125.

83. Szabo, M.; Vasarhelyi, B.; Balla, G.; Szabo, T.; Machay, T.; Tulassay, T. Acute postnatal increase of extracellular antioxidant defence of neonates: The role of iron metabolism. Acta Paediatr. 2001, 90, 1167-1170. [CrossRef]

84. Ritchie, R.F.; Palomaki, G.E.; Neveux, L.M.; Navolotskaia, O.; Ledue, T.B.; Craig, W.Y. Reference distributions for serum iron and transferrin saturation: A comparison of a large cohort to the world's literature. J. Clin. Lab. Anal. 2002, 16, 246-252. [CrossRef]

85. Mupfudze, T.G.; Stoltzfus, R.J.; Rukobo, S.; Moulton, L.H.; Humphrey, J.H.; Prendergast, A.J.; Team, S.P. Hepcidin decreases over the first year of life in healthy African infants. Br. J. Haematol. 2014, 164, 150-153. [CrossRef]

86. Jaeggi, T.; Moretti, D.; Kvalsvig, J.; Holding, P.A.; Tjalsma, H.; Kortman, G.A.; Joosten, I.; Mwangi, A.; Zimmermann, M.B. Iron status and systemic inflammation, but not gut inflammation, strongly predict gender-specific concentrations of serum hepcidin in infants in rural Kenya. PLoS ONE 2013, 8, e57513. [CrossRef]

87. Atkinson, S.H.; Armitage, A.E.; Khandwala, S.; Mwangi, T.W.; Uyoga, S.; Bejon, P.A.; Williams, T.N.; Prentice, A.M.; Drakesmith, H. Combinatorial effects of malaria season, iron deficiency, and inflammation determine plasma hepcidin concentration in African children. Blood 2014, 123, 3221-3229. [CrossRef]

88. Berglund, S.; Lonnerdal, B.; Westrup, B.; Domellof, M. Effects of iron supplementation on serum hepcidin and serum erythropoietin in low-birth-weight infants. Am. J. Clin. Nutr. 2011, 94, 1553-1561. [CrossRef]

89. Aranda, N.; Bedmar, C.; Arija, V.; Jardi, C.; Jimenez-Feijoo, R.; Ferre, N.; Tous, M. Defensas Study Investigators. Serum hepcidin levels, iron status, and hfe gene alterations during the first year of life in healthy Spanish infants. Ann. Hematol. 2018, 97, 1071-1080. [CrossRef]

90. Prentice, A.M.; Bah, A.; Jallow, M.W.; Jallow, A.T.; Sanyang, S.; Sise, E.A.; Ceesay, K.; Danso, E.; Armitage, A.E.; Pasricha, S.R.; et al. Respiratory infections drive hepcidin-mediated blockade of iron absorption leading to iron deficiency anemia in African children. Sci. Adv. 2019, 5, eaav9020. [CrossRef]

91. Daru, J.; Colman, K.; Stanworth, S.J.; De La Salle, B.; Wood, E.M.; Pasricha, S.R. Serum ferritin as an indicator of iron status: What do we need to know? Am. J. Clin. Nutr. 2017, 106, 1634S-1639S. [CrossRef]

92. Cook, J.D. Diagnosis and management of iron-deficiency anaemia. Best Pract. Res. Clin. Haematol. 2005, 18, 319-332. [CrossRef]

93. Namaste, S.M.; Aaron, G.J.; Varadhan, R.; Peerson, J.M.; Suchdev, P.S.; Group, B.W. Methodologic approach for the biomarkers reflecting inflammation and nutritional determinants of anemia (brinda) project. Am. J. Clin. Nutr. 2017, 106, 333S-347S.

94. Abdullah, K.; Birken, C.S.; Maguire, J.L.; Fehlings, D.; Hanley, A.J.; Thorpe, K.E.; Parkin, P.C. Re-evaluation of serum ferritin cut-off values for the diagnosis of iron deficiency in children aged 12-36 months. J. Pediatr. 2017, 188, 287-290. [CrossRef]

95. Powers, J.M.; Buchanan, G.R. Potential for improved screening, diagnosis, and treatment for iron deficiency and iron deficiency anemia in young children. J. Pediatr. 2017, 188, 8-10. [CrossRef]

96. Pfeiffer, C.M.; Looker, A.C. Laboratory methodologies for indicators of iron status: Strengths, limitations, and analytical challenges. Am. J. Clin. Nutr. 2017, 106, 1606S-1614S. [CrossRef]

97. Srinivasan, B.; Finkelstein, J.L.; O’Dell, D.; Erickson, D.; Mehta, S. Rapid diagnostics for point-of-care quantification of soluble transferrin receptor. EBioMedicine 2019. [CrossRef]

98. Srinivasan, B.; O’Dell, D.; Finkelstein, J.L.; Lee, S.; Erickson, D.; Mehta, S. Ironphone: Mobile device-coupled point-of-care diagnostics for assessment of iron status by quantification of serum ferritin. Biosens. Bioelectron. 2018, 99, 115-121. [CrossRef]

99. Mei, Z.; Flores-Ayala, R.C.; Grummer-Strawn, L.M.; Brittenham, G.M. Is erythrocyte protoporphyrin a better single screening test for iron deficiency compared to hemoglobin or mean cell volume in children and women? Nutrients 2017, 9, 557. [CrossRef] 
100. Cusick, S.E.; Georgieff, M.K.; Rao, R. Approaches for reducing the risk of early-life iron deficiency-induced brain dysfunction in children. Nutrients 2018, 10, 227. [CrossRef]

101. Brugnara, C.; Zurakowski, D.; DiCanzio, J.; Boyd, T.; Platt, O. Reticulocyte hemoglobin content to diagnose iron deficiency in children. JAMA 1999, 281, 2225-2230. [CrossRef]

102. Ratcliffe, L.E.; Thomas, W.; Glen, J.; Padhi, S.; Pordes, B.A.; Wonderling, D.; Connell, R.; Stephens, S.; Mikhail, A.I.; Fogarty, D.G.; et al. Diagnosis and management of iron deficiency in ckd: A summary of the nice guideline recommendations and their rationale. Am. J. Kidney Dis. 2016, 67, 548-558. [CrossRef]

103. Pasricha, S.R.; Atkinson, S.H.; Armitage, A.E.; Khandwala, S.; Veenemans, J.; Cox, S.E.; Eddowes, L.A.; Hayes, T.; Doherty, C.P.; Demir, A.Y.; et al. Expression of the iron hormone hepcidin distinguishes different types of anemia in African children. Sci. Transl. Med. 2014, 6, 235re3. [CrossRef]

104. Jonker, F.A.; Boele van Hensbroek, M.; Leenstra, T.; Vet, R.J.; Brabin, B.J.; Maseko, N.; Gushu, M.B.; Emana, M.; Kraaijenhagen, R.; Tjalsma, H.; et al. Conventional and novel peripheral blood iron markers compared against bone marrow in Malawian children. J. Clin. Pathol. 2014, 67,717-723. [CrossRef]

105. Moretti, D.; Goede, J.S.; Zeder, C.; Jiskra, M.; Chatzinakou, V.; Tjalsma, H.; Melse-Boonstra, A.; Brittenham, G.; Swinkels, D.W.; Zimmermann, M.B. Oral iron supplements increase hepcidin and decrease iron absorption from daily or twice-daily doses in iron-depleted young women. Blood 2015, 126, 1981-1989. [CrossRef]

106. Prentice, A.M.; Doherty, C.P.; Abrams, S.A.; Cox, S.E.; Atkinson, S.H.; Verhoef, H.; Armitage, A.E.; Drakesmith, H. Hepcidin is the major predictor of erythrocyte iron incorporation in anemic African children. Blood 2012, 119, 1922-1928. [CrossRef]

107. Schaap, C.C.; Hendriks, J.C.; Kortman, G.A.; Klaver, S.M.; Kroot, J.J.; Laarakkers, C.M.; Wiegerinck, E.T.; Tjalsma, H.; Janssen, M.C.; Swinkels, D.W. Diurnal rhythm rather than dietary iron mediates daily hepcidin variations. Clin. Chem. 2013, 59, 527-535. [CrossRef]

108. van der Vorm, L.N.; Hendriks, J.C.; Laarakkers, C.M.; Klaver, S.; Armitage, A.E.; Bamberg, A.; Geurts-Moespot, A.J.; Girelli, D.; Herkert, M.; Itkonen, O.; et al. Toward worldwide hepcidin assay harmonization: Identification of a commutable secondary reference material. Clin. Chem. 2016, 62, 993-1001. [CrossRef]

109. Diepeveen, L.E.; Laarakkers, C.M.M.; Martos, G.; Pawlak, M.E.; Uguz, F.F.; Verberne, K.; van Swelm, R.P.L.; Klaver, S.; de Haan, A.F.J.; Pitts, K.R.; et al. Provisional standardization of hepcidin assays: Creating a traceability chain with a primary reference material, candidate reference method and a commutable secondary reference material. Clin. Chem. Lab. Med. 2018. [CrossRef]

110. Girelli, D.; Nemeth, E.; Swinkels, D.W. Hepcidin in the diagnosis of iron disorders. Blood 2016, 127, 2809-2813. [CrossRef]

111. Aguilar, R.; Moraleda, C.; Quinto, L.; Renom, M.; Mussacate, L.; Macete, E.; Aguilar, J.L.; Alonso, P.L.; Menendez, C. Challenges in the diagnosis of iron deficiency in children exposed to high prevalence of infections. PLoS ONE 2012, 7, e50584. [CrossRef] [PubMed]

112. Kling, P.J.; Schmidt, R.L.; Roberts, R.A.; Widness, J.A. Serum erythropoietin levels during infancy: Associations with erythropoiesis. J. Pediatr. 1996, 128, 791-796. [CrossRef]

113. Siimes, M.A.; Addiego, J.E., Jr.; Dallman, P.R. Ferritin in serum: Diagnosis of iron deficiency and iron overload in infants and children. Blood 1974, 43, 581-590.

114. Ganz, T.; Nemeth, E. Iron homeostasis in host defence and inflammation. Nat. Rev. Immunol. 2015, 15, 500-510. [CrossRef]

115. Bullock, G.C.; Delehanty, L.L.; Talbot, A.L.; Gonias, S.L.; Tong, W.H.; Rouault, T.A.; Dewar, B.; Macdonald, J.M.; Chruma, J.J.; Goldfarb, A.N. Iron control of erythroid development by a novel aconitase-associated regulatory pathway. Blood 2010, 116, 97-108. [CrossRef]

116. Rishi, G.; Secondes, E.S.; Wallace, D.F.; Subramaniam, V.N. Hematopoietic deletion of transferrin receptor 2 in mice leads to a block in erythroid differentiation during iron-deficient anemia. Am. J. Hematol. 2016, 91, 812-818. [CrossRef]

117. Forejtnikova, H.; Vieillevoye, M.; Zermati, Y.; Lambert, M.; Pellegrino, R.M.; Guihard, S.; Gaudry, M.; Camaschella, C.; Lacombe, C.; Roetto, A.; et al. Transferrin receptor 2 is a component of the erythropoietin receptor complex and is required for efficient erythropoiesis. Blood 2010, 116, 5357-5367. [CrossRef]

118. Khalil, S.; Delehanty, L.; Grado, S.; Holy, M.; White, Z., 3rd; Freeman, K.; Kurita, R.; Nakamura, Y.; Bullock, G.; Goldfarb, A. Iron modulation of erythropoiesis is associated with scribble-mediated control of the erythropoietin receptor. J. Exp. Med. 2018, 215, 661-679. [CrossRef] 
119. Nai, A.; Lidonnici, M.R.; Rausa, M.; Mandelli, G.; Pagani, A.; Silvestri, L.; Ferrari, G.; Camaschella, C. The second transferrin receptor regulates red blood cell production in mice. Blood 2015, 125, 1170-1179. [CrossRef]

120. Papanikolaou, G.; Pantopoulos, K. Systemic iron homeostasis and erythropoiesis. IUBMB Life 2017, 69, 399-413. [CrossRef]

121. WHO. Haemoglobin Concentrations for the Diagnosis of Anaemia and Assessment of Severity; WHO: Geneva, Switzerland, 2011.

122. Pasricha, S.R.; Colman, K.; Centeno-Tablante, E.; Garcia-Casal, M.N.; Pena-Rosas, J.P. Revisiting who haemoglobin thresholds to define anaemia in clinical medicine and public health. Lancet Haematol. 2018, 5, e60-e62. [CrossRef]

123. Stevens, G.A.; Finucane, M.M.; De-Regil, L.M.; Paciorek, C.J.; Flaxman, S.R.; Branca, F.; Pena-Rosas, J.P.; Bhutta, Z.A.; Ezzati, M.; Nutrition Impact Model Study Group. Global, regional, and national trends in haemoglobin concentration and prevalence of total and severe anaemia in children and pregnant and non-pregnant women for 1995-2011: A systematic analysis of population-representative data. Lancet Glob. Health 2013, 1, e16-e25.

124. Pasricha, S.R.; Armitage, A.E.; Prentice, A.M.; Drakesmith, H. Reducing anaemia in low income countries: Control of infection is essential. BMJ 2018, 362, k3165. [CrossRef]

125. Muriuki, J.M.; Mentzer, A.J.; Kimita, W.; Ndungu, F.M.; Macharia, A.W.; Webb, E.L.; Lule, S.A.; Morovat, A.; Hill, A.V.S.; Bejon, P.; et al. Iron status and associated malaria risk among African children. Clin. Infect. Dis. 2018. [CrossRef]

126. Cusick, S.E.; Georgieff, M.K. The role of nutrition in brain development: The golden opportunity of the "first 1000 days". J. Pediatr. 2016, 175, 16-21. [CrossRef]

127. Grantham-McGregor, S.; Ani, C. A review of studies on the effect of iron deficiency on cognitive development in children. J. Nutr. 2001, 131, 649S-668S. [CrossRef]

128. Lozoff, B. Iron deficiency and child development. Food Nutr. Bull. 2007, 28, S560-S571. [CrossRef]

129. Horton, S.; Ross, J. The economics of iron deficiency. Food Policy 2003, 28, 51-75. [CrossRef]

130. Fretham, S.J.; Carlson, E.S.; Wobken, J.; Tran, P.V.; Petryk, A.; Georgieff, M.K. Temporal manipulation of transferrin-receptor-1-dependent iron uptake identifies a sensitive period in mouse hippocampal neurodevelopment. Hippocampus 2012, 22, 1691-1702. [CrossRef]

131. Siddappa, A.J.; Rao, R.B.; Wobken, J.D.; Leibold, E.A.; Connor, J.R.; Georgieff, M.K. Developmental changes in the expression of iron regulatory proteins and iron transport proteins in the perinatal rat brain. J. Neurosci. Res. 2002, 68, 761-775. [CrossRef]

132. Georgieff, M.K.; Brunette, K.E.; Tran, P.V. Early life nutrition and neural plasticity. Dev. Psychopathol. 2015, 27, 411-423. [CrossRef]

133. Guiang, S.F., 3rd; Georgieff, M.K.; Lambert, D.J.; Schmidt, R.L.; Widness, J.A. Intravenous iron supplementation effect on tissue iron and hemoproteins in chronically phlebotomized lambs. Am. J. Physiol. 1997, 273, R2124-R2131. [CrossRef]

134. Petry, C.D.; Eaton, M.A.; Wobken, J.D.; Mills, M.M.; Johnson, D.E.; Georgieff, M.K. Iron deficiency of liver, heart, and brain in newborn infants of diabetic mothers. J. Pediatr. 1992, 121, 109-114. [CrossRef]

135. Georgieff, M.K.; Schmidt, R.L.; Mills, M.M.; Radmer, W.J.; Widness, J.A. Fetal iron and cytochrome c status after intrauterine hypoxemia and erythropoietin administration. Am. J. Physiol. 1992, 262, R485-R491. [CrossRef]

136. Dallman, P.R.; Siimes, M.A.; Manies, E.C. Brain iron: Persistent deficiency following short-term iron deprivation in the young rat. Br. J. Haematol. 1975, 31, 209-215. [CrossRef]

137. Rao, R.; Tkac, I.; Townsend, E.L.; Gruetter, R.; Georgieff, M.K. Perinatal iron deficiency alters the neurochemical profile of the developing rat hippocampus. J. Nutr. 2003, 133, 3215-3221. [CrossRef]

138. Lozoff, B.; Georgieff, M.K. Iron deficiency and brain development. Semin. Pediatr. Neurol. 2006, 13, $158-165$. [CrossRef]

139. Zimmermann, M.B. The influence of iron status on iodine utilization and thyroid function. Annu. Rev. Nutr. 2006, 26, 367-389. [CrossRef] 
140. Bouhouch, R.R.; El-Fadeli, S.; Andersson, M.; Aboussad, A.; Chabaa, L.; Zeder, C.; Kippler, M.; Baumgartner, J.; Sedki, A.; Zimmermann, M.B. Effects of wheat-flour biscuits fortified with iron and edta, alone and in combination, on blood lead concentration, iron status, and cognition in children: A double-blind randomized controlled trial. Am. J. Clin. Nutr. 2016, 104, 1318-1326. [CrossRef]

141. Zimmermann, M.B.; Muthayya, S.; Moretti, D.; Kurpad, A.; Hurrell, R.F. Iron fortification reduces blood lead levels in children in bangalore, india. Pediatrics 2006, 117, 2014-2021. [CrossRef]

142. Barks, A.; Fretham, S.J.B.; Georgieff, M.K.; Tran, P.V. Early-life neuronal-specific iron deficiency alters the adult mouse hippocampal transcriptome. J. Nutr. 2018, 148, 1521-1528. [CrossRef]

143. Murray-Kolb, L.E. Examining consequence of brain iron deficiency in the absence of anemia. J. Nutr. 2018, 148, 1511-1512. [CrossRef]

144. Pasricha, S.R.; Hayes, E.; Kalumba, K.; Biggs, B.A. Effect of daily iron supplementation on health in children aged 4-23 months: A systematic review and meta-analysis of randomised controlled trials. Lancet Glob. Health 2013, 1, e77-e86. [CrossRef]

145. Bryan, J.; Osendarp, S.; Hughes, D.; Calvaresi, E.; Baghurst, K.; van Klinken, J.W. Nutrients for cognitive development in school-aged children. Nutr. Rev. 2004, 62, 295-306. [CrossRef]

146. Larson, L.M.; Phiri, K.S.; Pasricha, S.R. Iron and cognitive development: What is the evidence? Ann. Nutr. Metab. 2017, 71 (Suppl. 3), 25-38. [CrossRef]

147. Stoltzfus, R.J.; Kvalsvig, J.D.; Chwaya, H.M.; Montresor, A.; Albonico, M.; Tielsch, J.M.; Savioli, L.; Pollitt, E. Effects of iron supplementation and anthelmintic treatment on motor and language development of preschool children in zanzibar: Double blind, placebo controlled study. BMJ 2001, 323, 1389-1393. [CrossRef]

148. Lozoff, B.; Castillo, M.; Clark, K.M.; Smith, J.B. Iron-fortified vs. low-iron infant formula: Developmental outcome at 10 years. Arch. Pediatr. Adolesc. Med. 2012, 166, 208-215. [CrossRef]

149. Hasan, M.I.; Hossain, S.J.; Braat, S.; Dibley, M.J.; Fisher, J.; Grantham-McGregor, S.; Tofail, F.; Simpson, J.A.; Arifeen, S.E.; Hamadani, J.; et al. Benefits and risks of iron interventions in children (brisc): Protocol for a three-arm parallel-group randomised controlled field trial in bangladesh. BMJ Open 2017, 7, e018325. [CrossRef]

150. Angeles, I.T.; Schultink, W.J.; Matulessi, P.; Gross, R.; Sastroamidjojo, S. Decreased rate of stunting among anemic indonesian preschool children through iron supplementation. Am. J. Clin. Nutr. 1993, 58, 339-342. [CrossRef]

151. Majumdar, I.; Paul, P.; Talib, V.H.; Ranga, S. The effect of iron therapy on the growth of iron-replete and iron-deplete children. J. Trop. Pediatr. 2003, 49, 84-88. [CrossRef]

152. Samuel, A.; Brouwer, I.D.; Feskens, E.J.M.; Adish, A.; Kebede, A.; De-Regil, L.M.; Osendarp, S.J.M. Effectiveness of a program intervention with reduced-iron multiple micronutrient powders on iron status, morbidity and growth in young children in Ethiopia. Nutrients 2018, 10, 1508. [CrossRef]

153. Iannotti, L.L.; Tielsch, J.M.; Black, M.M.; Black, R.E. Iron supplementation in early childhood: Health benefits and risks. Am. J. Clin. Nutr. 2006, 84, 1261-1276. [CrossRef]

154. Dewey, K.G.; Domellof, M.; Cohen, R.J.; Landa Rivera, L.; Hernell, O.; Lonnerdal, B. Iron supplementation affects growth and morbidity of breast-fed infants: Results of a randomized trial in sweden and honduras. J. Nutr. 2002, 132, 3249-3255. [CrossRef]

155. Idjradinata, P.; Watkins, W.E.; Pollitt, E. Adverse effect of iron supplementation on weight gain of iron-replete young children. Lancet 1994, 343, 1252-1254. [CrossRef]

156. Brittenham, G.M.; Andersson, M.; Egli, I.; Foman, J.T.; Zeder, C.; Westerman, M.E.; Hurrell, R.F. Circulating non-transferrin-bound iron after oral administration of supplemental and fortification doses of iron to healthy women: A randomized study. Am. J. Clin. Nutr. 2014, 100, 813-820. [CrossRef]

157. Jaeggi, T.; Kortman, G.A.; Moretti, D.; Chassard, C.; Holding, P.; Dostal, A.; Boekhorst, J.; Timmerman, H.M.; Swinkels, D.W.; Tjalsma, H.; et al. Iron fortification adversely affects the gut microbiome, increases pathogen abundance and induces intestinal inflammation in Kenyan infants. Gut 2015, 64, 731-742. [CrossRef]

158. Paganini, D.; Uyoga, M.A.; Kortman, G.A.M.; Cercamondi, C.I.; Moretti, D.; Barth-Jaeggi, T.; Schwab, C.; Boekhorst, J.; Timmerman, H.M.; Lacroix, C.; et al. Prebiotic galacto-oligosaccharides mitigate the adverse effects of iron fortification on the gut microbiome: A randomised controlled study in Kenyan infants. Gut 2017, 66, 1956-1967. [CrossRef]

159. Lonnerdal, B. Excess iron intake as a factor in growth, infections, and development of infants and young children. Am. J. Clin. Nutr. 2017, 106, 1681S-1687S. [CrossRef] 
160. GBD-Collaborators. Global, regional, national, and selected subnational levels of stillbirths, neonatal, infant, and under-5 mortality, 1980-2015: A systematic analysis for the global burden of disease study 2015. Lancet 2016, 388, 1725-1774. [CrossRef]

161. Grassly, N.C.; Kang, G.; Kampmann, B. Biological challenges to effective vaccines in the developing world. Philos. Trans. R. Soc. Lond. B Biol. Sci. 2015, 370, 20140138. [CrossRef]

162. Kollmann, T.R. Variation between populations in the innate immune response to vaccine adjuvants. Front. Immunol. 2013, 4, 81. [CrossRef]

163. Dowling, D.J.; Levy, O. Ontogeny of early life immunity. Trends Immunol. 2014, 35, 299-310. [CrossRef]

164. Kollmann, T.R.; Kampmann, B.; Mazmanian, S.K.; Marchant, A.; Levy, O. Protecting the newborn and young infant from infectious diseases: Lessons from immune ontogeny. Immunity 2017, 46, 350-363. [CrossRef]

165. Olin, A.; Henckel, E.; Chen, Y.; Lakshmikanth, T.; Pou, C.; Mikes, J.; Gustafsson, A.; Bernhardsson, A.K.; Zhang, C.; Bohlin, K.; et al. Stereotypic immune system development in newborn children. Cell 2018, 174, 1277-1292.e1214. [CrossRef]

166. Brodin, P.; Jojic, V.; Gao, T.; Bhattacharya, S.; Angel, C.J.; Furman, D.; Shen-Orr, S.; Dekker, C.L.; Swan, G.E.; Butte, A.J.; et al. Variation in the human immune system is largely driven by non-heritable influences. Cell 2015, 160, 37-47. [CrossRef]

167. Carr, E.J.; Dooley, J.; Garcia-Perez, J.E.; Lagou, V.; Lee, J.C.; Wouters, C.; Meyts, I.; Goris, A.; Boeckxstaens, G.; Linterman, M.A.; et al. The cellular composition of the human immune system is shaped by age and cohabitation. Nat. Immunol. 2016, 17, 461-468. [CrossRef]

168. Ned, R.M.; Swat, W.; Andrews, N.C. Transferrin receptor 1 is differentially required in lymphocyte development. Blood 2003, 102, 3711-3718. [CrossRef]

169. Arrieta, M.C.; Stiemsma, L.T.; Amenyogbe, N.; Brown, E.M.; Finlay, B. The intestinal microbiome in early life: Health and disease. Front. Immunol. 2014, 5, 427. [CrossRef]

170. Belkaid, Y.; Harrison, O.J. Homeostatic immunity and the microbiota. Immunity 2017, 46, 562-576. [CrossRef]

171. Martins, A.C.; Almeida, J.I.; Lima, I.S.; Kapitao, A.S.; Gozzelino, R. Iron metabolism and the inflammatory response. IUBMB Life 2017, 69, 442-450. [CrossRef]

172. Saha, P.; Yeoh, B.S.; Olvera, R.A.; Xiao, X.; Singh, V.; Awasthi, D.; Subramanian, B.C.; Chen, Q.; Dikshit, M.; Wang, Y.; et al. Bacterial siderophores hijack neutrophil functions. J. Immunol. 2017, 198, 4293-4303. [CrossRef]

173. Soares, M.P.; Weiss, G. The iron age of host-microbe interactions. EMBO Rep. 2015, 16, 1482-1500. [CrossRef]

174. Nairz, M.; Haschka, D.; Demetz, E.; Weiss, G. Iron at the interface of immunity and infection. Front. Pharmacol. 2014, 5, 152. [CrossRef]

175. Pearce, E.L.; Poffenberger, M.C.; Chang, C.H.; Jones, R.G. Fueling immunity: Insights into metabolism and lymphocyte function. Science 2013, 342, 1242454. [CrossRef]

176. Sinclair, L.V.; Rolf, J.; Emslie, E.; Shi, Y.B.; Taylor, P.M.; Cantrell, D.A. Control of amino-acid transport by antigen receptors coordinates the metabolic reprogramming essential for $t$ cell differentiation. Nat. Immunol. 2013, 14, 500-508. [CrossRef]

177. Savy, M.; Edmond, K.; Fine, P.E.; Hall, A.; Hennig, B.J.; Moore, S.E.; Mulholland, K.; Schaible, U.; Prentice, A.M. Landscape analysis of interactions between nutrition and vaccine responses in children. J. Nutr. 2009, 139, 2154S-2218S. [CrossRef]

178. Seligman, P.A.; Kovar, J.; Gelfand, E.W. Lymphocyte proliferation is controlled by both iron availability and regulation of iron uptake pathways. Pathobiology 1992, 60, 19-26. [CrossRef]

179. Neckers, L.M.; Cossman, J. Transferrin receptor induction in mitogen-stimulated human tymphocytes is required for DNA synthesis and cell division and is regulated by interleukin 2. Proc. Natl. Acad. Sci. USA 1983, 80, 3494-3498. [CrossRef]

180. Ahluwalia, N.; Sun, J.; Krause, D.; Mastro, A.; Handte, G. Immune function is impaired in iron-deficient, homebound, older women. Am. J. Clin. Nutr. 2004, 79, 516-521. [CrossRef]

181. Thibault, H.; Galan, P.; Selz, F.; Preziosi, P.; Olivier, C.; Badoual, J.; Hercberg, S. The immune response in iron-deficient young children: Effect of iron supplementation on cell-mediated immunity. Eur. J. Pediatr. 1993, 152, 120-124. [CrossRef]

182. Galan, P.; Thibault, H.; Preziosi, P.; Hercberg, S. Interleukin 2 production in iron-deficient children. Biol. Trace Elem. Res. 1992, 32, 421-426. [CrossRef] 
183. Berger, J.; Dyck, J.L.; Galan, P.; Aplogan, A.; Schneider, D.; Traissac, P.; Hercberg, S. Effect of daily iron supplementation on iron status, cell-mediated immunity, and incidence of infections in 6-36 month old togolese children. Eur. J. Clin. Nutr. 2000, 54, 29-35. [CrossRef]

184. Bonaccorsi-Riani, E.; Danger, R.; Lozano, J.J.; Martinez-Picola, M.; Kodela, E.; Mas-Malavila, R.; Bruguera, M.; Collins, H.L.; Hider, R.C.; Martinez-Llordella, M.; et al. Iron deficiency impairs intra-hepatic lymphocyte mediated immune response. PLOS ONE 2015, 10, e0136106. [CrossRef]

185. Wang, Z.; Yin, W.; Zhu, L.; Li, J.; Yao, Y.; Chen, F.; Sun, M.; Zhang, J.; Shen, N.; Song, Y.; et al. Iron drives t helper cell pathogenicity by promoting rna-binding protein pcbp1-mediated proinflammatory cytokine production. Immunity 2018, 49, 80-92.e7. [CrossRef]

186. Jabara, H.H.; Boyden, S.E.; Chou, J.; Ramesh, N.; Massaad, M.J.; Benson, H.; Bainter, W.; Fraulino, D.; Rahimov, F.; Sieff, C.; et al. A missense mutation in tfrc, encoding transferrin receptor 1, causes combined immunodeficiency. Nat. Genet. 2016, 48, 74-78. [CrossRef]

187. Ganz, T. Iron in innate immunity: Starve the invaders. Curr. Opin. Immunol. 2009, 21, 63-67. [CrossRef]

188. Nunez, G.; Sakamoto, K.; Soares, M.P. Innate nutritional immunity. J. Immunol. 2018, 201, 11-18. [CrossRef]

189. Cassat, J.E.; Skaar, E.P. Iron in infection and immunity. Cell Host Microbe 2013, 13, 509-519. [CrossRef]

190. Gwamaka, M.; Kurtis, J.D.; Sorensen, B.E.; Holte, S.; Morrison, R.; Mutabingwa, T.K.; Fried, M.; Duffy, P.E. Iron deficiency protects against severe plasmodium falciparum malaria and death in young children. Clin. Infect. Dis. 2012, 54, 1137-1144. [CrossRef]

191. Jonker, F.A.; Calis, J.C.; van Hensbroek, M.B.; Phiri, K.; Geskus, R.B.; Brabin, B.J.; Leenstra, T. Iron status predicts malaria risk in Malawian preschool children. PLOS ONE 2012, 7, e42670. [CrossRef]

192. Nyakeriga, A.M.; Troye-Blomberg, M.; Dorfman, J.R.; Alexander, N.D.; Back, R.; Kortok, M.; Chemtai, A.K.; Marsh, K.; Williams, T.N. Iron deficiency and malaria among children living on the coast of Kenya. J. Infect. Dis. 2004, 190, 439-447. [CrossRef]

193. Clark, M.A.; Goheen, M.M.; Fulford, A.; Prentice, A.M.; Elnagheeb, M.A.; Patel, J.; Fisher, N.; Taylor, S.M.; Kasthuri, R.S.; Cerami, C. Host iron status and iron supplementation mediate susceptibility to erythrocytic stage plasmodium falciparum. Nat. Commun. 2014, 5, 4446. [CrossRef]

194. Sazawal, S.; Black, R.E.; Ramsan, M.; Chwaya, H.M.; Stoltzfus, R.J.; Dutta, A.; Dhingra, U.; Kabole, I.; Deb, S.; Othman, M.K.; et al. Effects of routine prophylactic supplementation with iron and folic acid on admission to hospital and mortality in preschool children in a high malaria transmission setting: Community-based, randomised, placebo-controlled trial. Lancet 2006, 367, 133-143. [CrossRef]

195. Tielsch, J.M.; Khatry, S.K.; Stoltzfus, R.J.; Katz, J.; LeClerq, S.C.; Adhikari, R.; Mullany, L.C.; Shresta, S.; Black, R.E. Effect of routine prophylactic supplementation with iron and folic acid on preschool child mortality in southern nepal: Community-based, cluster-randomised, placebo-controlled trial. Lancet 2006, 367, 144-152. [CrossRef]

196. Esan, M.O.; van Hensbroek, M.B.; Nkhoma, E.; Musicha, C.; White, S.A.; Ter Kuile, F.O.; Phiri, K.S. Iron supplementation in hiv-infected Malawian children with anemia: A double-blind, randomized, controlled trial. Clin. Infect. Dis. 2013, 57, 1626-1634. [CrossRef]

197. Veenemans, J.; Milligan, P.; Prentice, A.M.; Schouten, L.R.; Inja, N.; van der Heijden, A.C.; de Boer, L.C.; Jansen, E.J.; Koopmans, A.E.; Enthoven, W.T.; et al. Effect of supplementation with zinc and other micronutrients on malaria in Tanzanian children: A randomised trial. PLoS Med. 2011, 8, e1001125. [CrossRef]

198. Neuberger, A.; Okebe, J.; Yahav, D.; Paul, M. Oral iron supplements for children in malaria-endemic areas. Cochrane Database Syst. Rev. 2016, 2, CD006589. [CrossRef]

199. Soofi, S.; Cousens, S.; Iqbal, S.P.; Akhund, T.; Khan, J.; Ahmed, I.; Zaidi, A.K.; Bhutta, Z.A. Effect of provision of daily zinc and iron with several micronutrients on growth and morbidity among young children in pakistan: A cluster-randomised trial. Lancet 2013, 382, 29-40. [CrossRef]

200. Gera, T.; Sachdev, H.P. Effect of iron supplementation on incidence of infectious illness in children: Systematic review. BMJ 2002, 325, 1142. [CrossRef]

201. Chang, S.; El Arifeen, S.; Bari, S.; Wahed, M.A.; Rahman, K.M.; Rahman, M.T.; Mahmud, A.B.; Begum, N.; Zaman, K.; Baqui, A.H.; et al. Supplementing iron and zinc: Double blind, randomized evaluation of separate or combined delivery. Eur. J. Clin. Nutr. 2010, 64, 153-160. [CrossRef]

202. Richard, S.A.; Zavaleta, N.; Caulfield, L.E.; Black, R.E.; Witzig, R.S.; Shankar, A.H. Zinc and iron supplementation and malaria, diarrhea, and respiratory infections in children in the peruvian amazon. Am. J. Trop. Med. Hyg. 2006, 75, 126-132. [CrossRef] 
203. Zlotkin, S.; Newton, S.; Aimone, A.M.; Azindow, I.; Amenga-Etego, S.; Tchum, K.; Mahama, E.; Thorpe, K.E.; Owusu-Agyei, S. Effect of iron fortification on malaria incidence in infants and young children in Ghana: A randomized trial. JAMA 2013, 310, 938-947. [CrossRef]

204. Paganini, D.; Zimmermann, M.B. The effects of iron fortification and supplementation on the gut microbiome and diarrhea in infants and children: A review. Am. J. Clin. Nutr. 2017, 106, 1688S-1693S. [CrossRef]

205. Kortman, G.A.; Raffatellu, M.; Swinkels, D.W.; Tjalsma, H. Nutritional iron turned inside out: Intestinal stress from a gut microbial perspective. FEMS Microbiol. Rev. 2014, 38, 1202-1234. [CrossRef]

206. Wooldridge, K.G.; Williams, P.H. Iron uptake mechanisms of pathogenic bacteria. FEMS Microbiol. Rev. 1993, 12, 325-348. [CrossRef]

207. Deriu, E.; Liu, J.Z.; Pezeshki, M.; Edwards, R.A.; Ochoa, R.J.; Contreras, H.; Libby, S.J.; Fang, F.C.; Raffatellu, M. Probiotic bacteria reduce salmonella typhimurium intestinal colonization by competing for iron. Cell Host Microbe 2013, 14, 26-37. [CrossRef]

208. Tang, M.; Frank, D.N.; Hendricks, A.E.; Ir, D.; Esamai, F.; Liechty, E.; Hambidge, K.M.; Krebs, N.F. Iron in micronutrient powder promotes an unfavorable gut microbiota in Kenyan infants. Nutrients 2017, 9, 776. [CrossRef]

209. Zimmermann, M.B.; Chassard, C.; Rohner, F.; N’Goran, E.K.; Nindjin, C.; Dostal, A.; Utzinger, J.; Ghattas, H.; Lacroix, C.; Hurrell, R.F. The effects of iron fortification on the gut microbiota in African children: A randomized controlled trial in cote d'ivoire. Am. J. Clin. Nutr. 2010, 92, 1406-1415. [CrossRef]

210. Dostal, A.; Baumgartner, J.; Riesen, N.; Chassard, C.; Smuts, C.M.; Zimmermann, M.B.; Lacroix, C. Effects of iron supplementation on dominant bacterial groups in the gut, faecal scfa and gut inflammation: A randomised, placebo-controlled intervention trial in south African children. Br. J. Nutr. 2014, 112, 547-556. [CrossRef]

211. Simonyte Sjodin, K.; Domellof, M.; Lagerqvist, C.; Hernell, O.; Lonnerdal, B.; Szymlek-Gay, E.A.; Sjodin, A.; West, C.E.; Lind, T. Administration of ferrous sulfate drops has significant effects on the gut microbiota of iron-sufficient infants: A randomised controlled study. Gut 2018. [CrossRef]

212. Paganini, D.; Uyoga, M.A.; Cercamondi, C.I.; Moretti, D.; Mwasi, E.; Schwab, C.; Bechtler, S.; Mutuku, F.M.; Galetti, V.; Lacroix, C.; et al. Consumption of galacto-oligosaccharides increases iron absorption from a micronutrient powder containing ferrous fumarate and sodium iron edta: A stable-isotope study in Kenyan infants. Am. J. Clin. Nutr. 2017, 106, 1020-1031. [CrossRef]

213. Drakesmith, H.; Prentice, A.M. Hepcidin and the iron-infection axis. Science 2012, 338, 768-772. [CrossRef]

214. de Mast, Q.; Nadjm, B.; Reyburn, H.; Kemna, E.H.; Amos, B.; Laarakkers, C.M.; Silalye, S.; Verhoef, H.; Sauerwein, R.W.; Swinkels, D.W.; et al. Assessment of urinary concentrations of hepcidin provides novel insight into disturbances in iron homeostasis during malarial infection. J. Infect. Dis. 2009, 199, 253-262. [CrossRef]

215. Howard, C.T.; McKakpo, U.S.; Quakyi, I.A.; Bosompem, K.M.; Addison, E.A.; Sun, K.; Sullivan, D.; Semba, R.D. Relationship of hepcidin with parasitemia and anemia among patients with uncomplicated plasmodium falciparum malaria in Ghana. Am. J. Trop. Med. Hyg. 2007, 77, 623-626. [CrossRef]

216. Armitage, A.E.; Stacey, A.R.; Giannoulatou, E.; Marshall, E.; Sturges, P.; Chatha, K.; Smith, N.M.; Huang, X.; $\mathrm{Xu}, \mathrm{X}$.; Pasricha, S.R.; et al. Distinct patterns of hepcidin and iron regulation during hiv-1, hbv, and hcv infections. Proc. Natl. Acad. Sci. USA 2014, 111, 12187-12192. [CrossRef]

217. Minchella, P.A.; Donkor, S.; Owolabi, O.; Sutherland, J.S.; McDermid, J.M. Complex anemia in tuberculosis: The need to consider causes and timing when designing interventions. Clin. Infect. Dis. 2015, 60, 764-772. [CrossRef]

218. Kerkhoff, A.D.; Meintjes, G.; Burton, R.; Vogt, M.; Wood, R.; Lawn, S.D. Relationship between blood concentrations of hepcidin and anemia severity, mycobacterial burden, and mortality among patients with hiv-associated tuberculosis. J. Infect. Dis. 2016, 213, 61-70. [CrossRef]

219. Darton, T.C.; Blohmke, C.J.; Giannoulatou, E.; Waddington, C.S.; Jones, C.; Sturges, P.; Webster, C.; Drakesmith, H.; Pollard, A.J.; Armitage, A.E. Rapidly escalating hepcidin and associated serum iron starvation are features of the acute response to typhoid infection in humans. PLoS Negl. Trop. Dis. 2015, 9, e0004029. [CrossRef]

220. Portugal, S.; Carret, C.; Recker, M.; Armitage, A.E.; Goncalves, L.A.; Epiphanio, S.; Sullivan, D.; Roy, C.; Newbold, C.I.; Drakesmith, H.; et al. Host-mediated regulation of superinfection in malaria. Nat. Med. 2011, 17, 732-737. [CrossRef] 
221. Kim, D.K.; Jeong, J.H.; Lee, J.M.; Kim, K.S.; Park, S.H.; Kim, Y.D.; Koh, M.; Shin, M.; Jung, Y.S.; Kim, H.S.; et al. Inverse agonist of estrogen-related receptor gamma controls salmonella typhimurium infection by modulating host iron homeostasis. Nat. Med. 2014, 20, 419-424. [CrossRef]

222. Lim, D.; Kim, K.S.; Jeong, J.H.; Marques, O.; Kim, H.J.; Song, M.; Lee, T.H.; Kim, J.I.; Choi, H.S.; Min, J.J.; et al. The hepcidin-ferroportin axis controls the iron content of salmonella-containing vacuoles in macrophages. Nat. Commun. 2018, 9, 2091. [CrossRef]

223. Cross, J.H.; Bradbury, R.S.; Fulford, A.J.; Jallow, A.T.; Wegmuller, R.; Prentice, A.M.; Cerami, C. Oral iron acutely elevates bacterial growth in human serum. Sci. Rep. 2015, 5, 16670. [CrossRef]

224. Stoffel, N.U.; Lazrak, M.; Bellitir, S.; El Mir, N.; El Hamdouchi, A.; Barkat, A.; Zeder, C.; Moretti, D.; Aguenaou, H.; Zimmermann, M.B. The opposing effects of acute inflammation and iron deficiency anemia on serum hepcidin and iron absorption in young women. Haematologica 2019. [CrossRef]

225. Cercamondi, C.I.; Egli, I.M.; Ahouandjinou, E.; Dossa, R.; Zeder, C.; Salami, L.; Tjalsma, H.; Wiegerinck, E.; Tanno, T.; Hurrell, R.F.; et al. Afebrile plasmodium falciparum parasitemia decreases absorption of fortification iron but does not affect systemic iron utilization: A double stable-isotope study in young beninese women. Am. J. Clin. Nutr. 2010, 92, 1385-1392. [CrossRef]

226. Glinz, D.; Hurrell, R.F.; Righetti, A.A.; Zeder, C.; Adiossan, L.G.; Tjalsma, H.; Utzinger, J.; Zimmermann, M.B.; N'Goran, E.K.; Wegmuller, R. In ivorian school-age children, infection with hookworm does not reduce dietary iron absorption or systemic iron utilization, whereas afebrile plasmodium falciparum infection reduces iron absorption by half. Am. J. Clin. Nutr. 2015, 101, 462-470. [CrossRef]

227. Muriuki, J.M.; Atkinson, S.H. How eliminating malaria may also prevent iron deficiency in African children. Pharmaceuticals 2018, 11, 96. [CrossRef]

228. Pasricha, S.R.; Gheorghe, A.; Ashour, F.; Arcot, A.; Murray-Kolb, L.E.; Suchdev, P.; Bode, M. Risk-benefit and cost-effectiveness of universal iron interventions for public health control of anemia in young children in 78 countries: A microsimulation study. Blood 2018, 132, 2276.

229. Pasricha, S.R.; Drakesmith, H.; Black, J.; Hipgrave, D.; Biggs, B.A. Control of iron deficiency anemia in lowand middle-income countries. Blood 2013, 121, 2607-2617. [CrossRef]

230. Teshome, E.M.; Andang'o, P.E.A.; Osoti, V.; Terwel, S.R.; Otieno, W.; Demir, A.Y.; Prentice, A.M.; Verhoef, H. Daily home fortification with iron as ferrous fumarate versus nafeedta: A randomised, placebo-controlled, non-inferiority trial in Kenyan children. BMC Med. 2017, 15, 89. [CrossRef]

231. Verhoef, H.; Teshome, E.; Prentice, A.M. Micronutrient powders to combat anaemia in young children: Do they work? BMC Med. 2018, 16, 7. [CrossRef]

232. Gera, T.; Sachdev, H.S.; Boy, E. Effect of iron-fortified foods on hematologic and biological outcomes: Systematic review of randomized controlled trials. Am. J. Clin. Nutr. 2012, 96, 309-324. [CrossRef]

233. Garcia-Casal, M.N.; Pena-Rosas, J.P.; De-Regil, L.M.; Gwirtz, J.A.; Pasricha, S.R. Fortification of maize flour with iron for controlling anaemia and iron deficiency in populations. Cochrane Database Syst. Rev. 2018, 12, CD010187. [CrossRef]

234. Engle-Stone, R.; Nankap, M.; Ndjebayi, A.O.; Allen, L.H.; Shahab-Ferdows, S.; Hampel, D.; Killilea, D.W.; Gimou, M.M.; Houghton, L.A.; Friedman, A.; et al. Iron, zinc, folate, and vitamin b-12 status increased among women and children in yaounde and douala, cameroon, 1 year after introducing fortified wheat flour. J. Nutr. 2017, 147, 1426-1436. [CrossRef]

235. Suchdev, P.S.; Ruth, L.J.; Woodruff, B.A.; Mbakaya, C.; Mandava, U.; Flores-Ayala, R.; Jefferds, M.E.; Quick, R. Selling sprinkles micronutrient powder reduces anemia, iron deficiency, and vitamin a deficiency in young children in Western Kenya: A cluster-randomized controlled trial. Am. J. Clin. Nutr. 2012, 95, 1223-1230. [CrossRef]

236. Lynch, S.R. Why nutritional iron deficiency persists as a worldwide problem. J. Nutr. 2011, 141, 763S-768S. [CrossRef]

237. Nielsen, O.H.; Coskun, M.; Weiss, G. Iron replacement therapy: Do we need new guidelines? Curr. Opin. Gastroenterol. 2016, 32, 128-135. [CrossRef]

238. Glinz, D.; Kamiyango, M.; Phiri, K.S.; Munthali, F.; Zeder, C.; Zimmermann, M.B.; Hurrell, R.F.; Wegmuller, R. The effect of timing of iron supplementation on iron absorption and haemoglobin in post-malaria anaemia: A longitudinal stable isotope study in Malawian toddlers. Malar. J. 2014, 13, 397. [CrossRef] 
239. Frosch, A.E.; Ondigo, B.N.; Ayodo, G.A.; Vulule, J.M.; John, C.C.; Cusick, S.E. Decline in childhood iron deficiency after interruption of malaria transmission in Highland Kenya. Am. J. Clin. Nutr. 2014, 100, 968-973. [CrossRef]

240. WHO. Iron Deficiency Anaemia: Assessment, Prevention, and Control. A Guide for Programme Managers; World Health Organisation: Geneva, Switzerland, 2001.

241. WHO. Nutritional Anaemias: Tools for Effective Prevention and Control; World Health Organisation: Geneva, Switzerland, 2017.

242. Stoffel, N.U.; Cercamondi, C.I.; Brittenham, G.; Zeder, C.; Geurts-Moespot, A.J.; Swinkels, D.W.; Moretti, D.; Zimmermann, M.B. Iron absorption from oral iron supplements given on consecutive versus alternate days and as single morning doses versus twice-daily split dosing in iron-depleted women: Two open-label, randomised controlled trials. Lancet Haematol. 2017, 4, e524-e533. [CrossRef]

243. Camaschella, C. Iron deficiency. Blood 2019, 133, 30-39. [CrossRef]

244. Cable, R.G.; Brambilla, D.; Glynn, S.A.; Kleinman, S.; Mast, A.E.; Spencer, B.R.; Stone, M.; Kiss, J.E.; National Heart, L.; Blood Institute Recipient, E.; et al. Effect of iron supplementation on iron stores and total body iron after whole blood donation. Transfusion 2016, 56, 2005-2012. [CrossRef]

245. Rimon, E.; Kagansky, N.; Kagansky, M.; Mechnick, L.; Mashiah, T.; Namir, M.; Levy, S. Are we giving too much iron? Low-dose iron therapy is effective in octogenarians. Am. J. Med. 2005, 118, 1142-1147. [CrossRef]

246. Troesch, B.; Egli, I.; Zeder, C.; Hurrell, R.F.; de Pee, S.; Zimmermann, M.B. Optimization of a phytase-containing micronutrient powder with low amounts of highly bioavailable iron for in-home fortification of complementary foods. Am. J. Clin. Nutr. 2009, 89, 539-544. [CrossRef]

247. Hackl, L.S.; Abizari, A.D.; Speich, C.; Zungbey-Garti, H.; Cercamondi, C.I.; Zeder, C.; Zimmermann, M.B.; Moretti, D. Micronutrient-fortified rice can be a significant source of dietary bioavailable iron in schoolchildren from rural Ghana. Sci. Adv. 2019, 5, eaau0790. [CrossRef]

248. Wijaya-Erhardt, M.; Muslimatun, S.; Erhardt, J.G. Fermented soyabean and vitamin c-rich fruit: A possibility to circumvent the further decrease of iron status among iron-deficient pregnant women in Indonesia. Public Health Nutr. 2011, 14, 2185-2196. [CrossRef]

249. Mwangi, M.N.; Roth, J.M.; Smit, M.R.; Trijsburg, L.; Mwangi, A.M.; Demir, A.Y.; Wielders, J.P.; Mens, P.F.; Verweij, J.J.; Cox, S.E.; et al. Effect of daily antenatal iron supplementation on plasmodium infection in Kenyan women: A randomized clinical trial. JAMA 2015, 314, 1009-1020. [CrossRef]

250. Pena-Rosas, J.P.; De-Regil, L.M.; Garcia-Casal, M.N.; Dowswell, T. Daily oral iron supplementation during pregnancy. Cochrane Database Syst. Rev. 2015, CD004736. [CrossRef] 
Review

\title{
Anemia and Iron Deficiency in Cancer Patients: Role of Iron Replacement Therapy
}

\author{
Fabiana Busti, Giacomo Marchi, Sara Ugolini, Annalisa Castagna and Domenico Girelli * \\ Department of Medicine, Section of Internal Medicine, University of Verona, and EuroBloodNet Referral Center \\ for Iron Disorders, Azienda Ospedaliera Universitaria Integrata Verona, Policlinico G.B. Rossi, \\ 37134 Verona, Italy; fabiana.busti@univr.it (F.B.); markallbutone@gmail.com (G.M.); sara.ugolini@univr.it (S.U.); \\ annalisa.castagna@univr.it (A.C.) \\ * Correspondence: domenico.girelli@univr.it; Tel.: +39-045-812-4263
}

Received: 31 August 2018; Accepted: 28 September 2018; Published: 30 September 2018

\begin{abstract}
Anemia in cancer patients is quite common, with remarkable negative impacts on quality of life and overall prognosis. The pathogenesis is complex and typically multifactorial, with iron deficiency (ID) often being a major and potentially treatable contributor. In turn, ID in cancer patients can be due to multiple concurring mechanisms, including bleeding (e.g., in gastrointestinal cancers or after surgery), malnutrition, medications, and hepcidin-driven iron sequestration into macrophages with subsequent iron-restricted erythropoiesis. Indeed, either absolute or functional iron deficiency (AID or FID) can occur. While for absolute ID there is a general consensus regarding the laboratory definition (that is ferritin levels $<100 \mathrm{ng} / \mathrm{mL} \pm$ transferrin saturation (TSAT) $<20 \%$ ), a shared definition of functional ID is still lacking. Current therapeutic options in cancer anemia include iron replacement, erythropoietic stimulating agents (ESAs), and blood transfusions. The latter should be kept to a minimum, because of concerns regarding risks, costs, and limited resources. Iron therapy has proved to be a valid approach to enhance efficacy of ESAs and to reduce transfusion need. Available guidelines focus mainly on patients with chemotherapy-associated anemia, and generally suggest intravenous (IV) iron when AID or FID is present. However, in the case of FID, the upper limit of ferritin in association with TSAT $<20 \%$ at which iron should be prescribed is a matter of controversy, ranging up to $800 \mathrm{ng} / \mathrm{mL}$. An increasingly recognized indication to IV iron in cancer patients is represented by preoperative anemia in elective oncologic surgery. In this setting, the primary goal of treatment is to decrease the need of blood transfusions in the perioperative period, rather than improving anemia-related symptoms as in chemotherapy-associated anemia. Protocols are mainly based on experiences of Patient Blood Management (PBM) in non-oncologic surgery, but no specific guidelines are available for oncologic surgery. Here we discuss some possible approaches to the management of ID in cancer patients in different clinical settings, based on current guidelines and recommendations, emphasizing the need for further research in the field.
\end{abstract}

Keywords: iron deficiency; anemia; cancer; hepcidin; patient blood management

\section{Anemia in Cancer: Prevalence, Pathophysiology and Prognostic Impact}

Anemia is a common and potentially detrimental complication in cancer patients, that compromises quality and expectancy of life. Prompt recognition and management has been associated with improvement of clinical outcomes, favoring also a better tolerance and response to antitumoral therapy.

In a prospective epidemiological survey conducted in 34 European countries (European Cancer Anemia Survey (ECAS)) involving about 15,000 subjects diagnosed with solid or hematological tumors between 2001 and 2002, anemia $(\mathrm{Hb}<12 \mathrm{~g} / \mathrm{dL})$ was present in approximately $39 \%$ of patients at enrolment, and the overall prevalence increased to $67 \%$ during the 6 months' follow-up [1]. In most cases anemia was mild (defined as $\mathrm{Hb}>10 \mathrm{~g} / \mathrm{dL}$ according to the National Comprehensive Cancer 
Network guidelines [2]), but $\mathrm{Hb}$ values lower than $10 \mathrm{~g} / \mathrm{dL}$ were detected in $10 \%$ of patients at baseline and in $39.9 \%$ of patients during the follow-up. In another literature review published in 2004, the prevalence of cancer anemia was highly variable (from $30 \%$ to about $90 \%$ ), although this was partially due to different cut-offs used for the diagnosis $(\mathrm{Hb}<9$ versus $<11 \mathrm{~g} / \mathrm{dL})$ [3]. Anemia occurs more frequently in patients with tumor recurrence, at an advanced stage of disease (i.e., from $40 \%$ of patients with early-stage colon tumors to nearly $80 \%$ of patients with advanced disease), and in those receiving antitumoral treatment. Furthermore, its prevalence varies according to the type of cancer and is higher in patients with hematologic malignancies, such as multiple myeloma and lymphoma. Among solid tumors, the highest incidence of anemia has been reported among lung and breast tumors, followed by gynecological and gastrointestinal malignancies [4].

The pathogenesis of cancer anemia is complex and multi-factorial and, even in the same patient, different mechanisms can prevail at different times (e.g., after surgery or chemotherapy (ChT)) [5]. Anemia can develop as a consequence of malnutrition and malabsorption (leading to iron and other nutritional deficiency, e.g., folates or vitamin B12), acute and/or chronic bleeding, systemic inflammation, metastatic infiltration of bone marrow, and therapy-related myelosuppression. Less frequently, cancer anemia may derive from other mechanisms including hemolysis, hemophagocytosis, and hypersplenism (Figure 1). However, not all causes are of equal importance in different cancers. For example, overt or occult bleeding and iron deficiency are often prominent in gastrointestinal, urogenital and gynecological tumors, while bone marrow replacement by metastases is relatively frequent in breast and prostate cancer [6]. Anemia can also be attributed to a decline in endogenous erythropoietin (EPO) production (e.g., during concurrent chronic kidney disease) or a reduction in bone marrow response to EPO [7].

Cancer anemia may be associated with a broad spectrum of symptoms, depending on its severity and rapidity of development. Fatigue is the most debilitating symptom [8,9], followed by impaired mental capacity, confusion and depression, especially in elderly people. Nausea, loss of appetite, dyspnea, syncope and falls can also occur, particularly in patients with comorbidities such as cardio-pulmonary and renal dysfunctions. Of note, the decrease in quality of life (QoL) is particularly evident when $\mathrm{Hb}$ drops between 11.5 and $10 \mathrm{~g} / \mathrm{dL}$, which is classically considered as mild anemia and not perceived as a problem by most doctors [10]. Not infrequently, symptoms related to anemia represent the first alarm sign of an occult neoplasm, as it is classically observed in patients with colon cancer.

Anemia has been recognized as an independent predictor of poor prognosis in cancer patients. In a comprehensive systematic review of 60 studies evaluating survival, there was a $65 \%$ overall increase in the risk of mortality in cancer patients with anemia compared with those without anemia. This ranged from $19 \%$ in subjects with lung neoplasia to near $75 \%$ in patients with head and neck carcinoma or lymphoma [11]. The impact of anemia on survival has been related to delay in initiating, or failure to complete, the ChT regimens. A poorer response to anticancer treatments has also been evoked, as cytotoxicity induced by radiotherapy (RT) and some ChT agents require adequate tissue oxygen levels. Moreover, a decrease in the oxygen $\left(\mathrm{O}_{2}\right)$ transport capacity of the blood can facilitate intra-tumoral hypoxia, with activation of Hypoxia Inducible Factors (HIFs). Indeed, HIFs are considered master regulators of cancer progression [12-15] by up-regulation of target genes involved in angiogenesis, immune evasion, and metabolic reprogramming of cancer cells [16], making them resistant to ChT and RT [17,18].

Given the impact of anemia on QoL, disease progression and survival in cancer patients, adequate treatment strategies appear of paramount importance. Several studies have shown that the treatment of cancer anemia determines a marked improvement in QoL [19], particularly among patients with mild-to-moderate anemia. It may also have the potential to improve anti-cancer treatment tolerability and efficacy, with a possible impact on prognosis $[9,20,21]$. 


\section{Blood Transfusions and Erythropoietic Stimulating Agents: A Double-Edged Sword}

Management of anemia in cancer patients often requires a multidisciplinary approach, aimed at recognizing and treating the underlying cause (whenever possible) and at restoring hemoglobin levels. The above-mentioned ECAS survey showed that anemia was treated in less than $40 \%$ of patients, mainly with Erythropoietic Stimulating Agents (ESAs) and blood transfusions [1]. Indeed, until recently, blood transfusions have represented the most commonly employed treatment for cancer anemia. Whilst effective in providing an immediate increase in $\mathrm{Hb}$, the benefits of transfusions are transient and concerns about their negative effects have prompted clinicians to consider alternative treatment approaches. Indeed, transfusions are potentially associated with important adverse effects, such as anaphylactic reactions, transfusion-related acute lung injury (TRALI), circulatory overload, iron accumulation, infectious pathogens transmission, as well as an increased susceptibility to infections because of transfusion-related immunosuppression [22]. Blood transfusions have been independently associated to an increased risk for adverse outcomes also in cancer patients undergoing surgery. Numerous studies and meta-analysis have observed that cancer patients receiving transfusions during the perioperative period have an increased risk for mortality, morbidity and tumor recurrence [23-26]. A systematic review has shown that restrictive transfusion regimens (e.g., $\mathrm{Hb}$ thresholds set at 7-8 g/dL) in oncological surgery decrease blood utilization without increasing mortality and morbidity [27]. However, whether or not a restrictive regimen in cancer patients undergoing surgery is as safe as a liberal regimen remains debated, especially in critically ill patients [28-30].

On the other hand, since the 1990s, the development of recombinant human erythropoietin has represented an important alternative to blood transfusions for treating anemia. Earlier studies indicated that ESAs reduced transfusion requirements in cancer patients [31,32], as well as relieved the symptoms of anemia and improved QoL [32]. However, concerns on the use of ESAs in cancer patients arose in the late 2000s. Meta-analyses suggested that use of ESAs was associated with an increased risk of venous thromboembolism and mortality [33,34], particularly if target Hb levels exceeded 12 $\mathrm{g} / \mathrm{dL}$. An increase in mortality and/or disease progression were reported particularly in studies where ESAs were used off-label, such as in anemic patients receiving RT only [35], or receiving neither RT nor ChT [36,37]. The potential for ESAs to promote tumor progression or recurrence, possibly by stimulation of EPO receptors expressed by tumor cells [38], has long been debated. However, few studies have specifically addressed this issue, and the sparse preclinical and clinical data does not appear to support a direct or indirect effect of ESAs on tumor growth and disease progression [39-41]. More recent studies have given reassuring data when use of ESAs is restricted to patients receiving $\mathrm{ChT}$ with lower target $\mathrm{Hb}$ levels [42,43]. Anyway, at present there is a consensus that ESAs are not indicated in anemic cancer patients who are not receiving $\mathrm{ChT}$ (except for low-risk myelodysplastic syndromes) [44], while controversy remains in patients receiving ChT when cure is the goal.

Given the potential risks related to the use of blood transfusions and ESAs, and the growing knowledge regarding iron pathophysiology and its implication in cancer anemia, IV iron administration represents a promising, potentially valuable, therapeutic approach.

\section{Iron Deficiency in Cancer Patients: A Common Problem, but Difficult to Define}

\subsection{Impaired Iron Stores and Utilization in Cancer Patients}

ID with or without anemia is a frequent complication in cancer patients: in a single center survey involving $>1500$ patients with solid and hematological malignancies, the prevalence of ID (defined as TSAT $<20 \%$ ) was approximately $42 \%$ [45]. Subjects with pancreatic, colorectal and lung tumors were more frequently affected by ID, as well as patients with an advanced stage of disease or treated with chemotherapeutic agents. ID by itself, even in the absence of anemia, may be associated with impaired physical function, weakness, and fatigue, which can be ameliorated by iron therapy [46]. Cancer patients can have either functional or absolute iron deficiency (FID or AID, respectively). FID is 
most frequent [47] and represents a condition in which iron stores are apparently adequate, but there is insufficient iron supply for erythropoiesis. FID is mainly due to the release of cancer-associated pro-inflammatory cytokines (e.g., IL-6, IL-1, TNF- $\alpha$, and interferon- $\gamma$ ), that upregulate hepcidin synthesis in the liver $[48,49]$. Hepcidin is a small peptide hormone that represents the central regulator of systemic iron homeostasis. It acts by inhibiting the only known iron exporter-ferroportin, and hence reducing iron flows into plasma from macrophages involved in recycling of senescent erythrocytes, duodenal enterocytes involved in iron absorption from the diet, and hepatocytes iron stores [50]. FID is one of the major contributors to the so-called anemia of chronic disease [4,51], including cancer [45]. It may also develop during increased erythropoiesis mediated by ESAs therapy and, not infrequently, it is the cause of ESAs unresponsiveness.

On the other hand, AID is a condition in which iron stores are actually depleted. Nutritional deficiencies (e.g., tumor-induced anorexia or malabsorption in gastric or pancreatic cancer; or after resection of intestinal tumors) and, especially, blood losses (manifest or occult, e.g., in colon cancer or after surgery) contribute to AID in cancer patients.

Chronic kidney disease is a relatively frequent comorbidity in cancer patients, which can contribute to anemia not only through a reduction of EPO synthesis, but also through increased hepcidin levels leading to iron trapping within the macrophages, and eventually to FID [52,53].

Figure 1 summarizes the main mechanisms leading to anemia and perturbation of iron metabolism in cancer patients.

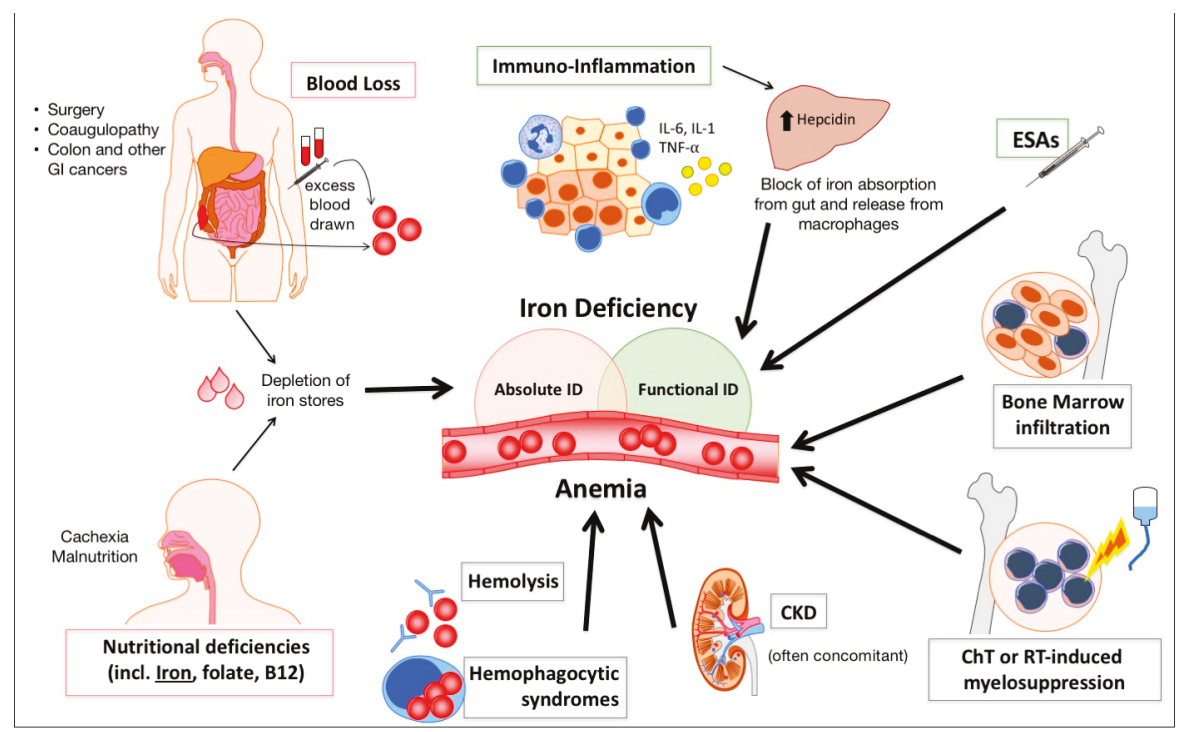

Figure 1. Schematic illustration of the main mechanisms contributing to anemia and iron deficiency in cancer patients. Blood losses due to tumor growth (especially in gastrointestinal cancers) or after surgery, possibly favored by concomitant coagulopathy, and inadequate iron intake due to cachexia and malnutrition lead to absolute iron deficiency (ID). Inflammation increases hepcidin synthesis in the liver, leading to functional ID. Treatment with erythropoiesis stimulating agents may contribute to functional ID, determining a discrepancy between iron need for erythropoiesis and iron supply from the stores. Other factors, such as bone marrow infiltration by tumor cells, myelosuppression caused by chemo- or radio-therapy, and concomitant chronic kidney disease (CKD), often contribute to the development of anemia in cancer patients. 


\subsection{Characterization of Iron Status in Cancer Patients}

In healthy individuals, ferritin reflects the status of iron stores, while various other parameters such as TSAT, percentage of hypochromic erythrocytes (\%HYPO), Hb-content of reticulocytes (CHr), and soluble transferrin receptor (sTfR), reflect the amount of biologically available iron. Unfortunately, most of these parameters are altered in cancer patients and the diagnosis of ID in this setting poses multiple challenges. Notably, ferritin is an acute-phase protein and may not correlate with iron stores during inflammatory states and liver disease, conditions that are relatively frequent in cancer patients. Thus, with respect to AID, while in otherwise normal individuals a serum ferritin level of $<20-30 \mathrm{ng} / \mathrm{mL}$ is virtually diagnostic, in cancer patients a higher ferritin cut-off (e.g., <100 ng/mL) appears more reliable [54], as suggested in other chronic inflammatory conditions such as kidney disease or heart failure [55]. Moreover, some studies noted that a ferritin level of $100 \mathrm{ng} / \mathrm{mL}$ might be a good threshold to identify patients better responsive to IV iron therapy $[56,57]$.

On the other hand, the ferritin cut-off for defining FID or, in a more practical way, for deciding whether or not iron supplementation should be considered in cancer patients, is much more debated and still unresolved. Indeed, most experts [58] and the few guidelines available [2,54] recommend testing both ferritin and TSAT, and considering FID when TSAT is $<20 \%$ with variable ferritin levels ranging from 100 up to $800 \mathrm{ng} / \mathrm{mL}$. However, TSAT also has some limitations in cancer patients, since reduced transferrin levels due to inflammation and/or malnutrition can result in falsely normal to high values.

An increased sTfR and a reduced sTfR/log ferritin index have been reported as possible indicators of FID [51], but sTfR lacks standardization [59] and the interpretation of this cumbersome equation in clinical practice is far from ideal $[47,50]$. Finally, although \%HYPO and $\mathrm{CHr}$ are cheap and theoretically informative tests (with thresholds of $>5 \%$ and $<28 \mathrm{pg}$, respectively), only few laboratories provide such data and most physicians overlook them.

Measurement of circulating hepcidin is a promising tool for assessing iron status [60]. While opposing stimuli can influence hormone levels, with inflammation increasing and ID decreasing them, ID tends to prevail when both are present [61]. Indeed, low hepcidin has been proven effective in distinguishing ID anemia from anemia of chronic disease in patients with different inflammatory disorders, like rheumatoid arthritis [62] and inflammatory bowel diseases [63]. Similar results have been reported in a small study on patients with cancer anemia [64], but further validation is needed. Of note, low hepcidin levels may be useful not only for diagnosis of ID, but also for predicting response to iron treatment [65]. This has been shown also in a study on patients with ChT-associated anemia treated with darbepoetin [66]. Whether or not this may be true also in cancer patients not treated with ESAs remains to be demonstrated. Currently, at international level, many laboratories are putting efforts into harmonizing the heterogeneous hepcidin assays in order to define standardized cut-offs, and hence allowing full implementation in clinical practice $[60,67]$.

\section{Evidence for Iron Treatment in Cancer Anemia}

To date, the majority of clinical trials have investigated the effects of iron treatment in combination with ESAs, demonstrating multiple benefits in term of hematological response (increase in $\mathrm{Hb}$ levels) [68-74], improvement of QoL [68], reduction of transfusions requirements [71] and lowering ESAs doses [69], as compared to treatment with ESAs only. A meta-analysis of eleven trials, including more than 1600 cancer patients randomized to treatment with IV iron, confirmed the activity of iron either as sole treatment or in combination with ESAs [75]. In particular, IV iron significantly increased hematopoietic response and decreased the rate of blood transfusions in trials both with and without ESAs. The increase in the hematological response rates correlated with total IV iron dose, regardless of baseline iron status. Similar results emerged in another meta-analysis, showing an increase of hematological response rates and a decrease of transfusion requirements with the addition of IV iron to ESAs therapy. In contrast, treatment with oral iron was not effective [76]. Growing evidence seems to confirm benefits of IV iron alone, particularly when the newer, third-generation compounds are 
used (for an extensive review on modern iron replacement therapy see [77]). Initially, three small studies in gynecological cancer patients receiving chemo-radiotherapy showed significant reductions of transfusion needs after IV administration of iron sucrose [78-80]. Subsequently, an observational study with ferric carboxymaltose (FCM) (median dose $1000 \mathrm{mg}$ ), including more than 600 patients with active malignancies and cancer anemia and/or ChT-induced anemia, revealed a similar hematological response in patients treated with IV iron alone as compared to the combination with ESAs [56]. $\mathrm{Hb}$ increase was higher in patients with low initial $\mathrm{Hb}$ levels $(<10$ versus $\geq 10 \mathrm{~g} / \mathrm{dL}$ ) and in those with serum ferritin levels $<100 \mathrm{ng} / \mathrm{mL}$. Noteworthy, patients with ferritin up to $500 \mathrm{ng} / \mathrm{mL}$ but low transferrin saturation also benefited from FCM treatment, highlighting that cancer patients can effectively respond to IV iron even when FID is present. In this line, a small prospective randomized controlled trial evaluated FCM without ESAs for correction of anemia in lymphoma patients with FID (defined as TSAT $\leq 20 \%$ and ferritin $>40 \mathrm{ng} / \mathrm{mL}$ in men and $>30 \mathrm{ng} / \mathrm{mL}$ in women). Patients in the FCM arm had a mean $\mathrm{Hb}$ increase significantly higher as compared to controls at week 8 [81]. IV FCM administration as monotherapy also effectively stimulated hematological response in a group of patients with gastrointestinal malignancies [57]. In agreement with Steinmetz et al., this trial suggested baseline ferritin levels $<100 \mathrm{ng} / \mathrm{mL}$ as the predictor of response. Treatment with FCM has also been associated with a significant increase of QoL in patients with various solid tumors [82].

At variance with IV iron, oral iron has not been associated with consistent clinical or hematological improvement in cancer patients $[68,70,75,76]$. In cancer patients, concurrent inflammation, gastrointestinal discomfort, polypharmacy, and malabsorption make oral iron a poorly suitable choice.

\section{The Emerging Role of Patient Blood Management Programs in Oncologic Surgery and the Contribution of Iron Treatment}

In recent years, the increasing awareness on the possible adverse effects related to the use of blood transfusions, especially in the perioperative period, led to the implementation of so-called programs of Patient Blood Management (PBM). This term refers to patient-centered, multi-disciplinary activities that promote safety, appropriateness, and evidence-based use of blood [83], with the aim of reducing the short and long-term adverse consequences related to blood transfusions. The PBM pillars include the optimization of erythropoiesis (e.g., by correcting ID) and hemostasis, as well as the use of anesthetic/surgical technologies aimed at minimizing of blood loss.

Preoperative anemia is the major predictive factor for allogeneic blood transfusion in surgical patients, therefore its optimal management represents one of the cornerstones of PBM programs [84] and, from 2010, is recommended by the World Health Organization (WHO). Multiple studies have demonstrated the effectiveness of preoperative anemia management, mainly through iron supplementation in elective orthopedic [85] and cardiothoracic surgery [86], not only by limiting blood transfusions, but also by reducing postoperative complications (such as acute kidney failure or infection) and length of hospitalization. By contrast, robust evidence for a similar efficacy in oncologic surgery is still lacking [87]. While in this setting the potential detrimental effects of transfusions have been confirmed $[23,88]$, it has some peculiarities, including the difficulties in defining ID (see Section 3.2) and the need to minimize delay in elective interventions because of the time required for anemia investigation and treatment. Nevertheless, a recent single-center retrospective study has shown a significant decrease in blood transfusions and an increased 2-year overall survival in cancer patients who underwent surgery after the implementation of a PBM program, as compared to the previous period [89].

Patients with colorectal carcinoma requiring surgery have a particularly high prevalence of ID and ID anemia, and have been more extensively studied. A systematic review of studies on iron supplementation for preoperative anemia in this setting [90] showed a general decrease of blood transfusion rate, but some discrepancies regarding the effect on $\mathrm{Hb}$ levels. Indeed, $\mathrm{Hb}$ significantly increased in some studies [91], but not in others [92,93], with heterogeneity being possibly attributed to different study design and iron doses. More recently, a multi-center observational study showed 
that preoperative treatment with FCM significantly reduced transfusion requirements and hospital length of stay [94]. Similar results have been reported by a randomized controlled trial on FCM for the management of preoperative anemia in major abdominal surgery, which mainly enrolled cancer patients [95].

Overall, in line with the proven efficacy of iron for the management of preoperative anemia in elective non-oncologic surgery, these studies suggest that the implementation of IV iron administration protocols may be an effective and safe strategy even in oncologic surgery.

\section{Possible Risks of Iron Treatment in Cancer Patients: Myth or Reality?}

Data from epidemiological studies and animal models have raised some concerns regarding the possible role of deregulated iron metabolism in certain cancer types [96,97], including promotion of tumor growth and enhanced oxidative stress [98]. However, the relevance of such experimental data for cancer patients is limited, since they were typically based on high iron doses, as well as injection routes and iron formulations that are not used in the clinical setting [99].

On the other hand, data from prospective trials evaluating long-term outcomes of IV iron therapy (alone or in combination with ESAs) in anemic cancer patients are relatively scarce. Short-term studies are reassuring, having not revealed an increased tumor progression in patients treated with IV iron and ESAs [54]. In 2015, a prospective randomized controlled trial evaluating treatment with IV iron and ESAs in a small number of patients with hematological malignancies and median follow-up of 1.4 years, did not find any negative effect on long-term outcomes or survival [100]. More recently, a retrospective cohort study, including patients who underwent surgery for colorectal carcinoma with an extended follow-up (median 3.9 years), confirmed that overall and disease-free survivals did not significantly differ in subjects treated with IV iron (FCM in the range of 1000-2000 mg) as compared to a matched group not receiving IV iron [101].

Regarding the risk of infections, no alarming signal has emerged in cancer patients treated with IV iron. Nevertheless, given the role of iron in immune response and microbial proliferation [102], current guidelines prudentially advise to avoid IV iron administration in patients with even suspected active infections [54].

\section{Available Guidelines: Field of Action, Limitations and Uncovered Issues}

Early this year, the European Society of Medical Oncology (ESMO) released updated Clinical Practice Guidelines on the management of anemia and iron deficiency in patients with cancer [54]. Accordingly, IV iron is indicated in patients with anemia $(\mathrm{Hb}<11 \mathrm{~g} / \mathrm{dL}$ ) and AID (defined as serum ferritin $<100 \mathrm{ng} / \mathrm{mL}$ ) or FID (defined as serum ferritin $>100 \mathrm{ng} / \mathrm{mL}$, but TSAT $<20 \%$ ) before or during administration of ESAs [54]. The definition of FID is not entirely satisfying, since no upper limit of ferritin is established. It has been argued that in patients with TSAT $<20 \%$ and ferritin levels $>500 \mathrm{ng} / \mathrm{mL}$, the decision regarding iron supplementation should be based on the risk-benefit profile of individual patients, and treatment should be discontinued if ferritin increases above $800 \mathrm{ng} / \mathrm{mL}$ [47]. Indeed, the National Comprehensive Cancer Network guidelines suggest that IV iron could be considered for ferritin levels up to $800 \mathrm{ng} / \mathrm{mL}$. However, it has to be noted that such guidelines are largely and explicitly limited to a specific clinical domain, that is patients receiving ChT. To this end, the ESMO guidelines state that "iron therapy should be limited to patients receiving chemotherapy" and discuss some specific conditions like patients receiving cardiotoxic ChT, in whom iron administration should not be synchronous with the anticancer agent [54]. The reason for limiting iron to patients receiving ChT lies on the absence of long-term pharmacovigilance studies in other settings. However, the management of preoperative anemia (see above) represents a notable exception to this prudential rule. Indeed, in this peculiar setting, the primary goal is not to relieve anemia-related clinical symptoms, but rather to reach $\mathrm{Hb}$ level able to minimize the risk of blood transfusion. Thus, even a mild preoperative anemia, e.g., $\mathrm{Hb} 11.5 \mathrm{~g} / \mathrm{dL}$ in a male cancer patient, is worth being corrected, irrespective of the presence of anemia-related clinical symptoms. Other substantial differences in 
the perioperative setting are: (1) ESAs should be used with caution, if not avoided, because of the inherent thromboembolic risk temporarily increased by surgery itself; (2) regarding IV iron, it is likely that it would be given just once before the intervention, with limited risk in the long-term follow-up. Notwithstanding the clinical relevance of this peculiar setting (see Section 5), no specific guidelines are available. In particular, no clear cut-off of iron biomarkers has been established to guide iron supplementation. While there is a general agreement on giving IV iron to a cancer patient with even a mild preoperative anemia and AID (again defined as ferritin $<100 \mathrm{ng} / \mathrm{mL}$ ), in cases of FID (defined as TSAT $<20 \%$ ) no consensus exists on the upper ferritin levels at which IV iron should be reasonably administered without risk. This represents a grey area, and there is a clear need of future high-quality prospective trials in the field. Whether or not hepcidin could help in driving iron therapy in cancer patients, as proposed in other settings [63,103], remains to be explored. At our hospital, an ongoing project is evaluating the role of hepcidin in diagnosis and treatment of preoperative anemia in oncologic surgery (Italian Ministry of Health research project no. CO-2016-02361206). Possible algorithms for the diagnosis and treatment of ID in cancer patients, based on the most recent pathophysiological and therapeutic advances in the field, are depicted in Figure 2.

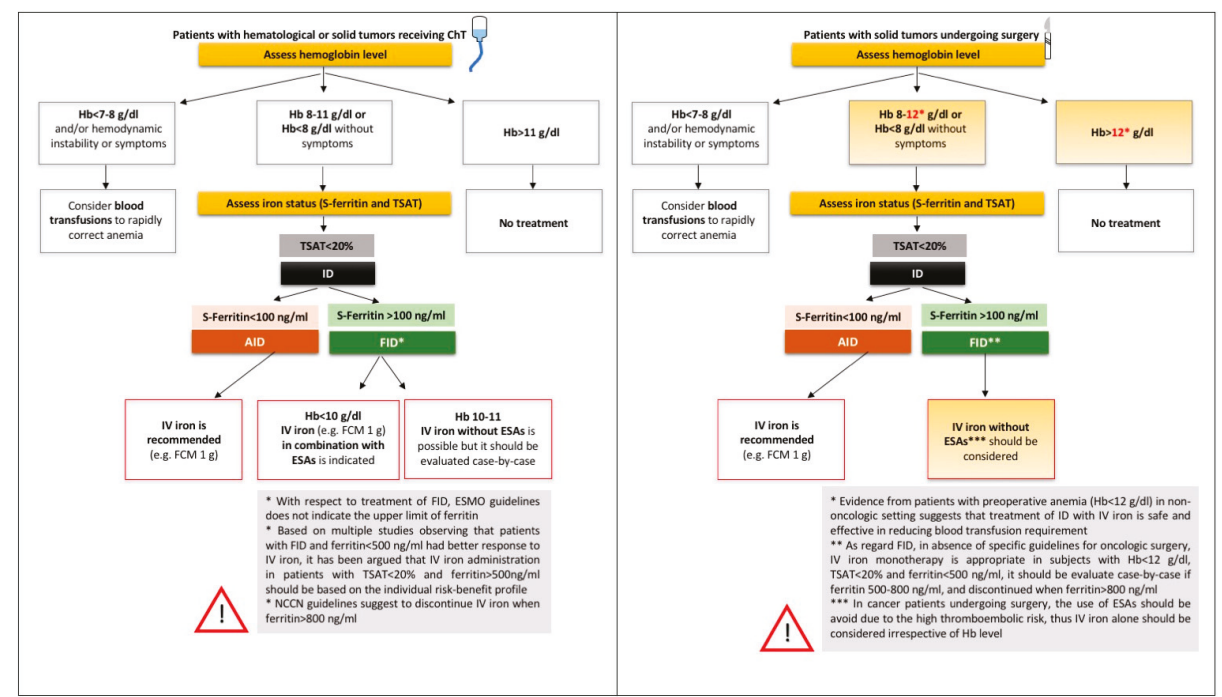

Figure 2. Possible algorithms for the diagnosis and treatment of ID anemia in cancer patients. The proposed algorithms are based on available guidelines for cancer anemia and the most recent clinical evidence regarding preoperative anemia management in the oncologic surgery field. Grey areas underline current uncovered issues.

\section{Concluding Remarks}

ID represents a major cause of cancer anemia, especially in patients with gastrointestinal tumors, advanced disease, receiving ChT, and in the perioperative setting. Nevertheless, ID in cancer often remains an overlooked and undertreated condition. This is partly due to difficulties in defining ID based on traditional laboratory biomarkers. Increasing evidence suggests the effectiveness of IV iron administration to treat anemia in cancer patients, alone or in combination with ESAs, in terms of improvement of QoL and reduction of transfusion needs. Further studies on better biomarkers of ID (including hepcidin) and on long-term safety of IV iron administration in this peculiar and challenging condition are required.

Author Contributions: Writing—original draft preparation: F.B., G.M. and S.U.; writing—review and editing: A.C. and D.G. 
Funding: This research was partially supported by funding for research on iron metabolism to D.G. by Fondazione Cariverona (2014.0851) and the Veneto Region (PRIHTA no. 2014-00000451).

Conflicts of Interest: The authors declare no relevant conflicts of interest.

\section{References}

1. Ludwig, H.; Van Belle, S.; Barrett-Lee, P.; Birgegard, G.; Bokemeyer, C.; Gascon, P.; Kosmidis, P.; Krzakowski, M.; Nortier, J.; Olmi, P.; et al. The European cancer anaemia survey (ecas): A large, multinational, prospective survey defining the prevalence, incidence, and treatment of anaemia in cancer patients. Eur. J. Cancer 2004, 40, 2293-2306. [CrossRef] [PubMed]

2. National Comprehensive Cancer Network. Available online: http://www.nccn.org/professionals/physici an_gls/PDF/anemia.pdf (accessed on 27 August 2018).

3. Knight, K.; Wade, S.; Balducci, L. Prevalence and outcomes of anemia in cancer: A systematic review of the literature. Am. J. Med. 2004, 116, 11S-26S. [CrossRef] [PubMed]

4. Grotto, H.Z. Anaemia of cancer: An overview of mechanisms involved in its pathogenesis. Med. Oncol. 2008, 25, 12-21. [CrossRef] [PubMed]

5. Gilreath, J.A.; Stenehjem, D.D.; Rodgers, G.M. Diagnosis and treatment of cancer-related anemia. Am. J. Hematol. 2014, 89, 203-212. [CrossRef] [PubMed]

6. Gaspar, B.L.; Sharma, P.; Das, R. Anemia in malignancies: Pathogenetic and diagnostic considerations. Hematology 2015, 20, 18-25. [CrossRef] [PubMed]

7. Adamson, J.W. The anemia of inflammation/malignancy: Mechanisms and management. Hematol. Am. Soc. Hematol. Educ. Program 2008, 2008, 159-165. [CrossRef] [PubMed]

8. van Eeden, R.; Rapoport, B.L. Current trends in the management of anaemia in solid tumours and haematological malignancies. Curr. Opin. Support Palliat. Care 2016, 10, 189-194. [CrossRef] [PubMed]

9. Harper, P.; Littlewood, T. Anaemia of cancer: Impact on patient fatigue and long-term outcome. Oncology 2005, 69, 2-7. [CrossRef] [PubMed]

10. Crawford, J.; Cella, D.; Cleeland, C.S.; Cremieux, P.Y.; Demetri, G.D.; Sarokhan, B.J.; Slavin, M.B.; Glaspy, J.A. Relationship between changes in hemoglobin level and quality of life during chemotherapy in anemic cancer patients receiving epoetin alfa therapy. Cancer 2002, 95, 888-895. [CrossRef] [PubMed]

11. Caro, J.J.; Salas, M.; Ward, A.; Goss, G. Anemia as an independent prognostic factor for survival in patients with cancer: A systemic, quantitative review. Cancer 2001, 91, 2214-2221. [CrossRef]

12. Schito, L.; Semenza, G.L. Hypoxia-inducible factors: Master regulators of cancer progression. Trends Cancer 2016, 2, 758-770. [CrossRef] [PubMed]

13. Deeb, G.; Vaughan, M.M.; McInnis, I.; Ford, L.A.; Sait, S.N.; Starostik, P.; Wetzler, M.; Mashtare, T.; Wang, E.S. Hypoxia-inducible factor-1alpha protein expression is associated with poor survival in normal karyotype adult acute myeloid leukemia. Leuk. Res. 2011, 35, 579-584. [CrossRef] [PubMed]

14. Morine, Y.; Shimada, M.; Utsunomiya, T.; Imura, S.; Ikemoto, T.; Mori, H.; Hanaoka, J.; Kanamoto, M.; Iwahashi, S.; Miyake, H. Hypoxia inducible factor expression in intrahepatic cholangiocarcinoma. Hepatogastroenterology 2011, 58, 1439-1444. [CrossRef] [PubMed]

15. Zheng, S.S.; Chen, X.H.; Yin, X.; Zhang, B.H. Prognostic significance of hif-1alpha expression in hepatocellular carcinoma: A meta-analysis. PLoS ONE 2013, 8, e65753.

16. Semenza, G.L. Hif-1 and tumor progression: Pathophysiology and therapeutics. Trends Mol. Med. 2002, 8, S62-S67. [CrossRef]

17. Harrison, L.B.; Chadha, M.; Hill, R.J.; Hu, K.; Shasha, D. Impact of tumor hypoxia and anemia on radiation therapy outcomes. Oncologist 2002, 7, 492-508. [CrossRef] [PubMed]

18. Vaupel, P.; Harrison, L. Tumor hypoxia: Causative factors, compensatory mechanisms, and cellular response. Oncologist 2004, 9, 4-9. [CrossRef] [PubMed]

19. Cella, D.; Dobrez, D.; Glaspy, J. Control of cancer-related anemia with erythropoietic agents: A review of evidence for improved quality of life and clinical outcomes. Ann. Oncol. 2003, 14, 511-519. [CrossRef] [PubMed]

20. Calabrich, A.; Katz, A. Management of anemia in cancer patients. Future Oncol. 2011, 7, 507-517. [CrossRef] [PubMed] 
21. Littlewood, T.J.; Bajetta, E.; Nortier, J.W.; Vercammen, E.; Rapoport, B.; Epoetin Alfa Study, G. Effects of epoetin alfa on hematologic parameters and quality of life in cancer patients receiving nonplatinum chemotherapy: Results of a randomized, double-blind, placebo-controlled trial. J. Clin. Oncol. 2001, 19, 2865-2874. [CrossRef] [PubMed]

22. Cata, J.P.; Wang, H.; Gottumukkala, V.; Reuben, J.; Sessler, D.I. Inflammatory response, immunosuppression, and cancer recurrence after perioperative blood transfusions. Br. J. Anaesth. 2013, 110, 690-701. [CrossRef] [PubMed]

23. Acheson, A.G.; Brookes, M.J.; Spahn, D.R. Effects of allogeneic red blood cell transfusions on clinical outcomes in patients undergoing colorectal cancer surgery: A systematic review and meta-analysis. Ann. Surg. 2012, 256, 235-244. [CrossRef] [PubMed]

24. Liu, L.; Wang, Z.; Jiang, S.; Shao, B.; Liu, J.; Zhang, S.; Zhou, Y.; Zhou, Y.; Zhang, Y. Perioperative allogenenic blood transfusion is associated with worse clinical outcomes for hepatocellular carcinoma: A meta-analysis. PLoS ONE 2013, 8, e64261. [CrossRef] [PubMed]

25. Luan, H.; Ye, F.; Wu, L.; Zhou, Y.; Jiang, J. Perioperative blood transfusion adversely affects prognosis after resection of lung cancer: A systematic review and a meta-analysis. BMC Surg. 2014, 14, 34. [CrossRef] [PubMed]

26. Sun, C.; Wang, Y.; Yao, H.S.; Hu, Z.Q. Allogeneic blood transfusion and the prognosis of gastric cancer patients: Systematic review and meta-analysis. Int. J. Surg. 2015, 13, 102-110. [CrossRef] [PubMed]

27. Prescott, L.S.; Taylor, J.S.; Lopez-Olivo, M.A.; Munsell, M.F.; VonVille, H.M.; Lairson, D.R.; Bodurka, D.C. How low should we go: A systematic review and meta-analysis of the impact of restrictive red blood cell transfusion strategies in oncology. Cancer Treat Rev. 2016, 46, 1-8. [CrossRef] [PubMed]

28. Boone, J.D.; Kim, K.H.; Marques, M.; Straughn, J.M. Compliance rates and outcomes associated with a restrictive transfusion policy in gynecologic oncology patients. Gynecol. Oncol. 2014, 132, 227-230. [CrossRef] [PubMed]

29. Alkhalid, Y.; Lagman, C.; Sheppard, J.P.; Nguyen, T.; Prashant, G.N.; Ziman, A.F.; Yang, I. Restrictive transfusion threshold is safe in high-risk patients undergoing brain tumor surgery. Clin. Neurol. Neurosurg. 2017, 163, 103-107. [CrossRef] [PubMed]

30. de Almeida, J.P.; Vincent, J.L.; Galas, F.R.; de Almeida, E.P.; Fukushima, J.T.; Osawa, E.A.; Bergamin, F.; Park, C.L.; Nakamura, R.E.; Fonseca, S.M.; et al. Transfusion requirements in surgical oncology patients: A prospective, randomized controlled trial. Anesthesiology 2015, 122, 29-38. [CrossRef] [PubMed]

31. Vansteenkiste, J.; Poulsen, E.; Rossi, G.; Glaspy, J. Darbepoetin alfa: Impact on treatment for chemotherapyinduced anemia and considerations in special populations. Oncology 2002, 16, 45-55. [PubMed]

32. Hedenus, M.; Adriansson, M.; San Miguel, J.; Kramer, M.H.; Schipperus, M.R.; Juvonen, E.; Taylor, K.; Belch, A.; Altes, A.; Martinelli, G.; et al. Efficacy and safety of darbepoetin alfa in anaemic patients with lymphoproliferative malignancies: A randomized, double-blind, placebo-controlled study. Br. J. Haematol. 2003, 122, 394-403. [CrossRef] [PubMed]

33. Bennett, C.L.; Silver, S.M.; Djulbegovic, B.; Samaras, A.T.; Blau, C.A.; Gleason, K.J.; Barnato, S.E.; Elverman, K.M.; Courtney, D.M.; McKoy, J.M.; et al. Venous thromboembolism and mortality associated with recombinant erythropoietin and darbepoetin administration for the treatment of cancer-associated anemia. JAMA 2008, 299, 914-924. [CrossRef] [PubMed]

34. Samaras, A.T.; Bennett, C.L. Risks of venous thromboembolism and mortality associated with erythropoiesis-stimulating agents for the treatment of cancer-associated anemia. Am. J. Hematol. Oncol. 2008, 7, 327-332. [PubMed]

35. Henke, M.; Laszig, R.; Rube, C.; Schafer, U.; Haase, K.D.; Schilcher, B.; Mose, S.; Beer, K.T.; Burger, U.; Dougherty, C.; et al. Erythropoietin to treat head and neck cancer patients with anaemia undergoing radiotherapy: Randomised, double-blind, placebo-controlled trial. Lancet 2003, 362, 1255-1260. [CrossRef]

36. Wright, J.R.; Ung, Y.C.; Julian, J.A.; Pritchard, K.I.; Whelan, T.J.; Smith, C.; Szechtman, B.; Roa, W.; Mulroy, L.; Rudinskas, L.; et al. Randomized, double-blind, placebo-controlled trial of erythropoietin in non-small-cell lung cancer with disease-related anemia. J. Clin. Oncol. 2007, 25, 1027-1032. [CrossRef] [PubMed]

37. Smith, R.E., Jr.; Aapro, M.S.; Ludwig, H.; Pinter, T.; Smakal, M.; Ciuleanu, T.E.; Chen, L.; Lillie, T.; Glaspy, J.A. Darbepoetin alpha for the treatment of anemia in patients with active cancer not receiving chemotherapy or radiotherapy: Results of a phase iii, multicenter, randomized, double-blind, placebo-controlled study. J. Clin. Oncol. 2008, 26, 1040-1050. [CrossRef] [PubMed] 
38. Farrell, F.; Lee, A. The erythropoietin receptor and its expression in tumor cells and other tissues. Oncologist 2004, 9, 18-30. [CrossRef] [PubMed]

39. Aapro, M.; Jelkmann, W.; Constantinescu, S.N.; Leyland-Jones, B. Effects of erythropoietin receptors and erythropoiesis-stimulating agents on disease progression in cancer. Br. J. Cancer 2012, 106, 1249-1258. [CrossRef] [PubMed]

40. Aapro, M.; Moebus, V.; Nitz, U.; O'Shaughnessy, J.; Pronzato, P.; Untch, M.; Tomita, D.; Bohac, C.; Leyland-Jones, B. Safety and efficacy outcomes with erythropoiesis-stimulating agents in patients with breast cancer: A meta-analysis. Ann. Oncol. 2015, 26, 688-695. [CrossRef] [PubMed]

41. Bennett, C.L.; Lai, S.Y.; Sartor, O.; Georgantopoulos, P.; Hrushesky, W.J.; Henke, M.; Armitage, J.O. Consensus on the existence of functional erythropoietin receptors on cancer cells. JAMA Oncol. 2016, 2, 134-136. [CrossRef] [PubMed]

42. Glaspy, J.; Crawford, J.; Vansteenkiste, J.; Henry, D.; Rao, S.; Bowers, P.; Berlin, J.A.; Tomita, D.; Bridges, K.; Ludwig, H. Erythropoiesis-stimulating agents in oncology: A study-level meta-analysis of survival and other safety outcomes. Br. J. Cancer 2010, 102, 301-315. [CrossRef] [PubMed]

43. Ohashi, Y.; Uemura, Y.; Fujisaka, Y.; Sugiyama, T.; Ohmatsu, H.; Katsumata, N.; Okamoto, R.; Saijo, N.; Hotta, T. Meta-analysis of epoetin beta and darbepoetin alfa treatment for chemotherapy-induced anemia and mortality: Individual patient data from japanese randomized, placebo-controlled trials. Cancer Sci. 2013, 104, 481-485. [CrossRef] [PubMed]

44. Rizzo, J.D.; Brouwers, M.; Hurley, P.; Seidenfeld, J.; Arcasoy, M.O.; Spivak, J.L.; Bennett, C.L.; Bohlius, J.; Evanchuk, D.; Goode, M.J.; et al. American society of hematology/american society of clinical oncology clinical practice guideline update on the use of epoetin and darbepoetin in adult patients with cancer. Blood 2010, 116, 4045-4059. [CrossRef] [PubMed]

45. Ludwig, H.; Muldur, E.; Endler, G.; Hubl, W. Prevalence of iron deficiency across different tumors and its association with poor performance status, disease status and anemia. Ann. Oncol. 2013, 24, 1886-1892. [CrossRef] [PubMed]

46. Aapro, M.; Osterborg, A.; Gascon, P.; Ludwig, H.; Beguin, Y. Prevalence and management of cancer-related anaemia, iron deficiency and the specific role of i.V. Iron. Ann. Oncol. 2012, 23, 1954-1962. [CrossRef] [PubMed]

47. Ludwig, H.; Evstatiev, R.; Kornek, G.; Aapro, M.; Bauernhofer, T.; Buxhofer-Ausch, V.; Fridrik, M.; Geissler, D.; Geissler, K.; Gisslinger, H.; et al. Iron metabolism and iron supplementation in cancer patients. Wien. Klin. Wochenschr. 2015, 127, 907-919. [CrossRef] [PubMed]

48. Nemeth, E.; Rivera, S.; Gabayan, V.; Keller, C.; Taudorf, S.; Pedersen, B.K.; Ganz, T. Il-6 mediates hypoferremia of inflammation by inducing the synthesis of the iron regulatory hormone hepcidin. J. Clin. Investig. 2004, 113, 1271-1276. [CrossRef] [PubMed]

49. Ganz, T.; Nemeth, E. Iron homeostasis in host defence and inflammation. Nat. Rev. Immunol. 2015, 15, 500-510. [CrossRef] [PubMed]

50. Goodnough, L.T.; Nemeth, E.; Ganz, T. Detection, evaluation, and management of iron-restricted erythropoiesis. Blood 2010, 116, 4754-4761. [CrossRef] [PubMed]

51. Weiss, G.; Goodnough, L.T. Anemia of chronic disease. N. Engl. J. Med. 2005, 352, 1011-1023. [CrossRef] [PubMed]

52. Ueda, N.; Takasawa, K. Role of hepcidin-25 in chronic kidney disease: Anemia and beyond. Curr. Med. Chem. 2017, 24, 1417-1452. [CrossRef] [PubMed]

53. Ueda, N.; Takasawa, K. Impact of inflammation on ferritin, hepcidin and the management of iron deficiency anemia in chronic kidney disease. Nutrients 2018, 10, 1173. [CrossRef] [PubMed]

54. Aapro, M.; Beguin, Y.; Bokemeyer, C.; Dicato, M.; Gascon, P.; Glaspy, J.; Hofmann, A.; Link, H.; Littlewood, T.; Ludwig, H.; et al. Management of anaemia and iron deficiency in patients with cancer: Esmo clinical practice guidelines. Ann. Oncol. 2018. [CrossRef]

55. Anand, I.S.; Gupta, P. Anemia and iron deficiency in heart failure: Current concepts and emerging therapies. Circulation 2018, 138, 80-98. [CrossRef] [PubMed]

56. Steinmetz, T.; Tschechne, B.; Harlin, O.; Klement, B.; Franzem, M.; Wamhoff, J.; Tesch, H.; Rohrberg, R.; Marschner, N. Clinical experience with ferric carboxymaltose in the treatment of cancer- and chemotherapyassociated anaemia. Ann. Oncol. 2013, 24, 475-482. [CrossRef] [PubMed] 
57. Verhaeghe, L.; Bruyneel, L.; Stragier, E.; Ferrante, M.; Dierickx, D.; Prenen, H. The effectiveness of intravenous iron for iron deficiency anemia in gastrointestinal cancer patients: A retrospective study. Ann. Gastroenterol. 2017, 30, 654-663. [CrossRef] [PubMed]

58. Cappellini, M.D.; Comin-Colet, J.; de Francisco, A.; Dignass, A.; Doehner, W.; Lam, C.S.; Macdougall, I.C.; Rogler, G.; Camaschella, C.; Kadir, R.; et al. Iron deficiency across chronic inflammatory conditions: International expert opinion on definition, diagnosis, and management. Am. J. Hematol. 2017, 92, 1068-1078. [CrossRef] [PubMed]

59. Pfeiffer, C.M.; Looker, A.C. Laboratory methodologies for indicators of iron status: Strengths, limitations, and analytical challenges. Am. J. Clin. Nutr. 2017, 106, 1606S-1614S. [CrossRef] [PubMed]

60. Girelli, D.; Nemeth, E.; Swinkels, D.W. Hepcidin in the diagnosis of iron disorders. Blood 2016, 127, $2809-2813$. [CrossRef] [PubMed]

61. Theurl, I.; Aigner, E.; Theurl, M.; Nairz, M.; Seifert, M.; Schroll, A.; Sonnweber, T.; Eberwein, L.; Witcher, D.R.; Murphy, A.T.; et al. Regulation of iron homeostasis in anemia of chronic disease and iron deficiency anemia: Diagnostic and therapeutic implications. Blood 2009, 113, 5277-5286. [CrossRef] [PubMed]

62. van Santen, S.; van Dongen-Lases, E.C.; de Vegt, F.; Laarakkers, C.M.; van Riel, P.L.; van Ede, A.E.; Swinkels, D.W. Hepcidin and hemoglobin content parameters in the diagnosis of iron deficiency in rheumatoid arthritis patients with anemia. Arthritis Rheum. 2011, 63, 3672-3680. [CrossRef] [PubMed]

63. Bergamaschi, G.; Di Sabatino, A.; Albertini, R.; Costanzo, F.; Guerci, M.; Masotti, M.; Pasini, A.; Massari, A.; Campostrini, N.; Corbella, M.; et al. Serum hepcidin in inflammatory bowel diseases: Biological and clinical significance. Inflamm. Bowvel Dis. 2013, 19, 2166-2172. [CrossRef] [PubMed]

64. Shu, T.; Jing, C.; Lv, Z.; Xie, Y.; Xu, J.; Wu, J. Hepcidin in tumor-related iron deficiency anemia and tumor-related anemia of chronic disease: Pathogenic mechanisms and diagnosis. Eur. J. Haematol. 2015, 94, 67-73. [CrossRef] [PubMed]

65. Prentice, A.M.; Doherty, C.P.; Abrams, S.A.; Cox, S.E.; Atkinson, S.H.; Verhoef, H.; Armitage, A.E.; Drakesmith, H. Hepcidin is the major predictor of erythrocyte iron incorporation in anemic African children. Blood 2012, 119, 1922-1928. [CrossRef] [PubMed]

66. Steensma, D.P.; Sasu, B.J.; Sloan, J.A.; Tomita, D.K.; Loprinzi, C.L. Serum hepcidin levels predict response to intravenous iron and darbepoetin in chemotherapy-associated anemia. Blood 2015, 125, 3669-3671. [CrossRef] [PubMed]

67. van der Vorm, L.N.; Hendriks, J.C.; Laarakkers, C.M.; Klaver, S.; Armitage, A.E.; Bamberg, A.; Geurts-Moespot, A.J.; Girelli, D.; Herkert, M.; Itkonen, O.; et al. Toward worldwide hepcidin assay harmonization: Identification of a commutable secondary reference material. Clin. Chem. 2016, 62, 993-1001. [CrossRef] [PubMed]

68. Auerbach, M.; Ballard, H.; Trout, J.R.; Mcllwain, M.; Ackerman, A.; Bahrain, H.; Balan, S.; Barker, L.; Rana, J. Intravenous iron optimizes the response to recombinant human erythropoietin in cancer patients with chemotherapy-related anemia: A multicenter, open-label, randomized trial. J. Clin. Oncol. 2004, 22, 1301-1307. [CrossRef] [PubMed]

69. Hedenus, M.; Birgegard, G.; Nasman, P.; Ahlberg, L.; Karlsson, T.; Lauri, B.; Lundin, J.; Larfars, G.; Osterborg, A. Addition of intravenous iron to epoetin beta increases hemoglobin response and decreases epoetin dose requirement in anemic patients with lymphoproliferative malignancies: A randomized multicenter study. Leukemia 2007, 21, 627-632. [CrossRef] [PubMed]

70. Henry, D.H. Epoetin alfa treatment for patients with chemotherapy-induced anemia. Support Cancer Ther. 2007, 4, 78-91. [CrossRef] [PubMed]

71. Bastit, L.; Vandebroek, A.; Altintas, S.; Gaede, B.; Pinter, T.; Suto, T.S.; Mossman, T.W.; Smith, K.E.; Vansteenkiste, J.F. Randomized, multicenter, controlled trial comparing the efficacy and safety of darbepoetin alpha administered every 3 weeks with or without intravenous iron in patients with chemotherapy-induced anemia. J. Clin. Oncol. 2008, 26, 1611-1618. [CrossRef] [PubMed]

72. Pedrazzoli, P.; Farris, A.; Del Prete, S.; Del Gaizo, F.; Ferrari, D.; Bianchessi, C.; Colucci, G.; Desogus, A.; Gamucci, T.; Pappalardo, A.; et al. Randomized trial of intravenous iron supplementation in patients with chemotherapy-related anemia without iron deficiency treated with darbepoetin alpha. J. Clin. Oncol. 2008, 26, 1619-1625. [CrossRef] [PubMed]

73. Auerbach, M.; Silberstein, P.T.; Webb, R.T.; Averyanova, S.; Ciuleanu, T.E.; Shao, J.; Bridges, K. Darbepoetin alfa 300 or 500 mug once every 3 weeks with or without intravenous iron in patients with chemotherapy-induced anemia. Am. J. Hematol. 2010, 85, 655-663. [CrossRef] [PubMed] 
74. Mhaskar, R.; Wao, H.; Miladinovic, B.; Kumar, A.; Djulbegovic, B. The role of iron in the management of chemotherapy-induced anemia in cancer patients receiving erythropoiesis-stimulating agents. Cochrane Database Syst. Rev. 2016, 2, CD009624. [CrossRef] [PubMed]

75. Gafter-Gvili, A.; Rozen-Zvi, B.; Vidal, L.; Leibovici, L.; Vansteenkiste, J.; Gafter, U.; Shpilberg, O. Intravenous iron supplementation for the treatment of chemotherapy-induced anaemia-Systematic review and meta-analysis of randomised controlled trials. Acta Oncol. 2013, 52, 18-29. [CrossRef] [PubMed]

76. Petrelli, F.; Borgonovo, K.; Cabiddu, M.; Lonati, V.; Barni, S. Addition of iron to erythropoiesis-stimulating agents in cancer patients: A meta-analysis of randomized trials. J. Cancer Res. Clin. Oncol. 2012, 138, 179-187. [CrossRef] [PubMed]

77. Girelli, D.; Ugolini, S.; Busti, F.; Marchi, G.; Castagna, A. Modern iron replacement therapy: Clinical and pathophysiological insights. Int. J. Hematol. 2018, 107, 16-30. [CrossRef] [PubMed]

78. Kim, Y.T.; Kim, S.W.; Yoon, B.S.; Cho, H.J.; Nahm, E.J.; Kim, S.H.; Kim, J.H.; Kim, J.W. Effect of intravenously administered iron sucrose on the prevention of anemia in the cervical cancer patients treated with concurrent chemoradiotherapy. Gynecol. Oncol. 2007, 105, 199-204. [CrossRef] [PubMed]

79. Dangsuwan, P.; Manchana, T. Blood transfusion reduction with intravenous iron in gynecologic cancer patients receiving chemotherapy. Gynecol. Oncol. 2010, 116, 522-525. [CrossRef] [PubMed]

80. Athibovonsuk, P.; Manchana, T.; Sirisabya, N. Prevention of blood transfusion with intravenous iron in gynecologic cancer patients receiving platinum-based chemotherapy. Gynecol. Oncol. 2013, 131, 679-682. [CrossRef] [PubMed]

81. Hedenus, M.; Karlsson, T.; Ludwig, H.; Rzychon, B.; Felder, M.; Roubert, B.; Birgegard, G. Intravenous iron alone resolves anemia in patients with functional iron deficiency and lymphoid malignancies undergoing chemotherapy. Med. Oncol. 2014, 31, 302. [CrossRef] [PubMed]

82. Coussirou, J.; Debourdeau, A.; Stancu, A.; Jean, C.; Azouza, W.; Chanet, B.; De Crozals, F.; Boustany, R.; Debourdeau, P. Impact of ferric carboxymaltose on the evolution of hemoglobin and ecog performance status in iron-deficient patients with solid tumors: A 3-month follow-up retrospective study. Support Care Cancer 2018, 26, 3827-3834. [CrossRef] [PubMed]

83. Clevenger, B.; Mallett, S.V.; Klein, A.A.; Richards, T. Patient blood management to reduce surgical risk. Br. J. Surg. 2015, 102, 1325-1337. [CrossRef] [PubMed]

84. Munoz, M.; Gomez-Ramirez, S.; Campos, A.; Ruiz, J.; Liumbruno, G.M. Pre-operative anaemia: Prevalence, consequences and approaches to management. Blood Transfus. 2015, 13, 370-379. [PubMed]

85. Rineau, E.; Chaudet, A.; Chassier, C.; Bizot, P.; Lasocki, S. Implementing a blood management protocol during the entire perioperative period allows a reduction in transfusion rate in major orthopedic surgery: A before-after study. Transfusion 2016, 56, 673-681. [CrossRef] [PubMed]

86. Yoo, Y.C.; Shim, J.K.; Kim, J.C.; Jo, Y.Y.; Lee, J.H.; Kwak, Y.L. Effect of single recombinant human erythropoietin injection on transfusion requirements in preoperatively anemic patients undergoing valvular heart surgery. Anesthesiology 2011, 115, 929-937. [CrossRef] [PubMed]

87. Ecker, B.L.; Simmons, K.D.; Zaheer, S.; Poe, S.L.; Bartlett, E.K.; Drebin, J.A.; Fraker, D.L.; Kelz, R.R.; Roses, R.E.; Karakousis, G.C. Blood transfusion in major abdominal surgery for malignant tumors: A trend analysis using the national surgical quality improvement program. JAMA Surg. 2016, 151, 518-525. [CrossRef] [PubMed]

88. Dixon, E.; Datta, I.; Sutherland, F.R.; Vauthey, J.N. Blood loss in surgical oncology: Neglected quality indicator? J. Surg. Oncol. 2009, 99, 508-512. [CrossRef] [PubMed]

89. Keding, V.; Zacharowski, K.; Bechstein, W.O.; Meybohm, P.; Schnitzbauer, A.A. Patient blood management improves outcome in oncologic surgery. World J. Surg. Oncol. 2018, 16, 159. [CrossRef] [PubMed]

90. Borstlap, W.A.; Stellingwerf, M.E.; Moolla, Z.; Musters, G.D.; Buskens, C.J.; Tanis, P.J.; Bemelman, W.A. Iron therapy for the treatment of preoperative anaemia in patients with colorectal carcinoma: A systematic review. Colorectal Dis. 2015, 17, 1044-1054. [CrossRef] [PubMed]

91. Keeler, B.D.; Simpson, J.A.; Ng, S.; Tselepis, C.; Iqbal, T.; Brookes, M.J.; Acheson, A.G. The feasibility and clinical efficacy of intravenous iron administration for preoperative anaemia in patients with colorectal cancer. Colorectal Dis. 2014, 16, 794-800. [CrossRef] [PubMed]

92. Edwards, T.J.; Noble, E.J.; Durran, A.; Mellor, N.; Hosie, K.B. Randomized clinical trial of preoperative intravenous iron sucrose to reduce blood transfusion in anaemic patients after colorectal cancer surgery. Br. J. Surg. 2009, 96, 1122-1128. [CrossRef] [PubMed] 
93. Lidder, P.G.; Sanders, G.; Whitehead, E.; Douie, W.J.; Mellor, N.; Lewis, S.J.; Hosie, K.B. Pre-operative oral iron supplementation reduces blood transfusion in colorectal surgery-A prospective, randomised, controlled trial. Ann. R. Coll. Surg. Engl. 2007, 89, 418-421. [CrossRef] [PubMed]

94. Calleja, J.L.; Delgado, S.; del Val, A.; Hervas, A.; Larraona, J.L.; Teran, A.; Cucala, M.; Mearin, F.; Colon Cancer Study, G. Ferric carboxymaltose reduces transfusions and hospital stay in patients with colon cancer and anemia. Int. J. Colorectal Dis. 2016, 31, 543-551. [CrossRef] [PubMed]

95. Froessler, B.; Palm, P.; Weber, I.; Hodyl, N.A.; Singh, R.; Murphy, E.M. The important role for intravenous iron in perioperative patient blood management in major abdominal surgery: A randomized controlled trial. Ann. Surg. 2016, 264, 41-46. [CrossRef] [PubMed]

96. Torti, S.V.; Torti, F.M. Iron and cancer: More ore to be mined. Nat. Rev. Cancer 2013, 13, 342-355. [CrossRef] [PubMed]

97. Manz, D.H.; Blanchette, N.L.; Paul, B.T.; Torti, F.M.; Torti, S.V. Iron and cancer: Recent insights. Ann. N. Y. Acad. Sci. 2016, 1368, 149-161. [CrossRef] [PubMed]

98. Gilreath, J.A.; Stenehjem, D.D.; Rodgers, G.M. Total dose iron dextran infusion in cancer patients: Is it safe2+? J. Natl. Compr. Cancer Netw. 2012, 10, 669-676. [CrossRef]

99. Beguin, Y.; Aapro, M.; Ludwig, H.; Mizzen, L.; Osterborg, A. Epidemiological and nonclinical studies investigating effects of iron in carcinogenesis-A critical review. Crit. Rev. Oncol. Hematol. 2014, 89, 1-15. [CrossRef] [PubMed]

100. Jaspers, A.; Baron, F.; Servais, S.; Lejeune, M.; Willems, E.; Seidel, L.; Hafraoui, K.; Bonnet, C.; Beguin, Y. Erythropoietin therapy after allogeneic hematopoietic cell transplantation has no impact on long-term survival. Am. J. Hematol. 2015, 90, E197-E199. [CrossRef] [PubMed]

101. Wilson, M.J.; Dekker, J.W.T.; Buettner, S.; Harlaar, J.J.; Jeekel, J.; Schipperus, M.; Zwaginga, J.J. The effect of intravenous iron therapy on long-term survival in anaemic colorectal cancer patients: Results from a matched cohort study. Surg. Oncol. 2018, 27, 192-199. [CrossRef] [PubMed]

102. Nairz, M.; Dichtl, S.; Schroll, A.; Haschka, D.; Tymoszuk, P.; Theurl, I.; Weiss, G. Iron and innate antimicrobial immunity-depriving the pathogen, defending the host. J. Trace Elem. Med. Biol. 2018, 48, 118-133. [CrossRef] [PubMed]

103. Busti, F.; Campostrini, N.; Martinelli, N.; Girelli, D. Iron deficiency in the elderly population, revisited in the hepcidin era. Front. Pharmacol. 2014, 5, 83. [CrossRef] [PubMed] 
Review

\title{
Iron Regulation: Macrophages in Control
}

\author{
Nyamdelger Sukhbaatar and Thomas Weichhart * \\ Medical University of Vienna, Center for Pathobiochemistry and Genetics, Vienna 1090, Austria; \\ nyamdelger.sukhbaatar@meduniwien.ac.at \\ * Correspondence: thomas.weichhart@meduniwien.ac.at; Tel.: +43-1-40160-56515
}

Received: 15 November 2018; Accepted: 12 December 2018; Published: 14 December 2018

\begin{abstract}
Macrophages are sentinel cells of the innate immune system and have important functions in development, tissue homeostasis, and immunity. These phylogenetically ancient cells also developed a variety of mechanisms to control erythropoiesis and the handling of iron. Red pulp macrophages in the spleen, Kupffer cells in the liver, and central nurse macrophages in the bone marrow ensure a coordinated metabolism of iron to support erythropoiesis. Phagocytosis of senescent red blood cells by macrophages in the spleen and the liver provide a continuous delivery of recycled iron under steady-state conditions and during anemic stress. Central nurse macrophages in the bone marrow utilize this iron and provide a cellular scaffold and niche to promote differentiation of erythroblasts. This review focuses on the role of the distinct macrophage populations that contribute to efficient iron metabolism and highlight important cellular and systemic mechanisms involved in iron-regulating processes.
\end{abstract}

Keywords: macrophage; central nurse macrophage; red pulp macrophage; Kupffer cell; iron metabolism; erythropoiesis; erythroblastic islands; erythrophagocytosis; inflammation

\section{Introduction}

Iron is a multifaceted metal that plays a versatile role in many basic cellular processes in the body, including DNA synthesis, cellular metabolism and respiration, as well as cell growth and death mechanisms through iron-containing and iron-sequestering proteins and enzymes [1,2]. Moreover, iron is the main component of hemoglobin $(\mathrm{Hgb})$ and is thus essential for oxygen transport within erythrocytes. As a redox-active metal, it can be found in two main oxidation states in the body that determine its features, functional roles, and toxicity. Whereas divalent ferrous iron $\left(\mathrm{Fe}^{2+}\right)$ is the active compound in $\mathrm{Hgb}$ and in many enzymes, it can cause cellular toxicity by means of intracellular free radical production by Fenton reactions [3,4]. Therefore, iron is usually intracellularly stored or systemically transported as oxidized trivalent ferric iron $\left(\mathrm{Fe}^{3+}\right)$. Iron metabolism is tightly regulated by a variety of redundant mechanisms that are often conserved throughout the mammalian kingdom to adjust iron concentrations on systemic and cellular levels. In response to iron and red blood cell (RBC) demand, an orchestrated interplay between iron-processing cells, including tissue macrophages, hepatocytes, erythrocytes, and duodenal epithelial cells controls and maintains iron homeostasis. In particular, macrophage populations play a key role as cellular components of iron metabolism to maintain the balance between the availability of sufficient iron levels and the prevention of toxic amounts of iron in the body. Tissue macrophages specialized for iron recycling include red pulp macrophages (RPMs) in the spleen, central nurse macrophages in bone marrow (BM), and Kupffer cells (KCs) in the liver. These macrophage populations have a tremendous ability to recycle between $90-95 \%$ of bodily iron and to maintain efficient erythropoiesis. Distortions in the equilibrium of iron demand and supply are sensed and corrected by a network of macrophages in their niches.

Erythrophagocytic macrophages that are in direct contact with labile heme and iron developed protective mechanisms to cope with their toxicity. On the contrary, erythropoiesis requires a 
continuous delivery of iron, supplied presumably through BM macrophages. In cases of blood loss, menstrual bleeding, or pregnancy, a higher iron requirement is adjusted by increasing the intestinal absorption, the only iron-regulatory process in which a role for macrophages is currently unknown. Recent observations, however, suggested a potential role of intestinal macrophages to transiently store iron [5]. Vertebrates do not possess active iron secretory mechanisms, but mainly lose iron due to shedding and renewing of the intestinal cell layer. Distinct types of macrophages control iron-processing mechanisms in interplay with other cellular components and environmental cues. In fact, in adipose tissues a macrophage population with a high iron recycling gene expression profile was identified [6]. In obesity, this macrophage population shows an impaired ability to handle iron and adipogenesis is linked to tissue iron overload [6-8]. These findings suggest the possible general importance of macrophages in tissue iron metabolism and the role of iron as a link to metabolic disease.

Here, we review the current knowledge of the cellular processes involved in iron metabolism and the regulatory mechanisms in iron-processing macrophages.

\section{Cellular Uptake and Metabolism of Iron in Macrophages}

Macrophages are important regulators of iron metabolism by controlling cellular iron import and export. While iron is taken up by macrophages in different forms, such as transferrin-bound iron, heme iron, Hgb-bound iron, and as free iron, iron egress from macrophages occurs only through ferroportin-1 (FPN1); encoded by the gene SLC40A1 (Figure 1).

Iron uptake mechanisms that are common to macrophages include the isolation of iron from senescent erythrocytes after phagocytosis; the import of transferrin-bound iron via transferrin receptor (TfR) or non-transferrin-bound iron (NTBI) via the divalent metal transporter 1 (DMT1), as well as zinc transporter ZIP14 (SLC39A14). Heme-bound iron can be taken up via different means. Heme-hemopexin ( $\mathrm{Hpx}$ ) complexes are internalized via its receptor CD91 (LDL receptor related protein 1, LRP1) and Hgb-bound iron in complex with its scavenger haptoglobin (Hp) is imported via its receptor CD163 (scavenger receptor cysteine-rich SRCR superfamily) (Figure 1). Additional pathways of iron transport into macrophages include natural resistance-associated macrophage protein 1 (NRAMP1/SLC11A1) and divalent cation transporter 1 (DCT1/NRAMP2) [9,10]. NRAMP1 is a divalent metal transporter that is expressed on the surface to mediate iron import, as well as within late endosomes and phagolysosomes to support intracellular iron recycling after erythrophagocytosis [11-13]. Other transporters that have been involved in cellular heme transportation include the heme-carrier protein 1 (HCP1) and the feline leukemia virus group C cellular receptor 1 (FLVCR1). HCP1 was first characterized as a cellular heme transporter, and later studies identified it as a proton-coupled folate transporter (PCFT/SLC46A1) [14,15]. Because HCP1 is abundantly expressed in macrophages and colocalizes with Hgb-Hp complexes, which are taken up via CD163, indeed suggest its dual role in cellular transport of heme and folate [16]. Besides implicated in heme uptake, other studies link FLVCR1 to cytoplasmic heme export that prevents intracellular heme overload [17,18]. Furthermore, heme responsive gene 1 (HRG1/SLC48A1) enables the transport of heme out of the phagolysosomes in erythrocyte-digesting macrophages. HRG1 is strongly expressed in macrophages and colocalizes with NRAMP1 to erythrophagolysosomes [19-21].

Ferritin is the main iron storage complex in cells (see below), but it can also be found in plasma. Two different ferritin receptors have been described that mediate uptake of ferritin-bound iron: Heavy chain H-ferritin (FtH) receptor T cell immunoglobulin and mucin domain 2 (TIM2) and light chain L-ferritin (FtL) receptor scavenger receptor, member 5 (Scara5) [22,23]. 


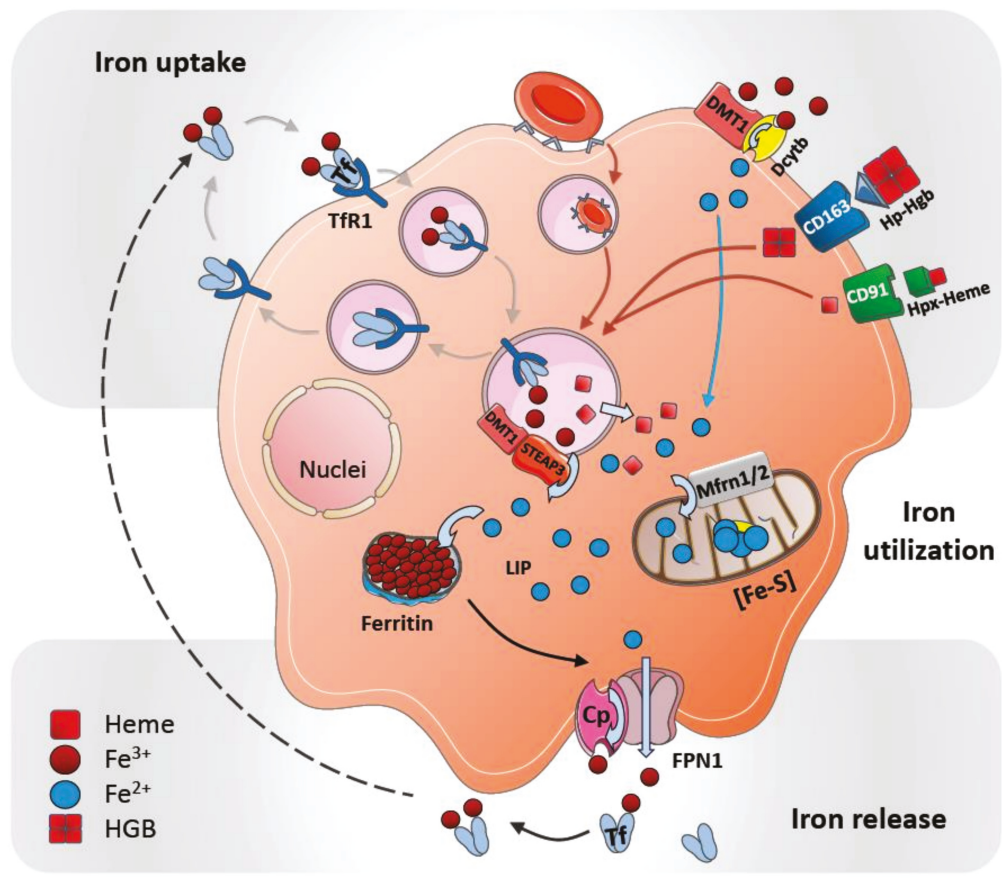

Figure 1. Iron metabolism by macrophages. General steps of iron uptake, acquisition, storage and release in the macrophage: In addition to iron extraction from red blood cells by erythrophagocytosis, macrophages express a variety of receptors to acquire iron from different sources. Transferrin-bound iron can be taken up by the transferrin receptor (TfR or CD71) and the complex is internalized by clathrin coated endocytosis followed by iron release at a low endosomal $\mathrm{pH}$. Empty apo-transferrin and transferrin receptor complex are recycled again (grey arrows). Non-transferrin iron can be acquired directly via divalent metal transporter 1 (DMT-1) that is associated with duodenal cytochrome B (DcytB) (blue arrow). CD91 (LRP1) receptors scavenge hemopexin-bound heme (Hpx-Heme) iron, whereas haptoglobin- hemoglobin ( $\mathrm{Hp}-\mathrm{Hgb}$ ) complex is taken up through CD163 receptor (red arrows). Iron transport across the endosomal membrane into the cytosol is accomplished through DMT1 after it is reduced by the endosomal reductase six-transmembrane epithelial antigen of the prostate 3 (STEAP3). The resulting intracellular free iron joins the labile iron pool (LIP), which is then either stored in ferritin or utilized in cellular processes for example in mitochondrial iron metabolism as ISC [Fe-S] after being transported through Mitoferrin 1/2 (Mfrn1/2). Iron can be exported through ferroportin 1 (FPN1) out of the cell, supported by the ferroxidase ceruloplasmin (Cp). Iron is then loaded to transferrin in order to be carried to the target cells.

After uptake, iron is liberated from the various iron-containing proteins via different mechanisms (described below). Afterwards, ferrous iron $\left(\mathrm{Fe}^{2+}\right)$ can be either translocated through the cytosol for further utilization in cellular processes, transported from the cell into the circulation or stored. In the cytosol iron becomes a part of a poorly described labile iron pool (LIP) [24,25]. It is assumed that the LIP directly triggers iron-utilizing cellular processes when cellular iron levels increase.

Excess iron is stored mainly in hepatocytes and macrophages as ferritin-a multimeric sphere-forming protein filled with up to 4500 iron atoms [26]. Ferritin consists of two distinct subunits: FtH and FtL [27]. Due to the ferroxidase activity of $\mathrm{FtH}$, cytosolic ferrous iron $\left(\mathrm{Fe}^{2+}\right)$ is oxidized into ferric iron $\left(\mathrm{Fe}^{3+}\right)$ prior to storage in the ferritin cavity [28]. Furthermore, inside splenic macrophages an iron deposition complex known as hemosiderin can be found; these deposits form 
paracrystalline structures and are surrounded by intralysosomal formations. It has been interpreted as an aggregated form of partially digested ferritin, which may be only poorly available to supply iron when needed $[29,30]$.

Iron within the cytosol of macrophages is utilized as a cofactor in many different cellular proteins that regulate energy production, hypoxic regulation, detoxification, and host defense and inflammation [31]. These proteins contain iron as part of two main cofactors: Iron-sulfur clusters (ISC) and heme groups. Both cofactors are synthesized in the mitochondria, where excess iron can also be stored as mitochondrial ferritin (FtMt). Iron is transported across the mitochondrial membrane in its ferrous form through mitoferrin 1 (Mfrn1) and Mfrn2 transporters [32]. Most complexes of the electron transport chain contain several ISC proteins that drive energy production. Important defense and inflammation-related proteins, such as myeloperoxidase, NADPH oxidase, indoleamine 2,3-dioxygenase, nitric oxide synthases or lipoxygenases that are produced by macrophages also contain iron.

Under steady-state conditions, iron is released from the main iron stores by means of FPN1, the only known iron exporter known until now. FPN1 is abundantly expressed on all iron-metabolizing macrophages [2,33]. In individuals with an FPN1 mutation-as well as when FPN1 is inactivated genetically in mice-a macrophage-specific iron overload in the spleen and liver has been observed [34-36]. These observations suggest a macrophage-specific release of iron through FPN1.

The function of FPN1 in iron-recycling macrophages is aided by a multicopper oxidase, ceruloplasmin (Cp, IREG1), which is synthesized and secreted by the liver and macrophages [37]. The transport of iron across all biological membranes is requires the oxidation and reduction of iron. Accordingly, different ferroxidases and ferroreductases are inevitable for iron transportation. $\mathrm{Cp}$ is commonly present on macrophage membranes and is thought to mediate iron oxidation to facilitate its export out of the cell by FPN1 [38]. Cp-deficient mice and humans with Cp mutations show hepatocyteand macrophage-specific iron accumulation and develop anemia indicating a critical role of $\mathrm{Cp}$ in the process of iron release from macrophages [39-41]. Cp can be expressed both as a circulating plasma protein and as a membrane-bound GPI-linked protein [42]. Interestingly, FPN1 internalization and degradation are specifically performed in the absence of membrane-bound Cp; this may suggest that $\mathrm{Cp}$ is involved in hepcidin-mediated iron regulation [39].

After oxidation to ferric iron $\left(\mathrm{Fe}^{3+}\right)$ and cellular egress, it is presumed that iron is loaded directly onto the glycoprotein transferrin, the main systemic iron transporter of ferric iron (Figure 1). Transferrin-bound iron is mostly utilized by developing erythrocytes and nurse macrophages in the BM to support erythropoiesis.

\section{Systemic Iron Metabolism}

Iron enters the body through epithelial cells of the duodenum and upper ilium in the small intestine. Iron absorption is adjusted to iron demands and can be increased to maintain iron requirements. The transfer of non-heme $\mathrm{Fe}^{3+}$ iron from the lumen of the duodenum into the epithelium is carried out by DMT1 (Figure 1).

Dietary ferric iron $\left(\mathrm{Fe}^{3+}\right)$ is first reduced at the apical brush border of the epithelium to enter the enterocytes; this relies on the activity of iron-reducing ferric reductase duodenal cytochrome B (Dcytb or CYBRD1) [43]. DMT1 is colocalized with Dcytb at the apical side of enterocytes when absorption is elevated, and their expression is induced under iron-deficient conditions. This suggests that at the apical surface of the epithelium, DMT1 and Dcytb serve as main transport coordinators $[44,45]$. As an important source of dietary iron, heme containing ferrous iron $\left(\mathrm{Fe}^{2+}\right)$ can also enter enterocytes through the heme transporter HCP1.

Once taken up, iron in the cytosol of the enterocytes might be transferred from the apical to the basolateral site by means of vesicular trafficking [46]. An alternative mechanism is that iron transfer might be mediated by "chaperones", such as the calreticulin-like protein mobilferrin [47]. 
The release of iron at the basolateral site of epithelium is facilitated by FPN1. The selective inactivation of FPN1 in the intestine results in a marked iron accumulation in duodenal enterocytes and systemic iron deficiency [48]. This confirms the essential function of FPN1 in the dietary iron release into the circulation [34,49]. Of particular relevance is the contribution of iron-oxidizing ferroxidases in FPN1-mediated egress of iron from the cellular environment. The membrane-bound ferroxidase hephaestin (HEPH), a closely related homolog to $\mathrm{Cp}$, is presumed to be responsible for iron oxidation of FPN1-exported iron specifically in the enterocytes [50,51]. In addition, several studies have revealed a significant role of $\mathrm{Cp}$ for iron absorption in enterocytes under iron-stress conditions, such as bleeding and iron deficiency [52].

Interestingly, HEPH colocalizes with apo-transferrin in enterocytes [53]. This suggests a direct transfer of iron to transferrin after its release from the intestinal epithelium. Upon binding of two ferric iron $\left(\mathrm{Fe}^{3+}\right)$ atoms, a holo-transferrin is formed, which enables a secure transport of ferric iron $\left(\mathrm{Fe}^{3+}\right)$ through plasma. In healthy human individuals, approximately $30 \%$ of the total transferrin is saturated [33]. Holo-transferrin can bind to its receptor TfR (CD71) on macrophages, erythrocytes, and other cell types, which is then internalized through receptor-mediated endocytosis.

\section{Systemic Iron Regulation by Hepcidin}

Iron homeostasis is regulated at the systemic and the cellular level by several well-coordinated mechanisms (Figure 2). Hepcidin is the main regulator of the systemic transportation of iron. It is a peptide hormone expressed mainly in the liver by hepatocytes and undergoes proteolytic processing to yield a bioactive molecule that is secreted into the bloodstream $[31,54,55]$. Hepcidin binds to FPN1 and mediates its phosphorylation, internalization and degradation. Thus, in FPN1-expressing cells, such as macrophages, hepatocytes, and duodenal epithelial cells, iron export is blocked [34,56,57].

Hepcidin expression is regulated by iron and iron-sensing mechanisms. Accordingly, the synthesis of hepcidin is increased by iron loading and decreased by anemia and hypoxia. In this manner, an increase of systemic transferrin iron leads to hepcidin expression that causes iron retention in the macrophages and blocks iron uptake in the enterocytes to avoid further systemic iron accumulation $[34,56,58]$. Inappropriate low hepcidin expression due to mutations in the hepcidin-encoding gene Hamp or mutations that impair hepcidin function are linked to hereditary hemochromatosis and total body iron overload [56,59-62]. On the contrary, pathological hepcidin excess caused by inflammatory disorders induces hypoferremia, anemia of inflammation, or anemia of chronic disease $[31,63,64]$. Therefore, hepcidin-mediated regulation is essential in maintaining iron homeostasis.

Hepcidin expression is controlled transcriptionally by various signals, such as transferrin saturation, erythropoietic activity, hypoxia and inflammation, rendering it an important player in the process of iron homeostasis. Organisms have evolved multitude mechanisms to sense iron and to activate hepcidin expression (Figure 2).

The molecular mechanism by which transferrin iron serves as a sensor for hepcidin expression is based on a coordinated interplay between TfR1 and TfR2 with the homeostatic iron regulator HFE, a major histocompatibility complex class I integral membrane protein $[65,66]$. Circulating transferrin-bound iron interacts with high affinity to TfR1, whereas TfR2 has a lower iron-binding affinity. Accordingly, under low transferrin saturation only TfR1 is engaged to transferrin iron. In this case only, HFE is able to associate with TfR1 and hepcidin expression is not induced, while TfR2 is directed to a lysosomal degradation pathway $[1,66,67]$. When transferrin iron levels increase in plasma, transferrin iron interacts also with TfR2, which leads to detachment of HFE from TfR1 and binding to TfR2 to induce hepcidin transcription [68-70]. Consequently, the competitive interaction between HFE and TfR1 or TfR2 determines iron regulation through hepcidin. In hemochromatosis patients with HFE gene mutations or in HFE-deficient mice, hepcidin synthesis is inappropriately low that induces systemic iron overload $[65,71]$. 


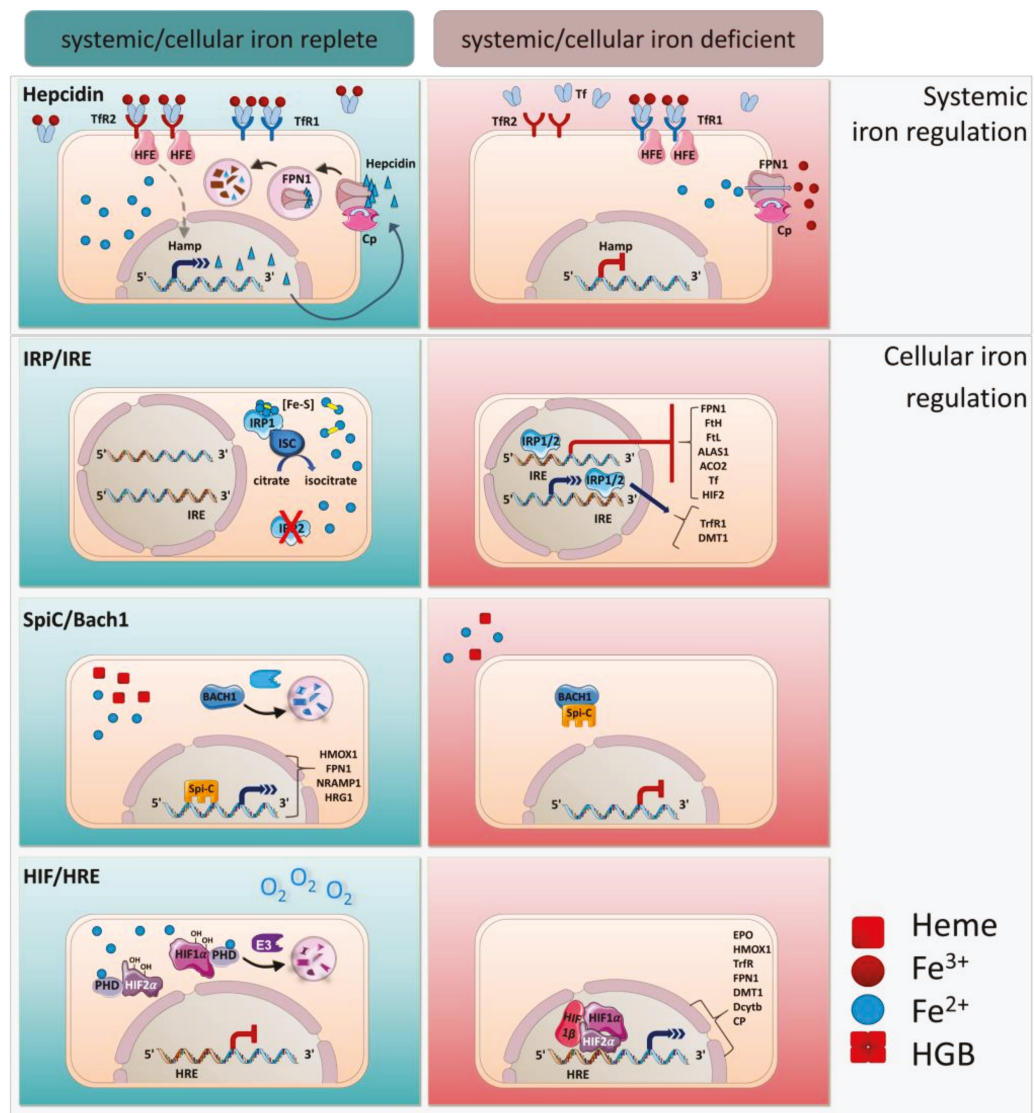

Figure 2. Main regulatory mechanisms of iron. Regulation of iron metabolism through hepcidin, the IRP/IRE, Spi-C/Bach1, and HIF/HRE. For details see text.

Furthermore, liver iron stimulates the bone morphogenetic protein (BMP) BMP6 signaling pathway to trigger hepcidin production [72,73]. Hepcidin induction by classical BMP signaling is dependent on the BMP co-receptor hemojuvelin (HJV or HFE2), a GPI-linked membrane protein. HJV binds to BMP6 and activates the Smad family of transcription factors to stimulate Hamp transcription [58].

Inflammatory mediators are major hepcidin-inducing factors. Lipopolysaccharide, interleukin-6 (IL-6), IL-1, or IL-22 induce hepcidin partially via signal transducer and activator of transcription 3 (STAT3) [64,74-76]. Hepcidin expression in response to infections rapidly lowers plasma iron to prevent iron sequestration of microbes that need iron for growth [77]. Additionally, macrophages are able to produce hepcidin locally in response to bacterial signals at the side of the infection to limit iron bioavailability for pathogens $[78,79]$. Thus, iron regulation by macrophages is an important defense mechanism during an infection [80].

On the contrary, hepcidin expression is blocked by hypoxia to stimulate iron mobilization and erythropoiesis [81,82]. Other hepcidin inhibitory factors were identified, including members of the growth factor beta (TGF- $\beta$ ) superfamily comprising growth differentiation factor 15 (GDF15), transforming growth factor beta (TGF- $\beta$ ), twisted gastrulation BMP signaling modulator 1 (TWSG1) and erythroid factor erythropoietin (Epo) [83,84]. 


\section{Cellular Regulation of Iron by IRE/IRPs}

Compared to the transcriptional regulation of hepcidin, many proteins involved in controlling intracellular iron metabolism are governed by posttranscriptional mechanisms. The main cellular iron uptake, transport, storage, utilization, and release processes are governed by the interplay of distinct mRNA-binding iron-regulatory proteins (IRPs), which have been extensively studied in macrophages and hepatocytes $[1,85]$. Two different IRPs are known: IRP1 and IRP2. IRPs bind to their target transcripts that contain cis-regulatory iron-regulatory elements (IREs), conserved RNA stem loop structures [86-88]. Besides iron status, the localization of IREs on transcripts determines whether a given IRP-IRE interaction stimulates or suppresses protein translation (Figure 2).

In cellular iron deficiency, IRPs bind to IREs at the $5^{\prime}$ untranslated region (UTR) of FPN1, FtH, $\mathrm{FtL}$, delta-aminolevulinate synthase 1 (ALAS1), aconitase 2 (ACO2), hypoxia-inducible factor 2 (HIF2) mRNAs to mediate the degradation of the transcripts of the IREs to decrease iron storage and export [89]. In addition, the binding of IRPs to IREs at 3' UTR of TfR1 and DMT1 mRNA stabilizes these transcripts and supports their translation to increase iron import $[37,85]$.

Conversely, under cellular iron-replete conditions, IRP2 gets ubiquitinated and degraded by the proteasome to inhibit binding to IREs [90-93]. IRP1 similarly loses its IRE-binding activity but acquires an ISC [4Fe-4S] to obtain cytosolic aconitase activity that converts citrate to isocitrate in the citric acid cycle [94]. Because the bi-functional IRP1 shifts between iron-regulation and metabolism-regulation, this mechanism suggests an interesting link between iron and cellular energy metabolism [95-98]. IRP1 $1^{-/}$and IRP2 ${ }^{-/-}$mice show massive impaired iron homeostasis suggesting that the IRP/IRE system is critical in cellular iron control $[95,98,99]$.

\section{Transcriptional Regulation by Spi-C and HIF}

Iron homeostasis on the cellular level is also regulated transcriptionally by the induction of the transcription factors Spi-C and HIFs. Endogenous labile heme derived from e.g., hemolysis binds to and liberates Spi-C from its repressor BTB domain and CNC homolog 1 (BACH1), which is subsequently degraded by the ubiquitin - protein ligase HOIL-1 [100-103]. Unbound Spi-C can enter the nucleus and directly stimulates important heme- and iron-regulating proteins, such as heme oxygenase 1 (HMOX1), FPN1, NRAMP1, and HRG1. Spi-C-mediated control of iron genes in macrophages has been reported to be particularly important when rapid iron metabolism is needed; for example, through increased erythrophagocytosis or hemolysis [102,104]. Iron-driven Spi-C activation is a critical factor for the development of iron-specific macrophages. Moreover, the number of BM macrophages and RPMs is drastically reduced in Spic ${ }^{-1-}$ mice suggesting that Spi-C-mediated regulation is indispensable for iron metabolism in these cells and for protection against iron toxicity $[100,105]$.

Additionally, iron metabolism is regulated in response to oxygen by means of HIF $1 \alpha$ and $\mathrm{HIF} 2 \alpha$. If sufficient levels of ferrous iron $\left(\mathrm{Fe}^{2+}\right)$ and oxygen are present, HIF1 $\alpha$ and HIF2 $\alpha$ are hydroxylated by oxygen prolyl hydroxylases (PHDs) and are then degraded by Ligase E3 [106,107]. In contrast, low iron levels in cells, as well as hypoxia, induce an accumulation of HIF1 $\alpha$ and HIF $2 \alpha$ in the nucleus and subsequently triggers the recruitment of HIF1 $\beta$. Accordingly, the HIF $\alpha / \operatorname{HIF} \beta$ complex binds to hypoxia-responsive elements (HRE) and promotes transcription of genes that are involved in iron metabolism such transferrin, TfR, DMT1, FPN1, Dcytb, Cp, and HMOX1 [108,109]. In line, the HIF1/2-HRE interaction in response to hypoxia and to low iron induces iron release from macrophages $[110,111]$. This process is not only important in macrophages, but also induces RBC generation and maturation through Epo [112]. HIF2 $\alpha$ contains IREs in its 5' UTR of mRNA and is thus under control of IRP1. These findings show that iron homeostasis depends on complex, global and cellular regulations at various levels of gene expression. 


\section{Steady-State Erythrophagocytosis by Macrophages in the Spleen}

The majority of iron (20-21 mg per day) is recycled from heme of erythrocytes in the spleen, whereas only 1-2 $\mathrm{mg}$ of iron is absorbed by the diet. Macrophages extract iron from senescent erythrocytes by disassembling Hgb. Approximately 1 billion iron atoms are extracted from 250-280 million Hgb molecules per erythrocyte [113]. Thus, almost all iron atoms pass through macrophages for further cellular and systemic utilization.

The first signal that stimulates iron digestion in macrophages is the recognition of senescent RBCs and the uptake of these cells by means of receptor-mediated erythrophagocytosis (Figure 3). The macrophage surface is equipped with various scavenging receptor proteins to recognize the "eat me" signals from aged RBCs [114,115]; these include, among others, signal-regulatory protein alpha (SIRP $\alpha$ ), glucose-6-phosphate dehydrogenase, phosphatidylserine (PS) receptors (such as TIM4 and TIM1), scavenger receptor type A member I (SR-AI), and CD36. The most popular presenters of the "eat me" signals are CD47 and PS, which are exposed to aging RBCs $[10,116,117]$. After internalization, RBCs-containing phagosomes merge with lysosomal vesicles to form phagolysosomes, where the RBCs are digested. Hgb breaks down into heme and heme is then transferred from the erythrophagolysosomes into the cytosol $[21,118]$. The transport of heme out of the erythrophagolysosome is facilitated by a heme transporter, known as HRG1, which is regulated posttranscriptionally by heme and iron [19]. HRG1 expression is high in the macrophages of the spleen, liver, as well as BM, and it localizes in erythrophagolysosomes one hour after erythrophagocytosis. In addition, the putative heme transporter HCP1 has been suggested to transport heme into the cytosol [16]. In the cytosol of macrophages, iron is immediately processed from the protoporphyrin ring of heme by means of HMOX1 [119]. Degradation of heme by HMOX1 generates equivalent amounts of $\mathrm{CO}$ and biliverdin in addition to iron [120]. HMOX1 is not present on the erythrophagocyte membrane, but has been located in the endoplasmic reticulum with its active site directed to cytosol; this process supports the idea that iron is extracted in the cytosol $[19,121]$. Moreover, HMOX1 expression can be detected immediately after erythrophagocytosis or after hemolysis corroborating its crucial role in iron and heme detoxication $[122,123]$. The role of HMOX 1 is underscored by the finding that HMOX1 deficiency causes a depletion of RPM and BM macrophages; suggesting that the survival and function of iron-metabolizing macrophages is dependent on HMOX1. In addition, there is a second heme oxygenase HMOX2, which is involved in removing intracellular heme. In contrast to HMOX1, which is inducible, HMOX2 is continuously expressed in most tissues and is involved in extracting iron in different cell types [122,123].

Recently, NRAMP1 (SLC11A1) has been identified as an important iron transporter in the macrophages, which is localized to erythrophagolysosomes after erythrophagocytosis [21,124]. NRAMP1-knockout mice retain iron in the macrophages, but release storage iron from hepatocytes to compensate for the impaired iron efflux from macrophages [124].

Depending on erythropoietic activity and other iron-consuming processes, iron can be either stored or released through FPN1, and its expression increases in macrophages within an hour after erythrophagocytosis $[49,125]$. Moreover, erythrophagocytosis-activated macrophages have concomitant high levels of heavy (H-) and light (L-)ferritin content, even several hours after erythrophagocytosis has occurred; this indicates that a substantial proportion of iron can be stored intracellularly within ferritin after erythrophagocytosis in the liver and the spleen $[29,126]$. An increase of cellular iron upon systemic hemolysis, when iron storage in KCs of the liver is saturated, iron has been found to be transferred into hepatocytes for long-term storage [127]. 


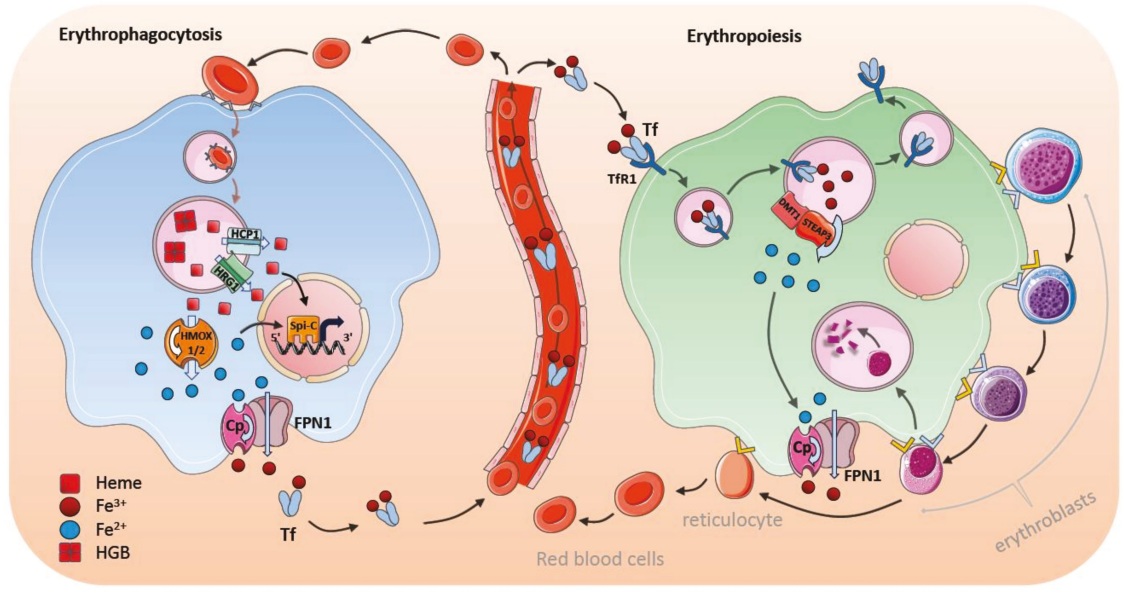

Figure 3. Macrophages in erythrophagocytosis and erythropoiesis. The majority of iron in a macrophage is obtained during erythrophagocytosis. Splenic red pulp macrophages (RPMs) and liver Kupffer cells (KCs) is the main source of iron in the body. Senescent red blood cells (RBCs) are recognized by macrophages and digested in the lysosomes. Heme is extracted in the phagolysosomes and transferred to the cytosol by heme transporters heme-carrier protein 1 (HCP1) and heme responsive gene 1 protein (HRG1). Heme degradation by heme oxygenase 1 (HMOX1) in the cytosol provides ferrous iron that enters the intracellular labile iron pool. Iron is either stored in ferritin or exported by ferroportin 1 (FPN1) and ceruloplasmin (Cp). The transcription factor (Spi-C) protects iron processing RPMs in the spleen and BM nurse macrophages. Central nurse macrophages in the bone marrow (BM) promote erythropoiesis in the erythroblastic island niche. These macrophages ubiquitously express transferrin receptors and thus, probably mainly utilize transferrin (Tf)-bound iron. Nurse macrophages are important for the development of erythroblasts. This is mediated by adhesion molecules that control proliferation and differentiation of erythroblasts, enable erythroblast nuclei ingestion, and control the subsequent release of reticulocytes into the blood stream. Central macrophages are supposed to be involved in supplying maturing erythrocytes with iron to trigger heme synthesis.

\section{Stress-Induced Erythrophagocytosis and Iron Metabolism}

Under steady-state conditions, heme iron is preferentially digested by RPMs in the spleen, whereas, under stress conditions, macrophages in the liver become essential for erythrophagocytosis. For example, during systemic hemolysis, $\mathrm{Ly}_{6} \mathrm{C}^{+}$monocytes migrate to the liver and, thereupon, differentiate into iron-recycling macrophages, but not to KCs [127]. Interestingly, colony stimulating factor 1 (CSF1) and nuclear factor erythroid 2-related factor 2 (Nrf2) transcription factor promote the development of these iron-recycling FPN1 ${ }^{+} \mathrm{Tim} 4^{\text {neg }}$ macrophages from blood-borne monocytes in the liver [127]. Moreover, iron recycling by RPMs in the spleen is not ameliorated to compensate for the increased iron need. Hence, FPN1+ Tim $4^{\text {neg }}$ iron-recycling liver handle and recycle heme and iron from senescent and damaged RBCs after massive hemolysis [10].

Macrophages have developed further elaborate mechanisms to remove systemic heme during hemolysis. The body responds immediately against toxic free $\mathrm{Hgb}$ and heme by producing the $\mathrm{Hgb}$-scavenging protein haptoglobin and the heme-binding serum protein hemopexin. Splenic RPMs and liver KCs express the receptors CD163 and CD91: these are involved in the clearance of excessive labile heme and, importantly, offer an acute protection mechanism [128,129]. Macrophages possess ferroxidases (such as $\mathrm{Cp}$ and HEPH) and proteins promoting ferrireductase activity (such as FtH and Dcytb); these enable the quick oxidation and reduction of iron, and ensure efficient transportation and utilization of iron within a cell [130]. Additionally, as described above, heme-mediated Spi-C 
induction in monocytes promotes the differentiation of erythrophagocytosing RPMs in the spleen and induces the expression of important heme- and iron-regulating proteins [100]. This facilitates a quick heme and iron processing and inhibits iron-induced toxicity in the cells $[21,29,100,101]$ (Figure 3).

Recently, it was demonstrated that labile heme released after massive hemolysis, following bacterial infection, suppresses the phagocytosing function of macrophages [131]. It is conceivable that the liberation of heme when erythrophagocytosis commences may function as a negative feedback loop and impairs further erythrophagocytosis by macrophages as a protective mechanism to sustain oxygen supply.

\section{Bone Marrow Macrophages and Erythroblastic Islands}

Erythropoiesis is a dynamic process that is regulated through environmental signals, nutrient availability, and cellular interplay. Most of the transferrin-bound iron is utilized for heme synthesis during definitive erythropoiesis in the BM. In the BM, CD169 (Sialoadhesin or Siglecß1) is expressed on certain macrophages-referred to as nurse macrophages. These form an erythroblastic island, in which the central nurse macrophage is surrounded by erythroid progenitors at different developmental stages and provides a niche for erythropoietic regulation [132-134] (Figure 3). Thus, the nursing macrophage supports erythropoiesis at different stages through varying the stimulating and repressing signals to control proliferation versus differentiation of erythroid progenitors, and to sustain survival signals $[134,135]$. Depending on the developmental stage, different soluble factors, such as BMP4, insulin-like growth factor 1 (ILGF1), IL-3, and granulocyte-macrophage colony-stimulating factor (GM-CSF) are secreted from the central nurse macrophages and induce proliferative and differential signals in erythroid progenitors $[136,137]$. In addition, negative regulators of erythropoiesis can be released by BM macrophages, including GATA binding protein 1 (GATA1), TGF- $\beta$, interferon gamma $(\mathrm{IFN} \gamma)$, and tumor necrosis factor alpha (TNF $\alpha)[136,138]$.

Central nurse macrophages are thought to be involved in phagocytosing the extruded nuclei from erythroblasts during their development. This process is based on recognition through PS exposure, TIM4 and MER proto-oncogene tyrosine kinase (MerTK) $[2,139]$. Because developing erythroblasts adhere to the central macrophage, it has also been hypothesized that BM macrophages regulate and determine the release of mature reticulocytes into the blood circulation. Prominent adhesion molecules that are involved in cell-cell interaction, signal transduction, and reticulocyte release controlled by macrophages include erythroblast macrophage protein, vascular cell adhesion protein 1 (VCAM1) and a4b1- or a4b5-integrins $[136,137,140]$. Ablation of macrophages, or one of the adhesion molecules, delays proerythroblast proliferation and differentiation at different developmental stages and to destroy the erythroblastic island [136,137,141]. Moreover, Spi-C-mediated signals are also essential for erythropoiesis, since Spi-C ablation causes a reduction in erythroblastic island numbers and a delay in RBC formation [100]. Interestingly, CD169+ macrophage ablation, which markedly reduces the number of erythroblasts in the bone marrow, only leads to a mild reduction of erythroid cells without overt anemia suggesting that erythropoietic compensatory mechanisms exist during homeostasis [141]. However, the induction of stress-induced anemia (for example, through phenylhydrazin treatment) promoted more severe delays in erythropoietic recovery in $\mathrm{CD} 169^{+}$-ablated animals. This indicates that BM macrophages promote fast recovery responses to stress-induced erythropoiesis [132]. On the contrary, pathological erythropoiesis in mouse models of polycythemia vera (PV) can be reversed through the ablation of central macrophages [142].

\section{Regulation of Iron Transfer by Central Nurse Macrophages}

Transferrin-bound iron is the main iron source for erythropoiesis. Iron-bound transferrin and its receptor are internalized by receptor-mediated endocytosis [143]. TfR expression on erythroblasts increases during erythrocyte development, but is downregulated after the release of reticulocytes [144]. Loss of transferrin impedes erythropoiesis and leads to an accumulation of iron in the storage organs; this indicates the importance of transferrin-bound iron as a crucial source for erythropoiesis [145]. 
BM nurse macrophages contribute to iron-loading of the erythroblasts, which might be especially pronounced during stress conditions. In the macrophage, iron atoms are released from transferrin in the acidic condition within endosomes ( $\mathrm{pH} 4.5)$, and transferrin, along with TfRs, is recycled back onto the macrophage surface. Ferric irons $\left(\mathrm{Fe}^{3+}\right)$ in the endosomes are reduced to ferrous irons $\left(\mathrm{Fe}^{2+}\right)$ by six-transmembrane epithelial antigen of the prostate 3 (STEAP3) - an endosomal ferrireductase located in endosomes [146]. Ferrous iron $\left(\mathrm{Fe}^{2+}\right)$ is then transported by means of DMT1 through the endosomal membrane and is released into the cytosol. It is not entirely clear how iron is subsequently translocated through the cellular cytosol and utilized for erythropoiesis. The high expression of FPN1 on the nurse macrophages and the observation that FPN1 deletion leads to an accumulation of iron in BM macrophages and a blockage of erythroblast development suggest that iron is released from macrophages prior to being loaded into the erythroblasts $[147,148]$. It is also possible that NRAMP1, which participates in iron transport in BM macrophages, is responsible for FPN1-associated iron release during erythropoiesis [124,149]. Interestingly, in the absence of transferrin-bound iron, macrophages utilize other forms of iron, such as secreted ferritin iron and heme iron to support erythropoiesis [150,151]. However, the importance of these alternative pathways in macrophage-dependent iron transfer remains to be determined.

\section{Concluding Remarks}

Efficient iron metabolism is a matter that decides between life and death and depends on complex parallel, compensatory, and complementary networks to meet the iron demand for erythropoiesis, as well as other cellular functions, but to prevent iron overload, which cause cellular and organismal toxicity. Tissue macrophages take center stage in iron homeostasis and their regulatory mechanisms are increasingly recognized. Except duodenal iron uptake, macrophages are implicated in every step of iron recycling and metabolism. Future studies may identify new functions of macrophages that regulate tissue-specific iron metabolism and contribute to metabolic disorders. One emerging theme from knock-out mice suggests that macrophage-mediated iron metabolism is particularly important during stress conditions. Whereas these mouse models show that under homeostatic conditions, compensatory mechanisms exist that maintain systemic iron metabolism, macrophages may still be the main iron regulators in unaltered wild-type mice. Evidence implicates the importance of the central macrophages in erythropoietic regulation, however, it is not known how macrophages sense erythropoietic need and whether macrophages coordinate erythropoiesis dependent on iron availability and oxygen demand. The sensing of these factors is essential for the proper regulation of RBC maturation. Thus, HIF-regulatory mechanisms may be an attractive candidate, because they can sense both iron and oxygen. The understanding of cellular and systemic regulation of iron homeostasis will help to develop novel therapeutic possibilities in anemic diseases and other conditions, such as malaria, acute blood loss, hematopoietic stem cell transplantation, or chronic kidney disease.

Author Contributions: N.S. and T.W. wrote, reviewed, and edited this manuscript.

Funding: Supported by grants from the Austrian Science Fund (FWF) P27701-B20 and P30857-B28 and the Foundation for Sarcoidosis Research. N.S. is supported by the [DOC] Doctoral Fellowship Programme of the Austrian Academy of Sciences. Figures are illustrated using Servier Medical Art.

Conflicts of Interest: The authors declare no conflict of interest.

$\begin{array}{ll}\text { Abbreviations } \\ \text { ACO2 } & \text { aconitase 2 } \\ \text { ALAS1 } & \text { delta-aminolevulinate synthase 1 } \\ \text { BACH1 } & \text { BTB domain and CNC homolog 1 } \\ \text { BM } & \text { bone marrow } \\ \text { BMP } & \text { Bone morphogenetic protein } \\ \text { Cp } & \text { ceruloplasmin } \\ \text { DCT1 } & \text { divalent cation transporter 1 }\end{array}$




\begin{tabular}{|c|c|}
\hline DcytB & duodenal cytochrome B \\
\hline DMT1 & divalent metal transporter 1 \\
\hline E3 & E3 ubiquitin ligase \\
\hline Epo & erythroid factor erythropoietin \\
\hline FLVCR1 & Feline leukemia virus group C cellular receptor 1 \\
\hline FPN1 & ferroportin 1 \\
\hline FtMt & Mitochondrial ferritin \\
\hline $\mathrm{FtH}$ & heavy chain $\mathrm{H}$-ferritin \\
\hline FtL & light chain L-ferritin \\
\hline GDF15 & growth differentiation factor 15 \\
\hline GM-CSF & granulocyte-macrophage colony-stimulating factor \\
\hline Hamp & hepcidin antimicrobial peptide \\
\hline HEPH & hephaestin \\
\hline HCP1 & heme-carrier protein 1 \\
\hline HFE & homeostatic iron regulator \\
\hline $\mathrm{Hgb}$ & hemoglobin \\
\hline HIF $1 \alpha / H I F 2 \alpha$ & hypoxia-inducible factor $1 \alpha / 2 \alpha$ \\
\hline HJV & hemojuvelin \\
\hline HMOX1 & heme oxygenase 1 \\
\hline $\mathrm{Hp}$ & haptoglobin \\
\hline Hpx & hemopexin \\
\hline HRE & hypoxia-responsive element \\
\hline HRG1 & heme responsive gene 1 protein \\
\hline ILGF1 & insulin-like growth factor 1 \\
\hline $\operatorname{IFN} \gamma$ & interferon gamma \\
\hline IRE & iron-regulatory element \\
\hline IRP1/IRP2 & iron-regulatory protein $1 / 2$ \\
\hline ISC & iron-sulfur cluster \\
\hline KC & Kupffer cell \\
\hline LIP & Labile iron pool \\
\hline Mfrn1/2 & Mitoferrin 1/2 \\
\hline MerTK & MER proto-oncogene tyrosine kinase \\
\hline NTBI & non-transferrin-bound iron \\
\hline NRAMP1 & natural resistance-associated macrophage protein 1 \\
\hline PHDs & oxygen prolyl hydroxylases \\
\hline PS & phosphatidylserine \\
\hline PV & polycythemia vera \\
\hline $\mathrm{RBC}$ & red blood cell \\
\hline RPM & red pulp macrophages \\
\hline $\operatorname{SIRP} \alpha$ & signal-regulatory protein alpha \\
\hline Spi-C & Spi-1/PU.1 related transcription factor \\
\hline SR-AI & scavenger receptor type A member I \\
\hline STAT3 & activator of transcription 3 \\
\hline STEAP3 & six-transmembrane epithelial antigen of the prostate 3 \\
\hline Tf & transferrin \\
\hline TfR1/2 & transferrin receptor $1 / 2$ \\
\hline $\mathrm{TNF} \alpha$ & tumor necrosis factor alpha \\
\hline TGF- $\beta$ & transforming growth factor beta \\
\hline TWSG1 & twisted gastrulation BMP signaling modulator 1 \\
\hline VCAM1 & vascular cell adhesion protein 1 \\
\hline UTR & untranslated region \\
\hline
\end{tabular}




\section{References}

1. Muckenthaler, M.U.; Rivella, S.; Hentze, M.W.; Galy, B. A red carpet for iron metabolism. Cell 2017, 168, 344-361. [CrossRef] [PubMed]

2. Soares, M.P.; Hamza, I. Macrophages and iron metabolism. Immunity 2016, 44, 492-504. [CrossRef] [PubMed]

3. Gozzelino, R.; Jeney, V.; Soares, M.P. Mechanisms of cell protection by heme oxygenase-1. Annu. Rev. Pharmacol. Toxicol. 2010, 50, 323-354. [CrossRef]

4. Larsen, R.; Gozzelino, R.; Jeney, V.; Tokaji, L.; Bozza, F.A.; Japiassú, A.M.; Bonaparte, D.; Cavalcante, M.M.; Chora, A.; Ferreira, A.; et al. A central role for free heme in the pathogenesis of severe sepsis. Sci. Transl. Med. 2010, 2, 51ra71. [CrossRef] [PubMed]

5. Fabiano, A.; Brilli, E.; Mattii, L.; Testai, L.; Moscato, S.; Citi, V.; Tarantino, G.; Zambito, Y. Ex vivo and in vivo study of sucrosomial ${ }^{\circledR}$ iron intestinal absorption and bioavailability. Int. J. Mol. Sci. 2018, 19, 2722. [CrossRef] [PubMed]

6. Orr, J.S.; Kennedy, A.; Anderson-Baucum, E.K.; Webb, C.D.; Fordahl, S.C.; Erikson, K.M.; Zhang, Y.; Etzerodt, A.; Moestrup, S.K.; Hasty, A.H. Obesity alters adipose tissue macrophage iron content and tissue iron distribution. Diabetes 2014, 63, 421-432. [CrossRef] [PubMed]

7. Chung, J.; Kim, M.S.; Han, S.N. Diet-induced obesity leads to decreased hepatic iron storage in mice. Nutr. Res. 2011, 31, 915-921. [CrossRef] [PubMed]

8. Festa, M.; Ricciardelli, G.; Mele, G.; Pietropaolo, C.; Ruffo, A.; Colonna, A. Overexpression of H ferritin and up-regulation of iron regulatory protein genes during differentiation of 3T3-L1 pre-adipocytes. J. Biol. Chem. 2000, 275, 36708-36712. [CrossRef]

9. Fleming, M.D.; Andrews, N.C. Mammalian iron transport: An unexpected link between metal homeostasis and host defense. J. Lab. Clin. Med. 1998, 132, 464-468. [CrossRef]

10. Nairz, M.; Theurl, I.; Swirski, F.K.; Weiss, G. "Pumping iron"-how macrophages handle iron at the systemic, microenvironmental, and cellular levels. Pflugers Arch. 2017, 469, 397-418. [CrossRef]

11. Gruenheid, S.; Pinner, E.; Desjardins, M.; Gros, P. Natural resistance to infection with intracellular pathogens: The Nramp1 protein is recruited to the membrane of the phagosome. J. Exp. Med. 1997, 185, 717-730. [CrossRef] [PubMed]

12. Forbes, J.R.; Gros, P. Iron, manganese, and cobalt transport by Nramp1 (Slc11a1) and Nramp2 (Slc11a2) expressed at the plasma membrane. Blood 2003, 102, 1884-1892. [CrossRef] [PubMed]

13. Soe-Lin, S.; Sheftel, A.D.; Wasyluk, B.; Ponka, P. Nramp1 equips macrophages for efficient iron recycling. Exp. Hematol. 2008, 36, 929-937. [CrossRef] [PubMed]

14. Inoue, K.; Nakai, Y.; Ueda, S.; Kamigaso, S.; Ohta, K.; Hatakeyama, M.; Hayashi, Y.; Otagiri, M.; Yuasa, H. Functional characterization of PCFT/HCP1 as the molecular entity of the carrier-mediated intestinal folate transport system in the rat model. Am. J. Physiol. Gastrointest. Liver Physiol. 2008, 294, G660-G668. [CrossRef] [PubMed]

15. Qiu, A.; Jansen, M.; Sakaris, A.; Min, S.H.; Chattopadhyay, S.; Tsai, E.; Sandoval, C.; Zhao, R.; Akabas, M.H.; Goldman, I.D. Identification of an intestinal folate transporter and the molecular basis for hereditary folate malabsorption. Cell 2006, 127, 917-928. [CrossRef] [PubMed]

16. Schaer, C.A.; Vallelian, F.; Imhof, A.; Schoedon, G.; Schaer, D.J. Heme carrier protein (HCP-1) spatially interacts with the CD163 hemoglobin uptake pathway and is a target of inflammatory macrophage activation. J. Leukoc. Biol. 2008, 83, 325-333. [CrossRef] [PubMed]

17. Quigley, J.G.; Yang, Z.; Worthington, M.T.; Phillips, J.D.; Sabo, K.M.; Sabath, D.E.; Berg, C.L.; Sassa, S.; Wood, B.L.; Abkowitz, J.L. Identification of a human heme exporter that is essential for erythropoiesis. Cell 2004, 118, 757-766. [CrossRef]

18. Keel, S.B.; Doty, R.T.; Yang, Z.; Quigley, J.G.; Chen, J.; Knoblaugh, S.; Kingsley, P.D.; De Domenico, I.; Vaughn, M.B.; Kaplan, J.; et al. A heme export protein is required for red blood cell differentiation and iron homeostasis. Science 2008, 319, 825-828. [CrossRef]

19. White, C.; Yuan, X.; Schmidt, P.J.; Bresciani, E.; Samuel, T.K.; Campagna, D.; Hall, C.; Bishop, K.; Calicchio, M.L.; Lapierre, A.; et al. HRG1 is essential for heme transport from the phagolysosome of macrophages during erythrophagocytosis. Cell Metab. 2013, 17, 261-270. [CrossRef]

20. Zhang, J.; Chambers, I.; Yun, S.; Phillips, J.; Krause, M.; Hamza, I. Hrg1 promotes heme-iron recycling during hemolysis in the zebrafish kidney. PLoS Genet. 2018, 14, e1007665. [CrossRef] 
21. Delaby, C.; Rondeau, C.; Pouzet, C.; Willemetz, A.; Pilard, N.; Desjardins, M.; Canonne-Hergaux, F. Subcellular localization of iron and heme metabolism related proteins at early stages of erythrophagocytosis. PLoS ONE 2012, 7, e42199. [CrossRef]

22. Li, J.Y.; Paragas, N.; Ned, R.M.; Qiu, A.; Viltard, M.; Leete, T.; Drexler, I.R.; Chen, X.; Sanna-Cherchi, S.; Mohammed, F.; et al. Scara5 is a ferritin receptor mediating non-transferrin iron delivery. Dev. Cell 2009, 16, 35-46. [CrossRef] [PubMed]

23. Han, J.; Seaman, W.E.; Di, X.; Wang, W.; Willingham, M.; Torti, F.M.; Torti, S.V. Iron uptake mediated by binding of H-ferritin to the TIM-2 receptor in mouse cells. PLoS ONE 2011, 6, e23800. [CrossRef] [PubMed]

24. Breuer, W.; Shvartsman, M.; Cabantchik, Z.I. Intracellular labile iron. Int. J. Biochem. Cell Biol. 2008, 40, 350-354. [CrossRef] [PubMed]

25. Rauen, U.; Springer, A.; Weisheit, D.; Petrat, F.; Korth, H.-G.; de Groot, H.; Sustmann, R. Assessment of chelatable mitochondrial iron by using mitochondrion-selective fluorescent iron indicators with different iron-binding affinities. Chembiochem 2007, 8, 341-352. [CrossRef] [PubMed]

26. Arosio, P.; Ingrassia, R.; Cavadini, P. Ferritins: A family of molecules for iron storage, antioxidation and more. Biochim. Biophys. Acta 2009, 1790, 589-599. [CrossRef] [PubMed]

27. Levi, S.; Yewdall, S.J.; Harrison, P.M.; Santambrogio, P.; Cozzi, A.; Rovida, E.; Albertini, A.; Arosio, P. Evidence of $\mathrm{H}$ - and L-chains have co-operative roles in the iron-uptake mechanism of human ferritin. Biochem. J. 1992, 288 Pt 2, 591-596. [CrossRef]

28. Harrison, P.M.; Arosio, P. The ferritins: Molecular properties, iron storage function and cellular regulation. Biochim. Biophys. Acta 1996, 1275, 161-203. [CrossRef]

29. Delaby, C.; Pilard, N.; Hetet, G.; Driss, F.; Grandchamp, B.; Beaumont, C.; Canonne-Hergaux, F. A physiological model to study iron recycling in macrophages. Exp. Cell Res. 2005, 310, 43-53. [CrossRef]

30. Ferreira, C.; Santambrogio, P.; Martin, M.E.; Andrieu, V.; Feldmann, G.; Hénin, D.; Beaumont, C. H ferritin knockout mice: A model of hyperferritinemia in the absence of iron overload. Blood 2001, 98, 525-532. [CrossRef]

31. Nemeth, E.; Ganz, T. Regulation of iron metabolism by hepcidin. Annu. Rev. Nutr. 2006, 26, 323-342. [CrossRef] [PubMed]

32. Sheftel, A.D.; Zhang, A.-S.; Brown, C.; Shirihai, O.S.; Ponka, P. Direct interorganellar transfer of iron from endosome to mitochondrion. Blood 2007, 110, 125-132. [CrossRef] [PubMed]

33. Hentze, M.W.; Muckenthaler, M.U.; Galy, B.; Camaschella, C. Two to tango: Regulation of Mammalian iron metabolism. Cell 2010, 142, 24-38. [CrossRef] [PubMed]

34. Donovan, A.; Lima, C.A.; Pinkus, J.L.; Pinkus, G.S.; Zon, L.I.; Robine, S.; Andrews, N.C. The iron exporter ferroportin/Slc40a1 is essential for iron homeostasis. Cell Metab. 2005, 1, 191-200. [CrossRef] [PubMed]

35. Montosi, G.; Donovan, A.; Totaro, A.; Garuti, C.; Pignatti, E.; Cassanelli, S.; Trenor, C.C.; Gasparini, P.; Andrews, N.C.; Pietrangelo, A. Autosomal-dominant hemochromatosis is associated with a mutation in the ferroportin (SLC11A3) gene. J. Clin. Investig. 2001, 108, 619-623. [CrossRef] [PubMed]

36. Njajou, O.T.; Vaessen, N.; Joosse, M.; Berghuis, B.; van Dongen, J.W.; Breuning, M.H.; Snijders, P.J.; Rutten, W.P.; Sandkuijl, L.A.; Oostra, B.A.; et al. A mutation in SLC11A3 is associated with autosomal dominant hemochromatosis. Nat. Genet. 2001, 28, 213-214. [CrossRef]

37. McKie, A.T.; Marciani, P.; Rolfs, A.; Brennan, K.; Wehr, K.; Barrow, D.; Miret, S.; Bomford, A.; Peters, T.J.; Farzaneh, F; ; et al. A novel duodenal iron-regulated transporter, IREG1, implicated in the basolateral transfer of iron to the circulation. Mol. Cell 2000, 5, 299-309. [CrossRef]

38. Dini, L.; Carbonaro, M.; Musci, G.; Calabrese, L. The interaction of ceruloplasmin with Kupffer cells. Eur. J. Cell Biol. 1990, 52, 207-212.

39. De Domenico, I.; Ward, D.M.; di Patti, M.C.B.; Jeong, S.Y.; David, S.; Musci, G.; Kaplan, J. Ferroxidase activity is required for the stability of cell surface ferroportin in cells expressing GPI-ceruloplasmin. EMBO J. 2007, 26, 2823-2831. [CrossRef]

40. Harris, Z.L.; Durley, A.P.; Man, T.K.; Gitlin, J.D. Targeted gene disruption reveals an essential role for ceruloplasmin in cellular iron efflux. Proc. Natl. Acad. Sci. USA 1999, 96, 10812-10817. [CrossRef]

41. Harris, Z.L.; Takahashi, Y.; Miyajima, H.; Serizawa, M.; MacGillivray, R.T.; Gitlin, J.D. Aceruloplasminemia: Molecular characterization of this disorder of iron metabolism. Proc. Natl. Acad. Sci. USA 1995, 92, 2539-2543. [CrossRef] [PubMed] 
42. Kennard, M.L.; Richardson, D.R.; Gabathuler, R.; Ponka, P.; Jefferies, W.A. A novel iron uptake mechanism mediated by GPI-anchored human p97. EMBO J. 1995, 14, 4178-4186. [CrossRef] [PubMed]

43. McKie, A.T.; Barrow, D.; Latunde-Dada, G.O.; Rolfs, A.; Sager, G.; Mudaly, E.; Mudaly, M.; Richardson, C.; Barlow, D.; Bomford, A.; et al. An iron-regulated ferric reductase associated with the absorption of dietary iron. Science 2001, 291, 1755-1759. [CrossRef] [PubMed]

44. Frazer, D.M.; Wilkins, S.J.; Becker, E.M.; Murphy, T.L.; Vulpe, C.D.; McKie, A.T.; Anderson, G.J. A rapid decrease in the expression of DMT1 and Dcytb but not Ireg1 or hephaestin explains the mucosal block phenomenon of iron absorption. Gut 2003, 52, 340-346. [CrossRef] [PubMed]

45. Dupic, F.; Fruchon, S.; Bensaid, M.; Loreal, O.; Brissot, P.; Borot, N.; Roth, M.P.; Coppin, H. Duodenal mRNA expression of iron related genes in response to iron loading and iron deficiency in four strains of mice. Gut 2002, 51, 648-653. [CrossRef] [PubMed]

46. Zhang, A.S.; Sheftel, A.D.; Ponka, P. The anemia of "haemoglobin-deficit" (hbd/hbd) mice is caused by a defect in transferrin cycling. Exp. Hematol. 2006, 34, 593-598. [CrossRef] [PubMed]

47. Umbreit, J.N.; Conrad, M.E.; Moore, E.G.; Latour, L.F. Iron absorption and cellular transport: The mobilferrin/paraferritin paradigm. Semin. Hematol. 1998, 35, 13-26. [PubMed]

48. Zhang, D.-L.; Hughes, R.M.; Ollivierre-Wilson, H.; Ghosh, M.C.; Rouault, T.A. A ferroportin transcript that lacks an iron-responsive element enables duodenal and erythroid precursor cells to evade translational repression. Cell Metab. 2009, 9, 461-473. [CrossRef]

49. Donovan, A.; Brownlie, A.; Zhou, Y.; Shepard, J.; Pratt, S.J.; Moynihan, J.; Paw, B.H.; Drejer, A.; Barut, B.; Zapata, A.; et al. Positional cloning of zebrafish ferroportin1 identifies a conserved vertebrate iron exporter. Nature 2000, 403, 776-781. [CrossRef]

50. Yeh, K.-Y.; Yeh, M.; Glass, J. Interactions between ferroportin and hephaestin in rat enterocytes are reduced after iron ingestion. Gastroenterology 2011, 141, 292-299.e1. [CrossRef]

51. Yeh, K.-Y.; Yeh, M.; Mims, L.; Glass, J. Iron feeding induces ferroportin 1 and hephaestin migration and interaction in rat duodenal epithelium. Am. J. Physiol. Gastrointest. Liver Physiol. 2009, 296, G55-G65. [CrossRef] [PubMed]

52. Cherukuri, S.; Potla, R.; Sarkar, J.; Nurko, S.; Harris, Z.L.; Fox, P.L. Unexpected role of ceruloplasmin in intestinal iron absorption. Cell Metab. 2005, 2, 309-319. [CrossRef] [PubMed]

53. Griffiths, T.A.M.; Mauk, A.G.; MacGillivray, R.T.A. Recombinant expression and functional characterization of human hephaestin: A multicopper oxidase with ferroxidase activity. Biochemistry 2005, 44, 14725-14731. [CrossRef] [PubMed]

54. Nemeth, E.; Preza, G.C.; Jung, C.-L.; Kaplan, J.; Waring, A.J.; Ganz, T. The N-terminus of hepcidin is essential for its interaction with ferroportin: Structure-function study. Blood 2006, 107, 328-333. [CrossRef] [PubMed]

55. Kulaksiz, H.; Gehrke, S.G.; Janetzko, A.; Rost, D.; Bruckner, T.; Kallinowski, B.; Stremmel, W. Pro-hepcidin: Expression and cell specific localisation in the liver and its regulation in hereditary haemochromatosis, chronic renal insufficiency, and renal anaemia. Gut 2004, 53, 735-743. [CrossRef] [PubMed]

56. Nemeth, E.; Tuttle, M.S.; Powelson, J.; Vaughn, M.B.; Donovan, A.; Ward, D.M.; Ganz, T.; Kaplan, J. Hepcidin regulates cellular iron efflux by binding to ferroportin and inducing its internalization. Science 2004, 306, 2090-2093. [CrossRef] [PubMed]

57. Qiao, B.; Sugianto, P.; Fung, E.; Del-Castillo-Rueda, A.; Moran-Jimenez, M.-J.; Ganz, T.; Nemeth, E. Hepcidin-induced endocytosis of ferroportin is dependent on ferroportin ubiquitination. Cell Metab. 2012, 15, 918-924. [CrossRef] [PubMed]

58. Lin, L.; Valore, E.V.; Nemeth, E.; Goodnough, J.B.; Gabayan, V.; Ganz, T. Iron transferrin regulates hepcidin synthesis in primary hepatocyte culture through hemojuvelin and BMP2/4. Blood 2007, 110, 2182-2189. [CrossRef]

59. Nicolas, G.; Bennoun, M.; Devaux, I.; Beaumont, C.; Grandchamp, B.; Kahn, A.; Vaulont, S. Lack of hepcidin gene expression and severe tissue iron overload in upstream stimulatory factor 2 (USF2) knockout mice. Proc. Natl. Acad. Sci. USA 2001, 98, 8780-8785. [CrossRef]

60. Nicolas, G.; Bennoun, M.; Porteu, A.; Mativet, S.; Beaumont, C.; Grandchamp, B.; Sirito, M.; Sawadogo, M.; Kahn, A.; Vaulont, S. Severe iron deficiency anemia in transgenic mice expressing liver hepcidin. Proc. Natl. Acad. Sci. USA 2002, 99, 4596-4601. [CrossRef] 
61. Altamura, S.; Kessler, R.; Gröne, H.-J.; Gretz, N.; Hentze, M.W.; Galy, B.; Muckenthaler, M.U. Resistance of ferroportin to hepcidin binding causes exocrine pancreatic failure and fatal iron overload. Cell Metab. 2014, 20, 359-367. [CrossRef] [PubMed]

62. Roetto, A.; Papanikolaou, G.; Politou, M.; Alberti, F.; Girelli, D.; Christakis, J.; Loukopoulos, D.; Camaschella, C. Mutant antimicrobial peptide hepcidin is associated with severe juvenile hemochromatosis. Nat. Genet. 2003, 33, 21-22. [CrossRef] [PubMed]

63. Nemeth, E.; Rivera, S.; Gabayan, V.; Keller, C.; Taudorf, S.; Pedersen, B.K.; Ganz, T. IL-6 mediates hypoferremia of inflammation by inducing the synthesis of the iron regulatory hormone hepcidin. J. Clin. Investig. 2004, 113, 1271-1276. [CrossRef] [PubMed]

64. Babitt, J.L.; Huang, F.W.; Wrighting, D.M.; Xia, Y.; Sidis, Y.; Samad, T.A.; Campagna, J.A.; Chung, R.T.; Schneyer, A.L.; Woolf, C.J.; et al. Bone morphogenetic protein signaling by hemojuvelin regulates hepcidin expression. Nat. Genet. 2006, 38, 531-539. [CrossRef] [PubMed]

65. Feder, J.N.; Gnirke, A.; Thomas, W.; Tsuchihashi, Z.; Ruddy, D.A.; Basava, A.; Dormishian, F.; Domingo, R.; Ellis, M.C.; Fullan, A.; et al. A novel MHC class I-like gene is mutated in patients with hereditary haemochromatosis. Nat. Genet. 1996, 13, 399-408. [CrossRef]

66. Fleming, R.E.; Sly, W.S. Hepcidin: A putative iron-regulatory hormone relevant to hereditary hemochromatosis and the anemia of chronic disease. Proc. Natl. Acad. Sci. USA 2001, 98, 8160-8162. [CrossRef]

67. Johnson, M.B.; Chen, J.; Murchison, N.; Green, F.A.; Enns, C.A. Transferrin receptor 2: Evidence for ligand-induced stabilization and redirection to a recycling pathway. Mol. Biol. Cell 2007, 18, 743-754. [CrossRef]

68. Schmidt, P.J.; Toran, P.T.; Giannetti, A.M.; Bjorkman, P.J.; Andrews, N.C. The transferrin receptor modulates Hfe-dependent regulation of hepcidin expression. Cell Metab. 2008, 7, 205-214. [CrossRef] [PubMed]

69. Nicolas, G.; Viatte, L.; Lou, D.-Q.; Bennoun, M.; Beaumont, C.; Kahn, A.; Andrews, N.C.; Vaulont, S. Constitutive hepcidin expression prevents iron overload in a mouse model of hemochromatosis. Nat. Genet. 2003, 34, 97-101. [CrossRef] [PubMed]

70. Gao, J.; Chen, J.; Kramer, M.; Tsukamoto, H.; Zhang, A.-S.; Enns, C.A. Interaction of the hereditary hemochromatosis protein HFE with transferrin receptor 2 is required for transferrin-induced hepcidin expression. Cell Metab. 2009, 9, 217-227. [CrossRef]

71. Ajioka, R.S.; Levy, J.E.; Andrews, N.C.; Kushner, J.P. Regulation of iron absorption in Hfe mutant mice. Blood 2002, 100, 1465-1469. [CrossRef] [PubMed]

72. Wallace, D.F.; Summerville, L.; Crampton, E.M.; Frazer, D.M.; Anderson, G.J.; Subramaniam, V.N. Combined deletion of Hfe and transferrin receptor 2 in mice leads to marked dysregulation of hepcidin and iron overload. Hepatology 2009, 50, 1992-2000. [CrossRef]

73. Ramey, G.; Deschemin, J.-C.; Vaulont, S. Cross-talk between the mitogen activated protein kinase and bone morphogenetic protein/hemojuvelin pathways is required for the induction of hepcidin by holotransferrin in primary mouse hepatocytes. Haematologica 2009, 94, 765-772. [CrossRef]

74. Kawabata, H.; Fleming, R.E.; Gui, D.; Moon, S.Y.; Saitoh, T.; O’Kelly, J.; Umehara, Y.; Wano, Y.; Said, J.W.; Koeffler, H.P. Expression of hepcidin is down-regulated in TfR2 mutant mice manifesting a phenotype of hereditary hemochromatosis. Blood 2005, 105, 376-381. [CrossRef] [PubMed]

75. Yu, H.; Lee, H.; Herrmann, A.; Buettner, R.; Jove, R. Revisiting STAT3 signalling in cancer: New and unexpected biological functions. Nat. Rev. Cancer 2014, 14, 736-746. [CrossRef]

76. Armitage, A.E.; Eddowes, L.A.; Gileadi, U.; Cole, S.; Spottiswoode, N.; Selvakumar, T.A.; Ho, L.-P.; Townsend, A.R.M.; Drakesmith, H. Hepcidin regulation by innate immune and infectious stimuli. Blood 2011, 118, 4129-4139. [CrossRef] [PubMed]

77. Cassat, J.E.; Skaar, E.P. Iron in infection and immunity. Cell Host Microbe 2013, 13, 509-519. [CrossRef] [PubMed]

78. Peyssonnaux, C.; Zinkernagel, A.S.; Datta, V.; Lauth, X.; Johnson, R.S.; Nizet, V. TLR4-dependent hepcidin expression by myeloid cells in response to bacterial pathogens. Blood 2006, 107, 3727-3732. [CrossRef] [PubMed]

79. Theurl, I.; Theurl, M.; Seifert, M.; Mair, S.; Nairz, M.; Rumpold, H.; Zoller, H.; Bellmann-Weiler, R.; Niederegger, H.; Talasz, H.; et al. Autocrine formation of hepcidin induces iron retention in human monocytes. Blood 2008, 111, 2392-2399. [CrossRef] 
80. Soares, M.P.; Weiss, G. The Iron age of host-microbe interactions. EMBO Rep. 2015, 16, 1482-1500. [CrossRef]

81. Pasricha, S.-R.; McHugh, K.; Drakesmith, H. Regulation of hepcidin by erythropoiesis: The story so far. Annu. Rev. Nutr. 2016, 36, 417-434. [CrossRef] [PubMed]

82. Pinto, J.P.; Ribeiro, S.; Pontes, H.; Thowfeequ, S.; Tosh, D.; Carvalho, F.; Porto, G. Erythropoietin mediates hepcidin expression in hepatocytes through EPOR signaling and regulation of C/EBPalpha. Blood 2008, 111, 5727-5733. [CrossRef] [PubMed]

83. Tanno, T.; Bhanu, N.V.; Oneal, P.A.; Goh, S.-H.; Staker, P.; Lee, Y.T.; Moroney, J.W.; Reed, C.H.; Luban, N.L.C.; Wang, R.-H.; et al. High levels of GDF15 in thalassemia suppress expression of the iron regulatory protein hepcidin. Nat. Med. 2007, 13, 1096-1101. [CrossRef] [PubMed]

84. Tanno, T.; Porayette, P.; Sripichai, O.; Noh, S.-J.; Byrnes, C.; Bhupatiraju, A.; Lee, Y.T.; Goodnough, J.B.; Harandi, O.; Ganz, T.; et al. Identification of TWSG1 as a second novel erythroid regulator of hepcidin expression in murine and human cells. Blood 2009, 114, 181-186. [CrossRef] [PubMed]

85. Wilkinson, N.; Pantopoulos, K. The IRP/IRE system in vivo: Insights from mouse models. Front. Pharmacol. 2014, 5, 176. [CrossRef] [PubMed]

86. Theil, E.C. Iron regulatory elements (IREs): A family of mRNA non-coding sequences. Biochem. J. 1994, 304 Pt 1, 1-11. [CrossRef]

87. Hentze, M.W.; Caughman, S.W.; Rouault, T.A.; Barriocanal, J.G.; Dancis, A.; Harford, J.B.; Klausner, R.D. Identification of the iron-responsive element for the translational regulation of human ferritin mRNA. Science 1987, 238, 1570-1573. [CrossRef]

88. Casey, J.L.; Hentze, M.W.; Koeller, D.M.; Caughman, S.W.; Rouault, T.A.; Klausner, R.D.; Harford, J.B. Iron-responsive elements: Regulatory RNA sequences that control mRNA levels and translation. Science 1988, 240, 924-928. [CrossRef]

89. Dandekar, T.; Hentze, M.W. Finding the hairpin in the haystack: Searching for RNA motifs. Trends Genet. 1995, 11, 45-50. [CrossRef]

90. Evstatiev, R.; Gasche, C. Iron sensing and signalling. Gut 2012, 61, 933-952. [CrossRef]

91. Vashisht, A.A.; Zumbrennen, K.B.; Huang, X.; Powers, D.N.; Durazo, A.; Sun, D.; Bhaskaran, N.; Persson, A.; Uhlen, M.; Sangfelt, O.; et al. Control of iron homeostasis by an iron-regulated ubiquitin ligase. Science 2009, 326, 718-721. [CrossRef] [PubMed]

92. Wang, J.; Fillebeen, C.; Chen, G.; Biederbick, A.; Lill, R.; Pantopoulos, K. Iron-dependent degradation of apo-IRP1 by the ubiquitin-proteasome pathway. Mol. Cell. Biol. 2007, 27, 2423-2430. [CrossRef]

93. Wang, J.; Chen, G.; Lee, J.; Pantopoulos, K. Iron-dependent degradation of IRP2 requires its C-terminal region and IRP structural integrity. BMC Mol. Biol. 2008, 9, 15. [CrossRef] [PubMed]

94. Gunshin, H.; Allerson, C.R.; Polycarpou-Schwarz, M.; Rofts, A.; Rogers, J.T.; Kishi, F.; Hentze, M.W.; Rouault, T.A.; Andrews, N.C.; Hediger, M.A. Iron-dependent regulation of the divalent metal ion transporter. FEBS Lett. 2001, 509, 309-316. [CrossRef]

95. Galy, B.; Ferring, D.; Minana, B.; Bell, O.; Janser, H.G.; Muckenthaler, M.; Schümann, K.; Hentze, M.W. Altered body iron distribution and microcytosis in mice deficient in iron regulatory protein 2 (IRP2). Blood 2005, 106, 2580-2589. [CrossRef] [PubMed]

96. Meyron-Holtz, E.G.; Ghosh, M.C.; Iwai, K.; LaVaute, T.; Brazzolotto, X.; Berger, U.V.; Land, W.; Ollivierre-Wilson, H.; Grinberg, A.; Love, P.; et al. Genetic ablations of iron regulatory proteins 1 and 2 reveal why iron regulatory protein 2 dominates iron homeostasis. EMBO J. 2004, 23, 386-395. [CrossRef] [PubMed]

97. Anderson, S.A.; Nizzi, C.P.; Chang, Y.-I.; Deck, K.M.; Schmidt, P.J.; Galy, B.; Damnernsawad, A.; Broman, A.T.; Kendziorski, C.; Hentze, M.W.; et al. The IRP1-HIF-2 $\alpha$ axis coordinates iron and oxygen sensing with erythropoiesis and iron absorption. Cell Metab. 2013, 17, 282-290. [CrossRef]

98. Cooperman, S.S.; Meyron-Holtz, E.G.; Olivierre-Wilson, H.; Ghosh, M.C.; McConnell, J.P.; Rouault, T.A. Microcytic anemia, erythropoietic protoporphyria, and neurodegeneration in mice with targeted deletion of iron-regulatory protein 2. Blood 2005, 106, 1084-1091. [CrossRef]

99. Ferring-Appel, D.; Hentze, M.W.; Galy, B. Cell-autonomous and systemic context-dependent functions of iron regulatory protein 2 in mammalian iron metabolism. Blood 2009, 113, 679-687. [CrossRef]

100. Haldar, M.; Kohyama, M.; So, A.Y.-L.; Kc, W.; Wu, X.; Briseño, C.G.; Satpathy, A.T.; Kretzer, N.M.; Arase, H.; Rajasekaran, N.S.; et al. Heme-mediated SPI-C induction promotes monocyte differentiation into iron-recycling macrophages. Cell 2014, 156, 1223-1234. [CrossRef] 
101. Kohyama, M.; Ise, W.; Edelson, B.T.; Wilker, P.R.; Hildner, K.; Mejia, C.; Frazier, W.A.; Murphy, T.L.; Murphy, K.M. Role for Spi-C in the development of red pulp macrophages and splenic iron homeostasis. Nature 2009, 457, 318-321. [CrossRef] [PubMed]

102. Kurotaki, D.; Uede, T.; Tamura, T. Functions and development of red pulp macrophages. Microbiol. Immunol. 2015, 59, 55-62. [CrossRef] [PubMed]

103. Zenke-Kawasaki, Y.; Dohi, Y.; Katoh, Y.; Ikura, T.; Ikura, M.; Asahara, T.; Tokunaga, F.; Iwai, K.; Igarashi, K. Heme induces ubiquitination and degradation of the transcription factor Bach1. Mol. Cell. Biol. 2007, 27, 6962-6971. [CrossRef] [PubMed]

104. Warnatz, H.-J.; Schmidt, D.; Manke, T.; Piccini, I.; Sultan, M.; Borodina, T.; Balzereit, D.; Wruck, W.; Soldatov, A.; Vingron, M.; et al. The BTB and CNC homology 1 (BACH1) target genes are involved in the oxidative stress response and in control of the cell cycle. J. Biol. Chem. 2011, 286, 23521-23532. [CrossRef] [PubMed]

105. Drakesmith, H.; Schimanski, L.M.; Ormerod, E.; Merryweather-Clarke, A.T.; Viprakasit, V.; Edwards, J.P.; Sweetland, E.; Bastin, J.M.; Cowley, D.; Chinthammitr, Y.; et al. Resistance to hepcidin is conferred by hemochromatosis-associated mutations of ferroportin. Blood 2005, 106, 1092-1097. [CrossRef] [PubMed]

106. Flashman, E.; Davies, S.L.; Yeoh, K.K.; Schofield, C.J. Investigating the dependence of the hypoxia-inducible factor hydroxylases (factor inhibiting HIF and prolyl hydroxylase domain 2) on ascorbate and other reducing agents. Biochem. J. 2010, 427, 135-142. [CrossRef] [PubMed]

107. Pappalardi, M.B.; McNulty, D.E.; Martin, J.D.; Fisher, K.E.; Jiang, Y.; Burns, M.C.; Zhao, H.; Ho, T.; Sweitzer, S.; Schwartz, B.; et al. Biochemical characterization of human HIF hydroxylases using HIF protein substrates that contain all three hydroxylation sites. Biochem. J. 2011, 436, 363-369. [CrossRef] [PubMed]

108. Hubert, N.; Hentze, M.W. Previously uncharacterized isoforms of divalent metal transporter (DMT)-1: Implications for regulation and cellular function. Proc. Natl. Acad. Sci. USA 2002, 99, 12345-12350. [CrossRef]

109. Peyssonnaux, C.; Zinkernagel, A.S.; Schuepbach, R.A.; Rankin, E.; Vaulont, S.; Haase, V.H.; Nizet, V.; Johnson, R.S. Regulation of iron homeostasis by the hypoxia-inducible transcription factors (HIFs). J. Clin. Investig. 2007, 117, 1926-1932. [CrossRef]

110. Fang, H.-Y.; Hughes, R.; Murdoch, C.; Coffelt, S.B.; Biswas, S.K.; Harris, A.L.; Johnson, R.S.; Imityaz, H.Z.; Simon, M.C.; Fredlund, E.; et al. Hypoxia-inducible factors 1 and 2 are important transcriptional effectors in primary macrophages experiencing hypoxia. Blood 2009, 114, 844-859. [CrossRef]

111. Chiabrando, D.; Fiorito, V.; Marro, S.; Silengo, L.; Altruda, F.; Tolosano, E. Cell-specific regulation of Ferroportin transcription following experimentally-induced acute anemia in mice. Blood Cells Mol. Dis. 2013, 50, 25-30. [CrossRef] [PubMed]

112. Mastrogiannaki, M.; Matak, P.; Mathieu, J.R.R.; Delga, S.; Mayeux, P.; Vaulont, S.; Peyssonnaux, C. Hepatic hypoxia-inducible factor-2 down-regulates hepcidin expression in mice through an erythropoietin-mediated increase in erythropoiesis. Haematologica 2012, 97, 827-834. [CrossRef] [PubMed]

113. Orkin, S.H.; Nathan, D.G.; Ginsburg, D.; Look, A.T.; Fisher, D.E.; Lux, S. Nathan and Oski's Hematology of Infancy and Childhood E-Book; Elsevier: Amsterdam, The Netherlands, 2008.

114. de Back, D.Z.; Kostova, E.B.; van Kraaij, M.; van den Berg, T.K.; van Bruggen, R. Of macrophages and red blood cells; a complex love story. Front. Physiol. 2014, 5, 9. [CrossRef] [PubMed]

115. Ulyanova, T.; Padilla, S.M.; Papayannopoulou, T. Stage specific functional roles of integrins in erythropoiesis. Exp. Hematol. 2014, 2, 404-409. [CrossRef] [PubMed]

116. Oldenborg, P.A.; Zheleznyak, A.; Fang, Y.F.; Lagenaur, C.F.; Gresham, H.D.; Lindberg, F.P. Role of CD47 as a marker of self on red blood cells. Science 2000, 288, 2051-2054. [CrossRef] [PubMed]

117. Bratosin, D.; Mazurier, J.; Tissier, J.P.; Estaquier, J.; Huart, J.J.; Ameisen, J.C.; Aminoff, D.; Montreuil, J. Cellular and molecular mechanisms of senescent erythrocyte phagocytosis by macrophages. A review. Biochimie 1998, 80, 173-195. [CrossRef]

118. Marro, S.; Chiabrando, D.; Messana, E.; Stolte, J.; Turco, E.; Tolosano, E.; Muckenthaler, M.U. Heme controls ferroportin1 (FPN1) transcription involving Bach1, Nrf2 and a MARE/ARE sequence motif at position -7007 of the FPN1 promoter. Haematologica 2010, 95, 1261-1268. [CrossRef]

119. Maines, M.D. The heme oxygenase system: A regulator of second messenger gases. Annu. Rev. Pharmacol. Toxicol. 1997, 37, 517-554. [CrossRef] 
120. Beaumont, C.; Delaby, C. Recycling iron in normal and pathological states. Semin. Hematol. 2009, 46, 328-338. [CrossRef]

121. Gottlieb, Y.; Truman, M.; Cohen, L.A.; Leichtmann-Bardoogo, Y.; Meyron-Holtz, E.G. Endoplasmic reticulum anchored heme-oxygenase 1 faces the cytosol. Haematologica 2012, 97, 1489-1493. [CrossRef]

122. Kovtunovych, G.; Eckhaus, M.A.; Ghosh, M.C.; Ollivierre-Wilson, H.; Rouault, T.A. Dysfunction of the heme recycling system in heme oxygenase 1-deficient mice: Effects on macrophage viability and tissue iron distribution. Blood 2010, 116, 6054-6062. [CrossRef] [PubMed]

123. Kovtunovych, G.; Ghosh, M.C.; Ollivierre, W.; Weitzel, R.P.; Eckhaus, M.A.; Tisdale, J.F.; Yachie, A.; Rouault, T.A. Wild-type macrophages reverse disease in heme oxygenase 1-deficient mice. Blood 2014, 124, 1522-1530. [CrossRef] [PubMed]

124. Soe-Lin, S.; Apte, S.S.; Andriopoulos, B.; Andrews, M.C.; Schranzhofer, M.; Kahawita, T.; Garcia-Santos, D.; Ponka, P. Nramp1 promotes efficient macrophage recycling of iron following erythrophagocytosis in vivo. Proc. Natl. Acad. Sci. USA 2009, 106, 5960-5965. [CrossRef] [PubMed]

125. Zhang, Z.; Zhang, F.; An, P.; Guo, X.; Shen, Y.; Tao, Y.; Wu, Q.; Zhang, Y.; Yu, Y.; Ning, B.; et al. Ferroportin1 deficiency in mouse macrophages impairs iron homeostasis and inflammatory responses. Blood 2011, 118, 1912-1922. [CrossRef] [PubMed]

126. Cohen, L.A.; Gutierrez, L.; Weiss, A.; Leichtmann-Bardoogo, Y.; Zhang, D.; Crooks, D.R.; Sougrat, R.; Morgenstern, A.; Galy, B.; Hentze, M.W.; et al. Serum ferritin is derived primarily from macrophages through a nonclassical secretory pathway. Blood 2010, 116, 1574-1584. [CrossRef] [PubMed]

127. Theurl, I.; Hilgendorf, I.; Nairz, M.; Tymoszuk, P.; Haschka, D.; Asshoff, M.; He, S.; Gerhardt, L.M.S.; Holderried, T.A.W.; Seifert, M.; et al. On-demand erythrocyte disposal and iron recycling requires transient macrophages in the liver. Nat. Med. 2016, 22, 945-951. [CrossRef] [PubMed]

128. Fabriek, B.O.; van Bruggen, R.; Deng, D.M.; Ligtenberg, A.J.M.; Nazmi, K.; Schornagel, K.; Vloet, R.P.M.; Dijkstra, C.D.; van den Berg, T.K. The macrophage scavenger receptor CD163 functions as an innate immune sensor for bacteria. Blood 2009, 113, 887-892. [CrossRef] [PubMed]

129. Graversen, J.H.; Madsen, M.; Moestrup, S.K. CD163: A signal receptor scavenging haptoglobin-hemoglobin complexes from plasma. Int. J. Biochem. Cell Biol. 2002, 34, 309-314. [CrossRef]

130. Eid, R.; Zhou, D.R.; Arab, N.T.T.; Boucher, E.; Young, P.G.; Mandato, C.A.; Greenwood, M.T. Heterologous expression of anti-apoptotic human 14-3-3 $\beta / \alpha$ enhances iron-mediated programmed cell death in yeast. PLoS ONE 2017, 12, e0184151. [CrossRef]

131. Martins, R.; Maier, J.; Gorki, A.-D.; Huber, K.V.M.; Sharif, O.; Starkl, P.; Saluzzo, S.; Quattrone, F.; Gawish, R.; Lakovits, K.; et al. Heme drives hemolysis-induced susceptibility to infection via disruption of phagocyte functions. Nat. Immunol. 2016, 17, 1361-1372. [CrossRef]

132. Chow, A.; Huggins, M.; Ahmed, J.; Hashimoto, D.; Lucas, D.; Kunisaki, Y.; Pinho, S.; Leboeuf, M.; Noizat, C.; van Rooijen, N.; et al. CD169+ macrophages provide a niche promoting erythropoiesis under homeostasis and stress. Nat. Med. 2013, 19, 429-436. [CrossRef] [PubMed]

133. Chow, A.; Lucas, D.; Hidalgo, A.; Méndez-Ferrer, S.; Hashimoto, D.; Scheiermann, C.; Battista, M.; Leboeuf, M.; Prophete, C.; van Rooijen, N.; et al. Bone marrow CD169+ macrophages promote the retention of hematopoietic stem and progenitor cells in the mesenchymal stem cell niche. J. Exp. Med. 2011, 208, 261-271. [CrossRef] [PubMed]

134. Bessis, M. Erythroblastic island, functional unity of bone marrow. Rev. Hematol. 1958, 13, 8-11. [PubMed]

135. Mohandas, N.; Prenant, M. Three-dimensional model of bone marrow. Blood 1978, 51, 633-643. [PubMed]

136. Klei, T.R.L.; Meinderts, S.M.; van den Berg, T.K.; van Bruggen, R. From the cradle to the grave: The role of macrophages in erythropoiesis and erythrophagocytosis. Front. Immunol. 2017, 8, 73. [CrossRef]

137. Sadahira, Y.; Yoshino, T.; Monobe, Y. Very late activation antigen 4-vascular cell adhesion molecule 1 interaction is involved in the formation of erythroblastic islands. J. Exp. Med. 1995, 181, 411-415. [CrossRef] [PubMed]

138. Zermati, Y.; Fichelson, S.; Valensi, F.; Freyssinier, J.M.; Rouyer-Fessard, P.; Cramer, E.; Guichard, J.; Varet, B.; Hermine, $\mathrm{O}$. Transforming growth factor inhibits erythropoiesis by blocking proliferation and accelerating differentiation of erythroid progenitors. Exp. Hematol. 2000, 28, 885-894. [CrossRef]

139. Toda, S.; Segawa, K.; Nagata, S. MerTK-mediated engulfment of pyrenocytes by central macrophages in erythroblastic islands. Blood 2014. [CrossRef] [PubMed] 
140. Hirsch, E.; Iglesias, A.; Potocnik, A.J.; Hartmann, U.; Fässler, R. Impaired migration but not differentiation of haematopoietic stem cells in the absence of $\beta 1$ integrins. Nature 1996, 380, 171-175. [CrossRef] [PubMed]

141. Heideveld, E.; van den Akker, E. Digesting the role of bone marrow macrophages on hematopoiesis. Immunobiology 2017, 222, 814-822. [CrossRef] [PubMed]

142. Ramos, P.; Casu, C.; Gardenghi, S.; Breda, L.; Crielaard, B.J.; Guy, E.; Marongiu, M.F.; Gupta, R.; Levine, R.L.; Abdel-Wahab, O; et al. Macrophages support pathological erythropoiesis in polycythemia vera and $\beta$-thalassemia. Nat. Med. 2013, 19, 437-445. [CrossRef] [PubMed]

143. Korolnek, T.; Hamza, I. Macrophages and iron trafficking at the birth and death of red cells. Blood 2015, 125, 2893-2897. [CrossRef] [PubMed]

144. Tacchini, L.; Gammella, E.; De Ponti, C.; Recalcati, S.; Cairo, G. Role of HIF-1 and NF-kappaB transcription factors in the modulation of transferrin receptor by inflammatory and anti-inflammatory signals. J. Biol. Chem. 2008, 283, 20674-20686. [CrossRef] [PubMed]

145. Levy, J.E.; Jin, O.; Fujiwara, Y.; Kuo, F.; Andrews, N.C. Transferrin receptor is necessary for development of erythrocytes and the nervous system. Nat. Genet. 1999, 21, 396-399. [CrossRef] [PubMed]

146. Lambe, T.; Simpson, R.J.; Dawson, S.; Bouriez-Jones, T.; Crockford, T.L.; Lepherd, M.; Latunde-Dada, G.O.; Robinson, H.; Raja, K.B.; Campagna, D.R.; et al. Identification of a Steap3 endosomal targeting motif essential for normal iron metabolism. Blood 2009, 113, 1805-1808. [CrossRef] [PubMed]

147. Knutson, M.D.; Oukka, M.; Koss, L.M.; Aydemir, F.; Wessling-Resnick, M. Iron release from macrophages after erythrophagocytosis is up-regulated by ferroportin 1 overexpression and down-regulated by hepcidin. Proc. Natl. Acad. Sci. USA 2005, 102, 1324-1328. [CrossRef] [PubMed]

148. Zhang, Z.; Song, Y.; Zhang, Z.; Li, D.; Zhu, H.; Liang, R.; Gu, Y.; Pang, Y.; Qi, J.; Wu, H.; et al. Distinct role of heme oxygenase-1 in early- and late-stage intracerebral hemorrhage in 12-month-old mice. J. Cereb. Blood Flow Metab. 2016, 37, 25-38. [CrossRef] [PubMed]

149. Schaer, C.A.; Deuel, J.W.; Schildknecht, D.; Mahmoudi, L.; Garcia-Rubio, I.; Owczarek, C.; Schauer, S.; Kissner, R.; Banerjee, U.; Palmer, A.F.; et al. Haptoglobin Preserves Vascular Nitric Oxide Signaling during Hemolysis. Am. J. Respir. Crit. Care Med. 2016, 193, 1111-1122. [CrossRef]

150. Leimberg, M.J.; Prus, E.; Konijn, A.M.; Fibach, E. Macrophages function as a ferritin iron source for cultured human erythroid precursors. J. Cell Biochem. 2008, 103, 1211-1218. [CrossRef]

151. Leimberg, J.M.; Konijn, A.M.; Fibach, E. Developing human erythroid cells grown in transferrin-free medium utilize iron originating from extracellular ferritin. Am. J. Hematol. 2003, 73, 211-212. [CrossRef]

(C) 2018 by the authors. Licensee MDPI, Basel, Switzerland. This article is an open access article distributed under the terms and conditions of the Creative Commons Attribution (CC BY) license (http:/ / creativecommons.org/licenses/by/4.0/). 


\title{
Review
}

\section{Iron Supplementation Therapy, A Friend and Foe of Mycobacterial Infections?}

\author{
Rafiou Agoro ${ }^{1, *}$ and Catherine Mura ${ }^{2, *}$ \\ 1 Medical and Molecular Genetics, Indiana University, School of Medicine, Indianapolis, IN 46202, USA \\ 2 Experimental and Molecular Immunology and Neurogenetics (INEM), Mixed Research Unit UMR7355, \\ National Center for Scientific Research and Orléans University, 45071 Orléans, France \\ * Correspondence: ragoro@iu.edu (R.A); catherine.mura@cnrs-orleans.fr (C.M.); \\ Tel.: +1-317-278-6140 (R.A.); +33-2-3825-7975 (C.M.)
}

Received: 28 April 2019; Accepted: 15 May 2019; Published: 17 May 2019

\begin{abstract}
Iron is an essential element that is required for oxygen transfer, redox, and metabolic activities in mammals and bacteria. Mycobacteria, some of the most prevalent infectious agents in the world, require iron as growth factor. Mycobacterial-infected hosts set up a series of defense mechanisms, including systemic iron restriction and cellular iron distribution, whereas mycobacteria have developed sophisticated strategies to acquire iron from their hosts and to protect themselves from iron's harmful effects. Therefore, it is assumed that host iron and iron-binding proteins, and natural or synthetic chelators would be keys targets to inhibit mycobacterial proliferation and may have a therapeutic potential. Beyond this hypothesis, recent evidence indicates a host protective effect of iron against mycobacterial infections likely through promoting remodeled immune response. In this review, we discuss experimental procedures and clinical observations that highlight the role of the immune response against mycobacteria under various iron availability conditions. In addition, we discuss the clinical relevance of our knowledge regarding host susceptibility to mycobacteria in the context of iron availability and suggest future directions for research on the relationship between host iron and the immune response and the use of iron as a therapeutic agent.
\end{abstract}

Keywords: iron; mycobacteria; immunity

\section{General Context}

Mycobacterial infections in human populations are increasing worldwide and remain a major cause of morbidity and mortality, making them a major public health concern. The emergence and spread of multi-drug resistant (MDR) and extensively drug-resistant (XDR) mycobacterial strains have shifted our interest to explore new therapeutic approaches. Iron plays a crucial role in the pathophysiology of mycobacteria and should be of great interest for future therapeutic strategies. In this context, the development of an effective iron-based therapy requires a detailed understanding of the role of iron during mycobacterial infections as a target involved in the resistance and/or susceptibility of host.

\section{Mycobacteria: The Smart Pathogens}

The genus Mycobacterium comprises more than 150 species that reside in a wide variety of habitats [1]. These bacteria are typically characterized by the structure of their cell envelope (see Figure 1 representing the structure of mycobacterial envelope and for review [2]). Mycobacteria are divided into three groups, the Mycobacterium tuberculosis complex (M. tuberculosis, M. africanum, M. bovis, M. canetti, and M. microti), lepromatous mycobacteria (Mycobacterium leprae), and non-tuberculosis mycobacteria (NTM), a group which contains only a few pathogenic species involved mostly in lung infection in immunocompromised individuals [3,4]. 


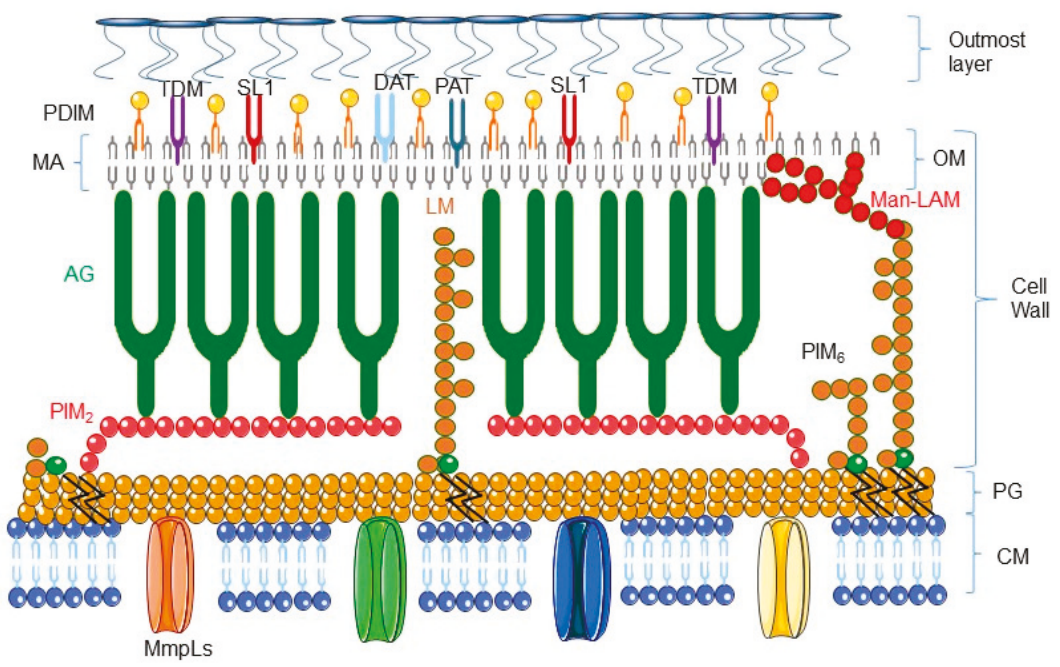

Figure 1. Schematic representation of the cell envelope of Mycobacterium tuberculosis (adapted from [2]). The cell envelope of $M$. tuberculosis includes an inner cell membrane (CM), a network of peptidoglycan (PG) with covalently attached macromolecules: AG, $\mathrm{PIM}_{2}, \mathrm{PIM}_{6}$, LM, and Man-LAM; an outer membrane (OM) composed of mycolic acid (MA), attached to TDM, DAT, PAT, PDIM, and SL-1; and an outmost layer of polysaccharides and proteins. AG: arabinogalactan; DAT: diacyltrehalose; LM: lipomannan; Man-LAM: mannose-capped lipoarabinomannan; PAT: poliacyltrehalose; PDIM: phthiocerol dimycocerosate; $\mathrm{PIM}_{2}$ : phospho-myo-inositol-dimannoside; $\mathrm{PIM}_{6}$ : phospho-myo-inositol-hexamannoside; MmpL: mycobacterial membrane protein large; TDM: trehalose dimycolate; SL-1: sulphoglycolipid.

Host immune systems have evolved antimicrobial strategies, whereas mycobacteria which are facultative intracellular pathogens have developed new ways to survive in previously inaccessible niches and hostile environment. The Mycobacterium tuberculosis complex species are mainly restricted to macrophages as host cells and induce a chronic immunopathology. Macrophages internalize mycobacteria by phagocytosis, but only pathogenic mycobacterial species can survive and proliferate inside these cells. In hosts cells, mycobacteria are located in the phagosome and thus exposed to hostile conditions, such as oxidative stress, hypoxia, and nutrient restriction also known as nutritional immunity.

The pathogenic mycobacteria have adapted to the hostile environment of the phagosome by entering into a dormant state. Indeed, during chronic infection, $M$. tuberculosis survives nutrient starvation by using the $\beta$-oxidation pathway, which allows fatty acids to be utilized as a unique carbon source. Dormant $M$. tuberculosis cells are characterized by a distinct cell wall lipid content. Indeed the $\beta$-oxidation pathway is a source of phthiocerol dimycocerosates (PDIM), glycolipids diacyltrehalose (DAT), and polyacyltrehalose (PAT), and sulfolipid (SL-1) [2]. To establish residence in macrophages, the pathogenic mycobacteria slow down their growth and can lay in a 'dormant' state for decades, further limiting the risk of destroying their host macrophages and allowing them to survive harsh living conditions.

\subsection{Host Response to Mycobacteria Through Immune Cell Activation}

The host sets up a complex immune response involving both innate and adaptive components that are specific to persistent intracellular pathogens. The host often sequesters mycobacteria in an organized structure named granuloma, composed of center of phagocytic cells surrounded by $\mathrm{T}$ and B lymphocytes, that regulates the immune-mediated containment of the infection. 
Granulomas are hypoxic and nutrient-restricted hostile environments for mycobacteria that contain the infection [5]. In most cases, granulomas do not develop into an active site of infection and can resolve infection or support bacterial survival over long period of time. The resident macrophages phagocytize and eradicate most infecting mycobacteria, preventing the mycobacteria colonization and further mycobacterial infection. Indeed, activated macrophages can induce bacteriostatic and bactericide effect on mycobacteria, but mycobacteria can reside within nondegradative macrophages. Once infected, only 5-10\% of immunocompetent humans exposed to $M$. tuberculosis develop disease. For a successful infection, mycobacteria must not only avoid destruction and survive within phagosomes but must also escape from the initially infected resident macrophage to spread to other areas and infect growth-permissive monocytes to cause disease. This reactivation process depends on the presence of metabolically active bacilli. M. tuberculosis infection can manifest as acute or chronic disease or be clinically asymptomatic with the potential to emerge from a latent form to an active form of infection [6]. Phagocytic cells are key biological element involved in the control of mycobacterial infection, although they also assist in their subsequent dissemination.

\subsection{Host Response to Mycobacteria Through Oxidative Stress Induction: A Critical Role of Iron}

Once stimulated, upon mycobacteria infection, TLRs promote the innate immune response and the production of microbicidal effectors, such as reactive nitrogen intermediates (RNI) and reactive oxygen species (ROS) produced by phagolysosomes from macrophages, and microbicidal peptides such as lactoferricin and defensins [7].

Accumulating evidence suggests an important role of macrophage-derived nitric oxide (NO) in protecting host cells against intracellular pathogens. Nitric oxide (NO) is a chemical mediator and regulator that has physiological and pathophysiological roles in mammals as well as a significant role in inflammation. NO is produced by the nitric oxide synthase (NOS) enzyme family, which catalyzes the two-step conversion of L-arginine to L-citrulline and NO. The inducible nitric oxide synthase (iNOS or NOS2), a form of NOS is transcriptionally induced in IFN $\gamma$-activated macrophages, inducing high production of NO [8]. NO possesses cytotoxic properties through interactions of reactive free NO radicals with iron containing enzymes or molecular oxygen and superoxide anion to produce reactive nitrogen species that cause massive oxidative injuries. NO is a powerful reactive molecule that plays a major role in controlling mycobacterial infections. Indeed, mice deficient in NOS2 activity are highly susceptible to acute and chronic M. tuberculosis infection compared to wild-type mice $[9,10]$.

Phagocytes can eliminate invading pathogens via oxygen-dependent and oxygen-independent mechanisms. The activated phagocytes induce the NADPH oxidase system, a membrane-bound complex located in the plasma membrane and in the phagosomal membranes of phagocytic cells that reduces $\mathrm{O}_{2}$ to superoxide anion $\left(\mathrm{O}_{2}{ }^{\bullet-}\right)$ and triggers oxidative bursts [11]. Superoxide anion $\left(\mathrm{O}_{2}{ }^{\bullet-}\right)$ spontaneously converts to hydrogen peroxide $\left(\mathrm{H}_{2} \mathrm{O}_{2}\right)$, and $\mathrm{H}_{2} \mathrm{O}_{2}$ can further undergo a Fenton reaction in the presence of iron to yield highly reactive hydroxyl radicals $\left(\mathrm{OH}^{\bullet}\right)$ (Figure 2) [12]. The presence of $\mathrm{O}_{2}{ }^{\bullet-}$ and $\mathrm{NO}$ will further generate peroxynitrite $\left(\mathrm{ONOO}^{-} / \mathrm{ONOOH}\right)$, the most injurious reactive nitrogen species (RNS), and other reactive free radicals (Figure 2) [13,14]. These molecules can damage a variety of biomolecules, including DNA, which effectively kills the pathogen and inhibits its dissemination [15]. Neutrophils are professional phagocytes that play protective roles in mycobacterial infections through the release of preformed oxidants and proteolytic enzymes which are discharged during the degranulation process [16,17]. Neutrophils contain cytoplasmic granules that contain large amount of myeloperoxidase (MPO) that uses $\mathrm{H}_{2} \mathrm{O}_{2}$ to catalyze the production of highly toxic ROS like hypochlorous acid $(\mathrm{HOCl})$ in the presence of anion chloride $\left(\mathrm{Cl}^{-}\right)$. The production of $\mathrm{ROS}_{2} \mathrm{O}_{2}^{-}, \mathrm{H}_{2} \mathrm{O}_{2}$, and $\mathrm{HOCl}$ by phagocytic cells in response to infection is a highly effective microbicidal mechanism that is also referred to as a respiratory burst. In contrast to neutrophils, mature macrophages contain much less concentrations of MPO and thus are unable to kill pathogenic intracellular microorganisms by this system [18]. 
In humans, genetic deficiency for one of the subunits of NADPH oxidase causes an inherited immunodeficiency, chronic granulomatous disease (CGD), which is characterized by dysregulated inflammation and recurrent infections with catalase-positive microorganisms, including $M$. tuberculosis and M. bovis BCG [19]. Moreover, subjects with MPO deficiency have an increased susceptibility to infection [20]. However, it has been demonstrated that MPO-loaded macrophages still ingest M. tuberculosis and do not show a significant mycobactericidal activity despite a highly susceptibility of mycobacteria to the system in vitro. This failure of peroxidase-loaded macrophages to kill M. tuberculosis may result from the presence of efficient detoxifying mechanisms in the mycobacteria [18]. The lack of granular MPO in mature macrophages may explain the tendency of mycobacteria to infect these cells that favor the survival and proliferation of pathogenic intracellular microorganisms.

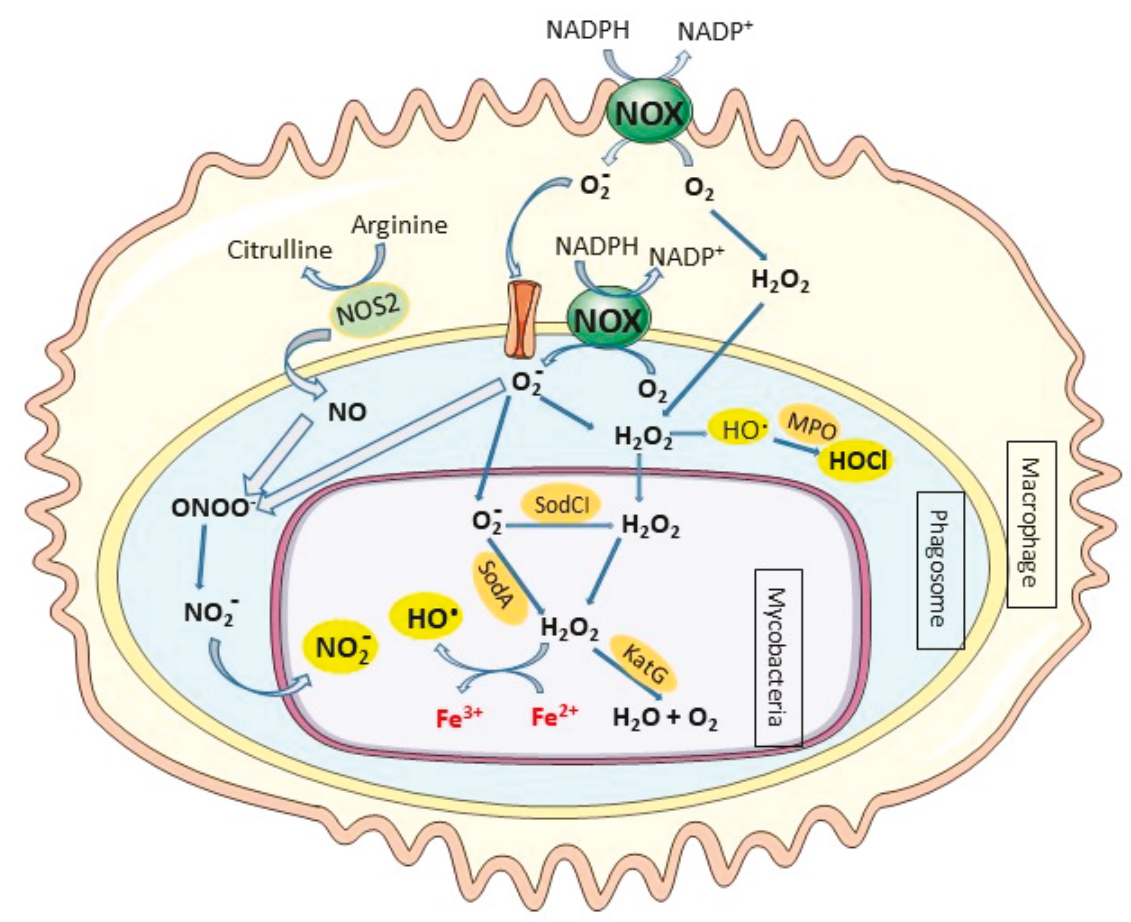

Figure 2. Series of reactive oxygen species generated in response to intracellular mycobacteria infection. Macrophages and neutrophils produce reactive oxygen species to kill intracellular microbes in a series of reaction which can be initiated by the conversion of NADPH to NADP ${ }^{+}$via the NADPH oxidase (NOX) and the production of superoxide $\mathrm{O}_{2}{ }^{-}$in presence of $\mathrm{O}_{2} \cdot \mathrm{O}_{2}{ }^{-}$can enter in the phagosome and later in the mycobacteria through porins or crosses the outer membrane that is partially permeabilized by antimicrobial peptides. $\mathrm{O}_{2}{ }^{-}$is a substrate for superoxide dismutase (SodCI, SodA) to produce $\mathrm{H}_{2} \mathrm{O}_{2}$ which can freely diffuse across membranes. The hydroxyl radical $\left(\mathrm{OH}^{\bullet}\right)$ is produced from $\mathrm{H}_{2} \mathrm{O}_{2}$ and superoxide via Fenton reaction. Mycobacteria produce the catalase KatG to detoxify $\mathrm{H}_{2} \mathrm{O}_{2}$. The production of NO from arginine metabolism via nitric oxide synthase (NOS2) can generate nitric oxide which in presence of $\mathrm{O}_{2}{ }^{-}$produce $\mathrm{ONOO}^{-}$and $\mathrm{NO}_{2}{ }^{-}$, which present some toxic proprieties against mycobacteria. 


\section{The Iron Tug-of-War Between Host and Mycobacteria}

\subsection{The Importance of Iron for Mycobacteria}

Iron is a crucial nutrient for mycobacteria, as it represents an essential structural and catalytic cofactor for many metabolic enzymes. In mycobacteria, iron is used as cofactor of enzymes involved in amino acid and nucleic acid biogenesis, such as those with pyrimidine synthesis and ribonucleotide reductase activities, as well as enzymes in the tricarboxylic acid cycle, superoxide dismutase, 3-deoxy-D-arabino-heptulosonate 7-phosphate synthase, and proteins participating in electron transport. Specifically, in $M$. tuberculosis, iron is an obligate cofactor for at least 40 different enzymes encoded in its genome [21].

In mycobacterial host mammals, iron is present in the cytoplasm of cells at a very low level in a ferrous soluble, chelatable state that constitutes the labile iron pool. The labile iron pool is potentially toxic as it can generate reactive oxygen species. Thus, most of the iron is sequestered in complexes with iron binding proteins. In blood, the free iron concentration is approximately between $10^{-18}$ and $10^{-12} \mu \mathrm{M}$ and that of total serum iron is $10-50 \mu \mathrm{M}$ and most iron circulates bound to transferrin glycoprotein or to lactoferrin [22]. Macrophages are characterized by high iron flux due to recycling of iron from senescent erythrocytes and the internalization of iron via specific cell surface receptors for transferrin, lactoferrin, and hemoglobin-haptoglobin [23], and thus represent a favorable niche for mycobacteria to acquire iron.

Granulomas are microenvironments in which mycobacteria brave starvation including iron deprivation. However, virulent mycobacteria are capable of long-term persistence without growth. Granulomas formation in response to $M$. tuberculosis infection are heterogeneous mainly characterized by solid cellular granulomas, cavitary granulomas and necrotic caseous granulomas in advanced tuberculosis infection [24]. Transcriptional analysis has indicated that solid cellular granulomas express high levels of iron uptake genes such as heme binding proteins, hemoglobin receptor, and transferrin receptor 1 encoded by TFRC; the cavity granulomas express high ferritin and heme oxygenase suggesting a permissive iron environment. Besides, necrotic and cavity granulomas exhibit gene expression of extracellular of iron, hemoglobin and heme sequesters such as transferrin, haptoglobin, and hemopexin, in addition to lactoferrin, lipocalin and calprotectin indicating host iron restriction [25].

In a prolonged iron starvation environment such as granulomas, $M$. tuberculosis stops the replication process but remains metabolically active, with intact cell envelope, high expression of iron acquisition mbt genes, reduced heme and iron-proteins synthesis and repressed oxidative phosphorylation [25]. Like all successful pathogens, mycobacteria have developed sophisticated mechanisms to compete with host iron-scavenger proteins for iron acquisition, to transport and store iron and to acquire iron from both extracellular transferrin, lactoferrin and intracellular iron pools [26].

\subsubsection{Siderophores: The Mycobacteria Iron Scavengers}

In iron-deficient environments, mycobacteria produce small iron-binding molecules called siderophores. These molecules have a high affinity for iron and scavenge metal ions from host insoluble and protein-bound iron. Mycobacterial siderophores can be divided into siderophores from non-pathogenic and pathogenic mycobacteria. Exochelins are extracellular and hydrophilic peptidic siderophores utilized mainly by non-pathogenic mycobacteria, such as $M$. smegmatis and M. neoaurum. M. leprae, a pathogenic mycobacterium also utilizes the siderophore exochelin for iron acquisition $[27,28]$. A structure of $M$. smegmatis exochelin siderophore showing its iron chelation abilities is represented in Figure 3 [29]. 


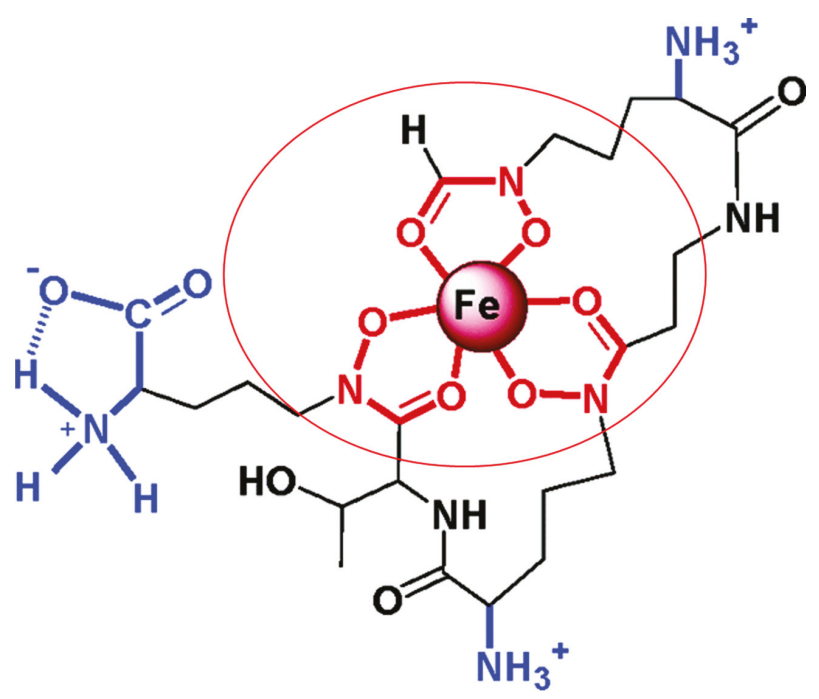

Figure 3. Structure of exochelin siderophore of M. smegmatis with its iron chelation proprieties. The iron-chelating residues of exochelin with their interaction with iron molecule is shown in red circle (adapted from [29]).

Mycobactins are derived from salicylic acid and include the mycobactin and carboxymycobactin forms of siderophores isolated from pathogenic mycobacteria (Figure 4), such as M. tuberculosis, M. bovis, M. bovis BCG, M. africanum and M. microti. Mycobactin is lipophilic and envelope-associated while carboxymycobactin is an extracellular hydrophilic molecule [30,31]. Desferricarboxymycobactin competes with host iron-binding proteins for iron; it chelates $\mathrm{Fe}^{3+}$ iron bound to host transferrin after phagosome fusion with early endosomes, as well as from lactoferrin and ferritin. In early endosomal phagosomes, mycobacteria communicate with the endocytic iron uptake system of the host macrophage and take advantage of this source of iron (Figure 5) [32,33]. Iron-siderophore complexes ferricarboxymycobactins are transported through the Msp (Mycobacterium smegmatis porin) family porins, a multisubunit transport system of the mycobacterial outer membrane. Subsequently, ferricarboxymycobactin transfers iron to the cell-wall associated mycobactin or delivers it to the inner membrane-bound iron-regulated transporter A and B (IrtAB). IrtAB, an ATP-binding cassette transporter synthesized in iron limited condition, mediates the reduction of the iron from internalized ferric-siderophore complexes into $\mathrm{Fe}^{2+}$ and its release [31,34-37]. The export and recycling of desferricarboxymycobactin through the inner membrane is carried out by the MmpS4/MmpL4-MmpS5/MmpL5 transporter complex formed with mycobacterial membrane proteins (Mmps). The recycling of desferricarboxymycobactin is critical for bacterial survival itself [38] (Figure 5). Indeed, genetic disruption of the recycling process induces the accumulation of these molecules in mycobacteria and poisons $M$. tuberculosis [38,39]. 


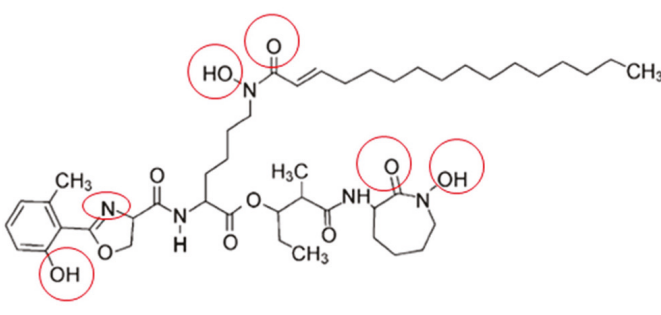

Mycobactin

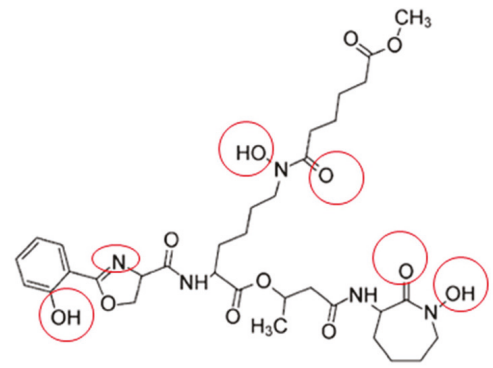

Carboxymycobactin

Figure 4. Structure of mycobactin and carboxymycobactin siderophores of pathogenic mycobacteria. This figure represents mycobactin and carboxymycobactin from $M$. tuberculosis with the iron-chelating residues circled in red.

Mycobactins are produced by nonribosomal peptide synthetase enzyme system and requires multiple enzymes encoded in two gene clusters mbtA-J and mbtK-N in M. tuberculosis [40,41]. Genetic disruption of siderophores expression impairs the growth of $M$. tuberculosis in mice and macrophages, demonstrating the essential role of iron acquisition for mycobacteria virulence [42]. The pathogenicity of bacteria depends on secretion systems for an efficient transport of biomolecules known as virulence factors. The secretion systems ESX, or Type VII systems, are specific to mycobacteria which required specialized mechanisms for protein transport across the lipid-rich outer membrane barrier. The genes encoding the ESX-1 system have been identified in the genome of the virulent $M$. tuberculosis strain $\mathrm{H} 37 \mathrm{Rv}$, but these genes are absent from the genome of $M$. bovis BCG, which corresponds to the genomic region of difference 1 (RD1) [43]. The ESX-3 system is crucial for iron acquisition in $M$. tuberculosis and $M$. smegmatis contributing to growth and virulence. The esx-3 mutants display severe growth defects in the presence of low concentrations of iron, which can be rescued by the addition of iron or heme [44,45]. Indeed, es $x-3$ is expressed in response to iron deficiency, and mycobacterial es $x-3$ mutant strains synthesize and accumulate dramatic amounts of mycobactin siderophores but are unable to take up iron and grow poorly. In M. tuberculosis, the addition of mycobactin has been shown to rescue the esx-3 mutant growth defect [46,47]. Further studies identified secreted PE5-PPE4 proteins encoded by esx-3 as being crucial for iron acquisition, while the virulence phenotype correlates with the secretion of EsxG-EsxH complex that impairs phagosomal maturation [47].

\subsubsection{Mycobacteria Heme-Iron Acquisition Systems}

Mycobacteria residing in macrophage phagosomes can also acquire heme as an iron source after the phagocytosis of senescent red blood cells by macrophages, a process termed erythrophagocytosis. Indeed, the attenuated growth of $M$. tuberculosis in low-iron medium or mycobactin-deficient mutant can be rescued by heme supplementation [48]. Extracellular heme can be recovered by mycobacteria through the secretion of hemolysin whose encoding gene $(t l y A)$ has been identified in several strain of mycobacteria (M. tuberculosis, M. bovis BCG, M. leprae, M. avium) [49]. Further, the heme-binding protein Rv0203 [35,50] and membrane heme import proteins from mycobacterial membrane proteins large family, MmpL3 and MmpL11 [50,51] might be involved in heme efflux to protect mycobacteria from the toxicity of excess heme [52]. PPE37 (also named Rv2123), member of the proline-proline-glutamic acid gene family restricted to virulent mycobacterial species, has been recently described as critical for heme-iron acquisition [53]. Ppe37 gene deletion in M. tuberculosis severely attenuates heme-iron acquisition and abrogates growth in a medium with hemin as the sole iron source [53,54]. PPE37 has been identified as a factor of virulence; $M$. bovis BCG has been described recently as severely deficient in heme-iron acquisition ability due to the lack of PPE37; importantly, M. bovis BCG exhibits heme iron acquisition as efficient as that of M. tuberculosis when complemented with M. tuberculosis PPE37 [53]. 
Once in mycobacteria cytosol, the heme degrading protein MhuD releases the iron from heme (Figure 5) [51].

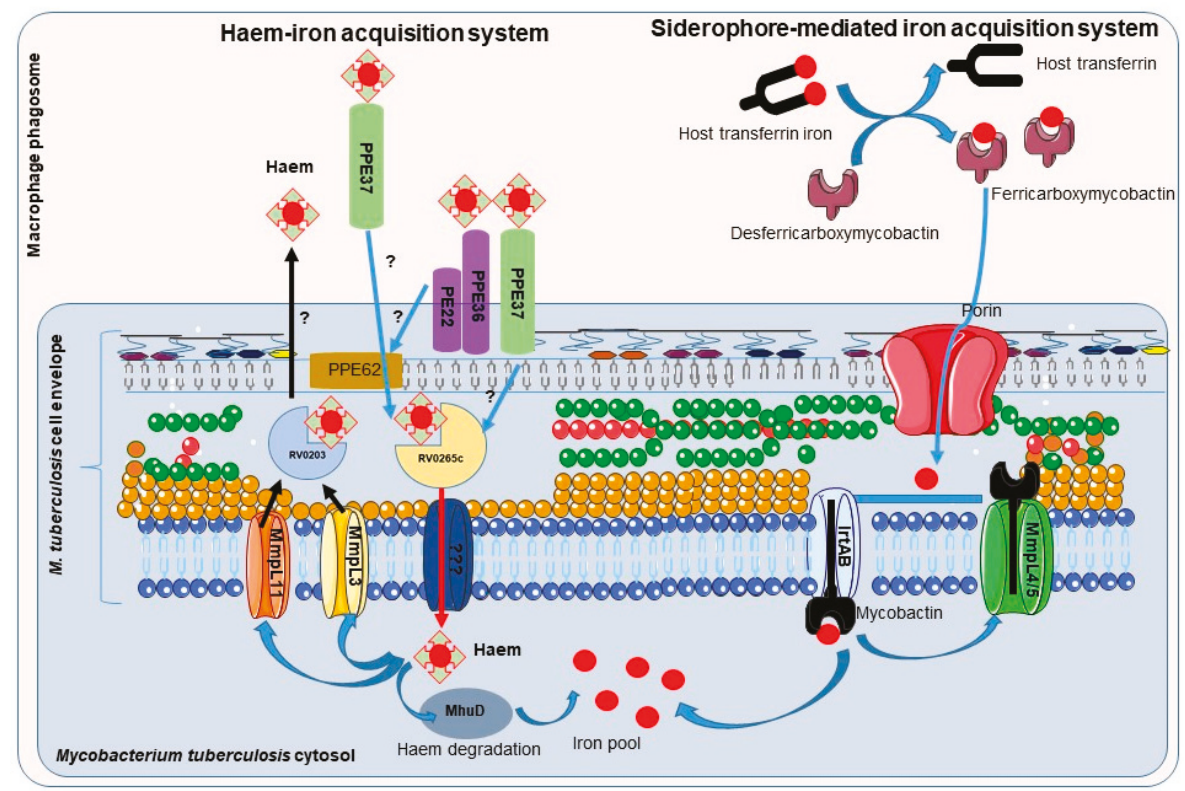

Figure 5. Heme-iron and siderophore-mediated iron acquisition of Mycobacterium tuberculosis in macrophage phagosome (adapted from [55]). M. tuberculosis has both heme and non-heme iron uptake pathways. M. tuberculosis secretes and express on its outer membrane PPE36/37 which can bind to heme and induce heme importation across the outer membrane. Then heme is linked to Rv0265c which facilitate heme transport to the cytosol using an unknown heme importer. In the cytosol, heme is degraded by the heme-degrading protein $\mathrm{MhuD}$ and iron is extracted from heme. It is also possible than heme can also be exported from cytosol through MmpL3/11 transporters and then linked to Rv0203 and later exported outside the bacteria. M. tuberculosis can also acquire iron through the siderophore-mediated iron acquisition system. M. tuberculosis desferricarboxymycobactin competes with host iron transferrin to acquire iron in phagosome. Iron is then bound to mycobactin which transports iron across the inner membrane through the IrtAB transporter complex. Once in the cytosol, iron is dissociated from mycobactin which is then exported from the cytosol through MmpS4/L4 and MmpS5/L5 complex.

\subsection{Mycobacteria Protection against the Harmful Effects of Iron, ROS and RNS}

For efficient infection and persistence, pathogenic bacteria have evolved to adapt their metabolism to the hostile environment of the phagosome to survive harmful antimicrobial host defense mechanisms such as iron limitation and the production of toxic reactive oxygen and nitrogen species. Iron is an essential structural and catalytic cofactor for many metabolic enzymes but is also a harmful component due to its ability to generate spontaneously ROS through the Fenton reaction. Therefore, bacterial intracellular iron homeostasis is closely linked to the response to oxidative stresses.

\subsubsection{Protection against Excess of Iron}

Once captured, iron can be utilized for various metabolic processes while specific proteins are synthesized to store iron and avoid its toxic effects. M. tuberculosis encodes two iron storage proteins, BfrA, a bacterioferritin, and BfrB, a ferritin-like protein [56]. Both proteins aggregate to form macromolecular structures consisting of 24 subunits that can hold 600 to 2400 iron atoms per 
molecule [41]. BfrA is required for the efficient release of stored iron under low iron conditions, while BfrB has a high capacity for iron storage and is a major defense protein under excessive iron conditions [57]. BfrB deleted mutant showed drastic loss of viability during iron depletion indicating that iron stored in ferritin is essential for $M$. tuberculosis to survive in iron depleted environment [25]. Several investigations using $M$. tuberculosis bfr $A$ and $b f r B$ mutant have demonstrated that these genes are crucial for the ability of mycobacteria to grow and withstand oxidative stress in vitro, as this mutant exhibits a marked reduction in survival inside human macrophages and is unable to establish successful infection in guinea pigs [56,58]. Therefore, although iron is an essential nutrient for mycobacterial growth, iron excess can be detrimental to these pathogens.

In mycobacteria, intracellular iron levels are regulated by controlling the transcription of genes involved in iron uptake, transport and storage through the iron-dependent transcription factors IdeR, a negative regulator and $\mathrm{HupB}$, a positive regulator $[59,60]$ Under high iron conditions in $M$. tuberculosis, IdeR binds $\mathrm{Fe}^{2+}$ and represses the transcription of siderophore synthesis by binding to the IdeR box in promoter of $m b t$ genes and iron transport genes as well as ppe37 gene while inducing the transcription of the genes encoding iron storage BfrA and BfrB proteins $[41,59,60]$. The disruption of the ideR gene in mycobacteria is lethal for these pathogens [59]. A conditional M. tuberculosis ideR mutant that is unresponsive to iron under non-permissive conditions is unable to repress iron acquisition and displays attenuated growth in vitro and in vivo, whereas increased cellular iron levels are associated with a high sensitivity to $\mathrm{NO}$ and $\mathrm{H}_{2} \mathrm{O}_{2}$ [61]. These results indicate that iron accumulation in mycobacteria exacerbates oxidative stress, providing an additional link between iron homeostasis and virulence in M. tuberculosis infection. A recent study has identified several inhibitors of IdeR which interestingly attenuate $M$. tuberculosis growth in vitro [62].

Furthermore, the HupB DNA-binding histone-like protein, which is repressed by IdeR-Fe ${ }^{2+}$ complex under increased iron levels, exerts a positive regulatory role on the expression of mycobactins by binding to the $m b t$ promoter upon iron limitation [41,61]. The HupB protein is essential for siderophore synthesis and deficient $h u p \mathrm{~B}$ (or Rv2986c) fails to grow inside the macrophages and in an axenic culture [61]. HupB plays a critical role in mycobacterial growth especially during exponential growth. Besides its role as a positive regulator of iron acquisition, HupB is involved also in several other biological functions such as cell wall assembly and immunoproliferation in M. tuberculosis [41].

\subsubsection{Antioxidant Systems in Mycobacteria}

The success of M. tuberculosis as pathogen is dependent on its ability to adapt to the harsh environmental and stressful conditions in granulomas. Granulomas impose multiple stress factors, such as $\mathrm{NO}, \mathrm{CO}$, and low $\mathrm{O}_{2}$, and these changes in redox balance cause $M$. tuberculosis to shift from aerobic to anaerobic metabolic pathways, leading cells to transition from an actively growing state to a dormant state. Mycobacteria express redox sensors during infection, allowing cells to sustain a redox balance that neutralizes the toxic effect of ROS and plays a role in mycobacterial virulence. The DosR/S/T system and the WhiB Fe-S cluster family of proteins are the two primary dormancy-induced signaling pathways in mycobacteria.

The DosR/S/T dormancy regulon is widely distributed among mycobacterial genomes excepted M. leprae which lacks DosR. This Dos regulon, essential for the long-term survival of mycobacteria includes a response regulator (DosR) and two heme iron-containing sensor kinases (DosS and DosT), which control roughly 50 genes that are essential for the establishment and maintenance of a dormant anaerobic state. The Dos regulon responds to diatomic gases $\left(\mathrm{NO}, \mathrm{CO}\right.$, and $\mathrm{O}_{2}$ ). The activation of the DosR transcription factor is modulated by the DosS and DosT heme containing kinases that are susceptible to the cellular redox state and the oxygen levels (Figure 6) [63]. In the presence of oxygen, the heme iron in DosS and DosT are in the ferric form and are inactive, whereas iron deoxidization or $\mathrm{NO} / \mathrm{CO}$ binding promote their kinase activities [63]. Although, iron deprivation of M. tuberculosis does not induce the dormancy regulon and $\operatorname{dos} R$ mutant survive to iron starvation [25]. 
In addition to the DosR/S/T system, $M$. tuberculosis senses redox signals such as $\mathrm{O}_{2}$ and $\mathrm{NO}$ via the WhiB family of iron-sulfur (Fe-S) cluster-containing transcription factors. The whiB-like genes are exclusive to actinomycetes, such as Mycobacterium and Streptomyces spp. M. tuberculosis genome contains seven whiB-like genes (whiB1 to whiB7). WhiB3 has been described to contribute to the persistence and virulence of $M$. tuberculosis. The WhiB3 Fe-S cluster senses changes in the intracellular redox environment associated with hypoxia and regulates the metabolic switch for the use of fatty acids as a carbon source, modulating the biosynthesis of the virulence-associated lipids PAT/DAT, SL-1, PDIM, and lipid inclusion bodies (triacylglycerol TAG) (Figure 6). WhiB3 gene expression is increased in mycobacteria residing in macrophages, enabling them to alleviate the potential harmful effects of redox imbalance [64]. WhiB3 expression increases in vitro under conditions resembling the phagosomal environment that act as signal for mycobacterial dormancy, such as acid-stress medium, oxidant medium, or low-nutrient concentrations, while it decreases under low iron conditions [65]. WhiB3 binds $\mathrm{NO}$ and is degraded by $\mathrm{O}_{2}$, and a $M$. tuberculosis whiB3-deletion mutant severely impairs growth on nutrient-depleted medium that cannot be rescued by nutrient supplementation [66]. Furthermore, WhiB3 allows mycobacteria to adapt to low oxygen tensions through transcriptional regulatory networks that maintain redox homeostasis.

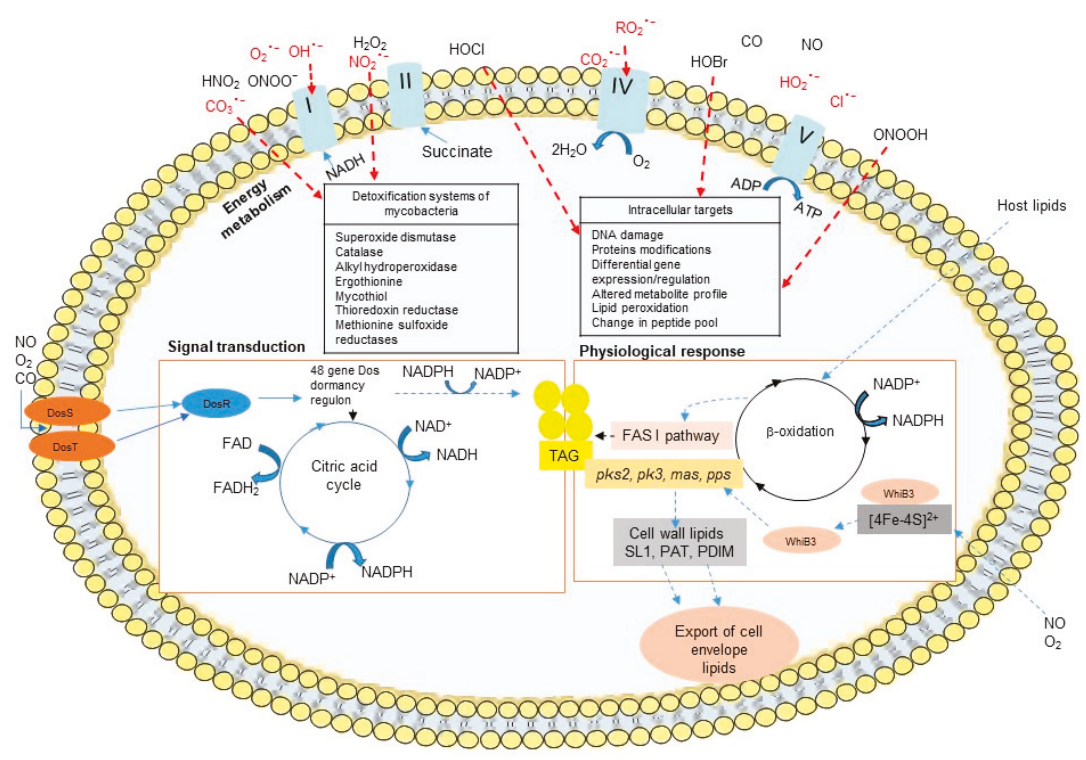

Figure 6. Mycobacterial stress sensors (adapted from [75]) Mammalian host cell generates radicals and gases as a mechanism to counter mycobacterial infection. M. tuberculosis senses these potentially damaging stresses and responds by adjusting its energy metabolism, physiology and signaling and counters the damage by detoxification processes. M. tuberculosis possesses sensing mechanisms such as the Dos dormancy regulon and the WhiB3 redox sensor detecting environmental gases and alterations in its intracellular redox state. The Dos regulon senses $\mathrm{O}_{2}, \mathrm{NO}$, and $\mathrm{CO}$ through the DosS and DosT heme proteins which transduce the signal to DosR leading to the induction of 48-member Dos dormancy regulon. WhiB3 functions as a regulator of cellular metabolism, which responds to $\mathrm{O}_{2}$ and $\mathrm{NO}$ through its Fe-S cluster and integrates it with intermediary metabolic pathways. WhiB3 is an intracellular redox regulator that dissipates reductive stress generated by utilization of host fatty acids through $\beta$-oxidation.

Besides WhiB3, others WhiBs functions have been described in mycobacteria. WhiB4 is highly sensitive to oxygen exposure regulating antioxidant systems as well as being required for the virulence-associated formation of well-organized granulomas during M. marinum infection [67]. 
The WhiB5 transcriptional regulator controls the expression of genes involved in $M$. tuberculosis reactivation and aerobic/anaerobic metabolism that modulate the levels of mycobacterial infection, granuloma formation and dissemination [68]. The WhiB6 regulator reacts with NO and regulates the expression of genes associated with the ESX-1 secretion system and Dos dormancy genes, modulating the virulence and granuloma formation as well as replication and dissemination of M. marinum [69].

In addition, mycobacteria express several oxidative response gene products that degrade microbicidal oxidative metabolites and are crucial for mycobacterial survival in macrophages. M. tuberculosis synthesizes the superoxide dismutase SodC that converts $\mathrm{O}_{2}^{-}$to $\mathrm{O}_{2}$ and $\mathrm{H}_{2} \mathrm{O}_{2}$ as well as the catalase-peroxidase KatG to degrade $\mathrm{H}_{2} \mathrm{O}_{2}$ [70-73]. Under high iron conditions, M. tuberculosis upregulates the expression of $k a t G, b f r A$, and $b f r B$ indicating the importance of increasing iron storage capacity and preventing oxidative damage that may be caused by excess iron. Other molecules such as redox enzymes such as thioredoxin reductase (TPx), alkyl hydroperoxidase (AhpC), and methionine sulfoxide reductases (MSRs), mycothiol and ergothioneine produced by mycobacteria, and lipoarabinomannan (LAM) a cell wall component and potent oxygen radical scavenger in $M$. tuberculosis and $M$. leprae species are also major virulence factors [74].

\section{Implication of Iron in the Host Arsenal Defense against Mycobacterial Infection}

Mammals have developed a series of strategies to fight pathogens by limiting nutrient access, such as iron and zinc, as part of a nutritional immunity process. Limiting the delivery of essential elements to microbes is a strategy to starve invading pathogens and inhibit pathogen growth and subsequently disease progression [76]. In mammals, the levels of circulating iron and zinc rapidly decrease with inflammation and during acute phase of infection, establishing the hypoferremia and hypozincemia conditions in consequence of the expression of acute phase proteins such as cytokines, cellular proteins, and hormones. The increase of acute phase protein restricts iron and zinc availability suppressing then pathogenic multiplication.

\subsection{Host Cellular Iron Metabolism during Mycobacteria Infection}

The host immune response regulates the expression of a series of mRNAs including iron metabolism proteins that have antimicrobial properties by scavenging iron. Iron within macrophages is limited through the activity of the immunomodulatory cytokine, interferon gamma (IFN $\gamma$ ). IFN $\gamma$-stimulated monocytes have been shown to inhibit Legionella pneumophila multiplication, which is neutralized by holo-transferrin, a source of iron [77]. In addition, lactoferrin, an abundant neutrophil-derived protein released upon activation at sites of inflammation, possesses a greater iron-binding affinity than transferrin and has a broad mycobacteriostatic activity, by sequestering iron; moreover, congenital lactoferrin deficiency leads to recurring infection $[78,79]$. Thus, during inflammation, the down-regulation of the transferrin receptor as well as the increase in lactoferrin iron-binding protein levels, deplete iron from activated macrophages. This decrease of iron uptake can be related in some studies by a decrease of intracellular iron-storage protein ferritin, although other investigations using Mycobacterium avium have reported an induction of ferritin expression in macrophages by activating toll-like receptor 2 [80].

In macrophages phagosomes, mycobacterial metabolism is influenced by the iron uptake system of the host early endosomal system. Thus, the increase in iron-binding proteins in the host during the immune response restricts iron bioavailability for intracellular pathogens. However, high iron levels in addition to ferritin and lactoferrin have been noticed in M. paratuberculosis infected mononuclear phagocytic cells compared to low levels observed in non-infected cells [81].

It is likely that siderophores efficiently capture iron from the host iron-binding proteins and provide a source of iron to mycobacteria, promoting their intracellular growth. Recently, it has been shown that mice lacking ferritin $\mathrm{H}$ in the myeloid-derived cell population rapidly succumb to $M$. tuberculosis infection. This phenomenon is associated with an alteration of iron homeostasis with an increased ferroportin expression in lung. Moreover, these cell-specific knockout mice exhibit, 
a strong Th-1 immune response upon infection with an upregulation of Arginase 1, an enzyme involved in the conversion of arginine to ornithine thus depleting the Arginine substrate for the enzyme iNOS to synthetize NO [82]. Thus, these observations highlight a role of iron distribution in the immune response against mycobacterial infection.

Natural resistance-associated macrophage protein 1 (Nramp1 or Solute carrier family 11A1) was the first host genetic locus shown to confer resistance to several intracellular microorganisms. The Slc11a1 gene encodes a protein primarily expressed in macrophages located within the late endocytic compartment and that is recruited to the membrane of the phagosome upon phagocytosis [83]. Early during infection, inbred mice strains can be separated as being resistant (DBA/2, C3H, CBA, and C.D2) or susceptible (C57BL/6 and BALB/c) to mycobacterial infection; these two different group of mouse strains have showed differential capacities of host macrophages to neutralize phagocytized mycobacteria and to control microbial replication in host cells [84-86]. Susceptible mouse strains infected with $M$. avium develop a more severe anemia (BALB/c) compared to a resistant mouse strains (C.D2) [87]. Slc11a1 transports divalent metals such as iron and manganese across phagolysosomal membrane and the susceptibility is caused by a single substitution in Slc11a1 conferring a null allele. Similarly, the Slc11a1-deficient mouse strain showed an uncontrolled early phase of T cell-mediated immunity with high intracellular bacterial replication, while the late phase was preserved [88-90].

The Slc11a1 metal transporter plays a role in the virulence of mycobacteria, however its function is still controversial. Slc11a1 could either transport metals into the phagosome and exert a protective effect against intracellular mycobacteria by triggering the production of NO and hydroxyl radicals and the acidification of the microbe-containing phagosome, or Slc11a1 could transport metals out of the phagosome, thus limiting the availability of essential metals [91]. In humans, a differential susceptibility to mycobacterial infections, such as M. tuberculosis, is associated with SLC11A1 polymorphisms and has been observed in a high-incidence community in South Africa [92-94].

\subsection{Systemic Iron Homeostasis during Mycobacterial Infections}

Hepcidin peptide, produced mainly by hepatocytes, is a master regulator of systemic iron homeostasis $[95,96]$. Hepcidin binds to ferroportin, the sole known iron exporter, and induces its internalization and degradation [97]. The increase in hepcidin reduces the level of ferroportin, resulting in the inhibition of iron flux to blood circulation. The expression of the Hamp1 gene that encodes hepcidin is upregulated by increased iron levels through TfR/HFE MHC class I-like protein interactions and the Bmp/Smad pathway. Hepcidin is also upregulated upon inflammation through LPS-induced stimulation and the IL-6 cytokine pathway [95,98] as well as by Smad signaling [95,98-103]. Other regulators of hepcidin have been identified, such as erythroferrone and heparin known as negative regulators of hepcidin [104-106].

In mice, upon inflammation, high hepcidin levels decrease intestinal iron absorption and the release of recycled iron from macrophages, inducing hyposideremia of acute inflammation that are associated with low plasma iron and transferrin saturation [100,107]. Thus, upon inflammation, the increase in hepcidin and lipocalin 2 levels promote hyposideremia and the development of anemia of inflammation upon long-term infection or chronic disease [108]. The upregulation of hepcidin is an attempt to limit iron bioavailability to pathogens and inhibit microbial growth. However, controversial results have been observed regarding the expression of hepcidin during mycobacterial infection.

Macrophages infection with M. avium and M. tuberculosis, and mycobacterial components such as Toll-like receptor agonists, have been shown to stimulate hepcidin expression in vitro [109,110]. However, in vivo, the levels of hepcidin mRNA have been observed to remain unchanged in wild-type mice infected with $M$. avium while lipocalin 2 is upregulated. In mice, hepcidin mRNA levels even decreases late post-infection in liver of wild-type mice infected with M. tuberculosis [111], while a study of mice infected with $M$. bovis BCG indicated a late increase in hepcidin levels in liver [112].

Mycobacterial infection models using mice infected with $M$. tuberculosis, M. bovis BCG and M. avium have revealed an increase in the expression of ferroportin mRNA $[87,111,112]$. Moreover, 
ferroportin overexpression in macrophages which promotes iron export leads to a lower mycobacterial burden, lower iNOS production, and phagocytic ability compared to normal macrophages infected with M. tuberculosis in vitro [113]. Mice given an iron rich diet and infected with M. bovis BCG showed a lack of increase of ferroportin and higher $i N O S$ expression compared to infected mice under a replete diet [112]. These results suggest that a reduction in intracellular iron levels may interfere with macrophage effector functions, such as NO production. Moreover, a human pilot study demonstrated an association between polymorphisms in the ferroportin gene and tuberculosis susceptibility, providing evidence of an interaction between iron distribution and mycobacterial growth [114].

\subsection{Iron and Antimicrobial Peptides}

The toll like receptor 4 agonist, LPS induces inflammation and a broad range of immune mechanisms, including hypoferremia with low serum iron and transferrin saturation. In the late 1960s, Kochan et al showed that the serum from guinea pigs which received a LPS treatment has a tuberculostatic effect in axenic culture [115]. Thus, it is likely that the synthesis of the iron regulatory proteins hepcidin and lactoferrin upon inflammation play a dual role against mycobacterial infection acting as an iron regulatory protein and an antimicrobial peptide.

Hepcidin was first isolated due to its antimicrobial properties [116,117]. Hepcidin is a peptide that is structurally similar to $\beta$-defensin and exhibits a direct bactericidal effect against a broad range of microorganisms, including mycobacteria [116,117]. Hepcidin is expressed at a basal level from hepatocytes and upregulated by high levels of iron in the body; hepcidin expression is also upregulated in hepatocytes and macrophages upon inflammation. Interestingly, hepcidin peptide has been reported to be expressed and localized in mycobacteria-containing phagosomes and is associated with a direct antibacterial activity against $M$. tuberculosis in vitro [109]. More recently, it has been shown that $M$. bovis BCG infection in mice upregulates hepcidin in the liver and in macrophages [112]. The upregulation of hepcidin expression in macrophages may play a local role in iron distribution and as an antimycobacterial defensin.

Some immune cells such as neutrophils have been described to contain important amounts of antimicrobial peptides containing in granules such as antimicrobial peptides of the $\beta$-defensin and cathelicidin families, myeloperoxidase, lactoferrin, and lipocalin 2. The infiltration of neutrophils on the sites of infection at the early stage of infection is critical for host defence against $M$. bovis BCG and M. tuberculosis mycobacterial infections due the presence of antimycobacterial peptides in these cells [17]. Importantly, some of neutrophils antimycobacterial peptides have also a role in iron homeostasis. For instance, lipocalin-2 secreted mainly by neutrophils, but also by epithelial cells and macrophages binds to siderophores including mycobacterial mycobactins [118] and neutralize their activity. Lipocalin 2 is a bacteriostatic agent that enhances phagocytic bacterial clearance in macrophages and causes iron restriction to inhibit extracellular bacterial and mycobacterial such as M. bovis BCG and M. tuberculosis growth; importantly, tissue bacterial loads have been described as severe in lipocalin 2 knock-out mice in comparison to wild type mice [87,118-122]. Moreover, lipocalin 2 promotes neutrophil recruitment, which contributes to innate immunity to M. tuberculosis, an activity associated with their antimicrobial properties [17].

\section{Future Therapeutic Use of Iron in Mycobacterial Infections: Iron, a Friend or Foe}

Mycobacterial infections are particularly difficult to treat due to their intrinsic impermeability, intracellular localization, and low growth rate. To aid in the fight against mycobacteria, it is of great importance that the crucial steps of infection be targeted including growth and entry into dormancy and reactivation. Indeed, the roles of iron acquisition such as siderophore and hemophore pathways, iron storage such as bacterioferritin expression and iron regulatory systems such as iron-based sensors and redox sensors in the mycobacterial proliferation and virulence may suggest that the modulation of iron levels could strengthen the host defense strategy and be used to develop new drug targets against mycobacteria. 
Because the availability of iron appears to be critical for the growth of mycobacteria, the development of drugs to weaken mycobacterial iron acquisition systems may negatively influence mycobacterial viability and dissemination. However, because iron-deficient conditions upregulate the production of siderophores, this condition would favor mycobacteria dormancy and may be detrimental to eradicating mycobacteria.

Iron can also influence the activity of immune cells and cell metabolism, such as the generation of ROS/NO toxic oxygen metabolites. Because iron plays dual roles in host defense, the modulation of the iron status may be either beneficial or detrimental. Iron-based defense strategies seem promising but require that all the consequences that may occur during infection and immune response are taken into account. A summary of our current knowledge on the effects of iron on mycobacteria is presented from different aspects of experimental procedure and human analysis.

\subsection{Investigation of the Effect of Iron on Mycobacterial Growth in Host Cell-Free Culture}

Several studies have confirmed the role of iron in mycobacterial growth in host cell-free culture. High iron levels promote mycobacterial growth, while iron restriction yields ambiguous results. Iron supplementation in host cell-free culture media promotes the growth of mycobacteria with higher increase in growth for fast growing mycobacteria such as M. smegmatis compared to slow growing mycobacteria such as $M$. tuberculosis and M. bovis BCG respectively [112,123-126]. Human serum containing low iron-saturated transferrin $(30 \%)$ and low serum iron concentration inhibits the growth of mycobacteria such as $M$. bovis BCG in vitro, whereas mycobacterial growth increases with high transferrin iron saturation, either from mice sera $(60 \%)$ or guinea pigs $(84 \%)[115,127]$.

Synthetic iron chelators and bacterial siderophores effectively remove iron from culture media and blood, such as the natural siderophore desferrioxamine (DFO) from Streptomyces pilosus used to treat secondary iron overload in humans. However, chelating agents are less effective at inhibiting the growth of mycobacteria in host cell-free culture. The natural siderophore DFO, as well as chemical chelators such as $\mathrm{N}, \mathrm{N}^{\prime}$ bis (2-hydroxybenzyl)-ethylenediamine-N,N'-diacetic acid (HBED), and the 1-amino-3-(2-bipyridyl)isoquinoline derivative VUF-8514 have showed a modest mycobacteriostatic effect on M. avium and M. tuberculosis in host cell-free culture [112,124,128], whereas phytosiderophore from the root-exudate of Tephrosia purpurea has demonstrated a strong effect on $M$. tuberculosis growth [129]. The efficiency of iron chelators may reflect their efficacy at chelating iron but also the countered effect of the induction of mycobacterial iron-acquisition systems in response to a low iron level, a stress signal which increased the capacity of the mycobacteria to acquire iron. Thus, iron restriction can either be detrimental for mycobacteria growth by starving mycobacteria or beneficial by promoting an efficient iron acquisition.

Therefore, future iron-based therapeutic approaches should be based on developing new compounds that directly inhibit the enzymes involved in siderophore biosynthesis or involved in the downregulation of siderophore genes (for review [130]) or the alteration of heme-iron acquisition pathway [131] or promoting the induction of endogenous siderophore ligands such as lipocalin 2, which acts as a siderophore antagonist by inhibiting mycobacteria growth.

Strategically, the siderophore-mediated iron uptake pathway of mycobacteria, as well as the heme uptake pathway, could be used as vehicle for the delivery of bactericidal molecules inside mycobacteria. These pathways represent an important opportunity to pass through the cell wall barrier of mycobacteria to import antibiotics to kill bacteria, this strategy is known as "Trojan horse" approach to gain access to mycobacteria. Based on this feature to overcome the cell wall barrier characteristic of mycobacteria, novel drug vectors can be formulated.

\subsection{Investigation of the Effect of Iron on Mycobacterial Growth in Macrophages}

Macrophages, the main host-cells of mycobacteria, restrict the growth and virulence of mycobacteria compared to host cell-free culture [126]. Both IFN $\gamma$ and LPS or a co-treatment activate macrophages resulting in a decrease of mycobacteria growth [132], indicating that phagocytosis and/or 
cell immune response inhibits mycobacterial multiplication. The differential growth of mycobacteria in cultured macrophages as a function of iron levels has been reported, but controversial results have been observed.

Indeed, several studies have indicated that supplementation of mammal cell culture media with free iron, ferrous sulfate or ferric ammonium citrate increases intracellular iron concentrations and enhances the growth of the M. paratuberculosis, M. avium, M. bovis, and M. tuberculosis in macrophages [112,126,128,132-134]. Similarly, to its effect on host cell-free culture, serum containing apo-transferrin limits the growth of $M$. avium in macrophages, which can be prevented by transferrin depletion or the addition of holo-transferrin $(500 \mu \mathrm{g} / \mathrm{mL})$ or iron $\left(8-80 \mu \mathrm{g} / \mathrm{mL}\right.$ of $\left.\mathrm{Fe}^{2+}\right)$ [135]. Other studies have showed that the supplementation of serum-free medium with apo-transferrin (50-500 $\mu \mathrm{g} / \mathrm{mL} ; 1.7 \mathrm{mg} / \mathrm{mL})$ or bovine lactoferrin $(2 \mathrm{mg} / \mathrm{mL} ; 0.5 \mathrm{mg} / \mathrm{mL})$ inhibits $M$. avium, M. bovis, and M. tuberculosis growth in macrophages $[124,132,135]$. Furthermore, the addition of the iron chelator lactoferrin increases the mycobacteriostatic effect of IFN $\gamma$-activated macrophages, while iron citrate $(5 \mu \mathrm{M})$ or holo-transferrin $(1.7 \mathrm{mg} / \mathrm{mL})$ supplementation abrogates the mycobacteriostatic effect of IFN $\gamma$-activated macrophages $[128,132]$. This result is also supported by a study indicating that iron loading influences macrophage polarization towards M2 phenotype [136]. Thus, multiple host and pathogen immune factors with dynamic interactions during mycobacterial infection could exhibit beneficial or detrimental activities for mycobacterial virulence.

The metabolism of macrophage is differentially influenced with iron level exhibiting different outcome of macrophage response to mycobacteria. A treatment of macrophages cell culture medium with a huge amount of iron ( $500 \mu \mathrm{M}$ of FeSO4) increases intracellular M. tuberculosis viability by compromising macrophage functions such as superoxide production [123]. In contrast, a moderate concentration of ferric ammonium citrate $(10 \mu \mathrm{M})$ correlates with the production of reactive oxygen species, an impairment in the uptake of $M$. bovis BCG within macrophages and a decrease of bacterial growth [112]. We and others recently showed that iron influences the M1/M2 balance [136138], which plays an important role in the polarization of the immune response. Furthermore, iron downregulates monocyte responsiveness by reducing IFN $\gamma$ signaling [139] but also decreases TNF $\alpha$ production and restricts $M$. tuberculosis growth [140]. Therefore, the level of iron in the cell culture medium influences intracellular iron levels and cell activities modulating ROS formation and cellular activities.

Iron chelators display varying inhibitory effects against the growth of mycobacteria and in macrophage host-cells activities. Both DFO and silybin iron chelators exert a mycobacteriostatic effect by reducing the growth and viability of extracellular $M$. avium or virulent $M$. tuberculosis. However, DFO suppresses the effects of excess iron on $M$. tuberculosis growth in macrophage culture, while silybin fails to prevent the effects of excess iron $[123,128,133]$. Indeed, DFO which does not enter into the cells, acts primarily as an iron chelator and has little influence on intracellular parameters, whereas silybin which enters into the host cells, inhibits the formation of superoxide anion radicals and nitric oxide, acting as an antioxidant and anti-inflammatory compound that could promote the transport of iron into mycobacteria $[123,128,133,141]$. Therefore, the level of iron plays a major role in the intracellular growth of mycobacteria as a nutrient and in the control of gene expression to alleviate iron restriction, but it also has a prominent role in cell defense activities, likely by promoting subsequent chemical reactions requiring iron.

Upon infection with M. avium, M. tuberculosis, and M. bovis BCG, macrophages upregulate hepcidin expression [110,112]. Furthermore, IFN $\gamma$-activated macrophages slightly upregulate hepcidin expression, and IFN $\gamma$ and mycobacteria infection synergistically induce high levels of hepcidin expression [110]. In infected macrophages, hepcidin has been localized into the mycobacteria-containing phagosomes [109]. The production of hepcidin could locally affect iron distribution with subsequent elevated macrophage iron levels that may either create an iron-favorable environment for pathogens or impair macrophage cytotoxic activity, although it could also have local antimicrobial activity. Therefore, both roles of hepcidin on macrophage defense activities, and mycobacterial viability should be assessed. 


\subsection{Investigation of the Effect of Iron on Mycobacterial Growth In Vivo}

Iron supplementation promotes mycobacterial growth in cell-free culture but gives controversial results in macrophages. Iron is important for mycobacterial growth as well as for macrophage cell properties. In vivo, a complex relationship between iron levels and immune defense against mycobacteria likely results from additional regulation of iron gene expression and immune cell activities. Host iron levels also influence the expression of protein-associated iron in circulating blood and in tissues. Indeed, iron depletion would decrease the expression of hepcidin and ferritin and increase that of the iron-transport protein transferrin. Conversely, iron supplementation increases the expression of hepcidin and decrease the levels of the iron-transport protein transferrin. Interestingly, the infection-induced-inflammation also controls iron metabolism-related genes through the expression of proteins that naturally control iron distribution by increasing the expression of the hormone hepcidin, the iron-binding protein lactoferrin, and the siderophore-binding protein lipocalin 2 and by decreasing the levels of the iron-transport protein transferrin, all of which contribute to anemia of chronic inflammation to maintain bactericidal conditions. Therefore, the scientific rationale behind the current attempts to use iron as therapeutic agent will require a thorough understanding of interaction between iron and the immune response.

\subsubsection{Investigation of the Effect of Iron on Mycobacterial Growth in Mice}

In mice, experimental iron overload can be generated either via the enteral route using an iron-enriched diet or drinking water or via the intraperitoneal route, which is typically accomplished by injecting single or multiple dose of iron-complex. In wild-type mice that received multiple iron-dextran injections (10 injections at $1.2 \mathrm{mg}$ per mouse), $\mathrm{M}$. avium (intravenous route $10^{6} \mathrm{CFU}$ ) growth was increased in the livers, lungs, and spleens of mice [133]. Similarly, iron-loading mice via polymaltose ferric hydroxide injections ( 6 injections at $1.25 \mathrm{mg}$ per mouse) allowed for significantly enhanced bacterial burden of virulent $M$. tuberculosis (intravenous route $7.2 \times 10^{3} \mathrm{CFU}$ ) in the lungs and spleens of mice compared to mice infected without iron loading [142]. The parenteral administration of a high iron dose increases serum iron levels, transferrin saturation and tissue iron deposits. Therefore, circulating iron provides high levels of iron for mycobacterial growth, and the bacteriostatic effect of hyposideremia induced during the first step of infection may be compromised in the presence of high circulating iron. In addition, tissue iron deposition may be toxic and detrimental to the host impacting thus, the host ability to respond efficiently to infection.

Iron deprivation induced by a low iron diet $(6.7 \mathrm{mg} / \mathrm{kg}$ for 2 weeks before infection) restricts the growth of $M$. avium (intravenous route infection at $10^{6} \mathrm{CFU}$ ) in the livers, spleens and lungs of immunocompetent mice and immunodeficient beige mice [128]. However, mice under dietary iron restriction or severe iron restriction (2 or 6 weeks at 2-6 ppm iron respectively) prior to $M$. tuberculosis aerosol infection does not reproducibly affect mycobacterial growth in the lungs and spleens of mice [111]. Moreover, iron restriction induced by intraperitoneal administration of chelators DFO or HBED in wild-type mice shows small effect on the inhibitory activity of M. avium in mice, possibly because chelators have little impact on the iron status [128]. Similarly, extracellular iron depletion by intranasal administration of lactoferrin $(1 \mathrm{mg} / \mathrm{mL}$ twice a week) did not alter the $M$. tuberculosis burden in wild type mice 22 days after infection [124]. Compared to wild-type mice, lipocalin 2-deficient mice are highly susceptible to intratracheal $M$. tuberculosis infection, with increased bacterial growth observed in alveolar epithelial cells indicating that lipocalin 2 efficiently reduces iron level and inhibits the growth of mycobacteria [120].

An experimental iron overload mouse model generated by iron administration via drinking water ( $25 \mathrm{mg} / \mathrm{mL}$ ) and aerosol infection with $M$. tuberculosis has been shown to exacerbate mycobacterium replication in tissues compared with infected control mice [124]. However, aerosol infection with M. tuberculosis in mice after intraperitoneal iron dextran injection $(20 \mathrm{mg})$, which causes high serum iron levels and iron loading in parenchymal cells and macrophages, did not exhibit significant differences in bacterial burdens in the lungs and spleens of mice [143]. Furthermore, mice fed with a mild 
iron-loaded diet over a long period of time, showed an increased transferrin saturation but mild tissue iron deposits in hepatocytes, which was associated with a decreased mycobacterial burden in liver after an intravenously infection with $M$. bovis BCG compared to uninfected mice [112]. Therefore, the iron distribution and the level of iron overload, as well as the route of iron administration, may yield contradictory results. For future therapeutic design, prospective studies are required to separate the early and long-term effects of circulating iron increase and tissue iron increase on mycobacteria virulence.

The lack of hepcidin which exhibited severe iron overload did not influence significantly M. tuberculosis growth in vivo although, in wild-type mice, a decrease in hepatic hepcidin mRNA levels was observed after M. tuberculosis aerosol infection [111]. Conversely, an upregulation of hepcidin gene expression was observed after an intravenous $M$. bovis BCG infection [112], indicating that the expression of hepcidin may depend on the route of infection, the level of mycobacteria inoculation and the virulence of mycobacteria. Eventually, it was shown that hepcidin is selectively protective against siderophilic extracellular pathogens but has no effect on intracellular pathogens [143].

The HFE gene encodes the $\alpha$ chain of the MHC class-I like molecule that associates with the $\beta$-2-microglobulin chain, and HFE gene defects are the primary cause of hereditary iron overload (hemochromatosis) in humans [99]. Due to the lack of hepcidin expression, Hfe-deficient mice are characterized by iron deposit, notably in hepatocytes, but low iron levels in monocytes was reported $[95,144,145]$. A more severe phenotype of iron loading is observed in $\beta$-2-microglobulin-knockout mice [146]. Both Hfe and $\beta$-2-microglobulin knockout mice exacerbated mycobacterial growth after infection compared to wild-type mice, although $\mathrm{Hfe}$ deficient mice exhibited lower bacterial loads than $\beta-2 m$ KO mice [124,146]. In addition, MHC-class I-knockout mice are far less susceptible to $M$. tuberculosis than $\beta$-2-microglobulin-knockout mice [147], and the depletion of $\mathrm{CD}^{+} \mathrm{T}$ cells does not affect the susceptibility of $H f e$-knockout mice to M. avium infection [146]. Furthermore, $\beta$-2-microglobulin-knockout mice treated with lactoferrin have decreased bacterial loads after mycobacterial infection compared to wild-type and MHC-I-knockout mice [124]. The hypothesis that iron overload increases the risk of active tuberculosis susceptibility is in contradiction with the results obtained using hepcidin knockout mice in mouse model of $M$. tuberculosis infection [111,143].

The modulation of the $\mathrm{T}$ cell immune response plays a pivotal role in mycobacterial growth and virulence. The activation of lymphocytes T CD4 ${ }^{+}$Th1-polarised cells is important for the control of intracellular mycobacteria, although $\mathrm{CD}^{+}$cytotoxic $\mathrm{T}$ cells also play a role in the immunity against mycobacteria. A recent study showed that infected mice with $M$. bovis BCG and fed moderately with enriched iron diet exhibited enhanced $\mathrm{CD}^{+}-\mathrm{T}$ cell recruitment to granulomas [112]. In this model, despite an increase of iron levels, also present in macrophages unlike the hepcidin knockout mouse model, the mycobacterial burden is affected. Thus, specific localization of iron in tissues may be crucial to cell defense activities preventing the growth of mycobacteria in vivo.

\subsubsection{Investigation of the Effect of Iron on Mycobacterial Growth in Human}

In humans, several reports have highlighted the influence of iron levels in the body on the outcome of M. tuberculosis infection. Iron overload or deficiency can have various causes in human populations, and conflicting observations have been reported. Most of these reports have come from African populations in which tuberculosis is highly prevalent. Studies of several cohorts revealed that high iron levels in the body correlate with an increase of $M$. tuberculosis pathogenicity.

Iron overload resulting from an increased dietary intake is common in sub-Saharan African adults in rural populations due to the intake of traditional fermented beverage with a high iron content. This affliction is characterized by prominent iron depositions in both macrophages and hepatic parenchymal cells, which is different to the parenchymal iron loading that is predominantly observed in individuals with HFE hemochromatosis. The iron overload disorder in the sub-Saharan African population is associated with a poor outcome in patients with tuberculosis [148,149]. In addition, from postmortem analyses of adults from southern Africa, splenic iron overload was significantly 
associated with death from tuberculosis, with hepatic iron levels having a lower association, suggesting that excess iron may impair the cytotoxic activity of macrophage [150].

Tuberculosis is a common opportunistic coinfection in human immunodeficiency virus (HIV)-infected patients, especially in sub-Sahara African countries where HIV is highly prevalent. A cohort study of uninfected or HIV-infected individuals from Zimbabwe, where dietary iron overload is prevalent revealed that increased dietary iron with increased serum ferritin concentrations is associated with a 3.5-fold increase in the estimated odds of developing active tuberculosis after adjusting for HIV status while HIV seropositivity is associated with a 17.3-fold increases risk [151]. The impaired function of T-cells in HIV-infected patients and the combination with dietary iron overload increase the risk for developing virulent tuberculosis. Therefore, it appears that decreasing the prevalence of dietary iron overload in African populations would be beneficial. However, a retrospective analysis from an HIV-infected human cohort from Gambia revealed a significantly greater risk of developing tuberculosis in patients having lower serum transferrin, iron, and hemoglobin, and higher levels of ferritin and hepcidin [152]. In these patients, the elevated hepcidin levels and iron distribution may result from chronic infectious and inflammatory conditions or dietary iron insufficiency, which are both widespread in sub-Saharan African populations and considered as an important contributing factor to anemia $[153,154]$. Iron supplementation in adult males with pulmonary tuberculosis associated with mild to moderate anemia improves serum iron markers and accelerates the resumption of hematopoiesis in the initial phases of treatment, although it has no influence in the growth of mycobacteria or the clinical outcome of tuberculosis [154]. Therefore, iron supplementation to treat iron deficiency anemia in malnutrition populations would unlikely increase the risk of developing tuberculosis.

Iron deficiency may restrict mycobacterial proliferation but be detrimental for the host. Nutritional iron deficiency is the primary risk factor for developing iron deficiency, with or without concomitant anemia and is highly prevalent in most developing countries but often obscured by infections and inflammatory disorders that are common in the same populations. A study of a cohort from Tanzania suggested that anemia and/or iron deficiency is positively associated with an increased risk of death and tuberculosis recurrence. Indeed, iron deficiency without anemia was observed to be associated with a 2.89-fold increase in the risk of death, while anemia without iron deficiency and iron deficiency anemia was associated with 2.72-and 2.13-fold increased risk of death [155]. Malnutrition, especially when associated with subsequent iron deficiency, modulates immune responses, and affects host defenses against $M$. tuberculosis [156]. Iron is required for proper cell immune functions, and iron deficiency has been shown to compromise cell-mediated immunity. Iron deficiency reduces the number of T-cells and the T cell-induced proliferative response [157-159] which can be reversed by the oral or parenteral administration of iron $[157,160]$. Iron status also modulates cytokine expression profile, leading to immune system impairments and influencing immune response. Indeed, iron-deficient patients show altered activation capability of T-cells and expression of cytokines, with decreased production of IL-6, IL2, IL1, TNF $\alpha$, IFN $\gamma$, and IL-12p40 and increased production of IL-4 and IL-10 compared to cells from healthy individuals [161-163]. A recent publication has shown that a mutation in TFRC that hinders TfR1-mediated iron internalization, results in defective $\mathrm{T}$ and $\mathrm{B}$ cell proliferation as well as an impairment of class-switching which is known to be critical for antibody production [164]. Therefore, future therapeutic design should take in consideration that iron modulation influences macrophages polarization and Th1/Th2 cytokine balance. This therapeutic design should also consider the influence of other factors such as the diet, co-infection consequences (co-infection with HIV and malaria), inflammatory disease, other causes of anemia without iron deficiency, and even microbiota which can influence significantly iron absorption [165].

\section{Conclusions}

To combat and eradicate mycobacteria, it is of great importance to tackle the critical paths of a successful infection, including growth, the establishment of mycobacterial dormancy, and mycobacterial escape of immune containment, which determine the outcome of the disease. Iron 
has either beneficial or detrimental roles in mycobacteria infection, as it is involved in mycobacterial virulence and in the immune cell response of the host. The overall benefit of iron supplementation or deprivation in combating mycobacterial infections may have significant implications for clinical management of individuals at high risk of mycobacterial infection in many developing countries, in coinfection situations, and in iron-deficient or iron overload populations. Conflicting data have been reported on the influence of iron levels on mycobacterial infection outcomes in vivo, which may result from factors affecting iron status, iron distribution and the efficiency of the immune response.

Diet iron supplementation could have a biphasic effect depending on the level of iron status in the host and its distribution in the context of mycobacterial infection. After a thorough literature review, we have identified and modelized in Figure 7 two different effects of iron supplementation on host during mycobacterial infection. As shown in Figure 7, moderate iron supplementation in host could exhibit an "iron benefit window" shown in green during mycobacterial infection. This short window of the beneficial effect of iron supplementation is associated with a moderated reactive oxygen species induction and an increased immune cell response that may attenuate inflammation and mycobacterial burden. Another benefit of this treatment would be the promotion of local hepcidin production, for which anti-mycobacterial proprieties have been described. It is clearly admitted in the literature that a lack of iron may increase the chance of getting an infection, thus it is possible that having a normal-high level of iron could be beneficial for the host in term of preventing mycobacterial infection and having a boosted immune response against infection. Beyond the maximum threshold of the "iron benefit window", iron supplementation may be detrimental for the host and benefit mycobacteria as shown in red in Figure 7. In this context, iron supplementation promotes bacterial growth and inflammation in response to mycobacterial infection resulting in a poor outcome and a susceptibility of host to infection.

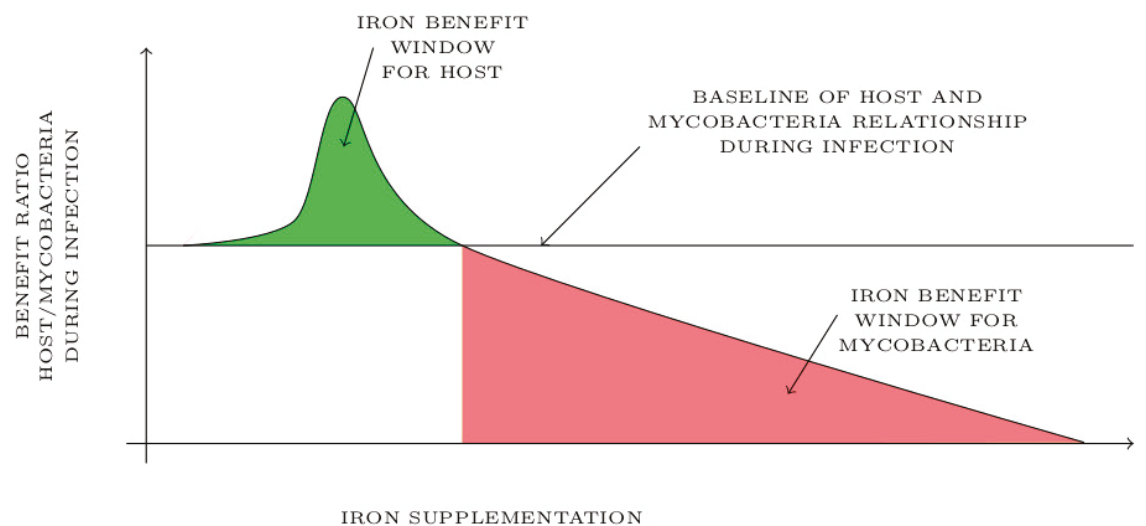

Figure 7. Suggested model of biphasic effect of iron supplementation during mycobacterial infection. A moderate concentration of iron supplementation can have a benefit effect for host during mycobacterial infection (shown in green). However, at high concentration of iron supplementation, iron can be beneficial for mycobacteria promoting growth and virulence (shown in red).

The future therapeutic use of iron as a pharmaceutical tool to treat or prevent mycobacterial disease will require delineation of the host iron benefit window in the context of infection. Iron treatment should be designed based on the concentration that neither induces host tissue damage as iron overload nor promotes mycobacterial growth. The host iron benefit window should be restrained, and its effectiveness may depend on the level of mycobacterial burden, co-infections and diet habit of host. It might be useful to design personalized co-treatment options against mycobacterial infections such as the combination of iron treatment with traditional drugs used in tuberculosis treatment, such as isoniazid/rifampicin, and determine whether iron status affects the efficacy of the chemotherapy. 
Author Contributions: Conceptualization, R.A. and C.M; Writing-original draft preparation, R.A. and C.M; Writing - review and editing, R.A. and C.M; Visualization, R.A. and C.M; Project administration, R.A.

Funding: This research received no external funding.

Acknowledgments: The authors thank Mohamed Cissé from French national research institute for the digital sciences INRIA-Lille (France) for the assistance in the modulization of the Figure 7.

Conflicts of Interest: The authors declare no conflict of interest.

\section{References}

1. Wang, J.; Behr, M.A. Building a better bacillus: The emergence of Mycobacterium tuberculosis. Front. Microbiol. 2014, 5, 139. [CrossRef]

2. Queiroz, A.; Riley, L.W. Bacterial immunostat: Mycobacterium tuberculosis lipids and their role in the host immune response. Rev. Soc. Bras. Med. Trop. 2017, 50, 9-18. [CrossRef] [PubMed]

3. Cosma, C.L.; Sherman, D.R.; Ramakrishnan, L. The secret lives of the pathogenic mycobacteria. Annu. Rev. Microbiol. 2003, 57, 641-676. [CrossRef]

4. Larsson, L.O.; Polverino, E.; Hoefsloot, W.; Codecasa, L.R.; Diel, R.; Jenkins, S.G.; Loebinger, M.R. Pulmonary disease by non-tuberculous mycobacteria-Clinical management, unmet needs and future perspectives. Expert Rev. Respir. Med. 2017, 11, 977-989. [CrossRef] [PubMed]

5. Davis, J.M.; Ramakrishnan, L. The role of the granuloma in expansion and dissemination of early tuberculous infection. Cell 2009, 136, 37-49. [CrossRef] [PubMed]

6. Davis, J.M.; Ramakrishnan, L. "The very pulse of the machine": The tuberculous granuloma in motion. Immunity 2008, 28, 146-148. [CrossRef]

7. Korbel, D.S.; Schneider, B.E.; Schaible, U.E. Innate immunity in tuberculosis: Myths and truth. Microbes Infect. 2008, 10, 995-1004. [CrossRef] [PubMed]

8. Nathan, C.F.; Hibbs, J.B., Jr. Role of nitric oxide synthesis in macrophage antimicrobial activity. Curr. Opin. Immunol. 1991, 3, 65-70. [CrossRef]

9. MacMicking, J.D.; North, R.J.; LaCourse, R.; Mudgett, J.S.; Shah, S.K.; Nathan, C.F. Identification of nitric oxide synthase as a protective locus against tuberculosis. Proc. Natl. Acad. Sci. USA 1997, 94, 5243-5248. [CrossRef]

10. Scanga, C.A.; Mohan, V.P.; Tanaka, K.; Alland, D.; Flynn, J.L.; Chan, J. The inducible nitric oxide synthase locus confers protection against aerogenic challenge of both clinical and laboratory strains of Mycobacterium tuberculosis in mice. Infect. Immun. 2001, 69, 7711-7717. [CrossRef]

11. DeLeo, F.R.; Allen, L.A.; Apicella, M.; Nauseef, W.M. NADPH oxidase activation and assembly during phagocytosis. J. Immunol. 1999, 163, 6732-6740. [PubMed]

12. Klebanoff, S.J. Myeloperoxidase: Friend and foe. J. Leukoc. Biol. 2005, 77, 598-625. [CrossRef] [PubMed]

13. Xia, Y.; Zweier, J.L. Superoxide and peroxynitrite generation from inducible nitric oxide synthase in macrophages. Proc. Natl. Acad. Sci. USA 1997, 94, 6954-6958. [CrossRef]

14. Dixon, S.J.; Stockwell, B.R. The role of iron and reactive oxygen species in cell death. Nat. Chem. Biol. 2014, 10, 9-17. [CrossRef] [PubMed]

15. Slauch, J.M. How does the oxidative burst of macrophages kill bacteria? Still an open question. Mol. Microbiol. 2011, 80, 580-583. [CrossRef]

16. Pedrosa, J.; Saunders, B.M.; Appelberg, R.; Orme, I.M.; Silva, M.T.; Cooper, A.M. Neutrophils play a protective nonphagocytic role in systemic Mycobacterium tuberculosis infection of mice. Infect. Immun. 2000, 68, 577-583. [CrossRef]

17. Martineau, A.R.; Newton, S.M.; Wilkinson, K.A.; Kampmann, B.; Hall, B.M.; Nawroly, N.; Packe, G.E.; Davidson, R.N.; Griffiths, C.J.; Wilkinson, R.J. Neutrophil-mediated innate immune resistance to mycobacteria. J. Clin. Investig. 2007, 117, 1988-1994. [CrossRef] [PubMed]

18. Mendoza-Aguilar, M.D.; Arce-Paredes, P.; Aquino-Vega, M.; Rodriguez-Martinez, S.; Rojas-Espinosa, O. Fate of Mycobacterium tuberculosis in peroxidase-loaded resting murine macrophages. Int. J. Mycobacteriol. 2013, 2, 3-13. [CrossRef]

19. Arnold, D.E.; Heimall, J.R. A Review of Chronic Granulomatous Disease. Adv. Ther. 2017, 34, $2543-2557$. [CrossRef] 
20. Parry, M.F.; Root, R.K.; Metcalf, J.A.; Delaney, K.K.; Kaplow, L.S.; Richar, W.J. Myeloperoxidase deficiency: Prevalence and clinical significance. Ann. Intern. Med. 1981, 95, 293-301. [CrossRef]

21. Cole, S.T.; Brosch, R.; Parkhill, J.; Garnier, T.; Churcher, C.; Harris, D.; Gordon, S.V.; Eiglmeier, K.; Gas, S.; Barry, C.E., 3rd; et al. Deciphering the biology of Mycobacterium tuberculosis from the complete genome sequence. Nature 1998, 393, 537-544. [CrossRef] [PubMed]

22. Griffiths, E.; Rogers, H.J.; Bullen, J.J. Iron, plasmids and infection. Nature 1980, 284, 508-509. [CrossRef]

23. Hamilton, T.A.; Gray, P.W.; Adams, D.O. Expression of the transferrin receptor on murine peritoneal macrophages is modulated by in vitro treatment with interferon gamma. Cell. Immunol. 1984, 89, 478-488. [CrossRef]

24. Marakalala, M.J.; Raju, R.M.; Sharma, K.; Zhang, Y.J.; Eugenin, E.A.; Prideaux, B.; Daudelin, I.B.; Chen, P.Y.; Booty, M.G.; Kim, J.H.; et al. Inflammatory signaling in human tuberculosis granulomas is spatially organized. Nat. Med. 2016, 22, 531-538. [CrossRef] [PubMed]

25. Kurthkoti, K.; Amin, H.; Marakalala, M.J.; Ghanny, S.; Subbian, S.; Sakatos, A.; Livny, J.; Fortune, S.M.; Berney, M.; Rodriguez, G.M. The Capacity of Mycobacterium tuberculosis To Survive Iron Starvation Might Enable It To Persist in Iron-Deprived Microenvironments of Human Granulomas. mBio 2017, 8, e1092-17. [CrossRef] [PubMed]

26. Olakanmi, O.; Schlesinger, L.S.; Ahmed, A.; Britigan, B.E. Intraphagosomal Mycobacterium tuberculosis acquires iron from both extracellular transferrin and intracellular iron pools. Impact of interferon-gamma and hemochromatosis. J. Biol. Chem. 2002, 277, 49727-49734. [CrossRef]

27. Sharman, G.J.; Williams, D.H.; Ewing, D.F.; Ratledge, C. Isolation, purification and structure of exochelin MS, the extracellular siderophore from Mycobacterium smegmatis. Biochem. J. 1995, 305 Pt 1, 187-196. [CrossRef]

28. Sharman, G.J.; Williams, D.H.; Ewing, D.F.; Ratledge, C. Determination of the structure of exochelin MN, the extracellular siderophore from Mycobacterium neoaurum. Chem. Biol. 1995, 2, 553-561. [CrossRef]

29. Dhungana, S.; Ratledge, C.; Crumbliss, A.L. Iron chelation properties of an extracellular siderophore exochelin MS. Inorg. Chem. 2004, 43, 6274-6283. [CrossRef] [PubMed]

30. Barclay, R.; Ratledge, C. Mycobactins and exochelins of Mycobacterium tuberculosis, M. bovis, M. africanum and other related species. J. Gen. Microbiol. 1988, 134, 771-776. [CrossRef] [PubMed]

31. Fang, Z.; Sampson, S.L.; Warren, R.M.; Gey van Pittius, N.C.; Newton-Foot, M. Iron acquisition strategies in mycobacteria. Tuberculosis 2015, 95, 123-130. [CrossRef] [PubMed]

32. Gobin, J.; Moore, C.H.; Reeve, J.R., Jr.; Wong, D.K.; Gibson, B.W.; Horwitz, M.A. Iron acquisition by Mycobacterium tuberculosis: Isolation and characterization of a family of iron-binding exochelins. Proc. Natl. Acad. Sci. USA 1995, 92, 5189-5193. [CrossRef] [PubMed]

33. Clemens, D.L.; Horwitz, M.A. The Mycobacterium tuberculosis phagosome interacts with early endosomes and is accessible to exogenously administered transferrin. J. Exp. Med. 1996, 184, 1349-1355. [CrossRef]

34. Farhana, A.; Kumar, S.; Rathore, S.S.; Ghosh, P.C.; Ehtesham, N.Z.; Tyagi, A.K.; Hasnain, S.E. Mechanistic insights into a novel exporter-importer system of Mycobacterium tuberculosis unravel its role in trafficking of iron. PLoS ONE 2008, 3, e2087. [CrossRef] [PubMed]

35. Hameed, S.; Pal, R.; Fatima, Z. Iron Acquisition Mechanisms: Promising Target Against Mycobacterium tuberculosis. Open Microbiol. J. 2015, 9, 91-97. [CrossRef]

36. Ryndak, M.B.; Wang, S.; Smith, I.; Rodriguez, G.M. The Mycobacterium tuberculosis high-affinity iron importer, IrtA, contains an FAD-binding domain. J. Bacteriol. 2010, 192, 861-869. [CrossRef] [PubMed]

37. Rodriguez, G.M.; Smith, I. Identification of an ABC transporter required for iron acquisition and virulence in Mycobacterium tuberculosis. J. Bacteriol. 2006, 188, 424-430. [CrossRef] [PubMed]

38. Wells, R.M.; Jones, C.M.; Xi, Z.; Speer, A.; Danilchanka, O.; Doornbos, K.S.; Sun, P.; Wu, F.; Tian, C.; Niederweis, M. Discovery of a siderophore export system essential for virulence of Mycobacterium tuberculosis. PLoS Pathog. 2013, 9, e1003120. [CrossRef]

39. Jones, C.M.; Wells, R.M.; Madduri, A.V.; Renfrow, M.B.; Ratledge, C.; Moody, D.B.; Niederweis, M. Self-poisoning of Mycobacterium tuberculosis by interrupting siderophore recycling. Proc. Natl. Acad. Sci. USA 2014, 111, 1945-1950. [CrossRef] [PubMed]

40. Quadri, L.E.; Sello, J.; Keating, T.A.; Weinreb, P.H.; Walsh, C.T. Identification of a Mycobacterium tuberculosis gene cluster encoding the biosynthetic enzymes for assembly of the virulence-conferring siderophore mycobactin. Chem. Biol. 1998, 5, 631-645. [CrossRef] 
41. Sritharan, M. Iron Homeostasis in Mycobacterium tuberculosis: Mechanistic Insights into Siderophore-Mediated Iron Uptake. J. Bacteriol. 2016, 198, 2399-2409. [CrossRef] [PubMed]

42. De Voss, J.J.; Rutter, K.; Schroeder, B.G.; Su, H.; Zhu, Y.; Barry, C.E., 3rd. The salicylate-derived mycobactin siderophores of Mycobacterium tuberculosis are essential for growth in macrophages. Proc. Natl. Acad. Sci. USA 2000, 97, 1252-1257. [CrossRef] [PubMed]

43. Groschel, M.I.; Sayes, F.; Simeone, R.; Majlessi, L.; Brosch, R. ESX secretion systems: Mycobacterial evolution to counter host immunity. Nat. Rev. Microbiol. 2016, 14, 677-691. [CrossRef]

44. Serafini, A.; Boldrin, F.; Palu, G.; Manganelli, R. Characterization of a Mycobacterium tuberculosis ESX-3 conditional mutant: Essentiality and rescue by iron and zinc. J. Bacteriol. 2009, 191, 6340-6344. [CrossRef] [PubMed]

45. Serafini, A.; Pisu, D.; Palu, G.; Rodriguez, G.M.; Manganelli, R. The ESX-3 secretion system is necessary for iron and zinc homeostasis in Mycobacterium tuberculosis. PLoS ONE 2013, 8, e78351. [CrossRef] [PubMed]

46. Siegrist, M.S.; Unnikrishnan, M.; McConnell, M.J.; Borowsky, M.; Cheng, T.Y.; Siddiqi, N.; Fortune, S.M.; Moody, D.B.; Rubin, E.J. Mycobacterial Esx-3 is required for mycobactin-mediated iron acquisition. Proc. Natl. Acad. Sci. USA 2009, 106, 18792-18797. [CrossRef]

47. Tufariello, J.M.; Chapman, J.R.; Kerantzas, C.A.; Wong, K.W.; Vilcheze, C.; Jones, C.M.; Cole, L.E.; Tinaztepe, E.; Thompson, V.; Fenyo, D.; et al. Separable roles for Mycobacterium tuberculosis ESX-3 effectors in iron acquisition and virulence. Proc. Natl. Acad. Sci. USA 2016, 113, E348-E357. [CrossRef] [PubMed]

48. Jones, C.M.; Niederweis, M. Mycobacterium tuberculosis can utilize heme as an iron source. J. Bacteriol. 2011, 193, 1767-1770. [CrossRef] [PubMed]

49. Wren, B.W.; Stabler, R.A.; Das, S.S.; Butcher, P.D.; Mangan, J.A.; Clarke, J.D.; Casali, N.; Parish, T.; Stoker, N.G. Characterization of a haemolysin from Mycobacterium tuberculosis with homology to a virulence factor of Serpulina hyodysenteriae. Microbiology 1998, 144 Pt 5, 1205-1211. [CrossRef]

50. Tullius, M.V.; Harmston, C.A.; Owens, C.P.; Chim, N.; Morse, R.P.; McMath, L.M.; Iniguez, A.; Kimmey, J.M.; Sawaya, M.R.; Whitelegge, J.P.; et al. Discovery and characterization of a unique mycobacterial heme acquisition system. Proc. Natl. Acad. Sci. USA 2011, 108, 5051-5056. [CrossRef]

51. Owens, C.P.; Chim, N.; Graves, A.B.; Harmston, C.A.; Iniguez, A.; Contreras, H.; Liptak, M.D.; Goulding, C.W. The Mycobacterium tuberculosis secreted protein Rv0203 transfers heme to membrane proteins MmpL3 and MmpL11. J. Biol. Chem. 2013, 288, 21714-21728. [CrossRef] [PubMed]

52. Mitra, A.; Speer, A.; Lin, K.; Ehrt, S.; Niederweis, M. PPE Surface Proteins Are Required for Heme Utilization by Mycobacterium tuberculosis. mBio. 2017, 8, e01720-16. [CrossRef] [PubMed]

53. Tullius, M.V.; Nava, S.; Horwitz, M.A. PPE37 Is Essential for Mycobacterium tuberculosis Heme-Iron Acquisition (HIA), and a Defective PPE37 in Mycobacterium bovis BCG Prevents HIA. Infect. Immun. 2019, 87, e00540-18. [CrossRef] [PubMed]

54. Ahmad, J.; Farhana, A.; Pancsa, R.; Arora, S.K.; Srinivasan, A.; Tyagi, A.K.; Babu, M.M.; Ehtesham, N.Z.; Hasnain, S.E. Contrasting Function of Structured N-Terminal and Unstructured C-Terminal Segments of Mycobacterium tuberculosis PPE37 Protein. mBio 2018, 9, e01712-17. [CrossRef] [PubMed]

55. Owens, C.P.; Chim, N.; Goulding, C.W. Insights on how the Mycobacterium tuberculosis heme uptake pathway can be used as a drug target. Future Med. Chem. 2013, 5, 1391-1403. [CrossRef]

56. Reddy, P.V.; Puri, R.V.; Khera, A.; Tyagi, A.K. Iron storage proteins are essential for the survival and pathogenesis of Mycobacterium tuberculosis in THP-1 macrophages and the guinea pig model of infection. J. Bacteriol. 2012, 194, 567-575. [CrossRef] [PubMed]

57. Khare, G.; Nangpal, P.; Tyagi, A.K. Differential Roles of Iron Storage Proteins in Maintaining the Iron Homeostasis in Mycobacterium tuberculosis. PLoS ONE 2017, 12, e0169545. [CrossRef]

58. Pandey, R.; Rodriguez, G.M. A ferritin mutant of Mycobacterium tuberculosis is highly susceptible to killing by antibiotics and is unable to establish a chronic infection in mice. Infect. Immun. 2012, 80, 3650-3659. [CrossRef]

59. Rodriguez, G.M.; Voskuil, M.I.; Gold, B.; Schoolnik, G.K.; Smith, I. ideR, An essential gene in mycobacterium tuberculosis: Role of IdeR in iron-dependent gene expression, iron metabolism, and oxidative stress response. Infect. Immun. 2002, 70, 3371-3381. [CrossRef]

60. Pandey, S.D.; Choudhury, M.; Yousuf, S.; Wheeler, P.R.; Gordon, S.V.; Ranjan, A.; Sritharan, M. Iron-regulated protein HupB of Mycobacterium tuberculosis positively regulates siderophore biosynthesis and is essential for growth in macrophages. J. Bacteriol. 2014, 196, 1853-1865. [CrossRef] 
61. Pandey, R.; Rodriguez, G.M. IdeR is required for iron homeostasis and virulence in Mycobacterium tuberculosis. Mol. Microbiol. 2014, 91, 98-109. [CrossRef] [PubMed]

62. Rohilla, A.; Khare, G.; Tyagi, A.K. Virtual Screening, pharmacophore development and structure based similarity search to identify inhibitors against IdeR, a transcription factor of Mycobacterium tuberculosis. Sci. Rep. 2017, 7, 4653. [CrossRef]

63. Kumar, A.; Toledo, J.C.; Patel, R.P.; Lancaster, J.R., Jr.; Steyn, A.J. Mycobacterium tuberculosis DosS is a redox sensor and DosT is a hypoxia sensor. Proc. Natl. Acad. Sci. USA 2007, 104, 11568-11573. [CrossRef]

64. Singh, A.; Crossman, D.K.; Mai, D.; Guidry, L.; Voskuil, M.I.; Renfrow, M.B.; Steyn, A.J. Mycobacterium tuberculosis WhiB3 maintains redox homeostasis by regulating virulence lipid anabolism to modulate macrophage response. PLoS Pathog. 2009, 5, e1000545. [CrossRef]

65. Geiman, D.E.; Raghunand, T.R.; Agarwal, N.; Bishai, W.R. Differential gene expression in response to exposure to antimycobacterial agents and other stress conditions among seven Mycobacterium tuberculosis whiB-like genes. Antimicrob. Agents Chemother. 2006, 50, 2836-2841. [CrossRef] [PubMed]

66. Singh, A.; Guidry, L.; Narasimhulu, K.V.; Mai, D.; Trombley, J.; Redding, K.E.; Giles, G.I.; Lancaster, J.R., Jr.; Steyn, A.J. Mycobacterium tuberculosis WhiB3 responds to $\mathrm{O}_{2}$ and nitric oxide via its [4Fe-4S] cluster and is essential for nutrient starvation survival. Proc. Natl. Acad. Sci. USA 2007, 104, 11562-11567. [CrossRef]

67. Wu, J.; Ru, H.W.; Xiang, Z.H.; Jiang, J.; Wang, Y.C.; Zhang, L.; Liu, J. WhiB4 Regulates the PE/PPE Gene Family and is Essential for Virulence of Mycobacterium marinum. Sci. Rep. 2017, 7, 3007. [CrossRef] [PubMed]

68. Casonato, S.; Cervantes Sanchez, A.; Haruki, H.; Rengifo Gonzalez, M.; Provvedi, R.; Dainese, E.; Jaouen, T.; Gola, S.; Bini, E.; Vicente, M.; et al. WhiB5, a transcriptional regulator that contributes to Mycobacterium tuberculosis virulence and reactivation. Infect. Immun. 2012, 80, 3132-3144. [CrossRef] [PubMed]

69. Chen, Z.; Hu, Y.; Cumming, B.M.; Lu, P.; Feng, L.; Deng, J.; Steyn, A.J.; Chen, S. Mycobacterial WhiB6 Differentially Regulates ESX-1 and the Dos Regulon to Modulate Granuloma Formation and Virulence in Zebrafish. Cell Rep. 2016, 16, 2512-2524. [CrossRef] [PubMed]

70. Wilson, T.M.; Collins, D.M. ahpC, a gene involved in isoniazid resistance of the Mycobacterium tuberculosis complex. Mol. Microbiol. 1996, 19, 1025-1034. [CrossRef] [PubMed]

71. Piddington, D.L.; Fang, F.C.; Laessig, T.; Cooper, A.M.; Orme, I.M.; Buchmeier, N.A. Cu,Zn superoxide dismutase of Mycobacterium tuberculosis contributes to survival in activated macrophages that are generating an oxidative burst. Infect. Immun. 2001, 69, 4980-4987. [CrossRef] [PubMed]

72. Liao, D.; Fan, Q.; Bao, L. The role of superoxide dismutase in the survival of Mycobacterium tuberculosis in macrophages. Jpn. J. Infect. Dis. 2013, 66, 480-488. [CrossRef]

73. Edwards, K.M.; Cynamon, M.H.; Voladri, R.K.; Hager, C.C.; DeStefano, M.S.; Tham, K.T.; Lakey, D.L.; Bochan, M.R.; Kernodle, D.S. Iron-cofactored superoxide dismutase inhibits host responses to Mycobacterium tuberculosis. Am. J. Respir. Crit. Care Med. 2001, 164, 2213-2219. [CrossRef] [PubMed]

74. Flynn, J.L.; Chan, J. Immunology of tuberculosis. Annu. Rev. Immunol. 2001, 19, 93-129. [CrossRef]

75. Kumar, A.; Farhana, A.; Guidry, L.; Saini, V.; Hondalus, M.; Steyn, A.J. Redox homeostasis in mycobacteria: The key to tuberculosis control? Expert Rev. Mol. Med. 2011, 13, e39. [CrossRef]

76. Hood, M.I.; Skaar, E.P. Nutritional immunity: Transition metals at the pathogen-host interface. Nat. Rev. Microbiol. 2012, 10, 525-537. [CrossRef] [PubMed]

77. Byrd, T.F.; Horwitz, M.A. Interferon gamma-activated human monocytes downregulate transferrin receptors and inhibit the intracellular multiplication of Legionella pneumophila by limiting the availability of iron. J. Clin. Investig. 1989, 83, 1457-1465. [CrossRef]

78. Garcia-Montoya, I.A.; Cendon, T.S.; Arevalo-Gallegos, S.; Rascon-Cruz, Q. Lactoferrin a multiple bioactive protein: An overview. Biochim. Biophys. Acta 2012, 1820, 226-236. [CrossRef]

79. Ward, P.P.; Paz, E.; Conneely, O.M. Multifunctional roles of lactoferrin: A critical overview. Cell. Mol. Life Sci. 2005, 62, 2540-2548. [CrossRef] [PubMed]

80. Silva-Gomes, S.; Bouton, C.; Silva, T.; Santambrogio, P.; Rodrigues, P.; Appelberg, R.; Gomes, M.S. Mycobacterium avium infection induces $\mathrm{H}$-ferritin expression in mouse primary macrophages by activating Toll-like receptor 2. PLOS ONE 2013, 8, e82874. [CrossRef]

81. Momotani, E.; Furugouri, K.; Obara, Y.; Miyata, Y.; Ishikawa, Y.; Yoshino, T. Immunohistochemical distribution of ferritin, lactoferrin, and transferrin in granulomas of bovine paratuberculosis. Infect. Immun. 1986, 52, 623-627. 
82. Reddy, V.P.; Chinta, K.C.; Saini, V.; Glasgow, J.N.; Hull, T.D.; Traylor, A.; Rey-Stolle, F.; Soares, M.P.; Madansein, R.; Rahman, M.A.; et al. Ferritin H Deficiency in Myeloid Compartments Dysregulates Host Energy Metabolism and Increases Susceptibility to Mycobacterium tuberculosis Infection. Front. Immunol. 2018, 9, 860. [CrossRef] [PubMed]

83. Gruenheid, S.; Pinner, E.; Desjardins, M.; Gros, P. Natural resistance to infection with intracellular pathogens: The Nramp1 protein is recruited to the membrane of the phagosome. J. Exp. Med. 1997, 185, 717-730. [CrossRef] [PubMed]

84. Gros, P.; Skamene, E.; Forget, A. Genetic control of natural resistance to Mycobacterium bovis (BCG) in mice. J. Immunol. 1981, 127, 2417-2421.

85. Skamene, E.; Gros, P.; Forget, A.; Patel, P.J.; Nesbitt, M.N. Regulation of resistance to leprosy by chromosome 1 locus in the mouse. Immunogenetics 1984, 19, 117-124. [CrossRef]

86. Stach, J.L.; Gros, P.; Forget, A.; Skamene, E. Phenotypic expression of genetically-controlled natural resistance to Mycobacterium bovis (BCG). J. Immunol. 1984, 132, 888-892. [PubMed]

87. Rodrigues, P.N.; Gomes, S.S.; Neves, J.V.; Gomes-Pereira, S.; Correia-Neves, M.; Nunes-Alves, C.; Stolte, J.; Sanchez, M.; Appelberg, R.; Muckenthaler, M.U.; et al. Mycobacteria-induced anaemia revisited: A molecular approach reveals the involvement of NRAMP1 and lipocalin-2, but not of hepcidin. Immunobiology 2011, 216, 1127-1134. [CrossRef] [PubMed]

88. Vidal, S.M.; Malo, D.; Vogan, K.; Skamene, E.; Gros, P. Natural resistance to infection with intracellular parasites: Isolation of a candidate for Bcg. Cell 1993, 73, 469-485. [CrossRef]

89. Vidal, S.; Tremblay, M.L.; Govoni, G.; Gauthier, S.; Sebastiani, G.; Malo, D.; Skamene, E.; Olivier, M.; Jothy, S.; Gros, P. The Ity/Lsh/Bcg locus: Natural resistance to infection with intracellular parasites is abrogated by disruption of the Nramp1 gene. J. Exp. Med. 1995, 182, 655-666. [CrossRef] [PubMed]

90. Vidal, S.M.; Pinner, E.; Lepage, P.; Gauthier, S.; Gros, P. Natural resistance to intracellular infections: Nramp1 encodes a membrane phosphoglycoprotein absent in macrophages from susceptible (Nramp1 D169) mouse strains. J. Immunol. 1996, 157, 3559-3568.

91. Wessling-Resnick, M. Nramp1 and Other Transporters Involved in Metal Withholding during Infection. J. Biol. Chem. 2015, 290, 18984-18990. [CrossRef] [PubMed]

92. Stead, W.W.; Senner, J.W.; Reddick, W.T.; Lofgren, J.P. Racial differences in susceptibility to infection by Mycobacterium tuberculosis. N. Engl. J. Med. 1990, 322, 422-427. [CrossRef]

93. Hoal, E.G.; Lewis, L.A.; Jamieson, S.E.; Tanzer, F.; Rossouw, M.; Victor, T.; Hillerman, R.; Beyers, N.; Blackwell, J.M.; Van Helden, P.D. SLC11A1 (NRAMP1) but not SLC11A2 (NRAMP2) polymorphisms are associated with susceptibility to tuberculosis in a high-incidence community in South Africa. Int. J. Tuberc. Lung Dis. 2004, 8, 1464-1471.

94. Fernandez-Mestre, M.; Villasmil, A.; Takiff, H.; Alcala, Z.F. NRAMP1 and VDR Gene Polymorphisms in Susceptibility to Tuberculosis in Venezuelan Population. Dis. Markers 2015, 2015, 860628. [CrossRef]

95. Pigeon, C.; Ilyin, G.; Courselaud, B.; Leroyer, P.; Turlin, B.; Brissot, P.; Loreal, O. A new mouse liver-specific gene, encoding a protein homologous to human antimicrobial peptide hepcidin, is overexpressed during iron overload. J. Biol. Chem. 2001, 276, 7811-7819. [CrossRef] [PubMed]

96. Nicolas, G.; Bennoun, M.; Devaux, I.; Beaumont, C.; Grandchamp, B.; Kahn, A.; Vaulont, S. Lack of hepcidin gene expression and severe tissue iron overload in upstream stimulatory factor 2 (USF2) knockout mice. Proc. Natl. Acad. Sci. USA 2001, 98, 8780-8785. [CrossRef]

97. Nemeth, E.; Tuttle, M.S.; Powelson, J.; Vaughn, M.B.; Donovan, A.; Ward, D.M.; Ganz, T.; Kaplan, J. Hepcidin regulates cellular iron efflux by binding to ferroportin and inducing its internalization. Science 2004, 306, 2090-2093. [CrossRef] [PubMed]

98. Nicolas, G.; Chauvet, C.; Viatte, L.; Danan, J.L.; Bigard, X.; Devaux, I.; Beaumont, C.; Kahn, A.; Vaulont, S. The gene encoding the iron regulatory peptide hepcidin is regulated by anemia, hypoxia, and inflammation. J. Clin. Investig. 2002, 110, 1037-1044. [CrossRef] [PubMed]

99. Feder, J.N.; Gnirke, A.; Thomas, W.; Tsuchihashi, Z.; Ruddy, D.A.; Basava, A.; Dormishian, F.; Domingo, R., Jr.; Ellis, M.C.; Fullan, A.; et al. A novel MHC class I-like gene is mutated in patients with hereditary haemochromatosis. Nat. Genet. 1996, 13, 399-408. [CrossRef] [PubMed]

100. Nemeth, E.; Rivera, S.; Gabayan, V.; Keller, C.; Taudorf, S.; Pedersen, B.K.; Ganz, T. IL-6 mediates hypoferremia of inflammation by inducing the synthesis of the iron regulatory hormone hepcidin. J. Clin. Investig. 2004, 113, 1271-1276. [CrossRef] [PubMed] 
101. Armitage, A.E.; Eddowes, L.A.; Gileadi, U.; Cole, S.; Spottiswoode, N.; Selvakumar, T.A.; Ho, L.P.; Townsend, A.R.; Drakesmith, H. Hepcidin regulation by innate immune and infectious stimuli. Blood 2011, 118, 4129-4139. [CrossRef]

102. Wrighting, D.M.; Andrews, N.C. Interleukin-6 induces hepcidin expression through STAT3. Blood 2006, 108, 3204-3209. [CrossRef]

103. Besson-Fournier, C.; Latour, C.; Kautz, L.; Bertrand, J.; Ganz, T.; Roth, M.P.; Coppin, H. Induction of activin B by inflammatory stimuli up-regulates expression of the iron-regulatory peptide hepcidin through $\operatorname{Smad} 1 / 5 / 8$ signaling. Blood 2012, 120, 431-439. [CrossRef] [PubMed]

104. Kautz, L.; Jung, G.; Valore, E.V.; Rivella, S.; Nemeth, E.; Ganz, T. Identification of erythroferrone as an erythroid regulator of iron metabolism. Nat. Genet. 2014, 46, 678-684. [CrossRef]

105. Poli, M.; Girelli, D.; Campostrini, N.; Maccarinelli, F.; Finazzi, D.; Luscieti, S.; Nai, A.; Arosio, P. Heparin: A potent inhibitor of hepcidin expression in vitro and in vivo. Blood 2011, 117, 997-1004. [CrossRef] [PubMed]

106. Brkljacic, J.; Pauk, M.; Erjavec, I.; Cipcic, A.; Grgurevic, L.; Zadro, R.; Inman, G.J.; Vukicevic, S. Exogenous heparin binds and inhibits bone morphogenetic protein 6 biological activity. Int. Orthop. 2013, 37, 529-541. [CrossRef] [PubMed]

107. Nemeth, E.; Valore, E.V.; Territo, M.; Schiller, G.; Lichtenstein, A.; Ganz, T. Hepcidin, a putative mediator of anemia of inflammation, is a type II acute-phase protein. Blood 2003, 101, 2461-2463. [CrossRef]

108. Weiss, G. Iron metabolism in the anemia of chronic disease. Biochim. Biophys. Acta 2009, 1790, 682-693. [CrossRef]

109. Sow, F.B.; Florence, W.C.; Satoskar, A.R.; Schlesinger, L.S.; Zwilling, B.S.; Lafuse, W.P. Expression and localization of hepcidin in macrophages: A role in host defense against tuberculosis. J. Leukoc. Biol. 2007, 82, 934-945. [CrossRef]

110. Sow, F.B.; Nandakumar, S.; Velu, V.; Kellar, K.L.; Schlesinger, L.S.; Amara, R.R.; Lafuse, W.P.; Shinnick, T.M.; Sable, S.B. Mycobacterium tuberculosis components stimulate production of the antimicrobial peptide hepcidin. Tuberculosis 2011, 91, 314-321. [CrossRef]

111. Harrington-Kandt, R.; Stylianou, E.; Eddowes, L.A.; Lim, P.J.; Stockdale, L.; Pinpathomrat, N.; Bull, N.; Pasricha, J.; Ulaszewska, M.; Beglov, Y.; et al. Hepcidin deficiency and iron deficiency do not alter tuberculosis susceptibility in a murine M.tb infection model. PLoS ONE 2018, 13, e0191038. [CrossRef]

112. Agoro, R.; Benmerzoug, S.; Rose, S.; Bouyer, M.; Gozzelino, R.; Garcia, I.; Ryffel, B.; Quesniaux, V.F.J.; Mura, C. An Iron-Rich Diet Decreases the Mycobacterial Burden and Correlates With Hepcidin Upregulation, Lower Levels of Proinflammatory Mediators, and Increased T-Cell Recruitment in a Model of Mycobacterium bovis Bacille Calmette-Guerin Infection. J. Infect. Dis. 2017, 216, 907-918. [CrossRef]

113. Johnson, E.E.; Sandgren, A.; Cherayil, B.J.; Murray, M.; Wessling-Resnick, M. Role of ferroportin in macrophage-mediated immunity. Infect. Immun. 2010, 78, 5099-5106. [CrossRef]

114. Baker, M.A.; Wilson, D.; Wallengren, K.; Sandgren, A.; Iartchouk, O.; Broodie, N.; Goonesekera, S.D.; Sabeti, P.C.; Murray, M.B. Polymorphisms in the gene that encodes the iron transport protein ferroportin 1 influence susceptibility to tuberculosis. J. Infect. Dis. 2012, 205, 1043-1047. [CrossRef] [PubMed]

115. Kochan, I.; Golden, C.A.; Bukovic, J.A. Mechanism of tuberculostasis in mammalian serum. II. Induction of serum tuberculostasis in guinea pigs. J. Bacteriol. 1969, 100, 64-70.

116. Park, C.H.; Valore, E.V.; Waring, A.J.; Ganz, T. Hepcidin, a urinary antimicrobial peptide synthesized in the liver. J. Biol. Chem. 2001, 276, 7806-7810. [CrossRef]

117. Krause, A.; Neitz, S.; Magert, H.J.; Schulz, A.; Forssmann, W.G.; Schulz-Knappe, P.; Adermann, K. LEAP-1, a novel highly disulfide-bonded human peptide, exhibits antimicrobial activity. FEBS Lett. 2000, 480, 147-150. [CrossRef]

118. Holmes, M.A.; Paulsene, W.; Jide, X.; Ratledge, C.; Strong, R.K. Siderocalin (Lcn 2) also binds carboxymycobactins, potentially defending against mycobacterial infections through iron sequestration. Structure 2005, 13, 29-41. [CrossRef]

119. Flo, T.H.; Smith, K.D.; Sato, S.; Rodriguez, D.J.; Holmes, M.A.; Strong, R.K.; Akira, S.; Aderem, A. Lipocalin 2 mediates an innate immune response to bacterial infection by sequestrating iron. Nature 2004, 432, 917-921. [CrossRef]

120. Saiga, H.; Nishimura, J.; Kuwata, H.; Okuyama, M.; Matsumoto, S.; Sato, S.; Matsumoto, M.; Akira, S.; Yoshikai, Y.; Honda, K.; et al. Lipocalin 2-dependent inhibition of mycobacterial growth in alveolar epithelium. J. Immunol. 2008, 181, 8521-8527. [CrossRef] [PubMed] 
121. Guglani, L.; Gopal, R.; Rangel-Moreno, J.; Junecko, B.F.; Lin, Y.; Berger, T.; Mak, T.W.; Alcorn, J.F.; Randall, T.D.; Reinhart, T.A.; et al. Lipocalin 2 regulates inflammation during pulmonary mycobacterial infections. PLoS ONE 2012, 7, e50052. [CrossRef] [PubMed]

122. Toyonaga, T.; Matsuura, M.; Mori, K.; Honzawa, Y.; Minami, N.; Yamada, S.; Kobayashi, T.; Hibi, T.; Nakase, H. Lipocalin 2 prevents intestinal inflammation by enhancing phagocytic bacterial clearance in macrophages. Sci. Rep. 2016, 6, 35014. [CrossRef]

123. Cronje, L.; Edmondson, N.; Eisenach, K.D.; Bornman, L. Iron and iron chelating agents modulate Mycobacterium tuberculosis growth and monocyte-macrophage viability and effector functions. FEMS Immunol. Med. Microbiol. 2005, 45, 103-112. [CrossRef] [PubMed]

124. Schaible, U.E.; Collins, H.L.; Priem, F.; Kaufmann, S.H. Correction of the iron overload defect in beta-2-microglobulin knockout mice by lactoferrin abolishes their increased susceptibility to tuberculosis. J. Exp. Med. 2002, 196, 1507-1513. [CrossRef] [PubMed]

125. Raghu, B.; Sarma, G.R.; Venkatesan, P. Effect of iron on the growth and siderophore production of mycobacteria. Biochem. Mol. Biol. Int. 1993, 31, 341-348.

126. Rook, G.A.; Steele, J.; Ainsworth, M.; Champion, B.R. Activation of macrophages to inhibit proliferation of Mycobacterium tuberculosis: Comparison of the effects of recombinant gamma-interferon on human monocytes and murine peritoneal macrophages. Immunology 1986, 59, 333-338. [PubMed]

127. Kochan, I.; Pellis, N.R.; Golden, C.A. Mechanism of Tuberculostasis in Mammalian Serum III. Neutralization of Serum Tuberculostasis by Mycobactin. Infect. Immun. 1971, 3, 553-558. [PubMed]

128. Gomes, M.S.; Dom, G.; Pedrosa, J.; Boelaert, J.R.; Appelberg, R. Effects of iron deprivation on Mycobacterium avium growth. Tuber Lung Dis. 1999, 79, 321-328. [CrossRef] [PubMed]

129. Rajiv, J.; Dam, T.; Kumar, S.; Bose, M.; Aggarwal, K.K.; Babu, C.R. Inhibition of the in-vitro growth of Mycobacterium tuberculosis by a phytosiderophore. J. Med. Microbiol. 2001, 50, 916-918. [CrossRef]

130. Lamb, A.L. Breaking a pathogen's iron will: Inhibiting siderophore production as an antimicrobial strategy. Biochim. Biophys. Acta 2015, 1854, 1054-1070. [CrossRef]

131. Silva-Gomes, S.; Appelberg, R.; Larsen, R.; Soares, M.P.; Gomes, M.S. Heme catabolism by heme oxygenase-1 confers host resistance to Mycobacterium infection. Infect. Immun. 2013, 81, 2536-2545. [CrossRef] [PubMed]

132. Denis, M.; Buddle, B.M. Iron modulates the replication of virulent Mycobacterium bovis in resting and activated bovine and possum macrophages. Vet. Immunol. Immunopathol. 2005, 107, 189-199. [CrossRef] [PubMed]

133. Gomes, M.S.; Boelaert, J.R.; Appelberg, R. Role of iron in experimental Mycobacterium avium infection. J. Clin. Virol. 2001, 20, 117-122. [CrossRef]

134. Wheeler, W.C.; Hanks, J.H. Utilization of External Growth Factors by Intracellular Microbes: Mycobacterium Paratuberculosis and Wood Pigeon Mycobacteria. J. Bacteriol. 1965, 89, 889-896. [PubMed]

135. Douvas, G.S.; May, M.H.; Crowle, A.J. Transferrin, Iron, and Serum-Lipids Enhance or Inhibit Mycobacterium-Avium Replication in Human Macrophages. J. Infect. Dis. 1993, 167, 857-864. [CrossRef] [PubMed]

136. Agoro, R.; Taleb, M.; Quesniaux, V.F.J.; Mura, C. Cell iron status influences macrophage polarization. PLoS ONE 2018, 13, e0196921. [CrossRef] [PubMed]

137. Corna, G.; Campana, L.; Pignatti, E.; Castiglioni, A.; Tagliafico, E.; Bosurgi, L.; Campanella, A.; Brunelli, S.; Manfredi, A.A.; Apostoli, P.; et al. Polarization dictates iron handling by inflammatory and alternatively activated macrophages. Haematologica 2010, 95, 1814-1822. [CrossRef]

138. Recalcati, S.; Locati, M.; Marini, A.; Santambrogio, P.; Zaninotto, F.; De Pizzol, M.; Zammataro, L.; Girelli, D.; Cairo, G. Differential regulation of iron homeostasis during human macrophage polarized activation. Eur. J. Immunol. 2010, 40, 824-835. [CrossRef]

139. Weiss, G.; Fuchs, D.; Hausen, A.; Reibnegger, G.; Werner, E.R.; Werner-Felmayer, G.; Wachter, H. Iron modulates interferon-gamma effects in the human myelomonocytic cell line THP-1. Exp. Hematol. 1992, 20, 605-610.

140. Byrd, T.F. Tumor necrosis factor alpha (TNFalpha) promotes growth of virulent Mycobacterium tuberculosis in human monocytes iron-mediated growth suppression is correlated with decreased release of TNFalpha from iron-treated infected monocytes. J. Clin. Investig. 1997, 99, 2518-2529. [CrossRef]

141. Gharagozloo, M.; Khoshdel, Z.; Amirghofran, Z. The effect of an iron (III) chelator, silybin, on the proliferation and cell cycle of Jurkat cells: A comparison with desferrioxamine. Eur. J. Pharmacol. 2008, 589, 1-7. [CrossRef] 
142. Lounis, N.; Truffot-Pernot, C.; Grosset, J.; Gordeuk, V.R.; Boelaert, J.R. Iron and Mycobacterium tuberculosis infection. J. Clin. Virol. 2001, 20, 123-126. [CrossRef]

143. Stefanova, D.; Raychev, A.; Arezes, J.; Ruchala, P.; Gabayan, V.; Skurnik, M.; Dillon, B.J.; Horwitz, M.A.; Ganz, T.; Bulut, Y.; et al. Endogenous hepcidin and its agonist mediate resistance to selected infections by clearing non-transferrin-bound iron. Blood 2017, 130, 245-257. [CrossRef]

144. Nicolas, G.; Bennoun, M.; Porteu, A.; Mativet, S.; Beaumont, C.; Grandchamp, B.; Sirito, M.; Sawadogo, M.; Kahn, A.; Vaulont, S. Severe iron deficiency anemia in transgenic mice expressing liver hepcidin. Proc. Natl. Acad. Sci. USA 2002, 99, 4596-4601. [CrossRef] [PubMed]

145. Cairo, G.; Recalcati, S.; Montosi, G.; Castrusini, E.; Conte, D.; Pietrangelo, A. Inappropriately high iron regulatory protein activity in monocytes of patients with genetic hemochromatosis. Blood 1997, 89, 2546-2553. [PubMed]

146. Gomes-Pereira, S.; Rodrigues, P.N.; Appelberg, R.; Gomes, M.S. Increased susceptibility to Mycobacterium avium in hemochromatosis protein HFE-deficient mice. Infect. Immun. 2008, 76, 4713-4719. [CrossRef]

147. Rolph, M.S.; Raupach, B.; Kobernick, H.H.; Collins, H.L.; Perarnau, B.; Lemonnier, F.A.; Kaufmann, S.H. MHC class Ia-restricted $\mathrm{T}$ cells partially account for beta2-microglobulin-dependent resistance to Mycobacterium tuberculosis. Eur. J. Immunol. 2001, 31, 1944-1949. [CrossRef]

148. Kasvosve, I.; Gangaidzo, I.T.; Gomo, Z.A.; Gordeuk, V.R. African iron overload. Acta Clin. Belg. 2000, 55, 88-93. [CrossRef] [PubMed]

149. Gordeuk, V.R. African iron overload. Semin. Hematol. 2002, 39, 263-269. [CrossRef] [PubMed]

150. Gordeuk, V.R.; McLaren, C.E.; MacPhail, A.P.; Deichsel, G.; Bothwell, T.H. Associations of iron overload in Africa with hepatocellular carcinoma and tuberculosis: Strachan's 1929 thesis revisited. Blood 1996, 87, 3470-3476.

151. Gangaidzo, I.T.; Moyo, V.M.; Mvundura, E.; Aggrey, G.; Murphree, N.L.; Khumalo, H.; Saungweme, T.; Kasvosve, I.; Gomo, Z.A.; Rouault, T.; et al. Association of pulmonary tuberculosis with increased dietary iron. J. Infect. Dis. 2001, 184, 936-939. [CrossRef] [PubMed]

152. Minchella, P.A.; Armitage, A.E.; Darboe, B.; Jallow, M.W.; Drakesmith, H.; Jaye, A.; Prentice, A.M.; McDermid, J.M. Elevated hepcidin at HIV diagnosis is associated with incident tuberculosis in a retrospective cohort study. Int. J. Tuberc. Lung Dis. 2014, 18, 1337-1339. [CrossRef]

153. McDermid, J.M.; Hennig, B.J.; van der Sande, M.; Hill, A.V.; Whittle, H.C.; Jaye, A.; Prentice, A.M. Host iron redistribution as a risk factor for incident tuberculosis in HIV infection: An 11-year retrospective cohort study. BMC Infect. Dis. 2013, 13, 48. [CrossRef]

154. Das, B.S.; Devi, U.; Mohan Rao, C.; Srivastava, V.K.; Rath, P.K.; Das, B.S. Effect of iron supplementation on mild to moderate anaemia in pulmonary tuberculosis. Br. J. Nutr. 2003, 90, 541-550.

155. Isanaka, S.; Aboud, S.; Mugusi, F.; Bosch, R.J.; Willett, W.C.; Spiegelman, D.; Duggan, C.; Fawzi, W.W. Iron status predicts treatment failure and mortality in tuberculosis patients: A prospective cohort study from Dar es Salaam, Tanzania. PLoS ONE 2012, 7, e37350. [CrossRef]

156. Chandrasekaran, P.; Saravanan, N.; Bethunaickan, R.; Tripathy, S. Malnutrition: Modulator of Immune Responses in Tuberculosis. Front. Immunol. 2017, 8, 1316. [CrossRef]

157. Chandra, R.K.; Saraya, A.K. Impaired immunocompetence associated with iron deficiency. J. Pediatr. 1975, 86, 899-902. [CrossRef]

158. Joynson, D.H.; Walker, D.M.; Jacobs, A.; Dolby, A.E. Defect of cell-mediated immunity in patients with iron-deficiency anaemia. Lancet 1972, 2, 1058-1059. [CrossRef]

159. Oppenheimer, S.J. Iron and its relation to immunity and infectious disease. J. Nutr. 2001, 131, 616S-633S. [CrossRef]

160. Esan, M.O.; van Hensbroek, M.B.; Nkhoma, E.; Musicha, C.; White, S.A.; Ter Kuile, F.O.; Phiri, K.S. Iron supplementation in HIV-infected Malawian children with anemia: A double-blind, randomized, controlled trial. Clin. Infect. Dis. 2013, 57, 1626-1634. [CrossRef]

161. Sipahi, T.; Akar, N.; Egin, Y.; Cin, S. Serum interleukin-2 and interleukin-6 levels in iron deficiency anemia. Pediatr. Hematol. Oncol. 1998, 15, 69-73. [CrossRef]

162. Rodriguez, L.; Gonzalez, C.; Flores, L.; Jimenez-Zamudio, L.; Graniel, J.; Ortiz, R. Assessment by flow cytometry of cytokine production in malnourished children. Clin. Diagn. Lab. Immunol. 2005, 12, 502-507. [CrossRef] [PubMed] 
163. Hassan, T.H.; Badr, M.A.; Karam, N.A.; Zkaria, M.; El Saadany, H.F.; Abdel Rahman, D.M.; Shahbah, D.A.; Al Morshedy, S.M.; Fathy, M.; Esh, A.M.; et al. Impact of iron deficiency anemia on the function of the immune system in children. Medicine 2016, 95, e5395. [CrossRef] [PubMed]

164. Jabara, H.H.; Boyden, S.E.; Chou, J.; Ramesh, N.; Massaad, M.J.; Benson, H.; Bainter, W.; Fraulino, D.; Rahimov, F.; Sieff, C.; et al. A missense mutation in TFRC, encoding transferrin receptor 1, causes combined immunodeficiency. Nat. Genet. 2016, 48, 74-78. [CrossRef]

165. Deschemin, J.C.; Noordine, M.L.; Remot, A.; Willemetz, A.; Afif, C.; Canonne-Hergaux, F.; Langella, P.; Karim, Z.; Vaulont, S.; Thomas, M.; et al. The microbiota shifts the iron sensing of intestinal cells. FASEB J. 2016, 30, 252-261. [CrossRef] [PubMed]

(C) 2019 by the authors. Licensee MDPI, Basel, Switzerland. This article is an open access article distributed under the terms and conditions of the Creative Commons Attribution (CC BY) license (http://creativecommons.org/licenses/by/4.0/). 
Review

\title{
Tuning the Anti(myco)bacterial Activity of 3-Hydroxy-4-pyridinone Chelators through Fluorophores
}

\author{
Maria Rangel ${ }^{1, *}$, Tânia Moniz ${ }^{2}$, André M. N. Silva ${ }^{2}$ and Andreia Leite ${ }^{2}$ \\ 1 REQUIMTE-LAQV, Instituto de Ciências Biomédicas de Abel Salazar, Universidade do Porto, \\ 4050-313 Porto, Portugal \\ 2 REQUIMTE-LAQV, Departamento de Química e Bioquímica, Faculdade de Ciências, Universidade do Porto, \\ 40169-007 Porto, Portugal; tania.moniz@fc.up.pt (T.M.); andre.silva@fc.up.pt (A.M.N.S.); \\ acleite@fc.up.pt (A.L.) \\ * Correspondence: mcrangel@fc.up.pt; Tel.: +35-122-040-2593
}

Received: 3 October 2018; Accepted: 18 October 2018; Published: 20 October 2018

\begin{abstract}
Controlling the sources of Fe available to pathogens is one of the possible strategies that can be successfully used by novel antibacterial drugs. We focused our interest on the design of chelators to address Mycobacterium avium infections. Taking into account the molecular structure of mycobacterial siderophores and considering that new chelators must be able to compete for $\mathrm{Fe}(\mathrm{III})$, we selected ligands of the 3-hydroxy-4-pyridinone class to achieve our purpose. After choosing the type of chelating unit it was also our objective to design chelators that could be monitored inside the cell and for that reason we designed chelators that could be functionalized with fluorophores. We didn't realize at the time that the incorporation a fluorophore, to allow spectroscopic detection, would be so relevant for the antimycobacterial effect or to determine the affinity of the chelators towards biological membranes. From a biophysical perspective, this is a fascinating illustration of the fact that functionalization of a molecule with a particular label may lead to a change in its membrane permeation properties and result in a dramatic change in biological activity. For that reason we believe it is interesting to give a critical account of our entire work in this area and justify the statement "to label means to change". New perspectives regarding combined therapeutic approaches and the use of rhodamine B conjugates to target closely related problems such as bacterial resistance and biofilm production are also discussed.
\end{abstract}

Keywords: fluorescent iron chelator; 3-hydroxy-4-pyridinone; fluorophore; rhodamine; membrane interactions; bacteria; antibacterial activity

\section{Introduction}

\subsection{Chelators and Iron}

Numerous transition metal ions have proved to be essential for life, though it is well known that transition metals can be toxic. Living organisms have resolved this paradigm by incorporating metal ions in complex biological structures and by developing highly complex regulatory mechanisms to keep the amounts of "free metal ion" available at any time very tiny, thus counteracting toxicity [1].

Chelation is a type of bonding normally used to bind metal ions to biomolecules, namely proteins and nucleic acids, as well as to uptake and/or deliver metal ions. A chelator is a ligand (molecule or anion; Lewis base) that has the capacity to bind a metal ion (Lewis acid) through at least two coordinate bonds. The chemical entity that is formed upon chelation is designated a metal-chelate. There is a large variety of molecules that can act as chelators and which use for chelation: (a) different types of atoms 
$(\mathrm{O}, \mathrm{N}, \mathrm{S})$ providing different coordination spheres and (b) different number of atoms $(2,3,4,6$, etc.) being classified as having different denticity (bidentate, tridentate, tetradentate, hexadentate, etc.).

The affinity of a chelator for a selected metal ion, in a particular oxidation state, is defined by the stability constant $(\log \beta)$ of the respective metal-chelate measured in standard thermodynamic conditions. The enhancement of stability, provided by replacement of ligands of lower denticity by chelators of higher denticity is known as the chelate effect [1].

It is important to bear in mind that, upon chelation the redox potential of the metal ion and protonation constants of the chelator are altered. In the case of iron ( $\mathrm{Fe})$, the first characteristic is particularly important since it allows the fine-tuning of redox potentials by choosing the appropriate ligands thus making it suitable to participate in electron transfer chains and providing an approach to diminish toxicity.

Iron is one of the most abundant elements in Earth's crust, and the most abundant transition metal, being an essential micronutrient for all living organisms [2], with the exceptions of Lactobacilli and Borrelia burgorferi [3-5]. Despite its abundance, the geological availability of Fe is compromised by the fact that the element exists in insoluble chemical forms making its uptake extremely difficult to living organisms. Bacteria and plants obtain iron from the environment by chelation, whereby the element is chemically bound to another substance (siderophore) making the whole complex (Fe-chelate) soluble and available.

Siderophores are chelators produced by living organisms to acquire Fe from the environment in response to a need of the element. More than 500 siderophores have been described and the chemical structure of approximately 260 siderophores is known [6]. Most siderophores are hexadentate chelators bearing hydroxamate (such as desferrioxamine) or catecholate units (such as enterobactin) for which the values of the $\mathrm{Fe}(\mathrm{III})$ stability constants are in the range $30<(\log \beta)<49$. The latter values are $c a 20$ orders of magnitude higher than those regarding the corresponding $\mathrm{Fe}$ (II) chelates thus favouring the release of the metal ion by reduction, a common step in the delivery of Fe into cells [7]. At this point it must be mentioned that, in physiological conditions, judgement of the effectiveness of a chelator to withdraw $\mathrm{Fe}(\mathrm{III})$ from the environment is better achieved by comparison of the respective $\mathrm{pFe}(\mathrm{III})$ $(-\log [\mathrm{Fe}(\mathrm{III})])$ values, which are calculated considering $\mathrm{pH} 7.4$, a total ligand concentration of $10^{-5} \mathrm{M}$ and a total $\mathrm{Fe}$ (III) concentration of $10^{-6} \mathrm{M}[8]$ in opposition to the standard thermodynamic conditions considered for the determination of the stability constant $(\log \beta)$ [9].

Iron is a cofactor in metalloproteins, and is involved in essential biological functions, from DNA biosynthesis and transcription to energy production and central metabolism [10]. The suitability of Fe arises from its unique physico-chemical properties to act in electron transfer, namely the possibility of existing in various oxidation states and the extreme variability of its redox potentials, which can be fine-tuned upon chelation [11,12]. Nevertheless, this redox activity can also be pernicious if the element exists in chemical forms with redox potentials that allow their participation in the generation of reactive oxygen species (ROS) [13].

The maintenance of Fe homeostasis demands a tight control of intracellular and systemic iron levels, which is achieved through sophisticated regulatory mechanisms [14]. Disruption of Fe homeostasis has consequences in the physiopathology and clinical evolution of a significant number of diseases in all medical areas. In clinical practice, and depending on the disease, various therapeutic approaches are used to regain Fe homeostasis and chelation therapy is one of the currently available choices [15-19].

The need to control Fe levels by chelation, in Fe unbalance related diseases, has prompted chemists to synthesize several types of chelators and the increasing knowledge about Fe metabolism and identification of specific targets, has been providing important feedback to the design of new and more effective chelators.

Natural and synthetic Fe chelators have first been used to treat iron overload diseases and at present three types of chelators (desferrioxamine (DFO), desferasirox (DFX) and deferiprone (DFP)) (Figure 1) are used in clinical practice $[18,20-22]$. The use of Fe chelators has been extended to address 
the control of Fe levels in other disease scenarios in which a disruption of $\mathrm{Fe}$ homeostasis has been identified such as inflammation, infection, cancer, neurodegenerative processes and diabetes [23-25].

Although we recognize the importance of the use of chelation therapeutic approaches in many diseases in this work we will focus on infection, particularly on mycobacterial infection.
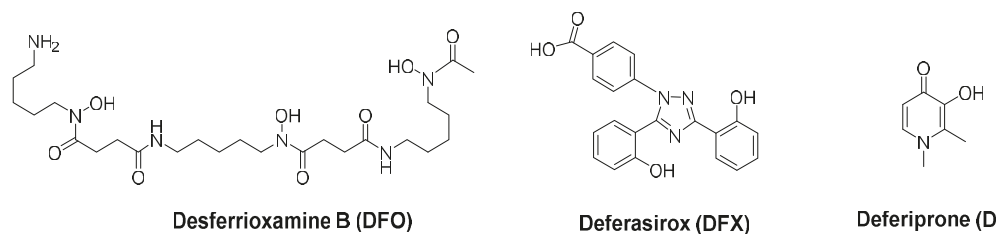

Deferasirox (DFX)

Deferiprone (DFP)

Figure 1. Iron chelators in clinical use: desferrioxamine B (DFO), deferasirox (DFX) and deferiprone (DFP).

\subsection{Iron and Infection}

The sharp control of transition metal ion concentration is of extreme importance in infection scenarios since transition metals are also nutrients for the invading pathogens. As referred above, living organisms counteract transition metal ion toxicity through mechanisms that maintain very tiny amounts of free metal ion available for redox cycling. Similar mechanisms seem to be used by living organisms to withhold nutrients from invading pathogens in a process, which has been termed "nutritional immunity" [26,27].

In fact, it has been described that the withholding of Fe is one of the primary defence mechanisms against pathogenic invaders $[26,28]$. The competition for Fe between pathogens and their hosts is dramatic and pathogenic bacteria have developed survival strategies like residing in specific intracellular niches within the host cell and the ability to use the host Fe sources. Mycobacteria, namely $M$. tuberculosis and M. avium, are examples of intracellular pathogens, being able to inhibit the maturation of phagosomes and taking profit of the host Fe acquisition mechanisms [29].

An increase in the susceptibility to infection was observed in patients suffering from Fe overload related diseases [30]. Due to the high levels of iron available in Haemochromatosis, the disease has been associated with an increased susceptibility to infection by several bacteria [27] such as Yersinia enterocolitica [31] and Vibrio vulnificus [32]. High levels of iron acquired from the diet lead to an exacerbation of M. tuberculosis infection symptoms in both humans and mice [33]. Moreover, it has been shown that iron overloaded haemochromatosis protein (HFE) deficient mice are more susceptible to M. avium infection [34]. These findings were reproduced in macrophages isolated from mice and infected with M. avium [35]. Several studies correlate the iron status in AIDS patients and the susceptibility to mycobacterial infections and experiments have shown that iron overload increases mycobacterial growth in immune-deficient mice [35,36], and iron redistribution towards macrophages in AIDS patients was shown to favour the progress of tuberculosis [37].

Taking advantage of the knowledge on the iron-related interplay between host and the pathogen and the evidence of a nutritional immunity, the development of many different antibacterial approaches based on the destabilisation of iron concentrations accessible for bacteria have been reported [26,38-40].

Amongst others, the process of iron acquisition represents one of the pathways, which can be successfully targeted by new antibacterial drugs and restriction of Fe was shown to improve the outcome of a number of infectious diseases including mycobacterial infections [29,41-44].

Considering that bacteria produce siderophores to gain access to iron from their environment one of the obvious choices to intervene in Fe acquisition is the administration of synthetic chelators that are able to compete with the natural ones. Preferably, from the chemical point of view the structure of new antimicrobial agents should differ from that of natural siderophores in order to prevent the recognition and uptake of the iron-chelate by the pathogens. 


\subsubsection{Iron Chelation-A Therapeutic Tool to Tackle Microbial Infection?}

Several reports have been produced, suggesting the application of chelation therapy for the control of infections [29,38,45-48].

The effect of iron chelators in the treatment of bacterial infections has been extensively investigated and one of the first molecules studied was 8-hydroxyquinoline and its related ligands [49]. Some chelators such as EDHPA, EDTA and DTPA have shown activity against Gram-positive and Gram-negative bacteria (reviewed in [50,51]). The effect of iron chelators against bacterial biofilms has also been proved, for instance in the biofilms produced by Pseudomonas aeruginosa [52-55] or Staphylococcus aureus [56].

The extensively used DFO and DFX have demonstrated antibacterial effect in a numerous range of bacterial pathogens [57-60]. However, these ligands offer some drawbacks. DFX is a tridentate ligand and consequently has lower iron affinity than most bacterial siderophores, which are hexadentate ligands. DFO is a hexadentate natural siderophore and some pathogenic bacteria possess specific receptors for capturing the iron loaded chelator and use the metal ion for their own growth $[59,61,62]$.

To overcome these disadvantages, the antimicrobial activity of chelating units, which are not present in natural siderophores, such as 3,4-HPO ligands, has been considered. DFP has shown efficacy against several bacteria, such as S. aureus and P. aeruginosa [59,62-64]. Other 3,4-HPO, have shown in vitro inhibitory activity against several Gram-positive and Gram-negative bacterial species, including S. aureus, P. aeruginosa and Escherichia coli [40,65-70].

\subsubsection{Mycobacterial Infections}

Mycobacteria

Mycobacterium is a genus of bacteria that comprises several species, such as Mycobacterium tuberculosis and Mycobacterium leprae, responsible for tuberculosis and leprosy. Other mycobacteria are responsible for opportunistic infections in humans and other animals, namely Mycobacterium avium. M. avium complex (MAC) includes M. avium and also the non-tuberculous mycobacteria, such as Mycobacterium intracellulare.

Mycobacterium species can be classified in different groups, according to their growth rate, as slow growers and fast growers. Both $M$. tuberculosis and M. avium are slowly growing mycobacteria while other mycobacteria, such as M. smegmatis comprises the fast growers group [71]. Mycobacteria can also be classified according to their morphotypes as smooth or rough, transparent or opaque. The smooth transparent morphotype is usually related with virulence in mouse while the rough opaque morphotypes was found in AIDS patients [72].

Both, the lipidic composition and the cell envelope architecture contribute to the pathogenicity of these microorganisms [73]. Mycobacteria's cell envelope is a unique and complex structure composed by the plasma membrane, the cell wall and the capsule (Figure 2) [74].

The lipidic composition of the plasma membrane includes different phospholipids and glycolipids embedded in the plasma membrane, Mycobacteria are unusual Gram-positive bacteria in which the cell wall contains peptidoglycan covalently bound to arabinogalactan esterified with long chain mycolic acids. The more external layer of the mycobacterial cell envelope, the capsule, is predominantly composed by glycoproteins, arabinomannan and mannan derived polysaccharides [74,75]. The particular characteristics of the cell envelope, mainly hydrophobicity and impermeability, contribute to the virulence of mycobacteria, constituting a barrier that compromises the uptake of many antibiotics. 


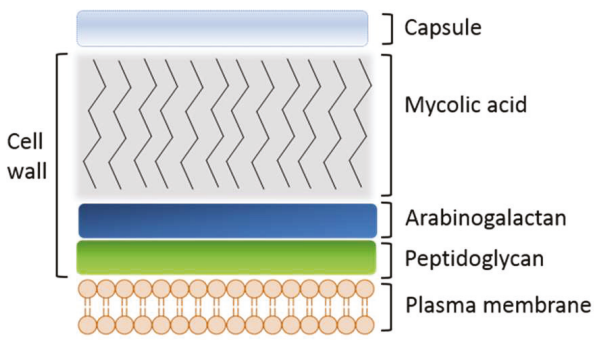

A

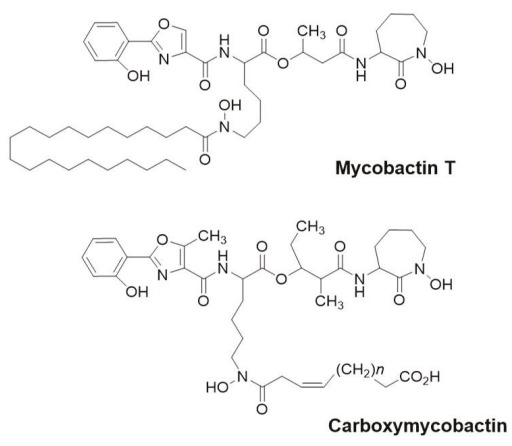

Exochelin MS

Figure 2. Schematic representation of the cell envelope of pathogenic mycobacteria (A, adapted from [74]); Structure of mycobacterial siderophores: Mycobactin T produced by M. tuberculosis (MB T); Carboxymycobactin synthetized for M. avium, M. tuberculosis e M. bovis $(n=2-9)$; Exochelin MS produced for M. smegmatis. (B, adapted from [76-78]).

Both M. tuberculosis and M. avium are facultative intracellular pathogens that reside primarily inside mononuclear phagocytes, namely monocytes and macrophages. These pathogens grow inside vacuoles, the phagosomes, and developed several strategies to survive and resist to host defenses [79-81].

To ensure survival and replication inside the phagosome in infected macrophages, mycobacteria developed strategies to retard phagosome maturation, namely by manipulating the host cell endocytic pathways in order to prevent the fusion of the phagosome with late endosomes and lysosomes [79,82]. Thus, the mycobacteria-containing phagosomes remain with characteristics of an early endosome. The levels of ATPase are low and the vacuole is not acidified (the neutral $\mathrm{pH}$ value is maintained).

\section{Mycobacterial Siderophores}

Mycobacteria have developed systems for sensing and regulating iron levels in the intracellular medium. They produce siderophores for iron acquisition and transport and also synthesize proteins to store the iron recruited from the host [83]. Mycobacteria differ from other bacteria by being able to produce different types of iron ligands, namely lipophilic molecules restricted to the cell envelope (mycobactins) and polar extracellular siderophores (carboxymycobactins and exochelins) [83,84] (Figure 2). $M$. leprae is an exception, lacking the gene cluster $(\mathrm{mbt})$ responsible for the synthesis o mycobactins [85]. Non-pathogenic species, such as Mycobacterium smegmatis and Mycobacterium neoaurum, produce exochelins while pathogenic mycobacteria synthesize carboxymycobactins [86,87]. Mycobactins are salicylate-containing siderophores, which are acylated with long chain fatty acids in order to remain associated with the bacterial membrane. The extracellular siderophores are exochelins, which have a peptide-based structure, and/or carboxymycobactins, in which the long alkyl chain of mycobactin is substituted with a short carboxylated acyl chain (Figure 2). Mycobacterial siderophores are hexadentate ligands possessing chelating units based on the phenyloxazolidine ring, ornithine- derived hydroxamates and salycilates [86]. In addition to their specific siderophores, mycobacteria produce salicylic and citric acids which may also play a role in iron acquisition [88]. 
After production of siderophores and chelation of iron, mycobacteria uptake this element for usage or storage and the mechanism of transport differs according to the type of siderophore and its localization. Mycobactins, located in the membrane, provide high stability constants for the formation of the Fe complex ( $\log \beta \sim 31$ ) [89] and these siderophores are able to remove iron from host proteins, such as transferrin and ferritin. However, due to their localization, the access to these proteins is difficult sometimes compromising acquisition of such iron sources. Thus, mycobactins bind iron previously bound by carboxymycobactins, which are extracellular siderophores, and then transfer the element through the bacterial membrane [76,87].

Several mechanisms to acquire and transport iron bound to mycobactins have been proposed and in an interesting study Groves et al. $[83,90]$ suggest that mycobactins may diffuse into the host macrophage and then mobilize iron available in the intracellular pools of the macrophage. The ferri-mycobactins are then associated to lipid droplets and return to the phagosomes.

In the case of exochelins, these ligands are able to transport iron through the cell membrane [86,91]. Exochelins, like carboxymycobactins, may also transfer iron to mycobactins. Moreover, it is also described in the literature that exochelins are taken up by active transport and access iron from ferritin, Tf and Lf [76,92].

\section{Iron Chelators to Control Mycobacterial Infection}

The use of chelators to control mycobacterial infection by iron deprivation has been successfully tested (reviewed in [16,42]). The use of chelators to restrict the iron available for mycobacterial growth has been reported [87], namely for M. tuberculosis [43,93] and M. avium [42,89,94,95].

DFO has been used to inhibit Mycobacterium aurum growth [96] and another study suggested that $\mathrm{DFO}$ in combination with silybin, an iron-chelating agent from plants, was able to reduce the extracellular growth of $M$. tuberculosis. However, both of these chelators induced slightly effects on the reduction of in intracellular growth of the pathogen [97], DFO also inhibited biofilm formation by M. smegmatis and M. bovis BCG [98].

Other ligands, namely spiro pyridopyrrolizines, pyrrolidines [99] and 4H-pyrano[3,2-c]pyridine derivatives [100], have been tested and the results have shown that the compounds are effective to inhibit the in vitro growth of $M$. tuberculosis. Spiropiperidin-4-ones derivatives also inhibited the growth of $M$. tuberculosis, both in vitro and in vivo [101]. 2-Hydrazinopyrimidin-4(3H)-one derivatives, have been tested against $M$. tuberculosis and several molecules have shown antimycobacterial activity [102].

The antimycobacterial activity of different chelators, namely DFO, HBED, dDFT and VUF-8514 against $M$. avium were investigated [42]. The results show that DFO, HBED e VUF8514 inhibit mycobacterial growth in axenic conditions and HBED and DFO also inhibit M. avium intramacrophagic. In vivo, the administration of DFO or HBED had small effect on the growth of the pathogen. Considering that inhibition of mycobacterial growth was observed in mice fed with a low iron diet, the authors assume that the limited effect of the chelation therapy is a consequence of a lack of efficacy of currently available chelators, stressing the requirement for new molecules, which can target the intracellular compartments where mycobacteria proliferate [73].

Also, the study of the effect of DFP and other 3,4-HPO, namely L1Net, L1NPr and L1NAll in in vitro studies revealed that the influence of the chelators in the replication of M. avium might depend on the tested concentration. Chelators enhanced intracellular and extracellular growth of M. avium at low concentrations. However, at high concentrations, they are effective in the control of M. avium infections [103].

Functionalized tetrahydro- $4(1 \mathrm{H})$-pyridinones have been synthesized and tested revealing in vitro activity against $M$. tuberculosis [104]. These studies, although demonstrating the effectiveness of an iron deprivation strategy to fight proliferation of mycobacteria also pointed out the necessity to design chelators with physico-chemical properties which allow them to reach the infection targets. 
Moreover, at the starting point of our work little was known about the cellular distribution of previously tested chelators thus suggesting the need to synthesize molecules that could be followed inside the cell in order to monitor the chelators pathways inside the cells.

Our research group has designed 3,4-HPO chelators to address M. avium infection and performed studies concerning their antimycobacterial activity, interaction with biological membranes and cellular distribution. In this work we discuss the design of chelators, structure activity relationships, combined therapeutic approaches and forthcoming perspectives regarding other bacterial infection scenarios.

\section{Design of 3-Hydroxy-4-pyridinone Chelators to Address Mycobacterial Infections}

\subsection{Overview}

The design of new antibacterial drugs with diverse modes of action is crucial to counteract bacterial resistance [105-107]. Within this scope, several studies demonstrated that iron deprivation induced by chelators could be a strategy to inhibit the proliferation of pathogenic bacteria but more effective iron chelators able to reach the infection targets are needed.

We focused our interest in the design of chelators to address mycobacterial infection, in particular infection by Mycobacterium avium. Considering the molecular structure of mycobacterial siderophores and bearing in mind that in order to compete for Fe different chelating units, that originate chelators with higher affinity for $\mathrm{Fe}(\mathrm{III})$ are necessary, we selected ligands of the 3-hydroxy-4-pyridinone class to achieve our purpose. This class of chelators and their complexes have proved to be useful in several fields of application [95,108-111]. In what concerns biomedical applications [112,113], Deferiprone (1,2-dimethyl-3-hydroxy-4-pyridinone) is one of the ligands in clinical use to treat iron overload in thalassemia major patients [114-117].

After choosing the type of chelating unit it was also our objective to design chelators that could be monitored inside the cell and for that reason we designed chelators that could be functionalized with fluorophores. We didn't realize at the time that the incorporation a fluorophore would be relevant for the antimycobacterial effect or determine the affinity of the chelators towards biological membranes. From a biophysical perspective, this is a fascinating illustration of the fact that functionalization of a molecule with a particular label, to allow spectroscopic detection, may lead to a change in the membrane permeation properties of the molecule and result in a dramatic change in biological activity.

Interesting works calling the attention for the alterations introduced by fluorophore labelling have been reported [118-125] for cell penetrating peptides (CPP) [123]. Two of the works [118,126] regard the antibacterial properties of rhodamine B-conjugated gelsolin-derived peptides and describe the importance of rhodamine $B$ fluorophore on the interaction of the peptides with the bacterial membrane. The authors demonstrate the existence of a positive correlation between the surface pressure activity of the peptides and its antibacterial function, which is based on membrane disruption.

More recently, two elegant studies report the influence of fluorophore labelling on the cellular distribution and cell viability of a set of CPPs [120] and on their interaction with biological membranes [122]. The studies point out the importance of the fluorophore labeling on the alteration of physicochemical properties and demonstrate the existence of correlations between: (i) physicochemical properties and uptake and toxicity of the CPPs [120] and (ii) physicochemical properties and mode and degree of interaction of CPPs with biological membranes [122]. In the latter study it has been found that the most hydrophobic compounds are those that induce the highest membrane disturbance. For the above reasons we believe it is interesting to give a critical account of our entire work in this area and justify the statement "to label means to change".

\subsection{3-Hydroxy-4-pyridinone (3,4-HPO) Chelators}

3-hydroxy-4-pyridinones are $\mathrm{N}$-heterocyclic compounds in which two adjacent carbonyl and hydroxyl groups provide the two potential coordinating oxygen atoms that confer the characteristics of a bidentate chelator (Figure 3). The 3,4-HPO ligands display superb chelating properties for M(III) 
and $\mathrm{M}(\mathrm{II})$ metal ions and form $\mathrm{M}(3,4-\mathrm{HPO})_{3}$ and $\mathrm{M}(3,4-\mathrm{HPO})_{2}$ neutral metal ion chelates. Since the structure of 3,4-HPO ligands allows modification of their hydrophilic/lipophilic balance (HBL) without significantly changing their metal ion affinity, these ligands are particularly suited for biomedical applications. The variation of the HBL of the ligand is also reflected in their corresponding M-chelates.

The versatile chemical structure of 3,4-HPO bidentate chelators has prompted their extensive use as chelating units to synthesize chelators with higher denticity (such as tetra- and hexadentate chelators) $[89,95,112,113,127,128]$.<smiles>[R]c1cc(=O)c(O)c([R])n1[R1]</smiles>

Figure 3. General formula of the 3,4-HPO bidentate chelating unit.

\subsection{Anti(myco)bacterial Effect in Intramacrophagic Growth of M. avium}

In order to perform a systematic study of 3,4-HPO chelators, and taking into account the results of a previous study regarding the inhibition of intramacrophagic growth of M. avium [42], we organized experiments to screen the influence of several properties of the chelators such as denticity, lipophilicity and structure of anchor molecules used to produce hexadentate chelators.

The results showed that, like deferiprone, none of the seven $N$-alkyl and $N$-aryl bidentate chelators was able to inhibit intramacrophagic growth of $M$. avium. Since the chelators tested exhibit variable lipophilicity we ruled out or the influence of the substituents for this first group of chelators [94]. Hexadentate chelators were synthesized using three types of anchor to bind the chelating bidentate units. One of the anchors (CP256, Figure 4) is based on a tetrahedral carbon atom thus providing an extra binding site further functionalization. This possibility was ideal for the synthesis of fluorescent chelators and being so, compounds labelled with rhodamine B (MRH7 in Figure 4, referred as CP777 in reference [94] and as ligand 4 in reference [89]) and fluorescein derivatives (CP851, CP852, Figure 4) were synthesized and tested against $M$. avium intracellular infection of bone marrow-derived macrophages (BMM).

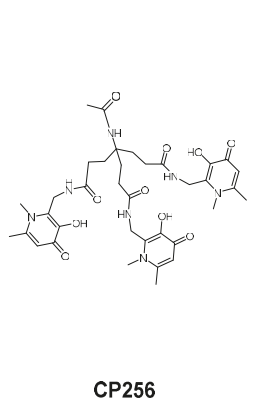

CP256

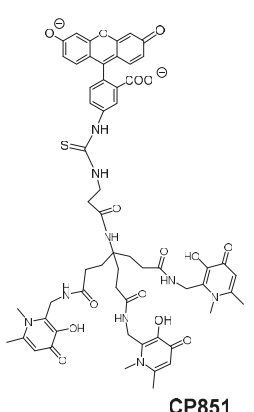

CP851

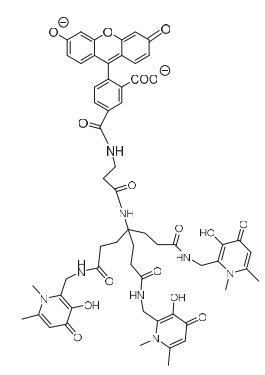

CP852

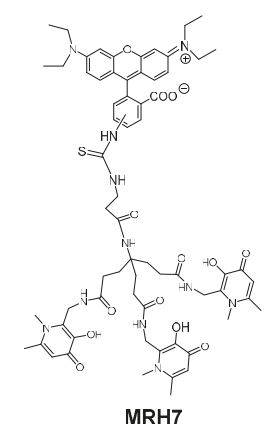

MRH7

Figure 4. Formulae of 3,4-HPO chelators, CP256 (non-fluorescent ligand), CP851, CP852 (green ligands) and MRH7 (red ligand).

The results showed that the chelating unit CP256 did not affect M. avium growth inside BMM but contrastingly the rhodamine B labelled chelator had a clear and reproducible inhibitory effect. In order to confirm that the effect of MRH7 was due to its capacity to chelate Fe we tested a parent chelator in which the chelating units were chemically blocked and the Fe(III) complex of MRH7. Upon addition of the latter compounds we observed no effect in $M$. avium growth. Comparison of the effect of chelators 
labelled with rhodamine B and fluorescein derivatives showed that, although all of them have a better effect than the non-functionalized chelating unit the effect of MRH7 is much better in particular for lower concentrations [94].

The differences in anti(myco)bacterial effect observed between the hexadentate unit and the rhodamine labelled chelator bearing the same chelating unit, were quite fascinating since both compounds have the same affinity for iron $\left(\log \beta\left(\mathrm{Fe}^{3+}\right)=34.4\right.$ and $\left.\mathrm{pFe}^{3+}=29.8\right)$, values which are greater than those of natural siderophores. The results demonstrate that a strong capacity to chelate iron is indispensable but that characteristic alone is not sufficient to inhibit M. avium growth. Moreover, the differences between chelators labelled with two types of fluorophore also suggest that the structure of the fluorescent group may be significant.

At this stage, we hypothesized that the better anti(myco)bacterial effect of the rhodamine B labelled chelator must also be associated with a special ability to penetrate the cell and to gain access to its targets. In order to get insight on such differences we studied the permeation properties and cellular distribution of chelators MRH7 (rhodamine B labelled) and CP852 (fluorescein labelled) [89]. The values of partition coefficients $\left(\log \mathrm{D}_{7.4}\right)$ and of partition constants $\left(K_{\mathrm{P}}\right)$ in liposomes showed that MRH7 is strongly lipophilic and has a strong affinity for lipid bilayers in contrast with CP852. The intracellular distribution of the two chelators is markedly different. Upon 20 min of incubation, chelator MRH7 is widely distributed in the cell and accumulates in phagosomes while CP852 is localized in vesicles and areas proximal to the plasma membrane but not inside phagosomes. The results suggest that the structure of the rhodamine labelled chelator seems to be more suited to progress within the cell and reach the niche that harbours M. avium.

To better understand the influence and consequence of the rhodamine B fragment we designed a hexadentate chelator conjugated with another rhodamine derivative (5(6)-carboxy-tetramethylrhodamine) and the corresponding bidentate chelators labelled with the same fluorophores [95] (Figure 5).
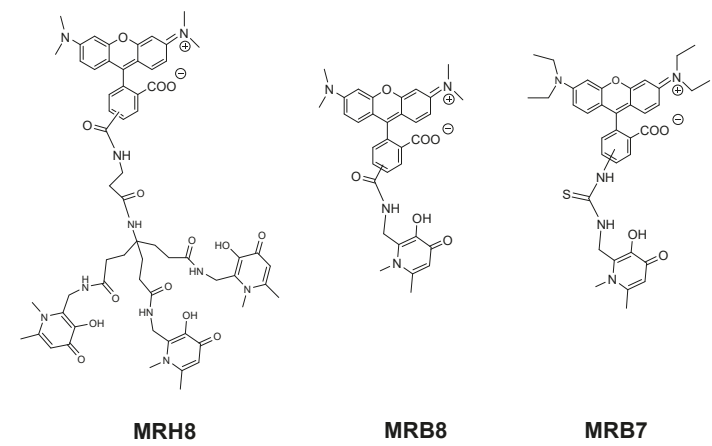

Figure 5. Formulae of fluorescent 3,4-HPO chelators, MRH8, MRB8 and MRB7. The abbreviation and numbering of compounds was assigned according to chelator denticity (MRB $i$ for bidentate and MRH $i$ for hexadentate) and fluorophore $(i=7,8)$.

The results of this new experiment showed that: (a) 5(6)-carboxytetramethylrhodamine- labelled chelators are capable to limit intracellular growth of M. avium; (b) administration of bidentate fluorescent chelators also restricts intracellular $M$. avium growth as long as the concentration used is corrected according to the stoichiometry of the Fe chelate; (c) the antibacterial effect is dependent on the structure of the fluorescent label and (d) the inhibitory effect of the rhodamine B labelled compounds (MRH7 and MRB7) is significantly superior to that observed for the tetramethylrhodamine labelled chelators (MRH8 and MRB8). This result points out the importance of the rhodamine B fluorophore and the thiourea linkage, which has been introduced in the molecular framework by the use of the reagent rhodamine B isothiocyanate in the synthetic procedure. For chelators MRH8 and MRB8 the rhodamine derivative used is 5(6)-carboxytetramethylrhodamine, which introduces an amide linkage. 
The type of linkage present in the chelators was not deliberate, but remarkably, the choice of different types of reagents revealed that apart from the fluorophore, the linkage between chelating unit and fluorophore must also be considered in the chelators 'design. We consider the possible relevance of the thiourea group since: (a) the more efficient chelators contain that type of linkage and (b) the antibacterial properties of isothiocyanate groups against $\mathrm{Gram}(+)$ and $\mathrm{Gram}(-)$ bacteria, which have been related to the capacity of the group to disorder the structure of the bacterial membrane, and are well-known [129-131].

We speculate that the presence of the thiourea linkage in the structure of the chelators may allow the targeting of the bacterial cell wall. This effect would not be related with the restriction of Fe sources but might threat the survival of the pathogen. This hypothesis led us to consider the design and testing of other compounds in which the thiourea linkage is now deliberately included in the molecular framework.

To achieve that purpose we synthesized the set of compounds in Figure 6 and tested their activity against $M$. avium in comparison with that of the lead chelator MRH7 [109]. The results showed that all the fluorescent chelators exhibit antimycobacterial effect and corroborated the relevance of the thiourea linkage, the ethyl substituents on the amino groups of the xanthene ring and the advantage of their associated inclusion in the molecular framework. The rhodamine B labelled chelator MRH7 proved to be the most active compound in controlling of the infection.

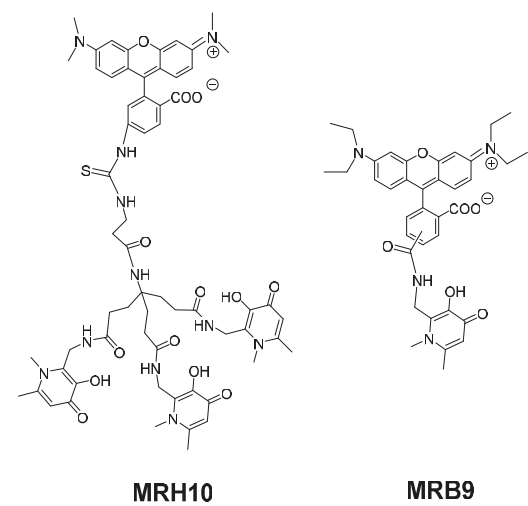

Figure 6. Formulae of fluorescent 3,4-HPO chelators, MRH10 and MRB9. The abbreviation and numbering of compounds was assigned according to chelator denticity (MRBi for bidentate and MRH $i$ for hexadentate) and fluorophore $(i=9-10)$.

In what concerns antimycobacterial infection we think that the next step is the use of combination therapies involving iron chelators and classic antimycobacterial antibiotics in clinical. Such combination allows intervention towards different targets and synergic effects are to be expected. The clinical potential of the combination of iron chelators with other antibiotics has been demonstrated to fight bacterial [39,40,57,58,70], fungal [132] and protozoal [133] infections.

In a first attempt, we investigated the combined administration of chelator MRH7 with the antibiotic ethambutol [109]. Ethambutol, acts by inhibiting the biosynthesis of components of the mycobacterial cell wall [134-136]. The compound is active against M. avium pathogens but high doses are necessary thus suggesting the application of combined therapeutic approaches. The results showed that the concomitant administration of chelator MRH7 and ethambutol is advantageous since a higher antimycobacterial effect is achieved. The results imply that this combination allows reduction of the amount of chelator used to obtain a significant biological effect and improves the activity of ethambutol. 


\subsection{Chelator Membrane Interactions}

In parallel to the antibacterial investigations, biophysical studies regarding the partition and distribution of fluorescein or rhodamine derived chelators have been performed in liposomes membrane models [89,137-139].

Drug-membrane interactions have enormous importance in drug design and the understanding of these interactions at a molecular level allows the development of more effective drugs [140-142]. In the context of $M$. avium infection, the ability of drugs to interact with and cross barriers is particularly important since M. avium is a facultative intracellular pathogen that resides within mammalian cells.

In our studies drug membrane interactions were assessed in liposome model membranes by fluorescence spectroscopy and nuclear magnetic resonance (NMR) and by computational studies, namely molecular dynamic (MD) simulations.

Steady-state fluorescence spectroscopy was used to determine partition constants $\left(K_{\mathrm{P}}\right)$ of chelators MRH7, MRB7, MRH8 and MRB8 in DMPC (1,2-dimyristoyl-sn-glycero-3-phosphocholine) and DMPG (1,2-dimyristoyl-sn-glycero-3-phospho-(1'-rac-glycerol)) liposomes [89,137].

Although we recognize that octanol-water $\log \mathrm{P}$ and $\log \mathrm{D}$ values give important information regarding the hydrophilic/lipophilic balance of a candidate drug, we believe that the values of partitions constants determined in liposome membrane models are more realistic. The values of $K_{P}$ allow a quantification of the interaction of compounds with a lipid bilayer and reflect their preference for the lipid or the aqueous phase. Preparation of liposomes, with lipids of different characteristics allow a better understanding of surface interactions and permeation properties. The values of $\log K_{\mathrm{P}}$ obtained for chelators with different fluorophores and linkages clearly indicate that compounds incorporating $N$-ethyl substituents in the amino groups of the xanthene ring and a thiourea linkage, have a greater affinity for the lipid phase ( $c a 10$ times) than those bearing $N$-methyl substituents and an amide linkage. The results demonstrate that the permeation and partition properties of rhodamine labelled chelators can be tuned by choosing appropriate substituents of the rhodamine moiety.

NMR spectroscopy was also used to determine the affinity of MRB7 and MBR8 for the phospholipid bilayer of DMPC liposomes in order to complement/corroborate the fluorescence studies. The permeation properties of the chelators were assessed by analysis of the alterations of NMR parameters, such as chemical shifts, line shape, spin-lattice relaxation time (T1), and translational diffusion coefficient of the lipids and the liposomes [138,139].

In a first study [138] we used a concentration of chelators within the range of those used in the biological experiments and observed changes in the chemical shifts of the protons associated with the different functional groups of the phospholipid. The latter can be related with a different distribution and location of MRB7 and MRB8 in the phospholipid bilayer of DMPC. The changes in the chemical shift values imply that chelator MRB7 strongly interacts with the choline head groups at the surface of the liposome sphere and is able to permeate deeper and reach the centre of hydrophobic area of the phospholipid bilayer as demonstrated by the significant perturbations of the proton resonances induced on the terminal protons of the acyl chains located in that area. In contrast, MRB8 molecules strongly interact with the polar surface of liposomes and seem to be preferably located between the polar interface and ester groups of the lipid bilayer thus justifying the non-perturbation of the proton resonances belonging to the lipid acyl chains. The presence of $N$-ethyl groups in the xanthene structure and the thiourea link in the structure of MRB7, as opposed to N-methyl groups in the xanthene structure and an amide link in the structure of MRB8, seem to facilitate the affinity of MRB7 molecules to the liposome surface and their ability to penetrate deeper into the hydrophobic interior of lipid bilayer.

A more extensive and detailed NMR analysis was performed using higher concentrations of chelators to allow generation of NMR signals of appropriate intensity for measurements based on the NMR resonance signals of the chelators [139]. This study revealed that these chelators, in particular MRB7, might be able to induce alterations in the structure of the liposome. This result 
is quite relevant since it is indicative that these chelators may be able to disturb the structure of the biological membranes.

MD simulation studies demonstrated that chelators interact with the lipid phases at different levels of the bilayer and that the interaction seems to be reinforced for the compounds that contain $\mathrm{N}$-ethyl groups and a thiourea linkage (MRB7 and MRH7). The rhodamine B labelled chelator MRB7 seems to have a superior insertion and residence time in the hydrophobic region of the membrane bilayer, in comparison to the tetramethylrhodamine labelled chelator MRB8. This observation is consistent with the partition constants determined by fluorescence spectroscopy and mainly with NMR results. Altogether, these results support the hypothesis that the effectiveness of the chelators as anti(myco)bacterials is related to a greater ability to permeate lipid bilayers $[95,138,139]$.

All the biophysical results are indicative that the more effective chelators are those that exhibit higher affinity towards lipid bilayers and better permeation properties across biological membranes. These results are in agreement with those obtained for cell penetrating peptides [118-126] thus reinforcing the idea that the presence of groups that enhance the partition and permeation properties within lipid bilayers is relevant in the design of new antibiotics.

\subsection{Intracellular Distribution and Co-Localization Studies of Rhodamine Labelled Chelators in Macrophages}

Comparison of the intracellular distribution patterns of a rhodamine B labelled chelator (MRH7) and a fluorescein labelled chelator (CP851) in macrophages suggested that distinct uptake and intracellular distributions are likely to account for different efficacy as anti(myco)bacterial agents. To gain insight on the uptake by macrophages and cellular distribution of the set of rhodamine labelled chelators under study we organized new confocal microscopy studies. The results obtained showed that: (i) all the rhodamine labelled chelators are taken up by macrophages; (ii) experiments performed with the same concentration of chelator provide images that suggest that the lipophilicity of the chelators may limit the amount of chelator which is internalized in the cell; (iii) the intracellular distribution and the interaction of the chelators with different cellular compartments within macrophages are similar for all tested chelators; (iv) the rhodamine labelled chelators are able to target the phagosome compartment (v) considering the similarity of the chelators' distribution patterns in the macrophage and its subcellular compartments, the pathways of all chelators appear to be the same although a considerably higher number of rhodamine B isothiocyanate derived chelators seems to cross the membrane in the same time frame as illustrated in Figure 7.

The concurrent incorporation of $\mathrm{N}$-ethyl substituents on the amino groups of the xanthene ring of rhodamine and of a thiourea linkage between chelating unit and the fluorophore produces chelators with enhanced permeation properties and which are superiorly up taken by macrophages. The latter chelators proved to be the most efficient in inhibiting the intramacrophagic growth of M. avium.

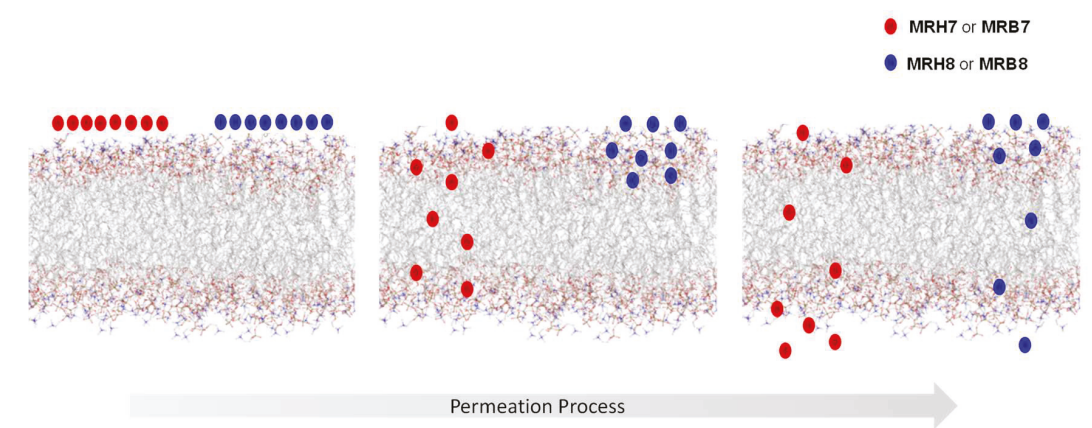

Figure 7. Scheme of a assumed mode of interaction and progress of the rhodamine labelled 3,4-HPO chelators, MRH7 and MRB7 (red) and MRH8 and MRB8 (blue) through the biological membranes, along the permeation process. 


\subsection{Suggested Mechanism in M. avium Infection}

The confocal microscopy studies are indicative that the rhodamine labelled chelators are able to target the phagosome compartment and are likely to preferentially reside in lipid environments. This result is quite relevant since the targeting of the phagosomal compartment was one of our goals. Since we realized that the presence of the fluorophores on the chelators molecular framework is crucial to target the phagosome we hypothesize that the role of rhodamine fluorophore is: (a) to enhance the chelators uptake by the macrophage; (b) to allow access to the phagosome and (c) to efficiently anchor the chelator in the outer and inner parts of the phagosomal membrane thus allowing an efficient competition with natural siderophores and restrict the iron supplies compromising the survival of bacteria (Figure 8). Considering this assumed role of the chelator fluorescent moiety, the better results obtained for the rhodamine B isothiocyanate labelled chelators can be assigned to their higher hydrophobicity and affinity for lipid bilayers.
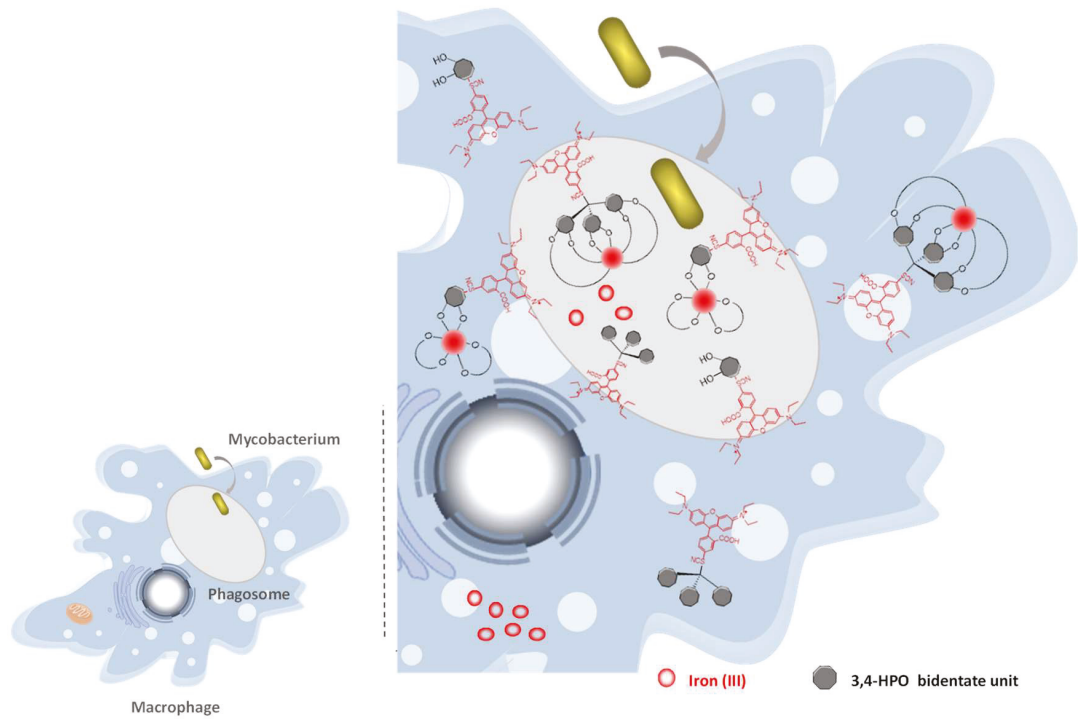

Figure 8. Outline of a hypothetical mechanism for the ironing-out effect produced by the rhodamine labelled 3,4-HPO chelators.

\subsection{First Studies in a Different Infection Scenario}

As previously referred there is an urgent need to develop new antibiotics that may act on different targets to counteract bacterial resistance. Within this scope, we believe that the use of chelators that are able to deprive bacteria from $\mathrm{Fe}$, can be a choice since the antibiotics currently in use do not target Fe metabolism.

Considering the results obtained in $M$. avium infection, we first investigated the activity of the same set of rhodamine labelled 3,4-HPO chelators towards a selected set of Gram (+/-) bacteria [143]. The results obtained showed that the activity of the fluorescent chelators in this new scenario is quite distinct from the observed in $M$. avium. We found that in Gram (+/-) bacteria only hexadentate chelators have a significant effect.

Regarding the results obtained with the hexadentate chelators we found that MRH7, MRH8, and MRH10 inhibit bacterial growth of Staphylococcus (S). aureus ATCC 25923 and S. epidermis ATCC 12228. The hexadentate chelator MRH7 is the only one that is able to inhibit the growth of Escherichia (E.) coli ATCC 25922. The relevance of the type of fluorophore that provides the thiourea linkage and $N$-ethyl substituents on the xanthene ring was confirmed. Curiously, MRH7 was the only chelator able to have 
an effect towards Gram (-). Chelator MRH7 exhibits the higher partition constant in liposomes and proved to be able to permeate lipid bilayers [137].

At this point it is interesting to bear in mind the different complexity and composition of Gram $(+)$ or Gram (-) bacterial cell walls. Gram (-) bacteria may be less accessible for the penetration of the chelators and the superior permeation properties like of MRH7 may be relevant to understand the result. However, further studies are necessary to establish structure-activity relationships.

For the same type of bacteria, we also investigated the activity of a new 3,4-HPO bidentate chelator labelled with a rosamine xanthene fluorophore (MRB20, Figure 9) in order to evaluate the effect of the chelators' charge [144]. The rosamine fluorophore is structurally related with the previously described rhodamine moieties but lacks one carboxylic acid substituent thus implying that the overall charge of the chelator is positive, at $\mathrm{pH}=7.4$, in contrast with the neutral charge of rhodamine labelled chelators. Chelator MRB20 revealed a promising antibacterial activity against Gram (+) strains including clinically relevant species as S. aureus, S. epidermidis, Enterococcus (E.) faecium and E. faecalis [144].

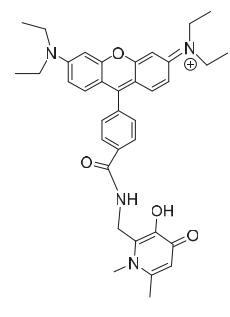

MRB20

Figure 9. Formula of rosamine-derived 3,4-HPO chelator, MRB20.

\section{Concluding Remarks and Future Perspectives}

The challenge that gave rise to the work described was "to design Fe chelators to ironing out mycobacteria". We consider that the objective was achieved and the work gave a significant contribution to produce chelators with adequate properties for macrophage uptake and distribution inside the cell.

The choice of the class of ligands seems to be adequate since the chelating units are able to compete with mycobacterial siderophores. Although determinant, this chelating capacity is not sufficient to achieve anti(myco)bacterial effect.

The labelling of the chelating unit with xanthene fluorophores proved to be crucial for the anti(myco)bacterial activity. Moreover, we found that the type of linkage that binds fluorophores to the chelating unit also seems to have an effect in anti(myco)bacterial activity . Fluorescein labelled chelators proved to be much less effective than the rhodamine parent compounds. For the latter group we found that the anti(myco)bacterial effect is dependent on the substituents of the xanthene ring groups. For rhodamine labelled chelators the simultaneous presence of $\mathrm{N}$-ethyl substituents on the amino groups of the xanthene ring and a thiourea linkage between chelating unit and the fluorophore, produces chelators with enhanced anti(myco)bacterial effect. The same chelators also have the better permeation properties across biological membranes and are superiorly up taken by macrophages. These results point out the significance of the conjugation of a rhodamine B label to the chelator through a thiourea link and suggest that the high affinity of rhodamine B towards lipid phases may be determinant to situate the chelator in a favourable position to successfully compete with mycobacterial siderophores.

We conclude that the effectiveness of the chelators to inhibit the intramacrophagic growth of M. avium is strongly dependant on its capacity to interact with and reside in the lipid bilayers. This capacity seems to provide better conditions to deprive mycobacteria from Fe. Confocal microscopy studies proved that rhodamine labelled chelators have access and are able to remain in to the phagosomal compartment, thus corroborating our hypothesis. 
It may be relevant to refer that, even though we performed confocal microscopy studies with genetically modified green mycobacteria we never observed co-localization of the red chelator MRH7 and the bacteria. The mode of action may not include the crossing of the bacterial cell-wall but its function may be just ironing out the phagosome or create a gradient between the various macrophage iron pools. However, as the fluorescence of MRH7 is quenched upon chelation of Fe we cannot exclude the possibility that the chelator reaches M. avium where it resides as a non-fluorescent Fe-chelate, which we are not able to detect.

In order to complement the studies described herein and regarding M. avium infection, we consider that we need to investigate the toxicity of these chelators in several conditions and also to test the chelators in in vivo models. The first results obtained in Gram (+/ -) infection scenarios encourage the pursuit of further studies and point out the need to explore the variety of functional groups and charge of the new molecules, as discussed in Section 2.7.

In the studied systems, it was found that chelators that presented a higher capacity to interact with biological membranes also lead to an increased antibacterial effect. In Table 1 we summarize all results regarding the antibacterial effect and partition properties in biological membranes obtained with this set of chelators together with their structural features.

Our results corroborate the findings of other authors [120,122] regarding the modifications induced by the introduction of fluorescent labels in the physico-chemical, biophysical and biological properties of a molecule. Moreover, the results also point out that the choice of reagent derivatives used in the synthesis of the fluorescent molecules may introduce functional groups that further enrich the molecule. The results reviewed herein illustrate the consequence of small changes in the structure of the biological relevant molecules and the influence that these modifications might have in drugmembrane interactions and biological activity.

Table 1. Summary of the antibacterial activity, structural features and membrane interaction of the fluorescent chelators. (0-no effect; +-low; ++ moderate; +++-high; ++++ very high effect; nd-not determined).

\begin{tabular}{|c|c|c|c|c|c|c|c|}
\hline \multirow[b]{2}{*}{ Chelator } & \multicolumn{2}{|c|}{ Structural Features } & \multirow[b]{2}{*}{$\begin{array}{c}\text { Charge } \\
\text { (at } \mathrm{pH}=7.4 \text { ) }\end{array}$} & \multicolumn{2}{|c|}{ Antibacterial Activity } & \multirow{2}{*}{$\begin{array}{l}\text { Membrane } \\
\text { Interaction }\end{array}$} & \multirow[b]{2}{*}{ Ref. } \\
\hline & $\begin{array}{c}\text { Type of } \\
\text { Fluorophore }\end{array}$ & Linker & & M. avium & $\begin{array}{l}\text { Gram } \\
(+/-)\end{array}$ & & \\
\hline MRB7 & & Thiourea & Neutral & ++++ & 0 & ++ & \\
\hline MRH7 & & Thiourea & Neutral & ++++ & +++ & +++ & \\
\hline MRB8 & & Amide & Neutral & + & 0 & + & $a$ \\
\hline MRH8 & & Amide & Neutral & + & + & + & \\
\hline MRB9 & & Amide & Neutral & ++ & 0 & nd & \\
\hline MRH10 & & Thiourea & Neutral & +++ & ++ & nd & \\
\hline MRB20 & & Amide & Positive & 0 & ++++ & nd & c \\
\hline
\end{tabular}

(a) $[95,137-139,143,144] ;$ (b) $[109,143] ;$ (c) $[144,145]$. 
Considering our results in conjunction with others described in the literature, namely those related with rhodamine derived liposome tags [146], mitochondrial probes [147] and antimicrobial peptides $[118,120,122,123,126]$, some other topics can be further explored.

We believe it is worth to investigate the use of rhodamine B conjugates to target mycobacterial infections and closely related problems such as bacterial resistance and biofilm production. Rhodamine $B$ has the advantage of being a fluorescent molecule whose properties are sensitive to its environment thus allowing following its pathway within the cell. Also, it is well known that the formation of biofilms is associated with a hydrated extracellular matrix composed by polysaccharides, nuclei acids, lipids and metal ions. We think that the use of 3,4-HPO chelators could have an effect in the disruption of biofilms produced by several bacterial strains and insight in this area are meaningful. A graphical representation of past and future fields of application of rhodamine B conjugates is depicted in Figure 10.

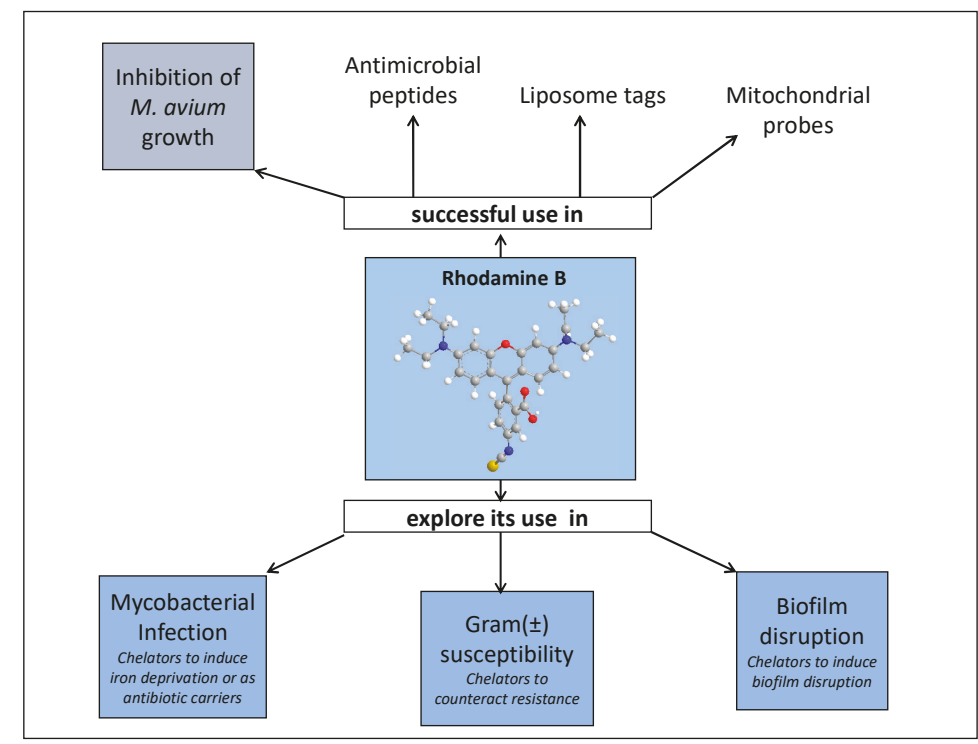

Figure 10. A graphical representation of past and future fields of application of rhodamine B conjugates.

Funding: This work was supported by the European Union (FEDER funds through COMPETE) under the framework of QREN through Project NORTE-07-0124-FEDER-000066 and NORTE-01-0145-FEDER-000024, and also through the European Union (FEDER funds through COMPETE) and National Funds (FCT, Fundação para a Ciência e Tecnologia) under the Partnership Agreement PT2020 through projects NORTE-07-0162-FEDER-000048 UID/QUI/50006/2013 and UID/QUI/50006/2013-POCI/01/0145/FEDER/007265 (LAQV/REQUIMTE). T. Moniz and A. Leite thank FCT for their grants, SFRH/BD/79874/2011 and SFRH/BPD/85793/2012, respectively. To all financing sources, the authors are greatly indebted.

Acknowledgments: The authors are also greatly indebted to all collaborators that somehow provided contributions to this work. This review paper is dedicated to Maria de Sousa.

Conflicts of Interest: The authors declare no conflict of interest.

\section{References}

1. Bertini, P.I.; Bertini, I.; Gray, H.B.; Gray, P.H.; Stiefel, E.I.; Stiefel, P.E.; Valentine, J.S. Biological Inorganic Chemistry: Structure and Reactivity (Tutorial II-Fundamentals of Coordination Chemistry), 1st ed.; University Science Books: Sausalito, CA, USA, 2007; ISBN 1-891389-43-2.

2. Crichton, R. Iron Metabolism: From Molecular Mechanisms to Clinical Consequences, 3rd ed.; John Wiley \& Sons Ltd.: Chichester, West Sussex, UK, 2009; ISBN 978-0-470-01028-0. 
3. Latunde-Dada, G.O. Iron metabolism: Microbes, mouse, and man. Bioessays 2009, 31, 1309-1317. [CrossRef] [PubMed]

4. Archibald, F. Lactobacillus plantarum, an organism not requiring iron. FEMS Microbiol. Lett. 1983, 19, 29-32. [CrossRef]

5. Posey, J.E.; Gherardini, F.C. Lack of a role for iron in the Lyme disease pathogen. Science 2000, 288, 1651-1653. [CrossRef] [PubMed]

6. Hider, R.C.; Kong, X. Chemistry and biology of siderophores. Nat. Prod. Rep. 2010, 27, 637-657. [CrossRef] [PubMed]

7. Boukhalfa, H.; Crumbliss, A.L. Chemical aspects of siderophore mediated iron transport. Biometals 2002, 15, 325-339. [CrossRef] [PubMed]

8. Raymond, K.; Müller, G.; Matzanke, B. Complexation of iron by siderophores a review of their solution and structural chemistry and biological function. Top. Curr. Chem. 1984, 123, 49-102.

9. Dhungana, S.; Harrington, J.M.; Gebhardt, P.; Mollmann, U.; Crumbliss, A.L. Iron chelation equilibria, redox, and siderophore activity of a saccharide platform ferrichrome analogue. Inorg. Chem. 2007, 46, 8362-8371. [CrossRef] [PubMed]

10. Oliveira, F.; Rocha, S.; Fernandes, R. Iron metabolism: From health to disease. J. Clin. Lab. Anal. 2014, 28, 210-218. [CrossRef] [PubMed]

11. Crichton, R.R.; Pierre, J.L. Old iron, young copper: From Mars to Venus. Biometals 2001, 14, 99-112. [CrossRef] [PubMed]

12. Lippard, S.J.; Berg, J.M. Principles of Bioinorganic Chemistry, 1st ed.; University Science Books: Mill Valley, CA, USA, 1994; ISBN 100935702725.

13. Valko, M.; Morris, H.; Cronin, M.T. Metals, toxicity and oxidative stress. Curr. Med. Chem. 2005, 12, 1161-1208. [CrossRef] [PubMed]

14. Bogdan, A.R.; Miyazawa, M.; Hashimoto, K.; Tsuji, Y. Regulators of Iron Homeostasis: New Players in Metabolism, Cell Death, and Disease. Trends Biochem. Sci. 2016, 41, 274-286. [CrossRef] [PubMed]

15. Fischer, R.; Longo, F.; Nielsen, P.; Engelhardt, R.; Hider, R.C.; Piga, A. Monitoring long-term efficacy of iron chelation therapy by deferiprone and desferrioxamine in patients with beta-thalassaemia major: Application of SQUID biomagnetic liver susceptometry. Br. J. Haematol. 2003, 121, 938-948. [CrossRef] [PubMed]

16. Cronje, L.; Bornman, L. Iron overload and tuberculosis: A case for iron chelation therapy. Int. J. Tuberc. Lung Dis. 2005, 9, 2-9. [PubMed]

17. Budimir, A. Metal ions, Alzheimer's disease and chelation therapy. Acta Pharm. 2011, 61, 1-14. [CrossRef] [PubMed]

18. Guariglia, R.; Martorelli, M.C.; Villani, O.; Pietrantuono, G.; Mansueto, G.; D'Auria, F.; Grieco, V.; Bianchino, G.; Lerose, R.; Bochicchio, G.B.; et al. Positive effects on hematopoiesis in patients with myelodysplastic syndrome receiving deferasirox as oral iron chelation therapy: A brief review. Leuk. Res. 2011, 35, 566-570. [CrossRef] [PubMed]

19. Rombout-Sestrienkova, E.; van Kraaij, M.G.J.; Koek, G.H. How we manage patients with hereditary haemochromatosis. Br. J. Haematol. 2016, 175, 759-770. [CrossRef] [PubMed]

20. Ceci, A.; Baiardi, P.; Felisi, M.; Cappellini, M.D.; Carnelli, V.; De Sanctis, V.; Galanello, R.; Maggio, A.; Masera, G.; Piga, A.; et al. The safety and effectiveness of deferiprone in a large-scale, 3-year study in Italian patients. Br. J. Haematol. 2002, 118, 330-336. [CrossRef] [PubMed]

21. Sharpe, P.C.; Richardson, D.R.; Kalinowski, D.S.; Bernhardt, P.V. Synthetic and natural products as iron chelators. Curr. Top. Med. Chem. 2011, 11, 591-607. [CrossRef] [PubMed]

22. Porter, J.; Gyparaki, M.; Burke, L.; Huehns, E.; Sarpong, P.; Saez, V.; Hider, R. Iron mobilization from hepatocyte monolayer cultures by chelators: The importance of membrane permeability and the iron-binding constant. Blood 1988, 72, 1497-1503. [PubMed]

23. Weinberg, E.D. Iron Out-of-Balance: A Risk Factor for Acute and Chronic Diseases. Hemoglobin 2008, 32, 117-122. [CrossRef] [PubMed]

24. Sebastiani, G.; Pantopoulos, K. Disorders associated with systemic or local iron overload: From pathophysiology to clinical practice. Metallomics 2011, 3, 971-986. [CrossRef] [PubMed]

25. Torti, S.V.; Torti, F.M. Iron and cancer: More ore to be mined. Nat. Rev. Cancer 2013, 13, 342-355. [CrossRef] [PubMed] 
26. Hood, M.I.; Skaar, E.P. Nutritional immunity: Transition metals at the pathogen-host interface. Nat. Rev. Microbiol. 2012, 10, 525-537. [CrossRef] [PubMed]

27. Becker, K.W.; Skaar, E.P. Metal limitation and toxicity at the interface between host and pathogen. FEMS Microbiol. Rev. 2014, 38, 1235-1249. [CrossRef] [PubMed]

28. Skaar, E.P. The Battle for Iron between Bacterial Pathogens and Their Vertebrate Hosts. PLoS Pathog. 2010, 6, e1000949. [CrossRef] [PubMed]

29. Schaible, U.E.; Kaufmann, S.H.E. Iron and microbial infection. Nat. Rev. Microbiol. 2004, 2, $946-953$. [CrossRef] [PubMed]

30. Khan, F.A.; Fisher, M.A.; Khakoo, R.A. Association of hemochromatosis with infectious diseases: Expanding spectrum. Int. J. Infect. Dis. 2007, 11, 482-487. [CrossRef] [PubMed]

31. Höpfner, M.; Nitsche, R.N.; Rohr, A.; Harms, D.; Schubert, S.; Fölsch, U.R. Yersinia enterocolitica Infection with Multiple Liver Abscesses Uncovering a Primary Hemochromatosis. Scand. J. Gastroenterol. 2001, 36, 220-224. [CrossRef] [PubMed]

32. Barton, J.C.; Acton, R.T. Hemochromatosis and Vibrio vulnificus Wound Infections. J. Clin. Gastroenterol. 2009, 43, 890-893. [CrossRef] [PubMed]

33. Gangaidzo, I.T.; Moyo, V.M.; Mvundura, E.; Aggrey, G.; Murphree, N.L.; Khumalo, H.; Saungweme, T.; Kasvosve, I.; Gomo, Z.A.; Rouault, T.; et al. Association of pulmonary tuberculosis with increased dietary iron. J. Infect. Dis. 2001, 184, 936-939. [CrossRef] [PubMed]

34. Gomes-Pereira, S.; Rodrigues, P.N.; Appelberg, R.; Gomes, M.S. Increased susceptibility to Mycobacterium avium in hemochromatosis protein HFE-deficient mice. Infect. Immun. 2008, 76, 4713-4719. [CrossRef] [PubMed]

35. Gomes, M.S.; Boelaert, J.R.; Appelberg, R. Role of iron in experimental Mycobacterium avium infection. J. Clin. Virol. 2001, 20, 117-122. [CrossRef]

36. De Monye, C.; Karcher, D.S.; Boelaert, J.R.; Gordeuk, V.R. Bone marrow macrophage iron grade and survival of HIV-seropositive patients. AIDS 1999, 13, 375-380. [CrossRef] [PubMed]

37. McDermid, J.M.; Hennig, B.J.; van der Sande, M.; Hill, A.V.; Whittle, H.C.; Jaye, A.; Prentice, A.M. Host iron redistribution as a risk factor for incident tuberculosis in HIV infection: An 11-year retrospective cohort study. BMC Infect. Dis. 2013, 13, 48. [CrossRef] [PubMed]

38. Foley, T.L.; Simeonov, A. Targeting iron assimilation to develop new antibacterials. Expert Opin. Drug Discov. 2012, 7, 831-847. [CrossRef] [PubMed]

39. Luo, G.; Spellberg, B.; Gebremariam, T.; Lee, H.; Xiong, Y.Q.; French, S.W.; Bayer, A.; Ibrahim, A.S. Combination therapy with iron chelation and vancomycin in treating murine staphylococcemia. Eur. J. Clin. Microbiol. Infect. Dis. 2014, 33, 845-851. [CrossRef] [PubMed]

40. Zhu, C.F.; Qiu, D.H.; Kong, X.L.; Hider, R.C.; Zhou, T. Synthesis and in-vitro antimicrobial evaluation of a high-affinity iron chelator in combination with chloramphenicol. J. Pharm. Pharmacol. 2013, 65, 512-520. [CrossRef] [PubMed]

41. Neres, J.; Labello, N.P.; Somu, R.V.; Boshoff, H.I.; Wilson, D.J.; Vannada, J.; Chen, L.; Barry, C.E., III; Bennett, E.M.; Aldrich, C.C. Inhibition of siderophore biosynthesis in Mycobacterium tuberculosis with nucleoside bisubstrate analogues: Structure-activity relationships of the nucleobase domain of 5'-O-[N-(salicyl)sulfamoyl]adenosine. J. Med. Chem. 2008, 51, 5349-5370. [CrossRef] [PubMed]

42. Gomes, M.S.; Dom, G.; Pedrosa, J.; Boelaert, J.R.; Appelberg, R. Effects of iron deprivation on Mycobacterium avium growth. Tuber. Lung Dis. 1999, 79, 321-328. [CrossRef] [PubMed]

43. Lounis, N.; Truffot-Pernot, C.; Grosset, J.; Gordeuk, V.R.; Boelaert, J.R. Iron and Mycobacterium tuberculosis infection. J. Clin. Virol. 2001, 20, 123-126. [CrossRef]

44. Douvas, G.S.; May, M.H.; Crowle, A.J. Transferrin, iron, and serum lipids enhance or inhibit Mycobacterium avium replication in human macrophages. J. Infect. Dis. 1993, 167, 857-864. [CrossRef] [PubMed]

45. Zhou, T.; Ma, Y.; Kong, X.; Hider, R.C. Design of iron chelators with therapeutic application. Dalton Trans. 2012, 41, 6371-6389. [CrossRef] [PubMed]

46. Bilitewski, U.; Blodgett, J.A.V.; Duhme-Klair, A.K.; Dallavalle, S.; Laschat, S.; Routledge, A.; Schobert, R. Chemical and Biological Aspects of Nutritional Immunity-Perspectives for New Anti-Infectives that Target Iron Uptake Systems. Angew. Chem. Int. Ed. 2017, 56, 14360-14382. [CrossRef] [PubMed]

47. Sheth, S. Iron chelation: An update. Curr. Opin. Hematol. 2014, 21, 179-185. [CrossRef] [PubMed] 
48. Ji, C.; Juárez-Hernández, R.E.; Miller, M.J. Exploiting bacterial iron acquisition: Siderophore conjugates. Future Med. Chem. 2012, 4, 297-313. [CrossRef] [PubMed]

49. Albert, A.; Rubbo, S.D.; Goldacre, R.J.; Balfour, B.G. The Influence of Chemical Constitution on Antibacterial Activity. Part III: A Study of 8-Hydroxyquinoline (Oxine) and Related Compounds. Br. J. Exp. Pathol. 1947, 28, 69-87. [PubMed]

50. Chew, B.P.; Tjoelker, L.W.; Tanaka, T.S. In vitro growth inhibition of mastitis causing bacteria by phenolics and metal chelators. J. Dairy Sci. 1985, 68, 3037-3046. [CrossRef]

51. Bergan, T.; Klaveness, J.; Aasen, A.J. Chelating Agents. Chemotherapy 2001, 47, 10-14. [CrossRef] [PubMed]

52. Reid, D.W.; O’May, C.; Kirov, S.M.; Roddam, L.; Lamont, I.L.; Sanderson, K. Iron chelation directed against biofilms as an adjunct to conventional antibiotics. Am. J. Physiol. Lung Cell Mol. Physiol. 2009, 296, L857-L858. [CrossRef] [PubMed]

53. Musk, D.J., Jr.; Hergenrother, P.J. Chelated iron sources are inhibitors of Pseudomonas aeruginosa biofilms and distribute efficiently in an in vitro model of drug delivery to the human lung. J. Appl. Microbiol. 2008, 105, 380-388. [CrossRef] [PubMed]

54. Sobke, A.; Klinger, M.; Hermann, B.; Sachse, S.; Nietzsche, S.; Makarewicz, O.; Keller, P.M.; Pfister, W.; Straube, E. The urinary antibiotic 5-nitro-8-hydroxyquinoline (Nitroxoline) reduces the formation and induces the dispersal of Pseudomonas aeruginosa biofilms by chelation of iron and zinc. Antimicrob. Agents Chemother. 2012, 56, 6021-6025. [CrossRef] [PubMed]

55. Liu, Y.; Yang, L.; Molin, S. Synergistic activities of an efflux pump inhibitor and iron chelators against Pseudomonas aeruginosa growth and biofilm formation. Antimicrob. Agents Chemother. 2010, 54, 3960-3963. [CrossRef] [PubMed]

56. Lin, M.-H.; Shu, J.-C.; Huang, H.-Y.; Cheng, Y.-C. Involvement of Iron in Biofilm Formation by Staphylococcus aureus. PLoS ONE 2012, 7, e34388. [CrossRef]

57. Van Asbeck, B.S.; Marcelis, J.H.; van Kats, J.H.; Jaarsma, E.Y.; Verhoef, J. Synergy between the iron chelator deferoxamine and the antimicrobial agents gentamicin, chloramphenicol, cefalothin, cefotiam and cefsulodin. Eur. J. Clin. Microbiol. 1983, 2, 432-438. [CrossRef] [PubMed]

58. Neupane, G.P.; Kim, D.M. In vitro time-kill activities of ciprofloxacin alone and in combination with the iron chelator deferasirox against Vibrio vulnificus. Eur. J. Clin. Microbiol. Infect. Dis. 2010, 29, 407-410. [CrossRef] [PubMed]

59. Chan, G.C.; Chan, S.; Ho, P.L.; Ha, S.Y. Effects of chelators (deferoxamine, deferiprone and deferasirox) on the growth of Klebsiella pneumoniae and Aeromonas hydrophila isolated from transfusion-dependent thalassemia patients. Hemoglobin 2009, 33, 352-360. [CrossRef] [PubMed]

60. Neupane, G.P.; Kim, D.M. Comparison of the effects of deferasirox, deferiprone, and deferoxamine on the growth and virulence of Vibrio vulnificus. Transfusion 2009, 49, 1762-1769. [CrossRef] [PubMed]

61. Collins, H.L.; Kaufmann, S.H.; Schaible, U.E. Iron chelation via deferoxamine exacerbates experimental salmonellosis via inhibition of the nicotinamide adenine dinucleotide phosphate oxidase-dependent respiratory burst. J. Immunol. 2002, 168, 3458-3463. [CrossRef] [PubMed]

62. Thompson, M.G.; Corey, B.W.; Si, Y.; Craft, D.W.; Zurawski, D.V. Antibacterial activities of iron chelators against common nosocomial pathogens. Antimicrob. Agents Chemother. 2012, 56, 5419-5421. [CrossRef] [PubMed]

63. Visca, P.; Bonchi, C.; Minandri, F.; Frangipani, E.; Imperi, F. The dual personality of iron chelators: Growth inhibitors or promoters? Antimicrob. Agents Chemother. 2013, 57, 2432-2433. [CrossRef] [PubMed]

64. Kim, C.M.; Shin, S.H. Effect of iron-chelator deferiprone on the in vitro growth of staphylococci. J. Korean Med. Sci. 2009, 24, 289-295. [CrossRef] [PubMed]

65. Zhou, Y.-J.; Liu, M.-S.; Osamah, A.R.; Kong, X.-L.; Alsam, S.; Battah, S.; Xie, Y.-Y.; Hider, R.C.; Zhou, T. Hexadentate 3-hydroxypyridin-4-ones with high iron(III) affinity: Design, synthesis and inhibition on methicillin resistant Staphylococcus aureus and Pseudomonas strains. Eur. J. Med. Chem. 2015, 94, 8-21. [CrossRef] [PubMed]

66. Zhang, M.X.; Zhu, C.F.; Zhou, Y.J.; Kong, X.L.; Hider, R.C.; Zhou, T. Design, Synthesis, and Antimicrobial Evaluation of Hexadentate Hydroxypyridinones with High Iron(III) Affinity. Chem. Biol. Drug Des. 2014, 84, 659-668. [CrossRef] [PubMed]

67. Qiu, D.-H.; Huang, Z.-L.; Zhou, T.; Shen, C.; Hider, R.C. In vitro inhibition of bacterial growth by iron chelators. FEMS Microbiol. Lett. 2011, 314, 107-111. [CrossRef] [PubMed] 
68. Xie, Y.-Y.; Liu, M.-S.; Hu, P.-P.; Kong, X.-L.; Qiu, D.-H.; Xu, J.-L.; Hider, R.; Zhou, T. Synthesis, physico-chemical properties, and antimicrobial evaluation of a new series of iron(III) hexadentate chelators. Med. Chem. Res. 2013, 22, 2351-2359. [CrossRef]

69. Xu, B.; Kong, X.L.; Zhou, T.; Qiu, D.H.; Chen, Y.L.; Liu, M.S.; Yang, R.H.; Hider, R.C. Synthesis, iron(III)-binding affinity and in vitro evaluation of 3-hydroxypyridin-4-one hexadentate ligands as potential antimicrobial agents. Bioorg. Med. Chem. Lett. 2011, 21, 6376-6380. [CrossRef] [PubMed]

70. Zhou, Y.J.; Zhang, M.X.; Hider, R.C.; Zhou, T. In vitro antimicrobial activity of hydroxypyridinone hexadentate-based dendrimeric chelators alone and in combination with norfloxacin. FEMS Microbiol. Lett. 2014, 355, 124-130. [CrossRef] [PubMed]

71. Tortoli, E. Clinical manifestations of nontuberculous mycobacteria infections. Clin. Microbiol. Infect. 2009, 15, 906-910. [CrossRef] [PubMed]

72. Li, Y.J.; Danelishvili, L.; Wagner, D.; Petrofsky, M.; Bermudez, L.E. Identification of virulence determinants of Mycobacterium avium that impact on the ability to resist host killing mechanisms. J. Med. Microbiol. 2010, 59, 8-16. [CrossRef] [PubMed]

73. Quesniaux, V.; Fremond, C.; Jacobs, M.; Parida, S.; Nicolle, D.; Yeremeev, V.; Bihl, F.; Erard, F.; Botha, T.; Drennan, M.; et al. Toll-like receptor pathways in the immune responses to mycobacteria. Microbes Infect. 2004, 6, 946-959. [CrossRef] [PubMed]

74. Guenin-Mace, L.; Simeone, R.; Demangel, C. Lipids of pathogenic Mycobacteria: Contributions to virulence and host immune suppression. Transbound. Emerg. Dis. 2009, 56, 255-268. [CrossRef] [PubMed]

75. Brennan, P.J. Structure, function, and biogenesis of the cell wall of Mycobacterium tuberculosis. Tuberculosis 2003, 83, 91-97. [CrossRef]

76. Ratledge, C.; Dover, L.G. Iron Metabolism in Pathogenic Bacteria. Annu. Rev. Microbiol. 2000, 54, 881-941. [CrossRef] [PubMed]

77. De Voss, J.J.; Rutter, K.; Schroeder, B.G.; Su, H.; Zhu, Y.; Barry, C.E. The salicylate-derived mycobactin siderophores of Mycobacterium tuberculosis are essential for growth in macrophages. Proc. Natl. Acad. Sci. USA 2000, 97, 1252-1257. [CrossRef] [PubMed]

78. Roosenberg, J.M., II; Lin, Y.M.; Lu, Y.; Miller, M.J. Studies and syntheses of siderophores, microbial iron chelators, and analogs as potential drug delivery agents. Curr. Med. Chem. 2000, 7, 159-197. [CrossRef] [PubMed]

79. Neyrolles, O.; Wolschendorf, F.; Mitra, A.; Niederweis, M. Mycobacteria, metals, and the macrophage. Immunol. Rev. 2015, 264, 249-263. [CrossRef] [PubMed]

80. Wagner, D.; Maser, J.; Moric, I.; Vogt, S.; Kern, W.V.; Bermudez, L.E. Elemental analysis of the Mycobacterium avium phagosome in Balb/c mouse macrophages. Biochem. Biophys. Res. Commun. 2006, 344, 1346-1351. [CrossRef] [PubMed]

81. Wagner, D.; Maser, J.; Lai, B.; Cai, Z.; Barry, C.E., 3rd; Honer Zu Bentrup, K.; Russell, D.G.; Bermudez, L.E. Elemental analysis of Mycobacterium avium-, Mycobacterium tuberculosis-, and Mycobacterium smegmatiscontaining phagosomes indicates pathogen-induced microenvironments within the host cell's endosomal system. J. Immunol. 2005, 174, 1491-1500. [CrossRef] [PubMed]

82. Weiss, G.; Schaible, U.E. Macrophage defense mechanisms against intracellular bacteria. Immunol. Rev. 2015, 264, 182-203. [CrossRef] [PubMed]

83. Banerjee, S.; Farhana, A.; Ehtesham, N.Z.; Hasnain, S.E. Iron acquisition, assimilation and regulation in mycobacteria. Infect. Genet. Evol. 2011, 11, 825-838. [CrossRef] [PubMed]

84. Sritharan, M. Iron Homeostasis in Mycobacterium tuberculosis: Mechanistic Insights into Siderophore-Mediated Iron Uptake. J. Bacteriol. 2016, 198, 2399-2409. [CrossRef] [PubMed]

85. Eiglmeier, K.; Parkhill, J.; Honore, N.; Garnier, T.; Tekaia, F.; Telenti, A.; Klatser, P.; James, K.D.; Thomson, N.R.; Wheeler, P.R.; et al. The decaying genome of Mycobacterium leprae. Lepr Rev. 2001, 72, 387-398. [PubMed]

86. Dhungana, S.; Ratledge, C.; Crumbliss, A.L. Iron chelation properties of an extracellular siderophore exochelin MS. Inorg. Chem. 2004, 43, 6274-6283. [CrossRef] [PubMed]

87. Ratledge, C. Iron, mycobacteria and tuberculosis. Tuberculosis 2004, 84, 110-130. [CrossRef] [PubMed]

88. De Voss, J.J.; Rutter, K.; Schroeder, B.G.; Barry, C.E., III. Iron Acquisition and Metabolism by Mycobacteria. J. Bacteriol. 1999, 181, 4443-4451. [PubMed] 
89. Nunes, A.; Podinovskaia, M.; Leite, A.; Gameiro, P.; Zhou, T.; Ma, Y.; Kong, X.; Schaible, U.E.; Hider, R.C.; Rangel, M. Fluorescent 3-hydroxy-4-pyridinone hexadentate iron chelators: Intracellular distribution and the relevance to antimycobacterial properties. J. Biol. Inorg. Chem. 2010, 15, 861-877. [CrossRef] [PubMed]

90. Luo, M.; Fadeev, E.A.; Groves, J.T. Mycobactin-mediated iron acquisition within macrophages. Nat. Chem. Biol. 2005, 1, 149-153. [CrossRef] [PubMed]

91. Dhungana, S.; Miller, M.J.; Dong, L.; Ratledge, C.; Crumbliss, A.L. Iron Chelation Properties of an Extracellular Siderophore Exochelin MN. J. Am. Chem. Soc. 2003, 125, 7654-7663. [CrossRef] [PubMed]

92. Wong, D.K.; Gobin, J.; Horwitz, M.A.; Gibson, B.W. Characterization of exochelins of Mycobacterium avium: Evidence for saturated and unsaturated and for acid and ester forms. J. Bacteriol. 1996, 178, 6394-6398. [CrossRef] [PubMed]

93. Russell, D.G. Mycobacterium tuberculosis: Here today, and here tomorrow. Nat. Rev. Mol. Cell Biol. 2001, 2, 569-586. [CrossRef] [PubMed]

94. Fernandes, S.S.; Nunes, A.; Gomes, A.R.; de Castro, B.; Hider, R.C.; Rangel, M.; Appelberg, R.; Gomes, M.S. Identification of a new hexadentate iron chelator capable of restricting the intramacrophagic growth of Mycobacterium avium. Microbes Infect. 2010, 12, 287-294. [CrossRef] [PubMed]

95. Moniz, T.; Nunes, A.; Silva, A.M.G.; Queirós, C.; Ivanova, G.; Gomes, M.S.; Rangel, M. Rhodamine labeling of 3-hydroxy-4-pyridinone iron chelators is an important contribution to target Mycobacterium avium infection. J. Inorg. Biochem. 2013, 121, 156-166. [CrossRef] [PubMed]

96. Bosne-David, S.; Bricard, L.; Ramiandrasoa, F.; DeRoussent, A.; Kunesch, G.; Andremont, A. Evaluation of growth promotion and inhibition from mycobactins and nonmycobacterial siderophores (Desferrioxamine and FR160) in Mycobacterium aurum. Antimicrob. Agents Chemother. 1997, 41, 1837-1839. [CrossRef] [PubMed]

97. Cronjé, L.; Edmondson, N.; Eisenach, K.D.; Bornman, L. Iron and iron chelating agents modulate Mycobacterium tuberculosis growth and monocyte-macrophage viability and effector functions. FEMS Immunol. Med. Microbiol. 2005, 45, 103-112. [CrossRef] [PubMed]

98. Ishida, S.; Arai, M.; Niikawa, H.; Kobayashi, M. Inhibitory effect of cyclic trihydroxamate siderophore, desferrioxamine E, on the biofilm formation of Mycobacterium species. Biol. Pharm. Bull. 2011, 34, 917-920. [CrossRef] [PubMed]

99. Kumar, R.R.; Perumal, S.; Senthilkumar, P.; Yogeeswari, P.; Sriram, D. A highly atom economic, chemo-, regio- and stereoselective synthesis, and discovery of spiro-pyrido-pyrrolizines and pyrrolidines as antimycobacterial agents. Tetrahedron 2008, 64, 2962-2971. [CrossRef]

100. Kumar, R.R.; Perumal, S.; Senthilkumar, P.; Yogeeswari, P.; Sriram, D. An atom efficient, solvent-free, green synthesis and antimycobacterial evaluation of 2-amino-6-methyl-4-aryl-8-[(E)-arylmethylidene]5,6,7,8-tetrahydro-4H-pyrano[3,2-c]pyridine-3-carbonitriles. Bioorg. Med. Chem. Lett. 2007, 17, 6459-6462. [CrossRef] [PubMed]

101. Kumar, R.R.; Perumal, S.; Senthilkumar, P.; Yogeeswari, P.; Sriram, D. Discovery of antimycobacterial spiro-piperidin-4-ones: An atom economic, stereoselective synthesis, and biological intervention. J. Med. Chem. 2008, 51, 5731-5735. [CrossRef] [PubMed]

102. Bairwa, R.; Tawari, N.R.; Alate, A.; Anam, S.; Degani, M.S.; Ray, M.; Rajan, R.M. Novel 2-hydrazino-pyrimidin-4(3H)-one derivatives with pseudofunctional- similarity to siderophores as potential antimycobacterial agents. Med. Chem. 2013, 9, 77-83. [CrossRef] [PubMed]

103. Douvas, G.S.; May, M.H.; Kolnagou, A.; Kontoghiorghes, G.J. Effects on Mycobacterium avium replication in normal human macrophages by deferiprone (L1) and other iron chelators. Possible implications on toxicity. Arzneimittelforschung 2002, 52, 45-52. [CrossRef] [PubMed]

104. Raja, V.P.A.; Perumal, S.; Yogeeswari, P.; Sriram, D. Synthesis and antimycobacterial activity of highly functionalized tetrahydro-4(1H)-pyridinones. Bioorg. Med. Chem. Lett. 2011, 21, 3881-3884. [CrossRef] [PubMed]

105. Yacoby, I.; Benhar, I. Targeted Anti Bacterial Therapy. Infect. Disord. Drug Targets 2007, 7, 221-229. [CrossRef] [PubMed]

106. Butler, M.S.; Cooper, M.A. Antibiotics in the clinical pipeline in 2011. J. Antibiot. 2011, 64, 413-425. [CrossRef] [PubMed] 
107. Nigam, A.; Gupta, D.; Sharma, A. Treatment of infectious disease: Beyond antibiotics. Microbiol. Res. 2014, 169, 643-651. [CrossRef] [PubMed]

108. Mesquita, R.B.R.; Suárez, R.; Cerdà, V.; Rangel, M.; Rangel, A.O.S.S. Exploiting the use of 3,4-HPO ligands as nontoxic reagents for the determination of iron in natural waters with a sequential injection approach. Talanta 2013, 108, 38-45. [CrossRef] [PubMed]

109. Moniz, T.; Silva, D.; Silva, T.; Gomes, M.S.; Rangel, M. Antimycobacterial activity of rhodamine 3,4-HPO iron chelators against Mycobacterium avium: Analysis of the contribution of functional groups and of chelator's combination with ethambutol. MedChemComm 2015, 6, 2194-2203. [CrossRef]

110. Suarez, R.; Mesquita, R.B.; Rangel, M.; Cerda, V.; Rangel, A.O. Iron speciation by microsequential injection solid phase spectrometry using 3-hydroxy-1(H)-2-methyl-4-pyridinone as chromogenic reagent. Talanta 2015, 133, 15-20. [CrossRef] [PubMed]

111. Santos, C.S.; Carvalho, S.M.P.; Leite, A.; Moniz, T.; Roriz, M.; Rangel, A.O.S.S.; Rangel, M.; Vasconcelos, M.W. Effect of tris(3-hydroxy-4-pyridinonate) iron(III) complexes on iron uptake and storage in soybean (Glycine max L.). Plant Physiol. Biochem. 2016, 106, 91-100. [CrossRef] [PubMed]

112. Cilibrizzi, A.; Abbate, V.; Chen, Y.-L.; Ma, Y.; Zhou, T.; Hider, R.C. Hydroxypyridinone Journey into Metal Chelation. Chem. Rev. 2018, 118, 7657-7701. [CrossRef] [PubMed]

113. Chaves, S.; Piemontese, L.; Hiremathad, A.; Santos, M.A. Hydroxypyridinone Derivatives: A Fascinating Class of Chelators with Therapeutic Applications-An Update. Curr. Med. Chem. 2018, 25, 97-112. [CrossRef] [PubMed]

114. Botzenhardt, S.; Li, N.Y.; Chan, E.W.; Sing, C.W.; Wong, I.C.K.; Neubert, A. Safety profiles of iron chelators in young patients with haemoglobinopathies. Eur. J. Haematol. 2017, 98, 198-217. [CrossRef] [PubMed]

115. Bollig, C.; Schell, L.K.; Rucker, G.; Allert, R.; Motschall, E.; Niemeyer, C.M.; Bassler, D.; Meerpohl, J.J. Deferasirox for managing iron overload in people with thalassaemia. Cochrane Database Syst. Rev. 2017, 8, CD007476. [CrossRef] [PubMed]

116. Azman, N.F.; Abdullah, W.Z.; Mohamad, N.; Bahar, R.; Johan, M.F.; Diana, R.; Sarifah, B.H.; Yusoff, S.; Nasir, A.; Othman, A.; et al. Practice of iron chelation therapy for transfusion-dependent thalassemia in Southeast Asia. Asian Biomed. 2016, 10, 537-547. [CrossRef]

117. Borgna-Pignatti, C.; Marsella, M. Iron Chelation in Thalassemia Major. Clin. Ther. 2015, 37, $2866-2877$. [CrossRef] [PubMed]

118. Bucki, R.; Pastore, J.J.; Randhawa, P.; Vegners, R.; Weiner, D.J.; Janmey, P.A. Antibacterial Activities of Rhodamine B-Conjugated Gelsolin-Derived Peptides Compared to Those of the Antimicrobial Peptides Cathelicidin LL37, Magainin II, and Melittin. Antimicrob. Agents Chemother. 2004, 48, 1526-1533. [CrossRef] [PubMed]

119. Sarkar, I.; Mishra, A.K. Fluorophore tagged bio-molecules and their applications: A brief review. Appl. Spectrosc. Rev. 2018, 53, 552-601. [CrossRef]

120. Birch, D.; Christensen, M.V.; Staerk, D.; Franzyk, H.; Nielsen, H.M. Fluorophore labeling of a cell-penetrating peptide induces differential effects on its cellular distribution and affects cell viability. Biochim. Biophys. Acta Biomembr. 2017, 1859, 2483-2494. [CrossRef] [PubMed]

121. Xia, M.-C.; Cai, L.; Zhang, S.; Zhang, X. Cell-Penetrating Peptide Spirolactam Derivative as a Reversible Fluorescent pH Probe for Live Cell Imaging. Anal. Chem. 2017, 89, 1238-1243. [CrossRef] [PubMed]

122. Hedegaard, S.F.; Derbas, M.S.; Lind, T.K.; Kasimova, M.R.; Christensen, M.V.; Michaelsen, M.H.; Campbell, R.A.; Jorgensen, L.; Franzyk, H.; Cárdenas, M.; et al. Fluorophore labeling of a cell-penetrating peptide significantly alters the mode and degree of biomembrane interaction. Sci. Rep. 2018, 8, 6327. [CrossRef] [PubMed]

123. Guidotti, G.; Brambilla, L.; Rossi, D. Cell-Penetrating Peptides: From Basic Research to Clinics. Trends Pharmacol. Sci. 2017, 38, 406-424. [CrossRef] [PubMed]

124. Jones, A.T.; Sayers, E.J. Cell entry of cell penetrating peptides: Tales of tails wagging dogs. J. Control. Release 2012, 161, 582-591. [CrossRef] [PubMed]

125. Hirose, H.; Takeuchi, T.; Osakada, H.; Pujals, S.; Katayama, S.; Nakase, I.; Kobayashi, S.; Haraguchi, T.; Futaki, S. Transient focal membrane deformation induced by arginine-rich peptides leads to their direct penetration into cells. Mol. Ther. 2012, 20, 984-993. [CrossRef] [PubMed] 
126. Bucki, R.; Janmey, P.A. Interaction of the Gelsolin-Derived Antibacterial PBP 10 Peptide with Lipid Bilayers and Cell Membranes. Antimicrob. Agents Chemother. 2006, 50, 2932-2940. [CrossRef] [PubMed]

127. Santos, M.A.; Marques, S.M.; Chaves, S. Hydroxypyridinones as "privileged" chelating structures for the design of medicinal drugs. Coord. Chem. Rev. 2012, 256, 240-259. [CrossRef]

128. Leite, A.; Silva, A.M.G.; Nunes, A.; Andrade, M.; Sousa, C.; Cunha-Silva, L.; Gameiro, P.; De Castro, B.; Rangel, M. Novel tetradentate chelators derived from 3-hydroxy-4-pyridinone units: Synthesis, characterization and aqueous solution properties. Tetrahedron 2011, 67, 4009-4016. [CrossRef]

129. Kim, H.W.; Lee, C.H.; Kim, M.G.; Lee, H.S. Antibacterial activities of phenethyl isothiocyanate and its derivatives against human oral pathogens. J. Korean Soc. Appl. Biol. Chem. 2009, 52, 555-559. [CrossRef]

130. Jang, M.; Hong, E.; Kim, G.H. Evaluation of antibacterial activity of 3-butenyl, 4-pentenyl, 2-phenylethyl, and benzyl isothiocyanate in Brassica vegetables. J. Food Sci. 2010, 75, M412-M416. [CrossRef] [PubMed]

131. Sofrata, A.; Santangelo, E.M.; Azeem, M.; Borg-Karlson, A.K.; Gustafsson, A.; Pütsep, K. Benzyl isothiocyanate, a major component from the roots of Salvadora persica is highly active against Gram-Negative bacteria. PLOS ONE 2011, 6, e23045. [CrossRef] [PubMed]

132. Ibrahim, A.S.; Gebremariam, T.; French, S.W.; Edwards, J.E., Jr.; Spellberg, B. The iron chelator deferasirox enhances liposomal amphotericin B efficacy in treating murine invasive pulmonary aspergillosis. J. Antimicrob. Chemother. 2010, 65, 289-292. [CrossRef] [PubMed]

133. Gehrke, S.S.; Pinto, E.G.; Steverding, D.; Pleban, K.; Tempone, A.G.; Hider, R.C.; Wagner, G.K. Conjugation to 4-aminoquinoline improves the anti-trypanosomal activity of Deferiprone-type iron chelators. Bioorg. Med. Chem. 2013, 21, 805-813. [CrossRef] [PubMed]

134. Lee, R.E.; Mikusova, K.; Brennan, P.J.; Besra, G.S. Synthesis of the mycobacterial arabinose donor $\beta$-D-arabinofuranosyl-1-monophosphoryldecaprenol, development of a basic arabinosyl-transferase assay, and identification of ethambutol as an arabinosyl transferase inhibitor. J. Am. Chem. Soc. 1995, 117, 11829-11832. [CrossRef]

135. Lety, M.A.; Nair, S.; Berche, P.; Escuyer, V. A single point mutation in the embB gene is responsible for resistance to ethambutol in Mycobacterium smegmatis. Antimicrob. Agents Chemother. 1997, 41, 2629-2633. [CrossRef] [PubMed]

136. Goude, R.; Amin, A.G.; Chatterjee, D.; Parish, T. The arabinosyltransferase EmbC is inhibited by ethambutol in Mycobacterium tuberculosis. Antimicrob. Agents Chemother. 2009, 53, 4138-4146. [CrossRef] [PubMed]

137. Moniz, T.; Leite, A.; Silva, T.; Gameiro, P.; Gomes, M.S.; de Castro, B.; Rangel, M. The influence of functional groups on the permeation and distribution of antimycobacterial rhodamine chelators. J. Inorg. Biochem. 2017, 175, 138-147. [CrossRef] [PubMed]

138. Coimbra, J.T.S.; Moniz, T.; Brás, N.F.; Ivanova, G.; Fernandes, P.A.; Ramos, M.J.; Rangel, M. Relevant Interactions of Antimicrobial Iron Chelators and Membrane Models Revealed by Nuclear Magnetic Resonance and Molecular Dynamics Simulations. J. Phys. Chem. B 2014, 118, 14590-14601. [CrossRef] [PubMed]

139. Moniz, T.; de Castro, B.; Rangel, M.; Ivanova, G. NMR study of the interaction of fluorescent 3-hydroxy-4-pyridinone chelators with DMPC liposomes. Phys. Chem. Chem. Phys. 2016, 18, 5027-5033. [CrossRef] [PubMed]

140. Lucio, M.; Lima, J.L.; Reis, S. Drug-membrane interactions: Significance for medicinal chemistry. Curr. Med. Chem. 2010, 17, 1795-1809. [CrossRef] [PubMed]

141. Santos, N.C.; Prieto, M.; Castanho, M.A.R.B. Quantifying molecular partition into model systems of biomembranes: An emphasis on optical spectroscopic methods. Biochim. Biophys. Acta 2003, 1612, 123-135. [CrossRef]

142. Epand, R.M.; Epand, R.F. Bacterial membrane lipids in the action of antimicrobial agents. J. Pept. Sci. 2011, 17, 298-305. [CrossRef] [PubMed]

143. Moniz, T.; Feio, M.; Silva, D.; de Castro, B.; Rangel, M. Study of the effect of thiourea and N-ethyl groups on antibacterial activity of rhodamine-labeled 3,4-HPO iron chelators against Gram (plus/-) bacteria. Med. Chem. Res. 2018, 27, 1472-1477. [CrossRef]

144. Novais, Â.; Moniz, T.; Rebelo, A.R.; Silva, A.M.G.; Rangel, M.; Peixe, L. New fluorescent rosamine chelator showing promising antibacterial activity against Gram-positive bacteria. Bioorg. Chem. 2018, 79, 341-349. [CrossRef] [PubMed] 
145. Moniz, T. Design of Novel 3-Hydroxy-4-Pyridinone Iron Chelators to Fight Mycobacterium Infection. Ph.D. Thesis, Department of Chemistry and Biochemistry, Faculty of Sciences, University of Porto, Porto, Portugal, 2016.

146. Meerovich, I.; Koshkaryev, A.; Thekkedath, R.; Torchilin, V.P. Screening and Optimization of Ligand Conjugates for Lysosomal Targeting. Bioconjug. Chem. 2011, 22, 2271-2282. [CrossRef] [PubMed]

147. Rauen, U.; Springer, A.; Weisheit, D.; Petrat, F.; Korth, H.G.; de Groot, H.; Sustmann, R. Assessment of chelatable mitochondrial iron by using mitochondrion-selective fluorescent iron indicators with different iron-binding affinities. ChemBioChem 2007, 8, 341-352. [CrossRef] [PubMed]

(C) 2018 by the authors. Licensee MDPI, Basel, Switzerland. This article is an open access article distributed under the terms and conditions of the Creative Commons Attribution (CC BY) license (http:/ / creativecommons.org/licenses/by/4.0/). 


\title{
Review \\ Iron Deficiency as a Therapeutic Target in Cardiovascular Disease
}

\author{
Samira Lakhal-Littleton \\ Department of Physiology, Anatomy \& Genetics, University of Oxford, Parks Road, Oxford OX1 3PT, UK; \\ samira.lakhal-littleton@dpag.ox.ac.uk
}

Received: 10 July 2019; Accepted: 22 August 2019; Published: 28 August 2019

\begin{abstract}
Iron deficiency is the most common nutritional disorder in the world. It is prevalent amongst patients with cardiovascular disease, in whom it is associated with worse clinical outcomes. The benefits of iron supplementation have been established in chronic heart failure, but data on their effectiveness in other cardiovascular diseases are lacking or conflicting. Realising the potential of iron therapies in cardiovascular disease requires understanding of the mechanisms through which iron deficiency affects cardiovascular function, and the cell types in which such mechanisms operate. That understanding has been enhanced by recent insights into the roles of hepcidin and iron regulatory proteins (IRPs) in cellular iron homeostasis within cardiovascular cells. These studies identify intracellular iron deficiency within the cardiovascular tissue as an important contributor to the disease process, and present novel therapeutic strategies based on targeting the machinery of cellular iron homeostasis rather than direct iron supplementation. This review discusses these new insights and their wider implications for the treatment of cardiovascular diseases, focusing on two disease conditions: chronic heart failure and pulmonary arterial hypertension.
\end{abstract}

Keywords: iron; hepcidin; iron regulatory proteins; cardiomyocyte; chronic heart failure; pulmonary arterial smooth muscle cells; pulmonary arterial hypertension

\section{Iron and Heart Function}

Iron deficiency is defined as reduced iron availability due to depleted iron stores (e.g., pregnancy), inadequate dietary iron intake (e.g., malnutrition), repressed iron absorption (e.g., inflammatory setting), or iron loss (e.g., menstrual blood loss in women of reproductive age). It has a significant negative impact on the quality of life. It affects intrauterine development, reduces physical and mental exercise capacity, and increases morbidity when concurrent with cardiovascular diseases, such as chronic heart failure $(\mathrm{CHF})$, acute heart failure $(\mathrm{AHF})$, pulmonary arterial hypertension $(\mathrm{PAH})$, chronic obstructive pulmonary disease (COPD), and abdominal aortic aneurysm (AAA) [1-8]. The aetiology of iron deficiency in cardiovascular diseases is not entirely clear, but evidence supports the role of inflammation, and particularly of the inflammatory cytokine interleukin-6 in blocking iron absorption in the gut $[9,10]$.

\subsection{Effects of Iron Deficiency on Heart Function}

In the heart, iron is present predominantly in ferritin and within the mitochondrial compartment [11,12]. The latter is in the form of iron-sulphur clusters and heme functional groups [13]. Iron in iron-sulphur and heme groups is required for electron transfer and oxygen activation in oxidative phosphorylation [14-16]. Additionally, labile-free iron is required for oxygen activation by dioxygenases $[17,18]$, and as a catalyst for the production of reactive oxygen species (ROS) which are essential for redox signalling $[19,20]$.

Iron deficiency is the most common cause of anaemia [21]. Anaemia indirectly affects cardiac function by reducing muscle exercise capacity, and directly by limiting oxygen availability for use in 
oxidative phosphorylation within cardiomyocytes [22-24]. As well as limiting iron availability to the bone marrow, iron deficiency also limits the iron that is available for uptake by non-erythroid tissues. Recently, the direct effects of limited iron availability in cardiomyocytes were demonstrated in a series of experimental models. These models were designed to generate iron deficiency in the heart while maintaining intact systemic iron homeostasis. In a mouse model lacking cardiomyocyte transferrin receptor 1 (TfR1), iron levels in the heart were severely reduced, resulting in fatal heart failure in the second week of age, in part, due to failure of mitochondrial respiration [25]. Another mouse model of cardiac iron deficiency, achieved through increased iron export in cardiomyocytes, also resulted in heart failure, likely explained by a decrease in the activity of the electron transport chain [26]. Studies of dietary iron restriction in animal models have also shown reduced cardiac contractility due to impaired calcium handling in the iron-deficient hearts [27]. The effects of iron deficiency on calcium handling recapitulated the changes induced by hypoxia in cultured cardiomyocytes, supporting the notion that they are driven by reduced oxygen delivery in anaemic animals [27]. However, the direct effects of iron deficiency on hypoxic signalling in the heart could also be important in this context. Indeed, oxygen sensing by hypoxia-inducible factor (HIF) prolyl hydroxylase (PHD) is modified by intracellular iron availability, due to the requirement of PHDs for iron as a co-factor [28]. In summary, iron deficiency affects heart function through anaemia-dependent and anaemia-independent mechanisms. These mechanisms involve changes in oxidative phosphorylation, calcium handling, and oxygen sensing.

\subsection{Treating Iron Deficiency in Heart Failure-Current Approaches}

Iron deficiency commonly co-exists with cardiovascular disease [4-8,29,30]. It is an established co-morbidity in both chronic and acute heart failure [4,5]. Some studies have reported iron deficiency in up to $50 \%$ of patients with heart failure $[29,30]$. Regardless of the presence or absence of anaemia, iron deficiency is associated with higher mortality, adverse cardiovascular events, and reduced quality of life in these patients $[4,5,30]$. In recent years, a number of trials have explored whether iron supplementation could be beneficial in patients with chronic heart failure. Oral iron supplements have had limited success, and this has been attributed to suboptimal absorption due to inflammation. However, intravenous iron preparations have shown clear benefits. For instance, ferric carboxymaltose and iron sucrose have both been shown to improve many outcomes in patients with chronic heart failure, such as mortality, self-reported patient global assessment, exercise capacity, hospitalization due to cardiovascular events, and mortality [31-33]. Consequently, intravenous iron replacement in chronic heart failure is now recommended by the European Society of Cardiology [34]. The benefits of iron supplementation in acute heart failure are less clear. One study reported that iron supplementation within four days of myocardial infarction (MI) improved infarct healing, and left ventricular(LV) remodelling at a three-month follow-up [35], while another found that high levels of serum iron correlated with short-term mortality following MI [36]. These conflicting results may simply reflect distinct and possibly opposing effects of iron availability on the extent of ischemia reperfusion injury and on subsequent cardiac repair.

\subsection{Treating Iron Deficiency in Heart Failure—New Approaches}

The beneficial effects of intravenous iron supplementation in patients with chronic heart failure likely depend on a combination of mechanisms, including an improvement in exercise capacity and oxygen delivery to tissues. Animal studies have also shown that such interventions can directly correct cardiac iron deficiency [26]. Myocardial iron content has been shown to be reduced in patients with heart failure, where it is shown to be associated with reduced activity of the citric acid cycle enzymes aconitase and citrate synthase [37]. Thus, correction of myocardial iron deficiency may well constitute an additional mechanism through which iron interventions improve outcomes in CHF. However, these iron preparations have been developed to correct anaemia. New approaches need to be considered to directly target myocardial iron deficiency, using compounds that can safely and efficiently replenish cardiomyocyte iron levels. In this context, avoidance of iron toxicity in the heart 
should be an important consideration. Indeed, the heart's function is particularly sensitive to excess iron accumulation, as demonstrated by the iron overload cardiomyopathy that occurs in patients with iron overload conditions such as hemochromatosis and thalassemia [38,39]. In line with this, a mouse model harbouring a cardiomyocyte-specific deletion of the iron export protein ferroportin (FPN) was also found to develop fatal cardiomyopathy as a consequence of cardiomyocyte iron-overload [40].

An alternative approach to supplementing iron to the heart is to target the molecular machinery of cellular iron homeostasis in cardiomyocytes. Like other cells in the body, cardiomyocytes utilise the iron regulatory proteins (IRPs) to orchestrate iron uptake, utilisation, and storage. Mice with the cardiac-specific deletion of IRPs fail to increase LV systolic function in response to the dobutamine challenge and have worse LV dysfunction and higher mortality following myocardial infarction [41]. At the same time, IRP activity has been shown to be reduced in the failing human heart [41]. Together, these findings support the notion that myocardial iron deficiency may develop as a consequence of reduced IRP activity in the failing heart, and that this, in turn, impairs cardiac reserve and response to injury. Enhancement of the IRP pathway, by increasing the expression or stability of IRPs, may, therefore, present novel therapeutic strategies in heart failure. The advantage of such an approach over systemically administered iron compounds is that it may enable a more measured correction of intracellular iron levels within cardiomyocytes, reducing the risk of iron toxicity.

Recently, another mechanism of cellular iron homeostasis was identified, in which cardiomyocytes utilise hepcidin, also known as human antimicrobial peptide (HAMP), in an autocrine manner to regulate the iron export protein FPN. Despite maintenance of normal systemic iron levels, deletion of hepcidin specifically in cardiomyocytes resulted in fatal LV failure in mice [26]. Cardiomyocyte-specific knock-in of the FPN isoform C326Y, which retains its iron export function but loses its hepcidin binding, also resulted in heart failure of a similar nature and time-course to that seen in animals lacking cardiomyocyte hepcidin [26]. In both mouse models, increased FPN-mediated iron export caused the depletion of iron from cardiomyocytes. Heart failure in cardiac hepcidin-knockouts could be prevented by intravenous iron supplementation. Additionally, animals with hepcidin-deficient hearts developed greater hypertrophic response to sustained dietary iron restriction than their littermate controls, indicating that the cardiac hepcidin/FPN axis functions to protect the heart in the setting of systemic iron deficiency [26]. These studies identify the cardiac hepcidin/FPN axis as a non-redundant component of cellular iron homeostasis in cardiomyocytes, and further show that the control of the intracellular iron pool in these cells is required for normal cardiac function [26]. Studies comparing mice harbouring tissue-specific with those harbouring a ubiquitous disruption of the hepcidin/FPN axis support the notion that intracellular iron levels within cardiovascular cells are the sum of fluxes through both the systemic and the local hepcidin/FPN axes [26,40]. A clearer understanding of the precise nature of the interplay between local and hepatic hepcidins in control of cardiovascular iron homeostasis is necessary to enable the development of strategies that can safely correct cardiovascular iron levels without impinging on systemic iron control. Such strategies, e.g., increasing cardiac hepcidin or decreasing cardiac FPN, could present a novel approach for the correction of myocardial iron deficiency. A number of human hepcidin agonists and FPN inhibitors are currently in clinical trials for the treatment of iron overload in hemochromatosis and thalassemia. It would be important to explore whether such compounds can correct myocardial iron deficiency in CHF patients. However, given the systemic role of hepcidin in the control of iron absorption and recycling, it may be more advantageous to target druggable differences between hepatic and cardiac hepcidins. Strategies for the treatment of iron deficiency in cardiovascular disease are outlined in Figure 1. 


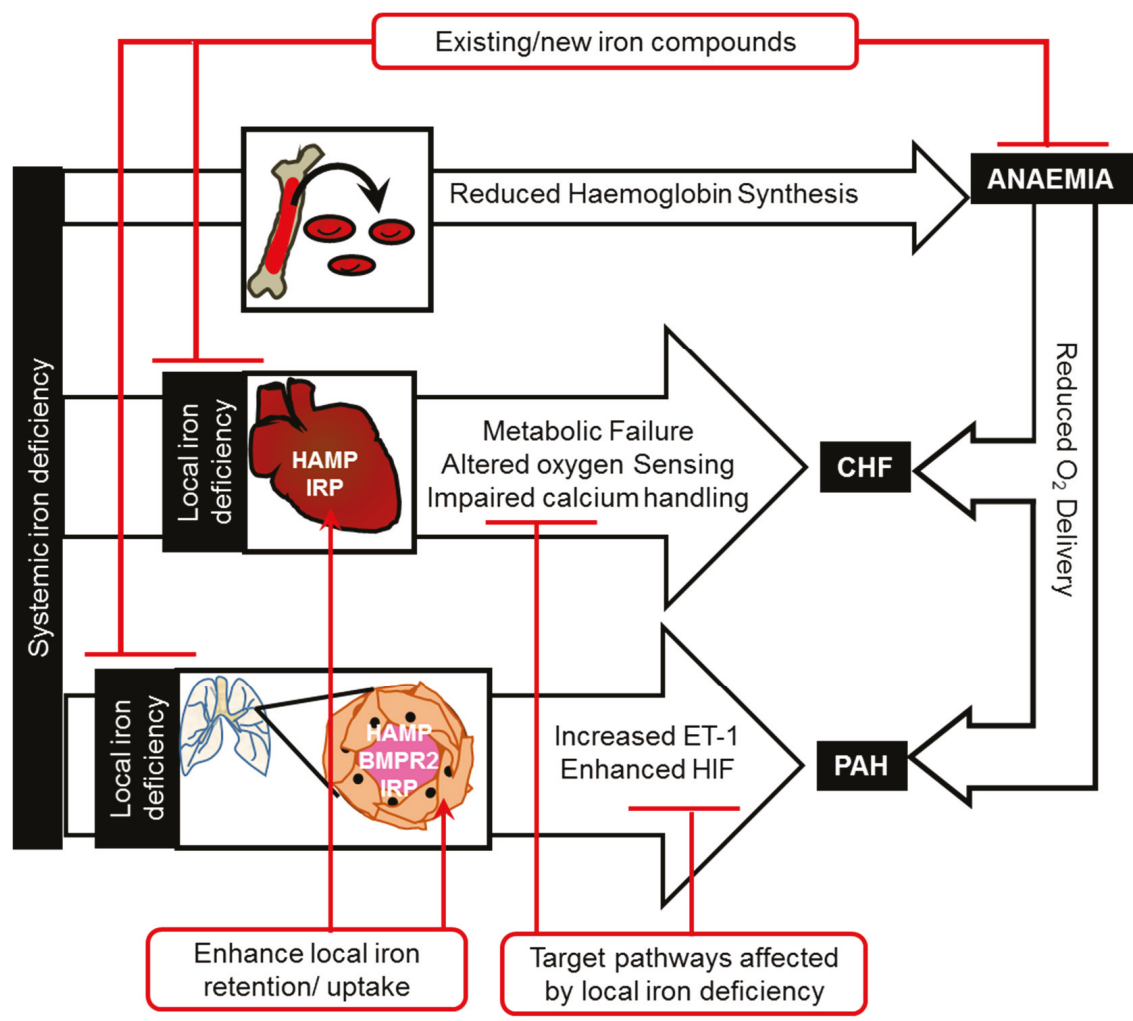

Figure 1. Mechanisms linking iron deficiency and cardiovascular disease.

Iron deficiency affects cardiovascular function through anaemia-dependent and anaemia-independent pathways. Anaemia-independent pathways include direct effects of cardiac iron deficiency on metabolism, oxygen sensing, and calcium handling in the heart, and of vascular iron deficiency on oxygen sensing and vasoconstriction in the pulmonary arteries. Iron therapies for chronic heart failure and pulmonary arterial hypertension could be devised to directly correct local iron deficiency, enhance iron uptake (by enhancing local IRPs) and retention (by enhancing local HAMP, e.g., using bone morphogenetic protein receptor 2(BMPR2) ligands for PAH), or to correct downstream changes in metabolism, oxygen sensing (e.g., HIF inhibitors), calcium handling, or vasoconstriction (e.g., endothelin-1 (ET-1) receptor antagonists).

\section{Iron and the Pulmonary Vasculature}

\subsection{Effects of Iron Deficiency on the Pulmonary Vasculature}

Systemic iron deficiency impinges on the pulmonary vasculature both in the context of normal physiological responses and in the setting of disease, e.g., pulmonary arterial hypertension (PAH). For instance, both clinical iron deficiency and acute infusion with the iron chelator deferoxamine augment the pulmonary vasoconstrictive response to hypoxia [42-45]. Iron deficiency is also prevalent in patients with $\mathrm{PAH}$, in whom it is associated with reduced performance in the six-minute walk test (6MWT), increased disease severity, and poor clinical outcome [46-48]. It is also associated with higher pulmonary arterial pressure in other disease settings $[49,50]$. Rats made iron-deficient (and anaemic) through dietary iron restriction also develop PAH [51]. The mechanistic links between iron deficiency and PAH have remained unclear, due to the limitation posed by the existing experimental models, 
which do not discern the systemic effects of anaemia on tissue oxygenation and exercise capacity, from the local effects of iron deficiency directly acting in the pulmonary vasculature. However, a direct cause/effect relationship between vascular iron deficiency and PAH has recently been demonstrated in mice [52]. It was shown that mice with a smooth muscle-specific knock-in of FPN C326Y develop PAH as a consequence of intracellular iron deficiency in pulmonary arterial smooth muscle cells (PASMCs). Iron deficiency directly exerted its effects on PASMCs by increasing the expression of the endogenous vasoconstrictor endothelin-1 (ET-1) [52]. The roles of ET-1 in normal vascular responses to hypoxia and in the aetiology of PAH have long been recognised. ET-1 is elevated in the lung and in the circulation of PAH patients [53,54], and a number of trials have demonstrated the benefits of ET receptor antagonists in this disease [55]. The $e d n 1$ gene is also a known HIF-regulated gene. The regulation of $e d n 1$ by iron represents another example of the interplay between oxygen and iron homeostasis, and suggests that iron levels in the vascular bed may alter the magnitude of HIF-driven responses to hypoxia.

\subsection{Targeting Iron Deficiency in Pulmonary Arterial Hypertension}

Intravenous iron infusion has been shown to decrease the magnitude of the normal acute hypoxic response in healthy individuals, attenuate the exaggerated hypoxic response in iron-deficient individuals, and improve performance in the six-minute walk test (6MWT) in PAH patients [42-46,56,57]. The mechanisms underlying these effects are not entirely clear, but as with heart function, they likely involve indirect effects via improved exercise capacity and tissue oxygenation, and direct effects on iron-dependent pathways in the pulmonary vascular bed. The latter mechanism is supported by the finding that intravenous iron replenishes intracellular iron levels in PASMCs in mice, decreasing ET-1 release, and preventing and partially reversing the development of PAH [52]. The effects of intracellular iron levels on ET-1 levels were further recapitulated in-vitro in human PASMCs, suggesting a direct effect of iron on the expression of $e d n 1$, possibly involving blunting of the HIF pathway [52]. This "direct" mechanism is further supported by the finding that intravenous iron, administered immediately before acute hypoxic exposure, blunts the magnitude of the rise in PAP, before any changes in haemoglobin levels [43]. This is associated with an inhibition of the rise in serum ET-1 that otherwise accompanies acute hypoxia exposure [52]. These data give rise to the notion that iron levels in the pulmonary vasculature should be considered as a new target in the treatment of PAH. Existing iron preparations in the clinic have been developed to correct anaemia, but it would be important to explore whether such compounds can safely and efficiently replenish iron in the pulmonary vasculature without causing iron toxicity in the long term.

An alternative approach to directly delivering iron to the vascular tissue would be to target the molecular machinery of local cellular iron homeostasis. As with cardiomyocytes, IRPs appear to be involved in intracellular iron homeostasis in PASMCs. Mice lacking IRP1 have been shown to develop PAH through a mechanism involving the translational derepression of HIF- $2 \alpha$ and subsequent increase in its target gene $\operatorname{edn1}$ [58]. More recently, the cell-autonomous control of intracellular iron through the autocrine action of the hepcidin/FPN axis was also demonstrated in PASMCs. The loss of such regulation was sufficient to cause PAH [52]. This study also provided evidence that the deregulation of this cell-autonomous pathway may be an aetiological factor in familial PAH. Indeed, PASMCs from patients with mutations in bone morphogenetic protein receptor 2 (bmpr2), which cause heritable $\mathrm{PAH}$, were shown to have decreased hepcidin expression, increased FPN levels, reduced intracellular iron levels, and increased levels of ET-1. All of these effects could be reversed in-vitro by treatment with iron or exogenous hepcidin peptide [52]. These findings present an entirely novel mechanism through which bmpr 2 mutations may cause PAH. Therefore, targeting the hepcidin/FPN axis in PASMCs may hold therapeutic potential in the treatment of PAH. This would require identification of druggable differences between hepcidin derived from PASMC and hepatic hepcidin. One possibility is the selective enhancement of BMPR2 signalling in PASMCs through the use of specific BMPR2 ligands, which stimulate hepcidin in PASMCs without affecting hepatic hepcidin. Further studies are warranted 
to identify the mechanisms of hepcidin regulation downstream of BMPR2 in PASMCs. Strategies for the treatment of iron deficiency in PAH are outlined in Figure 1.

\section{Conclusions}

Iron deficiency is a recognised co-morbidity in several cardiovascular diseases. In chronic heart failure and pulmonary arterial hypertension, direct effects of iron deficiency within the cardiovascular tissue have been demonstrated, highlighting local iron deficiency as a new therapeutic target in these diseases. Some clinically used iron preparations appear to exert their benefits, in part, by the direct replenishment of intracellular iron levels in the cardiovascular tissue. Recent insights into the molecular machinery of cellular iron homeostasis in the heart and the pulmonary vasculature provide novel therapeutic targets. These targets hold the potential to correct local iron deficiency in the cardiovascular tissue without impinging on systemic iron control.

Funding: This research is funded by a British Heart Foundation Intermediate Fellowship FS/12/63/29895.

Conflicts of Interest: The author has received research funding from Vifor Pharma. The funders had no role in the design of the study; in the collection, analyses, or interpretation of data; in the writing of the manuscript, or in the decision to publish the results.

\section{References}

1. Walker, S.P.; Wachs, T.D.; Gardner, J.M.; Lozoff, B.; Wasserman, G.A.; Pollitt, E.; Carter, J.A.; International Child Development Steering Group. Child development: Risk factors for adverse outcomes in developing countries. Lancet 2007, 369, 145-157. [CrossRef]

2. Buratti, P.; Gammella, E.; Rybinska, I.; Cairo, G.; Recalcati, S. Recent Advances in Iron Metabolism: Relevance for Health, Exercise, and Performance. Med. Sci. Sports Exerc. 2015, 47, 1596-1604. [CrossRef]

3. Scott, S.P.; Murray-Kolb, L.E. Iron Status Is Associated with Performance on Executive Functioning Tasks in Nonanemic Young Women. J. Nutr. 2016, 146, 30-37. [CrossRef]

4. Comin-Colet, J.; Enjuanes, C.; Gonzalez, G.; Torrens, A.; Cladellas, M.; Merono, O.; Ribas, N.; Ruiz, S.; Gómez, M.; Verdú, J.M.; et al. Iron deficiency is a key determinant of health-related quality of life in patients with chronic heart failure regardless of anaemia status. Eur. J. Heart Failure 2013, 15, 1164-1172. [CrossRef]

5. Jankowska, E.A.; Kasztura, M.; Sokolski, M.; Bronisz, M.; Nawrocka, S.; Oleskowska-Florek, W.; Zymliński, R.; Biegus, J.; Siwołowski, P.; Banasiak, W.; et al. Iron deficiency defined as depleted iron stores accompanied by unmet cellular iron requirements identifies patients at the highest risk of death after an episode of acute heart failure. Eur. Heart J. 2014, 35, 2468-2476. [CrossRef]

6. Rhodes, C.J.; Wharton, J.; Howard, L.; Gibbs, J.S.; Vonk-Noordegraaf, A.; Wilkins, M.R. Iron deficiency in pulmonary arterial hypertension: A potential therapeutic target. Eur. Respir. J. 2011, 38, 1453-1460. [CrossRef]

7. Jankowska, E.A.; Ponikowski, P. Anaemia (and iron deficiency?) in aortic stenosis-A bystander or a potential therapeutic target? Eur. J. Heart Failure 2015, 17, 994-996. [CrossRef]

8. Nickol, A.H.; Frise, M.C.; Cheng, H.Y.; McGahey, A.; McFadyen, B.M.; Harris-Wright, T.; Bart, N.K.; Curtis, M.K.; Khandwala, S.; O’Neill, D.P.; et al. A cross-sectional study of the prevalence and associations of iron deficiency in a cohort of patients with chronic obstructive pulmonary disease. BMJ Open 2015, 5, e007911. [CrossRef]

9. Nemeth, E.; Valore, E.V.; Territo, M.; Schiller, G.; Lichtenstein, A.; Ganz, T. Hepcidin, a putative mediator of anemia of inflammation, is a type II acute-phase protein. Blood 2003, 101, 2461-2463. [CrossRef]

10. Markousis-Mavrogenis, G.; Tromp, J.; Ouwerkerk, W.; Devalaraja, M.; Anker, S.D.; Cleland, J.G.; Dickstein, K.; Filippatos, G.S.; van der Harst, P.; Lang, C.C.; et al. The clinical significance of interleukin-6 in heart failure: Results from the BIOSTAT-CHF study. Eur. J. Heart Failure 2019, 21, 965-973.

11. Shuler, T.R.; Pootrakul, P.; Yarnsukon, P.; Nielsen, F.H. Effect of thalassemia/hemoglobin E disease on macro, trace, and ultratrace element concentration in human tissue. J. Trace Elem. Exp. Med. 1990, 3, 31-34.

12. Chua-anusorna, W.; Tran, K.C.; Webb, J.; Macey, D.J.; St Pierre, T.G. Chemical speciation of iron deposits in thalassemic heart tissue. Inorg. Chim. Acta 2000, 300-302, 932-936. [CrossRef] 
13. Wofford, J.D.; Chakrabarti, M.; Lindahl, P.A. Mossbauer Spectra of Mouse Hearts Reveal Age-dependent Changes in Mitochondrial and Ferritin Iron Levels. J. Biol. Chem. 2017, 292, 5546-5554. [CrossRef]

14. Beinert, H.; Holm, R.H.; Munck, E. Iron-sulfur clusters: Nature's modular, multipurpose structures. Science 1997, 277, 653-659. [CrossRef]

15. Meyer, J. Iron-sulfur protein folds, iron-sulfur chemistry, and evolution. J. Biol. Inorg. Chem. 2008, 13, 157-170. [CrossRef]

16. Sono, M.; Roach, M.P.; Coulter, E.D.; Dawson, J.H. Heme-Containing Oxygenases. Chem. Rev. 1996, 96, 2841-2888. [CrossRef]

17. Solomon, E.I.; Decker, A.; Lehnert, N. Non-heme iron enzymes: Contrasts to heme catalysis. Proc. Natl. Acad. Sci. USA 2003, 100, 3589-3594. [CrossRef]

18. Glickstein, H.; Ben-El, R.B.; Shvartsman, M.; Cabantchik, Z.I. Intracellular labile iron pools as direct targets of iron chelators: A fluorescence study of chelator action in living cells. Blood 2005, 106, 3242-3250. [CrossRef]

19. Burgoyne, J.R.; Mongue-Din, H.; Eaton, P.; Shah, A.M. Redox signaling in cardiac physiology and pathology. Circ. Res. 2012, 111, 1091-1106. [CrossRef]

20. Ratcliffe, P.J.; O’Rourke, J.F.; Maxwell, P.H.; Pugh, C.W. Oxygen sensing, hypoxia-inducible factor-1 and the regulation of mammalian gene expression. J. Exp. Biol. 1998, 201, 1153-1162.

21. WHO. Available online: http://www.who.int/nutrition/topics/ida/en/ (accessed on 19 July 2019).

22. Galan, P.; Yoon, H.C.; Preziosi, P.; Viteri, F.; Valeix, P.; Fieux, B.; Briançon, S.; Malvy, D.; Roussel, A.M.; Favier, A.; et al. Determining factors in the iron status of adult women in the SU.VI.MAX study. SUpplementation en VItamines et Mineraux AntioXydants. Eur. J. Clin. Nutr. 1998, 52, 383-388. [CrossRef]

23. Sinclair, L.M.; Hinton, P.S. Prevalence of iron deficiency with and without anemia in recreationally active men and women. J. Am. Diet. Assoc. 2005, 105, 975-978. [CrossRef]

24. Dhur, A.; Galan, P.; Hercberg, S. Effects of different degrees of iron deficiency on cytochrome P450 complex and pentose phosphate pathway dehydrogenases in the rat. J. Nutr. 1989, 119, 40-47. [CrossRef]

25. Xu, W.; Barrientos, T.; Mao, L.; Rockman, H.A.; Sauve, A.A.; Andrews, N.C. Lethal Cardiomyopathy in Mice Lacking Transferrin Receptor in the Heart. Cell Rep. 2015, 13, 533-545. [CrossRef]

26. Lakhal-Littleton, S.; Wolna, M.; Chung, Y.J.; Christian, H.C.; Heather, L.C.; Brescia, M.; Ball, V.; Diaz, R.; Santos, A.; Biggs, D.; et al. An essential cell-autonomous role for hepcidin in cardiac iron homeostasis. eLife 2016, 5, e19804. [CrossRef]

27. Chung, Y.J.; Luo, A.; Park, K.C.; Loonat, A.A.; Lakhal-Littleton, S.; Robbins, P.A.; Swietach, P. Iron-deficiency anemia reduces cardiac contraction by downregulating RyR2 channels and suppressing SERCA pump activity. JCI Insight 2019, 4, 125618. [CrossRef]

28. Mole, D.R. Iron homeostasis and its interaction with prolyl hydroxylases. Antioxid. Redox Signal. 2010, 12, 445-458. [CrossRef]

29. Klip, I.T.; Comin-Colet, J.; Voors, A.A.; Ponikowski, P.; Enjuanes, C.; Banasiak, W.; Lok, D.J.; Rosentryt, P.; Torrens, A.; Polonski, L.; et al. Iron deficiency in chronic heart failure: An international pooled analysis. Am. Heart J. 2013, 165, 575-582.e3. [CrossRef]

30. Okonko, D.O.; Mandal, A.K.; Missouris, C.G.; Poole-Wilson, P.A. Disordered iron homeostasis in chronic heart failure: Prevalence, predictors, and relation to anemia, exercise capacity, and survival. J. Am. Coll. Cardiol. 2011, 58, 1241-1251. [CrossRef]

31. Mordi, I.R.; Tee, A.; Lang, C.C. Iron Therapy in Heart Failure: Ready for Primetime? Card. Fail. Rev. 2018, 4, 28-32. [CrossRef]

32. Ponikowski, P.; van Veldhuisen, D.J.; Comin-Colet, J.; Ertl, G.; Komajda, M.; Mareev, V.; McDonagh, T.; Parkhomenko, A.; Tavazzi, L.; Levesque, V.; et al. Beneficial effects of long-term intravenous iron therapy with ferric carboxymaltose in patients with symptomatic heart failure and iron deficiency. Eur. Heart J. 2015, 36, 657-668. [CrossRef]

33. Anker, S.D.; Comin Colet, J.; Filippatos, G.; Willenheimer, R.; Dickstein, K.; Drexler, H.; Lüscher, T.F.; Bart, B.; Banasiak, W.; Niegowska, J.; et al. Ferric carboxymaltose in patients with heart failure and iron deficiency. N. Engl. J. Med. 2009, 361, 2436-2448. [CrossRef]

34. Lam, C.S.P.; Doehner, W.; Comin-Colet, J.; IRON CORE Group. Iron deficiency in chronic heart failure: Case-based practical guidance. ESC Heart Fail. 2018, 5, 764-771. [CrossRef] 
35. Florian, A.; Ludwig, A.; Rosch, S.; Yildiz, H.; Klumpp, S.; Sechtem, U.; Yilmaz, A. Positive effect of intravenous iron-oxide administration on left ventricular remodelling in patients with acute ST-elevation myocardial infarction-A cardiovascular magnetic resonance (CMR) study. Int. J. Cardiol. 2014, 173, 184-189. [CrossRef]

36. Fuernau, G.; Traeder, F.; Lele, S.S.; Rajapurkar, M.M.; Mukhopadhyay, B.; de Waha, S.; Desch, S.; Eitel, I.; Schuler, G.; Adams, V.; et al. Catalytic iron in acute myocardial infarction complicated by cardiogenic shock-A biomarker substudy of the IABP-SHOCK II-trial. Int. J. Cardiol. 2017, 227, 83-88. [CrossRef]

37. Melenovsky, V.; Petrak, J.; Mracek, T.; Benes, J.; Borlaug, B.A.; Nuskova, H.; Pluhacek, T.; Spatenka, J.; Kovalcikova, J.; Drahota, Z.; et al. Myocardial iron content and mitochondrial function in human heart failure: A direct tissue analysis. Eur. J. Heart Fail. 2017, 19, 522-530. [CrossRef]

38. Allen, K.J.; Gurrin, L.C.; Constantine, C.C.; Osborne, N.J.; Delatycki, M.B.; Nicoll, A.J.; McLaren, C.E.; Bahlo, M.; Nisselle, A.E.; Vulpe, C.D.; et al. Iron-overload-related disease in HFE hereditary hemochromatosis. N. Engl. J. Med. 2008, 358, 221-230. [CrossRef]

39. Lekawanvijit, S.; Chattipakorn, N. Iron overload thalassemic cardiomyopathy: Iron status assessment and mechanisms of mechanical and electrical disturbance due to iron toxicity. Can. J. Cardiol. 2009, 25, 213-218. [CrossRef]

40. Lakhal-Littleton, S.; Wolna, M.; Carr, C.A.; Miller, J.J.; Christian, H.C.; Ball, V.; Santos, A.; Diaz, R.; Biggs, D.; Stillion, R.; et al. Cardiac ferroportin regulates cellular iron homeostasis and is important for cardiac function. Proc. Natl. Acad. Sci. USA 2015, 112, 3164-3169. [CrossRef]

41. Haddad, S.; Wang, Y.; Galy, B.; Korf-Klingebiel, M.; Hirsch, V.; Baru, A.M.; Rostami, F.; Reboll, M.R.; Heineke, J.; Flögel, U.; et al. Iron-regulatory proteins secure iron availability in cardiomyocytes to prevent heart failure. Eur. Heart J. 2017, 38, 362-372.

42. Smith, T.G.; Talbot, N.P.; Privat, C.; Rivera-Ch, M.; Nickol, A.H.; Ratcliffe, P.J.; Dorrington, K.L.; León-Velarde, F.; Robbins, P.A. Effects of iron supplementation and depletion on hypoxic pulmonary hypertension: Two randomized controlled trials. JAMA 2009, 302, 1444-1450. [CrossRef]

43. Frise, M.C.; Cheng, H.Y.; Nickol, A.H.; Curtis, M.K.; Pollard, K.A.; Roberts, D.J.; Ratcliffe, P.J.; Dorrington, K.L.; Robbins, P.A. Clinical iron deficiency disturbs normal human responses to hypoxia. J. Clin. Investig. 2016, 126, 2139-2150. [CrossRef]

44. Bart, N.K.; Curtis, M.K.; Cheng, H.Y.; Hungerford, S.L.; McLaren, R.; Petousi, N.; Dorrington, K.L.; Robbins, P.A. Elevation of iron storage in humans attenuates the pulmonary vascular response to hypoxia. J. Appl. Physiol. 2016, 121, 537-544. [CrossRef]

45. Smith, T.G.; Balanos, G.M.; Croft, Q.P.; Talbot, N.P.; Dorrington, K.L.; Ratcliffe, P.J.; Robbins, P.A. The increase in pulmonary arterial pressure caused by hypoxia depends on iron status. J. Physiol. 2008, 586, 5999-6005. [CrossRef]

46. Viethen, T.; Gerhardt, F.; Dumitrescu, D.; Knoop-Busch, S.; ten Freyhaus, H.; Rudolph, T.K.; Baldus, S.; Rosenkranz, S. Ferric carboxymaltose improves exercise capacity and quality of life in patients with pulmonary arterial hypertension and iron deficiency: A pilot study. Int. J. Cardiol. 2014, 175, 233-239. [CrossRef]

47. Rhodes, C.J.; Howard, L.S.; Busbridge, M.; Ashby, D.; Kondili, E.; Gibbs, J.S.; Wharton, J.; Wilkins, M.R. Iron deficiency and raised hepcidin in idiopathic pulmonary arterial hypertension: Clinical prevalence, outcomes, and mechanistic insights. J. Am. Coll. Cardiol. 2011, 58, 300-309. [CrossRef]

48. Van Empel, V.P.; Lee, J.; Williams, T.J.; Kaye, D.M. Iron deficiency in patients with idiopathic pulmonary arterial hypertension. Heart Lung Circ. 2014, 23, 287-292. [CrossRef]

49. Ruiter, G.; Lanser, I.J.; de Man, F.S.; van der Laarse, W.J.; Wharton, J.; Wilkins, M.R.; Howard, L.S.; Vonk-Noordegraaf, A.; Voskuyl, A.E. Iron deficiency in systemic sclerosis patients with and without pulmonary hypertension. Rheumatology 2014, 53, 285-292. [CrossRef]

50. Plesner, L.L.; Schoos, M.M.; Dalsgaard, M.; Goetze, J.P.; Kjoller, E.; Vestbo, J.; Iversen, K. Iron Deficiency in COPD Associates with Increased Pulmonary Artery Pressure Estimated by Echocardiography. Heart Lung Circ. 2017, 26, 101-104. [CrossRef]

51. Cotroneo, E.; Ashek, A.; Wang, L.; Wharton, J.; Dubois, O.; Bozorgi, S.; Busbridge, M.; Alavian, K.N.; Wilkins, M.R.; Zhao, L. Iron homeostasis and pulmonary hypertension: Iron deficiency leads to pulmonary vascular remodeling in the rat. Circ. Res. 2015, 116, 1680-1690. [CrossRef]

52. Lakhal-Littleton, S.; Crosby, A.; Frise, M.C.; Mohammad, G.; Carr, C.A.; Loick, P.A.M.; Robbins, P.A. Intracellular iron deficiency in pulmonary arterial smooth muscle cells induces pulmonary arterial hypertension in mice. Proc. Natl. Acad. Sci. USA 2019, 116, 13122-13130. [CrossRef] 
53. Giaid, A.; Yanagisawa, M.; Langleben, D.; Michel, R.P.; Levy, R.; Shennib, H.; Kimura, S.; Masaki, T.; Duguid, W.P.; Stewart, D.J. Expression of endothelin-1 in the lungs of patients with pulmonary hypertension. N. Engl. J. Med. 1993, 328, 1732-1739. [CrossRef]

54. Stewart, D.J.; Levy, R.D.; Cernacek, P.; Langleben, D. Increased plasma endothelin-1 in pulmonary hypertension: Marker or mediator of disease? Ann. Intern. Med. 1991, 114, 464-469. [CrossRef]

55. Channick, R.; Badesch, D.B.; Tapson, V.F.; Simonneau, G.; Robbins, I.; Frost, A.; Roux, S.; Rainisio, M.; Bodin, F.; Rubin, L.J. Effects of the dual endothelin receptor antagonist bosentan in patients with pulmonary hypertension: A placebo-controlled study. J. Heart Lung Transplant. 2001, 20, 262-263. [CrossRef]

56. Mehmood, M.; Agarwal, R.; Raina, A.; Correa-Jaque, P.; Benza, R.L. Hemodynamic response to treatment of iron deficiency anemia in pulmonary arterial hypertension: Longitudinal insights from an implantable hemodynamic monitor. Pulm. Circ. 2016, 6, 616-618. [CrossRef]

57. Ruiter, G.; Manders, E.; Happe, C.M.; Schalij, I.; Groepenhoff, H.; Howard, L.S.; Wilkins, M.R.; Bogaard, H.J.; Westerhof, N.; van der Laarse, W.J.; et al. Intravenous iron therapy in patients with idiopathic pulmonary arterial hypertension and iron deficiency. Pulm. Circ. 2015, 5, 466-472. [CrossRef]

58. Ghosh, M.C.; Zhang, D.L.; Jeong, S.Y.; Kovtunovych, G.; Ollivierre-Wilson, H.; Noguchi, A.; Tu, T.; Senecal, T.; Robinson, G.; Crooks, D.R.; et al. Deletion of iron regulatory protein 1 causes polycythemia and pulmonary hypertension in mice through translational derepression of HIF2alpha. Cell Metab. 2013, 17, 271-281. [CrossRef]

(C) 2019 by the author. Licensee MDPI, Basel, Switzerland. This article is an open access article distributed under the terms and conditions of the Creative Commons Attribution (CC BY) license (http://creativecommons.org/licenses/by/4.0/). 


\title{
Review
}

\section{Influence of Iron on Bone Homeostasis}

\author{
Enikő Balogh ${ }^{1}$, György Paragh ${ }^{2}$ and Viktória Jeney ${ }^{1, *}$ \\ 1 Research Centre for Molecular Medicine, Faculty of Medicine, University of Debrecen, \\ 4012 Debrecen, Hungary; balogh.eniko@belklinika.com \\ 2 Department of Internal Medicine, Faculty of Medicine, University of Debrecen, 4012 Debrecen, Hungary; \\ paragh@internal.med.unideb.hu \\ * Correspondence: jeneyv@belklinika.com; Tel.: +36-70-217-1676
}

Received: 1 September 2018; Accepted: 12 October 2018; Published: 18 October 2018

\begin{abstract}
Bone homeostasis is a complex process, wherein osteoclasts resorb bone and osteoblasts produce new bone tissue. For the maintenance of skeletal integrity, this sequence has to be tightly regulated and orchestrated. Iron overload as well as iron deficiency disrupt the delicate balance between bone destruction and production, via influencing osteoclast and osteoblast differentiation as well as activity. Iron overload as well as iron deficiency are accompanied by weakened bones, suggesting that balanced bone homeostasis requires optimal—not too low, not too high-iron levels. The goal of this review is to summarize our current knowledge about how imbalanced iron influence skeletal health. Better understanding of this complex process may help the development of novel therapeutic approaches to deal with the pathologic effects of altered iron levels on bone.
\end{abstract}

Keywords: bone homeostasis; iron overload; iron deficiency; osteoclast; osteoblast; osteoporosis

\section{Introduction}

Bone is a metabolically active tissue that is continuously being remodeled, which enables growth in childhood, as well as repair and adaptation of the skeleton in adults. During bone remodeling, the adult skeleton is renewed approximately once every ten years. The two major cell types involved in bone remodeling are the osteoclasts, with a function of resorption of bone tissue and osteoblasts, with a role of new bone tissue formation. Osteoclasts originate from the monocyte/macrophage hematopoietic lineage, whereas osteoblasts originate from multipotent mesenchymal stem cells. Differentiation and activity of these two cell types must be tightly orchestrated in order to preserve skeletal health and integrity throughout life.

Iron overload as well as iron deficiency are associated with weakened bones, suggesting that balanced bone homeostasis requires optimal iron levels. Accumulating evidence suggests that both high iron and low iron influence the differentiation and activity of osteoclast and osteoblasts in a way that it promotes bone loss.

\section{Bone Homeostasis}

Bones are often stereotyped as simply a scaffold that holds the body together. But besides supporting the body structurally, bones have many different functions [1]. For example, bones protect our internal organs as well as the central nervous system from injury, and enable us to move. Also, bones serve as a reservoir for phosphorus and calcium and they provide an environment for hematopoiesis that occurs in the red bone marrow. Additionally, bones store energy in a form of lipids in adipose cells present in the yellow marrow.

Despite the first impression, bone is a metabolically active tissue that is continuously being remodeled, which is a process not only important for bone health and homeostasis of phosphorus and calcium, but also because it allows for adaptation of the skeleton to meet changing mechanical 
needs [2]. In the cycle of bone remodeling, old bone tissue is digested by osteoclasts, and the new bone tissue is made by osteoblasts in a tightly coordinated manner to assure similar rates of resorption and formation thus sustaining skeletal integrity [2]. Bone remodeling is orchestrated by systemic regulators including hormones (e.g., parathyroid-, growth-, and sex hormones), glucocorticoids, prostaglandins, calcitriol, calcitonin, bone morphogenetic proteins (BMP), as well as local regulators including many cytokines and growth factors [1].

\subsection{Osteoclasts}

Osteoclasts, the unique cells involved in bone resorption, originate from myeloid cells of the monocyte/macrophage lineage. Osteoclastogenesis is a multistep process, in which first osteoclast precursors differentiate into mononuclear pre-osteoclast, which then fuse into multinucleated mature osteoclasts, on further differentiation [3]. Terminally differentiated osteoclasts are involved in the resorption of bone tissue. They move on bone surfaces, seal the resorption bays, pump hydrogen ions and secrete proteolytic enzymes into the resorption cavity, to dissolve the inorganic bone matrix and degrade bone matrix proteins [4,5]. Mature osteoclasts are short-lived cells and undergo programmed cell death within a few days following maturation.

Osteoclastogenesis is a tightly regulated process in which diverse cytokines, steroids and lipids play pivotal roles [4,6]. Among them, both macrophage colony-stimulating factor (M-CSF) and receptor activator of nuclear factor $\mathrm{KB}$ ligand (RANKL) seem to be necessary to osteoclast differentiation. This notion is sustained by the observations that the absence of a functional M-CSF in the op/op mouse as well as RANKL deficiency are associated with a complete lack of mature osteoclasts resulting in profound osteopetrosis [3,7-10]. The binding of RANKL to RANK triggers the recruitment of adaptor molecules, such as tumor necrosis factor receptor-associated factor 6 (TRAF6) and eventually leads to the activation of multiple downstream signal transduction pathways, including c-Jun N-terminal kinase (JNK), p38, and extracellular signal-regulated kinase (ERK) pathways, nuclear factor-kB (NF- $\mathrm{kB}$ ), Src and Akt [11]. Importantly, RANKL/RANK signaling activates different transcription factors such as NF- $\mathrm{KB}$, microphthalmia transcription factor (MITF), c-Fos, and nuclear factor-activated T cells c1 (NFATc1) [11]. Among them, NFATc1 is considered to be the master transcription factor that drives terminal differentiation of osteclasts via regulating numerous osteoclast-specific genes such as tartrate-resistant acid phosphatase (TRAP), cathepsin $\mathrm{K}$ and calcitonin receptor [12,13].

Excessive osteoclastogenesis and bone resorption is prevented by osteoprotegerin (OPG) that regulates RANK/RANKL signaling. OPG is a soluble decoy receptor that binds RANKL and thus prevent its binding to RANK, therefore the RANKL-OPG ratio is an important regulator of bone mass and skeletal integrity $[8,14]$.

\subsection{Osteoblasts}

Osteoblasts, which are the unique bone forming cells, originate from multipotent mesenchymal stem cells (MSCs). To accomplish their role, MSCs first need to migrate to the site of active bone resorption, proliferate and differentiate into active osteoblasts. Migration of MSCs is regulated by growth factors deposited within the bone matrix and liberated during bone resorption, such as transforming growth factor beta 1 (TGF- $\beta 1$ ), platelet derived growth factor (PDGF), BMP2 and BMP4 $[15,16]$. Additionally, the activated osteoclast-derived chemokine sphingosine-1-phosphate also plays a critical role in the recruitment of MSCs to the bone resorption cavity [17]. These mechanisms ensure precise coupling of bone resorption and subsequent bone formation and therefore, contribute to maintenance of skeletal integrity [16].

MSCs are able to change into various cell types including osteoblasts, chondrocytes and adipocytes. The processes of commitment and differentiation of MSCs are driven by lineage-specific master transcription factors. Osteogenic differentiation of MSCs is driven by runt-related transcription factor 2 (Runx2), the master osteogenic transcription factor. Importantly, Runx2 deficient mice die shortly after birth because of impaired bone formation due to the absence of differentiated osteoblasts $[18,19]$. 
Runx2 has a wide variety of targets that includes the key bone tissue specific proteins such as osteopontin, osteocalcin (OCN), bone sialoprotein (BSP) and alkaline phosphatase (ALP) [20].

Runx2 activation and subsequent osteogenic differentiation of MSCs is triggered by diverse secreted differentiation factors, including TGF- $\beta 1$, fibroblast growth factor, and upstream signaling pathways such as BMP, Wnt and hedgehog [21,22]. Additionally, recent evidence highlighted the key role of reactive oxygen species (ROS) in osteogenesis as a common regulator of the diverse osteogenic signaling pathways [23]. Results showed that rigorously balanced ROS levels are crucial in proper osteogenic differentiation of MSCs [23].

\section{Bone Homeostasis in Iron Overload}

\subsection{Iron Overload}

Iron is a Janus face element, being both essential for life and dangerous, due to its involvement in unfettered ROS production. Because of this, diverse proteins keep the uptake (e.g., divalent metal transporter), the transfer (e.g., transferrin and serum ferritin), and the redistribution (e.g., transferrin receptor, ferritin) of iron under strict control on both systemic and cellular levels [24]. Most of the body iron present in red blood cells associated with hemoglobin is in a form of heme, therefore metabolism of heme via the action of heme oxygenase-1 (HO-1) is also an integral part of systemic iron metabolism [25]. The second largest pool of iron is stored within ferritin is mostly in hepatocytes and macrophages. When necessary, iron is liberated from ferritin via ferritinophagy and efficiently recycled [26]. Systematic regulation of iron homeostasis relies on the interactions between hepcidin and the iron exporter ferroportin, whereas cellular regulation of iron metabolism is carried out through the actions of iron-regulatory proteins and iron-responsive elements in a post-transcriptional way [27]. Determination of iron status relies on the measurement of serum indicators, mostly transferrin saturation, soluble transferrin receptor and serum ferritin. Additionally, protoporphyrin content of red blood cells also reflects iron status. Because of other influencing factors such as inflammation, determination of iron status is often based on the combination of several indicators [28].

Genetic or acquired perturbations in iron metabolism can lead to excessive accumulation of iron in the body. For example, hemochromatosis, characterized by increased dietary iron uptake and subsequent tissue iron overload, is caused by mutations in diverse genes involved in iron metabolism. In Caucasian population the most frequent type of hereditary hemochromatosis $(\mathrm{HH})$ is due to a mutation of the HFE gene (Cys282Tyr) [29,30]. Mutations of transferrin receptor-2 gene (TfR2) [31], hemojuvelin gene $(H J V)$ [32], hepcidin gene (HAMP) [33] and the ferroportin gene (SCL40A1) [34] contribute to less frequent forms of hereditary hemochromatosis.

Red blood cell lysis is a common feature of inherited and acquired anemias such as thalassemias, sickle cell disease and acquired refractory anemias. Massive intravascular hemolysis leads to the release of large amounts of hemoglobin and subsequent deposition of iron and hemosiderosis in diverse organs including heart, liver and kidney [35,36]. Allogeneic blood transfusion is frequently used as the first therapeutic option for the treatment of inherited anemias which improves dramatically the prognosis of these diseases, but repeated transfusions often cause secondary iron overload due to the lack of active mechanisms to remove excess iron [24,37].

Hepcidin, the peptide hormone that regulates systemic iron metabolism is produced by the liver therefore chronic liver diseases are frequently associated with iron overload. In line of this notion, high iron levels are present in patients with nonalcoholic fatty liver disease, alcoholic liver disease as well as hepatitis C viral infection [38].

Iron overload has been recognized as a potential hazard in postmenopausal women as well. The New York University Women's Health Study showed a more than two-fold increase in the mean serum ferritin concentration in postmenopausal women as compared to premenopausal women [39]. Studies showed positive correlation between serum ferritin levels and age, menopausal status, body mass index, cigarette smoking and non-white ethnicity [39,40]. Among dietary factors serum ferritin 
concentrations were associated positively with intake of meat, the use of multivitamins and alcohol consumption $[39,41]$. Another study found that dietary habits characterized by low intake of eggs and dairy products, high alcohol consumption, and increased intake of meat rich in heme iron is associated with increased serum ferritin levels in postmenopausal women [42].

\subsection{Bone Phenotype in Association with Iron Overload}

Accumulating evidence suggest that iron overload conditions $(\mathrm{HH}$, thalassemias, sickle cell disease) are associated with bone weakening, which is represented as decreased bone mass, osteoporosis osteopenia, altered bone microarchitecture and biomechanics, as well as frequent bone fractures [43] (Figure 1A).

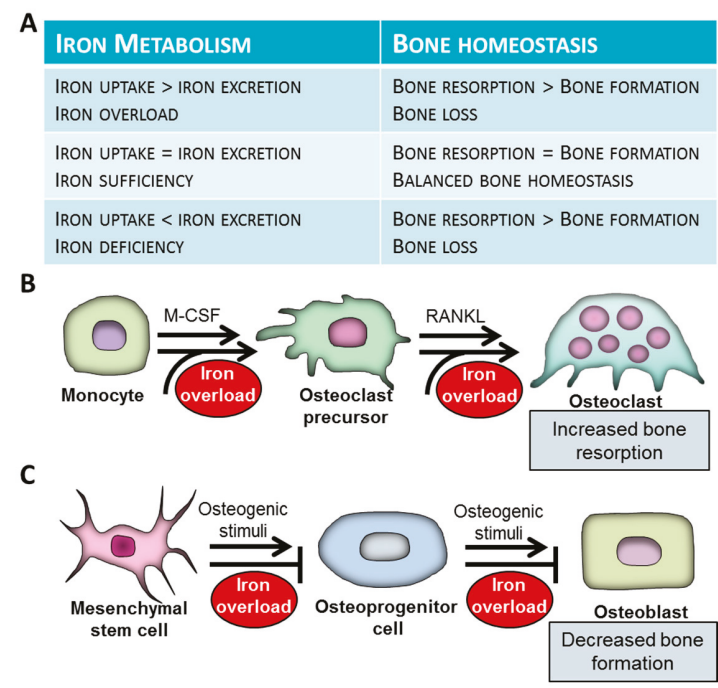

Figure 1. Associations of iron metabolism and bone homeostasis. (A) Association between iron metabolism and bone homeostasis. (B) The effect of iron overload on differentiation and function of osteoclasts. Osteoclasts derive from myeloid cells of the monocyte/macrophage lineage. Osteoclastogenesis is initiated by macrophage colony-stimulating factor (M-CSF). Bone-resorbing multinuclear osteoclasts are formed from mononuclear osteoclast precursors via fusion. The process is initiated by receptor activator of nuclear factor $\mathrm{kB}$ ligand (RANKL). Iron excess triggers osteoclast differentiation and activation and subsequent bone destruction. (C) Osteoblasts differentiate from multipotent mesenchymal stem cells (MSCs). Iron attenuates osteogenic differentiation of MSCs and function of mature osteoblasts. Weak bone phenotype observed in patients with systemic iron overload is a consequence of increased bone resorption by osteoclasts and decreased bone formation by osteoblasts.

There are several case reports and studies on small groups suggesting an association between $\mathrm{HH}$ and osteoporosis [44-47]. Based on these studies a positive correlation has been proposed between the development of osteoporosis and the severity of iron overload [44-47]. The incidence of osteoporosis in $\mathrm{HH}$ patients is about $25-34 \%$ and $40-80 \%$ of the patients suffer from osteopenia $[46,48]$. The largest case-control study of the field, with the involvement of about 600 subjects (HH patients and controls), confirmed the association between $\mathrm{HH}$ and increased prevalence of osteoporosis [49]. Osteoporosis can lead to pathologic fractures which have been reported in $\mathrm{HH}$ patients [50,51]. These studies also highlighted that the prevalence of fractures in $\mathrm{HH}$ patients is associated with the severity of iron overload [50,51]. 
Different mutations in the genes encoding the alpha and beta chains of hemoglobin $(\mathrm{Hb})$ cause hemoglobinopathies which are characterized by various degrees of anemia [52]. The most common types of hemoglobinopathies are thalassemias and sickle cell disease (SCD). In case of severe or persistent anemia, patients with hemoglobinopathies may receive blood transfusion therapy which cause iron overload [52]. To avoid iron accumulation patients receive iron chelation therapy [53]. Unfortunately, regardless of iron chelation therapy, most patients with thalassemia suffer from iron overload, which aggravates the development of end-organ damage associated with the disease.

Severe osteoporosis and pathologic fractures continued to be one of the most common co-morbidity in patients with thalassemia [54-56]. Improvement of chelation therapy resulted that the incidence of osteoporotic fractures decreased in thalassemia patients in recent decades [57-61]. On the other hand, due to efficient chelation regimen life expectancy of patients with thalassemia major and intermedia increased which was unfortunately associated with increased prevalence of lifetime fractures compared to control subjects [62]. Importantly, the risk of pathologic fractures correlates with the severity of anemia and the regularity of blood transfusion in patients with thalassemia. Regardless of optimal iron chelation, regimen bone mineral density (BMD) of thalassemia patients decreases gradually by age, which leads to low BMD in more than half of the adult patients [62]. Besides bone quantity, thalassemia has a detrimental effect on bone quality. In line with this notion, it was found that trabecular bone score is decreased in thalassemia patients in comparison with healthy subjects [63].

Besides thalassemias, bone involvement is very frequent in SCD. More than 70\% of adult SCD patients have low BMD that can lead to osteoporetic fractures and vertebral collapse [64-69]. According to a recent study, low BMD in SCD is accompanied with a high rate of erythrocyte lysis [70]. Iron status of SCD patients is not evident, iron overload as well as iron deficiency have been described [71,72]. This controversy may be due to the huge individual differences in iron depositions in patients with SCD and the abnormal distribution of iron that results in accumulation of iron in diverse organs including the liver, spleen and the kidney, and concomitant iron deficiency in the bone marrow [73]. Nevertheless, recently it has been shown that more than $70 \%$ of SCD patients with high serum iron suffer from low BMD, suggesting a detrimental effect of high iron on bone homeostasis in SCD [74].

Menopause is a complex process, characterized by hormonal alterations, such as a marked decline of estrogen level. Interestingly, studies revealed a negative correlation between estrogen and serum ferritin levels, and mounting evidence suggests that the 2-3-fold increase in iron/ferritin levels in postmenopausal women influences their health [75-77]. About one-third of post-menopausal women suffer from osteoporosis and subsequent osteoporotic fractures [78-80]. Recent studies addressed whether increased iron stores effect bone health in women following menopause. They showed that the rate of annual bone loss correlates to plasma ferritin levels highlighting that elevated total body iron stores is an independent risk factor for enhanced bone loss in postmenopausal women [81,82].

Interestingly, a recent study revealed that the prevalence of low BMD is lower in elderly ( $>60$ years) people with high serum ferritin levels $(<200 \mathrm{ng} / \mathrm{mL})$. This finding warrants the need of further studies to clarify the association between serum ferritin concentrations and BMD in different populations [83].

Animal models of iron overload provided further evidence regarding the harmful effect of iron on bone health. Chronic administration of iron dextran to mice results in tissue iron overload in different organs and osteoporosis [84]. Bone loss observed in this iron overload model was linked to elevation of the production of ROS [84]. Inhibition of unfettered ROS formation partially prevented bone loss in this model, emphasizing the key role of ROS in iron-overload associated bone loss [84]. Recently it has been shown that high iron stress induces rapid osteoporosis in zebrafish larvae and adults [85]. Investigations carried out on hemochromatosis animal models (i.e., Hfe and hepcidin deficient mice and hepcidin deficient zebrafish) also supported the detrimental effect of iron overload on bone health [86-90]. Besides altered iron metabolism, abnormal distribution of heme seems to influence skeletal health. In line of this notion, it was shown that the mice deficient of the cytoplasmic heme exporter, feline leukemia virus, subgroup C, receptor 1 (FLVCR1), exhibit craniofacial and limb 
deformities [91,92]. Furthermore, several studies were performed to investigate the bone phenotype in thalassemia and sickle cell disease mice. These studies revealed that thalassemia mice exhibit the same weak bone phenotype as the thalassemia patients [93-95]. Similarly, sickle cell disease mice are characterized by low BMD and harmful alterations in the microarchitecture and mechanics of bones $[96,97]$.

Additionally, chronic liver disease patients frequently suffer from osteoporosis [98,99]. The mechanism underlying chronic liver disease-associated osteoporosis is not entirely understood, but studies suggested that low BMD is mainly due to decreased bone production in these patients. Liver disease-associated osteoporosis seems to be multifactorial; retained substances such as bile acids and bilirubin, elevated iron and pro-inflammatory cytokines are assumed to play a pathophysiological role in low osteoblast activity $[98,100]$.

Ovariectomy-induced menopause mice model was used to address whether elevation of body iron stores play a pathophysiological role in postmenopausal osteoporosis [101]. These studies revealed that excess iron does contribute to bone loss after menopause, through the generation of oxidative stress [101,102].

\section{Bone Homeostasis in Iron Deficiency}

Iron deficiency is a common disease which affects almost 1.2 billion people worldwide [103]. The most frequent consequence of iron insufficiency is anemia, due to lack of iron for heme biosynthesis. Besides its fundamental role in oxygen delivery, iron is involved in diverse enzymatic systems throughout the body. Regarding bone physiology, iron is critically involved in 2 processes, i.e., collagen production and metabolism of vitamin $\mathrm{D}$ and therefore iron deficiency is considered to have a detrimental impact on bone homeostasis [104,105] (Figure 1A).

Bone tissue is rich in collagen type I, the synthesis of which involves hydroxylation of pro-collagen on proline and lysine residues. The reactions of hydroxylation are catalyzed by prolyl-4-hydroxylase and lysyl-hydroxylase, the enzymes of which require ferrous iron for their catalytic activities $[106,107]$.

Active vitamin D plays an important role in bone homeostasis through regulating intestinal uptake and tubular reabsorption of calcium and phosphate, the major inorganic components of bones [108]. Vitamin D activation is regulated by enzymes of the cytochrome P450 family which enzymes contain heme as a prosthetic groups, therefore their activities are dependent on availability of iron [109].

The effect of iron deficiency on bone health was addressed in several animal studies [104]. These studies revealed that severe nutritional iron restriction causes unbalanced bone turnover, leading eventually to bone weakening, characterized by low BMD and decreased bone mineral content [110-112]. Besides iron, nutritional restriction of other trace elements such as copper and selenium have been shown to compromise skeletal health [113].

On the other hand, we mostly lack information about the relevance of iron deficiency on bone health in humans. In a small study with the involvement of about 100 young iron-deficient but otherwise healthy women, the authors examined the relationship between bone metabolism and iron status [114]. This study revealed that the aminoterminal telopeptide of collagen I, that is a biomarker of bone resorption, negatively correlates to ferritin levels and concluded that iron deficiency is linked to higher rate of bone resorption [114]. Pharmacological iron treatment reduced accelerated bone remodeling in pre-menopausal women with iron-deficiency anemia [115].

\section{Cellular Mechanisms Underlying Bone Loss in Iron-Overload}

\subsection{Iron Overload and Bone Resorption}

Bone destruction is carried out by osteoclasts, the highly specialized cells originating from myeloid cells of the monocyte/macrophage lineage. Mounting evidence show that excess iron facilitates osteoclastogenesis and increases bone-resorbing activity of mature osteoclasts (Figure 1B). 
As it was previously discussed, the RANKL/OPG system is the central regulator of osteoclast differentiation and activation [116]. It has been shown that iron promotes RANKL-induced osteoclast differentiation of RAW264.7 cells, as well as bone marrow-derived macrophages [117]. Differentiation of osteoclasts is associated with remarkable changes of cellular iron homeostasis promoting iron uptake, utilization and reduced iron excretion. In line of this notion, it has been shown that expressions of divalent metal transporter 1 (DMT1) and transferrin receptor 1 (Tfr1) are responsible for cellular uptake of non-transferrin bound (NTB) and that transferrin-bound iron respectively are increased, together with Steap4, an endosomal ferrireductase, that plays a key role in cellular iron utilization, while the expression of ferroportin (FPN), the only known iron exporter, is downregulated at the initial stages of osteoclast differentiation [118-122]. Additionally, a recent study showed that deletion of FPN in myeloid cells in mice triggers accumulation of iron and stimulates osteoclastogenic differentiation in vitro as well as in vivo [123]. Deficiency of the heme degrading enzyme HO-1 paradoxically results in accumulation of non heme iron in diverse cells in both humans and mice [124,125]. Interestingly, it has been shown that HO-1 upregulation by heme inhibits osteoclastogenesis leading to decreased bone resorption [126]. Further investigation of this phenomenon revealed that HO-1 is involved in the early stage of osteoclast differentiation induced by RANKL [127].

Osteoclasts are considered high energy demand cells as they actively pump out protons to the absorption cavity to dissolve hydroxyapatite mineral, secrete proteolytic enzymes to degrade collagen, meanwhile they need to maintain their motility $[119,128,129]$. This high energy demand of osteoclasts requires much mitochondria $[119,128,129]$. Mitochondrial biogenesis is a process highly dependent on the availability of iron, which could explain the high iron demand, and metabolic adaptation towards increased iron uptake and reduced iron excretion of differentiating osteoclasts [119].

Iron participates in ROS generation, and some studies revealed that iron-induced accelerated Production of ROS plays a central role in iron-mediated promotion of osteoclastogenesis [101,121]. A recent study showed that iron stimulates osteoclastogenesis of bone marrow-derived macrophages in a mechanism dependent on ROS production and the activation of NF- $\mathrm{kB}$ signaling pathway [130]. Suppression of NF-kB signaling attenuates osteoclast differentiation [130].

Growing evidence suggests that iron not only affects osteoclastogenesis, but influences mature osteoclast activity and bone resorption too. Mature osteoclasts highly express TRAP, an enzyme that catalyzes the dephosphorylation of bone matrix proteins including bone sialoprotein and osteopontin [131]. Inhibition of TRAP activity in osteoclasts abolishes bone resorption and TRAP deficient mice have a mild osteopetrotic phenotype characterized by increased amount of bone tissue and elevated mineral density $[132,133]$. TRAP is an iron-containing enzyme, the activity of which is dependent on ferric iron $[134,135]$. Expression of TRAP is regulated by iron through an iron regulatory element located at the TRAP 5 '-flanking region [136].

Several in vivo studies concluded that bone-loss observed in iron-overload conditions is due to accelerated bone destruction rather than decreased bone formation. Different mice models of iron overload revealed that the osteoporotic phenotype is accompanied by elevation of osteoclast number in the bone tissue $[84,88]$. Furthermore, the level of C-telopeptide of type-I collagen, a serum marker of bone resorption was found to be elevated in hepcidin deficient mice, suggesting that elevated activity of osteoclasts induces bone-loss in association with iron-overload [87].

\subsection{Iron Overload and Bone Formation}

Osteoblasts derive from multipotent mesenchymal stem cells (MSCs), under the control of the master osteogenic transcription factor Runx2. Recently it has been shown that excess iron inhibits osteogenic differentiation of MSCs through the downregulation of Runx2 [137] (Figure 1C). The inhibitory effect of iron was dependent on the upregulation of ferritin, the key intracellular iron storage protein [137]. Some other studies reported that superparamagnetic iron oxide nanoparticles also impair osteogenesis of human MSCs, the effect of which is reversed by the iron chelator desferrioxamine (DFO) $[138,139]$. Iron loaded fetal rat calvaria cells lose the capacity to form mineralized bone nodules 
and show decreased expressions of osteoblast phenotypic markers, suggesting that iron not only attenuates osteogenic differentiation of MSCs, but disturbs mineralization of the extracellular matrix of osteoblasts [140].

This phenomenon was further investigated and early studies showed that excess iron attenuates proliferation as well as function of osteosarcoma cells [141]. Osteoblasts respond to iron overload by fast and persistent down-regulation of transferrin receptor and up-regulation of ferritin light and heavy chains (FtL and FtH) [140]. Parallel with these responses, suppression of osteoblast phenotype gene markers occurs, eventually leading to a reduction in the number of mineralized nodules [140]. Recently it has been shown that excess iron downregulates the expression of Runx 2 and its downstream targets OCN and ALP in human osteoblasts, leading eventually to attenuation of extracellular matrix mineralization in osteoblasts [142]. Increased expression of ferritin, and in particular, ferroxidase activity of the FtH subunit, seems to play a critical role in the iron-mediated suppression of osteoblast activity and the diminished extracellular matrix mineralization [142,143]. Further studies revealed that excess iron inhibits extracellular matrix mineralization of BMP2-induced osteoblasts through a mechanism dependent on HedgeHog signaling [144,145]. Additionally high iron inhibits extracellular matrix mineralization triggered by a mixture of activated vitamin $\mathrm{D}_{3}$ and $\beta$-glycerophosphate via the upregulation of FtH [146].

In vivo studies revealed that decreased bone formation contributes to bone-loss in iron-overload conditions such as in th 3 thalassemia mice and hemizygous $\beta$-globin knockout mice $[93,95]$. Additionally, Hfe deficiency is found to be associated with decreased numbers of active osteoblasts [89]. Decreased mRNA levels of osteoblast-specific proteins such as ALP, Runx2, osterix and OCN were detected in the tibia of Townes transgenic sickle mice [97]. Hepcidin deficiency was associated with decreased osteoblast activity characterized by low serum OCN level in mice and reduced mRNA levels of Runx2 and osterix in zebrafish [90]. A recent study revealed that iron treatment induces a reduction in Runx2 mRNA level in compact-bone resident osteoprogenitor cells in mice, suggesting that iron negatively influences osteogenic commitment and differentiation, in vivo [137].

\section{Effect of Iron Deficiency on Osteoclast and Osteoblast Differentiation and Function}

As discussed before, iron overload undoubtedly increases osteoclast differentiation and activity, while inhibiting osteoblast differentiation and function. The effect of iron deficiency on these cells has not been fully addressed and remained somehow controversial.

\subsection{Iron Deficiency and Bone Resorption}

Several studies suggested that iron deficiency decreases differentiation as well as activity of osteoclasts, which eventually leads to improvement of bone density. In line of this notion, it has been shown that lactoferrin, an endogenous iron-binding glycoprotein inhibits osteoclastogenic differentiation of monocytes, reduces the expression of RANKL, and improves bone density via decreasing RANKL/OPG ratio $[147,148]$. Further in vitro studies showed that the iron chelators clinoquinol and deferoxamine (DFO) inhibit osteoclast differentiation, as demonstrated by the attenuation of osteoclasts formation and suppression of osteoclast specific genes expression [149,150]. A recent in vivo study investigated the effect of iron chelators on the remodeling of bioceramic bone graft. The study revealed that local administration of iron chelators reduced graft resorption in correlation with a marked decrease in the number of osteoclasts at the interface of bone and the graft [151].

Ferric ion is needed for the activity of TRAP, therefore TRAP activity and osteoclast function is inhibited by a ferric chelator [134,135].

On the other hand, hypoxia response also contributes to the overall effect of iron chelation on osteoclast activity and bone resorption. Hypoxia response is regulated by the hypoxia inducible factor (HIF), a heterodimer transcription factor composed by an inducible alpha subunit (HIF-1 $\alpha$ ) and a constitutively expressed beta subunit (HIF- $\beta$ ). Under normoxic condition, HIF- $1 \alpha$ is hydroxylated by 
prolyl-4-hydroxylase enzymes (PHDs) and degraded in proteosome. Reduced PHD enzyme activity leads to HIF- $1 \alpha$ accumulation, nuclear translocation, dimerization with HIF- $\beta$, and binding to the hypoxia-response element of genes under the transcriptional control of HIF [152]. Catalytic activities of the PHDs require iron, and therefore, iron chelators inhibit hydroxylation of HIF- $1 \alpha$ and activate HIF signaling [153]. It has been shown that HIF activation enhances bone resorption activity of osteoclasts [154-156]. This mechanism might contribute to bone loss associated with chronic iron-deficiency [104].

\subsection{Iron Deficiency and Bone Formation}

Although the negative influence of excess iron on bone formation is quite clear, we have conflicting observations about how iron deficiency affects this process. Some studies describe a negative effect of bone restriction on osteoblast function and bone formation in rats [157,158]. Other studies found that iron chelation promotes osteogenic differentiation and osteoblast activity $[142,159,160]$. This discrepancy might be due to the different chelation procedures used in the different studies. A recent detailed study revealed that the effect of low iron is biphasic; mild low iron increases osteoblast activity, whereas very low levels of iron inhibits osteoblast activity [161]. Iron deficiency is often associated with anemia. The effect of this condition on bone homeostasis was investigated in a zebrafish model. Iron deficiency anemia was associated with defects in bone formation, assessed by reduced number of calcified vertebrae and decreased expression of osteoblast specific genes [162].

\section{Targeting Iron as a Therapeutic Approach to Treat Bone Loss in Association with Iron Ovreload}

Because of the close association between iron overload and osteoporosis, different therapeutic approaches to decrease iron level may have clinical potential for the prevention and/or treatment of iron overload-associated osteoporosis. In clinical practice, systemic iron overload is treated with iron chelators such as DFO, deferiprone, and deferasirox [163-165]. The effect of the iron chelation therapy on bone health was addressed in several studies performed with the involvement of iron-overload patients. Well-designed chelation therapy has been proved to prevent the occurrence of osteopenia and/or osteoporosis in the first twenty years in in thalassemia patients [166]. Deferasirox therapy prevented bone loss and decreased the prevalence of lumbar spine osteoporosis in adult $\beta$-thalassemia major patients [167]. In a recent study, the efficiency of the different iron chelators were compared in the prevention of bone disease in $\beta$-thalassemia major patients [168]. The authors found that deferasirox significantly increased the mean BMD T-score and decreased the occurrence of osteoporosis, but DFO or deferiprone alone or in combination, had no beneficial effects on the bones [168]. Despite the fact that these studies suggested that properly designed iron chelation therapy is able to prevent iron overload-associated bone abnormalities, bone disease remained an unsolved and caused quite frequent complication in patients with iron overload [169]. This warrants further studies to optimize the chelation regimen for different iron-overload conditions, and the search for alternative therapeutic strategies for lowering iron. Hepcidin, the master regulator of iron homeostasis seems to be a promising target in the treatment of iron overload-associated bone loss [170].

\section{Concluding Remarks}

There is an evident detrimental effect of iron excess or bone homeostasis which can manifest itself in different ways, including low BMD, osteoporosis or osteopenia as well as altered microarchitecture and biomechanics. These conditions increase the incidence of pathologic fractures in patients suffering from diverse types of iron overload. The effect of iron deficiency on bone health is less clear, but some studies suggest that this condition is also associated with weakened bones, highlighting that balanced bone homeostasis requires optimal—not too low, not too high—iron levels.

Bone homeostasis involves bone destruction driven by osteoclasts, and bone formation by osteoblasts, the processes of which are interconnected and tightly regulated, assuring the maintenance 
of skeletal health. Differentiation as well as cellular activity of both osteoclasts and osteoblasts is influenced by excess iron resulting to a net effect on bone loss.

Osteocytes, the third cell type in bone tissue have an emerging role in bone homeostasis and remodeling, but we lack complete information about whether iron excess or deficiency influences their activity and function [171]. Additionally, further studies are needed to identify the signaling mechanisms underneath the effect of iron excess and deficiency on the differentiation and function of osteoclasts and osteoblasts.

Iron lowering therapeutic interventions could prevent or improve iron overload-associated bone abnormalities. We need further studies to reveal that keeping serum iron concentration in the target zone with the use of iron chelators can normalize bone homeostasis in patients with different forms of iron overload. Additionally, trials are needed to investigate the efficiency of iron chelation therapy in the treatment of postmenopausal osteoporosis.

Author Contributions: Conceptualization, V.J.; Writing, Original Draft Preparation, E.B. and V.J.; Writing, Review and Editing, G.P. and V.J.; Supervision, V.J.; Funding Acquisition, G.P. and V.J.

Funding: This research was funded by the National Research, Development and Innovation Office (NKFIH) grant number K116024 and by the European Union and the European Social Fund, grant number GINOP-2.3.2-15-2016-00005.

Conflicts of Interest: The authors declare no conflict of interest.

\section{References}

1. Florencio-Silva, R.; da Silva Sasso, G.R.; Sasso-Cerri, E.; Simões, M.J.; Cerri, P.S. Biology of Bone Tissue: Structure, Function, and Factors That Influence Bone Cells. Biomed. Res. Int. 2015, 421746. [CrossRef] [PubMed]

2. Hadjidakis, D.J.; Androulakis, I.I. Bone remodeling. Ann. N. Y. Acad. Sci. 2006, 1092, 385-396. [CrossRef] [PubMed]

3. Soltanoff, C.S.; Chen, W.; Yang, S.; Li, Y.P. Signaling Networks that Control the Lineage Commitment and Differentiation of Bone Cells. Crit. Rev. Eukaryot. Gene Expr. 2009, 19, 1-46. [CrossRef] [PubMed]

4. Teitelbaum, S.L.; Ross, F.P. Genetic regulation of osteoclast development and function. Nat. Rev. Genet. 2003, 4, 638-649. [CrossRef] [PubMed]

5. Ikeda, K.; Takeshita, S. The role of osteoclast differentiation and function in skeletal homeostasis. J. Biochem. 2016, 159, 1-8. [CrossRef] [PubMed]

6. Amarasekara, D.S.; Yun, H.; Kim, S.; Lee, N.; Kim, H.; Rho, J. Regulation of Osteoclast Differentiation by Cytokine Networks. Immune Netw. 2018, 18, e8. [CrossRef] [PubMed]

7. Kodama, H.; Yamasaki, A.; Nose, M.; Niida, S.; Ohgame, Y.; Abe, M.; Kumegawa, M.; Suda, T. Congenital osteoclast deficiency in osteopetrotic (op/op) mice is cured by injections of macrophage colony-stimulating factor. J. Exp. Med. 1991, 173, 269-272. [CrossRef] [PubMed]

8. Yasuda, H.; Shima, N.; Nakagawa, N.; Yamaguchi, K.; Kinosaki, M.; Mochizuki, S.; Tomoyasu, A.; Yano, K.; Goto, M.; Murakami, A.; et al. Osteoclast differentiation factor is a ligand for osteoprotegerin osteoclastogenesis-inhibitory factor and is identical to TRANCE/RANKL. Proc. Natl. Acad. Sci. USA 1998, 95, 3597-3602. [CrossRef] [PubMed]

9. Takahashi, N.; Udagawa, N.; Suda, T. A new member of tumor necrosis factor ligand family, ODF/OPGL/TRANCE/RANKL, regulates osteoclast differentiation and function. Biochem. Biophys. Res. Commun. 1999, 256, 449-455. [CrossRef] [PubMed]

10. Kong, Y.Y.; Yoshida, H.; Sarosi, I.; Tan, H.L.; Timms, E.; Capparelli, C.; Morony, S.; Oliveira-dos-Santos, A.J.; Van, G.; Itie, A.; et al. OPGL is a key regulator of osteoclastogenesis, lymphocyte development and lymph-node organogenesis. Nature 1999, 397, 315-323. [CrossRef] [PubMed]

11. Takayanagi, H. Osteoimmunology: Shared mechanisms and crosstalk between the immune and bone systems. Nat. Rev. Immunol. 2007, 7, 292-304. [CrossRef] [PubMed]

12. Takayanagi, H.; Kim, S.; Koga, T.; Nishina, H.; Isshiki, M.; Yoshida, H.; Saiura, A.; Isobe, M.; Yokochi, T.; Inoue, J.; et al. Induction and activation of the transcription factor NFATc1 (NFAT2) integrate RANKL signaling in terminal differentiation of osteoclasts. Dev. Cell 2002, 3, 889-901. [CrossRef] 
13. Kim, J.H.; Kim, N. Regulation of NFATc1 in Osteoclast Differentiation. J. Bone Metab. 2014, 21, $233-241$. [CrossRef] [PubMed]

14. Boyce, B.F.; Xing, L. Biology of RANK, RANKL, and osteoprotegerin. Arthritis Res. Ther. 2007, 9, S1. [CrossRef] [PubMed]

15. Fiedler, J.; Röderer, G.; Günther, K.P.; Brenner, R.E. BMP-2, BMP-4, and PDGF-bb stimulate chemotactic migration of primary human mesenchymal progenitor cells. J. Cell Biochem. 2002, 87, 305-312. [CrossRef] [PubMed]

16. Tang, Y.; Wu, X.; Lei, W.; Pang, L.; Wan, C.; Shi, Z.; Zhao, L.; Nagy, T.R.; Peng, X.; Hu, J.; et al. TGF-beta1-induced migration of bone mesenchymal stem cells couples bone resorption with formation. Nat. Med. 2009, 15, 757-765. [CrossRef] [PubMed]

17. Pederson, L.; Ruan, M.; Westendorf, J.J.; Khosla, S.; Oursler, M.J. Regulation of bone formation by osteoclasts involves Wnt/BMP signaling and the chemokine sphingosine-1-phosphate. Proc. Natl. Acad. Sci. USA 2008, 105, 20764-20769. [CrossRef] [PubMed]

18. Otto, F.; Thornell, A.P.; Crompton, T.; Denzel, A.; Gilmour, K.C.; Rosewell, I.R.; Stamp, G.W.H.; Beddington, R.S.P.; Mundlos, S.; Olsen, B.R.; et al. Cbfa1, a candidate gene for cleidocranial dysplasia syndrome, is essential for osteoblast differentiation and bone development. Cell 1997, 89, 765-771. [CrossRef]

19. Komori, T.; Yagi, H.; Nomura, S.; Yamaguchi, A.; Sasaki, K.; Deguchi, K.; Shimizu, Y.; Bronson, R.T.; Gao, Y.H.; Inada, M.; et al. Targeted disruption of Cbfa1 results in a complete lack of bone formation owing to maturational arrest of osteoblasts. Cell 1997, 89, 755-764. [CrossRef]

20. Ducy, P.; Zhang, R.; Geoffroy, V.; Ridall, A.L.; Karsenty, G. Osf2/Cbfa1: A transcriptional activator of osteoblast differentiation. Cell 1997, 89,747-754. [CrossRef]

21. Hayrapetyan, A.; Jansen, J.A.; van den Beucken, J.J. Signaling pathways involved in osteogenesis and their application for bone regenerative medicine. Tissue Eng. Part B Rev. 2015, 21, 75-87. [CrossRef] [PubMed]

22. Franceschi, R.T.; Xiao, G.; Jiang, D.; Gopalakrishnan, R.; Yang, S.; Reith, E. Multiple signaling pathways converge on the Cbfa1/Runx2 transcription factor to regulate osteoblast differentiation. Connect. Tissue Res. 2003, 44, 109-116. [CrossRef] [PubMed]

23. Atashi, F.; Modarressi, A.; Pepper, M.S. The role of reactive oxygen species in mesenchymal stem cell adipogenic and osteogenic differentiation: A review. Stem Cells Dev. 2015, 24, 1150-1163. [CrossRef] [PubMed]

24. Muckenthaler, M.U.; Rivella, S.; Hentze, M.W.; Galy, B. A Red Carpet for Iron Metabolism. Cell 2017, 168, 344-361. [CrossRef] [PubMed]

25. Vijayan, V.; Wagener, F.; Immenschuh, S. The macrophage heme-heme oxygenase-1 system and its role in inflammation. Biochem. Pharmacol. 2018, 153, 159-167. [CrossRef] [PubMed]

26. Mancias, J.D.; Wang, X.; Gygi, S.P.; Harper, J.W.; Kimmelman, A.C. Quantitative proteomics identifies NCOA4 as the cargo receptor mediating ferritinophagy. Nature 2014, 509, 105-109. [CrossRef] [PubMed]

27. Hentze, M.W.; Muckenthaler, M.U.; Galy, B.; Camaschella, C. Two to Tango: Regulation of Mammalian Iron Metabolism. Cell 2010, 142, 24-38. [CrossRef] [PubMed]

28. Pfeiffer, C.M.; Looker, A.C. Laboratory methodologies for indicators of iron status: Strengths, limitations, and analytical challenges. Am. J. Clin. Nutr. 2017, 106, 1606S-1614S. [CrossRef] [PubMed]

29. McLaren, G.D.; Gordeuk, V.R. Hereditary hemochromatosis: Insights from the Hemochromatosis and Iron Overload Screening (HEIRS) Study. Hematol. Am. Soc. Hematol. 2009, 2009, 195-206. [CrossRef] [PubMed]

30. Feder, J.N.; Gnirke, A.; Thomas, W.; Tsuchihashi, Z.; Ruddy, D.A.; Basava, A.; Dormishian, F.; Domingo, R., Jr.; Ellis, M.C.; Fullan, A.; et al. A novel MHC class I-like gene is mutated in patients with hereditary haemochromatosis. Nat. Genet. 1996, 13, 399-408. [CrossRef] [PubMed]

31. Camaschella, C.; Roetto, A.; Calì, A.; De Gobbi, M.; Garozzo, G.; Carella, M.; Majorano, N.; Totaro, A.; Gasparini, P. The gene TFR2 is mutated in a new type of haemochromatosis mapping to 7q22. Nat. Genet. 2000, 25, 14-15. [CrossRef] [PubMed]

32. Papanikolaou, G.; Samuels, M.E.; Ludwig, E.H.; MacDonald, M.L.E.; Franchini, P.L.; Dubé, M.P.; Andres, L.; MacFarlane, J.; Sakellaropoulos, N.; Politou, M.; et al. Mutations in HFE2 cause iron overload in chromosome 1q-linked juvenile hemochromatosis. Nat. Genet. 2004, 36, 77-82. [CrossRef] [PubMed]

33. Roetto, A.; Papanikolaou, G.; Politou, M.; Alberti, F.; Girelli, D.; Christakis, J.; Loukopoulos, D.; Camaschella, C. Mutant antimicrobial peptide hepcidin is associated with severe juvenile hemochromatosis. Nat. Genet. 2003, 33, 21-22. [CrossRef] [PubMed] 
34. Pietrangelo, A. The ferroportin disease. Blood Cells Mol. Dis. 2004, 32, 131-138. [CrossRef] [PubMed]

35. ElAlfy, M.S.; Elsherif, N.H.K.; Ebeid, F.S.E.; Ismail, E.A.R.; Ahmed, K.A.; Darwish, Y.W.; Ibrahim, A.S.; Elghamry, I.R.F.; Shokrey, N.A.; Alajeil, D.N. Renal iron deposition by magnetic resonance imaging in pediatric beta-thalassemia major patients: Relation to renal biomarkers, total body iron and chelation therapy. Eur. J. Radiol. 2018, 103, 65-70. [CrossRef] [PubMed]

36. Ebert, E.C.; Nagar, M.; Hagspiel, K.D. Gastrointestinal and hepatic complications of sickle cell disease. Clin. Gastroenterol. Hepatol. 2010, 8, 483-489. [CrossRef] [PubMed]

37. Allali, S.; de Montalembert, M.; Brousse, V.; Chalumeau, M.; Karim, Z. Management of iron overload in hemoglobinopathies. Transfus. Clin. Biol. 2017, 24, 223-226. [CrossRef] [PubMed]

38. Milic, S.; Mikolasevic, I.; Orlic, L.; Devcic, E.; Starcevic-Cizmarevic, N.; Stimac, D.; Kapovic, M.; Ristic, S. The Role of Iron and Iron Overload in Chronic Liver Disease. Med. Sci. Monit. 2016, 22, 2144-2151. [CrossRef] [PubMed]

39. Kato, I.; Dnistrian, A.; Schwartz, M.; Toniolo, P.; Koenig, K.; Shore, R.; Zeleniuch-Jacquotte, A.; Akhmedkhanov, A.; Riboli, E. Risk of iron overload among middle-aged women. Int. J. Vitam. Nutr. Res. 2000, 70, 119-125. [CrossRef]

40. Cade, J.E.; Moreton, J.A.; O’Hara, B.; Greenwood, D.C.; Moor, J.; Burley, V.J.; Kukalizch, K.; Bishop, D.T.; Worwood, M. Diet and genetic factors associated with iron status in middle-aged women. Am. J. Clin. Nutr. 2005, 82, 813-820. [CrossRef]

41. Liu, J.M.; Hankinson, S.E.; Stampfer, M.J.; Rifai, N.; Willett, W.C.; Ma, J. Body iron stores and their determinants in healthy postmenopausal US women. Am. J. Clin. Nutr. 2003, 78, 1160-1167. [CrossRef] [PubMed]

42. Milman, N.; Byg, K.E.; Ovesen, L.; Kirchhoff, M.; Jürgensen, K.S.L. Iron status in Danish women, 1984-1994: A cohort comparison of changes in iron stores and the prevalence of iron deficiency and iron overload. Eur. J. Haematol. 2003, 71, 51-61. [CrossRef] [PubMed]

43. Jeney, V. Clinical Impact and Cellular Mechanisms of Iron Overload-Associated Bone Loss. Front. Pharmacol. 2017, 8, 77. [CrossRef] [PubMed]

44. Diamond, T.; Stiel, D.; Posen, S. Osteoporosis in hemochromatosis: Iron excess, gonadal deficiency, or other factors? Ann. Intern. Med. 1989, 110, 430-436. [CrossRef] [PubMed]

45. Sinigaglia, L.; Fargion, S.; Fracanzani, A.L.; Binelli, L.; Battafarano, N.; Varenna, M.; Piperno, A.; Fiorelli, G. Bone and joint involvement in genetic hemochromatosis: Role of cirrhosis and iron overload. J. Rheumatol. 1997, 24, 1809-1813. [PubMed]

46. Guggenbuhl, P.; Deugnier, Y.; Boisdet, J.F.; Rolland, Y.; Perdriger, A.; Pawlotsky, Y.; Chalès, G. Bone mineral density in men with genetic hemochromatosis and HFE gene mutation. Osteoporos. Int. 2005, 16, 1809-1814. [CrossRef] [PubMed]

47. Angelopoulos, N.G.; Goula, A.K.; Papanikolaou, G.; Tolis, G. Osteoporosis in HFE2 juvenile hemochromatosis. A case report and review of the literature. Osteoporos. Int. 2006, 17, 150-155. [CrossRef] [PubMed]

48. Valenti, L.; Varenna, M.; Fracanzani, A.L.; Rossi, V.; Fargion, S.; Sinigaglia, L. Association between iron overload and osteoporosis in patients with hereditary hemochromatosis. Osteoporos. Int. 2009, 20, 549-555. [CrossRef] [PubMed]

49. Richette, P.; Ottaviani, S.; Vicaut, E.; Bardin, T. Musculoskeletal complications of hereditary hemochromatosis: A case-control study. J. Rheumatol. 2010, 37, 2145-2150. [CrossRef] [PubMed]

50. Eyres, K.S.; McCloskey, E.V.; Fern, E.D.; Rogers, S.; Beneton, M.; Aaron, J.E.; Kanis, J.A. Osteoporotic fractures: An unusual presentation of haemochromatosis. Bone 1992, 13, 431-433. [CrossRef]

51. Duquenne, M.; Rohmer, V.; Legrand, E.; Chappard, D.; Barbot, N.W.; Basle, M.F.; Audran, M.; Bigorgne, J.C. Spontaneous multiple vertebral fractures revealed primary haemochromatosis. Osteoporos. Int. 1996, 6, 338-340. [CrossRef] [PubMed]

52. Weatherall, D.J. The thalassaemias. Br. Med. J. 1997, 314, 1675-1678. [CrossRef]

53. Bayanzay, K.; Alzoebie, L. Reducing the iron burden and improving survival in transfusion-dependent thalassemia patients: Current perspectives. J. Blood Med. 2016, 7, 159-169. [CrossRef] [PubMed]

54. Dede, A.D.; Trovas, G.; Chronopoulos, E.; Triantafyllopoulos, I.K.; Dontas, I.; Papaioannou, N.; Tournis, S. Thalassemia-associated osteoporosis: A systematic review on treatment and brief overview of the disease. Osteoporos. Int. 2016, 27, 3409-3425. [CrossRef] [PubMed] 
55. Gaudio, A.; Morabito, N.; Catalano, A.; Rapisarda, R.; Xourafa, A.; Lasco, A. Pathogenesis of Thalassemia Major-Associated Osteoporosis: Review of the Literature and Our Experience. J. Clin. Res. Pediatr. Endocrinol. 2018. [CrossRef] [PubMed]

56. De Sanctis, V.; Soliman, A.T.; Elsefdy, H.; Soliman, N.; Bedair, E.; Fiscina, B.; Kattamis, C. Bone disease in beta thalassemia patients: Past, present and future perspectives. Metabolism 2018, 80, 66-79. [CrossRef] [PubMed]

57. Exarchou, E.; Politou, C.; Vretou, E.; Pasparakis, D.; Madessis, G.; Caramerou, A. Fractures and epiphyseal deformities in beta-thalassemia. Clin. Orthop. Relat. Res. 1984, 189, 229-233. [CrossRef]

58. Finsterbush, A.; Farber, I.; Mogle, P.; Goldfarb, A. Fracture patterns in thalassemia. Clin. Orthop. Relat. Res. 1985, 192, 132-136. [CrossRef]

59. Dines, D.M.; Canale, V.C.; Arnold, W.D. Fractures in thalassemia. J. Bone Joint Surg. Am. 1976, 58, 662-666. [CrossRef] [PubMed]

60. Fung, E.B.; Harmatz, P.R.; Milet, M.; Coates, T.D.; Thompson, A.A.; Ranalli, M.; Mignaca, R.; Scher, C.; Giardina, P.; Robertson, S.; et al. Fracture prevalence and relationship to endocrinopathy in iron overloaded patients with sickle cell disease and thalassemia. Bone 2008, 43, 162-168. [CrossRef] [PubMed]

61. Ruggiero, L.; De Sanctis, V. Multicentre study on prevalence of fractures in transfusion-dependent thalassaemic patients. J. Pediatr. Endocrinol. Metab. 1998, 11, 773-778. [PubMed]

62. Vogiatzi, M.G.; Macklin, E.A.; Fung, E.B.; Vichinsky, E.; Olivieri, N.; Kwiatkowski, J.; Cohen, A.; Neufeld, E.; Giardina, P.J. Prevalence of fractures among the Thalassemia syndromes in North. America. Bone 2006, 38, 571-575. [CrossRef] [PubMed]

63. Baldini, M.; Ulivieri, F.M.; Forti, S.; Serafino, S.; Seghezzi, S.; Marcon, A.; Giarda, F.; Messina, C.; Cassinerio, E.; Aubry-Rozier, B.; et al. Spine bone texture assessed by trabecular bone score (TBS) to evaluate bone health in thalassemia major. Calcif. Tissue Int. 2014, 95, 540-546. [CrossRef] [PubMed]

64. Miller, R.G.; Segal, J.B.; Ashar, B.H.; Leung, S.; Ahmed, S.; Siddique, S.; Rice, T.; Lanzkron, S. High prevalence and correlates of low bone mineral density in young adults with sickle cell disease. Am. J. Hematol. 2006, 81, 236-241. [CrossRef] [PubMed]

65. Sadat-Ali, M.; Al-Elq, A.H.; Sultan, O.; Al-Turki, H.; Bukhari, R.; Al-Mulhim, E. Low bone mass due to sickle cell anemia: Is it becoming a real issue? West Afr. J. Med. 2008, 27, 218-223. [PubMed]

66. Sadat-Ali, M.; Al Elq, A.H. Sickle cell anaemia: Is it a cause for secondary osteoporosis? West Afr. J. Med. 2007, 26, 134-137. [PubMed]

67. Sarrai, M.; Duroseau, H.; D'Augustine, J.; Moktan, S.; Bellevue, R.; et al. Bone mass density in adults with sickle cell disease. Br. J. Haematol. 2007, 136, 666-672. [CrossRef] [PubMed]

68. Almeida, A.; Roberts, I. Bone involvement in sickle cell disease. Br. J. Haematol. 2005, 129, 482-490. [CrossRef] [PubMed]

69. Osunkwo, I. An update on the recent literature on sickle cell bone disease. Curr. Opin. Endocrinol. Diabetes Obes. 2013, 20, 539-546. [CrossRef] [PubMed]

70. Baldanzi, G.; Traina, F.; Marques Neto, J.F.; Santos, A.O.; Ramos, C.D.; Saad, S.T.; et al. Low bone mass density is associated with hemolysis in Brazilian patients with sickle cell disease. Clinics 2011, 66, 801-805. [CrossRef] [PubMed]

71. Koren, A.; Fink, D.; Admoni, O.; Tennenbaum-Rakover, Y.; Levin, C.; et al. Non-transferrin-bound labile plasma iron and iron overload in sickle-cell disease: A comparative study between sickle-cell disease and beta-thalassemic patients. Eur. J. Haematol. 2010, 84, 72-78. [CrossRef] [PubMed]

72. Koduri, P.R. Iron in sickle cell disease: A review why less is better. Am. J. Hematol. 2003, 73, 59-63. [CrossRef] [PubMed]

73. Natta, C.; Creque, L.; Navarro, C. Compartmentalization of iron in sickle cell anemia-An autopsy study. Am. J. Clin. Pathol. 1985, 83, 76-78. [CrossRef] [PubMed]

74. Sadat-Ali, M.; Sultan, O.; Al-Turki, H.; Alelq, A. Does high serum iron level induce low bone mass in sickle cell anemia? Biometals 2011, 24, 19-22. [CrossRef] [PubMed]

75. Milman, N.; Kirchhoff, M. Iron stores in 1359, 30- to 60-year-old Danish women: Evaluation by serum ferritin and hemoglobin. Ann. Hematol. 1992, 64, 22-27. [CrossRef] [PubMed]

76. Zacharski, L.R.; Ornstein, D.L.; Woloshin, S.; Schwartz, L.M. Association of age, sex, and race with body iron stores in adults: Analysis of NHANES III data. Am. Heart J. 2000, 140, 98-104. [CrossRef] [PubMed]

77. Jian, J.; Pelle, E.; Huang, X. Iron and menopause: Does increased iron affect the health of postmenopausal women? Antioxid. Redox Signal. 2009, 11, 2939-2943. [CrossRef] [PubMed] 
78. Black, D.M.; Rosen, C.J. Postmenopausal Osteoporosis. N. Engl. J. Med. 2016, 374, 2096-2097. [CrossRef] [PubMed]

79. Cummings, S.R.; Black, D.M.; Rubin, S.M. Lifetime risks of hip, Colles', or vertebral fracture and coronary heart disease among white postmenopausal women. Arch. Intern. Med. 1989, 149, 2445-2448. [CrossRef] [PubMed]

80. Cummings, S.R.; Melton, L.J. Epidemiology and outcomes of osteoporotic fractures. Lancet 2002, 359, 1761-1767. [CrossRef]

81. Kim, B.J.; Lee, S.H.; Koh, J.M.; Kim, G.S. The association between higher serum ferritin level and lower bone mineral density is prominent in women $\geq 45$ years of age (KNHANES 2008-2010). Osteoporos. Int. 2013, 24, 2627-2637. [CrossRef] [PubMed]

82. Kim, B.J.; Ahn, S.H.; Bae, S.J.; Kim, E.H.; Lee, S.H.; Kim, H.K.; Choe, J.W.; Koh, J.M.; Kim, G.S. Iron overload accelerates bone loss in healthy postmenopausal women and middle-aged men: A 3-year retrospective longitudinal study. J. Bone Miner. Res. 2012, 27, 2279-2290. [CrossRef] [PubMed]

83. Babaei, M.; Bijani, A.; Heidari, P.; Hosseini, S.R.; Heidari, B. Serum ferritin levels and bone mineral density in the elderly. Caspian J. Intern. Med. 2018, 9, 232-238. [PubMed]

84. Tsay, J.; Yang, Z.; Ross, F.P.; Cunningham-Rundles, S.; Lin, H.; Coleman, R.; Mayer-Kuckuk, P.; Doty, S.B.; Grady, R.W.; Giardina, P.J.; et al. Bone loss caused by iron overload in a murine model: Importance of oxidative stress. Blood 2010, 116, 2582-2589. [CrossRef] [PubMed]

85. Zhang, W.; Xu, J.; Qiu, J.; Xing, C.; Li, X.; Leng, B.; Su, Y.; Lin, J.; Lin, J.; Mei, X.; et al. Novel and rapid osteoporosis model established in zebrafish using high iron stress. Biochem. Biophys. Res. Commun. 2018, 496, 654-660. [CrossRef] [PubMed]

86. Shen, G.S.; Yang, Q.; Jian, J.L.; Zhao, G.Y.; Liu, L.L.; Wang, X.; Zhang, W.; Huang, X.; Xu, Y.J. Hepcidin1 knockout mice display defects in bone microarchitecture and changes of bone formation markers. Calcif. Tissue Int. 2014, 94, 632-639. [CrossRef] [PubMed]

87. Sun, L.; Guo, W.; Yin, C.; Zhang, S.; Qu, G.; Hou, Y.; Rong, H.; Ji, H.; Liu, S. Hepcidin deficiency undermines bone load-bearing capacity through inducing iron overload. Gene 2014, 543, 161-165. [CrossRef] [PubMed]

88. Guggenbuhl, P.; Fergelot, P.; Doyard, M.; Libouban, H.; Roth, M.P.; Gallois, Y.; Chales, G.; Loreal, O.; Chappard, D. Bone status in a mouse model of genetic hemochromatosis. Osteoporos. Int. 2011, 22, 2313-2319. [CrossRef] [PubMed]

89. Doyard, M.; Chappard, D.; Leroyer, P.; Roth, M.P.; Loreal, O.; Guggenbuhl, P. Decreased Bone Formation Explains Osteoporosis in a Genetic Mouse Model of Hemochromatosiss. PLoS ONE 2016, 11, e0148292. [CrossRef] [PubMed]

90. Jiang, Y.; Yan, Y.; Wang, X.; Zhu, G.; Xu, Y.J. Hepcidin inhibition on the effect of osteogenesis in zebrafish. Biochem. Biophys. Res. Commun. 2016, 476, 1-6. [CrossRef] [PubMed]

91. Keel, S.B.; Doty, R.T.; Yang, Z.; Quigley, J.G.; Chen, J.; Knoblaugh, S.; Kingsley, P.D.; De Domenico, I.; Vaughn, M.B.; Kaplan, J.; et al. A heme export protein is required for red blood cell differentiation and iron homeostasis. Science 2008, 319, 825-828. [CrossRef] [PubMed]

92. Chiabrando, D.; Marro, S.; Mercurio, S.; Giorgi, C.; Petrillo, S.; Vinchi, F.; Fiorito, V.; Fagoonee, S.; Camporeale, A.; Turco, E.; et al. The mitochondrial heme exporter FLVCR1b mediates erythroid differentiation. J. Clin. Investig. 2012, 122, 4569-4579. [CrossRef] [PubMed]

93. Vogiatzi, M.G.; Tsay, J.; Verdelis, K.; Rivella, S.; Grady, R.W.; Doty, S.; Giardina, P.J.; Boskey, A.L. Changes in bone microarchitecture and biomechanical properties in the th 3 thalassemia mouse are associated with decreased bone turnover and occur during the period of bone accrual. Calcif. Tissue Int. 2010, 86, 484-494. [CrossRef] [PubMed]

94. Thongchote, K.; Svasti, S.; Teerapornpuntakit, J.; Krishnamra, N.; Charoenphandhu, N. Running exercise alleviates trabecular bone loss and osteopenia in hemizygous beta-globin knockout thalassemic mice. Am. J. Physiol. Endocrinol. Metab. 2014, 306, E1406-E1417. [CrossRef] [PubMed]

95. Thongchote, K.; Svasti, S.; Teerapornpuntakit, J.; Suntornsaratoon, P.; Krishnamra, N.; Charoenphandhu, N. Bone microstructural defects and osteopenia in hemizygous $\beta^{\text {IVSII-654 }}$ knockin thalassemic mice: Sex-dependent changes in bone density and osteoclast function. Am. J. Physiol. Endocrinol. Metab. 2015, 309, E936-E948. [CrossRef] [PubMed] 
96. Green, M.; Akinsami, I.; Lin, A.; Banton, S.; Ghosh, S.; Chen, B.; Platt, M.; Osunkwo, I.; Ofori-Acquah, S.; Guldberg, R.; et al. Microarchitectural and mechanical characterization of the sickle bone. J. Mech. Behav. Biomed. Mater. 2015, 48, 220-228. [CrossRef] [PubMed]

97. Xiao, L.; Andemariam, B.; Taxel, P.; Adams, D.J.; Zempsky, W.T.; Dorcelus, V.; Hurley, M.M. Loss of Bone in Sickle Cell Trait and Sickle Cell Disease Female Mice Is Associated with Reduced IGF-1 in Bone and Serum. Endocrinology 2016, 157, 3036-3046. [CrossRef] [PubMed]

98. Guanabens, N.; Pares, A. Osteoporosis in chronic liver disease. Liver Int. 2018, 38, 776-785. [CrossRef] [PubMed]

99. Van Wagner, L.B.; Rinella, M.E. Extrahepatic Manifestations of Nonalcoholic Fatty Liver Disease. Curr. Hepatol. Rep. 2016, 15, 75-85. [CrossRef] [PubMed]

100. Ruiz-Gaspa, S.; Martinez-Ferrer, A.; Guanabens, N.; Dubreuil, M.; Peris, P.; Enjuanes, A.; Martinez de Osaba, M.J.; Alvarez, L.; Monegal, A.; Combalia, A.; et al. Effects of bilirubin and sera from jaundiced patients on osteoblasts: Contribution to the development of osteoporosis in liver diseases. Hepatology 2011, 54, 2104-2113. [CrossRef] [PubMed]

101. Xiao, W.; Beibei, F.; Guangsi, S.; Yu, J.; Wen, Z.; Xi, H.; Youjia, X. Iron overload increases osteoclastogenesis and aggravates the effects of ovariectomy on bone mass. J. Endocrinol. 2015, 226, 121-134. [CrossRef] [PubMed]

102. Isomura, H.; Fujie, K.; Shibata, K.; Inoue, N.; Iizuka, T.; Takebe, G.; Takahashi, K.; Nishihira, J.; Izumi, H.; Sakamoto, W. Bone metabolism and oxidative stress in postmenopausal rats with iron overload. Toxicology 2004, 197, 93-100. [CrossRef] [PubMed]

103. Grosbois, B.; Decaux, O.; Cador, B.; Cazalets, C.; Jego, P. Human iron deficiency. Bull. Acad. Natl. Med. 2005, 189, 1649-1663. [PubMed]

104. Toxqui, L.; Vaquero, M.P. Chronic Iron Deficiency as an Emerging Risk Factor for Osteoporosis: A Hypothesis. Nutrients 2015, 7, 2324-2344. [CrossRef] [PubMed]

105. Zofkova, I.; Davis, M.; Blahos, J. Trace Elements Have Beneficial, as Well as Detrimental Effects on Bone Homeostasis. Physiol. Res. 2017, 66, 391-402. [PubMed]

106. Gorres, K.L.; Raines, R.T. Prolyl 4-hydroxylase. Crit. Rev. Biochem. Mol. Biol. 2010, 45, 106-124. [PubMed]

107. Tuderman, L.; Myllyla, R.; Kivirikko, K.I. Mechanism of the prolyl hydroxylase reaction. 1. Role of co-substrates. Eur. J. Biochem. 1977, 80, 341-348. [CrossRef] [PubMed]

108. Goltzman, D. Functions of vitamin D in bone. Histochem. Cell Biol. 2018, 149, 305-312. [CrossRef] [PubMed]

109. Jones, G.; Prosser, D.E.; Kaufmann, M. Thematic Review Series: Fat-Soluble Vitamins: Vitamin D Cytochrome P450-mediated metabolism of vitamin D. J. Lipid Res. 2014, 55, 13-31. [CrossRef] [PubMed]

110. Medeiros, D.M.; Stoecker, B.; Plattner, A.; Jennings, D.; Haub, M. Iron deficiency negatively affects vertebrae and femurs of rats independently of energy intake and body weight. J. Nutr. 2004, 134, 3061-3067. [CrossRef] [PubMed]

111. Katsumata, S.I.; Katsumata-Tsuboi, R.; Uehara, M.; Suzuki, K. Severe Iron Deficiency Decreases Both Bone Formation and Bone Resorption in Rats. J. Nutr. 2009, 139, 238-243. [CrossRef] [PubMed]

112. Diaz-Castro, J.; Lopez-Frias, M.R.; Campos, M.S.; Lopez-Frias, M.; Alferez, M.J.M.; Nestares, T.; Ojeda, M.L.; Lopez-Aliaga, I. Severe nutritional iron-deficiency anaemia has a negative effect on some bone turnover biomarkers in rats. Eur. J. Nutr. 2012, 51, 241-247. [CrossRef] [PubMed]

113. Medeiros, D.M. Copper, iron, and selenium dietary deficiencies negatively impact skeletal integrity: A review. Exp. Biol. Med. 2016, 241, 1316-1322. [CrossRef] [PubMed]

114. Toxqui, L.; Perez-Granados, A.M.; Blanco-Rojo, R.; Wright, I.; de la Piedra, C.; Vaquero, M.P. Low iron status as a factor of increased bone resorption and effects of an iron and vitamin D-fortified skimmed milk on bone remodelling in young Spanish women. Eur. J. Nutr. 2014, 53, 441-448. [CrossRef] [PubMed]

115. Wright, I.; Blanco-Rojo, R.; Fernandez, M.C.; Toxqui, L.; Moreno, G.; Perez-Granados, A.M.; de la Piedra, C.; Remacha, A.F.; Vaquero, M.P. Bone remodelling is reduced by recovery from iron-deficiency anaemia in premenopausal women. J. Physiol. Biochem. 2013, 69, 889-896. [CrossRef] [PubMed]

116. Hofbauer, L.C.; Kuhne, C.A.; Viereck, V. The OPG/RANKL/RANK system in metabolic bone diseases. J. Musculoskelet. Neuronal Interact. 2004, 4, 268-275. [PubMed]

117. Jia, P.; Xu, Y.J.; Zhang, Z.L.; Li, K.; Li, B.; Zhang, W.; Yang, H. Ferric ion could facilitate osteoclast differentiation and bone resorption through the production of reactive oxygen species. J. Orthop. Res. 2012, 30, 1843-1852. [CrossRef] [PubMed] 
118. Ishii, K.A.; Fumoto, T.; Iwai, K.; Takeshita, S.; Ito, M.; Shimohata, N.; Aburatani, H.; Taketani, S.; Lelliott, C.J.; Vidal-Puig, A.; et al. Coordination of PGC-1 $\beta$ and iron uptake in mitochondrial biogenesis and osteoclast activation. Nat. Med. 2009, 15, 259-266. [CrossRef] [PubMed]

119. Roodman, G.D. Osteoclasts pump iron. Cell Metab. 2009, 9, 405-406. [CrossRef] [PubMed]

120. Gu, Z.; Wang, H.; Xia, J.; Yang, Y.; Jin, Z.; Xu, H.; Shi, J.; De Domenico, I.; Tricot, G.; Zhan, F. Decreased ferroportin promotes myeloma cell growth and osteoclast differentiation. Cancer Res. 2015, 75, 2211-2221. [CrossRef] [PubMed]

121. Zhou, J.; Ye, S.Q.; Fujiwara, T.; Manolagas, S.C.; Zhao, H.B. Steap4 Plays a Critical Role in Osteoclastogenesis in Vitro by Regulating Cellular Iron/Reactive Oxygen Species (ROS) Levels and cAMP Response Element-binding Protein (CREB) Activation. J. Biol. Chem. 2013, 288, 30064-30074. [CrossRef] [PubMed]

122. Xie, W.J.; Lorenz, S.; Dolder, S.; Hofstetter, W. Extracellular Iron is a Modulator of the Differentiation of Osteoclast Lineage Cells. Calcif. Tissue Int. 2016, 98, 275-283. [CrossRef] [PubMed]

123. Wang, L.; Fang, B.; Fujiwara, T.; Krager, K.; Gorantla, A.; Li, C.; Feng, J.Q.; Jennings, M.L.; Zhou, J.; Aykin-Burns, N.; et al. Deletion of ferroportin in murine myeloid cells increases iron accumulation and stimulates osteoclastogenesis in vitro and in vivo. J. Biol. Chem. 2018, 293, 9248-9264. [CrossRef] [PubMed]

124. Kawashima, A.; Oda, Y.; Yachie, A.; Koizumi, S.; Nakanishi, I. Heme oxygenase-1 deficiency: The first autopsy case. Hum. Pathol. 2002, 33, 125-130. [CrossRef] [PubMed]

125. Kovtunovych, G.; Eckhaus, M.A.; Ghosh, M.C.; Ollivierre-Wilson, H.; Rouault, T.A. Dysfunction of the heme recycling system in heme oxygenase 1-deficient mice: Effects on macrophage viability and tissue iron distribution. Blood 2010, 116, 6054-6062. [CrossRef] [PubMed]

126. Zwerina, J.; Tzima, S.; Hayer, S.; Redlich, K.; Hoffmann, O.; Hanslik-Schnabel, B.; Smolen, J.S.; Kollias, G.; Schett, G. Heme oxygenase 1 (HO-1) regulates osteoclastogenesis and bone resorption. FASEB J. 2005, 19, 2011-2013. [CrossRef] [PubMed]

127. Florczyk-Soluch, U.; Jozefczuk, E.; Stepniewski, J.; Bukowska-Strakova, K.; Mendel, M.; Viscardi, M.; Nowak, W.N.; Jozkowicz, A.; Dulak, J. Various roles of heme oxygenase-1 in response of bone marrow macrophages to RANKL and in the early stage of osteoclastogenesis. Sci. Rep. 2018, 8, 10797. [CrossRef] [PubMed]

128. Lemma, S.; Sboarina, M.; Porporato, P.E.; Zini, N.; Sonveaux, P.; Di Pompo, G.; Baldini, N.; Avnet, S. Energy metabolism in osteoclast formation and activity. Int. J. Biochem. Cell Biol. 2016, 79, 168-180. [CrossRef] [PubMed]

129. Arnett, T.R.; Orriss, I.R. Metabolic properties of the osteoclast. Bone 2018, 115, 25-30. [CrossRef] [PubMed]

130. Wang, X.; Chen, B.; Sun, J.; Jiang, Y.; Zhang, H.; Zhang, P.; Fei, B.; Xu, Y. Iron-induced oxidative stress stimulates osteoclast differentiation via NF-kB signaling pathway in mouse model. Metabolism 2018, 83, 167-176. [CrossRef] [PubMed]

131. Ek-Rylander, B.; Flores, M.; Wendel, M.; Heinegard, D.; Andersson, G. Dephosphorylation of osteopontin and bone sialoprotein by osteoclastic tartrate-resistant acid phosphatase. Modulation of osteoclast adhesion in vitro. J. Biol. Chem. 1994, 269, 14853-14856. [PubMed]

132. Zaidi, M.; Moonga, B.; Moss, D.W.; MacIntyre, I. Inhibition of osteoclastic acid phosphatase abolishes bone resorption. Biochem. Biophys. Res. Commun. 1989, 159, 68-71. [CrossRef]

133. Hayman, A.R.; Cox, T.M. Tartrate-resistant acid phosphatase knockout mice. J. Bone Miner. Res. 2003, 18, 1905-1907. [CrossRef] [PubMed]

134. Hayman, A.R.; Warburton, M.J.; Pringle, J.A.; Coles, B.; Chambers, T.J. Purification and characterization of a tartrate-resistant acid phosphatase from human osteoclastomas. Biochem. J. 1989, 261, 601-609. [CrossRef] [PubMed]

135. Hayman, A.R.; Cox, T.M. Purple acid phosphatase of the human macrophage and osteoclast. Characterization, molecular properties, and crystallization of the recombinant di-iron-oxo protein secreted by baculovirus-infected insect cells. J. Biol. Chem. 1994, 269, 1294-1300. [PubMed]

136. Alcantara, O.; Reddy, S.V.; Roodman, G.D.; Boldt, D.H. Transcriptional regulation of the tartrate-resistant acid phosphatase (TRAP) gene by iron. Biochem. J. 1994, 298, 421-425. [CrossRef] [PubMed]

137. Balogh, E.; Tolnai, E.; Nagy, B., Jr.; Nagy, B.; Balla, G.; Balla, J.; Jeney, V. Iron overload inhibits osteogenic commitment and differentiation of mesenchymal stem cells via the induction of ferritin. Biochim. Biophys. Acta 2016, 1862, 1640-1649. [CrossRef] [PubMed] 
138. Chang, Y.K.; Liu, Y.P.; Ho, J.H.; Hsu, S.C.; Lee, O.K. Amine-surface-modified superparamagnetic iron oxide nanoparticles interfere with differentiation of human mesenchymal stem cells. J. Orthop. Res. 2012, 30, 1499-1506. [CrossRef] [PubMed]

139. Chen, Y.C.; Hsiao, J.K.; Liu, H.M.; Lai, I.Y.; Yao, M.; Hsu, S.C.; Ko, B.S.; Chen, Y.C.; Yang, C.S.; Huang, D.M. The inhibitory effect of superparamagnetic iron oxide nanoparticle (Ferucarbotran) on osteogenic differentiation and its signaling mechanism in human mesenchymal stem cells. Toxicol. Appl. Pharmacol. 2010, 245, 272-279. [CrossRef] [PubMed]

140. Messer, J.G.; Kilbarger, A.K.; Erikson, K.M.; Kipp, D.E. Iron overload alters iron-regulatory genes and proteins, down-regulates osteoblastic phenotype, and is associated with apoptosis in fetal rat calvaria cultures. Bone 2009, 45, 972-979. [CrossRef] [PubMed]

141. Diamond, T.; Pojer, R.; Stiel, D.; Alfrey, A.; Posen, S. Does Iron Affect Osteoblast Function-Studies In vitro and in Patients with Chronic Liver-Disease. Calcif. Tissue Int. 1991, 48, 373-379. [CrossRef] [PubMed]

142. Zarjou, A.; Jeney, V.; Arosio, P.; Poli, M.; Zavaczki, E.; Balla, G.; Balla, J. Ferritin ferroxidase activity: A potent inhibitor of osteogenesis. J. Bone Miner. Res. 2010, 25, 164-172. [CrossRef] [PubMed]

143. Zarjou, A.; Jeney, V.; Arosio, P.; Poli, M.; Antal-Szalmas, P.; Agarwal, A.; Balla, G.; Balla, J. Ferritin prevents calcification and osteoblastic differentiation of vascular smooth muscle cells. J. Am. Soc. Nephrol. 2009, 20, 1254-1263. [CrossRef] [PubMed]

144. Doyard, M.; Fatih, N.; Monnier, A.; Island, M.L.; Aubry, M.; Leroyer, P.; Bouvet, R.; Chales, G.; Mosser, J.; Loreal, O.; et al. Iron excess limits HHIPL-2 gene expression and decreases osteoblastic activity in human MG-63 cells. Osteoporos. Int. 2012, 23, 2435-2445. [CrossRef] [PubMed]

145. Yang, Q.; Jian, J.; Abramson, S.B.; Huang, X. Inhibitory effects of iron on bone morphogenetic protein 2-induced osteoblastogenesis. J. Bone Miner. Res. 2011, 26, 1188-1196. [CrossRef] [PubMed]

146. Becs, G.; Zarjou, A.; Agarwal, A.; Kovacs, K.E.; Becs, A.; Nyitrai, M.; Balogh, E.; Banyai, E.; Eaton, J.W.; Arosio, P.; et al. Pharmacological induction of ferritin prevents osteoblastic transformation of smooth muscle cells. J. Cell. Mol. Med. 2016, 20, 217-230. [CrossRef] [PubMed]

147. Cornish, J.; Callon, K.E.; Naot, D.; Palmano, K.P.; Banovic, T.; Bava, U.; Watson, M.; Lin, J.M.; Tong, P.C.; Chen, Q.; et al. Lactoferrin is a potent regulator of bone cell activity and increases bone formation in vivo. Endocrinology 2004, 145, 4366-4374. [CrossRef] [PubMed]

148. Hou, J.M.; Xue, Y.; Lin, Q.M. Bovine lactoferrin improves bone mass and microstructure in ovariectomized rats via OPG/RANKL/RANK pathway. Acta Pharmacol. Sin. 2012, 33, 1277-1284. [CrossRef] [PubMed]

149. Kang, H.; Yan, Y.; Jia, P.; Yang, K.; Guo, C.; Chen, H.; Qi, J.; Qian, N.; Xu, X.; Wang, F.; et al. Desferrioxamine reduces ultrahigh-molecular-weight polyethylene-induced osteolysis by restraining inflammatory osteoclastogenesis via heme oxygenase-1. Cell Death Dis. 2016, 7, e2435. [CrossRef] [PubMed]

150. Guo, J.P.; Pan, J.X.; Xiong, L.; Xia, W.F.; Cui, S.; Xiong, W.C. Iron Chelation Inhibits Osteoclastic Differentiation in Vitro and in Tg2576 Mouse Model of Alzheimer's Disease. PLoS ONE 2015, 10, e0139395. [CrossRef] [PubMed]

151. Drager, J.; Sheikh, Z.; Zhang, Y.L.; Harvey, E.J.; Barralet, J.E. Local delivery of iron chelators reduces in vivo remodeling of a calcium phosphate bone graft substitute. Acta Biomater. 2016, 42, 411-419. [CrossRef] [PubMed]

152. Semenza, G.L. Regulation of mammalian $\mathrm{O}_{2}$ homeostasis by hypoxia-inducible factor 1. Annu. Rev. Cell Dev. Biol. 1999, 15, 551-578. [CrossRef] [PubMed]

153. Kaelin, W.G., Jr.; Ratcliffe, P.J. Oxygen sensing by metazoans: The central role of the HIF hydroxylase pathway. Mol. Cell 2008, 30, 393-402. [CrossRef] [PubMed]

154. Knowles, H.J.; Cleton-Jansen, A.M.; Korsching, E.; Athanasou, N.A. Hypoxia-inducible factor regulates osteoclast-mediated bone resorption: Role of angiopoietin-like 4. FASEB J. 2010, 24, 4648-4659. [CrossRef] [PubMed]

155. Hulley, P.A.; Bishop, T.; Vernet, A.; Schneider, J.E.; Edwards, J.R.; Athanasou, N.A.; Knowles, H.J. Hypoxia-inducible factor 1-alpha does not regulate osteoclastogenesis but enhances bone resorption activity via prolyl-4-hydroxylase 2. J. Pathol. 2017, 242, 322-333. [CrossRef] [PubMed]

156. Arnett, T.R.; Gibbons, D.C.; Utting, J.C.; Orriss, I.R.; Hoebertz, A.; Rosendaal, M.; Meghji, S. Hypoxia is a major stimulator of osteoclast formation and bone resorption. J. Cell. Physiol. 2003, 196, 2-8. [CrossRef] [PubMed] 
157. Parelman, M.; Stoecker, B.; Baker, A.; Medeiros, D. Iron restriction negatively affects bone in female rats and mineralization of hFOB osteoblast cells. Exp. Biol. Med. 2006, 231, 378-386. [CrossRef]

158. Messer, J.G.; Cooney, P.T.; Kipp, D.E. Iron chelator deferoxamine alters iron-regulatory genes and proteins and suppresses osteoblast phenotype in fetal rat calvaria cells. Bone 2010, 46, 1408-1415. [CrossRef] [PubMed]

159. Baschant, U.; Rauner, M.; Bulycheva, E.; Weidner, H.; Roetto, A.; Platzbecker, U.; Hofbauer, L.C. Wnt5a is a key target for the pro-osteogenic effects of iron chelation on osteoblast progenitors. Haematologica 2016. [CrossRef] [PubMed]

160. Qu, Z.H.; Zhang, X.L.; Tang, T.T.; Dai, K.R. Promotion of osteogenesis through beta-catenin signaling by desferrioxamine. Biochem. Biophys. Res. Commun. 2008, 370, 332-337. [CrossRef] [PubMed]

161. Zhao, G.Y.; Zhao, L.P.; He, Y.F.; Li, G.F.; Gao, C.; Li, K.; Xu, Y.J. A comparison of the biological activities of human osteoblast hFOB1.19 between iron excess and iron deficiency. Biol. Trace Elem. Res. 2012, 150, 487-495. [CrossRef] [PubMed]

162. Bo, L.; Liu, Z.; Zhong, Y.; Huang, J.; Chen, B.; Wang, H.; Xu, Y. Iron deficiency anemia's effect on bone formation in zebrafish mutant. Biochem. Biophys. Res. Commun. 2016, 475, 271-276. [CrossRef] [PubMed]

163. Maggio, A.; Filosa, A.; Vitrano, A.; Aloj, G.; Kattamis, A.; Ceci, A.; Fucharoen, S.; Cianciulli, P.; Grady, R.W.; Prossomariti, L.; et al. Iron chelation therapy in thalassemia major: A systematic review with meta-analyses of 1520 patients included on randomized clinical trials. Blood Cells Mol. Dis. 2011, 47, 166-175. [CrossRef] [PubMed]

164. Fabio, G.; Minonzio, F.; Delbini, P.; Bianchi, A.; Cappellini, M.D. Reversal of cardiac complications by deferiprone and deferoxamine combination therapy in a patient affected by a severe type of juvenile hemochromatosis (JH). Blood 2007, 109, 362-364. [CrossRef] [PubMed]

165. Kalpatthi, R.; Peters, B.; Kane, I.; Holloman, D.; Rackoff, E.; Disco, D.; Jackson, S.; Laver, J.H.; Abboud, M.R. Safety and efficacy of high dose intravenous desferrioxamine for reduction of iron overload in sickle cell disease. Pediatr. Blood Cancer 2010, 55, 1338-1342. [CrossRef] [PubMed]

166. Christoforidis, A.; Kazantzidou, E.; Tsatra, I.; Tsantali, H.; Koliakos, G.; Hatzipantelis, E.; Katzos, G.; Athanassiou-Metaxa, M. Normal lumbar bone mineral density in optimally treated children and young adolescents with beta-thalassaemia major. Hormones 2007, 6, 334-340. [CrossRef] [PubMed]

167. Casale, M.; Citarella, S.; Filosa, A.; De Michele, E.; Palmieri, F.; Ragozzino, A.; Amendola, G.; Pugliese, U.; Tartaglione, I.; Della Rocca, F; et al. Endocrine function and bone disease during long-term chelation therapy with deferasirox in patients with beta-thalassemia major. Am. J. Hematol. 2014, 89, 1102-1106. [CrossRef] [PubMed]

168. Poggi, M.; Sorrentino, F.; Pugliese, P.; Smacchia, M.P.; Daniele, C.; Equitani, F.; Terlizzi, F.; Guitarrini, M.R.; Monti, S.; Maffei, L.; et al. Longitudinal changes of endocrine and bone disease in adults with beta-thalassemia major receiving different iron chelators over 5 years. Ann. Hematol. 2016, 95, 757-763. [CrossRef] [PubMed]

169. Vogiatzi, M.G.; Macklin, E.A.; Fung, E.B.; Cheung, A.M.; Vichinsky, E.; Olivieri, N.; Kirby, M.; Kwiatkowski, J.L.; Cunningham, M.; Holm, I.A.; et al. Bone disease in thalassemia: A frequent and still unresolved problem. J. Bone Miner. Res. 2009, 24, 543-557. [CrossRef] [PubMed]

170. Li, G.F.; Pan, Y.Z.; Sirois, P.; Li, K.; Xu, Y.J. Iron homeostasis in osteoporosis and its clinical implications. Osteoporos. Int. 2012, 23, 2403-2408. [CrossRef] [PubMed]

171. Capulli, M.; Paone, R.; Rucci, N. Osteoblast and osteocyte: Games without frontiers. Arch. Biochem. Biophys. 2014, 561, 3-12. [CrossRef] [PubMed]

(C) 2018 by the authors. Licensee MDPI, Basel, Switzerland. This article is an open access article distributed under the terms and conditions of the Creative Commons Attribution (CC BY) license (http:/ / creativecommons.org/licenses/by/4.0/). 
Article

\title{
Iron Absorption in Iron-Deficient Women, Who Received $65 \mathrm{mg}$ Fe with an Indonesian Breakfast, Is Much Better from NaFe(III)EDTA than from $\mathrm{Fe}(\mathrm{II}) \mathrm{SO}_{4}$, with an Acceptable Increase of Plasma NTBI. A Randomized Clinical Trial
}

\author{
Eka Ginanjar ${ }^{1}$, Lilik Indrawati ${ }^{2}$, Iswari Setianingsih ${ }^{3}$, Djumhana Atmakusumah ${ }^{4}$, \\ Alida Harahap ${ }^{3}$, Ina S. Timan ${ }^{2}$ and Joannes J. M. Marx ${ }^{5, *}$ \\ 1 Department of Internal Medicine, Faculty of Medicine, University of Indonesia/Dr Cipto Mangunkusumo \\ Hospital, Jakarta 10430, Indonesia; ekginanjar@gmail.com \\ 2 Department of Clinical Pathology, Faculty of Medicine, University of Indonesia/Dr Cipto Mangunkusumo \\ Hospital, Jakarta 10430, Indonesia; lilikindrawati.dr@gmail.com (L.I.); ina_sutanto@yahoo.com (I.S.T.) \\ 3 Eijkman Institute for Molecular Biology, Jakarta 10430, Indonesia; ning@eijkman.go.id (I.S.); \\ alida@eijkman.go.id (A.H.) \\ 4 Division of Hematology and Medical Oncology, Department of Internal Medicine, Faculty of Medicine, \\ University of Indonesia/Dr Cipto Mangunkusumo Hospital, Jakarta 10430, Indonesia; endjum@hotmail.com \\ 5 Department of Medical Microbiology, University Medical Centre Utrecht, Heidelberglaan 100, \\ Utrecht 3584 CX, The Netherlands \\ * Correspondence: jjmmarx@me.com
}

Received: 13 August 2018; Accepted: 7 September 2018; Published: 10 September 2018

\begin{abstract}
Plasma non-transferrin-bound iron (NTBI) is potentially harmful due to the generation of free radicals that cause tissue damage in vascular and other diseases. Studies in iron-replete and iron-deficient subjects, receiving a single oral test dose of $\mathrm{Fe}(\mathrm{II}) \mathrm{SO}_{4}$ or $\mathrm{NaFe}(\mathrm{III}) \mathrm{EDTA}$ with water, revealed that $\mathrm{FeSO}_{4}$ was well absorbed when compared with NaFeEDTA, while only the $\mathrm{Fe}(\mathrm{II})$ compound showed a remarkable increase of NTBI. As NaFeEDTA is successfully used for food fortification, a double-blind randomized cross-over trial was conducted in 11 healthy women with uncomplicated iron deficiency. All subjects received a placebo, $6.5 \mathrm{mg} \mathrm{FeSO}_{4}, 65 \mathrm{mg} \mathrm{FeSO}$, $6.5 \mathrm{mg}$ NaFeEDTA, and $65 \mathrm{mg}$ NaFeEDTA with a traditional Indonesian breakfast in one-week intervals. Blood tests were carried out every $60 \mathrm{~min}$ for five hours. NTBI detection was performed using the fluorescein-labeled apotransferrin method. Plasma iron values were highly increased after $65 \mathrm{mg} \mathrm{NaFeEDTA}$, twice as high as after $\mathrm{FeSO}_{4}$. A similar pattern was seen for NTBI. After $6.5 \mathrm{mg}$ of $\mathrm{NaFeEDTA}$ and $\mathrm{FeSO}_{4}$, NTBI was hardly detectable. NaFeEDTA was highly effective for the treatment of iron deficiency if given with a meal, inhibiting the formation of nonabsorbable Fe-complexes, while NTBI did not exceed the range of normal values for iron-replete subjects.
\end{abstract}

Keywords: iron deficiency anemia; nutrient iron; oral iron therapy; $\mathrm{FeSO}_{4}$; NaFeEDTA; non-transferrin-bound iron (NTBI); developing countries; Indonesia

\section{Introduction}

Iron deficiency anemia (IDA) is a worldwide health problem, affecting about 2 billion people, particularly in developing countries like Indonesia [1]. IDA has a large impact on productivity, mental performance, child growth, immunity, and pregnancy outcome. About 20 years ago in Indonesia, $25-30 \%$ of the population (50 to 70 million subjects) suffered from IDA [2]. The management of iron deficiency by oral iron salts and food iron fortification were effective for raising plasma 
hemoglobin concentration in Indonesia as demonstrated by large family life surveys on anemia prevalence, estimated in 1997, 2000, and 2008 [3]. The prevalence of anemia decreased in all groups studied, e.g., in women $>15$ years from 36.0 to $26.6 \%$. Nevertheless, iron deficiency anemia remains a health problem in Indonesia due to insufficient nutrient daily intake [4].

Meanwhile, iron supplementation is commonly practiced by physicians in rural and urban areas. Furthermore, the community has easy access to oral iron supplements for their own consumption. Unfortunately, iron drugs are often consumed without a proper diagnosis of iron deficiency anemia, and are even used to combat lethargy or to gain strength and vitality. Measures to prevent iron deficiency should be specifically aimed at population groups at risk because actions to increase iron intake and bioavailability in the general population can be harmful for subjects with undiagnosed homozygous and heterozygous forms of iron overload diseases such as thalassemia intermedia [5].

Despite the fact that plasma-transferrin in iron-deficient patients has a large capacity of free iron-binding sites, treatment with a standard oral dose of $200 \mathrm{mg} \mathrm{FeSO}_{4}$ (ferrous sulfate, containing $65 \mathrm{mg}$ of elementary iron) was observed to generate potentially toxic amounts of non-transferrin-bound iron (NTBI) [6]. NTBI is the fraction of iron in plasma that is not tightly and safely bound to transferrin, including a heterogeneous mixture of labile and stable molecular species. NTBI is associated with oxygen radical formation and tissue damage in normal subjects and those with iron overload diseases [7]. In addition, NTBI and many other human iron-containing molecules can be utilized by microorganisms [8]. Therefore, the detection of NTBI after oral administration of regular iron medication, even in subjects with iron deficiency, needs further investigation. As iron-deficient subjects, with mainly free iron-binding sites on circulating transferrin, may be protected against iron-catalyzed reactive oxygen species, it is not clear whether the detection of NTBI after oral iron therapy can be harmful or is just associated with iron absorption physiology.

Not only should ferrous sulfate be investigated, being the standard treatment of iron deficiency, but also the Fe(III) compounds that have been used since 1950 for food iron fortification. In particular, $\mathrm{NaFe}(\mathrm{III}) \mathrm{EDTA}$ (Ferrazone, Akzo Nobel), recommended by the WHO as the preferred iron fortificant for wheat and maize flour, which are staple foods used by the whole population. Layrisse and co-workers described in 1977 that iron absorption from Fe(III)EDTA was about twice as high as that observed from ferrous sulfate [9].

NaFeEDTA is widely used in Indonesia, not only as a food fortificant, but also for the treatment of iron deficiency in children, which is recommended by the Pediatrician Association of Indonesia (IDAI). It is available as a syrup, Ferrostrane ${ }^{\circledR}$ (Teofarma S.r.l., Pavia, Italy), with one teaspoon $(5 \mathrm{~mL})$ containing $34 \mathrm{mg}$ of iron. For adults, three to six teaspoons per day are recommended (102-204 mg of iron).

In previous studies that investigated the iron absorption and generation of NTBI in subjects receiving a single oral therapeutic dose of $\mathrm{Fe}(\mathrm{II}) \mathrm{SO}_{4}$ or $\mathrm{NaFe}(\mathrm{III})$ EDTA with water, the absorption of iron from $\mathrm{FeSO}_{4}$ was much better when compared with NaFeEDTA, while only the $\mathrm{Fe}(\mathrm{II})$ compound showed a remarkable increase of NTBI. This was found in iron-replete [10] and in iron-deficient subjects [11].

In the present clinical crossover study in iron-deficient women (without signs or symptoms of inflammation), the post-absorption values for plasma iron and NTBI were measured during five hours from both a therapeutic elementary iron dose $(65 \mathrm{mg})$ and a dose relevant for iron fortification $(6.5 \mathrm{mg})$ in the form of $\mathrm{Fe}(\mathrm{II}) \mathrm{SO}_{4}$ and $\mathrm{NaFe}(\mathrm{III}) \mathrm{EDTA}$, all presented after a traditional Indonesian breakfast.

\section{Results}

\subsection{Selection of Participants and Data Collection}

After screening 63 apparently healthy female candidates, 11 were selected for a randomized clinical trial as described in the Materials and Methods. All selected subjects fulfilled the criteria for iron deficiency anemia with low values for hemoglobin $(\mathrm{Hb})$, mean cellular volume (MCV), 
mean cellular hemoglobin (MCH), low seum iron (SI), and high total iron binding capacity (TIBC). Mean transferrin saturation was $7.7 \%$ and serum ferritin was less than $20 \mu \mathrm{g} / \mathrm{L}$ These basic data were obtained from examination on minute 0 on the first day of the study when all subjects were only given the test meal: Group A received $\mathrm{FeSO}_{4}$ first, and Group B received NaFeEDTA first. There was no significant difference between any of the laboratory characteristics of the subjects from both groups.

In some samples, taken before the consumption of the standard meal, a raised level of $\mathrm{C}$-reactive protein (CRP) (>10 mg/L) was found, which was interpreted as a sign of inflammation. As iron absorption is decreased during inflammation [12], such episodes were removed from the final results. We also decided to remove investigation episodes if hemolytic blood samples were identified in the laboratory. The minimum number of episodes that could be analyzed, however, was never below six. In all three subjects with increased CRP, of whom the results were removed from the study, serum iron and NTBI curves after iron ingestion were flat, even after the administration of $65 \mathrm{mg}$ Fe as NaFeEDTA, and were no different from the $0 \mathrm{mg}$ Fe placebo dose.

The complete set of data collected during this investigation is available in the Appendix. One table indicates which data were excluded from further evaluation due to hemolysis of the blood sample or CRP-values $>10 \mathrm{mg} / \mathrm{L}$ as a nonspecific sign of inflammation. If a test subject's data for $\mathrm{FeSO}_{4}$ had to be removed, data for NaFeEDTA for the same iron dose $(6.5 \mathrm{or} 65 \mathrm{mg})$ were also removed.

\subsection{Results for Iron Absorption and NTBI Generation}

Presented are the results of the increase of serum iron values (Figure 1A) and NTBI (Figure 1B) after donation of one meal only and a meal with the addition of 6.5 or $65 \mathrm{mg}$ iron as either $\mathrm{FeSO}_{4}$ or NaFeEDTA. Such simple values represent the dynamic processes after ingestion of the meal with the specified test dose during migration through the stomach and upper intestine (all with a distinct function in iron absorption), and the binding of iron to and the release from transferrin in plasma.

Accumulatively, the increase of serum iron and NTBI after the different oral doses of $\mathrm{FeSO}_{4}$ and NaFeEDTA is demonstrated in Table 1 with the area under the curve (AUC) according to Conway et al. [13]. From the calculation of AUC, NTBI generation after $65 \mathrm{mg} \mathrm{FeSO}$ and $65 \mathrm{mg}$ $\mathrm{NaFeEDTA}$ was far higher when compared to the placebo and iron supplement of a lower dosage. NTBI generated after $65 \mathrm{mg} \mathrm{NaFeEDTA}$ was higher when compared to $65 \mathrm{mg} \mathrm{FeSO} 4$.

Table 1. Area under the curve (AUC) of serum iron and NTBI during $300 \mathrm{~min}$ after ingestion.

\begin{tabular}{ccc}
\hline Test Dose & AUC Serum Iron $(\mu \mathrm{mol} / \mathrm{L})$ & AUC NTBI $(\mu \mathrm{mol} / \mathrm{L})$ \\
\hline Fe $0.0 \mathrm{mg}$ (placebo) & 100 & 3.0 \\
$6.5 \mathrm{mg} \mathrm{FeSO}_{4}$ & 89 & -10.5 \\
$65 \mathrm{mg} \mathrm{FeSO}_{4}$ & 2017 & 203.7 \\
$6.5 \mathrm{mg} \mathrm{NaFeEDTA}$ & 370 & -1.8 \\
$65 \mathrm{mg} \mathrm{NaFeEDTA}$ & 2968 & 324 \\
\hline
\end{tabular}

With the method used, hardly any increase in serum iron and NTBI was observed after a meal only (placebo $0 \mathrm{mg} \mathrm{Fe}$ ), or $6.5 \mathrm{mg}$ iron as either $\mathrm{FeSO}_{4}$ or NaFeEDTA. Additionally, no significant difference could be seen for both parameters for all time points after the donation of $6.5 \mathrm{mg}$ iron between $\mathrm{FeSO}_{4}$ and NaFeEDTA.

There was a significant difference, however, in the increment of both serum iron and NTBI levels $(p<0.05)$ in subjects given a standard therapeutic dose of $65 \mathrm{mg}$ Fe of both $\mathrm{FeSO}_{4}$ and NaFeEDTA. It was remarkable, however, that both iron absorption (estimated by an increase of plasma iron) and the appearance of potentially harmful NTBI were about twice as high after the donation of NaFeEDTA than after $\mathrm{FeSO} 4$. 

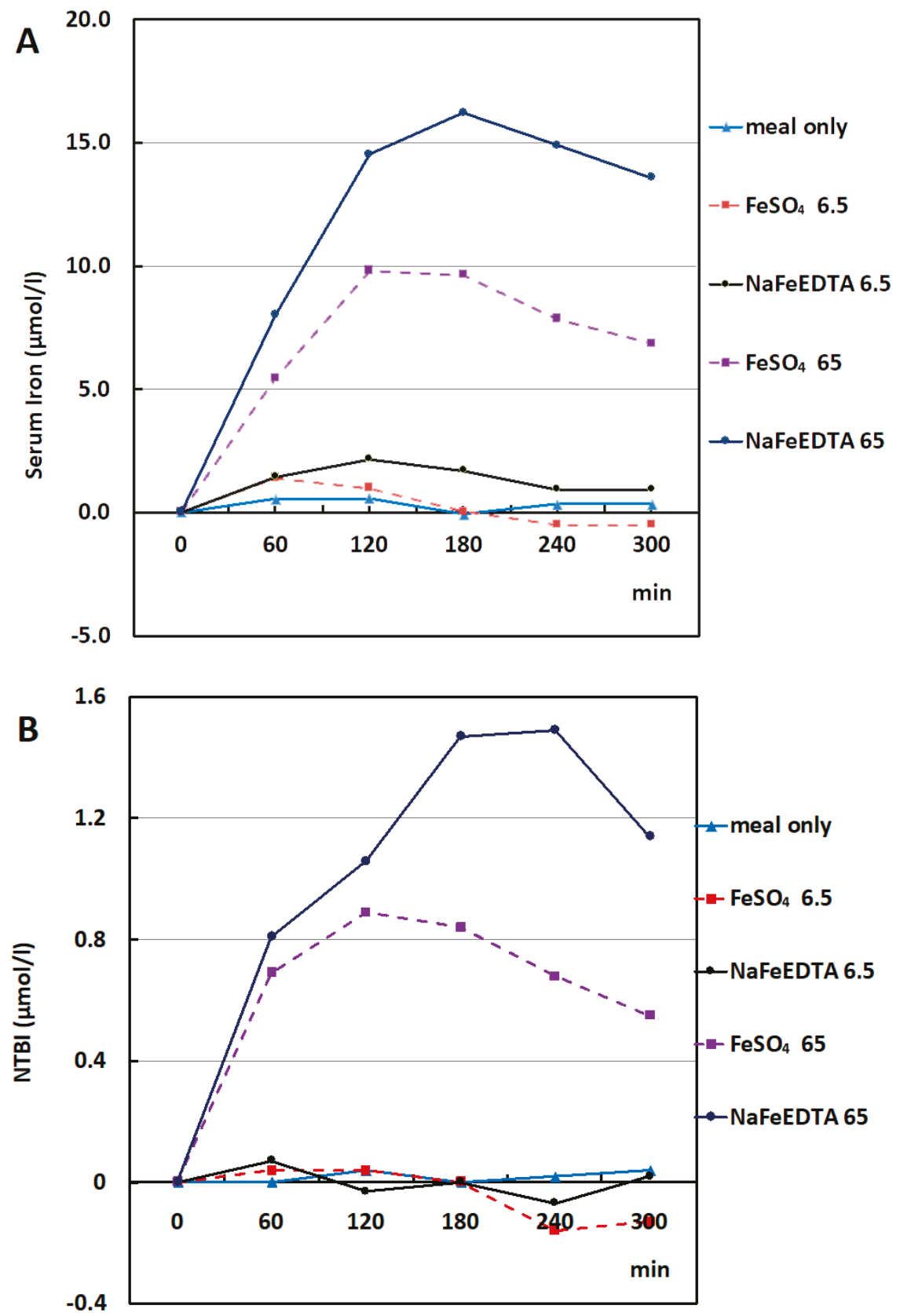

Figure 1. Increase of serum iron (A) and serum NTBI (B) after 6.5 and $65 \mathrm{mg}$ iron administered after a standard meal as $\mathrm{Fe}(\mathrm{II}) \mathrm{SO}_{4}$ or as $\mathrm{NaFe}(\mathrm{III}) \mathrm{EDTA}$.

In Table 2, more detailed data are presented for the NTBI values after the administration of $0 \mathrm{mg}$ (placebo) and the high, but therapeutically most relevant, dose of $65 \mathrm{mg} \mathrm{FeSO} 4$ and $\mathrm{NaFeEDTA}$ In both cases, a considerable increase of NTBI was observed. 
Table 2. NTBI ( $\mu \mathrm{mol} / \mathrm{L})$ generation after ingestion of a meal, followed by $0 \mathrm{mg}$ Fe (placebo), $65 \mathrm{mg}$ $\mathrm{FeSO}_{4}$ and $65 \mathrm{mg} \mathrm{NaFeEDTA.}$

\begin{tabular}{cccc}
\hline Minute & Placebo & $\mathbf{6 5} \mathbf{~ m g ~ F e S O}$ & $p$-Value \\
\hline 0 & 0 & 0 & - \\
60 & $-0.0034 \pm 0.1798$ & $0.6866 \pm 0.7498$ & 0.002 \\
120 & $0.0433 \pm 0.1565$ & $0.8886 \pm 0.9156$ & 0.012 \\
180 & $-0.0031 \pm 0.1781$ & $0.8412 \pm 0.7522$ & $<0.001$ \\
240 & $0.0154 \pm 0.2372$ & $0.6795 \pm 0.4329$ & 0.001 \\
300 & $0.0409 \pm 0.2194$ & $0.5531 \pm 0.6003$ & 0.020 \\
\hline Minute & Placebo & $\mathbf{6 5} \mathbf{~ m g ~ N a F e E D T A}$ & $p$-Value \\
\hline 0 & 0 & 0 & - \\
60 & $-0.0034 \pm 0.1798$ & $0.8106 \pm 0.8073$ & 0.007 \\
120 & $0.0433 \pm 0.1565$ & $1.0566 \pm 0.7181$ & 0.002 \\
180 & $-0.0031 \pm 0.1781$ & $1.4695 \pm 0.7247$ & $<0.001$ \\
240 & $0.0154 \pm 0.2372$ & $1.4922 \pm 0.7523$ & $<0.001$ \\
300 & $0.0409 \pm 0.2194$ & $1.1421 \pm 0.7509$ & $<0.001$ \\
\hline Minute & $\mathbf{6 5} \mathbf{m g}$ FeSO & $\mathbf{6 5} \mathbf{~ m g ~ N a F e E D T A}$ & $p$-Value \\
\hline 0 & 0 & 0 & - \\
60 & $0.6866 \pm 0.7498$ & $0.8106 \pm 0.8073$ & 0.530 \\
120 & $0.8886 \pm 0.9156$ & $1.0566 \pm 0.7181$ & 0.423 \\
180 & $0.8412 \pm 0.7522$ & $1.4695 \pm 0.7247$ & 0.017 \\
240 & $0.6795 \pm 0.4329$ & $1.4922 \pm 0.7523$ & 0.001 \\
300 & $0.5531 \pm 0.6003$ & $1.1421 \pm 0.7509$ & 0.011 \\
\hline
\end{tabular}

\subsection{Complications and Side Effects}

Blood loss. Due to this study protocol, all participants had considerable blood loss. During each of the five test episodes, there was $50 \mathrm{~mL}$ blood loss $(10 \mathrm{~mL}$ at minute $0 \mathrm{~min}$, then 5 times $8 \mathrm{~mL}$ ) with a total of $250 \mathrm{~mL}$. During the test period, hemoglobin concentration decreased around $0.7 \mathrm{~g} / \mathrm{dL}$. Therefore, at the end of the study protocol, all participants received iron supplement therapy.

Phlebitis in subject 11 after phlebotomy at the administration of $6.5 \mathrm{mg}$ NaFeEDTA. Topical heparin (Thrombophob ${ }^{\circledR}$ ) was applied and resolved the problem after three days.

Nausea in subject 1 after the administration of $6.5 \mathrm{mg} \mathrm{NaFeEDTA}$, in subject 4 after the administration of $65 \mathrm{mg}$ NaFeEDTA and in subject 10 after the administration of $6.5 \mathrm{mg} \mathrm{FeSO}$. All three subjects were given one omeprazole $20 \mathrm{mg}$ capsule and one domperidone $10 \mathrm{mg}$ tablet. The symptoms were resolved after $30 \mathrm{~min}$.

Other side effects or complications were not observed.

\section{Discussion}

\subsection{Comparison with Results from Studies Using Similar and Different Methodologies}

Numerous clinical studies on the absorption of iron for the treatment or prevention of iron deficiency have been published [14,15]. The method used in the present investigation is not able to provide absolute quantitative values, but iron uptake from the gut after presenting different compounds and amounts of iron can be compared. However, there is a limitation as small increases of non-radiolabelled iron in plasma are undetectable if low iron doses are given.

In this study, iron uptake and the appearance of potentially harmful non-transferrin-bound iron (NTBI) were investigated by administering doses relevant for iron therapy (65 $\mathrm{mg} \mathrm{Fe}$ ) and also for food iron fortification $(6.5 \mathrm{mg})$ to healthy, iron-deficient Indonesian females after an Indonesian standard breakfast. The compounds were $\mathrm{Fe}(\mathrm{II}) \mathrm{SO}_{4}$ (medication of choice for treatment of iron deficiency anemia) and $\mathrm{NaFe}$ (III)EDTA (supplement of choice for the fortification of food products and therefore for the prevention of iron deficiency anemia). Intestinal iron uptake was estimated by comparing the serum iron concentration during six hours, and increase of serum NTBI [6]. We compared our results 
with investigations from Guatemala, published in 2012 [10] and 2013 [11], to try to answer similar questions and use the same experimental approach, however, with a completely different outcome. In all three studies, NTBI tests were performed in the same laboratory in Utrecht.

In the 2012 study [10], an oral supplement of a $0 \mathrm{mg}$ Fe placebo dose in $200 \mathrm{~mL}$ water, a therapeutic dose of $100 \mathrm{mg}$ iron as $\mathrm{FeSO}_{4}$ (as a commercial syrup dissolved in $200 \mathrm{~mL}$ water) or $100 \mathrm{mg}$ of iron as $770 \mathrm{mg}$ of NaFeEDTA powder dissolved in $200 \mathrm{~mL}$ of water, was administered to healthy, iron-replete males after at least eight hours of fasting. In this cross-over study, each subject served as his own control. Venepuncture was performed at 0, 90, 180, and $270 \mathrm{~min}$. In the 2013 study [11], the design was identical, in particular, the donation of iron with water, but the test subjects were non-pregnant healthy women with low ferritin values $\left(<30 \mathrm{ng} / \mathrm{mL}\right.$ ). After $100 \mathrm{mg}$ iron as $\mathrm{FeSO}_{4}$, a considerable increase of serum iron was seen in men with adequate iron stores and normal CRP, and a much higher increase in females with low iron stores and normal CRP. Iron uptake from $100 \mathrm{mg}$ iron as NaFeEDTA in men was identical to that from water. Additionally, in iron-deficient females, the serum iron values were only a bit higher.

Troesch et al. [16] and Brittenham et al. [17] used stable isotopes to estimate the percentages of iron absorption in post-absorption curves, and iron utilization by circulating erythrocytes 14 days after ingestion of the labeled test doses. Troesch et al. investigated iron uptake from $6 \mathrm{mg}$ iron as $\mathrm{FeSO}_{4}$ with ascorbic acid (AA) and from $6 \mathrm{mg}$ iron as NaFeEDTA. Hardly any increase was seen for both $\mathrm{FeSO}_{4}$ and NaFeEDTA when the serum iron values were measured. When labeled with stable isotopes, the $6 \mathrm{mg}$ iron uptake curves were almost identical with those found by us after the uptake of $65 \mathrm{mg}$ iron. After $6 \mathrm{mg}$ iron, the increase of serum iron was higher after $\mathrm{FeSO}_{4}$ with AA than after NaFeEDTA.

Brittenham studied women with replete and reduced iron stores, receiving a $6 \mathrm{mg}$ or a $60 \mathrm{mg}$ iron dose as $\mathrm{FeSO}_{4}$ with a standard meal. Red blood cell iron utilization was measured using stable isotopes. With this approach, the values for real iron absorption could be calculated, which were higher for iron-deficient than for iron-replete women. Of interest was the percentage of iron absorption in iron-deficient women from the test dose given with a meal, which was $1.22 \mathrm{mg}(20.4 \%)$ from the $6 \mathrm{mg}$ dose, and $8.82 \mathrm{mg}(10.0 \%)$ from the $60 \mathrm{mg}$ dose. Peak values for NTBI were $0.1 \mu \mathrm{mol} / \mathrm{L}$ after the $6 \mathrm{mg}$ dose and $0.81 \mu \mathrm{mol} / \mathrm{L}$ after $60 \mathrm{mg}$ Fe. These values were almost identical with those from the comparable doses in our study. After the donation of $65 \mathrm{mg}$ Fe as NaFeEDTA, the mean peak NTBI values were twice as high, but remained below $1.5 \mu \mathrm{mol} / \mathrm{L}$.

Although the design of our study was similar to the two from Guatemala, there were crucial differences. Most importantly, our iron test dose was not given after eight hours of fasting but directly after ingestion of a standard breakfast. This resulted in a high uptake from $65 \mathrm{mg}$ iron as NaFeEDTA, even twice as high as that from $65 \mathrm{mg} \mathrm{Fe}$ as $\mathrm{FeSO}_{4}$ (Figure 1A). The conclusion was that the absorption of iron was much better if given with a meal than with water. The pattern for NTBI in plasma was almost identical, suggesting that NaFeEDTA may be less safe than $\mathrm{FeSO}_{4}$ (Figure 1B). In addition to a therapeutic dose of $65 \mathrm{mg} \mathrm{Fe}$, we studied a fortification dose of $6.5 \mathrm{mg}$ Fe. No NTBI could be detected in the serum for both iron compounds. Serum iron values were marginally higher for NaFeEDTA. The absolute NTBI values were low because all subjects were iron deficient.

\subsection{Aspects of Iron Absorption}

If iron is administered in an aqueous solution on an empty stomach, passage through the stomach and upper intestinal tract is rapid. This is an advantage for the uptake of iron from ferrous sulfate as Fe(II) is directly available for transport by the divalent metal transporter (DMT1) to the cytosol of duodenal mucosal cells by simple diffusion [18]. Complexed Fe(III) like in NaFeEDTA must first be reduced to $\mathrm{Fe}(\mathrm{II})$ by the reductase duodenal cytochrome B (DcytB) in direct proximity of DMT1. $\mathrm{Fe}(\mathrm{II})$ leaves the mucosal cells by ferroportin, mainly depending on the free iron binding sites for Fe(III) on transferrin. Oxidation of Fe(II) by hephestin (membrane) or ceruloplasmin (plasma) is needed for binding to transferrin. The mucosal cell function in processing absorbable iron is summarized in Figure 2. 


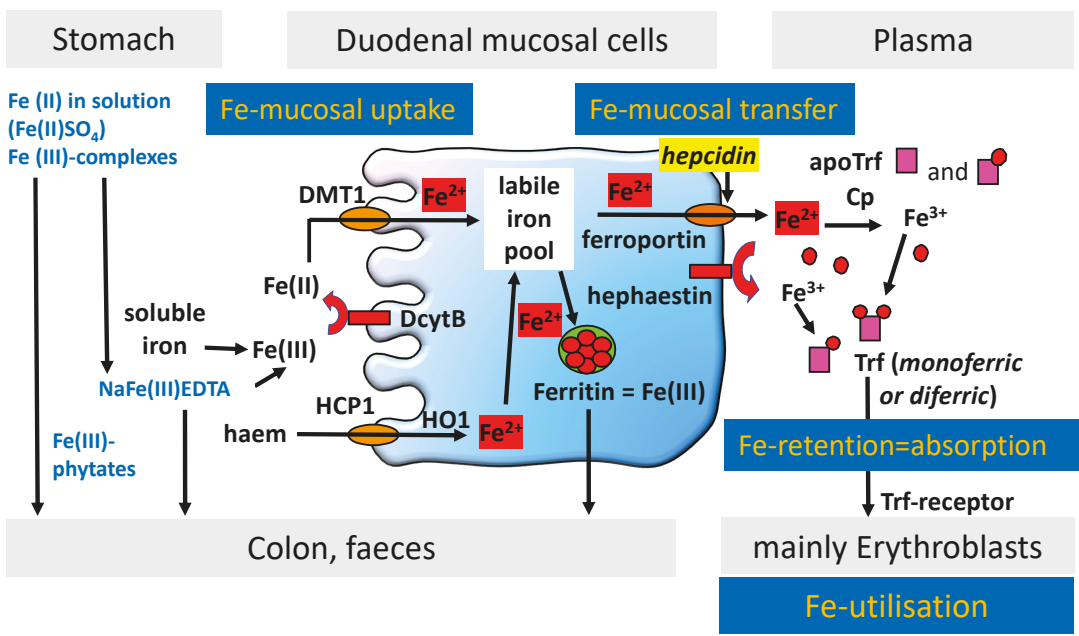

Figure 2. Processing of absorbable iron by the duodenal mucosal cells. DMT1 $=$ divalent metal transporter 1; DcytB = duodenal cytochrome B; HCP1 = hem carrier protein 1; HO1 = hem oxygenase-1; $\mathrm{Cp}=$ ceruloplasmin; $\operatorname{Trf}=$ transferrin.

Plasma iron concentration is the resultant of iron transported to the plasma, free iron-binding sites on transferrin, and iron demand for erythropoiesis, which is increased in iron deficiency and in hemolytic anemias.

After the duodenum, the nonabsorbed Fe(II) is oxidized in the intestinal lumen and forms complexes with a variety of ligands in more distal parts of the intestinal tract before being removed with the feces. While the results for $\mathrm{FeSO}_{4}$ in the Guatemalan studies can be explained by normal physiology, this was not the case with NaFeEDTA administered with water.

EDTA is a chelator that can combine with virtually every metal, depending on its stability constant with the metal. This is influenced by $\mathrm{pH}$, the molar ratio of the chelator to the metal ion, and the presence of competing metal ions and other ligands. Ferric iron has the highest stability constant with EDTA at 25.1 (optimum $\mathrm{pH}=1$ ), followed by ferrous iron (14.6) (optimum $\mathrm{pH}=5$ ) [19]. The intraluminal $\mathrm{pH}$ is rapidly changed from acidic in the stomach (empty state $\mathrm{pH} 4-5$, after meal $\mathrm{pH} 1.3$ ) to about $\mathrm{pH} 6$ in the duodenum. The $\mathrm{pH}$ gradually changes in the small intestine from $\mathrm{pH} 6$ to about $\mathrm{pH} 7.4$ in the terminal ileum, 5.7 in the cecum, and pH 6.7 in the rectum [20].

The binding of EDTA to iron is favored by the acidic environment of the stomach (due to the very high binding constant), but in the more alkaline surroundings of the duodenum, the iron is exchanged in part for other metals. EDTA protects iron in the stomach from inhibitory dietary ligands such as phytates and polyphenols and releases iron in the duodenum, where iron can be absorbed after reduction by DcytB and transport by DMT1. Phytates, present in many cereals and legumes, are powerful inhibitors of iron absorption. Some direct evidence of the ability of NaFeEDTA to prevent their action was obtained in an experiment where bran, a rich source of phytates, was shown to reduce the absorption of iron from ferrous sulfate eleven-fold. In contrast, no such inhibition occurred when bran was fed with NaFeEDTA [21].

$\mathrm{Fe}(\mathrm{III})$ reaches the cecum in complexed forms. With EDTA, however, it will form a stable complex. Nonabsorbed Fe as NaFeEDTA may reach the colon with a pH of 5.6 and a relatively low stability constant for $\mathrm{NaFe}(\mathrm{II}) \mathrm{EDTA}$. Iron absorption from the colon is possible [22]. Some DcytB has been found to be expressed in the large intestine, while ferroportin and DMT1 are expressed at significant levels and are increased in iron deficiency [23]. 


\subsection{Toxic Effects of NTBI in Plasma after Absorption of Iron}

NTBI includes plasma iron that is not bound to transferrin or is a structural part of other proteins in plasma including ferritin. While transferrin-bound iron is redox-inactive and safe, many forms of NTBI are labile and able to exchange iron with other molecular species that can cause the formation of toxic oxygen species and tissue damage. NTBI was first identified in 1978 in patients with beta thalassemia major and intermedia [24]. For decades, NTBI was exclusively associated with (severe) iron overload, although it was also associated with other pathological conditions.

After a publication on the appearance of NTBI in plasma after oral treatment with $\mathrm{FeSO}_{4}[6]$ and in hereditary hemochromatosis ( $\mathrm{HH}$ ) heterozygotes [25], the general view was that in these conditions, NTBI might also generate oxygen radicals. In a large epidemiological investigation, high mortality due to myocardial infarction and stroke was detected in female HH heterozygotes, but only in those reported with smoking and/or hypertension as combined risk factors [26]. In another large study investigating the relation of NTBI, serum iron, transferrin saturation, and serum ferritin with the risk of coronary heart disease (CHD) and acute myocardial infarction (AMI), the results did not show an excess risk of CHD or AMI within the highest NTBI tertile when compared with the lowest, but rather seemed to demonstrate a decreased risk [27]. The NTBI was measured with the same method as in the present study, and the total range of NTBI concentrations was -2.06 to $3.51 \mu \mathrm{mol} / \mathrm{L}$.

As we wanted to compare the post-absorption curves of NTBI in this study, for all compounds and Fe-doses, the 0-min NTBI was set to 0 with the appropriate correction of all NTBI values. When reviewing the complete range of all time-points including the high dose of $65 \mathrm{mg} \mathrm{Fe}$ as $\mathrm{FeSO}_{4}$ and NaFeEDTA, the range of all values of NTBI was between -0.59 and $0.37 \mu \mathrm{mol} / \mathrm{L}$. This was very low, and in agreement with the iron-deficient state of the test subjects.

As can be seen in Figure 1, only about 10\% of the absorbed iron was identified as NTBI. Many molecular species in plasma can bind iron, however, with a much lower affinity than apotransferrin. This was described in a review by Hider [28]. Most important are citrate and albumin. The citrate level in plasma is $100-120 \mu \mathrm{mol} / \mathrm{L}$, representing a considerable iron binding capacity. In our test subjects, the total iron binding capacity (TIBC) of transferrin was $45-73 \mu \mathrm{mol} / \mathrm{L}$. Citrate forms a wide range of oligomeric iron(III) species, which are stable complexes. Transfer of iron between an iron(III) citrate complex and desferrioxamine takes several hours to complete at pH 7.4 [29]. The rate-limiting step is the dissociation of iron from the polynuclear complex. Another molecule able to bind large amounts of iron in plasma is albumin [28]. Its concentration is $34-50 \mathrm{~g} / \mathrm{L}$ plasma, and albumin possesses a large number of negative carboxylate sites on its surface that are able to bind $\mathrm{Fe}(\mathrm{III})$. Absorbed iron bound to citrate or albumin cannot be considered as toxic labile NTBI.

Our conclusion is that humans, after being exposed for a longer time to NTBI values in plasma that can be reached after treatment with highly absorbable iron compounds with a rather moderate increase of serum NTBI, remained healthy. These considerations may contribute to the discussion on the maximum acceptable daily intake of EDTA for iron fortification and iron therapy [30].

\subsection{Iron Therapy in Developing Countries}

Iron is needed for microbial proliferation [8]. There is enormous diversity in the mechanisms of iron uptake and of iron species that can be processed. A minority of pathogenic microorganisms are able to use plasma NTBI, one important species being malaria parasites. This is a huge health problem as malaria, together with iron deficiency anemia, is endemic in many regions of the world [31].

Thalassemia has a high prevalence along the Mediterranean coast, Africa, Middle East, India, Burma, Southeast Asia including Indonesia, and Melanesia up to the Pacific Islands [32,33]. A total of $3-10 \%$ of the world's population are $\beta$ thalassemia carriers with the prevalence in Indonesia reaching $8 \%$ [34]. Thalassemia with iron overload and iron deficiency co-exists in the same population. Both are microcytic anemias, and clinical symptoms of iron deficiency and thalassemia heterozygotes are similar. Thalassemia patients frequently receive oral iron supplements for six months for up to two years. This practice is based on screening difficulties between iron deficiency anemia and anemia in 
Thalassemia trait or intermedia. Apart from that, the public has access to hematinics that are sold freely over the counter.

The result of this study, showing an increment of NTBI generation after the administration of oral iron supplements may create awareness in healthcare providers to include sufficiently informative laboratory tests before providing oral iron supplements for iron deficiency only and to exclude iron-replete subjects and thalassemia heterozygotes.

\section{Materials and Methods}

This investigation was a randomized double-blind phase III clinical trial. After randomization, a cross-over design was used. The trial was carried out at the Eijkman Institute Jakarta from November 2008 to April 2009. Laboratory tests were performed at the University of Indonesia/Dr Cipto Mangunkusumo Hospital, Jakarta, Indonesia. NTBI values were measured in the laboratory of the Department of Medical Microbiology, University Medical Centre Utrecht, Utrecht, The Netherlands.

\subsection{Selection of Test Subjects}

Inclusion criteria: (1) Female; (2) Age 15-60 years old; (3) Iron deficiency (serum Ferritin < 20 pg/mL); and (4) Informed consent to be involved in the research.

Exclusion criteria: (1) Suffering from a chronic illness; (2) Currently having an acute or severe chronic infection; (3) Currently under drug therapy or receiving an iron supplement in any form, minimum one week prior to the clinical investigation; (4) Oral iron supplement allergy; (5) Suffering from a disease or disorder of the alimentary tract; and (6) Pregnancy.

Eleven females were selected after screening 63 apparently healthy women: (1) students of the Faculty of Medicine University of Indonesia who went for Thalassemia screening at the Eijkman Institute for Molecular Biology of Jakarta who were found to have microcytic hypochromic anemia; and (2) healthy women from several areas in Jakarta who were known to be iron deficiency patients at the Hematology and Medical Oncology outpatient clinic in the department of Internal Medicine RSCM. Eleven iron-deficient females were finally selected for this investigation.

The age range of the research subjects was between 15 and 34 years with a mean age of 24.18 years. A major portion of the study subjects were of a low education level (seven persons) and nine persons of low income, thus can be assumed to be of low socioeconomic level. A description of the selected test subjects is provided in Table 3.

Table 3. Distribution characteristics of the selected subjects.

\begin{tabular}{lcc}
\hline \multicolumn{1}{c}{ Characteristic } & Mean & Reference Value \\
\hline & $(\mathrm{n}=11)$ & \\
Age & 24.18 & \\
\hline Education & & \\
Low & 7 subjects & \\
Medium & 3 subjects & \\
$\quad$ High & 1 subject & \\
\hline Income & & \\
Low & 9 subjects & \\
Medium & 2 subjects & \\
$\quad$ High & - & $12-14 \mathrm{gr} / \mathrm{dL}$ \\
Hemoglobin & 10.9 & $82-92 \mathrm{fl}$ \\
MCV & 74.9 & $27-31 \mathrm{pg}$ \\
MCH & 24.6 & $32-36 \mathrm{~g} / \mathrm{dL}$ \\
MCHC & 32.9 & $6.6-26.0 \mu \mathrm{mol} / \mathrm{L}$ \\
Serum Iron & 4.8 & $44.6-73.4 \mu \mathrm{mol} / \mathrm{L}$ \\
TIBC & 76.9 & $20-300 \mu \mathrm{g} / \mathrm{L}$ \\
Transferrin Saturation & 7.7 & $<15 \%=$ Iron Deficiency \\
Ferritin & 6.2 & \\
\hline
\end{tabular}




\subsection{Procedure of the Investigation}

The selected subjects were asked to visit the Eijkman Institute five times with one-week intervals to undergo the test procedure.

The subjects were divided into two groups of six (A) and five (B) subjects. A cross-over procedure was used as shown in Scheme 1. The procedure sequence towards the subjects was determined by double-blind randomization using a voting technique. Randomization and crossing-over were performed to determine who would receive either $\mathrm{FeSO}_{4}$ or NaFeEDTA first. Each subject needed to attend five times with a one-week interval as a wash-out period.

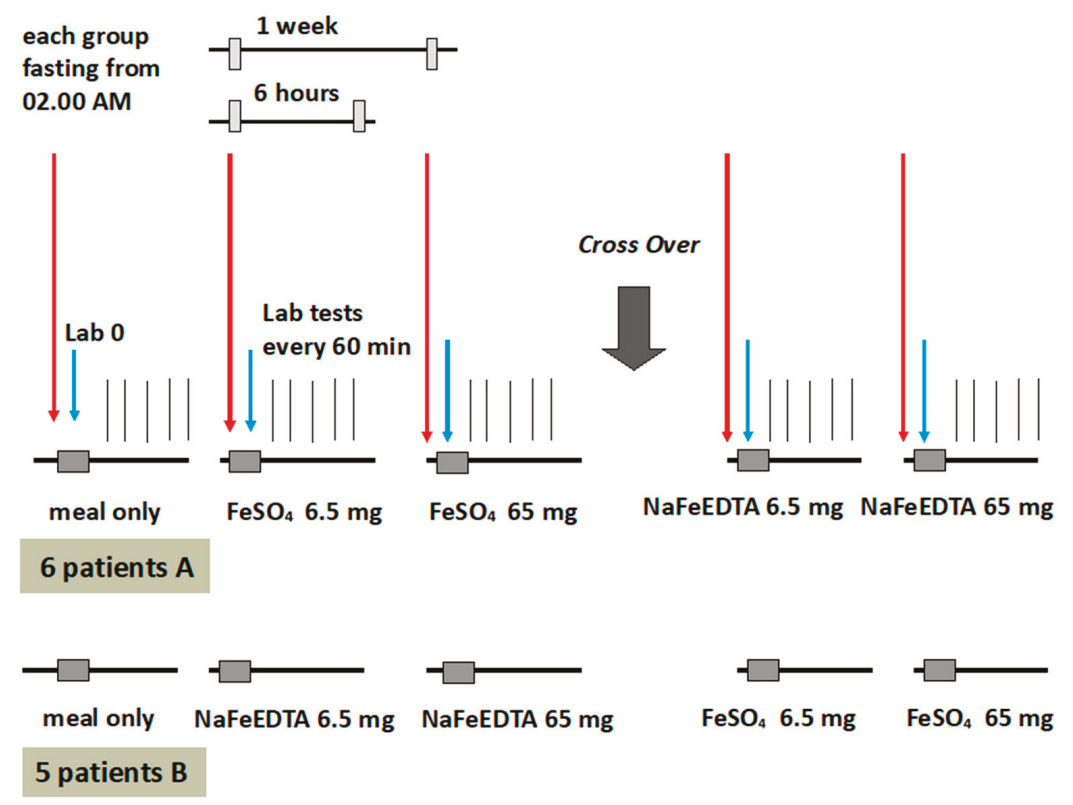

Scheme 1. Iron supplement administration schedule and iron doses.

Before any test episode (with or without receiving an iron dose), the test subjects were not allowed to take anything orally except plain water for at least six hours prior to the study. An intravenous catheter (Veinplon ${ }^{\circledR}$ ) with a saline lock method was applied to enable multiple blood drawings in all subjects. A quantity of $10 \mathrm{~mL}$ blood was taken for the first venous blood drawing for $\mathrm{Hb}, \mathrm{MCV}, \mathrm{MCH}$, MCHC, NTBI, Ferritin, SI, TIBC, transferrin saturation, CRP, and hepcidin.

Next, subjects were asked to consume a meal of rice with coconut milk (nasi uduk) and omelet, which is low in iron content, followed by the oral iron supplementation as shown in the table (see Scheme 2).

The mean reason why a meal prior to supplementation was included in the protocol was the reduction of side effects of oral iron supplementation like nausea, vomiting, epigastric pain, and burning sensation in the chest. A placebo dose was included to see the influence of the standard meal, and eventually circadian fluctuations of serum iron and NTBI.

After each test dose of oral iron supplement, $8 \mathrm{~mL}$ venous blood was taken at 60th, 120th, 180th, 240th, and 300th min for the measurement of NTBI, SI, TIBC, and transferrin saturation. Subjects were allowed to take anything orally after one hour of the test dose of oral iron supplement. Low iron snacks were provided during the whole procedure because subjects were at the research area for about six hours. 


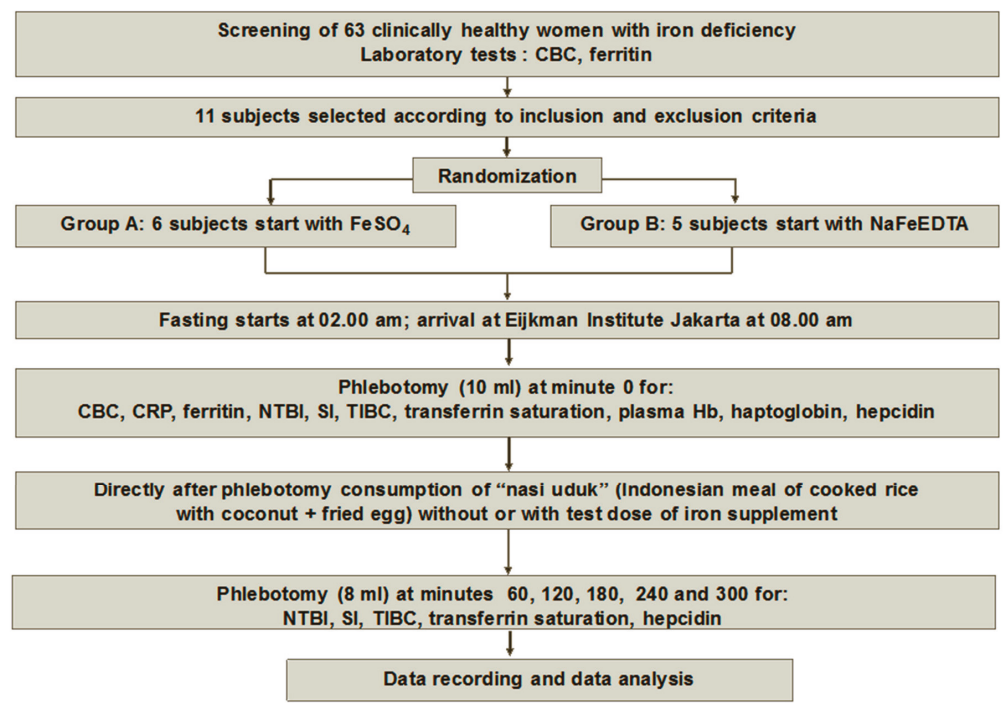

Scheme 2. Algorithm of the investigation.

\subsection{Production of NaFeEDTA Capsules}

Ferric sodium EDTA $\left(\mathrm{C}_{10} \mathrm{H}_{12} \mathrm{FeN}_{2} \mathrm{NaO}_{8} 3 \mathrm{H}_{2} \mathrm{O}\right) \mathrm{MW}=421.1$ was provided by Akzo Nobel, The Netherlands, as Ferrazone ${ }^{\circledR}$. The capsules were produced in the Pharmacy of Dr. Cipto Mangunkusumo Hospital, Jakarta, Indonesia. One capsule with $65 \mathrm{mg}$ elementary iron was composed of $490 \mathrm{mg} \mathrm{NaFeEDTA}$, and $110 \mathrm{mg}$ lactose. One capsule with $6.5 \mathrm{mg}$ elementary iron consisted of $49 \mathrm{mg} \mathrm{NaFeEDTA}$ and $600 \mathrm{mg}$ lactose.

\subsection{Composition of Test Meal}

Before taking the test dose of the iron supplement, all subjects consumed "nasi uduk" (a standard Indonesian meal of cooked rice with coconut + fried egg). This meal is free from fortified iron and has a very low amount of natural iron. Composition of one portion of rice $100 \mathrm{~g}=178$ calories: protein: $6.8 \mathrm{~g}$; fat: $0.7 \mathrm{~g}$; carbohydrate: $78.9 \mathrm{~g}$; and iron: $0.5 \mathrm{mg}$. One portion of fried egg $(50 \mathrm{~g})=105.8$ calories: protein: $9.3 \mathrm{~g}$; fat: $14.6 \mathrm{~g}$; carbohydrate: $1.5 \mathrm{~g}$; and iron: $2.7 \mathrm{mg}$.

\subsection{Laboratory Test Methods}

Routine laboratory tests were performed by the Laboratory of Clinical Pathology, Faculty of Medicine, University of Indonesia/Dr Cipto Mangunkusumo Hospital.

Laboratory test methods included hemoglobin: cyanide-free sodium lauryl sulfate (SLS) Sysmex XT-2000i; erythrocytes, leukocytes, hematocrit, MCV, MCH, MCHC: flow cytometry with semiconductor laser hydrodynamic focusing (Sysmex XT-2000i); serum iron and total iron binding capacity: Ferrozine (Cobas Integra 400, Roche Diagnostics, Risch-Rotkreuz, Switzerland) Transferrin saturation \%: SI/TIBC x \%; C-reactive protein (CRP): turbidimetric (Cobas Integra 400)

Non-transferrin iron (NTBI): fluorescein-labeled apotransferrin (Fl-aTf) [35] was performed at the Eijkman-Winkler Institute for Microbiology, Infectious Diseases, and Inflammation, University Medical Centre Utrecht, The Netherlands. Frozen samples were sent from Jakarta to Utrecht.

\subsection{Estimation of Iron Absorption}

For the estimation of iron absorption from the gut, the most superior technique is a double isotope method where iron is labeled with $\mathrm{Fe}^{59}$ and a nonabsorbable substance $\left({ }^{51} \mathrm{CrCl}\right)$, while the accumulation 
of both radioactive isotopes in the body can be measured simultaneously with a whole-body counter (WBC) [36]. As such methods, using in vivo radioactive material and very expensive equipment, are no longer available, stable isotopes or chemical laboratory techniques are used for comparing iron uptake from two different compounds. For a comparison of iron absorption from two non-labeled different iron compounds, with or without a meal, in different iron-doses, either Fe(II) or Fe(III), a comparison of serum iron curves is considered a reliable and powerful tool $[13,37]$. Absolute values for total iron absorption, however, cannot be estimated with this method.

\subsection{Data Management and Analysis}

Research data were recorded in tested research questionnaires. Verified data were analyzed and organized in text format, tables, or figures using SPSS version 16.0 and NCSS 2007 research software. Multivariate analysis was carried out using one-way ANOVA parametric tests to see the difference in NTBI level generation in each test dose of iron supplement and placebo every hour. Normality tests were performed before using the Shapiro-Wilk method in view of the small number of subjects (11 persons with $n<50$ ). The result of the normality tests showed a slightly abnormal distribution of data by which $\log 10$ transformation was carried out. However, in $6.5 \mathrm{mg} \mathrm{FeSO}$ from the 240th min, the distribution was still abnormal, thus a nonparametric Kruskal-Wallis test was performed followed by a Mann-Whitney test to have a look at the significance between test doses in the 240th min. One-way ANOVA was performed followed by post hoc analysis.

\subsection{Ethical Assessment}

Signed, informed consent was obtained from all test subjects before participation in the study. The study was conducted in accordance with the Declaration of Helsinki. Ethical assessment of the study protocol was conducted by the Ethical Committee of the Faculty of Medicine, University of Indonesia/Dr Cipto Mangunkusumo Hospital and was approved on 13 October 2008. The Project Identification Number is 338/PT02.FK/ETIK/2008.

The original protocol also contained an investigation, similar to the iron-deficient subjects, in apparently healthy females with nontransfused alpha thalassemia intermedia. This part of the study was not approved as it implicated the donation of iron to a potentially endangered group of patients.

\section{Conclusions}

1. In healthy iron-deficient females, intestinal iron uptake from $\mathrm{NaFe}(\mathrm{III}) \mathrm{EDTA}$, provided as a therapeutic dose of $65 \mathrm{mg} \mathrm{Fe}$, was twice as high as that from $\mathrm{Fe}(\mathrm{II}) \mathrm{SO}_{4}$ if ingested with a traditional Indonesian meal.

2. Measured in the same samples, non-transferrin-bound iron (NTBI) also increased with an almost identical time-related pattern.

3. When a $6.5 \mathrm{mg}$ iron dose (representing iron fortification) was ingested, the post-absorption curves and increase of NTBI of NaFeEDTA and $\mathrm{FeSO}_{4}$ were almost flat, being below the detection level of the method used. Such studies should be performed with stable isotopes, estimating red blood cell iron utilization.

4. For NTBI, the post-absorption concentration in plasma was representative for the whole circulation being the dilution volume. If the NTBI values remain within the range considered to be normal for iron-replete men after the therapeutic dose of $65 \mathrm{mg}$ iron, then one should not fear pathological side effects.

5. Although iron absorption from NaFeEDTA was almost zero if given with water, as was demonstrated for iron-replete men and women, its absorption was excellent (and even much better than that from $\mathrm{FeSO}_{4}$ ), if given with a meal as described in this study.

Supplementary Materials: Tables presenting a complete data set of serum iron and NTBI data. Annex 1: Complete set of serum iron values. Annex 2: Complete set of NTBI values. 
Author Contributions: Conceptualization, I.S. and J.J.M.M.; Data curation, E.G. and L.I.; Formal analysis, E.G. and L.I.; Funding acquisition, I.S. and J.J.M.M.; Investigation, E.G., L.I., A.H., and I.S.T.; Resources, D.A., A.H., and I.S.T.; Supervision, I.S., D.A., A.H., I.S.T., and J.J.M.M.; Visualization, E.G. and J.J.M.M.; Writing-original draft, E.G.; Writing—review \& editing, I.S., D.A., and J.J.M.M.

Funding: This research was funded by Akzo Nobel Functional Chemicals, Singapore. The founding sponsors had no role in the design of the study, in the collection, analyses, or interpretation of data, in the writing of the manuscript, and in the decision to publish the results.

Acknowledgments: Nanis S. Marzuki cooperated in the clinical study; Ari W. Satyagraha and Georgina Tapiheru supervised the laboratory tests; Henny van Kats-Renaud supervised and performed the NTBI tests at the University Medical Centre, Utrecht, The Netherlands; Sangkot Marzuki supported this investigation and provided the facilities as Director of the Eijkman Institute in Jakarta.

Conflicts of Interest: The authors declare no conflicts of interest.

\section{References}

1. Zimmermann, M.B.; Hurrell, R.F. Nutritional iron deficiency. Lancet 2007, 370, 511-520. [CrossRef]

2. Kodyat, B.; Kosen, S.; de Pree, S. Iron deficiency in Indonesia: Current situation and intervention. Nutr. Res. 1998, 18, 1953-1963. [CrossRef]

3. Barkley, J.S.; Kendrick, K.L.; Codling, K.; Muslimatun, S.; Pachón, H. Anaemia prevalence over time in Indonesia: Estimates from the 1997, 2000, and 2008 Indonesia Family Life Surveys. Asia Pac. J. Clin. Nutr. 2015, 24, 452-455. [CrossRef] [PubMed]

4. Darmawan, M.A.; Karima, N.N.; Maulida, N.N. Potential of Iron Fortification Complex Compounds against Soybean Food for Anemia Problem Solution in Indonesia. J. Adv. Agric. Technol. 2017, 4, 185-189. [CrossRef]

5. Marx, J.J.M. Iron deficiency in developed countries: Prevalence, influence of lifestyle factors and hazards of prevention. Eur. J. Clin. Nutr. 1997, 51, 491-494. [CrossRef] [PubMed]

6. Hutchinson, C.; Al-Ashgar, W.; Liu, D.Y.; Hider, R.C.; Powell, J.J.; Geissler, C.A. Oral ferrous sulphate leads to a marked increase in pro-oxidant nontransferrin-bound iron. Eur. J. Clin. Investig. 2004, 34, 782-784. [CrossRef] [PubMed]

7. Voest, E.E.; Vreugdenhil, G.; Marx, J.J.M. Iron chelating agents in non-iron overload conditions. Current and future perspectives. Ann. Intern. Med. 1994, 120, 490-499. [CrossRef] [PubMed]

8. Marx, J.J.M. Iron and infection: Competition between host and microbes for a precious element. Best Pract. Res. Clin. Haematol. 2002, 15, 411-426. [CrossRef] [PubMed]

9. Layrisse, M.; Martinez-Torres, C. EDTA-Fe(III) complex as iron fortification. Am. J. Clin. Nutr. 1977, 30, 166-1174. [CrossRef] [PubMed]

10. Schuemann, K.; Solomons, N.W.; Romero-Abal, M.E.; Orozco, M.; Weiss, G.; Marx, J.J.M. Oral administration of ferrous sulfate, but not of iron polymaltose or NaFeEDTA, results in a substantial increase of NTBI in healthy iron-adequate men. Food Nutr. Bull. 2012, 33, 128-136. [CrossRef] [PubMed]

11. Schuemann, K.; Solomons, N.W.; Orozco, M.; Romero-Abal, M.E.; Weiss, G. Differences in circulating NTBI after oral administration of ferrous sulfate, NaFeEDTA, or iron polymaltose in women with marginal iron stores. Food Nutr. Bull. 2013, 34, 185-193. [CrossRef] [PubMed]

12. Weber, J.; Werre, J.M.; Julius, H.W.; Marx, J.J.M. Decreased iron absorption in patients with active rheumatoid arthritis, with and without iron deficiency. Ann. Rheum. Dis. 1988, 47, 404-409. [CrossRef] [PubMed]

13. Conway, R.W.; Geissler, C.A.; Hider, R.C.; Thompson, R.P.H.; Powell, J.J. Serum Iron Curves Can Be Used to Estimate Dietary Iron Bioavailability in Humans. J. Nutr. 2006, 136, 1910-1914. [CrossRef] [PubMed]

14. Marx, J.J.M. Iron absorption and its regulation. A review. Haematologica 1979, 64, 479-493. [PubMed]

15. Bothwell, T.H.; Mac-Phail, A.P. The potential role of NaFeEDTA as an iron fortificant. Int. J. Vitam Nutr. Res. 2004, 74, 421-434. [CrossRef] [PubMed]

16. Troesch, B.; Egli, I.; Zeder, C.; Richard, F.; Hurrell, R.F.; Zimmermann, M.B. Fortification Iron as Ferrous Sulfate Plus Ascorbic Acid Is More Rapidly Absorbed Than as Sodium Iron EDTA but Neither Increases Serum Nontransferrin-Bound Iron in Women. J. Nutr. 2011, 141, 822-827. [CrossRef] [PubMed]

17. Brittenham, G.M.; Andersson, M.; Egli, I.; Foman, J.T.; Zeder, C.; Westerman, M.E.; Hurrell, R.F. Circulating non-transferrin-bound iron after oral administration of supplemental and fortification doses of iron to healthy women: A randomized study. Am. J. Clin. Nutr. 2014, 100, 813-820. [CrossRef] [PubMed] 
18. Marx, J.J.M.; Aisen, P. Uptake of iron by rabbit intestinal membrane vesicles. Biochim. Biophys. Acta 1981, 649, 297-304. [CrossRef]

19. West, T.S.; Sykes, A.S. Diamino-ethane-tetraacetic. In Analytical Applications of Diamino-Ethane-Tetra-Acetic-Acid, 2nd ed.; British Drug Houses, Laboratory Chemicals Divison: Poole, UK, 1960; pp. 9-22.

20. Fallingborg, J. Intraluminal pH of the human gastrointestinal tract. Dan. Med. Bull. 1999, 46, 183-196. [PubMed]

21. Gillooly, M.; Bothwell, T.H.; Charlton, R.E.; Torrance, J.D. Factors affecting the absorption of iron from cereals. Br. J. Nutr. 1984, 51, 37-46. [CrossRef] [PubMed]

22. Chernelch, M.; Fawwaz, R.; Sargent, T.; Winchell, H.S. Effect of phlebotomy and pH on iron absorption from the colon. J. Nucl. Med. 1969, 11, 25-27.

23. Takeushi, K.; Bjarnason, I.; Abas, H.; Laftah, A.H.; Latunde-Dada, G.O.; Simpson, R.J.; McKie, A.T. Expression of iron absorption genes in mouse large intestine. Scand. J. Gastroenterol. 2005, 40, 169-177. [CrossRef] [PubMed]

24. Hershko, C.; Graham, G.; Bates, G.W.; Rachmilewitz, E.A. Non-specific serum iron in thalassaemia: An abnormal serum iron fraction of potential toxicity. Br. J. Haematol. 1978, 40, 255-263. [CrossRef] [PubMed]

25. De Valk, B.; Addicks, M.A.; Gosriwatana, I.; Lu, S.; Hider, R.C.; Marx, J.J.M. Non-transferrin-bound iron is present in serum of hereditary haemochromatosis heterozygotes. Eur. J. Clin. Investig. 2000, 30, 248-251. [CrossRef]

26. Roest, M.; van der Schouw, Y.T.; de Valk, B.; Marx, J.J.M.; Tempelman, M.J.; de Groot, P.G.; Sixma, J.J.; Banga, J.D. Heterozygosity for a hereditary hemochromatosis gene is associated with cardiovascular death in women. Circulation 1999, 100, 1268-1273. [CrossRef] [PubMed]

27. Van der A, D.L.; Marx, J.J.M.; Grobbee, D.E.; Kamphuis, M.H.; Georgiou, N.A.; van Kats-Renaud, H.; Breuer, W.; Cabantchik, Z.I.; Mark Roest, M.; Voorbij, H.A.M.; et al. Non-Transferrin-Bound Iron and Risk of Coronary Heart Disease in Postmenopausal Women. Circulation 2006, 113, 1942-1949. [CrossRef] [PubMed]

28. Hider, R.C. Nature of nontransferrin-bound iron. Eur. J. Clin. Investig. 2002, 32 (Suppl. 1), 50-54. [CrossRef]

29. Faller, B.; Nick, H. Kinetics and mechanism of iron (III) removal from citrate by desferrioxamine B and 3-hydroxy-1, 2-dimethyl-4 pyridone. J. Am. Chem. Soc. 1994, 116, 3860-3865. [CrossRef]

30. Wreesmann, C.T.J. Reasons for raising the maximum acceptable daily intake of EDTA and the benefits for iron fortification of foods for children 6-24 months of age. Matem. Child Nutr. 2014, 10, 481-495. [CrossRef] [PubMed]

31. Sangaré, L.; van Eijk, A.M.; ter Kuile, F.O.; Walson, J.; Stergachis, A. The Association between Malaria and Iron Status or Supplementation in Pregnancy: A Systematic Review and Meta-Analysis. PLoS ONE 2014, 9, e87743. [CrossRef] [PubMed]

32. Fucharoen, S.; Winichagoon, P. Haemoglobinopathies in Southeast Asia. Indian J. Med. Res. 2011, 134, 498-506. [PubMed]

33. Weatherall, D. Fortnightly review: The thalassaemias. Br. Med. J. 1997, 314, 1675-1679. [CrossRef]

34. Setianingsih, I. $\beta$ thalassaemia in Indonesia: Molecular Basis and Phenotype-Genotype Correction. Ph.D. Thesis, University of Melbourne, Melbourne, Australia, 2000.

35. Breuer, W.; Cabantchik, Z.I. A fluorescence-based one-step assay for serum non-transferrin-bound iron. Anal Biochem. 2001, 299, 194-201. [CrossRef] [PubMed]

36. Marx, J.J.M. Mucosal uptake, mucosal transfer and retention of iron, measured by whole-body counting. Scand. Haematol. 1979, 23, 293-302. [CrossRef]

37. Dainty, J.R.; Roe, M.A.; Teucher, B.; Eagles, J.; Fairweather-Tait, S.J. Quantification of unlabeled non-haem iron absorption in human subjects: A pilot study. Br. J. Nutr. 2003, 90, 503-506. [CrossRef] [PubMed] 


\title{
Intravenous Irons: From Basic Science to Clinical Practice
}

\author{
Sunil Bhandari ${ }^{1}$, Dora I. A. Pereira ${ }^{2,3}$, Helen F. Chappell ${ }^{4}$ and Hal Drakesmith ${ }^{5,6, *}$ \\ 1 Hull and East Yorkshire Hospitals NHS Trust and Hull York Medical School, Hull HU3 2JZ, UK; \\ Sunil.Bhandari@hey.nhs.uk \\ 2 Department of Pathology, University of Cambridge, Cambridge CB2 1QP, UK; diap2@cam.ac.uk \\ 3 MRC Unit The Gambia at the London School of Hygiene \& Tropical Medicine, Banjul, Gambia \\ 4 School of Food Science and Nutrition, University of Leeds, Leeds LS2 9JT, UK; H.F.Chappell@leeds.ac.uk \\ 5 MRC Human Immunology Unit, Weatherall Institute of Molecular Medicine, University of Oxford, \\ Headington, Oxford OX3 9DS, UK \\ 6 Haematology Theme Oxford Biomedical Research Centre, Oxford OX3 9DS, UK \\ * Correspondence: alexander.drakesmith@ndm.ox.ac.uk; Tel.: +44-1865-222699
}

Received: 1 August 2018; Accepted: 23 August 2018; Published: 27 August 2018

\begin{abstract}
Iron is an essential trace mineral necessary for life, and iron deficiency anaemia (IDA) is one of the most common haematological problems worldwide, affecting a sixth of the global population. Principally linked to poverty, malnutrition and infection in developing countries, in Western countries the pathophysiology of IDA is primarily linked to blood loss, malabsorption and chronic disease. Oral iron replacement therapy is a simple, inexpensive treatment, but is limited by gastrointestinal side effects that are not inconsequential to some patients and are of minimal efficacy in others. Third generation intravenous (IV) iron therapies allow rapid and complete replacement dosing without the toxicity issues inherent with older iron preparations. Their characteristic, strongly-bound iron-carbohydrate complexes exist as colloidal suspensions of iron oxide nanoparticles with a polynuclear Fe(III)-oxyhydroxide/oxide core surrounded by a carbohydrate ligand. The physicochemical differences between the IV irons include mineral composition, crystalline structure, conformation, size and molecular weight, but the most important difference is the carbohydrate ligand, which influences complex stability, iron release and immunogenicity, and which is a unique feature of each drug. Recent studies have highlighted different adverse event profiles associated with third-generation IV irons that reflect their different structures. The increasing clinical evidence base has allayed safety concerns linked to older IV irons and widened their clinical use. This review considers the properties of the different IV irons, and how differences might impact current and future clinical practice.
\end{abstract}

Keywords: adverse event profile; anaemia; bioengineering; labile iron; intravenous iron; iron-carbohydrate complex; iron processing

\section{Introduction}

Iron, the most abundant element on earth, accounting for 35\% of the earth's mass, is an essential trace mineral necessary for a myriad of metabolic reactions in the body. These include a role in catalytic enzymes and proteins for DNA synthesis, transport of oxygen in haemoglobin and myoglobin, mitochondrial cell respiration, oxidative phosphorylation and adenosine triphosphate (ATP) formation in the tricarboxylic acid cycle [1-3]. The human body contains $3-5 \mathrm{~g}$ iron and is essential for life, but iron acquisition and assimilation in humans is challenging as oxidised iron is poorly soluble at neutral $\mathrm{pH}$, and within the body, "free" iron is toxic through the promotion of reactive oxygen species. Thus, multiple, complex systems have evolved in man to manage and retain iron, yet iron 
deficiency and iron deficiency anaemia (IDA) are common problems [4]. Oral iron therapy is a simple, inexpensive treatment, but is limited by gastrointestinal side effects that are not inconsequential to some patients and are of minimal efficacy in others [5]. Advances in our understanding of the pathophysiology of iron metabolism and the development of new pharmaceutical technologies have led to a better understanding of the need for and development of intravenous (IV) formulations for iron replacement when oral iron preparations are not efficacious or cannot be used. This review considers the properties of the different IV irons, and how differences might impact current and future clinical practice.

\section{Iron Deficiency Anaemia}

Iron deficiency is the most common nutritional deficiency worldwide. IDA is one of the most common haematological problems, and the most important cause of a microcytic, hypochromic anaemia. Globally, 1.24 billion people are affected by IDA, which corresponds to about a sixth of the global population [4]. The Global Burden of Disease project highlighted the significant public health importance of IDA, with around 35,000,000 disability-adjusted life years globally attributable to IDA, ranking it fourth in the top leading causes of disability [4]. It is associated with multiple disease states, including chronic kidney disease (CKD), inflammatory bowel disease (IBD) and congestive heart failure and contributes to loss of wellbeing and poor outcomes for patients [6,7]. From a health system perspective, identification and correction of perioperative IDA reduces rates of transfusion and mortality rates, as well as length of hospital stay [8,9]. Regardless of whether IDA is symptomatic, all patients should be treated-both by addressing the underlying cause of the iron deficiency and through adequate replenishment of iron stores. More recently, emerging data also suggest benefit in the treatment of non-anaemic iron deficiency (NAID) with replacement iron [10,11].

\subsection{Pathophysiology of IDA}

Principally linked to poverty, malnutrition and infection in developing countries, in western countries the pathophysiology of IDA is primarily linked to blood loss, malabsorption and chronic disease (Table 1) [7]. Chronic blood loss occurs in a range of conditions that include peptic ulcer disease, inflammatory bowel diseases, regular haemodialysis therapy, occult intestinal cancer and heavy menstrual bleeding. Impaired iron absorption is often apparent after gastrectomy and in inflammatory bowel diseases, and chronic diseases such as CKD are characterised by impaired erythropoiesis through iron restriction. Loss of iron in the urine can occur through rare forms of intravascular haemolysis, and IDA can be drug-related (proton-pump inhibitors, leading to impaired absorption due to increased gastric $\mathrm{pH}$ ) and genetic (iron-refractory iron-deficiency anaemia, IRIDA) [7].

Table 1. Main causes of iron deficiency in the western world [7].

\begin{tabular}{l|l}
\hline \multicolumn{1}{c}{ Cause } & \multicolumn{1}{c}{ Details } \\
\hline Insufficient uptake & Malnutrition or diet-related (low-iron, vegetarian, vegan) \\
\hline $\begin{array}{l}\text { Increased physiological } \\
\text { demand }\end{array}$ & $\begin{array}{l}\text { Rapid growth during infancy/adolescence, menstrual blood loss, pregnancy } \\
\text { (2nd/3rd trimesters) }\end{array}$ \\
\hline Chronic blood loss & Trauma, surgery, delivery, heavy menstrual bleeding \\
\hline Chronic disease & $\begin{array}{l}\text { Kidney disease, heart failure, inflammatory bowel disease, gastritis, peptic ulcer, } \\
\text { intestinal cancer and benign tumours }\end{array}$ \\
\hline Drug-related & $\begin{array}{l}\text { Glucocorticoids, salicylates, non-steroidal anti-inflammatory drugs, proton-pump } \\
\text { inhibitors, } \mathrm{H}_{2} \text {-receptor antagonists, drug-induced haemolytic anaemia }\end{array}$ \\
\hline Genetic & Iron-refractory iron-deficiency anaemia, thalassaemia and sickle cell anaemia \\
\hline
\end{tabular}

IRIDA is caused by mutations/polymorphisms in the gene TMPRSS6 (transmembrane protease, serine 6) [12]. This anaemia offers useful insights into the normal iron-control mechanisms in humans. The consequence of TMPRSS6 loss of function mutations is constitutively high levels of the 
iron-regulatory hormone hepcidin, a 25-amino acid peptide that together with the sole iron exporter in the body, ferroportin, control iron homeostasis (Figure 1). High levels of hepcidin result in ferroportin loss from cell membranes and cessation of iron export to plasma. This explains the inability to absorb intestinal iron in IRIDA cases and thus the muted response to treatment with oral iron preparations [13]. This can be partly overcome if sufficiently high quantities of oral iron are administered as demonstrated in studies of the phosphate binder ferric citrate [14].

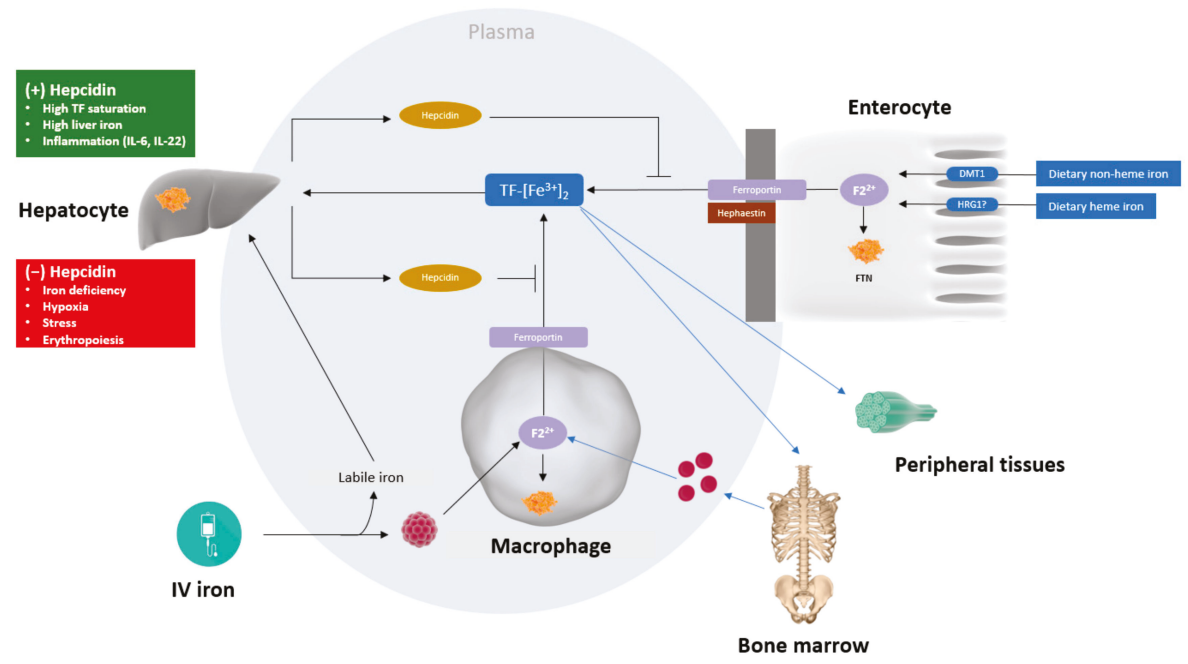

Figure 1. A simplified overview of iron metabolism. The major flow of iron in the body is via transferrin (TF), which transports iron from iron absorption in the enterocytes in the duodenum, the recycling of iron from senescent erythrocytes within macrophages of the reticuloendothelial system, and the mobilisation of iron storage within ferritin (FTN), that mainly resides within macrophages and hepatocytes. Iron export to plasma is mediated via the sole iron exporter, ferroportin and is controlled by its ligand, hepcidin, which is secreted into blood plasma mainly by hepatocytes. Hepcidin binds to ferroportin and controls ferroportin concentration through promoting its endocytosis. Almost all plasma iron is bound to TF, but after infusion of iron supplements, labile (unbound) iron may appear in plasma. The molecular structure of third generation IV irons confers stability on the iron complex, with the intention of limiting the amount of labile iron entering the plasma after infusion and ensuring a controlled release of iron from the complex once taken up by macrophages. How the different IV iron complexes are handled in the macrophage and the basis for their different solubility is not well characterised, but will be dependent not only on $\mathrm{pH}$, but the low molecular weight molecules that are present in the lysosome and their different iron-binding affinities and on macrophage polarisation/differentiation. Iron released from the iron-carbohydrate complex is either stored as ferritin or transported out of the macrophage and bound to TF.

Hepcidin and iron regulatory proteins (IRPs) are essential for maintaining iron homeostasis [15]. Hepcidin production from the liver is increased in the presence of inflammation, in particular in the presence of the inflammatory cytokine interleukin-6 and is an underlying mechanism of IDA associated with chronic disease [16]. Chronic inflammation, for example related to CKD, increases hepcidin production, in turn inhibiting both the uptake of dietary iron and the mobilization of stored iron from the reticuloendothelial system to circulating transferrin [17]. This restricts the availability of iron for erythropoiesis, which is often superimposed on underlying true iron deficiency and may, therefore, be termed functional iron deficiency as there are sufficient iron stores but an inability to access them due to elevated hepcidin $[18,19]$. 


\subsection{Iron Supplementation Strategies}

Historically, oral iron replacement therapy to treat IDA in the form of iron salts dates to the 17th century. Oral ferrous salts are the most commonly prescribed iron replacement therapy, reflecting their efficacy and simplicity of dosing [6,7]. However, long-term treatment of up to 6 months is usually required to adequately replete iron stores, and gastrointestinal side-effects that include nausea and pain are common. A meta-analysis of 43 randomised, controlled trials of 6831 patients reported gastrointestinal side-effects in up to $75 \%$ of patients [5]. These side effects can be underestimated regarding their impact on patients and adherence can be challenging [20].

For those who do not respond to oral iron, understanding the hepcidin-ferroportin axis has provided mechanistic insights into relative "iron resistance". This points to a potential role for hepcidin measurement in clinical practice, with a view to identifying patients most likely or least likely to respond to oral iron therapy. Also, recent studies of NAID have shown that alternate-day dosing of oral iron might optimise iron absorption, as the hepcidin levels fall in the alternate days without iron consumption $[10,11]$.

There is ongoing research interest in the development of original oral irons; in particular, the utilisation of nanotechnology to create novel oral iron nanoformulations [21-25]. One of the strategies proposed is to use the iron core of ferritin, the primary iron-storage protein in cells, as a model. Ferritin has evolved to serve as a highly efficient iron storage protein that is conserved across eukaryotes. Ferritin is composed of an iron oxide nanocore contained within a globular heteropolymeric protein, from which iron release is restricted and controlled [26]. Recently, a nanoparticulate mimetic of the ferritin core was proposed as a potentially side effect-free form of supplemental iron [27] and a paediatric trial is ongoing (NCT02941081). Other trials are on-going with many different oral iron formulations developed to improve absorption and/or tolerability $[14,23,28-30]$.

The first parenteral iron preparations to be used clinically in the early 20th century were colloidal ferric hydroxide preparations, but toxicity linked to the release of large amounts of labile ("free") iron limited their use. This prompted the development of preparations composed of an iron core and carbohydrate shell that prevented rapid release of the elemental iron [13,31]. The introduction of IV iron saccharide in 1947 and high-molecular-weight dextran (HMWD) iron in 1954 signalled a major change in perception of IV iron supplementation due to their efficacy and relative safety. Nonetheless, cases of severe hypersensitivity reactions, in particular the well-documented dextran-induced anaphylactic reactions, led to extreme caution within the medical community regarding the use of these IV irons [13,31].

In the 1990s, two new formulations-iron gluconate and iron sucrose-were developed that used non-dextran carbohydrates complexed with the iron core and these were associated with markedly fewer severe adverse events (SAE). It was shown that patients previously sensitive to HMWD were unlikely to be sensitised to these newer irons [13,31,32]. Development of new pharmaceutical technologies allowed the development of third generation IV irons in an attempt to circumvent the toxicity issues inherent with earlier preparations and the posology limitations of iron sucrose products. In the last ten years, three third-generation IV iron compounds were licensed for the treatment of IDA [13,31]. Two are currently approved for use in Europe-ferric carboxymaltose and iron isomaltoside 1000—and one in the United States—-ferumoxytol [33].

\section{Bioengineering and Metabolism of IV Iron}

IV iron preparations are bioengineered as iron-carbohydrate complexes to deliver high doses of iron in a stable, non-toxic form [34] and consist of colloidal suspensions of iron oxide nanoparticles with a polynuclear Fe(III)-oxyhydroxide/oxide core surrounded by a carbohydrate ligand [13,31,35-39] (Table 2). In essence, IV irons behave as prodrugs, retaining ionic iron until the iron-carbohydrate complex is metabolised [35,36]. The physicochemical differences between the IV irons include mineral composition, crystalline structure, conformation, size and molecular weight, but the key point of difference between IV iron products is the carbohydrate ligand, which influences complex 
stability, iron release and immunogenicity, and is a unique feature of each drug [13,31,34-38] (Table 3). Schematic models of a high molecular weight iron-carbohydrate complex (iron carboxymaltose) and a low molecular weight complex (iron gluconate) are compared in Figure 2, which illustrates that these are two different particles both in terms of overall size but also, and importantly, in terms of number of iron atoms and how accessible these are to undergo chemical reactions. Iron carboxymaltose contains around 110,000 iron atoms bound to 180,000 oxygen atoms in a dense structure with an approximate core diameter of $18 \mathrm{~nm}$. This makes it more difficult to break down once inside the cells, since the iron atoms are less accessible to chelators or redox reactions, whereas iron gluconate is smaller with a $6 \mathrm{~nm}$ diameter, is less compact and has fewer iron atoms (around 4200 iron atoms bound to 7000 oxygen atoms) and, therefore, the kinetics of iron release from iron gluconate is faster than that of iron release from iron carboxymaltose, meaning that iron gluconate is more labile than iron carboxymaltose.

Table 2. Clinical characteristics of currently available IV irons $[13,33,39]$.

\begin{tabular}{|c|c|c|c|c|c|c|}
\hline & Ferumoxytol & $\begin{array}{c}\text { Iron } \\
\text { Carboxymaltose }\end{array}$ & $\begin{array}{c}\text { Iron } \\
\text { Isomaltoside } \\
1000\end{array}$ & $\begin{array}{c}\text { Low Molecular } \\
\text { Weight Iron } \\
\text { Dextran }\end{array}$ & $\begin{array}{c}\text { Iron } \\
\text { Sucrose }\end{array}$ & $\begin{array}{c}\text { Iron } \\
\text { Gluconate }\end{array}$ \\
\hline Brand name & Feraheme $^{\circledR}$ & Ferinject $^{\circledR}$ & Monofer $^{\circledR}$ & Cosmofer $^{\circledR}$ & Venofer $^{\circledR}$ & Ferlixit $^{\circledR}$ \\
\hline $\begin{array}{l}\text { Maximum single } \\
\text { dose }\end{array}$ & $510 \mathrm{mg}$ & $1000 \mathrm{mg}$ & $20 \mathrm{mg} / \mathrm{kg}$ & $20 \mathrm{mg} / \mathrm{kg}$ & $200 \mathrm{mg}$ & $125 \mathrm{mg}$ \\
\hline $\begin{array}{l}\text { Minimum } \\
\text { administration time } \\
\text { (minutes) }\end{array}$ & 15 & 15 & 15 & 60 & 30 & $30-60$ \\
\hline $\begin{array}{l}\text { Replacement dose } \\
\text { possible in a single } \\
\text { infusion }\end{array}$ & No & Yes & Yes & Yes & No & No \\
\hline
\end{tabular}

Table 3. Comparison of physicochemical characteristics and pharmacokinetics of IV irons [37-39].

\begin{tabular}{|c|c|c|c|c|c|c|}
\hline & Ferumoxytol & $\begin{array}{c}\text { Iron } \\
\text { Carboxymaltose }\end{array}$ & $\begin{array}{c}\text { Iron } \\
\text { Isomaltoside } \\
1000\end{array}$ & $\begin{array}{c}\text { Low Molecular } \\
\text { Weight Iron } \\
\text { Dextran }\end{array}$ & $\begin{array}{c}\text { Iron } \\
\text { Sucrose }\end{array}$ & $\begin{array}{c}\text { Iron } \\
\text { Gluconate }\end{array}$ \\
\hline $\begin{array}{l}\text { Molecular weight } \\
\text { (Da) }\end{array}$ & 185,000 & 150,000 & 150,000 & 103,000 & 43,000 & 37,500 \\
\hline $\begin{array}{l}\text { Carbohydrate } \\
\text { ligand }\end{array}$ & $\begin{array}{l}\text { Polyglucose sorbitol } \\
\text { carboxymethylether }\end{array}$ & Carboxymaltose & Isomaltoside & $\begin{array}{c}\text { Dextran } \\
\text { polysaccharide }\end{array}$ & Sucrose & $\begin{array}{c}\text { Gluconate, } \\
\text { loosely } \\
\text { associated } \\
\text { sucrose }\end{array}$ \\
\hline $\begin{array}{c}\text { Relative stability } \\
\text { of iron } \\
\text { carbohydrate } \\
\text { complex }\end{array}$ & High & High & High & High & Medium & Low \\
\hline $\begin{array}{l}\text { Reactivity with } \\
\text { transferrin }\end{array}$ & Low & Low & Low & Low & Medium & High \\
\hline $\begin{array}{l}\text { Relative labile } \\
\text { iron release }\end{array}$ & Low & Low & Low & Medium & High & High \\
\hline $\begin{array}{c}\text { Plasma half-life } \\
\text { (hrs) }\end{array}$ & $\sim 15$ & $7-12$ & 20 & $5-20$ & 6 & $\sim 1$ \\
\hline
\end{tabular}



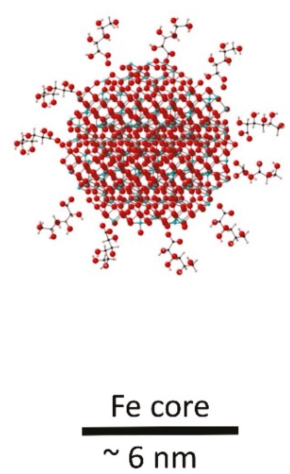

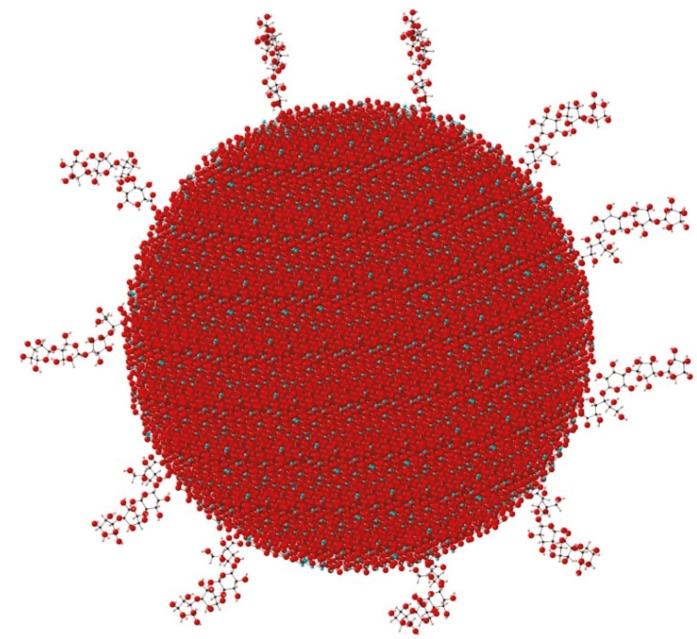

Fe core

$\sim 18 \mathrm{~nm}$

Figure 2. Schematic illustration of the relative size and composition of iron gluconate (left, low molecular weight, 37,500 Da) and iron carboxymaltose (right, high molecular weight, $150,000 \mathrm{Da})$. The models show iron-oxide cores, based on the neutron diffraction-derived structure of ferrihydrite [40], surrounded by the relevant organic ligands. Oxygen is shown in red, hydrogen in pink, carbon in black and iron in blue.

Upon IV infusion, the volume of distribution of IV irons corresponds roughly to the plasma volume. IV irons are processed in macrophages and release functional iron from the carbohydrate ligand $[35,36]$. The iron complex is endocytosed by macrophages within the reticuloendothelial system, mainly in the liver, spleen and bone marrow, but the precise mechanism of recognition and internalization is not fully defined [41]. Endosome-lysosome fusion creates an acidic endolysosome and, combined with endogenous iron-binding due to citric acid and other iron-complexing agents present in the lysosomes, drives iron release from the iron-carbohydrate complex [42]. This may be distinct from the mechanism of iron release from ferritin. Early in-vitro stability analyses suggest that the low $\mathrm{pH}$ of the endolysosome, the type and concentration of low-molecular-weight iron-ligands present in the endolysosome and the stabilities of the different IV iron-carbohydrate structures, are all important for iron liberation [42,43]. However, the precise mechanism of iron liberation is incompletely understood. This is an area of current interest-IV iron metabolism is likely to vary depending on the type and differentiation state of the macrophage processing the iron [44,45], and iron itself can alter macrophage polarisation [46], so that the different characteristics of each iron-carbohydrate complex may potentially affect macrophage function. The latter may well have relevance for the regulatory authorities when defining the extent of similarity between iron-formulations of the same class.

Iron is subsequently transported into the labile iron pool in the macrophage cytoplasm, where it can be stored, or exported into the plasma by ferroportin. The mechanism by which intracellular iron is delivered to ferroportin for export is not well characterised [47]. Upon export, iron is immediately oxidised by ferroxidases, and sequestered by plasma transferrin for transport to erythroid precursor cells for incorporation into haemoglobin or to other iron-requiring cells, or for liver storage in the form of ferritin [35-37] (Figure 1).

The stability of the iron-carbohydrate complex influences the amount of labile iron that is present in the formulation [32,37]. Strongly-bound iron-carbohydrate complexes characterise the 
third-generation IV irons. These stable, robust complexes bind iron tightly and do not release large amounts of labile, non-transferrin-bound iron (NTBI) into the blood before macrophage uptake. As a result, the risk of infusion reactions caused by labile iron is diminished and are clinically well-tolerated even at high doses $[13,31,32,35,37,39,48,49]$. This allows rapid, high-dose infusion of doses of 1000-1500 mg, thus offering the potential for complete iron replacement in 15-60 min (Table 2), although processing and distribution of the iron will obviously take longer. Comprehensive biochemical quantification of the different IV irons preparations confirms differences in complex stability and labile iron release (Figure 3) [32].

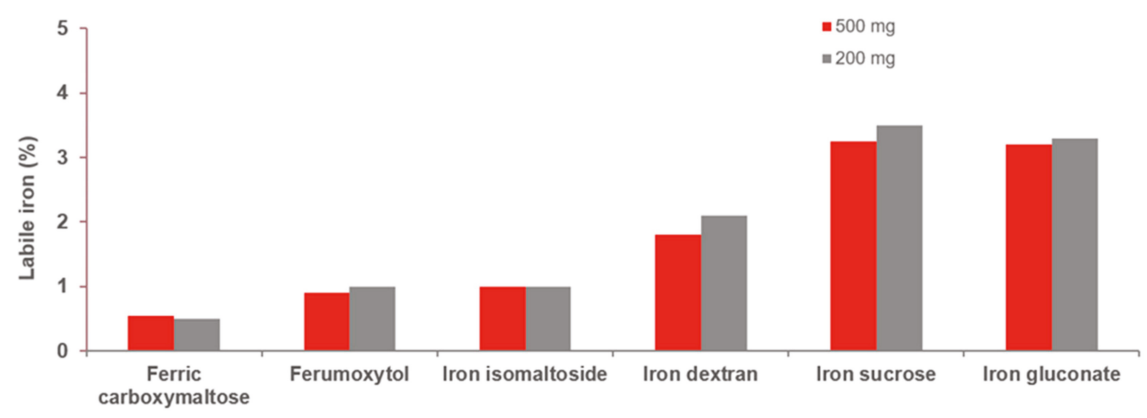

Figure 3. In vivo comparison of labile iron potential of IV iron preparations. Results of the determination of detectable labile iron in human serum as a percentage of total dose given (200 $\mathrm{mg}$ and $500 \mathrm{mg}$ ), using the Ferrozine ${ }^{\circledR}$-method (adapted from Jahn et al., 2011 [32]).

Compared with third-generation irons, the lower molecular weight iron sucrose complexes have lower complex stability, are termed semi-robust, moderately strong, and release larger amounts of NTBI into the blood [37]. As a result, maximal single doses are significantly lower with longer administration times [33,37]. Ferric gluconate preparations contain variable amounts of low-molecular-weight components $(<18,000$ Daltons), are characteristically labile and weak, and generate larger amounts of labile NTBI [37]. Labile iron also has the potential for formation of highly reactive free radicals causing oxidative stress [50]. Under normal physiological conditions, iron in the body exists in a non-redox-active form, i.e., it is not able to repetitively complete coupled reduction and oxidation, as in ferritin and transferrin. However, should iron infusions lead to complete or near-complete saturation of transferrin, the subsequent high levels of labile, redox-active iron, particularly with high-dose infusion, may contribute to formation of reactive oxygen species and reactive nitrogen species in an uncontrolled way. These entities cause oxidative and/or nitrosative stress that upsets normal cellular signalling mechanisms and has been shown to be involved in many diseases, including heart failure, and Alzheimer's disease, Friedreich's ataxia and Parkinson's disease [35,39].

A further consideration is the risk of dextran-related immune reactions and clinical hypersensitivity reactions more generally. Dextran, given intravenously, can result in IgG-mediated anaphylaxis [34]. Early IV formulations of high-molecular-weight iron dextran caused rare but serious allergic reactions that led to anaphylaxis [13,31]. The formulation of iron dextran (lower molecular weight) currently available is associated with markedly lower rates of adverse events [51-54]. For third-generation IV iron preparations, the carbohydrate component of the iron-carbohydrate complex is responsible for immune recognition and eliciting hypersensitivity reactions. It is now thought that a complement activation-related pseudo-allergy is likely a more common pathogenetic mechanism in acute reactions to currently licensed IV iron than a response that is immunological and IgE-mediated [55]. The response is likely triggered by iron nanoparticles and influenced by the unique carbohydrate-iron complex of each IV iron. 
Thus, the structure and physiochemical characteristics of IV irons have implications for therapy, impacting the maximum amount of iron that can be infused, the rate of infusion, the risk of minor infusion reactions, the risk of immune-mediated hypersensitivity reactions, and wider negative effects linked to the toxicity of labile iron.

\section{Regulatory View of IV Iron Formulations and Bioequivalence}

The complexity of the IV iron formulations underlies the ongoing issue regarding approval of generic copies of non-biologic complex drugs. The authorisation process for generic pharmaceuticals is currently based on pharmaceutical equivalence which encompasses demonstration of 'sameness' of the active pharmaceutical ingredient and bioequivalence to the listed reference product without the need for efficacy studies and establishing a safety profile. With the availability of iron sucrose similars in the European Union, differences in clinical efficacy and safety profiles to the originator drug have been reported [56-63].

With this background, the regulators have taken notice of the complexity of IV iron formulations. Both the Food and Drug Administration (FDA) and European Medicines Agency (EMA) acknowledge that IV iron-carbohydrate nanoparticle preparations cannot be authorised by this well-established generic approval paradigm for small molecules. The EMA and FDA have reflected on the data requirements to define similarity and the possibility of interchanging or switching between different IV iron formulations; these include stepwise in vitro, non-clinical and clinical testing as a prerequisite [64-66]. The EMA has concluded that the stability of IV iron-carbohydrate complexes and the physicochemical properties of both the iron and the carbohydrate impact the quality attributes of the different drugs, which have the potential to influence both safety and efficacy [66]. This position draws into question the view that IV irons are substitutable and interchangeable and suggests caution should be exercised when switching between IV irons, with appropriate efficacy and safety monitoring put in place.

\section{Clinical Use of IV Iron}

The prescribing of IV irons across a broad range of indications reflects the breadth of conditions that manifest IDA. IV iron use has dramatically increased, and the broad and increasing number of conditions for which IV iron has been investigated is at least in part supported by their safety profile. An extensive meta-analysis of $>10,000$ patients derived from 103 clinical trials offers important insights into the overall safety profile and allows comparison between IV and oral iron [67]. IV iron was not associated with an increase in serious AEs (SAE) when compared to oral iron and placebo (RR, 1.04; 95\% CI, 0.93-1.14). SAE were rare, estimated to occur in 1:200,000 doses with no fatal or anaphylactic reactions reported [67]. Although the study confirmed that minor infusion reactions do occur, the frequency of these adverse events must be considered in the context of the use of blood transfusions. In many cases, transfusions are the only alternative to IV iron to correct IDA when oral iron is ineffective or not tolerated or in acute situations when there is not enough time for oral iron to replenish iron levels.

A limitation of the meta-analysis is the short-term nature of randomised clinical trials (RCTs), with long-term adverse events not being tracked (67). For conditions such as CKD that are dependent on ongoing long-term dialysis and frequent iron infusions, there are some concerns about the long-term safety outcomes. This concern in part relates to the potential for oxidative stress linked to IV iron use, especially in the context of the ongoing chronic inflammatory processes characteristic of CKD. A large, clinical study (proactive IV iron therapy in haemodialysis patients, PIVOTAL, EudraCT number 2013-002267-25) has recently been completed and will report major adverse outcomes including major cardiovascular events in CKD patients [68].

There is extensive clinical trial evidence supporting the efficacy of IV iron preparations in patients with both non-dialysis-dependent and end-stage CKD [69-99] and patients with CHF [100-110], IBD [28,111-120], women's health (including abnormal uterine bleeding [121], peri and postpartum 
IDA [122-125], and prevention in pregnancy [126], and in various cancers [127-131], and in the perioperative management of anaemia [132]. Several observational cohort studies further support the efficacy and safety of IV iron in real-world clinical practice for IDA associated with CKD [133-142] (including dialysis patients hospitalised for infection [139]), IBD [143-145], pregnancy [146] and cancer $[147,148]$.

Multiple clinical guidelines relating to the management of iron deficiency in various healthcare fields including CKD, CHF, IBD, cancer and pregnancy note the benefit of IV iron as a treatment option for CKD for whom oral iron is not an option (lack of response, non-compliance, or intolerance) and for those patients with severe iron deficiency with the need for rapid iron replenishment $[149,150]$. As would be expected, the clinical evidence base underpinning these guidelines is strong. The 2018 European Society for Medical Oncology (ESMO) clinical practice guidelines for the management of anaemia and iron deficiency in patients with cancer reflect the most recent clinical data and strongly recommend IV iron in confirmed iron deficiency [151]. For chemotherapy-associated anaemia, IV iron makes an important contribution to improved response to erythropoiesis stimulating agents. In dialysis associated with CKD, IV iron is standard care practice [152].

\section{Evolving Evidence Base Identifies Differences between Third-Generation IV Irons}

Generally, reviews and meta-analyses provide valuable pooled results reporting the overall efficacy and safety profile of the class. Direct comparison between different irons are few, but with the increasing evidence pool and broadening of diseases assessed for IDA correction, some differences between irons are beginning to become apparent that may impact clinical practice.

In heart failure, iron deficiency is linked to disease severity and is only partly related to anaemia and is recognised as a marker of poor prognosis, independent of other prognostic factors [153-155]. IV iron improves patient well-being and New York Heart Association (NYHA) functional class, as reported in the FAIR-HF trial (Ferinject Assessment in Patients with Iron Deficiency and Chronic Heart Failure) in both anaemic and non-anaemic patients and exercise capacity over 24 weeks in the CONFIRM-HF trial (Ferric CarboxymaltOse evaluatioN on perFormance in patients with IRon deficiency in coMbination with chronic Heart Failure) [107,156]. In light of the evidence derived from trials of ferric carboxymaltose, the European Society of Cardiology guidelines for heart failure management makes a specific recommendation that ferric carboxymaltose should be considered in symptomatic patients to alleviate HF symptoms and improve exercise capacity and quality of life [150]. Whether other third generation irons have a similar impact is yet to be confirmed but is currently being investigated with results expected in 2021 (NCT02642562) [157].

Iron deficiency is highly prevalent in IBD, occurring in more than two-thirds of patients with Crohn's disease and ulcerative colitis $[158,159]$. Inflammatory bowel disease is perhaps a unique disease process with respect to IDA because of the multiple pathogenic mechanisms involved in its pathophysiology. Chronically inflamed intestinal mucosa with blood loss and micronutrient deficiency (iron and B12) are the primary mechanisms underlying the development of anaemia in IBD, with chronic inflammation, haemolysis, and medication-induced myelosuppression also thought to have roles [160]. A Bayesian network meta-analysis assessed the comparative efficacy and safety of different IV irons in patients with IBD and anaemia. This meta-analysis included five trials involving a relatively small number of patients $(n=1143)$ treated with IV iron (IS, ferric carboxymaltose, ferumoxytol, low-molecular-weight iron dextran, ferric gluconate, iron isomaltoside). Based on response rate, defined as $\mathrm{Hb}$ normalisation and/or increase by $\geq 2 \mathrm{~g} / \mathrm{dL}$, ferric carboxymaltose alone was shown to have superior efficacy than oral iron (OR $=1.9,95 \%$ CI: $1.1 ; 3.2)$ [161].

From a safety perspective, the two main side effects associated with IV iron are hypophosphataemia, apparent soon after infusion and lasting up to 2 weeks, and hypersensitivity reactions, as previously noted. The occurrence of hypophosphataemia has been investigated further. The underlying cause of the phenomenon is related to the expression of FGF-23, a hormone derived from osteocytes, with the ultimate consequence of renal phosphate excretion. A head-to-head 
retrospective analysis of 81 patients who received ferric carboxymaltose or iron isomaltoside identified hypophosphataemia almost exclusively in the ferric carboxymaltose-treated patients and caused by increased concentrations of FGF-23 [162]. A more recent study, the FIRM study in 1997 participants also demonstrated this difference in effect on phosphate when ferric carboxymaltose was compared with ferumoxytol [163]. This side effect highlights a subtle but potentially important different pharmacodynamic action of these two third generation IV irons. More data on hypophosphataemia is accruing; it is currently thought to be generally mild and usually without clinical consequence, but rare cases with clinical sequalae are apparent and this issue must be kept in consideration. The risk may be increased in patients with other disturbances of phosphate metabolism, such as hyperparathyroidism. A Danish retrospective analysis of 231 outpatients treated with IV iron infusions over a 2.5-year period, during which ferric carboxymaltose was switched to iron isomaltoside and back to ferric carboxymaltose in a stable cohort of patients largely with IBD [164], showed hypophosphataemia events were markedly more frequent in patients treated with ferric carboxymaltose than iron isomaltoside (64 vs. 9, $p<0.01$ ). The study also reported that significantly more patients experienced hypersensitivity reactions with iron isomaltoside than ferric carboxymaltose $(2.5 \% \mathrm{vs} .10 .7 \%, p<0.01)$, with no hypersensitivity crossover between the two drugs apparent. With the same amount of iron delivered with both drugs, this study suggests the differences in side effect profile relate to the different structures and properties of the two different IV iron drugs. More recent reviews have reassured that at least in patients with renal disease, the prevalence of serious adverse reactions is relatively low $[49,67,165,166]$.

\section{Conclusions}

IDA is a clinically important complication associated in particular with chronic inflammatory conditions, infection and other disease states and leads to chronic fatigue, reduced quality of life (QOL), increased risk of complications and increased mortality. Treatment of iron deficiency falls into two main categories, oral and IV iron formulations [167]. Clinical practice guidelines identify the benefits of IV iron preparations as a treatment option for patients with IDA who lack a response to, are non-compliant with, or are intolerant of oral iron treatment, as well as those who have severe iron deficiency and require rapid replenishment of available iron and $\mathrm{Hb}$ levels. IV iron has an important role in management of IDA perioperatively, particularly for emergency surgery, and there is now a robust clinical trial evidence base supporting the efficacy and safety of IV iron preparations in CKD, CHF, IBD, women's health and cancer.

The third generation of IV irons are characterised by unique carbohydrate ligands forming strongly bound iron-carbohydrate complexes. Their complexity is reflected in the guidance from regulators that generic formulations cannot be authorised by the generic approval process and goes against the view that IV irons are substitutable and interchangeable. The risk of infusion reactions is diminished compared with previous IV iron formulations, and these drugs are clinically well-tolerated at high doses to allow rapid, high-dose infusion that offers the potential for complete iron repletion in 15-60 min. As the evidence base and range of indications for which IV iron treatment is used expands, it is valuable to define the differences between these agents, in particular adverse event profiles, and reflect on how this might influence both the choice of iron and the decision to switch between IV irons in clinical practice.

Author Contributions: Conceptualization, S.B.; D.I.A.P. and H.D.; Writing-Original Draft Preparation, S.B.; Writing-Review \& Editing, S.B.; D.I.A.P.; H.F.C., and H.D; Visualization, H.F.C. Project Administration, S.B., and H.D.

Funding: This research received no external funding.

Acknowledgments: Search and editorial assistance was performed by Aidan McManus, PhD, of Edge Medical Communications, Dorking UK and was funded by Vifor Pharma Ltd.

Conflicts of Interest: D.I.A.P. is one of the inventors of an oral iron formulation for which she could receive future awards to inventors through the MRC Awards to Inventor scheme and has attended a Vifor-sponsored workshop. 
Notwithstanding, DIAP declares no conflict of interest with respect to this review manuscript. H.F.C. has no competing interest. S.B. has received honorarium for lectures from Vifor and Pharmacosmos in addition to funding to attend educational meetings. H.D. receives funding from Pfizer and La Jolla Pharmaceutical Company, and has attended a Vifor-sponsored Workshop, but declares no conflict of interest with respect to this review manuscript.

\section{References}

1. Paul, B.T.; Manz, D.H.; Torti, F.M.; Torti, S.V. Mitochondria and iron: Current questions. Expert Rev. Hematol. 2017, 10, 65-79. [CrossRef] [PubMed]

2. Anderson, C.P.; Shen, M.; Eisenstein, R.S.; Leibold, E.A. Mammalian iron metabolism and its control by iron regulatory proteins. Biochim. Biophys. Acta 2012, 1823, 1468-1483. [CrossRef] [PubMed]

3. Muckenthaler, M.U.; Rivella, S.; Hentze, M.W.; Galy, B. A red carpet for iron metabolism. Cell 2017, 168, 344-361. [CrossRef] [PubMed]

4. GBD 2016 Disease and Injury Incidence and Prevalence Collaborators. Global, regional, and national incidence, prevalence, and years lived with disability for 328 diseases and injuries for 195 countries, 1990-2016: A systematic analysis for the global burden of disease study 2016. Lancet 2017, 390, 1211-1259. [CrossRef]

5. Tolkien, Z.; Stecher, L.; Mander, A.P.; Pereira, D.I.; Powell, J.J. Ferrous sulfate supplementation causes significant gastrointestinal side-effects in adults: A systematic review and meta-analysis. PLoS ONE 2015, 10. [CrossRef] [PubMed]

6. Cappellini, M.D.; Comin-Colet, J.; de Francisco, A.; Dignass, A.; Doehner, W.; Lam, C.S.; Macdougall, I.C.; Rogler, G.; Camaschella, C.; Kadir, R.; et al. Iron deficiency across chronic inflammatory conditions: International expert opinion on definition, diagnosis, and management. Am. J. Hematol. 2017, 92, 1068-1078. [CrossRef] [PubMed]

7. Camaschella, C. Iron deficiency: New insights into diagnosis and treatment. Hematol. Am. Soc. Hematol. Educ. Program. 2015, 2015, 8-13. [CrossRef] [PubMed]

8. Butcher, A.; Richards, T. Cornerstones of patient blood management in surgery. Transfus. Med. 2017, 28, 150-157. [CrossRef] [PubMed]

9. Litton, E.; Xiao, J.; Ho, K.M. Safety and efficacy of intravenous iron therapy in reducing requirement for allogeneic blood transfusion: Systematic review and meta-analysis of randomised clinical trials. BMJ 2013, 347. [CrossRef] [PubMed]

10. Moretti, D.; Goede, J.S.; Zeder, C.; Jiskra, M.; Chatzinakou, V.; Tjalsma, H.; Melse-Boonstra, A.; Brittenham, G.; Swinkels, D.W.; Zimmermann, M.B. Oral iron supplements increase hepcidin and decrease iron absorption from daily or twice-daily doses in iron-depleted young women. Blood 2015, 126, 1981-1989. [CrossRef] [PubMed]

11. Stoffel, N.U.; Cercamondi, C.I.; Brittenham, G.; Zeder, C.; Geurts-Moespot, A.J.; Swinkels, D.W.; Moretti, D.; Zimmermann, M.B. Iron absorption from oral iron supplements given on consecutive versus alternate days and as single morning doses versus twice-daily split dosing in iron-depleted women: Two open-label, randomised controlled trials. Lancet Haematol. 2017, 4, e524-e533. [CrossRef]

12. Finberg, K.E.; Heeney, M.M.; Campagna, D.R.; Aydinok, Y.; Pearson, H.A.; Hartman, K.R.; Mayo, M.M.; Samuel, S.M.; Strouse, J.J.; Markianos, K.; et al. Mutations in tmprss6 cause iron-refractory iron deficiency anemia (irida). Nat. Genet. 2008, 40,569-571. [CrossRef] [PubMed]

13. Girelli, D.; Ugolini, S.; Busti, F.; Marchi, G.; Castagna, A. Modern iron replacement therapy: Clinical and pathophysiological insights. Int. J. Hematol. 2018, 107, 16-30. [CrossRef] [PubMed]

14. Fishbane, S.; Block, G.A.; Loram, L.; Neylan, J.; Pergola, P.E.; Uhlig, K.; Chertow, G.M. Effects of ferric citrate in patients with nondialysis-dependent ckd and iron deficiency anemia. J. Am. Soc. Nephrol. 2017, 28, 1851-1858. [CrossRef] [PubMed]

15. Camaschella, C. Iron and hepcidin: A story of recycling and balance. Hematol. Am. Soc. Hematol. Educ. Program. 2013, 2013, 1-8. [CrossRef] [PubMed]

16. Schmidt, P.J. Regulation of iron metabolism by hepcidin under conditions of inflammation. J. Biol. Chem. 2015, 290, 18975-18983. [CrossRef] [PubMed]

17. Fishbane, S.; Spinowitz, B. Update on anemia in esrd and earlier stages of ckd: Core curriculum 2018. Am. J. Kidney Dis. 2018, 71, 423-435. [CrossRef] [PubMed] 
18. Fishbane, S. Balance of benefit and risk in intravenous iron treatment in chronic kidney disease. Semin. Nephrol. 2016, 36, 119-123. [CrossRef] [PubMed]

19. Weiss, G.; Goodnough, L.T. Anemia of chronic disease. N. Engl. J. Med. 2005, 352, 1011-1023. [CrossRef] [PubMed]

20. Auerbach, M.; Munoz, M.; Macdougall, I.C. Intravenous iron: Out of sight, out of mind. Lancet Haematol. 2018, 5, e10-e12. [CrossRef]

21. Hilty, F.M.; Arnold, M.; Hilbe, M.; Teleki, A.; Knijnenburg, J.T.; Ehrensperger, F.; Hurrell, R.F.; Pratsinis, S.E.; Langhans, W.; Zimmermann, M.B. Iron from nanocompounds containing iron and zinc is highly bioavailable in rats without tissue accumulation. Nat. Nanotechnol. 2010, 5, 374-380. [CrossRef] [PubMed]

22. Powell, J.J.; Bruggraber, S.F.; Faria, N.; Poots, L.K.; Hondow, N.; Pennycook, T.J.; Latunde-Dada, G.O.; Simpson, R.J.; Brown, A.P.; Pereira, D.I. A nano-disperse ferritin-core mimetic that efficiently corrects anemia without luminal iron redox activity. Nanomedicine 2014, 10, 1529-1538. [CrossRef] [PubMed]

23. Pisani, A.; Riccio, E.; Sabbatini, M.; Andreucci, M.; Del Rio, A.; Visciano, B. Effect of oral liposomal iron versus intravenous iron for treatment of iron deficiency anaemia in ckd patients: A. randomized trial. Nephrol. Dial. Transplant. 2015, 30, 645-652. [CrossRef] [PubMed]

24. Shafie, E.H.; Keshavarz, S.A.; Kefayati, M.E.; Taheri, F.; Sarbakhsh, P.; Vafa, M.R. The effects of nanoparticles containing iron on blood and inflammatory markers in comparison to ferrous sulfate in anemic rats. Int. J. Prev. Med. 2016, 7. [CrossRef]

25. Garces, V.; Rodriguez-Nogales, A.; Gonzalez, A.; Galvez, N.; Rodriguez-Cabezas, M.E.; Garcia-Martin, M.L.; Gutierrez, L.; Rondon, D.; Olivares, M.; Galvez, J.; et al. Bacteria-carried iron oxide nanoparticles for treatment of anemia. Bioconjug. Chem. 2018, 29, 1785-1791. [CrossRef] [PubMed]

26. Ganz, T. Systemic iron homeostasis. Physiol. Rev. 2013, 93, 1721-1741. [CrossRef] [PubMed]

27. Pereira, D.I.; Bruggraber, S.F.; Faria, N.; Poots, L.K.; Tagmount, M.A.; Aslam, M.F.; Frazer, D.M.; Vulpe, C.D.; Anderson, G.J.; Powell, J.J. Nanoparticulate iron(iii) oxo-hydroxide delivers safe iron that is well absorbed and utilised in humans. Nanomedicine 2014, 10, 1877-1886. [CrossRef] [PubMed]

28. Gasche, C.; Ahmad, T.; Tulassay, Z.; Baumgart, D.C.; Bokemeyer, B.; Buning, C.; Howaldt, S.; Stallmach, A.; Group, A.S. Ferric maltol is effective in correcting iron deficiency anemia in patients with inflammatory bowel disease: Results from a phase-3 clinical trial program. Inflamm. Bowel Dis. 2015, 21, 579-588. [CrossRef] [PubMed]

29. Barraclough, K.A.; Brown, F.; Hawley, C.M.; Leary, D.; Noble, E.; Campbell, S.B.; Isbel, N.M.; Mudge, D.W.; van Eps, C.L.; Johnson, D.W. A randomized controlled trial of oral heme iron polypeptide versus oral iron supplementation for the treatment of anaemia in peritoneal dialysis patients: Hematocrit trial. Nephrol. Dial. Transplant. 2012, 27, 4146-4153. [CrossRef] [PubMed]

30. Nagaraju, S.P.; Cohn, A.; Akbari, A.; Davis, J.L.; Zimmerman, D.L. Heme iron polypeptide for the treatment of iron deficiency anemia in non-dialysis chronic kidney disease patients: A randomized controlled trial. BMC Nephrol. 2013, 14. [CrossRef] [PubMed]

31. Auerbach, M.; Macdougall, I. The available intravenous iron formulations: History, efficacy, and toxicology. Hemodial. Int. 2017, 21 (Suppl. 1), S83-S92. [CrossRef] [PubMed]

32. Jahn, M.R.; Andreasen, H.B.; Futterer, S.; Nawroth, T.; Schunemann, V.; Kolb, U.; Hofmeister, W.; Munoz, M.; Bock, K.; Meldal, M.; et al. A comparative study of the physicochemical properties of iron isomaltoside 1000 (monofer), a new intravenous iron preparation and its clinical implications. Eur. J. Pharm. Biopharm. 2011, 78, 480-491. [CrossRef] [PubMed]

33. Grzywacz, A.; Lubas, A.; Fiedor, P.; Fiedor, M.; Niemczyk, S. Safety and efficacy of intravenous administration of iron preparations. Acta Pol. Pharm. 2017, 74, 13-24. [PubMed]

34. Neiser, S.; Koskenkorva, T.S.; Schwarz, K.; Wilhelm, M.; Burckhardt, S. Assessment of dextran antigenicity of intravenous iron preparations with enzyme-linked immunosorbent assay (elisa). Int. J. Mol. Sci. 2016, 17. [CrossRef] [PubMed]

35. Koskenkorva-Frank, T.S.; Weiss, G.; Koppenol, W.H.; Burckhardt, S. The complex interplay of iron metabolism, reactive oxygen species, and reactive nitrogen species: Insights into the potential of various iron therapies to induce oxidative and nitrosative stress. Free Radic. Biol. Med. 2013, 65, 1174-1194. [CrossRef] [PubMed]

36. Toblli, J.E.; Angerosa, M. Optimizing iron delivery in the management of anemia: Patient considerations and the role of ferric carboxymaltose. Drug Des. Dev. Ther. 2014, 8, 2475-2491. [CrossRef] [PubMed] 
37. Neiser, S.; Rentsch, D.; Dippon, U.; Kappler, A.; Weidler, P.G.; Gottlicher, J.; Steininger, R.; Wilhelm, M.; Braitsch, M.; Funk, F.; et al. Physico-chemical properties of the new generation iv iron preparations ferumoxytol, iron isomaltoside 1000 and ferric carboxymaltose. Biometals 2015, 28, 615-635. [CrossRef] [PubMed]

38. Pai, A.B. Complexity of intravenous iron nanoparticle formulations: Implications for bioequivalence evaluation. Ann. N. Y. Acad. Sci. 2017, 1407, 17-25. [CrossRef] [PubMed]

39. Geisser, P.; Burckhardt, S. The pharmacokinetics and pharmacodynamics of iron preparations. Pharmaceutics 2011, 3, 12-33. [CrossRef] [PubMed]

40. Chappell, H.F.; Thom, W.; Bowron, D.T.; Faria, N.; Hasnip, P.J.; Powell, J.J. Structure of naturally hydrated ferrihydrite revealed through neutron diffraction and first-principles modeling. Phys. Rev. Mater. $2017,1$. [CrossRef]

41. Gustafson, H.H.; Holt-Casper, D.; Grainger, D.W.; Ghandehari, H. Nanoparticle uptake: The phagocyte problem. Nano Today 2015, 10, 487-510. [CrossRef] [PubMed]

42. Skotland, T.; Sontum, P.C.; Oulie, I. In vitro stability analyses as a model for metabolism of ferromagnetic particles (clariscan), a contrast agent for magnetic resonance imaging. J. Pharm. Biomed. Anal. 2002, 28, 323-329. [CrossRef]

43. Maneeprakorn, W.; Maurizi, L.; Siriket, H.; Wutikhun, T.; Dharakul, T.; Hofmann, H. Superparamagnetic nanohybrids with cross-linked polymers providing higher in vitro stability. J. Mater. Sci. 2017, 52, 9249-9261. [CrossRef]

44. Corna, G.; Campana, L.; Pignatti, E.; Castiglioni, A.; Tagliafico, E.; Bosurgi, L.; Campanella, A.; Brunelli, S.; Manfredi, A.A.; Apostoli, P.; et al. Polarization dictates iron handling by inflammatory and alternatively activated macrophages. Haematologica 2010, 95, 1814-1822. [CrossRef] [PubMed]

45. Nairz, M.; Theurl, I.; Swirski, F.K.; Weiss, G. "Pumping iron"-how macrophages handle iron at the systemic, microenvironmental, and cellular levels. Pflugers Arch. 2017, 469, 397-418. [CrossRef] [PubMed]

46. Agoro, R.; Taleb, M.; Quesniaux, V.F.J.; Mura, C. Cell iron status influences macrophage polarization. PLoS ONE 2018, 13. [CrossRef] [PubMed]

47. Drakesmith, H.; Nemeth, E.; Ganz, T. Ironing out ferroportin. Cell Metab. 2015, 22, 777-787. [CrossRef] [PubMed]

48. Macdougall, I.C.; Vernon, K. Complement activation-related pseudo-allergy: A fresh look at hypersensitivity reactions to intravenous iron. Am. J. Nephrol. 2017, 45, 60-62. [CrossRef] [PubMed]

49. Munoz, M.; Gomez-Ramirez, S.; Bhandari, S. The safety of available treatment options for iron-deficiency anemia. Expert Opin. Drug Saf. 2018, 17, 149-159. [CrossRef] [PubMed]

50. Slotki, I.; Cabantchik, Z.I. The labile side of iron supplementation in ckd. J. Am. Soc. Nephrol. 2015, 26, 2612-2619. [CrossRef] [PubMed]

51. Cooke, M.; Lamplugh, A.; Naudeer, S.; Edey, M.; Bhandari, S. Efficacy and tolerability of accelerated-dose low-molecular-weight iron dextran (cosmofer) in patients with chronic kidney disease. Am. J. Nephrol. 2012, 35, 69-74. [CrossRef] [PubMed]

52. Sinha, S.; Chiu, D.; Peebles, G.; Swoboda, P.; Kolakkat, S.; Lamerton, E.; Fenwick, S.; Bhandari, S.; Kalra, P.A. Accelerated total dose infusion of low molecular weight iron dextran is safe and efficacious in chronic kidney disease patients. QJM 2011, 104, 221-230. [CrossRef] [PubMed]

53. Chertow, G.M.; Mason, P.D.; Vaage-Nilsen, O.; Ahlmen, J. Update on adverse drug events associated with parenteral iron. Nephrol. Dial. Transplant. 2006, 21, 378-382. [CrossRef] [PubMed]

54. Auerbach, M.; Pappadakis, J.A.; Bahrain, H.; Auerbach, S.A.; Ballard, H.; Dahl, N.V. Safety and efficacy of rapidly administered (one hour) one gram of low molecular weight iron dextran (infed) for the treatment of iron deficient anemia. Am. J. Hematol. 2011, 86, 860-862. [CrossRef] [PubMed]

55. Rampton, D.; Folkersen, J.; Fishbane, S.; Hedenus, M.; Howaldt, S.; Locatelli, F.; Patni, S.; Szebeni, J.; Weiss, G. Hypersensitivity reactions to intravenous iron: Guidance for risk minimization and management. Haematologica 2014, 99, 1671-1676. [CrossRef] [PubMed]

56. Di Francesco, T.; Philipp, E.; Borchard, G. Iron sucrose: Assessing the similarity between the originator drug and its intended copies. Ann. N. Y. Acad. Sci. 2017, 1407, 63-74. [CrossRef] [PubMed]

57. Toblli, J.E.; Cao, G.; Giani, J.F.; Dominici, F.P.; Angerosa, M. Nitrosative stress and apoptosis by intravenous ferumoxytol, iron isomaltoside 1000, iron dextran, iron sucrose, and ferric carboxymaltose in a nonclinical model. Drug Res. 2015, 65, 354-360. [CrossRef] [PubMed] 
58. Rottembourg, J.; Guerin, A.; Diaconita, M.; Kadri, A. The complete study of the switch from iron-sucrose originator to iron-sucrose similar and vice versa in hemodialysis patients. J. Kidney 2016, 2. [CrossRef]

59. Rottembourg, J.; Kadri, A.; Leonard, E.; Dansaert, A.; Lafuma, A. Do two intravenous iron sucrose preparations have the same efficacy? Nephrol. Dial. Transplant. 2011, 26, 3262-3267. [CrossRef] [PubMed]

60. Aguera, M.L.; Martin-Malo, A.; Alvarez-Lara, M.A.; Garcia-Montemayor, V.E.; Canton, P.; Soriano, S.; Aljama, P. Efficiency of original versus generic intravenous iron formulations in patients on haemodialysis. PLoS ONE 2015, 10. [CrossRef] [PubMed]

61. Stein, J.; Dignass, A.; Chow, K.U. Clinical case reports raise doubts about the therapeutic equivalence of an iron sucrose similar preparation compared with iron sucrose originator. Curr. Med. Res. Opin. 2012, 28, 241-243. [CrossRef] [PubMed]

62. Martin-Malo, A.; Merino, A.; Carracedo, J.; Alvarez-Lara, M.A.; Ojeda, R.; Soriano, S.; Crespo, R.; Ramirez, R.; Aljama, P. Effects of intravenous iron on mononuclear cells during the haemodialysis session. Nephrol. Dial. Transplant. 2012, 27, 2465-2471. [CrossRef] [PubMed]

63. Lee, E.S.; Park, B.R.; Kim, J.S.; Choi, G.Y.; Lee, J.J.; Lee, I.S. Comparison of adverse event profile of intravenous iron sucrose and iron sucrose similar in postpartum and gynecologic operative patients. Curr. Med. Res. Opin. 2013, 29, 141-147. [CrossRef] [PubMed]

64. FDA. Draft Guidance on Iron Sucrose. Available online: https://www.fda.gov/downloads/Drugs/ GuidanceComplianceRegulatoryInformation/Guidances/UCM297630.pdf (accessed on 15 March 2018).

65. FDA. Draft Guidance on Sodium Ferric Gluconate Complex. Available online: https://www.fda.gov/ downloads/drugs/guidancecomplianceregulatoryinformation/guidances/ucm358142.pdf (accessed on 15 March 2018).

66. EMA. Reflection Paper on the Data Requirements for Intravenous Iron-Based Nano-Colloidal Products Developed with Reference to an Innovator Medicinal Product. Ema/chmp/swp/620008/2012. Available online: http://www.ema.europa.eu/docs/en_GB/document_library/Scientific_guideline/2015/ 03/WC500184922 (accessed on 23 February 2018).

67. Avni, T.; Bieber, A.; Grossman, A.; Green, H.; Leibovici, L.; Gafter-Gvili, A. The safety of intravenous iron preparations: Systematic review and meta-analysis. Mayo Clin. Proc. 2015, 90, 12-23. [CrossRef] [PubMed]

68. EU Clinical Trials Register. UK Multicentre Open-Label Randomised Controlled Trial of Iv Iron Therapy in Incident Haemodialysis Patients. 2013-002267-25. Available online: https:/ / www.clinicaltrialsregister.eu/ ctr-search/search (accessed on 07 June 2018).

69. Macdougall, I.C.; Bock, A.H.; Carrera, F.; Eckardt, K.U.; Gaillard, C.; Van Wyck, D.; Meier, Y.; Larroque, S.; Roger, S.D.; FIND-CKD Study investigators. Renal function in patients with non-dialysis chronic kidney disease receiving intravenous ferric carboxymaltose: An analysis of the randomized find-ckd trial. BMC Nephrol. 2017, 18. [CrossRef] [PubMed]

70. Gaillard, C.A.; Bock, A.H.; Carrera, F.; Eckardt, K.U.; Van Wyck, D.B.; Bansal, S.S.; Cronin, M.; Meier, Y.; Larroque, S.; Roger, S.D.; et al. Hepcidin response to iron therapy in patients with non-dialysis dependent ckd: An analysis of the find-ckd trial. PLoS ONE 2016, 11. [CrossRef] [PubMed]

71. Kalra, P.A.; Bhandari, S.; Saxena, S.; Agarwal, D.; Wirtz, G.; Kletzmayr, J.; Thomsen, L.L.; Coyne, D.W. A randomized trial of iron isomaltoside 1000 versus oral iron in non-dialysis-dependent chronic kidney disease patients with anaemia. Nephrol. Dial. Transplant. 2016, 31, 646-655. [CrossRef] [PubMed]

72. Syed, A.; Bhandari, S. Correction of iron deficiency anaemia using iv cosmofer in ckd patients with asthma: A prospective study. QJM 2016, 109, 187-190. [CrossRef] [PubMed]

73. Toblli, J.E.; Di Gennaro, F. Switching patients with non-dialysis chronic kidney disease from oral iron to intravenous ferric carboxymaltose: Effects on erythropoiesis-stimulating agent requirements, costs, hemoglobin and iron status. PLOS ONE 2015, 10. [CrossRef] [PubMed]

74. Macdougall, I.C.; Bock, A.H.; Carrera, F.; Eckardt, K.U.; Gaillard, C.; Van Wyck, D.; Roubert, B.; Nolen, J.G.; Roger, S.D.; Investigators, F.-C.S. Find-ckd: A randomized trial of intravenous ferric carboxymaltose versus oral iron in patients with chronic kidney disease and iron deficiency anaemia. Nephrol. Dial. Transplant. 2014, 29, 2075-2084. [CrossRef] [PubMed]

75. Bhandari, S.; Kalra, P.A.; Kothari, J.; Ambuhl, P.M.; Christensen, J.H.; Essaian, A.M.; Thomsen, L.L.; Macdougall, I.C.; Coyne, D.W. A randomized, open-label trial of iron isomaltoside 1000 (monofer(r)) compared with iron sucrose (venofer(r)) as maintenance therapy in haemodialysis patients. Nephrol. Dial. Transplant. 2015, 30, 1577-1589. [CrossRef] [PubMed] 
76. Kuji, T.; Toya, Y.; Fujikawa, T.; Kakimoto-Shino, M.; Nishihara, M.; Shibata, K.; Tamura, K.; Hirawa, N.; Satta, H.; Kawata, S.; et al. Acceleration of iron utilization after intravenous iron administration during activated erythropoiesis in hemodialysis patients: A randomized study. Ther. Apher. Dial. 2015, 19, 131-137. [CrossRef] [PubMed]

77. Macdougall, I.C.; Strauss, W.E.; McLaughlin, J.; Li, Z.; Dellanna, F.; Hertel, J. A randomized comparison of ferumoxytol and iron sucrose for treating iron deficiency anemia in patients with ckd. Clin. J. Am. Soc. Nephrol. 2014, 9, 705-712. [CrossRef] [PubMed]

78. Onken, J.E.; Bregman, D.B.; Harrington, R.A.; Morris, D.; Buerkert, J.; Hamerski, D.; Iftikhar, H.; Mangoo-Karim, R.; Martin, E.R.; Martinez, C.O.; et al. Ferric carboxymaltose in patients with iron-deficiency anemia and impaired renal function: The repair-ida trial. Nephrol. Dial. Transplant. 2014, 29, 833-842. [CrossRef] [PubMed]

79. Arogundade, F.A.; Soyinka, F.O.; Sanusi, A.A.; Ojo, O.E.; Akinsola, A. Iron status and benefit of the use of parenteral iron therapy in pre-dialysis chronic kidney disease patients. Niger. Postgrad. Med. J. 2013, 20, 299-304. [PubMed]

80. Charytan, C.; Bernardo, M.V.; Koch, T.A.; Butcher, A.; Morris, D.; Bregman, D.B. Intravenous ferric carboxymaltose versus standard medical care in the treatment of iron deficiency anemia in patients with chronic kidney disease: A randomized, active-controlled, multi-center study. Nephrol. Dial. Transplant. 2013, 28, 953-964. [CrossRef] [PubMed]

81. Wikstrom, B.; Bhandari, S.; Barany, P.; Kalra, P.A.; Ladefoged, S.; Wilske, J.; Thomsen, L.L. Iron isomaltoside 1000: A new intravenous iron for treating iron deficiency in chronic kidney disease. J. Nephrol. 2011, 24, 589-596. [CrossRef] [PubMed]

82. Adhikary, L.; Acharya, S. Efficacy of iv iron compared to oral iron for increment of haemoglobin level in anemic chronic kidney disease patients on erythropoietin therapy. J. Nepal Med. Assoc. 2011, 51, 133-136.

83. Qunibi, W.Y.; Martinez, C.; Smith, M.; Benjamin, J.; Mangione, A.; Roger, S.D. A randomized controlled trial comparing intravenous ferric carboxymaltose with oral iron for treatment of iron deficiency anaemia of non-dialysis-dependent chronic kidney disease patients. Nephrol. Dial. Transplant. 2011, 26, 1599-1607. [CrossRef] [PubMed]

84. Covic, A.; Mircescu, G. The safety and efficacy of intravenous ferric carboxymaltose in anaemic patients undergoing haemodialysis: A multi-centre, open-label, clinical study. Nephrol. Dial. Transplant. 2010, 25, 2722-2730. [CrossRef] [PubMed]

85. Bailie, G.R.; Mason, N.A.; Valaoras, T.G. Safety and tolerability of intravenous ferric carboxymaltose in patients with iron deficiency anemia. Hemodial. Int. 2010, 14, 47-54. [CrossRef] [PubMed]

86. Spinowitz, B.S.; Kausz, A.T.; Baptista, J.; Noble, S.D.; Sothinathan, R.; Bernardo, M.V.; Brenner, L.; Pereira, B.J. Ferumoxytol for treating iron deficiency anemia in ckd. J. Am. Soc. Nephrol. 2008, 19, 1599-1605. [CrossRef] [PubMed]

87. Agarwal, R.; Rizkala, A.R.; Bastani, B.; Kaskas, M.O.; Leehey, D.J.; Besarab, A. A randomized controlled trial of oral versus intravenous iron in chronic kidney disease. Am. J. Nephrol. 2006, 26, 445-454. [CrossRef] [PubMed]

88. Mircescu, G.; Garneata, L.; Capusa, C.; Ursea, N. Intravenous iron supplementation for the treatment of anaemia in pre-dialyzed chronic renal failure patients. Nephrol. Dial. Transplant. 2006, 21, 120-124. [CrossRef] [PubMed]

89. Van Wyck, D.B.; Roppolo, M.; Martinez, C.O.; Mazey, R.M.; McMurray, S.; United States Iron Sucrose Clinical Trials, G. A randomized, controlled trial comparing iv iron sucrose to oral iron in anemic patients with nondialysis-dependent ckd. Kidney Int. 2005, 68, 2846-2856. [CrossRef] [PubMed]

90. Charytan, C.; Qunibi, W.; Bailie, G.R.; Venofer Clinical Studies, G. Comparison of intravenous iron sucrose to oral iron in the treatment of anemic patients with chronic kidney disease not on dialysis. Nephron Clin. Pract. 2005, 100, C55-C62. [CrossRef] [PubMed]

91. Goldstein, S.L.; Morris, D.; Warady, B.A. Comparison of the safety and efficacy of 3 iron sucrose iron maintenance regimens in children, adolescents, and young adults with ckd: A randomized controlled trial. Am. J. Kidney Dis. 2013, 61, 588-597. [CrossRef] [PubMed]

92. Li, X.; Kshirsagar, A.V.; Brookhart, M.A. Safety of intravenous iron in hemodialysis patients. Hemodial. Int. 2017, 21 (Suppl. 1), S93-S103. [CrossRef] [PubMed] 
93. Aronoff, G.R.; Bennett, W.M.; Blumenthal, S.; Charytan, C.; Pennell, J.P.; Reed, J.; Rothstein, M.; Strom, J.; Wolfe, A.; Van Wyck, D.; et al. Iron sucrose in hemodialysis patients: Safety of replacement and maintenance regimens. Kidney Int. 2004, 66, 1193-1198. [CrossRef] [PubMed]

94. Chandler, G.; Harchowal, J.; Macdougall, I.C. Intravenous iron sucrose: Establishing a safe dose. Am. J. Kidney Dis. 2001, 38, 988-991. [CrossRef] [PubMed]

95. Charytan, C.; Levin, N.; Al-Saloum, M.; Hafeez, T.; Gagnon, S.; Van Wyck, D.B. Efficacy and safety of iron sucrose for iron deficiency in patients with dialysis-associated anemia: North American clinical trial. Am. J. Kidney Dis. 2001, 37, 300-307. [CrossRef] [PubMed]

96. Van Wyck, D.B.; Cavallo, G.; Spinowitz, B.S.; Adhikarla, R.; Gagnon, S.; Charytan, C.; Levin, N. Safety and efficacy of iron sucrose in patients sensitive to iron dextran: North American clinical trial. Am. J. Kidney Dis. 2000, 36, 88-97. [CrossRef] [PubMed]

97. Roger, S.D.; Gaillard, C.A.; Bock, A.H.; Carrera, F.; Eckardt, K.U.; Van Wyck, D.B.; Cronin, M.; Meier, Y.; Larroque, S.; Macdougall, I.C.; et al. Safety of intravenous ferric carboxymaltose versus oral iron in patients with nondialysis-dependent ckd: An analysis of the 1-year find-ckd trial. Nephrol. Dial. Transplant. 2017, 32, 1530-1539. [CrossRef] [PubMed]

98. Macdougall, I.C.; Bock, A.H.; Carrera, F.; Eckardt, K.U.; Gaillard, C.; Wyck, D.V.; Meier, Y.; Larroque, S.; Perrin, A.; Roger, S.D. Erythropoietic response to oral iron in patients with nondialysis-dependent chronic kidney disease in the find-ckd trial. Clin. Nephrol. 2017, 88, 301-310. [CrossRef] [PubMed]

99. Zeidan, A.; Bhandari, S. Anemia in peritoneal dialysis patients; iron repletion, current and future therapies. Perit. Dial. Int. 2017, 37, 6-13. [CrossRef] [PubMed]

100. Van Veldhuisen, D.J.; Ponikowski, P.; van der Meer, P.; Metra, M.; Bohm, M.; Doletsky, A.; Voors, A.A.; Macdougall, I.C.; Anker, S.D.; Roubert, B.; et al. Effect of ferric carboxymaltose on exercise capacity in patients with chronic heart failure and iron deficiency. Circulation 2017, 136, 1374-1383. [CrossRef] [PubMed]

101. Toblli, J.E.; Di Gennaro, F.; Rivas, C. Changes in echocardiographic parameters in iron deficiency patients with heart failure and chronic kidney disease treated with intravenous iron. Heart Lung Circ. 2015, 24, 686-695. [CrossRef] [PubMed]

102. Ponikowski, P.; van Veldhuisen, D.J.; Comin-Colet, J.; Ertl, G.; Komajda, M.; Mareev, V.; McDonagh, T.; Parkhomenko, A.; Tavazzi, L.; Levesque, V.; et al. Beneficial effects of long-term intravenous iron therapy with ferric carboxymaltose in patients with symptomatic heart failure and iron deficiencydagger. Eur. Heart J. 2015, 36, 657-668. [CrossRef] [PubMed]

103. Filippatos, G.; Farmakis, D.; Colet, J.C.; Dickstein, K.; Luscher, T.F.; Willenheimer, R.; Parissis, J.; Gaudesius, G.; Mori, C.; von Eisenhart Rothe, B.; et al. Intravenous ferric carboxymaltose in iron-deficient chronic heart failure patients with and without anaemia: A subanalysis of the fair-hf trial. Eur. J. Heart Fail. 2013, 15, 1267-1276. [CrossRef] [PubMed]

104. Beck-da-Silva, L.; Piardi, D.; Soder, S.; Rohde, L.E.; Pereira-Barretto, A.C.; de Albuquerque, D.; Bocchi, E.; Vilas-Boas, F.; Moura, L.Z.; Montera, M.W.; et al. Iron-hf study: A randomized trial to assess the effects of iron in heart failure patients with anemia. Int. J. Cardiol. 2013, 168, 3439-3442. [CrossRef] [PubMed]

105. Van Craenenbroeck, E.M.; Conraads, V.M.; Greenlaw, N.; Gaudesius, G.; Mori, C.; Ponikowski, P.; Anker, S.D. The effect of intravenous ferric carboxymaltose on red cell distribution width: A subanalysis of the fair-hf study. Eur. J. Heart Fail. 2013, 15, 756-762. [CrossRef] [PubMed]

106. Comin-Colet, J.; Lainscak, M.; Dickstein, K.; Filippatos, G.S.; Johnson, P.; Luscher, T.F.; Mori, C.; Willenheimer, R.; Ponikowski, P.; Anker, S.D. The effect of intravenous ferric carboxymaltose on health-related quality of life in patients with chronic heart failure and iron deficiency: A subanalysis of the fair-hf study. Eur. Heart J. 2013, 34, 30-38. [CrossRef] [PubMed]

107. Anker, S.D.; Comin Colet, J.; Filippatos, G.; Willenheimer, R.; Dickstein, K.; Drexler, H.; Luscher, T.F.; Bart, B.; Banasiak, W.; Niegowska, J.; et al. Ferric carboxymaltose in patients with heart failure and iron deficiency. N. Engl. J. Med. 2009, 361, 2436-2448. [CrossRef] [PubMed]

108. Okonko, D.O.; Grzeslo, A.; Witkowski, T.; Mandal, A.K.; Slater, R.M.; Roughton, M.; Foldes, G.; Thum, T.; Majda, J.; Banasiak, W.; et al. Effect of intravenous iron sucrose on exercise tolerance in anemic and nonanemic patients with symptomatic chronic heart failure and iron deficiency ferric-hf: A randomized, controlled, observer-blinded trial. J. Am. Coll. Cardiol. 2008, 51, 103-112. [CrossRef] [PubMed] 
109. Bolger, A.P.; Bartlett, F.R.; Penston, H.S.; O'Leary, J.; Pollock, N.; Kaprielian, R.; Chapman, C.M. Intravenous iron alone for the treatment of anemia in patients with chronic heart failure. J. Am. Coll. Cardiol. 2006, 48, 1225-1227. [CrossRef] [PubMed]

110. Minana, G.; Cardells, I.; Palau, P.; Llacer, P.; Facila, L.; Almenar, L.; Lopez-Lereu, M.P.; Monmeneu, J.V.; Amiguet, M.; Gonzalez, J.; et al. Changes in myocardial iron content following administration of intravenous iron (myocardial-iron): Study design. Clin. Cardiol. 2018, 41, 729-735. [CrossRef] [PubMed]

111. Dahlerup, J.F.; Jacobsen, B.A.; van der Woude, J.; Bark, L.A.; Thomsen, L.L.; Lindgren, S. High-dose fast infusion of parenteral iron isomaltoside is efficacious in inflammatory bowel disease patients with iron-deficiency anaemia without profound changes in phosphate or fibroblast growth factor 23. Scand. J. Gastroenterol. 2016, 51, 1332-1338. [CrossRef] [PubMed]

112. Reinisch, W.; Altorjay, I.; Zsigmond, F.; Primas, C.; Vogelsang, H.; Novacek, G.; Reinisch, S.; Thomsen, L.L. A 1-year trial of repeated high-dose intravenous iron isomaltoside 1000 to maintain stable hemoglobin levels in inflammatory bowel disease. Scand. J. Gastroenterol. 2015, 50, 1226-1233. [CrossRef] [PubMed]

113. Reinisch, W.; Staun, M.; Tandon, R.K.; Altorjay, I.; Thillainayagam, A.V.; Gratzer, C.; Nijhawan, S.; Thomsen, L.L. A randomized, open-label, non-inferiority study of intravenous iron isomaltoside 1,000 (monofer) compared with oral iron for treatment of anemia in ibd (proceed). Am. J. Gastroenterol. 2013, 108, 1877-1888. [CrossRef] [PubMed]

114. Nordfjeld, K.; Andreasen, H.; Thomsen, L.L. Pharmacokinetics of iron isomaltoside 1000 in patients with inflammatory bowel disease. Drug Des. Dev. Ther. 2012, 6, 43-51. [CrossRef] [PubMed]

115. Evstatiev, R.; Marteau, P.; Iqbal, T.; Khalif, I.L.; Stein, J.; Bokemeyer, B.; Chopey, I.V.; Gutzwiller, F.S.; Riopel, L.; Gasche, C.; et al. Fergicor, a randomized controlled trial on ferric carboxymaltose for iron deficiency anemia in inflammatory bowel disease. Gastroenterology 2011, 141, 846-853. [CrossRef] [PubMed]

116. Koutroubakis, I.E.; Oustamanolakis, P.; Karakoidas, C.; Mantzaris, G.J.; Kouroumalis, E.A. Safety and efficacy of total-dose infusion of low molecular weight iron dextran for iron deficiency anemia in patients with inflammatory bowel disease. Digest. Dis. Sci. 2010, 55, 2327-2331. [CrossRef] [PubMed]

117. Lindgren, S.; Wikman, O.; Befrits, R.; Blom, H.; Eriksson, A.; Granno, C.; Ung, K.A.; Hjortswang, H.; Lindgren, A.; Unge, P. Intravenous iron sucrose is superior to oral iron sulphate for correcting anaemia and restoring iron stores in ibd patients: A randomized, controlled, evaluator-blind, multicentre study. Scand. J. Gastroenterol. 2009, 44, 838-845. [CrossRef] [PubMed]

118. Kulnigg, S.; Stoinov, S.; Simanenkov, V.; Dudar, L.V.; Karnafel, W.; Garcia, L.C.; Sambuelli, A.M.; D’Haens, G.; Gasche, C. A novel intravenous iron formulation for treatment of anemia in inflammatory bowel disease: The ferric carboxymaltose (ferinject) randomized controlled trial. Am. J. Gastroenterol. 2008, 103, 1182-1192. [CrossRef] [PubMed]

119. Schroder, O.; Mickisch, O.; Seidler, U.; de Weerth, A.; Dignass, A.U.; Herfarth, H.; Reinshagen, M.; Schreiber, S.; Junge, U.; Schrott, M.; et al. Intravenous iron sucrose versus oral iron supplementation for the treatment of iron deficiency anemia in patients with inflammatory bowel disease-A randomized, controlled, open-label, multicenter study. Am. J. Gastroenterol. 2005, 100, 2503-2509. [CrossRef] [PubMed]

120. Erichsen, K.; Ulvik, R.J.; Nysaeter, G.; Johansen, J.; Ostborg, J.; Berstad, A.; Berge, R.K.; Hausken, T. Oral ferrous fumarate or intravenous iron sucrose for patients with inflammatory bowel disease. Scand. J. Gastroenterol. 2005, 40, 1058-1065. [CrossRef] [PubMed]

121. Mahey, R.; Kriplani, A.; Mogili, K.D.; Bhatla, N.; Kachhawa, G.; Saxena, R. Randomized controlled trial comparing ferric carboxymaltose and iron sucrose for treatment of iron deficiency anemia due to abnormal uterine bleeding. Int. J. Gynaecol. Obstet. 2016, 133, 43-48. [CrossRef] [PubMed]

122. Tariq, N.; Ayub, R.; Khan, W.U.; Ijaz, S.; Alam, A.Y. Parenteral iron therapy in the treatment of iron deficiency anemia during pregnancy: A randomized controlled trial. J. Coll. Physicians Surg. Pak. 2015, 25, 193-197. [PubMed]

123. Kochhar, P.K.; Kaundal, A.; Ghosh, P. Intravenous iron sucrose versus oral iron in treatment of iron deficiency anemia in pregnancy: A randomized clinical trial. J. Obstet. Gynaecol. Res. 2013, 39, 504-510. [CrossRef] [PubMed]

124. Ayub, R.; Tariq, N.; Adil, M.M.; Iqbal, M.; Junaid, A.; Jaferry, T. Efficacy and safety of total dose infusion of low molecular weight iron dextran in the treatment of iron deficiency anemia during pregnancy. J. Coll. Physicians Surg. Pak. 2008, 18, 424-427. [PubMed] 
125. Al, R.A.; Unlubilgin, E.; Kandemir, O.; Yalvac, S.; Cakir, L.; Haberal, A. Intravenous versus oral iron for treatment of anemia in pregnancy: A randomized trial. Obstet. Gynecol. 2005, 106, 1335-1340. [CrossRef] [PubMed]

126. Bencaiova, G.; von Mandach, U.; Zimmermann, R. Iron prophylaxis in pregnancy: Intravenous route versus oral route. Eur. J. Obstet. Gynecol. Reprod. Biol. 2009, 144, 135-139. [CrossRef] [PubMed]

127. Keeler, B.D.; Simpson, J.A.; Ng, O.; Padmanabhan, H.; Brookes, M.J.; Acheson, A.G.; Group, I.T. Randomized clinical trial of preoperative oral versus intravenous iron in anaemic patients with colorectal cancer. Br. J. Surg. 2017, 104, 214-221. [CrossRef] [PubMed]

128. Birgegard, G.; Henry, D.; Glaspy, J.; Chopra, R.; Thomsen, L.L.; Auerbach, M. A randomized noninferiority trial of intravenous iron isomaltoside versus oral iron sulfate in patients with nonmyeloid malignancies and anemia receiving chemotherapy: The profound trial. Pharmacotherapy 2016, 36, 402-414. [CrossRef] [PubMed]

129. Borstlap, W.A.A.; Buskens, C.J.; Tytgat, K.; Tuynman, J.B.; Consten, E.C.J.; Tolboom, R.C.; Heuff, G.; van Geloven, N.; van Wagensveld, B.A.; Wientjes, C.A.C.A.; et al. Multicentre randomized controlled trial comparing ferric(iii)carboxymaltose infusion with oral iron supplementation in the treatment of preoperative anaemia in colorectal cancer patients. BMC Surg. 2015, 15. [CrossRef]

130. Hedenus, M.; Karlsson, T.; Ludwig, H.; Rzychon, B.; Felder, M.; Roubert, B.; Birgegard, G. Intravenous iron alone resolves anemia in patients with functional iron deficiency and lymphoid malignancies undergoing chemotherapy. Med. Oncol. 2014, 31. [CrossRef] [PubMed]

131. Dangsuwan, P.; Manchana, T. Blood transfusion reduction with intravenous iron in gynecologic cancer patients receiving chemotherapy. Gynecol. Oncol. 2010, 116, 522-525. [CrossRef] [PubMed]

132. Froessler, B.; Cocchiaro, C.; Saadat-Gilani, K.; Hodyl, N.; Dekker, G. Intravenous iron sucrose versus oral iron ferrous sulfate for antenatal and postpartum iron deficiency anemia: A randomized trial. J. Matern. Fetal. Neonatal Med. 2013, 26, 654-659. [CrossRef] [PubMed]

133. Michels, W.M.; Jaar, B.G.; Ephraim, P.L.; Liu, Y.; Miskulin, D.C.; Tangri, N.; Crews, D.C.; Scialla, J.J.; Shafi, T.; Sozio, S.M.; et al. Intravenous iron administration strategies and anemia management in hemodialysis patients. Nephrol. Dial. Transplant. 2017, 32, 173-181. [CrossRef] [PubMed]

134. Brookhart, M.A.; Freburger, J.K.; Ellis, A.R.; Winkelmayer, W.C.; Wang, L.; Kshirsagar, A.V. Comparative short-term safety of sodium ferric gluconate versus iron sucrose in hemodialysis patients. Am. J. Kidney Dis. 2016, 67, 119-127. [CrossRef] [PubMed]

135. Airy, M.; Mandayam, S.; Mitani, A.A.; Chang, T.I.; Ding, V.Y.; Brookhart, M.A.; Goldstein, B.A.; Winkelmayer, W.C. Comparative outcomes of predominant facility-level use of ferumoxytol versus other intravenous iron formulations in incident hemodialysis patients. Nephrol. Dial. Transplant. 2015, 30, 2068-2075. [CrossRef] [PubMed]

136. Hazara, A.M.; Bhandari, S. Intravenous iron administration is associated with reduced platelet counts in patients with chronic kidney disease. J. Clin. Pharm. Ther. 2015, 40, 20-23. [CrossRef] [PubMed]

137. Zitt, E.; Sturm, G.; Kronenberg, F.; Neyer, U.; Knoll, F.; Lhotta, K.; Weiss, G. Iron supplementation and mortality in incident dialysis patients: An observational study. PLoS ONE 2014, 9. [CrossRef] [PubMed]

138. Schiller, B.; Bhat, P.; Sharma, A. Safety and effectiveness of ferumoxytol in hemodialysis patients at 3 dialysis chains in the united states over a 12-month period. Clin. Ther. 2014, 36, 70-83. [CrossRef] [PubMed]

139. Ishida, J.H.; Marafino, B.J.; McCulloch, C.E.; Dalrymple, L.S.; Dudley, R.A.; Grimes, B.A.; Johansen, K.L. Receipt of intravenous iron and clinical outcomes among hemodialysis patients hospitalized for infection. Clin. J. Am. Soc. Nephrol. 2015, 10, 1799-1805. [CrossRef] [PubMed]

140. Tangri, N.; Miskulin, D.C.; Zhou, J.; Bandeen-Roche, K.; Michels, W.M.; Ephraim, P.L.; McDermott, A.; Crews, D.C.; Scialla, J.J.; Sozio, S.M.; et al. Effect of intravenous iron use on hospitalizations in patients undergoing hemodialysis: A comparative effectiveness analysis from the decide-esrd study. Nephrol. Dial. Transplant. 2015, 30, 667-675. [CrossRef] [PubMed]

141. Miskulin, D.C.; Tangri, N.; Bandeen-Roche, K.; Zhou, J.; McDermott, A.; Meyer, K.B.; Ephraim, P.L.; Michels, W.M.; Jaar, B.G.; Crews, D.C.; et al. Intravenous iron exposure and mortality in patients on hemodialysis. Clin. J. Am. Soc. Nephrol. 2014, 9, 1930-1939. [CrossRef] [PubMed]

142. Kshirsagar, A.V.; Freburger, J.K.; Ellis, A.R.; Wang, L.; Winkelmayer, W.C.; Brookhart, M.A. Intravenous iron supplementation practices and short-term risk of cardiovascular events in hemodialysis patients. PLoS ONE 2013, 8. [CrossRef] [PubMed] 
143. Garcia-Lopez, S.; Bocos, J.M.; Gisbert, J.P.; Bajador, E.; Chaparro, M.; Castano, C.; Garcia-Erce, J.A.; Gomollon, F. High-dose intravenous treatment in iron deficiency anaemia in inflammatory bowel disease: Early efficacy and impact on quality of life. Blood Transfus. 2016, 14, 199-205. [CrossRef] [PubMed]

144. Cortes, X.; Borras-Blasco, J.; Moles, J.R.; Bosca, M.; Cortes, E. Safety of ferric carboxymaltose immediately after infliximab administration, in a single session, in inflammatory bowel disease patients with iron deficiency: A pilot study. PLoS ONE 2015, 10. [CrossRef] [PubMed]

145. Befrits, R.; Wikman, O.; Blomquist, L.; Hjortswang, H.; Hammarlund, P.; Bajor, A.; Klintman, D.; Blom, H. Anemia and iron deficiency in inflammatory bowel disease: An open, prospective, observational study on diagnosis, treatment with ferric carboxymaltose and quality of life. Scand. J. Gastroenterol. 2013, 48, 1027-1032. [CrossRef] [PubMed]

146. Froessler, B.; Collingwood, J.; Hodyl, N.A.; Dekker, G. Intravenous ferric carboxymaltose for anaemia in pregnancy. BMC Preg. Childbirth 2014, 14. [CrossRef] [PubMed]

147. Calleja, J.L.; Delgado, S.; del Val, A.; Hervas, A.; Larraona, J.L.; Teran, A.; Cucala, M.; Mearin, F.; Colon Cancer Study Group. Ferric carboxymaltose reduces transfusions and hospital stay in patients with colon cancer and anemia. Int. J. Colorectal Dis. 2016, 31, 543-551. [CrossRef] [PubMed]

148. Toledano, A.; Luporsi, E.; Morere, J.F.; Scotte, F.; Laribi, K.; Barriere, J.; Huot-Marchand, P.; Duvillie, L.; Concas, V.H.; Bugat, R. Clinical use of ferric carboxymaltose in patients with solid tumours or haematological malignancies in France. Support. Care Cancer 2016, 24, 67-75. [CrossRef] [PubMed]

149. KDIGO. Kidney disease: Improving global outcomes (kdigo) anemia work group. Kdigo clinical practice guideline for anemia in chronic kidney disease. Kidney Int. Suppl. 2012, 2, 279-335.

150. Ponikowski, P.; Voors, A.A.; Anker, S.D.; Bueno, H.; Cleland, J.G.; Coats, A.J.; Falk, V.; Gonzalez-Juanatey, J.R.; Harjola, V.P.; Jankowska, E.A.; et al. 2016 esc guidelines for the diagnosis and treatment of acute and chronic heart failure: The task force for the diagnosis and treatment of acute and chronic heart failure of the european society of cardiology (esc). Developed with the special contribution of the heart failure association (hfa) of the esc. Eur. J. Heart Fail. 2016, 18, 891-975. [CrossRef] [PubMed]

151. Aapro, M.; Beguin, Y.; Bokemeyer, C.; Dicato, M.; Gascon, P.; Glaspy, J.; Hofmann, A.; Link, H.; Littlewood, T.; Ludwig, H.; et al. Management of anaemia and iron deficiency in patients with cancer: Esmo clinical practice guidelines. Ann. Oncol. 2018. [CrossRef]

152. Mikhail, A.; Brown, C.; Williams, J.A.; Mathrani, V.; Shrivastava, R.; Evans, J.; Isaac, H.; Bhandari, S. Renal association clinical practice guideline on anaemia of chronic kidney disease. BMC Nephrol. 2017, 18. [CrossRef] [PubMed]

153. Jankowska, E.A.; Rozentryt, P.; Witkowska, A.; Nowak, J.; Hartmann, O.; Ponikowska, B.; Borodulin-Nadzieja, L.; Banasiak, W.; Polonski, L.; Filippatos, G.; et al. Iron deficiency: An ominous sign in patients with systolic chronic heart failure. Eur. Heart J. 2010, 31, 1872-1880. [CrossRef] [PubMed]

154. Klip, I.T.; Comin-Colet, J.; Voors, A.A.; Ponikowski, P.; Enjuanes, C.; Banasiak, W.; Lok, D.J.; Rosentryt, P.; Torrens, A.; Polonski, L.; et al. Iron deficiency in chronic heart failure: An international pooled analysis. Am. Heart J. 2013, 165, 575-582. [CrossRef] [PubMed]

155. Klip, I.T.; Jankowska, E.A.; Enjuanes, C.; Voors, A.A.; Banasiak, W.; Bruguera, J.; Rozentryt, P.; Polonski, L.; van Veldhuisen, D.J.; Ponikowski, P.; et al. The additive burden of iron deficiency in the cardiorenal-anaemia axis: Scope of a problem and its consequences. Eur. J. Heart Fail. 2014, 16, 655-662. [CrossRef] [PubMed]

156. Ponikowski, P.; Filippatos, G.; Colet, J.C.; Willenheimer, R.; Dickstein, K.; Luscher, T.; Gaudesius, G.; von Eisenhart Rothe, B.; Mori, C.; Greenlaw, N.; et al. The impact of intravenous ferric carboxymaltose on renal function: An analysis of the fair-hf study. Eur. J. Heart Fail. 2015, 17, 329-339. [CrossRef] [PubMed]

157. Clinicaltrials.Gov. Intravenous Iron Treatment in Patients with Heart Failure and Iron Deficiency: Ironman. NCT02642562. Available online: https:/ clinicaltrials.gov/ct2/show/NCT02642562 (accessed on 07 June 2018).

158. Alves, R.A.; Miszputen, S.J.; Figueiredo, M.S. Anemia in inflammatory bowel disease: Prevalence, differential diagnosis and association with clinical and laboratory variables. Sao Paulo Med. J. 2014, 132, 140-146. [CrossRef] [PubMed]

159. Filmann, N.; Rey, J.; Schneeweiss, S.; Ardizzone, S.; Bager, P.; Bergamaschi, G.; Koutroubakis, I.; Lindgren, S.; Morena Fde, L.; Moum, B.; et al. Prevalence of anemia in inflammatory bowel diseases in european countries: A systematic review and individual patient data meta-analysis. Inflamm. Bowel Dis. 2014, 20, 936-945. [CrossRef] [PubMed] 
160. Kaitha, S.; Bashir, M.; Ali, T. Iron deficiency anemia in inflammatory bowel disease. World J. Gastrointest. Pathophysiol. 2015, 6, 62-72. [CrossRef] [PubMed]

161. Aksan, A.; Isik, H.; Radeke, H.H.; Dignass, A.; Stein, J. Systematic review with network meta-analysis: Comparative efficacy and tolerability of different intravenous iron formulations for the treatment of iron deficiency anaemia in patients with inflammatory bowel disease. Aliment. Pharmacol. Ther. 2017, 45, 1303-1318. [CrossRef] [PubMed]

162. Schaefer, B.; Wurtinger, P.; Finkenstedt, A.; Braithwaite, V.; Viveiros, A.; Effenberger, M.; Sulzbacher, I.; Moschen, A.; Griesmacher, A.; Tilg, H.; et al. Choice of high-dose intravenous iron preparation determines hypophosphatemia risk. PLoS ONE 2016, 11. [CrossRef] [PubMed]

163. Adkinson, N.F.; Strauss, W.E.; Macdougall, I.C.; Bernard, K.E.; Auerbach, M.; Kaper, R.F.; Chertow, G.M.; Krop, J.S. Comparative safety of intravenous ferumoxytol versus ferric carboxymaltose in iron deficiency anemia: A randomized trial. Am. J. Hematol. 2018, 93, 683-690. [CrossRef] [PubMed]

164. Bager, P.; Hvas, C.L.; Dahlerup, J.F. Drug-specific hypophosphatemia and hypersensitivity reactions following different intravenous iron infusions. Br. J. Clin. Pharmacol. 2017, 83, 1118-1125. [CrossRef] [PubMed]

165. Wang, C.; Graham, D.J.; Kane, R.C.; Xie, D.; Wernecke, M.; Levenson, M.; MaCurdy, T.E.; Houstoun, M.; Ryan, Q.; Wong, S.; et al. Comparative risk of anaphylactic reactions associated with intravenous iron products. JAMA 2015, 314, 2062-2068. [CrossRef] [PubMed]

166. Kalra, P.A.; Bhandari, S. Safety of intravenous iron use in chronic kidney disease. Curr. Opin. Nephrol. Hypertens. 2016, 25, 529-535. [CrossRef] [PubMed]

167. Camaschella, C. Iron-deficiency anemia. N. Engl. J. Med. 2015, 372, 1832-1843. [CrossRef] [PubMed]

(C) 2018 by the authors. Licensee MDPI, Basel, Switzerland. This article is an open access article distributed under the terms and conditions of the Creative Commons Attribution (CC BY) license (http:/ / creativecommons.org/licenses/by/4.0/). 


\title{
Review
}

\section{Sucrosomial ${ }^{\circledR}$ Iron: A New Generation Iron for Improving Oral Supplementation}

\author{
Susana Gómez-Ramírez ${ }^{1}$, Elisa Brilli ${ }^{2}$, Germano Tarantino ${ }^{3}$ and Manuel Muñoz ${ }^{4, *}$ \\ 1 Department of Internal Medicine, University Hospital Virgen de la Victoria. Campus de Teatinos, \\ 2010 Málaga, Spain; susanagram@yahoo.es \\ 2 Scientific Department, Alesco S.r.l. Via delle Lenze, 216/B, 56122 Pisa, Italy; elisa.brilli@alescosrl.com \\ 3 Scientific Department, Pharmanutra S.p.A. Via delle Lenze, 216/B, 56122 Pisa, Italy; \\ g.tarantino@pharmanutra.it \\ 4 Perioperative Transfusion Medicine, Department of Surgical Specialties, Biochemistry and Immunology, \\ School of Medicine, Campus de Teatinos, 29071 Málaga, Spain \\ * Correspondence: mmunoz@uma.es; Tel.: +34-952-131-540
}

Received: 30 August 2018; Accepted: 2 October 2018; Published: 4 October 2018

\begin{abstract}
Iron deficiency (ID) is usually treated with oral iron salts, but up to $50 \%$ of patients complain of gastrointestinal side effects, leading to reduced compliance with treatment. Intravenous (IV) iron formulations are increasingly safe, but there is still a risk of infusion, hypersensitivity reactions and the need for venous access and infusion monitoring. Sucrosomial ${ }^{\circledR}$ Iron (SI) is an innovative oral iron formulation in which ferric pyrophosphate is protected by a phospholipid bilayer plus a sucrester matrix (sucrosome), which is absorbed through para-cellular and trans-cellular routes (M cells). This confers SI's unique structural, physicochemical and pharmacokinetic characteristics, together with its high iron bioavailability and excellent gastrointestinal tolerance. The analysis of the available evidence supports oral SI iron as a valid option for ID treatment, which is more efficacious and tolerable than oral iron salts. SI has also demonstrated a similar effectiveness, with lower risks, in patients usually receiving IV iron (e.g., chronic kidney disease, cancer, bariatric surgery). Thus, oral SI emerges as a valuable first option for treating ID, especially for subjects with intolerance to iron salts or those for whom iron salts are inefficacious. Moreover, SI should also be considered as an alternative to IV iron for initial and/or maintenance treatment in different patient populations.
\end{abstract}

Keywords: Anemia; iron deficiency; oral iron salts; intravenous iron; Sucrosomial ${ }^{\circledR}$ iron; M cells; bioavailability; tolerability; efficacy

\section{Introduction}

Data from 187 countries from 2010 revealed that anemia affected up to one-third of the global population, though prevalence varied widely across regions, and iron deficiency (ID) was responsible for about $50 \%$ of anemia cases [1]. In a systematic analysis in the Global Burden of Disease Study 2016, iron-deficiency anemia (IDA) was the fourth leading cause of years lived with disability, especially in women [2]. Thus, prophylaxis and management of ID is a first order public issue. The main causes of ID are increased demands, reduced absorption and/or increased loss of iron [3,4] (Table 1). 
Table 1. Main causes of iron deficiency.

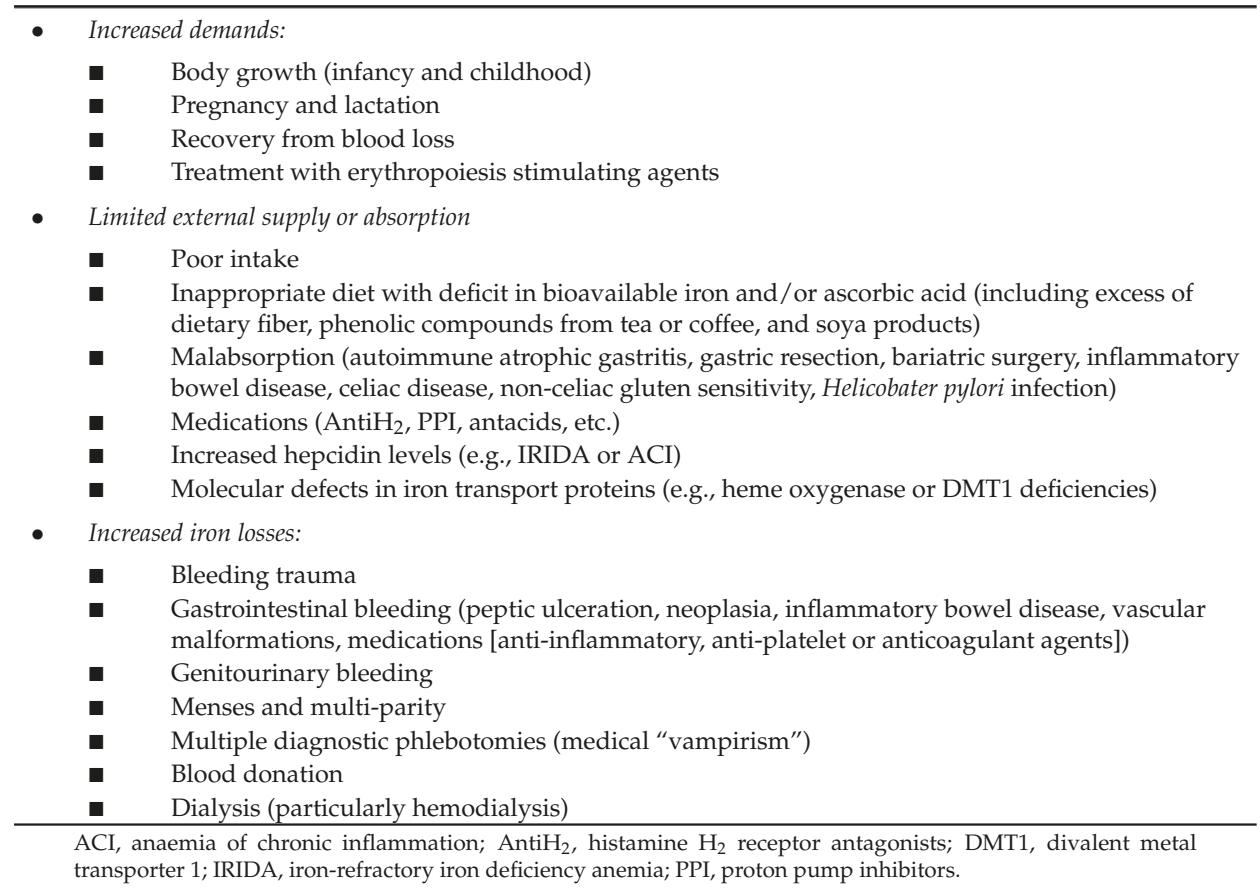

Nevertheless, the prevalence and consequences of ID may also vary depending on the clinical setting considered [5-13] (Figure 1). Following the diagnosis of ID, it is especially relevant to find and address the underlying cause, especially in unexplained and/or recurrent cases, as well as to choose the therapeutic option that safely meets the patient's needs [14-17].

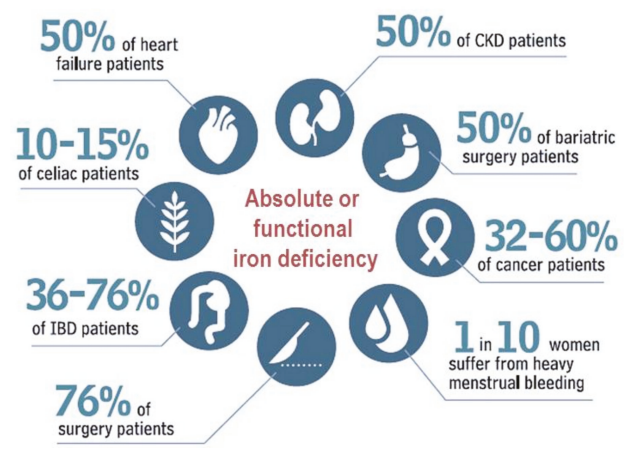

Figure 1. Prevalence of iron deficiency across pathologies. (Data taken from references [5-13]).

\section{Diagnosis of Iron Deficiency}

A correct diagnosis of ID is essential for a safe treatment, but it is sometime elusive. Importantly, the absence of anemia does not exclude ID, because a normal individual must lose most of his iron stores before the hemoglobin $(\mathrm{Hb})$ can fall to values defined by World Health Organization (WHO) as anemia $(\mathrm{Hb}<12 \mathrm{~g} / \mathrm{dL}$ for women and $\mathrm{Hb}<13 \mathrm{~g} / \mathrm{dL}$ for men). In fact, the WHO declares that "mild anemia" is a misnomer, as ID could be well advanced and causes clinical symptoms before $\mathrm{Hb}$ 
reaches the threshold for anemia [18]. The role of non-anemic ID, as a disease looking for recognition, has recently been reviewed: ID is the disease, and anemia is just one of its consequences $[17,19]$.

A patient's history (including signs and symptoms of ID and co-morbidities) and previous iron supplementation provide some clues. In individuals without anemia, chronic fatigue is the most important symptom (iron is needed for the enzymes involved in energy production). However, generally, clinicians will not relate chronic fatigue to ID. As a result, ID without anemia is almost invariably a casual laboratory finding [20].

In patients whose $\mathrm{Hb}$ level is within the normal range, ID should be suspected if a low mean corpuscular $\mathrm{Hb}(\mathrm{MCH}$; normal range 28-35 pg) or an increased red cell distribution width (RDW, normal range 11-15) is present $[4,21]$. The most accurate definition of true ID is a serum ferritin concentration $<30 \mathrm{ng} / \mathrm{mL}$ (sensitivity $92 \%$, specificity $98 \%$ ), though lower values are used in many laboratories [22] (Figure 2). A serum ferritin $<100 \mathrm{ng} / \mathrm{mL}$ with a transferrin saturation (TSAT) $<20 \%$ is also indicative of ID, especially in the presence of inflammation (Figure 2). In contrast, serum ferritin $>100 \mathrm{ng} / \mathrm{mL}$ with a TSAT $<20 \%$ usually indicates iron sequestration (also referred to as functional iron deficiency, FID). Treatment with erythropoiesis-stimulating agents (ESA) may also result in FID, as mobilization from stores may be not rapid enough to meet the increased bone marrow demands on iron (Figure 2) $[4,21,23]$. This provides the basis for iron supplementation in most patients receiving ESA treatment.

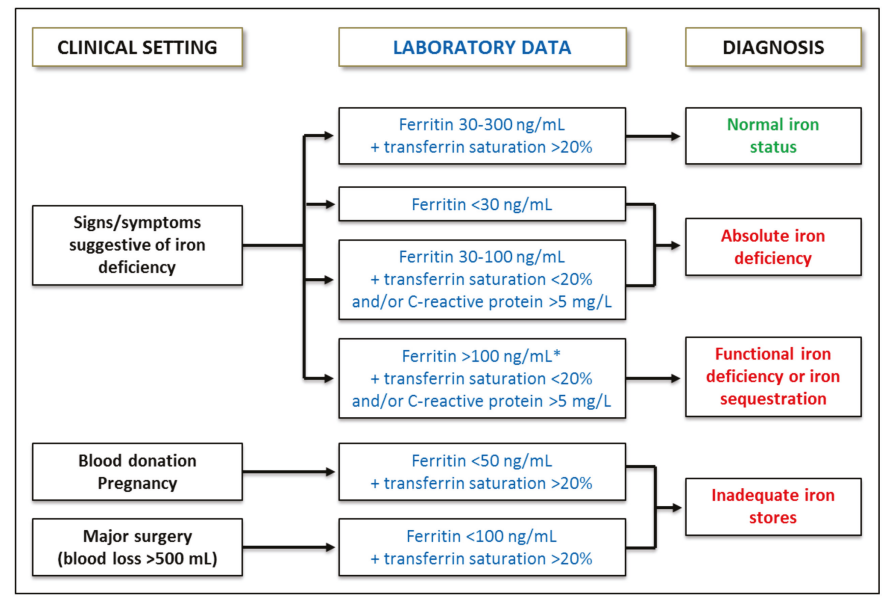

Figure 2. Laboratory assessment of iron status. ${ }^{*}$ Low reticulocyte $\mathrm{Hb}$ content $(<28 \mathrm{pg})$, increased hypochromic red cells $(>5 \%)$ or high soluble transferrin receptor to log ferritin ratio $(>2)$ could identify a component of an absolute iron deficiency in the presence of an inflammation-induced high ferritin level.

However, as it is an acute phase reactant, high ferritin levels do not exclude ID in patients presenting with an inflammatory status. In these cases, other parameters, such as a low reticulocyte $\mathrm{Hb}$ content $(<28 \mathrm{pg})$, increased hypochromic red cells $(>5 \%)$ or a high soluble transferrin receptor to $\log$ ferritin ratio $(>2)$, indicate a component of true ID. Should this be present, iron supplementation may be beneficial $[4,14,21]$.

\section{Treatment Options for Iron Deficiency}

In addition to searching and addressing the underlying cause, if possible, ID could be treated with oral iron, intravenous (IV) iron and/or blood transfusion, depending on the patient's Hb levels, tolerance and co-morbidity. Whether it is a new onset, recurrent, explained or unexplained should also be considered for choosing among the different ID treatment options 


\subsection{Oral Iron Supplementation}

Oral iron supplements, provided as ferrous or ferric salts, are usually the first line of treatment for uncomplicated ID, because of their availability, ease of administration, and relatively low cost $[14,15]$. Oral iron has usually been prescribed at a high dose (100-200 mg elemental iron), to be taken 1-3 times a day. However, the bioavailability is $10 \%$ to $15 \%$ for ferrous iron preparations (sulfate, gluconate, fumarate, etc.), and it is even lower for ferric iron salts or ferric iron complexes (amino acids, polysaccharide, ovo-albumin, etc.). The co-administration of other drugs, such as proton pump inhibitors or antacids, or meals, and the presence of an inflammatory status may further hamper the absorption of oral iron salts [24]. This may prolong the duration of treatment or even render it ineffective [24]. In addition, up to $50 \%$ of patients on oral iron (depending on the iron formulation) report gastrointestinal side effects due to the direct toxicity of ionic iron, which may lead to reduced tolerance and adherence to iron supplementation $[25,26]$.

Single low doses of iron supplements (40-60 mg/day) are associated with less gastrointestinal side effects and lower hepcidin secretion, resulting in better treatment compliance and enhanced fractional absorption [27,28]. In a randomized study, 90 octogenarian patients with IDA received $15 \mathrm{mg}$, $50 \mathrm{mg}$ or $150 \mathrm{mg}$ of elemental iron per day. After two months, there were no between-group differences in the levels of $\mathrm{Hb}$ (mean increase $1.4 \mathrm{~g} / \mathrm{dL}$ in all groups) or ferritin, but the adverse effects were significantly more common with higher doses [29]. Therefore, a low single daily dose (40-60 mg) and/or single alternate day dose (80-100 mg) are preferred in order to reduce the side effects and maximize fractional absorption [27-29]. Though not formally proven, this emerges as a new paradigm for oral iron supplementation in ID treatment [21].

\subsection{Intravenous Iron Supplementation}

Should the patient develop intolerance to one oral iron salt, or it was proven inefficacious, switching to another oral iron formulation or to intravenous (IV) iron may be appropriate [15]. Different IV iron formulations have been made commercially available for clinical use, such as ferric gluconate (FG), iron sucrose (IS), low molecular weight iron dextran (LMWID), ferric carboxymaltose (FCM), ferumoxytol (FXT), or iron isomaltoside 1000 (ISM). All of them have been shown to have a dose-dependent efficacy for correcting ID [17,24]. However, "newer" IV iron formulations, such as FCM or ISM, which allow for a short-time (15-60 min) infusion of high iron doses (1000 mg or more), are preferred by both physicians and patients, compared to "older" IV formulations [17,24].

Nevertheless, though increasingly safer, IV iron formulations are more expensive than oral iron and still carry the need for venous access (side effects at the injection site may occur) and infusion monitoring (there is still a risk of infusion and hypersensitivity reactions) [30]. In this regard, the European Medicines Agency states that "IV iron products should be administered only when staff is trained to evaluate and manage anaphylactic reactions, and resuscitation facilities are immediately available" [30]. In addition, except for the chronic kidney disease population [7], data on the long-term safety of IV iron are scant [24].

\subsection{Red Blood Cell Transfusion}

A patient presenting with severe IDA and alarming symptoms (e.g., hemodynamic instability) and/or risk criteria (e.g., coronary heart disease) should be treated with red blood cell transfusion, using the minimal amount necessary to achieve clinical stability. Adhering to patient-adapted restrictive transfusion criteria and transfusing one unit at the time, with post-transfusion reassessment, is strongly recommended by most guidelines [6,31-34].

Red blood cell transfusion produces a rapid, albeit transient, rise in $\mathrm{Hb}$, thus increasing oxygen-carrying capacity. However, severe IDA will recur unless the underlying cause is identified and addressed. After hemodynamic stability has been achieved by red blood cell transfusion, additional iron supplementation should be considered [17]. 


\section{Sucrosomial ${ }^{\circledR}$ Iron: Preclinical Data}

\subsection{Composition and Structure}

Commonly used oral iron salts are poorly absorbed, with unabsorbed iron leading to gastrointestinal side effects [25]. Newer oral iron supplements have been formulated to increase their tolerability [26]. However, there was still a need for new carriers that not only protect the iron but also enhance its intestinal absorption, thus reducing dosage and side effects [35].

Sucrester is a surfactant derived from the esterification of fatty acids with sucrose (sucrose esters) and has recently been shown to behave as an absorption enhancer because of its ability to reduce intestinal barrier resistance, thus facilitating the passage through para-cellular and trans-cellular routes [36,37]. Sucrester effects depend on both the hydrophilic-lipophilic balance and the fatty acid chain length; therefore, the choice of the appropriate raw material is crucial for developing a formulation with absorption enhancer properties. While there is evidence of the enhancer properties of sucrose esters for the accumulation of drugs in CACO-2 cells [38] and for intestinal permeability in animals [39], its use in oral medicinal product administration has been scarcely studied.

Sucrosomial ${ }^{\circledR}$ Iron (SI), developed by Alesco srl (Pisa, Italy), represents an innovative oral iron-containing carrier, in which ferric pyrophosphate is protected by a phospholipid bilayer membrane, mainly from sunflower lecithin, plus a sucrester matrix. Further stability and coating are obtained by adding other ingredients (tricalcium phosphate, starch), forming the "sucrosome" and allowing SI to be gastro-resistant and carried through the intestinal tract, without side effects from the interaction between iron and intestinal mucosa (Figure 3). To date, in vitro studies have shown that SI is mostly absorbed as a vesicle-like structure, bypassing the conventional iron absorption pathway. Due to its behavior in the gastrointestinal tract, SI is well tolerated and highly bioavailable, compared to conventional iron salts [40].

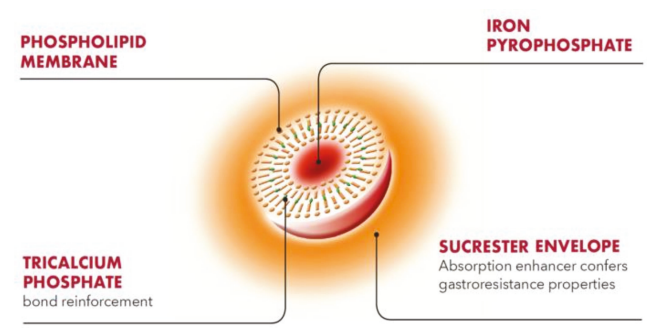

Figure 3. Schematic structure of Sucrosomial ${ }^{\circledR}$ iron.

\subsection{Gastro-Resistance and Intestinal Absorption}

The presence of sucrester confers gastro-resistance properties to SI [41], as demonstrated in in vitro studies using a simulated gastric fluid digestion ( $\mathrm{pH} 1.2$ ). After different digestion times (30 to $120 \mathrm{~min}$ ), the release of ferric iron $\left(\mathrm{III}^{+}\right)$from SI was very low $(<5 \%)$, compared to that of a sucrester-free iron preparation (75-85\%) (Figure 4A) [41].

Gastro-resistance allows the intact sucrosomes to reach the intestinal mucosa, where they are absorbed. Polled data from several studies indicate the presence of different pathways involved in SI absorption. Ex-vivo permeation experiments, carried out using the excised rat intestine model, have shown that the presence of sucrester protects trivalent pyrophosphate iron in SI against enzymatic reduction and promotes its absorption across the intestinal epithelium through a DMT-1 independent pathway, as it is not affected by BPDS activity (bathophenanthroline disulfonic acid, a divalent iron chelator) [40].

The presence of the phospholipids and the sucrester matrix allows the pyrophosphate iron in SI to be absorbed as a vesicle-like structure through para-cellular and trans-cellular routes. In vitro experiments using the MatTek EpiIntestinal human 3D tissue model have confirmed the 
presence of vesicle-like structures during the intestinal absorption of SI and its different absorption kinetics, compared to ferrous sulfate (FS) and ferrous bisglycinate (FeBIS) [42]. Over time, a greater increase of iron concentration in the basolateral compartment was observed in tissues treated with SI $(2.7 \pm 1.7 \mathrm{~g} / \mathrm{mg}$ protein), compared to samples treated with FS (1.3 $\pm 1.1 \mathrm{~g} / \mathrm{mg}$ protein) and FeBIS $(1.6 \pm 1.1 \mathrm{~g} / \mathrm{mg}$ protein), indicating an endocytosis-mediated cellular uptake, which was confirmed by transmission electron microscopy analysis [42].

Microfold cells of the Peyer's patches (M cells) are involved in the transfer of particles and microbes from the luminal side of the intestine to the lamina propria, where they are presented to immune cells. $M$ cells have been shown to provide a pathway for delivering orally administered vesicle-like particles to the lymphatic system $[43,44]$. However, the transfer efficacy of this pathway has also been shown to be greatly influenced by the physicochemical properties of the transported particles [43,44]. The possible role of an M cell-mediated pathway in SI absorption was investigated using an in vitro CACO2/RajiB co-culture system. Experimental data show that the presence of $\mathrm{M}$ cells (RajiB cells) increased the absorption of SI but not that of conventional oral iron salts, such as FS or FeBIS (Figure 4B). This evidence confirms that $\mathrm{M}$ cells can support the intestinal absorption of SI. In ex-vivo experiments using isolate rat intestine and fluorescein, labeled SI, it has been demonstrated that, after passing through M cells, SI was taken up by CD68+ macrophages [42].

\section{A. Gastro resistance}

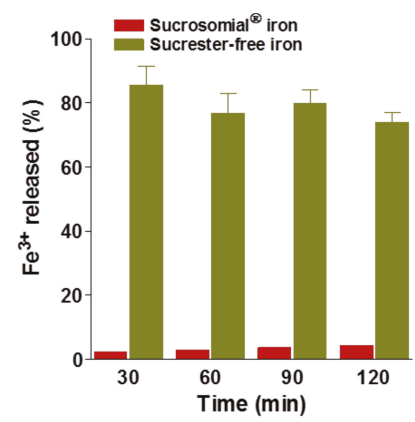

\section{B. M cell involvement}

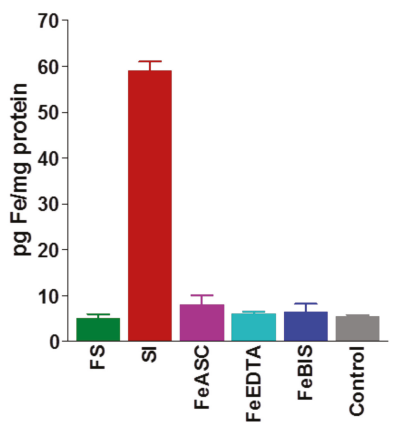

Figure 4. Gastro-resistance and intestinal absorption of Sucrosomial ${ }^{\circledR}$ iron. (A) Gastro-resistant properties of Sucrosomial ${ }^{\circledR}$ iron compared to a sucrester-free iron preparation in an in-vitro simulated gastric fluid digestion at $\mathrm{pH}$ 1.2. (B) The involvement of $\mathrm{M}$ cells in Sucrosomial ${ }^{\circledR}$ iron uptake was evaluated using an in vitro $\mathrm{CACO} 2 / \mathrm{RajiB}$ co-culture. The iron to protein ratio was significantly increased in co-culture cells treated with Sucrosomial ${ }^{\circledR}$ iron (SI), compared to other oral iron formulations: ferrous sulfate (FS), ferrous ascorbate (FeASC), ferrous ethylene-diamine-tetra-acetate (FeEDTA), ferrous bisglycinate (FeBIS), and control (no iron) (data are mean \pm SEM, ${ }^{*} p<0.05$ ) (Adapted from references [41,42]).

\subsection{Bioavailability}

Most probably, the involvement of different cellular routes in SI absorption underlies its high bioavailability, and this may explain its efficacy in improving hemoglobin and ferritin concentrations. Data from CACO-2 cell cultures show that the administration of SI increases 3-fold ferritin accumulation, compared to ferrous sulfate, and 3.5-fold, compared to phospholipid containing ferric pyrophosphate (Lipofer ${ }^{\circledR}$ ) or micronized, dispersible ferric pyrophosphate (SunActive ${ }^{\circledR}$ ) (Figure 5A), indicating that the SI technology increases ferritin iron accumulation within enterocytes [45]. Furthermore, in vitro experiments, comparing SI with commercially available iron salts, show that SI was able to significantly increase the ferritin concentration in CACO-2 cells, compared to tested iron salts (Figure 5B) [41]. 

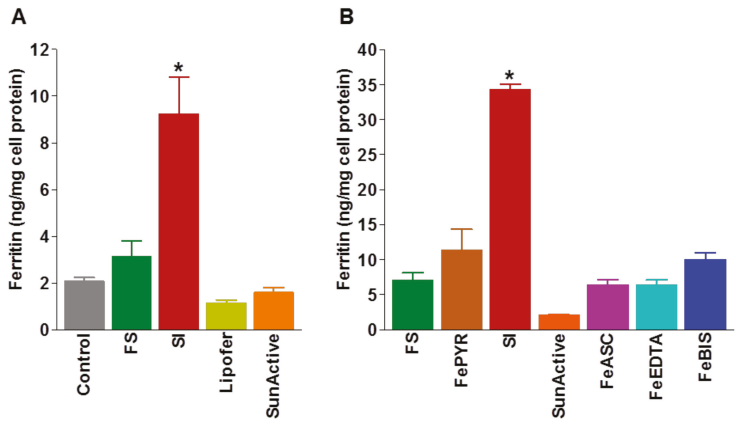

Figure 5. Bioavailability experiments on CACO-2 cells. Ferritin expression by cells treated with Sucrosomial ${ }^{\circledR}$ iron (SI) was significantly increased, compared to cells treated with ferrous sulfate (FS), phospholipid containing ferric pyrophosphate (Lipofer ${ }^{\circledR}$ ), or micronized, dispersible ferric pyrophosphate (SunActive ${ }^{\circledR}$ ) (A) or different iron salts, FS, ferric pyrophosphate (FePYR), ferrous ascorbate (FeASC), ferrous ethylene-diamine-tetra-acetate (FeEDTA), ferrous bisglycinate (FeBIS), and control (no iron) (B) (Data are mean \pm SEM, ${ }^{*} p<0.001$ SI vs. other iron compounds) (Adapted from references $[41,45])$.

Data from cell cultures show that SI was able to increase the ferritin expression in enterocytes in vitro, but this evidence was not sufficient to demonstrate the high bioavailability of SI in vivo. Therefore, SI bioavailability was subsequently investigated in iron deficient new-born piglets and mice. In piglets, a 4-week course of oral SI supplementation efficiently prevented the deterioration of the hematological status and contributed to the recovery from IDA, as shown by the significant increase in $\mathrm{Hb}$ concentration, compared to iron dextran treated animals. In addition, oral SI supplementation increased duodenal L-ferritin protein levels, compared with animals treated with parenteral iron dextran (Figure 6A) [46]. In anemic mice, treated with iron administered via gavage for 2 or 4 weeks, SI was able to improve the hemoglobin levels and iron status (Figure 6B) [47]. Bioavailability data obtained from animals are interesting, as they indicate that different animals affected by IDA respond to oral SI supplementation in a similar manner and that the efficacy of SI is comparable with all forms of oral iron salts. Remarkably, the efficacy of SI has been demonstrated, not only in animal models of uncomplicated IDA, but also in some clinical conditions, in which the absorption of oral iron is drastically reduced (e.g., celiac disease, post-bariatric surgery, ACI, IRIDA]) [48-52].

\section{A. Piglets}

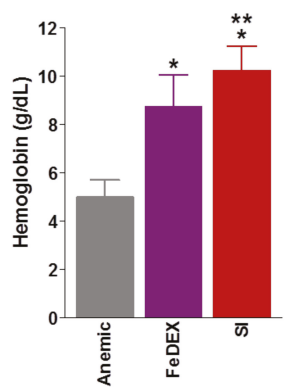

\section{B. Mice}

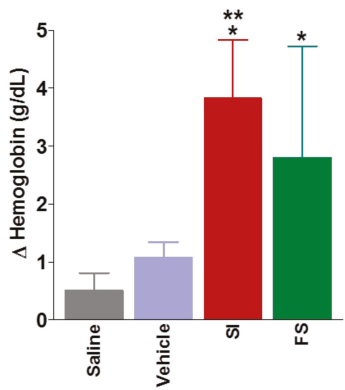

Figure 6. Iron supplementation in anemic piglets and mice. (A) Hemoglobin concentration in anemic piglets treated with iron dextran (FeDEX) or Sucrosomial ${ }^{\circledR}$ iron (SI) (Data are mean $\pm \mathrm{SD}$; ${ }^{*}<0.001$, treatment vs. anemic; ${ }^{* *} p<0.001$, SI vs. FeDEX). (B) Change in hemoglobin levels in anemic mice after a 14-day treatment with Sucrosomial ${ }^{\circledR}$ iron (SI) or ferrous sulfate (FS). (Data are mean $\pm \mathrm{SD} ;{ }^{*} p<0.01$, SI or FS vs. saline; ${ }^{* *} p<0.05$, FS vs. vehicle) (Adapted from references [46,47]). 


\subsection{Distribution}

Usually iron distribution and storage are measured by the quantification of the total iron and ferritin expression in target tissues. Ferritin-bound iron indicates the ability of the cell to internalize and store iron and, indirectly, the absorption of the administered iron. Anemic piglets and mice treated with SI were able to store iron in the ferritin of their spleens and livers. Moreover, a mild but significant increase of serum iron and transferrin saturation was observed in both IDA animal models [46,47].

A bioavailability study was also performed in healthy rats treated with ferric pyrophosphate or SI, in which the concentrations of trivalent iron in blood were measured over time (h). Blood concentrations of trivalent iron were higher in animals treated with SI after the first $3 \mathrm{~h}$. Pharmacokinetic profiles show that the area under the curve (AUC) and maximal plasma concentration of iron $\left(C_{\max }\right)$ for SI were significantly higher than those for ferric pyrophosphate. Furthermore, $5 \mathrm{~h}$ after the oral administration, SI, but not ferric pyrophosphate, led to a measurable increase of the trivalent iron content in liver and bone marrow [53]. These data suggest that SI has a greater bioavailability, and that the iron supply which exceeds the requirements for hematopoiesis and metabolic processes, is stored in the hepatocytes [54].

\subsection{Iron Homeostasis}

Hepcidin, a 25-amino acid peptide, synthetized by hepatocytes, regulates systemic iron homeostasis, and its levels can be increased in response to inflammation or iron overload [55]. Similarly, oral supplementation with iron salts also induces hepcidin up-regulation, which regulates iron release into the bloodstream and then to target organs [35].

The effects of oral supplementation with ferrous sulfate or SI, provided at the same concentration $(1 \mathrm{mg} / \mathrm{kg} /$ day), on liver hepcidin mRNA and circulating hepcidin levels were investigated in IDA mice. While SI-treated mice showed a minor, non-significant increase in liver hepcidin mRNA and serum hepcidin levels, both were significantly increased in ferrous sulfate-treated animals. In parallel, FS induced the expression of two inflammatory markers, as well as the suppressor of the cytokine signaling 3 (Socs3) and C-reactive protein (CRP), while SI did not [47]. This suggests that FS supplementation induces hepcidin up-regulation through a double mechanism. First, a direct effect of the absorbed iron on peri-portal hepatocytes was observed in ID women receiving FS at doses of $\geq 60 \mathrm{mg} /$ day [27]. Secondly, the direct toxicity of non-absorbed iron on intestinal mucosa induces an inflammatory response [56]. In contradistinction, most SI is not released into the portal blood stream, but into the lymphatic circulation ( $\mathrm{M}$ cells route) and, later, the arterial circulation, before reaching the liver. Moreover, the ferric pyrophosphate in SI does not interact with duodenal mucosa, as it is protected by the sucrosome, and it has also been suggested that the phospholipidic bilayer carriers may also exert anti-inflammatory properties [57]. Such a different behavior of SI could be relevant, since hepcidin reduces the iron availability by inhibiting the cellular iron export.

\section{Sucrosomial ${ }^{\circledR}$ Iron for the Management of Iron Deficiency in Different Clinical Settings}

As stated above, SI has unique structural, physicochemical and pharmacokinetic characteristics, together with a high iron bioavailability and excellent gastrointestinal tolerance. These properties make SI the most suitable formulation for the oral treatment of ID, even in clinical settings (e.g., CKD, cancer, bariatric surgery, etc.), where IV iron seemed to be the only therapeutic option [48-52]. We will review the efficacy and safety of oral SI for treating ID in the most common clinical scenarios.

\subsection{Obstetrics}

Iron deficiency in pregnancy continues to present a significant health problem throughout the world. There is evidence that ID and IDA are associated with an increased risk of a poor pregnancy outcome (e.g., low birth weight, prematurity), low neonatal iron deposits, preeclampsia and post-partum hemorrhage [5]. In a propensity score analysis $(n=12,470)$, severe pregnancy anemia 
was also associated with an increased risk of peri-partum mortality [58]. In the postpartum period, anemia is associated with decreased physical performance, reduced cognitive abilities and impaired lactation [5].

In order to reduce the risk of low birth weight, maternal anemia and iron deficiency, a recent consensus statement recommends daily oral supplementation of 30-60 mg iron and $400 \mu \mathrm{g}$ folic acid, as part of routine antenatal care (GRADE 1B) [5]. However, compliance with recommended oral iron intake among pregnant women varies, mostly due to the gastrointestinal side effects. Multivitamin and mineral compounds are not the best way for supplementation, mainly when ID or IDA is present, as most of them do not contain adequate amounts of iron, vitamin $B_{12}, C$ or D. Indeed, the EMPIRE study in Portugal found that IDA had a very high prevalence among pregnant women $(54.2 \%)$, despite the fact that over $80 \%$ of them were receiving iron supplementation, mostly administered as multivitamin and mineral products [59].

In this regard, a recent study on non-anemic pregnant women, presenting with $\mathrm{Hb}>10.5 \mathrm{~g} / \mathrm{dL}$ at 12-14 weeks of gestation, were randomly assigned to receive no iron (control; $\mathrm{n}=20$ ), ferrous iron $30 \mathrm{mg} /$ day (FI; $\mathrm{n}=20)$, SI $14 \mathrm{mg} /$ day (SI-14; $\mathrm{n}=20$ ) or SI $28 \mathrm{mg} /$ day (SI-28; $\mathrm{n}=20$ ) for up to 6 weeks postpartum (Table 2). Compared to the control and FI groups, the SI-28 group showed significantly higher $\mathrm{Hb}$ levels at 28 weeks and in the postpartum period. Ferritin levels at 20 and 28 weeks and at 6 weeks postpartum $(p<0.01)$ were significantly higher in the SI-28 group, compared to the control. Interestingly, fewer women from the SI-28 group developed anemia (10\%), compared to the control $(30 \%)$, FI $(25 \%)$, and SI-14 (25\%). Moreover, no differences in hematological parameters were observed between the group receiving SI $14 \mathrm{mg} /$ day and that receiving FI $30 \mathrm{mg} /$ day, thus demonstrating a higher bioavailability and allowing for the reduction of doses and side effects [60] (Table 2).

In a series of 148 consecutive deliveries, 8 non-anemic women (mean $\mathrm{Hb}: 12.1 \mathrm{~g} / \mathrm{dL}$ ), who developed postpartum anemia due to bleeding (mean: $858 \mathrm{~mL}$; range: $700-1600 \mathrm{~mL}$ ), received SI (60 $\mathrm{mg}$ twice daily). After one week, the mean $\mathrm{Hb}$ increase was $1.5 \mathrm{~g} / \mathrm{dL}$, and no gastrointestinal or systemic side effects were witnessed [61].

Thus, published evidence on SI in relation to preventing anemia during pregnancy is promising, and large studies, further evaluating the role of SI in pregnancy and in the postpartum period, would be helpful (Eudra CT: 2017-000994-35).

\subsection{Oncology}

Both ID and IDA are highly prevalent in onco-hematological patients. IDA and chemotherapy-induced anemia (CIA) are generally treated with red blood cell transfusion, ESAs and/or iron supplementation. However, there is controversy on the safety and cost issues regarding different iron compounds and administration routes [23,62].

A recent position statement recommends investigating the presence of anemia and/or iron deficiency in all cancer patients, but especially in those scheduled for cytotoxic chemotherapy, radiotherapy or surgery. This should be carried out before and during treatment in order to plan the most appropriate therapeutic strategy [23].

According to the most recent ESMO guidelines, patients with $\mathrm{CIA}(\mathrm{Hb} \leq 11 \mathrm{~g} / \mathrm{dL}$ or $\mathrm{Hb}$ decrease of $\geq 2 \mathrm{~g} / \mathrm{dL}$ from a baseline level of $\leq 12 \mathrm{~g} / \mathrm{dL}$ ) and absolute ID (serum ferritin $<100 \mathrm{ng} / \mathrm{mL}$ ) should receive iron treatment to correct ID. In the case of FID (TSAT $<20 \%$ and serum ferritin $>100 \mathrm{ng} / \mathrm{mL}$ ), iron treatment should be administered before the initiation of and/or during ESA therapy (with both the originator and biosimilar products, approved by the EMA), or as mono-therapy [6].

Regarding the iron formulation that should be used, ESMO guidelines indicate that oral iron is considered only for patients with both absolute ID and non-inflammatory conditions (CRP $<5 \mathrm{mg} / \mathrm{L}$ ). Even if ESMO guidelines recommend the use of IV iron in cases of FID, they stated that the long-term safety of IV iron in oncology has not yet fully established [6]. Therefore, SI could be taken into consideration in cases of inflammatory conditions and anemia, as SI absorption does not seem to be affected by hepcidin $[23,35]$. 
In several small case-series and pilot studies of anemic oncologic patients, with or without chemotherapy, oral SI (30-60 mg/day for 2-6 months) was shown to increase Hb levels, with very few gastrointestinal side effects (Supplementary material, Table S1). More recently, a retrospective study of patients presenting with moderate CIA ( $\mathrm{Hb} 8-10 \mathrm{~g} / \mathrm{dL}$ ), and no ID or FID, assessed the performance of oral SI ( $30 \mathrm{mg} /$ day; $\mathrm{n}=33$ ) in improving the $\mathrm{Hb}$ response to ESA (Darbepoetin $500 \mu \mathrm{g} / 3$ weeks), compared to IV FG (125 mg/week; $n=31)$ [51] (Table 2). After 8 weeks of treatment, there were no differences between the groups with respect to $\mathrm{Hb}$ response ( $70 \% \mathrm{vs.} 71 \%$, respectively), as defined by an increment in $\mathrm{Hb} \geq 2 \mathrm{~g} / \mathrm{dL}$ and/or a final $\mathrm{Hb} \geq 12 \mathrm{~g} / \mathrm{dL}$. There were also no differences in red cell transfusion rates (one patient in each group) or change in the quality of life. Oral SI was well tolerated, with only one patient showing gastrointestinal toxicity, whereas 2 infusion reactions were witnessed with IV FG.

\subsection{Nephrology}

Iron deficiency is one of the main causes of anemia in patients with CKD, and iron supplements, along with ESAs, constitute the basis of its treatment, both for patients not on dialysis (ND-CKD) and those who are hemodialysis-dependent (HD-CKD), but disparities exist in the guidelines and position papers for anemia treatment across the world $[7,63]$.

Though mortality and adverse effects rates in CKD patients receiving oral or IV iron supplementation are similar, a meta-analysis (24 studies, 3187 patients) found that hypotensive reactions were more frequent with IV iron, whereas more gastrointestinal adverse events were observed with oral iron [64]. A recent randomized, controlled trial in 128 anemic CDK patients suggested a possible higher incidence of cardiovascular events and hospitalization for infection in the IV iron arm, compared to the oral iron arm [65]. In contrast, a trial evaluating IV versus oral FS in 626 anemic ND-CKD patients, with ID and not receiving ESA therapy, found no difference in the infection rates or cardiac events between patients receiving a higher FCM dose (500-1000 mg/4 weeks), lower FCM dose (200 mg/4 weeks) or oral FS (200 mg/day) during the 56 weeks follow-up (3.9\%, 3.3\%, and 3.8\%, respectively) [66]. It is worth noting that, in this trial, only $21.6 \%$ of patients receiving oral iron showed an $\mathrm{Hb}$ increase of at least $1 \mathrm{~g} / \mathrm{dL}$, and $<30 \%$ of early non-responders responded at any subsequent time point during the follow-up, suggesting that the early consideration of alternative therapy would be beneficial in this population [67]. In a cohort of 58,058 HD-CKD patients, IV iron doses greater than $400 \mathrm{mg} /$ month were associated with higher cardiovascular death rates [68]. The conclusion should be that "too much iron is bad" for CKD patients, but further large clinical studies are needed (such as the on-going PIVOTAL trial; EudraCT Number: 2013-002267-25), whereas the oral versus IV administration of iron is an on-going debate $[24,63]$.

In several case series on ND-CKD patients (mostly with mild anemia), oral SI ( $30 \mathrm{mg} /$ day), with or without ESA, was shown to be efficacious in maintaining and/or increasing $\mathrm{Hb}$, ferritin and TSAT levels during different follow-up periods (from 3 to 24 months), with virtually no gastrointestinal side effects (Supplementary material, Table S2). In a randomized open-label trial, 99 ND-CKD patients with IDA ( $\mathrm{Hb} \leq 12 \mathrm{~g} / \mathrm{dL}$, ferritin $\leq 100 \mathrm{ng} / \mathrm{mL}$, TSAT $\leq 25 \%)$ were assigned (2:1) to receive oral SI (30 mg/day) for 3 months or a total dose of $1000 \mathrm{mg}$ of IV FG (125 mg/week), and they were followed-up for 4 months [50]. At the end of the treatment period, the Hb levels were similar in both groups (11.4 g/dL vs. $11.7 \mathrm{~g} / \mathrm{dL}$, respectively), though the replenishment of iron stores was greater in the IV FG group (ferritin $86 \mathrm{ng} / \mathrm{mL}$ vs. $239 \mathrm{ng} / \mathrm{mL}$, respectively; $p<0.05$ ) (Table 2). Hb concentrations decreased more rapidly after iron withdrawal, although significantly fewer adverse events were observed in the oral group $(p<0.001)$, and adherence to treatment was similar in the two groups. Therefore, this study shows that short-term, low-dose oral SI is as efficacious as IV FG for correcting anemia in ND-CKD patients and suggests that there is no risk of iron overload during its long-term use. Similar results were observed in two preliminary studies comparing oral IV and IV FG, with or without ESA, in 34 anemic HD-CKD patients (Supplementary material, Table S2). 
Recently, in 3 CKD patient populations (pre-dialysis, peritoneal dialysis, and post-transplant), who did not respond to conventional oral iron supplementation, Darbá et al. [69] assessed the economic impact of switching from intravenous iron (FCM or IS) to SI. Using a 4-year budget impact model (2017-2020), the progressive increase of SI use (up to 10\% of market shares) would lead to over $€ 750,000$ savings.

\subsection{Gastroenterology}

Anemia is the most frequent systemic complication in inflammatory bowel disease (IBD), celiac disease (CD), non-celiac gluten sensitivity (NCGS) and autoimmune atrophic gastritis (AAG) [70]. In IBD patients, anemia is more frequent among those with Crohn's disease, though its prevalence in studies varies according to the definition criteria, type of patients, and year of publication, but ID and ACD are the most common causes [9].

Oral iron supplementation in IBD patients may result in worsening disease symptoms (flares), which can be attributed to iron-induced oxidative stress, but also to microbiota alterations. After 3 months of iron supplementation, shifts in gut bacterial diversity and composition were found in IBD patients, with oral FS (120 mg of elemental iron per day) differentially affecting bacterial phylotypes and fecal metabolites, compared with IV iron sucrose therapy (3-4 doses of $300 \mathrm{mg}$ ) [71]. However, in an experimental model of colitis in mice (induced by the administration of dextran sodium sulfate [DSS]), the effect of dietary iron supplementation $(500 \mathrm{mg} / \mathrm{kg}$ ) on survival depended on the formulation used, and this was either beneficial (FeBIS) or highly detrimental (ferric ethylene-diamine-tetra-acetic acid), most likely due to the modulation of the microbiota [72]. In addition, a hem-enriched intestinal lumen (due to a hem-rich diet, hem-based iron supplementation or intestinal bleeding) led to changes in bacterial flora composition (with a decrease in Proteobacteria and a reduction of Firmicutes), which were similar to, though less pronounced than, those observed after DSS administration [72]. Therefore, oral iron supplementation in IBD patients with ID is challenging, and guidelines are prone to recommend the use of IV iron [9]. However, initial clinical data in IBD patients suggest that oral iron formulations with improved tolerability, such as SI or ferric maltol, may represent a viable alternative to IV iron [73].

In several case series of IBD patients with mild-to-moderate IDA ( $\mathrm{n}=92$, including 46 intolerant to ferrous sulfate [74]), SI (30-60 mg/day for 2-3 months) has been shown to be efficacious in rising $\mathrm{Hb}$ concentrations $(+0.92 \mathrm{~g} / \mathrm{dL})$, as well as ferritin and TSAT levels, with very few gastrointestinal side effects (Table 2) (Supplementary material, Table S3). In comparative 2-3 month treatment courses, the efficacy of SI (30-60 mg/day; $\mathrm{n}=38)$ in increasing $\mathrm{Hb}$ was higher than that of FS (105-210 mg/day, $\mathrm{n}=14)$ (mean $\mathrm{Hb}$ change $+2.7 \mathrm{~g} / \mathrm{dL}$ vs. $1.4 \mathrm{~g} / \mathrm{dL}$, respectively), despite lower elemental doses (Supplementary material, Table S3), and similar to that of IV iron sucrose (100 mg/session, up to 500-1000 mg) (mean Hb change: $+1.7 \mathrm{~g} / \mathrm{dL}$ vs. $+1.8 \mathrm{~g} / \mathrm{dL}$, respectively) [75] (Table 2).

Celiac disease is a common intestinal autoimmune pathology, which presents with laboratory abnormalities, irritable bowel syndrome, osteopenia, fertility problems and iron deficiency [76]. A prospective study evaluated the efficacy of a 3-month course of SI supplementation ( $30 \mathrm{mg} /$ day) in anemic patients with CD, who could not tolerate oral FS ( $\mathrm{n}=24)$ (NCT02916654) [48]. Additionally, naïve patients were assigned to receive oral FS (105 mg/day) $(n=19)$. After a 3-month follow-up, a significant improvement in all iron parameters was observed in both groups. Both treatments increased $\mathrm{Hb}$ levels, compared to the baseline, with a similar proportion of patients presenting $\mathrm{Hb}$ values within the normal range ( $70 \%$ vs. $82 \%$, respectively; $p=n$ ), although the elemental iron dose with SI was one-third of that with FS (Table 2). As evaluated by visual analog scale (VAS) scores, patients receiving SI reported a lower severity of abdominal symptoms and a higher increase in general well-being, compared to those receiving FS [48].

Sucrosomial ${ }^{\circledR}$ iron ( $30 \mathrm{mg} /$ day for 15 days, plus $15 \mathrm{mg} /$ day for 75 days) has also been shown to be effective in treating IDA, in a series of non-CD gluten-sensitivity patients $(n=28)$, and in increasing $\mathrm{Hb}(+2.8 \mathrm{~g} / \mathrm{dL})$ and ferritin levels $(+11 \mathrm{ng} / \mathrm{mL})$ (Supplementary material, Table S3). 
Autoimmune atrophic gastritis is another autoimmune entity, which may be triggered by Helicobacter pylori infection, in which autoantibodies against gastric parietal cells and/or an intrinsic factor are characteristically present. Mucosal atrophy leads to hypo- or achlorhydria, and most AAG patients develop anemia, either due to cobalamin deficiency (older patients) or ID (younger patients) [70]. Importantly, AAG is responsible for 20-27\% of IDA cases, which are refractory to oral iron supplements, and use to be treated with IV iron [77].

To assess the efficacy of oral SI, 20 consecutive AAG women (100\% with gastric parietal cells autoantibodies, $20 \%$ with intrinsic factor autoantibodies) with recently diagnosed IDA $(\mathrm{Hb}<120 \mathrm{~g} / \mathrm{dL}$ ) were enrolled in a prospective observational study [78]. Patients received SI (120 mg/daily, either fasting or during meals) for 8 weeks. Only 3 patients dropped out due to intolerance (2) or lack of compliance (1). Compared to the baseline values, after 8 weeks, there were significant increments in $\mathrm{Hb}$ (from $10.5 \mathrm{~g} / \mathrm{dL}$ to $12.5 \mathrm{~g} / \mathrm{dL}$ ), ferritin (from $7 \mathrm{ng} / \mathrm{mL}$ to $27 \mathrm{ng} / \mathrm{mL}$ ) and TSAT (from $8 \%$ to $18 \%$ ) (Table 2).

Bariatric surgery, especially the malabsorptive procedure, can be associated with a risk of nutritional deficiency, including iron, which increases over the years, and women of childbearing age are the most vulnerable group [10]. In a 4-year follow-up, after gastric bypass or sleeve gastrectomy procedures at a single institution ( $n=353,73 \%$ women), the investigators found that ID prevalence was significantly reduced in men ( $17.2 \%$ vs. $40 \%)$, but significantly increased in women ( $31.5 \%$ vs. $26.1 \%)$, especially in those of childbearing age $(<50$ years) [79]. In these settings, traditional oral iron formulations present clear and significant limitations regarding tolerance and efficacy, and patients use to be switched to IV iron.

A case-control study included 40 women of childbearing age, who were receiving IV iron sucrose supplementation after bariatric surgery (300 mg every 3 months). Of these women, 20 were switched to oral SI ( $28 \mathrm{mg} /$ day for 3 months), while another 20 received a dose of IV iron sucrose (300 $\mathrm{mg})$. Hemoglobin, ferritin, and TSAT levels were measured, before and three months after the treatment switch, and no between-group differences were found [49] (Table 2). Thus, for patients developing ID after bariatric surgery and requiring IV iron, oral SI could be an alternative maintenance therapy.

\subsection{Cardiology}

As stated above, iron is needed for proteins and enzymes involved in oxygen transport (hemoglobin), storage (myoglobin), and utilization for energy production (respiratory chain) in skeletal and cardiac muscle cells. ID, with or without anemia, affects 50\% of congestive heart failure (CHF) patients and is independently associated with a reduced physical performance, decreased quality of life and increased risk of mortality [8]. Treatment of ID, as defined by serum ferritin $<100 \mathrm{ng} / \mathrm{mL}$ or ferritin between 100 and $299 \mathrm{ng} / \mathrm{mL}$ and TSAT $<20 \%$, in patients with chronic heart failure, is strongly recommended by the European Society of Cardiology [80].

The mechanisms of ID in heart failure are still not well understood. Chronic heart failure is considered to have a low-grade inflammatory status, which increases the circulating levels of hepcidin. In turn, hepcidin binds ferroportin, especially at the enterocytes, promoting its internalization and degradation, thus preventing iron absorption, while iron recirculation from macrophages seems to be less affected $[4,14,55]$. The alteration in the composition of the intestinal microbiota, known as intestinal dysbiosis, may also contribute to the perpetuatation of the inflammatory status [35]. A high prevalence of malnutrition and reduced iron absorption due to intestinal edema could also be involved [35]. In a recent randomized controlled trial in CHF patients (the IRONOUT study), oral iron polysaccharide (150 mg, bid) was demonstrated to be inefficacious for correcting ID [81]. In contrast, the European guidelines recommend the administration of IV iron for treating ID in this patient population [80].

However, a prospective pilot study has evaluated the possible role of oral SI supplementation in 30 patients with CHF and ID iron deficiency, with or without anemia [82]. Twenty patients received oral SI (30 mg/day for 3 months) and 10 served as controls (no iron). All were on stable, evidence-based medical therapy for at least 1 month, and there were no differences in baseline clinical and laboratory 
parameters between groups. At 3 months, SI treatment improved iron parameters, while Hb levels remained stable. There was also an improvement in quality of life, as assessed by Kansas City Cardiomyopathy Questionnaire (from 55.7 to 61.8; $p=0.038$ ), and a trend towards a longer 6-min walked distance (from $318 \mathrm{~m}$ to $332 \mathrm{~m} ; p=0.065$ ) and lower B-natriuretic peptide (from 643 to 535 ; $p=0.360)$. All patients in the SI group adhered to the protocol, and no side effects were witnessed. No change in any of the assessed parameters was observed in the control group. These results are in line with those from 3 small case-series $(n=29)$ (Supplementary material, Table S4), but large, confirmatory studies are needed. In this regard, 2 randomized controlled trials, comparing oral SI with oral ferrous bisglycinate or a placebo (PREFER-HF study), or oral SI with IV FCM (IVOFER-HF study), are currently on-going.

\subsection{Internal Medicine}

Anemia is a frequent condition among hospitalized surgical and critically ill patients, compromising their clinical outcome. However, the role of anemia, as a risk factor for a poor outcome in other hospitalized patients, has hardly been investigated. In a random sample of patients, admitted to the internal medicine ward in 2015, the prevalence (53\%) and severity (46\% moderate, $7 \%$ severe) of anemia was high and most probably caused by chronic inflammation, blood loss, and/or hemodilution [83]. It seemed to be linked to older age, a higher Charlson comorbidity index, a longer length of hospital stay and increased in-hospital mortality, but it was underdiagnosed and undertreated [83]. On admission to the internal medicine ward, data from 771 consecutive patients revealed that $67 \%$ presented with anemia, which was associated with an increased risk of in-hospital mortality (RR $1.82,95 \%$ CI 1.21-2.74) [84]. Iron deficiency (58\%), with (41\%) or without (18\%) anemia, was also highly prevalent [84]. Therefore, an appropriate anemia management protocol for this patient population should be established, including an appropriate provision of iron supplementation.

Patients with myelodysplasia (MSD) frequently exhibit anemia with FID, for which IV iron may be effective [6]. However, preliminary data suggested that oral SI may be as effective as IV iron in MSD patients (Supplementary material, Table S5). More recently, the efficacy of SI (28 mg/day) in supporting the erythropoietic response to an originator (group A) or biosimilar (group B) epoetin- $\alpha$ was studied in 92 MSD patients with refractory anemia. Patients also received vitamin $B_{12}(400 \mathrm{mg} /$ day orally) and calcium levofolinate (7.5 mg/day orally) to avoid deficiencies of maturation factors [85]. Responder rates (as defined by an $\mathrm{Hb}$ increment of $\geq 1.5 \mathrm{~g} / \mathrm{dL}$ after 3 months of epoetin treatment) were similar in both groups (50\% and 43\%, respectively) and higher than that reported in the literature [86], thus suggesting the efficacy of oral SI supplementation.

In a small sample of young women with chronic inflammatory anemia due to autoimmune diseases (systemic erythematosus lupus, rheumatic fibromyalgia, connectivitis), the efficacy SI (60 mg/day, $\mathrm{n}=9$ ) was compared to that of FS (210 mg/day) over a 3-month course [86]. There were no differences in the baseline $\mathrm{Hb}(8.5 \mathrm{~g} / \mathrm{dL}$ vs. $9.0 \mathrm{~g} / \mathrm{dL}$, respectively), iron status (\%TSAT, Ferritin) or inflammatory markers (CRP). Compared to FS, SI resulted in significant improvements in $\mathrm{Hb}(11.5 \mathrm{~g} / \mathrm{dL}$ vs. $9.5 \mathrm{~g} / \mathrm{dL}$, respectively) and ferritin (260 ng/mL vs. $100 \mathrm{ng} / \mathrm{mL}$, respectively). Additionally, SI, but not FS, was associated with a significant reduction in ESR and CRP levels [87].

Bleeding is also a common cause of anemia in the internal medicine ward, with red blood cell transfusion being the default treatment, but in many cases we could care for patients without exclusively resorting to blood components. A recent study included 90 patients with moderate-to-severe IDA due to non-neoplastic gastrointestinal or gynecologic bleeding, without inflammation but with intolerance/refractoriness to FS [88]. Patients were randomized to receive a high dose of SI (120 mg/day for one month; SI group; $n=45)$, with or without food or antacid therapy, or IV FG (62.5 mg/day until cover total ID; FG group; $n=45)$. There were no differences in the baseline $\mathrm{Hb}$ concentration $(8.5 \mathrm{~g} / \mathrm{dL}$ vs. $8.2 \mathrm{~g} / \mathrm{dL}$, for SI and FG groups, respectively), and both treatments were equally effective in increasing the $\mathrm{Hb}(12.0 \mathrm{~g} / \mathrm{dL}$ vs. $12.5 \mathrm{~g} / \mathrm{dL}$, after 4 weeks, respectively) (Table 2), though treatment costs were significantly lower for the oral SI (120€/month) than for the IV ferric 
gluconate (300 €/month). Adverse drug events were observed in $12(26 \%)$ patients from the SI group (epigastric pain, diarrhea) and in 10 (22\%) from the FG group (hypotension, urticarial, headache), but no patient required transfusion (Table 2). These data seem to confirm those obtained with SI supplementation in several case series and observational studies of patients with IDA of different origins (mostly bleeding) (Supplementary material, Table S5).

In another multicenter study, 300 patients with moderate-to severe IDA $(\mathrm{Hb}<11 \mathrm{~g} / \mathrm{dL}$, ferritin $<30 \mathrm{ng} / \mathrm{mL})$ due to gastric $(44 \%)$ or intestinal $(56 \%)$ bleeding were randomized 1:1:1:1:1:1 to receive $60 \mathrm{mg}$ of elemental iron daily of oral FS, microencapsulated iron (Saccarate iron), micronized ferric pyrophosphate (SunActive ${ }^{\circledR}$ ), SI, heminic bisglycinated iron, or bisglycinated iron. Patients' characteristics and follow-up times (12-24 weeks) were similar in all six groups. Compared to any other oral iron formulation tested, SI led to consistently higher $\mathrm{Hb}$ increments from week 6, both for the whole study population (Figure 7A) and for the subgroup of patients presenting with inflammation (high CRP) (Figure 7B). At week 24, mean $\mathrm{Hb}$ concentrations in SI-treated patients were $13.2 \mathrm{~g} / \mathrm{dL}$ for the whole, and $12.5 \mathrm{~g} / \mathrm{dL}$ for the high CRP subgroup. Gastrointestinal side effect rates were low with all formulations (6-12\%), except for FS (30\%). Therefore, among the different oral iron formulations tested in this patient population, SI showed the fastest and greatest efficacy in correcting IDA, which was more evident in patients presenting with high CRP values [89].

\section{A. All anemic patients}
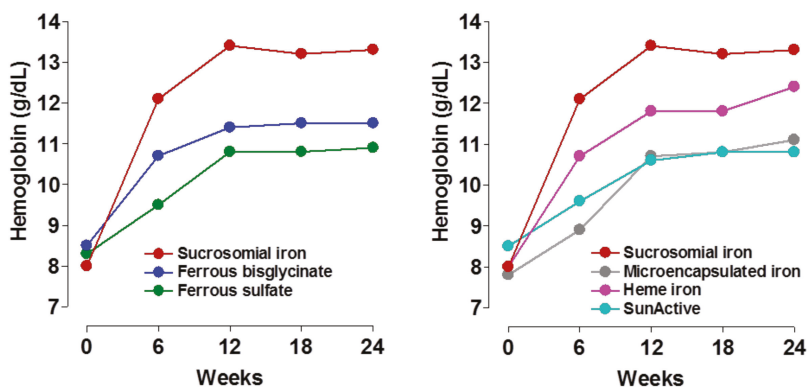

\section{B. Anemic patients with high CRP}
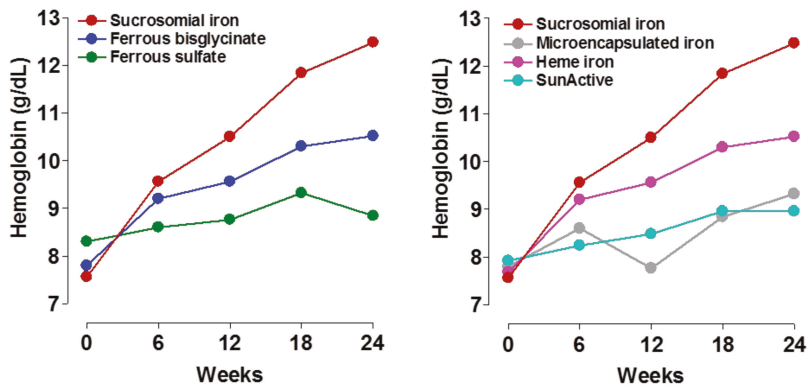

Figure 7. Comparative efficacy of different oral iron formulations for treating bleeding-induced moderate-to-severe anemia. SunActive ${ }^{\circledR}$, micronized ferric pyrophosphate. Each oral iron formulation was tested in 60 patients (Data taken from reference [89]).

\subsection{Surgery}

Pre-operative anemia is frequent among patients scheduled for major elective surgery (30-40\%) [13], being an independent risk factor for a poor outcome (increased rates of morbidity, mortality and readmission) and prolonged length of hospital stay [12], but enhancing the deleterious 
effects of blood loss and red cell transfusion. Postoperative anemia is even more frequent, affecting up to $80-90 \%$ of patients [90].

Absolute iron deficiency and iron sequestration are the leading causes of preoperative anemia (70\% of cases), whereas surgery-associated blood loss and inflammation may induce and/or maintain postoperative anemia [13]. Hematinic deficiencies without anemia are also frequent and may hamper pre-operative $\mathrm{Hb}$ optimization and/or recovery from postoperative anemia.

As modifiable risk factors, preoperative anemia ( $\mathrm{Hb}<13$ for both genders) and hematinic deficiencies should be detected, classified and treated prior to any major surgery [21]. However, the role of preoperative oral iron supplementation in treating ID, FID or IDA in these patient populations has been scarcely investigated, while available evidence indicated that it is not useful in the postoperative period $[21,24,90]$.

A retrospective study evaluated the efficacy of preoperative SI in 200 paired-matched patients undergoing prosthetic hip surgery (2106) in terms of blood transfusion requirements, length of hospital stay and postoperative $\mathrm{Hb}$ recovery [91]. Preoperative iron supplementation with SI (30 mg/day for 3-4 weeks, preoperatively) was offered to 100 patients with $\mathrm{Hb} 12-13.5 \mathrm{~g} / \mathrm{dL}$, for women, or $13-14 \mathrm{~g} / \mathrm{dL}$, for men, and ferritin $<100 \mathrm{ng} / \mathrm{mL}$ (ID) or ferritin $>100 \mathrm{ng} / \mathrm{mL}$, if there was an elevated CRP or TSAT $<20 \%$ (FID). Another 100 patients with the same demographic and laboratory characteristics, who had not received SI, served as a control group. Compared to the control group (no iron supplementation), SI supplementation led to a reduction in the number of transfused units ( 0 units vs. 7 units, respectively) and the length of the hospital stay (4 days vs. 6.5 days, respectively), with an estimated cost saving of $1763 € /$ patient. Additionally, higher $\mathrm{Hb}$ levels were observed in the SI group, 30 days after discharge (13.4 \pm 1.5 vs. $10.2 \pm 1.2$, respectively). Obviously, a confirmatory randomized control trial on the beneficial effects of SI supplementation is warranted.

In this regard, the CardioSideral Heart Surgery (NCT03560687), a prospective study in 1000 consecutive patients undergoing heart surgery, randomized to either SI supplementation or no treatment (control), is on-going. Its main outcome variable is the reduction in transfusion rates, but the changes in $\mathrm{Hb}$ and iron parameters, number of transfused units, postoperative quality of life (6-min walk test), tolerability and cost-effectiveness of SI will also be assessed. 
Pharmaceuticals 2018, 11, 97

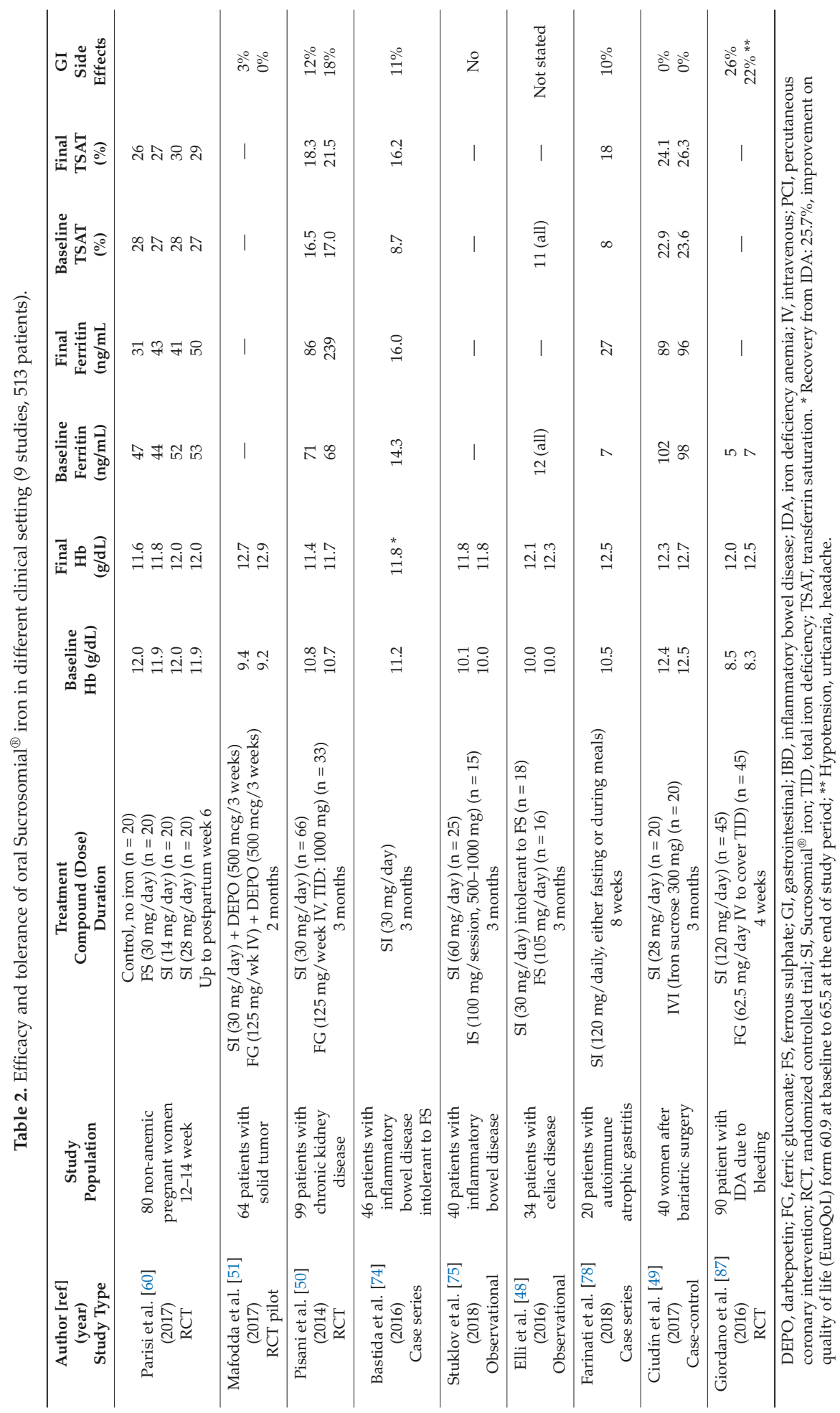




\title{
6. Efficacy of Sucrosomial®Iron: An Overview
}

Most relevant evidence on the bioavailability, tolerability and efficacy of oral SI in different preclinical and clinical settings has been presented as lectures or communications in the 3rd, 4th, 5th and 6th International Multidisciplinary Courses on Iron Anemia and other international meetings. However, a growing number of studies have been already published as full peer-review papers $[40,42,47-51,60,69,85,91]$. Characteristics and results for a number of clinical studies are summarized in Table 2.

Preclinical studies clearly demonstrated that SI has unique structural, physicochemical and pharmacokinetic characteristics. The presence of sucrester confers gastro-resistance to SI, protects its trivalent pyrophosphate iron against enzymatic reduction, and promotes its absorption across the intestinal epithelium by a DMT-1 independent pathway, which is greatly mediated by M cells. All this enables oral SI to have a high iron bioavailability and a low gastrointestinal toxicity.

The analysis of available clinical evidence seems to support oral SI as a new valid opportunity for iron supplementation, which is more comfortable, efficacious (lower doses, higher Hb increments and/or better replenishment of iron stores) and tolerable than traditional oral iron salts (Table 2). Sucrosomial iron has been also demonstrated to have a similar effectiveness, with lower risks, in clinical settings where IV iron was the usual treatment option (e.g., CKD, cancer, bariatric surgery, etc.) (Table 2).

Thus, the administration of oral SI emerges as a valuable first option for treating uncomplicated iron deficiency, especially for subjects with intolerance to iron salts or those for whom iron salts are inefficacious. Moreover, oral SI should also be considered as an alternative to IV iron for initial and/or maintenance treatment in different patient populations. Nevertheless, appropriately sized randomized control trials are needed to confirm the promising results obtained with oral SI supplementation in different clinical settings.

Supplementary Materials: The following are available online at http:/ /www.mdpi.com/1424-8247/11/4/97/s1, Table S1: Sucrosomial ${ }^{\circledR}$ iron (SI) administration in oncologic patients (10 studies, 241 patients), Table S2: Sucrosomial ${ }^{\circledR}$ iron (SI) administration in patients with chronic kidney disease (CKD) (11 studies, 294 patients), Table S3: Sucrosomial ${ }^{\circledR}$ iron (SI) administration in patients with gastrointestinal disease (7 studies, 122 patients), Table S4: Sucrosomial $^{\circledR}$ iron (SI) administration in cardiology patients (8 studies, 161 patients), Table S5: Sucrosomial ${ }^{\circledR}$ iron (SI) administration in Internal Medicine (10 studies, 236 patients).

Author Contributions: All authors have made substantial contributions to the conception or design of the work; acquisition, analysis, or interpretation of data; and/or writing or substantively revising the manuscript. In addition, all authors have approved the submitted version and agree to be personally accountable for the author's own contributions and for ensuring that questions related to the accuracy or integrity of any part of the work, even those in which the author was not personally involved, are appropriately investigated, resolved, and documented in the literature.

Funding: This research received no external funding.

Acknowledgments: We thank all the researchers, experts and physicians involved in the clinical studies and basic research experiments on Sucrosomial ${ }^{\circledR}$ iron, contributing to the study of its properties, mechanism of action and efficacy.

Conflicts of Interest: S.G.-R. has nothing to declare; E.B. is an Alesco S.r.l. employee; G.T. is a Pharmanutra S.p.A. employee; M.M. has received industry-supplied honoraria for consultancies, lectures and/or travel support from Pharmacosmos, Vifor Pharma, Zambon, Pharmanutra, Sandoz and Celgene, and is member of the editorial board of the journals, "Revista Española de Anestesiología y Reanimación", "Medicina Intensiva" and "Blood Transfusion".

\begin{abstract}
Abbreviations
AAG, autoimmune atrophic gastritis; ACI, anemia of chronic inflammation; AntiH2, histamine $\mathrm{H} 2$ receptor antagonists; AUC, area under the curve; BPDS, bathophenanthroline disulfonic acid; CACO2, human colon cancer cell line; $C D$, celiac disease; CHF, congestive heart failure; CIA, chemotherapy-induced anemia; CKD, chronic kidney disease; Cmax, maximal plasma concentration; CRP, C-reactive protein; DEPO, darbepoetin; DMT-1, divalent metal transporter-1; DSS, dextran sodium sulfate; ESA, erythropoiesis stimulating agent; FCM, ferric carboxymaltose; FeASC, ferrous ascorbate; FeBIS, ferrous bisglycinate; FeDEX, iron dextran; FeEDTA,
\end{abstract}


ferrous ethylene-diamine-tetra-acetate; FePYR, ferric pyrophosphate; FG, ferric gluconate; FI, ferrous iron; FID, functional iron deficiency; FS, ferrous sulfate; FXT, ferumoxytol;GI, gastrointestinal; $\mathrm{Hb}$, hemoglobin; HD-CKD, hemodialysis-dependent CKD; IBD, inflammatory bowel disease; ID, iron deficiency; IDA, iron deficiency anemia; IRIDA, iron-refractory iron deficiency anaemia; IS, iron sucrose; ISM, iron isomaltoside 1000; IV, intravenous; LMWID, low molecular weight iron dextran; M cell, microfold cell of Peyer's patches (RajiB cell); MCH, mean corpuscular hemoglobin; MCV, mean corpuscular volume; MSD, myelodysplasia; NCGS, non-celiac gluten sensitivity; ND-CKD, CKD non on dialysis; PCI, percutaneous coronary intervention; PPI, proton pump inhibitors; RCT, randomized controlled trial; SI, Sucrosomial ${ }^{\circledR}$ iron; Socs3, suppressor of cytokine signaling 3; TID, total iron deficiency; TSAT, transferrin saturation; VAS, visual analog scale; WHO, World Health Organization.

\section{References}

1. Kassebaum, N.J.; Jasrasaria, R.; Naghavi, M.; Wulf, S.K.; Johns, N.; Lozano, R.; Regan, M.; Weatherall, D.; Chou, D.P.; Eisele, T.P.; et al. A systematic analysis of global anemia burden from 1990 to 2010. Blood 2014, 123, 615-624. [CrossRef] [PubMed]

2. GBD 2016 Disease and Injury Incidence and Prevalence Collaborators. Global, regional, and national incidence, prevalence, and years lived with disability for 328 diseases and injuries for 195 countries, 1990-2016: A systematic analysis for the Global Burden of Disease Study 2016. Lancet 2017, 390, 1211-1259. [CrossRef]

3. Gómez-Ramírez, S.; Remacha-Sevilla, Á.F.; Muñoz-Gómez, M. Anaemia in the elderly. Med. Clin. 2017, 149, 496-503. [CrossRef]

4. Muñoz, M.; García-Erce, J.A.; Remacha, A.F. Disorders of iron metabolism. Part II: Iron deficiency and iron overload. J. Clin. Pathol. 2011, 64, 287-296. [CrossRef] [PubMed]

5. Muñoz, M.; Peña-Rosas, J.P.; Robinson, S.; Milman, N.; Holzgreve, W.; Breymann, C.; Goffinet, F.; Nizard, J.; Christory, F.; Samama, C.M.; et al. Patient blood management in obstetrics: Management of anaemia and haematinic deficiencies in pregnancy and in the post-partum period: NATA consensus statement. Transfus. Med. 2018, 28, 22-39. [CrossRef] [PubMed]

6. Aapro, M.; Beguin, Y.; Bokemeyer, C.; Dicato, M.; Gascon, P.; Glaspy, J.; Hofmann, A.; Link, H.; Littlewood, T.; Ludwig, H.; et al. Management of anaemia and iron deficiency in patients with cancer: ESMO Clinical Practice Guidelines. Ann. Oncol. 2018. [CrossRef]

7. Macdougall, I.C.; Bircher, A.J.; Eckardt, K.U.; Obrador, G.T.; Pollock, C.A.; Stenvinkel, P.; Swinkels, D.W.; Wanner, C.; Weiss, G.; Chertow, G.M.; et al. Iron management in chronic kidney disease: Conclusions from a "Kidney Disease: Improving Global Outcomes" (KDIGO) Controversies Conference. Kidney Int. 2016, 89, 28-39. [CrossRef] [PubMed]

8. Goodnough, L.T.; Comin-Colet, J.; Leal-Noval, S.; Ozawa, S.; Takere, J.; Henry, D.; Javidroozi, M.; Hohmuth, B.; Bisbe, E.; Gross, I.; et al. Management of anemia in patients with congestive heart failure. Am. J. Hematol. 2017, 92, 88-93. [CrossRef] [PubMed]

9. Dignass, A.U.; Gasche, C.; Bettenworth, D.; Birgegard, G.; Danese, S.; Gisbert, J.P.; Gomollon, F.; Iqbal, T.; Katsanos, K.; Koutroubakis, I.; et al. European consensus on the diagnosis and management of iron deficiency and anaemia in inflammatory bowel diseases. J. Crohns Colitis 2015, 9, 211-222. [CrossRef] [PubMed]

10. Muñoz, M.; Botella-Romero, F.; Gómez-Ramírez, S.; Campos, A.; Garcia-Erce, J.A. Iron deficiency and anaemia in bariatric surgical patients: Causes, diagnosis and proper management. Nutr. Hosp. 2009, 24, 640-654. [PubMed]

11. Cappellini, M.D.; Comin-Colet, J.; de Francisco, A.; Dignass, A.; Doehner, W.; Lam, C.S.; Macdougall, I.C.; Rogler, G.; Camaschella, C.; Kadir, R.; et al. Iron deficiency across chronic inflammatory conditions: International expert opinion on definition, diagnosis, and management. Am. J. Hematol. 2017, 92, 1068-1078. [CrossRef] [PubMed]

12. Muñoz, M.; Gómez-Ramírez, S.; Campos, A.; Ruiz, J.; Liumbruno, G.M. Pre-operative anaemia: Prevalence, consequences and approaches to management. Blood Transfus. 2015, 13, 370-379. [CrossRef] [PubMed]

13. Muñoz, M.; Laso-Morales, M.J.; Gómez-Ramírez, S.; Cladellas, M.; Nuñez-Matas, M.J.; Garcia-Erce, J.A. Pre-operative haemoglobin levels and iron status in a large multicentre cohort of patients undergoing major elective surgery. Anaesthesia 2017, 72, 826-834. [CrossRef] [PubMed]

14. Camaschella, C. Iron-deficiency anemia. N. Engl. J. Med. 2015, 372, 1832-1843. [CrossRef] [PubMed]

15. Auerbach, M.; Adamson, J.W. How we diagnose and treat iron deficiency anemia. Am. J. Hematol. 2016, 91, 31-38. [CrossRef] [PubMed] 
16. De Franceschi, L.; Iolascon, A.; Taher, A.; Cappellini, M.D. Clinical management of iron deficiency anemia in adults: Systemic review on advances in diagnosis and treatment. Eur. J. Intern. Med. 2017, 42, 16-23. [CrossRef] [PubMed]

17. Muñoz, M.; Gómez-Ramírez, S.; Besser, M.; Pavia, J.; Gomollon, F.; Liumbruno, G.M.; Bhandari, S.; Cladellas, M.; Shander, A.; Auerbach, M. Current misconceptions in diagnosis and management of iron deficiency. Blood Transfus. 2017, 15, 422-437. [CrossRef] [PubMed]

18. World Health Organization (WHO). Haemoglobin Concentrations for the Diagnosis of Anaemia and Assessment of Severity. WHO/NMH/NHD/MNM/11.1. Available online: http://www.who.int/vmnis/ indicators/haemoglobin.pdf (accessed on 15 April 2018).

19. Pratt, J.J.; Khan, K.S. Non-anaemic iron deficiency-A disease looking for recognition of diagnosis: A systematic review. Eur. J. Haematol. 2016, 96, 618-628. [CrossRef] [PubMed]

20. Cook, J.D. Diagnosis and management of iron-deficiency anaemia. Best Pract. Res. Clin. Haematol. 2005, 18, 319-332. [CrossRef] [PubMed]

21. Muñoz, M.; Acheson, A.G.; Auerbach, M.; Besser, M.; Habler, O.; Kehlet, H.; Liumbruno, G.M.; Lasocki, S.; Meybohm, P.; Rao Baikady, R.; et al. International consensus statement on the peri-operative management of anaemia and iron deficiency. Anaesthesia 2017, 72, 233-247. [CrossRef] [PubMed]

22. Walters, G.O.; Miller, F.M.; Worwood, M. Serum ferritin concentration and iron stores in normal subjects. J. Clin. Pathol. 1973, 26, 770-772. [CrossRef] [PubMed]

23. Barni, S.; Gascon, P.; Petrelli, F.; Garcia-Erce, J.A.; Pedrazzoli, P.; Rosti, G.; Giordano, G.; Mafodda, A.; Munoz, M. Position paper on management of iron deficiency in adult cancer patients. Expert Rev. Hematol. 2017, 10, 685-695. [CrossRef] [PubMed]

24. Muñoz, M.; Gómez-Ramírez, S.; Bhandari, S. The safety of available treatment options for iron-deficiency anemia. Expert Opin. Drug Saf. 2018, 17, 149-159. [CrossRef] [PubMed]

25. Tolkien, Z.; Stecher, L.; Mander, A.P.; Pereira, D.I.; Powell, J.J. Ferrous sulfate supplementation causes significant gastrointestinal side-effects in adults: A systematic review and meta-analysis. PLoS ONE 2015, 10, e0117383. [CrossRef] [PubMed]

26. Cancelo-Hidalgo, M.J.; Castelo-Branco, C.; Palacios, S.; Haya-Palazuelos, J.; Ciria-Recasens, M.; Manasanch, J.; Perez-Edo, L. Tolerability of different oral iron supplements: A systematic review. Curr. Med. Res. Opin. 2013, 29, 291-303. [CrossRef] [PubMed]

27. Moretti, D.; Goede, J.S.; Zeder, C.; Jiskra, M.; Chatzinakou, V.; Tjalsma, H.; Melse-Boonstra, A.; Brittenham, G.; Swinkels, D.W.; Zimmermann, M.B. Oral iron supplements increase hepcidin and decrease iron absorption from daily or twice-daily doses in iron-depleted young women. Blood 2015, 126, 1981-1989. [CrossRef] [PubMed]

28. Stoffel, N.U.; Cercamondi, C.I.; Brittenham, G.; Zeder, C.; Geurts-Moespot, A.J.; Swinkels, D.W.; Moretti, D.; Zimmermann, M.B. Iron absorption from oral iron supplements given on consecutive versus alternate days and as single morning doses versus twice-daily split dosing in iron-depleted women: Two open-label, randomised controlled trials. Lancet Haematol. 2017, 4, e524-e533. [CrossRef]

29. Rimon, E.; Kagansky, N.; Kagansky, M.; Mechnick, L.; Mashiah, T.; Namir, M.; Levy, S. Are we giving too much iron? Low-dose iron therapy is effective in octogenarians. Am. J. Med. 2005, 118, 1142-1147. [CrossRef] [PubMed]

30. European Medicines Agency. New Recommendations to Manage Risk of Allergic Reactions with Intravenous Iron Containing Medicines. EMA/579491/2013. Available online: http:/ /www.ema.europa.eu/docs/en_ GB/document_library/Referrals_document/IV_iron_31/WC500151308.pdf (accessed on 18 July 2018).

31. Leal-Noval, S.R.; Muñoz, M.; Asuero, M.; Contreras, E.; Garcia-Erce, J.A.; Llau, J.V.; Moral, V.; Paramo, J.A.; Quintana, M. Spanish Expert Panel on Alternatives to Allogeneic Blood T Spanish Consensus Statement on alternatives to allogeneic blood transfusion: The 2013 update of the "Seville Document". Blood Transfus. 2013, 11, 585-610. [CrossRef] [PubMed]

32. Franchini, M.; Marano, G.; Mengoli, C.; Pupella, S.; Vaglio, S.; Munoz, M.; Liumbruno, G.M. Red blood cell transfusion policy: A critical literature review. Blood Transfus. 2017, 15, 307-317. [CrossRef] [PubMed]

33. Carson, J.L.; Guyatt, G.; Heddle, N.M.; Grossman, B.J.; Cohn, C.S.; Fung, M.K.; Gernsheimer, T.; Holcomb, J.B.; Kaplan, L.J.; Katz, L.M.; et al. Clinical Practice Guidelines From the AABB: Red Blood Cell Transfusion Thresholds and Storage. JAMA 2016, 316, 2025-2035. [CrossRef] [PubMed] 
34. Vaglio, S.; Gentili, S.; Marano, G.; Pupella, S.; Rafanelli, D.; Biancofiore, G.; Antonioli, P.; Velati, C.; Liumbruno, G.M. The Italian Regulatory Guidelines for the implementation of Patient Blood Management. Blood Transfus. 2017, 15, 325-328. [CrossRef] [PubMed]

35. Girelli, D.; Ugolini, S.; Busti, F.; Marchi, G.; Castagna, A. Modern iron replacement therapy: Clinical and pathophysiological insights. Int. J. Hematol. 2018, 107, 16-30. [CrossRef] [PubMed]

36. Kis, L.; Szuts, A.; Otomo, N.; Szabo-Rvevz Deli, M.A. The Potential of sucrose esters to be used as oral absorption enhacers. Sci. Pharm. 2010, 78, 716. [CrossRef]

37. Kis, L.; Hellinger, E.; Pilbat, A.M.; Kittel, A.; Torok, Z.; Furedi, A.; Szakacs, G.; Veszelka, S.; Sipos, P.; Ozsvari, B.; et al. Sucrose esters increase drug penetration, but do not inhibit p-glycoprotein in Caco-2 intestinal epithelial cells. J. Pharm. Sci. 2014, 103, 3107-3119. [CrossRef] [PubMed]

38. Takaishi, N.; Satsu, H.; Shimizu, M. Enhanced daunomycin accumulation in human intestinal Caco-2 cells from non-ionic food emulsifiers unrelated to the p-glycoprotein inhibitory mechanism. Biosci. Biotechnol. Biochem. 2006, 70, 2703-2711. [CrossRef] [PubMed]

39. Quintanar-Guerrero, D.; Ganem-Quintanar, A.; Allemann, E.; Fessi, H.; Doelker, E. Influence of the stabilizer coating layer on the purification and freeze-drying of poly(D,L-lactic acid) nanoparticles prepared by an emulsion-diffusion technique. J. Microencapsul. 1998, 15, 107-119. [CrossRef] [PubMed]

40. Fabiano, A.; Brilli, E.; Fogli, S.; Beconcini, D.; Carpi, S.; Tarantino, G.; Zambito, Y. Sucrosomial ${ }^{\circledR}$ iron absorption studied by in vitro and ex-vivo models. Eur. J. Pharm. Sci. 2018, 111, 425-431. [CrossRef] [PubMed]

41. Brilli, E.; Romano, A.; Fabiano, A.; Zambito, Y.; Di Raimondo, F.; Tarantino, G. Sucrosomial ${ }^{\circledR}$ technology is able to promote ferric iron absorption: Pre-clinical and clinical evidences. Blood 2016, 128, 3618.

42. Fabiano, A.; Brilli, E.; Mattii, L.; Testai, L.; Moscato, S.; Citi, V.; Tarantino, G.; Zambito, Y. Ex vivo and in vivo study of Sucrosomial ${ }^{\circledR}$ iron intestinal absorption and bioavailability. Int. J. Mol. Sci. 2018, 19, 2722. [CrossRef] [PubMed]

43. Fievez, V.; Plapied, L.; Plaideau, C.; Legendre, D.; des Rieux, A.; Pourcelle, V.; Freichels, H.; Jerome, C.; Marchand, J.; Preat, V.; et al. In vitro identification of targeting ligands of human M cells by phage display. Int. J. Pharm. 2010, 394, 35-42. [CrossRef] [PubMed]

44. Mabbott, N.A.; Donaldson, D.S.; Ohno, H.; Williams, I.R.; Mahajan, A. Microfold (M) cells: Important immunosurveillance posts in the intestinal epithelium. Mucosal Immunol. 2013, 6, 666-677. [CrossRef] [PubMed]

45. Tarantino, G.; Brilli, E.; Zambito, Y.; Giordano, G.; Equitani, F. Sucrosomial ${ }^{\circledR}$ iron: A new highly bioavailable oral iron supplement. Blood 2015, 126, 4561-4562.

46. Starzynski, R.; Szudzik, M.; Staron, R.; Jonczy, A.; Smuda, E.; Pieszka, M.; Kamyczek, M.; Lipinski, P. Comparison of the therapeutical potential of oral Sucrosomial ${ }^{\circledR}$ iron and parenteral iron dextran supplementations in neonatal iron deficiency anemia in pigs. Am. J. Hematol. 2017, 92, E286.

47. Asperti, A.; Gryzik, M.; Brilli, E.; Castagna, A.; Corbella, M.; Gottardo, R.; Girelli, D.; Tarantino, G.; Arosio, P.; Poli, M. Sucrosomial ${ }^{\circledR}$ iron supplementation in mice: Effects on blood parameters, hepcidin, and inflammation. Nutrients 2018, 10, 1349. [CrossRef] [PubMed]

48. Elli, L.; Ferretti, F.; Branchi, F.; Tomba, C.; Lombardo, V.; Scricciolo, A.; Doneda, L.; Roncoroni, L. Sucrosomial ${ }^{\circledR}$ iron supplementation in anemic patients with celiac disease not tolerating oral ferrous sulfate: A prospective study. Nutrients 2018, 10, 330. [CrossRef] [PubMed]

49. Ciudin, A.; Simo-Servat, O.; Balibrea, J.M.; Vilallonga, R.; Hernandez, C.; Simo, R.; Mesa, J. Response to oral Sucrosomial ${ }^{\circledR}$ iron supplementation in patients undergoing bariatric surgery. The BARI-FER study. Endocrinol. Diabetes Nutr. 2018, 65, 17-20. [CrossRef] [PubMed]

50. Pisani, A.; Riccio, E.; Sabbatini, M.; Andreucci, M.; Del Rio, A.; Visciano, B. Effect of oral liposomal iron versus intravenous iron for treatment of iron deficiency anaemia in CKD patients: A randomized trial. Nephrol. Dial. Transplant. 2015, 30, 645-652. [CrossRef] [PubMed]

51. Mafodda, A.; Giuffrida, D.; Prestifilippo, A.; Azzarello, D.; Giannicola, R.; Mare, M.; Maisano, R. Oral Sucrosomial ${ }^{\circledR}$ iron versus intravenous iron in anemic cancer patients without iron deficiency receiving darbepoetin alfa: A pilot study. Support. Care Cancer 2017, 25, 2779-2786. [CrossRef] [PubMed]

52. Capra, A.P.; Ferro, E.; Cannavò, L.; La Rosa, M.A.; Zirilli, G. A child with severe iron-deficiency anemia and a complex TMPRSS6 genotype. Hematology 2017, 22, 559-564. [CrossRef] [PubMed] 
53. Brilli, E.; Barnadas, R.; Camacho, M.; Giordano, G.; Tarantino, G. Sucrosomial ${ }^{\circledR}$ Iron Absorption Involves M Cells Interaction. In Proceedings of the European Iron Club Annual Meeting, Zürich, Switzerland, 8-11 February 2018; p. 51.

54. Rishi, G.; Subramaniam, V.N. The liver in regulation of iron homeostasis. Am. J. Physiol. Gastrointest. Liver Physiol. 2017, 313, G157-G165. [CrossRef] [PubMed]

55. Ganz, T. Hepcidin, a key regulator of iron metabolism and mediator of anemia of inflammation. Blood 2003, 102, 783-788. [CrossRef] [PubMed]

56. Toblli, J.E.; Cao, G.; Olivieri, L.; Angerosa, M. Comparative study of gastrointestinal tract and liver toxicity of ferrous sulfate, iron amino chelate and iron polymaltose complex in normal rats. Pharmacology 2008, 82, 127-137. [CrossRef] [PubMed]

57. Wu, Z.; Nakanishi, H. Phosphatidylserine-containing liposomes: Potential pharmacological interventions against inflammatory and immune diseases through the production of prostaglandin $\mathrm{E}(2)$ after uptake by myeloid derived phagocytes. Arch. Immunol. Ther. Exp. 2011, 59, 195-201. [CrossRef] [PubMed]

58. Daru, J.; Zamora, J.; Fernandez-Felix, B.M.; Vogel, J.; Oladapo, O.T.; Morisaki, N.; Tuncalp, O.; Torloni, M.R.; Mittal, S.; Jayaratne, K.; et al. Risk of maternal mortality in women with severe anaemia during pregnancy and postpartum: A multilevel analysis. Lancet Glob. Health 2018, 6, e548-e554. [CrossRef]

59. Fonseca, C.; Araujo, M.; Moniz, P.; Marques, F.; Araujo, I.; Costa, L.; Rodrigues, J.; Frade, L.; Botella, A.; Jesus, S.; et al. Prevalence and prognostic impact of anemia and iron deficiency in patients hospitalized in an internal medicine ward: The PRO-IRON study. Eur. J. Haematol. 2017, 99, 505-513. [CrossRef] [PubMed]

60. Parisi, F.; Berti, C.; Mando, C.; Martinelli, A.; Mazzali, C.; Cetin, I. Effects of different regimens of iron prophylaxis on maternal iron status and pregnancy outcome: A randomized control trial. J. Matern. Fetal Neonatal Med. 2017, 30, 1787-1792. [CrossRef] [PubMed]

61. Berardi, S.; Foltran, L.; Pascoli, I.; Pepe, A.; Salmeri, M.G.; Busato, E. Efficacy of oral Sucrosomial ${ }^{\circledR}$ iron in puerperium anemia. Exp. Rev. Hematol. 2016, 9 (Suppl. S1), 40. [CrossRef]

62. Barni, S.; Lonati, V.; Ghilardi, M.; Borgonovo, K.F.; Cabiddu, M.; Astori, A.; Tarantino, G.; Petrelli, F. Upfront use of Sucrosomial ${ }^{\circledR}$ iron prevents transfusions in cancer patients on chemotherapy. Support. Care Cancer 2017, 25 (Suppl. S2), S144-S145.

63. Locatelli, F.; Mazzaferro, S.; Yee, J. Iron Therapy Challenges for the Treatment of Nondialysis CKD Patients. Clin. J. Am. Soc. Nephrol. 2016, 11, 1269-1280. [CrossRef] [PubMed]

64. Shepshelovich, D.; Rozen-Zvi, B.; Avni, T.; Gafter, U.; Gafter-Gvili, A. Intravenous versus oral iron supplementation for the treatment of anemia in CKD: An updated systematic review and meta-analysis. Am. J. Kidney Dis. 2016, 68, 677-690. [CrossRef] [PubMed]

65. Agarwal, R.; Kusek, J.W.; Pappas, M.K. A randomized trial of intravenous and oral iron in chronic kidney disease. Kidney Int. 2015, 88, 905-914. [CrossRef] [PubMed]

66. Macdougall, I.C.; Bock, A.H.; Carrera, F.; Eckardt, K.U.; Gaillard, C.; Van Wyck, D.; Roubert, B.; Nolen, J.G.; Roger, S.D.; Investigators F-CS. FIND-CKD: A randomized trial of intravenous ferric carboxymaltose versus oral iron in patients with chronic kidney disease and iron deficiency anaemia. Nephrol. Dial. Transplant. 2014, 29, 2075-2084. [CrossRef] [PubMed]

67. Macdougall, I.C.; Bock, A.H.; Carrera, F.; Eckardt, K.U.; Gaillard, C.; Wyck, D.V.; Meier, Y.; Larroque, S.; Perrin, A.; Roger, S.D. Erythropoietic response to oral iron in patients with nondialysis-dependent chronic kidney disease in the FIND-CKD trial. Clin. Nephrol. 2017, 88, 301-310. [CrossRef] [PubMed]

68. Kalantar-Zadeh, K.; Regidor, D.L.; McAllister, C.J.; Michael, B.; Warnock, D.G. Time-dependent associations between iron and mortality in hemodialysis patients. J. Am. Soc. Nephrol. 2005, 16, 3070-3080. [CrossRef] [PubMed]

69. Darba, J.; Ascanio, M. Budget Impact Analysis of Oral Fisiogen Ferro Forte((R)) versus Intravenous Iron for the Management of Iron Deficiency in Chronic Kidney Disease in Spain. Clin. Drug Investig. 2018. [CrossRef] [PubMed]

70. Bergamaschi, G.; Markopoulos, K.; Albertini, R.; Di Sabatino, A.; Biagi, F.; Ciccocioppo, R.; Arbustini, E.; Corazza, G.R. Anemia of chronic disease and defective erythropoietin production in patients with celiac disease. Haematologica 2008, 93, 1785-1791. [CrossRef] [PubMed]

71. Lee, T.; Clavel, T.; Smirnov, K.; Schmidt, A.; Lagkouvardos, I.; Walker, A.; Lucio, M.; Michalke, B.; Schmitt-Kopplin, P.; Fedorak, R.; et al. Oral versus intravenous iron replacement therapy distinctly alters the gut microbiota and metabolome in patients with IBD. Gut 2017, 66, 863-871. [CrossRef] [PubMed] 
72. Constante, M.; Fragoso, G.; Lupien-Meilleur, J.; Calve, A.; Santos, M.M. Iron Supplements Modulate Colon Microbiota Composition and Potentiate the Protective Effects of Probiotics in Dextran Sodium Sulfate-induced Colitis. Inflamm. Bowel Dis. 2017, 23, 753-766. [CrossRef] [PubMed]

73. Stein, J.; Aksan, A.; Farrag, K.; Dignass, A.; Radeke, H.H. Management of inflammatory bowel disease-related anemia and iron deficiency with specific reference to the role of intravenous iron in current practice. Expert Opin. Pharmacother. 2017, 18, 1721-1737. [CrossRef] [PubMed]

74. Bastida, G. Efficacy and tolerability of Sucrosomial iron supplementation in IBD patients with iron deficiency anemia and intolerance to iron oral salts. Exp. Rev. Hematol. 2016, 9 (Suppl. S1), 6-8. [CrossRef]

75. Stuklov, N.I.; Basiladze, I.G.; Pivnik, A.V.; Knyazev, O.V.; Parfenov, A.I. Characteristics and modern treatment of iron deficiency syndromes in inflammatory bowel diseases. Exp. Rev. Hematol. 2018, 10 (Suppl. S1), in press.

76. Rubio-Tapia, A.; Hill, I.D.; Kelly, C.P.; Calderwood, A.H.; Murray, J.A. ACG clinical guidelines: Diagnosis and management of celiac disease. Am. J. Gastroenterol. 2013, 108, 656-676, quiz 677. [CrossRef] [PubMed]

77. Hershko, C.; Camaschella, C. How I treat unexplained refractory iron deficiency anemia. Blood 2014, 123, 326-333. [CrossRef] [PubMed]

78. Farinati, F.; Maddalo, G. Iron and/or B12 deficient anemia in autoimmune gastritis. High dose sucrosomial iron supplementation: Preliminary data of a single center experience. Exp. Rev. Hematol. 2018, 10 (Suppl. S1), in press.

79. Shipton, M.; Johal, N.; Dutta, N.; Ahmed, B.; Ammori, B.; Senapati, SP.; Akhtar, K.; Summers, L.; New, J.; Syed, A. Deficiencies of vitamin B12, folate and iron over 4 years of follow-up post-bariatric surgery [abstract]. Br. J. Surg. 2018, 105 (Suppl. S4), 28.

80. Ponikowski, P.; Voors, A.A.; Anker, S.D.; Bueno, H.; Cleland, J.G.F.; Coats, A.J.S.; Falk, V.; Gonzalez-Juanatey, J.R.; Harjola, V.P.; Jankowska, E.A.; et al. 2016 ESC Guidelines for the diagnosis and treatment of acute and chronic heart failure: The Task Force for the diagnosis and treatment of acute and chronic heart failure of the European Society of Cardiology (ESC)Developed with the special contribution of the Heart Failure Association (HFA) of the ESC. Eur. Heart J. 2016, 37, 2129-2200. [CrossRef] [PubMed]

81. Lewis, G.D.; Malhotra, R.; Hernandez, A.F.; McNulty, S.E.; Smith, A.; Felker, G.M.; Tang, W.H.W.; LaRue, S.J.; Redfield, M.M.; Semigran, M.J.; et al. Effect of Oral Iron Repletion on Exercise Capacity in Patients With Heart Failure With Reduced Ejection Fraction and Iron Deficiency: The IRONOUT HF Randomized Clinical Trial. JAMA 2017, 317, 1958-1966. [CrossRef] [PubMed]

82. Karavidas, A.; Trogkanis, E.; Farmakis, D.; Papingiotis, G.; Matzaraki, V.; Perpinia, A.; Parissis, J. Oral sucrosomial iron improves quality of life in heart failure patients with iron deficiency: A preliminary proof-of-concept study. Exp. Rev. Hematol. 2018, 10 (Suppl. S1), in press.

83. Cabrera, P.; Gómez, S.; Herrero, V.; Martín, E.; Pavía, J.; Muñoz, M. Prevalence and consequences of anaemia among patients hospitalised at the internal medicine ward: A single centre audit. In Proceedings of the 15 th European Congress of Internal Medicine, Amsterdam, The Netherlands, 2-3 September 2016.

84. Fonseca, C.; Marques, F.; Robalo Nunes, A.; Belo, A.; Brilhante, D.; Cortez, J. Prevalence of anaemia and iron deficiency in Portugal: The EMPIRE study. Intern. Med. J. 2016, 46, 470-478. [CrossRef] [PubMed]

85. Giordano, G.; Mondello, P.; Tambaro, R.; Perrotta, N.; D'Amico, F.; D'Aveta, A.; Berardi, G.; Carabellese, B.; Patriarca, A.; Corbi, G.M.; et al. Biosimilar epoetin alpha is as effective as originator epoetin-alpha plus liposomal iron (Sideral(R)), vitamin B12 and folates in patients with refractory anemia: A retrospective real-life approach. Mol. Clin. Oncol. 2015, 3, 781-784. [CrossRef] [PubMed]

86. Santini, V. Clinical use of erythropoietic stimulating agents in myelodysplastic syndromes. Oncologist 2011, 16 (Suppl. S3), 35-42. [CrossRef] [PubMed]

87. Giordano, G. Reduction of inflammatory markers with liposomal iron (Sideral®). Pre-clinical and clinical results. Exp. Rev. Hematol. 2016, 9 (Suppl. S1), S17. [CrossRef]

88. Giordano, G. Oral high-dose Sucrosomial ${ }^{\circledR}$ Iron vs. intravenous iron in sideropenic anemia intolerant/refractory to iron sulfate. Multicentric randomized study. Exp. Rev. Hematol. 2016, 9 (Suppl. S1), 15-17. [CrossRef]

89. Giordano, G.; Parente, A.; Berardi, D.; Castaldi, D.; Cinotti, M.; Vedruccio, F.; Susca, V.; Petrella, L.; Berardi, G. Effectiveness of different oral iron formulations in iron deficiency anemia due to gastrointestinal bleeding: Multicentric randomized study; European Hematology Association: Stockholm, Sweden, 2018. 
90. Muñoz, M.; Franchini, M.; Liumbruno, G.M. The post-operative management of anaemia: More efforts are needed. Blood Transfus. 2018, 16, 324-325. [CrossRef] [PubMed]

91. Scardino, M.; Di Matteo, B.; Martorelli, F.; Tanzi, D.; Kon, E.; D'Amato, T. Improved patient blood management and cost saving in hip replacement surgery through the implementation of pre-operative Sucrosomial $^{\circledR}$ iron supplementation: A quality improvement assessment study. Int. Orthop. 2018, 1-8. [Epub ahead of print]. [CrossRef] [PubMed]

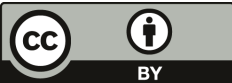

(C) 2018 by the authors. Licensee MDPI, Basel, Switzerland. This article is an open access article distributed under the terms and conditions of the Creative Commons Attribution (CC BY) license (http://creativecommons.org/licenses/by/4.0/). 
Review

\title{
Iron Supplementation in Suckling Piglets: An Ostensibly Easy Therapy of Neonatal Iron Deficiency Anemia
}

\author{
Mateusz Szudzik ${ }^{1}$, Rafał R. Starzyński ${ }^{1}$, Aneta Jończy ${ }^{1}$, Rafał Mazgaj ${ }^{1}$, \\ Małgorzata Lenartowicz ${ }^{2}$ and Paweł Lipiński ${ }^{1,3, *}$ \\ 1 Department of Molecular Biology, Institute of Genetics and Animal Breeding, Polish Academy of Sciences, \\ Jastrzębiec, 05-552 Magdalenka, Poland; m.szudzik@ighz.pl (M.S.); r.starzynski@ighz.pl (R.R.S.); \\ a.jonczy@ighz.pl (A.J.); r.mazgaj@ighz.pl (R.M.) \\ 2 Department of Genetics and Evolution, Institute of Zoology, Jagiellonian University, Gronostajowa 9, \\ 30-387 Kraków, Poland; malgorzata.lenartowicz@gmail.com \\ 3 Department of Genetics and Animal Breeding, Poznan University of Life Sciences, Wołyńska 33, \\ 60-637 Poznań, Poland \\ * Correspondence: p.lipinski@ighz.pl; Tel.: +48-22-736-7046
}

Received: 9 October 2018; Accepted: 19 November 2018; Published: 22 November 2018

\begin{abstract}
In pigs, iron deficiency anemia (IDA) is the most prevalent deficiency disorder during the early postnatal period, frequently developing into a serious illness. On the other hand, in humans, only low-birth-weight infants, including premature infants, are especially susceptible to developing IDA. In both human and pig neonates, the initial cause of IDA is low birth iron stores. In piglets this shortage of stored iron results mainly from genetic selection over the past few decades for large litter sizes and high birth weights. As a consequence, pregnant sows cannot provide a sufficient amount of iron to the increasing number of developing fetuses. Supplementation with iron is a common practice for the treatment of IDA in piglets. For decades, the preferred procedure for delivering iron supplements during early life stages has been through the intramuscular injection of a large amount of iron dextran. However, this relatively simple therapy, which in general, efficiently corrects IDA, may generate toxic effects, and by inducing hepcidin expression, may decrease bioavailability of supplemental iron. New iron supplements are considered herein with the aim to combine the improvement of hematological status, blunting of hepcidin expression, and minimizing the toxicity of the administered iron. We propose that iron-deficient piglets constitute a convenient animal model for performing pre-clinical studies with iron supplements.
\end{abstract}

Keywords: hepcidin; iron deficiency anemia; iron dextran; neonatal period; pig; supplementation

\section{Iron Deficiency Anemia (IDA) in Suckling Piglets}

Iron deficiency is a very common condition, which is widespread in the human population [1]. In humans, individuals at increased risk of developing iron deficiency are young children, adolescents, and postpartum women. There is evidence in humans that iron deficiency at birth is relatively rare with the exception of low birth-weight-infants, including premature infants [2]. Pigs (Sus scrofa domestica) are the only mammalian species, in which neonatal iron deficiency anemia (IDA) commonly occurs, the most serious consequence of iron deficiency [3-5]. This disorder affects piglets of all breeds but its outcome is particularly severe in animals of high performance breeds. The occurrence of IDA in suckling piglets has been known for long time: The first case of anemia in piglets has been reported at the end of the 19th century [6], then in 1924 a causal link had been made between iron deficiency and the appearance of anemia [7]. Finally, 5 years later it was shown that anemia may be prevented 
by the administration to piglets of iron salts $\left(\mathrm{FeSO}_{4}\right)$ [8]. The problem of neonatal IDA in piglets was first comprehensively drawn to the attention of the scientific community by Venn et al. in 1947 [3]. Thereafter, various aspects of IDA in piglets such as etiology, clinical aspects, diagnosis, prophylaxis and treatment have been the subject of several reviews [3-5,9-11].

IDA in suckling piglets is typically hypochromic, microcytic anemia characterized by a decrease in red blood cell (RBC) parameters such as mean corpuscular volume (MCV) and mean corpuscular hemoglobin concentration (MCHC). However, it is worth noting that physiological reference ranges for RBC indices of piglets in the early postnatal period (from birth to weaning, i.e., usually up to day 28 postpartum) commonly used to diagnose IDA are difficult to estimate. In swine production, iron supplementation of piglets is a routine and mandatory practice performed with the use of various iron supplements, administered by various routes, at differential doses of supplemental iron, and following various time schedules (reviewed in $[9,10]$ ). It is not surprising therefore that RBC parameters strongly vary in piglets depending on iron treatment protocols. On the other hand, without iron supplementation piglets rapidly develop IDA, and thus, by definition, RBC values measured in these animals (most frequently when pigs are used for research purposes) cannot be considered as normal ones. Nevertheless, there is a general consensus regarding hemoglobin concentration to set the cut-off level of anemia in suckling piglets at $8 \mathrm{~g} / \mathrm{dL}[12,13]$, although some authors propose higher values reaching $11-13 \mathrm{~g} / \mathrm{dL}$ [14]. It is clear from many studies [15-20] including our own [15-17] that such a level of $\mathrm{Hgb}$ is reachable only in piglets supplemented with very high doses of iron. Without iron supplementation IDA in piglets appears few days after birth. 1-day old piglets are usually not anemic showing Hgb concentration slightly above $8 \mathrm{~g} / \mathrm{dL}[12,15]$. It is important to underline that most iron supplementation therapies start on the 2nd or 3rd day after birth, therefore, this initial, sensu stricto normal $\mathrm{Hgb}$ value is a convenient starting point for testing the efficacy of new supplementation procedures in both veterinary practice and research. On day $3, \mathrm{Hgb}$ concentration in non-supplemented piglets drops to the level of 6-7 g/dL and at weaning is drastically decreased even down to $4-5 \mathrm{~g} / \mathrm{dL}$, which indicates a state of extreme anemia $[15,16,21]$. Due to the efficient supplementation widely used in suckling piglets (see chapter below), anemia was practically eliminated from pig husbandry, however, in research, anemic piglets still constitute an indispensable reference group for exploring the molecular background of systemic iron metabolism in neonatal and early postnatal periods.

\section{Etiology of IDA in Suckling Piglets}

Low iron stores. In most mammals iron accumulated during pregnancy in the fetal liver is the main source of this microelement for erythropoiesis and other iron-dependent processes in the neonatal period [22]. For example, infants born full term with an appropriate weight for gestation have iron stores that are adequate for their development during about half a year after birth [22]. In contrast, piglets are born with very limited iron reserves estimated at $50 \mathrm{mg}$, which are considered the lowest among mammalian newborns [3,4]. This reduced hepatic iron reservoir in pig neonates is reminiscent of that reported in low-birth-weight and preterm infants, congruent with the fact that the birth iron stores are generated primarily during the last period of gestation (last 10 weeks in pigs [23] and third trimester in humans [22]). In both humans and pigs, low iron stores are associated with increased risk of neonatal iron deficiency anemia. Iron content in the piglet at birth covers the requirement for only the first 3-4 days of postnatal life. Indeed, in non-supplemented piglets on day 4 after birth hepatic iron content is decreased by about 5 -fold compared to day 1 , and on day 7 is barely detectable [15]. In this context, the question why iron stores in normally born piglets are strikingly low arises. It is conceivable to propose that the main reason is the physiological inability of pregnant sow to meet iron demand for the greater number of fetuses. Unceasing improvement of the reproductive potential (including increasing litter size), is one of the objectives of modern pig husbandry. According to the Annual Report of the Polish Pig Breeders and Producers Association "POLSUS" the number of alive born piglets in two main Polish breeds (Polish Large White and Polish Landrace), increased by 0.5 and 0.7 between 2008 and 2017, respectively [24]. Such performance, which is an effect of intensive selection for 
reproductive traits, largely exceeds the physiological potential of sows to provide a sufficient amount of iron to their fetuses. Interestingly, wild boars (ancestors of domesticated pigs still present in the wild) having about half as many piglets in the litter as domestic pigs [25], seem to be not affected by neonatal IDA. Apparently, pigs domesticated from wild boars in Europe and Asia about 10,000 years ago [26] have not been able to evolve quickly enough to deal with high breeding pressure exerted only since the 19th century.

A second plausible explanation of deficient iron stores in pig fetuses and neonates is a low efficiency of iron transfer across the placenta. In this context, it is worth noting that iron supplementation of sows at various stages of pregnancy, using various iron supplements administered orally or parenterally has no significant impact on the improvement of the iron status of newborn piglets, and thus does not prevent suckling animals from becoming anemic (reviewed in [4]). The fact that despite iron abundance in pregnant sows, the iron status of their offspring still remains compromised, strongly suggests an insufficiency of the molecular machinery involved in iron transfer from mother to fetus. Obviously, this issue deserves further investigation. Our knowledge about placental iron trafficking and its regulation in pigs is poor. Surprisingly, even in mice and humans (in which iron metabolism is best studied among mammalian species) the placenta is considered the forgotten organ of iron transport, and regulatory mechanisms of iron transport from maternal to fetal circulation are only now emerging [27]. Moreover, when comparing placental iron transfer in various species, we should be aware of structural differences between human/rodent and pig placenta (hemochorial vs. epitheliorial type) because they may imply different regulations of iron trafficking across the placenta.

Low iron content in the sow's milk. Low iron concentration in the sow's colostrum and milk is commonly considered as risk factor in developing IDA in piglets [3-5]. Indeed, sow's milk is a very poor source of iron containing about half as much of this microelement as human milk. Iron content of sow's milk according to various reports ranges from 1.4-2.6 [28] to 0.2-4 mg/L [29]. Assuming that the daily milk intake per piglet is $0.5-1 \mathrm{~L}$ and that the absorption rate of milk iron is $60-90 \%$, the piglet absorbs approximately $1 \mathrm{mg}$ iron per day, an amount that is far below their daily requirement (about $7 \mathrm{mg}$ ) [3,30]. Importantly, attempts to increase the iron concentration in sow's milk by giving them high iron diets or by the injection of large amounts of iron dextran during late gestation and lactation have not been successful [3,31].

Immaturity of molecular iron absorption mechanisms? Immaturity of the molecular machinery involved in intestinal iron absorption and its regulation in newborn piglets have been claimed as a factor contributing to the development of IDA [15]. Although our understanding of processes of dietary iron uptake in the neonatal period of mammalian development is poor, there are strong indications from studies on rodents that mechanisms of iron absorption clearly established in adult mammals are not fully functional during early life [32-34]. In adults, iron absorption occurs mainly in the proximal part of duodenum. At the cellular level, iron is absorbed through the polarized simple columnar epithelial cells located at the mid to upper villus. The passage of non-heme iron through the absorptive enterocyte from the gut lumen into the portal circulation involves two major steps: (1) Transfer across the enterocyte brush border (apical) membrane by the iron transporter-divalent metal-ion transporter 1 (DMT1) [35], a process preceded by the enzymatic reduction of the dietary ferric iron by duodenal cytochrome $b$, (DcytB, an apical membrane ascorbate-dependent ferrireductase) [36]; (2) export from the enterocyte across the basolateral membrane into intestinal capillaries via the sole iron exporter known to date-ferroportin [37]; the trans-membrane ferroxidase, hephaestin, colocalizes with ferroportin in the basolateral membrane and oxidizes the exported ferrous iron back to ferric iron, which is then complexed to transferrin [38]. Both, DcytB and hephaestin seem not to be indispensable for dietary iron absorption at least in mice, as animals with targeted disruption of the Cybrd1 gene coding for DcytB show normal iron phenotypes [39], and in sla mice carrying a mutation in the heph gene, the transport of iron into the circulation is only diminished [38]. The efficiency of iron absorption is normally regulated in accord with iron status of the organism by hepcidin, a 25 amino acid peptide 
hormone released in to the blood plasma mainly by hepatocytes that negatively regulates the efflux of absorbed iron from enterocytes in the duodenum, the release of recycled iron from macrophages as well as the release of iron stored in hepatocytes [40]. This well-documented biological activity of hepcidin relies on its binding to ferroportin, which leads to its degradation [41]. Hepcidin is induced upon iron loading to decrease the iron level and in this way limits iron toxicity, whereas during iron deficiency there is increased erythropoietic activity and hypoxia, therefore, hepcidin expression is down-regulated to increase iron availability [40]. Recent studies demonstrated that the rate of dietary iron uptake is also locally controlled in absorptive enterocytes and that hepcidin-mediated regulation alone is insufficient to reduce iron absorption $[42,43]$. These studies showed the molecular mechanism of functioning of so called "mucosal block" [44], a concept of the regulation of iron absorption by duodenal ferritin, protein with an enormous capacity to store iron (up to $4500 \mathrm{Fe}$ atoms/molecule [45]), which determines the level of basolateral iron efflux from the duodenal epithelium. Local control of duodenal iron absorption also involves transcriptional and post-transcriptional regulation of genes involved in iron absorption by hypoxia inducible factor 2 [46] and iron regulatory protein 1 [43], respectively. Recent advances in the understanding of this gut regulation have been detailed elsewhere [47]. In Figure 1, we provide an outline of duodenal non-heme iron absorption and its regulation.

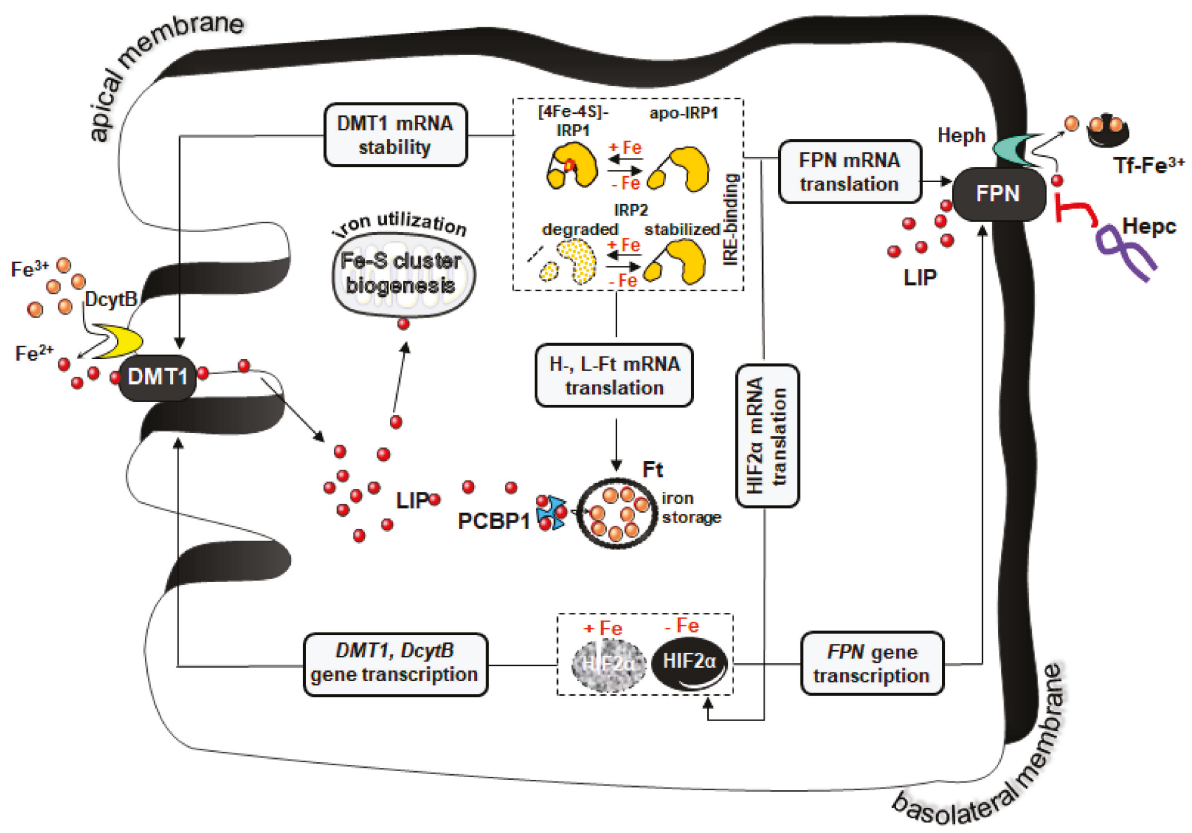

Figure 1. Intestinal uptake of non-heme iron and its regulation. Non-heme iron absorption occurs mainly in duodenal enterocytes. The first step in the transport of iron across the apical membrane of enterocytes is ferric $\left(\mathrm{Fe}^{3+}\right)$ to ferrous $\left(\mathrm{Fe}^{2+}\right)$ iron reduction, catalyzed by the membrane-associated ferrireductase duodenal cytochrome B (DcytB). Ferrous iron is subsequently transported into the enterocyte via the divalent metal transporter 1 (DMT1)-dependent pathway. After crossing the apical membrane, iron enters so called labile iron pool (LIP) in the cytosol and is subsequently used for cellular needs (e.g., for iron-sulfur cluster biogenesis in mitochondria), stored inside the cell in ferritin (Ft, which probably requires the chaperone PCBP1 (poly $(\mathrm{rC})$ binding protein 1 ) to delivers iron to $\mathrm{Ft}$ ), or exported into the circulation by the iron exporter ferroportin (FPN) present on the basolateral membrane. Iron export from enterocytes also requires hephaestin (Heph), a multi-copper oxidase, which oxidizes $\mathrm{Fe}^{2+}$ to $\mathrm{Fe}^{3+}$, prior to iron binding by transferrin (Tf) in the blood. The expression of genes involved in iron absorption is regulated intracellularly at the level of transcription by hypoxia 
inducible factor 2 alpha (HIF2 $\alpha$ ) and post-transcriptionally via iron regulatory proteins (IRP1 and IRP2). Under iron-deficient conditions, stabilization of HIF2 $\alpha$ protein leads to the transcriptional up-regulation of $D c y t B, D m t 1$ and Fpn genes. In contrast, in iron replete enterocytes HIF $2 \alpha$ undergoes accelerated proteosomal degradation resulting in the decrease of its transcriptional activity. At low intracellular iron concentrations, IRPs bind to specific iron regulatory elements (IREs) present in the $5^{\prime}$-UTR mRNAs encoding ferritin subunits ( $\mathrm{H}$ - and L-Ft) or FPN mRNAs and block their translation. On the other hand, direct interactions between IRPs and several IRE motifs in the $3^{\prime}$-UTR DMT1 mRNA stabilize this transcript. The converse regulation of Ft subunits, FPN and DMT1 synthesis, being a consequence of the lack of binding of IRPs to IRE, occurs in enterocytes with high iron level. Importantly, the presence of IRE has also been identified in HIF2 $\alpha$ mRNA. Binding of IRP1 (which under iron deficient conditions gains the ability to recognize IREs with high affinity) to the unique IRE in the $5^{\prime}$-UTR of HIF $2 \alpha$ mRNA blocks its translation. Iron trafficking across the enterocyte is also controlled extracellularly by the systemic iron regulatory hormone hepcidin (Hepc). Hepcidin can bind to FPN, causing its internalization and degradation, hence decreasing iron export from enterocytes into the blood plasma.

It seems that in neonatal piglets fed almost an exclusive milk diet (mean daily intake of solid feed by piglets during two first weeks after birth is only slightly above $3 \mathrm{~g}$ [17]) and in infants with exclusive breast feeding, this complex molecular machinery described above is not mandatory for iron absorption. Lactoferrin, a major iron-binding glycoprotein abundantly present in milk, retaining bound iron down to a $\mathrm{pH}$ of $~ 3.5$ [48], was postulated to be involved in intestinal iron absorption in suckling newborn animals and breast-fed infants. The identification of a specific receptor for lactoferrin (LfR) in the duodenum of newborn infants [49] and suckling piglets [50] is evidence that the Lf-LfR pathway is involved in iron absorption during early life. In this context, low duodenal expression of the two major iron transporters DMT1 and Fpn reported in pig neonates [15] may only impair absorption of iron contained in the solid diet and/or derived from dietary iron supplements and not Lf-bound iron, which uses an independent pathway to cross intestinal barrier.

High iron requirements in suckling piglets. Iron supply from natural sources such as hepatic iron stores and iron contained in the sow's milk cannot balance the extremely high iron demand in suckling piglets. According to various authors their daily iron requirements are estimated at the level between 7 and $16 \mathrm{mg}$ [20,30], which largely exceeds the amount of iron provided from natural sources. It is worth noting that upper reference values have been established for piglets with daily body weight gain of $250 \mathrm{~g}$ and more [20]. Indeed, high growth intensity of piglets in early postnatal life is a crucial factor determining this huge iron need. Piglets increase their body mass 2-, 4- and 10-fold within first week, 3 and 6 weeks after birth, respectively being the most rapidly growing animals among livestock species [5]. This impressive growth rate is accompanied by the expansion of blood volume, high erythropoietic activity resulting in an increased number of red blood cells that require an enormous amount of iron to maintain adequate hemoglobin level. Of note, a major part ( 70\%) of body iron is present associated with hemoglobin of developing erythroblasts in bone marrow and mature circulating erythrocytes.

\section{Iron Supplementation of Piglets}

\subsection{Intramuscular Supplementation with Iron Dextran (FeDex)—A Gold Standard?}

To counteract the development of anemia in young pigs, an exogenous iron source must be administered. Parenteral iron supplementation of piglets by intramuscular injection of $200 \mathrm{mg}$ Fe in the form of FeDex (high molecular weight iron complex composed of a polynuclear iron hydroxide with dextran (polyisomaltose)) within 2-3 days after birth is routinely practiced in pig breeding and commonly considered by breeders and veterinary surgeons a golden standard for the prevention/treatment of IDA in suckling piglets [9]. Multiple variants of this method (in terms of number of injections, their time schedules and the amount of injected FeDex) have been proved 
to be generally beneficial in correcting iron deficiency in newborn piglets $[15,18,20,51]$. However, it seems that high parenteral intake of supplemental iron given in a single dose or even twice is not efficiently metabolized and may perturb the tight control of systemic iron homeostasis. First, excess of iron introduced to the organism may strongly exceed its capacity to store and detoxify this biologically active metal with ferritin. It is worth noting that after intramuscular injection of FeDex, this complex enters macrophages of the reticuloendothelial system (RES) via lymphatic circulation [52]. In macrophages, iron released from FeDex is either stored in ferritin [53] or redirected from these cells into the circulation by ferroportin where it is bound to transferrin and transported mainly to the erythropoietic compartment. In piglets supplemented with large amounts of FeDex, iron has been detected in Browicz-Kupffer cells (hepatic macrophages) by Prussian blue staining in the form of massive iron deposits [15]. Moreover, ferritin in the liver of these piglets has been found to be fully saturated with iron pointing to heavy pathological iron overload [15]. When in excess, iron is toxic because it generates through the Fenton reaction, the hydroxyl radical that reacts nonspecifically with biological molecules. Accordingly, piglets excessively loaded with FeDex showed increased hepatic levels of 8-oxo-7,8-dihydro-2'-deoxyguanosine (8-oxodG), an oxidatively modified nucleoside in DNA, a biomarker of iron-induced oxidative stress $[15,54]$. These piglets showed also elevated levels of 8-isoprostane, a biomarker providing a reliable measure of oxidative stress in whole organism [55]. It is not surprising therefore that an acute toxicity of the overdose of FeDex has been reported in antioxidant-deficient piglets [56]. Sporadically, toxicity of FeDex given to piglets may be also assigned to dextran (sugar part of FeDex)-induced anaphylactic reactions [57].

Second, applying FeDex therapy to piglets also implies the necessity for caution due to the possibility of excessive induction of hepcidin expression by supplemental iron, and in consequence, inhibition of iron absorption from the diet as well as iron release from macrophages (utilization of iron freed from FeDex). In humans, the incidence of such risk has been clearly demonstrated in iron-supplemented women showing significantly decreased fractional iron absorption, which was associated with acute increase in hepcidin [58]. In our studies, we have performed for the first time a comprehensive analysis of hepcidin expression (we measured the abundance of hepcidin mRNA in the liver as well as hepcidin concentration in blood plasma and urine) in suckling piglets supplemented with FeDex and in anemic, non-supplemented animals [16,17,59]. Administration of large amounts of iron to piglets resulted in a significant increase in hepcidin expression, which appeared immediately (only one day) after the injection of FeDex and was sustained at high levels up to weaning (day 28 after birth). In contrast, in anemic piglets hepcidin was hardly detectable in the blood plasma [16,59]. Our observation suggests that in piglets abundantly supplemented with iron, absorption of this microelement from the diet may be reduced. This could be a potentially unfavorable phenomenon especially in the second part of the early postnatal period (from day 14 following birth up to weaning), when voluntary intake of solid feed (containing usually high amounts of inorganic iron) by piglets is increased and the diet becomes a valuable source of exogenous iron. With the aim to correct iron deficiency in piglets without increasing hepcidin expression, we have proposed a modified procedure of FeDex administration, which involves double injection of a carefully calculated, reduced amount FeDex on day 3 and 14 after birth. Although this procedure has been shown to achieve the objectives, its application in the practice is questionable due to labor considerations at farms [59].

\subsection{Oral Supplementation}

"Supplementation" with soil iron. Rooting is a natural behavior for pigs frequently used at all ages. Pigs root in the soil in different ways for different reasons including searching for food. Iron is a relatively abundant element $(20-40 \mathrm{~g} / \mathrm{kg})$ of the soil [60], which is considered a valuable source of this nutrient (mineral) for wild boar piglets living in their natural woodland habitat. In contrast, modern indoor farming systems prevent contact of piglets with soil and thus deprive them access to this source of iron. It has been suggested that in outdoor production iron supplementation of piglets occurs at least in part by ingesting this microelement from the soil [61]. However, experiments 
conducted on a large number of piglets (more than 2300 per group) clearly showed that outdoor-reared animals still need parenteral iron supplementation with FeDex, otherwise they develop anemia (Hgb level-5.1 g/dL) and show increased mortality [21]. Other studies demonstrated that environmental iron, ingested from the soil plays an essential role in maintaining correct iron status in domestic piglets during the pre-weaning period [62].

Iron supplements as feed additives. Over the years, various dietary iron supplements such as iron salts [63], iron chelates [13], carbonyl iron [64], iron polymaltose [65], and iron microparticles [66] have been used to prevent/treat IDA in piglets. Despite such huge diversity of oral iron supplements, there is a general consensus that dietary supplementation with iron is less efficient in rectifying hematological status of piglets compared with parenteral one (reviewed in [10]). On the other hand, supplementation per os, when it is based on voluntary intake of feed containing supplemental iron, it is a non-stressful, less time-consuming procedure, which avoids possible risks of iatrogenic disease transmission. However, low consumption of solid feed or drinking water by piglets during the first two weeks after birth strongly reduces the therapeutic efficiency of this strategy despite using various feeding devices and chemical attractants [17,67]. Although applying of excessive doses of supplemental iron added to the feed has been shown to improve iron status in piglets at a rate comparable to FeDex injection [67], the usefulness of this method seems to be doubtful because of strong adverse side effects observed mainly at the level of gastrointestinal tract and liver [68]. Regarding the oral route, iron can be also individually delivered to piglets in the form of a paste directly into the mouth [69]. In this case, the amount of administered iron can be tightly controlled. However, reports on the labor consumption of this procedure and its influence on the welfare of supplemented animals are controversial $[70,71]$.

Despite several limitations in oral supplementation of piglets with iron, the search is ongoing for new iron supplements characterized by high bioavailability and potentially overcoming canonical pathways of iron absorption. In some sense, heme is a good candidate for such new although already long known iron supplement. Heme, a ferrous iron protoporphyrin IX complex, is employed as a prosthetic group in diverse proteins (including hemoglobin) that participate in important biological processes [72]. On one side, dietary heme uptake has been recognized for more than 60 years [73] and many studies have since confirmed that in mammals (except from mice [74]) absorption of heme is far more efficient than that of inorganic iron [73]. Accordingly, heme iron has been successfully used as iron supplement to treat iron deficiency in humans [75,76]. On the other hand, the use of heme iron to prevent IDA in piglets has not attracted much interest from pig breeders. Nevertheless, some studies [17,66,77] including our own [17] clearly showed that supplementation of piglets based on voluntary intake of hemoglobin from the feed can rescue these animals from severe IDA (piglets maintained hemoglobin level at $8 \mathrm{~g} / \mathrm{dL}$ throughout the experimental period i.e., from day 3 to day 28 after birth) despite the reduced intake of solid feed during the first 10 days postpartum [17]. Importantly, dietary supplementation with hemoglobin promoted combating of severe IDA in piglets without inducing a disadvantageous increase in hepcidin expression [17]. We proposed that the well-known high bioavailability of heme iron may depend on a split pathway mediating the transport of heme-derived elemental iron as well as intact heme from the interior of duodenal enterocytes to the bloodstream.

The use of encapsulation technologies has been proposed not only to improve bioavailability of supplemental iron delivered by the oral route [78] but also to decrease its adverse effects in the gastrointestinal tract, due to the oxidative toxicity of ferrous iron [68]. Some of the novel oral iron supplements developed by encapsulating in various kinds of matrix inorganic and heme iron have been tested on anemic piglets and found to improve RBC indices [66,79]. Among encapsulation technologies, liposomes, bilayer phospholipid vesicles, have attracted much interest as efficient drug delivery systems [80]. In our recent studies we successfully used liposomal iron (Sideral ${ }^{\circledR}$ Pharmanutra, Pisa, Italy), a new generation iron (ferric phosphate) supplement containing phospholipids and sucrose esters of fatty acids, assuring its high bioavailability and tolerability [81]. The efficacy of this drug in correcting iron deficiency attested by the restoration of physiological hemoglobin levels has been 
proven in human and animal studies [82,83]. We show that liposomal iron given orally to suckling piglets is a suitable feed additive for the reinforcement of iron status in piglets in the critical period from birth to weaning. Oral supplementation with liposomal iron is not only as effective as the parenteral one with FeDex, but in addition it seems to be less toxic [55].

\section{Concluding Remarks}

Intramuscular administration of large amounts of FeDex to suckling piglets is long-established and commonly considered most favorable procedure used for preventing/treatment of IDA in the neonatal/early postnatal period. Here, we propose reconsidering this routine supplementation in the light of recent advances in molecular understanding of homeostatic regulation of iron in mammals [84], including mammalian neonates $[85,86]$. Our concept of optimal prophylaxis/treatment of IDA in suckling piglets is outlined in Figure 2. The main objective of iron supplementation is to meet current needs of this microelement for erythropoiesis, a physiological process consuming large amounts of iron. It seems that rebuilding of depleted hepatic iron stores of suckling piglets with supplemental iron is physiologically less important and plays a secondary role. The process of replenishment of iron reservoirs should proceed gradually and be driven by dietary iron contained in the basal feed routinely given to piglets during rearing. This approach will allow the reduction of the amount of supplemental iron administered to piglets. Lower dose iron given to piglets will primarily decrease its toxicity but will also minimize hepcidin expression and in consequence, maximize both natural iron absorption from the gut and supply of iron recovered from reticuloendothelial macrophages. Finally, when providing exogenous iron to piglets, we cannot leave aside neither the economical aspect of this procedure nor piglet welfare. In this context, oral supplementation based on voluntary intake of iron compounds added to the feed seems to be an optimal solution. However, major obstacles standing on this way are poor intake of solid feed by piglets during the first two weeks after birth, and neonatal immaturity of the piglets' absorption molecular mechanisms. For this reason, there is a need to test the therapeutic efficacy of new iron supplements such as iron nanoparticles and encapsulated iron compounds overcoming canonical pathways of iron absorption. Importantly, considering that pig is a recognized model for human nutrition $[87,88]$, we propose that piglet model of "physiological" IDA may be useful in preclinical studies for testing various iron food supplements in humans.

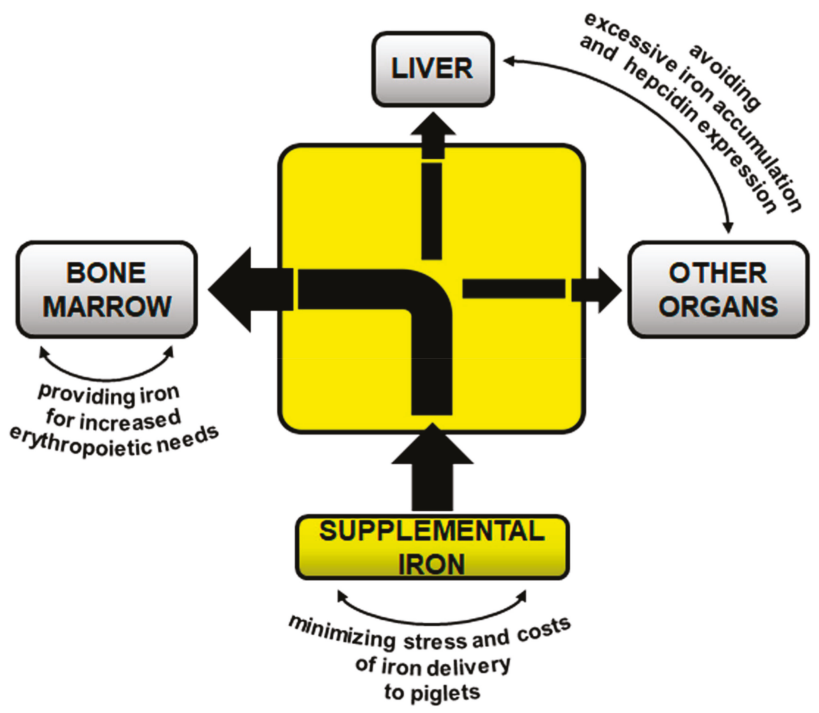

Figure 2. Main objectives of sustainable iron supplementation in suckling piglets. See description in the text for details. 
Author Contributions: Conceptualization, P.L., R.R.S., and M.S.; writing-original draft preparation, P.L.; writing—review \& editing, R.R.S., M.S., A.J., R.M., and M.L.; visualization, M.S.; project administration, R.R.S.

Funding: This work was supported by the National Science Centre, Poland (grant No. 2017/25/B/NZ9/01707).

Conflicts of Interest: Authors declare no conflict of interest with respect to this review manuscript.

\section{References}

1. Camaschella, C. New insights into iron deficiency and iron deficiency anemia. Blood Rev. 2016, 31, 225-233. [CrossRef] [PubMed]

2. Strauss, R.G. Anaemia of prematurity: Pathophysiology and treatment. Blood Rev. 2010, 24, 221-225. [CrossRef] [PubMed]

3. Venn, J.A.J.; McCance, R.A.; Widdowson, E.M. Iron metabolism in piglet anemia. J. Comp. Pathol. 1947, 5, 314-325. [CrossRef]

4. Svoboda, M.; Drabek, J. Iron deficiency in suckling piglets; ethiology, clinical aspects and diagnosis. Folia Vet. 2005, 49, 104-111.

5. Kim, J.C.; Wilcock, P.; Bedford, M.R. Iron status of piglets and impact of phytase superdosing on iron physiology: A review. Anim. Feed Sci. Technol. 2018, 235, 8-14. [CrossRef]

6. Boussingault, J.B. Du ironr contenu dans le sang et dans les aliments. Acad. Sci. Parts Rend. Acad. Sci. 1872, 74, 1353.

7. McGovan, J.P.; Crichton, A. Iron deficiency in pigs. Biochem. J. 1924, 18, 265-272. [CrossRef]

8. Hart, E.B.C.; Elvehjem, C.A.; Steenbock, H.; Bohstedt, G.; Fargo, J.M. Anemia in suckling pigs. J. Anim. Sci. 1929, 409. [CrossRef]

9. Svoboda, M.; Vaňhara, J.; Berlinská, J. Parenteral iron administration in suckling piglets—A review. Acta Vet. Brno 2017, 86, 249-261. [CrossRef]

10. Svoboda, M.; Pískova, K. Oral iron administration in suckling piglets-A review. Acta Vet. Brno 2018, 87, 77-83. [CrossRef]

11. Godyń, D.; Pieszka, M.; Lipiński, P.; Starzyński, R.R. Diagnostics of iron deficiency anaemia in piglets in the early postnatal period-A review. Anim. Sci. Pap. Rep. 2016, 34, 1-12.

12. Egeli, A.K.; Framstad, T.; Morberg, H. Clinical biochemistry, haematology and body weight in piglets. Acta Vet. Scand. 1998, 39, 381-393. [PubMed]

13. Kegley, E.B.; Spears, J.W.; Flowers, W.L.; Schoenherr, W.D. Iron methionine as a source of iron for the neonatal pig. Nutr. Res. 2002, 22, 1209-1217. [CrossRef]

14. Steinhardt, M.; Bünger, U.; Furcht, G.; Schönfelder, E. Determination of normal red blood picture values in piglets. Arch. Exp. Veterinarmed. 1982, 36, 707-719. [PubMed]

15. Lipiński, P.; Starzyński, R.R.; Canonne-Hergaux, B.; Tudek, R.; Oliński, P.; Kowalczyk, P.; Dziamam, T.; Thibaudeau, O.; Gralak, M.A.; Smuda, E.; et al. Benefits and risks of iron supplementation in anemic neonatal pigs. Am. J. Pathol. 2010, 177, 1233-1243. [CrossRef] [PubMed]

16. Staroń, R.; Van Swelm, R.P.L.; Lipiński, P.; Gajowiak, A.; Lenartowicz, M.; Bednarz, A.; Gajewska, M.; Pieszka, M.; Laarakkers, C.M.; Swinkels, D.W.; Starzyński, R.R. Urinary hepcidin levels in iron-deficient and iron-supplemented piglets correlate with hepcidin hepatic mRNA and serum levels and with body iron status. PLoS ONE 2015, 10, e0136695. [CrossRef] [PubMed]

17. Staroń, R.; Lipiński, P.; Lenartowicz, M.; Bednarz, A.; Gajowiak, A.; Smuda, E.; Krzeptowski, W.; Pieszka, M.; Korolonek, T.; Hamza, I.; et al. Dietary hemoglobin rescues young piglets from severe. iron deficiency anemia: Duodenal expression profile of genes involved in heme iron absorption. PLoS ONE 2017, 12, e0181117.

18. Egeli, A.K.; Framstad, T. An evaluation of iron-dextran supplementation in piglets administered by injection on the first, third or fourth day after birth. Res. Vet. Sci. 1999, 66, 179-184. [CrossRef] [PubMed]

19. Rincker, M.J.; Clarke, S.L.; Eisenstein, R.S.; Link, J.E.; Hill, G.M. Effects of iron supplementation on binding activity of iron regulatory proteins and the subsequent effect on growth performance and indices of hematological and mineral status of young pigs. J. Anim. Sci 2005, 83, 2137-2145. [CrossRef] [PubMed]

20. Jolliff, J.S.; Mahan, D.C. Effect of injected and dietary iron in young pigs on blood hematology and postnatal pig growth performance. J. Anim. Sci. 2011, 89, 4068-4080. [CrossRef] [PubMed]

21. Szabo, P.; Bilkei, G. Iron deficiency in outdoor pig production. J. Vet. Med. A Physiol. Pathol. Clin. Med. 2002, 49, 390-391. [CrossRef] [PubMed] 
22. Rao, R.; Georgieff, M.K. Iron in fetal and neonatal nutrition. Semin. Fetal Neonatal Med. 2007, 12, 54-63. [CrossRef] [PubMed]

23. McPherson, R.L.; Ji, F.; Wu, G.; Blanton, J.R.; Kim, S.W. Growth and compositional changes of fetal tissues in pigs. J. Anim. Sci 2004, 82, 2534-2540. [CrossRef] [PubMed]

24. Polish Pig Breeders and Producers Association "POLSUS". Performance Results Pigs. 2017, pp. 17-21. Available online: https://polsus.pl/images/photos/Wydawnictwa/Wyniki\%20Oceny/2017/ WynikiOcenyTCh2017.pdf (accessed on 22 November 2018).

25. Fernández-Llario, P.; Mateos-Quesada, P. Body size and reproductive parameters in the wild boar Sus scrofa. Acta Theriol. 1998, 43, 439-444. [CrossRef]

26. Larson, G.; Dobney, K.; Albarella, U.; Fang, M.; Matisoo-Smith, E.; Robins, J.; Lowden, S.; Finlayson, H.; Brand, T.; Willerslev, E.; et al. Worldwide phylogeography of wild boar reveals multiple centers of pig domestication. Science. 2005, 307, 1618-1621. [CrossRef] [PubMed]

27. Cao, C.; Fleming, M.D. The placenta: The forgotten essential organ of iron transport. Nutr. Rev. 2016, 74, 421-431. [CrossRef] [PubMed]

28. Brady, P.S.; Ku, P.K.; Ullrey, D.E.; Miller, E.R. Evaluation of an amino acid-iron chelate hematinic for the baby pig. J. Anim. Sci. 1978, 47, 1135-1140. [CrossRef] [PubMed]

29. Pfau, A.; Rudoplhi, K. Modelluntersuchungen zur oralen Eisensupplementierung beim Saugferkel. Zuchtungskd. 1978, 50, 227-233.

30. Braude, R.; Chamberlain, A.G.; Kotarbińska, M.; Mitchell, K.G. The metabolism of iron in piglets given labelled iron either orally or by injection. Br. J. Nutr. 1962, 16, 427-449. [CrossRef] [PubMed]

31. Pond, W.G.; Lowery, R. S.; Maner, J.H.; Looslu, J.K. Parental iron administration to sows during gestation and lactation. J. Anim. Sci. 1961, 20, 747-750. [CrossRef]

32. Leong, W.I.; Bowlus, C.L.; Tallkvist, J.; Lönnerdal, B. DMT1 and FPN1 expression during infancy: Developmental regulationof iron absorption. Am. J. Physiol. Gastrointest. Liver Physiol. 2003, 285, G1153-G1161. [CrossRef] [PubMed]

33. Leong, W.I.; Bowlus, C.L.; Tallkvist, J.; Lönnerdal, B. Iron supplementation during infancy-effects on expression of iron transporters, iron absorption, and iron utilization in rat pups. Am. J. Clin. Nutr. 2003, 8, 1203-1211. [CrossRef] [PubMed]

34. Lopez, V.; Suzuki, Y.A.; Lönnerdal, B. Ontogenic changes in lactoferrin receptor and DMT1 in mouse small intestine: Implications for iron absorption during early life. Biochem. Cell Biol. 2006, 84, 337-344.

35. Gunshin, H.; MacKenzie, B.; Berger, U.V.; Gunshin, Y.; Romero, M.F.; Boron, W.F.; Nussberger, S.; Gollan, J.L.; Hediger, M.A. Cloning and characterization of a mammalian proton-coupled metal-ion transporter. Nature 1997, 388, 482-488. [CrossRef] [PubMed]

36. McKie, A.T. The role of Dcytb in iron metabolism: An update. Biochem. Soc. Trans. 2008, 36, 1239-1241. [CrossRef] [PubMed]

37. Drakesmith, H.; Nemeth, E.; Ganz, T. Ironing out ferroportin. Cell Metab. 2015, 22, 777-787. [CrossRef] [PubMed]

38. Vulpe, C.D.; Kuo, Y.M.; Murphy, T.L.; Cowley, L.; Askwith, C.; Libina, N.; Gitschier, J.; Anderson, G.J. Hephaestin, a ceruloplasmin homologue implicated in intestinal iron transport, is defective in the sla mouse. Nat. Genet. 1999, 21, 195-199. [CrossRef] [PubMed]

39. Gunshin, H.; Starr, C.N.; Direnzo, C.; Fleming, M.D.; Jin, J.; Greer, E.L.; Sellers, V.M.; Galica, S.M.; Andrews, N.C. Cybrd1 (duodenal cytochrome b) is not necessary for dietary iron absorption in mice. Blood 2005, 106, 2879-2883. [CrossRef] [PubMed]

40. Ganz, T.; Nemeth, E. Hepcidin and iron homeostasis. Biochim. Biophys. Acta. 2012, 1823, 1434-1443. [CrossRef] [PubMed]

41. Nemeth, E.; Tuttle, M.S.; Powelson, J.; Vaughn, M.B.; Donovan, A.; Ward, D.M.; Ganz, T.; Kaplan, J. Hepcidin regulates cellular iron efflux by binding to ferroportin and inducing its internalization. Science. 2004, 306, 2090-2093. [CrossRef] [PubMed]

42. Vanoaica, L.; Darshan, D.; Richman, L.; Schümann, K.; Kühn, L.C. Intestinal ferritin H is required for an accurate control of iron absorption. Cell Metab. 2010, 12, 273-282. [CrossRef] [PubMed]

43. Galy, B.; Ferring-Appel, D.; Becker, C.; Gretz, N.; Gröne, H.J.; Schümann, K.; Hentze, M.W. Iron regulatory proteins control a mucosal block to intestinal ironabsorption. Cell Rep. 2013, 3, 844-857. [CrossRef] [PubMed] 
44. Granick, S. Ferritin; increase of the protein apoferritin in the gastrointestinal mucosa as a direct response to iron feeding; the function of ferritin in the regulation of iron absorption. J. Biol. Chem. 1946, 164, 737-746. [PubMed]

45. Harrison, P.M.; Arosio, P. The ferritins: Molecular properties, iron storage function and cellular regulation. Biochim. Biophys. Acta 1996, 1275, 161-203. [CrossRef]

46. Mastrogiannaki, M.; Matak, P.; Keith, B.; Simon, M.C.; Vaulont, S.; Peyssonnaux, C. HIF-2alpha, but not HIF-1alpha, promotes iron absorption in mice. J. Clin. Investig. 2009, 119, 1159-1166. [CrossRef] [PubMed]

47. Mastrogiannaki, M.; Matak, P.; Peyssonnaux, C. The gut in iron homeostasis: Role of HIF-2 under normal and pathological conditions. Blood 2013, 122, 885-892. [CrossRef] [PubMed]

48. Manzoni, P.; Dall'Agnola, A.; Tomé, D.; Kaufman, D.A.; Tavella, E.; Pieretto, M.; Messina, A.; De Luca, D.; Bellaiche, M.; Mosca, A.; et al. Role of lactoferrin in neonates and infants: An update. Am. J. Perinatol. 2018, 35, 561-565. [PubMed]

49. Suzuki, Y.A.; Shin, K.; Lönnerdal, B. Molecular cloning and functional expression of a human intestinal lactoferrin receptor. Biochemistry. 2001, 40, 15771-15779. [CrossRef] [PubMed]

50. Liao, Y.; Lopez, V.; Shafizadeh, T.B.; Halsted, C.H.; Lönnerdal, B. Cloning of a pig homologue of the human lactoferrinreceptor: Expression and localization during intestinal maturationin piglets. Comp. Biochem. Physiol. A. Mol. Integr. Physiol. 2007, 148, 584-590. [CrossRef] [PubMed]

51. Yu, I.T.; Lin, J.; Wu, J.F.; Yen, H.T.; Lee, S.L.; Yang, T.S. Reevaluation of the necessity of iron injection to newborn piglets. Asian-Australas. Anim. Sci. 2002, 15, 79-83. [CrossRef]

52. Geisser, P.; Baer, M.; Schaub, E. Structure/histotoxicity relationship of parenteral iron preparations. Arzneimittelforschung 1992, 42, 1439-1452. [PubMed]

53. Katkiewicz, M.; Malicka, E.; Preibisch, J. Effect of iron overload on the morphology of some organs in piglets. Pol. Arch. Vet. 1986, 25, 75.

54. Kruszewski, M.; Iwaneńko, T.; Bartłomiejczyk, T.; Woliński, J.; Starzyński, R.R.; Gralak, M.A.; Zabielski, R.; Lipiński, P. Hepatic iron content corresponds with the susceptibility of lymphocytes to oxidative stress in neonatal pigs. Mutat. Res. 2008, 657, 146-149. [CrossRef] [PubMed]

55. Starzyński, R.; Szudzik, M.; Staroń, R.; Jonczy, A.; Smuda, E.; Pieszka, M.; Kamyczek, M.; Lipiński, P. Comparison of the therapeutical potential of oral sucrosomial iron and parenteral iron dextran supplementations in neonatal iron deficiency anemia in pigs. Am. J. Hematol. 2017, 92, E286-E286.

56. Velásquez, J.I.; Aranzazu, D. An acute case of iron toxicity on newborn piglets from vitamin E/Se deficient sows. Rev. Colomb. Cienc. Pecu. 2004, 17, 60-62.

57. Ueberschär, S. Sudden death in suckling piglets following administration of iron-dextran. Dtsch. Tierarztl. Wochenschr. 1966, 73, 145-50. [PubMed]

58. Moretti, D.; Goede, J.S.; Zeder, C.; Jiskra, M.; Chatzinakou, V.; Tjalsma, H.; Melse-Boonstra, A.; Brittenham, G.; Swinkels, D.W.; Zimmermann, M.B. Oral iron supplements increase hepcidin and decrease iron absorption from daily or twice-daily doses in iron-depleted young women. Blood 2015, 126, 1981-1989. [CrossRef] [PubMed]

59. Starzyński, R.R.; Laarakkers, C.M.; Tjalsma, H.; Swinkels, DW.; Pieszka, M.; Styś, A.; Mickiewicz, M.; Lipiński, P. Iron supplementation in suckling piglets: How to correct iron deficiency anemia without affecting plasma hepcidin levels. PLoS ONE 2013, 8, e64022. [CrossRef] [PubMed]

60. Colombo, C.; Palumbo, G.; He, J.-Z.; Pinton, R.; Cesco, S. Review on iron availability in soil: Interaction of Fe minerals, plants, and microbes. J. Soils Sediments 2014, 14, 538. [CrossRef]

61. Bilkei, G. The management of veterinary extension activities and the practical experiences of pig breeding advisory bureaus in western Europe. In Proceedings of the Pig Days, Budapest, Hungary, 3-4 April 1996; Bilkei, G., Ed.; Self Publishing: Budapest, Hungary; pp. 1-3.

62. Kleinbeck, S.N.; McGlone, J.J. Intensive indoor versus outdoor swine production systems: Genotype and supplemental iron effects on blood hemoglobin and selected immune measures in young pigs. J. Anim. Sci. 1999, 77, 2384-2390. [CrossRef] [PubMed]

63. Rincker, M.J.; Hill, G.M.; Link, J.E.; Rowntree, J.E. Effects of dietary iron supplementation on growth performance, hematological status, and whole-body mineral concentrations of nursery pigs. J. Anim. Sci. 2004, 82, 3189-3197. [CrossRef] [PubMed]

64. Svoboda, M.; Ficek, R.; Synková, B.; Drábek, J. Efficiency of carbonyl iron in prevention of anaemia in piglets. Acta Vet. Brno 2007, 76, 179-185. [CrossRef] 
65. Svoboda, M.; Ficek, R.; Drábek, J. Evaluation of the efficacy of iron polymaltose complex in the prevention of anaemia in piglets. Bull. Vet. Inst. Pulawy 2008, 52, 119-123.

66. Antileo, R.; Figueroa, J.; Valenzuela, C. Characterization of a novel encapsulated oral iron supplement to prevent iron deficiency anemia in neonatal piglets. J. Anim. Sci. 2016, 94, 157-160. [CrossRef]

67. Maes, D.; Steyaert, M.; Vanderhaeghe, C.; López Rodríguez, A.; de Jong, E.; Del Pozo Sacristán, R.; Vangroenweghe, F.; Dewulf, J. Comparison of oral versus parenteral iron supplementation on the health and productivity of piglets. Vet. Rec. 2011, 168, 188. [CrossRef] [PubMed]

68. Zödl, B.; Sargazi, M.; Zeiner, M.; Roberts, N.B.; Steffan, I.; Marktl, W.; Ekmekcioglu, C. Toxicological effects of iron on intestinal cells. Cell Biochem. Funct. 2004, 22, 143-147. [CrossRef] [PubMed]

69. Loh, T.; Leong, K.; Too, H.; Mah, C.; Choo, P. The effects of iron supplementation in preweaning piglets. Malays. J. Nutr. 2001, 7, 41-49.

70. Marchant, J.N.; Broom, D.M.; Corning, S. The influence of sow behaviour on piglet mortality due to crushing in an open farrowing system. Anim. Sci. 2001, 72, 19-28. [CrossRef]

71. Valenzuela, C.; Lagos, G.; Figueroa, J.; Tadich, T. Behavior of suckling pigs supplemented with an encapsulated iron oral formula. J. Vet. Behav. 2016, 13, 6-9. [CrossRef]

72. Lin, Y.W.; Wang, J. Structure and function of heme proteins in non-native states: A mini-review. J. Inorg. Biochem. 2013, 129, 162-171. [CrossRef] [PubMed]

73. Anderson, G.J.; Frazer, D.M.; McKie, A.T.; Vulpe, C.D.; Smith, A. Mechanisms of haem and non-haem iron absorption: Lessons from inherited disorders of iron metabolism. Biometals 2005, 18, 339-348. [CrossRef] [PubMed]

74. Fillebeen, C.; Gkouvatsos, K.; Fragoso, G.; Calvé, A.; Garcia-Santos, D.; Buffle, R.M.; Becker, C.; Schümann, K.; Ponka, P.; Santos, M.M.; Pantopoulos, K. Mice are poor heme absorbers and do not require intestinal Hmox1 for dietary heme iron assimilation. Haematologica 2015, 100, e334-e337. [CrossRef] [PubMed]

75. González-Rosendo, G.; Polo, J.; Rodríguez-Jerez, J.J.; Puga-Díaz, R.; Reyes-Navarrete, E.G.; Quintero-Gutiérrez, A.G. Bioavailability of a heme-iron concentrate product added to chocolate biscuit filling in adolescent girls living in a rural area of Mexico. J. Food Sci. 2010, 75, H73-H78. [CrossRef] [PubMed]

76. Young, M.F.; Griffin, I.; Pressman, E.; McIntyre, A.W.; Cooper, E.; McNanley, T.; Harris, Z.L.; Westerman, M.; $\mathrm{O}^{\prime}$ Brien, K.O. Utilization of iron from an animal-based iron source is greater than that of ferrous sulfate in pregnant and nonpregnant women. J. Nutr. 2010, 140, 2162-2166. [CrossRef] [PubMed]

77. Quintero-Gutiérrez, A.G.; González-Rosendo, G.; Sánchez-Muñoz, J.; Polo-Pozo, J.; Rodríguez-Jerez, J.J. Bioavailability of heme iron in biscuit filling using piglets as an animal model for humans. Int. J. Biol. Sci. 2008, 4, 58-62. [CrossRef] [PubMed]

78. Zimmermann, M. The potential of encapsulated iron compounds in food fortification: A review. Int. J. Vitam. Nutr. Res. 2004, 74, 453-461. [CrossRef] [PubMed]

79. Bryszewska, M.A.; Laghi, L.; Zannoni, A.; Gianotti, A.; Barone, F.; Taneyo Saa, D.L.; Bacci, M.L.; Ventrella, D.; Forni, M. Bioavailability of microencapsulated iron from fortified bread assessed using piglet model. Nutrients. 2017, 9, 272. [CrossRef] [PubMed]

80. Allen, T.M.; Cullis, P.R. Liposomal drug delivery systems: From concept to clinical applications. Adv. Drug Deliv. Rev. 2013, 65, 36-48. [CrossRef] [PubMed]

81. Pisani, A.; Riccio, E.; Sabbatini, M.; Andreucci, M.; Del Rio, A.; Visciano, B. Effect of oral liposomal iron versus intravenous iron for treatment of iron deficiency anaemia in CKD patients: A randomized trial. Nephrol. Dial. Transplant. 2015, 30, 645-652. [CrossRef] [PubMed]

82. Giordano, G.; Mondello, P.; Tambaro, R.; Perrotta, N.; D'Amico, F.; D'Aveta, A.; Berardi, G.; Carabellese, B.; Patriarca, A.; Corbi, G.M.; et al. Biosimilar epoetin $\alpha$ is as effective as originator epoetin- $\alpha$ plus liposomal iron $\left(\right.$ Sideral $\left.{ }^{\circledR}\right)$, vitamin B12 and folates in patients with refractory anemia: A retrospective real-life approach. Mol. Clin. Oncol. 2015, 3, 781-784. [CrossRef] [PubMed]

83. Parisi, F.; Berti, C.; Mandò, C.; Martinelli, A.; Mazzali, C.; Cetin, I. Effects of different regimens of iron prophylaxis on maternal iron status and pregnancy outcome: A randomized control trial. J. Matern. Fetal Neonatal Med. 2017, 30, 1787-1792. [CrossRef] [PubMed]

84. Muckenthaler, M.U.; Rivella, S.; Hentze, M.W.; Galy, B. A red carpet for iron metabolism. Cell 2017, 168, 344-361. [CrossRef] [PubMed]

85. Lipiński, P.; Styś, A.; Starzyński, R.R. Molecular insights into the regulation of iron metabolism during the prenatal and early postnatal periods. Cell. Mol. Life Sci. 2013, 70, 23-38. [CrossRef] [PubMed] 
86. Collard, K.J. Iron homeostasis in the neonate. Pediatrics 2009, 123, 1208-1216. [CrossRef] [PubMed]

87. Miller, E.R.; Ullrey, D.E. The pig as a model for human nutrition. Annu. Rev. Nutr. 1987, 7, 361-382. [CrossRef] [PubMed]

88. Schook, L.; Beattie, C.; Beever, J.; Donovan, S.; Jamison, R.; Zuckermann, F.; Niemi, S.; Rothschild, M.; Rutherford, M.; Smith, D. Swine in biomedical research: Creating the building blocks of animal models. Anim. Biotechnol. 2005, 16, 183-190. [CrossRef] [PubMed]

(C) 2018 by the authors. Licensee MDPI, Basel, Switzerland. This article is an open access article distributed under the terms and conditions of the Creative Commons Attribution (CC BY) license (http:/ / creativecommons.org/licenses/by/4.0/). 
Correction

\title{
Correction: Mateusz, S., et al. Iron Supplementation in Suckling Piglets: An Ostensibly Easy Therapy of Neonatal Iron Deficiency Anemia. Pharmaceuticals $2018,11,128$
}

\author{
Mateusz Szudzik ${ }^{1}$, Rafał R. Starzyński ${ }^{1}$, Aneta Jończy ${ }^{1}$, Rafał Mazgaj ${ }^{1}$, \\ Małgorzata Lenartowicz ${ }^{2}$ and Paweł Lipiński ${ }^{1,3, *}$ \\ 1 Department of Molecular Biology, Institute of Genetics and Animal Breeding, Polish Academy of Sciences, \\ Jastrzębiec, 05-552 Magdalenka, Poland; m.szudzik@ighz.pl (M.S.); r.starzynski@ighz.pl (R.R.S.); \\ a.jonczy@ighz.pl (A.J.); r.mazgaj@ighz.pl (R.M.) \\ 2 Department of Genetics and Evolution, Institute of Zoology, Jagiellonian University, Gronostajowa 9, \\ 30-387 Kraków, Poland; malgorzata.lenartowicz@gmail.com \\ 3 Department of Genetics and Animal Breeding, Poznan University of Life Sciences, Wołyńska 33 , \\ 60-637 Poznań, Poland \\ * Correspondence: p.lipinski@ighz.pl; Tel.: +48-22-736-7046
}

Received: 9 October 2018; Accepted: 19 November 2018; Published: 29 January 2019

The authors wish to make the following corrections to this paper [1]: the term "liposomal" should be replaced with the term "sucrosomial" in the following places:

1. On page 7 , line 4 from the bottom;

2. On page 8 , line 1 from the top;

3. On page 8 , line 3 from the top.

The authors would like to apologize for any inconvenience caused to the readers by these changes.

\section{Reference}

1. Mateusz, S.; Rafał, R.S.; Aneta, J.; Rafał, M.; Małgorzata, L.; Paweł, L. Iron Supplementation in Suckling Piglets: An Ostensibly Easy Therapy of Neonatal Iron Deficiency Anemia. Pharmaceuticals 2018, 11, 128. [CrossRef]

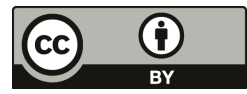

(c) 2019 by the authors. Licensee MDPI, Basel, Switzerland. This article is an open access article distributed under the terms and conditions of the Creative Commons Attribution (CC BY) license (http:/ / creativecommons.org/licenses/by/4.0/). 


\title{
Review
}

\section{Role of Dietary Flavonoids in Iron Homeostasis}

\author{
Marija Lesjak ${ }^{1, *}$ and Surjit K. S. Srai ${ }^{2, *}$ \\ 1 Department of Chemistry, Biochemistry and Environmental Protection, Faculty of Sciences, \\ University of Novi Sad, Trg Dositeja Obradovića 3, 21000 Novi Sad, Serbia \\ 2 Research Department of Structural and Molecular Biology, Division of Biosciences, \\ University College London, Darwin Building, Gower Street, London WC1E 6BT, UK \\ * Correspondence: marija.lesjak@dh.uns.ac.rs (M.L.); k.srai@ucl.ac.uk (S.K.S.S.); \\ Tel.: +381-21-485-2755 (M.L.); +4420-7679-2642 (S.K.S.S.)
}

Received: 1 June 2019; Accepted: 5 August 2019; Published: 8 August 2019

\begin{abstract}
Balancing systemic iron levels within narrow limits is critical for human health, as both iron deficiency and overload lead to serious disorders. There are no known physiologically controlled pathways to eliminate iron from the body and therefore iron homeostasis is maintained by modifying dietary iron absorption. Several dietary factors, such as flavonoids, are known to greatly affect iron absorption. Recent evidence suggests that flavonoids can affect iron status by regulating expression and activity of proteins involved the systemic regulation of iron metabolism and iron absorption. We provide an overview of the links between different dietary flavonoids and iron homeostasis together with the mechanism of flavonoids effect on iron metabolism. In addition, we also discuss the clinical relevance of state-of-the-art knowledge regarding therapeutic potential that flavonoids may have for conditions that are low in iron such as anaemia or iron overload diseases.
\end{abstract}

Keywords: iron homeostasis; iron absorption; non-haem iron; flavonoids

\section{Biological Importance of Iron}

Studying the chemistry of iron in detail, it is easy to see why iron is essential for life. Namely, under physiological conditions, iron is mainly present in two forms, ferrous $\left(\mathrm{Fe}^{2+}\right)$ and ferric $\left(\mathrm{Fe}^{3+}\right)$. $\mathrm{The}_{\mathrm{Fe}}^{3+} \mathrm{Fe}^{2+}$ system facilitates variety of redox potentials that can be fine adjusted by different ligands (from about $-0.5 \mathrm{~V}$ to about $+0.6 \mathrm{~V}$ ), which almost entirely corresponds to the redox potential range of utmost importance for biological systems. That is why iron complexes are uniquely suitable for a variety of catalytic processes and reactions which are of great biological significance, such as electron transfer and acid-base reactions [1,2].

Iron carries out a variety of significant roles in biological systems, mostly as a part of iron-containing proteins. Haemoproteins are a large group of iron-containing proteins where the iron is bound to a porphyrin molecule (haem) which is bound to the different proteins with diverse functions. There are three main categories of haem proteins: Oxygen carriers (haemoglobins, myoglobins and neuroglobins), activators of molecular oxygen (cytochrome oxidase, cytochrome P450s, catalases and peroxidases) and electron transport proteins (cytochromes) [3,4].

The second group of iron-containing proteins is the iron-sulphur proteins, where iron is bound to sulphur by thiol groups from cysteine or inorganic sulphide. Iron-sulphur proteins are widespread in all living organisms and express numerous actions. Namely, they are included in redox and non-redox reactions as part of different enzymes, like succinate dehydrogenase and aconitase, and proteins involved in the electron transfer chain $[1,5]$.

The third class of iron-containing proteins presents a diverse group of proteins that do not contain iron in a haem or iron-sulphur form. One group is mononuclear non-haem iron enzymes, which include lipoxygenases, aromatic amino-acid hydroxylases, prolyl and lysyl hydroxylases, etc. Additionally, 
there is the dinuclear non-haem iron protein group, consisting of ribonucleotide reductase and ferritins or proteins involved in iron transport, such as transferrins (Tfs) [1].

Summing activities of the above-mentioned proteins, it is apparent that iron is crucial for many important processes, such as: Oxygen transport and storage, cellular respiration and energy production, the electron transport chain of mitochondria, synthesis of DNA, RNA and proteins, regulation of gene expression, cell proliferation and differentiation. In addition, iron is indispensable for normal brain function, psychomotor development and cognitive performance (especially in infants), endurance and physical performance, the inflammatory response, pregnancy ( $40 \%$ of all maternal prenatal deaths are linked to anaemia), thyroid function, production and metabolism of catecholamines and other neurotransmitters, drug metabolism, etc. Hence it is evident that nearly every cell and organism require iron for life [3,6-10].

On the other hand, the property of iron to easily change its oxidative state can also be toxic, mainly due to its ability to produce free radicals when it is not bound by proteins and is free in a labile iron pool. Iron takes part in a reaction, known as the Fenton reaction, where the hydroxyl radical $\left(\mathrm{HO}^{\bullet}\right)$ is the end product. $\mathrm{HO}^{\bullet}$ is the most toxic reactive oxygen species (ROS) which can damage all classes of biomolecules. Consequently, unrestrained production of $\mathrm{HO}^{\bullet}$ leads to cell injuries and death and gives rise to numerous severe pathological states [11]. The Fenton reaction initiates the chain reaction (Equation (1)), which is then followed by the reactions (Equations (2) and (3)) in which more and more $\mathrm{HO}^{\bullet}$ is produced [12].

$$
\begin{gathered}
\mathrm{Fe}^{2+}+\mathrm{H}_{2} \mathrm{O}_{2} \rightarrow \mathrm{Fe}^{3+}+\mathrm{HO}^{\bullet}+\mathrm{HO}^{-} \\
\mathrm{HO}^{\bullet}+\mathrm{H}_{2} \mathrm{O}_{2} \rightarrow \mathrm{H}_{2} \mathrm{O}+\mathrm{O}_{2}^{\bullet-}+\mathrm{H}^{+} \\
\mathrm{O}_{2}^{\bullet-}+\mathrm{H}^{+}+\mathrm{H}_{2} \mathrm{O}_{2} \rightarrow \mathrm{O}_{2}+\mathrm{HO}^{\bullet}+\mathrm{H}_{2} \mathrm{O}
\end{gathered}
$$

Thus, balancing systemic iron levels within narrow limits in an organism is crucial, as both iron deficiency and iron overload lead to serious haematological, metabolic and neurodegenerative disorders, which belong to the most frequent disorders worldwide, as well as carcinogenesis [13].

\section{Distribution and Homeostasis of Body Iron}

The total iron content of the adult human organism is estimated around $4 \mathrm{~g}$ ( $\sim 35 \mathrm{mg} / \mathrm{kg}$ woman, $\sim 45 \mathrm{mg} / \mathrm{kg}$ for men). About $66 \%$ of total body iron is found as part of haemoglobin in circulating erythrocytes, erythrocyte precursors or as intracellular pool (liver and reticulo-endothelial macrophages), $7.5 \%$ in muscle as part of myoglobin, $0.5 \%$ as part of the catalytic center of a variety of enzymes (cytochromes, catalase, peroxidases, flavoproteins, etc.) and $0.1 \%$ as Tf-bound iron in the circulation (see Figure 1) [2,14].

Body iron homeostasis is maintained by regulating the iron levels in plasma (Tf-bound iron), which is determined by four coordinated processes: Duodenal iron absorption, macrophage iron recycling, hepatic iron storage and erythropoiesis. Erythropoiesis, the production of red blood cells in bone marrow, requires nearly $30 \mathrm{mg}$ iron each day, the main part of which comes from the recycling of iron via reticulo-endothelial macrophages ( $>28 \mathrm{mg} /$ day). Macrophages ingest old or damaged erythrocytes, process them and release recycled iron to plasma Tf. The pool of Tf-bound iron ( $\sim 3 \mathrm{mg})$ is very dynamic and undergoes recycling more than 10 times daily. Furthermore, when in balance, each day the body absorbs 1-2 mg of iron by duodenal enterocytes and at the same time loses 1-2 mg of iron by nonspecific iron losses, such as exfoliation of enterocyte, skin and hair loss, menstruation and some gastrointestinal blood loss (Figure 1). Bearing in mind that there is no known physiologic mechanism for controlling iron excretion and that macrophage-mediated iron recycling cannot be sufficient for maintaining erythropoiesis over the long term, absorption of dietary iron in duodenum is of great importance in keeping iron homeostasis in balance $[15,16]$. 


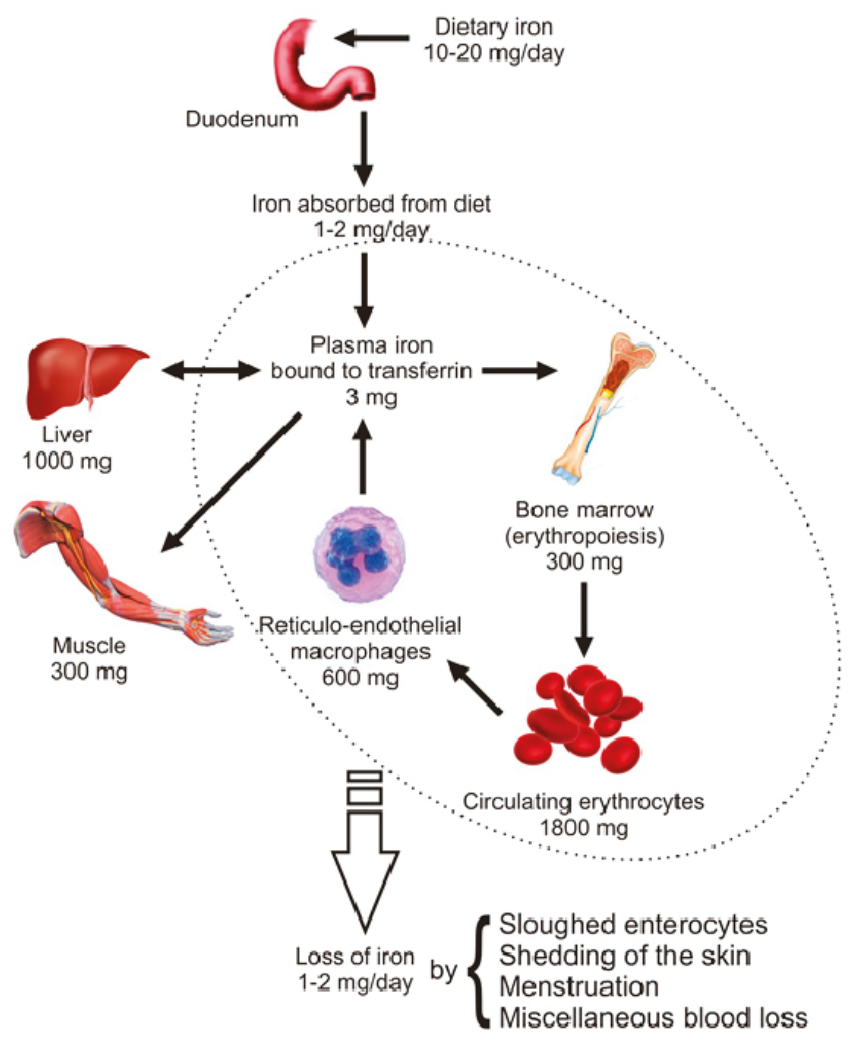

Figure 1. Distribution of body iron. The adult human body has approximately $4 \mathrm{~g}$ of iron, with more than half ( $>2 \mathrm{~g}$ ) incorporated in the haemoglobin of developing erythroid precursors ( $300 \mathrm{mg}$ ) and mature circulating erytrocytes $(1800 \mathrm{mg})$. The remaining body iron is found in a transit pool in reticulo-endothelial macrophages $(600 \mathrm{mg})$ or stored in hepatocytes $(1000 \mathrm{mg})$. A smaller part is present in muscles within myoglobin $(300 \mathrm{mg})$, while only a minor amount is present in plasma bound to transferrins ( $\mathrm{Tfs}, 3 \mathrm{mg}$ ) or incorporated in other proteins and enzymes that include iron in their structures. Approximately, 10-20 mg of iron is daily consumed by diet, from which only 1-2 mg is absorbed. The same amount is lost every day by blood loss of different etiology, shedding of the skin and sloughed enterocytes.

\section{Mechanism of Dietary Iron Uptake}

Nutritional iron absorption occurs primarily in the duodenum, on the apical (luminal) membrane of the enterocytes, and is tightly regulated by bioavailable iron, iron stores, erythropoietic drive and inflammation. The average diet daily contains about $10-20 \mathrm{mg}$ of iron from which only $1-2 \mathrm{mg}$ is absorbed. There are two types of dietary iron: Non-haem iron, which is present in food from both animal or plant origin, and haem iron, which is present only in food of animal origin. Absorption of non-haem iron in the intestine comprises the following (see Figure 2) [17]:

1. Reduction of $\mathrm{Fe}^{3+}$ and uptake of $\mathrm{Fe}^{2+}$ from the diet through the apical membrane of enterocytes. In the diet iron is mainly present as $\mathrm{Fe}^{3+}$. However, the absorption of $\mathrm{Fe}^{2+}$ is more efficient than $\mathrm{Fe}^{3+}$. In order to increase $\mathrm{Fe}^{3+}$ bioavailability, $\mathrm{Fe}^{3+}$ firstly needs to be reduced. Duodenal cytohrome b (Dcytb) is an iron-regulated ferric reductase, highly expressed on the apical membrane of duodenal enterocytes [18]. After being reduced by Dcytb, $\mathrm{Fe}^{2+}$ is transported across the apical membrane by the divalent metal transporter 1 (DMT1) [19]. 
2. Intracellular processing of iron and iron transport to the basolateral membrane of enterocytes. Even though mechanisms of intracellular iron transport are not fully elucidated, it is assumed that poly $\mathrm{r}(\mathrm{C})$-binding proteins (PCBPs) play important roles in this transport. Namely, PCBP1 is identified as an iron chaperone for ferritin, the main iron storage protein in the cell, while PCBP2 is assumed to transfer of iron from DMT1 to the cytosol and later to iron efflux transporter ferroportin (FPN). In addition, NCOA4 was identified as autophagic receptor for ferritin, which during iron deficiency in cell leads to ferritin autophagy and iron liberation [20]. In general, the fate of absorbed iron is closely related to the body's demands for iron. If there is a need for more iron, then iron is exported from the cell via the basolateral membrane of enterocytes which is followed by iron binding to $\mathrm{Tf}$ and transport to peripheral tissues that require iron. If there is no need for additional iron in the body, iron is stored in the cell in the form of ferritin, and returned to the lumen at a time when the villus enterocytes die [8].

3. Transfer of iron through the basolateral membrane to the circulation. The mechanism of $\mathrm{Fe}^{2+}$ transport through the basolateral membrane includes synchronized activity of two proteins, FPN [21-23] and transmembrane copper-dependent ferroxidase, hephaestin (Heph) [24,25]. Before entering circulation, $\mathrm{Fe}^{2+}$ firstly needs to be oxidized to the $\mathrm{Fe}^{3+}$ state, which is catalysed by hephaestin, the intestinal ferroxidase. $\mathrm{Fe}^{3+}$ then binds to the serum glycoprotein $\mathrm{Tf}$ [26], the key iron transporting protein in the serum and extracellular fluids.

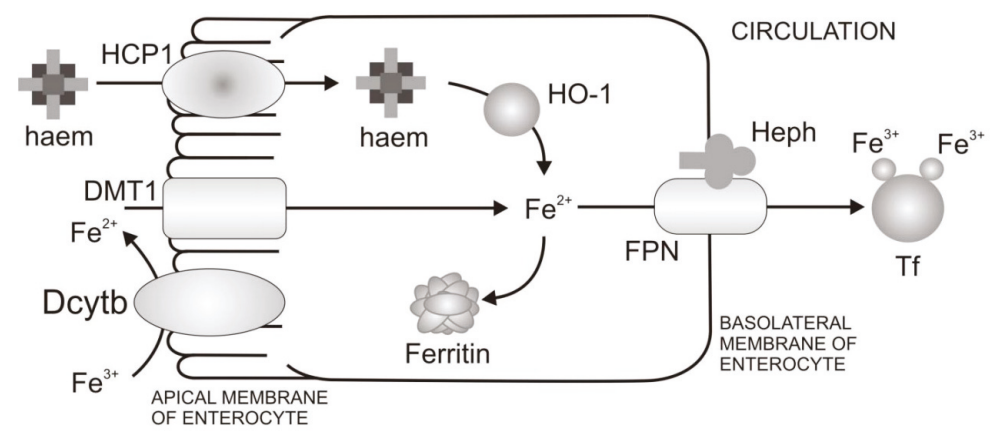

Figure 2. Mechanism of non-haem and haem iron absorption in duodenal cells. Non-haem iron from food is firstly reduced by the ferric reductase Dcytb yielding $\mathrm{Fe}^{2+}$, which afterwards enters the enterocytes via divalent metal transporter 1 (DMT1). On the other hand, haem is absorbed via haem carrier protein 1 (HCP1), subsequently broken down by $\mathrm{HO}-1$, after which free $\mathrm{Fe}^{2+}$ from haem joins a common cell iron pool with iron from the non-haem source. If body iron stores are high, iron may be stored in the cell complexed with ferritin as $\mathrm{Fe}^{3+}$ and eventually lost when the cell is discarded from the intestinal villus tip. Otherwise, iron efflux into the circulation via the iron efflux transporter ferroportin (FPN), subsequently being re-oxidised through hephaestin (Heph) to enable loading into Tf, after which it is transferred to peripheral tissues that require iron.

The uptake mechanism for non-haem and haem iron differs across the apical membrane of the enterocyte, while it follows the same pathway once iron is inside the cell (see Figure 2). Even though the mechanism of haem absorption is not fully characterized, haem carrier protein 1 (HCP1) was identified as protein for haem uptake on the apical membrane of duodenal enterocytes [27]. Currently, the role of HCP1 in haem transport is debated since it was also identified as the proton-coupled folate transporter [28]. In addition, the new heam transporter is identified, known as feline leukemia virus subgroup C cellular receptor family member 2 (FLVSC2), whose detailed characterisation is in process [29]. Once inside the cell, haem is degraded by haem oxygenase (HO-1) [30] and the released iron enters an intracellular iron pool. After that, absorbed iron from the haem source follows the pathway of absorbed non-haem iron. 


\section{Bioavailability of Iron}

To keep iron in balance, it is essential that iron is supplied by diet, especially during growth of infants, children and adolescents and the reproductive period in women, particularly during pregnancy. In Table 1 it can be clearly seen that daily requirements of absorbed iron differ greatly between individuals of different age, sex and state [31,32].

Table 1. Daily requirements of absorbed iron in individuals of different age, sex and state [32,33].

\begin{tabular}{cc}
\hline Age/State & Absorbed Iron in Duodenum ${ }^{\text {a }}$ (mg/day) \\
\hline 4-12 months & 0.96 \\
13-24 months & 0.61 \\
2-5 years & 0.70 \\
6-11 years & 1.17 \\
12-16 years (girls) & 2.02 \\
12-16 years (boys) & 1.82 \\
Adult males & 1.14 \\
Women during lactation & 1.31 \\
Women during menstruating period & 2.38 \\
Women during postmenopausal period & 0.96 \\
Women 1st trimester of pregnancy & 0.8 \\
Women 2nd \& 3rd trimester of pregnancy & 6.3 \\
\hline
\end{tabular}

${ }^{a}$ Calculations were done on the basis of average weight and average status.

As mentioned previously, dietary iron occurs in two forms: Haem and non-haem. Haem iron makes $10-15 \%$ of total iron from diet in meat-eating populations, but it is estimated to contribute $\geq 40 \%$ of total absorbed iron. However, non-haem iron absorption is much lower, and it varies between $2-20 \%$. In contrast to non-haem iron, whose bioavailability is highly dependent on the presence of iron absorption promoters or inhibitors in the diet, dietary factors have little effect on haem iron absorption [31].

\subsection{Anaemias}

The low bioavailability of non-haem iron contributes greatly to iron deficiency anaemia (IDA), which is the most prevalent nutritional deficiency worldwide, estimated to affect two billion people especially in low-income populations where consumption of meat is low. On the other hand, low bioavailability of non-haem iron is a problem in population groups eating only a plant-based diet, vegetarians and vegans, whose popularity is rising in modern societies [34].

Iron deficiency disorders are generally known as functional deficiency and anaemias. Commonly, anaemia is a condition in which there are not enough healthy erythrocytes in the circulation which leads to inadequate oxygen distribution and consequently disturbance in the maintenance of normal physiological function of tissues, such as liver, brain, muscles, etc. [33].There are many types of anaemia and these can arise as a result of a wide variety of causes that can be single, but more often coexist. Globally, the most significant contributor to the anaemia is IDA. The main causes for IDA are low dietary iron intake, poor absorption of iron from diet at a period of life when iron requirements are particularly high, such as growth periods among children, reproductive period among women, especially during pregnancy. Other recognized causes of anaemia, such as heavy blood loss, extensive menstruation or chronic bleeding are also recognized [35].

Additionally, anaemia and hypoferraemia that occurs as consequence of chronic infections and inflammatory disorders is known as anaemia of inflammation (AI) or anaemia of chronic disease. AI is a systemic iron disorder characterized with decreased iron, iron binding capacity and intestinal iron absorption, as well as impaired erythropoiesis, while iron is trapped in macrophages and liver, 
indicating impaired mobilization of iron from stores. AI is a consequence of cytokine (mainly IL-6) mediated induction of hepcidin production as a response to chronic inflammation [3,36].

To be more precise, anaemia is a consequence of both poor nutrition and poor health. Increased risk of maternal and child mortality is one of the main concerns of severe anaemia. Additionally, the negative consequences of IDA on cognitive and physical development of infants and on general performance, particularly work productivity in adults, are also great concern. The World Health Organization declares iron deficiency as one of the 10 leading risk factors for disease, disability and death in the world today. Iron deficiency affects mostly children and women in practically all countries. It can be estimated that most preschool children in non-developed countries and at least $30-40 \%$ in developed countries are iron-deficient, and nearly half of the pregnant women in the world are estimated to be anaemic $[6,34,35,37,38]$.

In order to compensate for lost iron and to keep iron homeostasis in balance, it is of utmost importance that absorption of iron is sufficient. Thus, it is essential to understand in detail the mechanism of iron absorption in the duodenum as well as to target its promoters or inhibitors. Additionally, for individuals affected with iron deficiency (anaemias) it is important to know what food is rich in highly bioavailable iron and try to consume it as much as possible. In Table 2 it can be seen what the average levels of total iron in common foods are.

Table 2. Amount of total iron in common foods [39].

\begin{tabular}{|c|c|}
\hline Food & $\mathrm{mg}$ Iron/100 g Food \\
\hline \multicolumn{2}{|c|}{ sources of non-haem iron } \\
\hline red bean & 6.69 \\
\hline parsley & 6.20 \\
\hline wheat flour, whole-grain & 3.71 \\
\hline corn flour, whole-grain, yellow & 2.38 \\
\hline garlic & 1.70 \\
\hline lettuce & 0.86 \\
\hline potato & 0.81 \\
\hline orange & 0.80 \\
\hline red cabbage & 0.80 \\
\hline broccoli & 0.73 \\
\hline blackberry & 0.62 \\
\hline kiwi & 0.54 \\
\hline red pepper & 0.43 \\
\hline cauliflower & 0.42 \\
\hline strawberry & 0.41 \\
\hline apricot & 0.39 \\
\hline fig & 0.37 \\
\hline carrot & 0.30 \\
\hline cucumber & 0.28 \\
\hline blueberry & 0.28 \\
\hline banana & 0.26 \\
\hline watermelon & 0.24 \\
\hline eggplant & 0.23 \\
\hline red onion & 0.21 \\
\hline apple & 0.12 \\
\hline \multicolumn{2}{|c|}{ sources of haem iron } \\
\hline goose, liver & 30.53 \\
\hline oyster & 3.86 \\
\hline beef meat & 1.69 \\
\hline lamb meat & 1.55 \\
\hline turkey meat & 1.09 \\
\hline chicken meat & 0.82 \\
\hline
\end{tabular}




\subsection{Dietary Inhibitors of Iron Absorption}

There are recognized inhibitors of iron absorption whose occurrence in food should be addressed in iron-deficient individuals. Major inhibitors of iron absorption from the diet are phytate, polyphenols (especially flavonoids), calcium and proteins.

Phytate (inositol hexakisphosphate; see Figure 3) is a primary phosphorous storage molecule in plants and cannot be digested by humans.

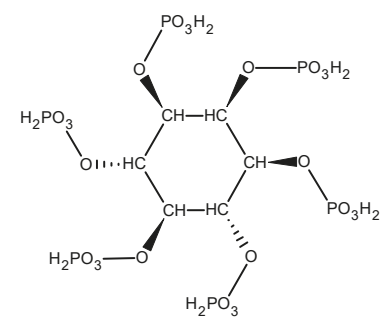

Figure 3. Structure of Phytate.

It is believed that phytate forms a complex with iron through its phosphate ester groups making it nonabsorbable and it is considered as the main inhibitor of non-haem iron absorption. The inhibitory effect of phytate has been proven, but particular food preparation methods, such as milling, heat treatment, soaking, germination, fermentation, addition of ascorbic acid or enzyme phytase, can remove or degrade phytate and thus partially or totally eliminate its negative effect on non-haem iron absorption. However, low concentrations of phytate $(2-10 \mathrm{mg} / \mathrm{meal})$ express a negative effect on non-haem iron absorption [31,40-42]. Considering that some foods contain phytate in considerable concentrations, even much more than common food containing non-haem iron (see Table 3), consumption of phytate rich plants should be under attention, especially together with iron supplementation. Plant foods not shown in Table 3 may be considered as not rich in phytate.

Table 3. Phytate and iron content in selected foods $[39,43]$.

\begin{tabular}{ccc}
\hline Food & g Phytate/100 g Food & mg Iron/100 g Food \\
\hline soybean seed & $1.0-2.22$ & 15.7 \\
sesame seed & $1.44-5.36$ & 14.5 \\
bean & $0.61-2.38$ & 9.0 \\
lentil & $0.27-1.51$ & 7.4 \\
flax seed & $2.15-3.69$ & 7.2 \\
indian walnut & $0.19-4.98$ & 6.7 \\
sunflower seeds & $3.9-4.3$ & 6.0 \\
wheat seed & $0.39-1.35$ & 5.3 \\
oats & $0.42-1.16$ & 4.7 \\
pea & $0.22-1.22$ & 4.7 \\
hazelnut & $0.23-0.92$ & 4.7 \\
peanut & $0.17-4.47$ & 4.5 \\
chickpeas & $0.28-1.60$ & 4.3 \\
rice & $0.06-1.08$ & 4.0 \\
pistachio nuts & $0.29-2.83$ & 3.9 \\
almond nuts & $0.35-9.42$ & 3.7 \\
corn & $0.72-2.22$ & 3.0 \\
walnut & $0.20-6.69$ & 2.9 \\
rye seed & $0.54-1.46$ & 2.6 \\
\hline
\end{tabular}

Calcium has been shown to have an inhibitory effect on both non-haem and haem iron absorption. The mechanism of the inhibitory effect of calcium on iron absorption is not known, but it is speculated 
that it could block initial iron uptake by the enterocyte [44]. Inhibition of iron absorption has been demonstrated even with a calcium concentration that is common in the daily dietary intake. This fact could represent a general health problem because widespread and recommended use of calcium supplements, manly for prevention of osteoporosis, can bring about problem with iron absorption [31,45].

Particular proteins are also proven to have an inhibitory effect on iron absorption such as: Milk, soybean and egg proteins, albumin, casein and whey [46-49].

\subsection{Dietary Enhancers of Iron Absorption}

The main dietary enhancers of iron absorption are ascorbic acid and muscle tissue. It is proven that ascorbic acid improves non-haem iron absorption, mainly due to its ability to reduce $\mathrm{Fe}^{3+}$ to $\mathrm{Fe}^{2+}$ and thus make it available for transport by DMT1. The amount of ascorbic acid that expresses a positive effect on non-haem iron absorption is approximately 30-100 $\mathrm{mg}$ daily, which corresponds to the recommended dietary intake for ascorbic acid. However, in foods of plant origin, such as, fruits and vegetables, the supporting effect of ascorbic acid might be reduced by the inhibiting effect of polyphenols and phytate [40,50-54]. In contrast to the positive effect of ascorbic acid on non-haem iron absorption after a single meal, improvement in iron status after chronic supplementation with ascorbic acid was not observed in humans. The reason for this occurrence is not yet fully understood [55].

Muscle tissue, known as the "meat factor", also showed a positive effect on non-haem iron absorption, the same as ascorbic acid, but it was hard to demonstrate the same activity after a longer consumption. There is evidence that this could be attributed to: Cysteine-containing peptides, glycosaminoglycans and L- $\alpha$-glycerophosphocholine and their ability to reduce and chelate iron [56-58].

\subsection{Ways to Prevent Anaemia}

Nowadays three approaches are recognized as ways to deal with IDA and raise amount of absorbed iron which can be practices alone or in combination with each other: Change in dietary habits by means of diversity and modification of the diet in order to improve nutritional value andiron bioavailability, supplementation (intake of iron in higher doses not with food), and fortification (the addition of iron into food during food processing).

A change of dietary habits so that intake of food rich in both haem and non-haem iron, as well as promoters of iron absorption, is increased, while intake of inhibitors of iron uptake should be decreased. Even though it showed significant practical limitations, a change of dietary habits is the favoured way of treating IDA. Apart from the fact that it is hard to change an individuals' dietary preference, food rich in highly bioavailable iron, such as meat, is expensive especially in developing countries.

Supplementation is an efficient and cost-effective way of treating IDA over short periods of time, such as pregnancy. However, insufficient coverage of all parts of the world and compliance is a major limitation to the effectiveness of iron supplementation programs [59]. Iron supplementation is carried out orally or, very rarely, by injection. Frequently used forms of iron in supplements include $\mathrm{Fe}^{2+}$ and $\mathrm{Fe}^{3+}$ salts, such as $\mathrm{SO}_{4}{ }^{2-}$, gluconate, fumarate and citrate. High doses of supplemental iron may cause gastrointestinal side effects, such as nausea and constipation. Other forms of supplemental iron, such as haem iron, carbonyl iron, iron amino-acid chelates and polysaccharide-iron complexes, are also available and are believed to manifest fewer gastrointestinal side effects compared with salts $[6,60]$.

Iron fortification of food is considered as the most cost-effective route for lowering incidence of IDA all over the world. Generally, iron fortification refers to the addition of iron to foods consumed by all or most of the population and it is regulated by the government. Milled cereals are frequently the subject of iron fortification and showed a successful outcome in making populations less iron deficient. In addition, it was estimated that iron fortification is economically more favourable than iron supplementation [60,61]. 


\section{Plant Polyphenols}

Polyphenols are plant secondary metabolites that include a great number of structurally diverse compounds. Chemically speaking, phenols are compounds which contain one (phenol) or more (polyphenols) aromatic rings, bearing one or more hydroxyl groups, which can be esterified, etherified or glycosylated. Generally, polyphenols represent all secondary metabolites whose syntheses go through the shikimate/phenylpropanoid or the "polyketide" acetate/malonate pathway, or by combination of two of them, producing monomeric or polymeric phenols. Additionally, phenols are uncommon in bacteria, fungi and algae but are ubiquitously present in the plant kingdom. The phenolic profile of an individual plant strongly depends on plant species and thus can be used as a reliable taxonomic marker [62]. Throughout evolution, plants have developed adaptive mechanisms which are reflected in their ability to produce a great number of phenolic secondary metabolites. Although phenols are not compulsory in the processes such as plant growth and development, they have pivotal role for plants' interactions with the environment, reproduction and defence. From an evolutionary point of view, it is easy to see why plants produce such a great collection of secondary compounds compared with animals. Namely, they cannot rely on physical mobility to escape predators or perform successful pollination. Thus, they had to developed exuberant chemical systems in order to survive. Plants need phenols for protection against herbivores, microbes, viruses or other plants, as signal compounds to attract pollinating or seed dispersing animals, protection from ultraviolet radiation or oxidants and fluctuation of organic and inorganic nutrients from soil [62].

Phenols are generally soluble in polar organic solvents, unless being entirely esterified, etherified or glycosylated. Also, most phenol glycosides are water-soluble but the corresponding aglycones are usually less so. Due to the presence of an aromatic ring, all phenols demonstrate intense absorption in the ultraviolet part of the spectrum. Furthermore, phenols that give colour to plants absorb light in the visible region as well. On the basis of the phenol skeleton, several classes of phenols have been categorized: $C_{6}$ (phenols, benzoquinones), $C_{6}-C_{1}$ (phenolic acids), $C_{6}-C_{2}$ (acetophenones, phenylacetic acids), $\mathrm{C}_{6}-\mathrm{C}_{3}$ (hydroxycinnamic acids, coumarins, phenylpropanes, chromones), $\mathrm{C}_{6}-\mathrm{C}_{4}$ (naphthoquinones), $\mathrm{C}_{6}-\mathrm{C}_{1}-\mathrm{C}_{6}$ (xanthones), $\mathrm{C}_{6}-\mathrm{C}_{2}-\mathrm{C}_{6}$ (stilbenes, anthraquinones), $\mathrm{C}_{6}-\mathrm{C}_{3}-\mathrm{C}_{6}$ (flavonoids, isoflavonoids), $\left(\mathrm{C}_{6}-\mathrm{C}_{3}\right)_{2}$ (lignans, neolignans), $\left(\mathrm{C}_{6}-\mathrm{C}_{3}-\mathrm{C}_{6}\right)_{2}$ (biflavonoids), $\left(\mathrm{C}_{6}-\mathrm{C}_{3}\right)_{\mathrm{n}}$ (lignins), $\left(\mathrm{C}_{6}\right)_{\mathrm{n}}$ (catecholmelanins) and $\left(\mathrm{C}_{6}-\mathrm{C}_{3}-\mathrm{C}_{6}\right)_{\mathrm{n}}$ (condensed tannins) [62-64].

\subsection{Flavonoids}

Flavonoids are one of the largest groups of plant phenols and, by now, more than 8000 structures of flavonoids have been identified. These secondary metabolites are widely distributed in plants and are classified in a number of subgroups, of which one representative of flavones, flavonols, isoflavones, flavanones, flavanonols, flavanols, anthocyanins, chalcones and aurones subgroup is presented in Figure 4. As with other phenols, flavonoids also have numerous functions in plants, such as: Protection against ultraviolet radiation and phytopathogens, a protective response during stress, signaling during development and growth, auxin transport and coloration of flowers for attraction of insects during pollination $[65,66]$.

Apart of being valuable for the plant kingdom, flavonoids are also beneficial to human health. Namely, flavonoids have played a key role in the successful traditional medical treatments of ancient times and their use has continued up to the present day $[67,68]$. For medicine, the most valuable property of flavonoids is their ability to effectively scavenge highly toxic free radicals and lower oxidative stress [69]. Free radical species occur in the course of numerous physiological processes and can initiate damage of nucleic acid, lipid and protein structures, resulting in disturbance of vital cellular functions and causing a wide range of disorders. Thus, today it is almost impossible to separate free radical reactions and oxidative stress from almost any disorder [70]. Apart from keeping biomolecules safe from free radical attack, flavonoids take part in many biochemical processes in an organism, such as: Regulation of expression of cell cycle regulatory proteins, and inhibition/activation of signal transduction pathways or enzyme activity. As a consequence, flavonoids express many 
beneficial health actions, such as: Lowering blood pressure and risk of cardiovascular disorders, decreasing the incidence of carcinogenesis and neurodegeneration, inhibiting platelet aggregation and the inflammatory response, as well as lowering levels of bad LDL cholesterol [67-74].<smiles>O=c1cc(-c2ccc(O)c(O)c2)oc2cc(O)cc(O)c12</smiles>

luteolin (flavone)<smiles>O=C1CC(c2ccc(O)cc2)Oc2cc(O)cc(O)c21</smiles>

naringenin (flavanone)<smiles>Oc1cc(O)c2cc(O)c(-c3ccc(O)c(O)c3)[o+]c2c1</smiles>

cyanidin (anthocyanidin)<smiles>O=c1c(O)c(-c2ccc(O)c(O)c2)oc2cc(O)cc(O)c12</smiles>

quercetin (flavonol)<smiles>O=C1c2c(O)cc(O)cc2OC(c2ccc(O)c(O)c2)C1O</smiles>

dihydroquercetin (flavanonol)<smiles>O=C(/C=C/c1ccc(O)c(O)c1)c1ccc(O)cc1O</smiles>

butein (chalcone)<smiles>O=c1c(-c2ccc(O)cc2)coc2cc(O)cc(O)c12</smiles>
genistein (isoflavone)<smiles>Oc1cc(O)c2c(c1)OC(c1ccc(O)c(O)c1)C(O)C2</smiles>

catechin (flavanol)<smiles>O=C1/C(=C/c2ccc(O)c(O)c2)Oc2cc(O)cc(O)c21</smiles>

Figure 4. Structure of some classes of flavonoids.

To give answer to question as to why flavonoids express numerous physiological properties is not easy, but the most probable answer lies in the fact that they are highly reactive and can enter into almost any type of reaction known to organic chemistry. Namely, they can take part in oxidation-reduction, acid-base and free radical reactions and hydrophobic interactions, while their substituents can modify electronic induction, resonance and steric hindrance. Additional, flavonoids make stable complexes with metal ions, such as iron, and thus express their antioxidative property, which is the focus of this review [75].

\subsection{Absorption and Metabolism of Flavonoids in Humans}

Absorption and metabolism of flavonoids will be explained with quercetin, as an example, since it is the most abundant flavonoid in human diet. However, other flavonoids follow the same or similar mechanism of absorption and metabolism as described for quercetin.

Quercetin is mainly present in plants in its highly hydrophilic glycosylated forms, mainly as $\beta$-glycosides of various sugars. The dominant types of quercetin glycosides differ in plants. However, main forms presented in plants are quercetin-3-O-rutinoside (rutin), quercetin-3-O-galactoside (hyperoside), quercetin-3-O-glucoside (isoquercitrin), quercetin-3-O-rhamnoside (quercitrin) and quercetin-4'-O-glucoside (spiraeoside) [75].

Prior to absorption in the gut, flavonoids firstly need to be free from plant tissue by chewing in oral cavity and then processed by digestive juices in the intestine or by microorganisms in the colon. 
Generally, there are two main routes of quercetin glycoside absorption by enterocyte. Firstly, absorption goes via transporter followed by deglycosilation within the enterocyte by cytosolic glycosidase. Secondly, deglycosilation can occur firstly by luminal hydrolases followed by transport of aglycone by passive diffusion or via different transporters. It is demonstrated that quercetin glucosides can be taken up by enterocyte through the sodium-dependent glucose transporter (SGLT1) with subsequent deglycosylation inside the enterocyte by cytosolic $\beta$-glycosidase. Also, quercetin glucosides can firstly undergo luminal hydrolysis by lactase phlorizin hydrolase (LPH) and afterwards absorbed inside the enterocyte by passive diffusion or transporter-mediated mechanism [76-79]. Specifically, quercetin can use glucose transporter (GLUT)-1, -3 and -4 to enter cells and thus operate as an inhibitor of glucose transport [80]. The nature of sugar moiety greatly influences the way and rate of quercetin absorption in the gut. Namely, it is suggested that absorption rate in the small intestine of 3-O-glucosylated form of quercetin is higher than the same of quercetin. On the other hand, quercetin glucosides containing rhamnose (rutin) could not be absorbed in the small intestine, and it is believed to be absorbed in the colon after deglycosylation $[78,81,82]$.

The definition of bioavailability states that bioavailability is the portion of an initially administered dose of drug that reaches the systemic circulation unchanged. Considering that, flavonoid bioavailability is very low mostly due to extensive metabolism at the intestinal level. Namely, further biotransformation of quercetin aglycone goes through glucuronidation, sulfonation and methylation of hydroxyl groups, which primarily occurs in enterocytes and hepatocytes. Specifically, major quercetin metabolites detected in plasma are quercetin-3'-sulphate and quercetin-3-glucuronide. It is assumed that they are produced in the small intestine, pass into the portal vein and are further converted into other metabolites in the liver, such as isorhamnetin-3-glucuronide, quercetin diglucuronide, quercetin glucuronide sulphate, methylquercetin diglucuronide, etc. After returning to the bloodstream they are excreted in urine via kidneys. Additionally, a portion of quercetin is converted to low molecular weight phenolic acids, such as 3-hydroxyphenylpropionic acid, 3,4-dihydroxyphenylpropionic acid and 3-methoxy-4-hydroxyphenylpropionic acid $[83,84]$.

\subsection{Occurrence and Intake of Dietary Flavonoids}

Nowadays, a growing body of research confirms different beneficial health effects of dietary flavonoids. Consequently, consumers take more and more interest in the levels and types of flavonoids that are taken up with diet. This is particularly interesting in the scope of the modern concept of functional food, food that apart from nutritional value express additional functions, such as health-promotion or disease prevention. Namely, flavanols and anthocyanidins have been associated with reduction of risk of cardiovascular disease, while anthocyanidins efficiently protect LDL cholesterol oxidation [85]. It had been shown that flavonoids express organ-specificity for cancer prevention, so intake of quercetin rich diet was proven to be in positive correlation with protection against lung and intestinal cancer $[86,87]$.

Flavonoids are present in nearly all edible fruits, vegetables and other food of plant origin. Generally, the human population is consuming notable amounts of flavonoids on a daily basis, being more in regions where diet is mainly based on plant sources. It is estimated that the average daily intake of flavonoids in the United States of America is 20-34 mg, in Finland $24 \mathrm{mg}$, Japan $63 \mathrm{mg}$ and The Netherlands $73 \mathrm{mg}$ [88]. In Table 4, flavonoids and iron content in selected foods that are regularly consumed in Western diet are listed. 
Table 4. Flavonoids and iron content of selected foods $[39,89]$.

\begin{tabular}{ccc}
\hline Food & mg Flavonoid/100 g & mg Iron/100 g \\
\hline parsley & 233.16 & 6.20 \\
garlic & 3.61 & 1.70 \\
lettuce & 4.63 & 0.86 \\
red cabbage & 210.67 & 0.80 \\
broccoli & 11.96 & 0.73 \\
red pepper & 0.86 & 0.43 \\
cauliflower & 1.02 & 0.42 \\
strawberry & 13.35 & 0.41 \\
fig & 8.07 & 0.37 \\
carrot & 0.60 & 0.30 \\
blueberry & 180.82 & 0.28 \\
cucumber & 0.17 & 0.28 \\
tomato & 5.95 & 0.27 \\
banana & 13.69 & 0.26 \\
cranberry & 132.08 & 0.23 \\
eggplant & 85.73 & 0.23 \\
red onion & 56.61 & 0.21 \\
apple & 15.15 & 0.12 \\
\hline
\end{tabular}

\subsection{Links between Flavonoids and Iron Homeostasis}

Over 30 years ago, it was shown that consumption of tea is in accordance with low non-haem iron bioavailability $[90,91]$. Consequently, flavonoids, or polyphenols, from the tea were recognized as the main cause for low non-haem iron absorption. Today, flavonoids, among them primarily quercetin, are considered as one of the main dietary inhibitors of iron absorption in the duodenum. Even though the exact mechanism of how flavonoids inhibit non-haem iron absorption is still not fully elucidated, it is strongly believed that its power to chelate iron is mainly responsible for this action [92,93]. In contrast, it was shown that quercetin may operate as a substrate for Dcytb by increasing its reduction potential and providing more $\mathrm{Fe}^{2+}$ for cellular uptake by DMT1 [94].

In diseases connected with an imbalance in iron homeostasis, organ-specific iron accumulation is present. In order to bring iron levels back into balance, chelato therapeutics are applied. Potent chelato therapeutics should be able to go through iron-over loaded tissues, complex iron by forming stable and redox-inactive iron and transfer it to Tf in the circulation. Known chelato therapeutic drugs fulfil more or less listed requirements [95]. However, it has been proven in vitro that quercetin is able to decrease intracellular iron and to transfer it to Tf. These significant findings suggest that quercetin could be a valuable representative of chelato therapeutics for iron-redistribution therapy. Yet, this fact still needs to be proven with in vivo studies [96]. On the other hand, it is clear that flavonoids should be avoided in IDA, especially during oral consumption of iron either as a natural constituent of the diet or as a food supplement.

Furthermore, flavonoids were shown to be potent in regulation of systemic iron metabolism. Namely, Bayele et al. [97] reported that quercetin increased expression of hepcidin, a main iron regulatory hormone, which might involve the Nrf2 pathway. Other authors showed in cells that quercetin is able to activate Nrf2 pathway by supporting its nuclear translocation and transcriptional activity [98]. In view of the fact that levels of FPN and H and L ferritin are also known to be transcriptionally up regulated by Nrf2 pathway quercetin could affect iron homeostasis and help cells defending against oxidative stress. Moreover, Vanhees et al. [99] showed that prenatal exposure to quercetin caused hepcidin induction in adult mice.

\subsubsection{Flavonoids as Iron Chelators}

Flavonoids are known for their numerous health benefits which are mostly attributed to their ability to scavenge highly reactive free radical species. However, flavonoids' antioxidative potential is, 
at least partially, associated with their ability to chelate iron. By chelating iron, flavonoids reduce the accessibility of iron to oxygen and consequently diminish oxygen high toxicity, e.g., by inhibiting the production of $\mathrm{HO}^{\bullet}$ in Fenton reaction [99].

The exact mechanism by which certain flavonoids reduce bioavailability of non-haem iron is not fully understood, but it is proposed that flavonoids are able to chelate non-haem iron [92,93,100-102].

Like most other flavonoids, it was proven that quercetin possesses a high ability to chelate iron [103]. The preferred site for iron chelation by flavonoids, such as quercetin, is its 3-hydroxyl and 4-carbonyl group. Specifically, for complexes containing one iron and one quercetin, the binding strength has an order 3-4>4-5>3'-4'. Moreover, the 3-4 chelation site is also preferred for complexes which are formed between one iron and two or three quercetin molecules (see Figure 5) [104]. In addition, it is estimated that quercetin, like most other flavonoids, forms a complex with $\mathrm{Fe}^{3+}$ with a greater stability than $\mathrm{Fe}^{2+}$. Even though when quercetin initially forms a complex with $\mathrm{Fe}^{2+}, \mathrm{Fe}^{2+}$ will autooxidise to $\mathrm{Fe}^{3+}[105]$.<smiles>OC1=CC(O)C2C(=C1)OC(c1ccc(O)c(O)c1)=C1O[CH]CC12</smiles><smiles></smiles><smiles>Oc1cc(O)c2c(c1)OC(c1ccc3c(c1)O[I-]O3)C(O)C2O</smiles>

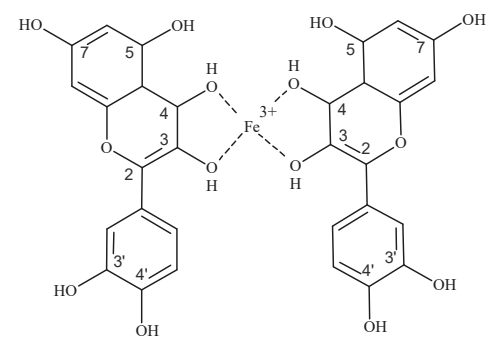

Figure 5. Structures of complexes between $\mathrm{Fe}^{3+}$ and quercetin.

Regarding inhibition of iron absorption by quercetin, it was clearly demonstrated in vivo that chelation of iron by the 3-hydroxyl group of quercetin is an important determinate of iron uptake in duodenum [93]. The authors confirmed that the decrease in duodenal iron transfer is due to chelation of iron by quercetin which increases apical uptake of iron, but prevents basolateral transport. Further information that supports this hypothesis is the fact that the quercetin-Fe complex is considerably stable in gastrointestinal conditions. Namely, it was shown in vitro, by mimicking conditions that occur in the stomach, that the recovery of quercetin-Fe complex is up to $45 \%$, which supports the importance of chelation of iron by quercetin in the human body [106]. However, the precise place of iron chelation by quercetin is still uncertain. It is still unknown whether chelation occurs in the duodenal lumen or the cytosol of duodenal enterocytes. One explanation could be that iron is chelated by quercetin in the duodenal lumen by forming the apical-membrane-permeable quercetin-Fe complex that cannot cross the basolateral membrane of enterocyte. Despite its great size, there are in vitro reports that support transport of the quercetin-Fe complex across the cell membrane in both directions [96]. Furthermore, there is evidence that the quercetin-Fe complex is transported by GLUTs transporters [107], which could also be the case in vivo. Furthermore, even though it was shown that quercetin can be transported via GLUTs 1, 3 and 4 transporters, quercetin is lipophilic enough so it can easily cross lipid bilayers without 
interaction with transporters $[80,107,108]$. A second possibility is that that quercetin could influx into the cell and then form a complex with free iron. Additionally, it was shown that quercetin may operate as a substrate for Dcytb by increasing its reduction potential and providing more $\mathrm{Fe}^{2+}$ for cellular uptake by DMT1 [94]. Knowing this, quercetin could firstly chemically reduce non-haem iron and thus increase apical uptake followed by formation of the quercetin-Fe complex inside the cell. Therefore, both luminal and cytosolic iron chelation, or their combination, can provoke iron accumulation within duodenal mucosa in vivo. However, in both cases the quercetin-Fe complex could remain in the enterocyte due to the inhibition of FPN function or simply because the quercetin-Fe complex would be too bulky to be transported by FPN. This explanation can be applied to all polyphenols that have a noticeable capacity to chelate iron, particularly those which are present in the diet and thus can directly affect iron absorption.

This phenomenon was previously shown for other polyphenols, particularly for (-)-epigallocatechin-3-gallate, but in in vitro conditions using Caco-2 cells as a model system [101,109]. Kim et al. [101,109] reported their finding as unexpected as it was common to think that polyphenols inhibit iron absorption by preventing mainly apical uptake of non-haem iron.

Furthermore, the quercetin-Fe complex inside the cell could be a negative signal for the iron regulatory protein/iron responsive element (IRE/IRP) system and thus destabilize FPN mRNA. Thus, by chelating iron, quercetin could lower free iron levels inside the cell and thus trigger the post-transcriptional IRE/IRP control system, such that when iron levels in tissue are reduced, the expression of FPN is decreased [110]. Furthermore, the possibility that quercetin or its metabolites have direct inhibitory effects on the function of FPN should not be discounted. In addition, bearing in mind that many proteins that have a pivotal role in iron homeostasis beside FPN, such as ferritin, DMT1, TfR1 and Hif- $2 \alpha$, are also regulated by the IRE/IRP system the role of flavonoids which are potent to chelate iron becomes even more important.

Together all these mechanisms could account for the increased mucosal iron retention observed in our studies [93,102]. Furthermore, if a quercetin-Fe complex is formed inside the cell, it could be proposed that quercetin could affect absorption of haem iron too. Namely, quercetin could also prevent the export of free iron for the haem source, after haem degradation by HO-1 which occurs in the cytosol after its absorption.

Potentially listed modes of action could be ascribed to all dietary polyphenols that have demonstrable capacity to chelate iron and this information could be useful in the design of iron chelators based on the structure of these common dietary polyphenols.

In marked contrast, work using Caco-2 cells showed that certain flavonoids promote iron bioavailability (i.e., epicatechin, kaempferol $[111,112])$. However, these are still in vitro results that needs to be confirmed in vivo.

\subsubsection{Flavonoids as Regulators of Systemic Iron Metabolism}

It was shown that flavonoids could play important role in regulation of systemic iron metabolism. Namely, a couple of studies have shown that flavonoids have a great effect on hepcidin levels in vivo. However, results are contradictory.

Bayele et al. [97] reported that intraperitoneal quercetin increased hepcidin expression which might involve the Nrf2 pathway, which also correlated with changes in serum iron levels and Tf saturation, as well as with reduction in FPN mRNA. Vanhees et al. [99] showed that prenatal exposure to quercetin caused hepcidin induction in adult mice and the authors hypothesized that after birth, when pups were no longer exposed to quercetin, improved bioavailability of dietary iron sensed as body iron overload. Lesjak et al. [102] showed that quercetin increased hepcidin mRNA levels in both liver and spleen. Increased levels of hepcidin were followed by decreased FPN levels.

However, previous results of others indicate contradictory results on how different dietary polyphenols affect hepcidin levels. Mu et al. [113] reported that the polyphenol myricetin inhibits hepcidin expression induction in vivo by the BMP/SMAD signalling pathway. Quercetin and myricetin 
are very similar in structure, with myricetin having an extra hydroxyl group. The differences in effect of these two similar polyphenols on iron absorption indicate the complexity of responses to polyphenols. Furthermore, Zhen et al. [114] and Patchen et al. [115] showed that genistein, a main polyphenol from soya, and ipriflavone, synthetic analogue derived from abundant dietary polyphenol daidzein, respectively, both strongly promote hepcidin expression in vivo. Recent studies by Grillo et al. [116] and Zhang et al. [117] indicate that other natural products apart from flavonoids could also have a major role in iron metabolism in vivo and may have potential in therapy of iron metabolism disorders. Namely, Grillo et al. [116] showed that hinokitiol, a natural product of terpenoid structure found in wood that strongly complex iron, could restore iron transport in vivo very effectively. Zhang et al. [117] elucidated that prenylated flavonoid glycoside icariin, which can be found in some Chinese herbal medicinal plants, are able to induce hepcidin expression in mice and change serum and tissue iron concentrations by activating Stat 3 and Smad1/5/8 signaling pathways.

Interestingly, it was shown that quercetin directly regulates FPN expression [93]. Namely, in Caco-2 cells exposed to quercetin there was a significant dose-dependent decrease in FPN protein and mRNA and this was associated with a significant decrease in iron transport across Caco-2 cell monolayers. This occurrence was associated with interactions between miRNA and 3'UTR of FPN mRNA. This data suggests a possible great role for miR-17 and potentially other microRNAs in mediating diet-gene interactions that can influence nutrient bioavailability [93].

\section{Conclusions}

All of the above-mentioned possible impacts of flavonoids on iron homeostasis become even more significant in the view that they are consumed regularly in considerable amounts and that nowadays their supplementation is supported due to numerous health benefits. On the other hand, as imbalance in iron homeostasis is connected with many diseases, flavonoids may have important applications in their treatment. Hence it is of great importance to fully understand how dietary flavonoids interact with intake and homeostasis of iron and thus research in this direction should be supported. Further testing of phenolic compounds with iron chelating and cell signaling properties in animal models of iron overload could provide the basis for novel approaches for treating clinical iron deficiency as well as overload in humans. Namely, they could lead to development of new dietary approaches to preventing and treating IDA. In addition, flavonoids might be beneficial for groups at risk of iron loading (e.g., patients with hereditary haemochromatosis), either by limiting the rate of intestinal iron absorption or by modifying tissue iron distribution.

Author Contributions: Conceptualization, M.L. and S.K.S.S.; writing-original draft preparation, M.L. and S.K.S.S.; writing—review and editing, M.L. and S.K.S.S.; visualization, M.L. and S.K.S.S.

Funding: This research received no external funding.

Acknowledgments: Marija Lesjak was supported by Ministry of Education, Science and Technological Development Republic of Serbia (Grant no. 172058), L'Oréal-UNESCO For Women in Science National Fellowship (Serbia) and a "Start Up for Science" scholarship awarded by the Leadership Development Center from Serbia with the financial support of Philip Morris Operations a.d. Niš, Serbia.

Conflicts of Interest: The authors declare no conflicts of interest.

\section{References}

1. Crichton, R.R. Inorganic Biochemistry of Iron Metabolism: From Molecular Mechanisms to Clinical Consequences, 2nd ed.; John Wiley \& Sons Ltd.: Chichester, UK, 2001.

2. Lieu, P.T.; Heiskala, M.; Peterson, P.A.; Yang, Y. The roles of iron in health and disease. Mol. Asp. Med. 2001, 22, 1-87. [CrossRef]

3. Yehuda, S.; Mostofsky, D.I. Iron Deficiency and Overload: From Basic Biology to Clinical Medicine; Humana Press: New York, NY, USA, 2010.

4. Ying-Wu, L.; Jiangyun, W. Structure and function of heme proteins in non-native states: A mini-review. J. Inorg. Biochem. 2013, 129, 162-171. 
5. Lill, R.; Muhlenhoff, U. Iron-sulfur protein biogenesis in eukaryotes: Components and mechanisms. Annu. Rev. Cell Dev. Biol. 2006, 22, 457-486. [CrossRef] [PubMed]

6. World Health Organization. Iron Deficiency Anaemia: Assessment, Prevention, and Control. A Guide for Programme Managers; WHO Press: Geneva, Switzerland, 2001.

7. Dunn, L.L.; Suryo Rahmanto, Y.; Richardson, D.R. Iron uptake and metabolism in the new millennium. Trends Cell Biol. 2007, 17, 93-100. [CrossRef] [PubMed]

8. Sharp, P.; Srai, S.K. Molecular mechanisms involved in intestinal iron absorption. World J. Gastroenterol. 2007, 13, 4716-4724. [CrossRef] [PubMed]

9. Martins, A.C.; Almeida, J.I.; Lima, I.S.; Kapitão, A.S.; Gozzelino, R. Iron Metabolism and the Inflammatory Response. IUBMB Life 2017, 69, 442-450. [CrossRef]

10. Wang, L.; Cherayil, B.J. Ironing out the wrinkles in host defense: Interactions between iron homeostasis and innate immunity. J. Innate Immun. 2009, 1, 455-464. [CrossRef]

11. Halliwell, B.; Gutteridge, J.M.C. Free Radicals in Biology and Medicine, 4th ed.; Oxford University Press: Oxford, UK, 2007.

12. Koppenol, W.H. The Haber-Weiss cycle-70 years later. Redox Rep. 2001, 6, 229-234. [CrossRef]

13. Hentze, M.W.; Muckenthaler, M.U.; Andrews, N.C. Balancing acts: Molecular control of mammalian iron metabolism. Cell 2004, 117, 285-297. [CrossRef]

14. Andrews, N.C. Disorders of iron metabolism. N. Engl. J. Med. 1999, 341, 1986-1995. [CrossRef]

15. Papanikolaoua, G.; Pantopoulos, K. Iron metabolism and toxicity. Toxicol. Appl. Pharmacol. 2005, 202, $199-211$. [CrossRef] [PubMed]

16. Beaumont, C.; Delaby, C. Recycling iron in normal and pathological states. Semin. Hematol. 2009, 46, 328-338. [CrossRef] [PubMed]

17. Srai, S.K.; Bomford, A.; McArdle, H.J. Iron transport across cell membranes: Molecular understanding of duodenal and placental iron uptake. Best Pract. Res. Clin. Haematol. 2002, 15, 243-259. [CrossRef] [PubMed]

18. McKie, A.T.; Barrow, D.; Latunde-Dada, G.O.; Rolfs, A.; Sager, G.; Mudaly, E.; Mudaly, M.; Richardson, C.; Barlow, D.; Bomford, A.; et al. An iron-regulated ferric reductase associated with the absorption of dietary iron. Science 2001, 291, 1755-1759. [CrossRef] [PubMed]

19. Gunshin, H.; Mackenzie, B.; Berger, U.V.; Gunshin, Y.; Romero, M.F.; Boron, W.F.; Nussberger, S.; Gollan, J.L.; Hediger, M.A. Cloning and characterization of a mammalian proton-coupled metal-ion transporter. Nature 1997, 388, 482-488. [CrossRef]

20. Philpott, C.C.; Ryu, M.S.; Frey, A.; Patel, S. Cytosolic iron chaperones: Proteins delivering iron cofactors in the cytosol of mammalian cells. J. Biol. Chem. 2017, 292, 12764-12771. [CrossRef]

21. Abboud, S.; Haile, D.J. A novel mammalian iron-regulated protein involved in intracellular iron metabolism. J. Biol. Chem. 2000, 275, 19906-19912. [CrossRef]

22. Donovan, A.; Brownlie, A.; Zhou, Y.; Shepard, J.; Pratt, S.J.; Moynihan, J.; Paw, B.H.; Drejer, A.; Barut, B.; Zapata, A.; et al. Positional cloning of zebrafish ferroportin 1 identifies a conserved vertebrate iron exporter. Nature 2000, 403, 776-781. [CrossRef]

23. McKie, A.T.; Marciani, P.; Rolfs, A.; Brennan, K.; Wehr, K.; Barrow, D.; Miret, S.; Bomford, A.; Peters, T.J.; Farzaneh, F.; et al. A novel duodenal iron-regulated transporter, IREG1, implicated in the basolateral transfer of iron to the circulation. Mol. Cell 2000, 5, 299-309. [CrossRef]

24. Vulpe, C.D.; Kuo, Y.M.; Murphy, T.L.; Cowley, L.; Askwith, C.; Libina, N.; Gitschier, J.; Anderson, G.J. Hephaestin, a ceruloplasmin homologue implicated in intestinal iron transport, is defective in the sla mouse. Nat. Genet. 1999, 21, 195-199. [CrossRef] [PubMed]

25. Chen, H.; Attieh, Z.K.; Su, T.; Syed, B.A.; Gao, H.; Alaeddine, R.M.; Fox, T.C.; Usta, J.; Naylor, C.E.; Evans, R.W.; et al. Hephaestin is a ferroxidase that maintains partial activity in sex-linked anemia mice. Blood 2004, 103, 3933-3939. [CrossRef] [PubMed]

26. MacGillivray, R.T.; Mendez, E.; Shewale, J.G.; Sinha, S.K.; Lineback-Zins, J.; Brew, K. The Primary Structure of Human Serum Transferrin; The structures of seven cyanogen bromide fragments and the assembly of the complete structure. J. Biol. Chem. 1983, 258, 3543-3553. [PubMed]

27. Shayeghi, M.; Latunde-Dada, G.O.; Oakhill, J.S.; Laftah, A.H.; Takeuchi, K.; Halliday, N.; Khan, Y.; Warley, A.; McCann, F.E.; Hider, R.C.; et al. Identification of an intestinal heme transporter. Cell 2005, 122, $789-801$. [CrossRef] [PubMed] 
28. Inoue, K.; Nakai, Y.; Ueda, S.; Kamigaso, S.; Ohta, K.-Y.; Hatakeyama, M.; Hayashi, Y.; Otagiri, M.; Yuasa, H. Functional characterization of PCFT/HCP1 as the molecular entity of the carrier-mediated intestinal folate transport system in the rat model. Am. J. Physiol. Gastrointest. Liver Physiol. 2008, 294, G660-G668. [CrossRef] [PubMed]

29. Duffy, S.P.; Shing, J.; Saraon, P.; Berger, L.C.; Eiden, M.V.; Wilde, A.; Tailor, C.S. The Fowler syndrome-associated protein FLVCR2 is an importer of heme. Mol. Cell. Biol. 2010, 30, 5318-5324. [CrossRef] [PubMed]

30. Tenhunen, R.; Marver, H.S.; Schmid, R. Microsomal heme oxygenase. Characterization of the enzyme. J. Biol. Chem. 1969, 244, 6388-6394. [PubMed]

31. Hurrell, R.; Egli, I. Iron bioavailability and dietary reference values. Am. J. Clin. Nutr. 2010, 91, 1461S-1467S. [CrossRef]

32. Abbaspour, N.; Hurrell, R.; Kelishadi, R. Review on iron and its importance for human health. J. Res. Med. Sci. 2014, 19, 164-174.

33. DeMaeyer, E.M.; Dallman, P.; Gurney, J.M.; Hallberg, L.; Sood, S.K.; Srikantia, S.G. Preventing and Controlling Iron Deficiency Anaemia Through Primary Health Care: A Guide for Health Administrators and Programme Managers; World Health Organization: Geneva, Switzerland, 1989.

34. World Health Organization. Assessing the Iron Status of Populations: Including Literature Reviews, 2nd ed.; WHO Press: Geneva, Switzerland, 2007.

35. World Health Organization. Worldwide Prevalence of Anaemia 1993-2005; WHO Press: Geneva, Switzerland, 2008.

36. Franchini, M.; Montagnana, M.; Lippi, G. Hepcidin and iron metabolism: From laboratory to clinical implications. Clin. Chim. Acta 2010, 411, 1565-1569. [CrossRef]

37. World Health Organization. The World Health Report 2002. Reducing Risks, Promoting Healthy Life; WHO Press: Geneva, Switzerland, 2002.

38. World Health Organization. The Global Prevalence of Anaemia in 2011; WHO Document Production Services: Geneva, Switzerland, 2017.

39. USDA. USDA Food Composition Databases. Available online: https://ndb.nal.usda.gov/ndb/search/list? home $=$ true (accessed on 4 July 2019).

40. Siegenberg, D.; Baynes, R.D.; Bothwell, T.H.; Macfarlane, B.J.; Lamparelli, R.D.; Car, N.G.; MacPhail, P.; Schmidt, U.; Tal, A.; Mayet, F. Ascorbic acid prevents the dose-dependent inhibitory effects of polyphenols and phytates on nonheme-iron absorption. Am. J. Clin. Nutr. 1991, 53, 537-541. [CrossRef]

41. Hurrell, R.F.; Reddy, M.B.; Juillerat, M.A.; Cook, J.D. Degradation of phytic acid in cereal porridges improves iron absorption by human subjects. Am. J. Clin. Nutr. 2003, 77, 1213-1219. [CrossRef] [PubMed]

42. Hurrell, R.F. Phytic acid degradation as a means of improving iron absorption. Int. J. Vitam. Nutr. Res. 2004, 74, 445-452. [CrossRef] [PubMed]

43. Schlemmer, U.; Frølich, W.; Prieto, R.M.; Grases, F. Phytate in foods and significance for humans: Food sources, intake, processing, bioavailability, protective role and analysis. Mol. Nutr. Food Res. 2009, 53, S330-S375. [CrossRef] [PubMed]

44. Hallberg, L.; Rossander-Hulten, L.; Brune, M.; Gleerup, A. Calcium and iron absorption: Mechanism of action and nutritional importance. Eur. J. Clin. Nutr. 1992, 46, 317-327. [PubMed]

45. Roughead, Z.K.F.; Zito, C.A.; Hunt, J.R. Inhibitory effects of dietary calcium on the initial uptake and subsequent retention of heme and nonheme iron in humans: Comparisons using an intestinal lavage method. Am. J. Clin. Nutr. 2005, 82, 589-597. [CrossRef] [PubMed]

46. Hurrell, R.F.; Lynch, S.R.; Trinidad, T.P.; Dassenko, S.A.; Cook, J.D. Iron absorption in humans: Bovine serum albumin compared with beef muscle and egg white. Am. J. Clin. Nutr. 1988, 47, 102-107. [CrossRef] [PubMed]

47. Hurrell, R.F.; Lynch, S.R.; Trinidad, T.P.; Dassenko, S.A.; Cook, J.D. Iron absorption in humans as influenced by bovine milk proteins. Am. J. Clin. Nutr. 1989, 49, 546-552. [CrossRef]

48. Cook, J.D.; Monsen, E.R. Food iron absorption in human subjects III. Comparison of the effect of animal proteins on nonheme iron absorption. Am. J. Clin. Nutr. 1976, 29, 859-867. [CrossRef]

49. Lynch, S.R.; Dassenko, S.A.; Cook, J.D.; Juillerat, M.A.; Hurrell, R.F. Inhibitory effect of a soybean-protein-related moiety on iron absorption in humans. Am. J. Clin. Nutr. 1994, 60, 567-572. [CrossRef] 
50. Gillooly, M.; Bothwell, T.H.; Torrance, J.D.; MacPhail, A.P.; Derman, D.P.; Bezwoda, W.R.; Mills, W.; Charlton, R.W. The effects of organic acids, phytates and polyphenols on the absorption of iron from vegetables. Br. J. Nutr. 1983, 49, 331-3423. [CrossRef]

51. Ballot, D.; Baynes, R.D.; Bothwell, T.H.; Gillooly, M.; MacFarlane, B.J.; MacPhail, A.P.; Lyons, G.; Derman, D.P.; Bezwoda, W.R.; Torrance, J.D.; et al. The effects of fruit juices and fruits on the absorption of iron from a rice meal. Br. J. Nutr. 1987, 57, 331-343. [CrossRef] [PubMed]

52. Hallberg, L.; Brune, M.; Rossander, L. Iron absorption in man: Ascorbic acid and dose-dependent inhibition by phytate. Am. J. Clin. Nutr. 1989, 49, 140-144. [CrossRef] [PubMed]

53. Carr, A.C.; Frei, B. Toward a new recommended dietary allowance for vitamin $\mathrm{C}$ based on antioxidant and health effects in humans. Am. J. Clin. Nutr. 1999, 69, 1086-1107. [CrossRef] [PubMed]

54. Teucher, B.; Olivares, M.; Cori, H. Enhancers of iron absorption: Ascorbic acid and other organic acids. Int. J. Vitam. Nutr. Res. 2004, 74, 403-419. [CrossRef] [PubMed]

55. Cook, J.D.; Reddy, M.B. Effect of ascorbic acid intake on nonheme-iron absorption from a complete diet. Am. J. Clin. Nutr. 2001, 73, 93-98. [CrossRef] [PubMed]

56. Hurrell, R.F.; Reddy, M.B.; Juillerat, M.; Cook, J.D. Meat protein fractions enhance nonheme iron absorption in humans. J. Nutr. 2006, 136, 2808-2812. [CrossRef] [PubMed]

57. Storcksdieck, S.; Bonsmann, G.; Hurrell, R.F. Iron-binding properties, amino acid composition, and structure of muscle tissue peptides from in vitro digestion of different meat sources. J. Food Sci. 2007, 72, S19-S29. [CrossRef] [PubMed]

58. Armah, C.N.; Sharp, P.; Mellon, F.A.; Pariagh, S.; Lund, E.K.; Dainty, J.R.; Teucher, B.; Fairweather-Tait, S.J. L-alpha-glycerophosphocholine contributes to meat's enhancement of nonheme iron absorption. J. Nutr. 2008, 138, 873-877. [CrossRef] [PubMed]

59. Yip, R.; Ramakrishnan, U. Experiences and Challenges in Developing Countries. J. Nutr. 2002, 132, 827S-830S. [CrossRef]

60. Lynch, S.R. The impact of iron fortification on nutritional anaemia. Best Pract. Res. Clin. Haematol. 2005, 18, 333-346. [CrossRef]

61. Baltussen, R.; Knai, C.; Sharan, M. Iron Fortification and Iron Supplementation are Cost-Effective Interventions to Reduce Iron Deficiency in Four Subregions of the World. J. Nutr. 2004, 134, 2678-2684. [CrossRef] [PubMed]

62. Cheynier, V.; Comte, G.; Davies, K.M.; Lattanzio, V.; Martens, S. Plant phenolics: Recent advances on their biosynthesis, genetics, and ecophysiology. Plant Physiol. Biochem. 2013, 72, 1-20. [CrossRef] [PubMed]

63. Robards, K. Strategies for the determination of bioactive phenols in plants, fruit and vegetables. J. Chromatogr. A 2003, 1000, 657-691. [CrossRef]

64. Lattanzio, V.; Lattanzio, V.M.T.; Cardinali, A. Role of phenolics in the resistance mechanisms of plants against fungal pathogents and insect. In Phytochemistry: Advances in Research; Imperato, F., Ed.; Research Signpost: Trivandrum, Kerala, India, 2006.

65. Bradshaw, H.D.; Schemske, D.W. Allele substitution at a flower colour locus produces a pollinator shift in monkeyflowers. Nature 2003, 426, 176-178. [CrossRef]

66. Falcone Ferreyra, M.L.; Rius, S.P.; Casati, P. Flavonoids: Biosynthesis, biological functions, and biotechnological applications. Front. Plant Sci. 2012, 3, 222. [CrossRef] [PubMed]

67. Sharma, R. Polyphenols in health and disease. Practice and mechanisms of benefits. In Polyphenols in Human Health and Disease; Watson, R.R., Preedy, V.R., Zibadi, S., Eds.; Academic Press: Cambridge, MA, USA, 2014; pp. 757-778.

68. Havsteen, B.H. The biochemistry and medical significance of the flavonoids. Pharmacol. Ther. 2002, 96, 67-202. [CrossRef]

69. Rietveld, A.; Wiseman, S. Antioxidant effects of tea: Evidence from human clinical trials. J. Nutr. 2003, 133, 3285S-3292S. [CrossRef]

70. Liguori, I.; Russo, G.; Curcio, F.; Bulli, G.; Aran, L.; Della-Morte, D.; Gargiulo, G.; Testa, G.; Cacciatore, F.; Bonaduce, D.; et al. Oxidative stress, aging, and diseases. Clin. Interv. Aging 2018, 13, 757-772. [CrossRef]

71. Marzocchella, L.; Fantini, M.; Benvenuto, M.; Masuelli, L.; Tresoldi, I.; Modesti, A.; Bei, R. Dietary flavonoids: Molecular mechanisms of action as anti- inflammatory agents. Recent Pat. Inflamm. Allergy Drug Discov. 2011, 5, 200-220. [CrossRef] 
72. Williamson, G.; Manach, C. Bioavailability and bioefficacy of polyphenols in humans II. Review of 93 intervention studies. Am. J. Clin. Nutr. 2005, 81, S243-S255. [CrossRef]

73. Hooper, L.; Kroon, P.A.; Rimm, E.B.; Cohn, J.S.; Harvey, I.; Le Cornu, K.A.; Ryder, J.J.; Hall, W.L.; Cassidy, A. Flavonoids, flavonoid-rich foods, and cardiovascular risk: A meta-analysis of randomized controlled trials. Am. J. Clin. Nutr. 2008, 88, 38-50. [CrossRef] [PubMed]

74. Egert, S.; Rimbach, G. Which sources of flavonoids: Complex diets or dietary supplements? Adv. Nutr. 2011, 2, 8-14. [CrossRef] [PubMed]

75. Lee, J.; Mitchell, A.E. Pharmacokinetics of Quercetin Absorption from Apples and Onions in Healthy Humans. J. Agric. Food Chem. 2012, 60, 3874-3881. [CrossRef]

76. Walle, T.; Otake, Y.; Walle, U.K.; Wilson, F.A. Quercetin glucosides are completely hydrolyzed in ileostomy patients before absorption. J. Nutr. 2000, 130, 2658-2661. [CrossRef]

77. Wolffram, S.; Blöck, M.; Ader, P. Quercetin-3-glucoside is transported by the glucose carrier SGLT1 across the brush border membrane of rat small intestine. J. Nutr. 2002, 132, 630-635. [CrossRef] [PubMed]

78. Day, A.J.; Gee, J.M.; DuPont, M.S.; Johnson, I.T.; Williamson, G. Absorption of quercetin-3-glucoside and quercetin- $4^{\prime}$-glucoside in the rat small intestine: The role of lactase phlorizin hydrolase and the sodium-dependent glucose transporter. Biochem. Pharmacol. 2003, 65, 1199-1206. [CrossRef]

79. Ziberna, L.; Fornasaro, S.; Čvorović, J.; Tramer, F.; Passamonti, S. Bioavailability of flavonoids: The role of cell membrane transporters. In Polyphenols in Human Health and Disease; Watson, R.R., Preedy, V.R., Zibadi, S., Eds.; Academic Press: Cambridge, MA, USA, 2014; pp. 489-511.

80. Strobel, P.; Allard, C.; Perez-Acle, T.; Calderon, R.; Aldunate, R.; Leighton, F. Myricetin, quercetin and catechin-gallate inhibit glucose uptake in isolated rat adipocytes. Biochem. J. 2005, 386, 471-478. [CrossRef] [PubMed]

81. Hollman, P.C.; Bijsman, M.N.; van Gameren, Y.; Cnossen, E.P.; de Vries, J.H.; Katan, M.B. The sugar moiety is a major determinant of the absorption of dietary flavonoid glycosides in man. Free Radic. Res. 1999, 31, 569-573. [CrossRef]

82. Morand, C.; Manach, C.; Crespy, V.; Remesy, C. Quercetin 3-O-beta-glucoside is better absorbed than other quercetin forms and is not present in rat plasma. Free Radic. Res. 2000, 33, 667-676. [CrossRef]

83. Olthof, M.R.; Hollman, P.C.H.; Buijsman, M.N.C.P.; Amelsvoort, J.M.M.; Katan, M.B. Chlorogenic acid, quercetin-3-rutinoside and black tea polyphenols are extensively metabolized in humans. J. Nutr. 2003, 133, 1806-1814. [CrossRef]

84. Mullen, W.; Edwards, C.A.; Crozier, A. Absorption, excretion and metabolite profiling of methyl-, glucuronyl-, glucosyl- and sulpho-conjugates of quercetin in human plasma and urine after ingestion of onions. Br. J. Nutr. 2006, 96, 107-116. [CrossRef] [PubMed]

85. Schroeter, H.; Heiss, C.; Spencer, J.P.; Keen, C.L.; Lupton, J.R.; Schmitz, H.H. Recommending flavanols and procyanidins for cardiovascular health: Current knowledge and future needs. Mol. Asp. Med. 2010, 31, 546-557. [CrossRef] [PubMed]

86. Lam, T.K.; Rotunno, M.; Lubin, J.H.; Wacholder, S.; Consonni, D.; Pesatori, A.C.; Bertazzi, P.A.; Chanock, S.J.; Burdette, L.; Goldstein, A.M.; et al. Dietary quercetin, quercetin-gene interaction, metabolic gene expression in lung tissue and lung cancer risk. Carcinogenesis 2010, 31, 634-642. [CrossRef] [PubMed]

87. Ekström, A.M.; Serafini, M.; Nyrén, O.; Wolk, A.; Bosetti, C.; Bellocco, R. Dietary quercetin intake and risk of gastric cancer: Results from a population-based study in Sweden. Ann. Oncol. 2011, 22, 438-443. [CrossRef] [PubMed]

88. Beecher, G.R. Overview of Dietary Flavonoids: Nomenclature, Occurrence and Intake. J. Nutr. 2003, 133, 3248S-3254S. [CrossRef] [PubMed]

89. Bhagwat, S.; Haytowitz, D.B.; Holden, J.M. USDA Database for the Flavonoid Content of Selected Foods; U.S. Department of Agriculture: Beltsville, MD, USA, 2014.

90. Disler, P.B.; Lynch, S.R.; Charlton, R.W.; Torrance, J.D.; Bothwell, T.H.; Walker, R.B.; Mayet, F. The effect of tea on iron absorption. Gut 1975, 16, 193-200. [CrossRef] [PubMed]

91. Rossander, L.; Hallberg, L.; Bjom-Rasmussen, E. Absorption of iron from breakfast meals. Am. J. Clin. Nutr. 1979, 32, 2484-2489. [CrossRef]

92. Petry, N. Polyphenols and low iron bioavailability. In Polyphenols in Human Health and Disease; Watson, R.R., Preedy, V.R., Zibadi, S., Eds.; Academic Press: Cambridge, MA, USA, 2014; pp. 311-322. 
93. Lesjak, M.; Hoque, R.; Balesaria, S.; Skinner, V.; Debnam, E.S.; Srai, S.K.; Sharp, P.A. Quercetin inhibits intestinal iron absorption and ferroportin transporter expression in vivo and in vitro. PLOS ONE 2014, 9, e102900. [CrossRef]

94. Vlachodimitropoulou, E.; Naftalin, R.J.; Sharp, P.A. Quercetin is a substrate for the transmembrane oxidoreductase Dcytb. Free Radic. Biol. Med. 2010, 48, 1366-1369. [CrossRef]

95. Poggiali, E.; Cassinerio, E.; Zanaboni, L.; Cappellini, M.D. An update on iron chelation therapy. Blood Transfus. 2012, 10, 411-422.

96. Baccan, M.M.; Chiarelli-Neto, O.; Pereira, R.M.S.; Espósito, B.P. Quercetin as a shuttle for labile iron. J. Inorg. Biochem. 2012, 107, 34-39. [CrossRef] [PubMed]

97. Bayele, H.K.; Balesaria, S.; Srai, S.K.S. Phytoestrogens modulate hepcidin expression by Nrf2: Implications for dietary control of iron absorption. Free Radic. Biol. Med. 2015, 89, 1192-1202. [CrossRef] [PubMed]

98. Granado-Serrano, A.B.; Martín, M.A.; Bravo, L.; Goya, L.; Ramos, S. Quercetin modulates Nrf2 and glutathione-related defenses in HepG2 cells: Involvement of p38. Chem. Biol. Interact. 2012, 195, 154-164. [CrossRef] [PubMed]

99. Vanhees, K.; Godschalk, R.W.; Sanders, A.; van Doorn, S.B.V.W.; van Schooten, F.J. Maternal quercetin intake during pregnancy results in an adapted iron homeostasis at adulthood. Toxicology 2011, 290, 350-358. [CrossRef] [PubMed]

100. Mladěnka, P.; Macáková, K.; Filipský, T.; Zatloukalová, L.; Jahodář, L.; Bovicelli, P.; Silvestri, I.P.; Hrdina, R.; Saso, L. In vitro analysis of iron chelating activity of flavonoids. J. Inorg. Biochem. 2011, 105, 693-701. [CrossRef] [PubMed]

101. Kim, E.Y.; Ham, S.; Bradke, D.; Ma, Q.; Han, O. Ascorbic acid offsets the inhibitory effect of bioactive dietary polyphenolic compounds on transepithelial iron transport in Caco-2 intestinal cells. J. Nutr. 2011, 141, 828-834. [CrossRef] [PubMed]

102. Lesjak, M.; Balesaria, S.; Skinner, V.; Debnam, E.S.; Srai, S.K.S. Quercetin inhibits intestinal non-haem iron absorption by regulating iron metabolism genes in the tissues. Eur. J. Nutr. 2019, 58, 743-753. [CrossRef] [PubMed]

103. Leopoldini, M.; Russo, N.; Chiodo, S.; Toscano, M. Iron chelation by the powerful antioxidant flavonoid quercetin. J. Agric. Food Chem. 2006, 54, 6343-6351. [CrossRef] [PubMed]

104. Ren, J.; Meng, S.; Lekka, C.E.; Kaxiras, E. Complexation of Flavonoids with Iron: Structure and Optical Signatures. J. Phys. Chem. B 2008, 112, 1845-1850. [CrossRef] [PubMed]

105. Perron, N.R.; Brumaghim, J.L. A Review of the Antioxidant Mechanisms of Polyphenol Compounds Related to Iron Binding. Cell Biochem. Biophys. 2009, 53, 75-100. [CrossRef]

106. Escudero, L.B.; Fusari, C.M.; Altamirano, J.C.; Camargo, A.B.; Wuilloud, R.G. Stability of Iron-Quercetin Complexes in Synthetic Wine under in vitro Digestion Conditions. J. Food Sci. 2014, 79, C1933-C1938. [CrossRef] [PubMed]

107. Vlachodimitropoulou, E.; Sharp, P.A.; Naftalin, R.J. Quercetin-iron chelates are transported via glucose transporters. Free Radic. Biol. Med. 2011, 50, 934-944. [CrossRef] [PubMed]

108. Cunningham, P.; Afzal-Ahmed, I.; Naftalin, R.J. Docking studies show that D-glucose and quercetin slide through the transporter GLUT1. J. Biol. Chem. 2006, 281, 5797-5803. [CrossRef] [PubMed]

109. Kim, E.; Ham, S.; Shigenaga, M.K.; Han, O. The inhibiting bioactive dietary polyphenolic compounds reduce nonheme iron transport across human intestinal cell monolayers. J. Nutr. 2008, 138, 1647-1651. [CrossRef] [PubMed]

110. Muckenthaler, M.U.; Galy, B.; Hentze, M.W. Systemic iron homeostasis and the iron-responsive element/iron-regulatory protein (IRE/IRP) regulatory network. Annu. Rev. Nutr. 2008, 28, 197-213. [CrossRef] [PubMed]

111. Hart, J.J.; Tako, E.; Kochian, L.V.; Glahn, R.P. Identification of black bean (Phaseolus vulgaris L.) polyphenols that inhibit and promote iron uptake by Caco-2 cells. J. Agric. Food Chem. 2015, 63, 5950-5956. [CrossRef] [PubMed]

112. Hart, J.J.; Tako, E.; Glahn, R.P. Characterization of polyphenol effects on inhibition and promotion of iron uptake by Caco-2 cells. J. Agric. Food Chem. 2017, 65, 3285-3294. [CrossRef]

113. Mu, M.; An, P.; Wu, Q.; Shen, X.; Shao, D.; Wang, H.; Zhang, Y.; Zhang, S.; Yao, H.; Min, J.; et al. The dietary flavonoid myricetin regulates iron homeostasis by suppressing hepcidin expression. J. Nutr. Biochem. 2016, 30, 53-61. [CrossRef] 
114. Zhen, A.W.; Nguyen, N.H.; Gibert, Y.; Motola, S.; Buckett, P.; Wessling-Resnick, M.; Fraenkel, E.; Fraenkel, P.G. The small molecule, genistein, increases hepcidin expression in human hepatocytes. Hepatology 2013, 58, 1315-1325. [CrossRef]

115. Patchen, B.; Koppe, T.; Cheng, A.; Seo, Y.A.; Wessling-Resnick, M.; Fraenkel, P.G. Dietary supplementation with ipriflavone decreases hepatic iron stores in wild type mice. Blood Cells Mol. Dis 2016, 60, 36-43. [CrossRef]

116. Grillo, A.S.; SantaMaria, A.M.; Kafina, M.D.; Cioffi, A.G.; Huston, N.C.; Han, M.; Seo, Y.A.; Yien, Y.Y.; Nardone, C.; Menon, A.V.; et al. Restored iron transport by a small molecule promotes absorption and hemoglobinization in animals. Science 2017, 356, 608-616. [CrossRef] [PubMed]

117. Zhang, M.; Liu, J.; Guo, W.; Liu, X.; Liu, S.; Yin, H. Icariin regulates systemic iron metabolism by increasing hepatic hepcidin expression through Stat3 and Smad1/5/8 signaling. Int. J. Mol. Med. 2016, 37, 1379-1388. [CrossRef] [PubMed]

(C) 2019 by the authors. Licensee MDPI, Basel, Switzerland. This article is an open access article distributed under the terms and conditions of the Creative Commons Attribution (CC BY) license (http://creativecommons.org/licenses/by/4.0/). 


\title{
Gut Microbiota and Iron: The Crucial Actors in Health and Disease
}

\author{
Bahtiyar Yilmaz ${ }^{1,2, *}$ and $\mathrm{Hai} \mathrm{Li}^{1,2}$ \\ 1 Maurice Müller Laboratories, Department of Biomedical Research, University of Bern, 3008 Bern, \\ Switzerland; hai.li@dbmr.unibe.ch \\ 2 University Clinic of Visceral Surgery and Medicine, Inselspital, 3010 Bern, Switzerland \\ * Correspondence: bahtiyar_yilmaz@outlook.com; Tel.: +41-31-632-86-82
}

Received: 12 September 2018; Accepted: 2 October 2018; Published: 5 October 2018

\begin{abstract}
Iron (Fe) is a highly ample metal on planet earth ( $35 \%$ of the Earth's mass) and is particularly essential for most life forms, including from bacteria to mammals. Nonetheless, iron deficiency is highly prevalent in developing countries, and oral administration of this metal is so far the most effective treatment for human beings. Notably, the excessive amount of unabsorbed iron leave unappreciated side effects at the highly interactive host-microbe interface of the human gastrointestinal tract. Recent advances in elucidating the molecular basis of interactions between iron and gut microbiota shed new light(s) on the health and pathogenesis of intestinal inflammatory diseases. We here aim to present the dynamic modulation of intestinal microbiota by iron availability, and conversely, the influence on dietary iron absorption in the gut. The central part of this review is intended to summarize our current understanding about the effects of luminal iron on host-microbe interactions in the context of human health and disease.
\end{abstract}

Keywords: iron; gut microbiota; iron supplementation; iron transporters; mucosal immunity; SCFA; intestinal inflammation; inflammatory bowel disease (IBD); colorectal cancer

\section{Introduction}

The availability of iron is enormously vital for many living organisms, particularly humans and microbes. Iron has a direct impact on host-microbiota interactions via altering microbial/viral growth, acting on the host immune system, and drafting in a range of biochemical processes critical to sustain life [1-3]. Most living beings have evolved to acquire iron from their proximate niche as an evolutionary conserved strategy. Iron mainly works as an universal co-factor for proteins such as hemoglobin, and for numerous enzymes involved in oxygen transport mechanisms, mitochondrial respiration, intermediary and xenobiotic metabolism, and fundamental biological processes such as cell growth and differentiation [4]. Nonetheless, iron deficiency, the most prevalent nutritional disorder, or iron overload in gut due to its malabsorption, can alter host mucosal immune responses. Notably, this is supported by several observations in the course of infectious disease or intestinal inflammatory disease $[3,5,6]$. Conversely, an accumulated body of evidence also suggests that immune activation can regulate iron metabolism that then leads to the development of iron-restricted anemia $[1,5,7,8]$. In this review, we meticulously cover the multifaceted aspects involved in iron-mediated host-microbe interactions in the gut, for a better understanding of bi-directional cross-talk between iron homeostasis and the mucosal immune system primed by gut microbiota. We begin with introducing general concepts of gut microbiota and metabolic stress in gut lumen. We then concisely present systemic iron metabolism and homeostasis concepts. The central part of this review focuses on our current knowledge about mechanisms mediating the effects of luminal iron on host intestinal immune responses, as well as the effects of abnormal gut immunity on iron homeostasis due to changes in 
abundance of commensal and pathogenic bacteria in gut. We last discuss the effects of iron metabolism on intestinal inflammation and colorectal cancers via modulation of the gut microbial profile.

\section{Mammalian Gut Microbiome in Health}

Humans and other animals co-exist with vast numbers of microorganisms in their lower intestine, and they are in continuous interaction with these entities on a daily basis. If one thinks of a human as a host-microbial super-organism, these prokaryotic constituents comprise $90 \%$ of our total cells and contain $99 \%$ of the aggregate gene pool [9]. The existence of highly co-evolved mutualism between microbes that inhabit body surfaces and the host immune system have promoted beneficial co-existence and interdependency over millions of years. Such mutualism starts at birth and continues throughout life, driven by the colonization of microbial consortia within specific niches. Mucosal surfaces are densely colonized by bacteria, fungi, archaea, viruses, and parasites that are mainly non-pathogenic in healthy hosts: the extended metabolic potential of biochemical pathways in microbes crucially contribute to host physiology, including digestive [10,11] and protective [12-15] functions, microbial catabolism of otherwise indigestible foodstuffs [16], provision of essential amino acids, maturation of host mucosal immune system [17-20], and completing the bile-salt cycle and pre-systemic metabolism of drugs and toxins [21-26]. By far, the gastrointestinal tract (GI) is the most heavily colonized organ in humans, and it contains over $70 \%$ of all the microbes in the body. The human gut has an estimated surface area of a tennis court, and it is a preferred site for colonization due to its constant physiological temperature and richness in molecules that can be used as nutrients by microbes. Though bacteria belonging to Bacteroidetes ( 16-23\%) and Firmicutes ( 49-76\%) phyla, and to a lesser extent, Actinobacteria $(<5 \%)$ and Proteobacteria $(<10 \%)$ constitute the main players in human intestines, besides, there is a greater diversity at lower taxonomic levels. Prominently, the viable intestinal microbiota are critical for retaining a healthy host [27]. However, host-microbial interactions are not always mutualistic; unfortunately, like any beautiful relationship, this mutualism can also turn sour $[26,28]$. Several features of the modern lifestyle directly contribute to this situation via antibiotics and other medications, including birth control and non-steroidal anti-inflammatory drugs, diets high in refined carbohydrates, sugar, and processed foods or low in fermentable fibers, dietary toxins such as gluten in wheat and industrial seed oils, and the modern plague chronic stress. Under these extreme pathophysiological conditions, the interactions can be subsumed in a pathogenic relationship, leading to alterations in the composition of microbial consortia and their metabolic functions, accompanied by a loss of fitness of the host-producing the occurrence or manifestation of disease [11], including many gastrointestinal disorders such as diarrhea, gastroenteritis, irritable bowel syndrome (IBS), and inflammatory bowel disease (IBD) [29-33]. However, the uncharacterized features of different prokaryotic constituents within the diverse microbiological environment that can provoke different types of host immune responses that still make it difficult to identify the source(s) of a soured mutualistic relationship.

Many characteristics concerning mammalian gut microbiota, including the dynamics impact of its assembly, which define the spatial distribution and functional features of its prokaryotic members, remain vague. Concurrently, the factors involved in shaping the gut microbiota were extensively studied in the last decade. Well-characterized factors that influence gut colonization during life are among diet (including breast feeding and formula-based feed in early life), hygiene, illness, medication, surgery, hospitalization, stress, sport activity, aging, and smoking and alcohol abuse, which all can be classified as environmental factors [34,35]. Even though gut microbial changes can partially be explained by host genetics [36-38], a recent study shows inter-individual gut similarities in the gut microbial profiles of genetically unrelated individuals sharing a household pattern, and that over $20 \%$ of the inter-individual microbiome variability is associated with environmental factors such as diet and medication [35]. Interestingly, this study additionally demonstrates that there is limited evidence for micro biome-genetic associations, based on an analysis performed on a cohort of 1046 healthy adults [35]. Even though there are minor heritable taxa and SNP associations, gut microbial composition is predominantly shaped by non-genetic factors [39-41]. Gaining mechanistic insight 
into the regulation of host-microbe interactions and the development of microbial consortia within a specific niche is of fundamental importance for discriminating the associations and causalities between the intestinal ecosystem and host immunity. This will undoubtedly lay the foundation for the future therapies of intestinal inflammation-linked diseases [26].

\section{Systemic Iron Metabolism and Homeostasis}

A healthy human can absorb 25-50 g of dietary iron over lifetime. The majority of body-constituent iron $(\sim 3-5 \mathrm{~g})$ is presented as heme, an iron-containing compound of the porphyrin class in the hemoglobin of red blood cells (RBCs), or in the myoglobin of muscles [42]. In order to replace iron losses through urine, sweat, and desquamated enterocytes, humans are able to absorb iron in a daily basis. On average, $2 \mathrm{mg}$ of iron is delivered by dietary absorption into the duodenum, which is balanced by an unregulated loss of $2 \mathrm{mg}$ of iron. Dietary iron has three forms: inorganic, heme, and ferritin. Inorganic dietary iron, existing in almost all diet sources, is mainly present in the oxidized form, $\mathrm{Fe}(\mathrm{III})$, and this needs to be reduced to the Fe(II) form via ferrireductases prior to intestinal uptake $[43,44]$. Although heme mainly derived from lean meat accounts for only 5-10\% dietary iron, it is more readily available compared to non-heme iron. Even though the uptake of dietary heme and ferritin mechanistically is not well identified, evidence suggests that iron is consequently released from these forms, and it enters a common pathway in the enterocyte as inorganic iron. The circulation of iron is relatively small, and it must have a turnover of few hours to meet the daily requirement of iron to support normal body functioning. The balance of iron level in human body is extremely important, and since humans do not have a physiological mechanism for iron excretion, intestinal iron absorption is a highly regulated dynamic process. Players such as macrophages in the spleen, liver, and bone marrow maintain a transient fraction of iron, while an excess of the metal is stored in the liver parenchyma within ferritin $[45,46]$. Despite rapid turnovers and changes in host iron utilization, plasma iron concentration is generally stable, indicating that the delivery of iron from recycling macrophages into plasma is homeostatically controlled. Iron is an essential bio-element for most life forms, and its importance lies in its ability to mediate electron transfer (The ferrous state of iron acts as an electron donor, and its ferric state acts as an acceptor). Therefore, iron plays a vital role in the catalysis of enzymatic reactions that involve electron transfer (reduction and oxidation, redox reaction). Even though it is a critically essential micronutrient, in reverse, it is a deleteriously toxic oxidative radical when allowed to exchange electrons in an unrestrained manner with hydrogen peroxide $\left(\mathrm{H}_{2} \mathrm{O}_{2}\right)$, which it leads into the production of hydroxyl radicals and hydroxide ions via Fenton chemistry. Hence, the balance between deficient or excessive levels of iron can be harmful for the host via damage to DNA, protein, and lipids [47]. Therefore, this balance is tightly regulated at the systemic and cellular levels by two distinct but interacting sets of regulatory mechanisms that humans and other organisms, therefore, evolved to have [4,42,48].

The uptake of all forms of iron occurs mainly in the duodenum and upper jejunum. Systemically, duodenal enterocytes absorb inorganic dietary non-heme ferric iron via divalent metal transporter 1 (SLC11A2 or DMT1) after reduction by membrane bound ferrireductases (DCYTB), the enzymes that reduce ferric iron to ferrous iron, often as a by-product of another operation (Figure 1). Iron can also adopt different spin states (high or low) in both the ferric and ferrous form, depending on its ligand environment. Enterocytes are also able to uptake heme iron via an undefined mechanism (however, the proposed transporter SLC46A1 in this study then appears to carry mostly folate) [49,50]. Iron translocation at the cellular level occurs through the enterocytes and is exported into circulation by the basolateral exporter ferroportin (SLC40A1) via a mechanism dependent on the oxidation of iron by a membrane-bound multi-copper oxidase hephaestin enabling binding between plasma transferrin (Tf) and iron. Most cells in the human body obtain iron from circulating diferric Tf (Tf-Fe(III)). This key form binds to transferrin receptor 1 (TfR1), which is highly expressed on hemoglobin-synthesizing erythroblast cell surfaces and is internalized as a Tf-Fe(III)-TfR1 complex by endocytosis. Later, ferric iron is released from Tf upon acidification of the endosomes, and this is followed by reduction via STEAP3. Upon the reduction, 
it is exported into the cytosol by DMT1. This cytosolic form of iron is used then for the formation of iron-containing proteins and by the mitochondria for the biosynthesis of heme and Fe-S clusters [51]. When enough iron is stored in the human system, iron export is reduced via hepcidin (a 25-amino acid peptide hormone)-mediated internalization and the degradation of ferroportin. Additionally, ferritin stores iron, which can be lost within three days by intestinal cells shedding (Figure 1) [51,52].

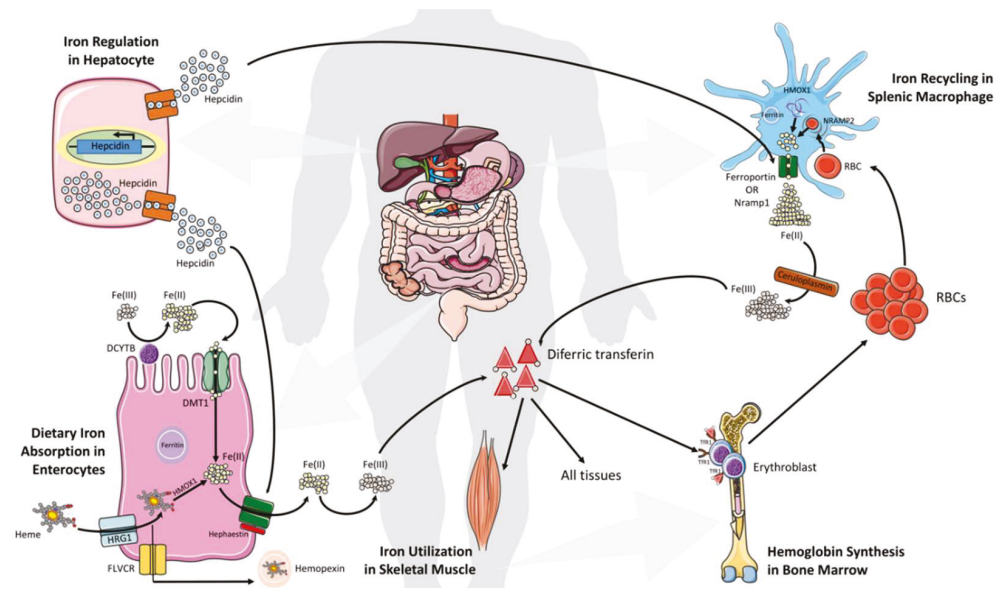

Figure 1. Systemic iron metabolism. Cells and organs involved in iron regulation are shown. Hepcidin produced in hepatocytes regulates iron efflux from other cells by regulating the stability of ferroportin. Hepatocytes sense iron levels and release hepcidin accordingly. Divalent metal transporter 1 (DMT1) on enterocytes internalize iron from the lumen of the duodenum after ferric $\mathrm{Fe}$ (III) is reduced to ferrous Fe(II) by ferrireductase. In parallel, free heme is internalized via HRG1 and hemoxygenase-1 (HMOX1) helps to release Fe(II). Ferroportin on the enterocyte's membrane that cooperates with hephaestin (HEPH) oxidizes Fe(II) to Fe(III). Besides, hepcidin binds to ferroportin on macrophages and duodenal enterocytes and splenic reticuloendothelial macrophages recycle iron from senescent red blood cells and release via ferroportin with the aid of natural resistance-associated macrophage protein 1 (Nramp1). Fe(II) is then oxidized into Fe(III) via ceruplasmin (Cp) in the circulation. Plasma transferrin (Tf) captures and circulates iron in the body, and $\mathrm{Tf}-\mathrm{Fe}_{2}$ supplies iron to all tissues in host body. Hepatocytes sense iron levels in host and release hepcidin, a hepatic hormone that regulates iron efflux from these cells by regulating the stability of ferroportin. The synthesis and secretion of hepcidin by hepatocytes is also influenced by several conditions in the host, including inflammation, endoplasmic reticulum (ER) stress, and hypoxia.

Daily absorbed iron (1-3 mg) represents only a fraction of the total body iron, while the recycling of heme from senescent erythrocytes by reticuloendothelial (RE) macrophages provides the main fraction of circulating iron [53]. Ferroportin exports the iron from heme into the circulation, and binds to apotransferrin for hemoglobin synthesis in the bone marrow. However, liver hepatocytes play a critical role in regulating serum iron levels via the integration of information on the systemic iron status, and secreting an appropriate amount of hepcidin that orchestrates systemic iron fluxes and controls plasma iron levels (Figure 1) [4,54]. Hepcidin also influences the internalization of ferroportin, decreasing iron export. An Increased level of hepatic iron ( $>30 \mu \mathrm{mol} / \mathrm{g}$ of dry weight) and inflammation are positively correlated with hepcidin production, and they are negatively correlated with ferroportin degradation in intestinal cell RE macrophages, which leads to an iron reduction in plasma $[55,56]$. Mechanistically, iron-transferrin complexes bind to TfR1 on hepatocytes, thereby displacing the TfR1-associated protein, HFE. Then, the binding interaction between HFE and hepatocyte-specific type 2 transferrin receptor (TfR2) transduces signals acting together with other signals from bone morphogenetic proteins (BMPs) to increase hepcidin secretion. This leads the binding of hepcidin 
to the transporter ferroportin on enterocytes and macrophages to induce its internalization and lysosomal degradation, thus reducing the entry of iron into the circulation and restoring homeostasis (Figure 1) [1,8]. In contrast, low levels of plasma iron control the inhibition of hepcidin expression and an increase in transporter ferroportin, which allow more iron into the blood circulation [1,8]. Of note, perturbations in hepcidin production, either inherited or acquired, consequently trigger iron deficiency (high hepcidin levels) or iron overload (hepcidin deficiency).

\section{Iron Regulation Along the Gastrointestinal Tract (GIT) Under the Shade of the Gut Microbiota}

The stomach is an oxygenic and acidic environment [57]. The nature of diets and the stomach leads the most of the dietary iron to reach the intestine in ferrous form, Fe(II), assisted by reducing agents, such as ascorbic acid [57,58]. Contrary to that, in the small intestine, the $\mathrm{pH}$ rises, and hence, the solubility of ferric iron decreases and the oxidation of iron increases [59]. Several studies demonstrate the role of colonic microbiota on this iron, with a shift in the valence state and the importance of siderophore production (Figure 2) [60-63]. Nevertheless, the iron solubility and availability in the colonic lumen for gut microbiota is extremely difficult to predict, due to the direct/indirect influence of many environmental and conditional factors. Depending on the dietary availability, only $\sim 15 \%$ of iron is absorbed in the duodenum, the primary site of iron absorption, and the remainder passes into the colon, where it is available for utilization by the gut microbiota. Despite a relative high theoretical concentration $(\sim 25 \mathrm{mmol} / \mathrm{L})$ of iron presenting in the large intestine, only a small proportion $(\sim 0.4 \mathrm{mmol})$ is bioavailable, likely due to the limited water solubility of inorganic iron in a non-acidic microenvironment [64]. Additionally, iron transporters such as DMT1 have been shown to express in the apical surfaces of the mammalian proximal colon, indicating an involvement of the host in exacerbating the iron availability in the bacteria-dense large intestine $[65,66]$. Iron speciation and the potential presence of lactoferrin, also known as lactotransferrin, lipocalin-2 (only expressed at low level in healthy host) and as-yet unidentified defence proteins in colonic mucosa might contribute to the limitation of iron at this site, which enables gut microbes to synthesize siderophores, the small, high-affinity iron-chelating compounds, for their needs under the circumstances of limited amount of iron in their surrounding environment (Figure 2) [67].

Not only oxygen and $\mathrm{pH}$, but also different dietary products can also affect the valency and the solubility of iron. Certain dietary products, mainly derived from plant sources including phytate [68,69], polyphenols [70], and tannins [69] negatively affect iron absorption by tightly binding to iron and decreasing iron bioavailability. Vitamin $\mathrm{C}$ is a water-soluble vitamin that is thought to increase the absorption of non-heme iron, and it acts as a reducing agent to facilitate iron absorption from the GIT [71,72]. Other organic acids such as tartaric, malic, succinic, fumaric, and citric acids can prevent the precipitation of ferric iron when the $\mathrm{pH}$ increases, and this enhances $\mathrm{Fe}(\mathrm{II})$ and $\mathrm{Fe}(\mathrm{III})$ uptake [71,73]. Moreover, the fluctuations in gut metabolites cause an increase in short-chain fatty acids (SCFAs), which can lower the $\mathrm{pH}$, promote solubility, and reduce iron into the ferrous state, and importantly, via stimulating the proliferation of epithelial cells, enhance the absorptive surface [63]. However, the efficiency of colonic iron absorption is only about $14 \%$ that of the duodenum. The expression of several critical genes in iron absorption pathway, including Dcytb, DMT1, TfR, and ferritin, are lower (not ferroportin) in the colon than in the duodenum $[74,75]$. In contrast, colonic epithelial cells express basolateral IREG1 in the same fashion as in the duodenum, and this protein could regulate colonic epithelial cell iron levels [60]. Mice studies clearly showed that iron absorption genes in the colon are up-regulated compared to iron-deficient mice, whereas Dcytb (a highly expressed duodenal reductase) is down-regulated [60]. This hints at the influential role of the colonic microbiota on the valence state of iron, by acting on extracellular reductases (Figure 2). A recent study indicates a direct role of host microbiota in iron regulation. The study reported a 10-fold increase in intestinal Dcytb and Dmt1 expression, and a two-fold reduction in ferroportin expression in germ-free (GF) mice, as compared to specific pathogen free (SPF) mice [76]. Therefore, in the absence of gut microbiota, the intestinal cells displayed very low iron stocks, and transport systems towards the body were very scarce. However, 
in the presence of gut microbiota, these cells acquired a considerable capacity for iron storage (in the form of ferritin), and favored its transport towards the body by increasing the expression of ferroportin. This shows that intestinal cells have a capacity to adapt their ability to distribute and store iron in the presence of gut microbiota. This notion is further supported with GF studies in rats, showing that the reduced level of iron uptake increased the loss of iron in their feces compared to specific-pathogen-free (SPF) rats [77], and they become anemic when fed on a low-iron diet [77]. The authors estimated that the absorption and net retention of iron decreased by around $25 \%$ in the absence of viable intestinal microbiota [77], in agreement with other studies that found a decreased absorption of iron after antibiotic treatment in rats [78] and rabbits [79]. Additionally, elevated ferritin expression and epithelial cells favoring iron storage upon gut colonization in GF mice provide an insight that gut microbes can establish a specific iron regulation signature for crosstalk with the host intestinal epithelium. Notably, due to the reduced environment in the colonic lumen, iron can form complex formations with mucins, certain amino acids, proteins, and other food components. However, we do not entirely know yet how accessible these insoluble forms of iron are for bacteria [80]. Somehow, ferrous and ferric forms of iron are be present in the colonic lumen to favor the viability of gut microbiota.

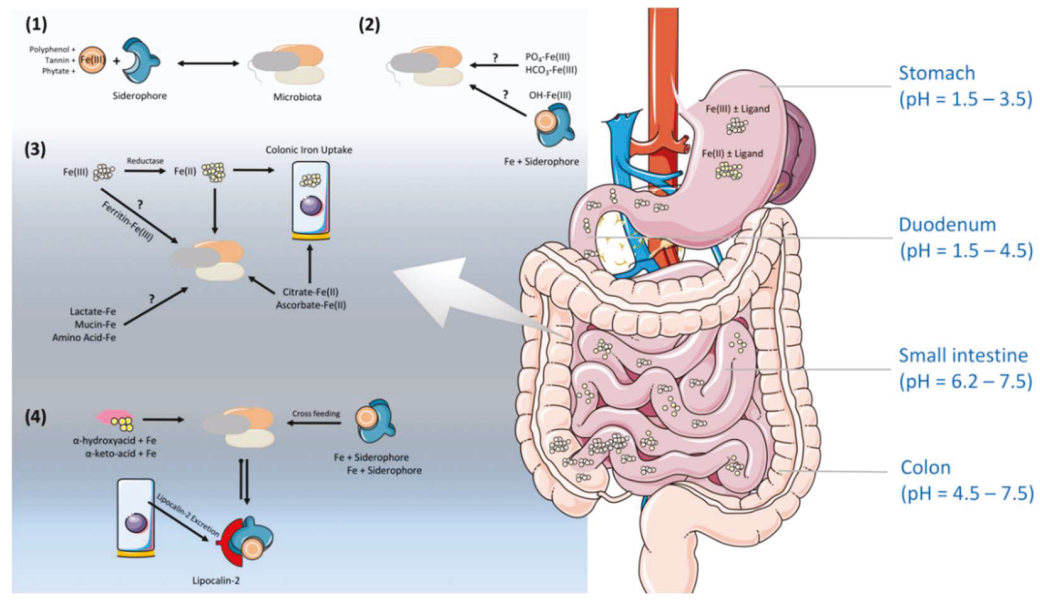

Figure 2. Several iron regulation mechanisms in the colonic lumen. The $\mathrm{pH}$ varies along the gastrointestinal tract (GIT), and food intake can also drive further $\mathrm{pH}$ fluctuations in the GIT. The stomach has a low $\mathrm{pH}(\mathrm{pH}=1.5-3.5)$ that favors the solubility of both ferric and ferrous iron with or without a ligand. Even though the $\mathrm{pH}$ is low in the duodenum $(\mathrm{pH}=1.5-4.5)$, the acidic nature of the environment, mixed with food components, can increase the $\mathrm{pH}$. A higher $\mathrm{pH}$ in the small intestine $(\mathrm{pH}=6.2-7.5)$ decreases the solubility of ferric iron, and within the colon, the $\mathrm{pH}$ can slightly drop due to lactate and short chain fatty acids (SCFAs; acetate, butyrate, and propionate) produced by the microbiota ( $\mathrm{pH}=4.5-7.5)$. In colonic lumen, (1) iron can bind to polyphenols, including tannins and phytate, that can make iron accessible via the enzymatic degradation or removal of the iron by siderophores; (2) An insoluble form of iron with phosphate, carbonate, or oxides can be made soluble again via as-yet unidentified mechanisms that drive bacterial reduction or siderophore chelation; (3) Host cells and/or gut microbes can utilize the reduced form of iron conjugated with citrate or ascorbate, and additionally, iron-bound lactate, mucin, or amino acids might be easier to access compared to an iron-ferritin complex by colonic microbiota via unknown mechanism(s); (4) The low-affinity siderophores, alpha-hydroxyacids and alpha-keto-acids may theoretically assist with the relatively easier access of iron, and they may also help for the iron cross-feeding by heterologous siderophores (a phenomenon where certain bacterial strains can compete for each other's siderophores) within the colonic microbiota. At last, lipocalin-2 in the colonic lumen may scavenge iron conjugated to siderophores to prevent uptake by pathobionts. 
We have more information on how the mammalian host cells in the gut are able to deal with iron; however, we are quite restricted on the roles of the gut microbiota on iron regulation, which remains speculative [65]. Iron availability for small intestinal microbiota, explicitly in the duodenum, are likely to be different to that for colonic microbiota, since small intestinal microbiota are home to a lower density of residing microorganisms compared to the colon. Nevertheless, colonic iron absorption can contribute more to defence mechanisms, as iron exclusion from the colonic lumen can contribute to nutritional immunity and restrain the gut pathobiont community [81]. Of note, oral iron administration can modify gut microbiota due to metabolic changes in the colonic lumen.

\section{The Effect of Iron on Gut Microbiota and Pathogens}

The human gut microbiota encounters a broad range of unabsorbed luminal iron concentrations acquired via a diet containing red meat and fortified cereals. Iron as an essential element, is also extensively required across the domain of bacteria by functioning as a co-factor in iron-containing proteins for redox reaction, metabolic pathways, and electron transport chain mechanisms [82,83]. These gut residents, just like humans, have evolved a number of mechanisms for obtaining iron from their human hosts for survival and proliferation.

Iron is critical for the replication and survival of almost all bacteria, with a few exceptions, which acquired alternative metabolic solutions from evolution. Lactobacillus plantarum was the first identified iron-independent microbial strain, which contains just one or two iron atoms-a level that is considered to be too low to provide iron with any conceivable biological function [84]. This feature also explains their presence in natural gut microbiota and milk, a highly iron-restricted environment due to the lactoferrin [85]. Another novel microorganism is Borrelia burgdorferi, a well-known pathogen causing Lyme disease transmitted to humans by the bite of infected ticks of the genus Ixodes. This pathogen have evolved in an iron-poor but a manganese-rich environment, by substituting Fe with $\mathrm{Mn}$ in their metalloproteins, which is an essential trigger for the activation of SodA superoxide dismutase (SOD), and which is essential for virulence [86]. This may facilitate infection in iron-free conditions that is tightly restricted within the host systemic compartment [87].

Alternatively, siderophores are small, high-affinity iron-chelating compounds that are secreted by bacteria, and they are the most prevalent strategies of aerobic and facultative anaerobic bacteria families such as Enterobacteriaceae, Streptomycetaceae, and Bacillaceae, in order to scavenge inorganic iron from the environment [88]. They are vastly produced by bacteria under low iron stress, due to their high ferric ion-specific chelating capacities $[83,89]$. There is no shared protein structure of siderophores due to the ability of the gut bacterial species to produce iron-siderophore complexes with specific transporters [88].

On the other hand, some gut strains like Bacteroides fragilis are strongly dependent on heme (or its precursor, protoporphyrin IX), since they have dispensed with the biosynthetic machinery that is required for heme elaboration. Microbes can take up heme by releasing either hemophores or expressing high-affinity heme outer membrane transporters [90]. In iron depletion, heme availability in the GIT is likely to be limited [91]. Thus, iron availability severely influences the gut bacterial ecosystem. Not surprisingly, different studies have investigated the effect of iron deficiency and/or supplementation on shaping the composition of the intestinal microbiota, both in animals and humans. These studies revealed well-defined patterns of microbial alterations in the gut which correlate with iron-deficient and iron-supplemented diets.

Numerous studies have investigated the effect of iron deficiency and supplementation on the gut microbiota (summarized in Figure 3). One of the oldest studies back in 1985, showed that infants given an iron-fortified cow's milk preparation had lower Bifidobacterium but higher counts of Bacteroides and E. coli than infants receiving an unfortified cow's milk preparation [92]. Another study on prolonged consumption of iron-supplemented biscuits by children from Côte d'Ivoire demonstrated a high proportion of fecal Enterobacteriaceae family and a low proportion of Lactobacillus, compared to a control group receiving non-supplemented biscuits [93]. Moreover, iron deficiency in young Indian 
women was associated with low levels of Lactobacillus acidophilus in the gut [94]. In a recent study, an iron-fortified micronutrient powder provided to Kenyan infants ranging from 6 to 10 months of age caused an increase of several taxa from Enterobacteriaceae family, especially the pathobiont $E$. coli, and a decrease of Bifidobacterium in their intestine [95]. Of note, the researchers also stated on higher levels of calprotectin in infants supplemented with iron, an indication of increased gut inflammation [95]. A lack of host factors such as iron status, immune system, and diet fluctuation in the gut might be drawbacks to studying iron and microbiota. Nevertheless, in vitro studies hint on microbial metabolism in the presence of iron and nutrients. An in vitro colonic fermentation study using immobilized human fecal microbiota to show the impact of Fe deficiency and sufficiency showed that during very low Fe conditions, several taxa, including Roseburia, [Eubacterium] ectale, Clostridium Cluster IV members, and Bacteroides were decreased, while members of the Lactobacillus and Enterobacteriaceae family were increased, consistent with a decrease of SCFA, namely butyrate and propionate [96].

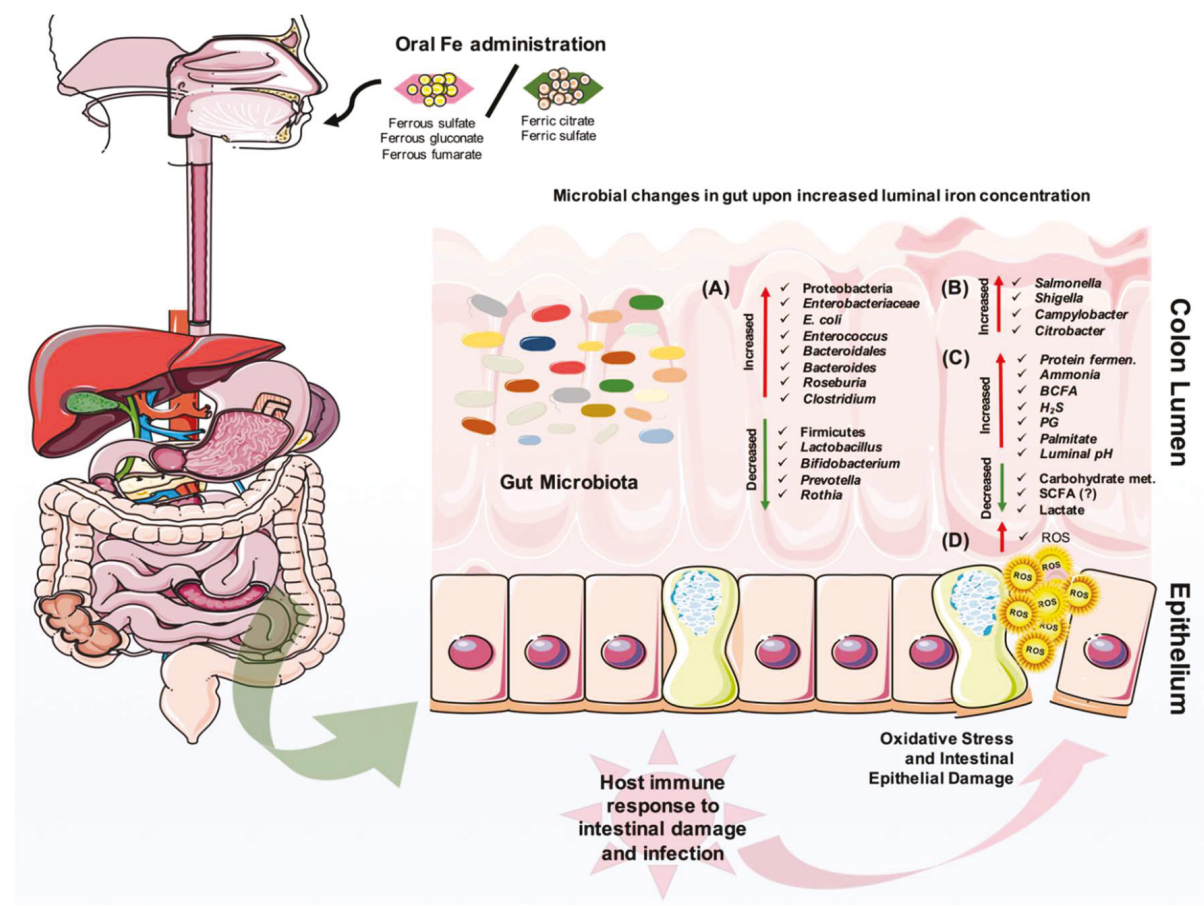

Figure 3. Microbial and metabolic changes in the colonic lumen after oral iron administration. Orally administered iron has a direct impact on alteration of microbial composition in the gut. It can result in reduction in the beneficial microbiota and the expansion of pathobionts (A), and this can also provide an opportunity for the expansion of enteric pathogens (B). The host metabolism is additionally influenced with an increase in protein fermentation and reduction in carbohydrate metabolism (C). Importantly, iron can induce the generation of reactive oxygen species (ROS) in the gut (D), which causes oxidative stress and consequently, intestinal epithelial damage. In turn, the host intestinal immune system responds with inflammation, intestinal damage, and possible infection.

Experimental animal studies further supported the findings in human studies. These studies pointed out the similar usual suspects, such as elevated abundance of the Lactobacillus, Enterobacteriaceae family as well as Enterococcus and reduced abundance of Bacteroides and Roseburia members in iron-deprived mice and young Sprague Dawley rats [97,98]. Besides, relatively low numbers of total anaerobes in the colons of iron-supplemented mice suggested that the provision of $\mathrm{Fe}(\mathrm{III})$ 
suppressed bacteria, likely by the oxidation of normally reduced environments [97]. In a study where researchers only assessed Bacteroidetes, the Enterobacteriaceae family, and Firmicutes, the influence of ferric iron on gut microbiota was investigated, but no effect was found [99]. In rats, iron dose and a time-dependent study showed changes in these usual suspects with addition of changes in Clostridium difficile enterotoxin [100]. In a further study with a genetic modification of iron metabolism in mice, the relative abundance of five lactic acid bacteria were significantly different among the mouse lines, suggesting that the deletion of iron metabolism-related genes in the host can affect the intestinal gut composition [101]. It was also shown that a heme-rich diet decreased gut microbial diversity. Major taxonomic changes included an increase in the relative abundance of Proteobacteria, and a decrease in the abundance of Firmicutes, similar to Dextran Sulfate Sodium (DSS)-induced colitis [102]. Additionally, the intestinal lumen may support the growth of bacteria-coding genes that are related to heme uptake and release from RBCs. In return, gut microbiota can play a critical role on iron absorption, as shown in a study in which metabolic changes due to prebiotic administration affected iron absorption [75] via increasing the expression of iron regulatory genes in the colon and duodenum, and an increase of Lactobacillaceae in the colon $[103,104]$. Further, a study with GF rats showed a decrease in iron uptake compared to SPF mice, as mentioned before [77]. Among all these studies, another important finding is that concentrations of SCFA and branched chain fatty acids (BCFAs; isobutyrate and isovalerate) were altered in adult fecal microbiota and during in vitro experimentation $[98,105]$. Specifically, low levels of butyrate and propionate were observed during a luminal iron deficiency condition in rats, and luminal iron absorption might be enhanced by Propionibacteria via the biosynthesis of propionate [106].

Not surprisingly, iron can promote the replication and virulence of gut enteric pathogens including Salmonella, Shigella, and Campylobacter (Figure 3). Iron availability in the colon lumen is a critical signal for the expression of virulent genes by pathogens and hosts. It has been shown that a ferroportin-mediated efflux of iron, and consequent changes in the amounts of available iron to Salmonella typhimurium can decrease the expression of the protein, favoring the growth of this pathogen [107]. This observation was also investigated with different organisms residing in macrophages, and it was supported with the general notion that cellular iron concentration is one of the critical determinants for infectivity [108,109]. Besides the impact of iron availability to pathogens, hepcidin-mediated iron sequestration also influences the host immune response by altering macrophage cytokine production and function [110]. An in vitro study demonstrated that moderate extracellular iron levels can give an advantage for invasion to Salmonella when it is cultured with intestinal epithelial cells [105]. Furthermore, the survival of this enteric pathogen in the host cell may partly depend on the host iron status. However, iron does not always elevate the viability and virulence of pathogens. A recent study with a Citrobacter infection experimental mouse model showed that dietary iron supplementation induced insulin resistance and increased glucose levels in the intestine that help to suppress the pathogenicity of this bacterium. Additionally, dietary iron was able to drive the selection of attenuated Citrobacter strains that can transmit and asymptomatically colonize naive hosts [111]. In general, iron availability in the gut can have a large impact on the infection cycle of a pathogen. The increased luminal iron and intracellular iron in enterocytes may exaggerate or reduce the virulence of enteric pathogens. So far, relatively little is known about a potential link between iron and intestinal infection, and more research is needed to investigate these concepts in detail.

Overall, oral iron intake can influence the gut microbiota of young and adult populations in the short-term. However, we have still no idea of what is the potential effect of oral iron supplementation in a long-term view for health and gastrointestinal-related infection problem. Given the importance of the microbiota in shaping the development and function of the intestinal immune system [17-19], iron-dependent changes in gut microbiota could have an impact on infant health and mucosal immune responsiveness, which need to be further investigated with a larger perspective, with randomized controlled trials in human patients yielding concrete clinical outcomes. 


\section{Iron and Inflammatory Bowel Disease (IBD)}

Dysbiosis, or imbalance of the gut microbial consortia disrupting their mutualism with the host, may cause intestinal or systemic pathology, including chronic inflammatory bowel disease (IBD) [112-114]. Crohn's disease (CD) and ulcerative colitis (UC) are the two main forms of IBD, each with an annual incidence of 10-30 per 100,000 in Europe and North America, and they are usually diagnosed before age of 35 . These are relapsing-remitting immune-mediated, chronic inflammatory intestinal diseases, each with very diverse sub-phenotypes and heterogeneous responsiveness to treatment $[28,115]$. Unfortunately, no treatment is satisfactory in about $30 \%$ of patients, leaving life-long morbidity, malnutrition, and risk of malignancy. Among many complications of the disease, anemia is the most common one and one third of IBD patients suffer from recurrent anemia. It is a condition that develops when the human system lacks either enough healthy red blood cells or hemoglobin. Many people carry on their lives without knowing that they have iron deficiency anemia. Therefore, people are likely to experience symptoms for years without ever knowing the reason behind them [116]. Iron deficiency anemia (IDA) and anemia of chronic disease (ACD) are the most common causes of anemia in these patients, and they often occur simultaneously. Chronic bleeding in the GIT or unbalanced iron absorption/iron homeostasis due to increased systemic hepcidin levels in the presence of ongoing inflammation are the main reasons behind iron deficiency $[8,117,118]$. This has tremendous impact on the quality of life of IBD patients. Chronic fatigue is commonly instigated by anemia, and it may debilitate patients as much as abdominal pain or diarrhea. The ultimate therapeutic goal is to improve the patient's quality of life by changing the hemoglobin concentration and iron level in those patients [119].

Iron absorption is down-regulated in IBD patients with the active disease, but it is normal in quiescent IBD patients [120]. Patients with the active disease generally require iron supplementation. However, one should be cautious with oral iron supplementation, which often leads to gastrointestinal side effects such as nausea, abdominal pain, and diarrhea. Several experimental animal model studies using transgenic models or chemically induced colitis suggested that oral iron administration could exacerbate intestinal inflammation [121-125]. Mechanistically, this might be due to ferrous forms of oral iron appearing to be poorly absorbed, and the iron-induced production of reactive oxygen species (ROS) within the lumen of the gut, or the increased growth of pathobionts in the GIT that thrive on iron and inflammation (Figure 3). It is well-characterized that the gut microbiota of IBD patients are relatively different than non-IBD subjects, mostly with an increase of enteropathogenic strains, as shown by many different groups [126-132]. Dietary iron supplementation leads to disease exacerbation and a higher risk of infection, and an increased abundance of Enterobacteriaceae. Additionally, it has been shown that the absence of luminal ferrous iron was associated with key changes in the intestinal microbiota [125]. Many animal studies that we have also mentioned in Section 5 support the idea that microbial differences might be enlarged upon iron supplementation into the gut.

In contrast, intravenous iron therapy offers effective alternative management for iron deficiency anemia, since it does not cause side effects and it is more efficient in restoring the iron status in patients [133]. This generally is preferred when iron deficiency co-exists with anemia in clinically active IBD patients. Direct administration of iron into the circulation requires formulations to prevent the cellular toxicity of iron salts, and hence, intravenous iron is usually administered as ferric gluconate, iron sucrose, iron dextran, and ferric carboxymaltose. A study with the intravenous administration of ferric carboxymaltose showed that this therapy was found to be effective and well-tolerated in IBD patients with iron deficiency [134]. In a complementary study in which iron was supplemented either orally or intravenously, the researchers analyzed the effect of iron supplementation of the gut microbiota and metabolites of IBD patients. Even though the route of supplementation did not affect the species richness in the gut, oral iron changed the abundance of F. prausnitzii and Bifidobacterium [135]. Metabolically, high levels of phosphatidylglycerol (PG), palmitate, and its derivatives in the orally iron-supplemented group were observed, whereas bile acids, tetrahydrodeoxycorticosterone, and other cholesterol derivatives were the characteristics of the intravenously iron-supplemented group [135]. 
This study identified that CD patients were more prone to iron-supplemented therapy shifts, and oral, but not intravenous, iron therapy affected the presence of specific bacterial species and their products.

Nowadays, there are many good reasons to pay careful attention to iron metabolism than ever before, when dealing with specifically IBD patients with anemia. Until we find a better treatment to IBD, the primary goal is the optimization of supportive care to enhance the patient's quality of life. To do that, we need to better understand the fine-tuned balance between iron metabolism and microbial population residing in the gut of IBD patients.

\section{Iron and Colorectal Cancer}

Iron is a limiting factor of growth for many pathobiont bacteria. Contrary, it can also promote a shift in the ratio between pathobionts and gut commensals, with an increase in specific metabolites and inflammation in the intestines. Therefore, a high concentration of iron in the colon leads us to question whether or not iron might also be involved in the initiation or promotion of colonic diseases, specifically colorectal cancer. Despite recent advances in cancer treatment, colorectal cancer still remains one of the deadliest cancer types, with a significantly increased incidence in developing countries with Westernized lifestyles. The incidence of colorectal cancer differs broadly between diverse human populations. It has been suggested that dietary fiber content is of utmost importance, and that it is inversely related to the occurrence of colonic cancer. Since Graf and Eton's editorial comment in 1985, multiple factors that drive the progression from healthy mucosa to colorectal carcinoma have been identified [136,137]. Accumulating evidences with many in vitro studies and in vivo interventions have consistently supported the role of iron in colorectal cancer risk via a mechanism of increased oxygen radical synthesis and the role of phytic acid, a potent inhibitor of iron-mediated generation of the hazardous oxidant, hydroxy radicals, reversing the augmentation of tumor risk [138-140].

A majority of the strongest studies confirm that both dietary iron and iron storage augment colorectal cancer risk, as reviewed in these manuscripts [139,141]. A positive association between iron storage (transferrin saturation) in the host system due to mutation in human hereditary hemochromatosis (a.k.a. iron overload disorder; a disorder that causes the body to absorb too much iron from the diet, and excess amount of iron is stored in the body's tissues and organs, particularly the skin, heart, liver, pancreas, and joints) gene (C282Y mutation), and the development of precancerous lesions in the colon, colonic adenomas, or polyps were reported [142,143]. Additionally, five prospective human cohort studies, including the data of 566,607 individuals and 4,734 cases of colon cancer, showed that a high intake of heme iron was linked with an increased risk of colon cancer, even though one cohort did not identify any association [144-148]. Yet, many critical studies hint on the significant role of diet as a major player in colorectal cancer development [149]. Even though the hemochromatosis gene probably does not play a major role in the majority of colorectal cancers, two different fields of research, genetic and nutritional oncology, have united to find out the mechanisms that drive this type of cancer. The findings that intraluminal iron via interactions with intestinal microbes, promotes of hydroxy radicals, brings the gut microbiota, the hot subjects over the last 5-6 years, to this unity as a third key factor, and shift recent investigations in the microbiota field, which have been largely driven by advances in DNA sequencing (particularly of highly conserved hyper-variable regions of the $16 \mathrm{~S}$ ribosomal RNA genes in bacteria).

Recent reports showed that Bacteroides/Prevotella, Clostridum, Streptococcus bovis, and Enterococcus faecalis can produce genotoxic metabolites, such as hydrogen sulphide and secondary bile salts, which likely promote inflammation and carcinogenesis [150-153]. In defence, B. longum and L. acidophilus are gut-protective commensals $[154,155]$. They form a protective barrier against colonization by pathogenic bacteria, and they produce butyrate that act as an anti-carcinogenic agent [156]. Additionally, strains of Bifidobacteriaceae family can affect free radical formation by binding iron to their surface, and they promote daily renewal of the colon epithelium, while strains of Lactobacillus can reduce the mutagenic effect of bile acids [154,155]. Moreover, antibiotic-based clearance of gut pathobionts reduced the incidence of colon cancer, and altered gut microbiota in mice [157]. These findings were supported 
with human studies. Advanced colorectal adenoma or carcinoma patients were shown to be deficient in lactic acid-producing commensals [158]. Whether reverting this microbial profile in the patient's gut might have an effect on disease progression is the one burning question, and even though gut microbiota-dependent dietary changes are promising against colorectal carcinoma, these methods still require further investigation.

\section{Concluding Remarks}

Iron deficiency is a globally serious problem, and it can be corrected to avoid any serious health issues in individuals suffering from it. In this review, we discussed the multi-faceted effects of iron, its administration, and its role on host-microbiota interaction(s) in health and disease (Figure 3). So far, we have a clear view that oral iron administration may impact the gut microbiota profile, and it is the main preferable therapy, even though this has serious gastrointestinal problems including diarrhea, morbidity, and mortality in children, mainly in Africa. From this, the "chicken-egg" question arises, as scientists struggle to find better explanations for iron homeostasis based on iron-dependent fluctuations in the host response, and the growth of gut bugs in the presence of inflammation. It is likely that intestinal microbiota and iron homeostasis are the key parts, but not the only parts, of a more complex interplay that triggers the inflammatory response in the intestines, which can lead to IBD or colorectal cancer. Impressive advancements have been made during the past few years in biomedical science and computation biology, and we are now at a level of better characterization of gut microbiota-dependent inflammatory responses and its direct connection to iron metabolism. Until today, many human studies have only reported observed correlations, and more work is necessary to prove a causal relationship between iron-gut bacteria interactions and the development of gut inflammatory diseases and colorectal cancer. Experimental animal models have assisted in understanding how the gut microbiota interact with excessive amounts of unabsorbed luminal iron, and modern iron therapeutic administration methods for iron deficient populations [159].

Author Contributions: Writing-Original Draft Preparation, B.Y.; Writing—Review \& Editing, B.Y. and H.L.; Visualization, B.Y.

Funding: This research received no external funding.

Acknowledgments: Figures were prepared using Medical Art by Servier, licensed under a Creative Commons Attribution 3.0 Unported License (CC BY 3.0) https: / / creativecommons.org/licenses/by/3.0/legalcode).

Conflicts of Interest: The authors declare no conflict of interest.

$\begin{array}{ll}\text { Abbreviations } \\ \text { ACD } & \text { Anaemia of chronic disease } \\ \text { BCFA } & \text { Branched chain fatty acids } \\ \text { BMPs } & \text { Bone morphogenetic proteins } \\ \text { CD } & \text { Crohn's disease } \\ \text { DCYTB } & \text { Duodenal Cytochrome B } \\ \text { DMT1 } & \text { Divalent Metal Transporter 1 } \\ \text { GF } & \text { Germ-free } \\ \text { GI } & \text { Gastrointestinal } \\ \text { H }{ }_{2} \mathbf{O}_{2} & \text { Hydrogen peroxide } \\ \text { HEPH } & \text { Hephaestin } \\ \text { HMOX1 } & \text { Heme Oxygenase 1 } \\ \text { IBD } & \text { Inflammatory bowel disease } \\ \text { IBS } & \text { Irritable bowel syndrome } \\ \text { IDA } & \text { Iron deficiency anemia } \\ \text { Nramp1 } & \text { Natural Resistance-Associated }\end{array}$




$\begin{array}{ll}\text { PG } & \text { Phosphatidylglycerol } \\ \text { RBC } & \text { Red blood cell } \\ \text { ROS } & \text { Reactive oxygen species } \\ \text { SCFA } & \text { Short-chain fatty acids } \\ \text { SLC40A1 } & \text { Solute Carrier Family 40 Member 1 } \\ \text { SLC46A1 } & \text { Solute Carrier Family 46 Member 1 } \\ \text { SNP } & \text { Single nucleotide polymorphisms } \\ \text { SOD } & \text { Superoxide dismutase } \\ \text { SPF } & \text { Specific pathogen-free } \\ \text { UC } & \text { Ulcerative colitis }\end{array}$

\section{References}

1. Wessling-Resnick, M. Iron homeostasis and the inflammatory response. Annu. Rev. Nutr. 2010, 30, 105-122. [CrossRef] [PubMed]

2. Nairz, M.; Schroll, A.; Sonnweber, T.; Weiss, G. The struggle for iron-A metal at the host-pathogen interface. Cell Microbiol. 2010, 12, 1691-1702. [CrossRef] [PubMed]

3. Markel, T.A.; Crisostomo, P.R.; Wang, M.; Herring, C.M.; Meldrum, K.K.; Lillemoe, K.D.; Meldrum, D.R. The struggle for iron: Gastrointestinal microbes modulate the host immune response during infection. J. Leukoc. Biol. 2007, 81, 393-400. [CrossRef] [PubMed]

4. Sheftel, A.D.; Mason, A.B.; Ponka, P. The long history of iron in the Universe and in health and disease. Biochim. Biophys. Acta 2012, 1820, 161-187. [CrossRef] [PubMed]

5. Ganz, T. Iron and infection. Int. J. Hematol. 2018, 107, 7-15. [CrossRef] [PubMed]

6. Stein, J.; Hartmann, F.; Dignass, A.U. Diagnosis and management of iron deficiency anemia in patients with IBD. Nat. Rev. Gastroenterol. Hepatol. 2010, 7, 599-610. [CrossRef] [PubMed]

7. Goodnough, L.T.; Nemeth, E.; Ganz, T. Detection, evaluation, and management of iron-restricted erythropoiesis. Blood 2010, 116, 4754-4761. [CrossRef] [PubMed]

8. Cherayil, B.J. Iron and immunity: Immunological consequences of iron deficiency and overload. Arch. Immunol. Ther. Exp. 2010, 58, 407-415. [CrossRef] [PubMed]

9. Hooper, L.V.; Wong, M.H.; Thelin, A.; Hansson, L.; Falk, P.G.; Gordon, J.I. Molecular analysis of commensal host-microbial relationships in the intestine. Science 2001, 291, 881-884. [CrossRef] [PubMed]

10. Hooper, L.V.; Midtvedt, T.; Gordon, J.I. How host-microbial interactions shape the nutrient environment of the mammalian intestine. Annu. Rev. Nutr. 2002, 22, 283-307. [CrossRef] [PubMed]

11. Hooper, L.V.; Macpherson, A.J. Immune adaptations that maintain homeostasis with the intestinal microbiota. Nat. Rev. Immunol. 2010, 10, 159-169. [CrossRef] [PubMed]

12. Stecher, B.; Macpherson, A.J.; Hapfelmeier, S.; Kremer, M.; Stallmach, T.; Hardt, W.D. Comparison of Salmonella enterica serovar Typhimurium colitis in germfree mice and mice pretreated with streptomycin. Infect. Immun. 2005, 73, 3228-3241. [CrossRef] [PubMed]

13. Yilmaz, B.; Portugal, S.; Tran, T.M.; Gozzelino, R.; Ramos, S.; Gomes, J.; Regalado, A.; Cowan, P.J.; d'Apice, A.J.; Chong, A.S.; et al. Gut microbiota elicits a protective immune response against malaria transmission. Cell 2014, 159, 1277-1289. [CrossRef] [PubMed]

14. Yilmaz, B.; Schibli, S.; Macpherson, A.J.; Sokollik, C. D-lactic Acidosis: Successful Suppression of D-lactate-Producing Lactobacillus by Probiotics. Pediatrics 2018. [CrossRef] [PubMed]

15. Soares, M.P.; Yilmaz, B. Microbiota Control of Malaria Transmission. Trends Parasitol. 2016, 32, 120-130. [CrossRef] [PubMed]

16. Uchimura, Y.; Fuhrer, T.; Li, H.; Lawson, M.A.; Zimmermann, M.; Yilmaz, B.; Zindel, J.; Ronchi, F.; Sorribas, M.; Hapfelmeier, S.; et al. Antibodies Set Boundaries Limiting Microbial Metabolite Penetration and the Resultant Mammalian Host Response. Immunity 2018, 49, 545-559. [CrossRef] [PubMed]

17. Smith, K.; McCoy, K.D.; Macpherson, A.J. Use of axenic animals in studying the adaptation of mammals to their commensal intestinal microbiota. Semin. Immunol. 2007, 19, 59-69. [CrossRef] [PubMed]

18. Cahenzli, J.; Balmer, M.L.; McCoy, K.D. Microbial-immune cross-talk and regulation of the immune system. Immunology 2013, 138, 12-22. [CrossRef] [PubMed] 
19. Ganal, S.C.; Sanos, S.L.; Kallfass, C.; Oberle, K.; Johner, C.; Kirschning, C.; Lienenklaus, S.; Weiss, S.; Staeheli, P.; Aichele, P.; et al. Priming of Natural Killer Cells by Nonmucosal Mononuclear Phagocytes Requires Instructive Signals from Commensal Microbiota. Immunity 2012, 37, 171-186. [CrossRef] [PubMed]

20. Macpherson, A.J.; Yilmaz, B.; Limenitakis, J.P.; Ganal-Vonarburg, S.C. IgA Function in Relation to the Intestinal Microbiota. Annu. Rev. Immunol. 2018, 36, 359-381. [CrossRef] [PubMed]

21. Holmes, E.; Li, J.V.; Athanasiou, T.; Ashrafian, H.; Nicholson, J.K. Understanding the role of gut microbiome-host metabolic signal disruption in health and disease. Trends Microbiol. 2011, 19, 349-359. [CrossRef] [PubMed]

22. Clayton, T.A.; Lindon, J.C.; Cloarec, O.; Antti, H.; Charuel, C.; Hanton, G.; Provost, J.P.; Le Net, J.L.; Baker, D.; Walley, R.J.; et al. Pharmaco-metabonomic phenotyping and personalized drug treatment. Nature 2006, 440, 1073-1077. [CrossRef] [PubMed]

23. Grundmann, O. The Gut Microbiome and Pre-systemic Metabolism: Current State and Evolving Research. J. Drug Metab. Toxicol. 2010, 1, 1-7. [CrossRef]

24. Nieuwdorp, M.; Gilijamse, P.W.; Pai, N.; Kaplan, L.M. Role of the microbiome in energy regulation and metabolism. Gastroenterology 2014, 146, 1525-1533. [CrossRef] [PubMed]

25. De Aguiar Vallim, T.Q.; Tarling, E.J.; Edwards, P.A. Pleiotropic roles of bile acids in metabolism. Cell Metab. 2013, 17, 657-669. [CrossRef] [PubMed]

26. Sekirov, I.; Russell, S.L.; Antunes, L.C.M.; Finlay, B.B. Gut Microbiota in Health and Disease. Physiol. Rev. 2010, 90, 859-904. [CrossRef] [PubMed]

27. Peterson, D.A.; Frank, D.N.; Pace, N.R.; Gordon, J.I. Metagenomic approaches for defining the pathogenesis of inflammatory bowel diseases. Cell Host Microbe 2008, 3, 417-427. [CrossRef] [PubMed]

28. Maloy, K.J.; Powrie, F. Intestinal homeostasis and its breakdown in inflammatory bowel disease. Nature 2011, 474, 298-306. [CrossRef] [PubMed]

29. Mazmanian, S.K.; Round, J.L.; Kasper, D.L. A microbial symbiosis factor prevents intestinal inflammatory disease. Nature 2008, 453, 620-625. [CrossRef] [PubMed]

30. Kamada, N.; Chen, G.Y.; Inohara, N.; Nunez, G. Control of pathogens and pathobionts by the gut microbiota. Nat. Immun. 2013, 14, 685-690. [CrossRef] [PubMed]

31. Distrutti, E.; Monaldi, L.; Ricci, P.; Fiorucci, S. Gut microbiota role in irritable bowel syndrome: New therapeutic strategies. World J. Gastroenterol. 2016, 22, 2219-2241. [CrossRef] [PubMed]

32. Chen, S.Y.; Tsai, C.N.; Lee, Y.S.; Lin, C.Y.; Huang, K.Y.; Chao, H.C.; Lai, M.W.; Chiu, C.H. Intestinal microbiome in children with severe and complicated acute viral gastroenteritis. Sci. Rep. 2017, 7. [CrossRef]

33. Duvallet, C.; Gibbons, S.M.; Gurry, T.; Irizarry, R.A.; Alm, E.J. Meta-analysis of gut microbiome studies identifies disease-specific and shared responses. Nat. Commun. 2017, 8. [CrossRef] [PubMed]

34. Org, E.; Parks, B.W.; Joo, J.W.J.; Emert, B.; Schwartzman, W.; Kang, E.Y.; Mehrabian, M.; Pan, C.; Knight, R.; Gunsalus, R.; et al. Genetic and environmental control of host-gut microbiota interactions. Genome Res. 2015, 25, 1558-1569. [CrossRef] [PubMed]

35. Rothschild, D.; Weissbrod, O.; Barkan, E.; Kurilshikov, A.; Korem, T.; Zeevi, D.; Costea, P.I.; Godneva, A.; Kalka, I.N.; Bar, N.; et al. Environment dominates over host genetics in shaping human gut microbiota. Nature 2018, 555, 210. [CrossRef] [PubMed]

36. Liu, J.Z.; van Sommeren, S.; Huang, H.; Ng, S.C.; Alberts, R.; Takahashi, A.; Ripke, S.; Lee, J.C.; Jostins, L.; Shah, T.; et al. Association analyses identify 38 susceptibility loci for inflammatory bowel disease and highlight shared genetic risk across populations. Nat. Genet. 2015, 47, 979-986. [CrossRef] [PubMed]

37. De Lange, K.M.; Moutsianas, L.; Lee, J.C.; Lamb, C.A.; Luo, Y.; Kennedy, N.A.; Jostins, L.; Rice, D.L.; Gutierrez-Achury, J.; Ji, S.G.; et al. Genome-wide association study implicates immune activation of multiple integrin genes in inflammatory bowel disease. Nat. Genet. 2017, 49, 256-261. [CrossRef] [PubMed]

38. Yilmaz, B.; Spalinger, M.R.; Biedermann, L.; Franc, Y.; Fournier, N.; Rossel, J.B.; Juillerat, P.; Rogler, G.; Macpherson, A.J.; Scharl, M. The presence of genetic risk variants within PTPN2 and PTPN22 is associated with intestinal microbiota alterations in Swiss IBD cohort patients. PLoS ONE 2018, 13, e0199664. [CrossRef] [PubMed]

39. Faith, J.J.; Guruge, J.L.; Charbonneau, M.; Subramanian, S.; Seedorf, H.; Goodman, A.L.; Clemente, J.C.; Knight, R.; Heath, A.C.; Leibel, R.L.; et al. The long-term stability of the human gut microbiota. Science 2013, 341, 1237439. [CrossRef] [PubMed] 
40. Arumugam, M.; Raes, J.; Pelletier, E.; Le Paslier, D.; Yamada, T.; Mende, D.R.; Fernandes, G.R.; Tap, J.; Bruls, T.; Batto, J.M.; et al. Enterotypes of the human gut microbiome. Nature 2011, 473, 174-180. [CrossRef] [PubMed]

41. Schloissnig, S.; Arumugam, M.; Sunagawa, S.; Mitreva, M.; Tap, J.; Zhu, A.; Waller, A.; Mende, D.R.; Kultima, J.R.; Martin, J.; et al. Genomic variation landscape of the human gut microbiome. Nature 2013, 493, 45-50. [CrossRef] [PubMed]

42. Wang, J.; Pantopoulos, K. Regulation of cellular iron metabolism. Biochem. J. 2011, 434, 365-381. [CrossRef] [PubMed]

43. Dev, S.; Babitt, J.L. Overview of iron metabolism in health and disease. Hemodial. Int. 2017, 21 (Suppl. 1), S6-S20. [CrossRef]

44. McKie, A.T.; Barrow, D.; Latunde-Dada, G.O.; Rolfs, A.; Sager, G.; Mudaly, E.; Mudaly, M.; Richardson, C.; Barlow, D.; Bomford, A.; et al. An iron-regulated ferric reductase associated with the absorption of dietary iron. Science 2001, 291, 1755-1759. [CrossRef] [PubMed]

45. Nunez, G.; Sakamoto, K.; Soares, M.P. Innate Nutritional Immunity. J. Immunol. 2018, 201, 11-18. [CrossRef] [PubMed]

46. Hentze, M.W.; Muckenthaler, M.U.; Galy, B.; Camaschella, C. Two to tango: Regulation of Mammalian iron metabolism. Cell 2010, 142, 24-38. [CrossRef] [PubMed]

47. Kumar, S.; Bandyopadhyay, U. Free heme toxicity and its detoxification systems in human. Toxicol. Lett. 2005, 157, 175-188. [CrossRef] [PubMed]

48. Chua, A.C.; Graham, R.M.; Trinder, D.; Olynyk, J.K. The regulation of cellular iron metabolism. Crit. Rev. Clin. Lab. Sci. 2007, 44, 413-459. [CrossRef] [PubMed]

49. Gunshin, H.; Mackenzie, B.; Berger, U.V.; Gunshin, Y.; Romero, M.F.; Boron, W.F.; Nussberger, S.; Gollan, J.L.; Hediger, M.A. Cloning and characterization of a mammalian proton-coupled metal-ion transporter. Nature 1997, 388, 482-488. [CrossRef] [PubMed]

50. Qiu, A.; Jansen, M.; Sakaris, A.; Min, S.H.; Chattopadhyay, S.; Tsai, E.; Sandoval, C.; Zhao, R.; Akabas, M.H.; Goldman, I.D. Identification of an intestinal folate transporter and the molecular basis for hereditary folate malabsorption. Cell 2006, 127, 917-928. [CrossRef] [PubMed]

51. Wallander, M.L.; Leibold, E.A.; Eisenstein, R.S. Molecular control of vertebrate iron homeostasis by iron regulatory proteins. Biochim. Biophys. Acta 2006, 1763, 668-689. [CrossRef] [PubMed]

52. Ganz, T. Erythropoietic regulators of iron metabolism. Free Radic. Biol. Med. 2018. [CrossRef] [PubMed]

53. Cherayil, B.J.; Ellenbogen, S.; Shanmugam, N.N. Iron and intestinal immunity. Curr. Opin. Gastroenterol. 2011, 27, 523-528. [CrossRef] [PubMed]

54. Nemeth, E.; Tuttle, M.S.; Powelson, J.; Vaughn, M.B.; Donovan, A.; Ward, D.M.; Ganz, T.; Kaplan, J. Hepcidin regulates cellular iron efflux by binding to ferroportin and inducing its internalization. Science 2004, 306, 2090-2093. [CrossRef] [PubMed]

55. Deugnier, Y.; Turlin, B. Pathology of hepatic iron overload. Semin. Liver Dis. 2011, 31, 260-271. [CrossRef] [PubMed]

56. Deugnier, Y.; Turlin, B. Pathology of hepatic iron overload. World J. Gastroenterol. 2007, 13, 4755-4760. [CrossRef] [PubMed]

57. Ovesen, L.; Bendtsen, F.; Tage-Jensen, U.; Pedersen, N.T.; Gram, B.R.; Rune, S.J. Intraluminal pH in the stomach, duodenum, and proximal jejunum in normal subjects and patients with exocrine pancreatic insufficiency. Gastroenterology 1986, 90, 958-962. [CrossRef]

58. Jacobs, A.; Miles, P.M. Intraluminal transport of iron from stomach to small-intestinal mucosa. Br. Med. J. 1969, 4, 778-781. [CrossRef] [PubMed]

59. Hedrich, S.; Schlomann, M.; Johnson, D.B. The iron-oxidizing proteobacteria. Microbiology 2011, 157, 1551-1564. [CrossRef] [PubMed]

60. Takeuchi, K.; Bjarnason, I.; Laftah, A.H.; Latunde-Dada, G.O.; Simpson, R.J.; McKie, A.T. Expression of iron absorption genes in mouse large intestine. Scand. J. Gastroenterol. 2005, 40, 169-177. [CrossRef] [PubMed]

61. Cowart, R.E. Reduction of iron by extracellular iron reductases: Implications for microbial iron acquisition. Arch. Biochem. Biophys. 2002, 400, 273-281. [CrossRef] 
62. Romanowski, K.; Zaborin, A.; Fernandez, H.; Poroyko, V.; Valuckaite, V.; Gerdes, S.; Liu, D.C.; Zaborina, O.Y.; Alverdy, J.C. Prevention of siderophore- mediated gut-derived sepsis due to P. aeruginosa can be achieved without iron provision by maintaining local phosphate abundance: Role of pH. BMC Microbiol. 2011, 11, 212. [CrossRef] [PubMed]

63. Salovaara, S.; Sandberg, A.S.; Andlid, T. Combined impact of $\mathrm{pH}$ and organic acids on iron uptake by Caco-2 cells. J. Agric. Food Chem. 2003, 51, 7820-7824. [CrossRef] [PubMed]

64. Lund, E.K.; Wharf, S.G.; Fairweather-Tait, S.J.; Johnson, I.T. Increases in the concentrations of available iron in response to dietary iron supplementation are associated with changes in crypt cell proliferation in rat large intestine. J. Nutr. 1998, 128, 175-179. [CrossRef] [PubMed]

65. Ohkawara, Y.; Bamba, M.; Nakai, I.; Kinka, S.; Masuda, M. The absorption of iron from the human large intestine. Gastroenterology 1963, 44, 611-614. [PubMed]

66. Johnston, K.L.; Johnson, D.M.; Marks, J.; Srai, S.K.; Debnam, E.S.; Sharp, P.A. Non-haem iron transport in the rat proximal colon. Eur. J. Clin. Investig. 2006, 36, 35-40. [CrossRef] [PubMed]

67. Xiao, X.; Yeoh, B.S.; Saha, P.; Tian, Y.; Singh, V.; Patterson, A.D.; Vijay-Kumar, M. Modulation of urinary siderophores by the diet, gut microbiota and inflammation in mice. J. Nutr. Biochem. 2017, 41, 25-33. [CrossRef] [PubMed]

68. Kruger, J.; Taylor, J.R.; Du, X.; De Moura, F.F.; Lonnerdal, B.; Oelofse, A. Effect of phytate reduction of sorghum, through genetic modification, on iron and zinc availability as assessed by an in vitro dialysability bioaccessibility assay, Caco-2 cell uptake assay, and suckling rat pup absorption model. Food Chem. 2013, 141, 1019-1025. [CrossRef] [PubMed]

69. Sotelo, A.; Gonzalez-Osnaya, L.; Sanchez-Chinchillas, A.; Trejo, A. Role of oxate, phytate, tannins and cooking on iron bioavailability from foods commonly consumed in Mexico. Int. J. Food Sci. Nutr. 2010, 61, 29-39. [CrossRef] [PubMed]

70. Hurrell, R.; Egli, I. Iron bioavailability and dietary reference values. Am. J. Clin. Nutr. 2010, 91, 1461S-1467S. [CrossRef] [PubMed]

71. Van Dokkum, W. Significance of iron bioavailability for iron recommendations. Biol. Trace Elem. Res. 1992, 35, 1-11. [CrossRef] [PubMed]

72. Hallberg, L.; Brune, M.; Rossander, L. The role of vitamin C in iron absorption. Int. J. Vitam. Nutr. Res. Suppl. 1989, 30, 103-108. [PubMed]

73. Salovaara, S.; Sandberg, A.S.; Andlid, T. Organic acids influence iron uptake in the human epithelial cell line Caco-2. J. Agric. Food Chem. 2002, 50, 6233-6238. [CrossRef] [PubMed]

74. Blachier, F.; Vaugelade, P.; Robert, V.; Kibangou, B.; Canonne-Hergaux, F.; Delpal, S.; Bureau, F.; Blottiere, H.; Bougle, D. Comparative capacities of the pig colon and duodenum for luminal iron absorption. Can. J. Physiol. Pharmacol. 2007, 85, 185-192. [CrossRef] [PubMed]

75. Tako, E.; Glahn, R.P.; Welch, R.M.; Lei, X.; Yasuda, K.; Miller, D.D. Dietary inulin affects the expression of intestinal enterocyte iron transporters, receptors and storage protein and alters the microbiota in the pig intestine. Br. J. Nutr. 2008, 99, 472-480. [CrossRef] [PubMed]

76. Deschemin, J.C.; Noordine, M.L.; Remot, A.; Willemetz, A.; Afif, C.; Canonne-Hergaux, F.; Langella, P.; Karim, Z.; Vaulont, S.; Thomas, M.; et al. The microbiota shifts the iron sensing of intestinal cells. FASEB J. 2016, 30, 252-261. [CrossRef] [PubMed]

77. Reddy, B.S.; Pleasants, J.R.; Wostmann, B.S. Effect of intestinal microflora on iron and zinc metabolism, and on activities of metalloenzymes in rats. J. Nutr. 1972, 102, 101-107. [CrossRef] [PubMed]

78. Forrester, R.H.; Conrad, M.E., Jr.; Crosby, W.H. Measurement of total body iron in animals using whole-body liquid scintillation detectors. Proc. Soc. Exp. Biol. Med. 1962, 111, 115-119. [CrossRef] [PubMed]

79. Stern, P.; Kosak, R.; Misirlija, A. The problem of iron resorption. Experientia 1954, 10, 227. [CrossRef] [PubMed]

80. Cremonesi, P.; Acebron, A.; Raja, K.B.; Simpson, R.J. Iron absorption: Biochemical and molecular insights into the importance of iron species for intestinal uptake. Pharmacol. Toxicol. 2002, 91, 97-102. [CrossRef] [PubMed]

81. Raymond, K.N.; Dertz, E.A.; Kim, S.S. Enterobactin: An archetype for microbial iron transport. Proc. Natl. Acad. Sci. USA 2003, 100, 3584-3588. [CrossRef] [PubMed]

82. Frawley, E.R.; Fang, F.C. The ins and outs of bacterial iron metabolism. Mol. Microbiol. 2014, 93, 609-616. [CrossRef] [PubMed] 
83. Andrews, S.C.; Robinson, A.K.; Rodriguez-Quinones, F. Bacterial iron homeostasis. FEMS Microbiol. Rev. 2003, 27, 215-237. [CrossRef]

84. Archibald, F. Lactobacillus plantarum, an organism not requiring iron. FEMS Microbiol. Lett. 1983, 19, $29-32$. [CrossRef]

85. Weinberg, E.D. The Lactobacillus anomaly: Total iron abstinence. Perspect. Biol. Med. 1997, 40, 578-583. [CrossRef] [PubMed]

86. Aguirre, J.D.; Clark, H.M.; McIlvin, M.; Vazquez, C.; Palmere, S.L.; Grab, D.J.; Seshu, J.; Hart, P.J.; Saito, M.; Culotta, V.C. A manganese-rich environment supports superoxide dismutase activity in a Lyme disease pathogen, Borrelia burgdorferi. J. Biol. Chem. 2013, 288, 8468-8478. [CrossRef] [PubMed]

87. Posey, J.E.; Gherardini, F.C. Lack of a role for iron in the Lyme disease pathogen. Science 2000, 288, 1651-1653. [CrossRef] [PubMed]

88. Neilands, J.B. Siderophores: Structure and function of microbial iron transport compounds. J. Biol. Chem. 1995, 270, 26723-26726. [CrossRef] [PubMed]

89. Hai, L.; Limenitakis, J.P.; Fuhrer, T.; Geuking, M.B.; Lawson, M.B.; Wyss, M.; Brugiroux, S.; Keller, I.; Macpherson, J.A.; Rupp, S.; et al. The outer mucus layer hosts a distinct intestinal microbial niche. Nat. Commun. 2015, 6, 8292.

90. Wandersman, C.; Stojiljkovic, I. Bacterial heme sources: The role of heme, hemoprotein receptors and hemophores. Curr. Opin. Microbiol. 2000, 3, 215-220. [CrossRef]

91. Otto, B.R.; Sparrius, M.; Verweij-van Vught, A.M.; MacLaren, D.M. Iron-regulated outer membrane protein of Bacteroides fragilis involved in heme uptake. Infect. Immun. 1990, 58, 3954-3958. [PubMed]

92. Mevissen-Verhage, E.A.; Marcelis, J.H.; Harmsen-Van Amerongen, W.C.; de Vos, N.M.; Verhoef, J. Effect of iron on neonatal gut flora during the first three months of life. Eur. J. Clin. Microbiol. 1985, 4, 273-278. [CrossRef] [PubMed]

93. Zimmermann, M.B.; Chassard, C.; Rohner, F.; N'Goran, E.K.; Nindjin, C.; Dostal, A.; Utzinger, J.; Ghattas, H.; Lacroix, C.; Hurrell, R.F. The effects of iron fortification on the gut microbiota in African children: A randomized controlled trial in Cote d'Ivoire. Am. J. Clin. Nutr. 2010, 92, 1406-1415. [CrossRef] [PubMed]

94. Balamurugan, R.; Mary, R.R.; Chittaranjan, S.; Jancy, H.; Shobana Devi, R.; Ramakrishna, B.S. Low levels of faecal lactobacilli in women with iron-deficiency anaemia in south India. Br. J. Nutr. 2010, 104, 931-934. [CrossRef] [PubMed]

95. Jaeggi, T.; Kortman, G.A.; Moretti, D.; Chassard, C.; Holding, P.; Dostal, A.; Boekhorst, J.; Timmerman, H.M.; Swinkels, D.W.; Tjalsma, H.; et al. Iron fortification adversely affects the gut microbiome, increases pathogen abundance and induces intestinal inflammation in Kenyan infants. Gut 2015, 64, 731-742. [CrossRef] [PubMed]

96. Dostal, A.; Fehlbaum, S.; Chassard, C.; Zimmermann, M.B.; Lacroix, C. Low iron availability in continuous in vitro colonic fermentations induces strong dysbiosis of the child gut microbial consortium and a decrease in main metabolites. FEMS Microbiol. Ecol. 2013, 83, 161-175. [CrossRef] [PubMed]

97. Tompkins, G.R.; O'Dell, N.L.; Bryson, I.T.; Pennington, C.B. The effects of dietary ferric iron and iron deprivation on the bacterial composition of the mouse intestine. Curr. Microbiol. 2001, 43, 38-42. [CrossRef] [PubMed]

98. Dostal, A.; Chassard, C.; Hilty, F.M.; Zimmermann, M.B.; Jaeggi, T.; Rossi, S.; Lacroix, C. Iron depletion and repletion with ferrous sulfate or electrolytic iron modifies the composition and metabolic activity of the gut microbiota in rats. J. Nutr. 2012, 142, 271-277. [CrossRef] [PubMed]

99. Ettreiki, C.; Gadonna-Widehem, P.; Mangin, I.; Coeffier, M.; Delayre-Orthez, C.; Anton, P.M. Juvenile ferric iron prevents microbiota dysbiosis and colitis in adult rodents. World J. Gastroenterol. 2012, 18, 2619-2629. [CrossRef] [PubMed]

100. Benoni, G.; Cuzzolin, L.; Zambreri, D.; Donini, M.; Del Soldato, P.; Caramazza, I. Gastrointestinal effects of single and repeated doses of ferrous sulphate in rats. Pharmacol. Res. 1993, 27, 73-80. [CrossRef] [PubMed]

101. Buhnik-Rosenblau, K.; Moshe-Belizowski, S.; Danin-Poleg, Y.; Meyron-Holtz, E.G. Genetic modification of iron metabolism in mice affects the gut microbiota. Biometals 2012, 25, 883-892. [CrossRef] [PubMed]

102. Constante, M.; Fragoso, G.; Lupien-Meilleur, J.; Calve, A.; Santos, M.M. Iron Supplements Modulate Colon Microbiota Composition and Potentiate the Protective Effects of Probiotics in Dextran Sodium Sulfate-induced Colitis. Inflamm. Bowel Dis. 2017, 23, 753-766. [CrossRef] [PubMed] 
103. Yeung, C.K.; Glahn, R.P.; Welch, R.M.; Miller, D.D. Prebiotics and iron Bioavailability-Is there a connection? J. Food Sci. 2005, 70, R88-R92. [CrossRef]

104. Weinborn, V.; Valenzuela, C.; Olivares, M.; Arredondo, M.; Weill, R.; Pizarro, F. Prebiotics increase heme iron bioavailability and do not affect non-heme iron bioavailability in humans. Food Funct. 2017, 8, 1994-1999. [CrossRef] [PubMed]

105. Kortman, G.A.; Boleij, A.; Swinkels, D.W.; Tjalsma, H. Iron availability increases the pathogenic potential of Salmonella typhimurium and other enteric pathogens at the intestinal epithelial interface. PLoS ONE 2012, 7, e29968. [CrossRef] [PubMed]

106. Bougle, D.; Vaghefi-Vaezzadeh, N.; Roland, N.; Bouvard, G.; Arhan, P.; Bureau, F.; Neuville, D.; Maubois, J.L. Influence of short-chain fatty acids on iron absorption by proximal colon. Scand. J. Gastroenterol. 2002, 37, 1008-1011. [CrossRef] [PubMed]

107. Chlosta, S.; Fishman, D.S.; Harrington, L.; Johnson, E.E.; Knutson, M.D.; Wessling-Resnick, M.; Cherayil, B.J. The iron efflux protein ferroportin regulates the intracellular growth of Salmonella enterica. Infect. Immun. 2006, 74, 3065-3067. [CrossRef] [PubMed]

108. Paradkar, P.N.; De Domenico, I.; Durchfort, N.; Zohn, I.; Kaplan, J.; Ward, D.M. Iron depletion limits intracellular bacterial growth in macrophages. Blood 2008, 112, 866-874. [CrossRef] [PubMed]

109. Olakanmi, O.; Schlesinger, L.S.; Britigan, B.E. Hereditary hemochromatosis results in decreased iron acquisition and growth by Mycobacterium tuberculosis within human macrophages. J. Leukoc. Biol. 2007, 81, 195-204. [CrossRef] [PubMed]

110. Pagani, A.; Nai, A.; Corna, G.; Bosurgi, L.; Rovere-Querini, P.; Camaschella, C.; Silvestri, L. Low hepcidin accounts for the proinflammatory status associated with iron deficiency. Blood 2011, 118, 736-746. [CrossRef] [PubMed]

111. Sanchez, K.K.; Chen, G.Y.; Schieber, A.M.P.; Redford, S.E.; Shokhirev, M.N.; Leblanc, M.; Lee, Y.M.; Ayres, J.S. Cooperative Metabolic Adaptations in the Host Can Favor Asymptomatic Infection and Select for Attenuated Virulence in an Enteric Pathogen. Cell 2018. [CrossRef] [PubMed]

112. Tamboli, C.P.; Neut, C.; Desreumaux, P.; Colombel, J.F. Dysbiosis in inflammatory bowel disease. Gut 2004, 53, 1-4. [CrossRef] [PubMed]

113. Kaur, N.; Chen, C.C.; Luther, J.; Kao, J.Y. Intestinal dysbiosis in inflammatory bowel disease. Gut Microbes 2011, 2, 211-216. [CrossRef] [PubMed]

114. Kamada, N.; Seo, S.U.; Chen, G.Y.; Nunez, G. Role of the gut microbiota in immunity and inflammatory disease. Nat. Rev. Immunol. 2013, 13, 321-335. [CrossRef] [PubMed]

115. Xavier, R.J.; Podolsky, D.K. Unravelling the pathogenesis of inflammatory bowel disease. Nature 2007, 448, 427-434. [CrossRef] [PubMed]

116. World Health Organization. The Global Prevalence of Anaemia in 2011; WHO Press: Geneva, Switzarland, 2015.

117. Dignass, A.U.; Gasche, C.; Bettenworth, D.; Birgegard, G.; Danese, S.; Gisbert, J.P.; Gomollon, F.; Iqbal, T.; Katsanos, K.; Koutroubakis, I.; et al. European consensus on the diagnosis and management of iron deficiency and anaemia in inflammatory bowel diseases. J. Crohns Colitis 2015, 9, 211-222. [CrossRef] [PubMed]

118. Cherayil, B.J. Cross-talk between iron homeostasis and intestinal inflammation. Gut Microbes 2010, 1, 65-69. [CrossRef] [PubMed]

119. Gasche, C.; Lomer, M.C.; Cavill, I.; Weiss, G. Iron, anaemia, and inflammatory bowel diseases. Gut 2004, 53, 1190-1197. [CrossRef] [PubMed]

120. Lomer, M.C.E.; Cook, W.B.; Jan-Mohamed, H.J.B.; Hutchinson, C.; Liu, D.Y.; Hider, R.C.; Powell, J.J. Iron requirements based upon iron absorption tests are poorly predicted by haematological indices in patients with inactive inflammatory bowel disease. Br. J. Nutr. 2012, 107, 1806-1811. [CrossRef] [PubMed]

121. Carrier, J.C.; Aghdassi, E.; Jeejeebhoy, K.; Allard, J.P. Exacerbation of dextran sulfate sodium-induced colitis by dietary iron supplementation: Role of NF-kappa B. Int. J. Colorectal. Dis. 2006, 21, 381-387. [CrossRef] [PubMed]

122. Erichsen, K.; Milde, A.M.; Arslan, G.; Helgeland, L.; Gudbrandsen, O.A.; Ulvik, R.J.; Berge, R.K.; Hausken, T.; Berstad, A. Low-dose oral ferrous fumarate aggravated intestinal inflammation in rats with DSS-induced colitis. Inflamm. Bowel Dis. 2005, 11, 744-748. [CrossRef] [PubMed]

123. Reifen, R.; Matas, Z.; Zeidel, L.; Berkovitch, Z.; Bujanover, Y. Iron supplementation may aggravate inflammatory status of colitis in a rat model. Digest. Dis. Sci. 2000, 45, 394-397. [CrossRef] [PubMed] 
124. Seril, D.N.; Liao, J.; Ho, K.L.K.; Warsi, A.; Yang, C.S.; Yang, G.Y. Dietary iron supplementation enhances DSS-induced colitis and associated colorectal carcinoma development in mice. Digest. Dis. Sci. 2002, 47, 1266-1278. [CrossRef] [PubMed]

125. Werner, T.; Wagner, S.J.; Martinez, I.; Walter, J.; Chang, J.S.; Clavel, T.; Kisling, S.; Schuemann, K.; Haller, D. Depletion of luminal iron alters the gut microbiota and prevents Crohn's disease-like ileitis. Gut 2011, 60, 325-333. [CrossRef] [PubMed]

126. Gevers, D.; Kugathasan, S.; Denson, L.A.; Vazquez-Baeza, Y.; Van Treuren, W.; Ren, B.Y.; Schwager, E.; Knights, D.; Song, S.J.; Yassour, M.; et al. The Treatment-Naive Microbiome in New-Onset Crohn's Disease. Cell Host Microbe 2014, 15, 382-392. [CrossRef] [PubMed]

127. Juillerat, P.; Yilmaz, B.; Wiest, R.; Rogler, G.; Macpherson, A.J. The clinical determinants affect gut microbial profile of inflammatory bowel disease patients. J. Crohns Colitis 2018, 12, S14. [CrossRef]

128. Morgan, X.C.; Tickle, T.L.; Sokol, H.; Gevers, D.; Devaney, K.L.; Ward, D.V.; Reyes, J.A.; Shah, S.A.; LeLeiko, N.; Snapper, S.B.; et al. Dysfunction of the intestinal microbiome in inflammatory bowel disease and treatment. Genome Biol. 2012, 13. [CrossRef] [PubMed]

129. Norman, J.M.; Handley, S.A.; Baldridge, M.T.; Droit, L.; Liu, C.Y.; Keller, B.C.; Kambal, A.; Monaco, C.L.; Zhao, G.; Fleshner, P.; et al. Disease-Specific Alterations in the Enteric Virome in Inflammatory Bowel Disease. Cell 2015, 160, 447-460. [CrossRef] [PubMed]

130. Schreiner, P.; Yilmaz, B.; Franc, Y.; Rossel, J.B.; Misselwitz, B.; Scharl, M.; Zeitz, J.; Frei, P.; Greuter, T.; Vavricka, S.; et al. Vegetarian and gluten-free diet in patients with IBD-associated with a different microbiota compared with omnivore IBD patients. J. Crohns Colitis 2018, 12, S549. [CrossRef]

131. Sokol, H.; Leducq, V.; Aschard, H.; Pham, H.P.; Jegou, S.; Landman, C.; Cohen, D.; Liguori, G.; Bourrier, A.; Nion-Larmurier, I.; et al. Fungal microbiota dysbiosis in IBD. Gut 2017, 66, 1039-1048. [CrossRef] [PubMed]

132. Willing, B.P.; Dicksved, J.; Halfvarson, J.; Andersson, A.F.; Lucio, M.; Zheng, Z.; Jarnerot, G.; Tysk, C.; Jansson, J.K.; Engstrand, L. A Pyrosequencing Study in Twins Shows That Gastrointestinal Microbial Profiles Vary With Inflammatory Bowel Disease Phenotypes. Gastroenterology 2010, 139, 1844-1854. [CrossRef] [PubMed]

133. Zhu, A.; Kaneshiro, M.; Kaunitz, J.D. Evaluation and treatment of iron deficiency anemia: A gastroenterological perspective. Dig. Dis. Sci. 2010, 55, 548-559. [CrossRef] [PubMed]

134. Kangaspunta, M.; Haapamaki, J.; Farkkila, M.; Arkkila, P. Inflammatory bowel disease and anemia: Intravenous iron treatment. Scand. J. Gastroenterol. 2018, 53, 430-434. [CrossRef] [PubMed]

135. Lee, T.; Clavel, T.; Smirnov, K.; Schmidt, A.; Lagkouvardos, I.; Walker, A.; Lucio, M.; Michalke, B.; Schmitt-Kopplin, P.; Fedorak, R.; et al. Oral versus intravenous iron replacement therapy distinctly alters the gut microbiota and metabolome in patients with IBD. Gut 2017, 66, 863-871. [CrossRef] [PubMed]

136. Graf, E.; Eaton, J.W. Suppression of colonic cancer by dietary phytic acid. Nutr. Cancer 1993, 19, 11-19. [CrossRef] [PubMed]

137. Graf, E.; Eaton, J.W. Dietary suppression of colonic cancer. Fiber or phytate? Cancer 1985, 56, 717-718. [CrossRef]

138. Nelson, R.L. Dietary iron and colorectal cancer risk. Free Radic. Biol. Med. 1992, 12, 161-168. [CrossRef]

139. Ashmore, J.H.; Rogers, C.J.; Kelleher, S.L.; Lesko, S.M.; Hartman, T.J. Dietary Iron and Colorectal Cancer Risk: A Review of Human Population Studies. Crit. Rev. Food Sci. Nutr. 2016, 56, 1012-1020. [CrossRef] [PubMed]

140. Babbs, C.F. Free radicals and the etiology of colon cancer. Free Radic. Biol. Med. 1990, 8, 191-200. [CrossRef]

141. Nelson, R.L. Iron and colorectal cancer risk: Human studies. Nutr. Rev. 2001, 59, 140-148. [CrossRef] [PubMed]

142. Nelson, R.L.; Davis, F.G.; Sutter, E.; Sobin, L.H.; Kikendall, J.W.; Bowen, P. Body iron stores and risk of colonic neoplasia. J. Natl. Cancer Inst. 1994, 86, 455-460. [CrossRef] [PubMed]

143. Bird, C.L.; Witte, J.S.; Swendseid, M.E.; Shikany, J.M.; Hunt, I.F.; Frankl, H.D.; Lee, E.R.; Longnecker, M.P.; Haile, R.W. Plasma ferritin, iron intake, and the risk of colorectal polyps. Am. J. Epidemiol. 1996, 144, $34-41$. [CrossRef] [PubMed]

144. Lee, D.H.; Anderson, K.E.; Harnack, L.J.; Folsom, A.R.; Jacobs, D.R., Jr. Heme iron, zinc, alcohol consumption, and colon cancer: Iowa Women's Health Study. J. Natl. Cancer Inst. 2004, 96, 403-407. [CrossRef] [PubMed]

145. Larsson, S.C.; Adami, H.O.; Giovannucci, E.; Wolk, A. Re: Heme iron, zinc, alcohol consumption, and risk of colon cancer. J. Natl. Cancer Inst. 2005, 97, 232-233. [CrossRef] [PubMed] 
146. Kabat, G.C.; Miller, A.B.; Jain, M.; Rohan, T.E. A cohort study of dietary iron and heme iron intake and risk of colorectal cancer in women. Br. J. Cancer 2007, 97, 118-122. [CrossRef] [PubMed]

147. Balder, H.F.; Vogel, J.; Jansen, M.C.; Weijenberg, M.P.; van den Brandt, P.A.; Westenbrink, S.; van der Meer, R.; Goldbohm, R.A. Heme and chlorophyll intake and risk of colorectal cancer in the Netherlands cohort study. Cancer Epidemiol. Biomarkers Prev. 2006, 15, 717-725. [CrossRef] [PubMed]

148. Cross, A.J.; Ferrucci, L.M.; Risch, A.; Graubard, B.I.; Ward, M.H.; Park, Y.; Hollenbeck, A.R.; Schatzkin, A.; Sinha, R. A large prospective study of meat consumption and colorectal cancer risk: An investigation of potential mechanisms underlying this association. Cancer Res. 2010, 70, 2406-2414. [CrossRef] [PubMed]

149. Nelson, R.L.; Persky, V.; Turyk, M. Determination of factors responsible for the declining incidence of colorectal cancer. Dis. Colon. Rectum 1999, 42, 741-752. [CrossRef] [PubMed]

150. Sobhani, I.; Tap, J.; Roudot-Thoraval, F.; Roperch, J.P.; Letulle, S.; Langella, P.; Corthier, G.; Tran Van Nhieu, J.; Furet, J.P. Microbial dysbiosis in colorectal cancer (CRC) patients. PLoS ONE 2011, 6, e16393. [CrossRef] [PubMed]

151. Nicholson, J.K.; Holmes, E.; Kinross, J.; Burcelin, R.; Gibson, G.; Jia, W.; Pettersson, S. Host-gut microbiota metabolic interactions. Science 2012, 336, 1262-1267. [CrossRef] [PubMed]

152. Huycke, M.M.; Gaskins, H.R. Commensal bacteria, redox stress, and colorectal cancer: Mechanisms and models. Exp. Biol. Med. 2004, 229, 586-597. [CrossRef]

153. Gold, J.S.; Bayar, S.; Salem, R.R. Association of Streptococcus bovis bacteremia with colonic neoplasia and extracolonic malignancy. Arch. Surg. 2004, 139, 760-765. [CrossRef] [PubMed]

154. McIntosh, G.H.; Royle, P.J.; Playne, M.J. A probiotic strain of L. acidophilus reduces DMH-induced large intestinal tumors in male Sprague-Dawley rats. Nutr. Cancer 1999, 35, 153-159. [CrossRef] [PubMed]

155. Kot, E.; Bezkorovainy, A. Binding of ferric iron to the cell walls and membranes of Bifidobacterium thermophilum: Effect of free radicals. J. Agric. Food Chem. 1999, 47, 4606-4610. [CrossRef] [PubMed]

156. Vipperla, K.; O'Keefe, S.J. The microbiota and its metabolites in colonic mucosal health and cancer risk. Nutr. Clin. Pract. 2012, 27, 624-635. [CrossRef] [PubMed]

157. Engle, S.J.; Ormsby, I.; Pawlowski, S.; Boivin, G.P.; Croft, J.; Balish, E.; Doetschman, T. Elimination of colon cancer in germ-free transforming growth factor beta 1-deficient mice. Cancer Res. 2002, 62, 6362-6366. [PubMed]

158. Feng, Q.; Liang, S.; Jia, H.; Stadlmayr, A.; Tang, L.; Lan, Z.; Zhang, D.; Xia, H.; Xu, X.; Jie, Z.; et al. Gut microbiome development along the colorectal adenoma-carcinoma sequence. Nat. Commun. 2015, 6, 6528. [CrossRef] [PubMed]

159. Girelli, D.; Ugolini, S.; Busti, F.; Marchi, G.; Castagna, A. Modern iron replacement therapy: Clinical and pathophysiological insights. Int. J. Hematol. 2018, 107, 16-30. [CrossRef] [PubMed]

(C) 2018 by the authors. Licensee MDPI, Basel, Switzerland. This article is an open access article distributed under the terms and conditions of the Creative Commons Attribution (CC BY) license (http:/ / creativecommons.org/licenses/by/4.0/). 


\title{
Review
}

\section{Ironing out Macrophage Immunometabolism}

\author{
Stefania Recalcati, Elena Gammella and Gaetano Cairo * \\ Department of Biomedical Sciences for Health, University of Milan, 20133 Milan, Italy; \\ stefania.recalcati@unimi.it (S.R.); elena.gammella@unimi.it (E.G.) \\ * Correspondence: gaetano.cairo@unimi.it
}

Received: 31 May 2019; Accepted: 17 June 2019; Published: 19 June 2019

\begin{abstract}
Over the last decade, increasing evidence has reinforced the key role of metabolic reprogramming in macrophage activation. In addition to supporting the specific immune response of different subsets of macrophages, intracellular metabolic pathways also directly control the specialized effector functions of immune cells. In this context, iron metabolism has been recognized as an important component of macrophage plasticity. Since macrophages control the availability of this essential metal, changes in the expression of genes coding for the major proteins of iron metabolism may result in different iron availability for the macrophage itself and for other cells in the microenvironment. In this review, we discuss how macrophage iron can also play a role in immunometabolism.
\end{abstract}

Keywords: macrophages; iron; metabolism; inflammation

\section{Introduction}

Over the last decade, interest in immunometabolism - the interaction between immunological and metabolic systems at both the body and cellular levels-has grown considerably. Although the metabolic pathways of several types of immune cells, such as T cells-which contribute to immune modulation in cancer through their metabolic connection with tumor cells [1] —have received attention, most studies have focused on macrophage immunometabolism. In fact, it is increasingly appreciated that the functions of these cells extend beyond immune defense. Indeed, metabolism is not only a system to produce energy, but also a source of a variety of intermediates with relevant biological function in innate immunity and inflammatory response. Under the influence of signals from the microenvironment, cells of the monocyte-macrophage lineage undergo a complex reprogramming toward distinct functional phenotypes [2]. Emerging evidence has shown that immunometabolism is an important factor of the functional phenotype that characterizes the different macrophage populations, such as those present in sites of infections, tissue injury, tumors, atherosclerotic plaques, adipose tissue, etc. In this review, we address the cell-intrinsic metabolic functions that contribute to determine the functional activity of macrophages focusing in particular on iron metabolism, which has been recognized as one of the selected metabolic features of different classes of macrophages [3].

\section{Macrophage Polarization}

Macrophages play a variety of distinct roles both in pathological conditions, such as inflammation, and physiological tissue homeostasis. To fulfil these tasks, macrophage populations are able to acquire different phenotypes depending on environmental and immune signals, which polarize macrophages to a range of activation states classified in two major groups: classical pro-inflammatory (M1) macrophages endowed with cytotoxic and microbicidal functions, which are typically induced following activation of toll-like receptors (TLR) by pathogen products such as lipopolysaccharide (LPS), or alternative anti-inflammatory (M2) macrophages, which respond to anti-inflammatory cytokines like interleukin 4 (IL-4) and are involved in cell growth and tissue remodelling [4] (Figure 1). In spite of 
the oversimplification, this classification faithfully represents the polarization of macrophages in most pathophysiological settings. The behaviour and the gene expression profile of differently polarized macrophages show considerable differences, but recent studies have shown that several divergences in cellular metabolism also contribute significantly to the diversity of the M1 and M2 populations. Notably, the metabolic changes, which are influenced by signals from the microenvironment, in turn support the specialized functions of macrophage subsets [5]. In addition, recent studies showed that altering macrophage metabolism can also reshape their functions [6]. This may offer the possibility to exploit metabolic pathways to alter the role of macrophages in a variety of pathologic conditions in which myelomonocytic cells are a key component, such as tumors, obesity, atherosclerosis.
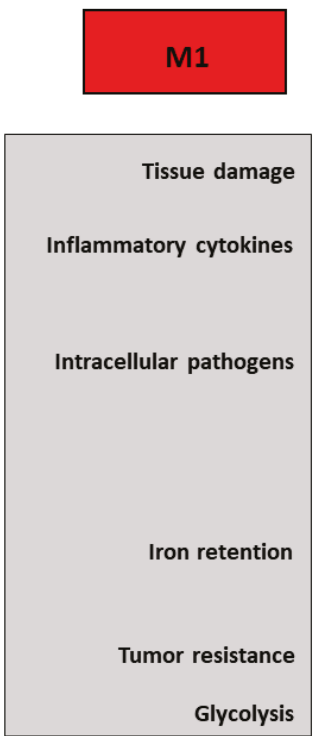
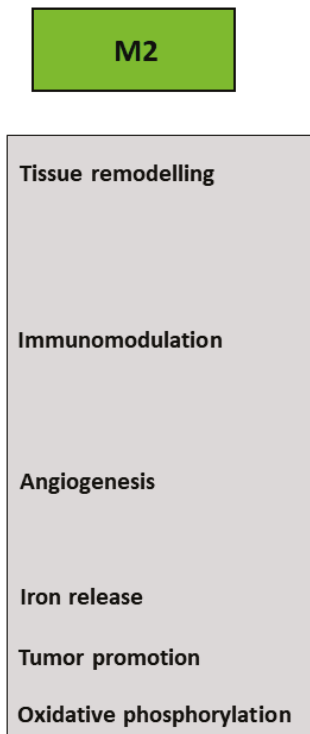

Figure 1. M1 and M2 macrophages represent the extremes of a spectrum. The major properties and functions of polarized macrophages are summarized in the boxes. The differential expression of representative molecules and effectors is also shown.

\section{Macrophage Diversity and Metabolism}

\subsection{Amino Acid Metabolism}

Macrophage plasticity includes changes in amino acid metabolism (Figure 1); in fact, a well-known distinctive feature of M1 macrophages is the inducible conversion of arginine into nitric oxide (NO), a reactive compound important for microbial killing. Conversely, arginase-dependent metabolism of arginine in $\mathrm{M} 2$ cells on the one hand depletes arginine required for $\mathrm{NO}$ synthesis in macrophages and for T cell immunity [7]; on the other hand leads to the production of ornithine, thus possibly contributing to collagen synthesis, consistent with the healing function of M2 [3,5].

The metabolism of tryptophan which can be converted in different compounds along two main pathways represents another example of the connection between immune function and amino acid metabolism. Tryptophan can be metabolized by the heme-containing indoleamine 2,3-dioxygenase 1 (IDO1) or tryptophan mono-oxygenase: IDO1 catalyzes the initial reaction of the pathway that transforms tryptophan into kynurenine, a product that exerts major immunosuppressive effects by inhibiting T cell immunity and impairing chemotaxis of neutrophils [7] (Figure 2). IDO1 can be induced in several types of myeloid cells, including macrophages [8], in response to stimulation of innate immunity [9]. The immunosuppressive activity of IDO1, which is also considered a marker of M2 
polarization, has been ascribed to its ability to deplete the microenvironmental tryptophan pools for $\mathrm{T}$ cells while favoring the accumulation of kynurenine and the production of ligands for the aryl hydrocarbon receptor with ensuing synthesis of pro-inflammatory cytokines [10]. Consistent with the inhibitory role of kynurenine, lack of tetrahydrobiopterine (BH4), which is a cofactor for tryptophan mono-oxygenase, favored tryptophan metabolism by IDO1, thus repressing $\mathrm{T}$ cells proliferation and impairing mitochondrial respiration and energy production [11].

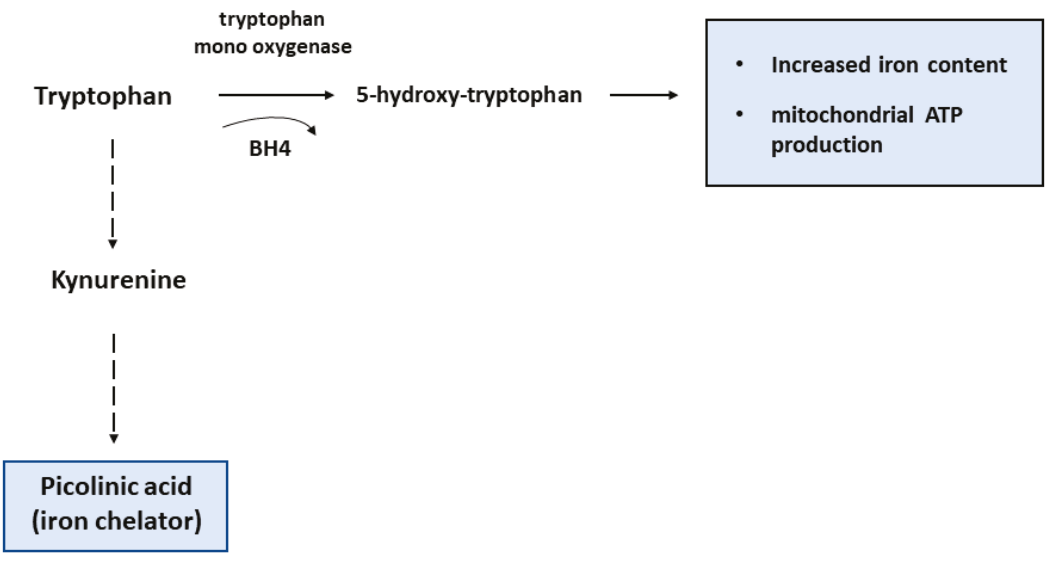

Figure 2. Schematic diagram of different tryptophan metabolism pathways. According to results found in T cells lacking tetrahydrobiopterin (BH4) (see text), it is conceivable that the conversion of tryptophan by tryptophan mono-oxygenase results in high iron levels and efficient mitochondrial activity, whereas the kynurenine pathway initiated by IDO1 activity leads to the formation of the iron chelator picolinic acid.

\subsection{Glucose Metabolism}

The differences in amino acid metabolism described above are well-known and have long been used to define macrophages subsets, but recently a growing interest highlighted the role of glucose metabolism in this context (reviewed in Reference [12-14]) (Figure 1). M1 macrophages produce ATP mainly through aerobic glycolysis, i.e., the metabolism of glucose to lactate despite oxygen availability. Reactive oxygen species-mediated hypoxia inducible factor $1 \alpha(\mathrm{HIF} 1 \alpha)$ induction results in glycolysis upregulation [15]. This pathway is less efficient in generating ATP than the mitochondrial respiration, but it allows the cells to generate building blocks needed for the synthesis of nucleotides, amino acids and lipids. Moreover, the higher levels of glucose 6-phosphate generated by increased glycolysis can stimulate the pentose phosphate pathway, thus also providing more of the reduced form of nicotinamide adenine dinucleotide phosphate (NADPH), a key cofactor for a variety of biosynthetic processes, including lipid synthesis. Therefore, M1 macrophages adapt their energy metabolism to secure enough ATP, while also supporting biosynthetic functions needed to sustain proliferation and synthesis of cell structures and inflammatory molecules. At the same time, the other metabolic process observed in M1 macrophages is the inhibition of mitochondrial oxidative phosphorylation [12]. This is attained by suppressing the tricarboxylic acid (TCA) cycle at two distinct levels, with concomitant generation of intermediates that are used for protein and lipid synthesis. The block of isocitrate dehydrogenase (IDH) results in the accumulation of acetyl CoA and citrate, which is then exported from the mitochondria to the cytosol where it can be converted by acetyl-CoAcarboxylase (ACC) to malonyl-CoA, which is then used to synthesize fatty acids, important precursors for the expansion of membranes, such as the endoplasmic reticulum. Suppression of succinate dehydrogenase (SDH) is obtained through a recently discovered pathway based on TLR4-mediated induction of cis-aconitic acid decarboxylase/immune-responsive gene 1 (CAD/Irg1), 
an enzyme that drives the conversion of cis-aconitate, the intermediate between citrate and isocitrate in the TCA cycle, to itaconate, a metabolite possessing both anti-inflammatory and anti-microbial properties [16] (Figure 3). It has been shown that itaconate, known as industrial polymer since almost a century [17], inhibits SDH activity, thereby decreasing fumarate production. Since SDH is also a component of the complex II of the electron transport chain, induction of CAD/Irg1 activity affects two key steps of cellular oxidative energy production. Moreover, by inhibiting the prolyl hydroxylases involved in HIF1 $\alpha$ degradation pathway, succinate accumulation may concur to the induction of glycolysis reported above. The latter effect is also achieved by itaconate-mediated repression of fatty acid biosynthesis from glucose. Interestingly, itaconate is also endowed with antimicrobial properties against a variety of microorganisms, as it is transported from the mitochondria, where CAD/Irg1 is located, to phagosomes in which it inhibits microbial isocitrate lyase, an enzyme involved in the glyoxylate pathway required for survival when glucose availability is limited [16]. Itaconate is also secreted [17], as revealed by its presence in serum, and hence it also traverses the cytoplasm. Therefore, mitochondrial or cytosolic itaconate might play regulatory roles while phagosomal and extracellular itaconate participates in anti-microbial action. A recent study [18] reported that the activity of one isoform (BCAT1) of branched chain aminotransferases, multi-level regulators of the TCA cycle and oxidative phosphorylation, is required for itaconate production and metabolic reprogramming in human macrophages, thus showing the interaction of different nutrient metabolism (amino acids and glucose) in pro-inflammatory macrophage function.

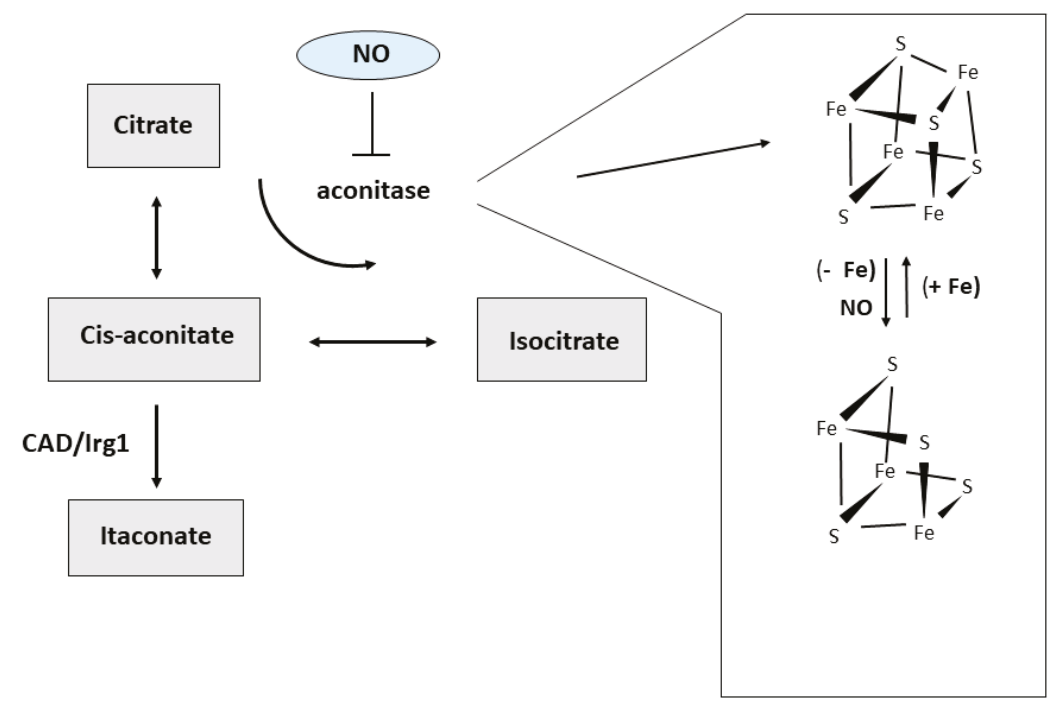

Figure 3. Alternative pathways of cis-aconitate metabolism. Iron availability and reactive molecules produced under inflammatory condition like nitric oxide (NO) can target the iron-sulfur cluster and alter aconitase activity, thus affecting the amount of cis-aconitate available for the decarboxylating activity of CAD/Irg1 and the production of itaconate.

Notably, the link between macrophage metabolism and functionality is underlined by the evidence that metabolic pathways of M1 macrophages contribute specifically to their pro-inflammatory role. Moreover, metabolites can also be employed as immunoregulators in order to control the extent and duration of the inflammatory response. For example, the lactate produced by activated M1 macrophages through glycolysis accumulate and exerts an immunosuppressive function by stimulating M2 polarization of macrophages. Interestingly, lactate appears to be one of the factors produced by tumor cells that promote the formation of M2-like tumor associated macrophages (TAM) [19]. 
On the other hand, M2 cells show high levels of oxidative phosphorylation and mitochondrial activity. The TCA cycle is fueled by consumption of fatty acids undergoing beta oxidation and also by glutamine utilization to form $\alpha$-ketoglutarate. To support these reactions, mitochondrial biogenesis is also induced. Interestingly, the key metabolic regulator mechanistic target of rapamycin (mTOR) is involved also in macrophage metabolism and activation. In fact, inducers of M2 polarization like IL-4 signal through the mTOR pathway to promote fatty acid oxidation (FAO) and glucose consumption for oxidative phosphorylation, two metabolic changes that are critical for macrophage alternative activation [20]. A recent study has demonstrated that upregulating FAO in macrophages of hypercholesterolemic mice via miR-33 inhibition drives macrophages toward an M2 state and reduces atherosclerosis [21]. This study emphasizes how metabolic reprogramming of macrophages can influence disease outcome.

The anti-inflammatory and pro-resolving function of M2 macrophages is involved also in efferocytosis, the process by which apoptotic cells are cleared by phagocytes, primarily resident macrophages. Recent findings have shown that two distinct metabolic pathways are required to prevent unwanted inflammation and promote repair by creating an anti-inflammatory tissue environment. One study showed the importance of glycolysis and lactate release [22], whereas Zhang et al. [23] described how FAO starts a mechanism leading to the production of anti-inflammatory IL-10. These results indicate that macrophages adopt separate but converging mechanisms to alter their metabolism and thus drive an anti-inflammatory response.

Amino acid and glucose metabolism are linked in reprogramming macrophage function. In fact, recent findings have shown that $\mathrm{NO}$ also impacts on mitochondrial cell bioenergetic pathways, probably thanks to its reactivity against iron-containing Fe-S clusters and heme moieties that are present in several proteins of the electron transport chain and TCA cycle. In fact, knock down of iNOS restored mitochondrial ATP production through oxidative metabolism in M1 macrophages. These forces activated macrophages to bring in glucose and use glycolytic metabolism to produce energy [12]. Notably, both the accumulation of citrate described above and the generation of glucose 6-phosphate by glycolysis, with consequent stimulation of the pentose phosphate pathway, favor NO production, thereby inducing a feedforward loop of inflammatory activation.

Despite our increased understanding of macrophage immunometabolism as an important determinant of the pathophysiological conditions in which macrophages are involved, it should be kept in mind that several issues remain to be explored and clarified. Some of the major challenges and concerns are reported below. In the same way as the distinction of M1 and M2 macrophages between pro- and anti-inflammatory, respectively, is an oversimplification, also describing their metabolism as glycolytic or depending on oxidative phosphorylation does not reflect the variety of phenotypes and metabolic profiles that can be obtained by in vitro exposure to different stimuli or, even more, to the distinct macrophage subsets occurring in vivo. An example of the diverse effects on metabolism of different M1 polarizing stimuli is represented by the response of mitochondrial metabolism to LPS, which is downregulated in bone marrow-derived macrophages and upregulated in peritoneal macrophages, despite a similarly strong inflammatory response [24]. Another striking example is provided by TAM, which are usually considered M2-like but show a glycolytic metabolism similar to that of in vitro polarized M1 cells (discussed in Reference [14]). Moreover, IRG1-itaconic acid production, which is typical of M1 cells, has been shown to be linked to the modulation of M2-like macrophage polarization in the revascularization of ischaemic muscle [25]. It should be also kept in mind that most studies investigating immunometabolism were performed in mouse models and in several instances the maintenance of the observed effects in humans remains to be investigated and demonstrated. Indeed, several differences exist between mouse and human macrophages, such as the inability of human macrophages to produce significant amounts of a key regulator of metabolic reprogramming like NO. 


\section{Macrophages and Iron Metabolism}

Iron is a redox-active metal required for the activity of essential enzymes involved in a variety of cellular functions, but excess iron is potentially toxic as a catalyst of oxidative stress. Therefore, the appropriate iron concentration in the cells and organisms is homeostatically maintained by several mechanisms. The role of macrophages in iron metabolism has been covered extensively in this Special Issue [26]. At the systemic level, macrophages are key regulators of iron trafficking [27,28]. Spi-C-dependent splenic reticuloendothelial cells clear senescent erythrocytes and release iron back to circulation, thus providing iron needed for erythroid precursors proliferation and hemoglobin synthesis [29]. On the other hand, iron sequestration by pro-inflammatory macrophages represents a recognized and efficient bacteriostatic response [30,31]. Moreover, iron is required for hemoproteins essential for macrophage activity in inflammation, such as NADPH oxidase 2, cyclooxygenases 1 and 2, inducible nitric oxide synthase, etc. [29]. Consistent with their different functions in homeostatic and inflammatory conditions, polarized macrophages also show a distinct expression of genes involved in iron homeostasis [28,32], in which M1 cells withhold iron whereas M2 are prone to iron release to tissues (Figure 1). High expression of the iron storage protein ferritin correlates with iron retention by in vitro polarized M1 macrophages. On the other hand, alternatively activated M2 macrophages show an elevated capacity for CD163-dependent uptake and heme oxygenase-mediated catabolism of heme-associated iron, as well as high expression of ferroportin (FPN), the only known mammalian iron exporter [33]. This FPN-mediated sustained iron release may significantly contribute to the role of M2 macrophages in various pathophysiological conditions, such as tissue repair, and also tumor growth [28], as TAM acquire a M2-like phenotype [34]. However, the effect of iron on TAM polarization remains to be fully understood. In fact, it has been shown that high doses of iron can shift TAM, which usually have a pro-tumor activity, to the anti-tumor M1 phenotype [35]. Conversely, it has been described that an intracellular iron-chelator can switch TAM from their iron-release phenotype toward iron storage [36]. In this context, it is interesting that TAM macrophages can also be a source of extracellular ferritin in the tumor microenvironment and ferritin was able to stimulate the growth of cancer cells in an iron-independent way, at least in vitro [37].

Moreover, we recently demonstrated that macrophage FPN-dependent supply of iron to the microenvironment is necessary for stromal and parenchymal cells multiplication, differentiation and activity, both in the physiological context of hair follicle growth and in the pathophysiological setting of wound healing, two conditions sharing many similarities including fast cell replication [38]. In fact, loss of macrophage FPN causes hair follicle alterations and alopecia by inhibiting the proliferation of neighbouring hair follicle cells. Similarly, iron retention in macrophages delayed wound healing in mice lacking FPN in macrophages by affecting stromal cells proliferation, blood and lymphatic vessels formation and fibrogenesis. These findings indicated that iron should be included in the list of trophic mediators produced by macrophages that are required for tissue homeostasis and repair. Although in these settings iron retention in macrophages had no impact on the inflammatory processes accompanying wound healing [38], other studies suggested that under conditions of massive iron deposition caused by hemolysis iron accumulation in macrophages can activate them to a pro-inflammatory M1 phenotype [39-41]. The conflicting results may be related to the amount of iron stored as well as to the exposure to different iron sources, as heme iron is highly toxic [42].

\section{Macrophage Iron and Immunometabolism}

The differences in iron metabolism existing in the various macrophage subsets can be relevant also for immunometabolism. As reported above, in pro-inflammatory macrophages CAD/Irg1 decarboxylates cis-aconitate to generate itaconate, a compound with antimicrobial functions $[16,17]$. Cis-aconitate, an intermediate in the conversion of citrate to isocitrate, is the substrate of both mitochondrial and cytosolic aconitases. The latter represents an alternative form of iron-regulatory protein 1 (IRP1), an RNA-binding protein which controls the synthesis of proteins involved in intracellular iron usage, storage or transport [43]. The availability of iron to assemble the iron-sulfur 
cluster dictates the switch between the enzymatically active holoprotein endowed with aconitase activity and the RNA-binding apoform which controls iron homeostasis [44] (Figure 3). We have shown that in macrophages NO is able to induce concomitant inactivation of cytosolic aconitase and activation of IRP1, attributable to disassembly of the Fe-S cluster [45]. This switch should result in cis-aconitate accumulation and increased availability of this substrate to CAD/Irg1-mediated conversion to itaconate. Therefore, this process could represent a still unexplored pathway used by NO-producing inflammatory macrophages to favor the generation of an antimicrobial compound. In addition, by targeting iron-sulfur clusters the generation of $\mathrm{NO}$ can also affect macrophage metabolic activities [46]. In fact, in Toll-like receptor-activated mouse macrophages, NO-mediated damage to iron-sulfur proteins compromises mitochondrial oxidative metabolism and thus constitutes an additional mechanism contributing to the shift toward the glycolytic pathway that characterizes M1 cells. Notably, genes involved in iron-sulfur cluster biogenesis, such as ISCU and NSF1, were found to be preferentially expressed in M2 polarized human macrophages [32], which rely on mitochondrial oxidative phosphorylation for energy production. In the same context, by influencing the formation of the iron-sulfur cluster of mitochondrial aconitase, iron availability in the mitochondria could determine whether cis-aconitate is decarboxylated by CAD/Irg1 or converted to isocitrate by aconitase (Figure 3).

Iron may be involved also in amino acid catabolism. Tryptophan mono-oxygenase-mediated tryptophan metabolism contributes to maintain high iron levels and efficient mitochondrial respiration [11], whereas tryptophan degradation by IDO1 through the kynurenine pathway leads to formation of picolinic acid, which is an iron chelator [47] (Figure 2). By depleting the cells of iron, which is essential for enzymes involved in DNA synthesis like ribonucleotide reductase [48], iron sequestration by picolinic acid may contribute to the immunosuppressive activity of the kynurenine pathway, which impairs T cells proliferation and activity [49]. Moreover, the ability of picolinic acid to amplify IFN- $\gamma$-mediated NO production in macrophages, an event connecting arginine and tryptophan metabolism [50], may depend on the induction of nitric oxide synthase (NOS) mRNA expression by the hypoxia inducible transcription factor (HIF), which is also induced by iron deficiency [51]. Therefore, iron may contribute to the immunosuppressive activity that renders IDO1 an interesting target of pharmacological inhibitors for cancer therapy [52].

A link between metabolic, inflammatory, and iron-regulatory pathways has been provided by evidence showing that mTOR regulates iron homeostasis by decreasing transferrin receptor (TfR1) stability and hence iron uptake. mTOR activates tristetraprolin (TTP), a protein involved in suppression of immune responses, which binds to TfR1 mRNA and enhances its degradation [53]. At the same time, TTP, which is induced by iron deficiency, promotes downregulation of iron-requiring genes, in particular those coding for mitochondrial proteins involved in energy production, thus facilitating survival when iron is scarce. Although these results were found in fibroblasts and myoblasts, it is tempting to speculate that a similar process can occur in macrophages, consistent with the demonstration that metabolic reprogramming mediated by the mTOR pathway is required for macrophage alternative activation [20].

Another example of the interaction between iron and immunometabolism was provided by the comparison of differences in gene expression profiles between mouse non-activated bone marrow-derived macrophages and non-activated peritoneal macrophages, which highlighted a differential expression of genes involved in heme biosynthesis [24], thus confirming a previous observation in human in vitro polarized macrophages [32].

\section{Concluding Remarks}

Recent advances in the availability of molecular and biochemical methods have highlighted that intracellular metabolic pathways control the effector functions of macrophages, as exemplified by the distinct metabolic signature of differently polarized macrophages, which show significant differences in pathways of energy production, amino acid metabolism and iron homeostasis. These processes are intertwined and we have tried to draw attention to the role of iron in these settings. 
In particular, the effect of variations in iron availability on immunometabolism may impinge on the relevant role played by macrophages in several pathologic conditions like obesity, diabetes, cardiovascular diseases, tumors. Indeed, iron homeostasis is altered in adipose tissue associated macrophages, which have a pathogenetic role in obesity favoring insulin resistance [54], and macrophage iron is key in the development and progression of atherosclerotic plaques (discussed in Reference [55]).

Author Contributions: Conceptualization, S.R.; E.G. and G.C.; Writing, Review \& Editing, S.R., E.G. and G.G.; Visualization, S.R. and E.G.

Funding: This research was funded by Piano di sostegno alla ricerca of the University of Milan grant number PSR 18.

Acknowledgments: The authors are supported by grants from the Ministry of University and Research.

Conflicts of Interest: The authors declare no conflicts of interest.

\section{References}

1. Jiang, S.; Yan, W. T-cell immunometabolism against cancer. Cancer Lett. 2016, 382, 255-258. [CrossRef] [PubMed]

2. Mantovani, A.; Sica, A.; Locati, M. Macrophage polarization comes of age. Immunity 2005, 23, 344-346. [CrossRef] [PubMed]

3. Biswas, S.K.; Mantovani, A. Orchestration of metabolism by macrophages. Cell Metab. 2012, 15, 432-437. [CrossRef] [PubMed]

4. Murray, P.J. Macrophage Polarization. Annu. Rev. Physiol. 2017, 79, 541-566. [CrossRef] [PubMed]

5. O'Neill, L.A.; Kishton, R.J.; Rathmell, J. A guide to immunometabolism for immunologists. Nat. Rev. Immunol. 2016, 16, 553-565. [CrossRef] [PubMed]

6. Mills, E.L.; Kelly, B.; Logan, A.; Costa, A.S.H.; Varma, M.; Bryant, C.E.; Tourlomousis, P.; Däbritz, J.H.M.; Gottlieb, E.; Latorre, I.; et al. Succinate Dehydrogenase Supports Metabolic Repurposing of Mitochondria to Drive Inflammatory Macrophages. Cell 2016, 167, 457-470.e413. [CrossRef] [PubMed]

7. El-Zaatari, M.; Kao, J.Y. Role of Dietary Metabolites in Regulating the Host Immune Response in Gastrointestinal Disease. Front. Immunol. 2017, 8, 51. [CrossRef] [PubMed]

8. Rani, R.; Jordan, M.B.; Divanovic, S.; Herbert, D.R. IFN- $\gamma$-driven IDO production from macrophages protects IL-4R $\alpha$-deficient mice against lethality during Schistosoma mansoni infection. Am. J. Pathol. 2012, 180, 2001-2008. [CrossRef] [PubMed]

9. Munn, D.H.; Shafizadeh, E.; Attwood, J.T.; Bondarev, I.; Pashine, A.; Mellor, A.L. Inhibition of T cell proliferation by macrophage tryptophan catabolism. J. Exp. Med. 1999, 189, 1363-1372. [CrossRef] [PubMed]

10. Memari, B.; Bouttier, M.; Dimitrov, V.; Ouellette, M.; Behr, M.A.; Fritz, J.H.; White, J.H. Engagement of the Aryl Hydrocarbon Receptor in Mycobacterium tuberculosis-Infected Macrophages Has Pleiotropic Effects on Innate Immune Signaling. J. Immunol. 2015, 195, 4479-4491. [CrossRef] [PubMed]

11. Cronin, S.J.F.; Seehus, C.; Weidinger, A.; Talbot, S.; Reissig, S.; Seifert, M.; Pierson, Y.; McNeill, E.; Longhi, M.S.; Turnes, B.L.; et al. The metabolite BH4 controls T cell proliferation in autoimmunity and cancer. Nature 2018, 563, 564-568. [CrossRef] [PubMed]

12. Langston, P.K.; Shibata, M.; Horng, T. Metabolism Supports Macrophage Activation. Front. Immunol. 2017, 8, 61. [CrossRef] [PubMed]

13. Loftus, R.M.; Finlay, D.K. Immunometabolism: Cellular Metabolism Turns Immune Regulator. J. Biol. Chem. 2016, 291, 1-10. [CrossRef] [PubMed]

14. Van den Bossche, J.; O’Neill, L.A.; Menon, D. Macrophage Immunometabolism: Where Are We (Going)? Trends Immunol. 2017, 38, 395-406. [CrossRef] [PubMed]

15. Cramer, T.; Yamanishi, Y.; Clausen, B.E.; Förster, I.; Pawlinski, R.; Mackman, N.; Haase, V.H.; Jaenisch, R.; Corr, M.; Nizet, V.; et al. HIF-1alpha is essential for myeloid cell-mediated inflammation. Cell 2003, 112, 645-657. [CrossRef]

16. Luan, H.H.; Medzhitov, R. Food Fight: Role of Itaconate and Other Metabolites in Antimicrobial Defense. Cell Metab. 2016, 24, 379-387. [CrossRef] [PubMed]

17. Cordes, T.; Michelucci, A.; Hiller, K. Itaconic Acid: The Surprising Role of an Industrial Compound as a Mammalian Antimicrobial Metabolite. Annu. Rev. Nutr. 2015, 35, 451-473. [CrossRef] [PubMed] 
18. Papathanassiu, A.E.; Ko, J.H.; Imprialou, M.; Bagnati, M.; Srivastava, P.K.; Vu, H.A.; Cucchi, D.; McAdoo, S.P.; Ananieva, E.A.; Mauro, C.; et al. BCAT1 controls metabolic reprogramming in activated human macrophages and is associated with inflammatory diseases. Nat. Commun. 2017, 8, 16040. [CrossRef]

19. Sica, A.; Strauss, L.; Consonni, F.M.; Travelli, C.; Genazzani, A.; Porta, C. Metabolic regulation of suppressive myeloid cells in cancer. Cytokine Growth Factor Rev. 2017, 35, 27-35. [CrossRef]

20. Huang, S.C.; Smith, A.M.; Everts, B.; Colonna, M.; Pearce, E.L.; Schilling, J.D.; Pearce, E.J. Metabolic Reprogramming Mediated by the mTORC2-IRF4 Signaling Axis Is Essential for Macrophage Alternative Activation. Immunity 2016, 45, 817-830. [CrossRef]

21. Ouimet, M.; Ediriweera, H.N.; Gundra, U.M.; Sheedy, F.J.; Ramkhelawon, B.; Hutchison, S.B.; Rinehold, K.; van Solingen, C.; Fullerton, M.D.; Cecchini, K.; et al. MicroRNA-33-dependent regulation of macrophage metabolism directs immune cell polarization in atherosclerosis. J. Clin. Investig. 2015, 125, 4334-4348. [CrossRef] [PubMed]

22. Morioka, S.; Perry, J.S.A.; Raymond, M.H.; Medina, C.B.; Zhu, Y.; Zhao, L.; Serbulea, V.; Onengut-Gumuscu, S.; Leitinger, N.; Kucenas, S.; et al. Efferocytosis induces a novel SLC program to promote glucose uptake and lactate release. Nature 2018, 563, 714-718. [CrossRef] [PubMed]

23. Zhang, S.; Weinberg, S.; DeBerge, M.; Gainullina, A.; Schipma, M.; Kinchen, J.M.; Ben-Sahra, I.; Gius, D.R.; Yvan-Charvet, L.; Chandel, N.S.; et al. Efferocytosis Fuels Requirements of Fatty Acid Oxidation and the Electron Transport Chain to Polarize Macrophages for Tissue Repair. Cell Metab. 2019, 29, 443-456.e445. [CrossRef] [PubMed]

24. Artyomov, M.N.; Sergushichev, A.; Schilling, J.D. Integrating immunometabolism and macrophage diversity. Semin. Immunol. 2016, 28, 417-424. [CrossRef] [PubMed]

25. Ganta, V.C.; Choi, M.H.; Kutateladze, A.; Fox, T.E.; Farber, C.R.; Annex, B.H. A MicroRNA93-Interferon Regulatory Factor-9-Immunoresponsive Gene-1-Itaconic Acid Pathway Modulates M2-Like Macrophage Polarization to Revascularize Ischemic Muscle. Circulation 2017, 135, 2403-2425. [CrossRef] [PubMed]

26. Sukhbaatar, N.; Weichhart, T. Iron Regulation: Macrophages in Control. Pharmaceuticals 2018, $11,137$. [CrossRef] [PubMed]

27. Recalcati, S.; Locati, M.; Cairo, G. Systemic and cellular consequences of macrophage control of iron metabolism. Semin. Immunol. 2012, 24, 393-398. [CrossRef] [PubMed]

28. Cairo, G.; Recalcati, S.; Mantovani, A.; Locati, M. Iron trafficking and metabolism in macrophages: Contribution to the polarized phenotype. Trends Immunol. 2011, 32, 241-247. [CrossRef] [PubMed]

29. Soares, M.P.; Hamza, I. Macrophages and Iron Metabolism. Immunity 2016, 44, 492-504. [CrossRef]

30. Weiss, G.; Goodnough, L.T. Anemia of chronic disease. N. Engl. J. Med. 2005, 352, 1011-1023. [CrossRef]

31. Ganz, T.; Nemeth, E. Iron homeostasis in host defence and inflammation. Nat. Rev. Immunol. 2015, 15, 500-510. [CrossRef] [PubMed]

32. Recalcati, S.; Locati, M.; Marini, A.; Santambrogio, P.; Zaninotto, F.; De Pizzol, M.; Zammataro, L.; Girelli, D.; Cairo, G. Differential regulation of iron homeostasis during human macrophage polarized activation. Eur. J. Immunol. 2010, 40, 824-835. [CrossRef] [PubMed]

33. Drakesmith, H.; Nemeth, E.; Ganz, T. Ironing out Ferroportin. Cell Metab. 2015, 22, 777-787. [CrossRef] [PubMed]

34. Mantovani, A.; Sozzani, S.; Locati, M.; Allavena, P.; Sica, A. Macrophage polarization: Tumor-associated macrophages as a paradigm for polarized M2 mononuclear phagocytes. Trends Immunol. 2002, 23, 549-555. [CrossRef]

35. Zhou, Y.; Que, K.T.; Zhang, Z.; Yi, Z.J.; Zhao, P.X.; You, Y.; Gong, J.P.; Liu, Z.J. Iron overloaded polarizes macrophage to proinflammation phenotype through ROS/acetyl-p53 pathway. Cancer Med. 2018, 7, 4012-4022. [CrossRef] [PubMed]

36. Zhou, J.; Ye, S.; Fujiwara, T.; Manolagas, S.C.; Zhao, H. Steap4 plays a critical role in osteoclastogenesis in vitro by regulating cellular iron/reactive oxygen species (ROS) levels and cAMP response element-binding protein (CREB) activation. J. Biol. Chem. 2013, 288, 30064-30074. [CrossRef]

37. Alkhateeb, A.A.; Han, B.; Connor, J.R. Ferritin stimulates breast cancer cells through an iron-independent mechanism and is localized within tumor-associated macrophages. Breast Cancer Res. Treat. 2013, 137, 733-744. [CrossRef]

38. Recalcati, S.; Gammella, E.; Buratti, P.; Doni, A.; Anselmo, A.; Locati, M.; Cairo, G. Macrophage ferroportin is essential for stromal cell proliferation in wound healing. Haematologica 2019, 104, 47-58. [CrossRef] 
39. Sindrilaru, A.; Peters, T.; Wieschalka, S.; Baican, C.; Baican, A.; Peter, H.; Hainzl, A.; Schatz, S.; Qi, Y.; Schlecht, A.; et al. An unrestrained proinflammatory M1 macrophage population induced by iron impairs wound healing in humans and mice. J. Clin. Investig. 2011, 121, 985-997. [CrossRef]

40. Kroner, A.; Greenhalgh, A.D.; Zarruk, J.G.; Passos Dos Santos, R.; Gaestel, M.; David, S. TNF and increased intracellular iron alter macrophage polarization to a detrimental M1 phenotype in the injured spinal cord. Neuron 2014, 83, 1098-1116. [CrossRef]

41. Vinchi, F.; Costa da Silva, M.; Ingoglia, G.; Petrillo, S.; Brinkman, N.; Zuercher, A.; Cerwenka, A.; Tolosano, E.; Muckenthaler, M.U. Hemopexin therapy reverts heme-induced proinflammatory phenotypic switching of macrophages in a mouse model of sickle cell disease. Blood 2016, 127, 473-486. [CrossRef] [PubMed]

42. Gozzelino, R.; Jeney, V.; Soares, M.P. Mechanisms of cell protection by heme oxygenase-1. Annu. Rev. Pharmacol. Toxicol. 2010, 50, 323-354. [CrossRef] [PubMed]

43. Cairo, G.; Recalcati, S. Iron-regulatory proteins: molecular biology and pathophysiological implications. Expert Rev. Mol. Med. 2007, 9, 1-13. [CrossRef] [PubMed]

44. Beinert, H.; Kennedy, M.C. Aconitase, a two-faced protein: enzyme and iron regulatory factor. FASEB J. 1993, 7, 1442-1449. [CrossRef] [PubMed]

45. Cairo, G.; Ronchi, R.; Recalcati, S.; Campanella, A.; Minotti, G. Nitric oxide and peroxynitrite activate the iron regulatory protein-1 of J774A.1 macrophages by direct disassembly of the Fe-S cluster of cytoplasmic aconitase. Biochemistry 2002, 41, 7435-7442. [CrossRef]

46. Tong, W.H.; Maio, N.; Zhang, D.L.; Palmieri, E.M.; Ollivierre, H.; Ghosh, M.C.; McVicar, D.W.; Rouault, T.A. TLR-activated repression of Fe-S cluster biogenesis drives a metabolic shift and alters histone and tubulin acetylation. Blood Adv. 2018, 2, 1146-1156. [CrossRef]

47. Pastorino, S.; Carta, L.; Puppo, M.; Melillo, G.; Bosco, M.C.; Varesio, L. Picolinic acid- or desferrioxamineinducible autocrine activation of macrophages engineered to produce IFNgamma: An approach for gene therapy. Gene Ther. 2004, 11, 560-568. [CrossRef]

48. Cairo, G.; Bernuzzi, F.; Recalcati, S. A precious metal: Iron, an essential nutrient for all cells. Genes Nutr. 2006, 1, 25-39. [CrossRef]

49. Prodinger, J.; Loacker, L.J.; Schmidt, R.L.; Ratzinger, F.; Greiner, G.; Witzeneder, N.; Hoermann, G.; Jutz, S.; Pickl, W.F.; Steinberger, P.; et al. The tryptophan metabolite picolinic acid suppresses proliferation and metabolic activity of CD4+ T cells and inhibits c-Myc activation. J. Leukoc. Biol. 2016, 99, 583-594. [CrossRef]

50. Melillo, G.; Cox, G.W.; Biragyn, A.; Sheffler, L.A.; Varesio, L. Regulation of nitric-oxide synthase mRNA expression by interferon-gamma and picolinic acid. J. Biol. Chem. 1994, 269, 8128-8133.

51. Recalcati, S.; Gammella, E.; Cairo, G. New perspectives on the molecular basis of the interaction between oxygen homeostasis and iron metabolism. Hypoxia 2015, 2015, 93-103.

52. Buqué, A.; Bloy, N.; Aranda, F.; Cremer, I.; Eggermont, A.; Fridman, W.H.; Fucikova, J.; Galon, J.; Spisek, R.; Tartour, E.; et al. Trial Watch-Small molecules targeting the immunological tumor microenvironment for cancer therapy. Oncoimmunology 2016, 5, e1149674. [CrossRef] [PubMed]

53. Bayeva, M.; Khechaduri, A.; Puig, S.; Chang, H.C.; Patial, S.; Blackshear, P.J.; Ardehali, H. mTOR regulates cellular iron homeostasis through tristetraprolin. Cell Metab. 2012, 16, 645-657. [CrossRef] [PubMed]

54. Orr, J.S.; Kennedy, A.; Anderson-Baucum, E.K.; Webb, C.D.; Fordahl, S.C.; Erikson, K.M.; Zhang, Y.; Etzerodt, A.; Moestrup, S.K.; Hasty, A.H. Obesity alters adipose tissue macrophage iron content and tissue iron distribution. Diabetes 2014, 63, 421-432. [CrossRef] [PubMed]

55. Guo, L.; Sakamoto, A.; Cornelissen, A.; Hong, C.C.; Finn, A.V. Ironing-Out the Role of Hepcidin in Atherosclerosis. Arterioscler. Thromb. Vasc. Biol. 2019, 39, 303-305. [CrossRef] [PubMed] 
Article

\title{
The Antitumor Didox Acts as an Iron Chelator in Hepatocellular Carcinoma Cells
}

\author{
Michela Asperti, Luca Cantamessa, Simone Ghidinelli, Magdalena Gryzik, Andrea Denardo, \\ Arianna Giacomini, Giovanna Longhi, Alessandro Fanzani, Paolo Arosio and Maura Poli * \\ Department of Molecular and Translational Medicine, University of Brescia, Viale Europa 11, 25123 Brescia, Italy \\ * Correspondence: maura.poli@unibs.it, Tel.: +39-0303717303
}

Received: 18 July 2019; Accepted: 29 August 2019; Published: 2 September 2019

\begin{abstract}
Ribonucleotide reductase (RR) is the rate-limiting enzyme that controls the deoxynucleotide triphosphate synthesis and it is an important target of cancer treatment, since it is expressed in tumor cells in proportion to their proliferation rate, their invasiveness and poor prognosis. Didox, a derivative of hydroxyurea (HU), is one of the most potent pharmaceutical inhibitors of this enzyme, with low in vivo side effects. It inhibits the activity of the subunit RRM2 and deoxyribonucleotides (dNTPs) synthesis, and it seems to show iron-chelating activity. In the present work, we mainly investigated the iron-chelating properties of didox using the HA22T/VGH cell line, as a model of hepatocellular carcinoma (HCC). We confirmed that didox induced cell death and that this effect was suppressed by iron supplementation. Interestingly, cell treatments with didox caused changes of cellular iron content, TfR1 and ferritin levels comparable to those caused by the iron chelators, deferoxamine (DFO) and deferiprone (DFP). Chemical studies showed that didox has an affinity binding to $\mathrm{Fe}^{3+}$ comparable to that of DFO and DFP, although with slower kinetic. Structural modeling indicated that didox is a bidentated iron chelator with two theoretical possible positions for the binding and among them that with the two hydroxyls of the catechol group acting as ligands is the more likely one. The iron chelating property of didox may contribute to its antitumor activity not only blocking the formation of the tyrosil radical on Tyr122 (such as HU) on RRM2 (essential for its activity) but also sequestering the iron needed by this enzyme and to the cell proliferation.
\end{abstract}

Keywords: didox; iron chelators; antitumor compound; iron metabolism; RRM2

\section{Introduction}

Ribonucleotide reductase (RR) is one of the fifty genes reported to be overexpressed in highly malignant tumors with poor prognosis [1-5]. RR is essential for DNA synthesis during cell division encoding the rate-limiting enzyme that catalyzes the conversion of ribonucleotides (NTPs) into deoxyribonucleotides (dNTPs) [3,6-8]. The enzyme is composed of two catalytic (RRM1) and two regulatory (RRM2 or p53R2) subunits [9]. RRM1 expression is detectable throughout the cell cycle in all tissues [10], while RRM2 and p53R2 are preferentially expressed during cell mitosis and in response to DNA damage, respectively. The reductase activity of RRM2 subunit requires two $\mathrm{Fe}^{3+}$ ions for the formation of the tyrosil radical on Tyr122 that has a key role in the enzyme activity [6]. Hydroxyurea (HU), gemcitabine, fludarabine and chlorodeoxydenoside are compounds targeting RRM2 activity that showed effects in cancer therapy in vitro, but with some side effects in vivo. In order to improve their efficacy in the inhibition of RRM2 and reduce the side effects, some derivatives of polyhydroxy-substituted benzohydroxamic have been synthesized $[3,11,12]$ and among them there is 3,4 dihydroxybenzohydroxamic acid (didox) in which the amino group of $\mathrm{HU}$ is substituted by a catechol group (Figure 1A,B). 
A

\section{Hydroxyurea}<smiles>NC(=O)NO</smiles>

B<smiles>O=C(NO)c1ccc(O)c(O)c1</smiles>

Figure 1. Chemical structure of hydroxyurea and its derivative didox. The structure of hydroxyurea (HU) (A) has been modified to obtain that one of didox (B) in which the amino group of HU has been substituted by a catechol group.

This compound, targeting RRM2 subunits, was found to trigger cell apoptosis with a different extent depending on the cell types [13-15] by increasing the levels of the pro-apoptotic protein Bax and release of cytochrome $C$ from the mitochondria [16]. Didox revealed good efficacy against multiple myeloma cells [15], prostate tumor [16], breast cancer cells [17] and acute and chronic myeloid leukemia HL-60 and K562 cell lines [14]. Mouse models have shown that didox significantly caused growth inhibition of breast cancer [17] and human leukemia [18]. Furthermore, in phase I/II clinical trials, didox showed minimal toxicity in cancer patients $[19,20]$.

Interestingly, it was also reported that didox forms iron complexes recognized by photometric methods [21]. The finding that the antiproliferative effect of didox was partially inhibited by iron suggested that iron chelation may be important for its pharmacological activity [21]. Tumor cells are often characterized by an "iron addiction" status requiring abundant iron to sustain proliferation [22,23], thus it has been indicated that iron chelators may improve the chemotherapeutic effects [24-28]. The potential clinical impact of the new generation of iron chelators has increased recently due to the improvement of their pharmacokinetic and pharmacodynamic properties [29]. Iron chelators act to inhibit cell proliferation, by subtracting the iron needed for cellular metabolism, by inducing apoptosis and also by contributing to the generation of reactive oxygen species. This depends largely by the coordination of the chelant, deferoxamine (DFO; Desferal ${ }^{\circledR}$ ) is a hexadentate iron chelator that blocks the interaction of iron with oxygen, making it inert. Instead, bidentate chelators such as deferiprone (DFP; Ferriprox ${ }^{\circledR}$ ), or the tridentate deferasirox bind iron in a 3:1 or 2:1 chelator to iron ratio, resulting in a less stable iron complex, thus allowing the formation of potentially toxic free radicals [30,31].

The iron binding properties of didox have been described only by Fritzer-Szekeres [21] but its pharmacological effects and its impact on iron metabolism have not been further studied. In the present work we studied the effect of didox on the proliferation of the hepatocellular carcinoma HA22T/VGH cell line and we characterized the iron-chelating properties of didox in vitro and in cells, specifically focusing our study to determine the iron binding capacity of didox and its effect on iron related proteins.

\section{Results}

\subsection{Didox Suppresses the Viability of Hepatocellular Carcinoma HA22T/VGH Cell Line}

The hepatocellular carcinoma (HCC) HA22T/VGH cell line was chosen as a model to study didox antitumor activity. It has a detectable level of RRM2 and high levels of intracellular iron and iron-related proteins, in line with its hepatic origin (not shown). The cells were incubated with different concentrations of didox $(1,10,25,50,100,200$ and $500 \mu \mathrm{M})$ for $24-48$ and $72 \mathrm{~h}$ and then their viability analyzed by an MTT assay. Didox reduced cell viability in dose- and time-dependent manner (Figure 2) with increasing potency at the concentration of 100, 200 and $500 \mu \mathrm{M}$ and after 48 and $72 \mathrm{~h}$ (Figure 2). 
The half maximal inhibitory dose $\left(\mathrm{IC}_{50}\right)$ at $48 \mathrm{~h}$ was $283.36 \pm 18.82 \mu \mathrm{M}$ and at $72 \mathrm{~h}$ was $132.98 \pm 7.97 \mu \mathrm{M}$, indicating that time of exposure is important in this cell line (Table S1).

We confirmed the results with a second HCC cell line, HuH7, with the same doses and time of exposure used for HA22T/VGH and we observed that the sensitivity to the drug was similar in the two HCC cells (Figure 2 and Figure S1) with an $\mathrm{IC}_{50}$ for HuH7 similar to that of HA22T/VGH $(329.31 \pm 31.55 \mu \mathrm{M}$ at $48 \mathrm{~h}$ and $122.92 \pm 13.21 \mu \mathrm{M}$ at $72 \mathrm{~h})$, confirming that time exposure is important in both cell lines (Table S1).

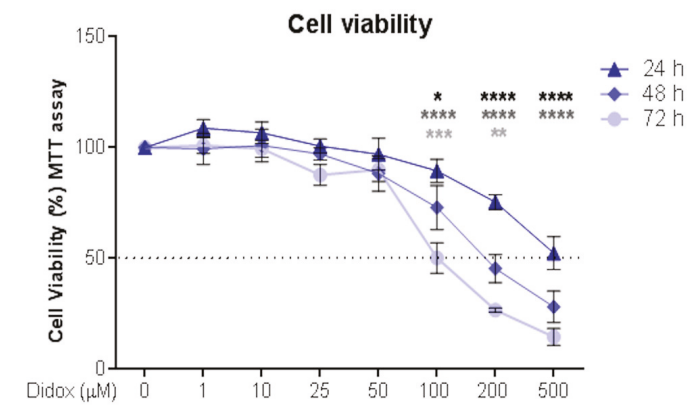

Figure 2. Didox reduced cell viability in HA22T/VGH cell line in time and a dose-dependent manner. HA22T/VGH were treated with 0, 1, 10, 25, 50, 100, 200 and $500 \mu \mathrm{M}$ of didox for 24 (triangle, blue line), 48 (diamond, blue-sky line) and 72 (circle, light blue line) hours. An MTT assay was performed to verify cell viability after treatment. The values are expressed as \% of viable cells over the not treated cells (0) at the indicated time point. The black dot line is drawn in correspondence to the half maximal inhibitory dose $\left(\mathrm{IC}_{50}\right)$. The graph represents the means of three independent experiments $(N=3)$ with three internal values for each experiment. The black stars correspond to the comparison between 24 and $48 \mathrm{~h}$; the grey stars between 24 and $72 \mathrm{~h}$ and the light grey stars between 48 and $72 \mathrm{~h} .{ }^{*} p<0.05$; ${ }^{* *} p<0.01 ;{ }^{* * *} p<0.001 ;{ }^{* * * *} p<0.0001$.

\subsection{Didox Induces Apoptosis and Increases Mitochondrial ROS}

Didox was previously shown to cause cell death by an apoptotic mechanism with an increase of AnnexinV positive cells of about $30-50 \%$ after $24-48 \mathrm{~h}$ at $250 \mu \mathrm{M}$ and only at high concentration to cause a little induction of caspase 8 and 9 in HL-60 and K562 cells $[14,16]$. To verify this, we treated HA22T/VGH with $200 \mu \mathrm{M}$ didox for 24, 48 and $72 \mathrm{~h}$. Then the cells were labeled for AnnexinV-FITC and with propidium iodide (PI) and analyzed with flow-cytometry. Staining cells simultaneously with AnnexinV-FITC and PI allows the discrimination of intact cells (AnnexinV-FITC negative and PI negative), early apoptotic (AnnexinV-FITC positive and PI negative) and late apoptotic or necrotic cells (AnnexinV-FITC positive and PI positive). Didox caused a time dependent increase of apoptotic cells (considering early and late apoptosis) to about $8 \%$ after $72 \mathrm{~h}$ (Figure $3 \mathrm{~A}$ ).

To detect the level of mitochondrial ROS the HA22T/VGH cells were treated with $200 \mu \mathrm{M}$ didox for 24, 48 and $72 \mathrm{~h}$ and then labeled with a MitoSOX probe and the fluorescence measured on flow-cytometry. This probe is used for the selective detection of superoxide in the mitochondria in fact, once in the mitochondria; it is oxidized by superoxide and shows red fluorescence. Didox caused an increase of MitoSOX fluorescence of about 10-12\% after 48-72 h meaning an increase of mitochondrial ROS levels (Figure 3B). In parallel experiments, we found that the iron (III) chelator DFO induced similar increases of AnnexinV positive cells and mitochondrial ROS in this cell line (not shown). 

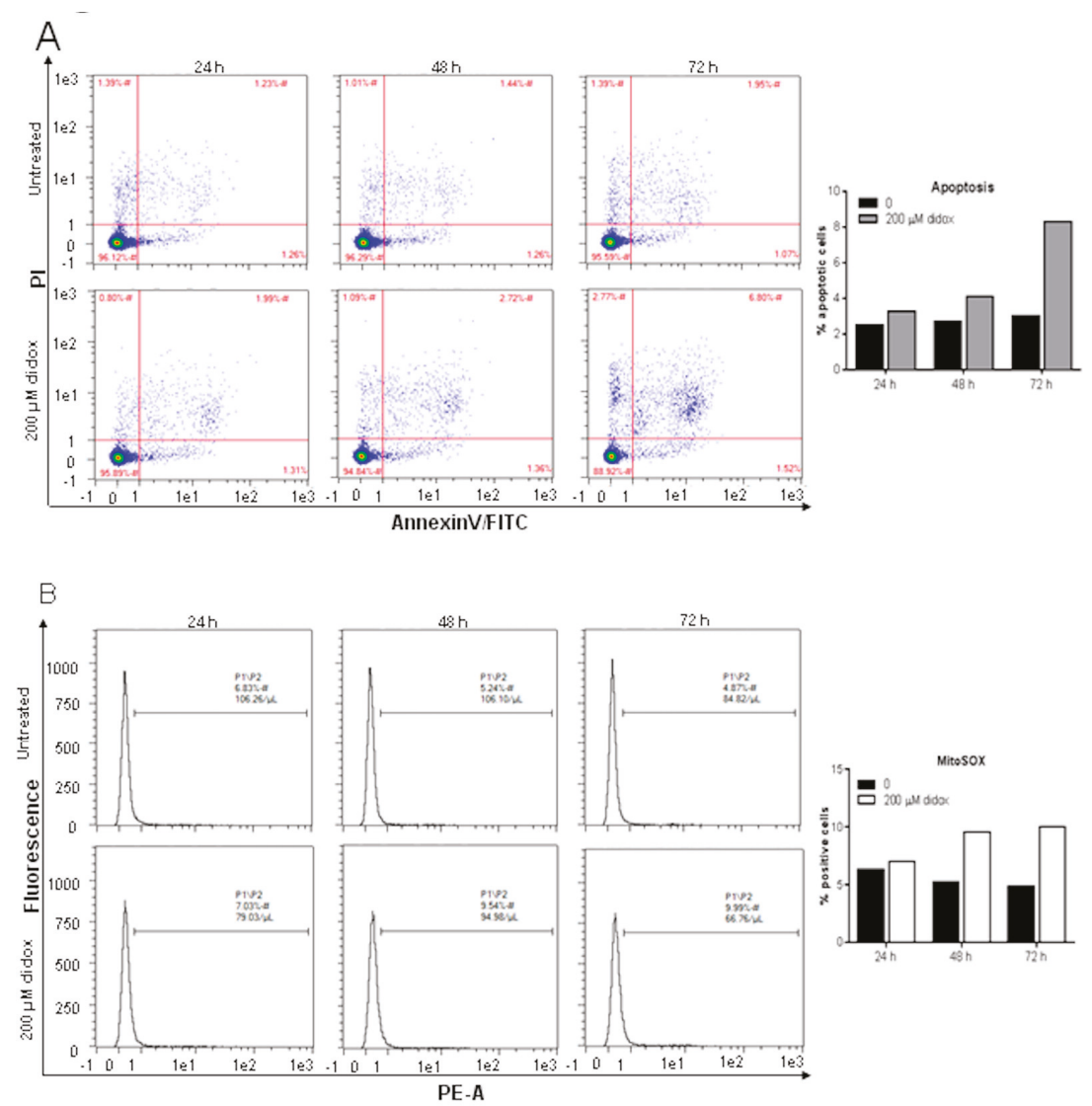

Figure 3. Didox induced apoptotic cell death and mitochondrial oxidative stress in HA22T/VGH cell lines. Cells were untreated or treated with $200 \mu \mathrm{M}$ of didox for 24, 48 and $72 \mathrm{~h}$. At each time point, cells were analyzed for apoptotic cell death combining AnnexinV/FITC/PI (A) or using MitoSOX Red mitochondrial superoxide indicator (B) and analyzed by flow-cytometry. The histograms show the percentage of apoptotic cell death, positive to AnnexinV (A) or fluorescent cells positive to MitoSOX mitochondrial superoxide indicator (PE-A,) (B).

\subsection{Didox Inhibits Cell Viability Similarly to DFO and DFP}

It is known that the iron chelators cause cell death sequestering the iron essential for the cell proliferation. To compare the potency to inhibit cell viability of didox to its precursor (HU) and other well known chelators (such as DFO and DFP), HA22T/VGH cells were treated with increasing concentrations of didox, HU, DFO and DFP $(1,10,25,50,100,200$ and $500 \mu \mathrm{M})$ for $24-48$ and $72 \mathrm{~h}$, and then cell viability was monitored using MTT assay. HU was the least potent of the four compounds with an $\mathrm{IC}_{50}$ of about $400 \mu \mathrm{M}$ at $72 \mathrm{~h}$, that was about four-fold higher than that of didox, DFO and DFP (of about $100 \mu \mathrm{M}$ at $72 \mathrm{~h}$; Figure 4A-C). Didox, DFO and DFP showed a very similar time-dependent activity that is possibly due to the progressive chelation of intracellular iron and the inhibition of different cellular activity. 
A

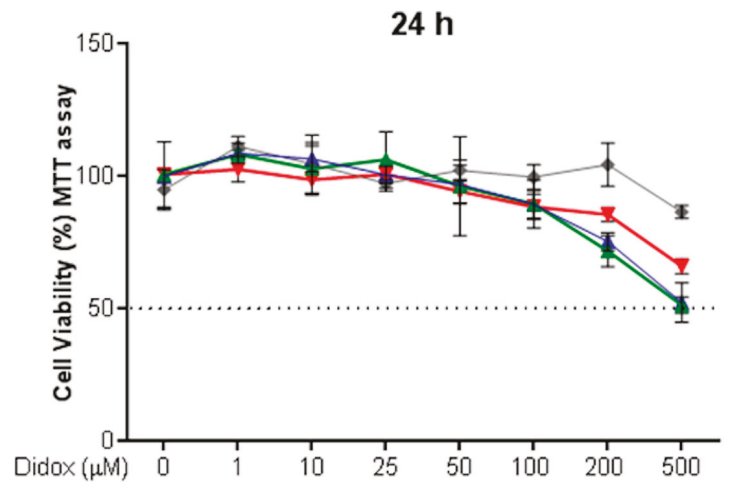

B

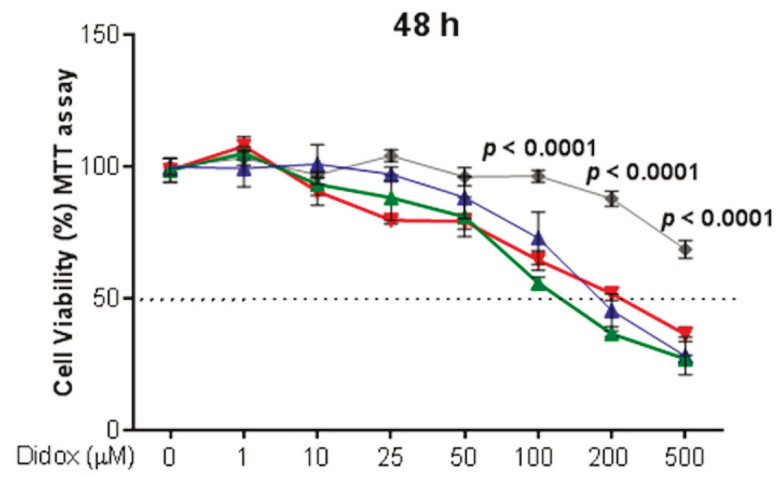

C

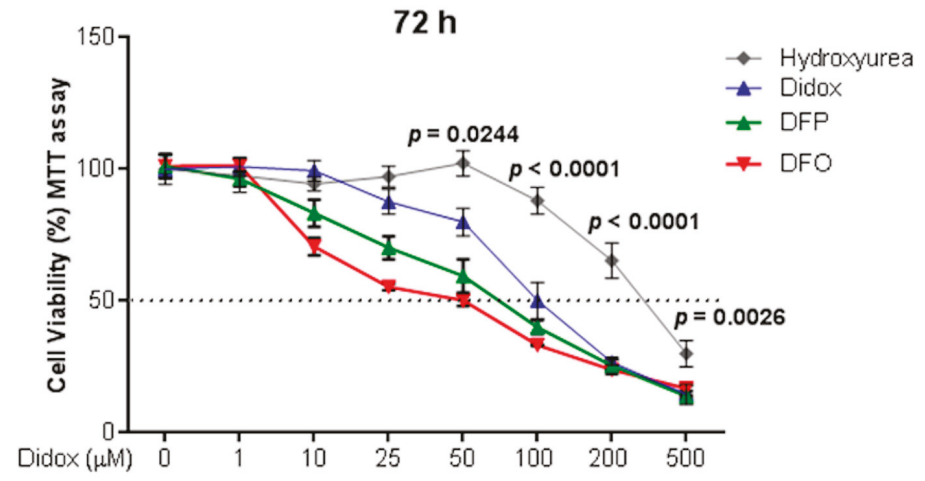

Figure 4. Didox was more effective than hydroxyurea in reducing cell viability in HA22T/VGH. HA22T/VGH cells were treated with $0,1,10,25,50,100,200$ and $500 \mu \mathrm{M}$ of didox (blue lines) or HU (grey lines) or deferoxamine (DFO; red lines) or deferiprone (DFP; green lines) for 24 (A), 48 (B) and $72 \mathrm{~h}(\mathrm{C})$. MTT assay was performed to verify cell viability after treatment. The values are expressed as $\%$ of viable cells over the not treated cells $(0)$ at the indicated time point. The graphs represent the means of three independent experiments $(N=3)$ with three internal values for each experiment and statistic obtained comparing with each other the efficacy of the compounds at a certain dose of treatment. The black dot line is drawn in correspondence to the half maximal inhibitory dose $\left(\mathrm{IC}_{50}\right)$. 


\subsection{Didox Binds $\mathrm{Fe}^{3+}$ in a Time-Dependent Manner}

As shown in the Figure 4, didox had higher efficacy than HU in inhibiting HA22T/VGH cell viability, a property that may be due to the didox iron-binding capacity, which seems to be absent in HU (Figure 4A-C). To elucidate this point, we used the in vitro calcein assay. Calcein is a fluorescent probe, which its signal is quenched by the binding to iron (II) as is well reported in the paper of Breuer W. [32]. Only the addition of iron (III) chelators (such as DFO and DFP) can restore the fluorescence of the probe, removing iron from the iron-calcein complex [32].

Iron (II) as ferrous ammonium sulfate $(1 \mu \mathrm{M})$ was added to calcein $(1 \mu \mathrm{M})$ at a 1:1 molar ratio causing $60 \%$ fluorescence quenching. Then the chelators were added. The well-characterized iron (III) chelators DFO and DFP $(100 \mu \mathrm{M})$ caused a fast and complete dequenching, while HU $(100 \mu \mathrm{M})$ and also bathophenantroline disulfonic acid (BPS, $100 \mu \mathrm{M})$ had no evident effect and didox $(100 \mu \mathrm{M})$ had an intermediate behavior, slowly causing fluorescence dequenching that was almost complete after one hour (Figure 5A).

A

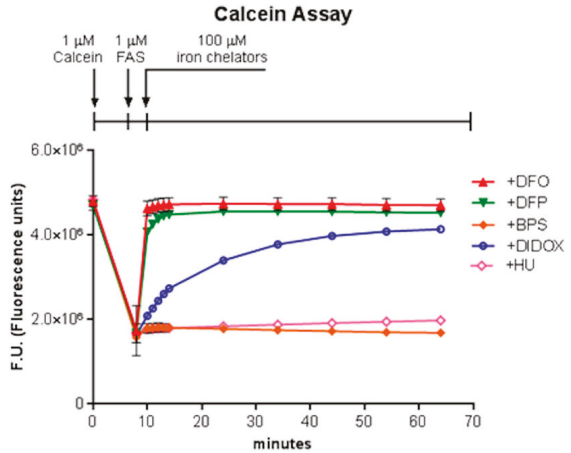

C

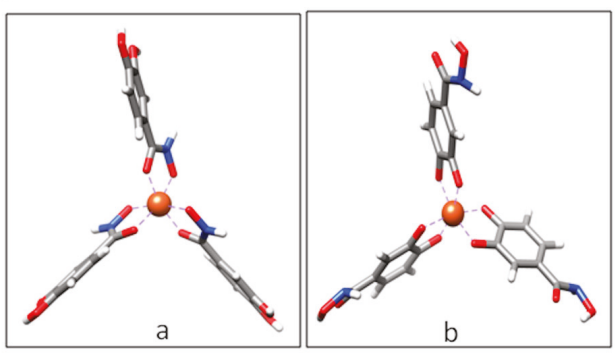

B
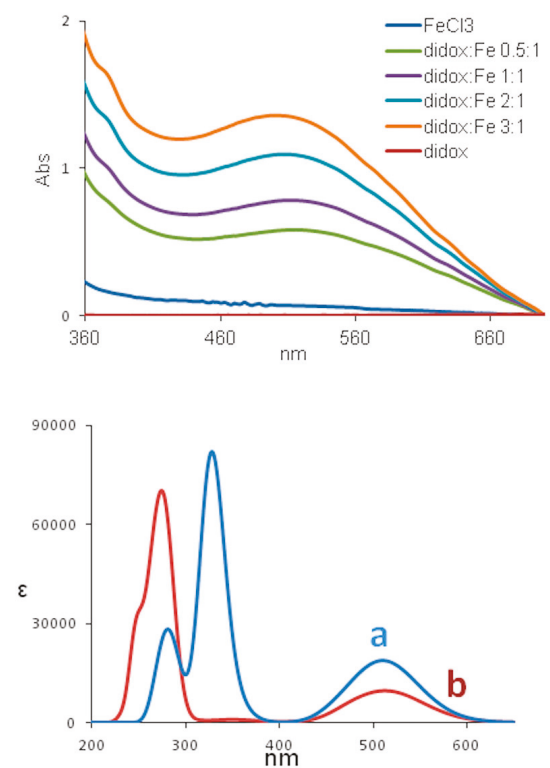

Figure 5. Didox retains the capacity to dequench the fluorescence of calcein forming a complex with iron (III). (A) The fluorescence of $1 \mu \mathrm{M}$ calcein was determined, to set the basal level of the fluorescence at the beginning of the assay. Iron (II), as $1 \mu \mathrm{M}$ FAS (ferrous ammonium sulfate), was added and allowed to equilibrate and form calcein-iron complexes for $8 \mathrm{~min}$. Subsequently, $100 \mu \mathrm{M}$ iron (III) chelators (such as DFO, red lines; DFP, green line), $100 \mu \mathrm{M}$ iron (II) chelator (BPS, orange line), $100 \mu \mathrm{M}$ didox (blue line) or $100 \mu \mathrm{M} \mathrm{HU}$ (pink line) were added. The fluorescence was measured after 1, 2, 3, 4, $5,15,25,35,45,55$ and 65 min after the addition of the compounds. (B) UV-vis spectra for complexes formed by base titration at constant concentration $\mathrm{FeCl} 3(300 \mu \mathrm{M})$ with increasing concentrations $(0-900 \mu \mathrm{M})$ of didox in $25 \mathrm{mM}$ Tris- $\mathrm{HCl}$ pH 7.2 buffer. (C) Left: Didox complexed with iron in the hydroxamic type of chelate (a) and catechol type of chelate (b). Right: Calculated UV-vis spectra of didox-iron complex $a$ and $b$. 
Then we incubated the colorless didox with increasing amounts of iron (III) salts. This produced a colored component with a maximum absorbance at $510 \mathrm{~nm}$ attributed to the didox-iron complex (Figure 5B). Next we carried out density functional theory (DFT) calculations to test the possible structures, as done before in the study of similar ferric complex structures [33]. The results indicate that didox acts as a bidentate ligand that can chelate iron either through the hydroxaminic group (complex a in Figure 5C) or through the catechol moiety (complex b in Figure 5C). Modeling (C3 point group symmetry) and optimization calculations were carried out for low, intermediate and high spin states. The high spin complex was the one with the lowest energy in both models. The calculated UV-Vis spectra are shown in Figure 5B. TD-DFT calculations predicted absorption spectra presenting a band centered at $510 \mathrm{~nm}$ of absorbance, for both the a and b complex, originated from a metal to ligand charge transfer transition, in good correspondence with the experimental spectra. Thus, calculations confirmed that both complexes didox-iron are stable but the hydroxaminic group is also present in $\mathrm{HU}$ that has no binding affinity, while the catechol moiety is present in DFP that has high iron affinity binding. Thus b seems to be the likely complex.

\subsection{Didox Alters the Iron Status of HA22T/VGH Cells Similarly to DFO and DFP}

It is well known that an iron chelator causes the reduction of both L- and H-ferritin and the labile iron pool (LIP) and the increase of transferrin receptor 1 (TfR1) expression. Thus to verify how didox modifies the iron status of the HCC cells in comparison with DFP and DFO, HA22T/VGH cells were treated with $100 \mu \mathrm{M}$ Didox, or DFP or DFO for 4, 8, 24 and $48 \mathrm{~h}$ and analyzed for L- and H-ferritin content by an ELISA assay (Figure 6A,B) and for TfR1 by western blotting (Figure 6C).

DFO and didox caused a significant and parallel time-dependent reduction of H-ferritin that was maintained up to $48 \mathrm{~h}$, whereas DFP started losing its efficacy at $48 \mathrm{~h}$ (Figure 6A). A similar behavior was evident for L-ferritin (Figure 6B). TfR1 increased of about two-fold during the time, in DFO, DFP and didox treated cells, as expected, due to the effect of iron chelation (Figure 6C). LIP was determined by calcein-AM fluorescent assay after $4 \mathrm{~h}$ of treatment and the values expressed as fluorescence fold change over the untreated cells (Figure 6D). Didox, DFP and DFO caused a similar increase of calcein fluorescence, which indicated a significant and comparable reduction of LIP (Figure 6D). These results suggested that didox iron-chelating activity in the cells is comparable to that of DFO and DFP.

\subsection{Iron Supplementation Suppresses the Cell Toxicity of Didox in HA22T/VGH}

If didox acts as an iron chelator, the addition of iron could decrease or completely abolish the activity of the compound in inhibiting cell viability. To prove that, HA22T/VGH cells were treated with $100 \mu \mathrm{M}$ didox together with different concentrations of ferric ammonium citrate (FAC, 25, 50, 100, 200 and $400 \mu \mathrm{M}$ ), and the cell viability evaluated after 48 and $72 \mathrm{~h}$ with an MTT assay. FAC reduced didox cell toxicity in a dose-dependent manner starting at a concentration of $50 \mu \mathrm{M}$ at $48 \mathrm{~h}$ and of $100 \mu \mathrm{M}$ at $72 \mathrm{~h}$ abolishing the inhibitory activity of didox (Figure 7A,B). With a similar trend, FAC reduced the cell mortality induced also by DFO and DFP starting at concentration of $25 \mu \mathrm{M}$ both at 48 and $72 \mathrm{~h}$ for DFO and DFP (Figure S2A,B). On the opposite, the inhibitory activity of HU was not affected by the iron addition of FAC at all the concentrations and time points tested (Figure S2A,B). 
A

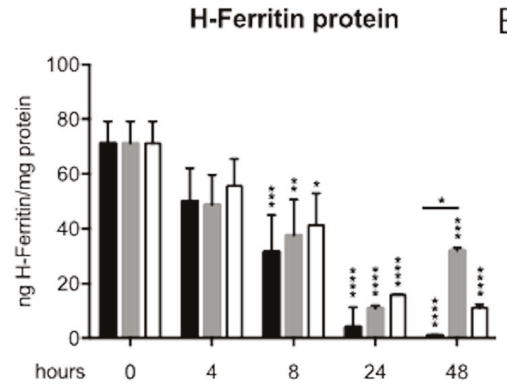

B

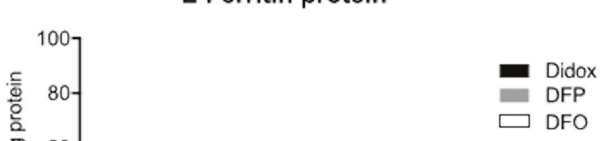

C

Didox
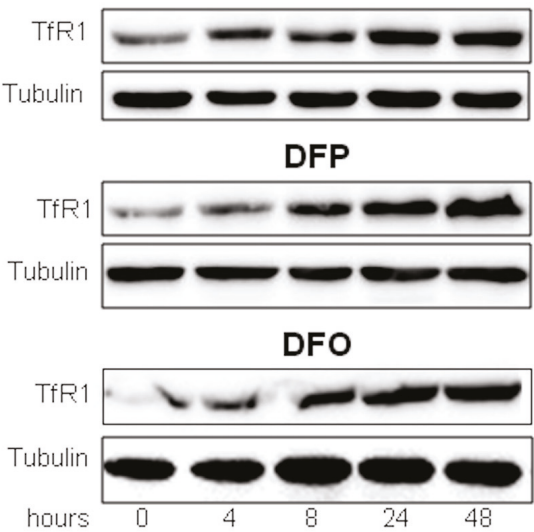

TfR1 protein

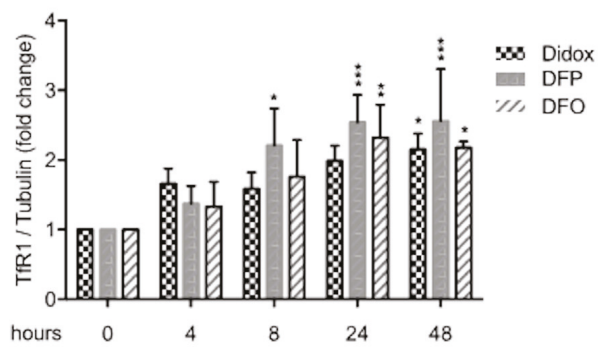

D Labile iron pool

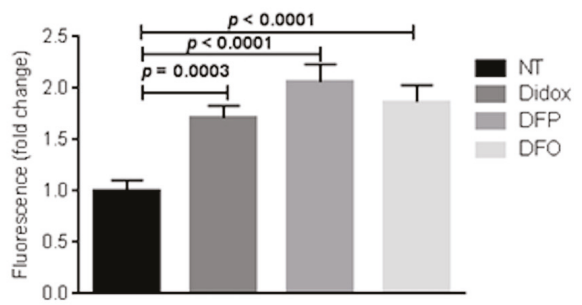

Figure 6. Didox reduced the ferritin level and labile iron pool (LIP) and induced a TfR1 increase in HA22T/VGH cells. (A) and (B) An ELISA assay for H- and L-ferritin in HA22T/VGH cells treated with didox, DFP and DFO $100 \mu \mathrm{M}$ at 4, 8, 24 and $48 \mathrm{~h}$; (C) TfR1 and tubulin western blotting analysis with didox, DFO and DFP $100 \mu \mathrm{M}$ at 4, 8, 24 and 48 h; (D) calcein-AM assay in cells treated with didox, DFP and DFO $100 \mu \mathrm{M}$ at $4 \mathrm{~h}$. The graphs are means of three independent experiments $(N=3)$. $p$-values, showed in the graphs, were obtained by an ordinary one-way ANOVA.

In other experiments the cells were pre-treated with $200 \mu \mathrm{M}$ didox for $16 \mathrm{~h}$ and then $400-800 \mu \mathrm{M}$ FAC was added and the cells collected after another 48 and $72 \mathrm{~h}$ (pre-treatment, in Figure 7C,D), as control didox and FAC were added together (combined, in Figure $7 \mathrm{C}, \mathrm{D})$. The iron supplementation suppressed didox activity when added together and also when added after $16 \mathrm{~h}$ didox (pre-treatment) with a rescue of about $50-60 \%$ at $48 \mathrm{~h}$ and $60-70 \%$ at $72 \mathrm{~h}$ (Figure $7 \mathrm{C}, \mathrm{D}$ ). 
A

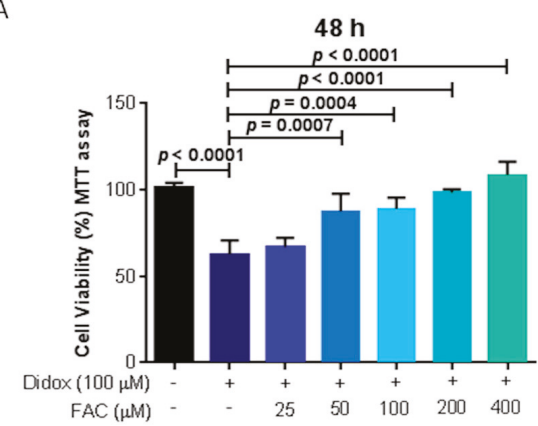

C

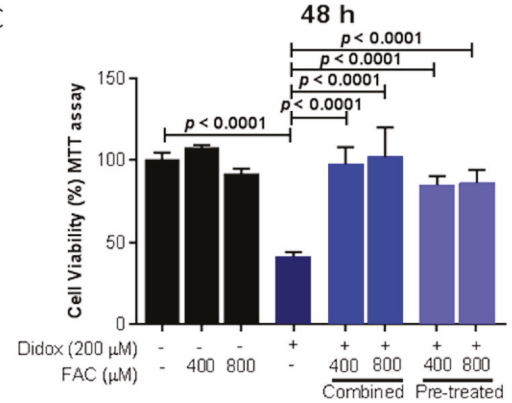

B

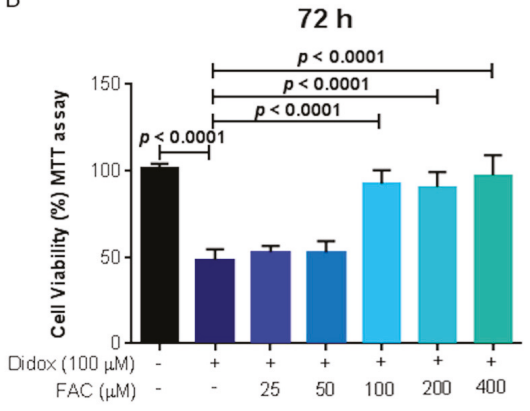

D

$72 \mathrm{~h}$

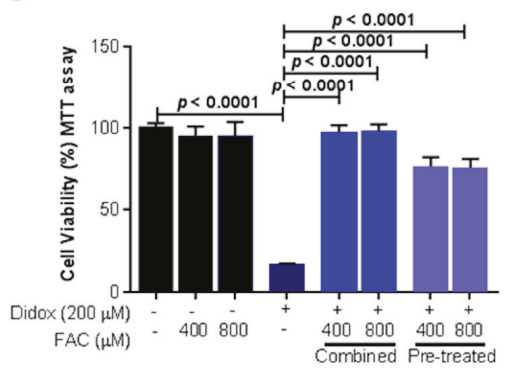

Figure 7. Treatment with equimolar concentration of iron rescued didox-induced cell death. HA22T/VGH cells were untreated or treated with: $100 \mu \mathrm{M}$ didox alone or in combination with increasing concentration of FAC $(25,50,100,200$ and $400 \mu \mathrm{M})$ for 48 (A) and $72 \mathrm{~h}$ (B). (C,D) HA22T/VGH cells were untreated or treated with $400-800 \mu \mathrm{M}$ FAC, $200 \mu \mathrm{M}$ didox for 48 and $72 \mathrm{~h}$, in combination FAC plus didox (combined) or HA22T/VGH cells were pre-treated with $200 \mu \mathrm{M}$ didox (for $16 \mathrm{~h}$ ) and then $400-800 \mu \mathrm{M}$ FAC was added to the cells (pre-treated) for 48-72 h. Cell viability was verified by an MTT assay and the values expressed as \% of viable cells over the untreated cells at the indicated time point. The graphs are means of three independent experiments $(N=3)$ with three internal values for each experiment.

To verify if the iron supplementation inhibits didox activity restoring the proper level of iron related proteins (such as ferritins and TfR1), the HA22T/VGH cells were treated with $100 \mu \mathrm{M}$ didox or with $100 \mu \mathrm{M}$ FAC alone or in combination. Didox alone caused a reduction of both $\mathrm{H}$ - and L-ferritins (Figure 8A,B) and an increase of TfR1 (Figure 8C) after 48 and $72 \mathrm{~h}$ (as previously shown in Figure 6A-C), FAC alone treatment caused ferritin to increase and TfR1 to decrease, as expected. Interestingly, the co-treatment with FAC and didox restored the basal levels of ferritins and TfR1, demonstrating an effect also on iron related proteins connected to the iron binding activity of didox. 
A

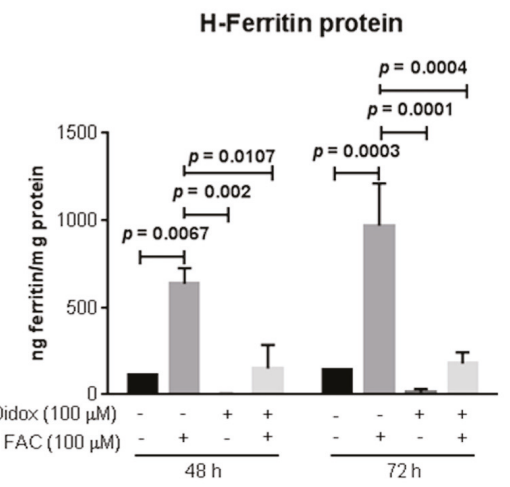

C

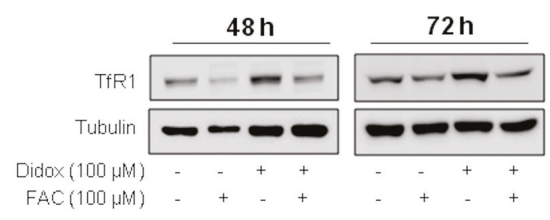

B

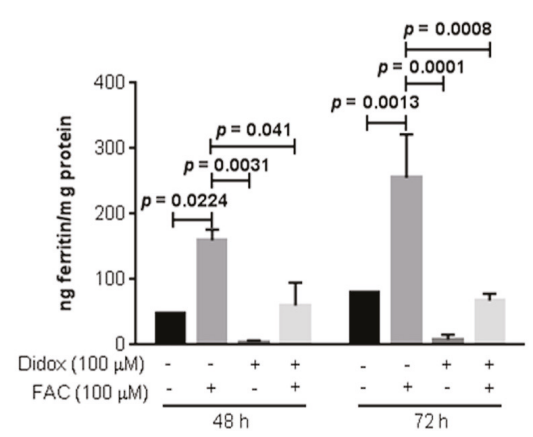

TfR1 protein

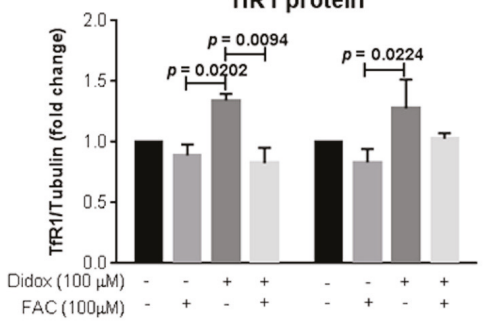

Figure 8. Treatment with equimolar concentration of iron restored iron-related protein content. HA22T/VGH cells were untreated or treated with: $100 \mu \mathrm{M}$ didox alone or in combination with FAC $(100 \mu \mathrm{M})$ for 48 and $72 \mathrm{~h}$. Protein extracts were analyzed for H- and L-ferritin content (A,B) by an ELISA assay and for TfR1 by western blotting (C), using tubulin as a loading control. The graphs are the mean of three independent experiments $(N=3)$. $p$-values, showed in the graphs, were obtained by an ordinary one-way ANOVA.

\section{Discussion}

Didox has been used for many years as an antitumor agent [14-17]. It targets and inhibits RRM2, the enzyme involved in the critical conversion of ribonucleotides to deoxyribonucleotides, essential in DNA replication and one of the most expressed enzymes in tumor cells. Didox is a derivative of HU that is known to inhibit RRM2 activity by quenching the tyrosyl free radical at the active site of the enzyme that is essential for the reductase activity [34]. The free radical quenching moiety of $\mathrm{HU}$ is partially conserved in didox, and it contains an additional catechol group that is known to have iron-chelating properties. In fact, a major class of bacterial siderophores uses catechol as an iron ligand [35]. The iron-chelating properties of didox were previously studied to define the formation of the iron complex and to show that iron supplementation reduced the cellular toxicity of didox in L1210 leukemia cells [21]. We used the hepatocellular carcinoma (HCC) cell lines, as a cellular model to study didox antitumor activity since HCC is the most common type of liver cancer. HCC are solid tumors, with a large angiogenic capacity and are often resistant to apoptosis and they are classified on the degree of malignancy and the level of differentiation [36]. HCC cells derive from liver, which has a high intracellular iron level, and high expression of iron-related proteins, detectable RRM2 levels and normal proliferation rate. The HuH7 cells are highly differentiated while HA22T/VGH cells are poorly differentiated. We found that these cells are similarly sensitive to didox with an $\mathrm{IC}_{50}$ as low as $132 \mu \mathrm{M}$ in HA22T/VGH and $122 \mu \mathrm{M}$ in HuH7 after $72 \mathrm{~h}$ of incubation. We concluded that the differentiation state did not modify cell sensitivity to the drug, thus we continued the study on the HA22T/VGH cells. We confirmed that didox induced apoptosis also in HA22T/VGH cells with an increase of AnnexinV and mitochondrial ROS production, similar to previous studies reported in 
multiple myeloma cells [15]. We compared the antitumor activity and iron binding capacity of didox with those of the two clinically used iron chelators, DFP, which is a catechol bidentate structurally similar to didox, and DFO a hexadentate structurally unrelated to didox. When given to the cells, didox caused modifications of the iron status that were very similar in extent to those caused by the two chelators: changes in the level of TfR1 and ferritins and of the intracellular labile iron. Moreover we found that DFO and DFP had a cytotoxic effect on our cells that was comparable to that of didox, and that was relieved by iron supplementation to the cells at concentrations in the same range of that of the chelators. The cytotoxic potency of HU was lower and, more important, not affected by iron supplementation, indicating a different mechanism of action. Iron is essential for many tumor cells, that require it to proliferate, the so-called "iron addition", thus the iron chelation activity promoted by didox, DFO and DFP inhibits the growth capacity of tumor cells. For example, sub-lethal concentrations of didox affected the capacity of HCC to close the wound (not shown), showing that iron is important also in this process. Our modeling studies indicate that didox binds iron as a bidentate to form a complex didox-iron of 3:1 and the binding probably occurs through the catechol moiety as it occurs in DFP. Didox seems to combine the free-radical scavenging activity of HU that blocks the tyrosil radical of RRM2 with an iron chelating activity of DFP and DFO, which sequesters iron from many key enzymes, among which RRM2 is central. Thus the observation that didox targets RRM2 with two different mechanisms should make it superior to the iron chelators or $\mathrm{HU}$ as antitumor agent.

The published data on the use of didox to treat different tumors and our results on HCC in vitro are promising. In vivo studies on HCC, using didox alone or in combination with different chemotherapeutic drugs, could be an interesting point to be defined in the future to finalize the use of this compound as an antitumor drug.

\section{Materials and Methods}

\subsection{Antibodies and Chemicals}

Antibodies used were anti-TfR1 (no. 136800, Thermo Scientific, Waltham, MA, USA) and anti-tubulin (no. T5168, Sigma-Aldrich, Saint Louis, MO, USA). HRP-conjugated secondary antibodies used were anti-mouse (no. sc-516102) and anti-rabbit (no. sc-2357; Santa Cruz Biotechnology, Dallas, TX, USA). The chemicals used in this study were: Didox (3,4 dihydroxybenzohydroxamic acid; no. 10009081, Cayman Chemicals, MI, USA) and hydroxyurea (no. H8627, Sigma-Aldrich, Saint Louis, MO, USA) dissolved in dimethylsulfoxide (DMSO), three different well known iron chelators such as DFO (deferoxamine; no. S0080A, Novartis, Basel, Switzerland), DFP (deferiprone, kind gift of Prof. P. Ponka, University, Montreal, QC, Canada) and BPS (batophenantroline disulfonic acid, no. B1375); FAC (ferric ammonium citrate, no. F5879); FAS (ferrous ammonium sulfate, no. F2262); $\mathrm{FeCl}_{3}$ (ferric chloride, no. 157740) and ascorbic acid (no. A4034; Sigma-Aldrich, Saint Louis, MO, USA) all dissolved in water. Calcein (no. 21030 Sigma-Aldrich, Saint Louis, MO, USA), calcein-AM (no. ALX-610-026 Calcein-acetoxymethyl ester, Enzo Life, Lausen, Switzerland) and MTT (thiazolyl blue tetrazolium bromide, no. M5655 Sigma-Aldrich, Saint Louis, MO, USA) were also used.

\subsection{Cell Culture}

The human hepatoma cell lines, HuH7 (from IZSLER, Brescia, Italy), were cultured in Dulbecco modified eagle medium (DMEM; Gibco, Life Technologies, Carlsbad, CA, USA) supplemented with $10 \%$ endotoxin-free fetal bovine serum (Gibco, Life Technologies, Carlsbad, CA, USA), $0.04 \mathrm{mg} / \mathrm{mL}$ gentamicin (Gibco, Life Technologies, Carlsbad, CA, USA), 2 mM L-glutamine (Gibco, Life Technologies, Carlsbad, CA, USA) and $1 \mathrm{mM}$ sodium pyruvate (Carlo Erba, Milan, Italy). The HA22T/VGH cell lines, a kind gift of Dr. A. Salvi and Prof. G. De Petro (University of Brescia, Brescia, Italy), were maintained in RPMI-1640 (Gibco, Life Technologies, Carlsbad, CA, USA) supplemented with 10\% endotoxin-free fetal bovine serum, Fungizone (Gibco, Life Technologies, Carlsbad, CA, USA), 0.04 mg/mL gentamicin (Gibco, Life Technologies, Carlsbad, CA, USA), 2 mM L-glutamine (Life Technologies, Carlsbad, CA, 
USA) and $1 \mathrm{mM}$ sodium pyruvate (Carlo Erba, Milan, Italy). The cell lines were maintained at $37^{\circ} \mathrm{C}$ in a $5 \% \mathrm{CO}_{2}$ incubator.

\subsection{Cell Treatments and Cell Viability Analysis}

The cells were seeded in a 96-well plate (at a density of $2 \times 10^{3}$ cells for HA22T/VGH; $1.5 \times 10^{3}$ cells for HuH7) and exposed to various concentrations of didox and only HA22T/VGH also to hydroxyurea, $\operatorname{DFO}$ or DFP $(0,1,10,25,50,100,200$ and $500 \mu \mathrm{M})$ for 24,48 and $72 \mathrm{~h}$. In other experiments, HA22T/VGH were seeded in 96-well plates and treated with a single dose of didox, HU, DFO, DFP alone or in combination with increasing doses of FAC $(25,50,100,200$ and $400 \mu \mathrm{M})$ for 48-72 h. In other type of treatment, HA22T/VGH cells were or pre-treated for $16 \mathrm{~h}$ with a single dose of didox $(200 \mu \mathrm{M})$ and then treated in combination with FAC $(400-800 \mu \mathrm{M})$ or directly in combination didox-FAC for 48-72 $\mathrm{h}$.

Cell viability was evaluated with an MTT assay (Sigma-Aldrich, Saint Louis, MO). After the indicated time points and treatments, the supernatant was removed and $100 \mu \mathrm{L}$ of the MTT solution $(0.5 \mathrm{mg} / \mathrm{mL})$ diluted in the cell medium was added to the wells. After $3.5 \mathrm{~h}$ of incubation at $37^{\circ} \mathrm{C}$ and $5 \% \mathrm{CO}_{2}$, the MTT medium was removed and $75 \mu \mathrm{L}$ of DMSO was added to each well. Plates were shaken for $15 \mathrm{~min}$ at $37^{\circ} \mathrm{C}$ until complete dissolution and absorbance was measured at $540 \mathrm{~nm}$ emission wavelengths using a Multiskan ${ }^{\odot}$ EX plate reader (Thermo Scientific, Waltham, MA, USA). Average percentage of cell viability at each concentration was calculated using Microsoft Excel 2016 software.

\subsection{Protein Extraction}

Cells extracts were prepared using a lysis buffer $(200 \mathrm{mM}$ Tris- $\mathrm{HCl} \mathrm{pH}$ 8, $100 \mathrm{mM} \mathrm{NaCl}, 1 \mathrm{mM}$ EDTA, $0.5 \%$ NP-40, 10\% glycerol, $1 \mathrm{mM}$ sodium fluoride and $1 \mathrm{mM}$ sodium orthovanadate; Complete Protease Inhibitor Cocktail; Sigma-Aldrich). The protein concentration was quantified using Micro BCA $^{\mathrm{TM}}$ Protein Assay Kit (Sigma-Aldrich, Saint Louis, MO, USA) and used for different analysis by western blotting and ELISA assays.

\subsection{Western Blot Analysis}

Western blot was used to analyze protein expression. In brief, after extraction, equal amounts of protein homogenates were boiled at $99^{\circ} \mathrm{C}$ for $5 \mathrm{~min}$ before separation by SDS-polyacrylamide gel electrophoresis and transferred to a polyvinylidene fluoride (PVDF) membrane (GE healthcare, Little Chalfont, UK). Membranes were blocked for $30 \mathrm{~min}$ at $37^{\circ} \mathrm{C}$ with Tris-buffered saline with $1 \%$ Tween-20 (TBS-T) with $2 \%$ milk and incubated overnight at $4{ }^{\circ} \mathrm{C}$ or $2 \mathrm{~h}$ at $37^{\circ} \mathrm{C}$ with the primary antibodies (reported in the material and methods paragraph). Following the TBS-T wash, membranes were incubated with HRP-conjugated secondary antibodies for $1 \mathrm{~h}$ and $30 \mathrm{~min}$ at RT. Membranes were washed again in TBS-T prior to signal visualization using enhanced chemiluminescence (PDS kit, Protein Detection System, GeneSpin, Milan, Italy). The signal was visualized with a Lycor Odyssey instrument and densitometric analysis was performed using ImageJ software (NIH, Bethesda, MD, USA) and normalized against tubulin, as a loading control.

\subsection{ELISA Assay}

The plates (96 wells) were coated with $0.1 \mathrm{~mL}$ of primary antibody against L-ferritin (LFO3) or $\mathrm{H}$-ferritin (RH02; $10 \mu \mathrm{g} / \mathrm{mL}$ diluted in $50 \mathrm{mM}$ carbonate buffer $\mathrm{pH} 9.6$ ) for $18 \mathrm{~h}$ at $4{ }^{\circ} \mathrm{C}$. After three washes with PBS-T (phosphate buffer saline with $0.05 \%$ Tween 20 ), the wells were over-coated by adding $0.1 \mathrm{~mL}$ of $3 \%$ bovine serum albumin (BSA) diluted in PBS for $30 \mathrm{~min}$ at $37^{\circ} \mathrm{C}$. After washing with PBS-T, $20 \mu \mathrm{g}$ of protein extract for L-ferritin and $5 \mu \mathrm{g}$ of protein extract for the $\mathrm{H}$-ferritin analysis were aliquot in duplicate, diluted in $1 \%$ BSA-PBST and incubated at $37^{\circ} \mathrm{C}$ for $2 \mathrm{~h}$. A standard curve using recombinant human L- or H-ferritin was added into the plate, as a calibrator. After three washings in PBST, $0.1 \mathrm{~mL}$ of anti-L- or H-ferritin antibody HRP labeled (diluted 1:500 in 1\% BSA-PBS, respectively) were added and plate incubated for $1 \mathrm{~h}$ at $37^{\circ} \mathrm{C}$. After three washings in PBS-T, HRP activity was detected using $1 \mathrm{mg} / \mathrm{mL}$ tetramethylbenzene (TMB) dissolved in dimethyl sulfoxide 
(DMSO) and diluted 1:10 in phosphate-citrate buffer $\mathrm{pH} 5$ with added fresh hydrogen peroxide to a final concentration of $0.006 \%$ and the absorbance read at $620 \mathrm{~nm}$ by Multiskan ${ }^{\odot} \mathrm{EX}$ plate reader. The reaction was stopped by adding $1 \mathrm{~N}$ sulphuric acid and the absorbance was measured at $405 \mathrm{~nm}$. The concentration of ferritins was extrapolated from the calibrator curve and expressed as ng of ferritin/mg of protein extract.

\subsection{Labile Iron Pool Assay and Calcein-AM Assay}

The cellular LIP was measured as described elsewhere, with minor modification [37]. Briefly, HA22T/VGH cells $\left(3 \times 10^{4}\right)$ were seeded on 96-well plates and treated with $100 \mu \mathrm{M}$ DFO, DFP or didox for $4 \mathrm{~h}$. The cells were incubated with $0.25 \mu \mathrm{M}$ calcein-AM in MEM with $1 \mathrm{mg} / \mathrm{mL}$ BSA for $30 \mathrm{~min}$ at $37^{\circ} \mathrm{C}$. After washing with $1 \mathrm{X}$ phosphate-buffered saline (PBS), $100 \mu \mathrm{L}$ of $1 \mathrm{X}$ Hank's Balanced Salt Solution (HBSS) was added to the cells and the fluorescence was monitored at an excitation of $488 \mathrm{~nm}$ and an emission of $517 \mathrm{~nm}$ using an EnSight Multimode plate reader (Perkin Elmer). Cells were then fixed in $4 \%$ PFA, stained with crystal violet solution ( $0.1 \%$ crystal violet, $20 \%$ methanol) for $15 \mathrm{~min}$. After washings, $100 \mu \mathrm{L}$ of $10 \%$ acetic acid was added and absorbance was detected at $540 \mathrm{~nm}$ using a Multiskan ${ }^{\odot}$ EX plate reader (Thermo Scientific, Waltham, MA, USA). The data were expressed as fold change over the not treated cells (ratio of fluorescence of calcein-AM/absorbance at 540 of crystal violet). The quenching of calcein-AM is inversely proportional to the concentration of intracellular iron.

\subsection{MitoSOX ${ }^{\text {TM }}$ Red Mitochondrial Superoxide Indicator Assay}

HA22T/VGH cells were seeded in six-well plates and $24 \mathrm{~h}$ after seeding, treated with $200 \mu \mathrm{M}$ didox, respectively. After 24,48 and $72 \mathrm{~h}$, cells were collected and labeled with $5 \mu \mathrm{M}$ MitoSOX ${ }^{\mathrm{TM}}$ (Molecular Probes) diluted in medium and incubated in the dark for $20 \mathrm{~min}$ at $37^{\circ} \mathrm{C}$. Cells were then washed and suspended in medium and fluorescence detected by a citofluorimeter instrument (MACSQuant Analyzer, Miltenyi Biotec, Germany).

\subsection{AnnexinV/Propidium Iodide Assay}

HA22T/VGH cells were seeded in six-well plates $\left(250 \times 10^{5}\right.$ cells/well). Twenty-four hours after the seeding, cells were untreated or treated with $200 \mu \mathrm{M}$ didox and the apoptotic cell death analyzed after 24, 48 and $72 \mathrm{~h}$ using the commercial kit AnnexinV-FITC Apoptosis Detection (Immunostep) and following the manufacturer's instructions. Briefly, cells were harvested, washed with 1X PBS and resuspended in 1X Annexin-binding buffer followed by the addition of $5 \mu \mathrm{L}$ of AnnexinV-FITC and $5 \mu \mathrm{L}$ of propidium iodide (PI). The cells were then incubated at RT for $15 \mathrm{~min}$ in darkness. After incubation, $400 \mu \mathrm{L}$ of $1 \mathrm{X}$ Annexin-binding buffer was added and cells analyzed by flow cytometry within one hour, using the MACSQuant Analyzer (Miltenyi Biotec). Analysis of apoptosis was performed by counting cells stained simultaneously with AnnexinV-FITC and PI, to discriminate intact cells (AnnexinV-FITC and PI negative) from cells in the early apoptotic state (AnnexinV-FITC positive and PI negative) and late apoptotic state (AnnexinV-FITC and PI positive). The percentage of cells positive to each dye was represented in the plot, whereas the histogram showed the cells positive to AnnexinV-FITC (the sum of the percentage of cells in early and late apoptosis).

\subsection{Dequencing of Calcein Fluorescence In Vitro}

Calcein fluorescence (excitation $488 \mathrm{~nm}$; emission $517 \mathrm{~nm}$ ) was detected by an EnSight Multimode plate reader (Perkin Elmer), following the protocol from Breuer W. et al. (1995) [32]. Briefly, $1 \mu \mathrm{M}$ of calcein (Sigma-Aldrich, Saint Louis, MO, USA) was incubated with an equimolar concentration of iron (II), as $1 \mu \mathrm{M}$ FAS (ferrous ammonium sulfate) and allowed to equilibrate for $8 \mathrm{~min}$ before analyzing the quenching of fluorescence. Iron (III) chelators such as DFO and DFP, or iron (II) chelator such as BPS, or didox or $\mathrm{HU}$ were subsequentially added at the final concentration of $100 \mu \mathrm{M}$. The dequenching of calcein fluorescence was analyzed after 1, 2, 3, 4, 5, 15, 25, 35, 45, 55 and $65 \mathrm{~min}$. 


\subsection{UV-Vis Spectroscopy}

The absorption spectra of didox combined with iron (III) were measured with a Jasco 815SE instrument. Conditions were 2-nm resolution, $200 \mathrm{~nm} / \mathrm{min}$ scan speed and $1 \mathrm{~cm}$ quartz cuvette. A solution of $300 \mu \mathrm{M}$ of ferric chloride was prepared in the Tris- $\mathrm{HCl}$ buffer, $25 \mathrm{mM}, \mathrm{pH}$ 7.2. Increasing amounts of didox (from 0 to a final concentration of $900 \mu \mathrm{M}$ ) were added to the solution. After each addition of didox, the solution was left for $30 \mathrm{~min}$ at $25^{\circ} \mathrm{C}$, then $\mathrm{UV}$-vis spectra were recorded.

\subsection{Computational Method}

Geometry optimizations and UV-vis spectra calculations were performed with the use of the Gaussian16 program (Gaussian 16, Revision B.01, M. J. Frisch 2016), with CAM-B3LYP functional and $6-31+G^{* *}$ basis set and MDF10 pseudopotential in the IEF-PCM approximation for the solvent. The $0.2 \mathrm{eV}$ broad Gaussian band-shape was used.

\subsection{Statistical Analysis}

Data are presented as mean \pm standard error of mean (SD). Statistical significance was assessed by a two-way ANOVA, unless otherwise indicated in the figure legends, and performed by GraphPad Prism 5 (GraphPad Software, Inc., La Jolla, CA). $p$-values $<0.05$ were considered significant.

Supplementary Materials: The following are available online at http://www.mdpi.com/1424-8247/12/3/129/s1, Figure S1: Didox reduced cell viability in the HCC cell line in time and a dose-dependent manner. Table S1: Calculation of $\mathrm{IC}_{50}$, Figure S2: Treatment with an equimolar concentration of iron rescued DFO- and DFP- but not HU-induced cell death.

Author Contributions: M.A. and L.C. performed most of the experiments; M.G. and A.D. supported M.A. in the experiments in vitro and with cells; G.S. and G.L. performed the computational and UV-vis spectra analysis and interpret the results, they analyzed the in vitro iron binding properties of didox; A.G. performed the flow cytometry analysis; P.A. and A.F. supported M.P. in the preparation of the manuscript; M.P. designed the study, analyzed the data and wrote the paper.

Funding: This research received no external funding.

Acknowledgments: This work was supported by the University of Brescia (ex 60\%) to M.P. M.A. was supported by Associazione Italiana per la Ricerca sul Cancro, AIRC Fellowship, for Italy (two year fellowship "Loredana Guarandi Sabotti" rif.22482); M.G. was supported by Associazione Garda Vita with "Roberto Tosoni Fellowship".

Conflicts of Interest: The authors declare that they have no conflict of interest.

\section{References}

1. Chen, Y.R.; Tsou, B.; Hu, S.; Ma, H.; Liu, X.; Yen, Y.; Ann, D.K. Autophagy induction causes a synthetic lethal sensitization to ribonucleotide reductase inhibition in breast cancer cells. Oncotarget 2016, 7, 1984-1999. [CrossRef]

2. Elford, H.L.; Freese, M.; Passamani, E.; Morris, H.P. Ribonucleotide reductase and cell proliferation. I. Variations of ribonucleotide reductase activity with tumor growth rate in a series of rat hepatomas. J. Biol. Chem. 1970, 245, 5228-5233.

3. Elford, H.L.; Wampler, G.L.; Riet, B.V. New ribonucleotide reductase inhibitors with antineoplastic activity. Cancer Res. 1979, 39, 844-851. [PubMed]

4. Hsu, N.Y.; Wu, J.Y.; Liu, X.; Yen, Y.; Chen, C.Y.; Chou, M.C.; Lin, C.H.; Lee, H.; Cheng, Y.W. Expression status of ribonucleotide reductase small subunits hRRM2/p53R2 as prognostic biomarkers in stage I and II non-small cell lung cancer. Anticancer Res. 2011, 31, 3475-3481. [PubMed]

5. Takeda, E.; Weber, G. Role of ribonucleotide reductase in expression in the neoplastic program. Life Sci. 1981, 28, 1007-1014. [CrossRef]

6. Eklund, H.; Uhlin, U.; Färnegårdh, M.; Logan, D.T.; Nordlund, P. Structure and function of the radical enzyme ribonucleotide reductase. Prog. Biophys. Mol. Biol. 2001, 77, 177-268. [CrossRef]

7. Elford, H.L.; Riet, B.V. Inhibition of nucleoside diphosphate reductase by hydroxybenzohydroxamic acid derivatives. Pharmacol. Ther. 1985, 29, 239-254. [CrossRef] 
8. Reichard, P. Interactions Between Deoxyribonucleotide and DNA Synthesis. Annu. Rev. Biochem. 1988, 57, 349-374. [CrossRef] [PubMed]

9. Bepler, G.; Zheng, Z.; Gautam, A.; Sharma, S.; Cantor, A.; Sharma, A.; Cress, W.D.; Kim, Y.C.; Rosell, R.; McBride, C.; et al. Ribonucleotide reductase M1 gene promoter activity, polymorphisms, population frequencies, and clinical relevance. Lung Cancer 2005, 47, 183-192. [CrossRef] [PubMed]

10. Zhou, B.; Liu, X.; Mo, X.; Xue, L.; Darwish, D.; Qiu, W.; Shih, J.; Hwu, E.B.; Luh, F.; Yen, Y. The human ribonucleotide reductase subunit hRRM2 complements p53R2 in response to UV-induced DNA repair in cells with mutant p53. Cancer Res. 2003, 63, 6583-6594. [PubMed]

11. Szekeres, T.; Fritzer-Szekeres, M.; Elford, H.L.; Jayaram, H.M. The Enzyme Ribonucleotide Reductase: Target for Antitumor and Anti-HIV Therapy. Crit. Rev. Clin. Lab. Sci. 1997, 34, 503-528. [CrossRef] [PubMed]

12. Riet, B.V.; Wampler, G.L.; Elford, H.L. Synthesis of hydroxy- and amino-substituted benzohydroxamic acids: Inhibition of ribonucleotide reductase and antitumor activity. J. Med. Chem. 1979, 22, 589-592. [CrossRef] [PubMed]

13. Al-Abd, A.M.; Al-Abbasi, F.A.; Asaad, G.F.; Abdel-Naim, A.B. Didox potentiates the cytotoxic profile of doxorubicin and protects from its cardiotoxicity. Eur. J. Pharmacol. 2013, 718, 361-369. [CrossRef] [PubMed]

14. Grusch, M. Activation of caspases and induction of apoptosis by novel ribonucleotide reductase inhibitors amidox and didox. Exp. Hematol. 2001, 29, 623-632. [CrossRef]

15. Raje, N.; Kumar, S.; Hideshima, T.; Ishitsuka, K.; Yasui, H.; Chhetri, S.; Vallet, S.; Vonescu, E.; Shiraishi, N.; Kiziltepe, T.; et al. Didox, a ribonucleotide reductase inhibitor, induces apoptosis and inhibits DNA repair in multiple myeloma cells. Br. J. Haematol. 2006, 135, 52-61. [CrossRef] [PubMed]

16. Inayat, M.S.; Chendil, D.; Mohiuddin, M.; Elford, H.L.; Gallicchio, V.S.; Ahmed, M.M. Didox (A Novel Ribonucleotide Reductase Inhibitor) Overcomes bcl-2 Mediated Radiation Resistance in Prostate Cancer Cell Line PC-3. Cancer Biol. Ther. 2002, 1, 539-545. [CrossRef]

17. Shah, K.; Wilson, E.A.; Malla, R.; Elford, H.L.; Faridi, J.S. Targeting ribonucleotide reductase M2 and NF$\mathrm{B}$ activation with Didox to circumvent tamoxifen resistance in breast cancer. Mol. Cancer Ther. 2015, 14, 2411-2421. [CrossRef]

18. Cook, G.J.; Caudell, D.L.; Elford, H.L.; Pardee, T.S. The Efficacy of the Ribonucleotide Reductase Inhibitor Didox in Preclinical Models of AML. PLoS ONE 2014, 9, e112619. [CrossRef]

19. Carmichael, J.; Cantwell, B.; Mannix, K.; Veale, D.; Elford, H.; Blackie, R.; Kerr, D.; Kaye, S.; Harris, A. A phase I and pharmacokinetic study of didox administered by 36 hour infusion. Br. J. Cancer 1990, 61, 447-450. [CrossRef]

20. Veale, D.; Carmichael, J.; Cantwell, B.; Elford, H.; Blackie, R.; Kerr, D.; Kaye, S.; Harris, A. A phase 1 and pharmacokinetic study of didox: A ribonucleotide reductase inhibitor. Br. J. Cancer 1988, 58, 70-72. [CrossRef]

21. Fritzer-Szekeres, M.; Novotný, L.; Vachálková, A.; Findenig, G.; Elford, H.L.; Szekeres, T. Iron binding capacity of didox (3,4-dihydroxybenzohydroxamic acid) and amidox (3,4-dihydroxybenzamidoxime) new inhibitors of the enzyme ribonucleotide reductase. Life Sci. 1997, 61, 2231-2237. [CrossRef]

22. Fanzani, A.; Poli, M. Iron, Oxidative Damage and Ferroptosis in Rhabdomyosarcoma. Int. J. Mol. Sci. 2017, 18, 1718. [CrossRef] [PubMed]

23. Torti, S.V.; Torti, F.M. Iron and cancer: More ore to be mined. Nat. Rev. Cancer 2013, 13, 342-355. [CrossRef] [PubMed]

24. Blatt, J.; Stitely, S. Antineuroblastoma activity of desferoxamine in human cell lines. Cancer Res. 1987, 47, 1749-1750. [PubMed]

25. Reddel, R.R.; Hedley, D.W.; Sutherland, R.L. Cell cycle effects of iron depletion on T-47D human breast cancer cells. Exp. Cell Res. 1985, 161, 277-284. [CrossRef]

26. Richardson, D.R.; Milnes, K. The potential of iron chelators of the pyridoxal isonicotinoyl hydrazone class as effective antiproliferative agents II: The mechanism of action of ligands derived from salicylaldehyde benzoyl hydrazone and 2-hydroxy-1-naphthylaldehyde benzoyl hydrazone. Blood 1997, 89, 3025-3038. [PubMed]

27. Richardson, D.R.; Tran, E.H.; Ponka, P. The potential of iron chelators of the pyridoxal isonicotinoyl hydrazone class as effective antiproliferative agents. Blood 1995, 86, 4295-4306.

28. Cazzola, M.; Bergamaschi, G.; Dezza, L.; Arosio, P. Manipulations of cellular iron-metabolism for modulating normal and malignant-cell proliferation-Achievements and prospects. Blood 1990, 75, 1903-1919. 
29. Lui, G.Y.; Kovacevic, Z.; Richardson, V.; Merlot, A.M.; Kalinowski, D.S.; Richardson, D.R. Targeting cancer by binding iron: Dissecting cellular signaling pathways. Oncotarget 2015, 6, 18748-18779. [CrossRef]

30. Bogdan, A.R.; Miyazawa, M.; Hashimoto, K.; Tsuji, Y. Regulators of Iron Homeostasis: New Players in Metabolism, Cell Death, and Disease. Trends Biochem. Sci. 2016, 41, 274-286. [CrossRef]

31. Hatcher, H.C.; Singh, R.N.; Torti, F.M.; Torti, S.V. Synthetic and natural iron chelators: Therapeutic potential and clinical use. Future Med. Chem. 2009, 1, 1643-1670. [CrossRef] [PubMed]

32. Epsztejn, S.; Breuer, W.; Cabantchik, Z.I. Iron Acquired from Transferrin by K562 Cells Is Delivered into a Cytoplasmic Pool of Chelatable Iron(II). J. Biol. Chem. 1995, 270, 24209-24215.

33. Šebestík, J.; Šafařík, M.; Bouř, P. Ferric Complexes of 3-Hydroxy-4-pyridinones Characterized by Density Functional Theory and Raman and UV-vis Spectroscopies. Inorg. Chem. 2012, 51, 4473-4481. [CrossRef] [PubMed]

34. Yarbro, J.W. Mechanism of action of hydroxyurea. Semin. Oncol. 1992, 19, 1-10. [PubMed]

35. Andrews, S.C.; Robinson, A.K.; Rodriguez-Quinones, F. Bacterial iron homeostasis. FEMS Microbiol. Rev. 2003, 27, 215-237. [CrossRef]

36. Schlachterman, A.; Craft, W.W., Jr.; Hilgenfeldt, E.; Mitra, A.; Cabrera, R. Current and future treatments for hepatocellular carcinoma. World J. Gastroenterol. 2015, 21, 8478-8491. [CrossRef] [PubMed]

37. Agoro, R.; Benmerzoug, S.; Rose, S.; Bouyer, M.; Gozzelino, R.; Quesniaux, V.F.J.; Mura, C.; Garcia, I.; Ryffel, B. An Iron-Rich Diet Decreases the Mycobacterial Burden and Correlates with Hepcidin Upregulation, Lower Levels of Proinflammatory Mediators, and Increased T-Cell Recruitment in a Model of Mycobacterium bovis Bacille Calmette-Guerin Infection. J. Infect. Dis. 2017, 216, 907-918. [CrossRef]

(C) 2019 by the authors. Licensee MDPI, Basel, Switzerland. This article is an open access article distributed under the terms and conditions of the Creative Commons Attribution (CC BY) license (http://creativecommons.org/licenses/by/4.0/). 

MDPI

St. Alban-Anlage 66

4052 Basel

Switzerland

Tel. +41616837734

Fax +41 613028918

www.mdpi.com

Pharmaceuticals Editorial Office

E-mail: pharmaceuticals@mdpi.com

www.mdpi.com/journal/pharmaceuticals

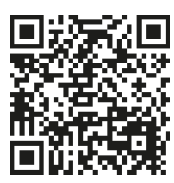



MDPI

St. Alban-Anlage 66

4052 Basel

Switzerland

Tel: +41 616837734

Fax: +41 613028918

www.mdpi.com 